\title{
SPECIAL ANALYSIS OF OPERATIONAL STORMWATER RUNOFF COVERS OVER SLIT TRENCHES
}

\author{
L. B. Collard \\ L. L. Hamm
}

DECEMBER 18, 2008

Savannah River National Laboratory

Savannah River Nuclear Solutions

Savannah River Site

Aiken, SC 29808 


\section{DISCLAIMER}

This work was prepared under an agreement with and funded by the U.S. Government. Neither the U.S. Government or its employees, nor any of its contractors, subcontractors or their employees, makes any express or implied:

1. warranty or assumes any legal liability for the accuracy, completeness, or for the use or results of such use of any information, product, or process disclosed; or

2. representation that such use or results of such use would not infringe privately owned rights; or

3. endorsement or recommendation of any specifically identified commercial product, process, or service.

Any views and opinions of authors expressed in this work do not necessarily state or reflect those of the United States Government, or its contractors, or subcontractors.

Printed in the United States of America

Prepared For

U.S. Department of Energy 
Key Words:

PA, SA

Inventory limits

Retention:

Permanent

\title{
SPECIAL ANALYSIS OF OPERATIONAL STORMWATER RUNOFF COVERS OVER SLIT TRENCHES
}

\author{
L. B. Collard
}

L. L. Hamm

DECEMBER 18, 2008

Savannah River National Laboratory

Savannah River Nuclear Solutions

Savannah River Site

Aiken, SC 29808 


\section{APPROVALS}

\section{Authors}

L.B. Collard, Co-author, Radiological Performance Assessment

Date

L.L. Hamm, Co-author, Engineering Modeling \& Simulation

Date

\section{SRNL Approvals}

J.M. Jordan, Peer Reviewer, Engineering Modeling \& Simulation

Date

T. Hang, Peer Reviewer, Engineering Modeling \& Simulation

Date

B.T. Butcher, Program Manager, Radiological Performance Assessment

Date

D.A. Crowley, Manager, Radiological Performance Assessment

Date

S.L. Marra, Manager, E\&CPT Programs

Date

\section{E-Area Facility Approvals}

W.T. Goldston, DAS Manager, Regulatory Integration

Date

M.G. Looper, Manager, Solid Waste Management Engineering

Date

K.W. Johns-Hughes, Manager, Solid Waste Facility

Date 


\section{TABLE OF CONTENTS}

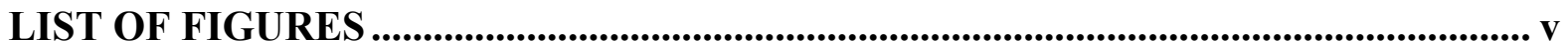

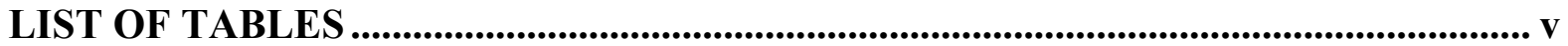

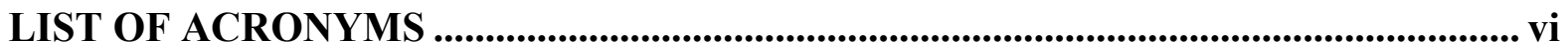

1.0 EXECUTIVE SUMMARY ........................................................................................... 1

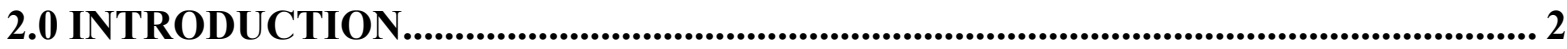

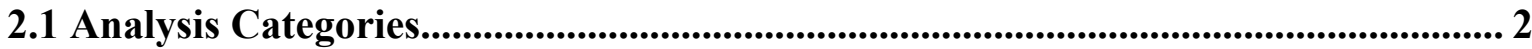

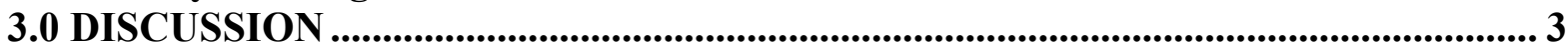

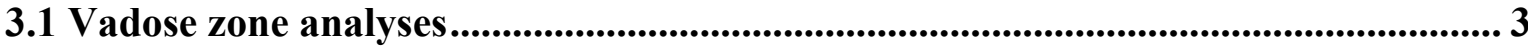

3.1.1 Vadose zone model changes......................................................................................... 3

3.1.2 Vadose zone model implementation ................................................................ 4

3.1.3 Vadose zone model results ................................................................................. 5

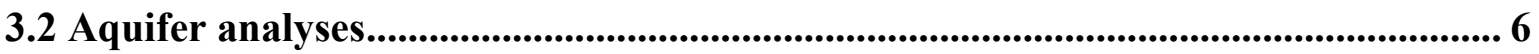

3.2.1 Aquifer model changes................................................................................................6 6

3.2.2 Aquifer model implementation ........................................................................ 7

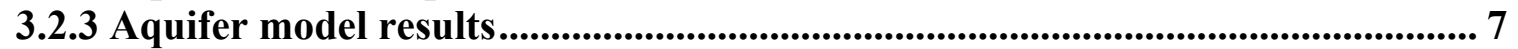

3.3 Inventory Limits ................................................................................................... 7

3.3.1 Inventory limit trends and observations ................................................................ 18

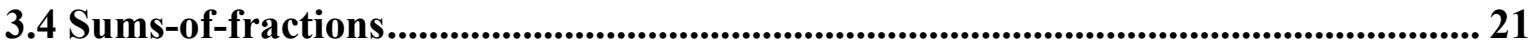

3.4.1 Sums-of-fractions trends and observations................................................ 26

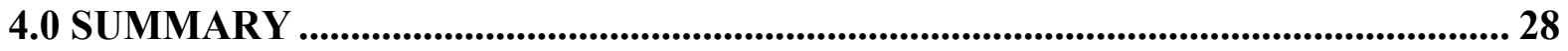

5.0 Additional Key Inputs and Assumptions ............................................................ 28

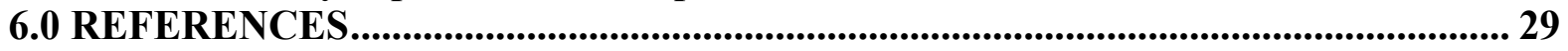




\section{LIST OF FIGURES}

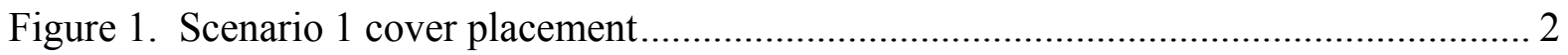

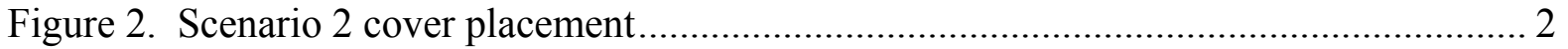

Figure 3. Slit trench disposal unit plan view................................................................... 3

Figure 4. Geometry for vadose zone model of a single slit trench ........................................... 4

Figure 5. Aquifer center trench and edge trench source node locations ................................... 6

\section{LIST OF TABLES}

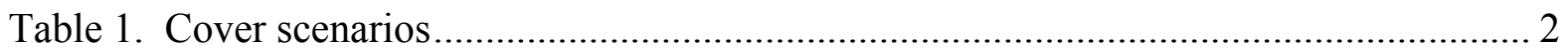

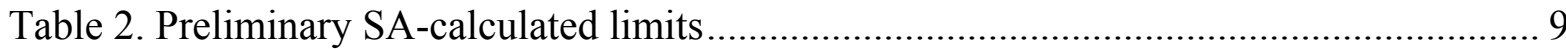

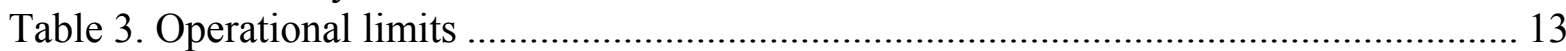

Table 4. Minimal operational limits............................................................................ 17

Table 5. Significant relative differences for SA-calculated preliminary limits between one cover or two covers over ST1 through ST4 placed at 5 years ........................................ 18

Table 6. Limit comparisons for 5-year cover vs. PA showing major changes ........................ 21

Table 7. Sums-of-fractions for Slit Trench 1 ....................................................................... 23

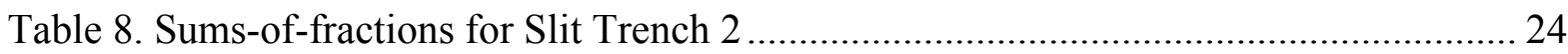

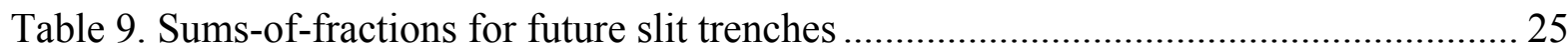

Table 10. Sums-of-fractions for existing inventory in Slit Trench 1 .................................... 26

Table 11. Sums-of-fractions for existing inventory in Slit Trench 2 .................................... 27

Table 12. Sums-of-fractions for projected inventory in future slit trenches........................... 27 


\section{LIST OF ACRONYMS}

$\begin{array}{ll}\text { CDP } & \text { Cellulose Degradation Products } \\ \text { CERCLA } & \text { Comprehensive Environmental Response, Compensation, and Liability Act } \\ \text { CIG } & \text { Components-in-Grout } \\ \text { DOE } & \text { United States Department of Energy } \\ \text { EPA } & \text { United States Environmental Protection Agency } \\ \text { SA } & \text { Special Analysis } \\ \text { PA } & \text { Performance Assessment } \\ \text { SCDHEC } & \text { South Carolina Department of Health and Environmental Control } \\ \text { SOF } & \text { Sum-of-Fractions } \\ \text { ST } & \text { Slit Trench } \\ \text { SWM } & \text { Solid Waste Management }\end{array}$


SRNL-STI-2008-00397, REVISION 0

\subsection{EXECUTIVE SUMMARY}

Solid Waste Management (SWM) commissioned this Special Analysis (SA) to determine the effects of placing operational stormwater runoff covers (referred to as covers in the remainder of this document) over slit trench (ST) disposal units ST1 through ST7 (the center set of slit trenches). Previously the United States Department of Energy (DOE) entered into an agreement with the United States Environmental Protection Agency (EPA) and the South Carolina Department of Health and Environmental Control (SCDHEC) to place covers over Slit Trenches 1 and 2 to be able to continue disposing Comprehensive Environmental Response, Compensation, and Liability Act (CERCLA) solid waste (see USDOE 2008). Because the covers changed the operating conditions, DOE Order 435.1 (DOE 1999) required that an SA be performed to assess the impact.

This Special Analysis has been prepared to determine the effects of placing covers over slit trenches at about years 5, 10 and 15 of the 30 -year operational period. Because some slit trenches have already been operational for about 15 years, results from analyzing covers at 5 years and 10 years provide trend analysis information only.

This SA also examined alternatives of covering Slit Trenches 1 and 2 with one cover and Slit Trenches 3 and 4 with a second cover versus covering them all with a single cover. Based on modeling results, minimal differences exist between covering Slit Trench groups 1-2 and 3-4 with two covers or one large cover.

This SA demonstrates that placement of covers over slit trenches will slow the subsequent release and transport of radionuclides in the vadose zone in the early time periods (from time of placement until about 100 years). Release and transport of some radionuclides in the vadose zone beyond 100 years were somewhat higher than for the case without covers. The sums-of-fractions (SOFs) were examined for the current waste inventory in ST1 and ST2 and for estimated inventories at closure for ST3 through ST7. In all cases SOFs were less than one (except for one SOF for ST5 that remained at one), indicating that there should be no unacceptable impacts on operations from placing covers for the cover alternatives that were analyzed.

Minimal operational limits provided in Table 4 should be used as the new set of limits for Slit Trenches 1 through 7. ST1 and ST2 are expected to be covered about 15 years after the first disposal in ST1. Because the time of actual placement of covers over the other slit trenches is unknown, this SA did not consider limit increases, only limit decreases. Thus, each minimal operational limit is the minimum of the Performance Assessment (PA) final limit and the limit calculated in this SA if covers were placed at about 5, 10 or 15 years. If other cover times are desired, further analysis will be required. 


\subsection{INTRODUCTION}

A Special Analysis (SA) has been completed to assess the effects of placing covers over slit trench (ST) disposal units ST1 through ST7 (the center set of slit trenches) at year 15 of the 30-year operational period. A second part of this SA examined the effects of covers placed at year 5 and year 10 . Because some of the slit trenches have already been operational for about 15 years results from analyzing covers at 5 years and 10 years provide trend analysis information only.

Solid Waste Management identified two scenarios for covering ST1 to ST4. The scenarios are described in Table 1. Cover scenarios and Figures 1-2. The only differences are the two Edge Trenches between ST2 and ST3 shown in Scenario 1.

Table 1. Cover scenarios

\begin{tabular}{|c|c|c|c|}
\hline Scenario & $\begin{array}{c}\text { Slit Trench Disposal Units } \\
\text { covered by Cover } 1\end{array}$ & $\begin{array}{c}\text { Slit Trench Disposal Units } \\
\text { covered by Cover 2 }\end{array}$ & $\begin{array}{c}\text { Slit Trench Disposal Units } \\
\text { covered by Cover } 3\end{array}$ \\
\hline 1 & ST1-2 & ST3-4 & ST5-7 \\
\hline 2 & ST1-4 & NA & ST5-7 \\
\hline
\end{tabular}
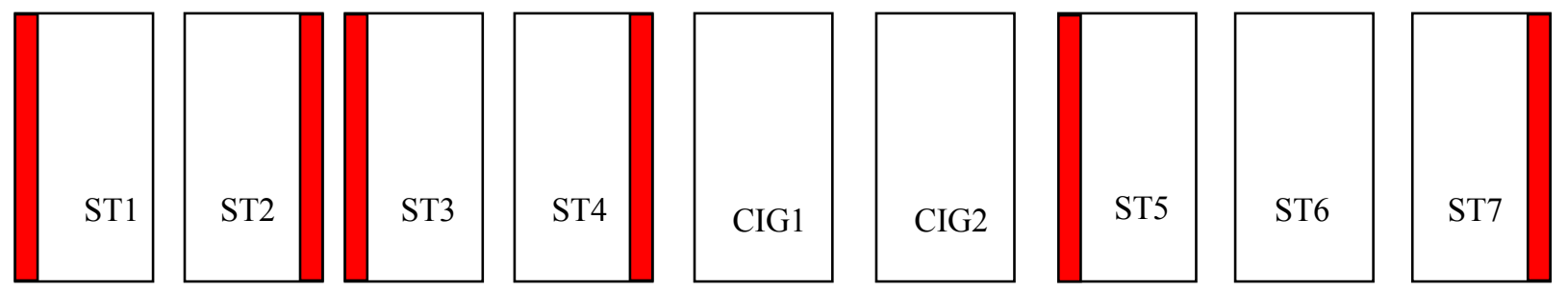

Figure 1. Scenario 1 cover placement
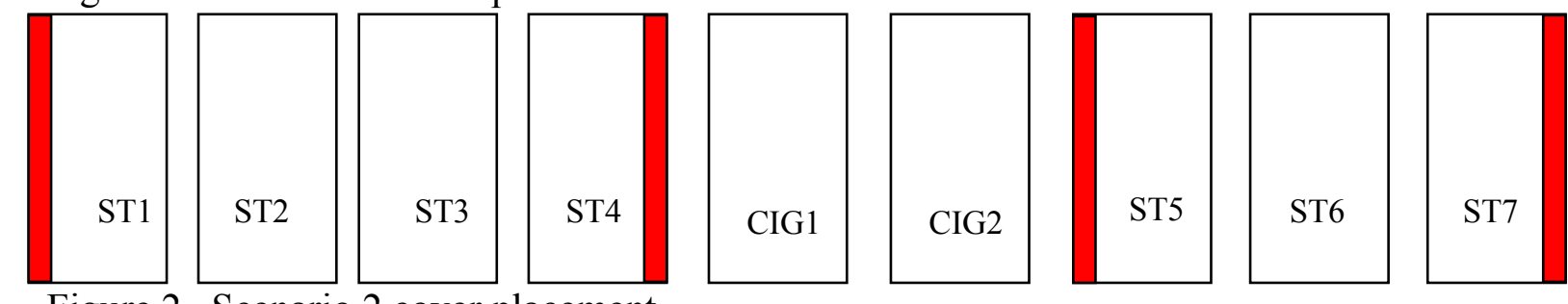

Figure 2. Scenario 2 cover placement

Legend: Edge Trench

Components-in-Grout (CIG) trenches between Slit Trenches 4 and 5 were ignored.

\subsection{ANALYSIS CATEGORIES}

Analyses to satisfy DOE Order 435.1 (DOE 1999) included the following categories:
1. Groundwater pathway
2. Air pathway
3. All-Pathways
4. Inadvertent intruder
5. Radon 
Because the cover was so thin relative to other materials, it was ignored for the air pathway, the inadvertent intruder and the radon analysis categories. The addition of the cover is considered a beneficial measure for these exposure pathways, and does not adversely impact the previous analysis. Therefore only the groundwater pathway and all-pathways limits change from the Performance Assessment (WSRC 2008) and other limits will not be discussed further.

Because it was assumed in the PA that air doses had no impact on the all-pathways analysis, the all-pathways reduces to a groundwater all-pathways. The groundwater pathway was combined with the groundwater all-pathways analysis in this SA.

\subsection{DISCUSSION}

\subsection{VADOSE ZONE ANALYSES}

The vadose zone model for the SA differed from the PA model in two aspects. First was the inclusion of a cover. This cover required the creation of "center" trenches where the trench and side areas were completely covered and "edge" trenches where some of the area away from the disposal unit was not covered. The second aspect was the extension of the modeling time to 1130 years for highly mobile contaminants. Both aspects are discussed below along with other model implementation information.

\subsubsection{Vadose zone model changes}

Each cover will enclose the entire waste area for a disposal unit and any non-excavated area between those slit trenches. The cover would enclose the colored area and the interspersed white areas shown in Figure 3. When a single cover encloses multiple disposal units, the nonexcavated area between disposal units would also be covered. A 10-ft wide drainage ditch will abut each long side of the cover (parallel to the Y-direction shown in Figure 3).

Both the cover and the drainage ditch were assumed to have a recharge rate (to the water table) of $0.36 \mathrm{inch} / \mathrm{yr}$ (Phifer, 2008). All water entering the drainage ditch exceeding $0.36 \mathrm{inch} / \mathrm{yr}$ was assumed to be conveyed beyond the area where it could affect the waste.

The 2D geometry from the PA was used for the vadose zone model. The PA conceptual geometry (Figure 4) includes a single, 20 -ft wide slit trench with 20 -ft wide areas on both sides. For a "center" trench the entire $60-\mathrm{ft}$ wide domain was assumed to be covered. For an "edge" trench the 20 -ft wide left-side and the 20 - $\mathrm{ft}$ wide trench were

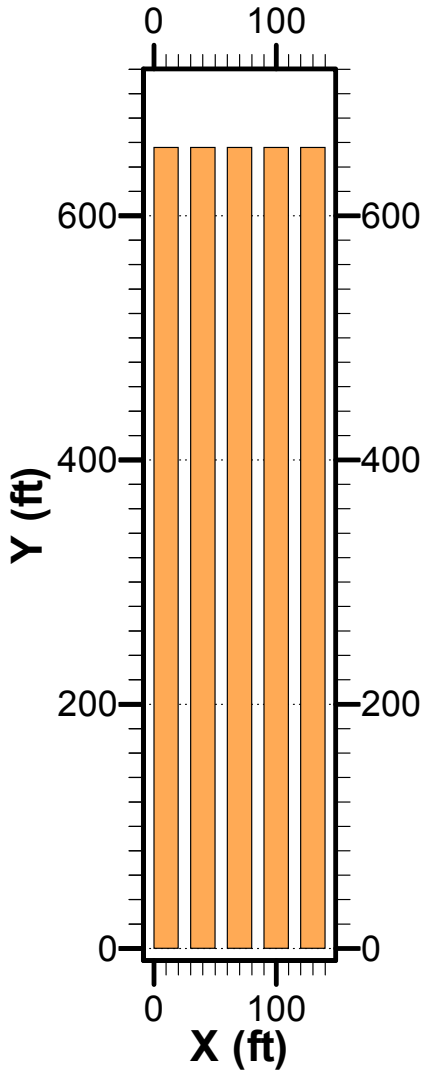

Figure 3. Slit trench disposal unit plan view 
assumed to be covered. The adjacent 10 - $\mathrm{ft}$ wide drainage ditch on the right-side was assumed to have the same recharge rate as the cover. The outermost $10-\mathrm{ft}$ of the rightside was uncovered and was assumed to have a typical uncovered recharge rate of about $15 \mathrm{in} / \mathrm{yr}$.

Sample Center trench

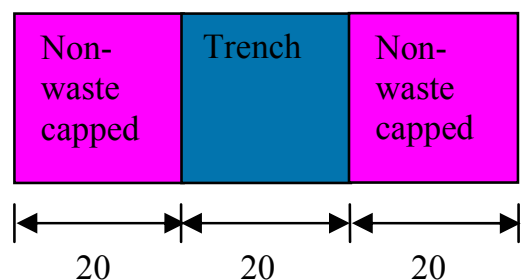

Sample Edge trench

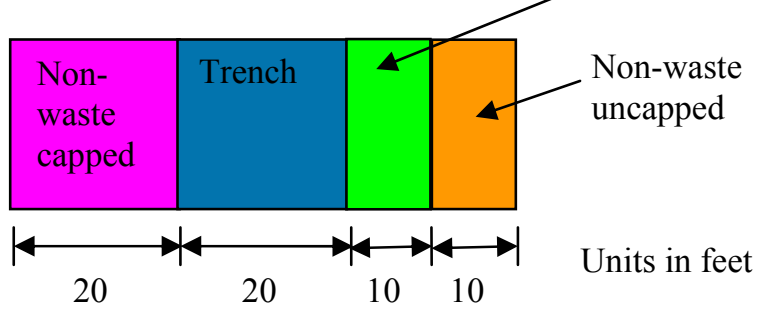

Figure 4. Geometry for vadose zone model of a single slit trench

The PA approach for modeling highly mobile contaminants was modified in this SA. For such contaminants the analysis was extended from the PA duration of 130 years to the full 1130 years. This extension allowed the effects of "non-crushable" containers (that collapse at 130 years) to manifest themselves and provided explicit model information beyond the 130 year period.

A design checker questioned the accuracy of using only a single time step for the time until the cover was placed, which occurred for some radionuclides. That time step had originally been selected to duplicate the PA analysis as closely as possible. Based on this question, plots were examined to determine which radionuclides were analyzed using such an initial time step. Four parent radionuclides were identified as follows:

1. $\mathrm{K}-40$

2. $\mathrm{Sn}-126$

3. $\mathrm{Se}-79$

4. U-233.

Subsequently vadose zone analyses were performed using time step increments for both solving and recording of one year. A sample set of plots comparing the original results with results from using the new set of time step increments are provided in Appendix A as the last four figures. Examining the full set of plots indicated that the fluxes at the water table from the original analyses were always higher for all the radionuclides other than K-40. Because the higher fluxes would produce higher concentrations and lower limits no changes were made for any of the radionuclides except K-40. K-40 was reanalyzed using smaller time steps (both in the vadose zone and the aquifer) and its limits were calculated based on the new analyses.

\subsubsection{Vadose zone model implementation}

The analyses had to consider cases with the presence or absence of Cellulose Degradation Products (CDP, e.g., from wood or laboratory clothing) and the effectiveness of dynamic compaction at the end of institutional control (130 years). The PA considered two basic possibilities for the effectiveness as follows: 
1. All containers were crushable by the time of dynamic compaction, because metal containers would corrode and lose strength

2. 10 percent of the containers had sufficient residual structural integrity to resist crushing at the time of dynamic compaction, because the initial thickness of the metal containers was much greater than the thickness of B-25 boxes. That 10 percent was assumed to fail immediately after placement of the cover, when institutional control no longer applied - later failures and spreading failures over time were not investigated.

The four cases analyzed in this SA are listed below:

\begin{tabular}{|l|l|l|}
\hline Case & CDP & Description \\
\hline 1 & Off & All containers were crushed via dynamic compaction at 130 years. \\
\hline 2 & On & All containers were crushed via dynamic compaction at 130 years. \\
\hline 3 & Off & $\begin{array}{l}90 \% \text { of containers were crushed via dynamic compaction at 130 years, } 10 \% \\
\text { collapsed immediately after the cover was completed and institutional control was } \\
\text { lost, causing the cover to fail. }\end{array}$ \\
\hline 4 & On & $\begin{array}{l}\text { 90\% of containers were crushed via dynamic compaction at 130 years, } 10 \% \\
\text { collapsed immediately after the cover was completed and institutional control was } \\
\text { lost, causing the cover to fail. }\end{array}$ \\
\hline
\end{tabular}

Intermediate steps were required to develop the cases where only $90 \%$ of the containers crushed via dynamic compaction (the same steps as were performed in the PA). The first step was to conduct an analysis where $0 \%$ of the containers crushed via dynamic compaction. The second step was to blend the contaminant flux at the water table by summing $90 \%$ of each flux from the case where $100 \%$ crushed with $10 \%$ of the corresponding flux from the case where $0 \%$ crushed.

Ultimately, results for a combination of the four cases were developed whereby the worst case in terms of the highest well concentration and the lowest inventory limits was selected. That process is more fully described in the section on limits.

Each of the four cases was analyzed in the vadose zone for the scenarios of cover placement at 5, 10 and 15 years. Separate vadose zone analyses were conducted for edge trenches and for center trenches.

\subsubsection{Vadose zone model results}

Results for vadose zone models consist of contaminant fluxes at the water table for edge trenches and center trenches. Those results were produced for cases with CDP on and CDP off and for $100 \%$ crushable containers and $0 \%$ crushable containers. Other blended results were calculated (without further modeling) for the $90 \%$ crushable container case by summing results from the $100 \%$ crushable containers case multiplied by 0.90 and results from the $0 \%$ crushable containers case multiplied by 0.10 , or

$$
\text { Flux }_{\text {blended }}=0.90 * \text { Flux }_{100 \% \text { crushable }}+0.10 * \text { Flux }_{0 \% \text { crushable }}
$$

Plots of contaminant fluxes at the water table are provided in Appendix A. Cover placement immediately reduces contaminant fluxes at the water table based on the method of modeling. 


\subsection{AQUIFER ANALYSES}

After completion of the vadose zone analyses and blending operations, vadose zone outputs in the form of contaminant flux at the water table were input to aquifer contaminant transport models. The aquifer model for the SA differed from that in the PA in two aspects. First, the inclusion of a cover required segregating the aquifer source cells (where the contaminant flux at the water table was input) into those representing edge trenches and center trenches. To check source cell changes, a test case was run where some contaminant fluxes from the PA model were injected into all the SA source cells. SA results in the form of well concentrations matched the PA results. A more refined model would have provided more accurate results but the intent was to minimize the deviation from the PA model, so no further refinements were made. The second aspect was extending the modeling time for highly mobile contaminants. Both aspects are discussed below along with other model implementation information.

\subsubsection{Aquifer model changes}

The contaminant flux from the edge trenches was injected into the aquifer edge trench source cells and the contaminant flux from the center trenches was injected into the aquifer center trench source cells (see Figure 5). Aquifer source cells were designated as purely edge trench or purely center trench even though the mesh did not perfectly align with the physical slit trenches. Thus source cells that underlie a combination of center trenches, edge trenches and unexcavated areas were assigned as only a center source cell or only an edge source cell.

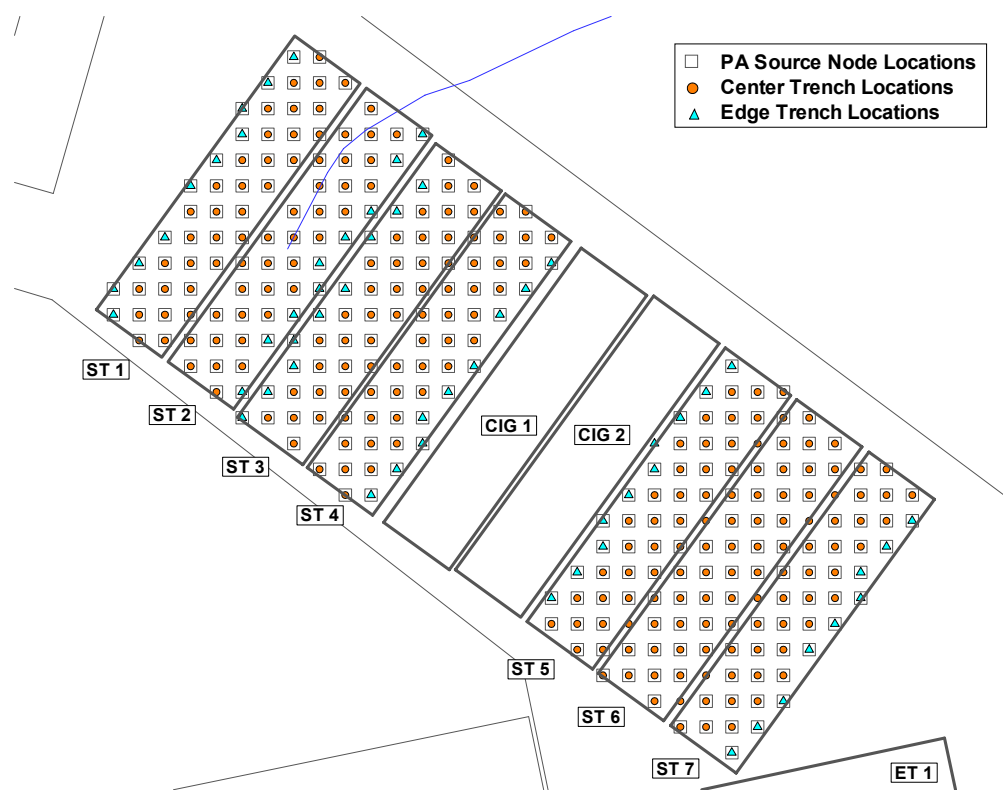

Figure 5. Aquifer center trench and edge trench source node locations 
The contaminant flux calculated in the vadose zone model was based on an initial inventory of $1 \mathrm{~g}$-mole of each parent uniformly spread throughout the waste zone. The actual flux injected into the aquifer edge trench source cells was the vadose zone model contaminant flux from the edge trenches multiplied by the volume fraction of aquifer source cells that were edge trenches, or Edge Cell Source aquifer $=$ Edge Trench Flux vadose zone $* \frac{\text { Vol Edge Source Cells }}{\text { aquifer }}$

Likewise contaminant flux from the center trenches was scaled by the volume fraction of aquifer source cells that were center trenches, or

Center Cell Source $_{\text {aquifer }}=$ Center Trench Flux vadosezone $* \frac{\text { Vol Center Source Cells }_{\text {aquifer }}}{\sum \text { Vol Source Cells }}$

The area fraction could have been used, but the area fraction differed from the volume fraction by less than $1 \%$ in all but one instance where the difference was about $3 \%$. Those differences would not be discernable in the final limits that display only two significant digits.

The analysis period for the highly mobile contaminants was extended from the PA finish at 130 years to the SA finish at 1130 years.

As noted in Section 3.1.1 modeling changes were made based on the results of the design check. Specifically, K-40 was reanalyzed using smaller time steps.

\subsubsection{Aquifer model implementation}

As was done for the vadose zone, the aquifer analyses had to consider cases with the presence or absence of Cellulose Degradation Products (CDP) and the effectiveness of dynamic compaction at the end of institutional control (130 years). Each of the four cases described in the vadose zone section was analyzed in the aquifer for the scenarios of cover placement at 5, 10 and 15 years.

\subsubsection{Aquifer model results}

Results for aquifer models consist of well concentrations. Those results were produced for cases with CDP on and CDP off and for 100\% crushable containers and $90 \%$ crushable containers. Plots of well concentrations are provided in Appendix A. Cover placement that immediately reduced contaminant fluxes at the water table in the vadose zone models also quickly reduced contaminant well concentrations based on the method of modeling.

\subsection{INVENTORY LIMITS}

Following the methodology of the PA, a variety of limits were calculated for the SA. First, preliminary limits were established for each of the four cases based strictly on modeling results. These are deemed preliminary limits, because it is unknown when each slit trench will be covered and the assumption that all slit trenches are covered simultaneously is known to be incorrect. These preliminary limits were calculated for each of the four cases presented above. Per the PA protocol, the modeling results (well 
concentrations) were multiplied by 7.06 to account for the amount of waste area in the center set of slit trenches. Even though there were only seven slit trench disposal units in the center set of slit trenches, in the PA modeling the overall footprint was deemed to occupy the equivalent of 7.06 such disposal units and that same factor was applied in this SA.

Second, combined preliminary limits were calculated by selecting the minimum limit from among the four cases for each specific limit category and time interval. Third, uncertainty and plume interaction were considered to produce final SA-calculated limits. In the PA, the uncertainty analyses concluded that the limits need not be reduced for uncertainty. In the PA for plume interaction a constant limit multiplier of 0.85 was selected for all parent nuclides to be applied to the center set of slit trenches, which is also applied in this SA. Fourth, the lower of the final SA-calculated limits and the final PA limits were selected to produce the operational limits. Limits from the second and last steps (preliminary SA-calculated limits and operational limits, respectively) are provided in Table 2 and Table 3 for four scenarios (combinations of cover placement at 5 and 15 years and one or two covers over ST1 to ST4). Tables for cover placement at 10 years are not provided because their results generally fall between the results from the 5year and 15-year analyses. The final step was to select the minimal operational limits from among the cases analyzed. These limits are shown in Table 4. 
Table 2. Preliminary SA-calculated limits

\begin{tabular}{|c|c|c|c|c|c|c|c|c|c|c|c|c|c|}
\hline \multicolumn{3}{|c|}{ Scenario1 - 2 sets of 2 trenches covered at $15 \mathrm{yrs}$} & \multirow[b]{2}{*}{ 100-1130 } & \multirow[b]{2}{*}{ 0-1000 } & \multirow[b]{2}{*}{\begin{tabular}{|c|} 
Gross Alpha \\
$1000-1120$ \\
\end{tabular}} & & \multirow{2}{*}{\multicolumn{3}{|c|}{ Radium }} & \multirow[b]{2}{*}{\begin{tabular}{|c|} 
Uranium \\
0-1130 \\
\end{tabular}} & & \multirow[b]{2}{*}{$\begin{array}{l}\text { Pathways } \\
1000-1130\end{array}$} \\
\hline & \begin{tabular}{|l|}
$0-12$ \\
\end{tabular} & \begin{tabular}{|c|} 
Beta-Gamma \\
\end{tabular} & & & & & & & & & & & \\
\hline $\begin{array}{l}\text { Parent Nuclide } \\
\text { nat }\end{array}$ & yrs & 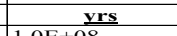 & yrs & yrs & yrs & yrs & yrs & $\underline{\mathbf{y r s}}$ & vrs & & yrs & vrs & Yrs \\
\hline & $4.6 \mathrm{E}+09$ & $\frac{1.0 \mathrm{E}+08}{2.5 \mathrm{E}+19}$ & $\frac{1.3 \mathrm{E}+04}{5.7 \mathrm{E}+02}$ & $\frac{2.6 \mathrm{E}+02}{7.8 \mathrm{E}+01}$ & $\frac{1.5 \mathrm{E}+02}{3.0 \mathrm{E}+01}$ & $1.4 \mathrm{E}+022$ & NA & NA & NA & $\frac{1.9 \mathrm{E}+12}{1.5 \mathrm{E}+12}$ & $7.4 \mathrm{E}+02$ & $9.4 \mathrm{E}+01$ & $\frac{5.3 \mathrm{E}+01}{1.01}$ \\
\hline \begin{tabular}{|l|l|l|l}
$\mathrm{Am}-243$ \\
$\mathrm{C}-14$
\end{tabular} & $3.3 \mathrm{E}-01$ & $3.3 \mathrm{E}-01$ & $\frac{1.0 \mathrm{E}+01}{1.01}$ & NA & $\frac{\mathrm{NA}}{\mathrm{NA}}$ & $\frac{2.8 \mathrm{E}+\mathrm{OI}}{\mathrm{NA}}$ & $\frac{\mathrm{NA}}{\mathrm{NA}}$ & $\frac{\mathrm{NA}}{\mathrm{NA}}$ & $\frac{\mathrm{NA}}{\mathrm{NA}}$ & $\frac{1.5 \mathrm{E}+12}{\mathrm{NA}}$ & $\frac{3.4 \mathrm{E}+10}{1.3 \mathrm{E}+01}$ & $\frac{3.0 \mathrm{E}+01}{2.4 \mathrm{E}+01}$ & $\frac{1.1 \mathrm{E}+01}{6.0 \mathrm{E}+02}$ \\
\hline C-14 NR.Pump & & & $2.9 \mathrm{E}+00$ & NA & NA & $\frac{N A}{N A}$ & $\frac{\text { NA }}{\text { NA }}$ & $\frac{\mathrm{NA}}{\mathrm{NA}}$ & $\frac{\text { NA }}{\text { NA }}$ & & $3.6 \mathrm{E}+01$ & $\frac{2.4 \mathrm{E}+01}{3.1 \mathrm{E}+00}$ & $\frac{0.0 \mathrm{E}+\mathrm{O} 2}{1.2 \mathrm{E}+02}$ \\
\hline Cf- 249 & $1.4 \mathrm{E}+17$ & $1.3 \mathrm{E}+15$ & $3.8 \mathrm{E}+04$ & $3.7 \mathrm{E}+02$ & $1.6 \mathrm{E}+02$ & $1.6 \mathrm{E}+02$ & NA & NA & NA & $1.1 \mathrm{E}+14$ & $2.2 \mathrm{E}+06$ & $1.2 \mathrm{E}+02$ & $4.9 \mathrm{E}+01$ \\
\hline Cf-251 & & & $2.0 \mathrm{E}+08$ & $1.6 \mathrm{E}+02$ & $6.5 \mathrm{E}+01$ & $6.1 \mathrm{E}+01$ & NA & NA & NA & $9.7 \mathrm{E}+17$ & $4.2 \mathrm{E}+18$ & $4.4 \mathrm{E}+01$ & $1.8 \mathrm{E}+01$ \\
\hline Cl-36 & $1.1 \mathrm{E}-01$ & $1.2 \mathrm{E}-01$ & $3.5 \mathrm{E}+00$ & & & & & NA & & & $2.3 \mathrm{E}+00$ & $4.1 \mathrm{E}+00$ & $9.6 \mathrm{E}+01$ \\
\hline \begin{tabular}{|l|}
$\mathrm{Cm}-244$ \\
$\mathrm{Cm}-245$
\end{tabular} & & & $1.1 \mathrm{E}+18$ & $9.4 \mathrm{E}+10$ & $1.2 \mathrm{E}+10$ & $1.0 \mathrm{E}+10$ & $1.9 \mathrm{E}+18$ & $1.5 \mathrm{E}+18$ & $1.4 \mathrm{E}+18$ & $1.3 \mathrm{E}+18$ & & $3.7 \mathrm{E}+10$ & $4.0 \mathrm{E}+09$ \\
\hline \begin{tabular}{|l|}
$\mathrm{Cm}-245$ \\
$\mathrm{Cm}-246$ \\
\end{tabular} & $2.0 \mathrm{E}+13$ & $2.4 \mathrm{E}+11$ & $\frac{1.4 \mathrm{E}+03}{9.2 \mathrm{E}+14}$ & $\frac{4.3 \mathrm{E}+01}{8.3 \mathrm{E}+01}$ & $\frac{1.6 \mathrm{E}+01}{3.2 \mathrm{E}+01}$ & $\frac{1.5 \mathrm{E}+01}{3.0 \mathrm{E}+01}$ & $\frac{\mathrm{NA}}{1.4 \mathrm{E}+16}$ & $\frac{\mathrm{NA}}{4.3 \mathrm{E}+15}$ & $\mid \frac{\mathrm{NA}}{3.9 \mathrm{E}+15}$ & $\frac{2.1 \mathrm{E}+12}{2.3 \mathrm{E}+13}$ & $7.7 \mathrm{E}+03$ & $\frac{1.6 \mathrm{E}+01}{3.1 \mathrm{E}+01}$ & $\frac{5.7 \mathrm{E}+00}{1.1 \mathrm{E}+01}$ \\
\hline $\mathrm{Cm}-247$ & --- & --- & $4.3 \mathrm{E}+03$ & $6.6 \mathrm{E}+01$ & $2.5 \mathrm{E}+01$ & $\frac{3.0 \mathrm{E}+01}{2.3 \mathrm{E}+01}$ & $\frac{1.4 \mathrm{E}+16}{\mathrm{NA}}$ & $\frac{4.5 E+15}{\text { NA }}$ & NA & $\frac{1.5 \mathrm{E}+13}{1.6 \mathrm{E}+13}$ & $7.4 \mathrm{E}+12$ & $\frac{3.1 \mathrm{E}+01}{2.6 \mathrm{E}+01}$ & $\mid \begin{array}{l}1.1 \mathrm{E}+01 \\
9.3 \mathrm{E}+00 \\
\end{array}$ \\
\hline Cm-248 & & & $3.7 \mathrm{E}+09$ & $7.8 \mathrm{E}+01$ & $3.0 \mathrm{E}+01$ & $2.8 \mathrm{E}+01$ & & & & $3.4 \mathrm{E}+17$ & & $7.2 \mathrm{E}+00$ & $2.6 \mathrm{E}+00$ \\
\hline & $6.3 \mathrm{E}+00$ & $6.4 \mathrm{E}+00$ & $2.4 \mathrm{E}+04$ & NA & NA & NA & NA & NA & NA & NA & $3.9 \mathrm{E}+06$ & $3.0 \mathrm{E}+08$ & \\
\hline \begin{tabular}{|l|} 
H-3_Concrete \\
H-3_ETF Carbon
\end{tabular} & $1.5 \mathrm{E}+01$ & $1.5 \mathrm{E}+01$ & $\begin{array}{l}5.6 \mathrm{E}+04 \\
66 \mathrm{E}+04 \\
\end{array}$ & $\frac{\mathrm{NA}}{\mathrm{NA}}$ & $\frac{\mathrm{NA}}{\mathrm{NA}}$ & $\frac{\text { NA }}{\text { NA }}$ & $\frac{\text { NA }}{\text { NA }}$ & NA & NA & NA & $9.1 \mathrm{E}+06$ & $7.0 \mathrm{E}+08$ & \\
\hline \begin{tabular}{|l} 
H-3_ETF.Carbon \\
I-129
\end{tabular} & $\frac{\mid-2}{1.9 \mathrm{E}-04}$ & $\mid$\begin{tabular}{|l|}
$1.8 \mathrm{E}-04$ \\
\end{tabular} & $\frac{\mid 6.6 \mathrm{E}+04}{7.4 \mathrm{E}-03}$ & $\frac{\mathrm{NA}}{\mathrm{NA}}$ & $\frac{\mathrm{NA}}{\mathrm{NA}}$ & $\frac{\mathrm{NA}}{\mathrm{NA}}$ & $\frac{\mathrm{NA}}{\mathrm{NA}}$ & $\frac{\mathrm{NA}}{\mathrm{NA}}$ & $\frac{\mathrm{NA}}{\mathrm{NA}}$ & $\frac{\mathrm{NA}}{\mathrm{NA}}$ & $\frac{1.7 \mathrm{E}+06}{5.4 \mathrm{E}-01}$ & $\frac{\frac{1.3 \mathrm{E}+09}{6.4 \mathrm{E}-01}}{\mid}$ & $3,2 \mathrm{E}+00$ \\
\hline I-129_ETF.Carbon & & & $2.0 \mathrm{E}-01$ & $\mathrm{NA}$ & NA & $\mathrm{NA}$ & NA & $\mathrm{NA}$ & & & $2.5 \mathrm{E}+01$ & & \\
\hline I-129_ETF.GT.73 & $1.4 \mathrm{E}+00$ & $8.8 \mathrm{E}-01$ & $2.7 \mathrm{E}-01$ & $\mathrm{NA}$ & $\mathrm{NA}$ & NA & NA & NA & $\mathrm{NA}$ & $\mathrm{NA}$ & $3,3 \mathrm{E}+01$ & $7 \mathrm{~F}+01$ & $1.2 \mathrm{E}+\mathrm{OI}$ \\
\hline I-129 F.Carbon & $1.8 \mathrm{E}+01$ & $1.2 \mathrm{E}+01$ & $3.5 \mathrm{E}+00$ & $\mathrm{NA}$ & $\mathrm{NA}$ & $\mathrm{NA}$ & $\mathrm{NA}$ & $\mathrm{NA}$ & $\mathrm{NA}$ & $\mathrm{NA}$ & $4.4 \mathrm{E}+02$ & $3 \mathrm{E}+02$ & $\frac{1.6 \mathrm{E}+\mathrm{OI}}{2.1 \mathrm{E}+02}$ \\
\hline I-129 F.C & & $4.5 \mathrm{E}-03$ & $3.8 \mathrm{E}-03$ & & & & NA & $\mathrm{NA}$ & NA & NA & $2.3 \mathrm{E}-01$ & $3.8 \mathrm{E}-01$ & $1.2 \mathrm{E}+00$ \\
\hline I-129_F.Dowex.21K & $9.3 \mathrm{E}-01$ & 6.0E-01 & $1.9 \mathrm{E}-01$ & $\mathrm{NA}$ & $\mathrm{NA}$ & NA & $\mathrm{NA}$ & NA & NA & NA & $2.2 \mathrm{E}+01$ & $1.2 \mathrm{E}+01$ & $1.1 \mathrm{E}+01$ \\
\hline I-129_F.Filtercake & $7.8 \mathrm{E}-03$ & $5.1 \mathrm{E}-03$ & $4.1 \mathrm{E}-03$ & NA & NA & NA & NA & NA & NA & NA & $2.5 \mathrm{E}-01$ & 4.0E-01 & $1.2 \mathrm{E}+00$ \\
\hline I-129_H.Carbon & $7.9 \mathrm{E}+00$ & $5.1 \mathrm{E}+00$ & $1.6 \mathrm{E}+00$ & NA & NA & NA & NA & NA & NA & NA & $1.9 \mathrm{E}+02$ & $1.0 \mathrm{E}+02$ & $9.4 \mathrm{E}+01$ \\
\hline I-129_H.CG.8 & $5.2 \mathrm{E}-02$ & $3.4 \mathrm{E}-02$ & $1.7 \mathrm{E}-02$ & NA & NA & NA & NA & NA & NA & NA & $1.3 \mathrm{E}+00$ & $1.1 \mathrm{E}+0 \mathrm{OO}$ & $1.0 \mathrm{E}+00$ \\
\hline 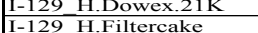 & $\frac{2.1 \mathrm{E}+00}{8.9 \mathrm{E}-02}$ & $\frac{1.4 \mathrm{E}+00}{5.8 \mathrm{E}-02}$ & \begin{tabular}{|l|}
$\frac{4.2 \mathrm{E}-01}{2.6 \mathrm{E}-02}$ \\
\end{tabular} & $\frac{\mathrm{NA}}{\mathrm{NA}}$ & $\frac{\mathrm{NA}}{\mathrm{NA}}$ & NA & NA & $\frac{\mathrm{NA}}{\mathrm{NA}}$ & $\frac{\text { NA }}{N A}$ & $\begin{array}{l}\text { NA } \\
\text { NA }\end{array}$ & $\frac{5.1 \mathrm{E}+01}{2.2 \mathrm{E}+00}$ & $2.7 \mathrm{E}+01$ & $\begin{array}{l}2.5 \mathrm{E}+01 \\
15 \mathrm{E}+00\end{array}$ \\
\hline $\begin{array}{l}\text { I-129. } \text { H.Filtercake } \\
\text { I-129 }\end{array}$ & $\frac{8.9 \mathrm{E}-02}{4.2 \mathrm{E}+0 \mathrm{O}}$ & $\frac{5.8 \mathrm{E}-02}{2.4 \mathrm{E}+00}$ & \begin{tabular}{|l}
$2.6 \mathrm{E}-02$ \\
$.5 \mathrm{E}-01$ \\
\end{tabular} & $\frac{\mathrm{NA}}{\mathrm{NA}}$ & $\frac{\mathrm{NA}}{\mathrm{NA}}$ & $\frac{\mathrm{NA}}{\mathrm{NA}}$ & $\frac{\mathrm{NA}}{\mathrm{NA}}$ & $\frac{\mathrm{NA}}{\mathrm{NA}}$ & $\frac{\mathrm{NA}}{\mathrm{NA}}$ & $\frac{\mathrm{NA}}{\mathrm{NA}}$ & $\frac{2.2 \mathrm{E}+00}{6.7 \mathrm{E}+01}$ & $\frac{1.7 \mathrm{E}+00}{2.7 \mathrm{E}+01}$ & $\mid \frac{1.5 \mathrm{E}+00}{8.9 \mathrm{E}+01}$ \\
\hline K-40 & $7.7 \mathrm{E}-02$ & $6.9 \mathrm{E}-02$ & $\frac{2.3 \mathrm{E}+00}{2.3 \mathrm{E}}$ & NA & NA & NA & NA & NA & NA & $\mathrm{NA}$ & $6.0 \mathrm{E}+00$ & $7.3 \mathrm{E}+00$ & \begin{tabular}{|l}
$.9 \mathrm{E}+01$ \\
$3.7 \mathrm{E}+01$ \\
\end{tabular} \\
\hline 93 & $2,6 \mathrm{E}-01$ & $\frac{0.35-02}{2.6 \mathrm{E}-01}$ & 4 & Nat & NA & NA & NA & $\mathrm{NA}$ & NA & $\frac{1}{N}$ & $5 \mathrm{E}+00$ & $44 \mathrm{E}+00$ & $\frac{3.9 \mathrm{E}+\mathrm{O} 1}{12 \mathrm{E}+03}$ \\
\hline & $1.3 \mathrm{E}-01$ & $1.3 \mathrm{E}-01$ & $3.9 \mathrm{E}+00$ & $\frac{\mathrm{NA}}{\mathrm{NA}}$ & $\frac{\mathrm{NA}}{\mathrm{NA}}$ & NA & NA & $\frac{\mathrm{NA}}{\mathrm{NA}}$ & $\frac{\mathrm{NA}}{\mathrm{NA}}$ & $\frac{\text { NA }}{\text { NA }}$ & $\frac{\mid 2.5 \mathrm{E}+01}{2.7 \mathrm{E}+00}$ & $\frac{4.4 \mathrm{E}+\mathrm{OI}}{4.8 \mathrm{E}+00}$ & $\mid \frac{1.2 \mathrm{E}+03}{1.2 \mathrm{E}+02}$ \\
\hline$\overline{N i-59}$ & $6.8 \mathrm{E}+19$ & $1.2 \mathrm{E}+13$ & $5.3 \mathrm{E}+00$ & NA & NA & NA & NA & NA & NA & NA & $2.0 \mathrm{E}+06$ & $2.5 \mathrm{E}+03$ & $1.3 \mathrm{E}+03$ \\
\hline$N p-237$ & $2.8 \mathrm{E}+03$ & $9.0 \mathrm{E}+01$ & $1.9 \mathrm{E}+00$ & $9.6 \mathrm{E}-02$ & $1.8 \mathrm{E}-01$ & 4.4E-01 & NA & $\mathrm{NA}$ & NA & $2.7 \mathrm{E}+08$ & $3.2 \mathrm{E}-02$ & $3.0 \mathrm{E}-02$ & $5.7 \mathrm{E}-02$ \\
\hline Pd-107 & & $1.4 \mathrm{E}+15$ & $6.4 \mathrm{E}$ & & & & NA & NA & & & $3.1 \mathrm{E}+06$ & $3.9 \mathrm{E}+03$ & $2.0 \mathrm{E}+03$ \\
\hline Pu-238 & --- & - & $1.2 \mathrm{E}$ & & & $1.3 \mathrm{E}+05$ & $4.4 \mathrm{E}+05$ & $1.4 \mathrm{E}+05$ & $1.3 \mathrm{E}+05$ & & $2.8 \mathrm{E}$ & $1.3 \mathrm{E}+06$ & $3.8 \mathrm{E}+05$ \\
\hline $\mid \frac{P u-239}{P u-240}$ & 1.1E+18 & $1.9 \mathrm{E}+15$ & $\begin{array}{l}1.3 \mathrm{E}+07 \\
2.7 \mathrm{E}+15\end{array}$ & \begin{tabular}{|l|l|l|l|l|}
$1.1 \mathrm{E}+07$ \\
$3.2 \mathrm{E}+08$
\end{tabular} & $\begin{array}{l}8.0 \mathrm{E}+06 \\
3.9 \mathrm{E}+07\end{array}$ & $\begin{array}{l}7.7 \mathrm{E}+06 \\
3.4 \mathrm{E}+07\end{array}$ & $\frac{\mathrm{NA}}{4.9 \mathrm{E}+15}$ & $\frac{\mathrm{NA}}{3.8 \mathrm{E}+15}$ & $\frac{N A}{36 E+15}$ & $\begin{array}{l}4.0 \mathrm{E}+15 \\
4.3 \mathrm{E}+15\end{array}$ & $5.1 \mathrm{E}+07$ & $\begin{array}{l}1.4 \mathrm{E}+06 \\
1.3 \mathrm{E}+08\end{array}$ & $1.2 \mathrm{E}+06$ \\
\hline \begin{tabular}{|l}
$\mathrm{Pu}-24 \mathrm{O}$ \\
$\mathrm{Pu}-241$ \\
\end{tabular} & $1.7 \mathrm{E}+12$ & $2.8 \mathrm{E}+10$ & $\begin{array}{l}\frac{2.7 \mathrm{E}+15}{3.9 \mathrm{E}+05} \\
\end{array}$ & $\begin{array}{l}\frac{3.2 \mathrm{E}+08}{7.8 \mathrm{E}+03} \\
\end{array}$ & $\frac{3.9 \mathrm{E}+07}{4.4 \mathrm{E}+03}$ & $\frac{3.4 \mathrm{E}+07}{4.2 \mathrm{E}+03}$ & $\begin{array}{l}4.9 \mathrm{E}+15 \\
\mathrm{NA}\end{array}$ & $\frac{3.8 \mathrm{E}+15}{\mathrm{NA}}$ & $\begin{array}{l}3.6 \mathrm{E}+15 \\
\mathrm{NA}\end{array}$ & $\frac{4.3 \mathrm{E}+15}{5.9 \mathrm{E}+13}$ & $\frac{1.5 \mathrm{E}+18}{2.6 \mathrm{E}+04}$ & $\frac{1.3 \mathrm{E}+08}{2.8 \mathrm{E}+03}$ & \begin{tabular}{|l|l|l|l}
$1.3 \mathrm{E}+07$ \\
$1.6 \mathrm{E}+03$
\end{tabular} \\
\hline $\begin{array}{l}\mathrm{Pu}-242 \\
\end{array}$ & --- & --- & $1.2 \mathrm{E}+14$ & $2.9 \mathrm{E}+08$ & $3.5 \mathrm{E}+07$ & 3.0 & & & & 年 & $3.9 \mathrm{E}+17$ & $1.05+03$ & \begin{tabular}{|l|l|}
$1.2 \mathrm{E}+07$ \\
\end{tabular} \\
\hline Pu-244 & & & $2.5 \mathrm{E}$ & 2.6 & 3.11 & $2.7 \mathrm{E}+07$ & & & $1.4 \mathrm{I}$ & $3.7 \mathrm{E}+\mathrm{t}-\mathrm{s}$ & & $1 \mathrm{E}+08$ & +07 \\
\hline $\mathrm{Ra}_{-}$ & $2.7 \mathrm{E}+17$ & $5.5 \mathrm{E}+10$ & $3.5 \mathrm{E}+00$ & & & 1.5 & 41. & $4.55-5,50$ & 4.5 & & & 10 & \\
\hline 26 Cooling Tower & & $4.9 \mathrm{E}+15$ & $1.6 \mathrm{E}$ & $2.7 \mathrm{E}-01$ & $1.5 \mathrm{E}+00$ & $1.2 \mathrm{E}+00$ & $2.7 \mathrm{E}-01$ & $1.5 \mathrm{E}+00$ & $1.2 \mathrm{E}+00$ & $\mathrm{~N}$ & $2.5 \mathrm{E}+04$ & 7.8E-01 & $\frac{1.5 \mathrm{E}-01}{3.6 \mathrm{E}+00}$ \\
\hline Se-79 & -- & --- & $3.9 \mathrm{E}+19$ & $\mathrm{NA}$ & $\mathrm{NA}$ & NA & NA & $\mathrm{NA}$ & NA & NA & & --- & $4.1 \mathrm{E}+19$ \\
\hline Sn-126 & & & & NA & NA & $\mathrm{N}$ & NA & NA & & NA & & & \\
\hline $\begin{array}{l}\frac{S r-90}{S-90} \\
\text { Se-90 }\end{array}$ & $1.2 \mathrm{E}+15$ & $7.9 \mathrm{E}+09$ & $8.8 \mathrm{E}+01$ & NA & $\mathrm{N}$ & & & $N$ & $\mathrm{~N}$ & & 1.0 & 1.71 & $3.2 \mathrm{E}+10$ \\
\hline \begin{tabular}{|l} 
Sr-90_Mk50A \\
$T C-99$
\end{tabular} & $\frac{1.6 \mathrm{E}+18}{18}$ & $9.3 \mathrm{E}+12$ & 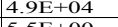 & NA & 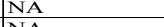 & & & & & & $4.5 \mathrm{E}+06$ & $\frac{05}{21}$ & $4.0 \mathrm{E}+12$ \\
\hline \begin{tabular}{|l|l} 
Tc-99 \\
Tc-99 Mk $50 \Delta$ \\
\end{tabular} & 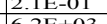 & $\left.\frac{1.8}{2.8}-x\right)$ & $\begin{array}{l}\frac{5.5 \mathrm{E}+00}{3.9 \mathrm{E}+02} \\
\end{array}$ & NA & $\mathrm{N} /$ & NA & $\frac{N A}{N A}$ & $\frac{\mathrm{NA}}{\mathrm{NA}}$ & $\frac{\mathrm{NA}}{\mathrm{NA}}$ & $\frac{N 2}{N}$ & $9.2 \mathrm{E}+00$ & $\frac{1.3 \mathrm{E}+01}{5.8 \mathrm{E}+02}$ & $\frac{1.0 \mathrm{E}+02}{2.0 \mathrm{E}+03}$ \\
\hline Th- & $0.2 \mathrm{E}+03$ & $\frac{2.81}{6.71}$ & $\begin{array}{l}\frac{3.9 \mathrm{E}+02}{1.0 \mathrm{E}+01} \\
\end{array}$ & & & & & & & & 1.1 & $\frac{12}{b 0}$ & $2.0 \mathrm{E}+03$ \\
\hline Cooling Tower & & & & & & & & & & & & & \\
\hline Cooming. 10wer & $7.1 \mathrm{E}+16$ & \begin{tabular}{|l}
$0.1 \mathrm{E}+10$ \\
$6 \mathrm{E}+12$ \\
\end{tabular} & $\frac{1.31}{3.11}$ & & & & $\frac{45+1}{4.25+1}$ & $9.9 \mathrm{E}+$ & $\frac{2.0 \mathrm{E}+\mathrm{C}}{1.3}$ & & $2.0 \mathrm{E}-\mathrm{C}$ & & \\
\hline & & --- & $5.7 \mathrm{E}$ & 1.4 & & & & & & & $=0$ & $4.6 \mathrm{E}+10$ & $4.6 \mathrm{E}+09$ \\
\hline U-234 & $\mid---$ & $3.8 \mathrm{E}+18$ & $3.0 \mathrm{E}$ & & & & & & & & 2.8 & $3.3 \mathrm{E}+02$ & $1.0 \mathrm{E}+02$ \\
\hline U-234_MGlass & & & $1.3 \mathrm{E}$ & & & & $4.3 \mathrm{E}+04$ & $1.5 \mathrm{E}+04$ & $1.4 \mathrm{E}+04$ & & $4.8 \mathrm{E}$ & $1.3 \mathrm{E}+05$ & $4.1 \mathrm{E}+04$ \\
\hline$U-235^{-1}$ & $2.0 \mathrm{E}+09$ & $4.3 \mathrm{E}+06$ & $7.3 \mathrm{E}+00$ & $5.7 \mathrm{E}$ & & & & NA & NA & & $3.8 \mathrm{E}+00$ & $6.8 \mathrm{E}-01$ & 7.4E-01 \\
\hline U-235_MGlass & $2.7 \mathrm{E}+12$ & $3.1 \mathrm{E}+09$ & $2.9 \mathrm{E}+03$ & $2.4 \mathrm{~F}$ & $2.2 \mathrm{E}-$ & $2.3 \mathrm{E}$ & $\mathrm{N}$ & $\mathrm{N}$ & $\mathrm{N} /$ & $9.5 \mathrm{E}+12$ & $9.0 \mathrm{E}+03$ & $3.1 \mathrm{E}+02$ & $2.8 \mathrm{E}+02$ \\
\hline \begin{tabular}{|l} 
U-235_Paducah.Cask \\
$U-236$
\end{tabular} & $6.6 \mathrm{E}+13$ & $7.5 \mathrm{E}+10$ & $\frac{3.1 \mathrm{E}+04}{2.8 \mathrm{E}+10}$ & 2.7 & $\frac{2.4}{2.9}$ & & & & & $\frac{1.0}{4.8}$ & $\frac{1.2 \mathrm{E}+05}{3.0 \mathrm{E}+12}$ & $\frac{3.31}{7.01}$ & $3.1 \mathrm{E}+03$ \\
\hline MGlass & --- & --- & $\begin{array}{l}2.8 \mathrm{E}+10 \\
1.9 \mathrm{E}+13\end{array}$ & 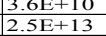 & $\frac{2.4}{2.5}$ & & & & & 14 & $\frac{2}{5}$ & & 0 \\
\hline Nidiass & & $1--$ & $3.9 \mathrm{E}+06$ & 1.5 & & & & & & & & & \\
\hline$\frac{U-2}{U-2}+a^{2}$ & & & $1.5 \mathrm{E}+09$ & $5.6 \mathrm{E}$ & $1.8 \mathrm{E}$ & 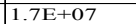 & & & & & & & \\
\hline$\frac{\mathrm{Zr}-93}{3}+2-3$ & $1.7 \mathrm{E}+00$ & $1.0 \mathrm{~F}$ & $8.8 \mathrm{E}-01$ & NA & $\mathrm{NA}$ & NA & NA & & & & $1.1 \mathrm{E}+01$ & $5.7 \mathrm{E}+00$ & $5.2 \mathrm{E}+00$ \\
\hline
\end{tabular}


Table 2 (continued)

\begin{tabular}{|c|c|c|c|c|c|c|c|c|c|c|c|c|c|}
\hline \multicolumn{4}{|l|}{ cenario1b-2s } & \multirow[b]{2}{*}{$0-1000$} & \multirow{2}{*}{$\begin{array}{c}\text { Gross Alpha } \\
1000-1120\end{array}$} & \multirow[b]{2}{*}{$1120-1130$} & \multicolumn{3}{|c|}{ Radium } & \multirow{2}{*}{\begin{tabular}{|c|} 
Uranium \\
$0-1130$
\end{tabular}} & \multirow{2}{*}{\begin{tabular}{|r|} 
Grounn \\
$130-200$ \\
\end{tabular}} & \multirow[b]{2}{*}{$\begin{array}{l}\text { dwater All- } \\
200-1000\end{array}$} & \multirow{2}{*}{$\begin{array}{l}\text { Pathways } \\
1000-1130\end{array}$} \\
\hline & $0-12$ & $\begin{array}{l}\text { Beta-Gammaa } \\
12-100\end{array}$ & $100-1130$ & & & & 0- & \begin{tabular}{|c|}
$1000-1120$ \\
\end{tabular} & $1120-1130$ & & & & \\
\hline Parent Nuclide & $\frac{\text { yrs }}{1}$ & $\frac{\text { yrs }}{10}$ & yrs & yrs & $\frac{\text { yrs }}{155+02}$ & yrs & yrs & yrs & yrs & yrs & yrs & yrs & yrs \\
\hline \begin{tabular}{|l|} 
Am-241 \\
$\mathrm{Am}-243$
\end{tabular} & & & $\begin{array}{l}1.3 E+04 \\
5.7 E+02\end{array}$ & $\begin{array}{l}\frac{2.0 E+02}{7.9 E+01} \\
\end{array}$ & $\frac{1.0 E+02}{3.0 E+01}$ & $\frac{1.4 E+02}{2.9 E+01}$ & NA & NA & NA & $\begin{array}{l}1.9 E+12 \\
1.5 E+12\end{array}$ & $\frac{1.4 E+U 2}{3.4 E+10}$ & $\frac{9.4 E+O 1}{3.0 E+01}$ & $\begin{array}{l}5.4 \mathrm{E}+01 \\
1.1 \mathrm{E}+01\end{array}$ \\
\hline & $3.9 \mathrm{E}+\mathrm{OO}$ & $4.7 E+00$ & $3.8 \mathrm{E}+0 \mathrm{O}$ & & NA & & NA & NA & NA & & $3.9 E+0 O$ & $1.1 \mathrm{E}+01$ & $\frac{1 E+01}{9 E+02}$ \\
\hline Pump & & & $2.9 \mathrm{E}+00$ & NA & NA & NA & NA & NA & NA & NA & $3.6 E+00$ & $3.1 \mathrm{E}+0 \mathrm{O}$ & $\frac{1.9 \mathrm{C}+\mathrm{OL}}{1.2 \mathrm{E}+02}$ \\
\hline Cf-249 & $1.2 \mathrm{E}+19$ & $7.1 \mathrm{E}+17$ & $3.9 E+04$ & $3.8 \mathrm{E}+02$ & $1.7 E+02$ & $1.6 E+02$ & NA & NA & NA & $1.1 E+14$ & $2.2 E+06$ & $1.2 \mathrm{E}+02$ & $4.9 E+01$ \\
\hline Cf-251 & & & $2.0 E+08$ & $1.6 \mathrm{E}+02$ & $6.5 \mathrm{E}+01$ & $6.2 \mathrm{E}+01$ & NA & NA & NA & $9.7 E+17$ & $4.2 \mathrm{E}+18$ & $4.5 E+01$ & $1.8 \mathrm{E}+01$ \\
\hline \begin{tabular}{|l|l|}
$\mathrm{Cl}-36$ \\
$\mathrm{C}-3$
\end{tabular} & $1.4 \mathrm{E}+\mathrm{OO}$ & $1.7 \mathrm{E}+\mathrm{OO}$ & $1.3 \mathrm{E}+\mathrm{OO}$ & & & & & NA & NA & & $6.9 \mathrm{E}-01$ & $1.9 \mathrm{E}+\mathrm{OO}$ & $4.6 \mathrm{E}+01$ \\
\hline \begin{tabular}{|l|}
$\mathrm{Cm}-244$ \\
$\mathrm{Cm}-245$ \\
\end{tabular} & 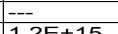 & & $1.1 \mathrm{E}+18$ & 1. $0 E+11$ & $1.3 \mathrm{E}+1 \mathrm{O}$ & $1.1 \mathrm{E}+10$ & $1.9 E+18$ & $1.5 \mathrm{E}+18$ & $1.4 \mathrm{E}+18$ & $1.4 \mathrm{E}+18$ & & $4.1 \mathrm{E}+10$ & $4.4 \mathrm{E}+09$ \\
\hline $\mid \frac{\mathrm{Cm}-245}{\mathrm{Cm}-246}$ & $1.2 E+15$ & 1.0E+14 & $\begin{array}{l}\frac{1.4 \mathrm{E}+\mathrm{O} 3}{9.3 \mathrm{E}+14} \\
\end{array}$ & $\begin{array}{l}\frac{4.3 \mathrm{E}+01}{8.3 \mathrm{E}+01} \\
\end{array}$ & \begin{tabular}{|l|}
$1.7 E+01$ \\
$3.2 E+01$
\end{tabular} & $\frac{1.5 \mathrm{E}+01}{3.0 \mathrm{E}+01}$ & $\begin{array}{l}\text { NA } \\
1.4 E+16\end{array}$ & $\frac{N A}{4.3 E+15}$ & $\frac{N A}{3.9 E+15}$ & $\mid \begin{array}{l}2.1 \mathrm{E}+12 \\
2.3 \mathrm{E}+13\end{array}$ & $\begin{array}{l}7.7 E+03 \\
---\end{array}$ & $\begin{array}{l}\frac{1.6 \mathrm{E}+01}{3.1 \mathrm{E}+01} \\
\end{array}$ & $\begin{array}{l}5.7 \mathrm{E}+\mathrm{OO} \\
1 . \mathrm{E}+01\end{array}$ \\
\hline $\mathrm{Cm}-247$ & ---- & --- & $\begin{array}{l}\text { 3. } \\
4.3 E+14 \\
E+03\end{array}$ & 6. $6.6 \mathrm{E}+01$ & $2.5 \mathrm{E}+01$ & $2.3 E+01$ & NA & NA & NA & $1.6 \mathrm{E}+13$ & $7.4 E+12$ & $\frac{3.1 E+01}{2.6 E+01}$ & $\begin{array}{l}1.1 \mathrm{E}+01 \\
9.3 \mathrm{E}+0 \mathrm{O}\end{array}$ \\
\hline $\mathrm{Cm}-248$ & & & 3.7E+09 & $7.9 \mathrm{E}+01$ & $3.0 E+01$ & $2.8 \mathrm{E}+01$ & & & & $3.5 E+17$ & & $7.3 \mathrm{E}+0 \mathrm{O}$ & $2.6 \mathrm{E}+\mathrm{OO}$ \\
\hline $\mathrm{H}-3$ & $6.2 \mathrm{E}+01$ & $1.0 \mathrm{E}+\mathrm{O} 2$ & $2.3 \mathrm{E}+\mathrm{O} 4$ & NA & NA & NA & NA & NA & NA & NA & $1.7 \mathrm{E}+06$ & $3.2 E+08$ & $1--$ \\
\hline \begin{tabular}{|l}
$\mathrm{H}-3$ - Concrete \\
$\mathrm{H}-3$ ETF Carbon
\end{tabular} & $1.5 \mathrm{E}+02$ & $\frac{2.4 \mathrm{E}+02}{---1}$ & \begin{tabular}{|l|}
$5.4 E+04$ \\
$6.6 E+04$
\end{tabular} & $\frac{N A}{N A}$ & $\frac{\text { NA }}{\text { NA }}$ & $\frac{N A}{N A}$ & $\frac{N A}{N A}$ & $\frac{N A}{N A}$ & NA & NA & $\begin{array}{l}4.0 E+06 \\
17 E+06 \\
7\end{array}$ & $\begin{array}{l}7.4 E+08 \\
13 E+09\end{array}$ & \\
\hline$\frac{\mathrm{H}-3=\text { ETF.Carbon }}{1-129}$ & \begin{tabular}{|l|}
--- \\
$3 \mathrm{E}-03$ \\
\end{tabular} & $3.2 \mathrm{E}-03$ & $\frac{6.6 \mathrm{E}+04}{1.7 \mathrm{E}-03}$ & NA & $\frac{\mathrm{NA}}{\mathrm{NA}}$ & $\frac{N A}{N A}$ & $\frac{N A}{N A}$ & $\frac{\mathrm{NA}}{\mathrm{NA}}$ & $\frac{N A}{N A}$ & $\frac{N A}{N A}$ & $\frac{1.7 E+06}{1.0 E-01}$ & $\frac{1.3 \mathrm{E}+09}{2.2 \mathrm{E}-01}$ & $2.5 \mathrm{E}+0 \mathrm{O}$ \\
\hline 1-129_ETF.Carbon & & & $2.0 \mathrm{E}-01$ & NA & NA & NA & NA & NA & NA & NA & $2.5 \mathrm{E}+01$ & $1.3 \mathrm{E}+01$ & $1.2 E+01$ \\
\hline 1-129_ETF.GT.73 & $1.1 \mathrm{E}+01$ & $1.7 \mathrm{E}+01$ & 2.7E-01 & NA & NA & NA & NA & NA & NA & NA & $3.3 E+01$ & $1.7 E+01$ & $1.6 E+01$ \\
\hline I-129_F.Carbon & $1.5 \mathrm{E}+\mathrm{O} 2$ & $2.3 E+02$ & $3.5 \mathrm{E}+\mathrm{OO}$ & NA & NA & NA & NA & NA & NA & NA & $\begin{array}{l}4.4 \mathrm{E}+02 \\
2.2 \mathrm{E}-01\end{array}$ & $2.3 E+02$ & $2.1 \mathrm{E}+02$ \\
\hline \begin{tabular}{|l} 
I-129_F.CG.8 \\
$1-129$ F.Dowex.21K
\end{tabular} & \begin{tabular}{|l|}
$5.7 E-02$ \\
$7.6 E+00$
\end{tabular} & \begin{tabular}{|l|}
$8.7 \mathrm{E}-\mathrm{O}-2$ \\
$1.2 \mathrm{E}+01$
\end{tabular} & $\begin{array}{l}3.6 \mathrm{E}-\mathrm{O} 3 \\
1.9 \mathrm{E}-01 \\
\end{array}$ & $\begin{array}{l}\text { NA } \\
\text { NA }\end{array}$ & $\frac{\text { NA }}{\text { NA }}$ & $\begin{array}{l}\text { NA } \\
\text { NA }\end{array}$ & $\begin{array}{l}\text { NA } \\
\text { NA }\end{array}$ & $\frac{\mathrm{NA}}{\mathrm{NA}}$ & $\begin{array}{l}\text { NA } \\
\text { NA }\end{array}$ & NA & $\frac{2.2 E-01}{2.3 E+01}$ & \begin{tabular}{|l|}
$3.6 \mathrm{E}-\mathrm{O} 1$ \\
$1.2 \mathrm{E}+01$
\end{tabular} & $\frac{1.2 \mathrm{E}+\mathrm{OO}}{1.1 \mathrm{E}+\mathrm{O} 1}$ \\
\hline 1-129_F.Filtercake & $6.4 \mathrm{E}-02$ & $9.9 \mathrm{E}-02$ & $3.9 \mathrm{E}-03$ & NA & NA & NA & NA & NA & NA & NA & $2.4 \mathrm{E}-01$ & $3.8 \mathrm{E}-01$ & $1.2 \mathrm{E}+\mathrm{OO}$ \\
\hline 1-129_H.Carbon & $6.5 E+01$ & $1.0 E+02$ & $1.6 \mathrm{E}+00$ & NA & NA & NA & NA & NA & NA & NA & $1.9 E+02$ & $1.0 E+02$ & $9.4 \mathrm{E}+01$ \\
\hline 1-129_H.C & 4.3E-01 & 6.6E-01 & 1.6E-02 & NA & NA & NA & NA & NA & NA & NA & $1.3 \mathrm{E}+0 \mathrm{O}$ & $1.1 \mathrm{E}+0 \mathrm{O}$ & 9.9E-01 \\
\hline 1-129_H.Dowex.21K & 1.7E+01 & $\begin{array}{l}2.7 \mathrm{E}+01 \\
1.5+00\end{array}$ & $4.2 \mathrm{E}-01$ & NA & NA & NA & NA & NA & NA & NA & $5.2 \mathrm{E}+01$ & $2.7 \mathrm{E}+01$ & $2.5 \mathrm{E}+01$ \\
\hline $\begin{array}{l}\text { I-129_H.Filtercake } \\
\text { L-129 MK50A }\end{array}$ & \begin{tabular}{|l|}
$7.3 \mathrm{E}-01$ \\
$4.9 \mathrm{E}+01$
\end{tabular} & $\frac{1.1 \mathrm{E}+\mathrm{OO}}{6.9 \mathrm{E}+01}$ & $\begin{array}{l}2.5 \mathrm{E}-02 \\
4.4 \mathrm{E}-01\end{array}$ & $\begin{array}{l}\text { NA } \\
\text { NA }\end{array}$ & $\begin{array}{l}\text { NA } \\
\text { NA }\end{array}$ & $\frac{N A}{N A}$ & $\begin{array}{l}\text { NA } \\
\text { NA }\end{array}$ & $\begin{array}{l}\text { NA } \\
\text { NA }\end{array}$ & $\begin{array}{l}\text { NA } \\
\text { NA }\end{array}$ & $\begin{array}{l}\text { NA } \\
\text { NA }\end{array}$ & $\frac{2.2 E+00}{6.3 E+01}$ & $\frac{1.7 E+00}{2.7 E+01}$ & $\begin{array}{l}1.5 \mathrm{E}+0 \mathrm{OO} \\
8.9 \mathrm{E}+01\end{array}$ \\
\hline K-40 = IVKJOA & \begin{tabular}{|l|}
$4.9 E+01$ \\
$4.6 E-01$
\end{tabular} & $\begin{array}{l}\mid .9 \mathrm{E}+\mathrm{U} 1 \\
7.1 \mathrm{E}-01\end{array}$ & $\begin{array}{l}\frac{4}{4.4 E-1} \\
5.9 E-(\end{array}$ & NA & NA & NA & NA & NA & NA & NA & 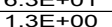 & $\frac{2.1 \mathrm{E}+\mathrm{UI}}{2.5 \mathrm{E}+0 \mathrm{O}}$ & $\frac{8.9 E+01}{2.7 E+01}$ \\
\hline 3 & \begin{tabular}{|l|} 
3.0E- \\
$3 E+00$
\end{tabular} & $\frac{1.1 E-01}{2.7 E+00}$ & \begin{tabular}{|l|}
$1.5 E+00$ \\
\end{tabular} & NA & NA & NA & NA & NA & NA & $\frac{\mathrm{IA}}{\mathrm{JA}}$ & $7.3 E+00$ & $\frac{1}{21 \mathrm{E}+01}$ & $\frac{2.9+\mathrm{E}+\mathrm{O1}}{5.6 \mathrm{E}+02}$ \\
\hline$\frac{4}{4}$ & $1.5 E+00$ & $1.8 \mathrm{E}+0 \mathrm{OO}$ & & NA & NA & NA & NA & NA & NA & $\mathrm{NA}$ & $3.1 \mathrm{E}-01$ & $\frac{2.2 \mathrm{E}+}{2.2}$ & $5.5 E+01$ \\
\hline & & $6.0 E+16$ & +00 & $\mathrm{~N} / \mathrm{s}$ & $\mathrm{N}$ & & NA & NA & NA & & 2.6 & 2.6 & $1.4 E+03$ \\
\hline $\mathrm{Np}-237$ & $7.0 E+04$ & $1.2 \mathrm{E}+04$ & $1.9 \mathrm{E}+\mathrm{OO}$ & 9.3E-02 & $1.8 \mathrm{E}-01$ & $4.3 \mathrm{E}-01$ & NA & NA & NA & $2.8 \mathrm{E}+08$ & $3.1 \mathrm{E}$ & $2.9 \mathrm{E}-02$ & 5.6E-02 \\
\hline Pd-107 & --- & $7.3 E+18$ & $6.7 \mathrm{E}+02$ & & & INA & & NA & NA & NA & 4.0 C.+00 & $3.9 \mathrm{E}+03$ & $2.1 \mathrm{E}+03$ \\
\hline $\begin{array}{l}\text { Pu-238 } \\
\text { Pu-239 }\end{array}$ & & & 1.2 & & & $1.3 E+05$ & $4.4 \mathrm{E}+05$ & $1.4 \mathrm{E}+05$ & $1.3 \mathrm{E}+05$ & 17 & 9 & 1.3 & $3.8 \mathrm{E}+05$ \\
\hline $\begin{array}{l}\mathrm{Pu}-239 \\
\mathrm{Pu}-240\end{array}$ & $2.5 \mathrm{E}+19$ & $\begin{array}{l}4.5 E+17 \\
---\end{array}$ & \begin{tabular}{|l|l|}
$1.3 E+07$ \\
$27 E+15$
\end{tabular} & $\begin{array}{l}1.1 \mathrm{E}+07 \\
3.3 \mathrm{E}+08\end{array}$ & $\begin{array}{l}8.0 E+06 \\
40 E+07\end{array}$ & $\begin{array}{l}7.7 E+06 \\
3.4 E+07\end{array}$ & $\frac{N A}{4.9 E+15}$ & $\frac{N A}{38 E+15}$ & $\frac{N A}{36 E+15}$ & \begin{tabular}{|l}
$4.1 \mathrm{E}+15$ \\
$4.4 \mathrm{E}+15$ \\
\end{tabular} & $\begin{array}{l}5.1 \mathrm{E}+07 \\
1.5 \mathrm{E}+18 \\
\end{array}$ & $\begin{array}{l}1.4 E+06 \\
1.3 E+08\end{array}$ & $\begin{array}{l}1.2 \mathrm{E}+06 \\
1.3 \mathrm{E}+07\end{array}$ \\
\hline \begin{tabular}{|l}
$\mathrm{Pu}-240$ \\
$\mathrm{Pu}-241$
\end{tabular} & $7.8 \mathrm{E}+13$ & $8.8 \mathrm{E}+12$ & \begin{tabular}{|l|l|}
2.7 E +15 \\
$3.9 E+05$
\end{tabular} & $\begin{array}{l}3.3 \mathrm{E}+08 \\
7.8 \mathrm{E}+03\end{array}$ & $\frac{4.0 E+07}{4.4 E+03}$ & $\begin{array}{l}3.4 \mathrm{E}+\mathrm{OT} \\
4.2 \mathrm{E}+03\end{array}$ & $\frac{4.9 E+15}{N A}$ & $\frac{3.8 E+15}{\mathrm{NA}}$ & \begin{tabular}{|l} 
3.6E +15 \\
NA
\end{tabular} & $\begin{array}{l}\frac{4.4 E+15}{5.9 E+13} \\
5.95\end{array}$ & $\frac{1.5 E+18}{2.6 E+04}$ & $\frac{1.3 \mathrm{E}+08}{2.8 \mathrm{E}+03}$ & $\begin{array}{l}1.3 \mathrm{E}+07 \\
1.6 \mathrm{E}+03\end{array}$ \\
\hline & --- & --- & $1.2 \mathrm{E}+14$ & $3.0 \mathrm{E}$ & 3.61 & $\frac{4.2 \mathrm{~L}+00}{3.0 \mathrm{E}+07}$ & $4.4 \mathrm{E}$ & $1.4 \mathrm{E}$ & & t.joc & 2.0달 & 2.0 & $1.02+05$ \\
\hline & & & 2.6 & & 3.2 & 07 & & & & $3.7 \mathrm{E}$ & & -08 & +07 \\
\hline & $4.7 E+18$ & $2.2 E+14$ & & & $4: 5<5$ & $4.5 \mathrm{E}-02$ & & & & & & $2.7 \mathrm{E}-01$ & \\
\hline 26 Cooling.Tower & & $3.9 E+19$ & $1.6 E+01$ & 2.7E-01 & $1.7 E+00$ & $1.4 \mathrm{E}+\mathrm{OO}$ & $2.7 \mathrm{E}-01$ & $1.7 E+00$ & $1.4 E+0 O$ & NA & $3.6 E+04$ & 7.8E-01 & $4.1 \mathrm{E}+\mathrm{OO}$ \\
\hline Se-79 & --- & --- & $4.0 E+19$ & NA & NA & NA & NA & NA & NA & NA & & & $4.2 E+19$ \\
\hline Sn-126 & & 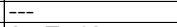 & & $\mathrm{N}$ & NA & $N$ & NA & $N$ & $\mathrm{~N}$ & NA & & & \\
\hline Mk50A & $2.3 E+16$ & $3.5 \mathrm{E}+13$ & $9.1 \mathrm{E}+$ & $N$ & $N$ & & NA & $N$ & $N$ & NA & $\frac{04}{96}$ & 1.8 & +10 \\
\hline $\begin{array}{l}\text { Sr-90_Mk50A } \\
\text { TC-99 }\end{array}$ & $3.6 E+19$ & $\begin{array}{l}5.2 \mathrm{E}+16 \\
3 . \mathrm{E}+00\end{array}$ & $\begin{array}{l}5.0 \\
1.5 \\
1.5\end{array}$ & $N /$ & NA & & NA & NA & NA & IA & & $\begin{array}{l}9.6 \mathrm{E}+05 \\
42 \mathrm{E}+00\end{array}$ & $E+12$ \\
\hline $\begin{array}{l}\text { TC-99 } \\
\text { TC-99 Mk50A }\end{array}$ & \begin{tabular}{|l|}
$8.8 E+00$ \\
$9.5 E+04$
\end{tabular} & $\begin{array}{l}3.0 E+0 O \\
9.2 E+04\end{array}$ & $\begin{array}{l}1.5 \mathrm{E} \\
3.8 \mathrm{E}\end{array}$ & $\frac{N A}{N A}$ & $\begin{array}{l}\text { NA } \\
\text { NA }\end{array}$ & $\frac{N A}{N A}$ & $\frac{N A}{N A}$ & $\begin{array}{l}\text { NA } \\
\text { NA }\end{array}$ & $\begin{array}{l}\text { NA } \\
\text { NA }\end{array}$ & $\begin{array}{l}\text { NA } \\
\text { NA }\end{array}$ & $\frac{2.3}{1.6}$ & $\begin{array}{l}\frac{4.2 E+0 O}{5.7 E+02} \\
\end{array}$ & $\begin{array}{l}\frac{5.4 E+01}{2.0 E+03} \\
.0 E+03\end{array}$ \\
\hline Th-230 & & $3.8 \mathrm{E}+17$ & & & & & & & & NA & 1.8 & $1.1 \mathrm{E}+\mathrm{OO}$ & $3.6 \mathrm{E}-01$ \\
\hline Th-230_Cooling.Tower & & & & & & 2.0 & & & & $\mathrm{~N}$ & $6.8 \mathrm{E}$ & 6.6 & 5. \\
\hline Th-23 & $1.6 \mathrm{E}+18$ & $8.8 \mathrm{E}+16$ & & & & & $4.2 \mathrm{E}+03$ & $9.9 E+03$ & $1.3 \mathrm{E}+04$ & & $2.0 E+04$ & 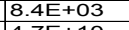 & 2050 \\
\hline & --- & $\frac{---}{---}$ & $\frac{5.8 E+11}{3.0 E+03}$ & $\frac{1.4 \mathrm{E}}{1.1 \mathrm{E}}$ & $\frac{1.5}{3.6}$ & $\frac{1.2}{3.4}$ & & & $\frac{\mathrm{NA}}{3.4}$ & & & $\frac{4.7}{3.3}$ & \\
\hline MGlass & & & & & & & $4.3 \mathrm{E}$ & $1.5 \mathrm{E}$ & $1.4 \mathrm{E}$ & & & & 04 \\
\hline $\mathrm{U}-$ & $3.3 E+10$ & $7.5 \mathrm{E}+08$ & 7.5 & & & 7. & $\mathrm{~N}$ & $\mathrm{~N}$ & $\mathrm{~N}$ & 1.6 & & $6.8 \mathrm{E}-01$ & 7. \\
\hline U-235_MGlass & $5.3 \mathrm{E}+13$ & 1.1E+12 & $2.9 \mathrm{E}+03$ & $2.5 E+03$ & $2.2 \mathrm{E}+03$ & $2.3 E+03$ & $N$ & $N$ & $\mathrm{~N}$ & $9.7 \mathrm{E}+12$ & $9.1 \mathrm{E}+03$ & $3.1 \mathrm{E}+02$ & $2.8 \mathrm{E}+02$ \\
\hline U-235_Paducah.Cask & $1.3 E+15$ & $2.6 \mathrm{E}+13$ & $\frac{3.1 \mathrm{E}}{28 \mathrm{E}}$ & $\frac{2.7}{3.7}$ & $\frac{2.4 \mathrm{E}}{2.9 \mathrm{E}}$ & $\frac{2.5 \mathrm{E}+04}{2.8 \mathrm{E}+10}$ & $\frac{N A}{491}$ & $\frac{N A}{391}$ & $\frac{\text { NA }}{38}$ & $\frac{1.1}{4.8}$ & $\frac{1 .}{3}$. & 03 & $E+03$ \\
\hline U-236_MGlass & $-\ldots$ & ---- & $\begin{array}{l}\frac{2.8 \mathrm{E}+10}{1.9 \mathrm{E}+13} \\
\end{array}$ & $\frac{3.7}{2.5}$ & $\frac{2.9}{2.0}$ & $\frac{2.8}{2.0}$ & $\frac{4.91}{3.31}$ & $\frac{3.91}{2.7}$ & & $\frac{4.8}{2.9}$ & $\frac{3.0}{4.1}$ & -13 & $E+12$ \\
\hline $\mathrm{U}-238$ & --- & --- & $3.9 E+06$ & $1.5 \mathrm{E}$ & $4.6 \mathrm{E}$ & 4.31 & 1.5 & $4.6 \mathrm{E}$ & 4.3 & $2.5 \mathrm{E}$ & $2.1 \mathrm{E}$ & & \\
\hline 3 MGlass & & & $\begin{array}{l}\frac{1.5 \mathrm{E}+09}{8.8 \mathrm{E}-01} \\
\end{array}$ & $6 E-2+2$ & $\begin{array}{l}1.8 \mathrm{E} \\
\mathrm{NA}\end{array} \mathrm{C} \mathrm{C}$ & $\frac{1.71}{N A}$ & $5.6 E+$ & $\frac{.8 \mathrm{E}+07}{\mathrm{VA}}$ & NA & $15 \mathrm{E}$ & & & \\
\hline & & & & & & & & & & & & & \\
\hline
\end{tabular}


Table 2 (continued)

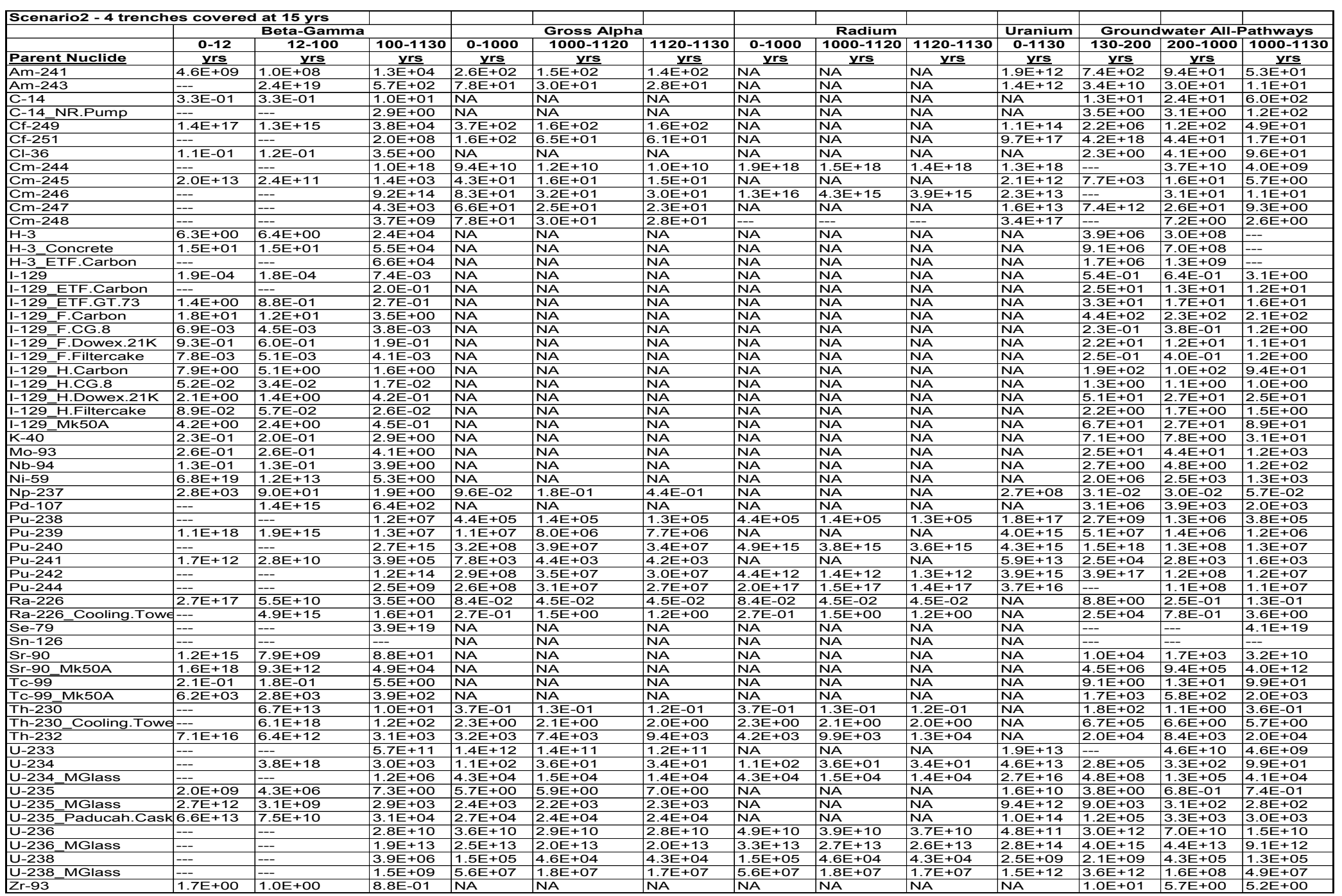


Table 2 (continued)

\begin{tabular}{|c|c|c|c|c|c|c|c|c|c|c|c|c|c|}
\hline \multicolumn{3}{|c|}{ Scenario2b - 4 trenches covered at 5 yrs } & \multirow{2}{*}{$100-1130$} & \multirow[b]{2}{*}{$0-1000$} & \multirow{2}{*}{\begin{tabular}{|c} 
Gross Alpha \\
$1000-1120$ \\
\end{tabular}} & \multirow{2}{*}{$1120-1130$} & \multirow{2}{*}{\multicolumn{3}{|c|}{ Radium }} & \multirow[b]{2}{*}{\begin{tabular}{|c|} 
Uranium \\
$0-1130$ \\
\end{tabular}} & \multirow[b]{2}{*}{ Groun } & \multirow[b]{2}{*}{ dwater All-1 } & \multirow{2}{*}{$\begin{array}{l}\text { Pathways } \\
1000-1130 \\
\end{array}$} \\
\hline & $0-12$ & \begin{tabular}{|c|} 
Beta-Gamma \\
$12-100$
\end{tabular} & & & & & & & & & & & \\
\hline Parent Nuclide & yrs & yrs & $\frac{\text { yrs }}{13+04}$ & $\frac{\text { yrs }}{2}$ & $\begin{array}{c}\text { yrs } \\
\end{array}$ & $\frac{\text { yrs }}{14 \mathrm{~F}^{2}}$ & yrs & yrs & yrs & yrs & yrs & yrs & \begin{tabular}{|c|} 
yrs \\
$5.4 \mathrm{E}+\mathrm{O} 1$
\end{tabular} \\
\hline Am-243 & & & $\frac{1.3 E+04}{5.7 E+02}$ & $\begin{array}{l}2.6 \mathrm{E}+02 \\
7.9 \mathrm{E}+01\end{array}$ & $\frac{1.5 E+02}{3.0 E+01}$ & $\frac{1.4 \mathrm{E}+02}{2.8 \mathrm{E}+01}$ & $\frac{N A}{N A}$ & NA & NA & $\mid \begin{array}{l}1.9 \mathrm{E}+12 \\
1.5 \mathrm{E}+12\end{array}$ & $\begin{array}{ll}7.3 \mathrm{E}+\mathrm{O} 2 \\
3.4 \mathrm{E}+10 \\
\end{array}$ & \begin{tabular}{|l|l|}
$9.4 \mathrm{E}+01$ \\
$3.0 \mathrm{E}+01$
\end{tabular} & $\frac{5.4 \mathrm{E}+01}{1.1 \mathrm{E}+01}$ \\
\hline $\mathrm{C}-14$ & $3.9 E+00$ & $4.8 \mathrm{E}+0 \mathrm{O}$ & $3.8 \mathrm{E}+00$ & & & & NA & NA & NA & & 3.45E+00 & $1.1 \mathrm{E}+01$ & $2.5 \mathrm{E}+02$ \\
\hline NR.Pump & & & $2.9 E+00$ & NA & & & NA & NA & NA & & $3.5 \mathrm{E}+0 \mathrm{OO}$ & $3.1 \mathrm{E}+0 \mathrm{OO}$ & $1.2 \mathrm{E}+02$ \\
\hline & $1.2 \mathrm{E}+19$ & $7.2 \mathrm{E}+17$ & $3.9 \mathrm{E}+04$ & $3.8 \mathrm{E}+02$ & $1.7 \mathrm{E}+02$ & $1.6 \mathrm{E}+02$ & NA & NA & NA & 1.1E+14 & $2.2 \mathrm{E}+06$ & $1.2 \mathrm{E}+02$ & $4.9 E+01$ \\
\hline$\frac{\mathrm{Cf}-1}{\mathrm{Cl}-}$ & $-\frac{-}{1.4 E+00}$ & $1.7 \mathrm{E}+\mathrm{OO}$ & $\frac{2.0 E+08}{1.3 E+00}$ & $\frac{1.6 \mathrm{E}+02}{\mathrm{NA}}$ & $\frac{6.5 \mathrm{E}+01}{\mathrm{NA}}$ & $\frac{6.2 \mathrm{E}+01}{\mathrm{NA}}$ & $\frac{N A}{N A}$ & NA & $\frac{N A}{N A}$ & $\begin{array}{ll}9.7 \mathrm{E}+17 \\
\mathrm{NA}\end{array}$ & $\frac{4.2 E+18}{6.9 E-01}$ & $\frac{4.5 \mathrm{E}+01}{1.9 \mathrm{E}+00}$ & $\frac{1.8 \mathrm{E}+01}{4.0 \mathrm{E}+01}$ \\
\hline $\mathrm{Cm}$ & & & 1.0E+18 & $1.0 E+11$ & $1.3 E+10$ & $\frac{N A}{1.1 E+10}$ & $\frac{N A}{1.9 E+18}$ & $\frac{\mathrm{NA}}{1.5 \mathrm{E}+18}$ & $1.4 E+18$ & $\frac{N A}{1.4 E+18}$ & $6.9 \mathrm{E}-01$ & $\frac{1.9 E+00}{4.1 E+10}$ & $\frac{4.0 E+01}{4.4 E+09}$ \\
\hline & $1.2 \mathrm{E}+15$ & $1.0 E+14$ & $1.4 E+03$ & 4.3E+01 & $1.6 \mathrm{E}+01$ & $1.5 \mathrm{E}+01$ & & & & 2.1E+12 & $7.7 \mathrm{E}+03$ & 1.6E+01 & $5.7 \mathrm{E}+00$ \\
\hline & & & $9.3 E+14$ & $8.3 \mathrm{E}+01$ & $2 E+01$ & $3.0 \mathrm{E}+01$ & $1.3 E+16$ & $4.3 \mathrm{E}$ & $3.9 \mathrm{E}$ & $2.3 E+13$ & & $3.1 \mathrm{E}+01$ & $1.1 \mathrm{E}+01$ \\
\hline$\frac{\mathrm{Cm}}{\mathrm{Cm}}$ & & --- & $\frac{4.3 E+03}{3.75+09}$ & $\begin{array}{l}6.6 E+01 \\
7.9 E+01\end{array}$ & $\frac{2.5 \mathrm{E}+01}{30 \mathrm{E}+01}$ & $\begin{array}{l}2.3 \mathrm{E}+01 \\
2.8 \mathrm{E}+01\end{array}$ & NA & NA & NA & 1. $6 E+13$ & $7.4 \mathrm{E}+12$ & 01 & $\begin{array}{ll}3 E+0 O \\
65+00\end{array}$ \\
\hline \begin{tabular}{|l}
$\mathrm{Cm}-3$ \\
$\mathrm{H}-3$
\end{tabular} & $6.2 \mathrm{E}+01$ & $\mid--\overline{0 E}+02$ & $\frac{3.7 E+09}{2.3 E+04}$ & $\begin{array}{l}7.9 E+01 \\
N A\end{array}$ & $\begin{array}{l}3.0 E+01 \\
\text { NA }\end{array}$ & $\begin{array}{l}2.8 \mathrm{E} \\
\mathrm{NA}\end{array}$ & NA & NA & NA & $\begin{array}{l}3.5 E+17 \\
\text { NA }\end{array}$ & $\mid---7$ & $\mid \begin{array}{l}7.3 E+00 \\
3.2 E+08\end{array}$ & $2.6 E+00$ \\
\hline $\mathrm{H}-3$ _Concrete & $1.4 \mathrm{E}+02$ & $2.4 \mathrm{E}+02$ & $5.3 E+04$ & NA & NA & NA & NA & NA & NA & NA & & & 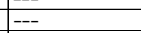 \\
\hline ETF.Carbon & & & & NA & NA & NA & NA & NA & NA & NA & $7 E+06$ & & \\
\hline TF Carbon & $3.7 \mathrm{E}-03$ & $3.3 \mathrm{E}-03$ & 1.7E-03 & NA & NA & NA & NA & NA & NA & NA &. $\mathrm{OE}$ & & $2.4 \mathrm{E}+\mathrm{OO}$ \\
\hline 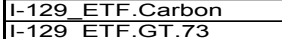 & $1.1 \mathrm{E}+01$ & $1.7 E+01$ & $\frac{2.0 E-01}{2.7 E-01}$ & $\begin{array}{l}\text { NA } \\
\text { NA }\end{array}$ & $\begin{array}{l}\text { NA } \\
\text { NA }\end{array}$ & $\begin{array}{l}\text { NA } \\
\text { NA }\end{array}$ & $\begin{array}{l}\text { NA } \\
\text { NA }\end{array}$ & \begin{tabular}{|l} 
NA \\
NA
\end{tabular} & $\begin{array}{l}\text { NA } \\
\text { NA }\end{array}$ & NA & $\begin{array}{l}2.5 E+01 \\
3.3 E+01\end{array}$ & 51 & \begin{tabular}{|l|}
$1.2 \mathrm{E}+01$ \\
$1.6 \mathrm{E}+01$
\end{tabular} \\
\hline 1-129_F.Carbon & $1.5 \mathrm{E}+02$ & $2.3 \mathrm{E}+02$ & $\begin{array}{l}2.7 E-01 \\
3.5 E+00\end{array}$ & NA & $\begin{array}{l}\text { NA } \\
\text { NA }\end{array}$ & NA & NA & NA & NA & NA & $\frac{1.3 \mathrm{E}+\mathrm{OT}}{4.4 \mathrm{E}+02}$ & $\frac{1.7 E+U 1}{2.3 E+02}$ & $\frac{1.6 \mathrm{E}+\mathrm{O} 1}{2.1 \mathrm{E}+02}$ \\
\hline F.CG.8 & 5.7E-02 & 8.7E-02 & 3.6E-03 & NA & NA & NA & NA & NA & NA & NA & 2.2E-01 & E-01 & $1.2 \mathrm{E}+\mathrm{OO}$ \\
\hline $.21 \mathrm{~K}$ & $\frac{7.6 \mathrm{E}+\mathrm{OO}}{6.4 \mathrm{E}-02}$ & $1.2 \mathrm{E}+01$ & $\begin{array}{l}1.9 \mathrm{E}-01 \\
3.9 \mathrm{E}-03\end{array}$ & NA & NA & NA & NA & NA & NA & NA & 2.2E+01 & $1.2 \mathrm{E}+01$ & 1.1E+01 \\
\hline F.Fil & $\frac{6.4 \mathrm{E}-\mathrm{O} 2}{6.5 \mathrm{E}+01}$ & $\mid \frac{9.9 E-02}{1.0 E+02}$ & $\frac{9 E-03}{6 E+00}$ & $\frac{N A}{N A}$ & $\frac{N A}{N A}$ & $\frac{N A}{N A}$ & $\frac{N A}{N A}$ & $\frac{\text { NA }}{\text { NA }}$ & $\frac{N A}{N A}$ & $\frac{N A}{\text { NA }}$ & $2.4 \mathrm{E}-01$ & $\frac{3.8 \mathrm{E}-\mathrm{O} 1}{11.0 \mathrm{E}+02}$ & $\frac{1.1 \mathrm{E}+\mathrm{OO}}{9.4 \mathrm{E}+\mathrm{O} 1}$ \\
\hline I-129_H.CG.8 & $4.2 \mathrm{E}-01$ & $6 \mathrm{E}-01$ & $1.6 \mathrm{E}-\mathrm{O} 2$ & NA & NA & NA & NA & NA & NA & NA & $1.3 E+0 O$ & $1.1 \mathrm{E}+0 \mathrm{O}$ & $9.9 \mathrm{E}-01$ \\
\hline ex.21K & $1.7 \mathrm{E}+01$ & +01 & $4.2 \mathrm{E}-01$ & NA & NA & NA & NA & NA & NA & NA & $5.2 \mathrm{E}+01$ & 2. & $2.5 \mathrm{E}+01$ \\
\hline $129 \mathrm{Mk} 50 \mathrm{~A}$ & & & & NA & NA & NA & NA & NA & NA & NA & & & $1.5 \mathrm{E}+\mathrm{OO}$ \\
\hline I-129_Mk50A & $\begin{array}{l}4.9 \mathrm{E}+01 \\
5.2 \mathrm{E}+00\end{array}$ & $\begin{array}{l}7.0 E+01 \\
2.7 E+00\end{array}$ & $\begin{array}{l}4.4 \mathrm{E}-\mathrm{O} 1 \\
1.3 \mathrm{E}+\mathrm{OO}\end{array}$ & $\begin{array}{l}\text { NA } \\
\text { NA }\end{array}$ & NA & $\begin{array}{l}\text { NA } \\
\text { NA }\end{array}$ & $\begin{array}{l}\text { NA } \\
\text { NA }\end{array}$ & \begin{tabular}{|l} 
NA \\
NA
\end{tabular} & $\begin{array}{l}\text { NA } \\
\text { NA }\end{array}$ & $\begin{array}{l}\text { NA } \\
\text { NA }\end{array}$ & $\begin{array}{l}5.3 E+01 \\
3.5 E+00\end{array}$ & 01 & \begin{tabular}{|l|}
$8.9 E+01$ \\
$27 E+01$
\end{tabular} \\
\hline \begin{tabular}{|l|l}
$\mathrm{Mo}$ \\
\end{tabular} & $\frac{5.2 \mathrm{E}+00}{3.5 \mathrm{E}+0 \mathrm{O}}$ & $\frac{2.7 \mathrm{E}+\mathrm{OO}}{2.7 \mathrm{E}+\mathrm{OO}}$ & $\frac{\frac{1.3 E+0 O}{1.5 E+0 O}}{100}$ & $\frac{N A}{N A}$ & $\frac{N A}{N A}$ & $\frac{N A}{N A}$ & $\frac{N A}{N A}$ & NA & $\frac{N A}{N A}$ & $\frac{N A}{N A}$ & $\frac{.5 E+00}{.3 E+0 O}$ & $\frac{2.4}{2.4}$ & $\frac{2.7 E+01}{4.9 E+02}$ \\
\hline & $1.5 \mathrm{E}+0 \mathrm{O}$ & $1.8 \mathrm{E}+0 \mathrm{O}$ & O & NA & $\mathrm{N}$ & $N$ & NA & NA & NA & NA & 3.1 & & $4.9 \mathrm{E}+01$ \\
\hline & $\frac{1}{---}$ & 6. $0 E+16$ & & 2 & 01 & & NA & INA & NA & NA & & & $1.4 \mathrm{E}+03$ \\
\hline & 7.0E+04 & $\begin{array}{l}1.3 E+04 \\
7.3 E+18\end{array}$ & & 9.3E-02 & $1.8 \mathrm{E}-01$ & 4.3E-01 & NA & 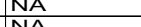 & NA & $2.8 \mathrm{E}+08$ & $3.1 \mathrm{E}$ & $\frac{72}{03}$ & 5.6E-02 \\
\hline & & $7.3 E+18$ & $\frac{6.7 E+02}{1.2 E+07}$ & 4. & $\mid \begin{array}{l}\mathrm{NA} \\
1.4 \mathrm{E}+05\end{array}$ & $\frac{N A}{1.3 E+05}$ & $\frac{N A}{4.4 E+05}$ & $\frac{\mathrm{NA}}{1.4 \mathrm{E}+05}$ & $\frac{N A}{1.3 E+05}$ & $\frac{\mathrm{NA}}{1.8 \mathrm{E}+17}$ & $\frac{4.0 E+06}{2.8 E+09}$ & $\mid$\begin{tabular}{|l|l|}
$3.9 E+03$ \\
$1.3 E+06$
\end{tabular} & $\frac{2.1 E+03}{3.8 E+05}$ \\
\hline & $2.5 \mathrm{E}+19$ & $4.5 \mathrm{E}+17$ & & & & & & & & & & & $1.2 \mathrm{E}+06$ \\
\hline & $795+4$ & & & & & & 4.9 & & $3.6 \mathrm{E}$ & & & & \\
\hline & $7.8 \mathrm{E}+13$ & $8.9 E+12$ & & & & & & & & & & & +03 \\
\hline & $-\cdots$ & ]$^{--}$ & $\begin{array}{l}-14 \\
-09\end{array}$ & $\frac{3.01}{2.71}$ & $\mid \begin{array}{l}3.6 \mathrm{E} \\
3.2 \mathrm{E}\end{array}$ & $\frac{3.0}{2.7}$ & $\frac{4.4 \mathrm{l}}{2.01}$ & & & $\frac{3.9 \mathrm{E}}{3.7 \mathrm{E}}$ & 3.9E+17 & & $\begin{array}{l}E+07 \\
E+07\end{array}$ \\
\hline & $4.7 E+18$ & $2.2 \mathrm{E}+14$ & & $9.0 \mathrm{E}-02$ & & & & & & & & & \\
\hline Cooling.Tower & ta & $3.9 E+19$ & & $2.7 \mathrm{E}$ & $1.7 \mathrm{t}$ & & 2.75 & 1.12 & & & & & \\
\hline & --- & - & 4.0E+19 & NA & NA & & $\mathrm{N} / \mathrm{s}$ & & $N$ & NA & & & $4.2 E+19$ \\
\hline & 2. & 13 & & $\frac{\mathrm{NA}}{\mathrm{NA}}$ & & & $\frac{N}{N}$ & & $\frac{N}{N}$ & $\frac{N A}{N A}$ & & & \\
\hline $1 \mathrm{k} 50 \mathrm{~A}$ & & & & $\mathrm{~N}$ & & & & & & & & & \\
\hline & & & & $\mathrm{N}$ & & & & & & & & & \\
\hline Mk50A & $9.5 \mathrm{E}+04$ & |9.4E+04 & & & & & & & & $N$ & & 22 & $2.0 \mathrm{E}+03$ \\
\hline Cooling Tr & & \begin{tabular}{|c|c|}
$3.8 E+17$ \\
----
\end{tabular} & & & & & & & & $\frac{N}{N}$ & & & E-01 \\
\hline 32_Cooling. I ower & $1.6 \mathrm{E}+18$ & $8.8 \mathrm{E}+16$ & & $\frac{2.3}{3.2}$ & $\frac{2.4}{7.4}$ & & $\begin{array}{l}2.3 E+00 \\
4.2 E+03\end{array}$ & \begin{tabular}{|l|l|l|l|}
$2.1 E+00$ \\
$9.9 E+03$
\end{tabular} & $\begin{array}{l}\frac{2.0 E+00}{1.3 E+04} \\
1.3\end{array}$ & NA & $\frac{6.8 E+05}{2.0 E+04}$ & & $=+04$ \\
\hline & --- & --- & & & & & & & & & & & \\
\hline MClases & --- & -- & & & & & 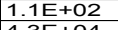 & 01 & 3.41 & & & & $E+02$ \\
\hline MGlass & & & & & & & $\begin{array}{l}\text { 4.3E- } \\
\text { NA }\end{array}$ & \begin{tabular}{|l|}
$1.5 E+04$ \\
NA
\end{tabular} & $\begin{array}{l}1.4 \mathrm{E}+04 \\
\mathrm{NA}\end{array}$ & & & & 04 \\
\hline & & & & & & & NA & NA & NA & & & & \\
\hline sk & $.3 E+1$ & $2.6 E+13$ & & & & & & & & & & & \\
\hline & & & & & & & & & & & & & \\
\hline Glass & $\cdots$ & $\cdots$ & & & & & & & & & & & \\
\hline & - & $1--$ & & & & & & & & & & & \\
\hline $\begin{array}{l}-238 \text {-238_MGlass } \\
r-93\end{array}$ & & $3.4 E+01$ & $\begin{array}{l}1.5 \mathrm{E}+09 \\
3.8 \mathrm{E}-01\end{array}$ & $5.6 E+07$ & 1.8E+07 & $1.7 E+07$ & $5.6 E+07$ & $.8 E+07$ & $1.7 \mathrm{E}+07$ & $1.5 E+12$ & $\begin{array}{l}.7 E+12 \\
0 E+012\end{array}$ & $\begin{array}{l}1.6 E+08 \\
5.7 E+00\end{array}$ & $52 E+00$ \\
\hline
\end{tabular}


Table 3. Operational limits

\begin{tabular}{|c|c|c|c|c|c|c|c|c|c|c|c|c|c|}
\hline Scenario1 -2 sets of & trenches & covered a & 15 yrs: $P$ & \&SA & & & & & & & & ater $\mathbf{A I}$ & \\
\hline & & Beta-Gamm & & $0-1000$ & Gross Alph & & & $\begin{array}{l}\text { Radium } \\
\text { 1000-1120 }\end{array}$ & $\mid$ & $\begin{array}{l}\text { Uranium } \\
0-1130\end{array}$ & $\begin{array}{l}\text { Grounn } \\
130-200 \\
\end{array}$ & $\frac{\text { watar Ali- }}{200-1000}$ & \\
\hline Parent Nuclide & $\frac{0-12}{\mathbf{y r s}}$ & $\frac{12-100}{\mathrm{yrs}}$ & $\frac{100-1130}{y r s}$ & $\begin{array}{l}0-1000 \\
y r s\end{array}$ & \begin{tabular}{|c|}
$1000-1120$ \\
$r s$
\end{tabular} & \begin{tabular}{|c|c|c|}
$1120-1130$ \\
$\mathrm{yrs}$
\end{tabular} & $\frac{0-1000}{y r s}$ & $\frac{1000-1120}{\mathrm{yrs}}$ & $1120-113$ & $0-1130$ & $\frac{130-200}{\mathbf{y r s}}$ & $200-1000$ & $\frac{1000-1130}{y r s}$ \\
\hline $\mathrm{m}-241$ & $3.900 \mathrm{E}-$ & $1.8 \mathrm{E}+06$ & $1.1 \mathrm{E}+04$ & $2.2 \mathrm{E}+02$ & $1.3 \mathrm{E}+02$ & $1.2 \mathrm{E}+02$ & NA & NA & NA & $1.6 \mathrm{E}+12$ & $6.3 \mathrm{E}+\mathrm{O}$ & $79 \mathrm{E}+01$ & $\frac{\text { grs }}{4.5 \mathrm{E}+01}$ \\
\hline Am-243 & & $5.3 \mathrm{E}+16$ & $4.8 \mathrm{E}+02$ & $6.6 \mathrm{E}+01$ & $2.6 \mathrm{E}+01$ & $2.4 \mathrm{E}+01$ & $\mathrm{NA}$ & $\mathrm{NA}$ & $\mathrm{NA}$ & $1.2 \mathrm{E}+12$ & $2.9 \mathrm{E}+10$ & $2.5 \mathrm{E}+01$ & $9.1 \mathrm{E}+00$ \\
\hline $\mathrm{C}-14$ & $2.5 \mathrm{E}-01$ & $2.5 \mathrm{E}-01$ & $8.6 \mathrm{E}+\mathrm{OO}$ & NA & NA & NA & NA & NA & NA & $\mathrm{NA}$ & $1.1 \mathrm{E}+01$ & $1.1 \mathrm{E}+01$ & $1.1 \mathrm{E}+01$ \\
\hline$-14 \_N$ & & & & & & & NA & NA & NA & NA & $3.0 \mathrm{E}+00$ & & \\
\hline$f-249$ & $1.2 \mathrm{E}+17$ & $3.1 \mathrm{E}+12$ & $3.2 \mathrm{E}+04$ & $3.1 \mathrm{E}+02$ & $\frac{1.4 \mathrm{E}+02}{5.5 \mathrm{E}}$ & $1.3 \mathrm{E}+02$ & NA & NA & NA & $9.3 \mathrm{E}+13$ & $1.8 \mathrm{E}+06$ & $9.7 \mathrm{E}+01$ & $4.1 \mathrm{E}+\mathrm{O} 1$ \\
\hline \begin{tabular}{|l}
$\mathrm{Cf}-251$ \\
$\mathrm{C} 1-36$
\end{tabular} & $\frac{--}{8.6 \mathrm{E}-02}$ & $\frac{-.-}{8.6 \mathrm{E}-02}$ & $\begin{array}{r}1.7 \mathrm{E}+08 \\
3.0 \mathrm{E}+00\end{array}$ & $\frac{1.3 \mathrm{E}+02}{\mathrm{NA}}$ & $\frac{5.5 \mathrm{E}+01}{\mathrm{NA}}$ & $\frac{5.2 \mathrm{E}+01}{\mathrm{NA}}$ & $\frac{\mathrm{NA}}{\mathrm{NA}}$ & $\frac{\mathrm{NA}}{\mathrm{NA}}$ & $\frac{N A}{N A}$ & $8.1 \mathrm{E}+17$ & $\frac{3.6 \mathrm{E}+18}{2.0 \mathrm{E}+00}$ & $\begin{array}{l}3.7 \mathrm{E}+01 \\
2.0 \mathrm{E}+00\end{array}$ & $1.5 \mathrm{E}+01$ \\
\hline $\mathrm{Cm}-244$ & & & $8.9 \mathrm{E}+17$ & $7.0 \mathrm{E}+10$ & $9.2 \mathrm{E}+09$ & $7.9 \mathrm{E}+09$ & $1.6 \mathrm{E}+18$ & $1.2 \mathrm{E}+18$ & $1.2 \mathrm{E}+18$ & $9.8 \mathrm{E}+17$ & & $2.7 \mathrm{E}+10$ & $\begin{array}{l}2.0 \mathrm{E}+00 \\
3.1 \mathrm{E}+09\end{array}$ \\
\hline$m-245$ & $1.7 \mathrm{E}+13$ & $1.1 \mathrm{E}+09$ & $1.2 \mathrm{E}+03$ & $3.6 \mathrm{E}+01$ & $1.4 \mathrm{E}+01$ & $1.3 \mathrm{E}+01$ & NA & NA & NA & $1.8 \mathrm{E}+12$ & $6.6 \mathrm{E}+03$ & $1.3 \mathrm{E}+01$ & $4.8 \mathrm{E}+00$ \\
\hline$m-246$ & --- & 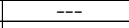 & & $7.0 \mathrm{E}+01$ & $2.7 \mathrm{E}+\mathrm{O} 1$ & $2.5 \mathrm{E}+01$ & $1.1 \mathrm{E}+16$ & $3.6 \mathrm{E}+15$ & $3.3 \mathrm{E}+15$ & & & $2.6 \mathrm{E}+01$ & $9.4 \mathrm{E}+0 \mathrm{O}$ \\
\hline$\frac{m-247}{m-248}$ & -- & -- & $3.6 \mathrm{E}+03$ & $5.5 \mathrm{E}+01$ & $2.1 \mathrm{E}+01$ & & NA & NA & NA & $\frac{1.4 \mathrm{E}+13}{2.9 \mathrm{E}+17}$ & $6.3 \mathrm{E}+12$ & $2.2 \mathrm{E}+\mathrm{O} 1$ & $7.8 \mathrm{E}+00$ \\
\hline \begin{tabular}{|l}
$\mathrm{Cm}-248$ \\
$\mathrm{H}-3$
\end{tabular} & $\frac{--}{4.7 \mathrm{E}+0 \mathrm{O}}$ & $\frac{---}{4.8 \mathrm{E}+0 \mathrm{O}}$ & $\begin{array}{l}3.1 \mathrm{E}+09 \\
.0 \mathrm{E}+04\end{array}$ & $\frac{6.6 \mathrm{E}+01}{\mathrm{NA}}$ & $\frac{2.5 \mathrm{E}+\mathrm{OO} 1}{\mathrm{NA}}$ & $\frac{2.4 \mathrm{E}+\mathrm{OO1}}{\mathrm{NA}}$ & NA & $\mathrm{NA}$ & $\mathrm{NA}$ & $\frac{2.9 \mathrm{E}+17}{\mathrm{NA}}$ & $\begin{array}{l}2.3 \mathrm{E}+19 \\
3.3 \mathrm{E}+06\end{array}$ & $\begin{array}{r}6.1 \mathrm{E}+00 \\
4.1 \mathrm{E}+06\end{array}$ & $\frac{2.2 \mathrm{E}+0 \mathrm{O}}{4.1 \mathrm{E}+06}$ \\
\hline H-3_Concrete & $1.1 \mathrm{E}+01$ & $1.1 \mathrm{E}+01$ & $4.7 \mathrm{E}+04$ & $\mathrm{NA}$ & $\mathrm{NA}$ & $\mathrm{NA}$ & NA & NA & $\mathrm{NA}$ & NA & $7.8 \mathrm{E}+06$ & $9.4 \mathrm{E}+06$ & $9.4 \mathrm{E}+06$ \\
\hline H-3_ETF.Carbon & & & & & NA & & NA & NA & & & $1.5 \mathrm{E}+06$ & $1.1 \mathrm{E}+09$ & \\
\hline $1-129$ & $1.4 \mathrm{E}-04$ & $1.4 \mathrm{E}-04$ & $6.3 \mathrm{E}-03$ & NA & NA & NA & NA & NA & NA & NA & $4.5 \mathrm{E}-01$ & $4.5 \mathrm{E}-01$ & $4.5 \mathrm{E}-01$ \\
\hline 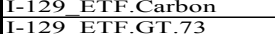 & $1.2 \mathrm{E}+00$ & $5.8 \mathrm{E}-01$ & $\frac{1.7 \mathrm{E}-\mathrm{O} 1}{2.3 \mathrm{E}-\mathrm{O}}$ & $\frac{\mathrm{NA}}{\mathrm{NA}}$ & $\frac{\mathrm{NA}}{\mathrm{NA}}$ & $\frac{\mathrm{NA}}{\mathrm{NA}}$ & $\frac{\mathrm{NA}}{\mathrm{NA}}$ & $\frac{\mathrm{NA}}{\mathrm{NA}}$ & $\frac{\mathrm{NA}}{\mathrm{NA}}$ & $\frac{\mathrm{NA}}{\mathrm{NA}}$ & $\frac{2.1 \mathrm{E}+01}{2.8 \mathrm{E}+01}$ & $\frac{1.1 \mathrm{E}+01}{1.5 \mathrm{E}+\mathrm{O} 1}$ & $\frac{1.0 \mathrm{E}+01}{1.4 \mathrm{E}+01}$ \\
\hline I-129 F.Carbon & $1.5 \mathrm{E}+01$ & $7.7 \mathrm{E}+00$ & $3.0 \mathrm{E}+\mathrm{OO}$ & NA & NA & NA & NA & NA & NA & $\frac{N A}{N A}$ & $3.7 \mathrm{E}+02$ & $\frac{1.5 \mathrm{E}+01}{1.9 \mathrm{E}+02}$ & $\frac{1.4 \mathrm{E}+01}{1.8 \mathrm{E}+02}$ \\
\hline 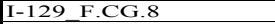 & & 3.0E-03 & $3.2 \mathrm{E}-03$ & & & & & & & $\mathrm{NA}$ & OE-O1 & $3.2 \mathrm{E}-01$ & \\
\hline $29 \mathrm{~F} \cdot \mathrm{D}$ & $7.9 \mathrm{E}-01$ & $4.0 \mathrm{E}-01$ & $1.6 \mathrm{E}-\mathrm{O} 1$ & $\mathrm{NA}$ & $\mathrm{NA}$ & $\mathrm{NA}$ & $\mathrm{N} A$ & 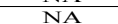 & $\mathrm{N}_{2}$ & $\mathrm{NA}$ & $1.9 \mathrm{E}+01$ & 01 & $E+00$ \\
\hline $\mid$ & 6.6E-03 & $3.3 \mathrm{E}-03$ & $3.5 \mathrm{E}-03$ & $\overline{\mathrm{N} A}$ & NA & NA & $\mathrm{N} / 2$ & $\mathrm{~N} / \mathrm{A} / \mathrm{C}$ & $\mathrm{NA}$ & $\mathrm{NA}$ & $\frac{12 \mathrm{E}-\mathrm{O} 1}{2.1}$ & $3.4 \mathrm{E}-\mathrm{O} 1$ & $\frac{9.0 \mathrm{E}+00}{9.9 \mathrm{E}-01}$ \\
\hline I-129_H.C & $7 \mathrm{E}+00$ & $3.4 \mathrm{E}+00$ & $1.3 \mathrm{E}+00$ & NA & NA & NA & NA & NA & NA & NA & $1.6 \mathrm{E}+02$ & $8.5 \mathrm{E}+01$ & $8.0 \mathrm{E}+01$ \\
\hline I-129_H.CG.8 & $4.4 \mathrm{E}-02$ & $2.2 \mathrm{E}-02$ & $1.4 \mathrm{E}-02$ & NA & NA & NA & NA & NA & NA & NA & $1.1 \mathrm{E}+00$ & $9.0 \mathrm{E}-\mathrm{O} 1$ & $8.5 \mathrm{E}-01$ \\
\hline I-129_H.I & $1.8 \mathrm{E}+\mathrm{OO}$ & 9.1E-01 & 3.6E-01 & $\mathrm{NA}$ & NA & NA & $\mathrm{N}$ & $\mathrm{N}$ & $\mathrm{N}$ & 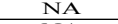 & $4.4 \mathrm{E}+\mathrm{C}$ & $2.3 \mathrm{E}+01$ & \\
\hline |1-129-4.. & $.5 E-02$ & $3.8 \mathrm{E}-02$ & $2.2 \mathrm{E}-\mathrm{O} 2$ & & NA & & N 2 & $\mathrm{NA}$ & NA & $N$ & $1.8 \mathrm{E}+0 \mathrm{O}$ & $1.5 \mathrm{E}+0 \mathrm{OO}$ & +00 \\
\hline$\frac{1-129-111}{K-40}$ & $\begin{array}{l}3.6 \mathrm{E}+0 \mathrm{O} \\
65 \mathrm{E}-02\end{array}$ & $\frac{1.4 E+00}{5.9 E-02}$ & & $\frac{N A}{N A}$ & NA & NA & $N A$ & NA & $N A$ & $\frac{N}{N}$ & $\frac{3.95+10}{4.5+00}$ & $\frac{2.3 \mathrm{E}+01}{5.2 \mathrm{E}+00}$ & $\begin{array}{l}+01 \\
+01 \\
+01\end{array}$ \\
\hline \begin{tabular}{|l|l|} 
Mo-93 \\
\end{tabular} & $\frac{0.0 \mathrm{E}-02}{1.9 \mathrm{E}-01}$ & $\frac{3.9 \mathrm{E}-02}{1.9 \mathrm{E}-01}$ & $\frac{1.05+00}{3.5 \mathrm{E}+00}$ & NA & NA & $\mathrm{NA}$ & $\frac{N A}{N A}$ & $\mathrm{NA}$ & $\mathrm{NA}$ & $\frac{\mathrm{NA}}{\mathrm{NA}} \mathrm{C}, \mathrm{C}$ & $\frac{4.25+01}{2.1 \mathrm{E}+01}$ & $\frac{3.2 \mathrm{~L}+00}{2.1 \mathrm{E}+01}$ & $\frac{2.6 \mathrm{E}+01}{2.1 \mathrm{E}+01}$ \\
\hline p-94 & $9.4 \mathrm{E}-02$ & $9.4 \mathrm{E}-02$ & & & & & $\mathbf{N}$ & $\mathrm{N} A$ & & & & & \\
\hline Ni-59 & $5.8 \mathrm{E}+19$ & $3.4 \mathrm{E}+09$ & 4.1 & $\mathrm{NA}$ & $\mathrm{N}$ & $\mathrm{NA}$ & $\mathrm{N}$ & $\mathrm{N} A$ & $N$ & $\mathrm{NA}$ & $98 \mathrm{~F}+05$ & $2.2 \mathrm{E}+03$ & +03 \\
\hline & 03 & $\begin{array}{l}\frac{3.45}{3.9 E+00} \\
3\end{array}$ & & $8.1 \mathrm{E}-02$ & 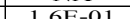 & $37 \mathrm{~F}-\mathrm{O}+\mathrm{S}$ & & $N A$ & & 08 & - 02 & $5-02$ & \\
\hline$\frac{1-107}{d-107}$ & - & $4.2 \mathrm{E}+11$ & 49 & NA & $\mathrm{NA}$ & NA & $N A$ & $N$ & $N$ & NA & 102 & $\frac{1.35-62}{3.3}+03$ & -02 \\
\hline Pu-238 & & & $9.8 \mathrm{E}+06$ & $3.7 \mathrm{E}+05$ & $1.2 \mathrm{E}+05$ & $1.1 \mathrm{E}+05$ & $3.7 \mathrm{E}+05$ & $1.2 \mathrm{E}+05$ & $\frac{1 \mathrm{NA}}{1.1 \mathrm{E}+05}$ & $1.5 \mathrm{E}+17$ & $\frac{1.3 \mathrm{E}+0 \mathrm{O}}{2.3 \mathrm{E}+09}$ & $1.1 \mathrm{E}+06$ & $\frac{1.6 \mathrm{E}+03}{3.2 \mathrm{E}+05}$ \\
\hline & $9.6 \mathrm{E}+17$ & $6.7 \mathrm{E}+12$ & $1.1 \mathrm{I}$ & $9.5 \mathrm{E}+06$ & $6.7 \mathrm{E}+06$ & $6.5 \mathrm{E}+06$ & NA & NA & $N=$ & $3.3 \mathrm{E}+15$ & $4.3 \mathrm{E}+07$ & $1.2 \mathrm{E}+06$ & $9.9 \mathrm{E}+05$ \\
\hline & 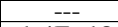 & GT & & & 3.3 & & $4.1 \mathrm{E}+15$ & $3.2 \mathrm{E}+15$ & $3.1 \mathrm{E}+15$ & & 1.3 & 1.0 & +07 \\
\hline $\mathrm{Pu}-241$ & $1.4 \mathrm{E}+12$ & $2.5 \mathrm{E}+08$ & 3.31 & & 3.7 & & NA & NA & Tu & & $2.2 \mathrm{E}+04$ & $2.4 \mathrm{E}+03$ & $1.3 \mathrm{E}+03$ \\
\hline & & & $\begin{array}{l}1.0 \mathrm{E}+14 \\
2.1 \mathrm{E}+09\end{array}$ & $\frac{2.4 \mathrm{E}+08}{2.2 \mathrm{E}+08}$ & $\frac{2.9 \mathrm{E}+07}{2.6 \mathrm{E}+07}$ & $\frac{2.5 \mathrm{E}+07}{2.2 \mathrm{E}+07}$ & $3.7 \mathrm{E}+12$ & $1.2 \mathrm{E}+12$ & $\frac{1.1 \mathrm{E}+12}{1.2 \mathrm{E}+17}$ & $\begin{array}{l}3.2 \mathrm{E}+15 \\
3.0 \mathrm{E}+16\end{array}$ & $3.3 \mathrm{E}+17$ & $\frac{9.9 \mathrm{E}+07}{9.0 \mathrm{E}+07}$ & $\begin{array}{l}1.0 \mathrm{E}+07 \\
92 \mathrm{E}+06\end{array}$ \\
\hline Ra-226 & $2.3 \mathrm{E}+17$ & $2.5 \mathrm{E}+07$ & $\frac{2.1 \mathrm{E}+09}{2.9 \mathrm{E}+00}$ & $\frac{2.2 \mathrm{E}+08}{6.4 \mathrm{E}-02}$ & $\frac{2.0 \mathrm{E}+\mathrm{O} /}{3.8 \mathrm{E}-02}$ & $\frac{2.2 \mathrm{E}+\mathrm{O} /}{3.8 \mathrm{E}-02}$ & $\frac{1.7 \mathrm{E}+11}{6.02}$ & $\frac{1.2 \mathrm{E}+17}{3.8 \mathrm{E}-02}$ & $\frac{1.2 \mathrm{E}+17}{3.8 \mathrm{E}-02}$ & $\frac{3.0 \mathrm{E}+1 \mathrm{IC}}{\mathrm{NA}}$ & $5.2 \mathrm{E}+00$ & $1.9 \mathrm{E}-01$ & $\frac{9.2 \mathrm{E}+06}{1.1 \mathrm{E}-01}$ \\
\hline Ra-226_Cooling.Tower & 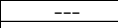 & $1.2 \mathrm{E}+12$ & $1.4 \mathrm{E}+01$ & $2.3 \mathrm{E}-\mathrm{C}$ & $9.8 \mathrm{E}-\mathrm{O}$ & 8.3 & $2.3 \mathrm{E}$ & 9 & 8.3 & & $1.0 \mathrm{E}+04$ & $6.6 \mathrm{E}-01$ & $2.4 \mathrm{E}+00$ \\
\hline$e-7$ & -- & & $3.2 \mathrm{E}+19$ & NA & NA & NA & $\mathrm{N}$ & NA & +2 & $\frac{N}{N}$ & & & $3.4 \mathrm{E}+19$ \\
\hline & $E+14$ & $4 \mathrm{E}$ & & $\frac{\mathrm{N} A}{\mathrm{~N} A}$ & & N & & & & & 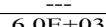 & $14 \mathrm{E}+1$ & \\
\hline Sr-90_Mk50A & $1.4 \mathrm{E}+18$ & $\frac{3.41}{3.21}$ & 4.0 & $\mathrm{~N}$ & $\mathrm{~N}$ & NA & NA & NA & $\mathrm{N}$ & NA & $3.1 \mathrm{E}+06$ & $7.7 \mathrm{E}+05$ & $\frac{2.4 \mathrm{E}+10}{3.3 \mathrm{E}+12}$ \\
\hline Tc-9 & & & & & & & & & & & & 7.71 & \\
\hline Mk50A & $5.3 \mathrm{E}+03$ & 1.3 & 3.7 & 2 & 10 & NA & 23 & 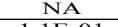 & $\mathrm{N} 2$ & $\mathrm{~N}$ & +03 & 5.6 & $8+03$ \\
\hline \begin{tabular}{|l} 
Th-230 \\
$T h-230$ \\
$T$
\end{tabular} & & $2.0 \mathrm{E}$ & & & & & $3.1 \mathrm{E}$ & $\begin{array}{l}1.1 \mathrm{E}-01 \\
1.8 \mathrm{E}+00\end{array}$ & 1.71 & $N$ & $\frac{1.41}{4.99}$ & $\begin{array}{l}9.2 \mathrm{E}-01 \\
5.6 \mathrm{E}+00\end{array}$ & 3.0E-01 \\
\hline 3232 Cooling.Tower & $6.0 \mathrm{E}+16$ & $\frac{1.0 \mathrm{E}+15}{3.8 \mathrm{E}+09}$ & $\frac{1.1 \mathrm{E}+02}{2.7 \mathrm{E}+03}$ & $\frac{1.9 \mathrm{E}+00}{2.7 \mathrm{E}+03}$ & $\frac{1.8}{6.3}$ & $\frac{1.7 \mathrm{E}+\mathrm{C}}{8.0 \mathrm{E}+\mathrm{c}}$ & $\frac{1.9 \mathrm{E}+0 \mathrm{O}}{3.6 \mathrm{E}+03}$ & $\frac{1.8 \mathrm{E}+00}{8.4 \mathrm{E}+03}$ & $\frac{1.7 \mathrm{E}+00}{1.1 \mathrm{E}+04}$ & $N$ & $\frac{4.9 \mathrm{E}+05}{1.7 \mathrm{E}+04}$ & $\frac{5.6 \mathrm{E}+00}{7.2 \mathrm{E}+03}$ & $\frac{4.9 \mathrm{E}+\mathrm{OO}}{1.7 \mathrm{E}+\mathrm{O} 4}$ \\
\hline & & & 4.7 & 1.2 & & & & & & & & & $1.7 \mathrm{ET}+4$ \\
\hline & --- & $7.5 \mathrm{E}+14$ & & & & & & & & & & & \\
\hline ilass & & 1.1 & & & & & 3.6 & 1.3 & $1.2 \mathrm{E}$ & & & & \\
\hline & $7 \mathrm{E}+09$ & 3.0 & & & & & NA & $\mathrm{NA}$ & $\mathrm{NA}$ & $1.3 \mathrm{E}$ & $3.2-30$ & $5.8 \mathrm{E}-01$ & $\frac{3.3 \mathrm{E}-1}{6.3 \mathrm{E}}$ \\
\hline $\mathrm{U}_{-}^{-}$ & $2.3 \mathrm{E}+12$ & 1.7 & 2.41 & & & & $\bar{N}$ & $\overline{\mathrm{N}}$ & $\mathbf{N}$ & & $7.5 \mathrm{E}+03$ & $2.6 \mathrm{E}$ & $2.4 \mathrm{E}+02$ \\
\hline Cask & $5.6 \mathrm{E}+13$ & & & & & & $\mathrm{~N} / \mathrm{t} / \mathrm{t}$ & & $\mathbf{N}$ & & & & $2.6 \mathrm{E}+03$ \\
\hline $\begin{array}{ll}U-236 \\
-236 & \mathrm{MGla} \\
\end{array}$ & 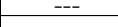 & $2.3 \mathrm{E}+$ & & $\frac{3.1}{2.1}$ & & 2. & $\frac{4.1 \mathrm{E}}{28 \mathrm{E}}$ & E- & & & & & \\
\hline \begin{tabular}{|l}
-236 M- Milass \\
$U-238$
\end{tabular} & --- & --- & $1.0 \mathrm{E}+13$ & $\frac{2.1 \mathrm{E}+13}{1.2 \mathrm{E}+05}$ & $\frac{1.1}{3.9}$ & $\frac{1.6}{3.6}$ & $\frac{2.8 \mathrm{E}+13}{1.3 \mathrm{E}+05}$ & $\frac{2.3 \mathrm{E}+13}{3.9 \mathrm{E}+04}$ & & & $\frac{3.3 \mathrm{E}+15}{1.8 \mathrm{E}+09}$ & & \\
\hline $\mathrm{U}-23$ & & & $1.3 \mathrm{E}+09$ & $4.7 \mathrm{E}+07$ & $1.5 \mathrm{E}+07$ & $1.4 \mathrm{E}+07$ & $4.7 \mathrm{E}+07$ & $1.5 \mathrm{E}+07$ & $1.4 \mathrm{E}+07$ & $1.2 \mathrm{E}+12$ & $3.0 \mathrm{E}+12$ & $1.4 \mathrm{E}+08$ & $\frac{1.1 \mathrm{E}+}{4.1 \mathrm{E}+}$ \\
\hline & $1.5 \mathrm{E}+00$ & $6.4 \mathrm{E}-01$ & $7.4 \mathrm{E}-01$ & $\mathrm{NA}$ & NA & NA & NA & NA & NA & NA & $8.9 \mathrm{E}+00$ & $4.8 \mathrm{E}+0 \mathrm{O}$ & $4.4 \mathrm{E}+0 \mathrm{O}$ \\
\hline
\end{tabular}


Table 3 (continued)

\begin{tabular}{|c|c|c|c|c|c|c|c|c|c|c|c|c|c|}
\hline cenario1b - 2 sets 0 & ench & 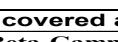 & $5 \mathrm{~s}$ & $\mathbf{S A}$ & & & & & & & & & \\
\hline & 0-12 & $\frac{t a-G a m n}{12-100}$ & $100-1130$ & 0-1000 & $\begin{array}{l}\text { Gross Alph } \\
1000-1120\end{array}$ & 11 & 0-1000 & \begin{tabular}{|c|} 
Radium \\
$1000-1120$
\end{tabular} & 1130 & $\frac{\text { Uranium }}{\text { 0-1130 }}$ & $\begin{array}{l}\text { Grounc } \\
130-200 \\
\end{array}$ & $\begin{array}{l}\text { water All- } \\
\text { 200-1000 }\end{array}$ & $\begin{array}{l}\text { athways } \\
\text { 1000-113 } \\
\end{array}$ \\
\hline Parent Nuclide & $\frac{\text { yrs }}{2 \text { rs }}$ & \begin{tabular}{|c|} 
yrs \\
$18 \mathrm{E}+06$
\end{tabular} & \begin{tabular}{|c|} 
yrs \\
\end{tabular} & $\frac{\text { yrs }}{2 \mathrm{rs}+02}$ & $\begin{array}{l}\text { yrs } \\
13 \mathrm{E}+02\end{array}$ & yrs & yrs & yrs & $\mathrm{yrs}$ & $\frac{\text { yrs }}{16 \mathrm{E}+12}$ & $\frac{\text { yrs }}{62 \mathrm{r}+02}$ & $\frac{\text { yrs }}{79 \mathrm{E}+01}$ & $\frac{\mathbf{y r s}}{4.5 \mathrm{E}+01}$ \\
\hline$\frac{A m-241}{A m-243}$ & $3.9 \mathrm{E}+09$ & $\begin{array}{l}1.8 \mathrm{E}+06 \\
5.3 \mathrm{E}+16\end{array}$ & \begin{tabular}{|l|}
$1.1 \mathrm{E}+04$ \\
$4.8 \mathrm{E}+02$ \\
\end{tabular} & $\frac{2.2 \mathrm{E}+02}{6.6 \mathrm{E}+01}$ & $\frac{1.3 \mathrm{E}+02}{2.6 \mathrm{E}+01}$ & $\frac{1.2 \mathrm{E}+02}{2.4 \mathrm{E}+01}$ & $\frac{\mathrm{NA}}{\mathrm{NA}}$ & $\frac{\text { NA }}{\text { NA }}$ & NA & $\frac{1.6 \mathrm{E}+12}{1.2 \mathrm{E}+12}$ & $\frac{6.2 \mathrm{E}+02}{2.9 \mathrm{E}+10}$ & $\frac{7.9 \mathrm{E}+01}{2.5 \mathrm{E}+01}$ & $\begin{array}{l}4.5 \mathrm{E}+\mathrm{O} 1 \\
9.1 \mathrm{E}+00\end{array}$ \\
\hline $\mathrm{Am}-14$ & $2.5 \mathrm{E}-01$ & $2.5 \mathrm{E}-01$ & & & & & $\frac{N A}{N A}$ & NA & $\frac{\mathrm{NA}}{\mathrm{NA}}$ & & & $\frac{2.5 \mathrm{E}+01}{9.4 \mathrm{E}+0 \mathrm{O}}$ & $1.1 \mathrm{E}+01$ \\
\hline $\mathrm{C}-1$ & & & $2.5 \mathrm{E}+00$ & NA & NA & NA & NA & NA & NA & NA & $3.0 \mathrm{E}+00$ & $2.6 \mathrm{E}+00$ & $1.0 \mathrm{E}+02$ \\
\hline \begin{tabular}{|l} 
Cf-249 \\
$C-251$
\end{tabular} & $1.2 \mathrm{E}+17$ & $3.1 \mathrm{E}+12$ & $\begin{array}{l}3.2 \mathrm{E}+04 \\
1 . \mathrm{E}+08\end{array}$ & $3.1 \mathrm{E}+02$ & $\frac{1.4 \mathrm{E}+02}{5.5 \mathrm{E}+01}$ & $\frac{1.3 \mathrm{E}+02}{5.2 \mathrm{E}+01}$ & NA & NA & NA & $9.3 \mathrm{E}+13$ & $1.8 \mathrm{E}+06$ & $9.7 \mathrm{E}+01$ & $\frac{4.1 \mathrm{E}+01}{1.5 \mathrm{E}+01}$ \\
\hline Cl-36 & $8.6 \mathrm{E}-02$ & $8.6 \mathrm{E}-02$ & $1.1 \mathrm{E}+0 \mathrm{OO}$ & $\frac{1.3 \mathrm{E}+\mathrm{O} 2}{\mathrm{NA}}$ & $\frac{3.5 \mathrm{E}+01}{\mathrm{NA}}$ & $\frac{3.2 \mathrm{E}+\mathrm{OI}}{\mathrm{NA}}$ & $\frac{\mathrm{NA}}{\mathrm{NA}}$ & $\frac{\mathrm{NA}}{\mathrm{NA}}$ & $\frac{\mathrm{NA}}{\mathrm{NA}}$ & $\frac{8.1 \mathrm{E}+17}{\mathrm{NA}}$ & $\frac{3.6 \mathrm{E}+18}{5.9 \mathrm{E}-01}$ & $\frac{3.7 \mathrm{E}+01}{1.6 \mathrm{E}+00}$ & $\frac{1.5 \mathrm{E}+01}{2.0 \mathrm{E}+00}$ \\
\hline $\mathrm{Cm}-244$ & & & $8.9 \mathrm{E}+17$ & $7.0 \mathrm{E}+10$ & $9.2 \mathrm{E}+09$ & $7.9 \mathrm{E}+09$ & $1.6 \mathrm{E}+18$ & $1.2 \mathrm{E}+18$ & $1.2 \mathrm{E}+18$ & & & & $3.15+09$ \\
\hline & $1.7 \mathrm{E}+13$ & $1.1 \mathrm{E}+09$ & $1.2 \mathrm{E}+03$ & $3.6 \mathrm{E}+01$ & $1.4 \mathrm{E}+01$ & $1.3 \mathrm{E}+01$ & NA & NA & NA & $1.8 \mathrm{E}+12$ & $6.6 \mathrm{E}+03$ & $1.3 \mathrm{E}+01$ & $4.8 \mathrm{E}+00$ \\
\hline $\mathrm{Cn}$ & --- & --- & $7.7 E+14$ & & & $2.5 \mathrm{E}+\mathrm{O} 1$ & $1.1 \mathrm{E}+16$ & $3.6 \mathrm{E}+15$ & $3.3 \mathrm{E}+15$ & +13 & & $2.6 \mathrm{E}+01$ & $\frac{9.4 \mathrm{E}+0 \mathrm{OO}}{7.8 \mathrm{E}+00 \mathrm{a}}$ \\
\hline$\frac{\mathrm{Cm}-247}{\mathrm{Cm}-248}$ & --- & --- & $\frac{3.6 \mathrm{E}+03}{3.1 \mathrm{E}+09}$ & $\frac{5.5 \mathrm{E}+01}{6.6 \mathrm{E}+01}$ & $\frac{2.1 \mathrm{E}+01}{2.5 \mathrm{E}+01}$ & $\frac{2.0 \mathrm{E}+01}{2.4 \mathrm{E}+01}$ & NA & NA & NA & $\frac{1.4 \mathrm{E}+13}{2.9 \mathrm{E}+17}$ & $\frac{6.3 \mathrm{E}+12}{2.3 \mathrm{E}+19}$ & $\frac{2.2 \mathrm{E}+01}{6.1 \mathrm{E}+00}$ & 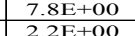 \\
\hline & $4.7 \mathrm{E}+0 \mathrm{O}$ & $4.8 \mathrm{E}+0 \mathrm{O}$ & $1.9 \mathrm{E}+04$ & $\frac{6.6 \mathrm{E}+\mathrm{OI}}{\mathrm{NA}}$ & $\frac{2.5 \mathrm{EA}+\mathrm{O}}{\mathrm{NA}}$ & $\frac{2.4 \mathrm{E}+\mathrm{OI}}{\mathrm{NA}}$ & NA & NA & NA & $\frac{2.9 \mathrm{E}+1 /}{\mathrm{NA}}$ & $\frac{2.3 \mathrm{E}+19}{1.5 \mathrm{E}+06}$ & $\frac{6.1 \mathrm{E}+0 \mathrm{O}}{4.1 \mathrm{E}+06}$ & $\frac{2.2 \mathrm{E}+00}{4.1 \mathrm{E}+06}$ \\
\hline 10 & $1.1 \mathrm{E}+\mathrm{O} 1$ & $1.1 \mathrm{E}+01$ & & & & NA & $\mathrm{NA}$ & NA & $\mathrm{NA}$ & $\mathrm{NA}$ & $3.4 \mathrm{E}+06$ & $9.4 \mathrm{E}+06$ & $9.4 \mathrm{E}+06$ \\
\hline $\mathrm{H}-$ & 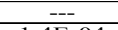 & -- & 5.6 & NA & NA & NA & NA & $\mathrm{N} / \mathrm{s}$ & NA & & $1.5 \mathrm{E}+06$ & $1.1 \mathrm{E}+09$ & $5 \Gamma$ \\
\hline$\frac{I-12}{\mid-12}$ & $1.4 \mathrm{E}-\mathrm{O} 4$ & $1.4 \mathrm{E}-04$ & $\begin{array}{l}1.4 \mathrm{E}-03 \\
1.7 \mathrm{E}-01\end{array}$ & NA & NA & $\frac{\mathrm{N} /}{\mathrm{N} /}$ & $\frac{N A}{N A}$ & $\frac{\mathrm{NA}}{\mathrm{NA}}$ & $\frac{N A}{N A}$ & $N$ & $\frac{8.6 \mathrm{E}-02}{2}$ & $1.9 \mathrm{E}-01$ & $\frac{4.5 \mathrm{E}-\mathrm{O} 1}{1.0 \mathrm{E}+\mathrm{O} 1}$ \\
\hline 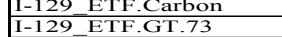 & $1.2 \mathrm{E}+00$ & $5.8 \mathrm{E}-01$ & $\frac{1.7 \mathrm{E}-01}{2.3 \mathrm{E}-01}$ & NA & NA & $\frac{\mathrm{NA}}{\mathrm{NA}}$ & $\frac{\mathrm{N} /}{\mathrm{N} /}$ & $\frac{\mathrm{NA}}{\mathrm{NA}}$ & $\frac{\mathrm{NA}}{\mathrm{NA}}$ & $\frac{\mathrm{NA}}{\mathrm{NA}}$ & $\frac{2.1 \mathrm{E}+01}{2.8 \mathrm{E}+01}$ & $\frac{1.1 \mathrm{E}+01}{1.5 \mathrm{E}+01}$ & $\frac{1.0 \mathrm{E}+01}{1.4 \mathrm{E}+01}$ \\
\hline & & & & & & & $N$ & & & & $3.7 \mathrm{E}+02$ & $9 \mathrm{E}+02$ & \\
\hline & $9 \mathrm{E}-03$ & OE-03 & $1 \mathrm{E}-03$ & $\mathrm{NA}$ & $\frac{\mathrm{N} t}{\mathrm{~N} t}$ & $\frac{\mathrm{N} t}{\mathrm{~N} t}$ & $\frac{N}{N}$ & $\frac{\mathrm{N}_{2}}{\mathrm{~N}_{2}}$ & $\frac{\mathrm{NA}}{\mathrm{NA}}$ & $\frac{N A}{N A}$ & $\frac{3.6 \mathrm{E}+\mathrm{O} 2}{1.9 \mathrm{E}-01}$ & $\frac{02}{5-01}$ & $\frac{8 \mathrm{E}+\mathrm{C}+\mathrm{O}+\mathrm{O}}{\mathrm{O}}$ \\
\hline $.2111<>3$ & $9 \mathrm{E}-\mathrm{O} 1$ & & & & & & & $\frac{N}{N}$ & & & $\frac{1.9 \mathrm{E}-\mathrm{C1}}{1.9 \mathrm{E}+01}$ & $1.0 \mathrm{E}+01$ & $\frac{1.0 \mathrm{E}+}{9.6 \mathrm{E}+}$ \\
\hline & $6.6 \mathrm{E}-03$ & $3.3 \mathrm{E}-03$ & 03 & $\mathrm{NA}$ & $\mathrm{NA}$ & NA & $\mathbf{N} A$ & NA & NA & NA & $2.0 \mathrm{E}-01$ & $3.3 \mathrm{E}-01$ & $9.8 \mathrm{E}-\mathrm{O}$ \\
\hline-12 & $7 \mathrm{E}+0 \mathrm{O}$ & $4 \mathrm{E}+\mathrm{C}$ & $\mathrm{E}+0 \mathrm{O}$ & NA & $\mathrm{N} / \mathrm{H}$ & NA & $\mathrm{N} / \mathrm{H}$ & NA & NA & NA & $1.6 \mathrm{E}+02$ & $8.5 \mathrm{E}+01$ & $8.0 \mathrm{E}+0$ \\
\hline & 4E-02 & & $8-02$ & & & $\mathrm{~N} / \mathrm{H}$ & & $\mathrm{N}$ & & & $1.1 \mathrm{E}+00$ & $8.9 \mathrm{E}-01$ & $8.4 \mathrm{E}-\mathrm{O}$ \\
\hline & $8 \mathrm{E}+00$ & E-01 & E-01 & NA & $\mathrm{N}$ & $\mathrm{N}$ & $\mathrm{N}$ & $N$ & $N$ & & $4.4 \mathrm{E}+01$ & $2.3 \mathrm{E}+01$ & $\mathrm{E}+01$ \\
\hline 1 & $\begin{array}{ll}.5 \mathrm{E}-02 \\
6 \mathrm{E}+00\end{array}$ & 20 & & $N$ & & $\frac{N}{N}$ & $N$ & $\frac{N}{N}$ & & & $\frac{1.8 \mathrm{E}+\mathrm{OC}}{5.4 \mathrm{E}+01}$ & $1.5 \mathrm{E}+0 \mathrm{OO}$ & $\frac{1.3 \mathrm{E}+00}{7.6 \mathrm{E}+01}$ \\
\hline 112 & $\frac{3.0 \mathrm{E}+00}{1.9 \mathrm{E}-01}$ & 1 & & $\frac{N t}{N A}$ & & $\frac{\mathrm{N} t}{\mathrm{~N} t}$ & $N$ & $N_{2}$ & $N$ & & $\frac{3.4 \mathrm{E}+\mathrm{OI}}{1.1 \mathrm{E}+0 \mathrm{O}}$ & $\frac{2.3 \mathrm{E}+0 \mathrm{O}}{2.1 \mathrm{E}+00}$ & $7.6 \mathrm{E}-\mathrm{-}$ \\
\hline & $9 \mathrm{E}-01$ & & & $\frac{N}{N}$ & $\sqrt{N}$ & $N_{2}$ & $\frac{N}{N}$ & $\frac{N_{2}}{N_{2}}$ & $\frac{N}{N}$ & & +00 & 21 & \\
\hline & $\frac{1}{62}$ & & & $N$ & & & & & & & & & \\
\hline & $\frac{52}{19}$ & & & & & & & & & & 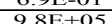 & $\frac{1}{23}$ & $\frac{E+00}{E+03}$ \\
\hline & $4 \mathrm{E}+03$ & & & 7.9E-02 & $1.5 \mathrm{I}$ & $3.6 \mathrm{E}-\mathrm{O} 1$ & & $\mathrm{~N}$ & & 2.21 & & & $4.8 \mathrm{E}-\mathrm{O}$ \\
\hline & & $4.2 \mathrm{E}+11$ & 4 & & & $\mathrm{~N}$ & $\mathrm{~N}$ & N & $N$ & $\mathrm{~N}$ & $1.5 \mathrm{E}+06$ & $3.3 \mathrm{E}+03$ & $1.6 \mathrm{E}+\mathrm{O}$ \\
\hline & & & & & & & & & & & & & \\
\hline & $9.6 \mathrm{E}+17$ & $6.7 \mathrm{E}+12$ & & & & & & & & & & & $E+05$ \\
\hline & $4 \mathrm{~F}=12$ & $25 \mathrm{~F}+08$ & & & & & & & & & & & $\frac{1 E+07}{3 E+03}$ \\
\hline & $4 \mathrm{E}+12$ & $2.5 \mathrm{E}+08$ & \begin{tabular}{|l|}
3.3 \\
10 \\
\end{tabular} & $\frac{6.61}{2.41}$ & 3. & $3.6 \mathrm{E}-$ & & $\frac{N}{21}$ & $\frac{1}{11}$ & & $2.2 \mathrm{E}+\mathrm{C}$ & $2.4 \mathrm{E}+03$ & $\frac{1.3 \mathrm{E}+03}{1.0 \mathrm{E}+07}$ \\
\hline & & & $\frac{1.01}{2.11}$ & $\frac{2.4}{2.2}$ & 2.91 & $\frac{2.3 \mathrm{E}+\mathrm{O} / 7}{2.2 \mathrm{E}+07}$ & 3.1 & $1.2 \mathrm{E}$ & $1.1 \mathrm{t}$ & & & +07 & $\frac{1.0 \mathrm{E}+\mathrm{OT}}{9.2 \mathrm{E}+06}$ \\
\hline & $.3 \mathrm{E}+17$ & 77 & & & & & & & & & & & 01 \\
\hline ooling.To & & $1.2 \mathrm{E}+12$ & & $2.3 \mathrm{E}$ & & 8.3 & $2.3 \mathrm{E}-\mathrm{O} 1$ & $9.9 \mathrm{E}-01$ & $8.3 \mathrm{E}$ & & 1.0 & $6.6 \mathrm{E}-01$ & $\frac{2.4 \mathrm{E}+0 \mathrm{C}}{3.4 \mathrm{E}}$ \\
\hline & $\ldots$ & & $3.2 \mathrm{E}$ & & & $\frac{N}{N}$ & & & & & & & $3.4 \mathrm{E}+19$ \\
\hline & $9 \mathrm{E}+14$ & 6 & 7.1 & & & & $\mathrm{~N}$ & $\mathbf{N}$ & $\frac{1}{N}$ & & 6. & $1.4 \mathrm{E}+03$ & 2.4 \\
\hline $\mathrm{A}$ & 1. & & & & & & & & & & & & $3 \mathrm{E}+12$ \\
\hline & 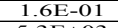 & & & & & & & & & & & $8+00$ & $1.7 \mathrm{E}+00$ \\
\hline $\mathbf{M}$ & $5.3 \mathrm{E}+03$ & & & & & & & $1.1 .7+3$ & & $N$ & $1.4 \mathrm{E}$ & $\frac{4.9}{9 .}$ & $\frac{1.7 \mathrm{E}+03}{3.0 \mathrm{E}-01}$ \\
\hline Cooling. 1 & & & & & & & & & & & & & 4. \\
\hline & $6.0 \mathrm{E}+16$ & 3 & & & & & & & 1 & & i+c & & 100 \\
\hline & --- & & & & & & & & & & & & +09 \\
\hline & --- & & & & & & $9.5 \mathrm{E}$ & & $2.9 \mathrm{E}$ & & & & +04 \\
\hline & & 1. & & & & & $3.6 \mathrm{E}$ & $1.3 \mathrm{I}$ & $1.2 \mathrm{E}+04$ & & & & $\begin{array}{l}\frac{+04}{-01} \\
-\frac{+}{2}\end{array}$ \\
\hline & & & & & & & & & & & & & \\
\hline & $5.6 \mathrm{E}+$ & & & & & & & & & & & & \\
\hline & & $2.3 \mathrm{E}+$ & & & & & & & & & & & \\
\hline & & & & & & & & & & & & & \\
\hline & $\cdots$ & $-\ldots$ & 3. & & & & & & & & & 5 & +05 \\
\hline$\frac{1-238}{1-93}$ & $15 \mathrm{E} \pm 00$ & $64 \mathrm{~F}-\mathrm{O}$ & $1.3 \mathrm{E}+09$ & $\frac{4.7 \mathrm{E}+0}{2}$ & $1.5 \mathrm{E}+$ & 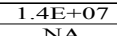 & $\bar{N}$ & $\mathrm{NA}$ & $4 \mathrm{E}+\mathrm{c}$ & $2 \mathrm{E}+12$ & $3.0 \mathrm{E}+12$ & $.4 \mathrm{E}+08$ & 年 $1.15+01$ \\
\hline
\end{tabular}


Table 3 (continued)

\begin{tabular}{|c|c|c|c|c|c|c|c|c|c|c|c|c|c|}
\hline cenario2 - 4 trenche & covered & at 15 yrs: & \&SA & & & & & & & & & all $\mathbf{A l}$ & \\
\hline & 0-12 & $\frac{3 \text { eta-Gamn }}{12-100}$ & 100-11 & & $\begin{array}{l}\text { Gross Alph } \\
1000-1120\end{array}$ & $1120-11$ & -106 & $\begin{array}{l}\text { Radium } \\
\text { 1000-1120 }\end{array}$ & & Uranium & $\begin{array}{l}\text { Grounc } \\
130-200 \\
\end{array}$ & ater All- & \\
\hline Parent Nuclide & yrs & yrs & $\frac{y-1130}{\text { yrs }}$ & yrs & yrs & $\begin{array}{l}\text { yrs } \\
\end{array}$ & yrs & yrs & yrs & $\frac{0-1130}{y r s}$ & yrs & yrs & $\frac{100-1}{\text { yrs }}$ \\
\hline $\mid \frac{A m-241}{A m-243}$ & & $\frac{1.8 \mathrm{E}+06}{5.3 \mathrm{E}+16}$ & $\frac{1.1 \mathrm{E}+04}{4.8 \mathrm{E}+02}$ & $\frac{2.2 \mathrm{E}+02}{6.6 \mathrm{E}+01}$ & $\frac{1.3 \mathrm{E}+02}{2.6 \mathrm{E}+01}$ & $1.2 \mathrm{E}+02$ & NA & NA & NA & $\frac{1.6 \mathrm{E}+12}{1-2 \mathrm{E}+12}$ & $\frac{6.3 \mathrm{E}+02}{29 \mathrm{E}+\mathrm{0}}$ & $\frac{7.9 \mathrm{E}+01}{25 \mathrm{E}+0.01}$ & $\frac{4.5 \mathrm{E}+01}{9.1 \mathrm{E}+00}$ \\
\hline $\mathrm{C}-14$ & $2.5 \mathrm{E}-01$ & $\frac{2.5 \mathrm{E}-01}{2}$ & $8.5 \mathrm{E}+00$ & $\frac{6.6 \mathrm{E}+01}{\mathrm{NA}}$ & $\frac{2.6 \mathrm{E}+\mathrm{OI}}{\mathrm{NA}}$ & $\frac{2.4 \mathrm{E}+\mathrm{OI}}{\mathrm{NA}}$ & NA & $\frac{\mathrm{NA}}{\mathrm{NA}}$ & NA & $\frac{1.2 \mathrm{E}+12}{\mathrm{NA}}$ & $\frac{2.9 \mathrm{E}+\mathrm{OO}}{1.1 \mathrm{E}+01}$ & $\frac{2.5 \mathrm{E}+01}{1.1 \mathrm{E}+01}$ & $\frac{9.1 \mathrm{E}+00}{1.1 \mathrm{E}+01}$ \\
\hline$-14 \_1$ & & & & $\mathrm{NA}$ & & NA & NA & NA & NA & NA & $3.0 \mathrm{E}+00$ & & $1.0 \mathrm{E}+02$ \\
\hline & $1.2 \mathrm{E}+17$ & $3.1 \mathrm{E}+12$ & $3.2 \mathrm{E}+04$ & $3.1 \mathrm{E}+02$ & $\frac{1.4 \mathrm{E}+02}{5.5 \mathrm{E}+02}$ & $1.3 \mathrm{E}+02$ & NA & NA & NA & $9.3 \mathrm{E}+13$ & $1.8 \mathrm{E}+06$ & $9.7 \mathrm{E}+01$ & $4.1 \mathrm{E}+01$ \\
\hline $\mid \frac{\mathrm{C}-25}{\mathrm{Cl}-36}$ & $8.6 \mathrm{E}-02$ & $8,6 \mathrm{E}-02$ & $\frac{1.7 \mathrm{E}+08}{3.0 \mathrm{E}+00}$ & $\frac{1.3 \mathrm{E}+02}{\mathrm{NA}}$ & $\frac{5.5 \mathrm{E}+01}{\mathrm{NA}}$ & $\frac{5.2 \mathrm{E}+\mathrm{O} 1}{\mathrm{NA}}$ & $\frac{N A}{N A}$ & $\frac{\text { NA }}{\text { NA }}$ & $\frac{\text { NA }}{\text { NA }}$ & $8.1 \mathrm{E}+17$ & $\frac{3.6 \mathrm{E}+18}{200 \mathrm{E}+00}$ & $\frac{3.7 \mathrm{E}+01}{20 \mathrm{E}+00}$ & $\frac{1.4 \mathrm{E}+01}{2.0 \mathrm{E}+00}$ \\
\hline $\mathrm{Cm}-244$ & & & $8.5 \mathrm{E}+17$ & $7.0 \mathrm{E}+10$ & $9.2 \mathrm{E}+09$ & $7.9 \mathrm{E}+09$ & $\frac{1 \mathrm{NA}+18}{1.6 \mathrm{E}+1}$ & $1.3 \mathrm{E}+18$ & $\frac{\mathrm{NA}}{1.2 \mathrm{E}+18}$ & $\frac{N A}{9.8 E+17}$ & & $\frac{2.0 \mathrm{E}+0 \mathrm{O}}{2.7 \mathrm{E}+10}$ & $\frac{2.0 \mathrm{E}+00}{3.1 \mathrm{E}+09}$ \\
\hline & $1.7 \mathrm{E}+13$ & $1.1 \mathrm{E}+09$ & $1.2 \mathrm{E}+03$ & $3.6 \mathrm{E}+01$ & $1.4 \mathrm{E}+01$ & $1.3 \mathrm{E}+01$ & NA & & NA & $1.8 \mathrm{E}+12$ & $6.5 \mathrm{E}+03$ & $1.3 \mathrm{E}+01$ & $4.8 \mathrm{E}+00$ \\
\hline & --- & --- & $7.7 \mathrm{E}+14$ & $7.0 \mathrm{E}+01$ & $2.7 \mathrm{E}+01$ & $2.5 \mathrm{E}+01$ & $1.1 \mathrm{E}+16$ & $3.6 \mathrm{E}+15$ & $3 \mathrm{E}+15$ & $1.9 \mathrm{E}+13$ & & $2.6 \mathrm{E}+01$ & $9.4 \mathrm{E}+00$ \\
\hline & --- & -- & $3.6 \mathrm{E}+03$ & $5.5 \mathrm{E}+01$ & $\frac{2.1 \mathrm{E}+01}{2.5 \mathrm{E}+01}$ & $2.0 \mathrm{E}+\mathrm{O} 1$ & NA & NA & NA & $1.4 \mathrm{E}+13$ & $6.3 \mathrm{E}+12$ & $2.2 \mathrm{E}+01$ & $\frac{7.8 \mathrm{E}+00}{2.2 \mathrm{E}+00}$ \\
\hline & $\frac{--}{4.7 \mathrm{E}+00}$ & $\frac{--}{4.8 \mathrm{E}+0 \mathrm{O}}$ & $\begin{array}{l}3.1 \mathrm{E}+09 \\
2.0 \mathrm{E}+04\end{array}$ & $\frac{6.6 \mathrm{E}+01}{\mathrm{NA}}$ & $\frac{2.5 \mathrm{E}+\mathrm{O} 1}{\mathrm{NA}}$ & $\frac{2.4 \mathrm{E}+\mathrm{OI}}{\mathrm{NA}}$ & NA & NA & NA & $\frac{2.9 \mathrm{E}+1}{\mathrm{NA}}$ & $\begin{array}{r}2.3 \mathrm{E}+19 \\
3.3 \mathrm{E}+06 \\
\end{array}$ & $\begin{array}{l}6.1 \mathrm{E}+00 \\
4.1 \mathrm{E}+06\end{array}$ & $\begin{array}{r}2.2 \mathrm{E}+00 \\
4.1 \mathrm{E}+06\end{array}$ \\
\hline H-3_Concrete & $1.1 \mathrm{E}+01$ & $1.1 \mathrm{E}+01$ & $4.7 \mathrm{E}+04$ & NA & NA & $\mathrm{NA}$ & NA & $\mathrm{NA}$ & NA & NA & $7.7 \mathrm{E}+06$ & $9.4 \mathrm{E}+06$ & $9.4 \mathrm{E}+06$ \\
\hline ETF.Carbon & & & & & & & & & & & & $1.1 \mathrm{E}+09$ & \\
\hline & $1.4 \mathrm{E}-04$ & $1.4 \mathrm{E}-04$ & & & NA & NA & $\mathbf{N}$ & & & & $4.5 \mathrm{E}-01$ & $4.5 \mathrm{E}-01$ & $4.5 \mathrm{E}-01$ \\
\hline 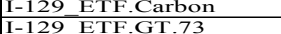 & $1.2 \mathrm{E}+00$ & $5.8 \mathrm{E}-01$ & $\frac{1.7 \mathrm{E}-01}{2.3 \mathrm{E}-01}$ & $\frac{\mathrm{NA}}{\mathrm{NA}}$ & $\frac{\text { NA }}{\text { NA }}$ & $\frac{\mathrm{NA}}{\mathrm{NA}}$ & $\frac{\mathrm{NA}}{\mathrm{NA}}$ & $\frac{\mathrm{NA}}{\mathrm{NA}}$ & $\frac{\text { NA }}{\text { NA }}$ & $\frac{\mathrm{NA}}{\mathrm{NA}}$ & $\frac{2.1 \mathrm{E}+01}{2.8 \mathrm{E}+01}$ & $\frac{1.1 \mathrm{E}+01}{1.4 \mathrm{E}+01}$ & $\frac{1.0 \mathrm{E}+01}{1.4 \mathrm{E}+01}$ \\
\hline I-129_F.Carbon & $1.5 \mathrm{E}+01$ & $7.7 \mathrm{E}+00$ & $3.0 \mathrm{E}+\mathrm{OO}$ & NA & NA & NA & NA & NA & NA & NA & $3.7 \mathrm{E}+02$ & $1.9 \mathrm{E}+02$ & $\frac{1.4 \mathrm{E}+01}{1.8 \mathrm{E}+02}$ \\
\hline F.C & $5.9 \mathrm{E}-03$ & $3.0 \mathrm{E}-03$ & $3.2 \mathrm{E}-03$ & NA & NA & NA & NA & NA & $\mathrm{N}$ & NA & $2.0 \mathrm{E}-01$ & $3.2 \mathrm{E}-01$ & $1.0 \mathrm{E}+\mathrm{O0}$ \\
\hline$\frac{e x .21 K}{e c k}$ & $7.9 \mathrm{E}-01$ & $\frac{O E-01}{O D E}$ & $\begin{array}{l}1.6 \mathrm{E}-01 \\
3.5 \mathrm{E}-03 \\
\end{array}$ & & $\mathrm{~N} / \mathrm{s}$ & $\mathrm{N}_{2}$ & $\mathbf{N}$ & $\mathrm{N}$ & $N$ & & $1.9 \mathrm{E}+01$ & $1.0 \mathrm{E}+01$ & $\frac{9.4 \mathrm{E}+00}{19 \mathrm{E}+00}$ \\
\hline I-129_F.F & $\frac{6 \mathrm{E}-03}{7 \mathrm{E}+00}$ & $\frac{3 \mathrm{E}-03}{4 \mathrm{E}+00}$ & $3.5 \mathrm{E}-03$ & $\mathrm{~N} / \mathrm{H}$ & & $N /$ & $\mathrm{N}$ & $\mathrm{N} / \mathrm{s}$ & $\frac{N}{N}$ & $\frac{N}{N}$ & $\begin{array}{l}2.1 \mathrm{E}-01 \\
1.6 \mathrm{E}+02\end{array}$ & $\frac{3.4 \mathrm{E}-01}{8.5 \mathrm{E}+01}$ & $\frac{1.0 \mathrm{E}+00}{8.0 \mathrm{E}+01}$ \\
\hline $\begin{array}{l}-\frac{129}{129} \text { H.C } \\
-129 \text { H.C }\end{array}$ & $\frac{6.7 \mathrm{E}+\mathrm{OO}}{4.4 \mathrm{E}-02}$ & $\frac{3.4 \mathrm{E}+\mathrm{OOO}}{2.2 \mathrm{E}-\mathrm{O} 2}$ & $\frac{1.3 \mathrm{E}+00}{1.4 \mathrm{E}-02}$ & $\frac{\mathrm{NA}}{\mathrm{NA}}$ & $\overline{\mathrm{NA}}$ & $\frac{\mathrm{NA}}{\mathrm{NA}}$ & $\frac{\mathrm{N} /}{\mathrm{N} /}$ & $\frac{\mathrm{N} /}{\mathrm{N} /}$ & $\frac{\mathrm{N}_{2}}{\mathrm{~N}}$ & $\begin{array}{l}\text { NA } \\
\text { NA }\end{array}$ & $\frac{1.6 \mathrm{E}+02}{1.1 \mathrm{E}+00}$ & $\frac{8.5 \mathrm{E}+01}{9.1 \mathrm{E}-01}$ & $\frac{8.0 \mathrm{E}+01}{8.5 \mathrm{E}-01}$ \\
\hline $129 \mathrm{H.I}$ & & & & & & & & & & & 01 & $3 \mathrm{E}+01$ & $E-01$ \\
\hline-1291 & $5 \mathrm{E}-02$ & -02 & & $N$ & $\mathbf{N} /$ & $\mathrm{N}$ & $\mathbf{N}$ & $N$ & & & +00 & $4 \mathrm{E}+0 \mathrm{O}$ & \\
\hline-12 & 0 & & & & & & & & & & & $\frac{1}{1}$ & $\frac{E+}{E+}$ \\
\hline & & & & & & & & & & & 4.2 & 0 & $2.6 \mathrm{E}+\mathrm{C}$ \\
\hline Mo-93 & $1.9 \mathrm{E}-01$ & $1.9 \mathrm{E}-01$ & $\overline{00}$ & $\mathrm{~N}$ & $\overline{\mathrm{N} /}$ & NA & N. & $\mathrm{N}$ & $\mathrm{N}_{2}$ & NA & $2.1 \mathrm{E}+01$ & $2.1 \mathrm{E}+01$ & $2.1 \mathrm{E}+\mathrm{O}$ \\
\hline $5-$ & & & & & & $\mathrm{N}$ & & 10 & & NA & 2. & $2.3 \mathrm{E}+00$ & $2.3 \mathrm{E}+00$ \\
\hline & & & & & & & & & & 1 & & $2.1 \mathrm{E}+03$ & $1.0 \mathrm{E}+$ \\
\hline & $.4 \mathrm{E}+03$ & $3.9 \mathrm{E}+00$ & & $\frac{8.2 \mathrm{E}-02}{\mathrm{Na}}$ & $.5 \mathrm{E}-\mathrm{O} 1$ & $.7 \mathrm{E}$ & $N$ & $\frac{N}{N}$ & $\mathrm{~N}$ & $2.2 \mathrm{E}+08$ & $2.6 \mathrm{E}-02$ & $\frac{2.6 \mathrm{E}-02}{3.3 \mathrm{E}+0.3}$ & $\frac{4.8 \mathrm{E}-02}{1.6 \mathrm{E}+03}$ \\
\hline & & $4.2 \mathrm{E}+11$ & & & & & $3.7 \mathrm{E}$ & $\frac{\mathrm{NA}}{1.2 \mathrm{E}+05}$ & $\frac{\mathrm{NA}}{1.1 \mathrm{E}+6}$ & & $\frac{1.5 \mathrm{E}+06}{2.3 \mathrm{E}+09}$ & $\frac{3.3 \mathrm{E}+03}{1.1 \mathrm{E}+06}$ & $\frac{1.6 \mathrm{E}+03}{3.2 \mathrm{E}+05}$ \\
\hline & $9.4 \mathrm{E}+17$ & $6.7 \mathrm{E}+12$ & & & & & 3.114 & & 1.15 & & $2.3 E+09$ & 1.2 & $9.9 \mathrm{E}+05$ \\
\hline & & 25 & & & & & & & 3.1 & & & 8 & $=$ \\
\hline & $1.4 \mathrm{E}+12$ & $2.5 \mathrm{E}+08$ & & & & & & & & & & & +03 \\
\hline \begin{tabular}{|l}
$\mathrm{Pu}-242$ \\
$\mathrm{Pu}-244$
\end{tabular} & $\ldots$ & - & & & & & & & & $30 \mathrm{E}+1$ & $3.3 \mathrm{E}+1$ & & +06 \\
\hline $\mathrm{Pu}$ & $3 \mathrm{E}+17$ & $2.5 \mathrm{E}+07$ & & & & & & & & $\frac{3.0 \mathrm{E}+1}{\mathrm{NA}}$ & & $\frac{07}{11}$ & tec \\
\hline Cooling.Tower & 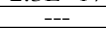 & $1.2 \mathrm{E}+12$ & & & & & & & & & $1.0 \mathrm{E}-$ & $6.6 \mathrm{E}-01$ & $2.4 \mathrm{E}+\mathrm{OC}$ \\
\hline & $\ldots$ & & 3.2 & & & & & & & & & - & $3.4 \mathrm{E}+19$ \\
\hline & & & & & & & & & & & & & \\
\hline Mk50A & 1.41 & & & & & $N$ & & $N$ & $N$ & $\mathrm{~N}$ & 3.1 & $\frac{3}{5}$ & $3.3 \mathrm{E}+12$ \\
\hline & & & & & & & & & & & & & 7 \\
\hline Mks & $5.3 \mathrm{E}+03$ & & & & & & & & & $N$ & & 02 & $8+03$ \\
\hline To & & & & & & & & & & & & & $8+00$ \\
\hline Towe & $6.0 \mathrm{E}+16$ & $\frac{1.0 \mathrm{E}+15}{3.8 \mathrm{E}+09}$ & & & & & & & & & $\frac{4.9}{1.7}$ & & $\frac{4.8 \mathrm{E}+0 \mathrm{O}}{1.7 \mathrm{E}+04}$ \\
\hline & & & & & & & & & & & & & $1.15+0$ \\
\hline & --- & 7.5 & & & & & & & & & & & \\
\hline Glass & & & & & & & & & & & & & \\
\hline- & $\mathrm{E}+$ & & & & & & & & & & & 58 & \\
\hline cab & $\frac{2.3 \mathrm{E}+12}{5.6 \mathrm{E}+13}$ & $\frac{1.7 \mathrm{E}-}{41 \mathrm{E}}$ & & & & & & & & & & 2 & \\
\hline Icah.Cask & 3.05 & & & & & & & & & & & & +1 \\
\hline MG & --- & 2.05 & & & & & & & & $2.3 \mathrm{E}$ & & $\frac{5.91}{3.71}$ & $7.4 \mathrm{E}+12$ \\
\hline & $-\cdots-$ & --- & & & & & & & & & & & 7.4 \\
\hline $\mathrm{J}-2$ & & & & & & & & & & & & & \\
\hline & & & .41 & NA & & $\overline{\mathrm{NA}}$ & $\mathrm{N}$ & $\mathrm{NA}$ & N & $N A$ & $8.5 \mathrm{E}+00$ & $4.8 \mathrm{E}+00$ & $1.4 \mathrm{E}+$ \\
\hline
\end{tabular}


Table 3 (continued)

\begin{tabular}{|c|c|c|c|c|c|c|c|c|c|c|c|c|c|}
\hline \multirow{2}{*}{\begin{tabular}{|l} 
Scenario2b - 4 trenches \\
\end{tabular}} & \multirow{2}{*}{\multicolumn{3}{|c|}{$\begin{array}{c}\text { covered at } 5 \text { yrs: PA \& } \\
\text { Beta-Gamma }\end{array}$}} & \multirow{2}{*}{\multicolumn{3}{|c|}{\begin{tabular}{|l|} 
\\
Gross Alpha \\
\end{tabular}}} & \multirow{2}{*}{\multicolumn{3}{|c|}{ Radium }} & \multirow[b]{2}{*}{$\frac{\text { Uranium }}{\text { O-1130 }}$} & \multirow{2}{*}{ Ground } & \multirow{2}{*}{\multicolumn{2}{|c|}{\begin{tabular}{|l|l|} 
Water All-Pathways \\
wathe
\end{tabular}}} \\
\hline & & & & & & & & & & & & & \\
\hline Parent Nuclide & yrs & yrs & yrs & yrs & yrs & \begin{tabular}{|l|} 
yrs \\
\end{tabular} & yrs & yrs & yrs & & & & \\
\hline & $.9 \mathrm{E}+09$ & & $1.1 \mathrm{E}+04$ & $2.2 \mathrm{E}+02$ & $1.3 \mathrm{E}+02$ & $1.2 \mathrm{E}+02$ & NA & NA & & $1.6 \mathrm{E}+12$ & $6.2 \mathrm{E}+02$ & $9 \mathrm{E}+01$ & $4.5 \mathrm{E}+0$ \\
\hline & & & $4.8 \mathrm{E}+\mathrm{O} 2$ & $6.6 \mathrm{E}+01$ & $2.6 \mathrm{E}+01$ & $2.4 \mathrm{E}+01$ & NA & NA & NA & $1.2 \mathrm{E}+12$ & $2.9 \mathrm{E}+10$ & $2.5 \mathrm{E}+01$ & $9.1 \mathrm{E}+0 \mathrm{O}$ \\
\hline C-14_NR.Pump & $2.5 \mathrm{E}-01$ & 2.5 & $\frac{3.2 \mathrm{E}+0 \mathrm{O}}{2.5 \mathrm{E}+0 \mathrm{O}}$ & $\frac{\mathrm{NA}}{\mathrm{NA}}$ & $\mathrm{NA}$ & $\frac{\text { NA }}{\text { NA }}$ & $\frac{\text { NA }}{\text { NA }}$ & $\frac{\mathrm{NA}}{\mathrm{NA}}$ & $\frac{\mathrm{NA}}{\mathrm{NA}}$ & $\frac{\mathrm{NA}}{\mathrm{NA}}$ & $\frac{3.3 \mathrm{E}+\mathrm{OO}}{3.0 \mathrm{E}+\mathrm{OO}}$ & $\frac{9.4 \mathrm{E}+\mathrm{OO}}{2.6 \mathrm{E}+\mathrm{OO}}$ & $\begin{array}{l}\frac{1.1 \mathrm{E}+\mathrm{O} 1}{1.0 \mathrm{E}+02} \\
\end{array}$ \\
\hline Cf-249 & $1.2 \mathrm{E}+17$ & $3.1 \mathrm{E}+12$ & $3.2 \mathrm{E}+04$ & $3.1 \mathrm{E}+02$ & $1.4 \mathrm{E}+02$ & $1.3 \mathrm{E}+02$ & NA & NA & NA & $9.3 \mathrm{E}+13$ & $1.8 \mathrm{E}+06$ & $9.7 \mathrm{E}+01$ & $4.1 \mathrm{E}+01$ \\
\hline Cf-2 & & & & & & & & & & $8.1 \mathrm{E}+17$ & $3.6 \mathrm{E}+18$ & $3.7 \mathrm{E}+01$ & $1.5 \mathrm{E}+01$ \\
\hline $\mathrm{Cl}-3$ & $8.6 \mathrm{E}-02$ & $8.6 \mathrm{E}-02$ & $1.1 \mathrm{E}+\mathrm{OO}$ & NA & NA & NA & NA & NA & $\mathrm{NA}$ & NA & $5.9 \mathrm{E}-01$ & $1.6 \mathrm{E}+0 \mathrm{O}$ & $\frac{2.0 \mathrm{E}+0 \mathrm{OO}}{3.1 \mathrm{E}+09}$ \\
\hline \begin{tabular}{|l|l}
$\mathrm{Cm}-2$ \\
$\mathrm{Cm}-2$
\end{tabular} & $7 \mathrm{E}+13$ & $1.1 \mathrm{E}+09$ & $\frac{8.5 \mathrm{E}+17}{1.2 \mathrm{E}+03}$ & $\begin{array}{l}7.0 \mathrm{E}+10 \\
3.6 \mathrm{E}+01\end{array}$ & $\frac{9.2 \mathrm{E}+09}{1.4 \mathrm{E}+01}$ & \begin{tabular}{|l|}
$7.9 \mathrm{E}+09$ \\
$1.3 \mathrm{E}+01$ \\
\end{tabular} & $\frac{1.6 \mathrm{E}+18}{\mathrm{NA}}$ & $\frac{1.3 \mathrm{E}+18}{\mathrm{NA}}$ & $\frac{1.2 \mathrm{E}+18}{\mathrm{NA}}$ & $\frac{9.8 \mathrm{E}+17}{1.8 \mathrm{E}+12}$ & $6.5 \mathrm{E}+03$ & $\frac{2.7 \mathrm{E}+10}{1.3 \mathrm{E}+01}$ & $\begin{array}{l}3.1 \mathrm{E}+09 \\
4.8 \mathrm{E}+00\end{array}$ \\
\hline $\mathrm{Cm}-246$ & --- & --- & $7.7 \mathrm{E}+14$ & $7.0 \mathrm{E}+\mathrm{O} 1$ & $2.7 \mathrm{E}+01$ & \begin{tabular}{|l}
$1.5 \mathrm{E}+01$ \\
$2.5 \mathrm{E}+01$ \\
\end{tabular} & $\frac{1 \mathrm{NA}}{1.1 \mathrm{E}+16}$ & $3.6 \mathrm{E}+15$ & $3.3 \mathrm{E}+15$ & $1.9 \mathrm{E}+13$ & & $\frac{1.3 \mathrm{E}+01}{2.6 \mathrm{E}+01}$ & $\frac{4.8 \mathrm{E}+0 \mathrm{O}}{9.4 \mathrm{E}+0 \mathrm{O}}$ \\
\hline & --- & --- & $3.6 \mathrm{E}+03$ & $5.5 \mathrm{E}+01$ & $2.1 \mathrm{E}+01$ & $2.0 \mathrm{E}+01$ & NA & NA & NA & $1.4 \mathrm{E}+13$ & $6.3 \mathrm{E}+12$ & $2.2 \mathrm{E}+01$ & $7.8 \mathrm{E}+00$ \\
\hline $\mathrm{Cm}-248$ & & & $3.1 \mathrm{E}+09$ & $6.6 \mathrm{E}+01$ & $2.5 \mathrm{E}+01$ & $2.4 \mathrm{E}+01$ & & & $\overline{1}$ & $2.9 \mathrm{E}+17$ & $2.3 \mathrm{E}+19$ & $6.1 \mathrm{E}+00$ & $2.2 \mathrm{E}+00$ \\
\hline$\frac{\mathrm{H}-3}{\mathrm{H}-3}$ & $4.7 \mathrm{E}+0 \mathrm{O}$ & $4.8 \mathrm{E}+0 \mathrm{OO}$ & $2.0 \mathrm{E}+04$ & NA & NA & NA & NA & NA & NA & NA & $1.4 \mathrm{E}+06$ & $4.1 \mathrm{E}+06$ & $\frac{4.1 \mathrm{E}+06}{9.4 \mathrm{E}+06}$ \\
\hline $\begin{array}{l}\text { H-3_Concrete } \\
\text { H-3 ETF.Carbon }\end{array}$ & $\frac{1.1 \mathrm{E}+\mathrm{OO}}{--}$ & $1.1 \mathrm{E}+\mathrm{O}-1$ & $\frac{4.5 \mathrm{E}+04}{5.6 \mathrm{E}+04}$ & NA & $\mathrm{NA}$ & NA & NA & $\frac{\mathrm{NA}}{\mathrm{NA}}$ & $\frac{N A}{N A}$ & $\frac{\mathrm{NA}}{\mathrm{NA}}$ & $\frac{3.4 \mathrm{E}+06}{1.4 \mathrm{E}+06}$ & $\frac{9.4 \mathrm{E}+06}{1.1 \mathrm{E}+09}$ & \\
\hline$I-12$ & $1.4 \mathrm{E}-04$ & $1.4 \mathrm{E}-04$ & $1.4 \mathrm{E}-03$ & NA & NA & NA & NA & NA & $\mathrm{NA}$ & NA & $8.5 \mathrm{E}-02$ & $1.9 \mathrm{E}-01$ & $4.5 \mathrm{E}-01$ \\
\hline 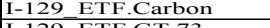 & & & & NA & NA & NA & NA & NA & NA & NA & $2.1 \mathrm{E}+01$ & $1.1 \mathrm{E}+01$ & $1.0 \mathrm{E}+01$ \\
\hline$\frac{1-12}{-12}$ & $\frac{1.2 \mathrm{E}+0 \mathrm{OO}}{1.5 \mathrm{E}+01}$ & $\begin{array}{r}5.8 \mathrm{E}-01 \\
7.7 \mathrm{E}+00\end{array}$ & $\begin{array}{l}2.3 \mathrm{E}-\mathrm{O} 1 \\
3.0 \mathrm{E}+00\end{array}$ & NA & NA & NA & NA & NA & NA & NA & $\frac{2.8 \mathrm{E}+01}{3.7 \mathrm{E}}$ & $1.4 \mathrm{E}+01$ & $1.4 \mathrm{E}+01$ \\
\hline $\mid$\begin{tabular}{|l|l}
$\mid-129$ & $F . C$ \\
-129 & $F . C$
\end{tabular} & $\frac{1.5 \mathrm{E}+01}{5.9 \mathrm{E}-03}$ & $\begin{array}{l}7.7 \mathrm{E}+0 \mathrm{O} \\
3.0 \mathrm{E}-03\end{array}$ & $\frac{3.0 \mathrm{E}+0 \mathrm{O}}{3.1 \mathrm{E}-03}$ & $\frac{\mathrm{NA}}{\mathrm{NA}}$ & $\frac{\mathrm{NA}}{\mathrm{NA}}$ & $\frac{\mathrm{NA}}{\mathrm{NA}}$ & $\frac{\mathrm{NA}}{\mathrm{NA}}$ & $\frac{\mathrm{NA}}{\mathrm{NA}}$ & $\frac{\mathrm{NA}}{\mathrm{NA}}$ & $\frac{\mathrm{NA}}{\mathrm{NA}}$ & $\frac{3.7 \mathrm{E}+02}{1.9 \mathrm{E}-01}$ & $\frac{1.9 \mathrm{E}+02}{3.1 \mathrm{E}-01}$ & $\frac{1.8 \mathrm{E}+02}{1.0 \mathrm{E}+00}$ \\
\hline$I-129$ F.I & $7.9 \mathrm{E}-01$ & 4.01 & $1.6 \mathrm{E}-01$ & & $\mathrm{NA}$ & NA & NA & $\mathrm{NA}$ & $\mathrm{NA}$ & $\mathrm{NA}$ & $1.9 \mathrm{E}+01$ & $1.0 \mathrm{E}+\mathrm{O} 1$ & $9.4 \mathrm{E}+0 \mathrm{O}$ \\
\hline$[-1$ & $6.6 \mathrm{E}-03$ & 3.31 & 3.3 & NA & $N A$ & NA & NA & NA & $\mathrm{NA}$ & $\pi$ & $2.0 \mathrm{E}-01$ & $3.2 \mathrm{E}-01$ & $9.4 \mathrm{E}-01$ \\
\hline$\frac{I-12}{I-12}$ & $6.7 \mathrm{E}+00$ & & $1.3 \mathrm{H}$ & NA & NA & NA & $\mathrm{N}$ & $\mathrm{N}$ & $\mathrm{N}$ & & $1.6 \mathrm{E}+02$ & \begin{tabular}{|l|l|}
$8.5 \mathrm{E}+\mathrm{O} 1$ \\
9
\end{tabular} & $8.0 \mathrm{E}+01$ \\
\hline $\mid \begin{array}{l}\mathrm{I}-129-\mathrm{H} \\
\mathrm{I}-129 \mathrm{~F}\end{array}$ & $\frac{4.4 \mathrm{E}-02}{1.8 \mathrm{E}+00}$ & 2.21 & $\begin{array}{l}1.41 \\
3.61\end{array}$ & $\begin{array}{l}\mathrm{NA} \\
\mathrm{NA}\end{array}$ & $\frac{\mathrm{N} t}{\mathrm{~N} t}$ & $\frac{\mathrm{NA}}{\mathrm{NA}}$ & $\frac{\mathrm{NA}}{\mathrm{NA}}$ & $\frac{\mathrm{NA}}{\mathrm{NA}}$ & $\frac{\text { NA }}{\text { NA }}$ & $\frac{N}{N}$ & $\frac{1.1 \mathrm{E}+0 \mathrm{O}}{4.4 \mathrm{E}+01}$ & $\frac{9.1 \mathrm{E}-01}{2.3 \mathrm{E}+01}$ & $\frac{8.4 \mathrm{E}-01}{2.1 \mathrm{E}+01}$ \\
\hline $\mathrm{I}-129 \mathrm{H}$ & $7.5 \mathrm{E}-02$ & $3.8 \mathrm{t}$ & 2.11 & NA & NA & NA & NA & NA & NA & $\mathrm{N}$ & $1.8 \mathrm{E}+0 \mathrm{O}$ & $1.4 \mathrm{E}+0 \mathrm{OO}$ & $\frac{2.1 \mathrm{E}+\mathrm{O}}{1.3 \mathrm{E}+\mathrm{O}}$ \\
\hline $\mathrm{I}-12$ & 3.6 & & & NA & & NA & $\mathrm{N}$ & NA & NA & & & & +0 \\
\hline 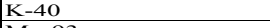 & 1 & & & NA & & NA & & $\mathrm{N}$ & & & 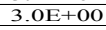 & 00 & $3 \mathrm{E}-1$ \\
\hline & . & & & & & $\mathrm{N}$ & & & & & $2 \mathrm{E}+\mathrm{OOO}$ & 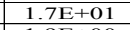 & \\
\hline & 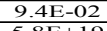 & & & $N$ & $\mathrm{~N}$ & $\mathrm{~N}$ & & & & & - & & $O E E_{2}$ \\
\hline & $5.8 \mathrm{E}+19$ & & 4.1 & $\frac{\mathrm{N}}{79 \mathrm{~F}}$ & $\frac{\mathrm{N}}{15 \mathrm{E}}$ & $\mathrm{NA}$ & $N$ & $\mathrm{~N}$ & $\mathrm{~N}$ & & $9.8 \mathrm{E}$ & $\frac{03}{27}$ & OE \\
\hline & $2.4 \mathrm{E}+03$ & 1 & & 7.9 & $\frac{1.5}{n}$ & \begin{tabular}{|c|}
$3.7 \mathrm{E}-\mathrm{O} 1$ \\
$\mathrm{NA}$
\end{tabular} & $\mathbf{N}$ & $\mathrm{N}$ & $\mathrm{N}$ & & 15 & 03 & $\mathrm{E}+\mathrm{Oz}^{3}>$ \\
\hline & & $\frac{4.2 \mathrm{E}+11}{---}$ & 9.8 & $3.7 \mathrm{E}+05$ & 1.2 & $\frac{1 \mathrm{~V}}{1.1 \mathrm{E}}$ & $\frac{\mathrm{NA}}{3.7 \mathrm{E}+05}$ & & $\mathrm{~N}$ & & & $\frac{3 . .4}{1.1}$ & $\begin{array}{l}2+03 \\
-03\end{array}$ \\
\hline & $9.6 \mathrm{E}+17$ & $6.7 \mathrm{E}+12$ & & $9.4 \mathrm{E}-\mathrm{C}-\mathrm{C}$ & & & 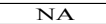 & $\mathrm{NA}$ & NA & & & & $9.9 \mathrm{E}+\mathrm{O}$ \\
\hline & & & $2.3 \mathrm{E}$ & $2.7 \mathrm{E}+08$ & 3.3 & $2.8 \mathrm{E}$ & $4.1 \mathrm{E}+15$ & $3.2 \mathrm{E}+15$ & $3.1 \mathrm{E}+15$ & & $1.3 \mathrm{E}+18$ & 1.0 & $1.1 \mathrm{E}+\mathrm{O}$ \\
\hline & $1.4 \mathrm{E}+12$ & $2.5 \mathrm{E}+08$ & & 6. & & 3.6 & & & & & 2.11 & & $1.3 \mathrm{E}+03$ \\
\hline & --- & -4 & & & & 2.5 & & & & & $3.3 \mathrm{E}$ & & +07 \\
\hline & $2,3 \mathrm{E}+17$ & & & & & $2.2 \mathrm{E}+07$ & & $\frac{1.2 \mathrm{E}}{3.8 \mathrm{I}}$ & $38 \mathrm{E}$ & & $5 \cdot 25+00$ & & $\frac{2 E+06}{1 E-01}$ \\
\hline $\begin{array}{l}\mathrm{Ra} \\
\mathrm{Ra}\end{array}$ & $\frac{2.3 \mathrm{E}+17}{---}$ & $\frac{2.5 \mathrm{E}+07}{1.2 \mathrm{E}+12}$ & $\frac{3.0}{1.4}$ & $\frac{6.4 \mathrm{E}-02}{2.3 \mathrm{E}-01}$ & 3.8 & \begin{tabular}{|r|}
$3.7 \mathrm{E}-\mathrm{O} 2$ \\
$8.3 \mathrm{E}-01$
\end{tabular} & $\frac{6.4 \mathrm{E}-02}{2.02}$ & $\frac{3.8 \mathrm{E}-02}{9.9 \mathrm{E}-01}$ & $\frac{3.8 \mathrm{E}-02}{8.02}$ & $N$ & $\frac{5.2 \mathrm{E}+0 \mathrm{O}}{1.0 \mathrm{E}+04}$ & $\begin{array}{l}1.9 \mathrm{E}-01 \\
6.6 \mathrm{E}-01\end{array}$ & $\frac{1.1 \mathrm{E}-01}{2.4 \mathrm{E}+0 \mathrm{OO}}$ \\
\hline & -7 & & $3.2 \mathrm{E}+19$ & NA & NA & $\frac{\mathrm{NA}}{\mathrm{NA}}$ & NA & NA & NA & NA & & & $3.4 \mathrm{E}+19$ \\
\hline & & & & $\mathrm{N}$ & & $N$ & & $\bar{N}$ & $\mathrm{~N}$ & & & & \\
\hline & 4 & & & & & $N$ & & & & & 3 & $\frac{03}{05}$ & 2.4 \\
\hline Mk5OA & $\frac{18}{1}$ & & & & & $\mathrm{~N}$ & $\mathbf{N}$ & $N$ & & & $\overline{0}$ & $\frac{05}{00}$ & $\frac{3.3 \mathrm{E}+12}{7.7 \mathrm{E}+0 \mathrm{OC}}$ \\
\hline & $\frac{.65-01}{3 E+03}$ & & & & & & & & & & 2.0 & 22 & $1.15+0 \mathrm{C}$ \\
\hline & --- & & & & & & & & & & & & \\
\hline & & & & & & & & & & & & & \\
\hline & $6.0 \mathrm{E}+16$ & $3.8 \mathrm{E}+\mathrm{C}$ & & & & & & & & & & & \\
\hline & & & & & & & & & & & & & 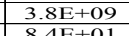 \\
\hline & - & & & & & & & & & & & & \\
\hline & & & & & & & & & & & & & \\
\hline & & & & & & & & & & & & & \\
\hline & $\frac{2}{3}$ & & & & & & & & & & & & \\
\hline & 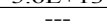 & $2.3 \mathrm{E}$ & & & & & & & & & & & \\
\hline & & & & & & & & & & & & & \\
\hline & - & & & & & & & & & & & & \\
\hline -238_MGlass & 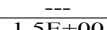 & & $1.3 \mathrm{E}+09$ & $4.7 \mathrm{E}+07$ & 07 & 07 & 4 & & & & & & \\
\hline & $5 \mathrm{E}+0 \mathrm{O}$ & $.4 \mathrm{E}$ & 7.4E-01 & & & & & & & & & & \\
\hline
\end{tabular}




\section{Table 4. Minimal operational limits}

Minimal limits 2 sets of 2 trenches from PA and covers at 5,10, and 15 years

\begin{tabular}{|c|c|c|c|c|c|c|c|c|c|c|c|c|c|}
\hline \multirow{3}{*}{$\begin{array}{l}\text { Parent Nuclide } \\
\text { Am-241 }\end{array}$} & vars & $\begin{array}{l}\text { ta-Gamm } \\
12-100 \\
\text { yrs }\end{array}$ & ${ }^{2} 100-1130$ & 0-1000 & $\begin{array}{l}\text { Gross Alpha } \\
\text { 1000-1120 }\end{array}$ & $1120-1130$ & 0-1000 & $\begin{array}{l}\text { Radium } \\
\text { 1000-1120 }\end{array}$ & $1120-1130$ & O-1130 & $\begin{array}{l}\text { Ground } \\
\text { 130-200 }\end{array}$ & $\begin{array}{l}\text { vater All-P } \\
200-1000\end{array}$ & $\begin{array}{l}\text { Pathways } \\
1000-1130\end{array}$ \\
\hline & 3. $\begin{array}{l}\text { yrs } \\
\text { E }+09\end{array}$ & & 1.1E+04 & $\begin{array}{l}\text { yrs } \\
2.2 \mathrm{E}+02\end{array}$ & & $\begin{array}{l}\text { yrs } \\
1.2 \mathrm{E}+02\end{array}$ & & & & & & & $\begin{array}{c}\text { yrs } \\
4 \mathrm{5E+01}\end{array}$ \\
\hline & $---9 E+09$ & $\begin{array}{l}\text { l.8E+06 } \\
5.3 \mathrm{E}+16\end{array}$ & $\begin{array}{l}1.1 \mathrm{E}+04 \\
4.8 \mathrm{E}+02\end{array}$ & $6.6 \mathrm{E}+\mathrm{O} 1$ & $\begin{array}{l}1.3 \mathrm{E}+\mathrm{OL2} \\
2.6 \mathrm{E}+01\end{array}$ & $\begin{array}{l}\text { 1.2E+02 } \\
2.4 \mathrm{E}+01\end{array}$ & & & & $1.2 \mathrm{E}$ & $2.9 \mathrm{E}$ & $2.5 \mathrm{E}$ & 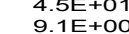 \\
\hline & 2.5E-01 & 2.5E-01 & $3.2 \mathrm{E}+\mathrm{OO}$ & --- = n & --- & --- & NA & NA & NA & NA & 00 & & 01 \\
\hline C-14_NR.Pump & -- & (3) & $2.5 \mathrm{E}+\mathrm{OOO}$ & --- & -- & & & & & & & & \\
\hline-249 & $1.2 \mathrm{E}+17$ & $3.1 \mathrm{E}+12$ & $3.2 E+04$ & $3.1 \mathrm{E}+02$ & $1.4 E+0$ & $1.3 E+02$ & 2NA & NA & $\mathrm{N}$ & $9.3 E+13$ & 1.8E $>\Rightarrow$ & $9.7 \mathrm{E}+01$ & $1 E+01$ \\
\hline-25 & & & $1.7 \mathrm{E}+08$ & $1.3 \mathrm{E}+02$ & $5.5 \mathrm{E}+01$ & $5.2 E+01$ & I NA & NA & & $8.1 \mathrm{E}-\mathrm{H}-\mathrm{P}$ & 18 & 51 & $=01$ \\
\hline $\begin{array}{ll}\mathrm{Cl}-36 \\
\mathrm{Cm}-244\end{array}$ & 8.6E-02 & 8.6E-02 & $1.1 \mathrm{E}+\mathrm{OO}$ & NA & NA & NA & & & & & 5.9E-O1 & $1.6 E+00$ & $2.0 E+O O$ \\
\hline $\mathrm{Cm}-244$ & 17 & & $8.9 E+17$ & 7.OE+10 & $9.2 E+09$ & 7.9 & 1.6 & $3 \quad 1.2$ & 1.2 & 9.8 & & 2.7E+10 & $3.1 \mathrm{E}+09$ \\
\hline $\begin{array}{l}\mathrm{Cm}-245 \\
\mathrm{Cm}-246\end{array}$ & $1.7 E+13$ & 1.1E+09 & 1.2E+03 & 3.6E+01 & 1.4E+01 & 1.3 & & NA & NA & $1.8 E+12$ & $6.6 E+03$ & +01 & 4. \\
\hline $\begin{array}{l}n-246 \\
n-247\end{array}$ & - & -- & $\begin{array}{l}7.7 E+14 \\
36 E+03\end{array}$ & $\begin{array}{l}\text { 7.OE+01 } \\
5.5 E+01\end{array}$ & $\begin{array}{l}2.7 E+01 \\
2.1 E+01\end{array}$ & $\begin{array}{l}2.5 E+01 \\
2.0 E+01\end{array}$ & 1.1 & 3.6 & $\begin{array}{r}3.3 \\
N A\end{array}$ & $\begin{array}{l}1.9 E+13 \\
1.4 E+13\end{array}$ & & $\begin{array}{l}2.6 \mathrm{E}+01 \\
2.2 \mathrm{E}+01\end{array}$ & 9.4E+OO \\
\hline $\begin{array}{l}n-247 \\
n-248\end{array}$ & $\cdots$ & --- & $\begin{array}{l}3.6 \mathrm{E}+03 \\
3.1 \mathrm{E}+09\end{array}$ & $\begin{array}{l}\text { 5.5E+01 } \\
6.6 \mathrm{E}+01\end{array}$ & $\begin{array}{l}2.1 E+01 \\
2.5 E+01\end{array}$ & $\begin{array}{l}2.0 E+01 \\
2.4 E+01\end{array}$ & NA & NA & NA & $\begin{array}{l}1.4 E+13 \\
2.9 E+17\end{array}$ & $\begin{array}{l}6.3 E+12 \\
2.3 E+19\end{array}$ & $\begin{array}{l}2.2 \mathrm{E}+01 \\
6.1 \mathrm{E}+00\end{array}$ & $\begin{array}{l}7.8 \mathrm{E}+\mathrm{OO} \\
2.2 \mathrm{E}+\mathrm{OO}\end{array}$ \\
\hline & $4.7 E+O O$ & $4.8 \mathrm{E}$ & $1.9 \mathrm{E}+04$ & NA & $\mathrm{NA}$ & NA $2.4 \mathrm{E}+\mathrm{OT}$ & NA & NA & NA & NA & $1.5 E+06$ & $4.1 \mathrm{E}+06$ & $\begin{array}{l}2.2 \mathrm{E}+\mathrm{OO} \\
4.1 \mathrm{E}+\mathrm{O}\end{array}$ \\
\hline 3_ & 1.1 & $1.1 \mathrm{E}$ & $4.5 \mathrm{E}+04$ & NA & NA & NA & & & & & & & $\begin{array}{l}+\infty 6 \\
+\infty 6 \\
+06\end{array}$ \\
\hline BE & & & $5.6 \mathrm{E}$ & & NA & NA & NA & NA & & & $1.5 \mathrm{E}$ & & \\
\hline - & 1.4E-04 & 1.4E-04 & 1.4E-03 & NA & NA & NA & NA & NA & NA & NA & 8.6E-02 & 2.9E-01 & \\
\hline Carbon & & & 1.7E-01 & NA & NA & NA & NA & NA & NA & NA & 2.1E+01 & $1.1 \mathrm{E}+01$ & \\
\hline 1-129_ETF.GT.73 & $1.2 \mathrm{E}+\mathrm{OO}$ & $5.8 \mathrm{E}-01$ & 2.3E-01 & NA & NA & NA & NA & NA & NA & NA & $2.8 \mathrm{E}+01$ & $1.5 \bar{E}+01$ & +01 \\
\hline I-129_F.Carbon & 1.5E+01 & 7.7E+OO & 3.OE+OO & NA & NA & NA & NA & NA & NA & NA & $3.7 E+02$ & $1.9 \mathrm{E}+\mathrm{O} 2$ & \\
\hline 129 & 5.9E-O3 & 3.0E-03 & 3.1E-03 & NA & NA & NA & NA & NA & NA & NA & & & \\
\hline 125 & 7.9E-01 & 4.OE-01 & 1.6E-01 & & & & & & & & $1.9 \mathrm{E}-\mathrm{C}-\mathrm{c}$ & & \\
\hline 1-129_F.Filterca & 6.6Е-03 & 3.3Е-03 & 3.3E-03 & NA & NA & NA & NA & NA & & A & 11 & & $9.8 \mathrm{E}-\mathrm{O} 1$ \\
\hline I-129_H.Carbon & $6.7 E+00$ & $3.4 \mathrm{E}+\mathrm{OO}$ & $1.3 E+0 O$ & NA & NA & NA & NA & NA & NA & NA & 1.6E+02 & $28.5 E+01$ & $8.0 E+01$ \\
\hline I-129_H.CG.8 & 4.4E-02 & $2.2 \mathrm{E}-02$ & 1.4E-02 & NA & NA & NA & NA & NA & & NA & 1.1 & 8. & E-01 01 \\
\hline $11 \mathrm{~K}$ & $1.8 \mathrm{E}$ & 9.1E-01 & $3.5 \mathrm{E}$ & NA & NA & NA & NA & NA & NA & NA & & & \\
\hline $\mathrm{C}^{-1}$ & 7.5E-02 & 3.8E-02 & 2.2E-02 & & NA & & & & & & $1.8 \mathrm{E}>2 \mathrm{C}$ & & \\
\hline $1-129$ & $3.6 \mathrm{E}, \mathrm{C}-\mathrm{s}$ & $1.4 \mathrm{E}-\longrightarrow \mathrm{C}$ & 3.7E-01 & & & & & & & & & & $+01-12-3$ \\
\hline $\mathrm{K}-4 \mathrm{O}$ & $6.5 \mathrm{E}-02$ & 5.9E-02 & 5.OE-O1 & NA & NA & NA & NA & NA & NA & NA & $1.1 \mathrm{E}+\mathrm{OO}$ & ) $2.1 \mathrm{E}+0 \mathrm{O}$ & +01 \\
\hline Mo-93 & 1.9E-01 & $1.9 \mathrm{E}$ & $1.3 E$ & NA & NA & NA & NA & NA & & NA & $6.2 \div 3+2>$ & & \\
\hline $\mathrm{Nb}-94$ & & & $1.2 \mathrm{E}>>+2$ & NA & NA & NA & NA & & & NA & -01 & & \\
\hline-59 & $5.8 E+19$ & $3.4 \mathrm{E}+09$ & 4.1E+OO & NA & NA & NA & NA & NA & NA & & 9.8 & $\begin{array}{l}5.2 \\
2.210\end{array}$ & \\
\hline o-237 & $2.4 \mathrm{E}+03$ & 3.9E+OO & 1.6E+OO & $7.9 \mathrm{E}-02$ & 1.5E-01 & 3.6E-01 & NA & NA & NA & $?$ & & & $=-02$ \\
\hline $\begin{array}{l}-1-1 \\
-1\end{array}$ & --- & $4.2 E+11$ & $\begin{array}{l}4.9 E+02 \\
9.9 E+06\end{array}$ & NA & NA & NA $1 F+05$ & NA & & NA & & & & \\
\hline $1-2$ & & -- & $9.8 \mathrm{E}+06$ & & & & & & & 1.5 & & & \\
\hline & & & & & & & & & & & & & \\
\hline & & & 2.3 & & & & & & & & & & \\
\hline $1-24$ & $.4 E+12$ & $2.5 \mathrm{E}+08$ & $3.3 \mathrm{E}>\mathrm{C}-\mathrm{s}$ & & & & & $\mathrm{N}$ & $\mathrm{N}$ & & & & \\
\hline & & & $1.0 \quad>>2$ & & & & & & & & & & \\
\hline $1-2$ & -- & - & & $2.2 \mathrm{E}$ & 2.6 & $2.2 \mathrm{E}$ & 1.7 & 1.2 & & & & 9.0 & \\
\hline$a-2$ & $2.3 E+17$ & $2.5 E+07$ & $2.9 \mathrm{E}+2 \mathrm{C}$ & & & & & & & NA & & & \\
\hline Cooling. $\mathrm{T}$ & -- & $1.2 \mathrm{E}$ & $1.4 \mathrm{E}-\mathrm{r}=\mathrm{l}$ & 2.3 & -01 & 8 & 2 & 9. & 8 & & 1.0 & 6.6E-01 & 2.4 \\
\hline$-12+2+3$ & -- & -- & $3.2 \mathrm{E}$ & NA & NA & NA & NA & NA & $\hat{N}$ & $N$ & - & & 3.4 \\
\hline $\operatorname{sn}-12+2$ & $-9.9 \mathrm{E}$ & & & $\begin{array}{l}\text { NA } \\
\text { NA }\end{array}$ & $\begin{array}{l}\text { NA } \\
\text { NA }\end{array}$ & $\begin{array}{l}\text { NA } \\
\text { NA }\end{array}$ & $\begin{array}{l}\text { NA } \\
\text { NA }\end{array}$ & NA & & $\begin{array}{l}\text { NA } \\
\text { NA }\end{array}$ & & & \\
\hline-90 & & & & NA & $\begin{array}{l}\text { NA } \\
\text { NA }\end{array}$ & NA & NA & $\mathrm{N} /$ & $N$ & NA & & & \\
\hline tist & & & 1.3 & $\mathrm{~N}$ & NA & $\mathrm{N}$ & $\mathrm{N}$ & $\mathrm{N}$ & & & & & \\
\hline TS & $5.3 \mathrm{E}>\longrightarrow$ & 1.3 & & & NA & NA & NA & $\mathrm{N}$ & & & & & \\
\hline $1-23$ & & $2.0 \mathrm{E}^{2} \mathrm{C}$ & $8.8 \mathrm{E}+00$ & 3. & 1.1 & 1.0 & 3.1 & & & NA & & & \\
\hline & & & 1.1 & & & & & & & NA & 4.9 & & \\
\hline Th-23 & $6.0 E+16$ & $3.8 \mathrm{E}+09$ & $2.7 E$ & 2.7 & $6.3 \mathrm{E}-\mathrm{C}-\mathrm{C}$ & 8.0 & $3.6 \mathrm{E}$ & $8.4 \mathrm{E}$ & 1.1 & NA & $1.7 E+04$ & & \\
\hline $2=$ & & & $4.7 \mathrm{E}$ & 1.2 & & & NA & NA & & & & & \\
\hline$U-2$ & --- & & & & & & & & & & & & \\
\hline & & & & & & & & & & & & & \\
\hline & & & $6.2 \mathrm{E}$ & $4.8 \mathrm{E}>->1$ & $5.0>->>$ & 6.0 & & & & & & & \\
\hline$u=$ & $2.3 \mathrm{E}$ & & $2.4 \mathrm{E}$ & & & & NA & NA & $\mathrm{N}$ & & & & \\
\hline h.Cask & 5.6E & $4.1 \mathrm{E}$ & & & & & & NA & & & & & \\
\hline U & & $2.3 E+19$ & 2.3 & & 2.5 & & & 3.3 & & & & & \\
\hline J-236_MGlass & -- & -- & 1.6E & $\begin{array}{l}2.1 E+13 \\
1.2 E+05\end{array}$ & 1.7E+13 & 1.6 & 2.8 & 2.3 & & & & 53.7 & 7 \\
\hline $\begin{array}{l}-238 \\
J-238\end{array}$ & & --- & $\begin{array}{l}3.3 E+06 \\
1.3 E+09\end{array}$ & $\begin{array}{l}1.2 \mathrm{E}+05 \\
4.7 \mathrm{E}+07\end{array}$ & $\begin{array}{l}\text { 3. } 9 \mathrm{E}+04 \\
1.5 \mathrm{E}+07\end{array}$ & 04 & $\begin{array}{l}1.3 \mathrm{E} \\
4.7 \mathrm{E}\end{array}$ & $\begin{array}{l}3.9 \mathrm{E} \\
1.5 \mathrm{E} \\
\end{array}$ & & & & & \\
\hline $\begin{array}{l}-238 \text {-MGlass } \\
\text { r-93 }\end{array}$ & $5 E+00$ & 6.4E-01 & $\begin{array}{r}1.3 E+09 \\
7.4 E-01\end{array}$ & $\begin{array}{l}4.7 E+07 \\
N A\end{array}$ & NA $\begin{array}{l}1.5 E+07 \\
\text {. }\end{array}$ & $\mathrm{NA}^{1.4 \mathrm{E}+07}$ & $\begin{array}{l}4.7 E+07 \\
N A\end{array}$ & NA $1.5 E+07$ & $N^{1.4 E+07}$ & $\mathrm{NA}^{1.2 \mathrm{E}+12}$ & $\begin{array}{l}\text { 3.OE+122 } \\
\text { 8.9E+OO }\end{array}$ & $\begin{array}{l}1.4 \mathrm{E}+\mathrm{OO} \\
4.8 \mathrm{E}+\mathrm{OO}\end{array}$ & $\begin{array}{l}4.1 \mathrm{E}+\mathrm{O} 7 \\
4.4 \mathrm{E}+\mathrm{OC}\end{array}$ \\
\hline
\end{tabular}




\subsubsection{Inventory limit trends and observations}

Limit trends were analyzed by generating comparison spreadsheets (not shown) and automatically highlighting major differences or examining maximum differences. Those differences are discussed below in this section.

A similarity that applies across all limit categories and all time periods is that minimal differences (less than 0.6\%) exist between covering Slit Trench groups 1-2 and 3-4 with two covers or one cover at 15 years. The only difference in the analysis was including two additional edge trenches when two covers were employed rather than one cover. This similarity was examined based on initial analyses for 5-year and 15-year covers (before design checking) hence limits in this discussion may not agree with the final analyses. This similarity is expected to apply to final results and the option for a single cover has not been selected, so further analysis is not warranted.

For the same set of alternatives but with a cover at 5 years, twenty preliminary limits differed by more than one percent. The maximum relative differences defined as [ $\mid\left(\right.$ limit $_{\text {one cover }}-$ limit $\left._{\text {two covers }}\right) /$ limit $\left.{ }_{\text {two covers }} \mid\right]$ (after rounding) are presented in Table 5. For the early years ( 0 -100 years) the single cover performed slightly better, with the reverse relationship holding for later years. Subsequent discussions in this SA will focus on results for the scenarios with two covers only, because the operational limits (after considering the PA limits) for one cover and two covers are the same.

Table 5. Significant relative differences for SA-calculated preliminary limits between one cover or two covers over ST1 through ST4 placed at 5 years

\begin{tabular}{|c|c|c|c|c|}
\hline Isotope & Limit category & $\begin{array}{c}\text { Relative diff. } \\
(\%)\end{array}$ & $\begin{array}{c}\text { Two Covers } \\
\text { limit }(\mathrm{Ci})\end{array}$ & $\begin{array}{c}\text { One Cover } \\
\text { limit (Ci) }\end{array}$ \\
\hline K-40 & $0-12$ yrs $\beta \gamma$ & 16 & 4.5 & 5.2 \\
\hline Am-241 & $12-100$ yrs $\beta \gamma$ & 4.3 & $2.3 \mathrm{E} 10$ & $2.4 \mathrm{E} 10$ \\
\hline C-14 & $12-100$ yrs $\beta \gamma$ & 2.1 & 4.7 & 4.8 \\
\hline Cf-249 & $12-100$ yrs $\beta \gamma$ & 1.4 & $7.1 \mathrm{E} 17$ & $7.2 \mathrm{E} 17$ \\
\hline Cl-36 & $12-100$ yrs $\beta \gamma$ & 6.2 & 1.6 & 1.7 \\
\hline I-129 & $12-100$ yrs $\beta \gamma$ & 3.1 & $3.2 \mathrm{E}-3$ & $3.3 \mathrm{E}-3$ \\
\hline I-129_Mk50A & $12-100$ yrs $\beta \gamma$ & 1.4 & 69 & 70 \\
\hline K-40 & $12-100$ yrs $\beta \gamma$ & 1.3 & 2.4 & 2.7 \\
\hline Mo-93 & $12-100$ yrs $\beta \gamma$ & 3.8 & 2.6 & 2.7 \\
\hline Np-237 & $12-100$ yrs $\beta \gamma$ & 8.3 & 12,000 & 13,000 \\
\hline Pu-241 & $12-100$ yrs $\beta \gamma$ & 1.1 & $8.8 \mathrm{E} 12$ & $8.9 \mathrm{E} 12$ \\
\hline Tc-99 & $12-100$ yrs $\beta \gamma$ & 3.3 & 3.0 & 3.1 \\
\hline Tc-99_Mk50A & $12-100$ yrs $\beta \gamma$ & 3.3 & 91,000 & 94,000 \\
\hline & & 14 & 290 & 250 \\
\hline C-14 & $1000-1130$ yrs GW All-pathways & 14 & 46 & 40 \\
\hline Cl-36 & $1000-1130$ yrs GW All-pathways & 13 & 2.5 & 2.4 \\
\hline I-129 & $1000-1130$ yrs GW All-pathways & 4.0 & 28 & 27 \\
\hline K-40 & $1000-1130$ yrs GW All-pathways & 3.6 & 560 & 490 \\
\hline Mo-93 & $1000-1130$ yrs GW All-pathways & 13 & 55 & 49 \\
\hline Nb-94 & $1000-1130$ yrs GW All-pathways & 11 & 54 & 51 \\
\hline Tc-99 & $1000-1130$ yrs GW All-pathways & 5.6 & & \\
\hline
\end{tabular}


For preliminary SA-calculated limits (before considering the preliminary PA limits) the following generalizations are applicable:

- For the 0 to 12 year period:

$\circ$ For a cover placed at 15 years, no SA-calculated limit changes should occur versus the PA. However, because the size of time increments was changed versus the PA some limits for the highly mobile contaminants do change. The maximum increase was 17 percent of the PA value, while the maximum decrease was 65 percent of the original for K-40.

- For a cover placed at 10 years, SA-calculated limits (for limits $<$ $1 \mathrm{E} 20 \mathrm{Ci}$ ) the maximum increase was 44 percent of the original, while the maximum decrease was 60 percent of the original for K-40.

- For a cover placed at 5 years, SA-calculated limits (for limits $<$ $1 \mathrm{E} 20 \mathrm{Ci}$ ) the maximum increase was 8230 percent of the original, with no decreases.

- As the time delay for cover placement shortened, most SAcalculated limits increased.

- For the 12 to 100 year period:

O For a cover placed at 15 years, the maximum decrease was 58 percent for K-40. All other limits of less than 1E20 Ci increased with a maximum increase of 520,000 percent.

○ For a cover placed at 10 years, the maximum decrease was 46 percent for K-40. All other limits of less than 1E20 Ci increased with a maximum increase of $1.67 \mathrm{E} 7$ percent.

- For a cover placed at 5 ears, no decreases occurred. All limits of less than 1E20 Ci increased with a maximum increase of $2.75 \mathrm{E} 9$ percent.

- For all other time intervals (they each included 100 years and beyond):

○ Some SA-calculated limits decreased with greater decreases occurring for earlier cover placement. The maximum decrease was 81 percent (for a 5-year cover I-129 changed from a PA limit of $0.53 \mathrm{Ci}$ to $0.10 \mathrm{Ci}$ for the Groundwater All-Pathways from 130 to 200 years). These decreases typically occurred because the cover placement delayed contaminant releases until later times. Greater decreases typically occurred for more highly mobile contaminants. However, there were exceptions, e.g., I-129 limits increased across the board for cover placement at 15 years (for limits $<1 \mathrm{E} 20 \mathrm{Ci}$ ), likely the result of serendipitous timing of cover placement.

For operational limits (the smaller of final PA limits and final SA-calculated limits) the following generalizations are applicable:

- By definition, no limits increased. 
- For time intervals with a maximum of 100 years or less, the only limits that decreased were for K- 40 and only for covers placed at 10 and 15 years. The decreases ranged from 46 percent to 60 percent.

- For time intervals that ended after 100 years minor changes occurred for covers placed at 15 years: six decreases of greater than 10 percent occurred with four of them attributed to $\mathrm{H}-3$ and $\mathrm{H}-3$ _Concrete. The greatest decrease was 20 percent for H-3 for the Groundwater AllPathways from 120 to 200 years.

- For time intervals that ended after 100 years, greater changes occurred for covers placed at 10 years: fourteen limits decreased by more than 10 percent. The greatest decrease was 56 percent for I-129 in the 130 to 200 year period for the Groundwater All-Pathways.

- For time intervals that ended after 100 years, much greater changes occurred for covers placed at 5 years: thirty-four limits decreased by more than 10 percent. The greatest decrease was 81 percent for I-129 in the 130 to 200 year period for the Groundwater All-Pathways. Limit comparisons for the cover with the greatest changes (the 5-year cover) are shown in Table 6. The greatest decrease was $81 \%$ which is highlighted in red in Table 6.

Major decreases (greater than 20\%) occurred for the beta-gamma pathway for the time intervals from 100 to 1130 years and for the groundwater allpathways for the time intervals from 130 to 200 years and from 200 to 1000 years. Most major changes occurred for highly-mobile isotopes that were modeled beyond the 130 years where the PA analysis terminated. Similar to the PA, tritium-in-concrete was always assigned a higher limit than generic tritium, even when its concentration was higher than generic tritium for a specific time interval. 
Table 6. Limit comparisons for 5-year cover vs. PA showing major changes

\begin{tabular}{|c|c|c|c|c|c|}
\hline Isotope & Pathway & Time Interval (yr) & PA limit $(\mathrm{Ci})$ & New limit (Ci) & Relative change (\%) \\
\hline $\mathrm{C}-14$ & $\mathrm{~B} \gamma$ & $100-1130$ & $8.6 \mathrm{E}+00$ & $3.20 \mathrm{E}+00$ & -63 \\
\hline Cl-36 & $\mathrm{B} \gamma$ & $100-1130$ & $3.0 \mathrm{E}+00$ & $1.10 \mathrm{E}+00$ & -63 \\
\hline H-3 & $\mathrm{B} \gamma$ & $100-1130$ & $2.30 \mathrm{E}+04$ & $1.90 \mathrm{E}+04$ & -17 \\
\hline H-3 Concrete & $\mathrm{B} \gamma$ & $100-1130$ & $5.40 \mathrm{E}+04$ & $4.50 \mathrm{E}+04$ & -17 \\
\hline I-129 & $\mathrm{B} \gamma$ & $100-1130$ & $6.3 \mathrm{E}-03$ & $1.40 \mathrm{E}-03$ & -78 \\
\hline I-129 F.CG. 8 & $\mathrm{~B} \gamma$ & $100-1130$ & $3.50 \mathrm{E}-03$ & $3.10 \mathrm{E}-03$ & -11 \\
\hline I-129_F.Filtercake & $\mathrm{B} \gamma$ & $100-1130$ & $3.80 \mathrm{E}-03$ & $3.30 \mathrm{E}-03$ & -13 \\
\hline $\mathrm{K}-40$ & $\mathrm{~B} \gamma$ & $100-1130$ & $1.6 \mathrm{E}+00$ & $5.00 \mathrm{E}-01$ & -69 \\
\hline Mo-93 & $\mathrm{B} \gamma$ & $100-1130$ & $3.5 \mathrm{E}+00$ & $1.30 \mathrm{E}+00$ & -63 \\
\hline $\mathrm{Nb}-94$ & $\mathrm{~B} \gamma$ & $100-1130$ & $3.3 \mathrm{E}+00$ & $1.20 \mathrm{E}+00$ & -64 \\
\hline Tc-99 & $\mathrm{B} \gamma$ & $100-1130$ & $4.5 \mathrm{E}+00$ & $1.30 \mathrm{E}+00$ & -71 \\
\hline C-14 & GW-All & $130-200$ & $1.1 \mathrm{E}+01$ & $3.30 \mathrm{E}+00$ & -70 \\
\hline Cl-36 & GW-All & $130-200$ & $2.0 \mathrm{E}+00$ & $5.90 \mathrm{E}-01$ & -71 \\
\hline H-3 & GW-All & $130-200$ & $4.1 \mathrm{E}+06$ & $1.50 \mathrm{E}+06$ & -63 \\
\hline H-3 Concrete & GW-All & $130-200$ & $9.4 \mathrm{E}+06$ & $3.40 \mathrm{E}+06$ & -64 \\
\hline I-129 & GW-All & $130-200$ & $4.5 \mathrm{E}-01$ & $8.60 \mathrm{E}-02$ & -81 \\
\hline I-129 F.Filtercake & GW-All & $130-200$ & $2.30 \mathrm{E}-01$ & $2.00 \mathrm{E}-01$ & -13 \\
\hline I-129 Mk50A & GW-All & $130-200$ & $6.40 \mathrm{E}+01$ & $5.40 \mathrm{E}+01$ & -16 \\
\hline $\mathrm{K}-40$ & GW-All & $130-200$ & $4.2 \mathrm{E}+00$ & $1.10 \mathrm{E}+00$ & -74 \\
\hline Mo-93 & GW-All & $130-200$ & $2.1 \mathrm{E}+01$ & $6.20 \mathrm{E}+00$ & -70 \\
\hline Nb-94 & GW-All & $130-200$ & $2.3 \mathrm{E}+00$ & $6.90 \mathrm{E}-01$ & -70 \\
\hline Tc-99 & GW-All & $130-200$ & $7.7 \mathrm{E}+00$ & $1.90 \mathrm{E}+00$ & -75 \\
\hline Tc-99 Mk50A & GW-All & $130-200$ & $1.60 \mathrm{E}+03$ & $1.40 \mathrm{E}+03$ & -13 \\
\hline C-14 & GW-All & $200-1000$ & $1.1 \mathrm{E}+01$ & $9.40 \mathrm{E}+00$ & -15 \\
\hline Cl-36 & GW-All & $200-1000$ & $2.0 \mathrm{E}+00$ & $1.60 \mathrm{E}+00$ & -20 \\
\hline I-129 & GW-All & $200-1000$ & $4.5 \mathrm{E}-01$ & $1.90 \mathrm{E}-01$ & -58 \\
\hline I-129 F.CG.8 & GW-All & $200-1000$ & $3.50 \mathrm{E}-01$ & $3.00 \mathrm{E}-01$ & -14 \\
\hline I-129 F.Filtercake & GW-All & $200-1000$ & $3.70 \mathrm{E}-01$ & $3.30 \mathrm{E}-01$ & -11 \\
\hline $\mathrm{K}-40$ & GW-All & $200-1000$ & $5.20 \mathrm{E}+00$ & $2.10 \mathrm{E}+00$ & -60 \\
\hline Mo-93 & GW-All & $200-1000$ & $2.1 \mathrm{E}+01$ & $1.70 \mathrm{E}+01$ & -19 \\
\hline $\mathrm{Nb}-94$ & GW-All & $200-1000$ & $2.3 \mathrm{E}+00$ & $1.90 \mathrm{E}+00$ & -17 \\
\hline $\mathrm{Np}-237$ & GW-All & $200-1000$ & $2.70 \mathrm{E}-02$ & $2.40 \mathrm{E}-02$ & -11 \\
\hline Tc-99 & GW-All & $200-1000$ & $7.7 \mathrm{E}+00$ & $3.50 \mathrm{E}+00$ & -55 \\
\hline K-40 & GW-All & $1000-1130$ & $2.60 \mathrm{E}+01$ & $2.30 \mathrm{E}+01$ & -12 \\
\hline
\end{tabular}

\subsection{SUMS-OF-FRACTIONS}

While limits may decrease, even significantly, their importance is only revealed when the inventory is explicitly considered in calculating fractions and sums-of-fractions (SOFs). SOFs were calculated based on the final operational limits. By definition the operational limits are the lesser of the final PA limits and the SA-calculated limits.

SOFs were calculated for Slit Trenches 1 and 2 based on actual inventories provided in the PA and for other slit trenches in the center set based on projected closure inventories 
from the PA. The projected closure inventories are a type of averaged inventory because some existing inventories exceed the projected closure inventories.

The projected inventories for other slit trenches were adjusted by removing H3F projections for tritium-in-concrete (from 232F). These projections were removed because unique conditions applicable to this specific waste form are not likely to be repeated. The original SA (Flach et al., 2005) considered unique conditions including specific rubble sizes and distributions and actual placements in time and space for both generic tritium and tritium-in-concrete for Slit Trenches 1 and 2. Unless all these unique conditions are repeated the limits are not applicable for future waste.

SOFs are provided for the existing inventory in ST1 in Table 7, for the existing inventory in ST2 in Table 8 and for the adjusted projected inventory in future slit trenches in Table 9. The gray shading represents fractions between $1 \%$ and $10 \%$ and the magenta shading represents fractions greater than $10 \%$. 
SRNL-STI-2008-00397, REVISION 0

Table 7. Sums-of-fractions for Slit Trench 1

Sum-of-fractions for Slitt

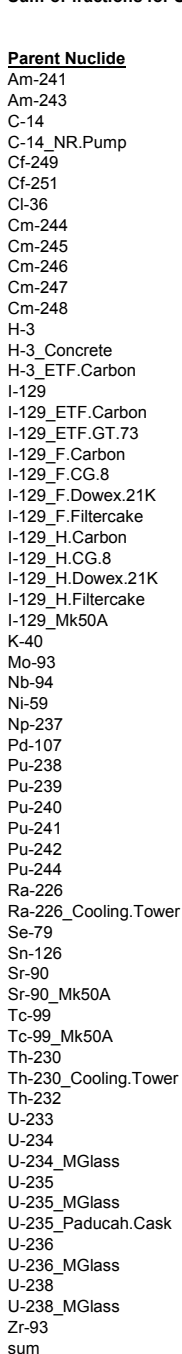

\begin{tabular}{|c|c|c|c|c|}
\hline & 0-12 & $\begin{array}{l}\text { Beta-Gamma } \\
12-100\end{array}$ & $100-1130$ & $0-1000$ \\
\hline 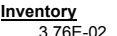 & yrs & & & $\frac{\text { yrs }}{175}$ \\
\hline & $\begin{array}{r}9.6 E-12 \\
0\end{array}$ & & & \\
\hline $\begin{array}{l}6.1 .12 E-05 \\
8.92 E-03\end{array}$ & $\begin{array}{l}0.0 \mathrm{E}+00 \\
3.6 \mathrm{E}-02\end{array}$ & $\begin{array}{l}\begin{array}{l}1.2 E-21 \\
3.6 E-02\end{array}\end{array}$ & $\begin{array}{l}1.3 \mathrm{~B}-07 \\
2.8 \mathrm{E}-03\end{array}$ & $\begin{array}{c}9.3-3 E-07 \\
0.0 E+00\end{array}$ \\
\hline $5.22 \mathrm{E}-02$ & $0.0 E+00$ & $0.0 \mathrm{E}+00$ & $2.1 \mathrm{E}-02$ & $0.0 E+00$ \\
\hline & & & 2) & \\
\hline $6.59 \mathrm{E}-05$ & $0.0 \mathrm{E}++0$ & $0.0 E+00$ & $3.9 \mathrm{E}-13$ & $5.11-07$ \\
\hline $0.00 \mathrm{E}+00$ & $0.0 E++0$ & $0.0 \mathrm{E}+00$ & $0.0 E+00$ & $0.0 \mathrm{E}+00$ \\
\hline $3.84 \mathrm{E}-02$ & $0.0 \mathrm{E}+00$ & $0.0 \mathrm{E}+00$ & 4.3E-20 & \\
\hline $2.74 \mathrm{E}-07$ & 1.6E-20 & $2.5 \mathrm{E}-16$ & 2.3E-10 & 7.6E-09 \\
\hline $1.53 \mathrm{E}-06$ & $0.0 \mathrm{E}+00$ & $0.0 E+00$ & $2.0 \mathrm{E}-21$ & 2.2E- -08 \\
\hline $\begin{array}{l}1.43 \mathrm{E}-06 \\
1.43 \mathrm{E}-06\end{array}$ & $\begin{array}{l}0.0 E+00 \\
0.0+00\end{array}$ & $0.0 E+00$ & $\begin{array}{l}4.0 E-10 \\
\end{array}$ & \\
\hline $\begin{array}{l}1.43-0-06 \\
8.47 \mathrm{E}-01\end{array}$ & & $\begin{array}{l}0.0 E+00 \\
18 E-01\end{array}$ & $\begin{array}{r}4.6 \mathrm{E}-16 \\
45-05\end{array}$ & $\begin{array}{l}2.2 E-08 \\
0.0+00\end{array}$ \\
\hline $\begin{array}{r}8.47 \mathrm{~V}-01 \\
3.87 \mathrm{E}+00\end{array}$ & $\begin{array}{l}3.0-01 \\
3.5 E-01\end{array}$ & 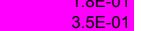 & $\begin{array}{l}\begin{array}{l}4.5-05 \\
8.6 \mathrm{E}-05\end{array} \\
8\end{array}$ & $\begin{array}{l}0.0 E+00 \\
0.0 F+00\end{array}$ \\
\hline $0.00 \mathrm{E}+00$ & $0.0 \mathrm{E}+00$ & 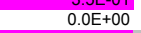 & $0.0 \mathrm{E}+00$ & $0.0 \mathrm{E}+00$ \\
\hline $1.99 \mathrm{E}-05$ & & 1.4E-01 & $1.4 \mathrm{E}-02$ & $0.0 \mathrm{E}+00$ \\
\hline $0.00 \mathrm{E}+00$ & $0.0 \mathrm{E}+00$ & $0.0 \mathrm{E}+00$ & $0.0 E+00$ & $0.0 \mathrm{E}+00$ \\
\hline $0.00 E+00$ & $0.0 \mathrm{E}+00$ & $0.0 \mathrm{E}+00$ & $0.0 E+00$ & $0.0 \mathrm{E}+00$ \\
\hline $0.00 E+00$ & $0.0 E+00$ & $0.0 E+00$ & $0.0 E+00$ & $0.0 \mathrm{E}+00$ \\
\hline $0.00 E+00$ & & $0.0 E+00$ & $0.0 E+00$ & $0.0 E+00$ \\
\hline $0.00 \mathrm{E}+00$ & $0.0 \mathrm{E}+00$ & $0.0 \mathrm{E}+00$ & $0.0 E+00$ & $0.0 E+00$ \\
\hline 8.14E-05 & 1.2E-02 & $2.5 E-02$ & $2.5 \mathrm{E}-02$ & $0.0 E+00$ \\
\hline $0.00 E+00$ & $0.0 E+00$ & $0.0 E+00$ & $0.0 E+00$ & $0.0 \mathrm{E}+00$ \\
\hline $0.00 E+00$ & $0.0 E+00$ & & $0.0 E+00$ & $0.0 E+00$ \\
\hline $0.00 E+00$ & $0.0 \mathrm{O}+00$ & $0.0 E+00$ & $0.0 E+00$ & \\
\hline 7E-07 & 3.7E- -06 & 7.3E-06 & $1.3 \mathrm{E}-05$ & $0.0 E+00$ \\
\hline $0.00 \mathrm{E}+00$ & $0.0 E+00$ & $0.0 E+00$ & $0.0 E+00$ & $0.0 E+00$ \\
\hline $4.12 \mathrm{E}-03$ & 6.3E-02 & 7.0E-02 & 8.2E-03 & $0.0 \mathrm{E}+00$ \\
\hline $\begin{array}{l}1.15 \mathrm{E}-05 \\
1.08 \mathrm{E}\end{array}$ & $\begin{array}{l}6.0 \mathrm{E}-05 \\
111-02\end{array}$ & $\begin{array}{l}6.0 E-05 \\
1.1 E-02\end{array}$ & $\begin{array}{l}8.8 \mathrm{E}-06 \\
90-04\end{array}$ & $\begin{array}{l}0.0 E+00 \\
0\end{array}$ \\
\hline $\begin{array}{l}1.08-08-03 \\
2.24 \mathrm{E}-02\end{array}$ & $\begin{array}{l}1.11-1-02 \\
3.9 E-22\end{array}$ & 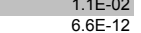 & $\begin{array}{l}9.0 \mathrm{E}-04 \\
5.5 \mathrm{E}-03\end{array}$ & $\begin{array}{l}0.0 \mathrm{EE}+00 \\
0.0 \mathrm{E}+00\end{array}$ \\
\hline $\begin{array}{l}2.244-02 \\
1.18 \mathrm{E}-03\end{array}$ & 4.9E- 07 & 3.0E-04 & 7.4E-04 & $1.5 \mathrm{E}-02$ \\
\hline $1.10 \mathrm{E}-07$ & $0.0 E+00$ & $2.6 \mathrm{E}-19$ & $2.3 \mathrm{E}-10$ & $0.0 E+00$ \\
\hline $3.27 \mathrm{E}-01$ & $0.0 E+00$ & $0.0 \mathrm{E}+00$ & 3.3E- 08 & $8.8 \mathrm{E}-07$ \\
\hline $2.56 \mathrm{E}-02$ & $2.7 \mathrm{E}-20$ & $3.8 \mathrm{E}-15$ & 2.3E- 09 & 2.7E-09 \\
\hline 7.27E-03 & $0.0 E+00$ & $0.0 E+00$ & 3.2E-18 & 2.7E-11 \\
\hline & & & & \\
\hline $1.11 \mathrm{E}-04$ & $0.0 E+00$ & $0.0 E+00$ & 1.1E-18 & $4.6 \mathrm{E}-13$ \\
\hline $2.35 \mathrm{E}-15$ & & $0.0 \mathrm{E}+00$ & & 1.1EE-23 \\
\hline 3.18E-03 & 1.4E- 20 & 1.3E-10 & 1.1.E-03 & $5.0 \mathrm{E}-02$ \\
\hline $0.00 E+00$ & $0.0 E+00$ & $0.0 E+00$ & $0.0 E+00$ & $0.0 E+00$ \\
\hline $2.70 \mathrm{E}-04$ & & $0.0 E+00$ & 8.4E-24 & \\
\hline $\begin{array}{l}1.82 \mathrm{E}-04 \\
\end{array}$ & $0.0 E+00$ & $\begin{array}{l}0.0 E+00 \\
9.95-07\end{array}$ & $0.0 E+00$ & $0.0 E+00$ \\
\hline $3.24 \mathrm{E}+00$ & $\begin{array}{l}3.3 E-15 \\
\end{array}$ & $\begin{array}{l}9.5 E-07 \\
\end{array}$ & 4.6E-02 & $0.0 E+00$ \\
\hline $0.00 E+00$ & $0.0 \mathrm{E}+00$ & $0.0 E+00$ & $0.0 \mathrm{E}+00$ & $0.0 \mathrm{E}+00$ \\
\hline $5.31 \mathrm{E}-03$ & $\begin{array}{l}3.3 \mathrm{E}-02 \\
0.025+02\end{array}$ & $\begin{array}{l}\text { 4.1E-02 } \\
\text { n }\end{array}$ & 4.1E-03 & $0.0 \mathrm{E}+00$ \\
\hline $0.00 E+00$ & $\begin{array}{c}0.0 E+00 \\
0.0 E+00\end{array}$ & $\begin{array}{l}0.0 E+00 \\
1.4 E-14\end{array}$ & $\begin{array}{l}0.0 E+00 \\
3.3 E-05\end{array}$ & $\begin{array}{l}0.0 E+00 \\
03 E-04\end{array}$ \\
\hline $0.00+0$ & $0.00+00$ & $0.0 \mathrm{E}+00$ & $\begin{array}{c}3.3 .3-05 \\
0.0 \mathrm{E}+00\end{array}$ & $\begin{array}{l}9.3 E-04 \\
0.0+00\end{array}$ \\
\hline $2.34 \mathrm{E}$ & $3.9 \mathrm{E}-20$ & $6.2 E-13$ & $8.7 \mathrm{E}-07$ & $8.7 E-07$ \\
\hline & $0.0 E+00$ & $0.0 \mathrm{E}+00$ & $7.3 \mathrm{E}-16$ & $2.9 E-16$ \\
\hline & $0.0 \mathrm{E}+00$ & 1.0E-16 & 3.0E -05 & $8.1 \mathrm{E}-04$ \\
\hline & $0.0 E+00$ & $0.0 \mathrm{E}+00$ & $0.0 E+00$ & $0.0 \mathrm{E}+00$ \\
\hline 4.45 & $2.6 \mathrm{E}-13$ & $1.5 \mathrm{E}-08$ & 7.2E-05 & $9.3 \mathrm{E}-05$ \\
\hline & $0.0 E+00$ & $0.0 E+00$ & $0.0 E+00$ & $0.0 \mathrm{OE}+00$ \\
\hline & & $\begin{array}{l}0.0 E+00 \\
1.4 E-22\end{array}$ & $\begin{array}{l}0.0 E+00 \\
1.4 F-13\end{array}$ & $\begin{array}{l}0.0 E+00 \\
1 . E-13\end{array}$ \\
\hline & $0.0 \mathrm{E}+00$ & $\begin{array}{l}0.0 E+00 \\
0.0 E+10\end{array}$ & $\begin{array}{l}4.4 E-13 \\
0 E+00\end{array}$ & $\begin{array}{l}1.13 \\
0.0 F+00\end{array}$ \\
\hline & & $0.0 \mathrm{E}+00$ & 08 & 06 \\
\hline & & & & \\
\hline & $1.8 \mathrm{E}-05$ & 4.2E-05 & $3.7 \mathrm{E}-05$ & $0.0 \mathrm{E}+00$ \\
\hline
\end{tabular}

Gross Alpha

yrs $2.9 \mathrm{E}-04$

120-1130 0-1000 yrs yrs

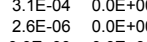
$\begin{array}{ll}0.0 E+00 & 0.0 E+00 \\ 5.1 E-08 & 0.0 E+00\end{array}$ $\begin{array}{ll}5.1 \mathrm{E}-08 & 0.0 \mathrm{E}+00 \\ 1.32-06 & 0.0 E+00\end{array}$ $\begin{array}{ll}0.0 E+00 & 0.0 E+00 \\ 4.9 E-12 & 2.4 E-20 \\ 0.15-08 & 14 E-22\end{array}$ $\begin{array}{lll}2.1 E-08 & 0.0 E+00 \\ 0.1 E-08 & 1.4 E-22\end{array}$ $\begin{array}{ll}7.22-08 & 0.0 E+00 \\ 6.0 E-08 & 0.0 E+00\end{array}$ $0.0 E+00 \quad 0.0 E+0$ $0.0 \mathrm{E}+00 \quad 0.0 \mathrm{E}+00$ $\begin{array}{ll}0.0 \mathrm{E}+00 & 0.0 \mathrm{E}+00 \\ 0.0 \mathrm{E}+00 & 0.0 \mathrm{E}+00 \\ 0.0 \mathrm{E}+00 & 0.0 \mathrm{E}\end{array}$ $0.0 E+00 \quad 0.0 E+00$ $0.0 E+00 \quad 0.0 E++00$

$\begin{array}{ll}0.0 \mathrm{E}+00 & 0.0 \mathrm{E}+00 \\ 0.0 \mathrm{E}+00 & 0.0 \mathrm{E}+00\end{array}$ $0.0 \mathrm{E}+00 \quad 0.0 \mathrm{E}+00$

$0.0 \mathrm{E}+00 \quad 0.0 \mathrm{E}+00$
0.020

$\begin{array}{ll}0.0 \mathrm{E}+00 & 0.0 \mathrm{E}+00 \\ 0.0 \mathrm{E}+00 & 0.0 \mathrm{E}+00 \\ 0.0 E+00 & 0.0 E+00\end{array}$

$\begin{array}{lll}0.0 E+00 & 0.0 E++00 \\ 0.0 E+00 & 0.0 E+00\end{array}$

$\begin{array}{lll}0.0 E+00 & 0.0 \mathrm{E}+00 \\ 0.0 E+00 & 0.0 E+00\end{array}$

$0.0 \mathrm{E}+00 \quad 0.0 \mathrm{E}+00$
0

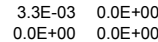

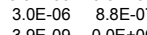
$\begin{array}{ll}3.6 \mathrm{E}-10 & 1.0 \mathrm{E}-18 \\ 2.20 & -1.00\end{array}$ $\begin{array}{ll}6.2 \mathrm{E}-\mathrm{-}-5 & 0.0 \mathrm{E}+00 \\ 4.4 \mathrm{E}-12 & 3.0 \mathrm{E}-17 \\ 1.8 \mathrm{E}-22 & 1.4 \mathrm{E}-32\end{array}$ $2.0 \mathrm{E}-32 \quad 2.0 \mathrm{E}-32$

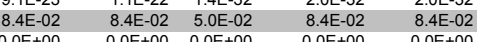
$\begin{array}{lll}0.0 \mathrm{E}+00 & 0.0 \mathrm{E}+00 & 0.0 \mathrm{E}+00\end{array}$ $\begin{array}{lll}0.0 E+00 & 0.0 E+00 & 0.0 E+00 \\ 0.0 E+00 & 0.0 E+00 & 0.0 E+00\end{array}$ O.OE $\begin{array}{lll}0.0 \mathrm{E}+00 & 0.0 \mathrm{E}+00 & 0.0 \mathrm{E}+0 \\ 0.0 \mathrm{E}+00\end{array}$

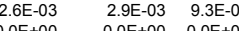
$3.7 \mathrm{E}-07$ $2.9 \mathrm{E}-15 \quad 3.5 \mathrm{E}-15 \quad 0.0 \mathrm{E}+00$ $\begin{array}{lll}2.5 E-03 & 2.7 E-03 & 8.1 \mathrm{E}-04 \\ 0.0 \mathrm{E}+00 & 0.0 \mathrm{E} & -20\end{array}$ $\begin{array}{lll}8.9 \mathrm{E}-05 & 7.4 \mathrm{E}-05 & 0.0 \mathrm{E}+00\end{array}$ $\begin{array}{lll}0.0 \mathrm{E}+00 & 0.0 \mathrm{E}+00 & 0.0 \mathrm{E}+00 \\ 0.0 \mathrm{E}+00 & 0.0 \mathrm{E}+00 & 0.0 \mathrm{E}+00 \\ 13 \mathrm{E} & 1\end{array}$ $1.3 \mathrm{E}-13 \quad 1.4 \mathrm{E}-13 \quad 8.0 \mathrm{E}-14$ $\begin{array}{lll}1.0 \mathrm{E}+00 & 0.0 \mathrm{E}+00 & 0.0 \mathrm{E}+00 \\ 3.8 \mathrm{E}-06 & 4.2 \mathrm{E}-06 & 1.2 \mathrm{E}-06\end{array}$ $\begin{array}{lll}0.0 \mathrm{E}+00 & 0.0 \mathrm{E}+00 & 0.0 \mathrm{E}+00 \\ 9 & 0.0 \mathrm{E}+00\end{array}$ $0.0 \mathrm{E}+00$ $0.0 \mathrm{E}+00$
$0.0 \mathrm{E}+00$ $0.0 \mathrm{E}+00$ O.0E+00 $0.0 \mathrm{E}+00$
$0.0 \mathrm{E}+00$ $0.0 \mathrm{E}+00$
$0.0 \mathrm{E}+00$ $0.0 \mathrm{E}+00$ $0.0 \mathrm{O}+00$ $0.0 \mathrm{E}+00$
$0.0 \mathrm{E}+00$
$0.0 \mathrm{E}$ $0.0 \mathrm{E}+00$
$0.0 \mathrm{E}+00$ $0.0 \mathrm{E}+00$
$0.0 \mathrm{E}+00$
$0.0 \mathrm{E}+00$ $0.0 \mathrm{E}+00$
$0.0 \mathrm{E}+00$
$0.0 \mathrm{E}+00$ $0.0 \mathrm{E}+00$ $0.0 E+00$
$0.0 E+00$
$0.0 E$ $0.0 \mathrm{E}+00$
$2.7 \mathrm{E}-06$
0.06 $3.0 \mathrm{E}-06$ $\begin{array}{ll}0.0 \mathrm{E}+00 & 0.0 \mathrm{E}+00 \\ 2.3 \mathrm{E}-18 & 2.3 \mathrm{E}-18 \\ 0.0 \mathrm{E}+00 & 0.0 \mathrm{E}-00\end{array}$ $\begin{array}{ll}0.0 E+00 & 0.0 E+00 \\ 0.0 E+00 & 0.0 E+00 \\ 0.0 E+00 & 0.0 E+00\end{array}$ $0.0 E+00$ $0.0 \mathrm{E}+00$ $0.0 \mathrm{E}+00$
$2.6 \mathrm{E}-03$ $2.5 E-03$
$0.0 \mathrm{E}+00$ $\begin{array}{ll}0.0 \mathrm{E}+00 \\ 0.0 \mathrm{E}+00 \\ 0.0 \mathrm{E} & 0.0 \mathrm{E}+00 \\ 0.00 & 0.0 \mathrm{E}+0\end{array}$

\begin{tabular}{cccc}
$\begin{array}{c}\text { Radium } \\
1000-1120\end{array}$ & $1120-1130$ & Uranium & \multicolumn{2}{c}{ Groundwater All-Pathways } \\
$0-1130$ & $130-200$ & $200-1000$ & $1000-1130$
\end{tabular}

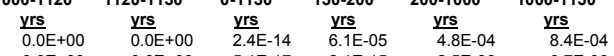
$\begin{array}{llllll}3.2 \mathrm{E}-20 & 3.2 \mathrm{E}-20 & 0.0 \mathrm{EE}-00 & 0.0 \mathrm{E}+00 & 0.0 \mathrm{E}+00 & 0.0 \mathrm{E}+00 \\ & 3.9 \mathrm{E}-20 & 0.0 \mathrm{E}+00 & 1.4 \mathrm{E}-12 & 1.2 \mathrm{E}-11\end{array}$

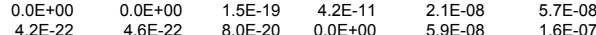

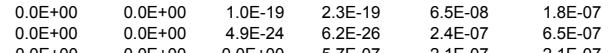
$\begin{array}{ccc}0.0 \mathrm{E}+00 & 0.0 \mathrm{EE}+00 & 0.0 \mathrm{EE}+00 \\ 2.1 \mathrm{E}-06\end{array}$

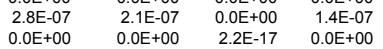
$\begin{array}{rrr}0.0 \mathrm{E}+00 & 2.0 \mathrm{E}-15 & 3.3 \mathrm{E}-07 \\ 0.0 \mathrm{E}+00 & 0.0 \mathrm{E}+00 \\ 0.0 \mathrm{E}+00 & 3.4 \mathrm{E}-14 & 1.4 \mathrm{E}-04\end{array}$ 
SRNL-STI-2008-00397, REVISION 0

Table 8. Sums-of-fractions for Slit Trench 2

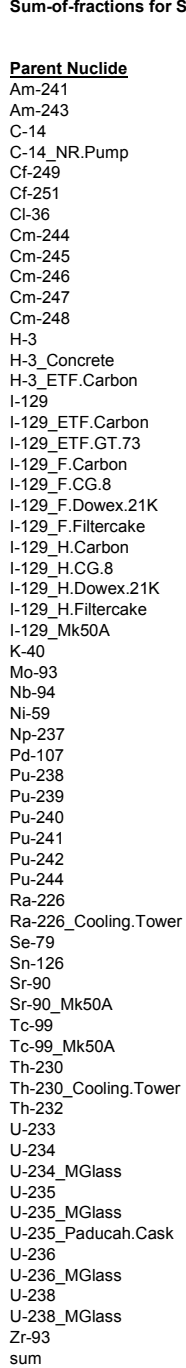

\begin{tabular}{|c|c|c|c|c|c|c|c|c|c|}
\hline & & & \\
\hline & $0-12$ & 2-100 & 100-1130 & $0-1000$ & $1000-1120$ & $20-1130$ & $0-1000$ & $1000-1120$ & $1120-1130$ \\
\hline Inventory $1.59 \mathrm{E}-01$ & $\frac{\mathrm{yrs}}{4.1 \mathrm{r}-11}$ & $\begin{array}{l}\mathrm{yrs} \\
8.9 \mathrm{E}-08\end{array}$ & $\frac{\mathrm{yrs}}{1.5 \mathrm{E}-05}$ & $\frac{\mathrm{yrs}}{7.2 \mathrm{E}-04}$ & $\frac{\frac{\text { yrs }}{1.2 E-03}}{1}$ & $\frac{\mathrm{yrs}}{1.3 \mathrm{E}-03}$ & $\begin{array}{l}\frac{\mathrm{yrs}}{0.0 \mathrm{E}}+00 \\
\end{array}$ & $\frac{\mathrm{yrs}}{0.0 \mathrm{E}+}$ & $\frac{\text { yrs }}{0.0}$ \\
\hline & $0.0 \mathrm{E}+00$ & 3.2E-20 & $3.5 \mathrm{E}-06$ & $\begin{array}{l}2.6 \mathrm{E}-05 \\
2\end{array}$ & & $7.0 \mathrm{E}-05$ & $0.0 \mathrm{E}+00$ & $0.0 E+00$ & \\
\hline & & & $1.4 \mathrm{E}-02$ & 00 & & & $0.0 \mathrm{E}+00$ & $0.0 \mathrm{E}+00$ & \\
\hline $88 \mathrm{E}-0$ & $0.0 \mathrm{E}+00$ & $0.0 \mathrm{E}+00$ & 3.1 $\mathrm{E}-02$ & $0.0 \mathrm{E}+00$ & $0.0 \mathrm{E}+00$ & $0.0 \mathrm{E}+00$ & $0.0 \mathrm{E}++0$ & $0.0 E+00$ & \\
\hline $3 E-04$ & $5.2 \mathrm{E}-21$ & $2.0 \mathrm{E}-16$ & $2.0 \mathrm{E}-08$ & $2.0 E-06$ & $4.5 \mathrm{E}-06$ & & $0.0 \mathrm{E}+00$ & $0.0 E+00$ & \\
\hline $6.68 \mathrm{E}$ & $0.0 E+00$ & $0.0 E+00$ & $3.9 E-12$ & $5.1 E-06$ & $\begin{array}{l}1.2 \mathrm{E}-05 \\
\end{array}$ & $1.3 \mathrm{E}-05$ & +00 & $.0 E+00$ & \\
\hline & $\begin{array}{l}1.2 \mathrm{E}-04 \\
0.0+00\end{array}$ & $\begin{array}{l}1.2 E-04 \\
0.0 E+00\end{array}$ & $\begin{array}{l}9.6 \mathrm{E}-06 \\
12 \mathrm{E}-19\end{array}$ & $\begin{array}{l}0.0 \mathrm{E}+00 \\
16 \mathrm{~F}-12\end{array}$ & $\begin{array}{l}0.0 \mathrm{E}+00 \\
1.5-11\end{array}$ & $\begin{array}{l}0.0 \mathrm{E}+00 \\
14-11\end{array}$ & & $+\infty 0$ & \\
\hline & . & $\begin{array}{l}00 \\
15\end{array}$ & $\begin{array}{r}1.2 \mathrm{E}-19 \\
2.4 \mathrm{E}-09\end{array}$ & $\begin{array}{l}1.6 E-12 \\
8.1 E-08\end{array}$ & $\begin{array}{l}1.21-11 \\
\text { 2.1E-07 }\end{array}$ & $\begin{array}{l}1.4 \mathrm{E}-11 \\
2.2 \mathrm{E}-07\end{array}$ & $\begin{array}{c}6.9 E-20 \\
0.0+00\end{array}$ & $\begin{array}{r}9.2 E-20 \\
0.0 E+20\end{array}$ & \\
\hline 2. & $\begin{array}{l}1.0 \mathrm{E}-19 \\
0.0 \mathrm{t}+00\end{array}$ & $\begin{array}{l}2.0 \mathrm{E}-15 \\
0.0 \mathrm{2}+00\end{array}$ & $\begin{array}{l}2.4 \mathrm{LE}-09 \\
2.8 \mathrm{a}-20\end{array}$ & -07 & E-07 & $\begin{array}{l}\text {. } \\
8.8 \mathrm{E}-07\end{array}$ & $2.0 \mathrm{E}-21$ & $6.1 \mathrm{E}-21$ & $E-2$ \\
\hline & & $0.0 E+00$ & $6.9 \mathrm{E}-13$ & -11 & & & $.0 \mathrm{E}+00$ & & \\
\hline & $0.0 \mathrm{E}+00$ & $0.0 E+00$ & $E-15$ & $3.9 E-07$ & & & & & \\
\hline & $2.3 E-01$ & $\begin{array}{l}2.2 E-01 \\
\end{array}$ & & $0.0 E+00$ & & $0.0 E+00$ & $0.0 \mathrm{E}+00$ & $0.0 E+00$ & \\
\hline & & & $0.0 \mathrm{E}+00$ & $0.0 \mathrm{E}+00$ & & $0.0 \mathrm{E}+00$ & $0.0 \mathrm{E}+00$ & $0.0 E+00$ & \\
\hline 0.00 & $0.0 E+00$ & $0.0 \mathrm{E}+00$ & $0.0 \mathrm{E}+00$ & $0.0 \mathrm{E}+00$ & $0.0 \mathrm{E}+00$ & $0.0 E+00$ & $0.0 \mathrm{E}+00$ & $0.0 E+00$ & \\
\hline & 1.4E-01 & $\begin{array}{l}1.4 E-01 \\
0.05+00\end{array}$ & $\begin{array}{l}1.4 E-02 \\
0.00+00\end{array}$ & & & & & & \\
\hline & $\begin{array}{l}0.0 E+00 \\
72 F-05\end{array}$ & $\begin{array}{l}0.0 E+00 \\
1.5 E-04\end{array}$ & & & & & & 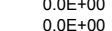 & \\
\hline & $0.0 \mathrm{E}+00$ & 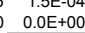 & $\begin{array}{l}3.8 \mathrm{E}-04 \\
0.0 \mathrm{E}+00\end{array}$ & $0.0 \mathrm{E}+00$ & $\begin{array}{l}0 \mathrm{E}+00 \\
0 \mathrm{E}\end{array}$ & $\begin{array}{l}0.0 \mathrm{E}+00 \\
0 \mathrm{E}+0\end{array}$ & $E+00$ & $0.0 \mathrm{E}+00$ & \\
\hline & $8.7 E-03$ & $1.7 \mathrm{E}-02$ & $1.7 \mathrm{E}-02$ & $0.0 \mathrm{E}+00$ & $0.0 \mathrm{E}+00$ & $0.0 E+00$ & $0.0 \mathrm{E}+00$ & $0.0 E+00$ & \\
\hline & $5.6 \mathrm{E}-03$ & 1.1.E-02 & $2.8 \mathrm{E}-02$ & & & & & & \\
\hline & & & & $0.0 \mathrm{E}+00$ & & $0.0 \mathrm{E}+00$ & $0.0 \mathrm{E}+00$ & $0.0 \mathrm{E}+00$ & \\
\hline & $0.0 E+00$ & $0.0 E+00$ & $0.0 \mathrm{E}+00$ & $0.0 \mathrm{E}+00$ & 00 & +00 & & & \\
\hline 1.18E-04 & $2.7 E-03$ & $\begin{array}{l}3 \\
5.4 \mathrm{E}-03\end{array}$ & $8.5 \mathrm{E}-03$ & $0.0 E+00$ & $0 E+00$ & $0.0 E+00$ & $E+00$ & $0.0 E+00$ & \\
\hline & $0.0 E+00$ & & & & & & & & \\
\hline & $\begin{array}{c}0.0 E+00 \\
0.0 F+00\end{array}$ & $\begin{array}{l}0.0 \mathrm{E}+00 \\
0.0 \mathrm{E}+0\end{array}$ & $\begin{array}{l}0.0 \mathrm{E}+00 \\
0.0 \mathrm{E}+00\end{array}$ & $\begin{array}{l}0.0 \mathrm{E}+00 \\
0.0+00\end{array}$ & & $\begin{array}{l}0.0 \mathrm{E}+00 \\
0.0 \mathrm{E}+00\end{array}$ & & $\begin{array}{l}+\infty 0 \\
+00 \\
+00\end{array}$ & \\
\hline $3.22 \mathrm{E}-06$ & $\begin{array}{l}0.0 E+00 \\
5.0 \mathrm{E}-05\end{array}$ & $\begin{array}{c}E=05 \\
E-05\end{array}$ & $\begin{array}{l}6.4 \mathrm{E}-06 \\
6\end{array}$ & $0.0 \mathrm{E}+00$ & & $0.0 E+00$ & & $\begin{array}{l}0.0 E+00 \\
0.0 E+00\end{array}$ & \\
\hline $3.40 \mathrm{E}$ & $1.8 \mathrm{E}-06$ & E $E-06$ & $2.6 \mathrm{E}-07$ & $0.0 \mathrm{E}+00$ & & & & $E+00$ & \\
\hline & 2.4E-02 & & & & & & & & \\
\hline 3.6 & $6.3 \mathrm{E}-22$ & $\begin{array}{l}21.1 \mathrm{E}-11 \\
2\end{array}$ & & $0.0 \mathrm{E}+00$ & & +00 & & & \\
\hline $\begin{array}{l}2.07 \\
1.83\end{array}$ & $\begin{array}{l}8.6 E-07 \\
O Q 0 E+00\end{array}$ & $\begin{array}{l}5.3 \\
44\end{array}$ & $\begin{array}{l}1.35 E-03 \\
3.7 F-13\end{array}$ & $\begin{array}{l}2.6 E-02 \\
0.020\end{array}$ & & & & & \\
\hline & $\begin{array}{l}0.0 E+00 \\
0.0 E+00\end{array}$ & $\begin{array}{c}4.4 \mathrm{E}-22 \\
0 \\
0.0 \mathrm{E}+00\end{array}$ & & & & & & & \\
\hline & 19 & 3. & & & & & & & \\
\hline & & & & & & & & & \\
\hline 2.2 & 1.6 & & & & & & & & \\
\hline & & & 1.0 & & & & & & \\
\hline & 0.6 & & & & & & & & \\
\hline & 2.8 & & & & & & & & \\
\hline & & & & & & & & & \\
\hline & 0.0 & $0.0 \mathrm{E}+00$ & 1.8 & & & & & & \\
\hline & & $\quad 0.0 \mathrm{E}+00$ & & & & & & & \\
\hline & 4.8 & & & & & & & & \\
\hline & $\begin{array}{l}0.0 E E-00 \\
13 E-01\end{array}$ & $\begin{array}{ll}0 & 0.0 \mathrm{E}+00 \\
1 & 1\end{array}$ & $\begin{array}{l}0.0 \mathrm{E}+00 \\
16 \mathrm{E}-02\end{array}$ & $\begin{array}{l}0.0 \mathrm{E} \\
0.0 \mathrm{E}\end{array}$ & $\begin{array}{l}00 \\
00\end{array}$ & $\begin{array}{l}\begin{array}{l}.0 E+00 \\
0.0 E+00\end{array}\end{array}$ & & & \\
\hline & & $\begin{array}{l}1.0 E-v 1 \\
0.0 E+00\end{array}$ & $\begin{array}{l}.0 .0 E-02 \\
0.0 E+00\end{array}$ & & & & & & \\
\hline & & . & $0.0 \mathrm{E}+00$ & & & & & & \\
\hline & & & & & & & & & \\
\hline & & & & & & & & & \\
\hline & & & & & & & & & \\
\hline & & & & & & & & & \\
\hline & & & & & & & & & \\
\hline & & & & & & & & & \\
\hline & & & & & & & & & \\
\hline & & & & & & & & & \\
\hline & & & & & & & & & \\
\hline & & & & & & & & & \\
\hline & & & & & & & & & \\
\hline & & 3.5E-05 & & $.0 \mathrm{E}+00$ & $.0 E+00$ & $E+00$ & $0.0 E+00$ & $=+0$ & \\
\hline
\end{tabular}

\begin{tabular}{|c|c|c|c|}
\hline $\begin{array}{l}\text { Uranium } \\
0-1130\end{array}$ & $\begin{array}{c}\text { Grou } \\
130-200\end{array}$ & $\begin{array}{l}\text { Iwater All-Pa } \\
200-1000\end{array}$ & $\begin{array}{l}\text { thways } \\
1000-1130\end{array}$ \\
\hline $\begin{array}{l}\text { yrs } \\
10\end{array}$ & $\begin{array}{l}\text { yrs } \\
\frac{\text { res }}{65 F}\end{array}$ & yrs & yrs \\
\hline $\begin{array}{l}\begin{array}{l}1.0 \mathrm{E}-13 \\
1.4 \mathrm{E}-15\end{array} \\
1\end{array}$ & 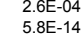 & $\begin{array}{l}2.0 .0 \mathrm{E}-03 \\
6.8 \mathrm{E}-05\end{array}$ & $\begin{array}{l}3.5 \mathrm{E}-03 \\
1.9 \mathrm{E}-04\end{array}$ \\
\hline $0.0 E+00$ & $1.4 \mathrm{E}-02$ & $4.9 \mathrm{E}-03$ & 4.2E-03 \\
\hline $0.0 E+00$ & 2.6E-02 & 3.0E-02 & $\begin{array}{l}7.7 E-04 \\
1\end{array}$ \\
\hline $\begin{array}{l}6.7 E-18 \\
83 E-22\end{array}$ & $\begin{array}{l}3.5 \mathrm{E}-10 \\
1.9 \mathrm{E}-22\end{array}$ & $\begin{array}{l}6.4 \mathrm{E}-06 \\
18 \mathrm{E}-05\end{array}$ & $\begin{array}{l}1.5 E-05 \\
45 E-05\end{array}$ \\
\hline $\begin{array}{l}8.3 E-22 \\
0.0 E+00\end{array}$ & 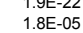 & $\begin{array}{l}1.88-05 \\
6.6 \mathrm{E}-06\end{array}$ & $\begin{array}{l}\begin{array}{l}4.5 \mathrm{E}-05 \\
5.3 \mathrm{E}-06\end{array} \\
\text { s. }\end{array}$ \\
\hline 1.1E-19 & & 4.1E-12 & \\
\hline $\begin{array}{l}1.6 E-18 \\
112=-18\end{array}$ & 4.4E-10 & 2.2E- 07 & $\begin{array}{l}6.1 \mathrm{E}-07 \\
2 \mathrm{E}\end{array}$ \\
\hline $\begin{array}{l}1.2 E-18 \\
1.8 E-22\end{array}$ & $\begin{array}{l}0.0 \mathrm{E}+00 \\
3 . \mathrm{E}-22\end{array}$ & $\begin{array}{l}8.4 \mathrm{E}-07 \\
11-10\end{array}$ & $\begin{array}{l}2.3 \mathrm{E}-06 \\
32 \mathrm{E}-10\end{array}$ \\
\hline $\begin{array}{l}1.8 \mathrm{E}-22 \\
89 \mathrm{E}-23\end{array}$ & $\begin{array}{l}3.9 E-22 \\
1.11-24\end{array}$ & $\begin{array}{l}1.1 \mathrm{E}-10 \\
4.2 \mathrm{E}-06\end{array}$ & $\begin{array}{l}3.2 \mathrm{E}-10 \\
1.2 \mathrm{E}-05\end{array}$ \\
\hline $\begin{array}{l}0.0 E+00 \\
0.0 E+23\end{array}$ & $\begin{array}{l}7.1 \mathrm{E}-0 \mathrm{C} \\
7\end{array}$ & 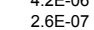 & $\begin{array}{l}2.2 \mathrm{E}-\mathrm{E}-07 \\
2.6 \mathrm{0}\end{array}$ \\
\hline 0 & $0.0 \mathrm{~F}+00$ & $\begin{array}{c}2.06-07 \\
0.0 \mathrm{E}+00\end{array}$ & $\begin{array}{c}2.0 E-07 \\
0.0 E+00\end{array}$ \\
\hline $0.0 \mathrm{E}+00$ & $0.0 \mathrm{E}+00$ & & \\
\hline $0.0 E+00$ & $2.3 \mathrm{E}-04$ & $1.0 \mathrm{E}-04$ & 4.4E- 05 \\
\hline & & $0.0 \mathrm{E}+00$ & $0.0 \mathrm{E}+00$ \\
\hline $0.0 E+00$ & 3.1E-06 & 5.8E-06 & $\begin{array}{r}6.2 \mathrm{E}-06 \\
\end{array}$ \\
\hline $\begin{array}{l}0.0 E++00 \\
0.0+00\end{array}$ & $\begin{array}{l}0.0 E+00 \\
2.7 E-04\end{array}$ & $\begin{array}{l}0.0 \mathrm{E}+00 \\
17 \mathrm{E}-04\end{array}$ & $\begin{array}{l}0.0 \mathrm{E}+00 \\
5.2 \mathrm{E}-05\end{array}$ \\
\hline $\begin{array}{l}0.0 E++00 \\
0.0+00\end{array}$ & $\begin{array}{l}\begin{array}{l}2.7 E-04 \\
23 E-04\end{array} \\
23 E\end{array}$ & $\begin{array}{l}1.7 \mathrm{E}-04 \\
4 \mathrm{AE}-04\end{array}$ & $\begin{array}{l}5.2 \mathrm{E}-05 \\
4.6 \mathrm{E}-04\end{array}$ \\
\hline O & $\begin{array}{l}2.36-0 \\
17 F-0 .\end{array}$ & $\begin{array}{l}4.4-4-04 \\
1.0 E-03\end{array}$ & $\begin{array}{l}4.6 \mathrm{E}-04 \\
3.5 \mathrm{E}-04\end{array}$ \\
\hline $\begin{array}{l}0.0 \mathrm{E}+00 \\
0\end{array}$ & 0 & $\begin{array}{l}1.0 E=03 \\
0.0 E+00\end{array}$ & $\begin{array}{l}3.5 E-54 \\
0.0 \mathrm{E}+00\end{array}$ \\
\hline $0.0 E+00$ & $1.1 \mathrm{E}-04$ & $1.3 \mathrm{E}-04$ & $1.4 \mathrm{E}-04$ \\
\hline $0.0 E+00$ & $0.0 \mathrm{E}+00$ & $0.0 \mathrm{E}+00$ & $0.0 \mathrm{E}+00$ \\
\hline $0.0 E+00$ & $0.0 \mathrm{E}+00$ & $0.0 \mathrm{E}+00$ & $0.0 \mathrm{E}+00$ \\
\hline $0.0 E+00$ & $0.0 \mathrm{E}+00$ & $0.0 E+00$ & $0.0 \mathrm{E}+00$ \\
\hline $\begin{array}{l}0.0 E++00 \\
0.0 F+00\end{array}$ & $\begin{array}{l}2.9 \mathrm{E}-06 \\
55 \mathrm{~F}-08\end{array}$ & $\begin{array}{l}1.5 E-06 \\
20 F-08\end{array}$ & $\begin{array}{l}\text { 1.4E- }-07 \\
16 \mathrm{E}-08\end{array}$ \\
\hline $\begin{array}{l}0.0 E+00 \\
0.0 F+00\end{array}$ & $\begin{array}{l}5.3 \mathrm{E}-08 \\
3.3 \mathrm{E}-03\end{array}$ & $\begin{array}{l}2.0 \mathrm{E}-08 \\
1.2-03\end{array}$ & $\begin{array}{l}1.6 \mathrm{E}-08 \\
9.8 \mathrm{E}-04\end{array}$ \\
\hline $\begin{array}{l}0.0 E+00 \\
0.0 E+00\end{array}$ & $\begin{array}{l}3.3 E-03 \\
3.7 E-08\end{array}$ & $\begin{array}{l}1.2 E-03 \\
1.7 E-05\end{array}$ & $\begin{array}{r}9.8 \mathrm{E}-04 \\
37 \mathrm{E}-05\end{array}$ \\
\hline & & $\begin{array}{l}8.16-0-0 \\
866-2\end{array}$ & 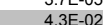 \\
\hline $0.0 E+00$ & $1.2 \mathrm{E}-16$ & $5.6 E-14$ & 1.1. $\mathrm{E}-13$ \\
\hline $4.3 \mathrm{E}-18$ & $2.8 \mathrm{E}-10$ & $5.9 \mathrm{E}-07$ & $2.0 \mathrm{E}-06$ \\
\hline $6.0 \mathrm{E}-17$ & 4.6E-09 & $1.7 \mathrm{E}-07$ & $2.0 \mathrm{E}-07$ \\
\hline 2.1E-17 & $5.9 E-20$ & 7.7E-10 & $\begin{array}{l}7.0 E-09 \\
717=02\end{array}$ \\
\hline $\begin{array}{l}4.5 E-14 \\
3.3 E-19\end{array}$ & $\begin{array}{l}1.0 \mathrm{E}-04 \\
31 \mathrm{E}-21\end{array}$ & $\begin{array}{l}9.3 \mathrm{E}-04 \\
10 \mathrm{E}-11\end{array}$ & $\begin{array}{l}1.7 \mathrm{EE}-03 \\
10 \mathrm{D}-10\end{array}$ \\
\hline $\begin{array}{l}3.2 E-19 \\
1.7 E-31\end{array}$ & $\begin{array}{l}3.1 .1-21 \\
0.0 E+00\end{array}$ & $\begin{array}{l}1.0 \mathrm{E}-11 \\
55 \mathrm{E}-23\end{array}$ & $\begin{array}{l}1.0 E-10 \\
5.5 E-22\end{array}$ \\
\hline $\begin{array}{l}1.1 \mathrm{E}-31 \\
0.0 \mathrm{E}+00\end{array}$ & $\begin{array}{l}0.1 \mathrm{E}+00 \\
13 \mathrm{E}-06\end{array}$ & $\begin{array}{l}5 . / 6-23 \\
34 E-05\end{array}$ & $\begin{array}{l}5.5 \mathrm{E}-2 \mathrm{Z} \\
5.9 \mathrm{E}-05\end{array}$ \\
\hline $0.0 E+00$ & $0.0 \mathrm{E}+00$ & $\begin{array}{l}0.4-0 \mathrm{E} \\
0.0 \mathrm{E}+00\end{array}$ & $0.0 \mathrm{E}+00$ \\
\hline $0.0 \mathrm{E}+00$ & $0.0 \mathrm{E}+00$ & $0.0 \mathrm{E}+00$ & $1.7 \mathrm{E}-23$ \\
\hline $0.0 \mathrm{E}+00$ & $0.0 \mathrm{E}+00$ & $0.0 \mathrm{E}+00$ & $0.0 \mathrm{E}+00$ \\
\hline $0.0 \mathrm{E}+00$ & $7.8 \mathrm{E}-04$ & $3.4 \mathrm{E}-03$ & 2.0E-10 \\
\hline $0.0 \mathrm{0E}+00$ & $0.0 \mathrm{E}+00$ & $0.0 \mathrm{E}+00$ & $0.0 \mathrm{E}+00$ \\
\hline $0.0 E+00$ & 1.1E-02 & $\begin{array}{r}5.8 \mathrm{E}-03 \\
\end{array}$ & $\begin{array}{l}2.6 \mathrm{E}-03 \\
0 \mathrm{O}=00\end{array}$ \\
\hline $\begin{array}{l}0.0 E+00 \\
0.0 E+00\end{array}$ & $\begin{array}{l}0.0 \mathrm{E}+00 \\
0.0 \mathrm{E}+00\end{array}$ & $\begin{array}{l}\begin{array}{l}0 . \mathrm{E}+00 \\
0.0 \mathrm{E}+00\end{array}\end{array}$ & $\begin{array}{l}0.0 \mathrm{E}+00 \\
0.0 \mathrm{E}+00\end{array}$ \\
\hline $0.0 E+00$ & $0.0 \mathrm{E}+00$ & $0.0 \mathrm{E}+00$ & $0.0 \mathrm{E}+00$ \\
\hline $0.0 E+00$ & 2.1E-10 & $\begin{array}{l}4.9 E-10 \\
\end{array}$ & 2.1E-10 \\
\hline $\begin{array}{l}9.8 \mathrm{E}-17 \\
94 \mathrm{E}-15\end{array}$ & $\begin{array}{l}0.0 \mathrm{E}+00 \\
16 \mathrm{E}-06\end{array}$ & 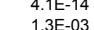 & $\begin{array}{l}4.1 \mathrm{E}-13 \\
4.3 \mathrm{E}-03\end{array}$ \\
\hline $\begin{array}{l}9.4 \mathrm{E}-15 \\
13 \mathrm{E}-16\end{array}$ & $\begin{array}{l}1.16 E-06 \\
7.0-09\end{array}$ & $\begin{array}{l}1.35-03 \\
25 E-05\end{array}$ & $\begin{array}{l}4.3 \mathrm{E}-03 \\
80 \mathrm{E}-05\end{array}$ \\
\hline 7.3E-10 & $\begin{array}{r}3.2 E \\
30=-04\end{array}$ & 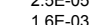 & $\begin{array}{l}0.00=0.03 \\
15 E-03\end{array}$ \\
\hline & $25 \mathrm{E}-05$ & $72-04$ & $78 E-04$ \\
\hline & $0.0 \mathrm{0}+00$ & $0.0 \mathrm{E}+00$ & $0.0 \mathrm{E}+00$ \\
\hline 3.0 & $4.6 \mathrm{E}-15$ & $2.0 \mathrm{E}-13$ & $9.6 \mathrm{E}-13$ \\
\hline & $4.3 \mathrm{E}-17$ & $3.9 E-15$ & \\
\hline & 7.6E-10 & 06 & \\
\hline & $\begin{array}{l}3.5 E-12 \\
25 E-06\end{array}$ & $\begin{array}{l}7.5-08 \\
77 E-06\end{array}$ & \\
\hline & & & \\
\hline
\end{tabular}


SRNL-STI-2008-00397, REVISION 0

Table 9. Sums-of-fractions for future slit trenches

\begin{tabular}{|c|c|c|c|c|c|c|c|c|c|c|c|c|c|c|}
\hline \multicolumn{3}{|c|}{ Sum-of-fractions for adjusted projected inventory } & \multirow{2}{*}{\multicolumn{3}{|c|}{$\begin{array}{c}\text { Beta-Gamma } \\
12-100\end{array}$}} & \multirow{2}{*}{\multicolumn{3}{|c|}{ Gross Alpha }} & & \multirow[b]{2}{*}{$\begin{array}{l}\text { Uranium } \\
0-1130\end{array}$} & \\
\hline & & $0-12$ & & & & & & & $\begin{array}{l}\text { Kandum } \\
1000-1120\end{array}$ & $1120-1130$ & & $\begin{array}{c}\text { Grou } \\
130-200\end{array}$ & $\begin{array}{l}\text { whater An-1-Pat } \\
\text { 200-1000 }\end{array}$ & $\begin{array}{l}\text { thways } \\
1000-1130\end{array}$ \\
\hline$\frac{\text { Parent Nuclide }}{\text { Am-241 }}$ & $\frac{\text { Inventory }}{5.30 \mathrm{E}-01}$ & $\frac{\mathrm{yrs}}{14 \mathrm{E}-10}$ & $\begin{array}{l}\text { yrs } \\
2.9 E-07\end{array}$ & $\frac{\mathrm{yrs}}{48 \mathrm{E}-05}$ & $\frac{\mathrm{yrs}}{2 \mathrm{AS}-03}$ & $\frac{\mathrm{yrs}}{41 \mathrm{E}-03}$ & 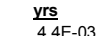 & $\frac{\text { yrs }}{0.0 E+00}$ & $\frac{\mathrm{yrs}}{0.0 \mathrm{E}+\mathrm{c}}$ & $\frac{\mathrm{yrs}}{0.0 \mathrm{E}+0 \mathrm{C}}$ & $\frac{\mathrm{yrs}}{3.3 \mathrm{E}-1:}$ & $\frac{\text { yrs }}{86 E-04}$ & $\begin{array}{l}\text { yrs } \\
6.7 E-0\end{array}$ & $\frac{\mathrm{yrs}}{12 \mathrm{E}-02}$ \\
\hline 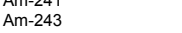 & 4.30E-02 & $0.0 \mathrm{E}+00$ & 8.1 & $\begin{array}{l}4.0 \mathrm{C} \\
9.0 \mathrm{E} \\
\mathrm{a}\end{array}$ & $\begin{array}{l}2.45 \\
6.5 \mathrm{E} \\
-\end{array}$ & 1.7 & $\begin{array}{l}4.8 \mathrm{E}-03 \\
1\end{array}$ & & $0.0 \mathrm{E}$ & & & & & $\begin{array}{l}4.7 \mathrm{~L}=03 \\
-03\end{array}$ \\
\hline & & & & & & & & & & & & & & \\
\hline -14_NR.Pump & $8.20 \mathrm{E}-02$ & $0.0 E+00$ & $0.0 \mathrm{E}+00$ & 3.3E-02 & $0.0 \mathrm{E}+00$ & $0.0 \mathrm{E}+00$ & $0.0 \mathrm{E}+00$ & $0.0 \mathrm{E}+00$ & $0.0 \mathrm{E}+00$ & $0.0 \mathrm{E}+00$ & $0.0 \mathrm{E}+00$ & $2.7 \mathrm{E}-02$ & $3.2 \mathrm{E}-02$ & $8.2 E-04$ \\
\hline Cf- 249 & $8.30 \mathrm{E}-02$ & $6.9 E-19$ & $2.7 E-14$ & $2.6 E-06$ & $2.7 E-04$ & $5.9 \mathrm{E}-04$ & $6.4 \mathrm{EE}-04$ & $0.0 \mathrm{E}+00$ & $0.0 \mathrm{E}+00$ & $0.0 E+00$ & $8.9 E-16$ & $4.6 \mathrm{E}-08$ & $8.6 \mathrm{E}-04$ & $2.0 \mathrm{E}-03$ \\
\hline Cf-251 & $7.50 \mathrm{E}-02$ & $0.0 E+00$ & $0.0 E+00$ & 4.4E-10 & $5.8 \mathrm{E}-04$ & 1.4E-03 & 1.4E-03 & $0.0 \mathrm{E}+00$ & $0.0 E+00$ & $0.0 E+00$ & $9.3 \mathrm{E}-20$ & $2.1 \mathrm{E}-20$ & $2.0 \mathrm{E}-03$ & $5.0 \mathrm{E}-03$ \\
\hline Cl-36 & $1.10 \mathrm{E}-05$ & $1.3 \mathrm{E}-04$ & $1.3 \mathrm{E}-04$ & $1.0 \mathrm{E}-05$ & $0.0 E+00$ & $0.0 \mathrm{E}+00$ & $0.0 E+00$ & $0.0 E+00$ & $0.0 \mathrm{E}+00$ & $0.0 E+00$ & $0.0 \mathrm{E}+00$ & $1.9 \mathrm{E}-05$ & 6.9E--06 & $5.5 E-06$ \\
\hline & $\begin{array}{l}3.20 E+00 \\
1.0 E-03\end{array}$ & $\begin{array}{l}0.0 E+00 \\
6.5 E-17\end{array}$ & $\begin{array}{l}0.0 E+00 \\
10 E-12\end{array}$ & $\begin{array}{l}3.6 E-18 \\
92 E-07\end{array}$ & $\begin{array}{l}4.6 E-11 \\
311\end{array}$ & $\begin{array}{l}3.5 E-10 \\
7.9 E-05\end{array}$ & $\begin{array}{l}4.1 \mathrm{E}-10 \\
85 \mathrm{~F}\end{array}$ & $\begin{array}{l}2.0 E-18 \\
2\end{array}$ & $\begin{array}{l}2.7 E-18 \\
\end{array}$ & $\begin{array}{l}2.7 E-18 \\
\end{array}$ & $\begin{array}{l}3.3 E-18 \\
6.1 F-16\end{array}$ & $\begin{array}{l}0.0 E+00 \\
17 F-07\end{array}$ & $\begin{array}{l}1.2 E-10 \\
85 E-05\end{array}$ & $\begin{array}{l}1.0 E-09 \\
23 E-04\end{array}$ \\
\hline $\begin{array}{l}m-245 \\
m-246\end{array}$ & $\begin{array}{l}\begin{array}{l}1.10 E \mathrm{E}-03 \\
4.10 \mathrm{E}-04\end{array} \\
4\end{array}$ & $\begin{array}{l}\begin{array}{l}6.5 E-17 \\
0.0 E+00\end{array} \\
0.00\end{array}$ & $\begin{array}{l}1.0 \mathrm{E}-12 \\
0.0 \mathrm{E}+00\end{array}$ & $\begin{array}{l}9.2 \mathrm{E}-07 \\
5.3 \mathrm{E}-19\end{array}$ & $\begin{array}{l}3.1 \mathrm{E}-05 \\
5.9 \mathrm{E}-06\end{array}$ & $\begin{array}{l}7.9 \mathrm{E}-05 \\
1.5 \mathrm{E}-05\end{array}$ & $\begin{array}{l}8.5 \mathrm{E}-\mathrm{-}-5 \\
1.6 \mathrm{E}-05\end{array}$ & $\begin{array}{l}0.0 E+00 \\
3.7 E-20\end{array}$ & $\begin{array}{l}0.0 E+00 \\
1.1 E-19\end{array}$ & $\begin{array}{l}0.0 E+00 \\
1.2 E-19\end{array}$ & $\begin{array}{l}6.1 E-16 \\
2.2 E-17\end{array}$ & $\begin{array}{l}1.1 E-0 / \\
0.0 E+00\end{array}$ & $\begin{array}{l}8.5 \mathrm{E}-05 \\
16 \mathrm{E}-05\end{array}$ & $\begin{array}{l}3 E-04 \\
4-05\end{array}$ \\
\hline $\begin{array}{l}m \\
m-247\end{array}$ & 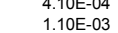 & $\begin{array}{l}0.0 \mathrm{E}+00 \\
0.0 \mathrm{E}+00\end{array}$ & $\begin{array}{l}0.0 E+00 \\
0.0 E+00\end{array}$ & $\begin{array}{l}5.3 E-19 \\
3.1 E-07\end{array}$ & $\begin{array}{l}\text {. } 2.9-9-06 \\
2.0 \mathrm{E}-05\end{array}$ & $\begin{array}{l}1.5 \mathrm{E}-\mathrm{-}-5 \\
5.2 \mathrm{E}-05\end{array}$ & $\begin{array}{l}1.0 \mathrm{E}-\mathrm{Co} \\
5.5 \mathrm{E}-05\end{array}$ & $0.0 \mathrm{E}+00$ & $0.0 \mathrm{E}+00$ & $\begin{array}{l}0.0 E-19 \\
0.00\end{array}$ & $\begin{array}{l}2.9 E-17 \\
7.9 E-17\end{array}$ & $\begin{array}{l}0.0 E-16 \\
1.8 E-16\end{array}$ & $\begin{array}{l}1.0 \mathrm{E}-\mathrm{-}=0 \\
5.0 \mathrm{E}-05\end{array}$ & $\begin{array}{l}4.4 E-05 \\
14 E-04\end{array}$ \\
\hline$n-248$ & & $0.0 \mathrm{E}+00$ & $0.0 E+00$ & & & & & & & & & & & \\
\hline . & $1.00 \mathrm{E}+00$ & & & $5.3 \mathrm{E}-05$ & $0.0 \mathrm{E}+00$ & $0.0 \mathrm{E}+00$ & $0.0 E+00$ & $0.0 \mathrm{E}+00$ & $0.0 \mathrm{E}+00$ & $0.0 E+00$ & $0.0 \mathrm{E}+00$ & $6.7 \mathrm{E}-07$ & $2.4 \mathrm{E}-07$ & 2.4 \\
\hline Concrete & $0.00 \mathrm{E}+00$ & $0.0 \mathrm{E}+00$ & $0.0 \mathrm{E}+00$ & $0.0 \mathrm{E}+00$ & $0.0 \mathrm{E}+00$ & $0.0 \mathrm{E}+00$ & $0.0 \mathrm{E}+00$ & $0.0 \mathrm{E}+00$ & $0.0 \mathrm{E}+00$ & $0.0 E+00$ & $0.0 \mathrm{E}+00$ & $0.0 E+00$ & $0.0 \mathrm{E}+00$ & $0.0 \mathrm{E}+00$ \\
\hline H-3_ETF.Carbon & $2.80 \mathrm{E}-01$ & $0.0 E+00$ & $0.0 \mathrm{E}+00$ & $5.0 \mathrm{E}-06$ & $0.0 \mathrm{E}+00$ & $0.0 \mathrm{E}+00$ & $0.0 E+00$ & $0.0 E+00$ & $0.0 E+00$ & $0.0 E+00$ & $0.0 E+00$ & $1.9 \mathrm{E}-07$ & $2.6 \mathrm{E}-10$ & $0.0 \mathrm{E}+00$ \\
\hline I-129 & $3.00 E-05$ & 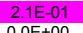 & 2.1E-01 & 2.1E-02 & $0.0 E+00$ & $0.0 E+00$ & $0.0 E+00$ & $0.0 \mathrm{E}+00$ & $0.0 E+00$ & $0.0 E+00$ & $0.0 E+00$ & $3.5 \mathrm{E}-04$ & $1.6 \mathrm{E}-04$ & \\
\hline I-129_ETF.Carbon & & $0.0 E+00$ & $0.0 \mathrm{E}+00$ & 9.4E-02 & $0.0 \mathrm{E}+00$ & $0.0 E+00$ & & $0.0 \mathrm{E}+00$ & & & $E+\infty 0$ & & & 1.6E-03 \\
\hline $\begin{array}{l}\text { I-129-ETFFGT.73 } \\
\text { I-129F.Carbon }\end{array}$ & $\begin{array}{l}8.60 \mathrm{E}-05 \\
0.00 \mathrm{E}+00\end{array}$ & 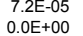 & $\begin{array}{r}1.5-5-04 \\
0.0 \mathrm{E}+00\end{array}$ & $\begin{array}{l}3.7 \mathrm{~F}-04 \\
0.0 \mathrm{E}+00\end{array}$ & $\begin{array}{l}0.0 E+00 \\
0.0 E+00\end{array}$ & $\begin{array}{l}0.0 \mathrm{E}+00 \\
0.0 \mathrm{E}+00\end{array}$ & $\begin{array}{l}0.0 \mathrm{E}+00 \\
0.0 \mathrm{E}+00\end{array}$ & $\begin{array}{l}0.0 \mathrm{E}+00 \\
0.0 \mathrm{E}+00\end{array}$ & $\begin{array}{l}0.0 \mathrm{E}+00 \\
0.0 \mathrm{E}+00\end{array}$ & $\begin{array}{l}0.0 E+00 \\
0.0 E+00\end{array}$ & $\begin{array}{l}0 E+00 \\
0 E+00\end{array}$ & $\begin{array}{l}\text { 3.1E- }-66 \\
\end{array}$ & $\begin{array}{l}5.7 E-06 \\
0.0 F+00\end{array}$ & $\begin{array}{l}6.1 E-06 \\
\text { 6.1E+00 }\end{array}$ \\
\hline $\begin{array}{l}129 \text { F.CG. } 8 \\
\text { 12.Can }\end{array}$ & $\begin{array}{l}5.0 \mathrm{E}+0 \mathrm{E} \\
5.20 \mathrm{E}\end{array}$ & $\begin{array}{l}0.0 E-03 \\
8.8 E+00\end{array}$ & $\begin{array}{l}0.0 E+00 \\
1.7 E-02\end{array}$ & $\begin{array}{l}0.0 E+00 \\
1.7 E-02\end{array}$ & $\begin{array}{l}0.0 E+00 \\
0.0 E+00\end{array}$ & $\begin{array}{l}0.0 \mathrm{E}+00 \\
0.00\end{array}$ & $\begin{array}{l}0.0 \mathrm{E}+00 \\
0.0 \mathrm{E}\end{array}$ & $\begin{array}{l}0.0 \mathrm{E}+00 \\
0.0 \mathrm{E}+00\end{array}$ & $\begin{array}{l}0.0 E+00 \\
0.0 E+00\end{array}$ & $\begin{array}{l}0.0 E+00 \\
0.0 E+00\end{array}$ & $\begin{array}{l}0.0 \mathrm{E}+00 \\
0.00\end{array}$ & $\begin{array}{l}0.0 E+00 \\
2.7 E-04\end{array}$ & $\begin{array}{l}0.0 E-04 \\
1.7 E-04\end{array}$ & $\begin{array}{l}0.0 E+00 \\
52 E-05\end{array}$ \\
\hline 129_F.Dowex.21K & 4.40E-03 & $5.6 \mathrm{E}-03$ & 1.1E-02 & $2.8 \mathrm{E}-02$ & $0.0 \mathrm{E}+00$ & $0.0 \mathrm{E}+00$ & $0.0 \mathrm{E}+00$ & $0.0 \mathrm{E}+00$ & $0.0 \mathrm{E}+00$ & $0.0 \mathrm{E}+00$ & $0.0 \mathrm{E}+00$ & $2.3 \mathrm{E}-04$ & 4.4E- -04 & 4.6E-04 \\
\hline tercake & $7.00 \mathrm{E}-05$ & 1.1E- 02 & 2.1EE-02 & & $0.0 E+00$ & $0.0 \mathrm{E}+00$ & $0.0 \mathrm{E}+00$ & $0.0 \mathrm{E}+00$ & $=+\infty$ & +00 & $\mathrm{E}+00$ & $3.5 E-04$ & & \\
\hline 29_H.Carbon & $0.00 E+00$ & $0.0 E+00$ & $0.0 \mathrm{E}+00$ & $0.0 \mathrm{E}+00$ & $0.0 \mathrm{E}+00$ & $0.0 \mathrm{E}+00$ & $0.0 \mathrm{E}+00$ & $0.0 \mathrm{E}+00$ & $0 \mathrm{E}+00$ & $0.0 \mathrm{E}+00$ & $0 \mathrm{E}+00$ & $0.0 \mathrm{E}+00$ & $0.0 \mathrm{E}+00$ & $0.0 \mathrm{E}+00$ \\
\hline 129-H.CG.8 & $1.20 \mathrm{E}-04$ & $2.7 \mathrm{E}-03$ & $5.5 \mathrm{E}-03$ & $8.6 E-03$ & $0.0 E+00$ & $0.0 \mathrm{E}+00$ & $0.0 \mathrm{E}+00$ & $0.0 E+00$ & $0.0 \mathrm{E}+00$ & $0.0 E+00$ & $0.0 \mathrm{E}+00$ & 1.1E- -04 & $1.4 \mathrm{E}-04$ & $1.4 \mathrm{E}-04$ \\
\hline I-129_H.Dowex.21K & $0.00 E+00$ & $0.0 E+00$ & $0.0 E+00$ & $0.0 E+00$ & $0.0 E+00$ & $0.0 \mathrm{E}+00$ & $0.0 E+00$ & $0.0 \mathrm{E}+00$ & $0 E+00$ & $0.0 E+00$ & $E+00$ & $0.0 \mathrm{E}+00$ & $0.0 E+00$ & $0.0 E+00$ \\
\hline I-129_H.Filtercake & $2.80 E-07$ & $3.7 E-06$ & $\begin{array}{l}\text { 7.4E-06 } \\
-5\end{array}$ & $1.3 \mathrm{E}-05$ & $0.0 \mathrm{E}+00$ & 0. & 00 & 0.0 & & & & & & $E-07$ \\
\hline $\begin{array}{l}\text { I-129_Mk50A } \\
\text { K-40 }\end{array}$ & $\begin{array}{l}8.20 \mathrm{E}=-06 \\
100-04\end{array}$ & $\begin{array}{l}2.3 E-06 \\
1.5 E-03\end{array}$ & $\begin{array}{l}5.9 E-06 \\
17 E-3\end{array}$ & $\begin{array}{l}2.2 \mathrm{E}-05 \\
20 \mathrm{E}-04\end{array}$ & $0.0 E+00$ & $\begin{array}{l}0.0 \mathrm{E}+00 \\
0.0 \mathrm{E}+00\end{array}$ & $0.0 \mathrm{E}+00$ & $0.0 E+00$ & $\begin{array}{l}E+\infty \\
+\infty\end{array}$ & $0.0 E+00$ & $\begin{array}{c}E+00 \\
E+00\end{array}$ & $\begin{array}{l}1.5 \mathrm{E}-07 \\
015-05\end{array}$ & $\begin{array}{l}\mathrm{E}-07 \\
\mathrm{E}-07\end{array}$ & E-07 \\
\hline $\begin{array}{l}\text { K-40 } \\
\text { Mo-93 }\end{array}$ & $\begin{array}{l}1.00 \mathrm{E}-04 \\
1.00-03\end{array}$ & & & $\begin{array}{l}2.0 E-04 \\
7.7 E-04\end{array}$ & $\begin{array}{l}0.0 \mathrm{E}+00 \\
0.0 \mathrm{E}+00\end{array}$ & $\begin{array}{l}0.0 \mathrm{E}+00 \\
0.0 \mathrm{E}+00\end{array}$ & $\begin{array}{l}0.0 \mathrm{E}+00 \\
0.0 \mathrm{E}+00\end{array}$ & $\begin{array}{l}0.0 \mathrm{E}+00 \\
0.0 \mathrm{E}+00\end{array}$ & $\begin{array}{l}0.0 \mathrm{E}+00 \\
0.0 \mathrm{E}+00\end{array}$ & $\begin{array}{l}0.0 E+00 \\
0.0 E+00\end{array}$ & $\begin{array}{l}0.0 E+00 \\
0.0 \mathrm{E}+00\end{array}$ & $\begin{array}{l}9.1 \mathrm{E}-05 \\
1.6 \mathrm{E}-04\end{array}$ & $\begin{array}{l}\begin{array}{l}4.8 \mathrm{E}-05 \\
5.9 \mathrm{E}-05\end{array} \\
\end{array}$ & $\begin{array}{l}4.4 \mathrm{E}-06 \\
48 \mathrm{E}-05\end{array}$ \\
\hline $\begin{array}{l}0.93 \\
0-94\end{array}$ & $\begin{array}{l}1.00 E=03 \\
5.00 E-04\end{array}$ & $\begin{array}{l}5.3 \mathrm{EZ}-03 \\
5.3 \mathrm{E}-03\end{array}$ & $\begin{array}{l}5.3 \mathrm{E}-03 \\
5.3 \mathrm{E}-03\end{array}$ & 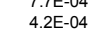 & $\begin{array}{l}0.0 \mathrm{E}+0 \\
0.0 \mathrm{E}+00\end{array}$ & $\begin{array}{l}0.0 \mathrm{E}+0 \\
0.0 \mathrm{E}+00\end{array}$ & $\begin{array}{l}0.0 \mathrm{E}+00 \\
0.0 \mathrm{E}+00\end{array}$ & $\begin{array}{l}0.0 \mathrm{E}+00 \\
0.0 \mathrm{E}+0\end{array}$ & $\begin{array}{l}0.0 \mathrm{E}+00 \\
0.0 \mathrm{E}+00\end{array}$ & $\begin{array}{l}0.0 E+00 \\
0.0 E+00\end{array}$ & $0.0 \mathrm{E}+00$ & $\begin{array}{l}7.02-04 \\
7.3 E-04\end{array}$ & 2.6E-04 & $\begin{array}{l}4.8 E-05 \\
2.2 E-04\end{array}$ \\
\hline-59 & $3.60 \mathrm{E}-02$ & $6.2 \mathrm{E}-22$ & 1.1E-11 & $8.8 \mathrm{E}-03$ & $0.0 \mathrm{E}+00$ & 00 & $\begin{array}{l}0.0 \mathrm{E}+00 \\
0.00\end{array}$ & $0.0 \mathrm{E}+00$ & & & $\mathrm{EE}+00$ & $\begin{array}{l}3.7 \mathrm{E}-08 \\
\end{array}$ & $\begin{array}{l}2.00 \mathrm{E}-05 \\
1.65\end{array}$ & 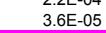 \\
\hline-237 & $8.00 \mathrm{E}-03$ & $3.3 \mathrm{E}-06$ & 3 & $5.0 \mathrm{E}-03$ & 1.0E-01 & 2 & $2.2 \mathrm{E}-02$ & $0.0 \mathrm{E}+00$ & & & & & & \\
\hline 107 & $1.10 \mathrm{E}-07$ & $0.0 \mathrm{E}+00$ & 2.6E-19 & $2.2 \mathrm{E}-10$ & $0.0 \mathrm{E}+00$ & 10 & $0.0 \mathrm{E}+00$ & $0.0 \mathrm{E}+00$ & & & $0.0 \mathrm{E}+00$ & $7.3 \mathrm{E}-14$ & 3.3 & $6.9 \mathrm{E}$ \\
\hline Pu-238 & $2.50 E+01$ & $0.0 E+00$ & $0.0 E+00$ & $2.6 \mathrm{E}-06$ & $6.8 \mathrm{E}-05$ & 2.1E- 04 & $2.3 \mathrm{E}-04$ & $6.8 \mathrm{E}-05$ & & & $1.7 E-16$ & 1.11E-08 & $2.3 \mathrm{E}-05$ & $7.8 \mathrm{E}-05$ \\
\hline Pu-239 & 1.60E+00 & 1.7 & & & & & & & & & & & & 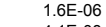 \\
\hline $\begin{array}{l}\text { Pu-240 } \\
\text { Pu-241 }\end{array}$ & 1 & $0.0 \mathrm{E}$ & & & & & & & & & & & & \\
\hline $\begin{array}{l}\text { Pu-241 } \\
\text { Pu-242 }\end{array}$ & $\begin{array}{l}8.40 \mathrm{~A}+00 \\
1.50 \mathrm{E}-02\end{array}$ & 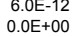 & $\begin{array}{r}3.4 .4-08 \\
0.0 \mathrm{E}+00\end{array}$ & $\begin{array}{l}2.6 \mathrm{E}-55 \\
1.5 \mathrm{E}-16\end{array}$ & $\begin{array}{l}1.3 \mathrm{~B}-03 \\
6.3 \mathrm{E}-11\end{array}$ & $\begin{array}{l}\begin{array}{l}2.3 \mathrm{E}-\mathrm{-}-3 \\
5.2 \mathrm{E}-10\end{array} \\
\text { a }\end{array}$ & $\begin{array}{l}2.3 \mathrm{E}-\mathrm{E}-3 \\
6.0 \mathrm{E}-10\end{array}$ & $\begin{array}{l}0.0 E+00 \\
4.1 E-15\end{array}$ & $\begin{array}{l}0.0 E+00 \\
1.3 E-14\end{array}$ & $\begin{array}{l}0.0 E+00 \\
1.4 E-14\end{array}$ & $\begin{array}{l}1.7 \mathrm{E}-13 \\
4.7 \mathrm{E}-18\end{array}$ & $\begin{array}{l}3.8 \mathrm{E}-04 \\
4.6 \mathrm{E}-20\end{array}$ & $\begin{array}{l}3.5 \mathrm{E}-03 \\
1.5 \mathrm{E}-10\end{array}$ & $\begin{array}{l}55-03 \\
5-09\end{array}$ \\
\hline $\begin{array}{l}\text { Pu-242 } \\
\text { Pu-244 }\end{array}$ & $\begin{array}{l}1.50 E=02 \\
5.10 E-15\end{array}$ & $\begin{array}{l}0.0 \mathrm{E}+00 \\
0.0 \mathrm{E}+00\end{array}$ & $\begin{array}{l}0.0 E+00 \\
0.0 E+00\end{array}$ & $\begin{array}{l}1.5 \mathrm{E}-16 \\
2.4 \mathrm{E}-24\end{array}$ & $\begin{array}{l}6.3 \mathrm{~B}-11 \\
2.3 \mathrm{E}-23\end{array}$ & $\begin{array}{l}5.2 E-10 \\
2.0 E-22\end{array}$ & $\begin{array}{l}6.0 E-10 \\
2.3 E-22\end{array}$ & $\begin{array}{l}\text {.4.1E-15 } \\
3.0 E-32\end{array}$ & $\begin{array}{l}1.5 \\
4.3\end{array}$ & $\begin{array}{l}1.4 E-14 \\
4.3 E-32\end{array}$ & $\begin{array}{l}4.6 \\
1.7 \mathrm{~K}\end{array}$ & & E-23 & $\begin{array}{l}1.5 E-09 \\
5.5-22\end{array}$ \\
\hline$=20$ & $\begin{array}{l}5.10 E=-10 \\
3.20 E-03\end{array}$ & $\begin{array}{l}0.0 E+40 \\
1.4 E-20\end{array}$ & 1.3E-10 & 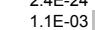 & $\begin{array}{l}2.3 .5-23 \\
5.0 E-02\end{array}$ & $\begin{array}{l}2.0 \mathrm{E}-22 \\
\text { 8.4E-02 }\end{array}$ & $\begin{array}{l}2.3 E-22 \\
8.4 E-02\end{array}$ & $\begin{array}{l}5.0 E-02 \\
5.02\end{array}$ & $8.4 .45 y-4.45$ & 02 & $0.0 \mathrm{E}+00$ & $6.2 \mathrm{E}-04$ & $1.7 \mathrm{E}-02$ & $\begin{array}{l}5.3 E-22 \\
2.9 E-02\end{array}$ \\
\hline ling.Tower & $4.00 \mathrm{E}-02$ & $0.0 \mathrm{E}$ & 3.3 & & $1.7 \mathrm{E}-01$ & 4.1E & . & 1.7 & & & -00 & & 6.1 & TE-02 \\
\hline s & $8.60 \mathrm{E}-03$ & & $0.0 E+00$ & $2.7 \mathrm{E}-22$ & $0.0 \mathrm{E}+00$ & & 00 & $0.0 \mathrm{E}+00$ & & 00 & 00 & & 0 & $2.5 E-22$ \\
\hline Sn-126 & 0.0 & $0.0 \mathrm{E}+00$ & $0.0 \mathrm{E}+00$ & $0.0 E+00$ & $0.0 \mathrm{E}$ & 0. & 00 & 0.0 & & & 00 & $0.0 E+00$ & $0.0 E+00$ & $0.0 \mathrm{E}+00$ \\
\hline Sr-90 & $1.20 \mathrm{E}$ & 1.2E- & $3.5 \mathrm{E}-06$ & $1.1 \mathrm{E}=-U_{1}$ & $0.0 \mathrm{E}$ & & & & & & & & & \\
\hline Sr-90_Mk50A & 7.40E- & $5.3 E-18$ & $2.3 E-09$ & $1.9 \mathrm{E}-$ & & & & & & & & & & \\
\hline $\begin{array}{l}\text { Tc-99 } \\
\text { Tc-99, }\end{array}$ & $\begin{array}{l}5.00 \mathrm{E}-02 \\
1.80-03 \\
\end{array}$ & $3.4 \mathrm{E}$ & 1.4 & $\begin{array}{l}3.9 \mathrm{E}-02 \\
5.5 \mathrm{E}-06\end{array}$ & $\begin{array}{l}0.0 \mathrm{E} \\
0.0 \mathrm{E}\end{array}$ & $\begin{array}{l}0.0 \mathrm{E} \\
0.0 \mathrm{E}\end{array}$ & & & & & & & 02 & $\begin{array}{ll}5 E-03 \\
E-0.06\end{array}$ \\
\hline Th-2 & $3.90 E-04$ & $0.0 E+00$ & $\begin{array}{l}2.0 \mathrm{E}-14 \\
2.14\end{array}$ & $\begin{array}{l}\text { 4. } \\
\text { 4. } 4 \mathrm{EE}-0.5\end{array}$ & $1.3 \mathrm{E}-03$ & 3.6E-03 & $\begin{array}{l}3.9 \mathrm{E}-03 \\
3\end{array}$ & $\begin{array}{l}1.0 \mathrm{E}-03 \\
-3\end{array}$ & & -03 & 00 & 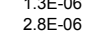 & $\begin{array}{l}3.7 \mathrm{E}-06 \\
4.2 \mathrm{E}-04\end{array}$ & 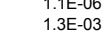 \\
\hline CCooling.Tower & 4.00 & $0.0 \mathrm{E}$ & & & & & & & & & & & & \\
\hline$n-2$ & & & & & & & & & & & & & & \\
\hline & & & & & & & & & & & & & & \\
\hline U-23 & 1.8 & $0.0 E$ & & & $1.9 \mathrm{E}$ & & & & & & & & & $2.1 \mathrm{E}-02$ \\
\hline Slass & 2.80 & $0.0 \mathrm{E}$ & 2.6 & & 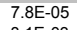 & 2.2 & 2.3 & & & & 1.3 & 7. & $5^{5}$ & 8.0 \\
\hline & & & & & & & 6.5 & & & & & & & -02 \\
\hline $\begin{array}{l}\text { U-235_MGlass } \\
\text { U-235 Paducah.C }\end{array}$ & $\begin{array}{l}1.90 E-01 \\
3.90-01\end{array}$ & & & & $9.1 \mathrm{E}-2 \mathrm{l}$ & & $\begin{array}{l}1.0 \mathrm{E}-04 \\
1.0 \mathrm{E}-05\end{array}$ & & & & & & & \\
\hline U-236- & $\begin{array}{l}3.90 \mathrm{E}-01 \\
2.60 \mathrm{E}-02\end{array}$ & $\begin{array}{l}7.0 \mathrm{E} \\
0.0 \mathrm{E}\end{array}$ & $\begin{array}{l}9.9 E-10 \\
1.1 E-21\end{array}$ & $\begin{array}{l}1.5 \mathrm{E} \\
1.1 \mathrm{E}\end{array}$ & $\begin{array}{l}1.7 \mathrm{E}-8.4 \mathrm{E}-2 \\
8\end{array}$ & & $\begin{array}{l}1.9 \mathrm{E}-05 \\
1.1 \mathrm{E}-12\end{array}$ & $\begin{array}{l}0.06 \\
6.31 \\
\end{array}$ & & & & & $\begin{array}{l}1.4 E-04 \\
44 E-13\end{array}$ & $\frac{4}{2}$ \\
\hline Glass & 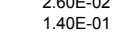 & $\begin{array}{l}0.0 \mathrm{E} \\
0.0 \mathrm{E}\end{array}$ & $\begin{array}{l}1.1 \mathrm{E} \\
0.0 \mathrm{E}\end{array}$ & $8.8 \mathrm{E}$ & 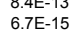 & & $\begin{array}{l}1.1 \mathrm{E}-12 \\
8.8 \mathrm{E}-15\end{array}$ & 5.01 & & & & & & $9 E-14$ \\
\hline & $3.30 \mathrm{E}+00$ & $0.0 \mathrm{E}$ & $0.0 \mathrm{E}$ & $1.0 \mathrm{E}-06$ & $2.8 \mathrm{E}$ & & & & & & & & & \\
\hline & 1.10E +01 & $0.0 \mathrm{E}+00$ & $0.0 E$ & $8.5 \mathrm{E}-09$ & $2.3 \mathrm{E}-07$ & $7.3 \mathrm{E}-07$ & $7.9 \mathrm{E}-07$ & $2.3 \mathrm{E}-07$ & & 7.9 & & & $7.9 \mathrm{E}-08$ & 7 \\
\hline & $2.70 \mathrm{E}-05$ & $1.8 \mathrm{E}-05$ & $4.2 \mathrm{E}-05$ & $3.7 \mathrm{E}-05$ & $0.0 \mathrm{E}+00$ & $0.0 E+00$ & $0.0 E+00$ & $0.0 \mathrm{E}+00$ & $0.0 \mathrm{E}+$ & $0.0 \mathrm{E}+0$ & & $3.0 \mathrm{E}-06$ & $5.6 \mathrm{E}-06$ & $6.1 \mathrm{E}-06$ \\
\hline & & & & & & & & & & & L- & & & \\
\hline
\end{tabular}




\subsubsection{Sums-of-fractions trends and observations}

For Slit Trenches 1 and 2 and for future slit trenches, all SOFs are less than one and most SOFs changed minimally. The SOFs are shown by themselves in Tables 10 through 12 for ST1, ST2 and future slit trenches, respectively. Noticeable changes (greater than 0.01 before rounding) are highlighted in gold in those tables.

Four SOFs for ST1 changed noticeably: all beta-gamma limits increased by about 0.04 and the groundwater all-pathways SOF for the time interval from 130 to 200 years increased by 0.01 . Three SOFs for ST2 changed noticeably with the largest being an increase of 0.05 (from 0.26 to 0.31 ) for the beta-gamma pathway in the time interval from 100 to 1130 years. The same three SOFs increased for the future trenches, with all increases being about 0.05 . For the three sets of inventories, most changes of a significant nature occur for future trenches.

Most SOF changes were minimal. The major cause for minimal SOF changes is that the final limits are the smaller of the PA limits and the SA calculated limits. Many SAcalculated limits are higher in the early years, but the lower PA limits were used which produced no change in the corresponding SOFs. In later years, greater decreases in limits typically occurred for the more highly mobile contaminants creating higher fractions, which were manifested in the noticeable changes highlighted below.

A second cause for minimal SOF changes is the selection of time intervals. The PA time intervals were applied in this SA. The PA time intervals were selected to help optimize the limits for the PA, however the best method to optimize the limits for the SA would be to select time intervals based on SA results.

Table 10. Sums-of-fractions for existing inventory in Slit Trench 1

\begin{tabular}{|c|c|c|c|}
\hline Pathway & $\begin{array}{l}\text { Time Interval } \\
(\mathrm{yr})\end{array}$ & $\begin{array}{l}\text { PA } \\
\text { SOF }\end{array}$ & $\begin{array}{l}\min \\
\text { SOF }\end{array}$ \\
\hline$\beta \gamma$ & $0-12$ & $7.9 \mathrm{E}-01$ & 8.3E-01 \\
\hline$\beta \gamma$ & $12-100$ & 8.1E-01 & 8.5E-01 \\
\hline$\beta \gamma$ & $100-1130$ & $1.0 \mathrm{E}-01$ & 1.3E-01 \\
\hline$\alpha$ & $0-1000$ & $6.5 \mathrm{E}-02$ & 6.7E-02 \\
\hline$\alpha$ & $1000-1120$ & 9.4E-02 & 9.7E-02 \\
\hline$\alpha$ & $1120-1130$ & 9.1E-02 & 9.3E-02 \\
\hline Radium & $0-1000$ & $5.1 \mathrm{E}-02$ & 5.1E-02 \\
\hline Radium & $1000-1120$ & 8.7E-02 & 8.9E-02 \\
\hline Radium & $1120-1130$ & 8.7E-02 & 8.9E-02 \\
\hline Uranium & $0-1130$ & 8.0E-11 & 8.0E-11 \\
\hline Groundwater all-pathways & $130-200$ & $6.4 \mathrm{E}-02$ & 7.6E-02 \\
\hline Groundwater all-pathways & $200-1000$ & 8.8E-02 & 9.6E-02 \\
\hline Groundwater all-pathways & $1000-1130$ & $5.9 \mathrm{E}-02$ & $6.0 \mathrm{E}-02$ \\
\hline
\end{tabular}


Table 11. Sums-of-fractions for existing inventory in Slit Trench 2

\begin{tabular}{|l|l|r|r|}
\hline Pathway & $\begin{array}{l}\text { Time Interval } \\
(\mathrm{yr})\end{array}$ & $\begin{array}{l}\text { PA } \\
\text { SOF }\end{array}$ & min SOF \\
\hline$\beta \gamma$ & $0-12$ & $7.7 \mathrm{E}-01$ & $7.7 \mathrm{E}-01$ \\
\hline$\beta \gamma$ & $12-100$ & $8.6 \mathrm{E}-01$ & $8.6 \mathrm{E}-01$ \\
\hline$\beta \gamma$ & $100-1130$ & $2.6 \mathrm{E}-01$ & $3.1 \mathrm{E}-01$ \\
\hline$\alpha$ & $0-1000$ & $2.9 \mathrm{E}-02$ & $3.2 \mathrm{E}-02$ \\
\hline$\alpha$ & $1000-1120$ & $2.7 \mathrm{E}-02$ & $2.8 \mathrm{E}-02$ \\
\hline$\alpha$ & $1120-1130$ & $2.1 \mathrm{E}-02$ & $2.1 \mathrm{E}-02$ \\
\hline Radium & $0-1000$ & $4.0 \mathrm{E}-03$ & $4.0 \mathrm{E}-03$ \\
\hline Radium & $1000-1120$ & $1.2 \mathrm{E}-02$ & $1.2 \mathrm{E}-02$ \\
\hline Radium & $1120-1130$ & $1.3 \mathrm{E}-02$ & $1.3 \mathrm{E}-02$ \\
\hline Uranium & $0-1130$ & $7.1 \mathrm{E}-10$ & $7.1 \mathrm{E}-10$ \\
\hline Groundwater all-pathways & $130-200$ & $1.1 \mathrm{E}-01$ & $1.4 \mathrm{E}-01$ \\
\hline Groundwater all-pathways & $200-1000$ & $1.3 \mathrm{E}-01$ & $1.4 \mathrm{E}-01$ \\
\hline Groundwater all-pathways & $1000-1130$ & $6.3 \mathrm{E}-02$ & $6.5 \mathrm{E}-02$ \\
\hline
\end{tabular}

Table 12. Sums-of-fractions for projected inventory in future slit trenches

\begin{tabular}{|l|l|r|r|}
\hline Pathway & $\begin{array}{l}\text { Time Interval } \\
(\mathrm{yr})\end{array}$ & $\begin{array}{l}\text { PA } \\
\text { SOF }\end{array}$ & min SOF \\
\hline$\beta \gamma$ & $0-12$ & $8.2 \mathrm{E}-01$ & $8.2 \mathrm{E}-01$ \\
\hline$\beta \gamma$ & $12-100$ & $9.2 \mathrm{E}-01$ & $9.2 \mathrm{E}-01$ \\
\hline$\beta \gamma$ & $100-1130$ & $4.1 \mathrm{E}-01$ & $4.6 \mathrm{E}-01$ \\
\hline$\alpha$ & $0-1000$ & $3.7 \mathrm{E}-01$ & $3.8 \mathrm{E}-01$ \\
\hline$\alpha$ & $1000-1120$ & $2.8 \mathrm{E}-01$ & $2.8 \mathrm{E}-01$ \\
\hline$\alpha$ & $1120-1130$ & $2.6 \mathrm{E}-01$ & $2.6 \mathrm{E}-01$ \\
\hline Radium & $0-1000$ & $2.7 \mathrm{E}-01$ & $2.7 \mathrm{E}-01$ \\
\hline Radium & $1000-1120$ & $2.1 \mathrm{E}-01$ & $2.1 \mathrm{E}-01$ \\
\hline Radium & $1120-1130$ & $2.2 \mathrm{E}-01$ & $2.2 \mathrm{E}-01$ \\
\hline Uranium & $0-1130$ & $1.7 \mathrm{E}-09$ & $1.7 \mathrm{E}-09$ \\
\hline Groundwater all-pathways & $130-200$ & $3.4 \mathrm{E}-01$ & $3.8 \mathrm{E}-01$ \\
\hline Groundwater all-pathways & $200-1000$ & $5.2 \mathrm{E}-01$ & $5.7 \mathrm{E}-01$ \\
\hline Groundwater all-pathways & $1000-1130$ & $3.4 \mathrm{E}-01$ & $3.5 \mathrm{E}-01$ \\
\hline
\end{tabular}




\subsection{SUMMARY}

Covering changed the movement of contaminants to the water table and the hypothetical well. Early movements typically decreased because the cover decreased the flow of water from the surface through the contaminants. Later movements typically increased because less of the inventory had been released than for the uncovered cases analyzed in the PA.

These effects on contaminant movement translated into higher SA-calculated limits relative to PA limits in the early years and some lower SA-calculated limits relative to PA limits in the later years. Because the lower of the two sets of limits was always selected as the operational limit, the net effect was to lower limits in the later years (typically 100 years and later). Earlier covers at 5 years magnified the changes.

The effect on operations depends on the inventory which is used to calculate the SOFs. The SOFs for ST1 and ST2 changed relatively little and all SOFs were less than unity. Because ST1 and ST2 are already operationally closed, those changes will have no effect on operations. For future STs, SOFs were calculated for projected inventories at closure for a generic ST. While some SOFs increased a few percent they were still far less than unity, so they should not affect operations. One difference between the projected inventories at closure in the SA versus those found in Appendix C of the PA is the elimination of the tritium-in-concrete waste form. The tritium-in-concrete waste form cannot realistically be expected to occur (see Section 3.4) based on the unique features assumed for its earlier SA (Flach et al., 2005). There is no impact from this change as this particular waste stream is no longer being generated.

This SA also extended the duration of the analysis for highly mobile contaminants past the 130 years applied in the PA. This time extension captures the effects of dynamic compaction and subsequent degradation of the cover.

Results of this analysis are not directly applicable to the sets of East and West Slit Trenches, because the flow fields differ from the current analysis. However, the behavior of the results is not expected to vary, such that early covering tends to increase early SA-calculated limits and to decrease later SA-calculated limits.

\subsection{KEY INPUTS AND ASSUMPTIONS}

The following key inputs and assumptions supplement all other key inputs and assumptions presented in the PA:

5.1.The recharge through the cover and the abutting ditches must not exceed 0.36 inches per year from the time the cover is installed until the final operational cover is placed. The time of final cover placement is expected to be about 30 years from the start of operations. 
All runoff water from the covered area must be removed from the Slit Trench area so that it does not enter the area included in the vadose model which extends $60 \mathrm{ft}$ laterally and vertically to the ground water table. As a result, water must drain away from the covered trenches and not accumulate near the filled trenches. Proper use of concrete or asphalt drainage ditches will ensure that runoff water is removed.

Beyond the modeled area, background infiltration is assumed, so no engineering actions are required beyond the modeled area.

5.2. Waste designated as tritium-in-concrete (H3F) was developed for the specific waste in Slit Trench \#1. Therefore, assumptions and waste characterization related to this tritium-in-concrete waste cannot be used for future waste disposals in other locations.

\subsection{REFERENCES}

DOE 1999. Radioactive Waste Management, Order 435.1, U.S. Department of Energy.

Flach et al., 2005. WSRC-TR-2005-00093, Preliminary Closure Analysis for Slit Trenches \#1 and \#2, Flach, G.P., L.B. Collard, M.A. Phifer, K.P. Crapse, K.L. Dixon, L.D. Koffman and E.L. Wilhite, March 2005, Westinghouse Savannah River Company LLC, Savannah River Site, Aiken, SC 29808.

WSRC 2008. WSRC-STI-2007-00306, REVISION 0; E-Area Low-Level Waste Facility DOE 435.1 Performance Assessment, July 2008, Washington Savannah River Company LLC, Savannah River Site, Aiken, SC 29808.

Phifer, 2008. Personal communication with M.A. Phifer.

USDOE 2008. WSRC-RP-2008-4083, Interim Action Proposed Plan for the E-Area Low Level Waste Facility, 643-26E (Slit Trench Disposal Units 1 and 2) Draft A, December 2008, United States Department of Energy, Savannah River Site, Aiken, SC 29808. 


\section{APPENDIX A. PLOTS OF CONTAMINANT FLUXES AT THE WATER TABLE AND PLOTS OF WELL CONCENTRATIONS}

\subsection{PLOTS OF CONTAMINANT FLUXES AT THE WATER TABLE}

Plots of contaminant fluxes at the water table are presented in sections. The two major sections are center trenches and edge trenches. Within each major section, plots for four cases are presented as shown in Table A-1. Because results are very similar for the scenarios with one or two covers over ST1 to ST4, only the plots for the scenario with two covers are provided. Plots are provided for covers placed at 15 years, 5 years and 10 years.

Table A- 1. Case Descriptions

\begin{tabular}{|l|l|l|}
\hline Case & CDP & Description \\
\hline $01 \mathrm{n} 11$ & Off & $\begin{array}{l}\text { 90\% of containers were crushed via dynamic compaction at 130 years. } \\
10 \% \text { collapsed immediately after the final cover was completed causing } \\
\text { the cover to fail. }\end{array}$ \\
\hline $01 n 11$ & On & $\begin{array}{l}\text { 90\% of containers were crushed via dynamic compaction at 130 years. } \\
10 \% \text { collapsed immediately after the final cover was completed causing } \\
\text { the cover to fail. }\end{array}$ \\
\hline 01 & Off & All containers were crushed via dynamic compaction at 130 years \\
\hline 01 & On & All containers were crushed via dynamic compaction at 130 years \\
\hline
\end{tabular}

\subsubsection{Center trench flux plots for 15-year cover}

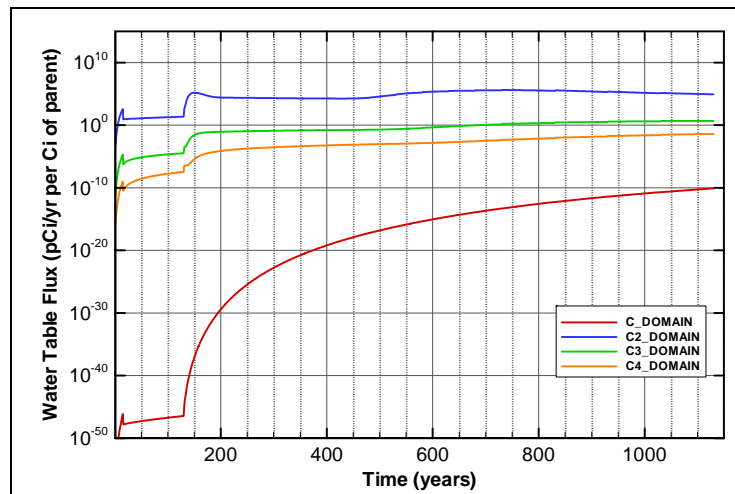

Figure A-1. Flux at water table for Case01n11_off Am-241

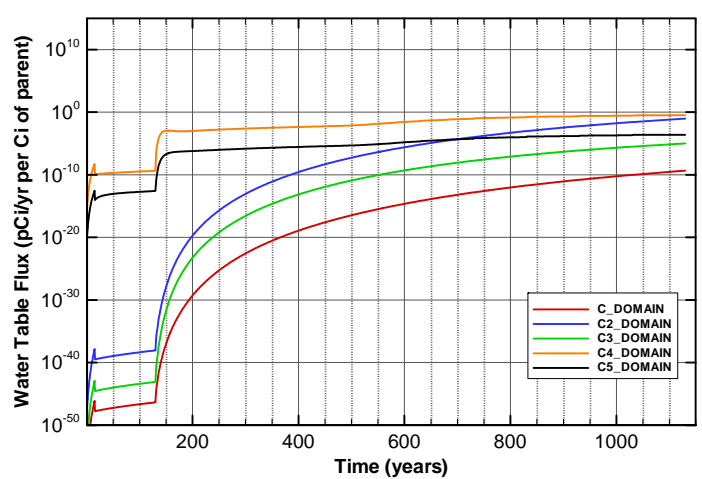

Figure A-2. Flux at water table for Case01n11_off Am-243 
SRNL-STI-2008-00397, REVISION 0

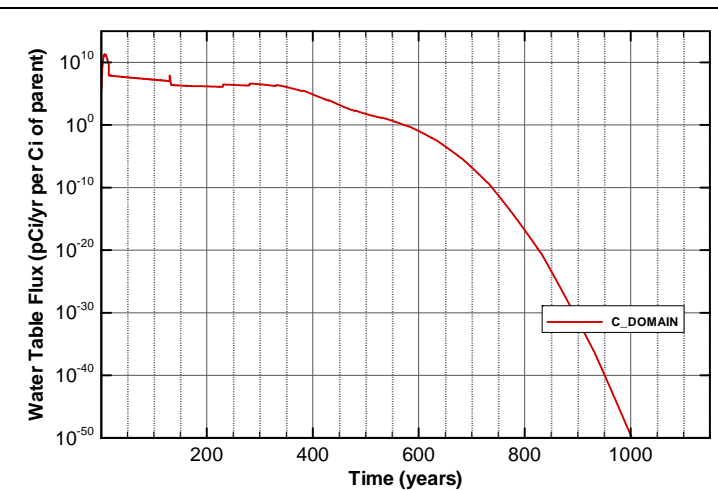

Figure A-3. Flux at water table for Case01n11_off C-14

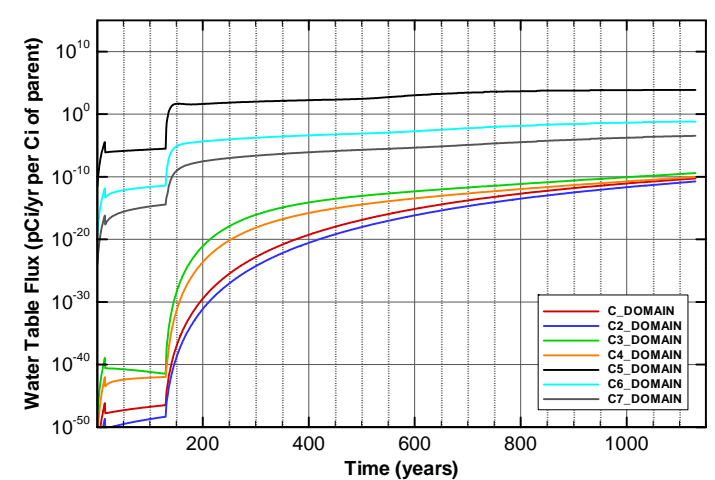

Figure A-5. Flux at water table for Case01n11_off Cf-249

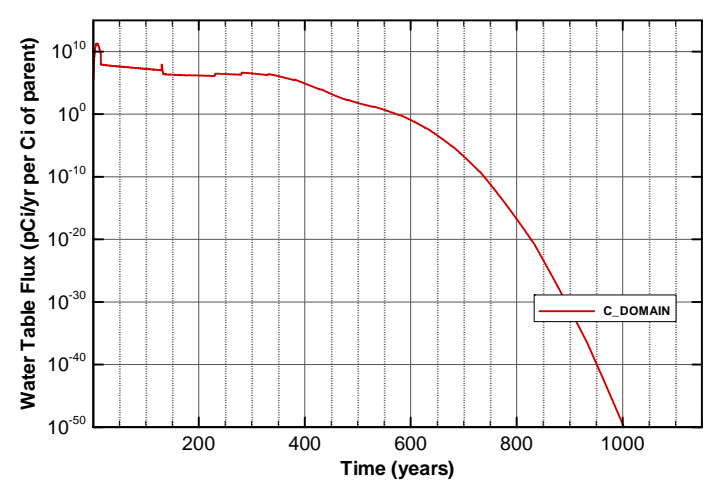

Figure A-7. Flux at water table for Case01n11_off Cl-36

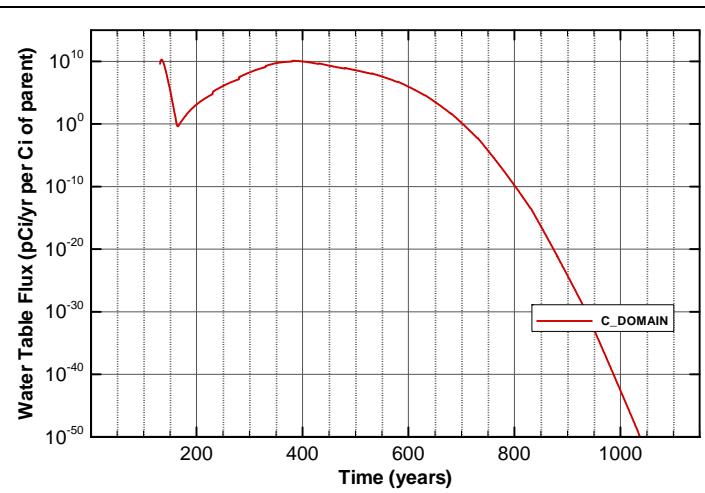

Figure A-4. Flux at water table for Case01n11_off C-14_NR.Pump

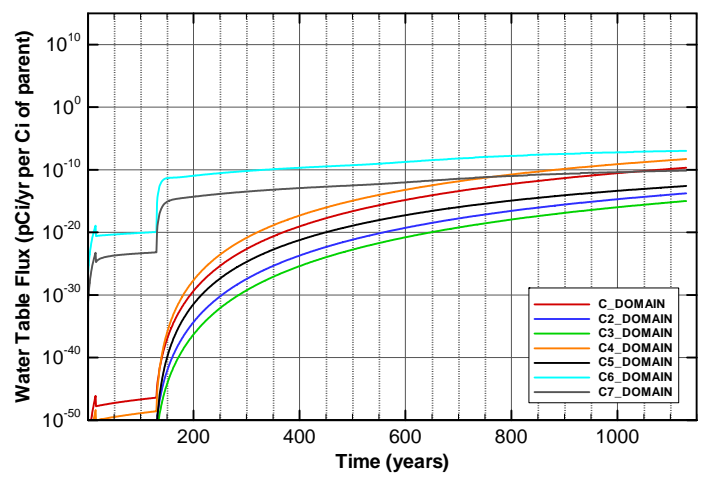

Figure A-6. Flux at water table for Case01n11_off Cf-251

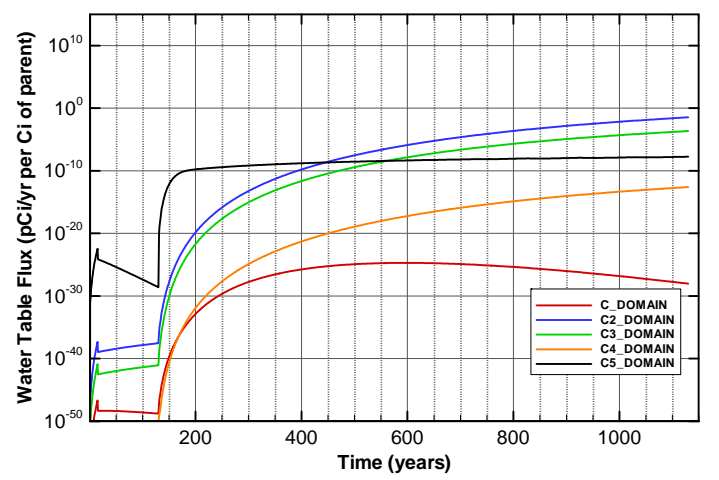

Figure A-8. Flux at water table for Case01n11_off Cm-244 


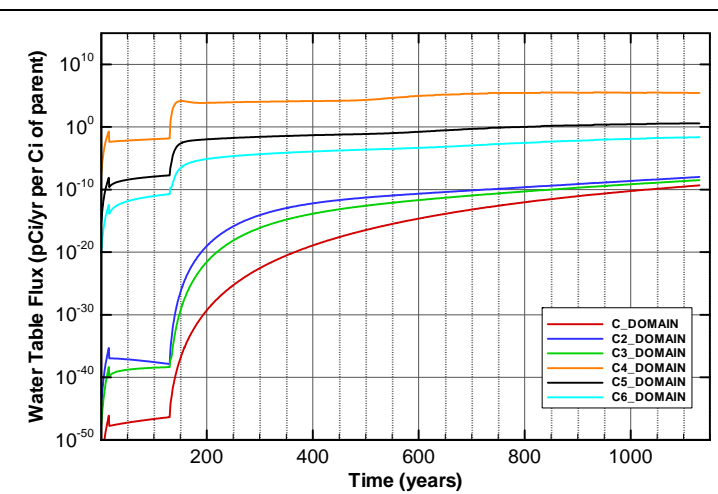

Figure A-9. Flux at water table for Case01n11_off Cm-245

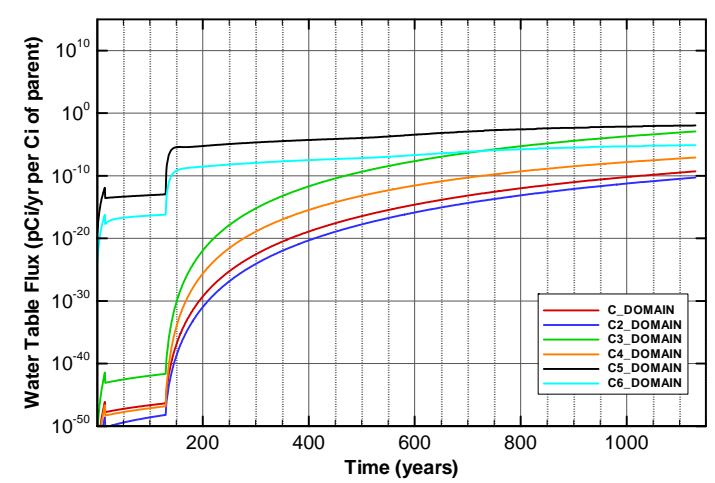

Figure A-11. Flux at water table for Case01n11_off Cm-247

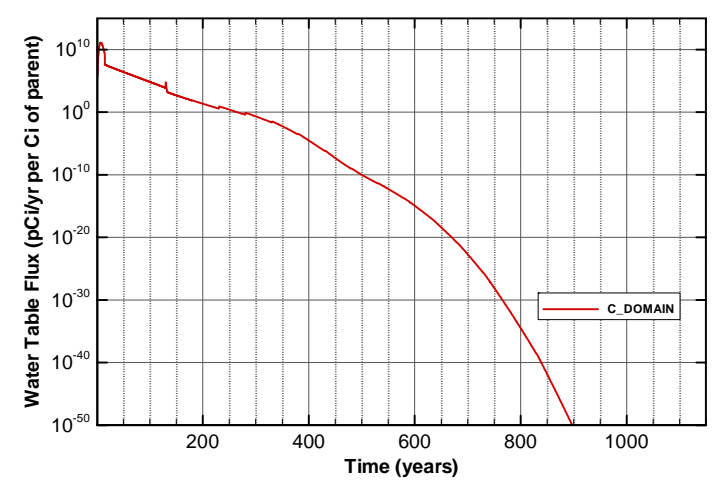

Figure A-13. Flux at water table for Case01n11_off H-3

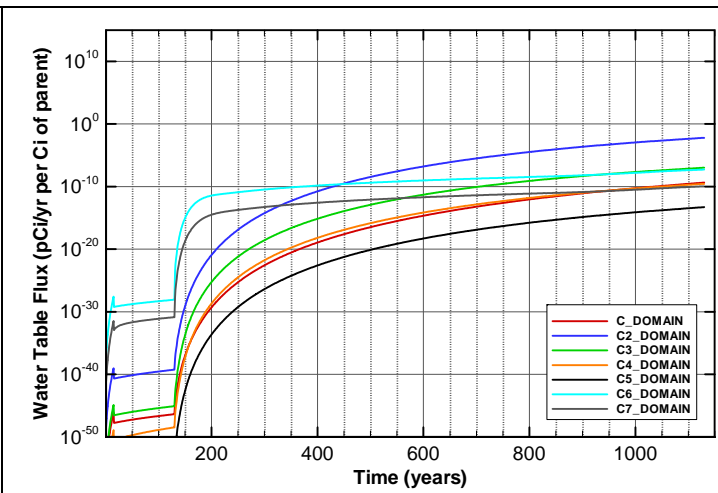

Figure A-10. Flux at water table for Case01n11_off Cm-246

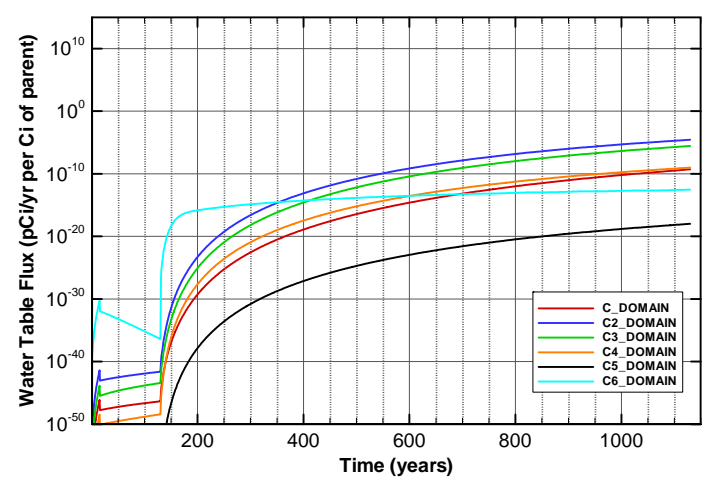

Figure A-12. Flux at water table for Case01n11_off Cm-248

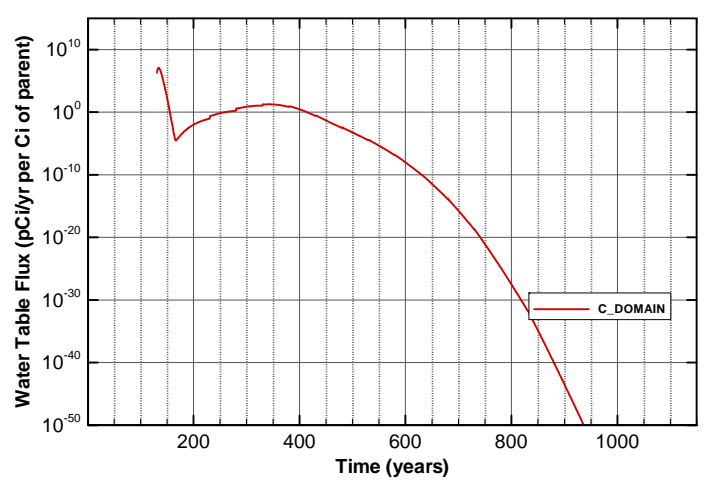

Figure A-14. Flux at water table for Case01n11_off H-3_ETF.Carbon 


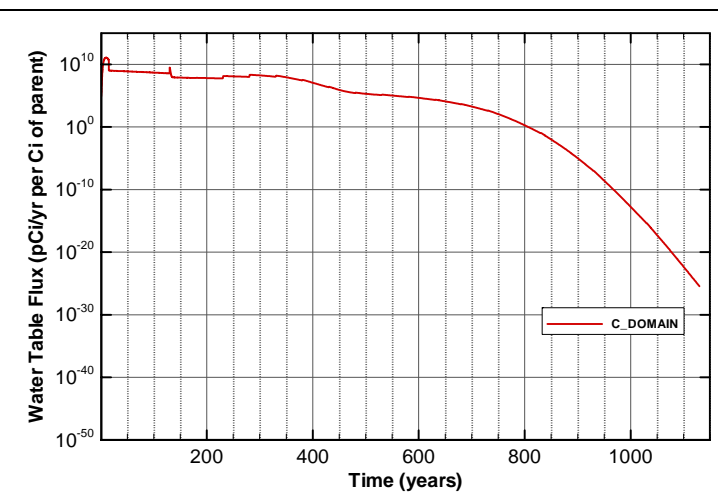

Figure A-15. Flux at water table for Case01n11_off I-129

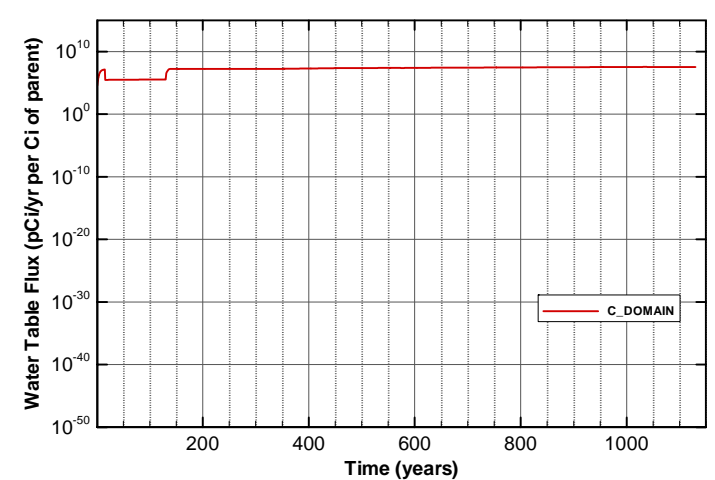

Figure A-17. Flux at water table for Case01n11_off I-129_ETF.GT.73

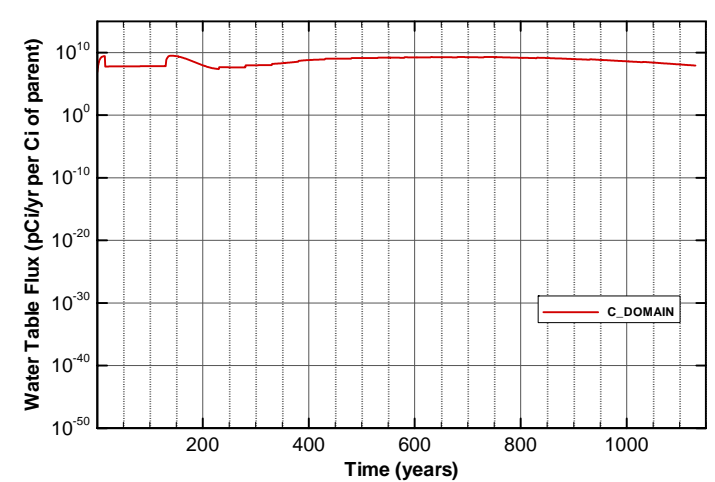

Figure A-19. Flux at water table for Case01n11_off I-129_F.CG.8

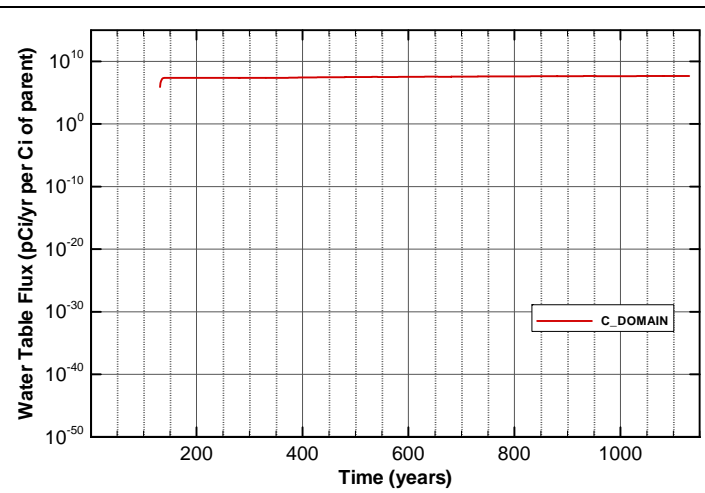

Figure A-16. Flux at water table for Case01n11_off I-129_ETF.Carbon

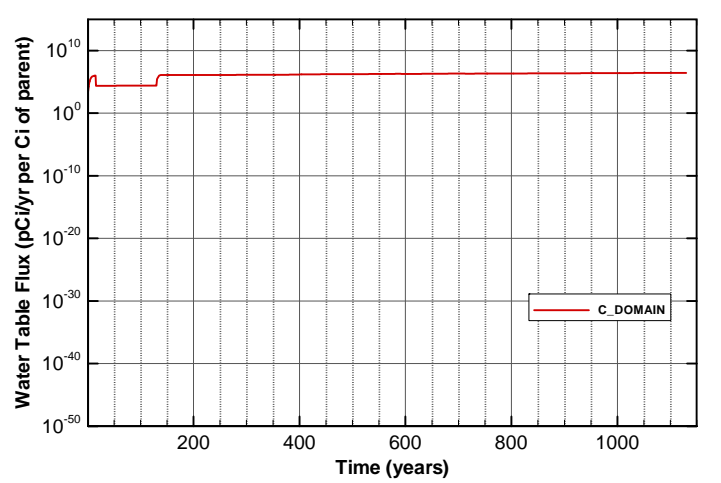

Figure A-18. Flux at water table for Case01n11_off I-129_F.Carbon

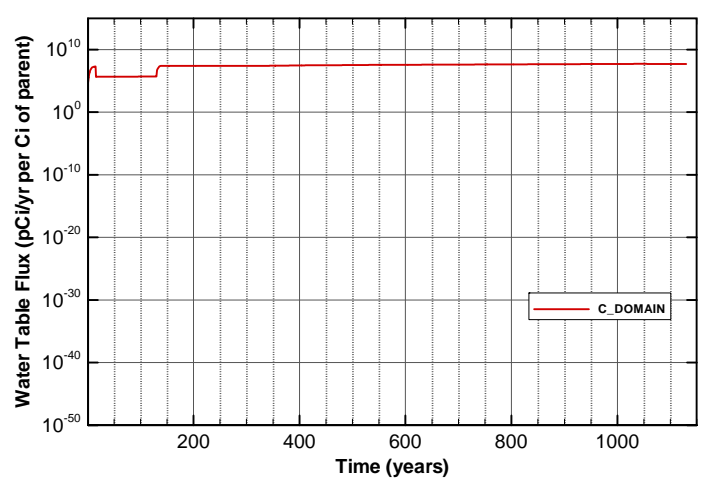

Figure A-20. Flux at water table for Case01n11_off I-129_F.Dowex.21K 


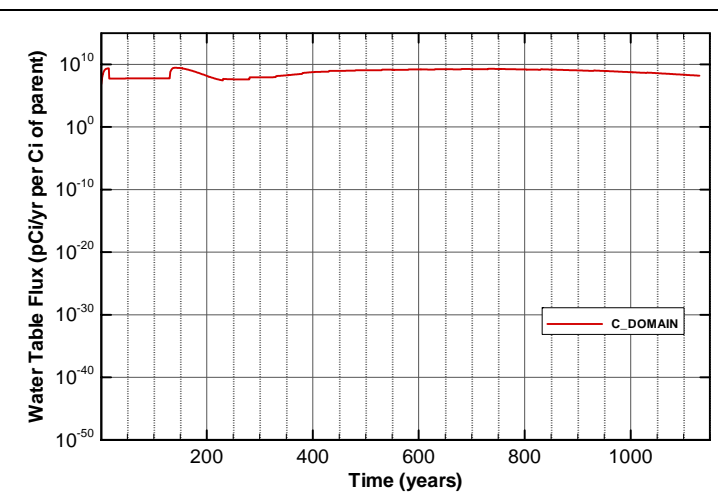

Figure A-21. Flux at water table for Case01n11_off I-129_F.Filtercake

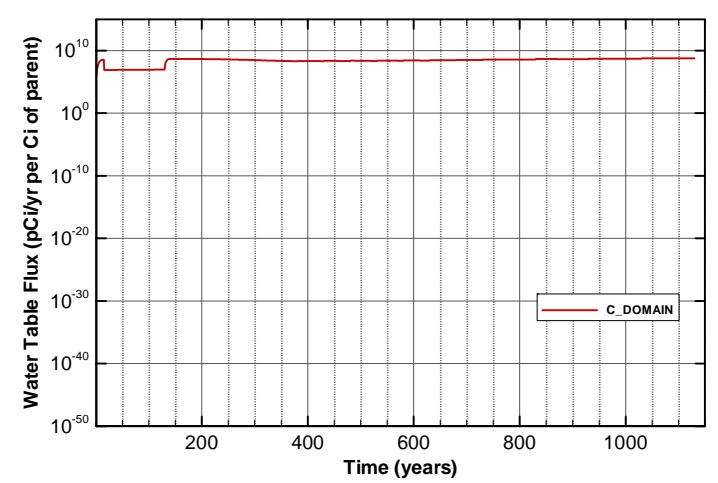

Figure A-23. Flux at water table for Case01n11_off I-129_H.CG.8

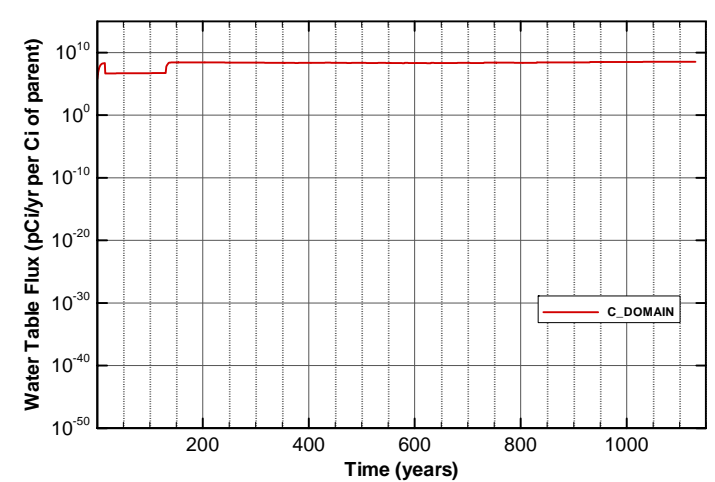

Figure A-25. Flux at water table for Case01n11_off I-129_H.Filtercake

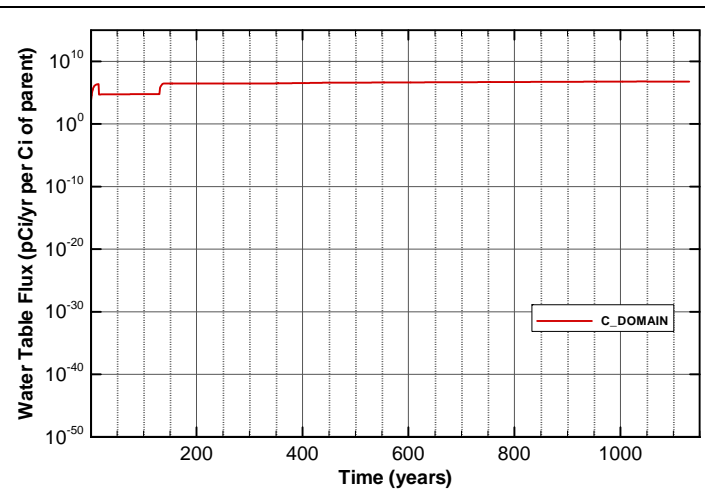

Figure A-22. Flux at water table for Case01n11_off I-129_H.Carbon

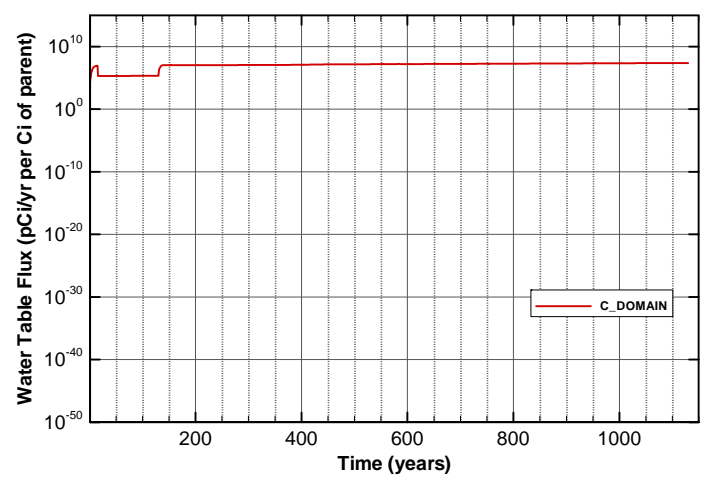

Figure A-24. Flux at water table for Case01n11_off I-129_H.Dowex.21K

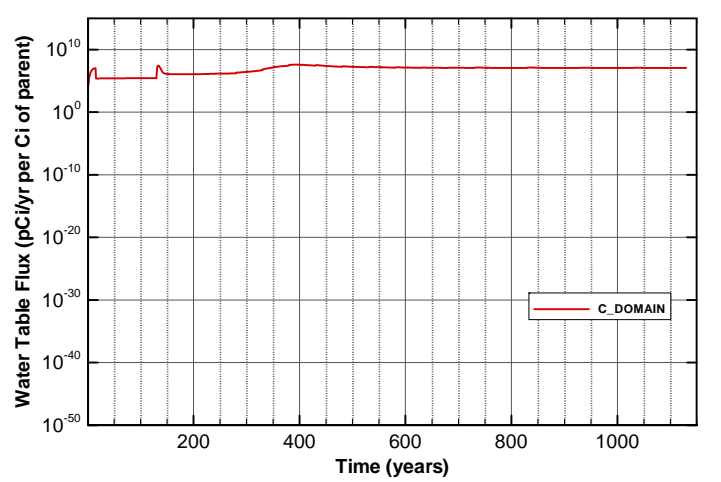

Figure A-26. Flux at water table for Case01n11_off I-129_Mk50A 


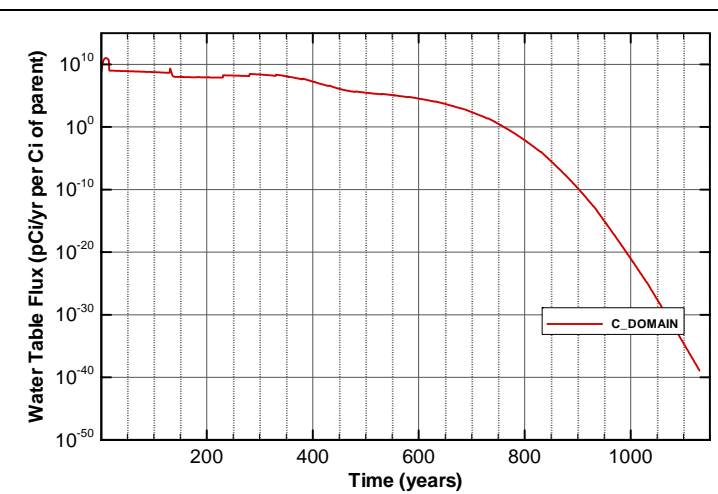

Figure A-27. Flux at water table for Case01n11_off K-40

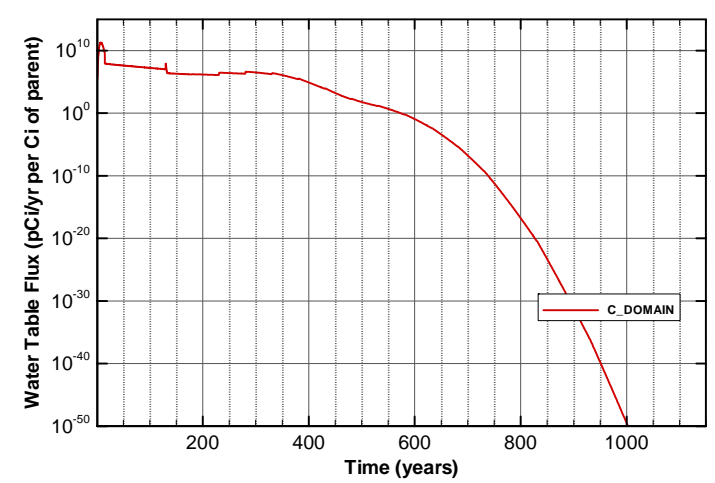

Figure A-29. Flux at water table for Case01n11_off Nb-94

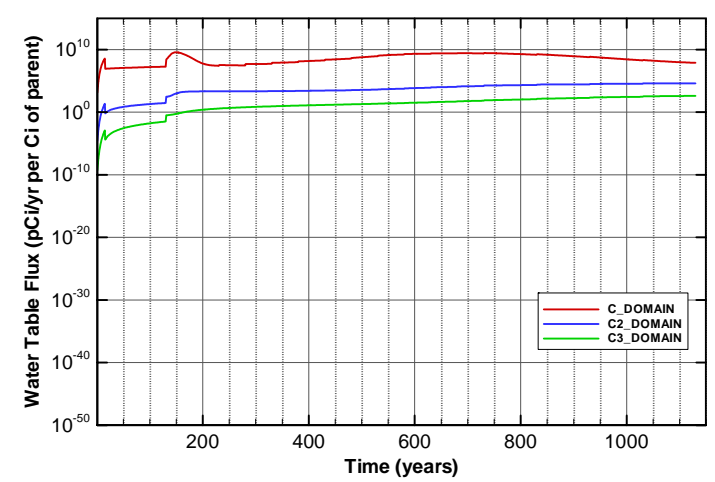

Figure A-31. Flux at water table for Case01n11_off Np-237

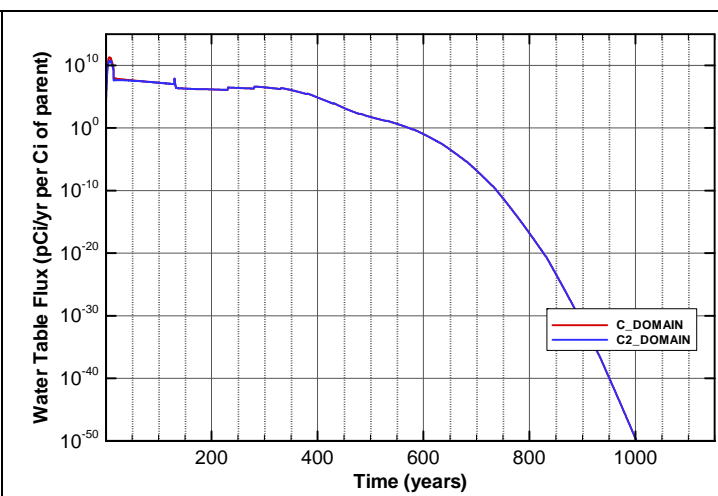

Figure A-28. Flux at water table for Case01n11_off Mo-93

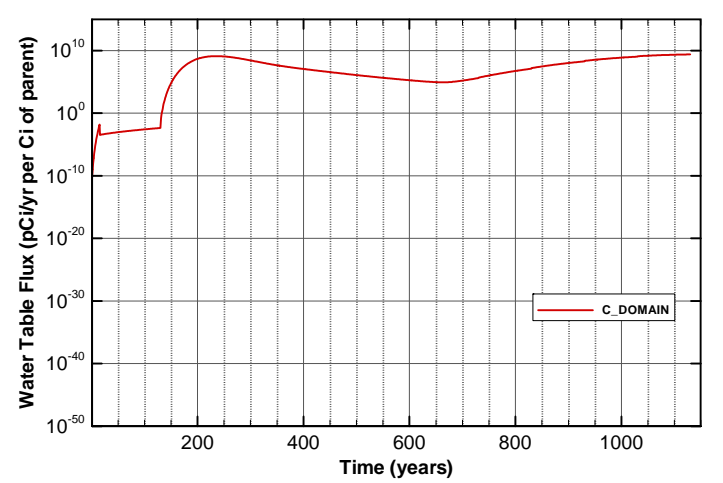

Figure A-30. Flux at water table for Case01n11_off Ni-59

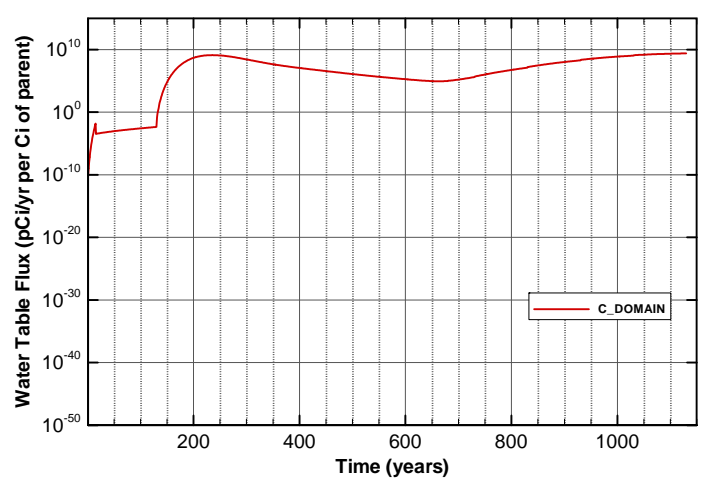

Figure A-32. Flux at water table for Case01n11_off Pd-107 
SRNL-STI-2008-00397, REVISION 0
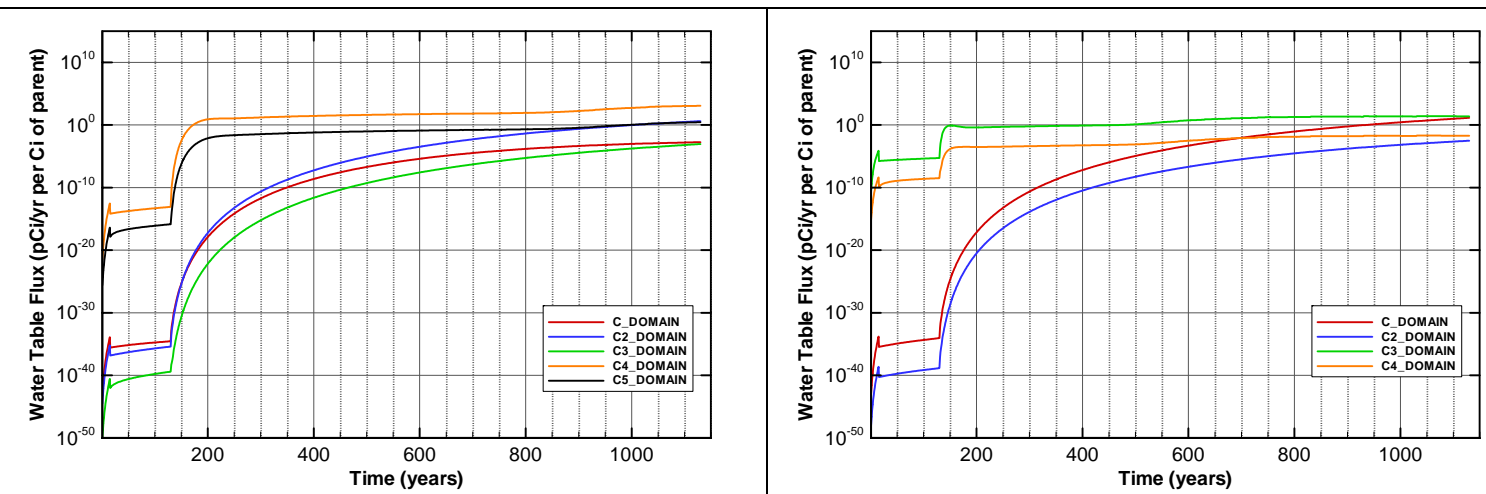

Figure A-33. Flux at water table for Case01n11_off Pu-238

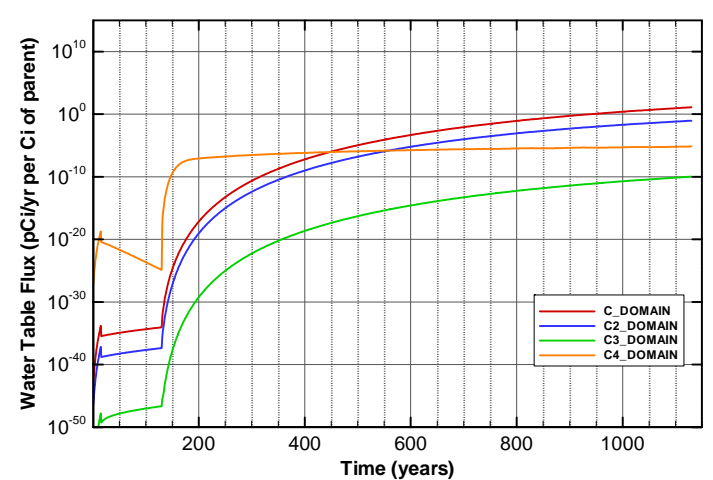

Figure A-35. Flux at water table for Case01n11_off Pu-240

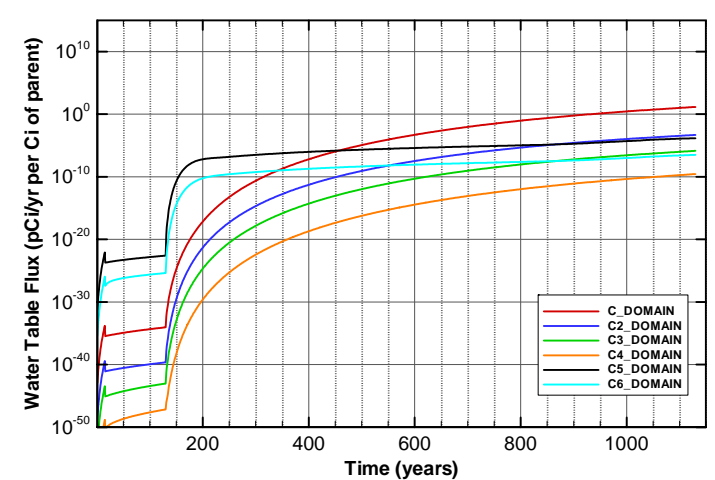

Figure A-37. Flux at water table for Case01n11_off Pu-242

Figure A-34. Flux at water table for Case01n11_off Pu-239

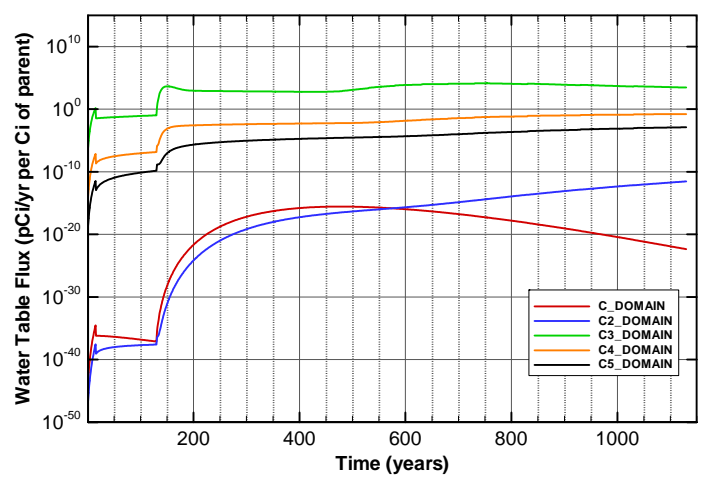

Figure A-36. Flux at water table for Case01n11_off Pu-241

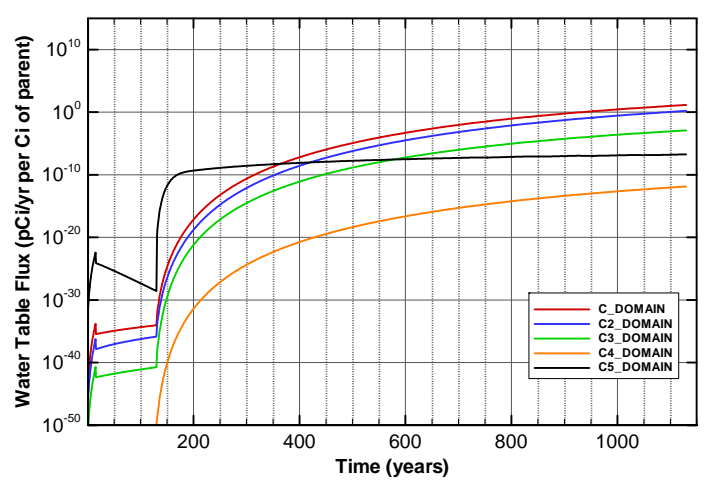

Figure A-38. Flux at water table for Case01n11_off Pu-244 


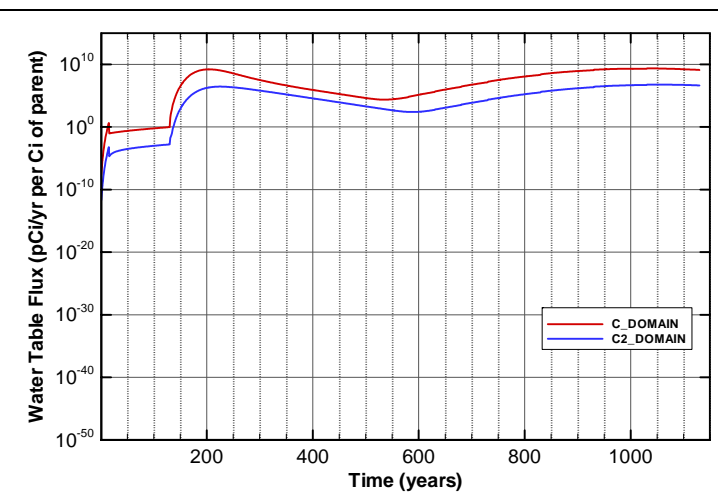

Figure A-39. Flux at water table for Case01n11_off Ra-226

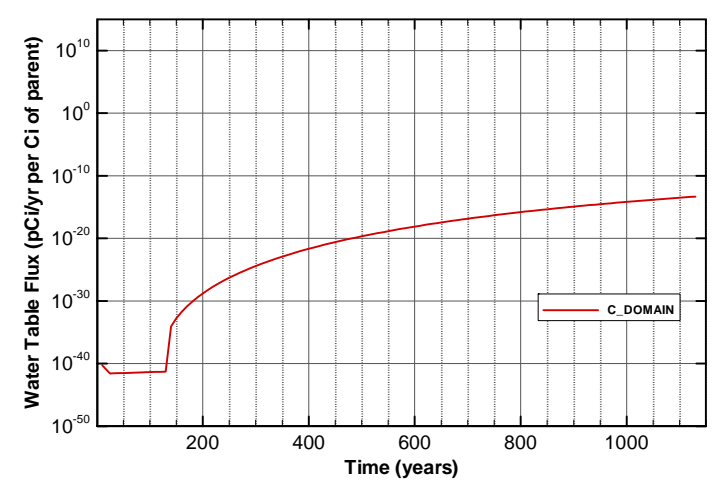

Figure A-41. Flux at water table for Case01n11_off Sn-126

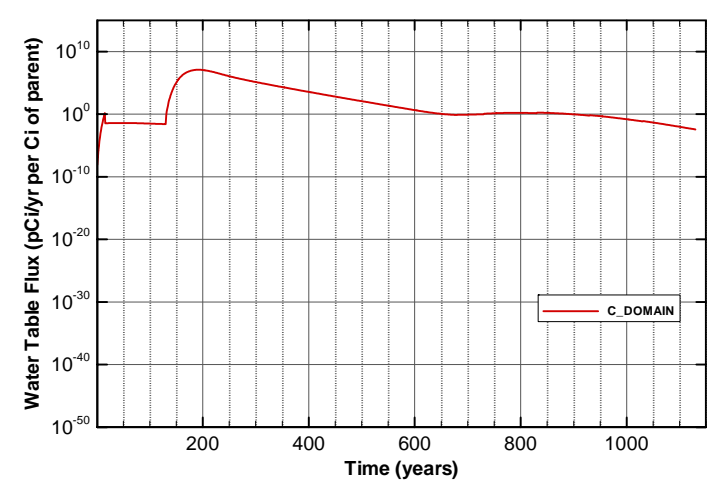

Figure A-43. Flux at water table for Case01n11_off Sr-90_Cask

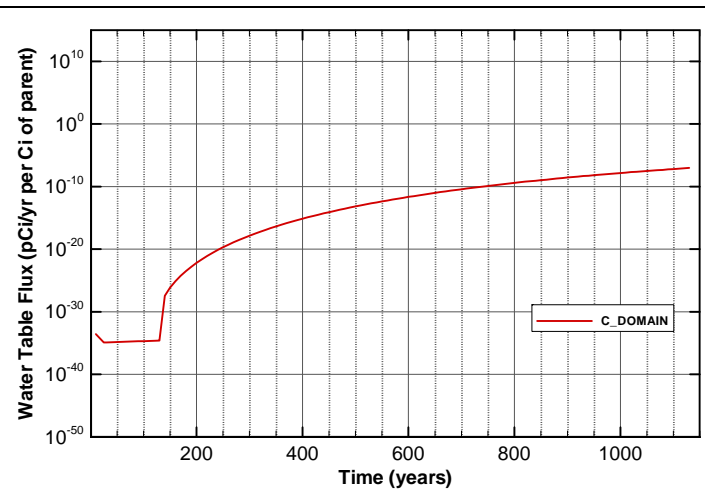

Figure A-40. Flux at water table for Case01n11_off Se-79

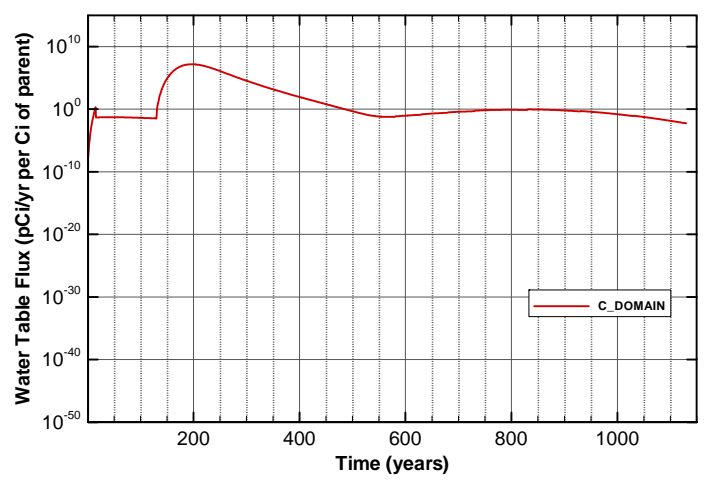

Figure A-42. Flux at water table for Case01n11_off Sr-90

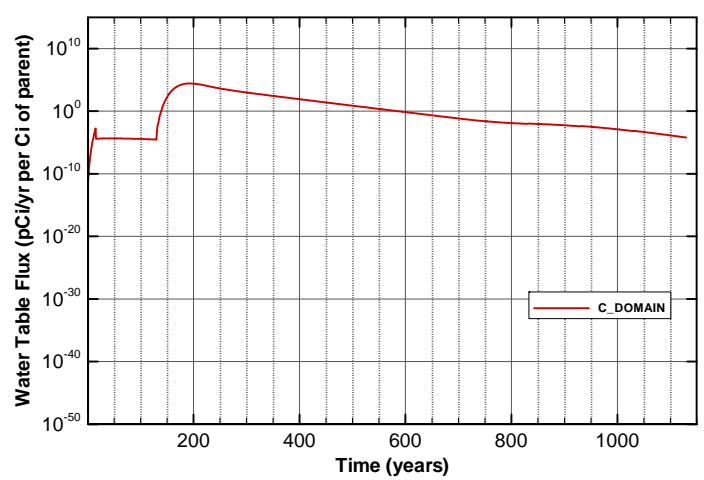

Figure A-44. Flux at water table for Case01n11_off Sr-90_Mk50A 


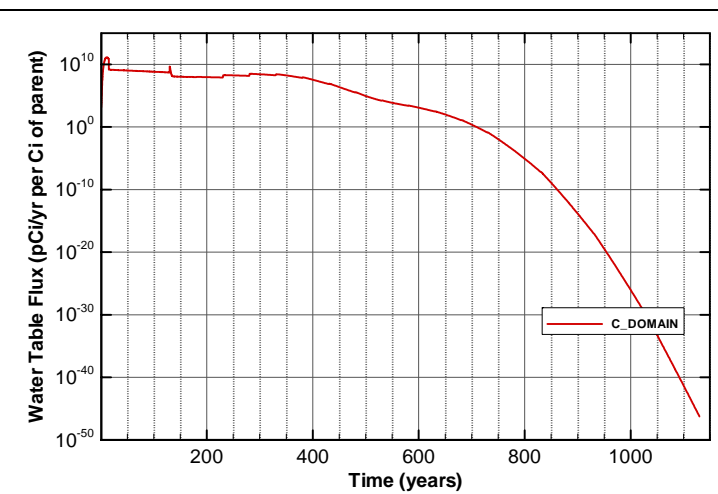

Figure A-45. Flux at water table for Case01n11_off Tc-99

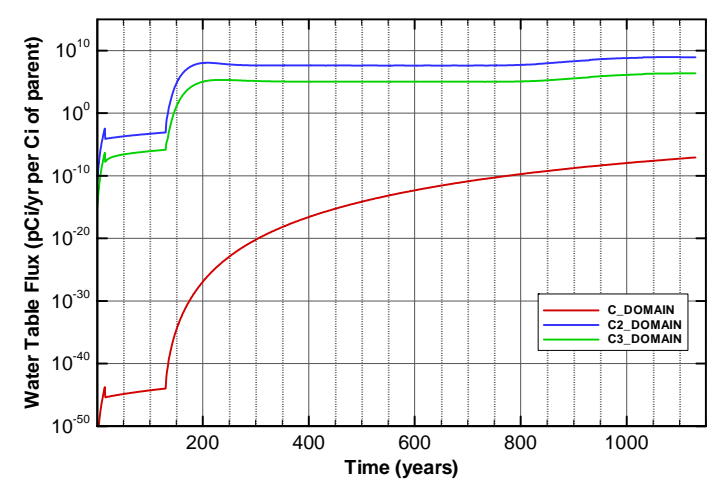

Figure A-47. Flux at water table for Case01n11_off Th-230

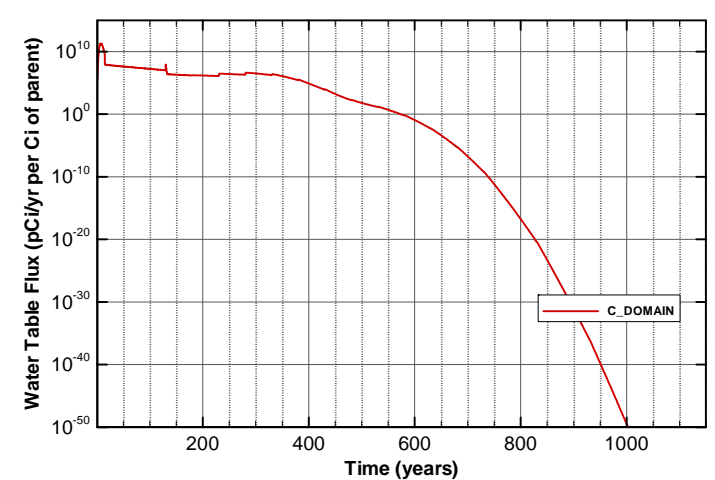

Figure A-49. Flux at water table for Case01n11_off Tracer

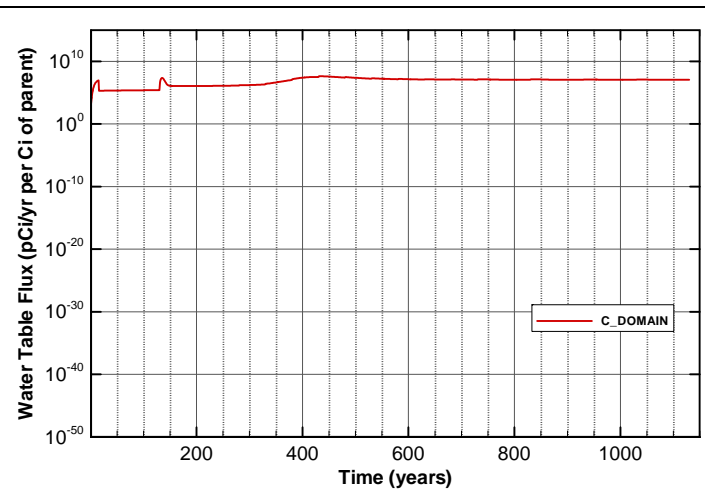

Figure A-46. Flux at water table for Case01n11_off Tc-99_Mk50A

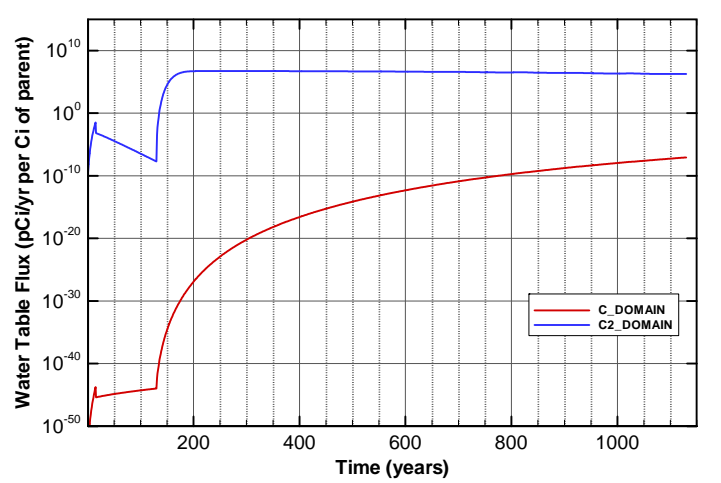

Figure A-48. Flux at water table for Case01n11_off Th-232

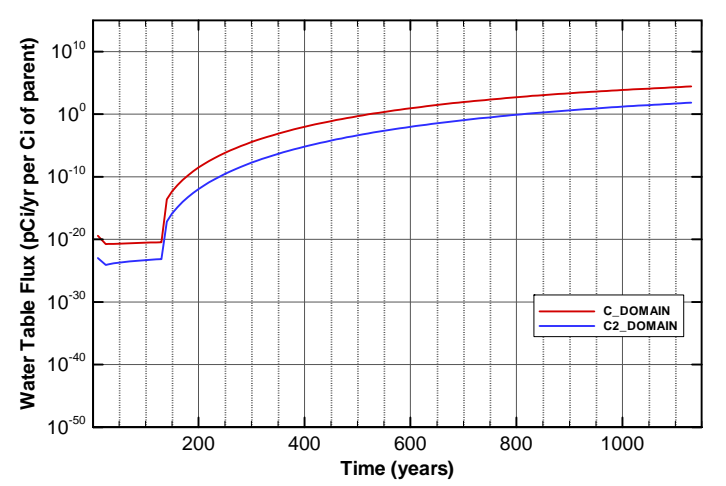

Figure A-50. Flux at water table for Case01n11_off U-233 


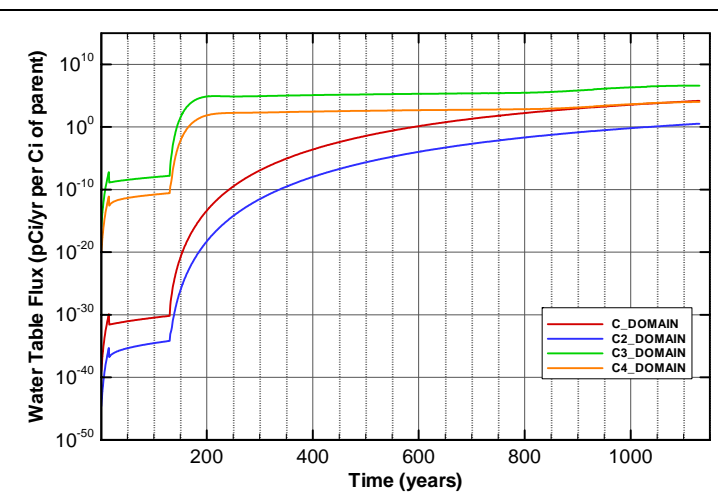

Figure A-51. Flux at water table for Case01n11_off U-234

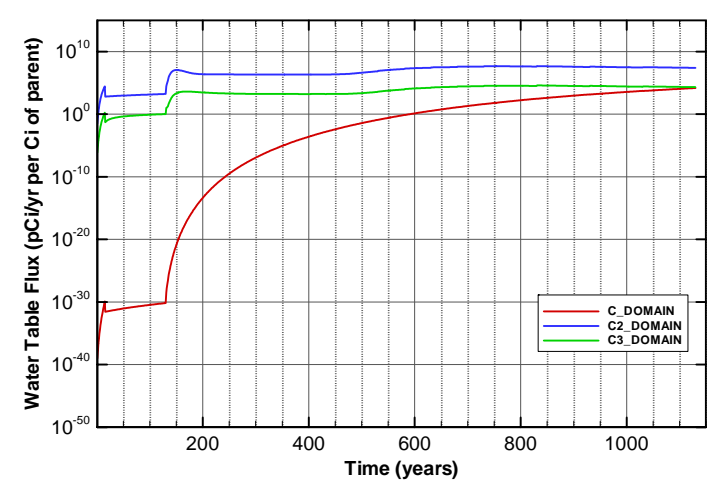

Figure A-53. Flux at water table for Case01n11_off U-235

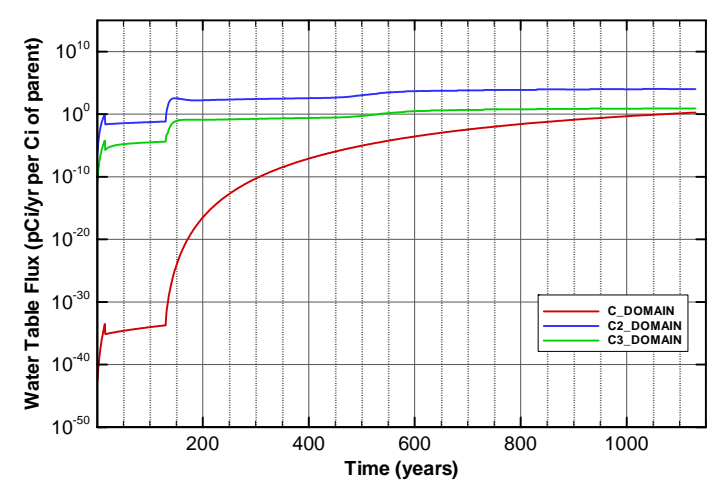

Figure A-55. Flux at water table for Case01n11_off U-235_Paducah.Cask

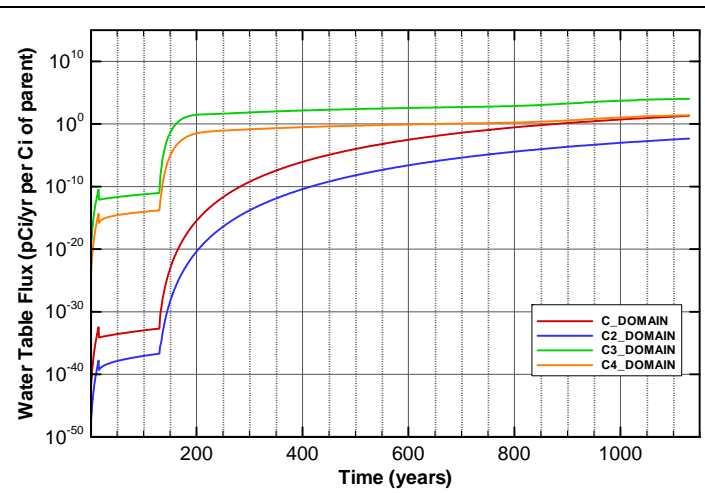

Figure A-52. Flux at water table for Case01n11_off U-234_Mglass

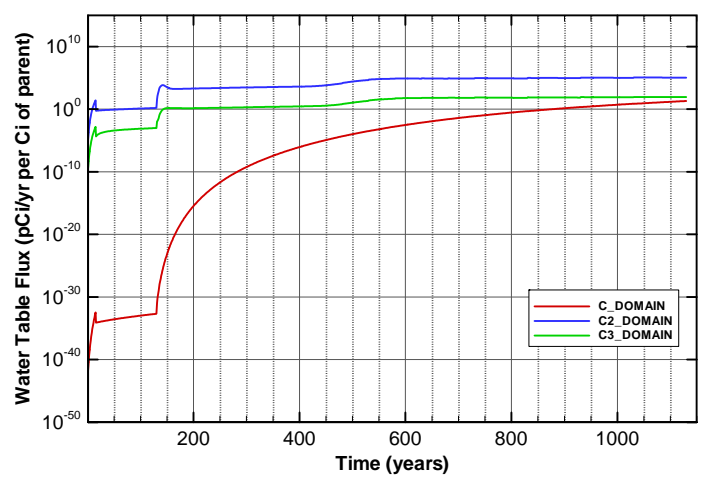

Figure A-54. Flux at water table for Case01n11_off U-235_Mglass

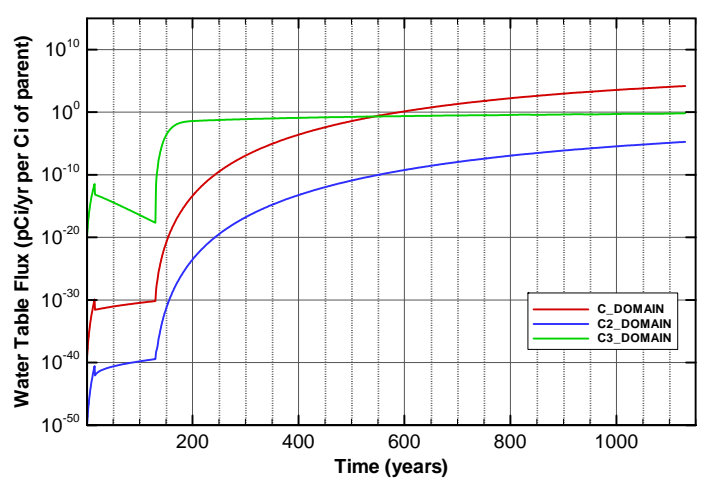

Figure A-56. Flux at water table for Case01n11_off U-236 


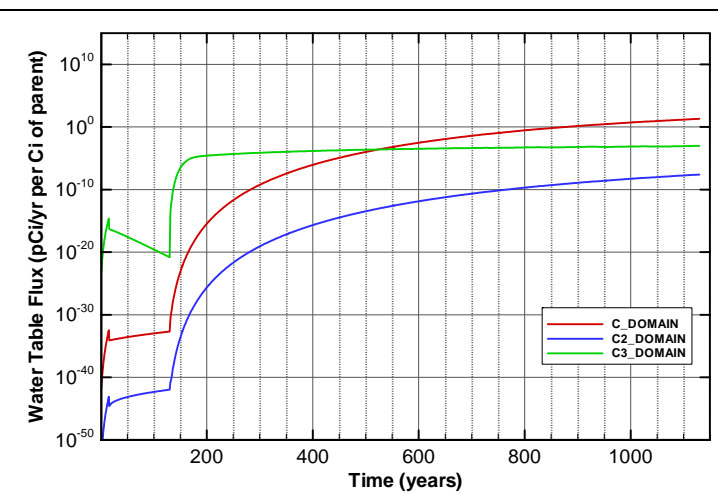

Figure A-57. Flux at water table for Case01n11_off U-236_Mglass

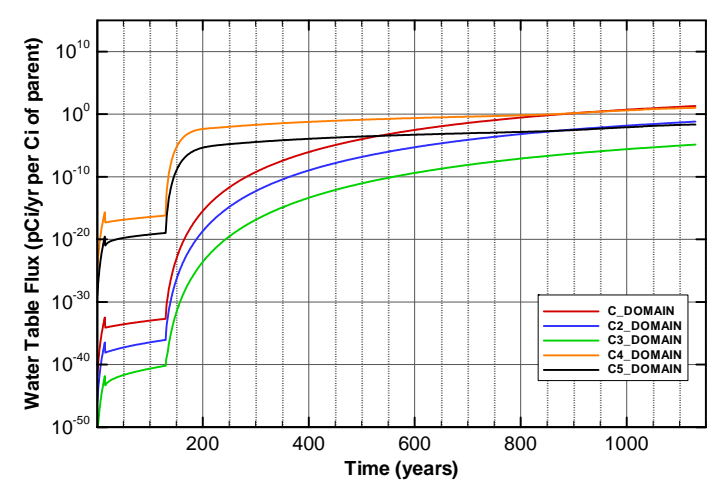

Figure A-59. Flux at water table for Case01n11_off U-238_Mglass

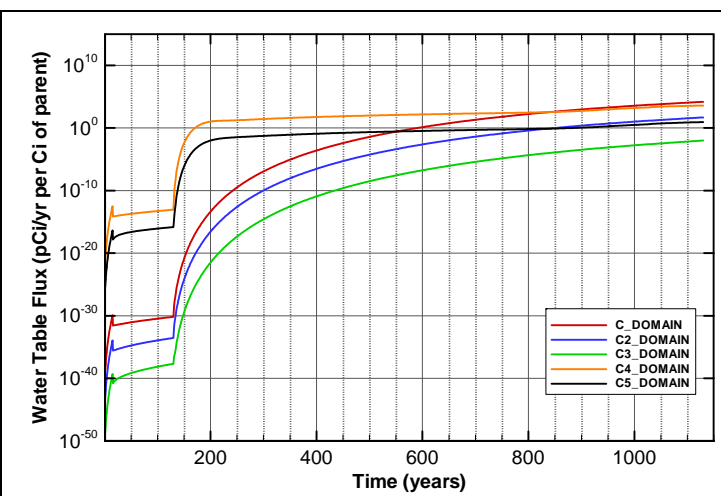

Figure A-58. Flux at water table for Case01n11_off U-238

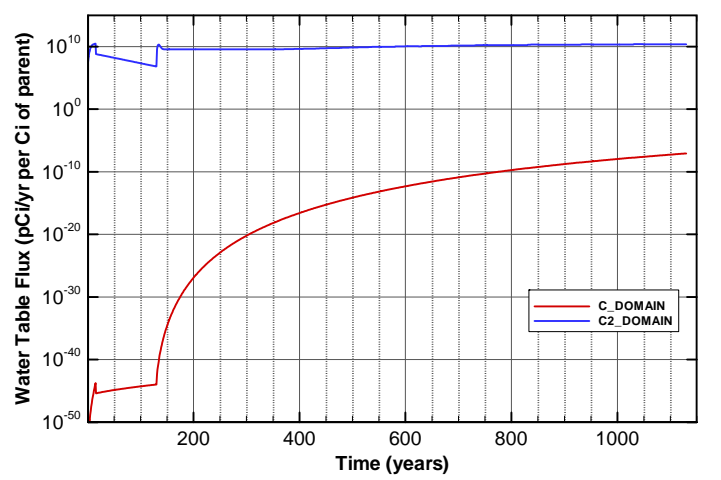

Figure A-60. Flux at water table for Case01n11_off Zr-93

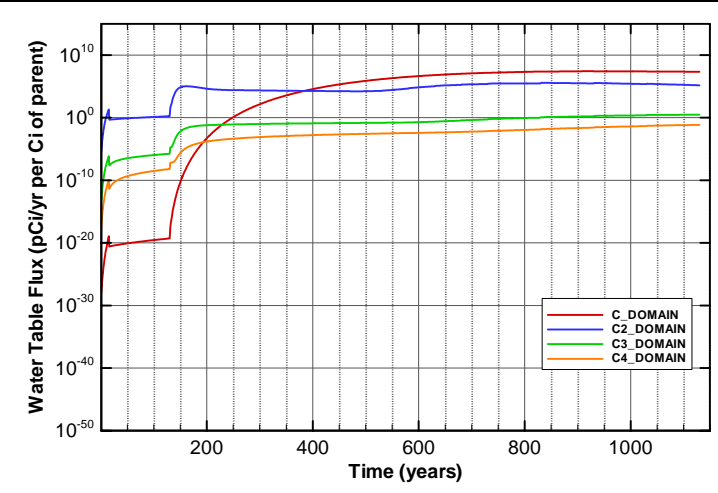

Figure A-61. Flux at water table for Case01n11_on Am-241

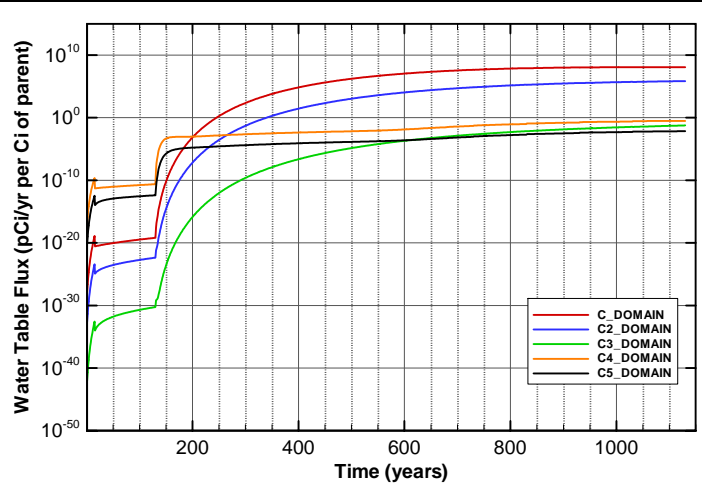

Figure A-62. Flux at water table for Case01n11_on Am-243 
SRNL-STI-2008-00397, REVISION 0

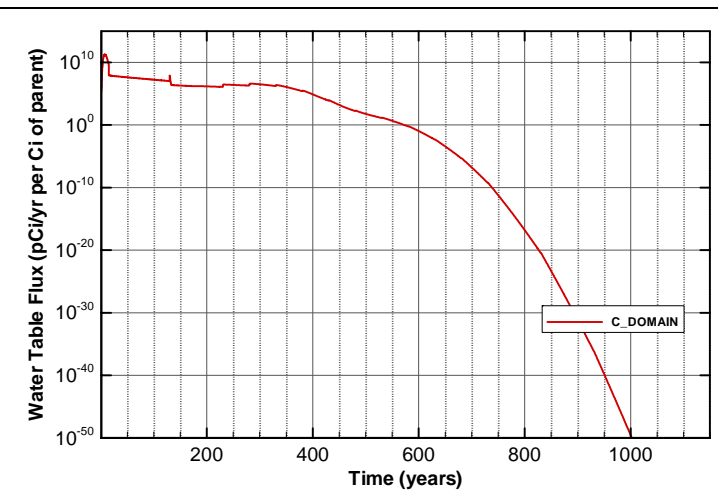

Figure A-63. Flux at water table for Case01n11_on C-14

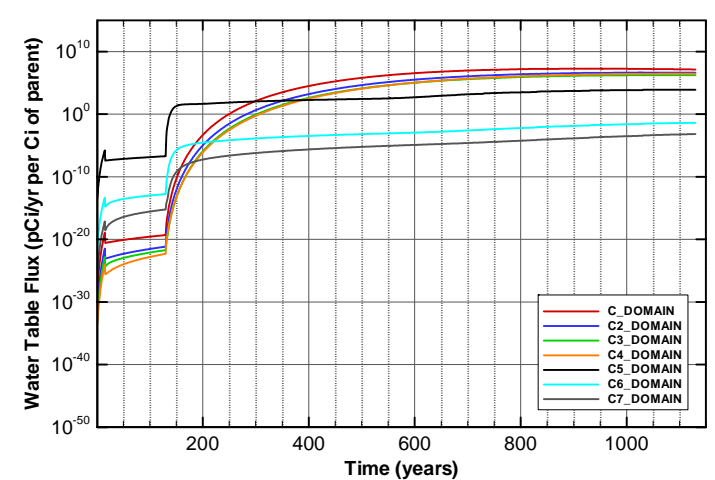

Figure A-65. Flux at water table for Case01n11_on Cf-249

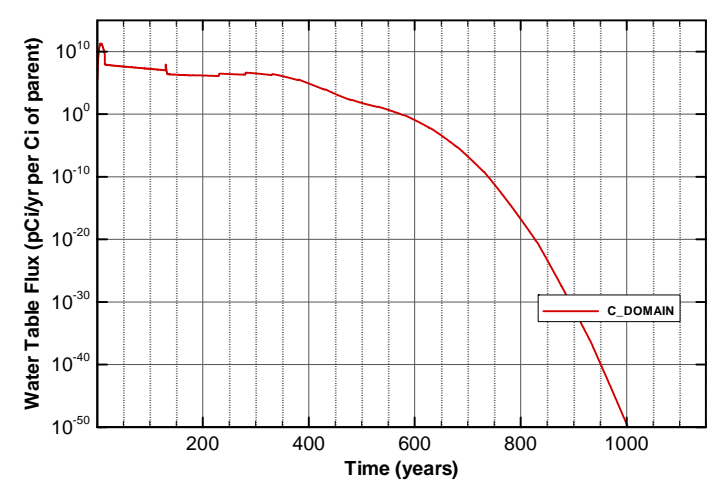

Figure A-67. Flux at water table for Case01n11_on Cl-36

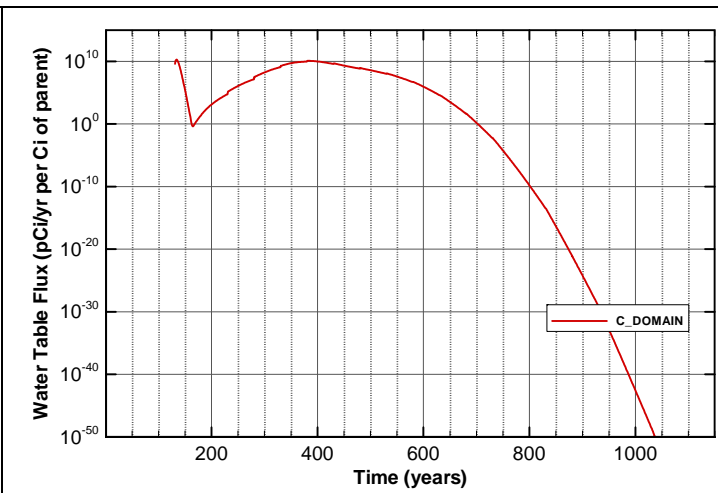

Figure A-64. Flux at water table for Case01n11_on C-14_NR.Pump

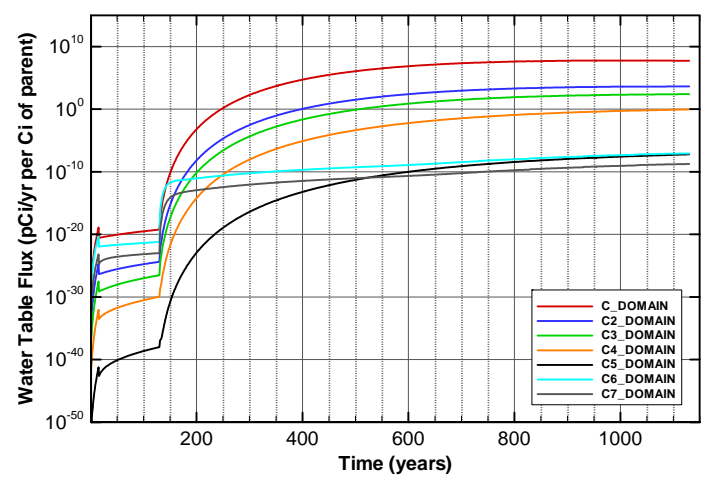

Figure A-66. Flux at water table for Case01n11_on Cf-251

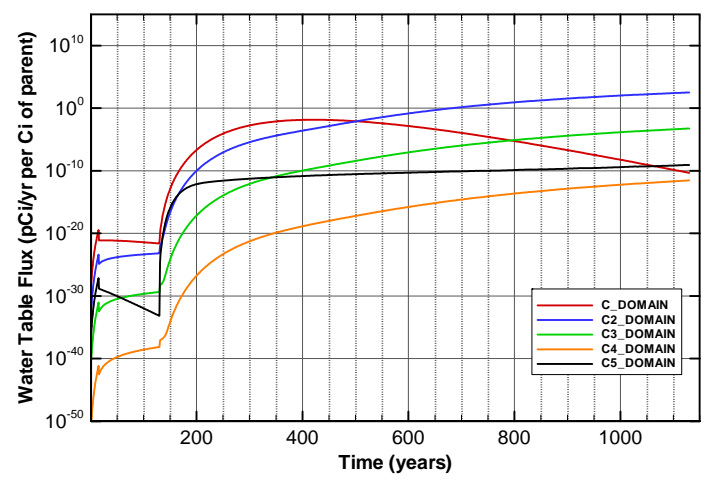

Figure A-68. Flux at water table for Case01n11_on Cm-244 


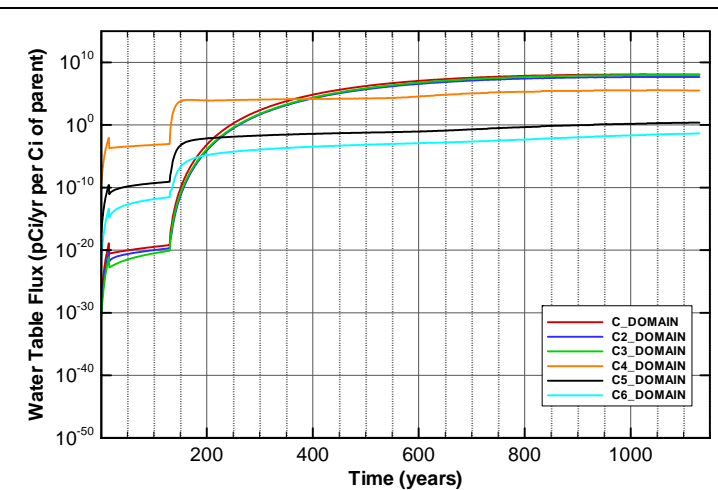

Figure A-69. Flux at water table for Case01n11_on Cm-245

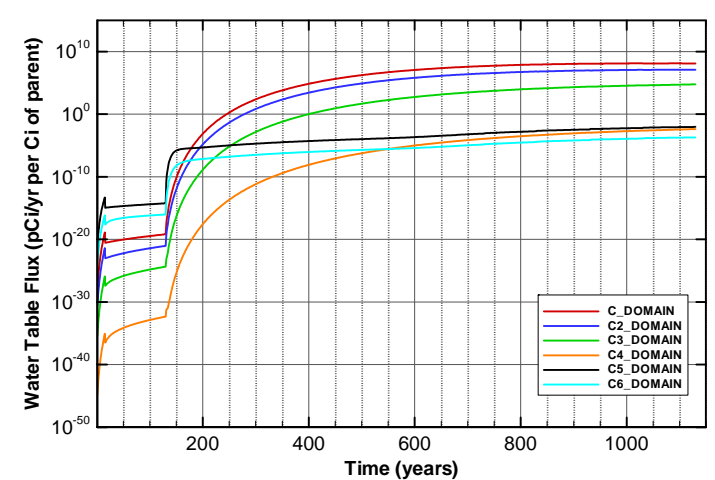

Figure A-71. Flux at water table for Case01n11_on Cm-247

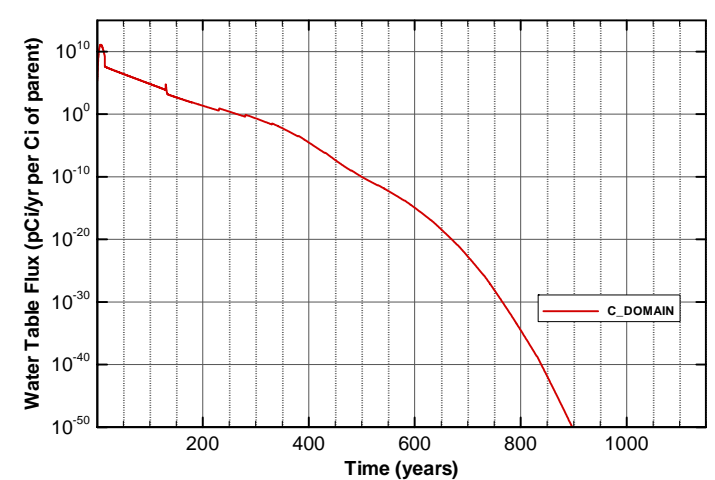

Figure A-73. Flux at water table for Case01n11_on H-3

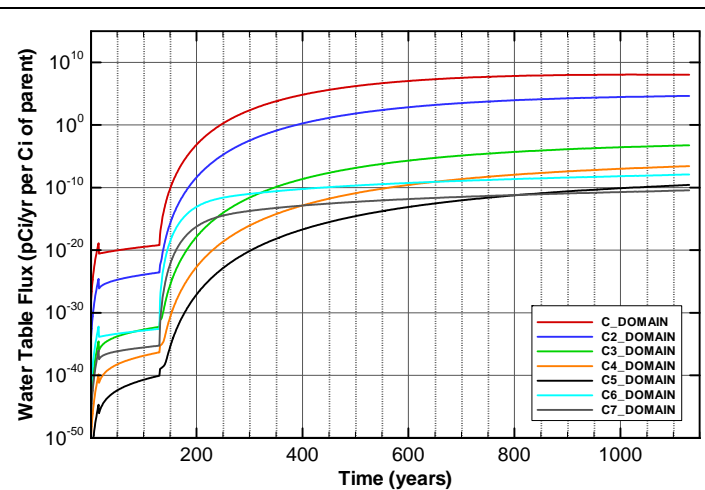

Figure A-70. Flux at water table for Case01n11_on Cm-246

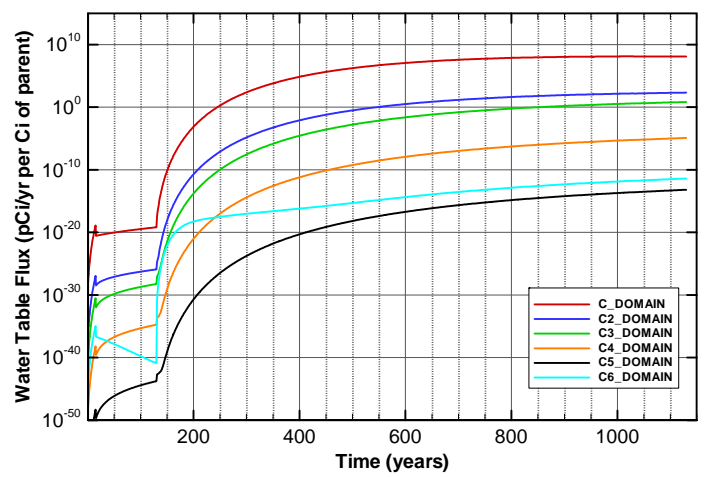

Figure A-72. Flux at water table for Case01n11_on Cm-248

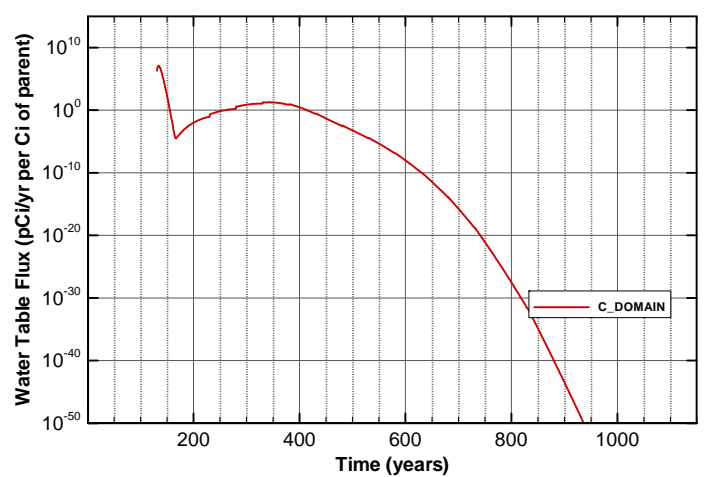

Figure A-74. Flux at water table for Case01n11_on H-3_ETF.Carbon 


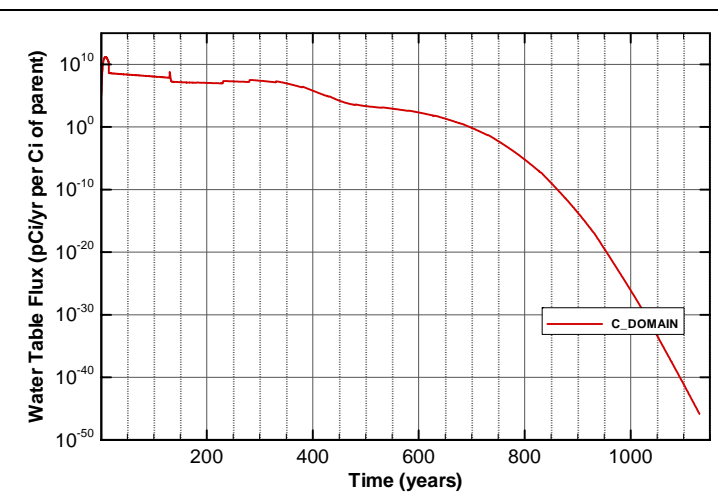

Figure A-75. Flux at water table for Case01n11_on I-129

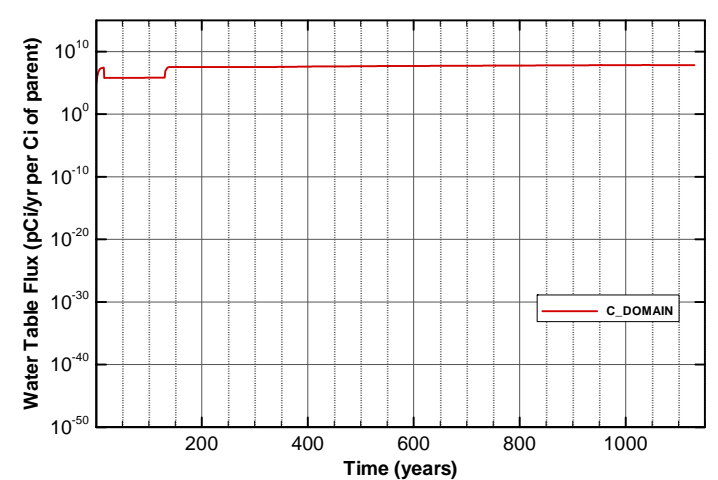

Figure A-77. Flux at water table for Case01n11_on I-129_ETF.GT.73

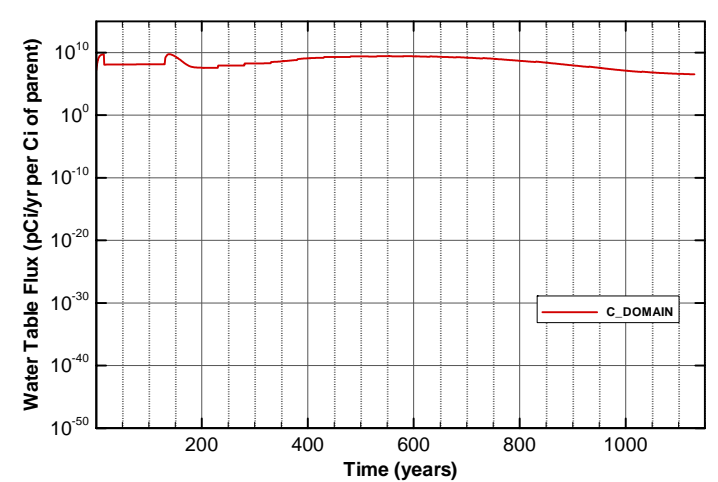

Figure A-79. Flux at water table for Case01n11_on I-129_F.CG.8

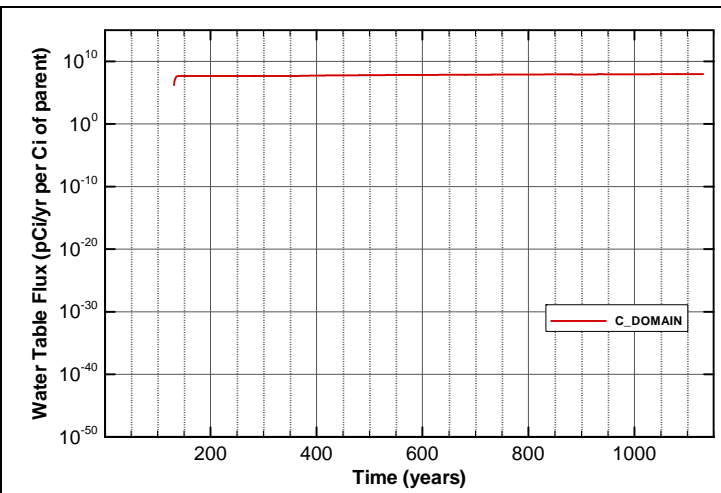

Figure A-76. Flux at water table for Case01n11_on I-129_ETF.Carbon

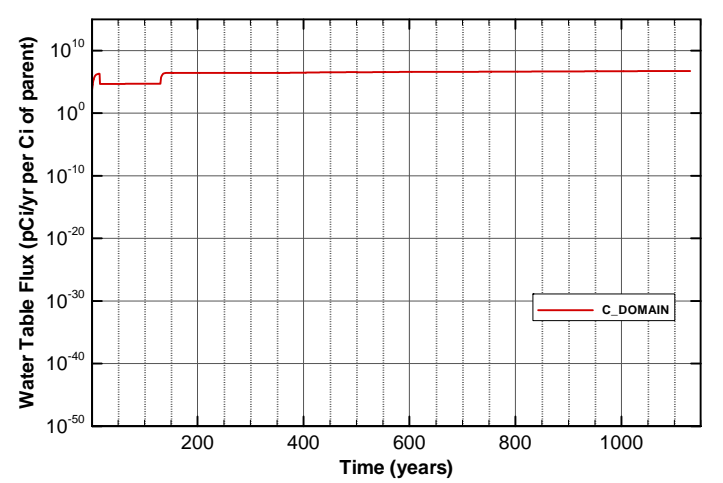

Figure A-78. Flux at water table for Case01n11_on I-129_F.Carbon

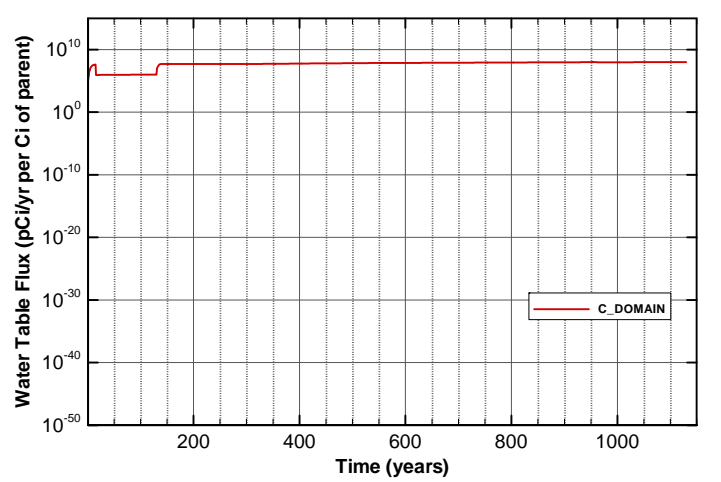

Figure A-80. Flux at water table for Case01n11_on I-129_F.Dowex.21K 


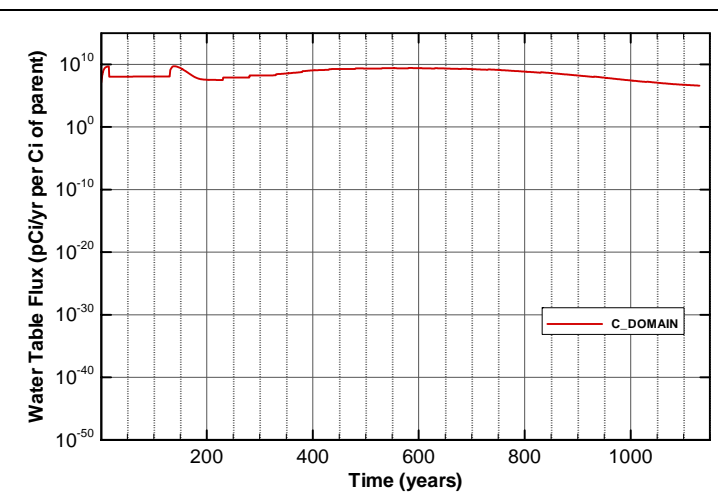

Figure A-81. Flux at water table for Case01n11_on I-129_F.Filtercake

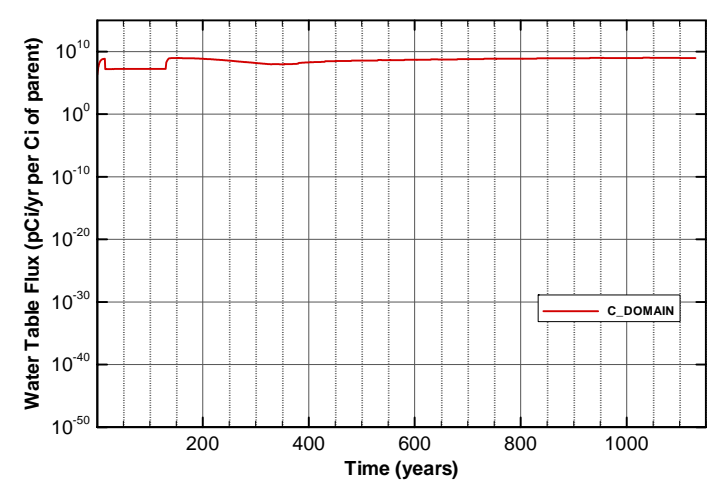

Figure A-83. Flux at water table for Case01n11_on I-129_H.CG.8

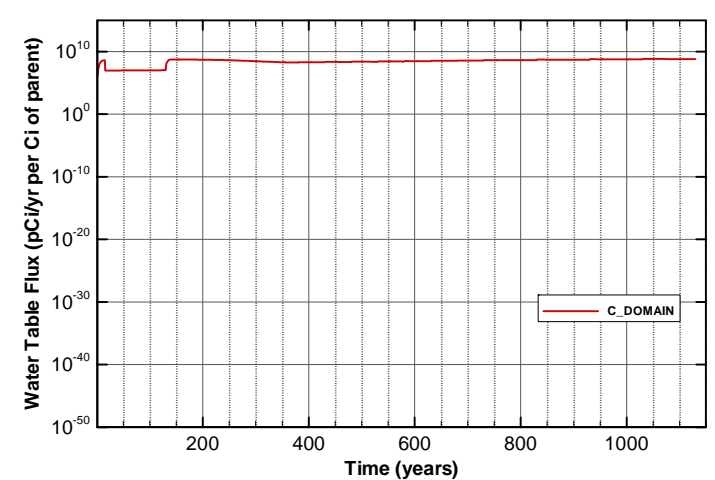

Figure A-85. Flux at water table for Case01n11_on I-129_H.Filtercake

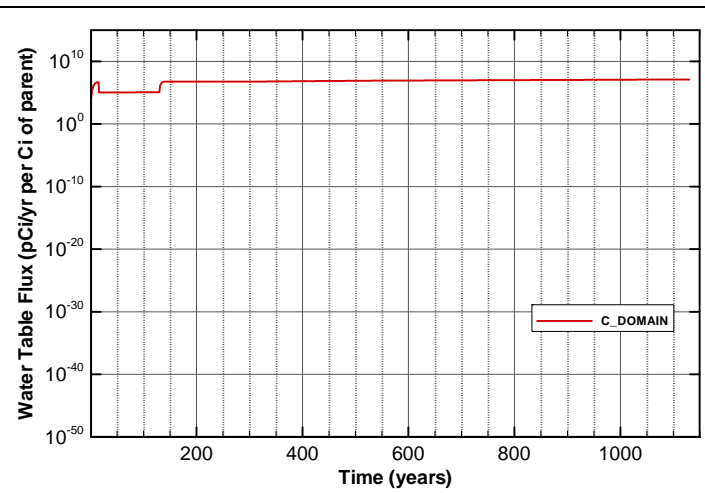

Figure A-82. Flux at water table for Case01n11_on I-129_H.Carbon

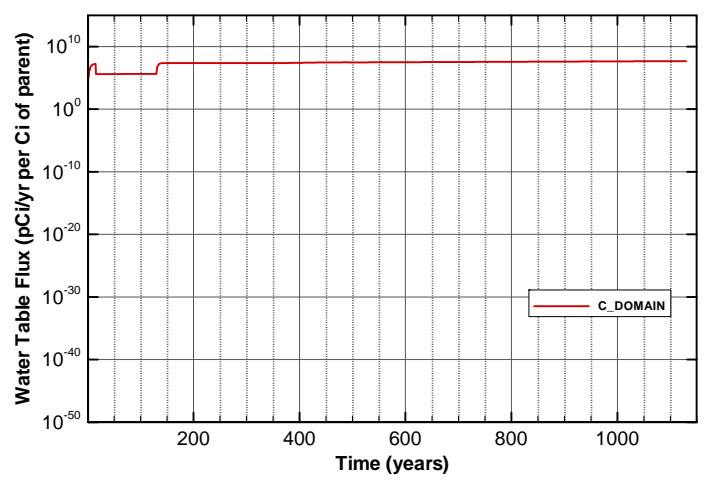

Figure A-84. Flux at water table for Case01n11_on I-129_H.Dowex.21K

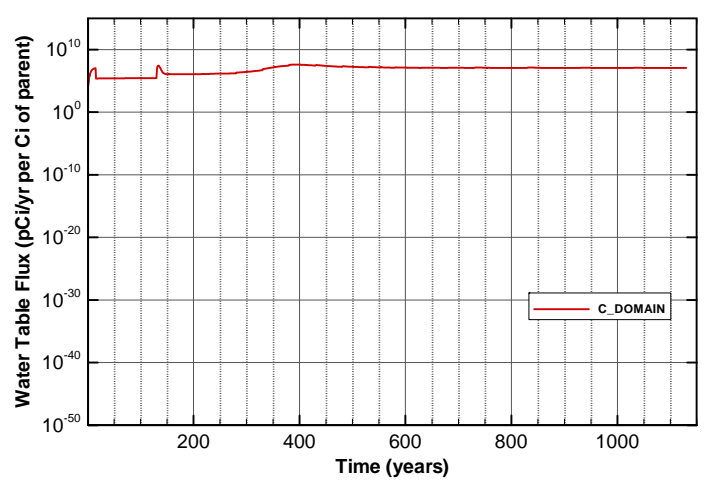

Figure A-86. Flux at water table for Case01n11_on I-129_Mk50A 


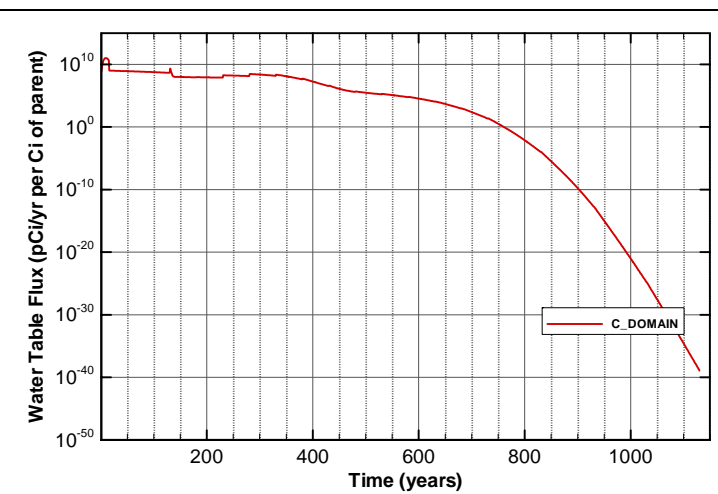

Figure A-87. Flux at water table for Case01n11_on K-40

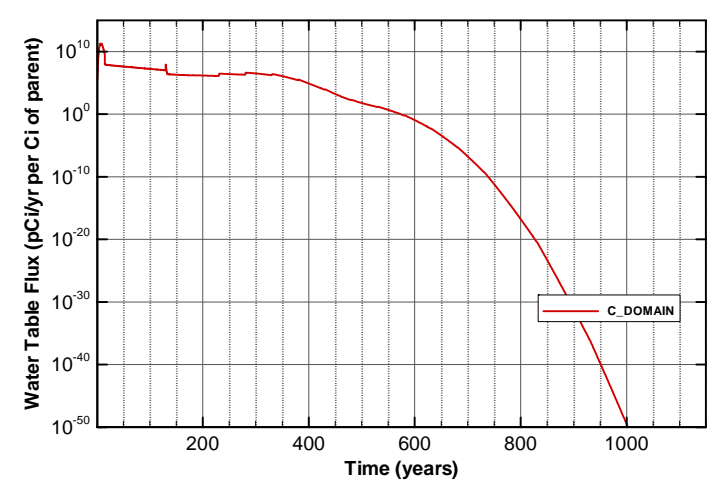

Figure A-89. Flux at water table for Case01n11_on Nb-94

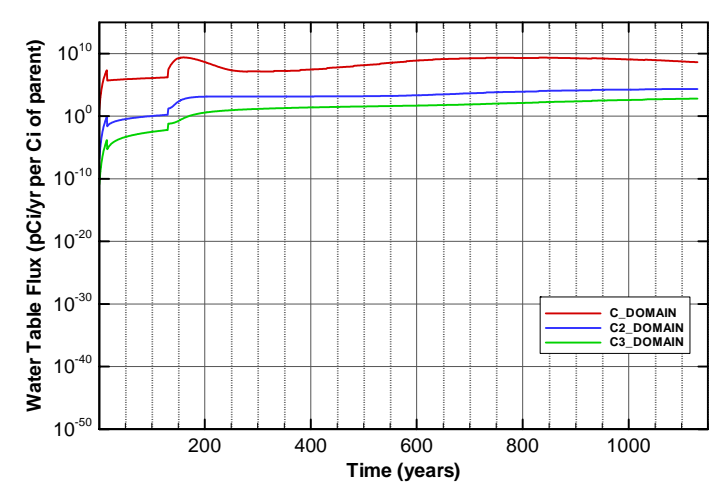

Figure A-91. Flux at water table for Case01n11_on Np-237

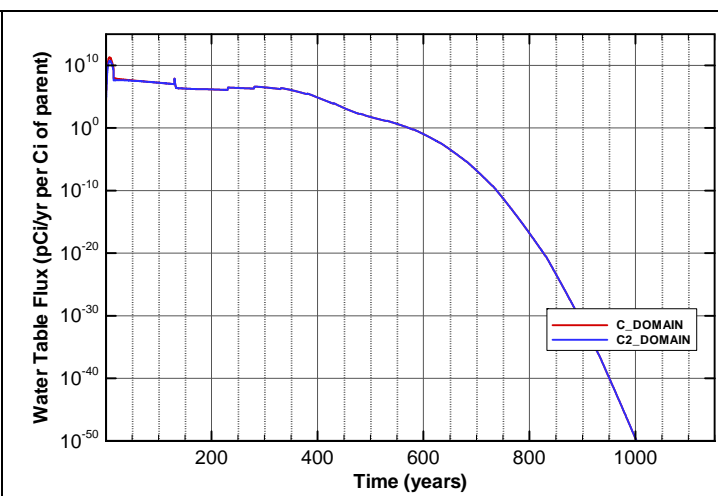

Figure A-88. Flux at water table for Case01n11_on Mo-93

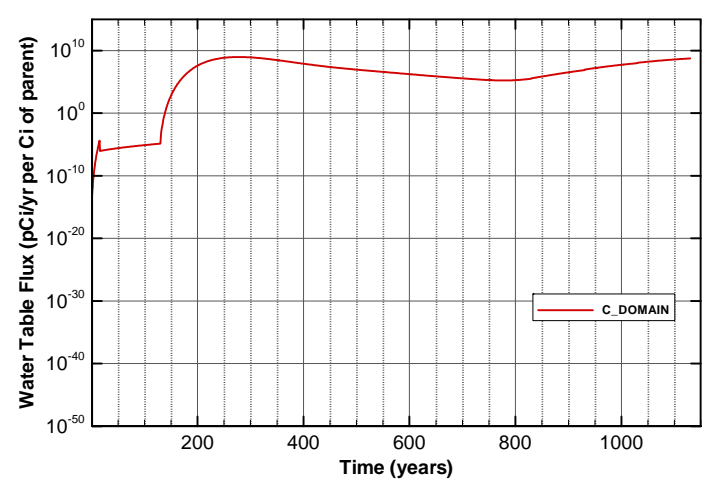

Figure A-90. Flux at water table for Case01n11_on Ni-59

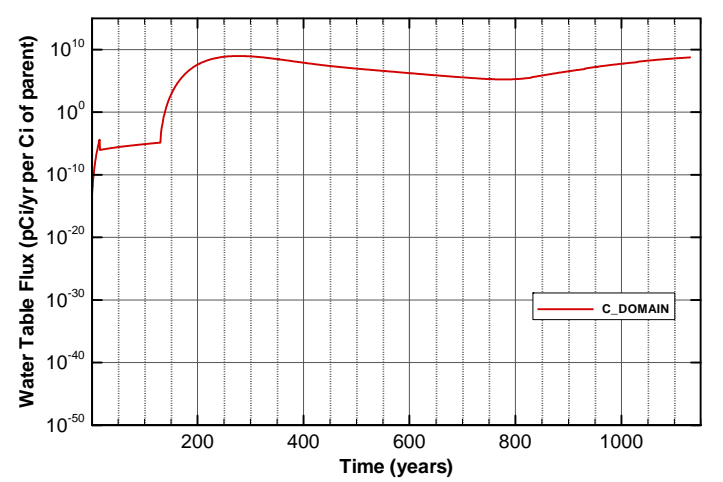

Figure A-92. Flux at water table for Case01n11_on Pd-107 
SRNL-STI-2008-00397, REVISION 0
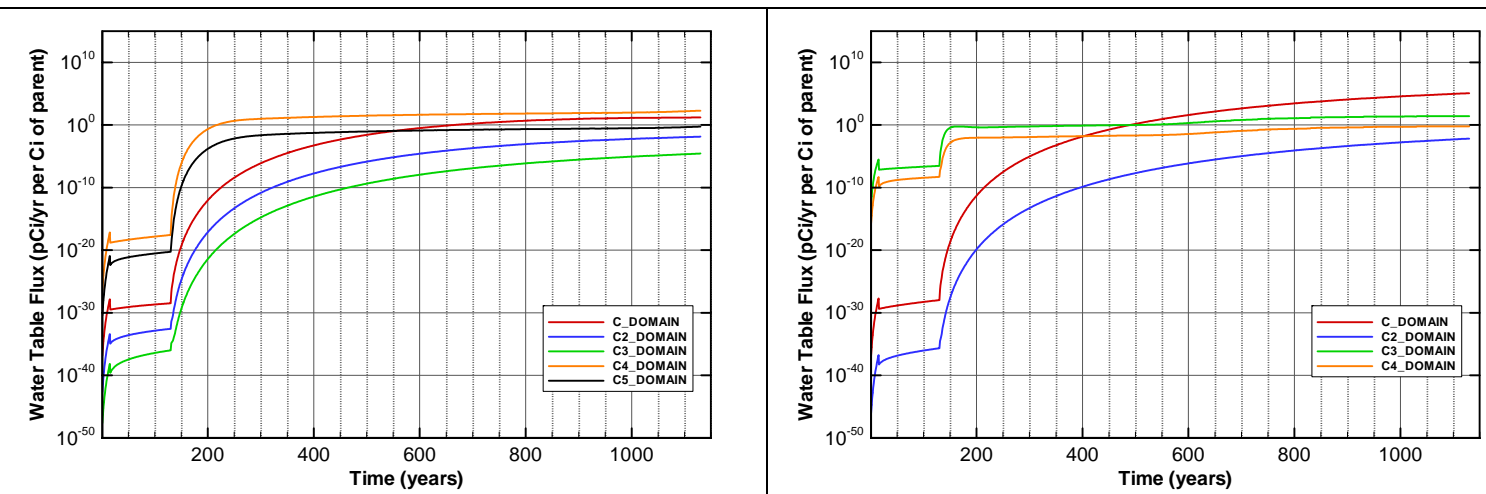

Figure A-93. Flux at water table for Case01n11_on Pu-238

Figure A-94. Flux at water table for Case01n11_on Pu-239

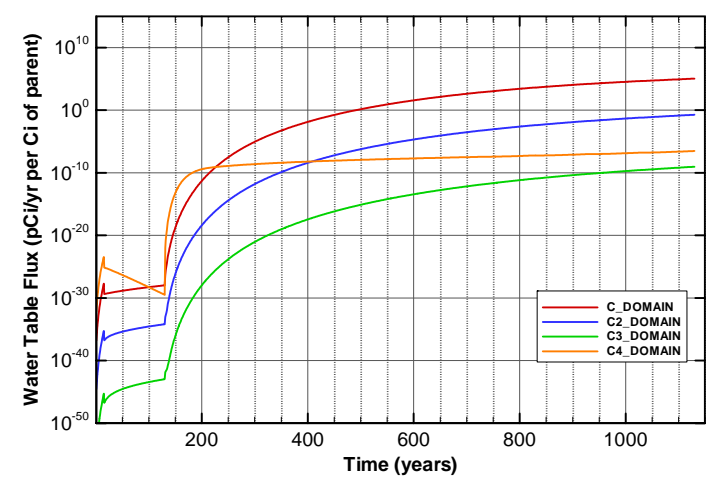

Figure A-95. Flux at water table for Case01n11_on Pu-240

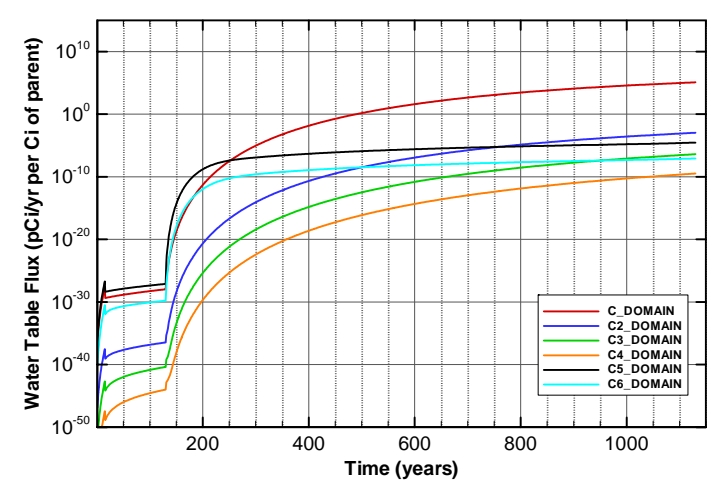

Figure A-97. Flux at water table for Case01n11_on Pu-242

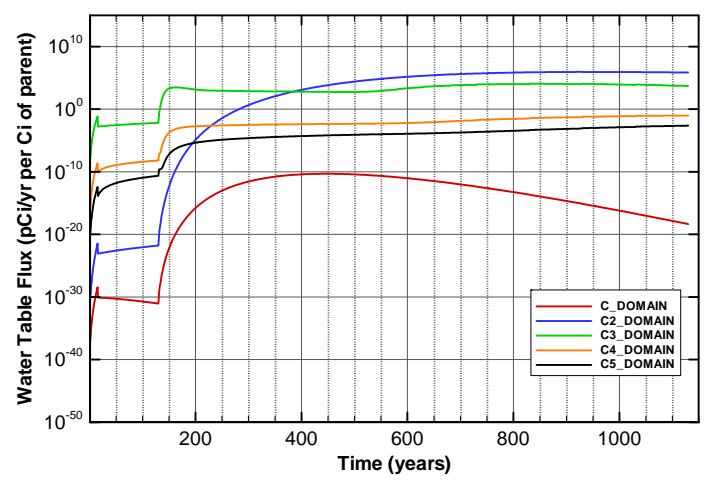

Figure A-96. Flux at water table for Case01n11_on Pu-241

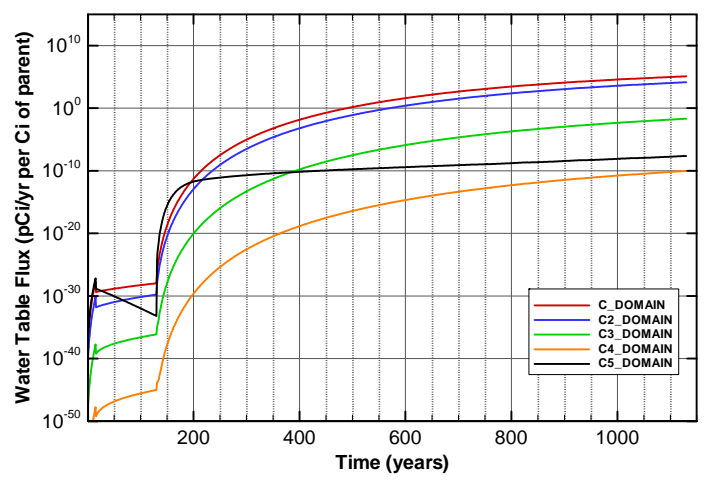

Figure A-98. Flux at water table for Case01n11_on Pu-244 


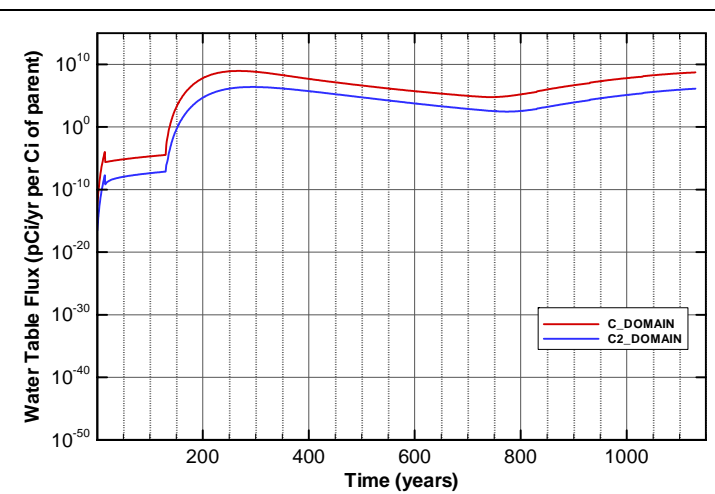

Figure A-99. Flux at water table for Case01n11_on Ra-226

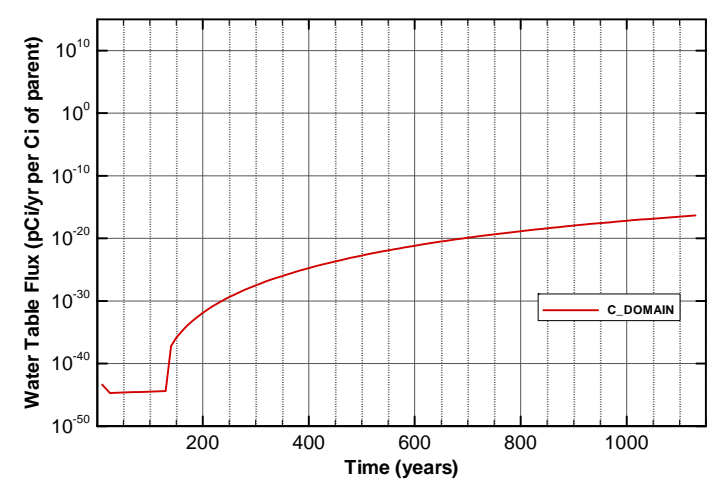

Figure A-101. Flux at water table for Case01n11_on Sn-126

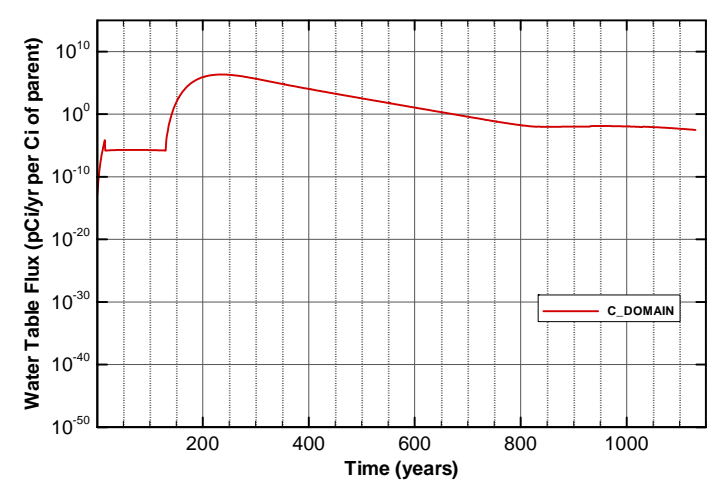

Figure A-103. Flux at water table for Case01n11_on Sr-90_Cask

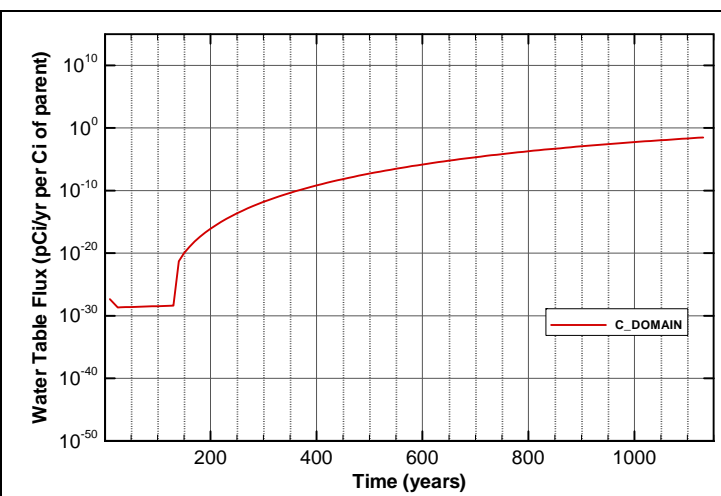

Figure A-100. Flux at water table for Case01n11_on Se-79

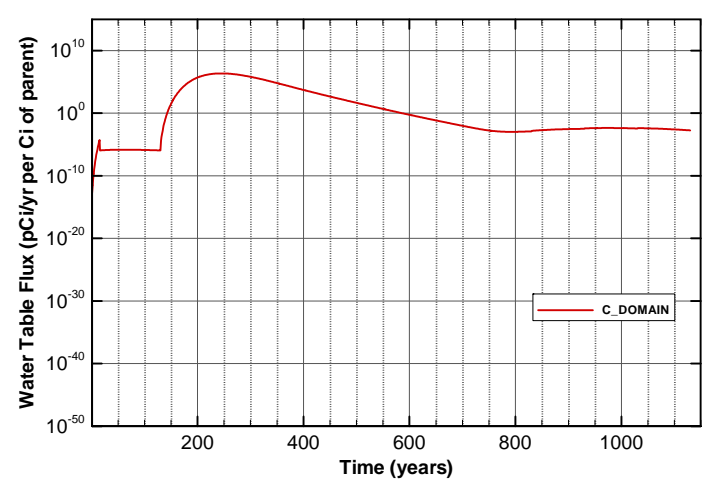

Figure A-102. Flux at water table for Case01n11_on Sr-90

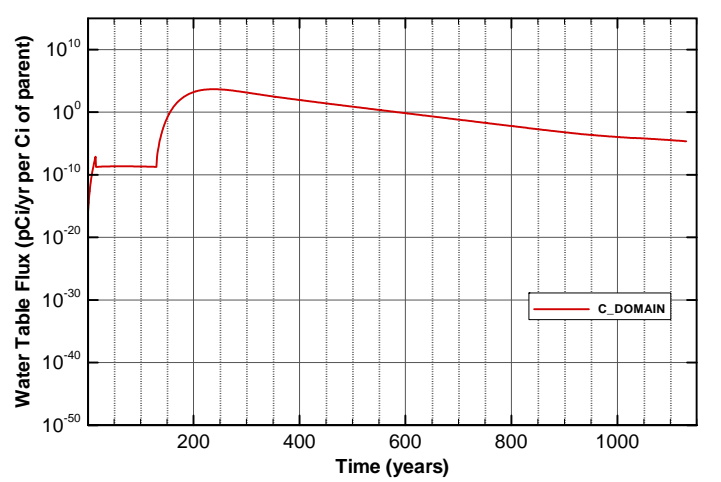

Figure A-104. Flux at water table for Case01n11_on Sr-90_Mk50A 


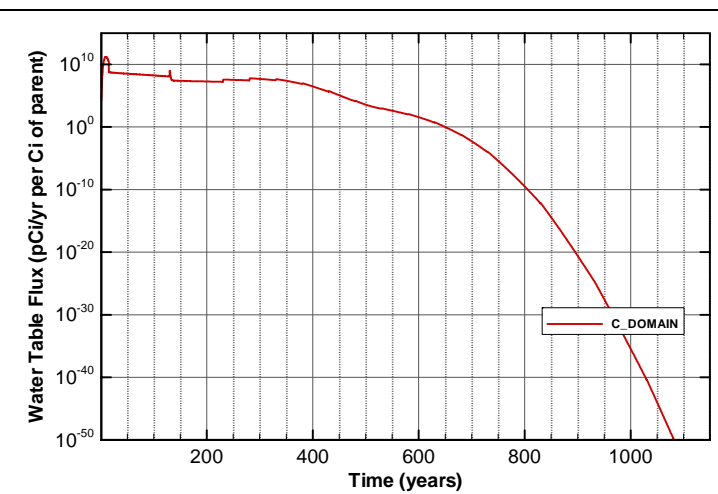

Figure A-105. Flux at water table for Case01n11_on Tc-99

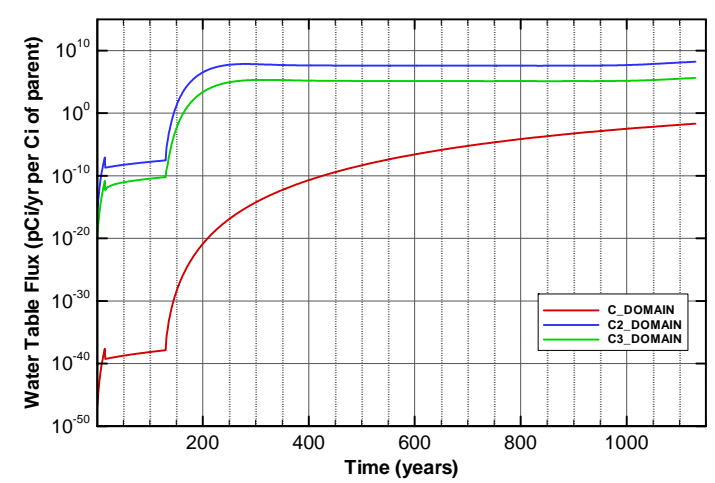

Figure A-107. Flux at water table for Case01n11_on Th-230

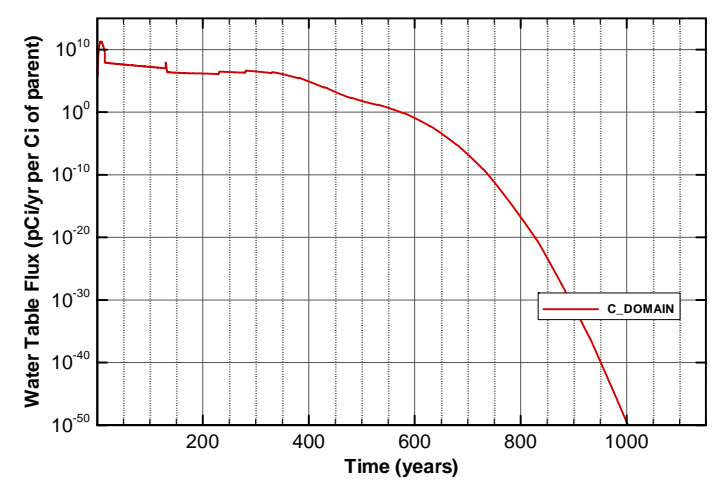

Figure A-109. Flux at water table for Case01n11_on Tracer

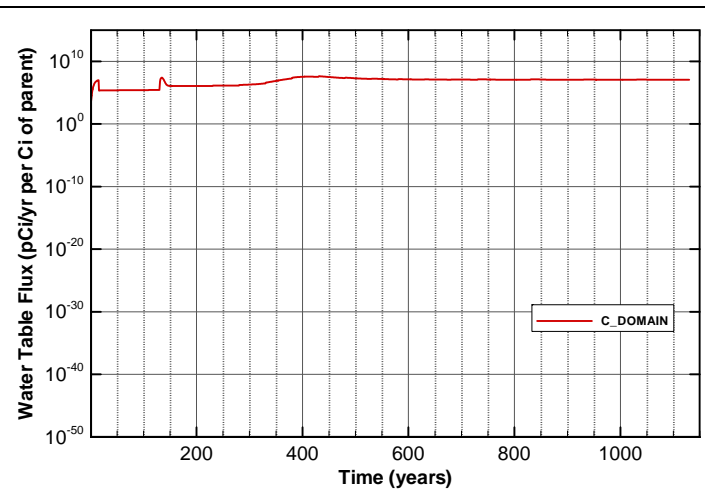

Figure A-106. Flux at water table for Case01n11_on Tc-99_Mk50A

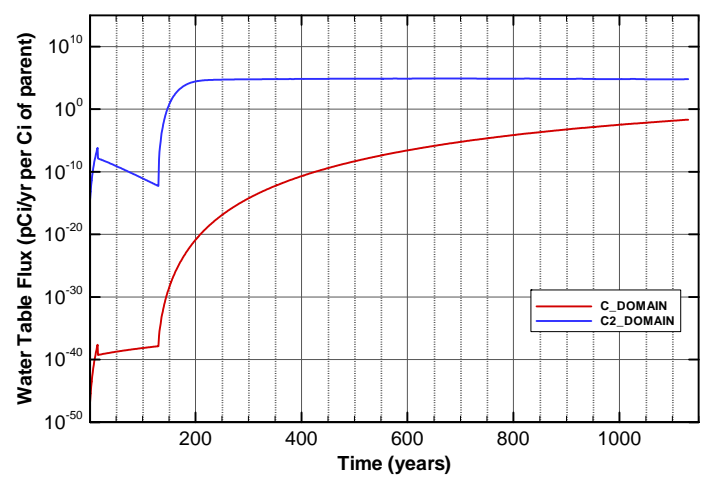

Figure A-108. Flux at water table for Case01n11_on Th-232

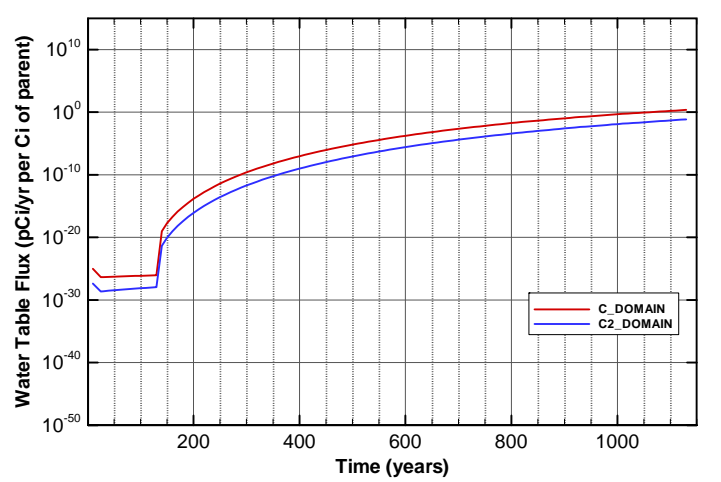

Figure A-110. Flux at water table for Case01n11_on U-233 


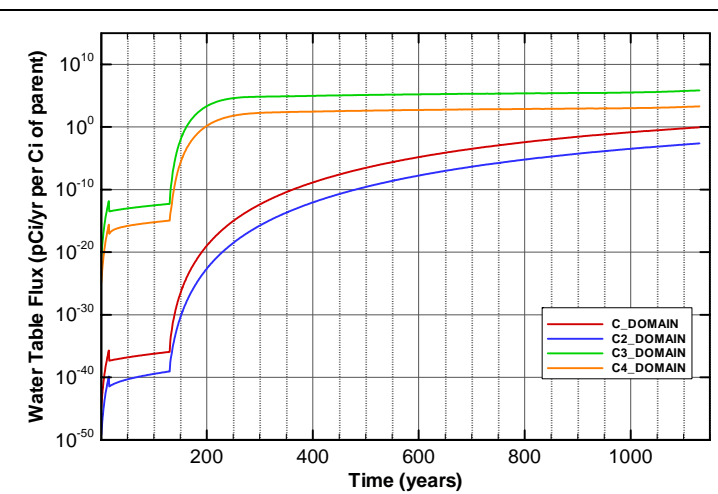

Figure A-111. Flux at water table for Case01n11_on U-234

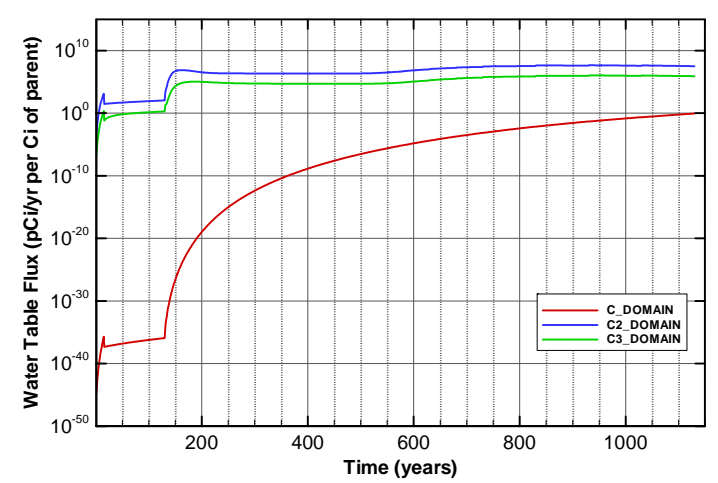

Figure A-113. Flux at water table for Case01n11_on U-235

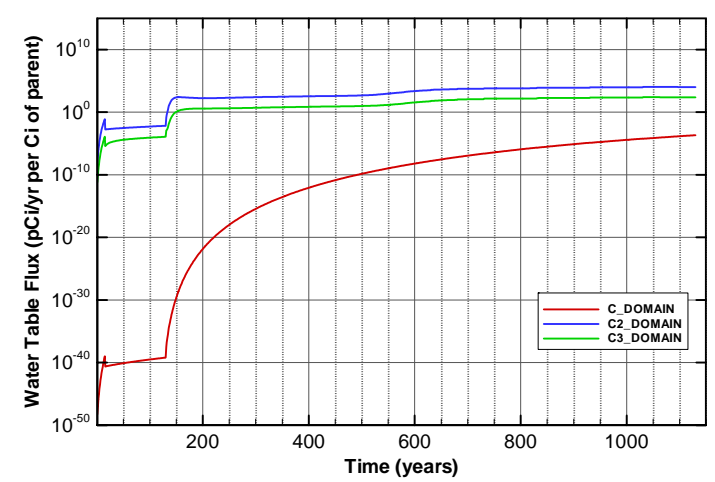

Figure A-115. Flux at water table for Case01n11_on U-235_Paducah.Cask

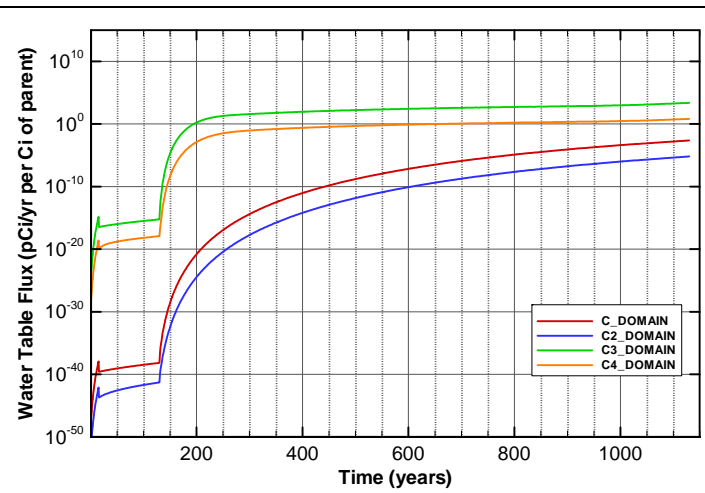

Figure A-112. Flux at water table for Case01n11_on U-234_Mglass

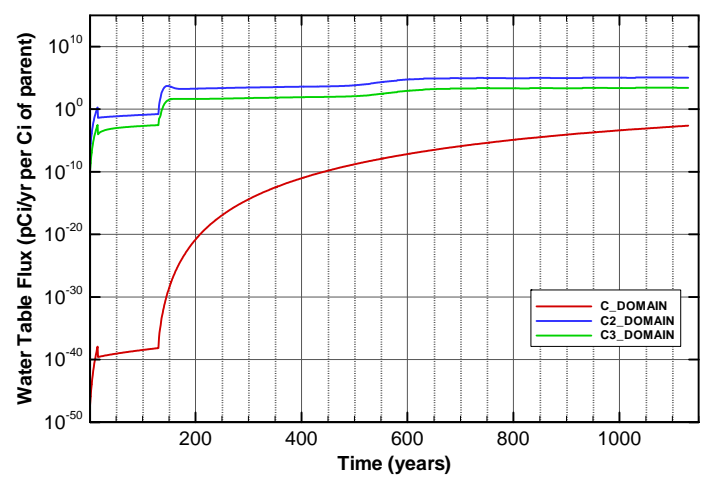

Figure A-114. Flux at water table for Case01n11_on U-235_Mglass

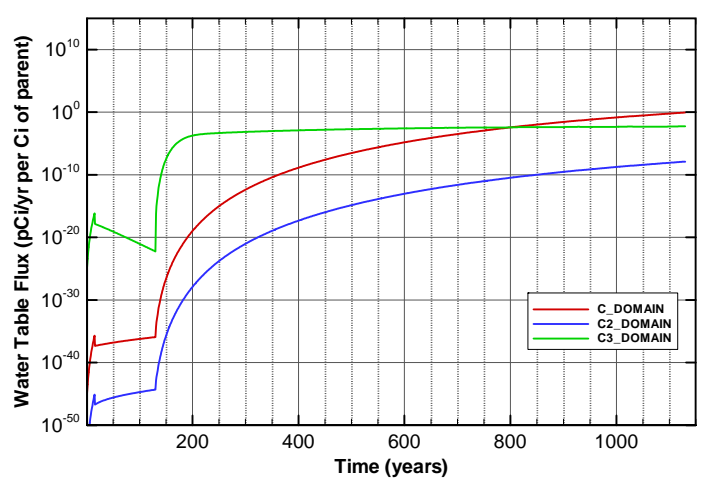

Figure A-116. Flux at water table for Case01n11_on U-236 


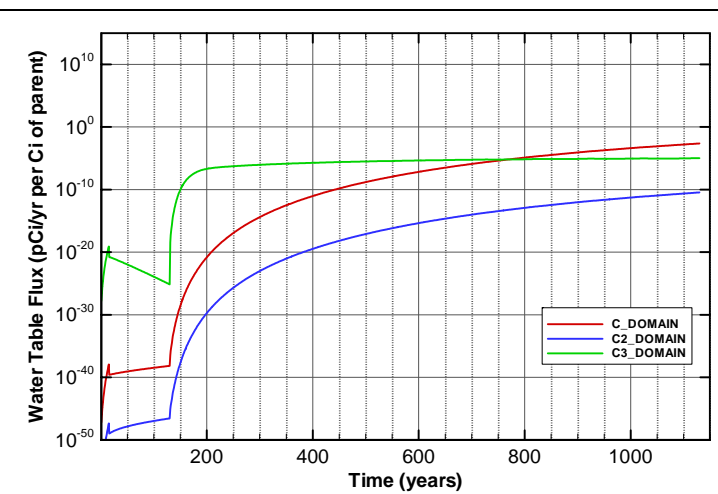

Figure A-117. Flux at water table for Case01n11_on U-236_Mglass

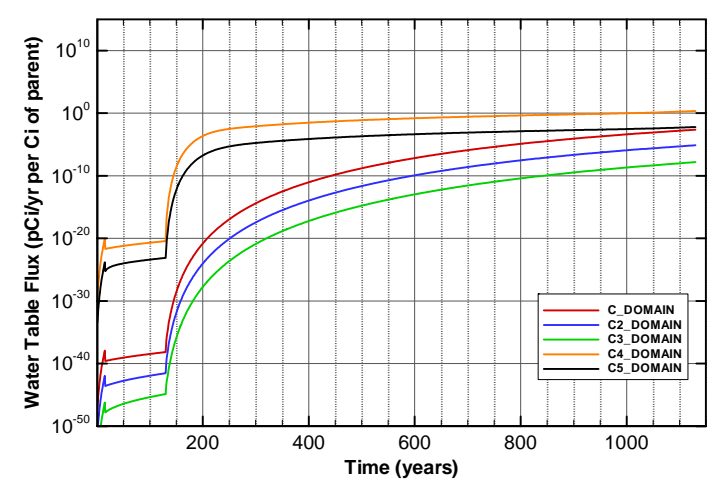

Figure A-119. Flux at water table for Case01n11_on U-238_Mglass

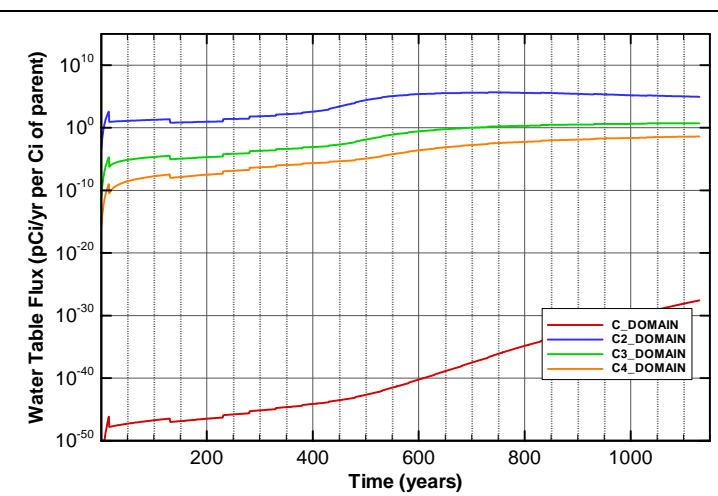

Figure A-121. Flux at water table for Case01_off Am-241

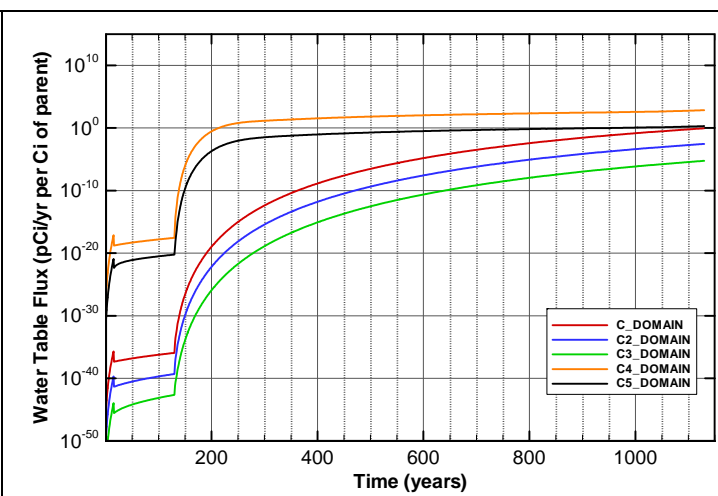

Figure A-118. Flux at water table for Case01n11_on U-238

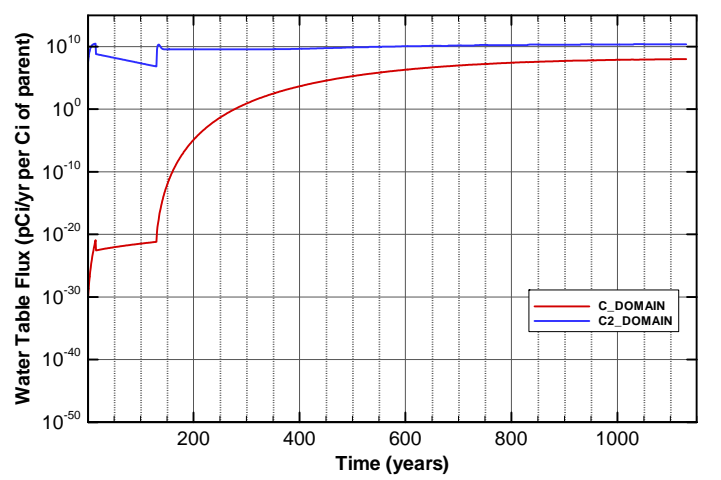

Figure A-120. Flux at water table for Case01n11_on Zr-93

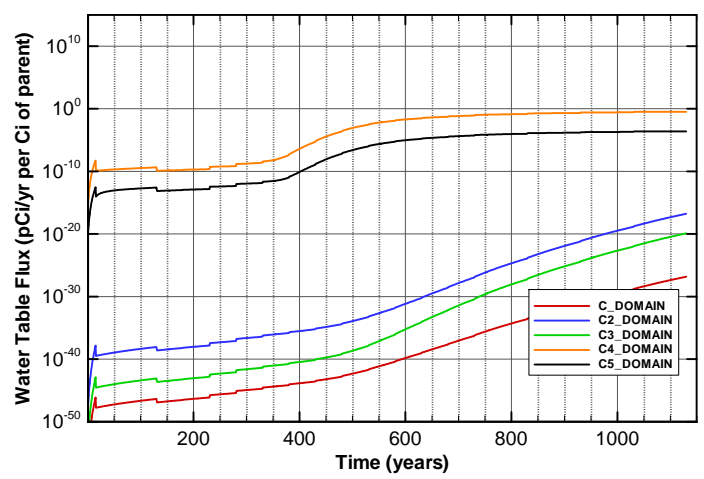

Figure A-122. Flux at water table for Case01_off Am-243 
SRNL-STI-2008-00397, REVISION 0
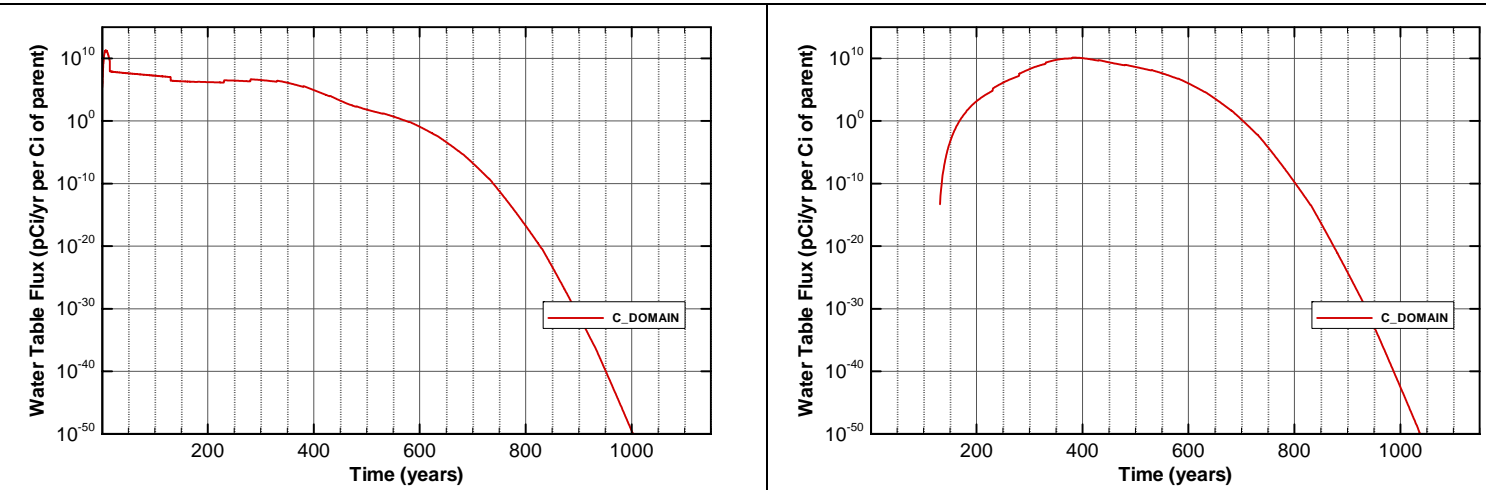

Figure A-123. Flux at water table for Case01_off C-14

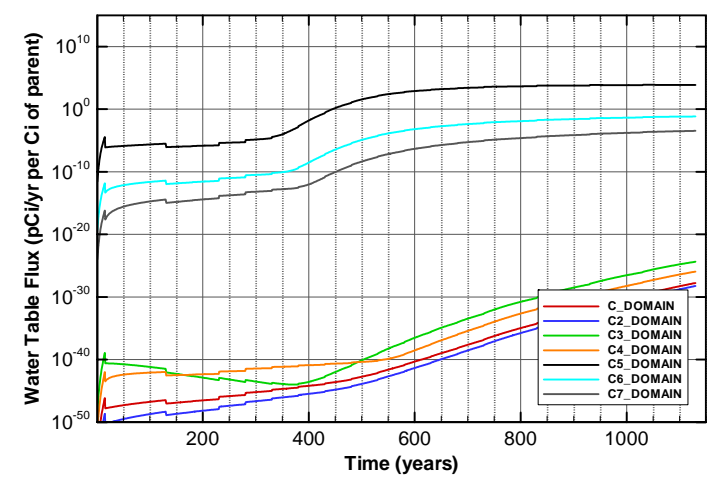

Figure A-125. Flux at water table for Case01_off Cf-249

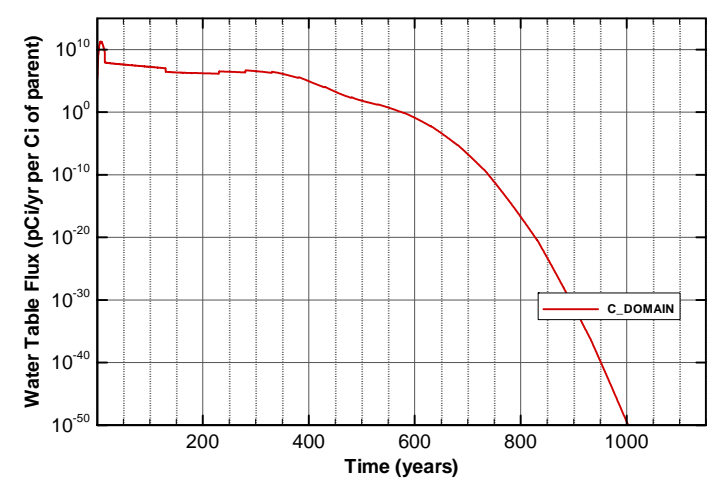

Figure A-127. Flux at water table for Case01_off Cl-36

Figure A-124. Flux at water table for Case01_off C-14_NR.Pump

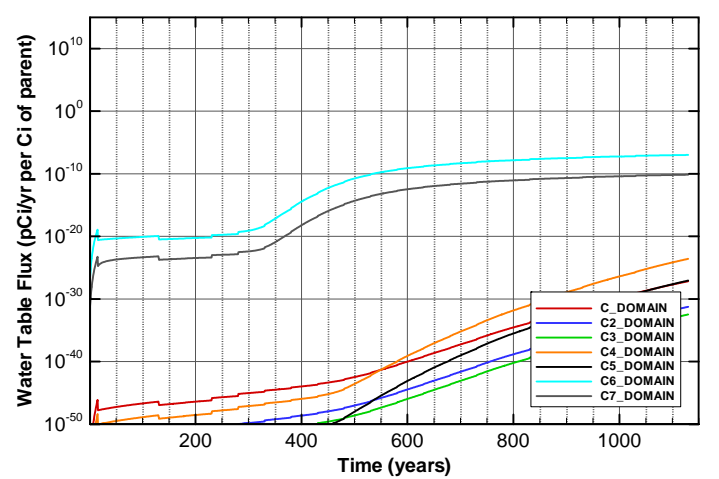

Figure A-126. Flux at water table for Case01_off Cf-251

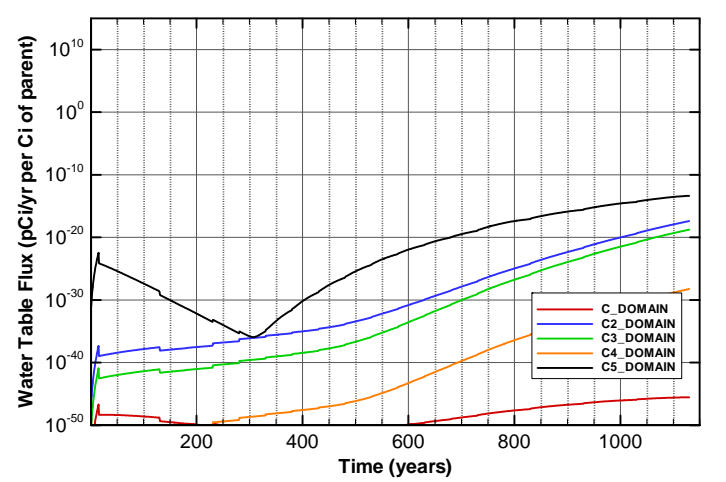

Figure A-128. Flux at water table for Case01_off Cm-244 
SRNL-STI-2008-00397, REVISION 0

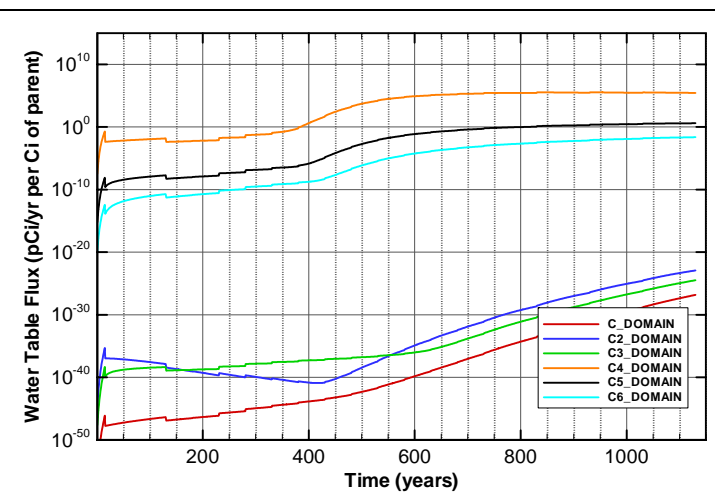

Figure A-129. Flux at water table for Case01_off Cm-245

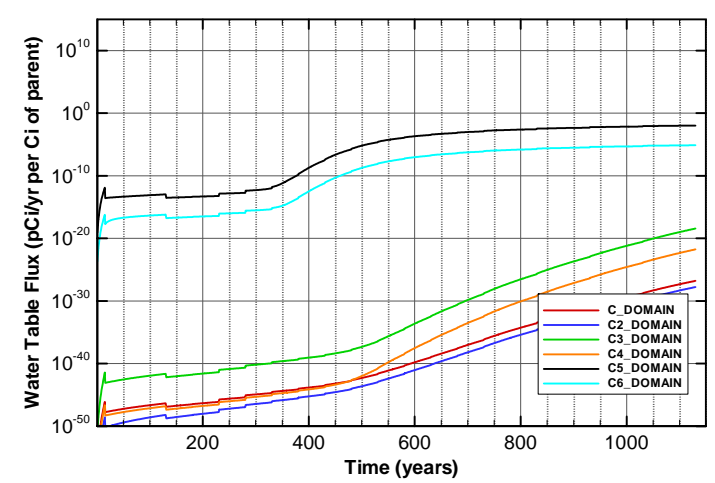

Figure A-131. Flux at water table for Case01_off Cm-247

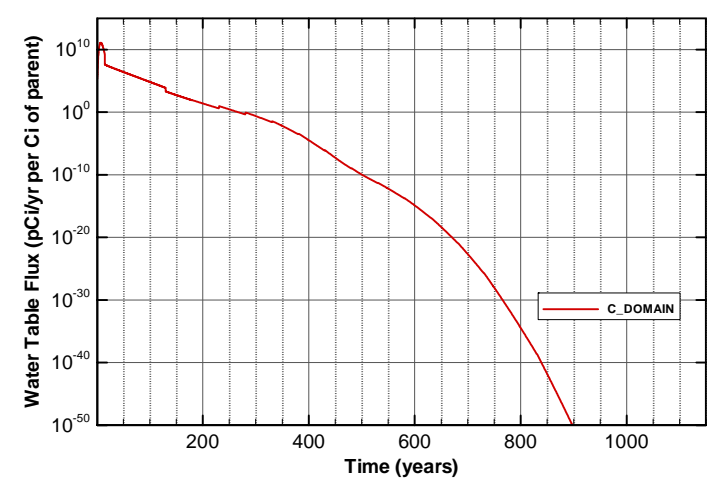

Figure A-133. Flux at water table for Case01_off H-3

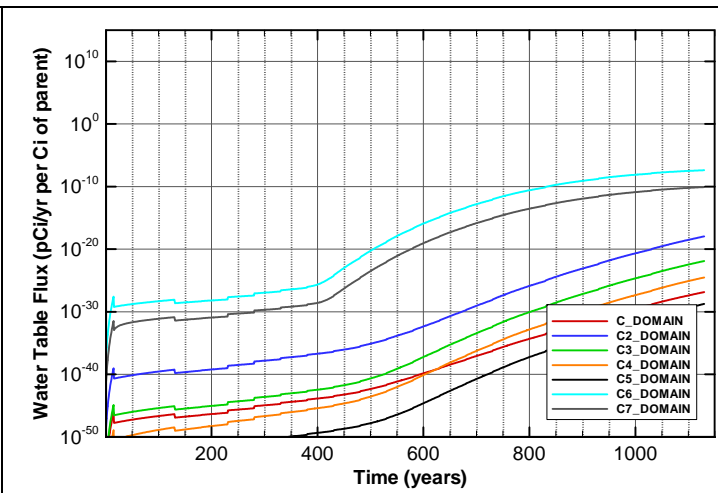

Figure A-130. Flux at water table for Case01_off Cm-246

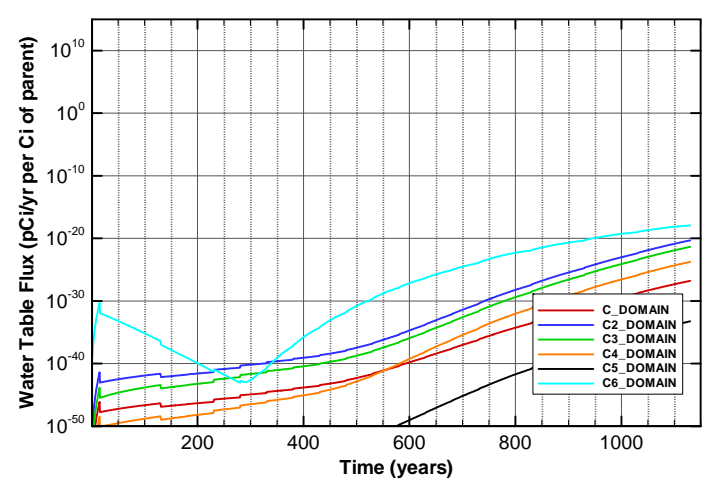

Figure A-132. Flux at water table for Case01_off Cm-248

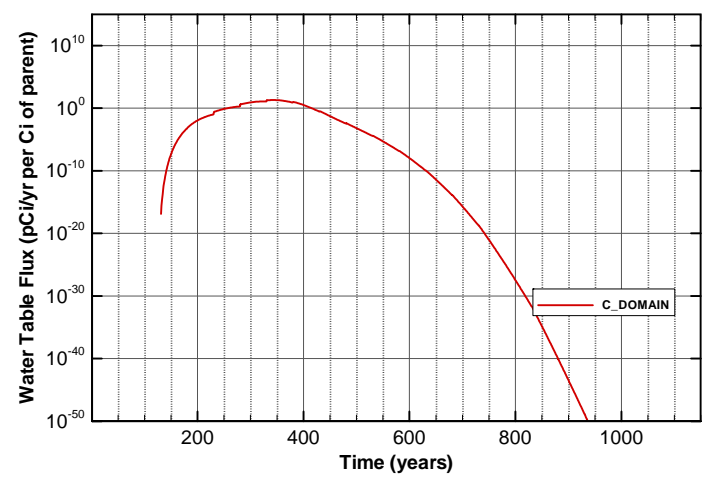

Figure A-134. Flux at water table for Case01_off H-3_ETF.Carbon 


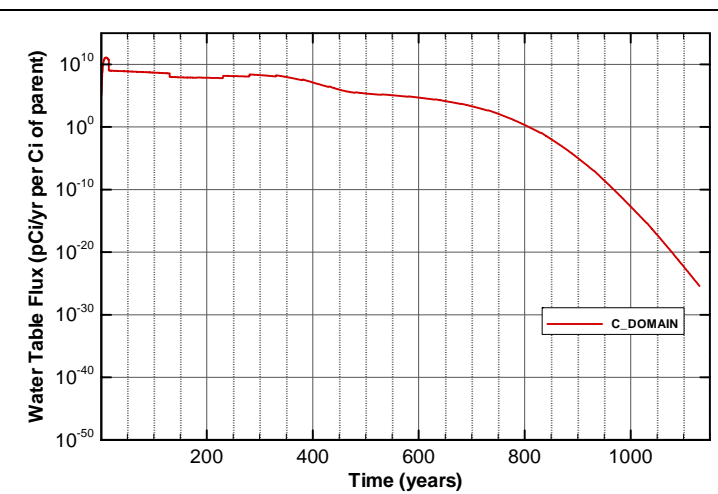

Figure A-135. Flux at water table for Case01_off I-129

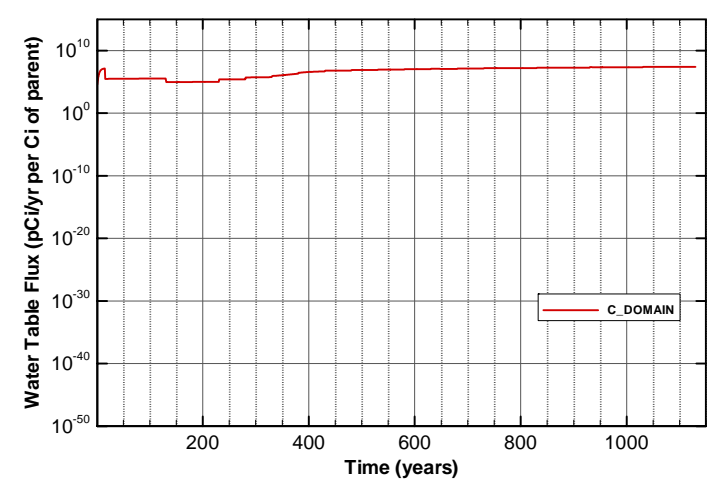

Figure A-137. Flux at water table for Case01_off I-129_ETF.GT.73

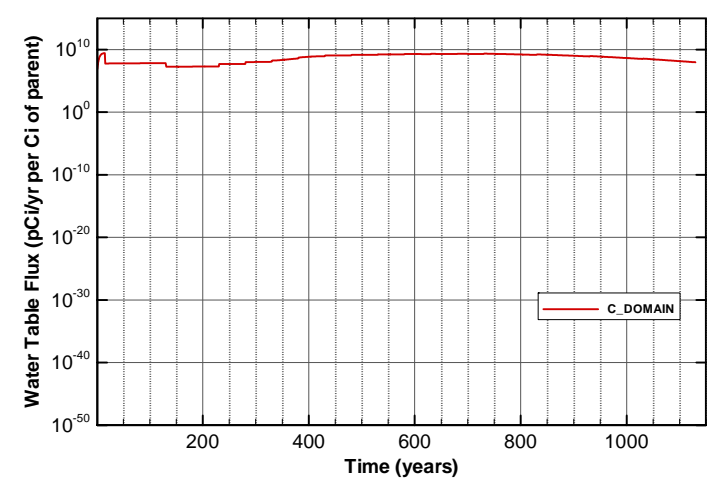

Figure A-139. Flux at water table for Case01_off I-129_F.CG.8

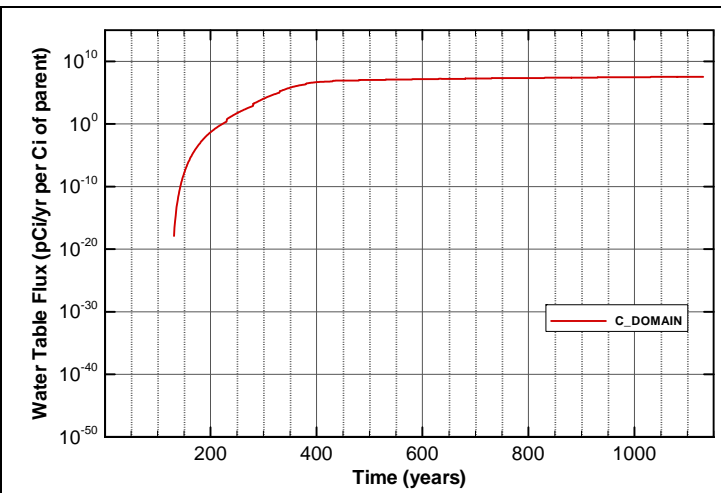

Figure A-136. Flux at water table for Case01_off I-129_ETF.Carbon

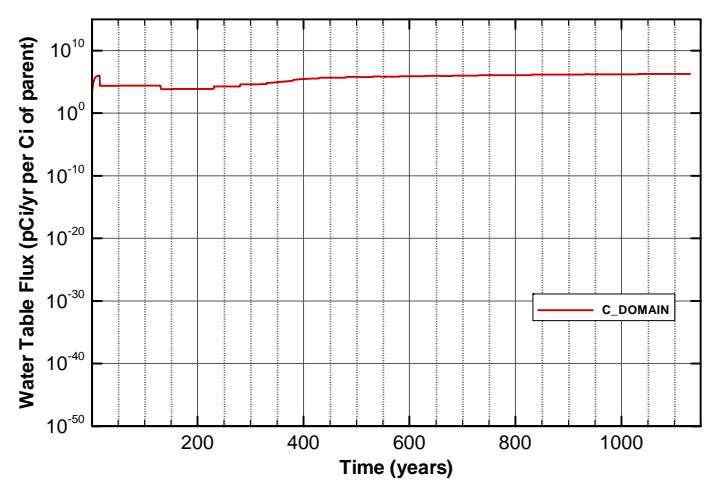

Figure A-138. Flux at water table for Case01_off I-129_F.Carbon

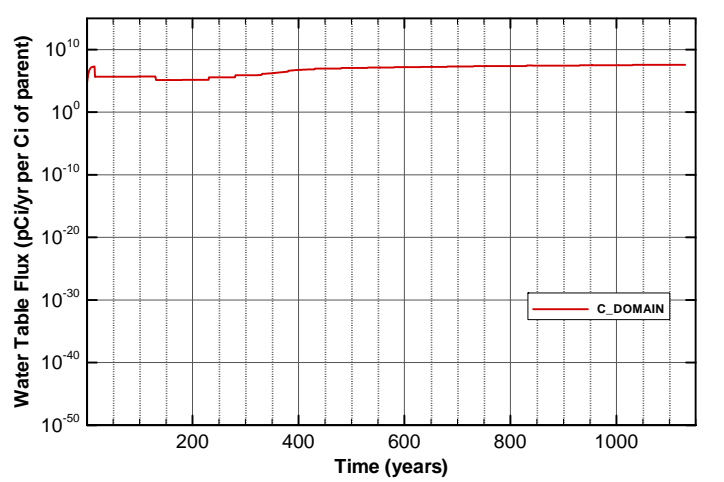

Figure A-140. Flux at water table for Case01_off I-129_F.Dowex.21K 


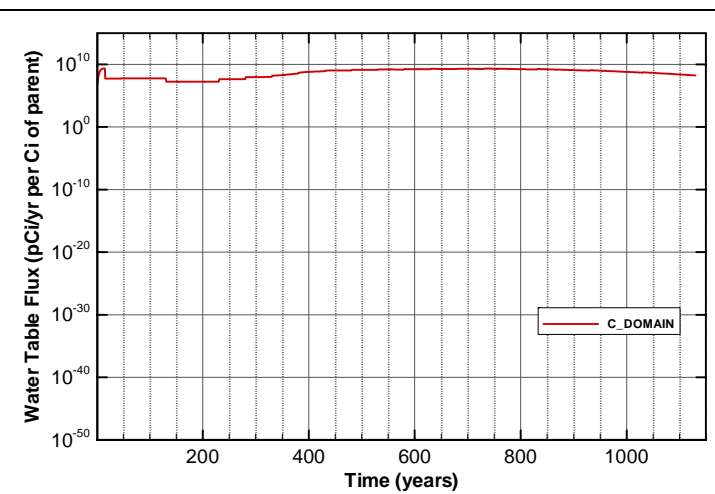

Figure A-141. Flux at water table for Case01_off I-129_F.Filtercake

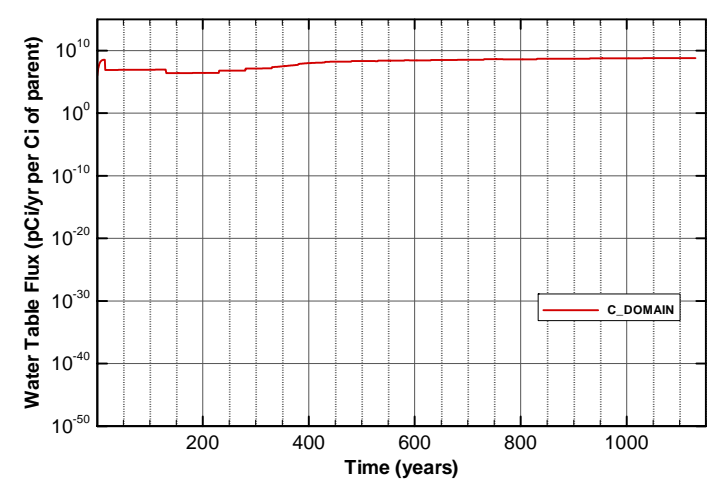

Figure A-143. Flux at water table for Case01_off I-129_H.CG.8

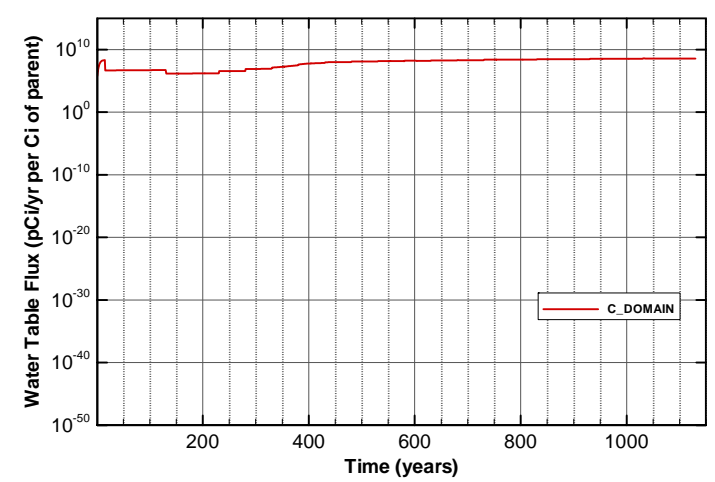

Figure A-145. Flux at water table for Case01_off I-129_H.Filtercake

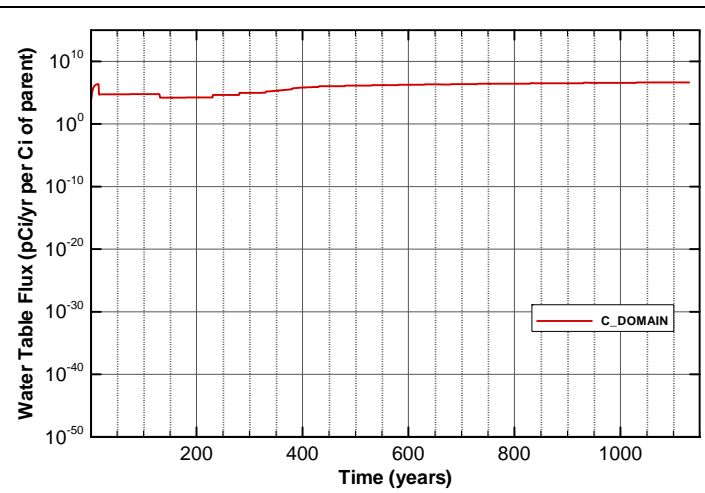

Figure A-142. Flux at water table for Case01_off I-129_H.Carbon

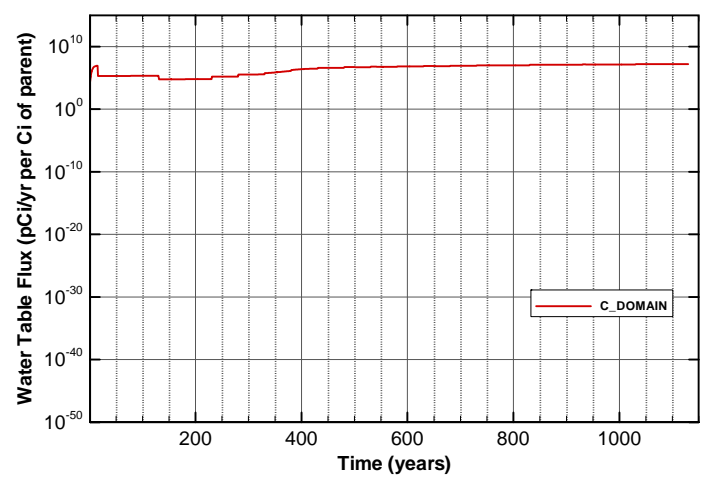

Figure A-144. Flux at water table for Case01_off I-129_H.Dowex.21K

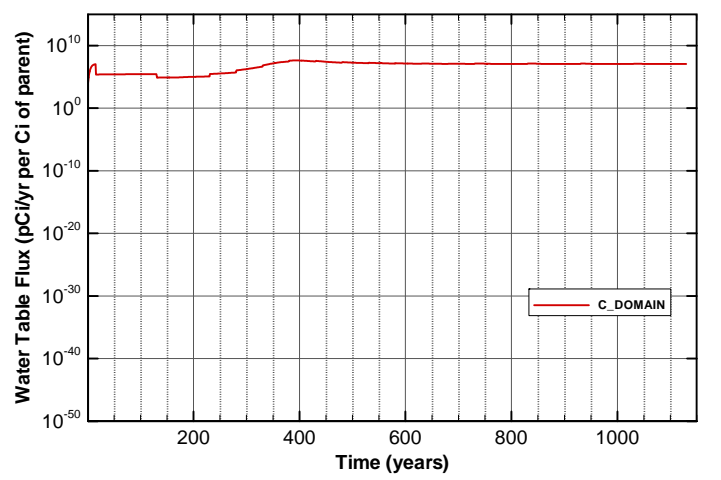

Figure A-146. Flux at water table for Case01_off I-129_Mk50A 


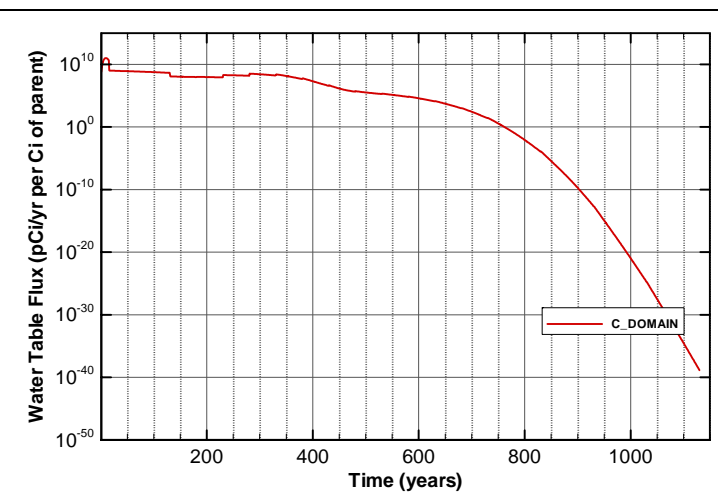

Figure A-147. Flux at water table for Case01_off K-40

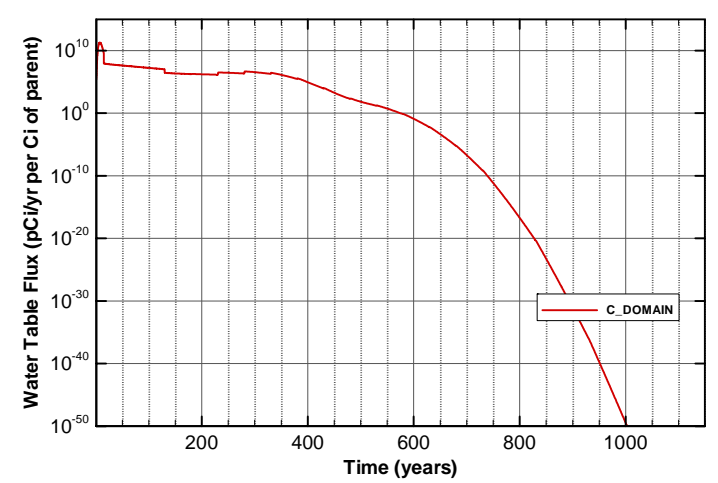

Figure A-149. Flux at water table for Case01_off Nb-94

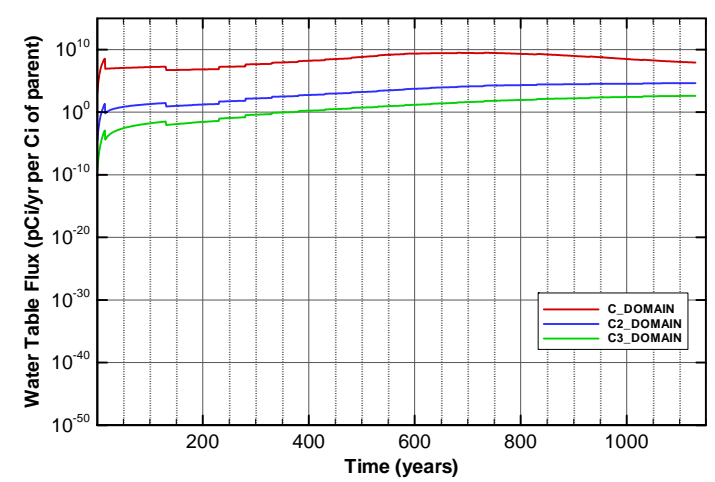

Figure A-151. Flux at water table for Case01_off Np-237

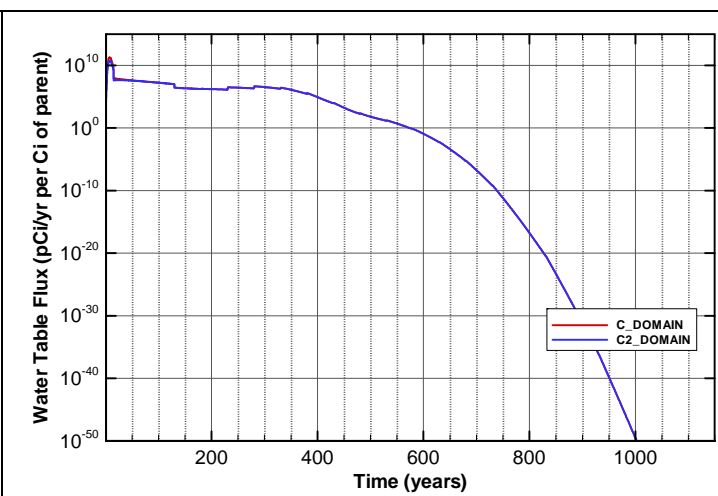

Figure A-148. Flux at water table for Case01_off Mo-93

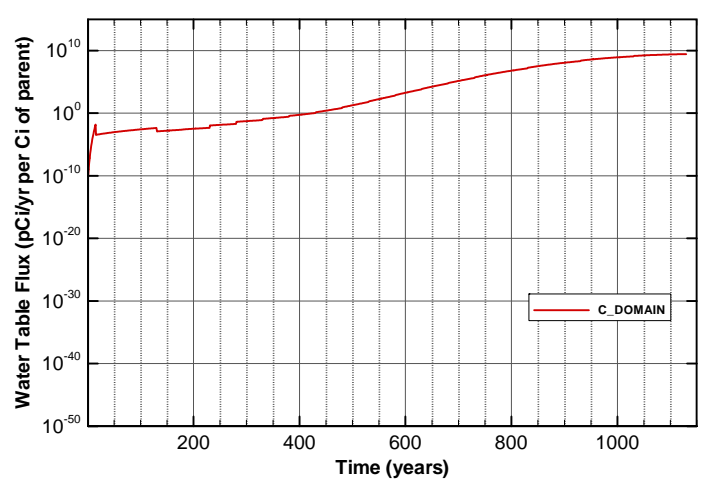

Figure A-150. Flux at water table for Case01_off Ni-59

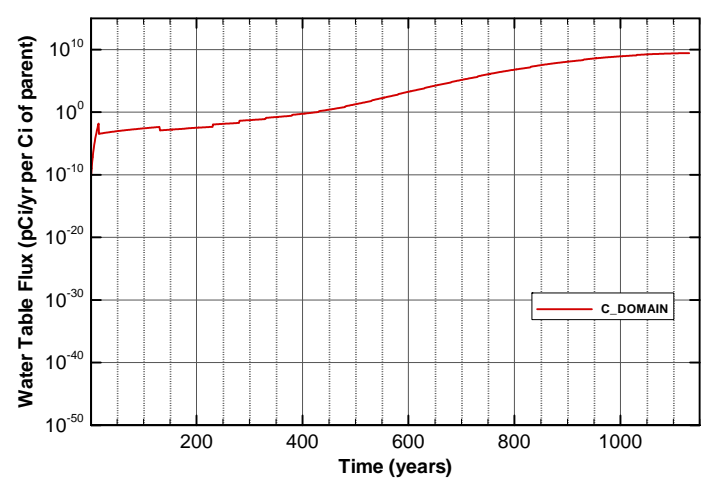

Figure A-152. Flux at water table for Case01_off Pd-107 
SRNL-STI-2008-00397, REVISION 0
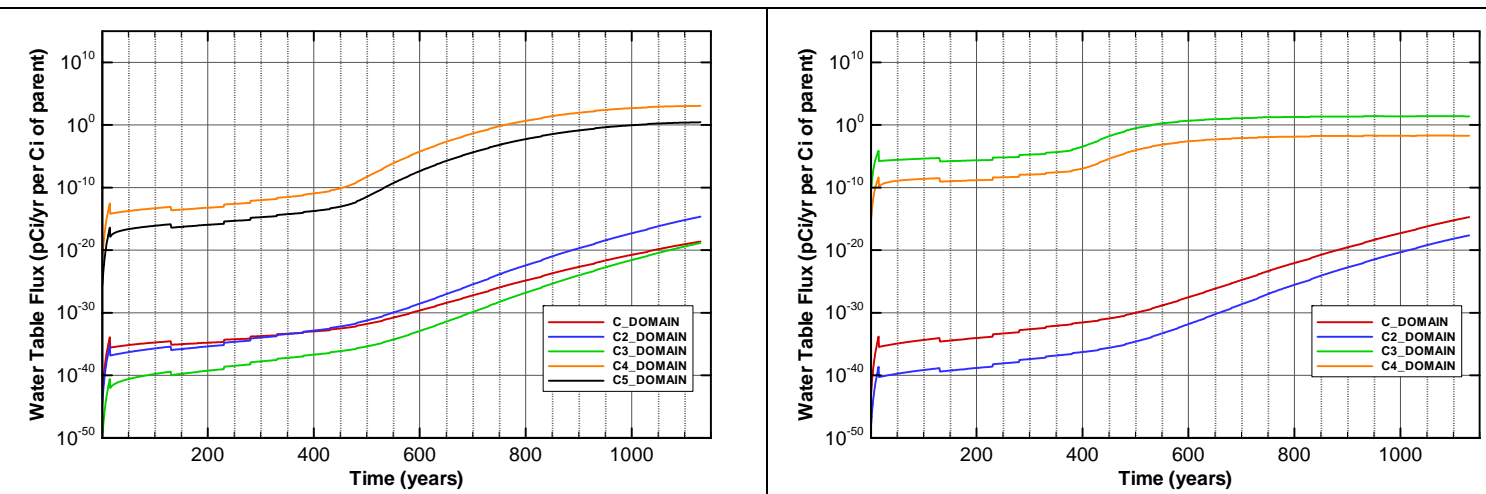

Figure A-153. Flux at water table for Case01_off Pu-238

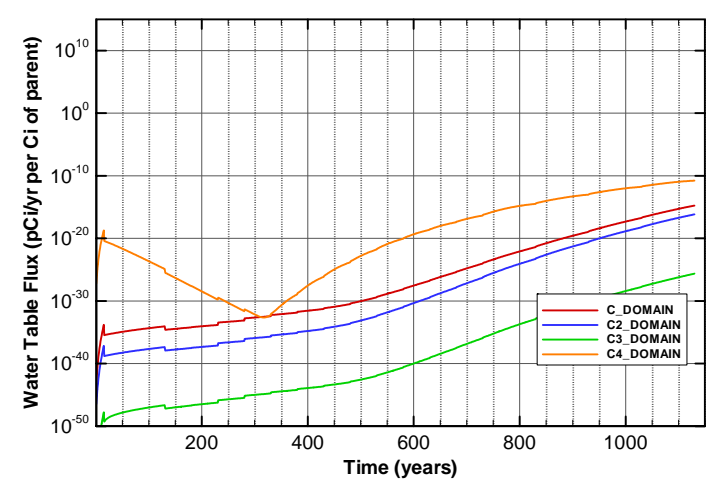

Figure A-155. Flux at water table for Case01_off Pu-240

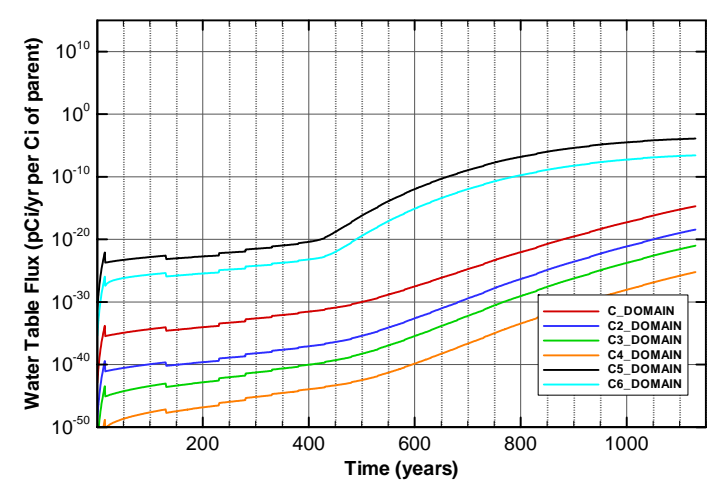

Figure A-157. Flux at water table for Case01_off Pu-242

Figure A-154. Flux at water table for Case01_off Pu-239

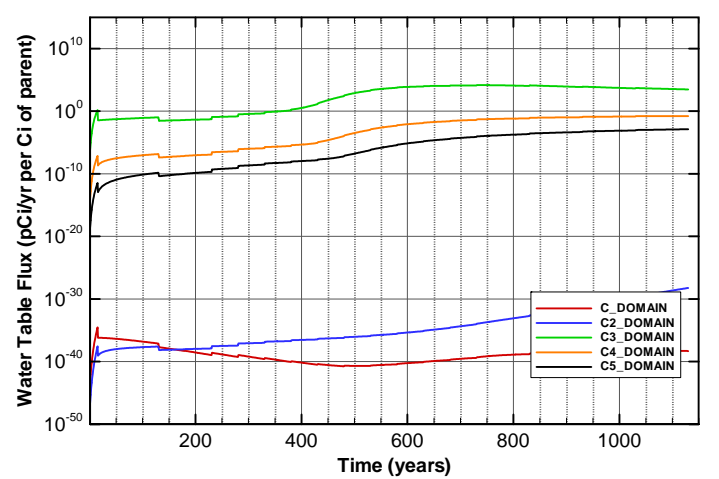

Figure A-156. Flux at water table for Case01_off Pu-241

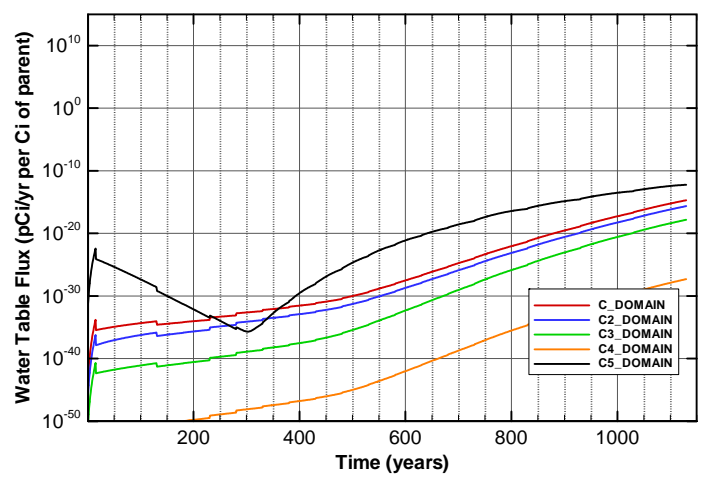

Figure A-158. Flux at water table for Case01_off Pu-244 


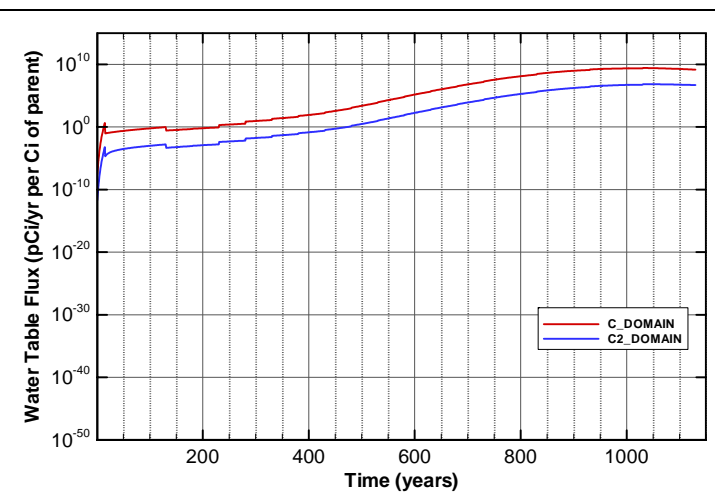

Figure A-159. Flux at water table for Case01_off Ra-226

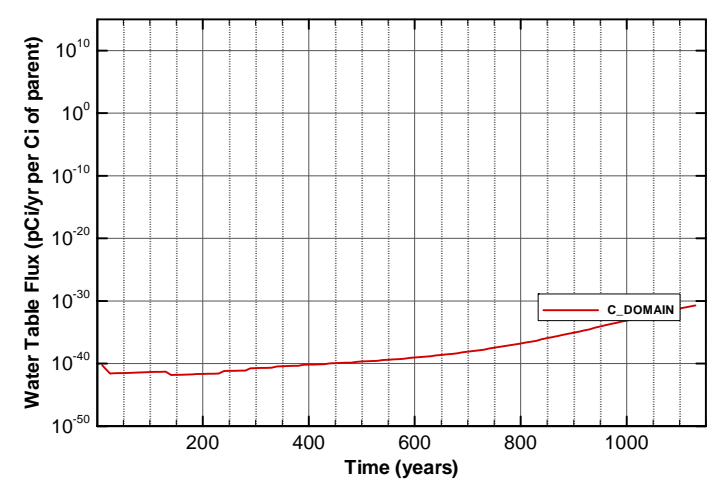

Figure A-161. Flux at water table for Case01_off Sn-126

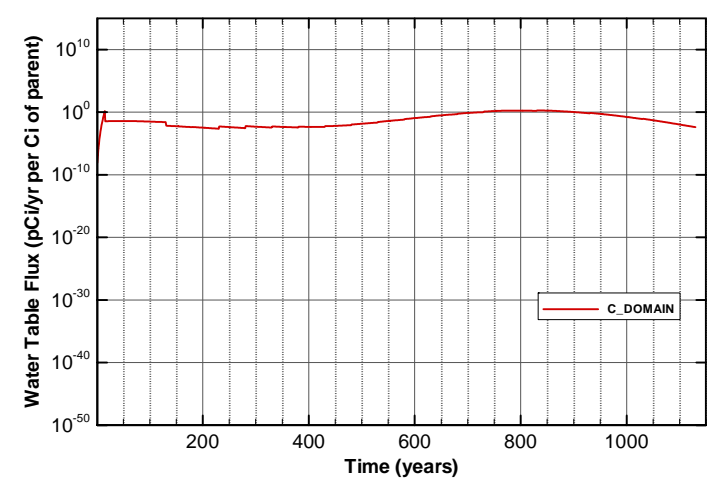

Figure A-163. Flux at water table for Case01_off Sr-90_Cask

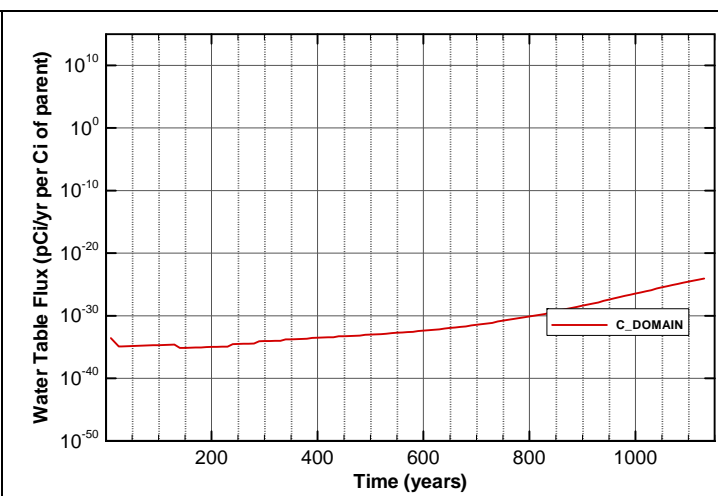

Figure A-160. Flux at water table for Case01_off Se-79

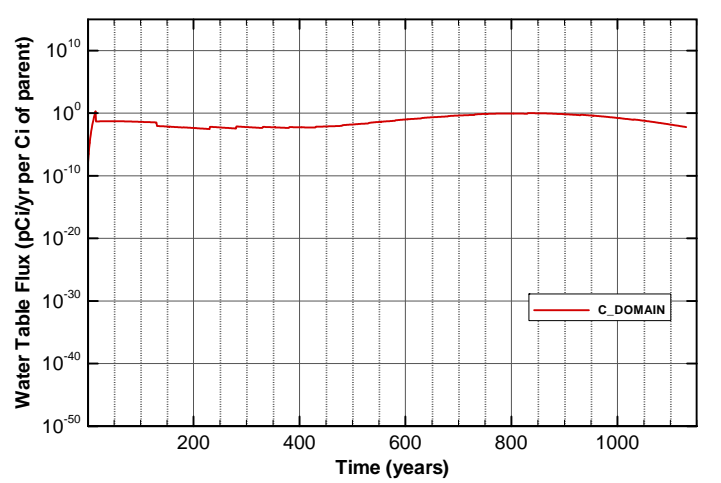

Figure A-162. Flux at water table for Case01_off Sr-90

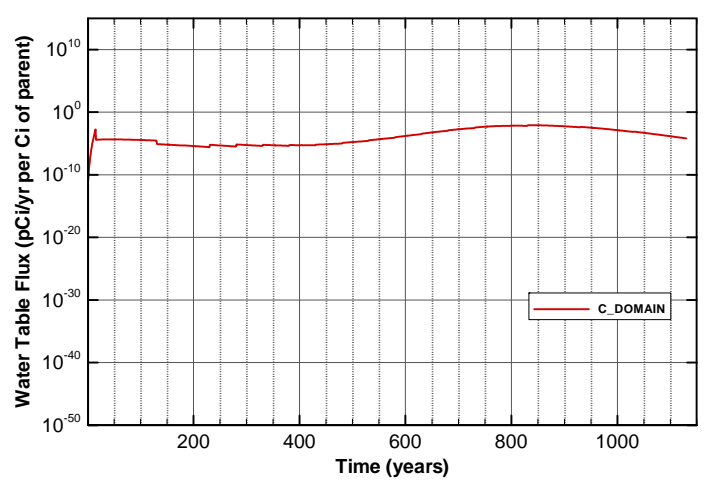

Figure A-164. Flux at water table for Case01_off Sr-90_Mk50A 


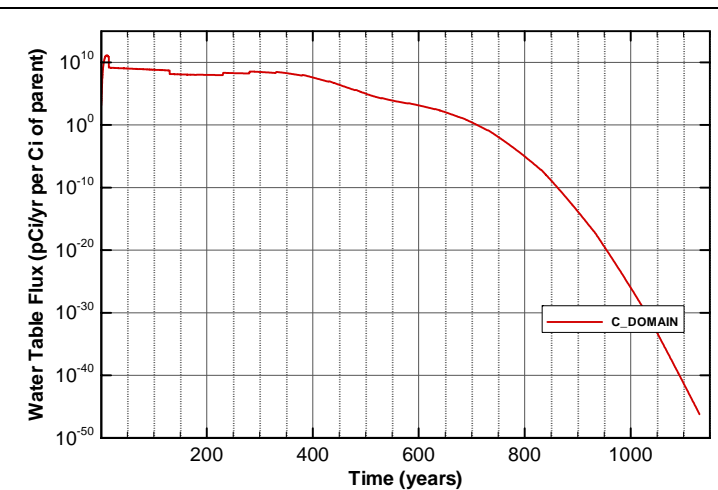

Figure A-165. Flux at water table for Case01_off Tc-99

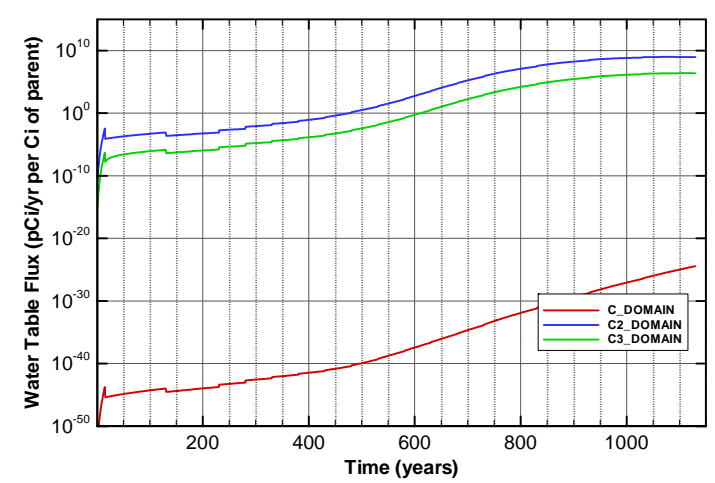

Figure A-167. Flux at water table for Case01_off Th-230

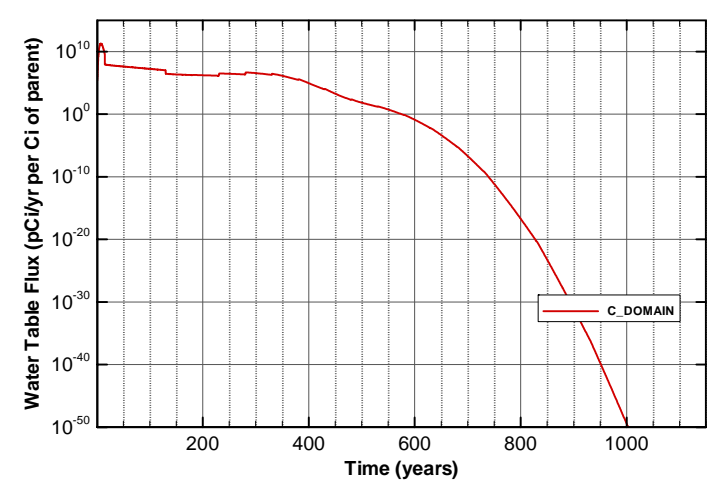

Figure A-169. Flux at water table for Case01_off Tracer

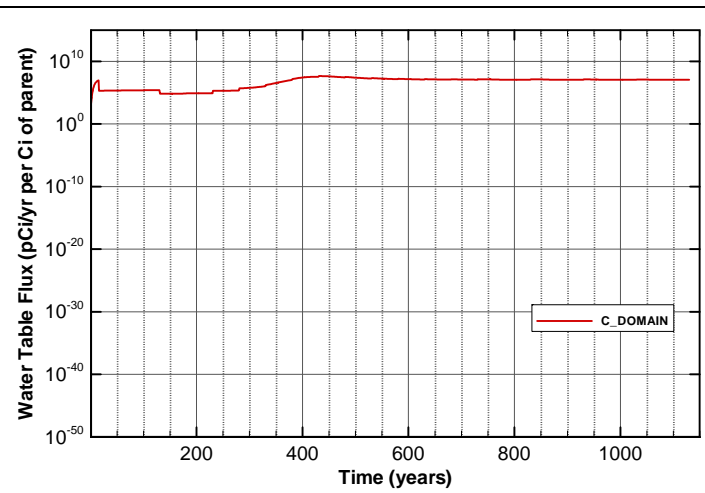

Figure A-166. Flux at water table for Case01_off Tc-99_Mk50A

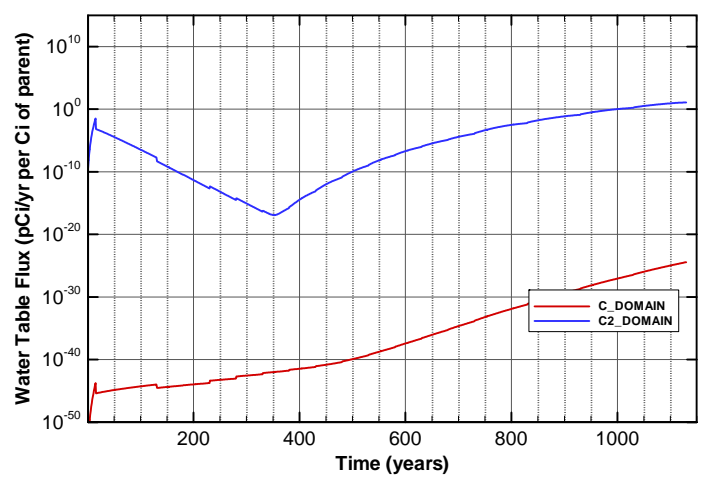

Figure A-168. Flux at water table for Case01_off Th-232

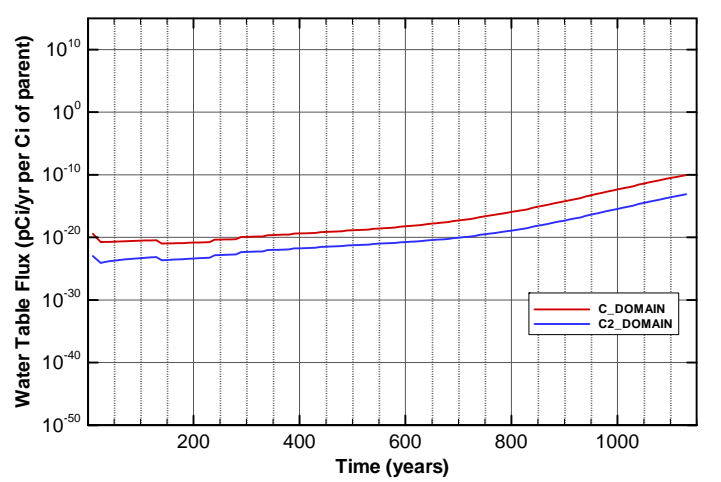

Figure A-170. Flux at water table for Case01_off U-233 
SRNL-STI-2008-00397, REVISION 0
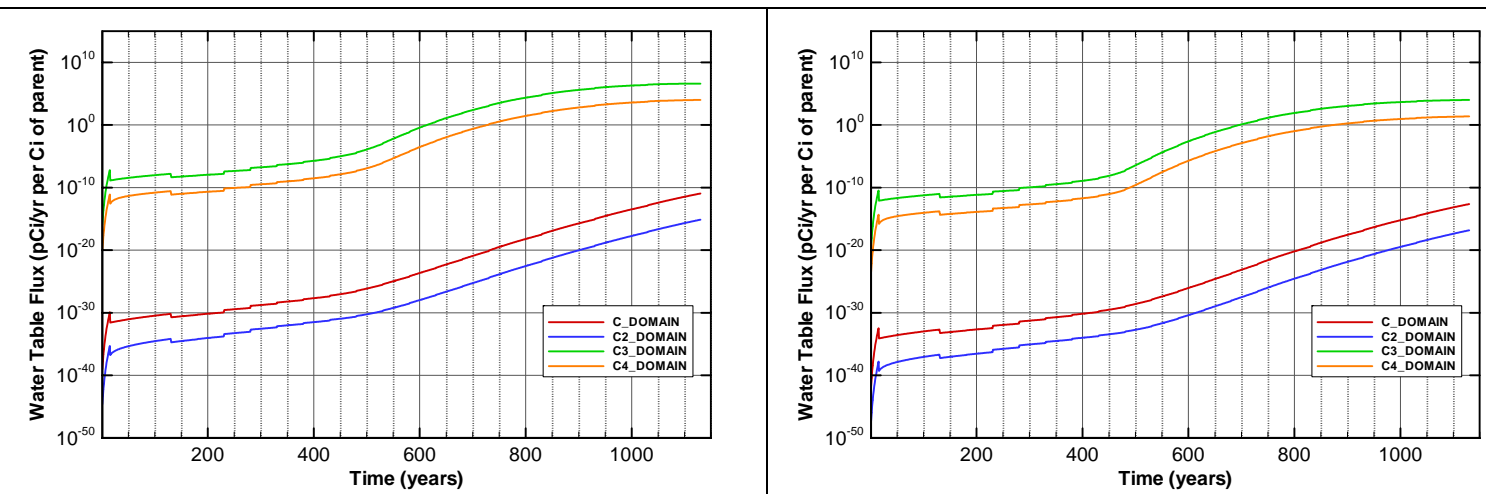

Figure A-171. Flux at water table for Case01_off U-234

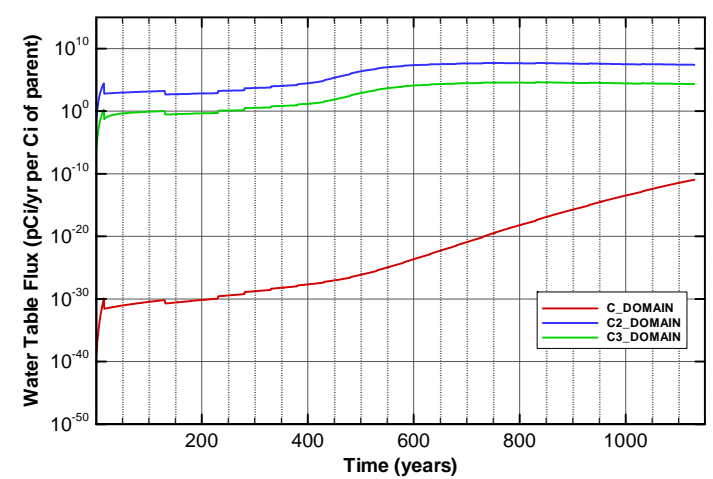

Figure A-173. Flux at water table for Case01_off U-235

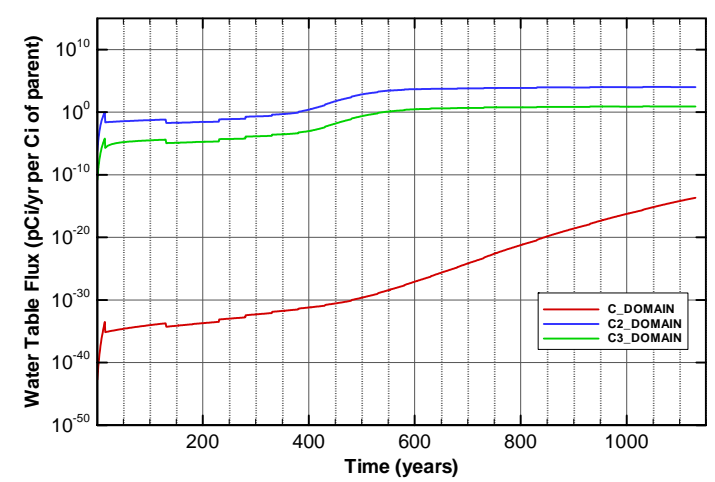

Figure A-175. Flux at water table for Case01_off U-235_Paducah.Cask

Figure A-172. Flux at water table for Case01_off U-234_Mglass

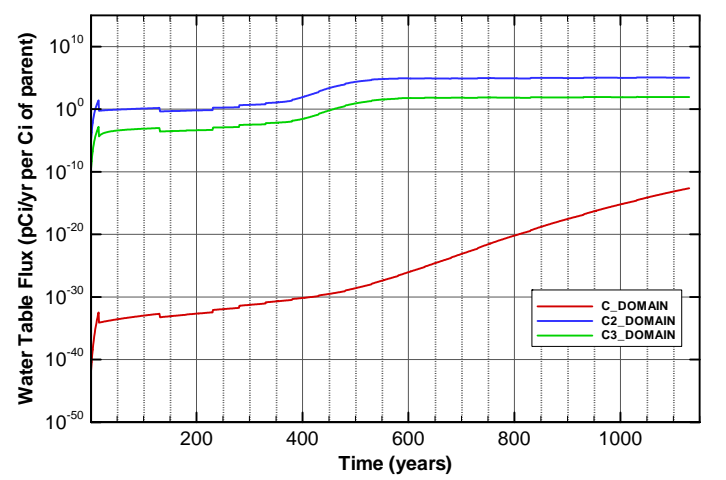

Figure A-174. Flux at water table for Case01_off U-235_Mglass

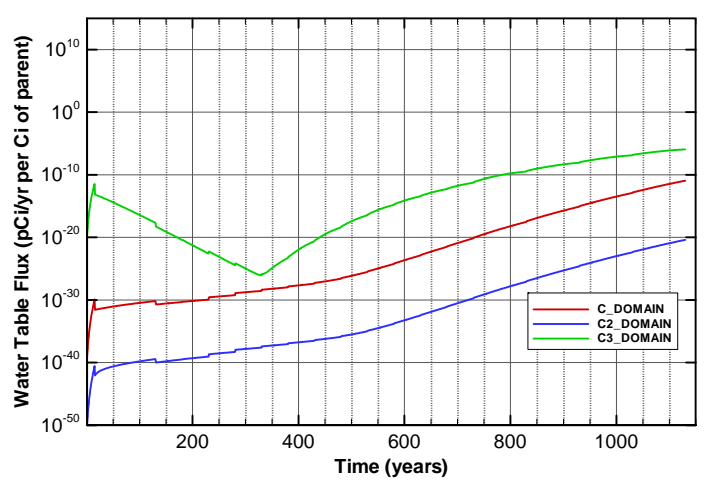

Figure A-176. Flux at water table for Case01_off U-236 
SRNL-STI-2008-00397, REVISION 0
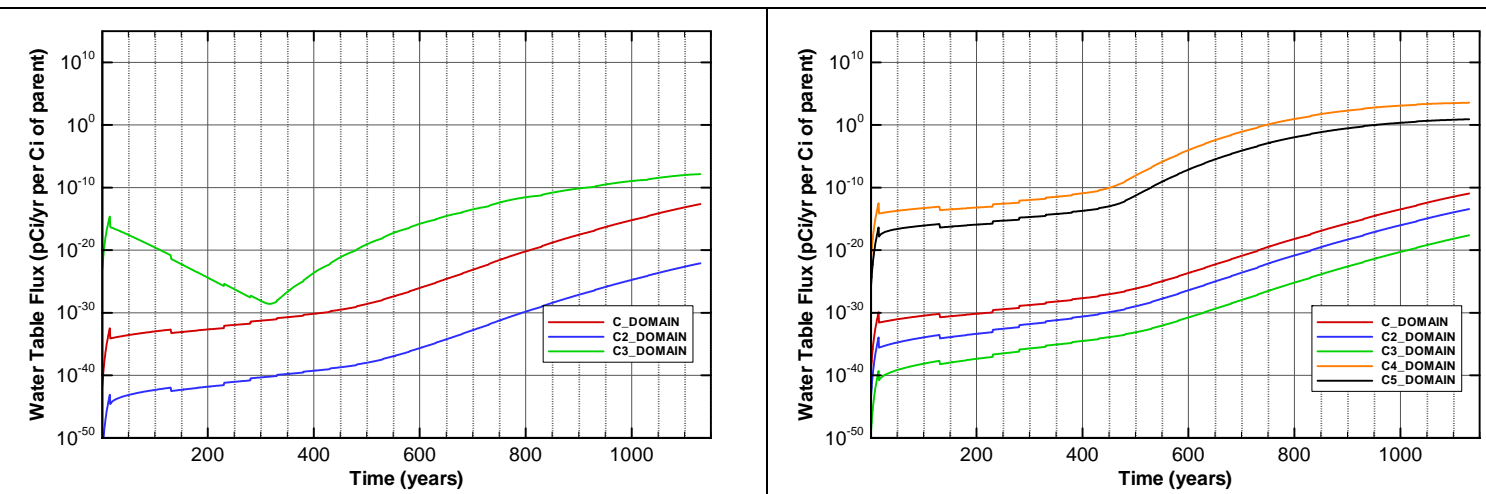

Figure A-177. Flux at water table for Case01_off U-236_Mglass

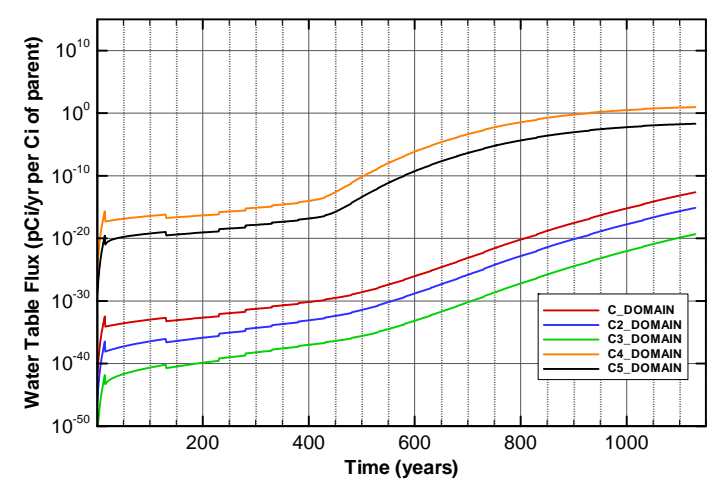

Figure A-179. Flux at water table for Case01_off U-238_Mglass

Figure A-178. Flux at water table for Case01_off U-238

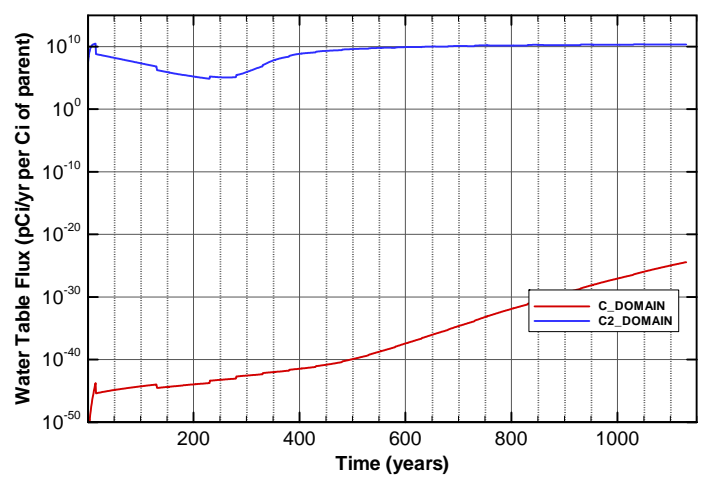

Figure A-180. Flux at water table for Case01_off Zr-93

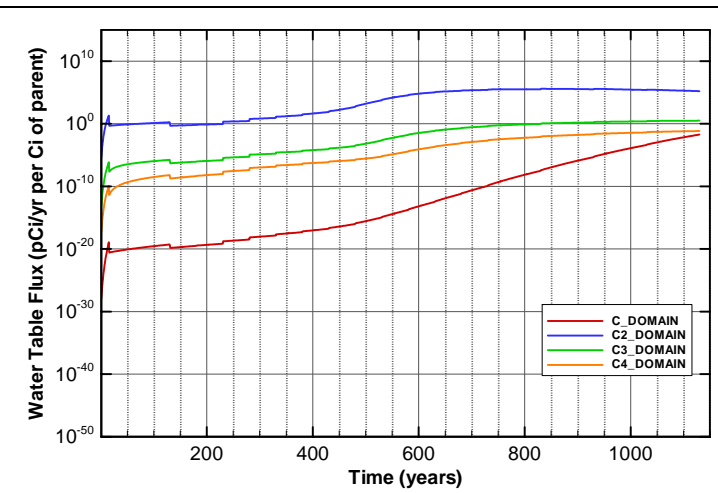

Figure A-181. Flux at water table for Case01_on Am-241

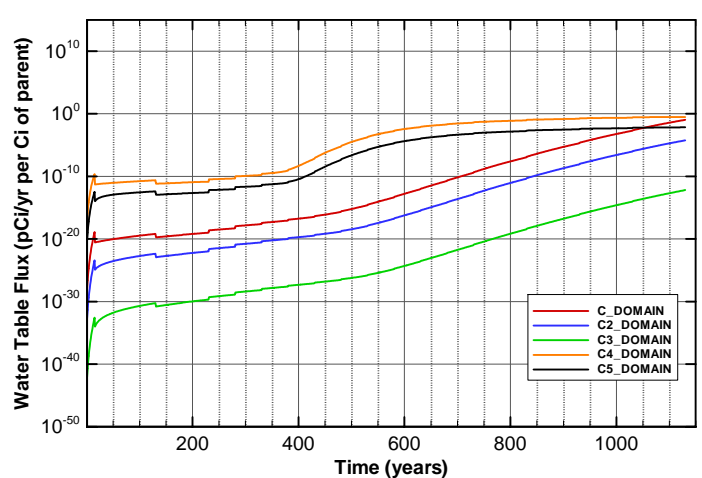

Figure A-182. Flux at water table for Case01_on Am-243 
SRNL-STI-2008-00397, REVISION 0
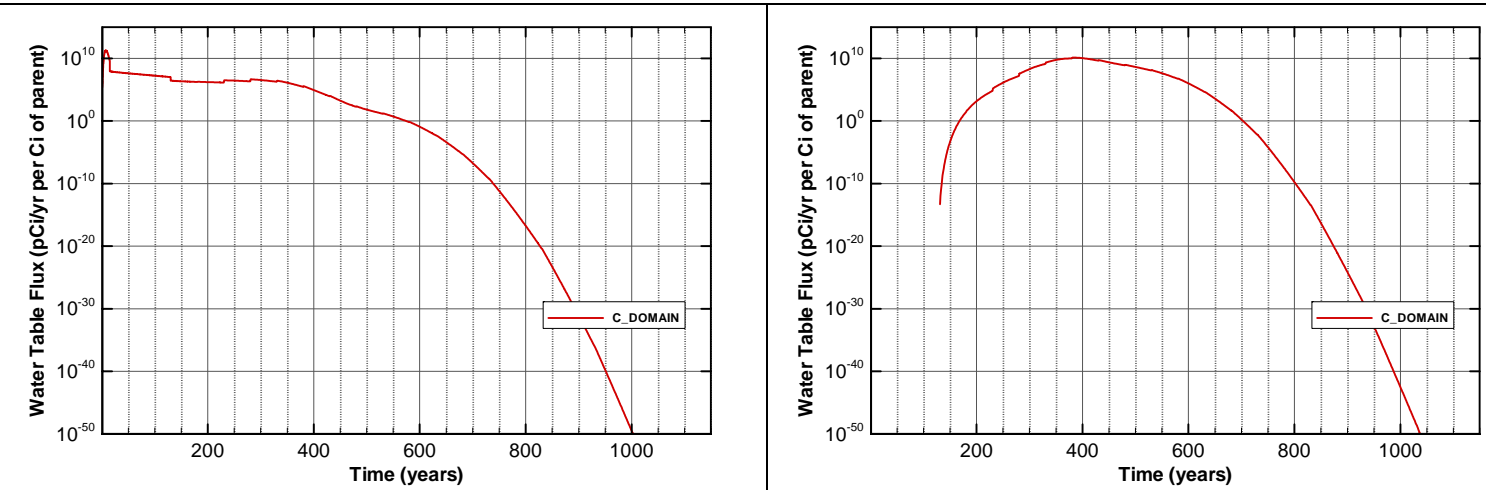

Figure A-183. Flux at water table for Case01_on C-14

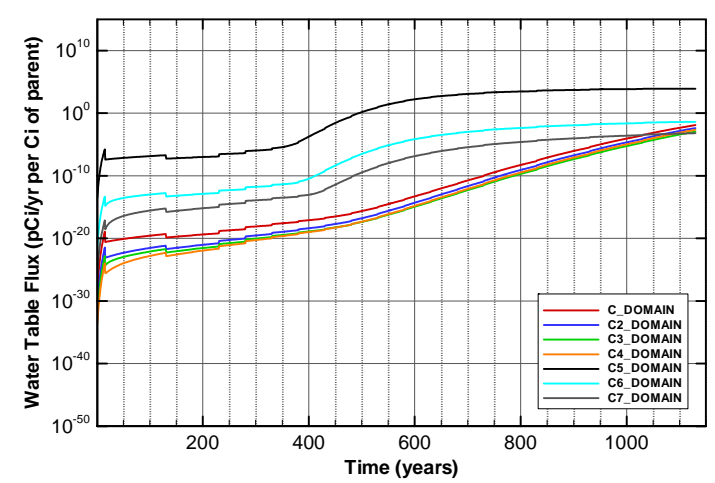

Figure A-185. Flux at water table for Case01_on Cf-249

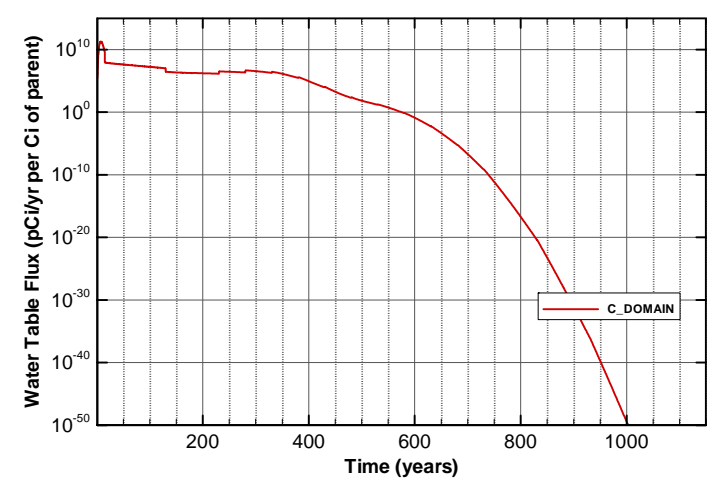

Figure A-187. Flux at water table for Case01_on Cl-36

Figure A-184. Flux at water table for Case01_on C-14_NR.Pump

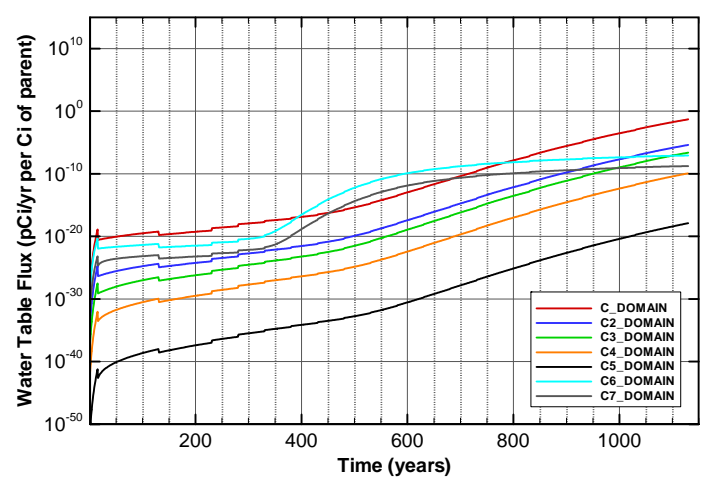

Figure A-186. Flux at water table for Case01_on Cf-251

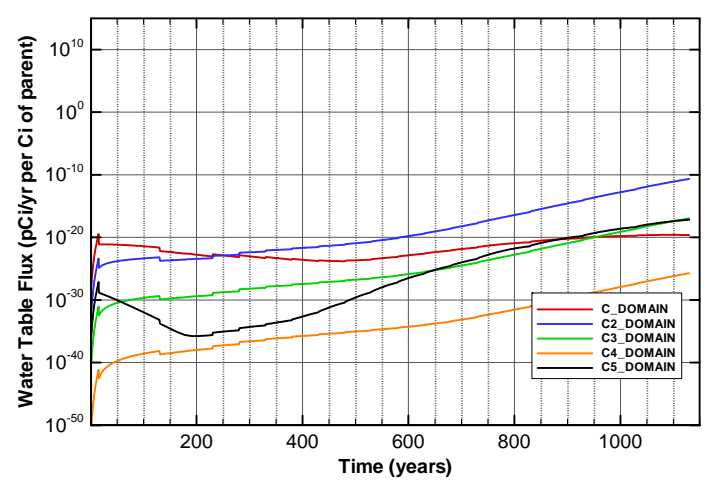

Figure A-188. Flux at water table for Case01_on Cm-244 
SRNL-STI-2008-00397, REVISION 0
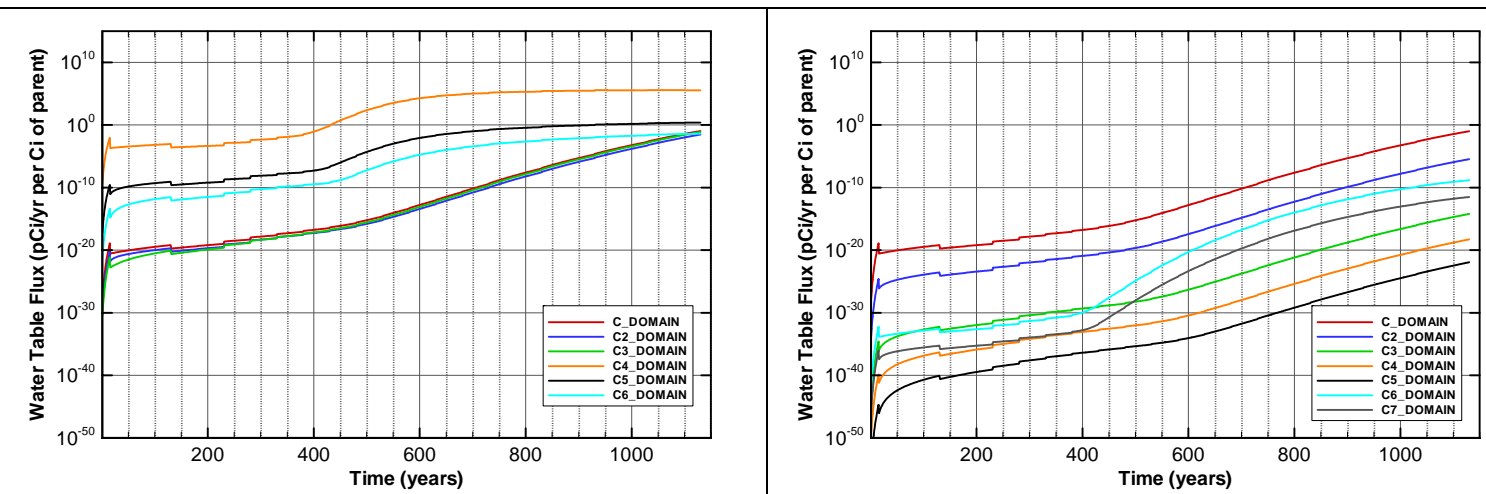

Figure A-189. Flux at water table for Case01_on Cm-245

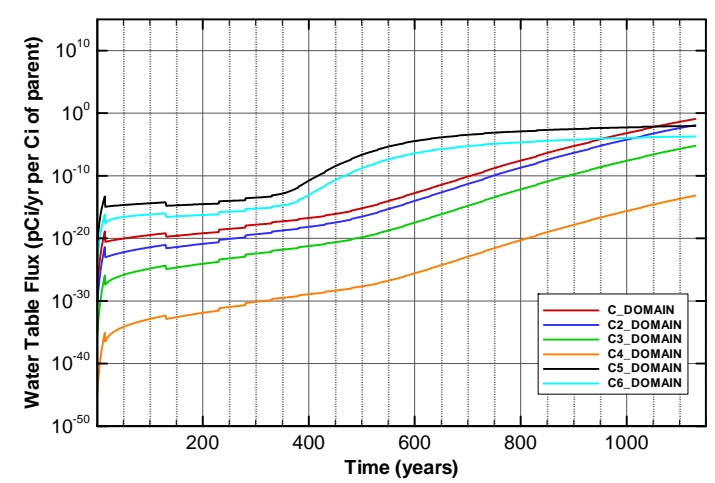

Figure A-191. Flux at water table for Case01_on Cm-247

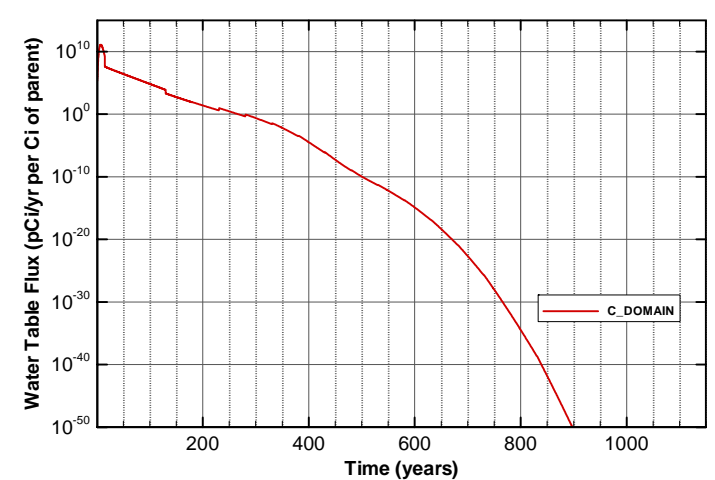

Figure A-193. Flux at water table for Case01_on H-3

Figure A-190. Flux at water table for Case01_on Cm-246

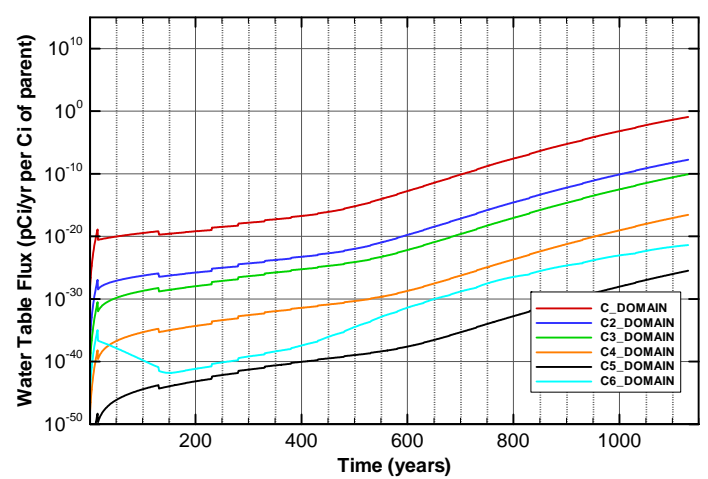

Figure A-192. Flux at water table for Case01_on Cm-248

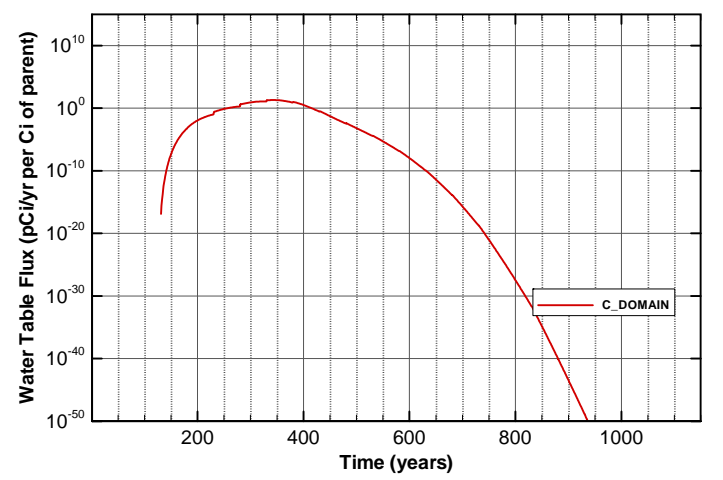

Figure A-194. Flux at water table for Case01_on H-3_ETF.Carbon 


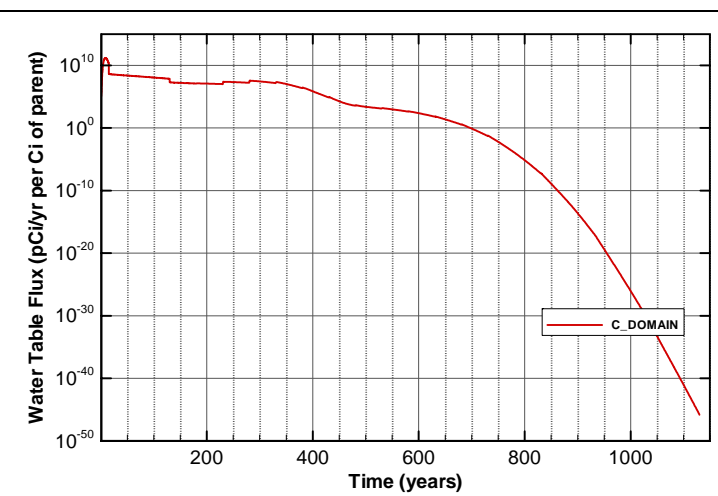

Figure A-195. Flux at water table for Case01_on I-129

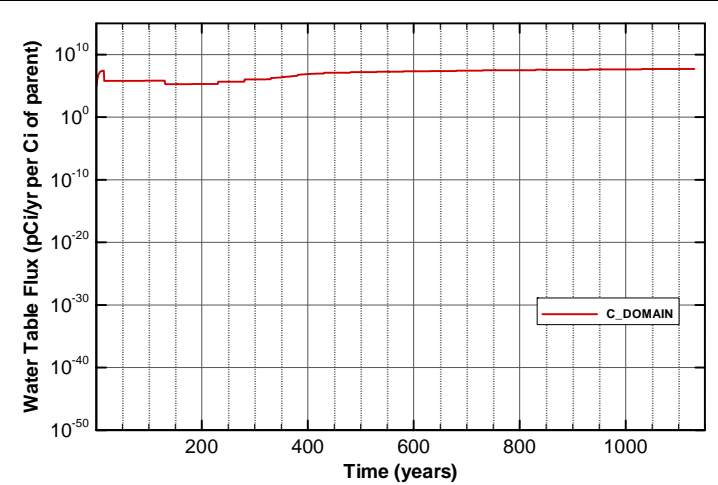

Figure A-197. Flux at water table for Case01_on I-129_ETF.GT.73

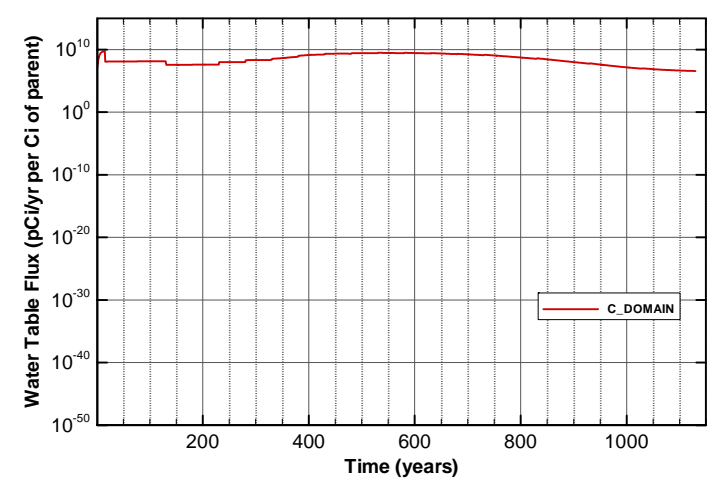

Figure A-199. Flux at water table for Case01_on I-129_F.CG.8

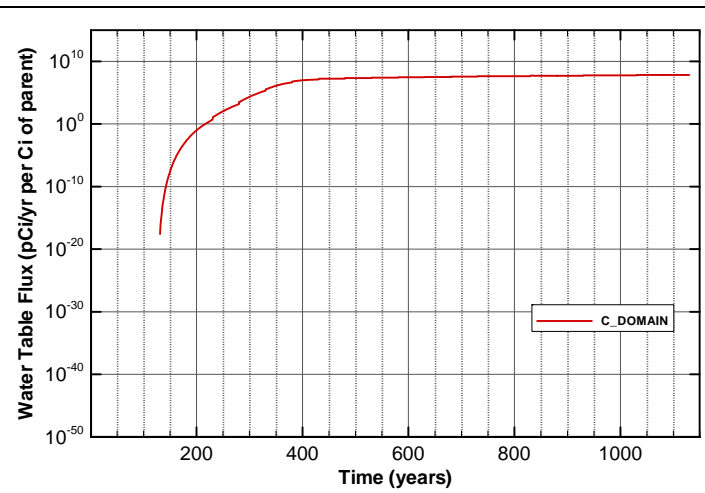

Figure A-196. Flux at water table for Case01_on I-129_ETF.Carbon

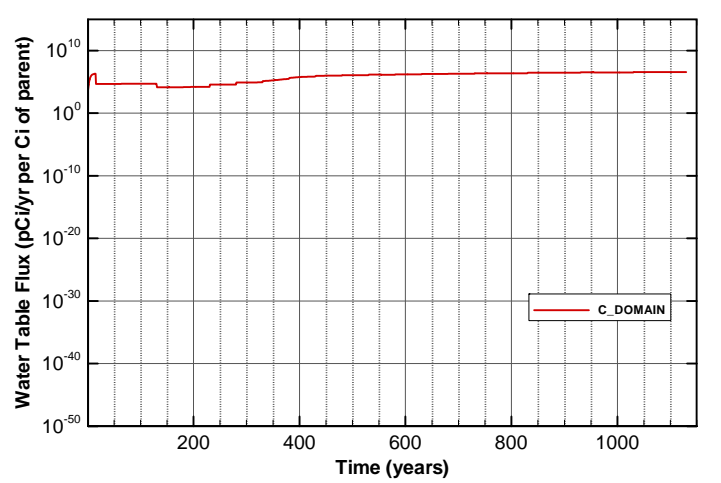

Figure A-198. Flux at water table for Case01_on I-129_F.Carbon

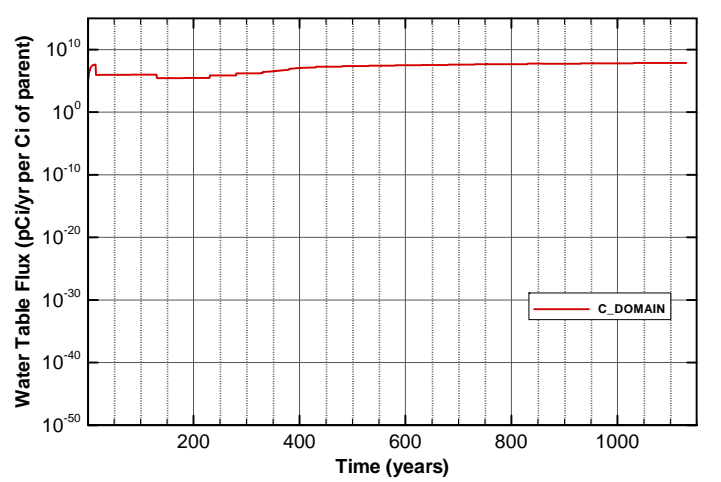

Figure A-200. Flux at water table for Case01_on I-129_F.Dowex.21K 


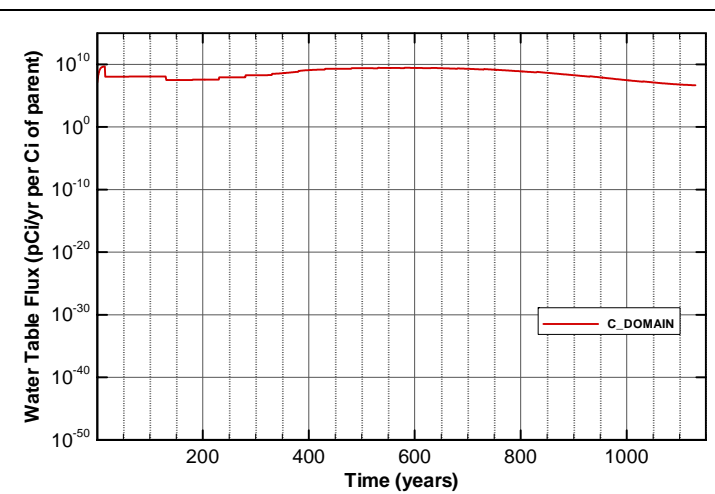

Figure A-201. Flux at water table for Case01_on I-129_F.Filtercake

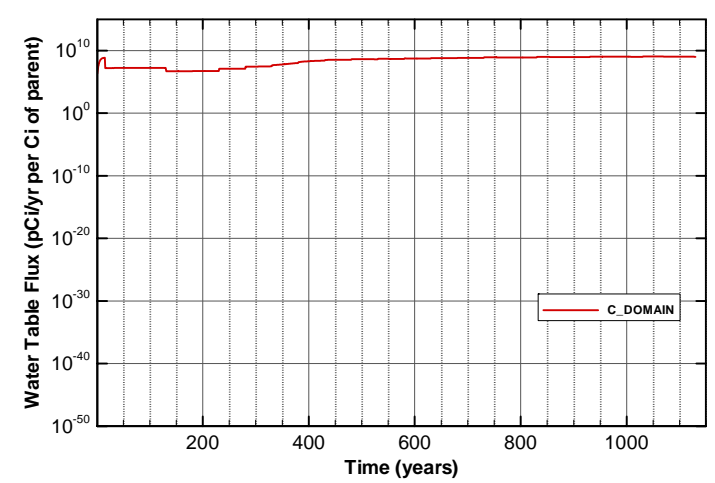

Figure A-203. Flux at water table for Case01_on I-129_H.CG.8

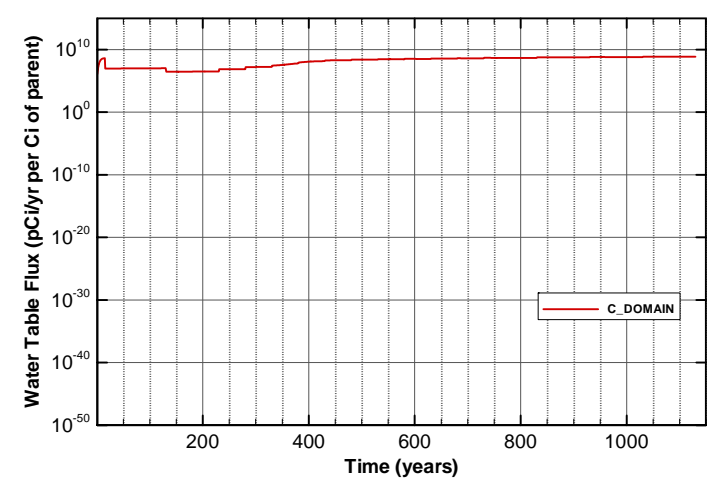

Figure A-205. Flux at water table for Case01_on I-129_H.Filtercake

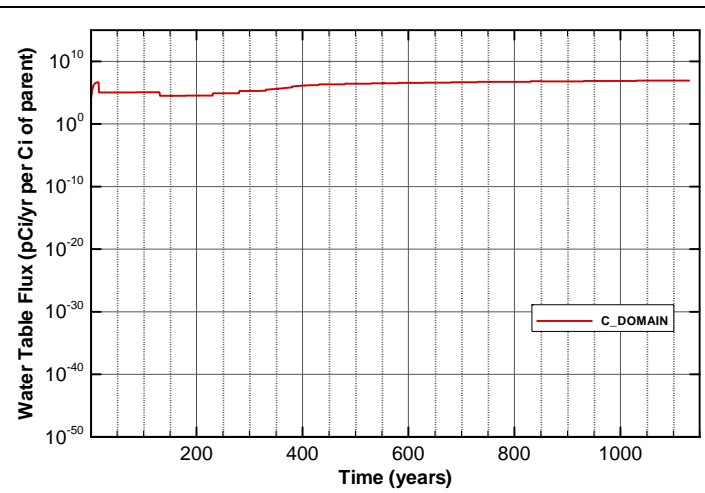

Figure A-202. Flux at water table for Case01_on I-129_H.Carbon

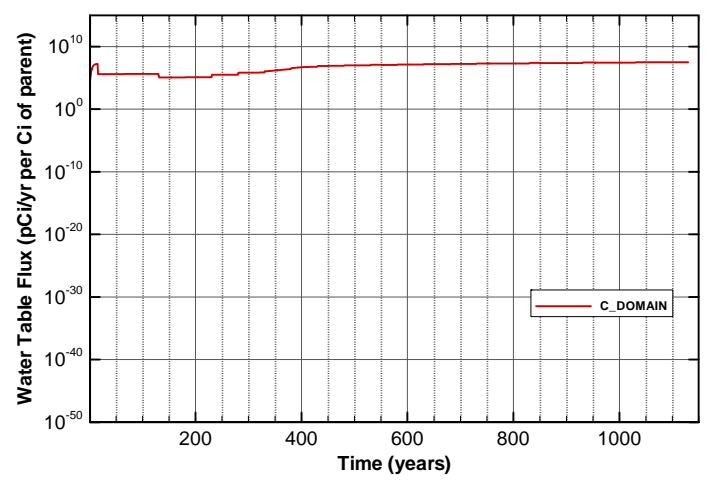

Figure A-204. Flux at water table for Case01_on I-129_H.Dowex.21K

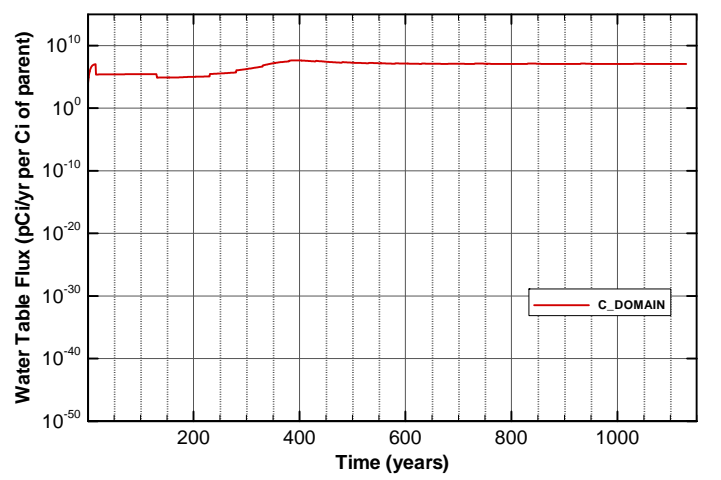

Figure A-206. Flux at water table for Case01_on I-129_Mk50A 


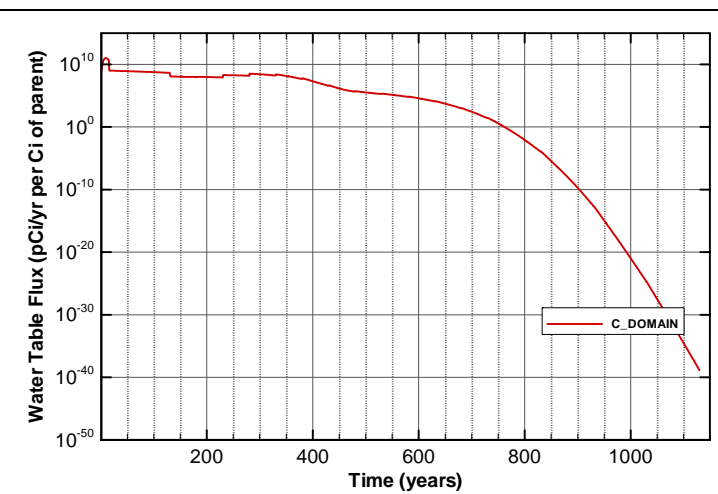

Figure A-207. Flux at water table for Case01_on K-40

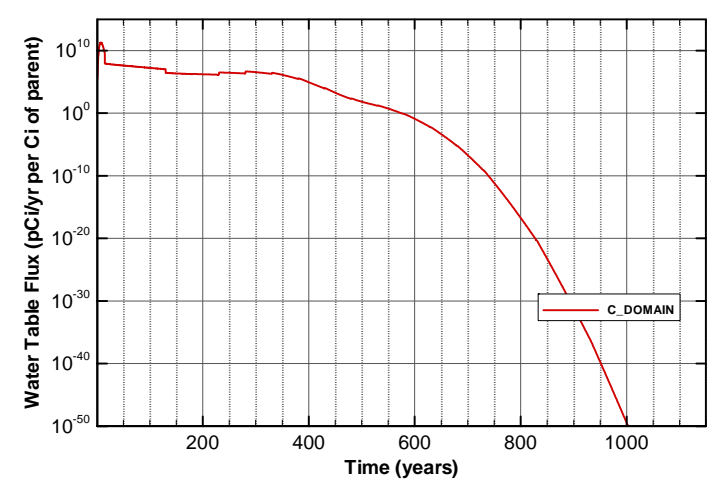

Figure A-209. Flux at water table for Case01_on Nb-94

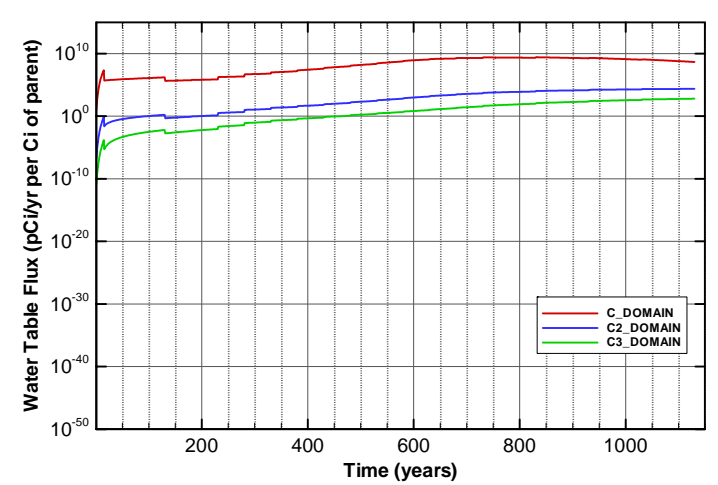

Figure A-211. Flux at water table for Case01_on Np-237

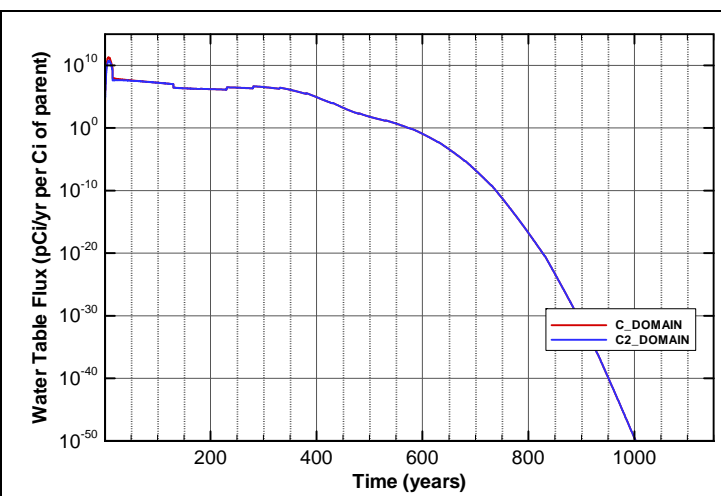

Figure A-208. Flux at water table for Case01_on Mo-93

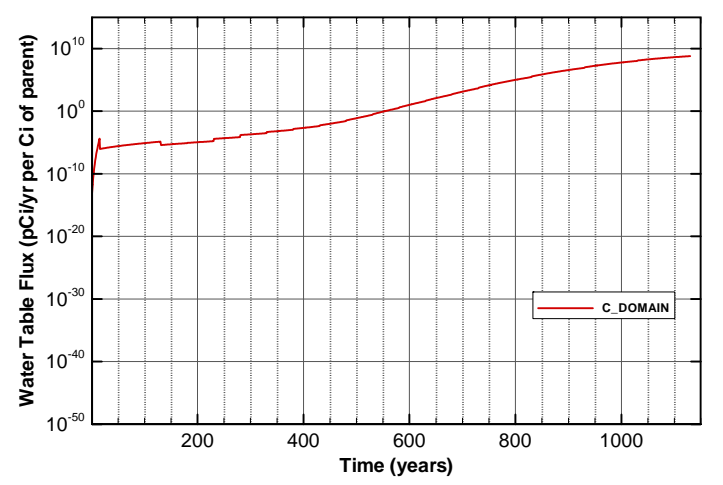

Figure A-210. Flux at water table for Case01_on Ni-59

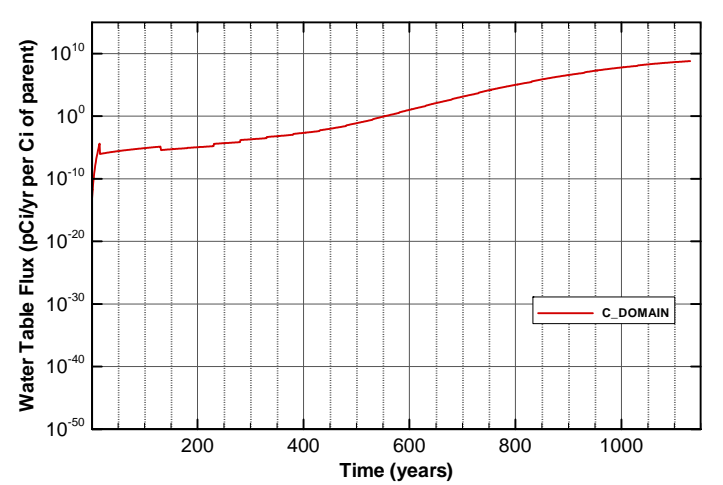

Figure A-212. Flux at water table for Case01_on Pd-107 
SRNL-STI-2008-00397, REVISION 0
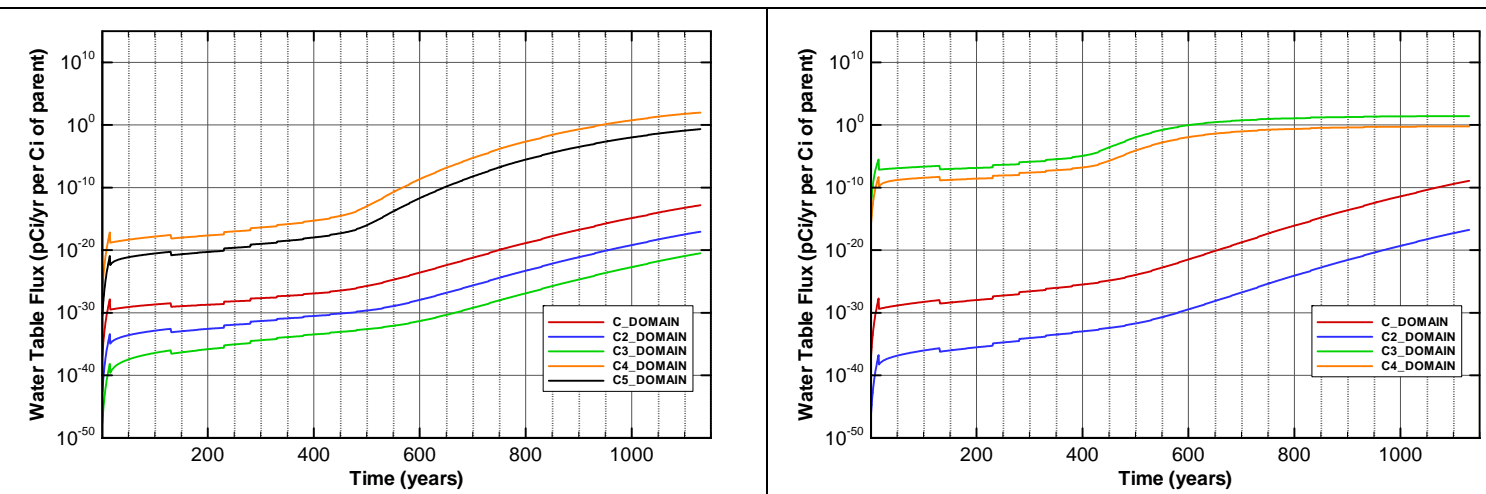

Figure A-213. Flux at water table for Case01_on Pu-238

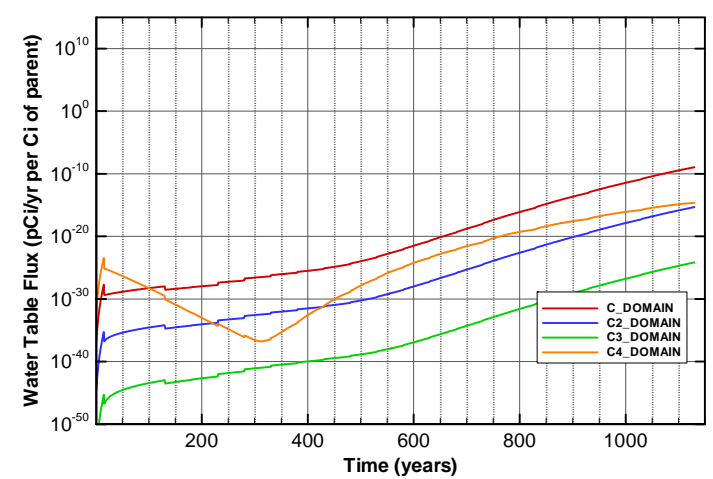

Figure A-215. Flux at water table for Case01_on Pu-240

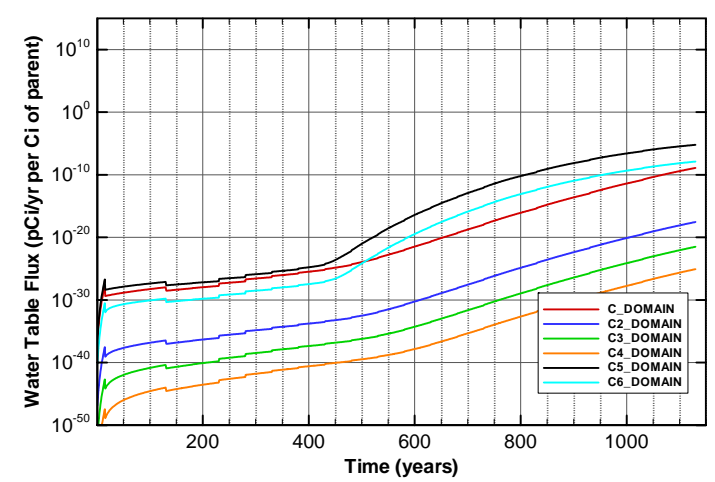

Figure A-217. Flux at water table for Case01_on Pu-242

Figure A-214. Flux at water table for Case01_on Pu-239

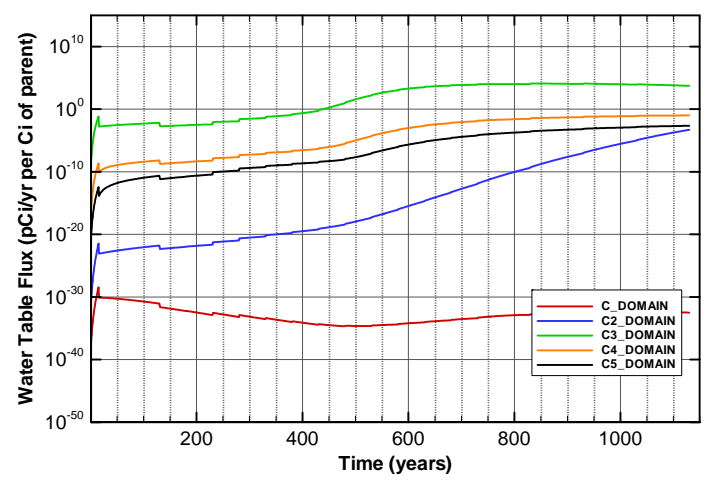

Figure A-216. Flux at water table for Case01_on Pu-241

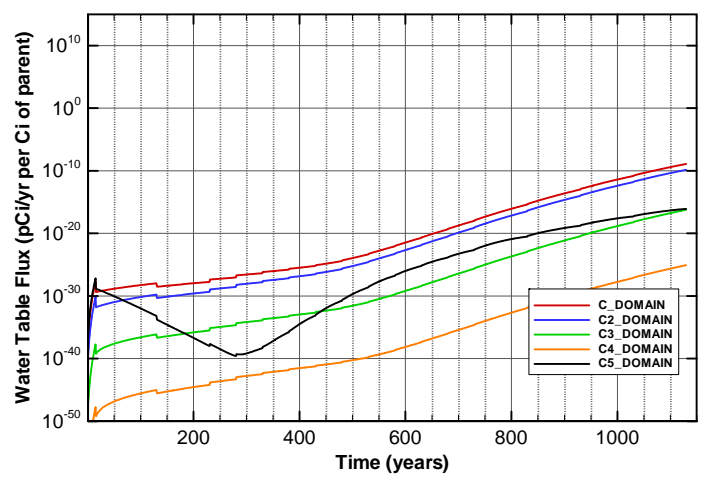

Figure A-218. Flux at water table for Case01_on Pu-244 
SRNL-STI-2008-00397, REVISION 0

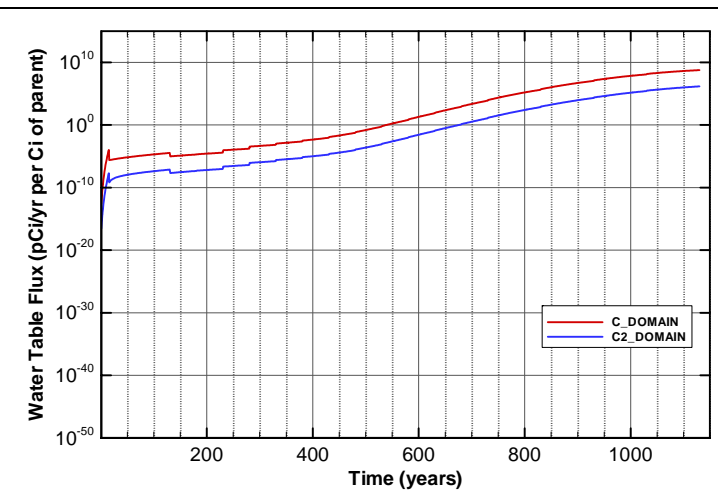

Figure A-219. Flux at water table for Case01_on Ra-226

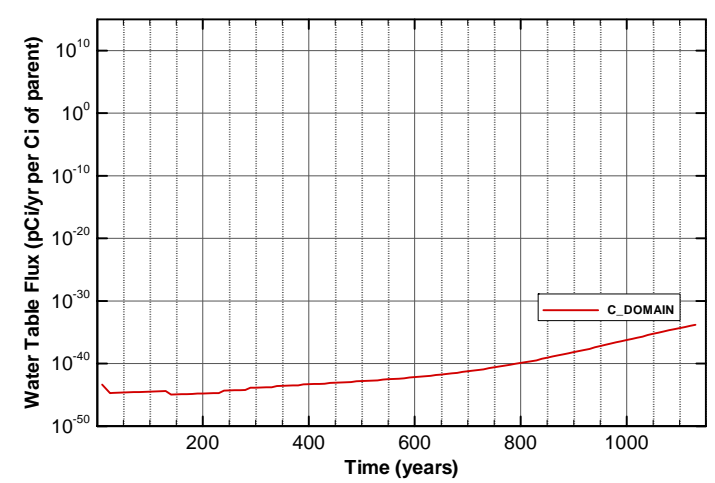

Figure A-221. Flux at water table for Case01_on Sn-126

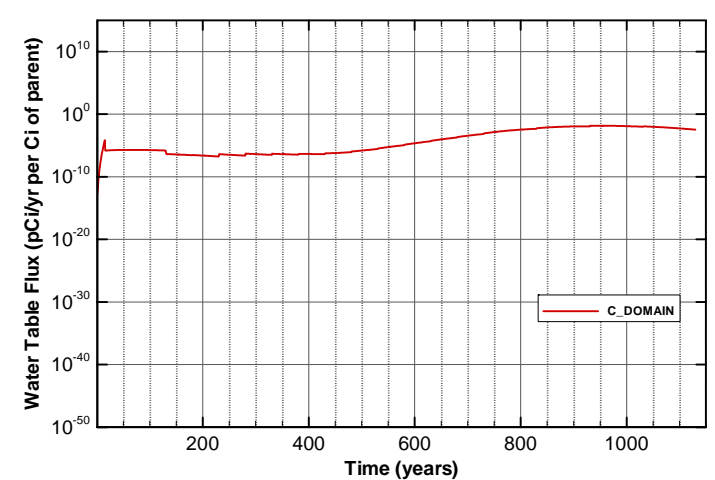

Figure A-223. Flux at water table for Case01_on Sr-90_Cask

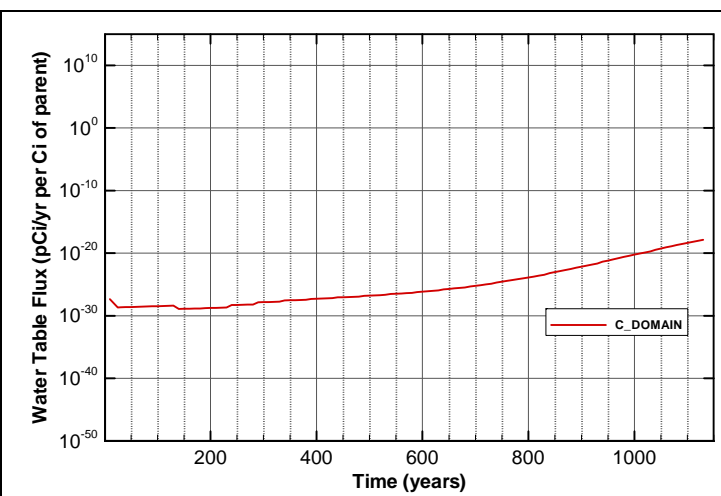

Figure A-220. Flux at water table for Case01_on Se-79

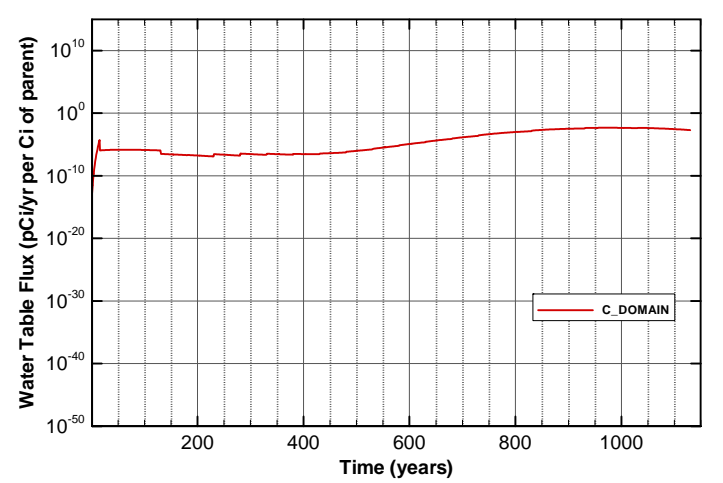

Figure A-222. Flux at water table for Case01_on Sr-90

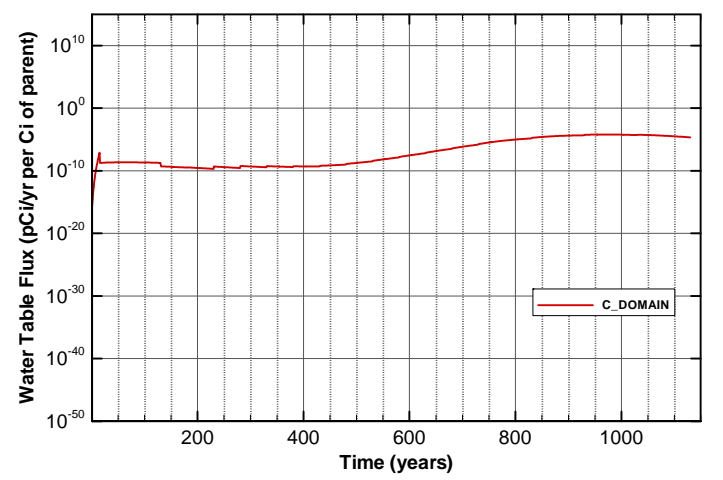

Figure A-224. Flux at water table for Case01_on Sr-90_Mk50A 


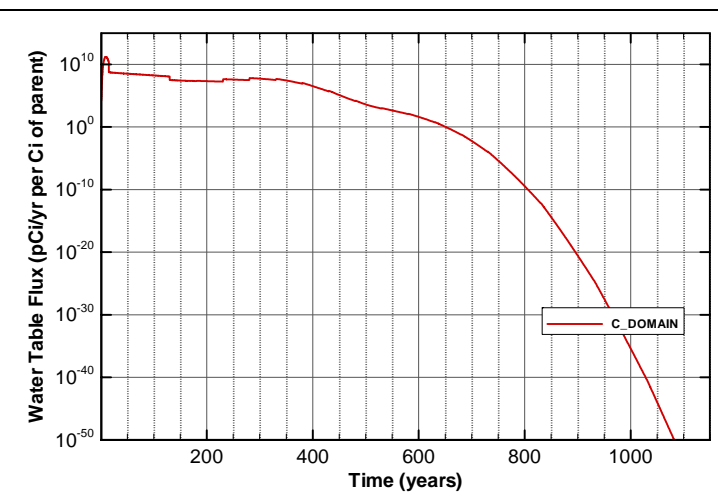

Figure A-225. Flux at water table for Case01_on Tc-99

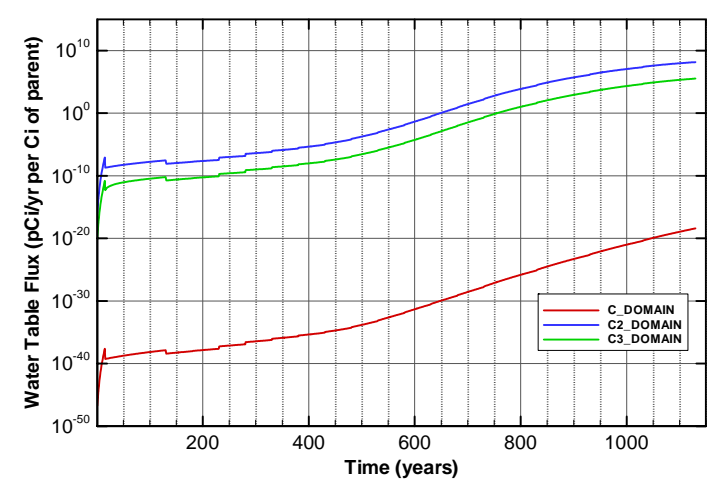

Figure A-227. Flux at water table for Case01_on Th-230

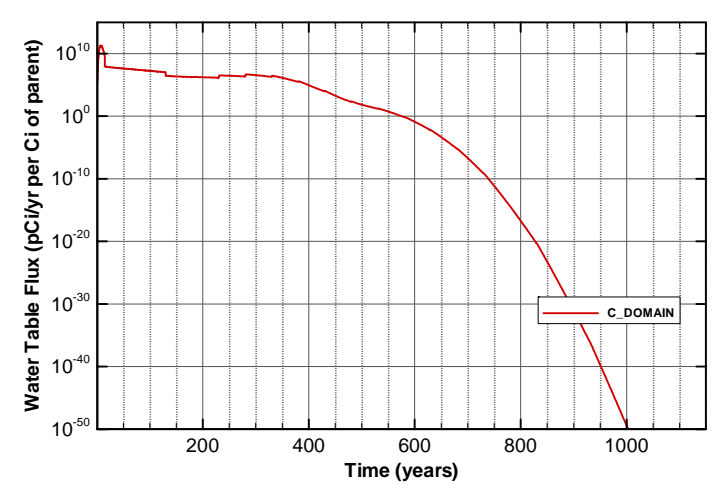

Figure A-229. Flux at water table for Case01_on Tracer

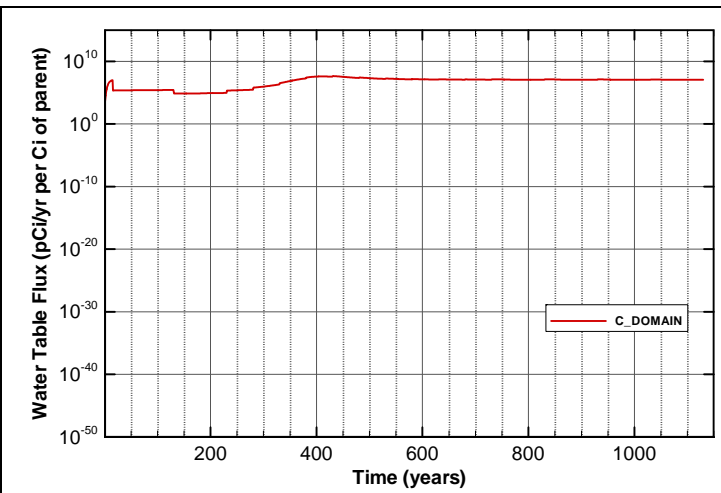

Figure A-226. Flux at water table for Case01_on Tc-99_Mk50A

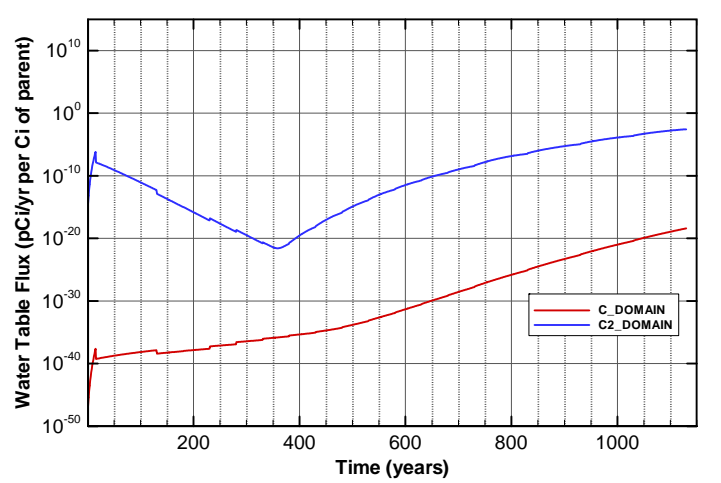

Figure A-228. Flux at water table for Case01_on Th-232

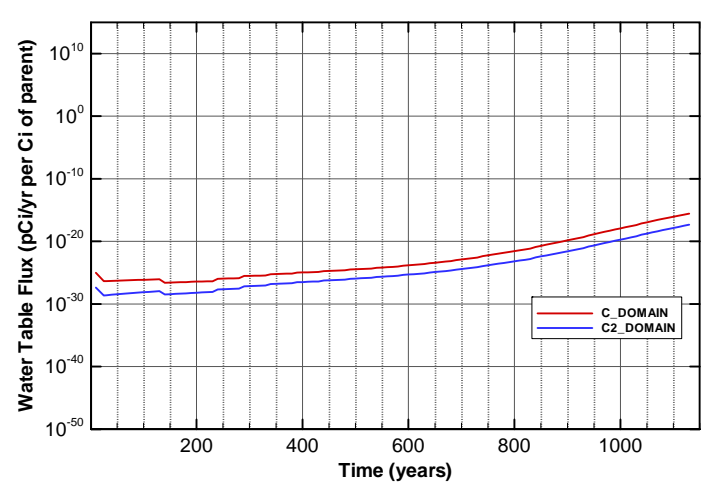

Figure A-230. Flux at water table for Case01_on U-233 
SRNL-STI-2008-00397, REVISION 0
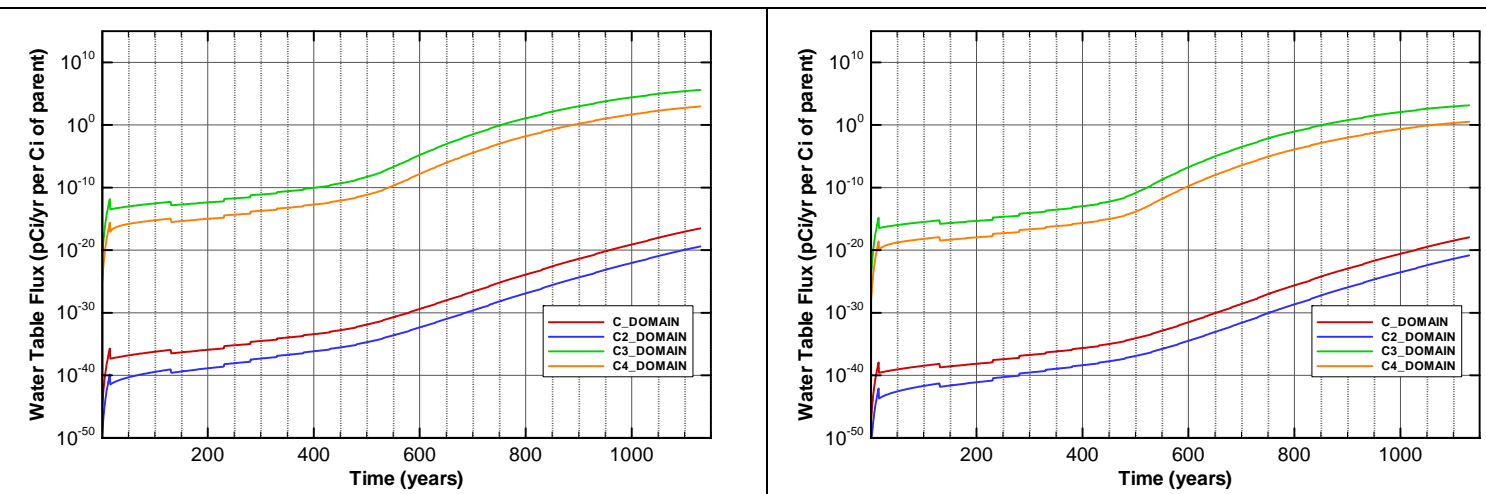

Figure A-231. Flux at water table for Case01_on U-234

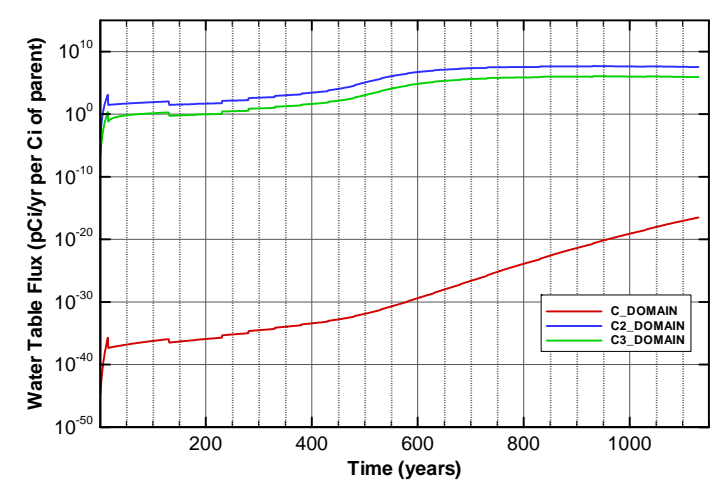

Figure A-233. Flux at water table for Case01_on U-235

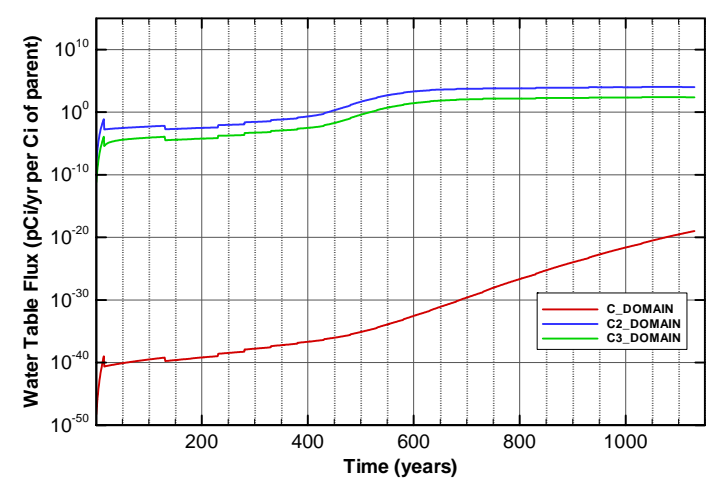

Figure A-235. Flux at water table for Case01_on U-235_Paducah.Cask

Figure A-232. Flux at water table for Case01_on U-234_Mglass

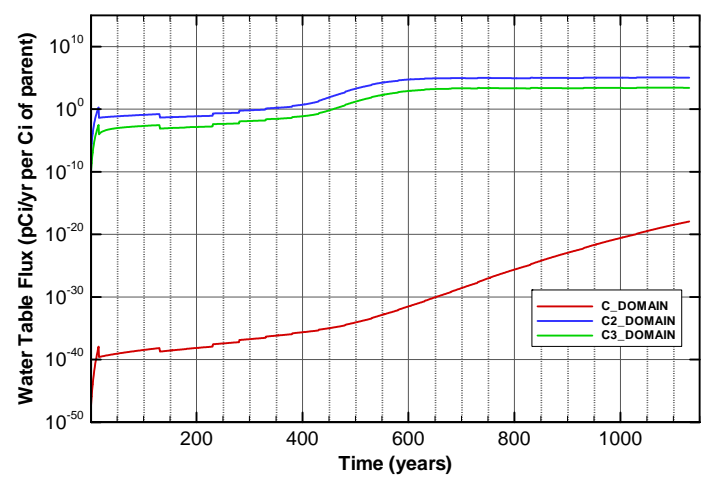

Figure A-234. Flux at water table for Case01_on U-235_Mglass

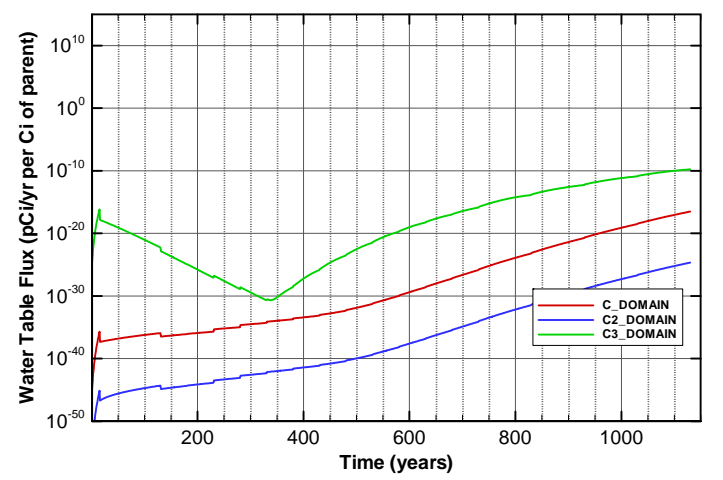

Figure A-236. Flux at water table for Case01_on U-236 
SRNL-STI-2008-00397, REVISION 0

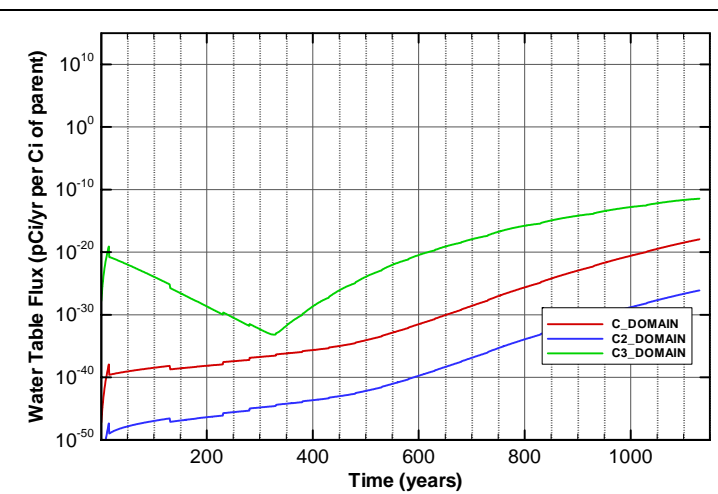

Figure A-237. Flux at water table for Case01_on U-236_Mglass

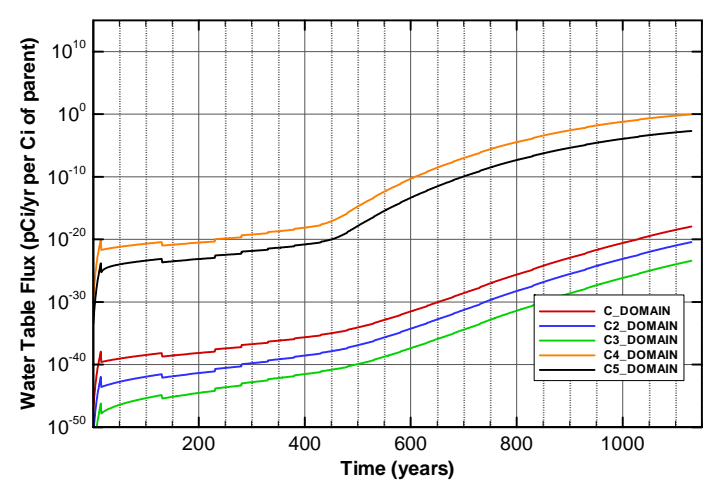

Figure A-239. Flux at water table for Case01_on U-238_Mglass

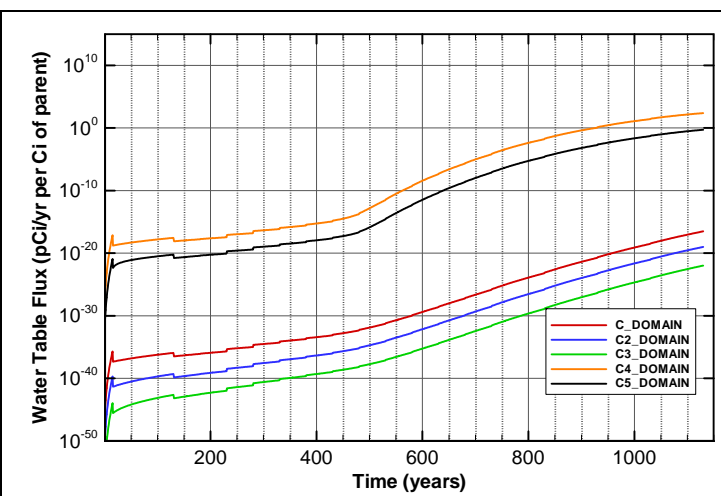

Figure A-238. Flux at water table for Case01_on U-238

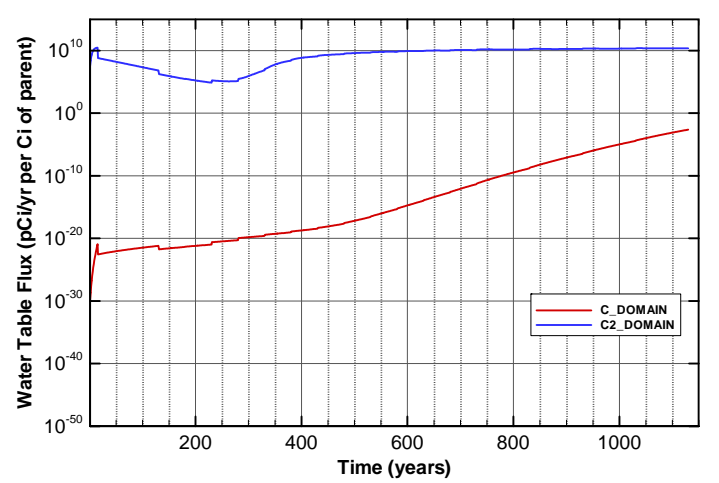

Figure A-240. Flux at water table for Case01_on Zr-93

\subsubsection{Center trench flux plots for 5-year cover}

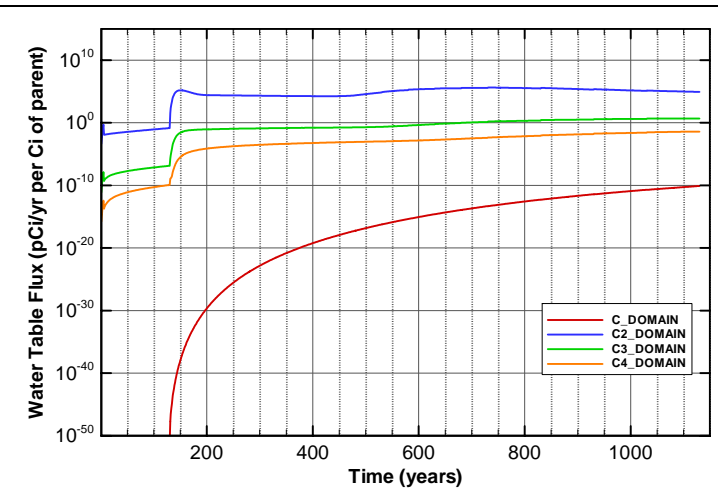

Figure A-241. Flux at water table for Case01n11_off Am-241

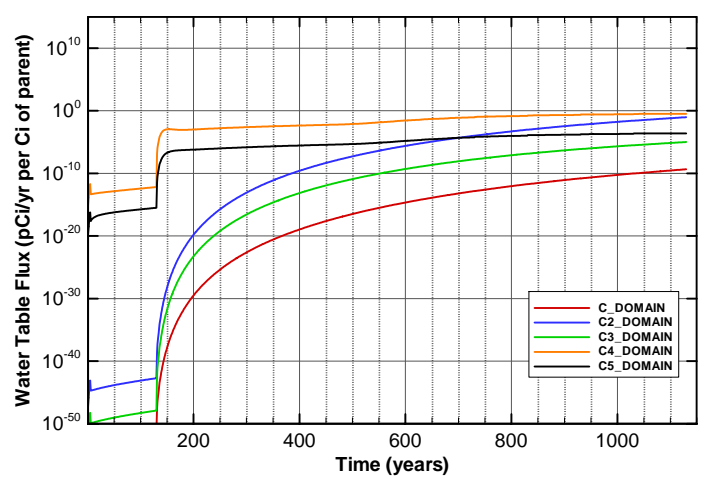

Figure A-242. Flux at water table for Case01n11_off Am-243 
SRNL-STI-2008-00397, REVISION 0

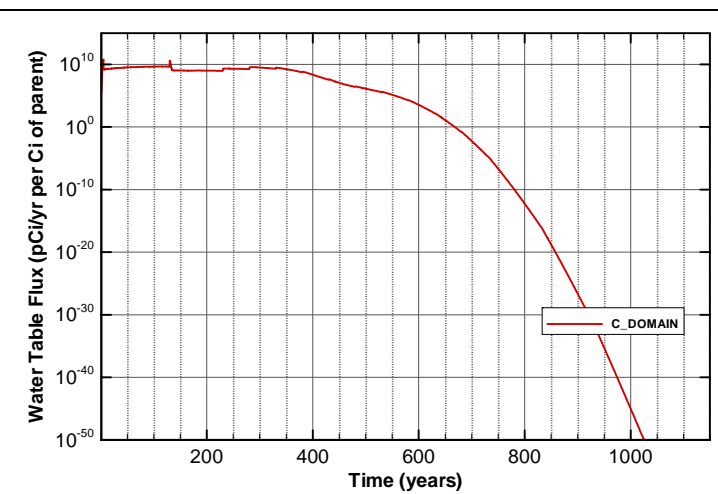

Figure A-243. Flux at water table for Case01n11_off C-14

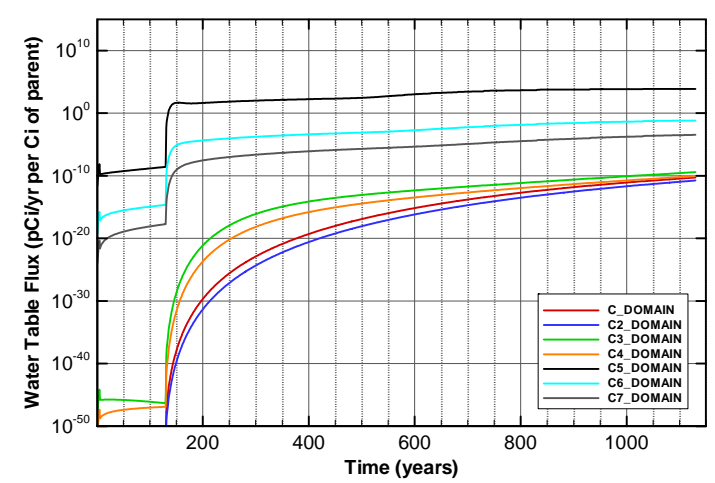

Figure A-245. Flux at water table for Case01n11_off Cf-249

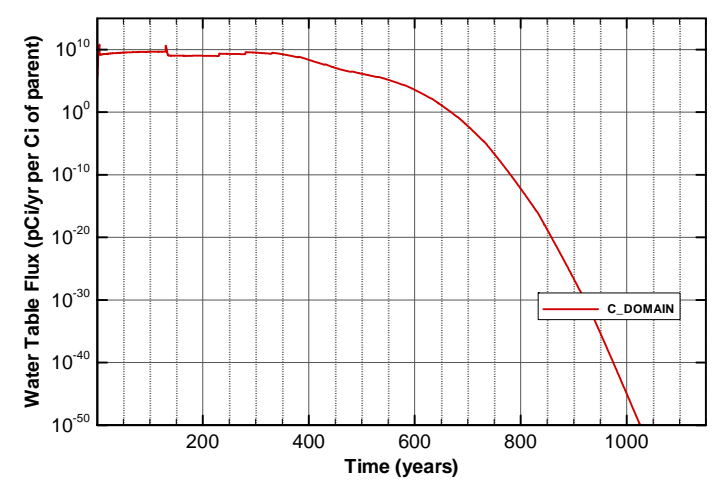

Figure A-247. Flux at water table for Case01n11_off Cl-36

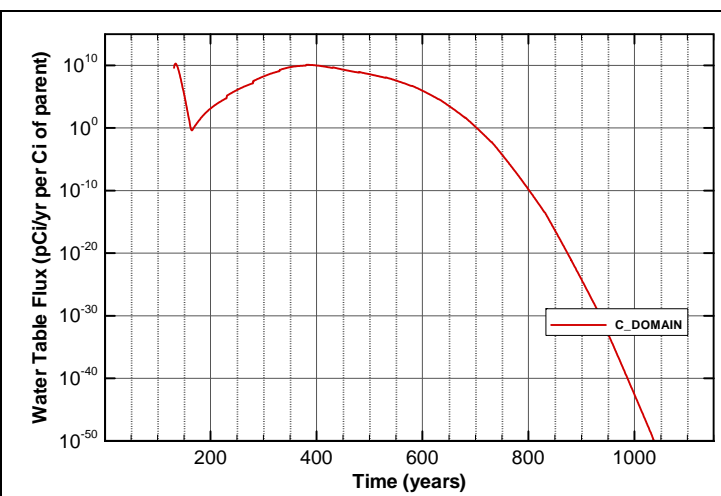

Figure A-244. Flux at water table for Case01n11_off C-14_NR.Pump

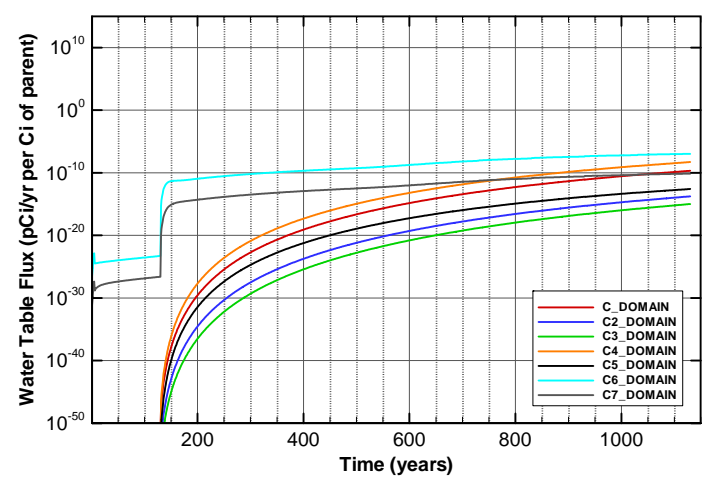

Figure A-246. Flux at water table for Case01n11_off Cf-251

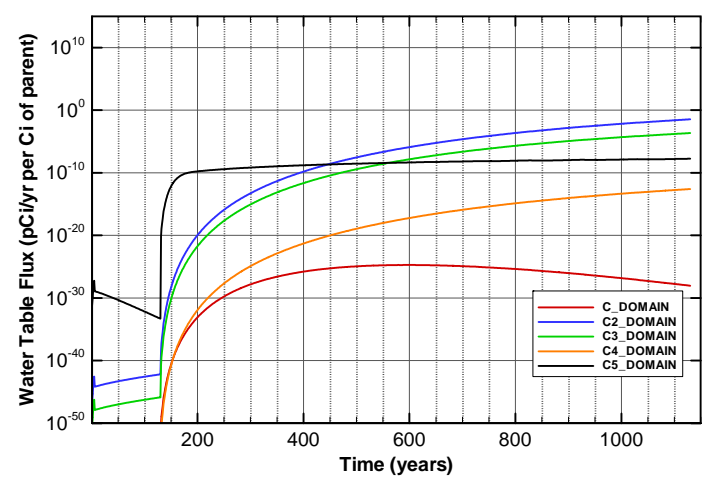

Figure A-248. Flux at water table for Case01n11_off Cm-244 
SRNL-STI-2008-00397, REVISION 0

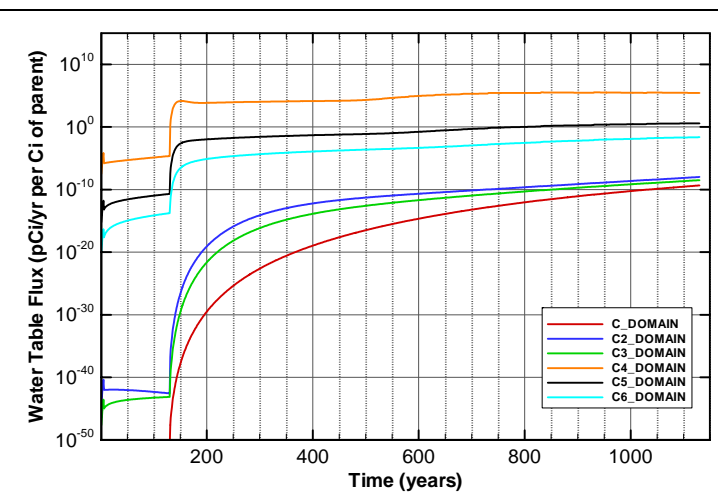

Figure A-249. Flux at water table for Case01n11_off Cm-245

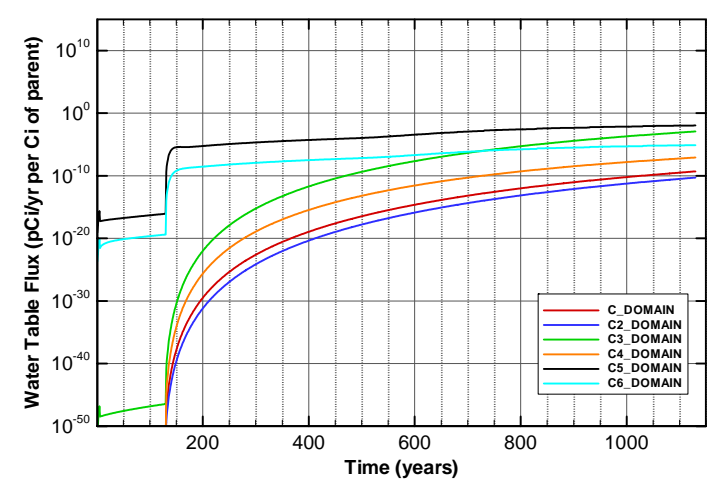

Figure A-251. Flux at water table for Case01n11_off Cm-247

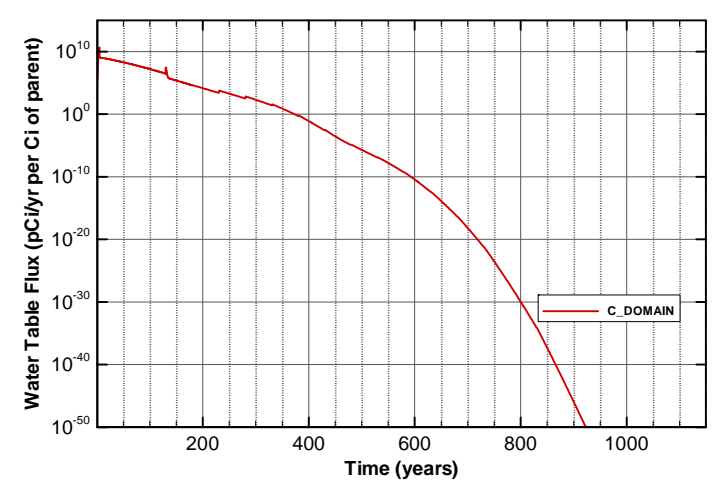

Figure A-253. Flux at water table for Case01n11_off H-3

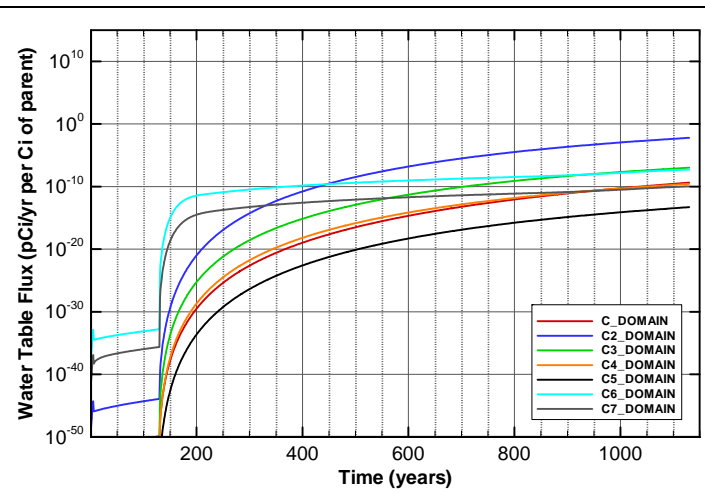

Figure A-250. Flux at water table for Case01n11_off Cm-246

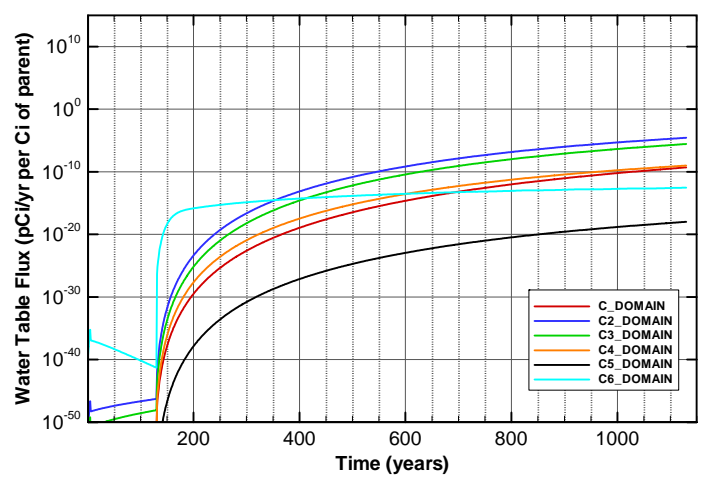

Figure A-252. Flux at water table for Case01n11_off Cm-248

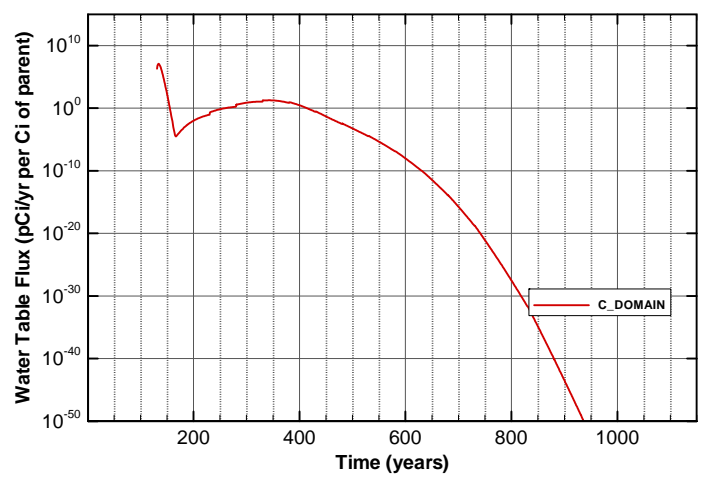

Figure A-254. Flux at water table for Case01n11_off H-3_ETF.Carbon 


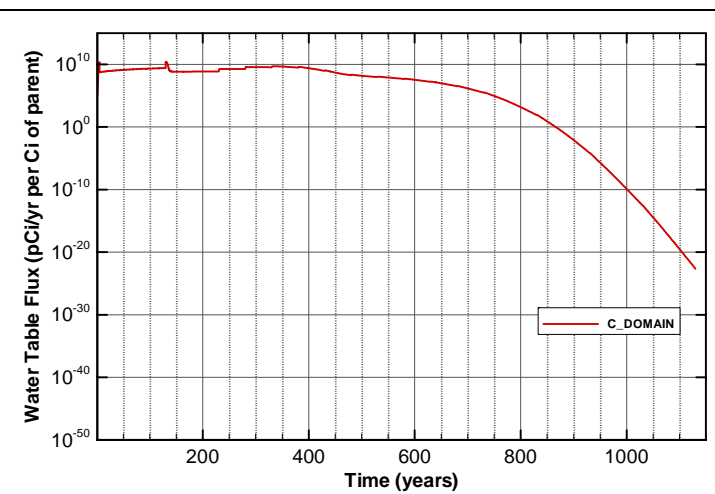

Figure A-255. Flux at water table for Case01n11_off I-129

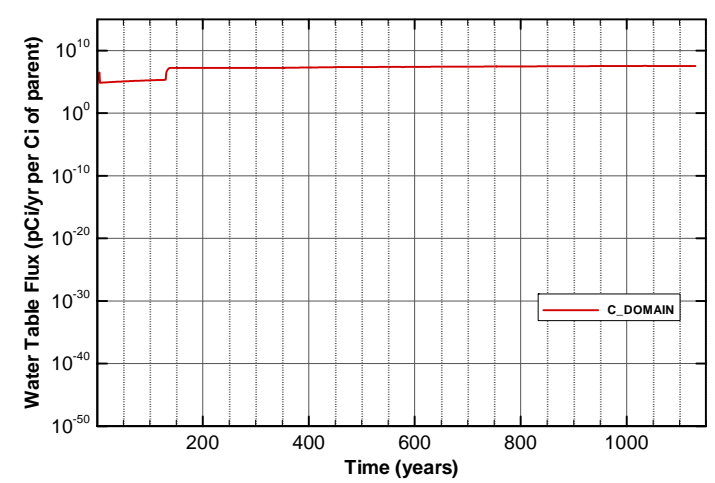

Figure A-257. Flux at water table for Case01n11_off I-129_ETF.GT.73

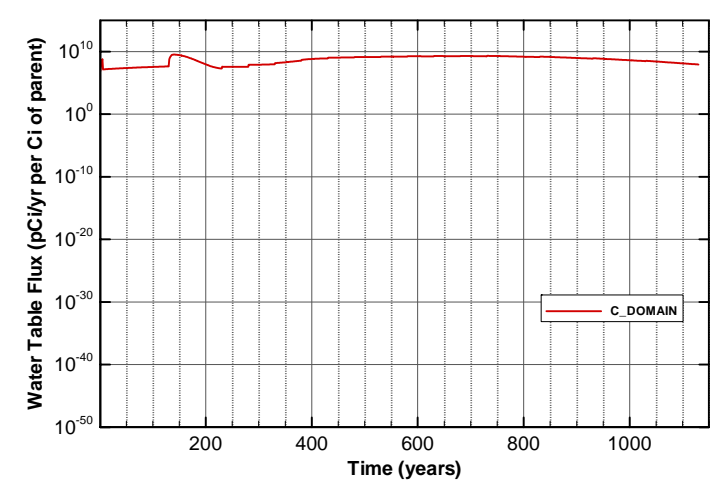

Figure A-259. Flux at water table for Case01n11_off I-129_F.CG.8

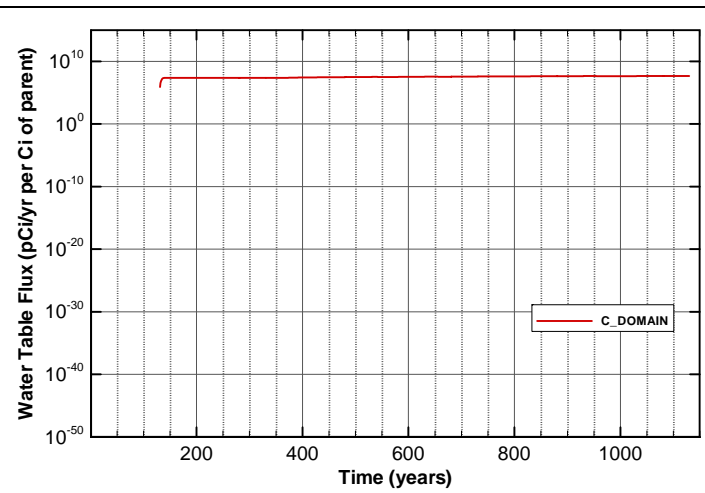

Figure A-256. Flux at water table for Case01n11_off I-129_ETF.Carbon

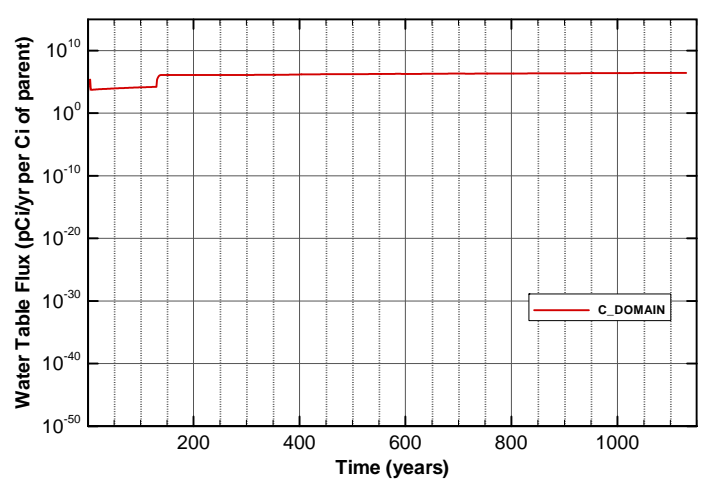

Figure A-258. Flux at water table for Case01n11_off I-129_F.Carbon

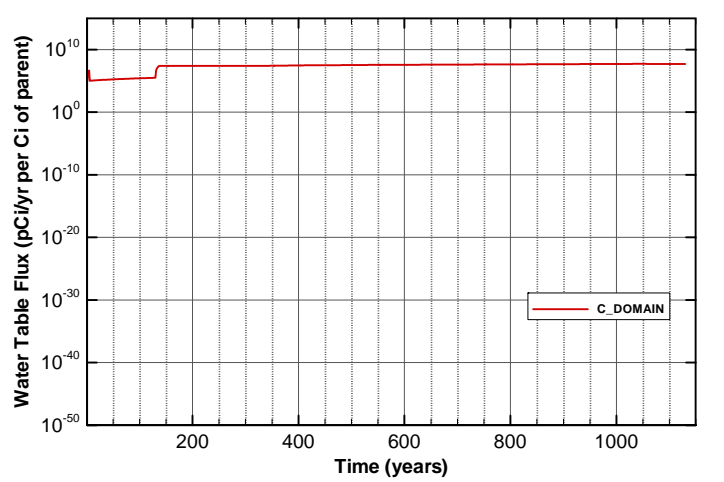

Figure A-260. Flux at water table for Case01n11_off I-129_F.Dowex.21K 


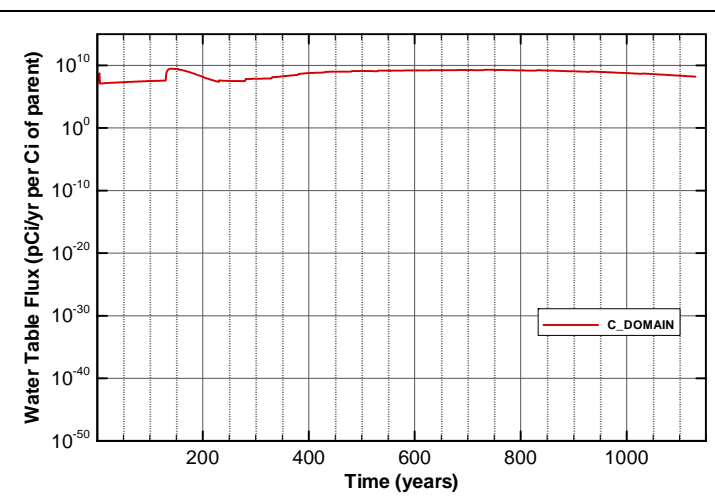

Figure A-261. Flux at water table for Case01n11_off I-129_F.Filtercake

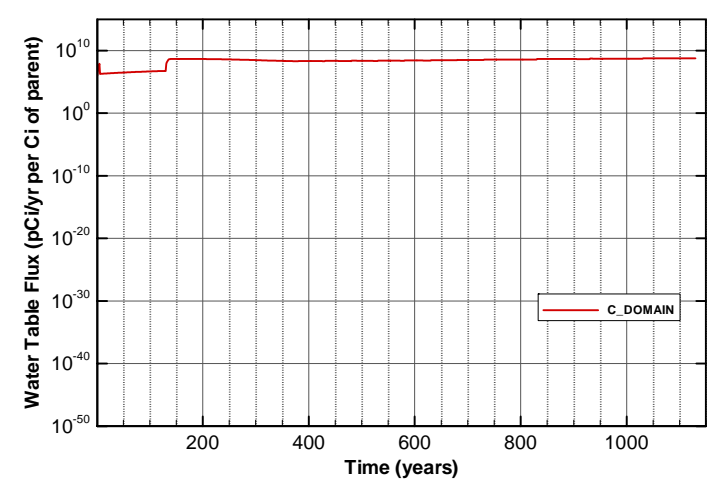

Figure A-263. Flux at water table for Case01n11_off I-129_H.CG.8

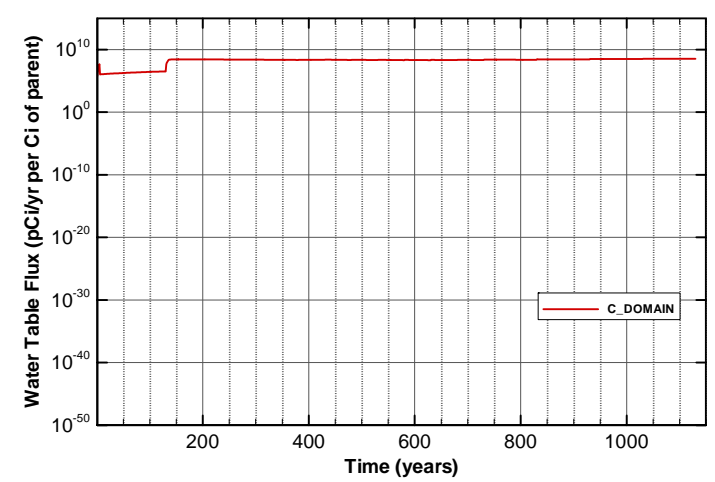

Figure A-265. Flux at water table for Case01n11_off I-129_H.Filtercake

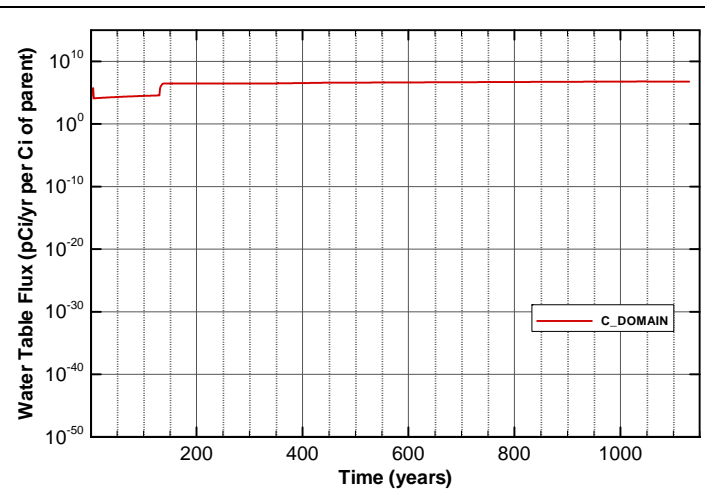

Figure A-262. Flux at water table for Case01n11_off I-129_H.Carbon

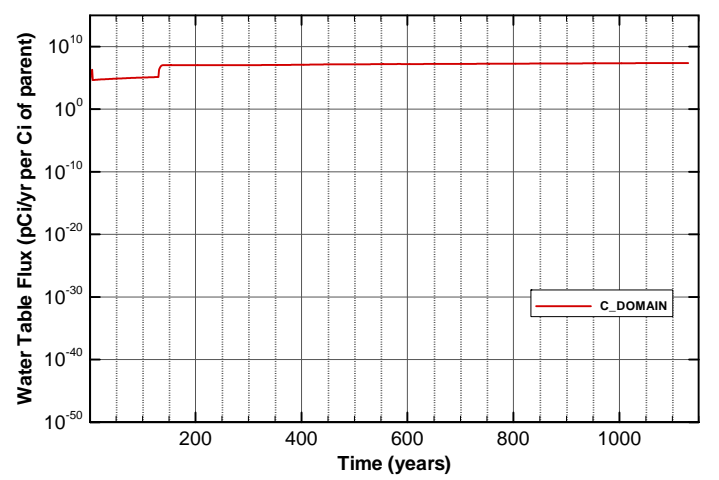

Figure A-264. Flux at water table for Case01n11_off I-129_H.Dowex.21K

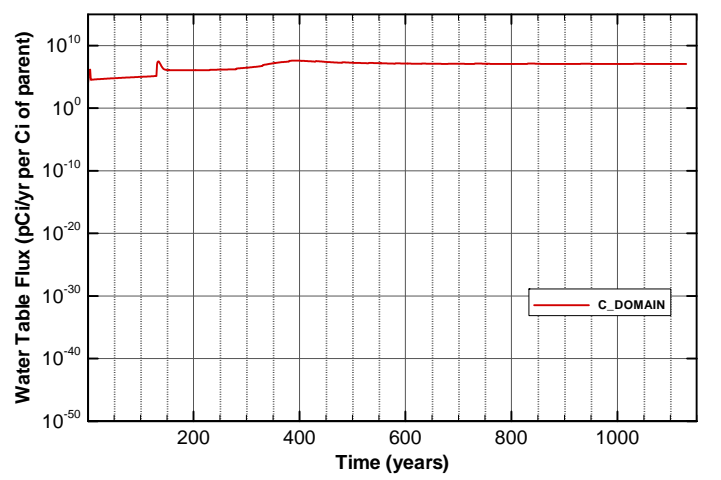

Figure A-266. Flux at water table for Case01n11_off I-129_Mk50A 


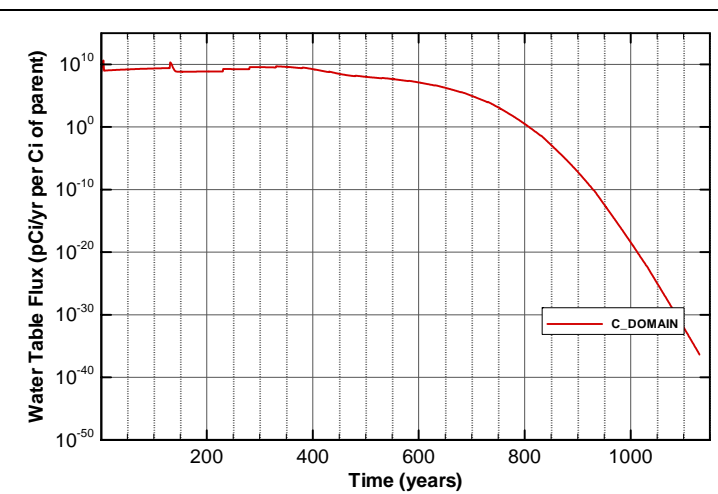

Figure A-267. Flux at water table for Case01n11_off K-40

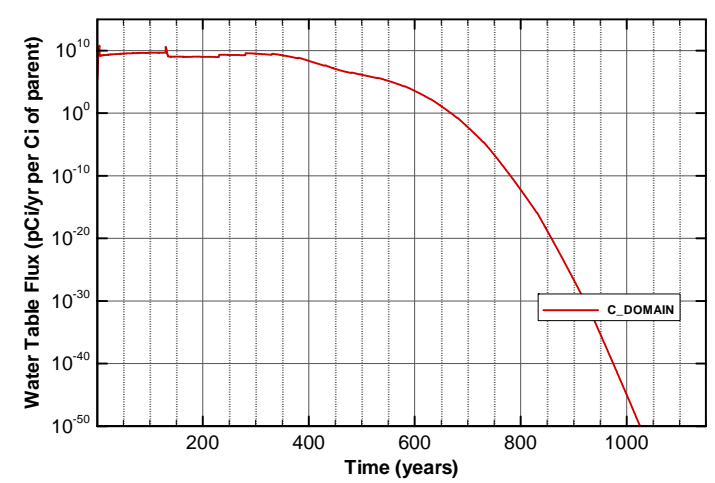

Figure A-269. Flux at water table for Case01n11_off Nb-94

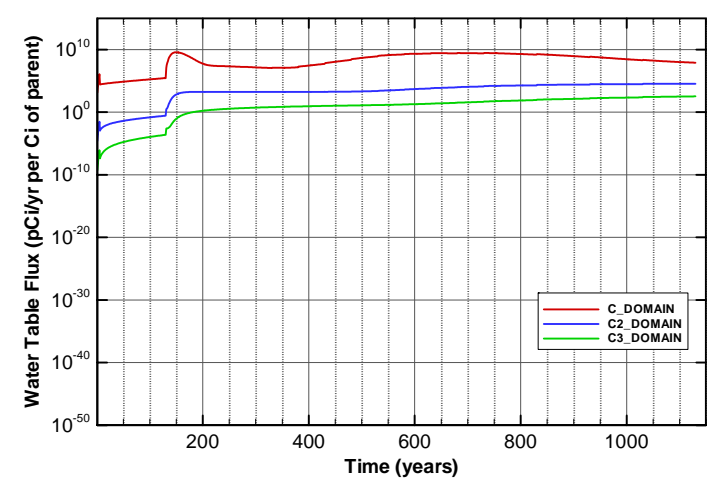

Figure A-271. Flux at water table for Case01n11_off Np-237

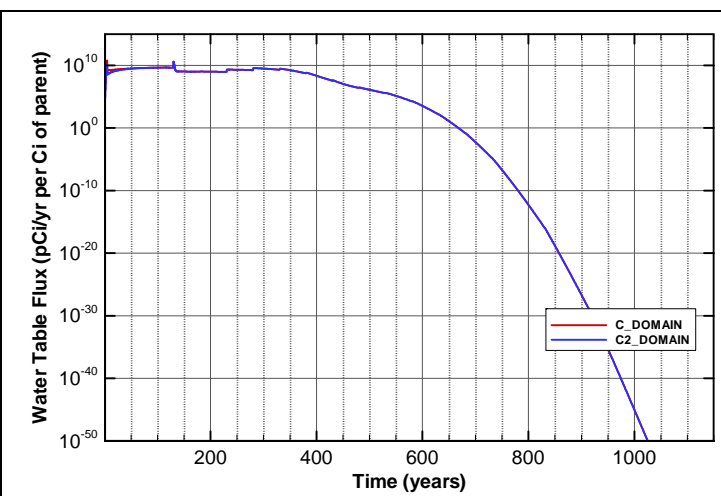

Figure A-268. Flux at water table for Case01n11_off Mo-93

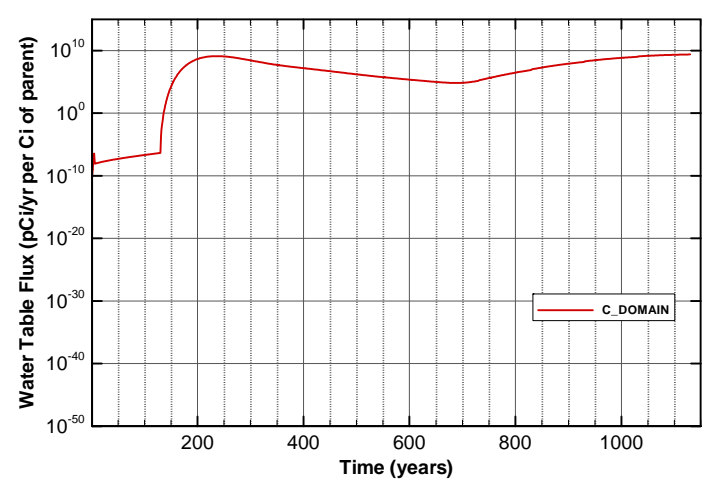

Figure A-270. Flux at water table for Case01n11_off Ni-59

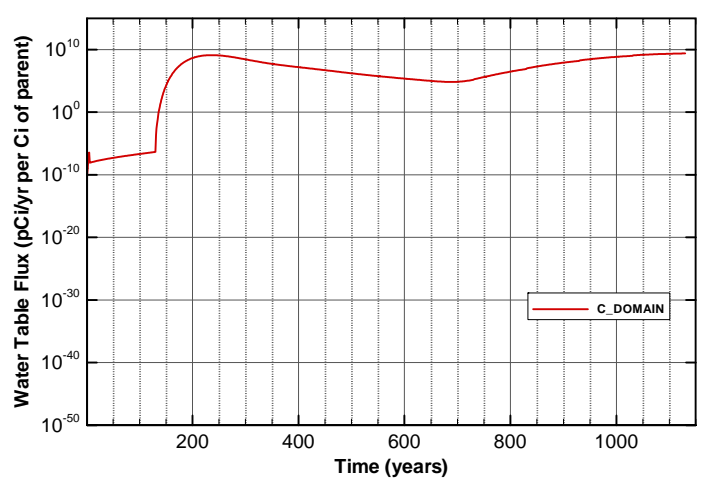

Figure A-272. Flux at water table for Case01n11_off Pd-107 
SRNL-STI-2008-00397, REVISION 0
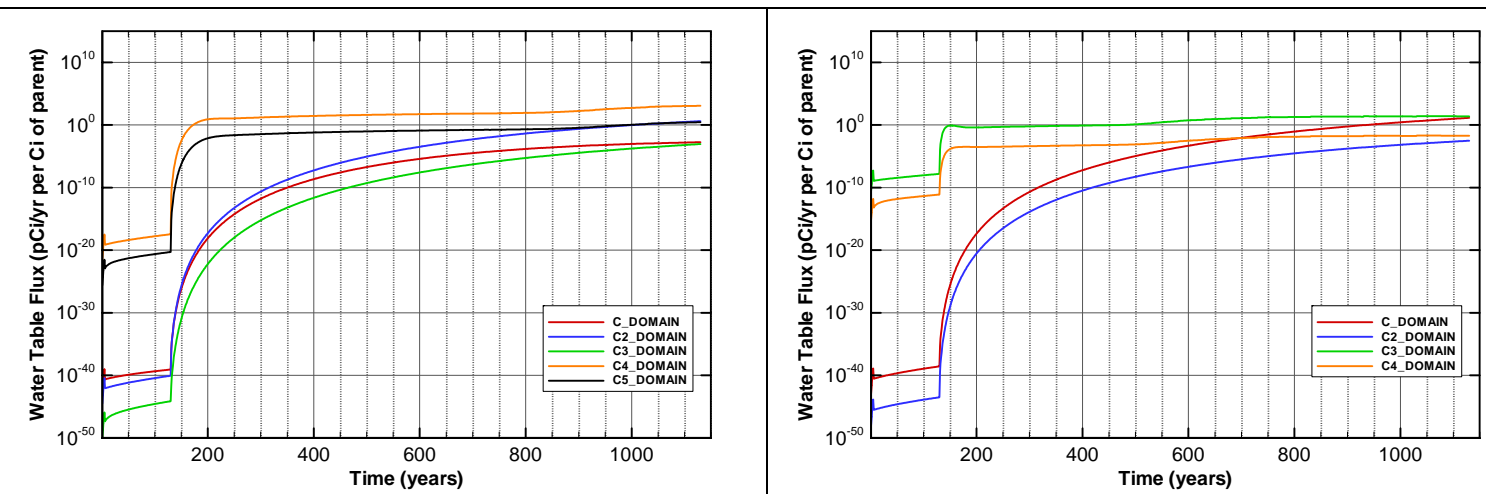

Figure A-273. Flux at water table for Case01n11_off Pu-238

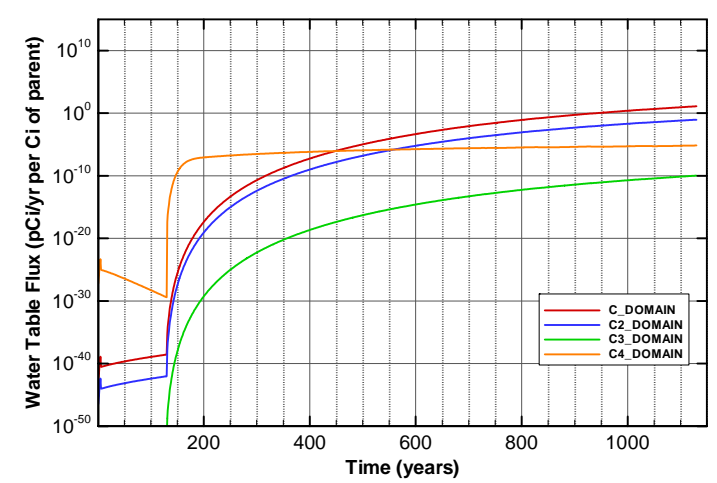

Figure A-275. Flux at water table for Case01n11_off Pu-240

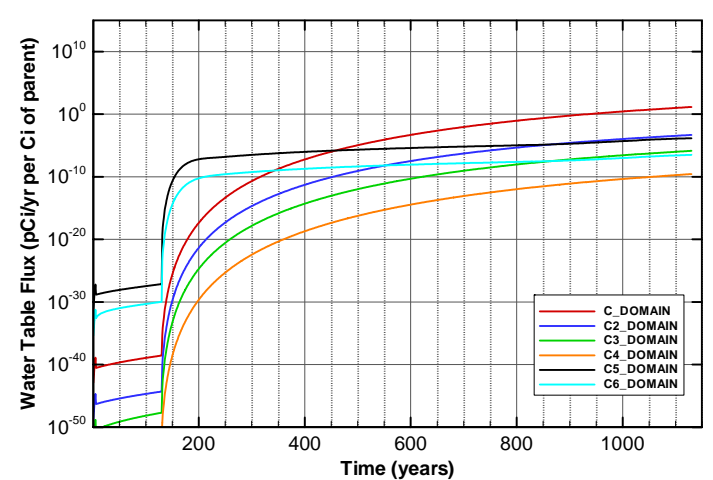

Figure A-277. Flux at water table for Case01n11_off Pu-242

Figure A-274. Flux at water table for Case01n11_off Pu-239

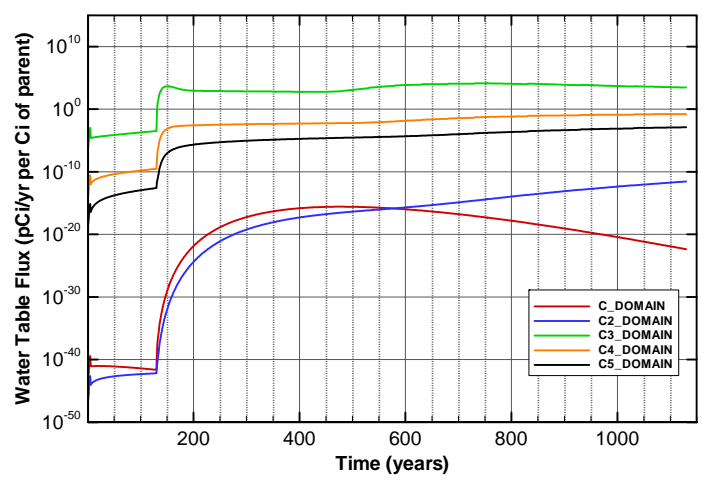

Figure A-276. Flux at water table for Case01n11_off Pu-241

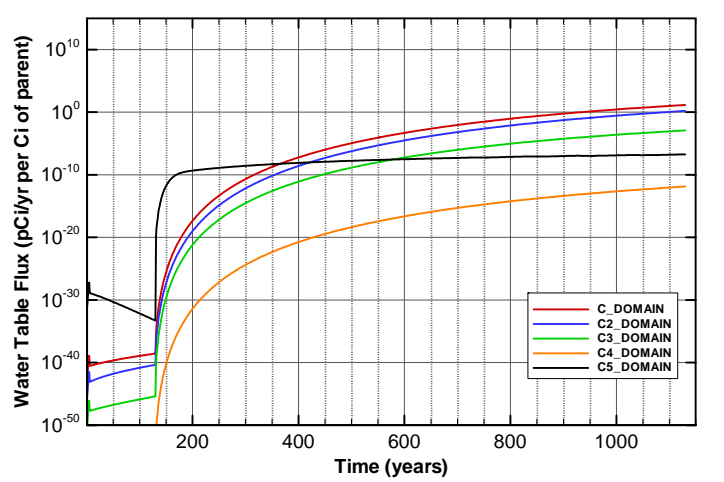

Figure A-278. Flux at water table for Case01n11_off Pu-244 


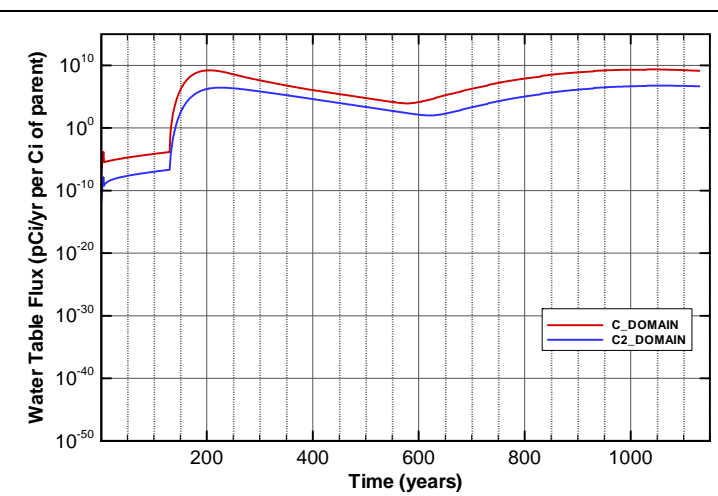

Figure A-279. Flux at water table for Case01n11_off Ra-226

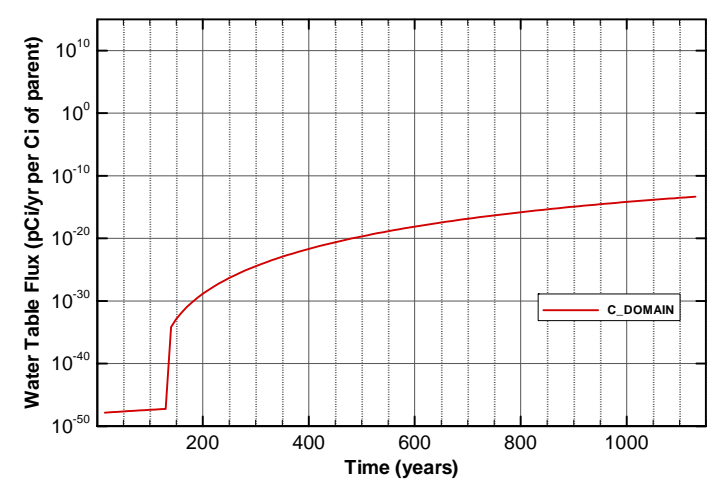

Figure A-281. Flux at water table for Case01n11_off Sn-126

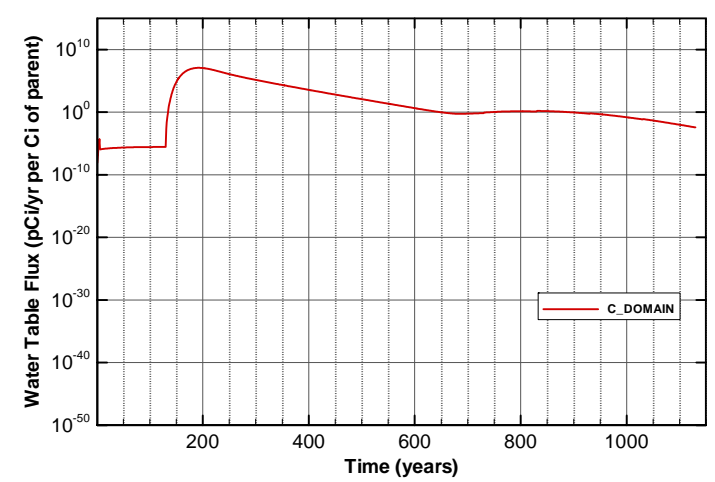

Figure A-283. Flux at water table for Case01n11_off Sr-90_Cask

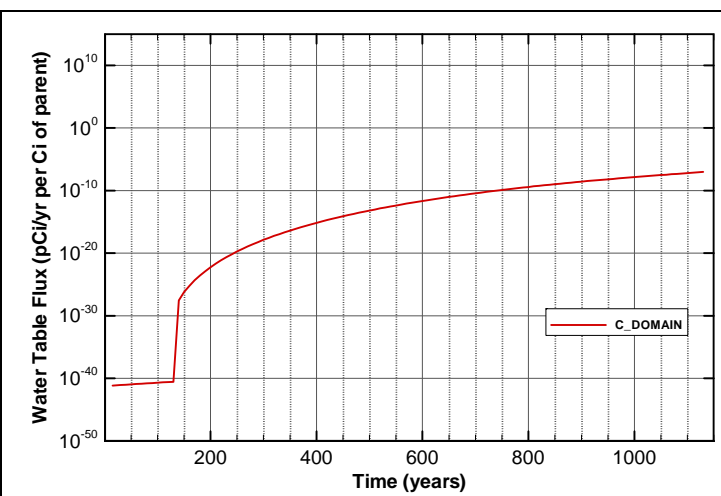

Figure A-280. Flux at water table for Case01n11_off Se-79

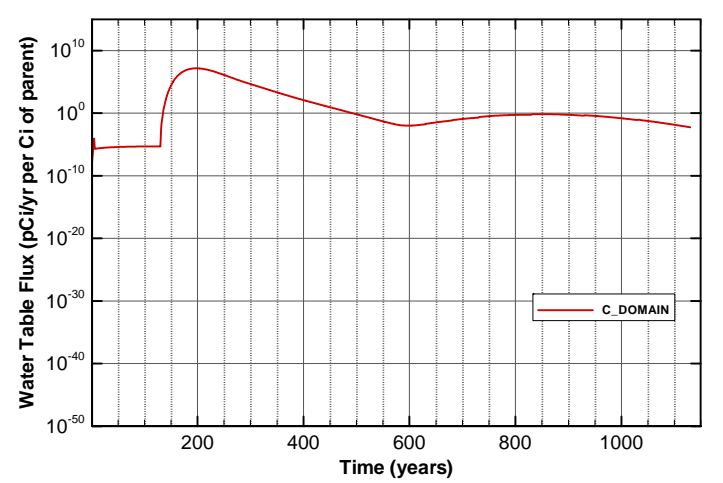

Figure A-282. Flux at water table for Case01n11_off Sr-90

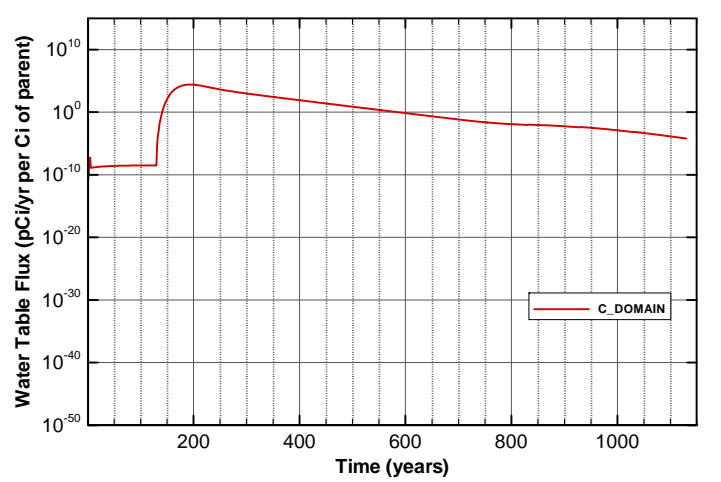

Figure A-284. Flux at water table for Case01n11_off Sr-90_Mk50A 


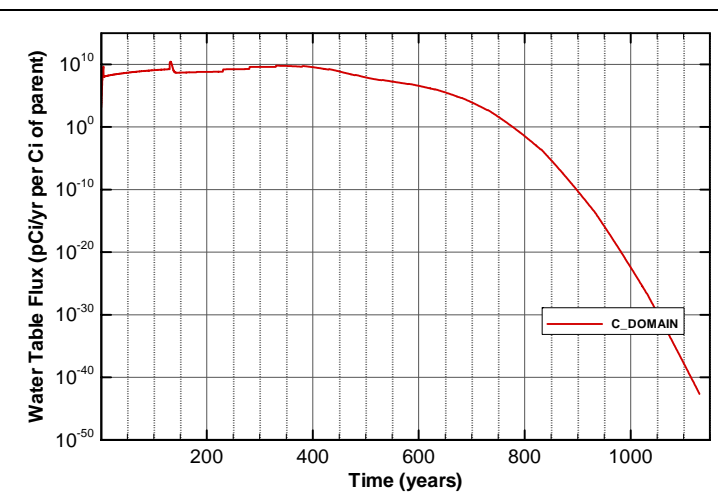

Figure A-285. Flux at water table for Case01n11_off Tc-99

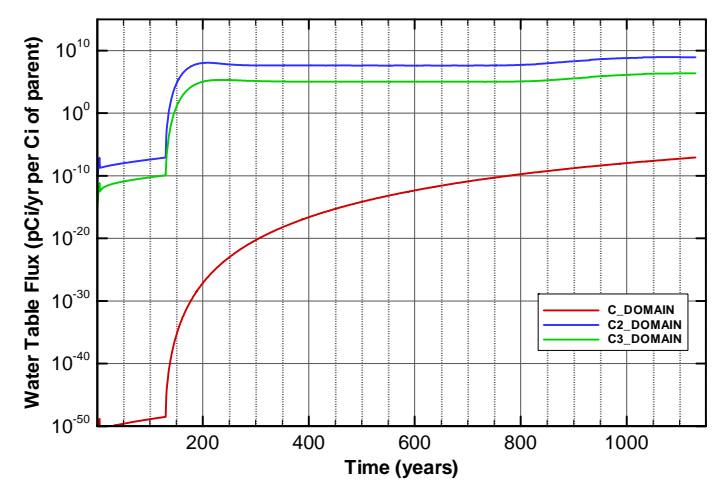

Figure A-287. Flux at water table for Case01n11_off Th-230

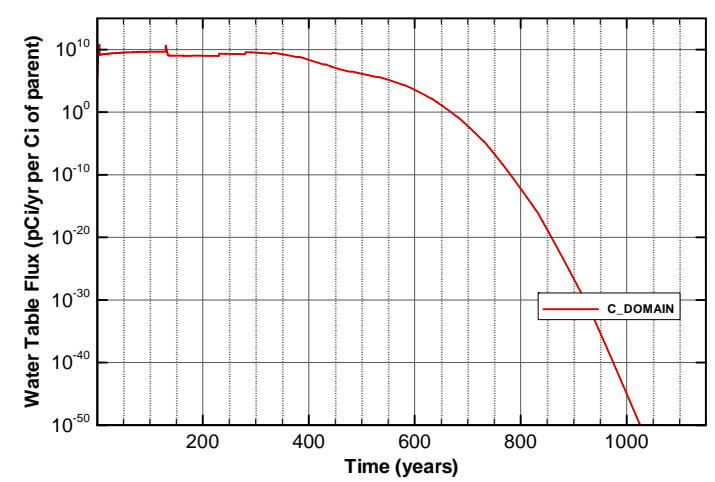

Figure A-289. Flux at water table for Case01n11_off Tracer

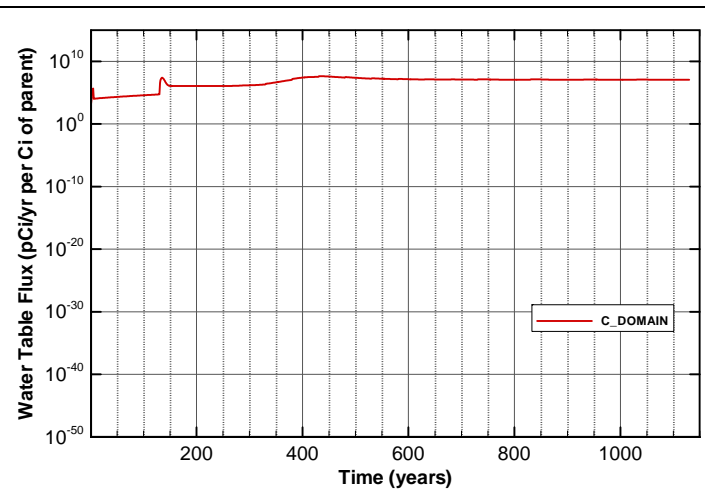

Figure A-286. Flux at water table for Case01n11_off Tc-99_Mk50A

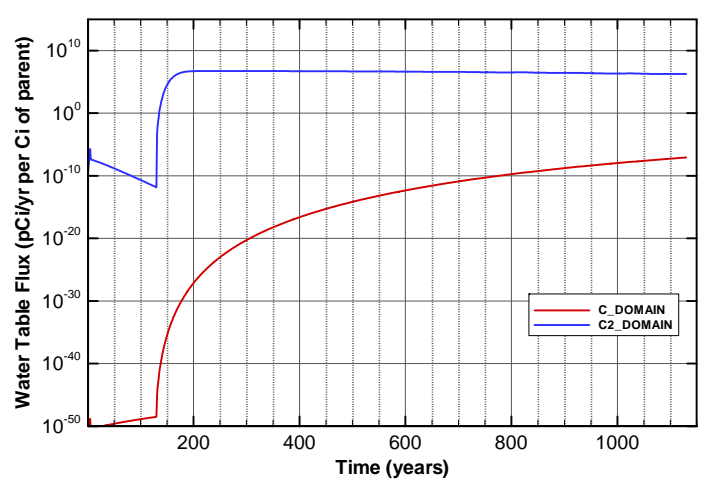

Figure A-288. Flux at water table for Case01n11_off Th-232

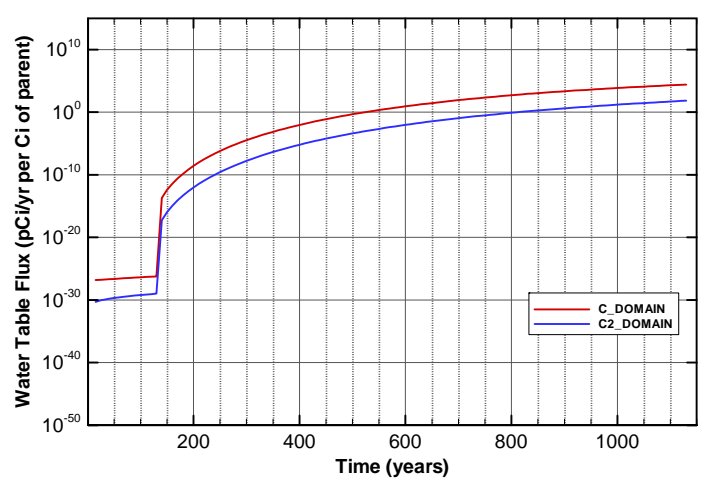

Figure A-290. Flux at water table for Case01n11_off U-233 


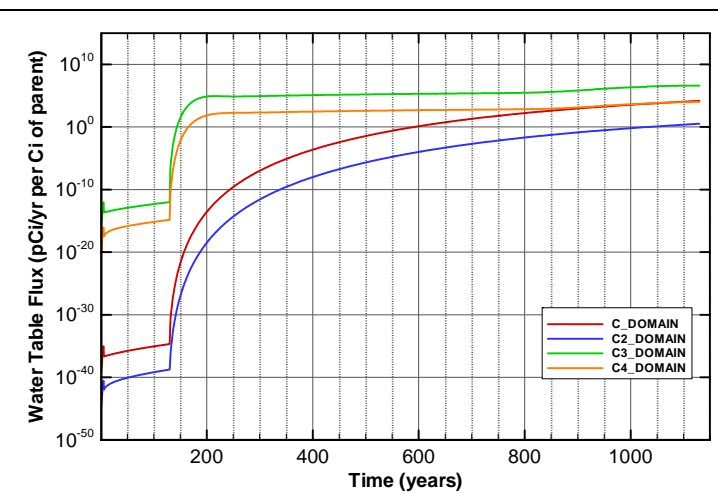

Figure A-291. Flux at water table for Case01n11_off U-234

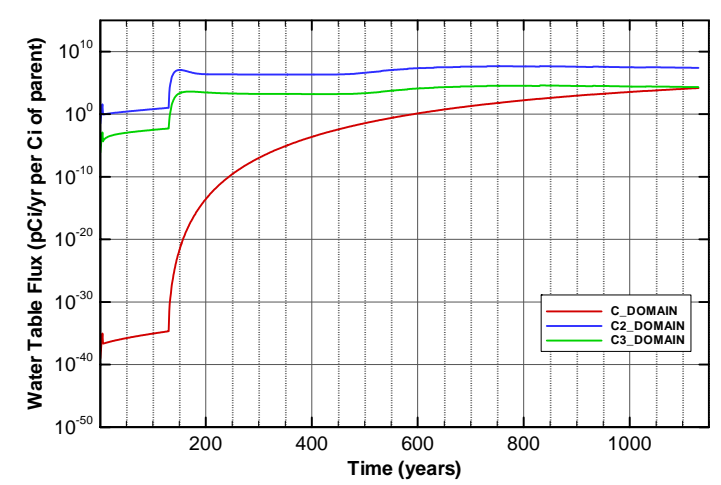

Figure A-293. Flux at water table for Case01n11_off U-235

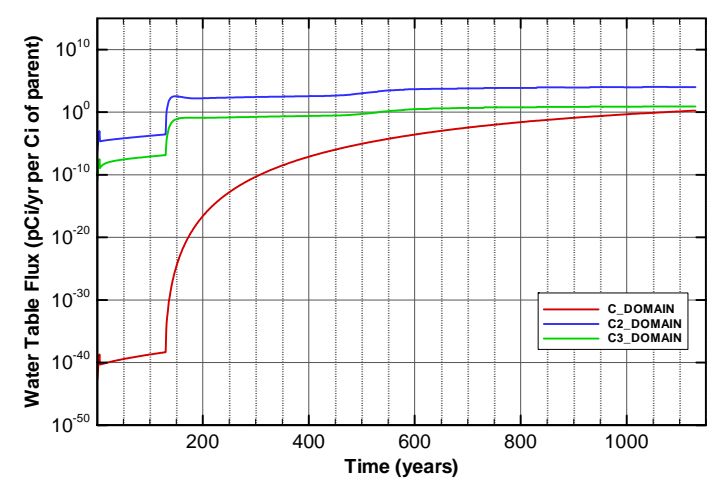

Figure A-295. Flux at water table for Case01n11_off U-235_Paducah.Cask

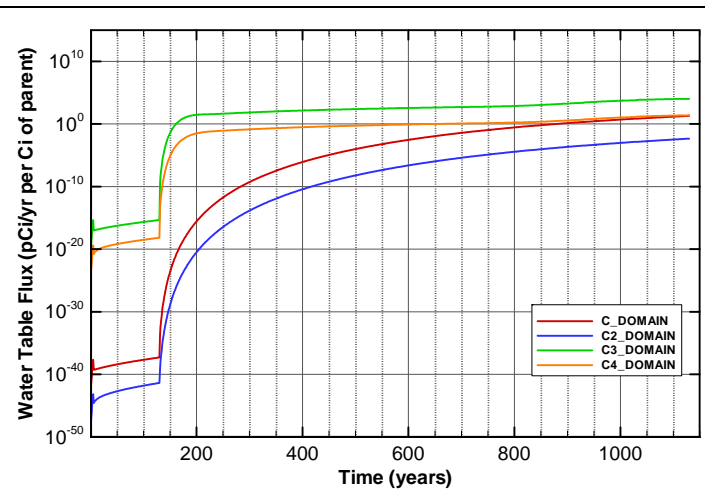

Figure A-292. Flux at water table for Case01n11_off U-234_Mglass

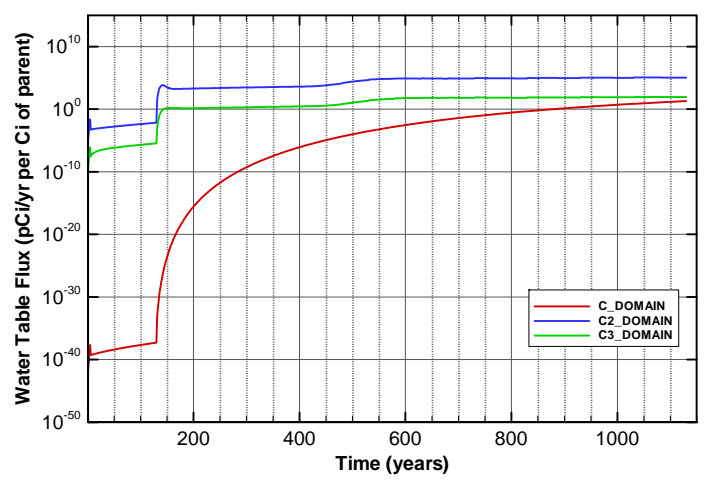

Figure A-294. Flux at water table for Case01n11_off U-235_Mglass

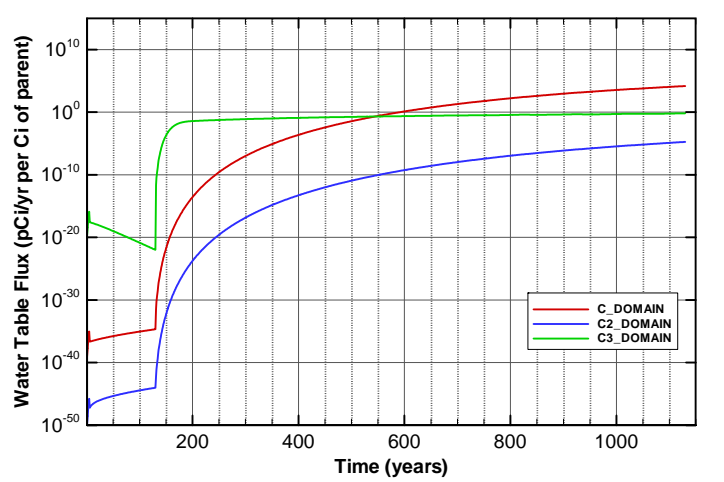

Figure A-296. Flux at water table for Case01n11_off U-236 


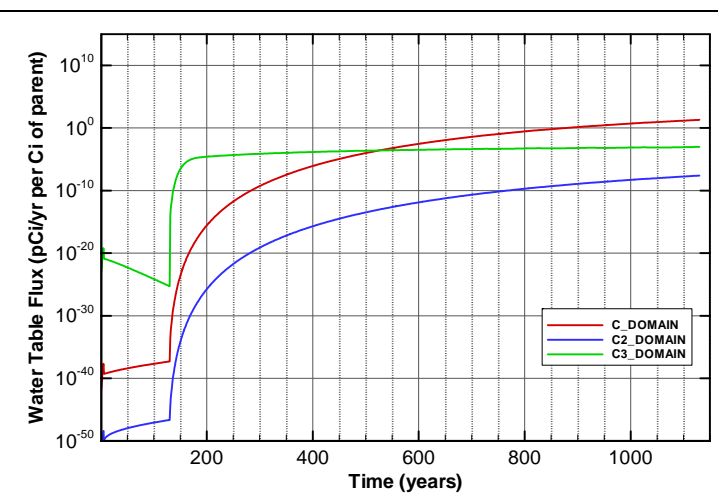

Figure A-297. Flux at water table for Case01n11_off U-236_Mglass

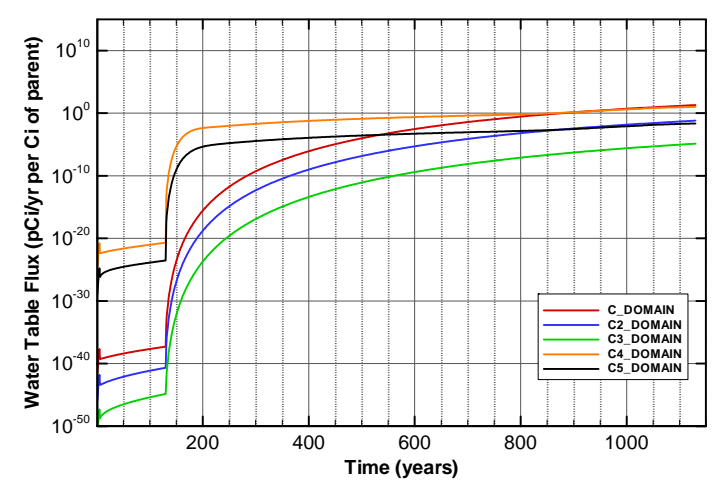

Figure A-299. Flux at water table for Case01n11_off U-238_Mglass

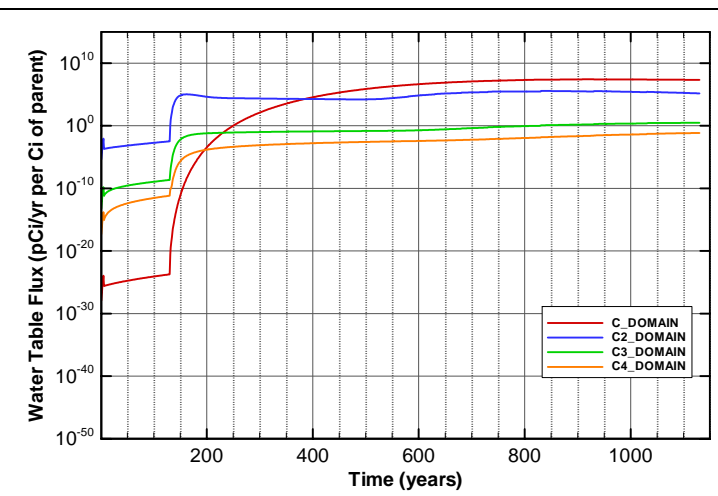

Figure A-301. Flux at water table for Case01n11_on Am-241

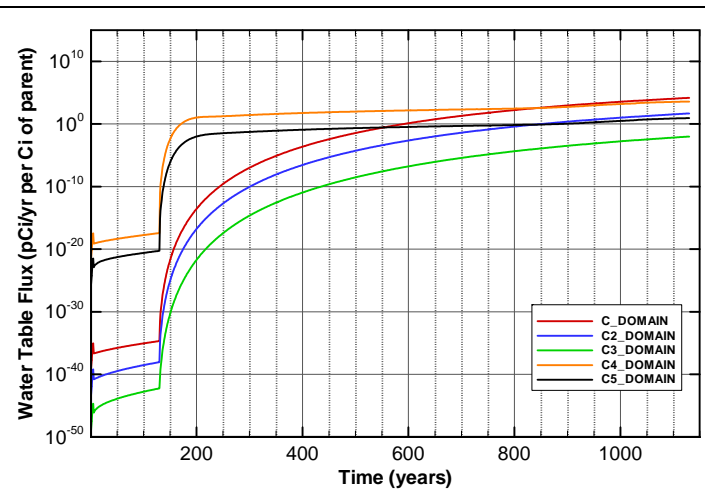

Figure A-298. Flux at water table for Case01n11_off U-238

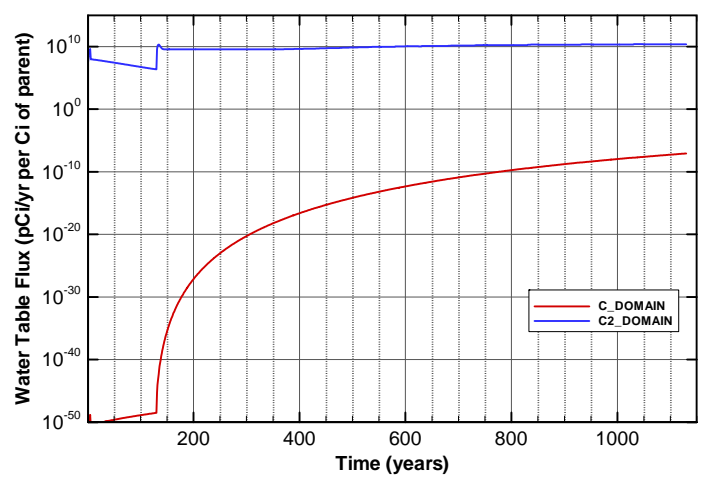

Figure A-300. Flux at water table for Case01n11_off Zr-93

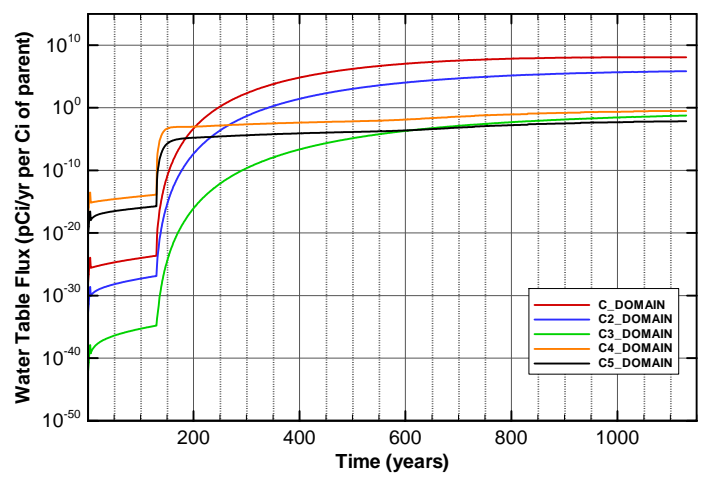

Figure A-302. Flux at water table for Case01n11_on Am-243 
SRNL-STI-2008-00397, REVISION 0
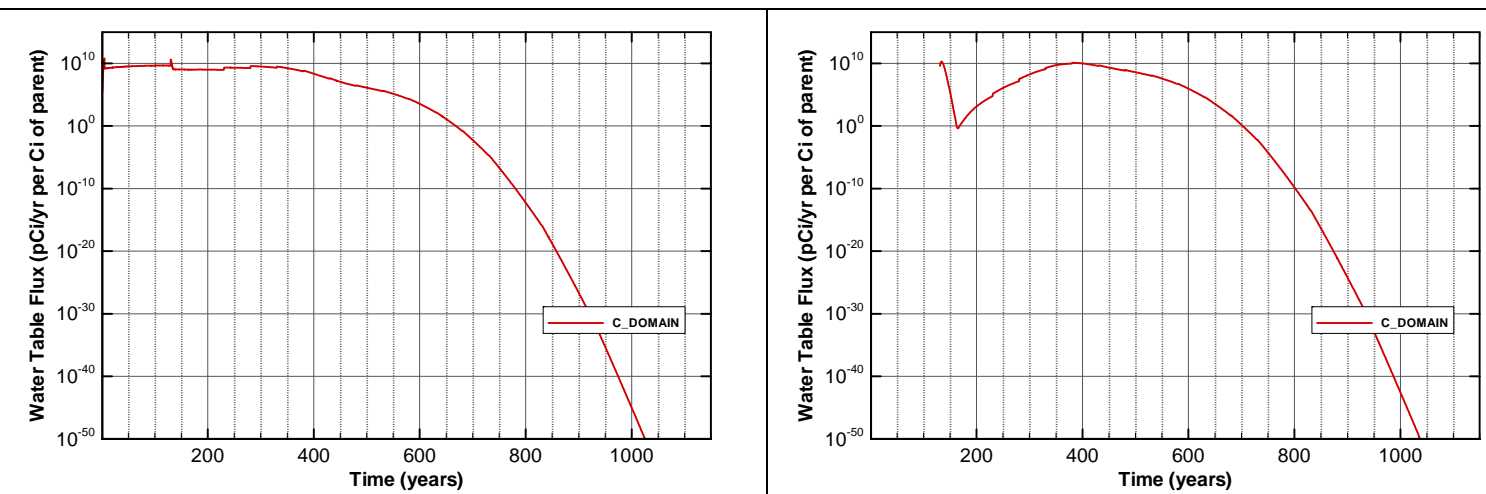

Figure A-303. Flux at water table for Case01n11_on C-14

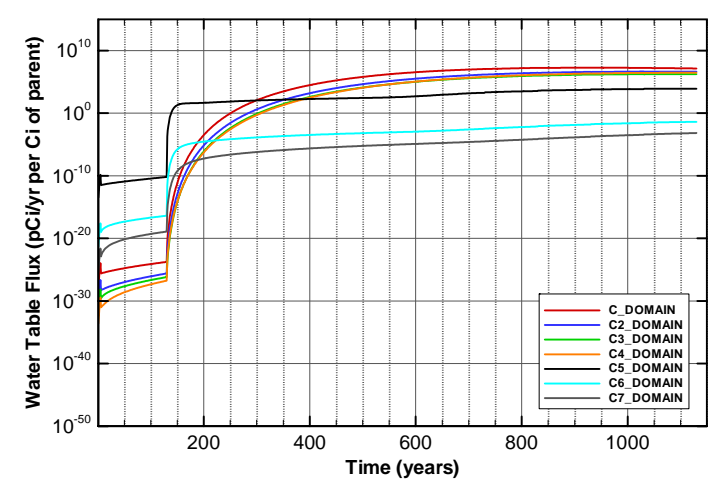

Figure A-305. Flux at water table for Case01n11_on Cf-249

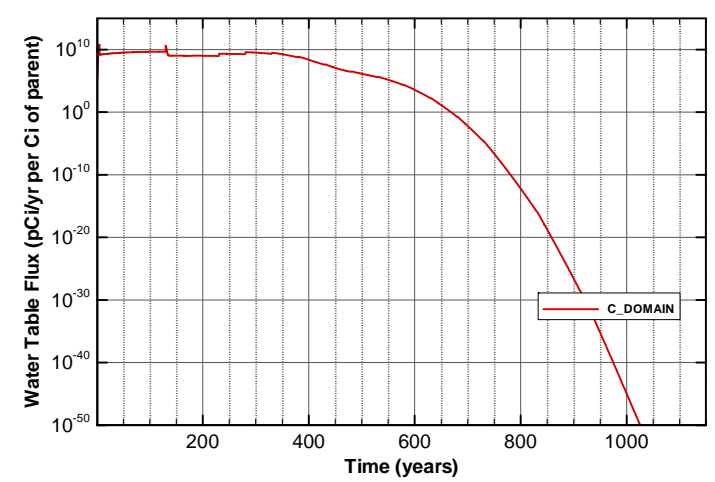

Figure A-307. Flux at water table for Case01n11_on Cl-36

Figure A-304. Flux at water table for Case01n11_on C-14_NR.Pump

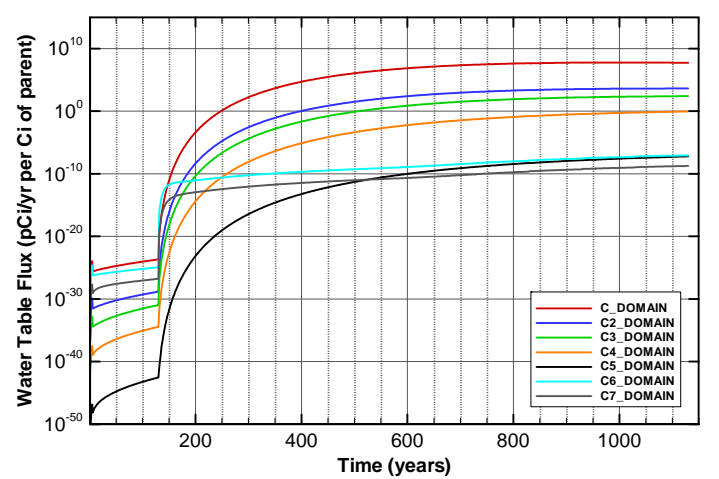

Figure A-306. Flux at water table for Case01n11_on Cf-251

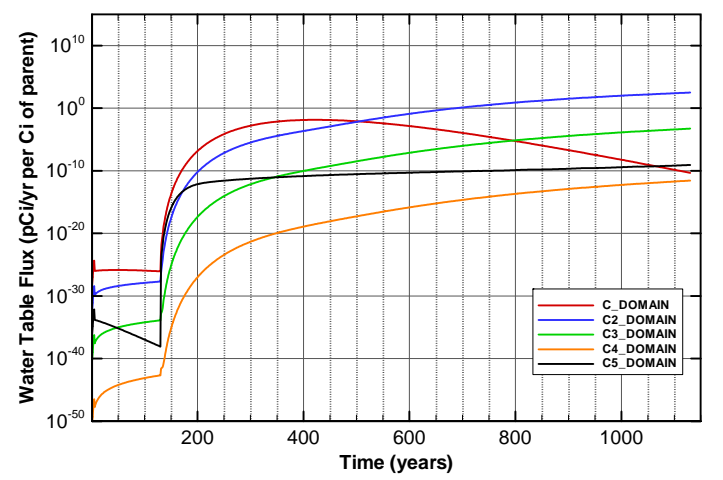

Figure A-308. Flux at water table for Case01n11_on Cm-244 


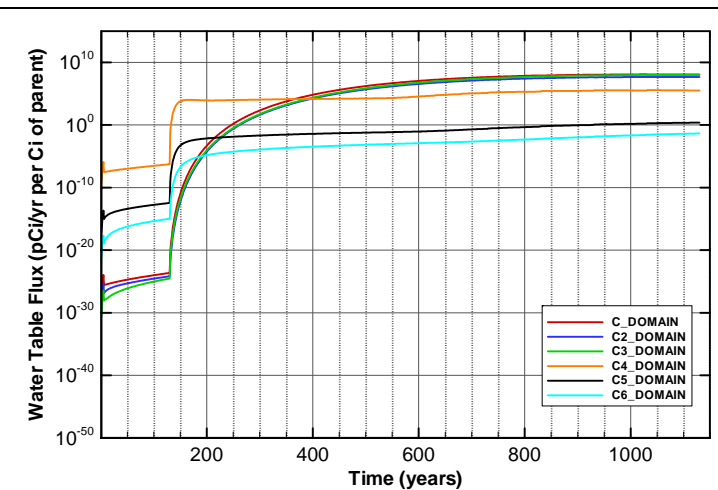

Figure A-309. Flux at water table for Case01n11_on Cm-245

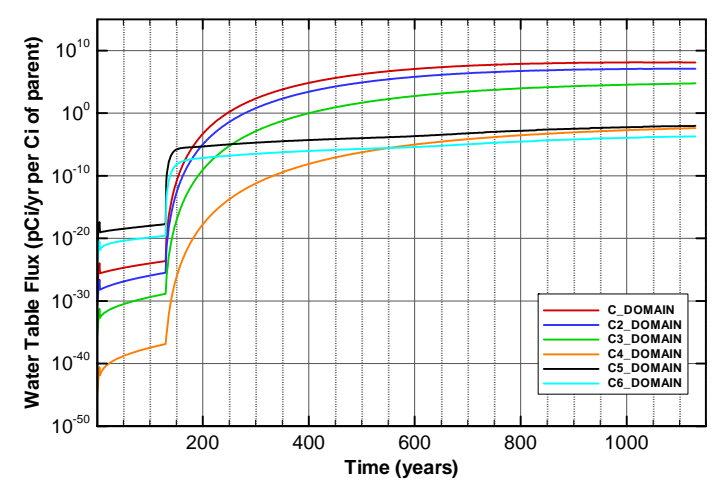

Figure A-311. Flux at water table for Case01n11_on Cm-247

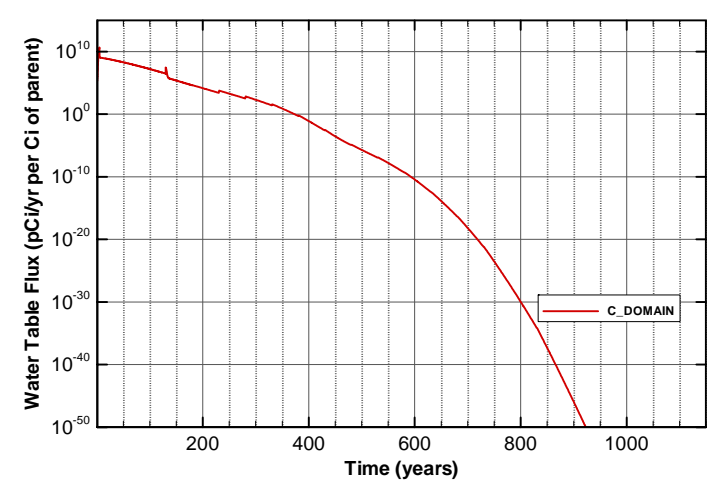

Figure A-313. Flux at water table for Case01n11_on H-3

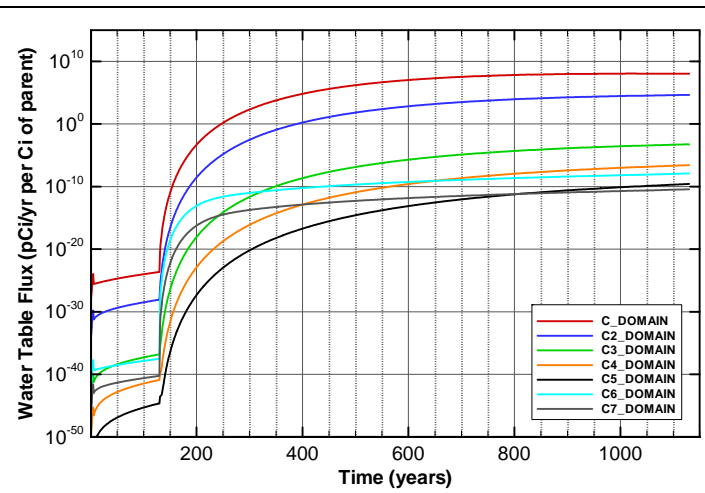

Figure A-310. Flux at water table for Case01n11_on Cm-246

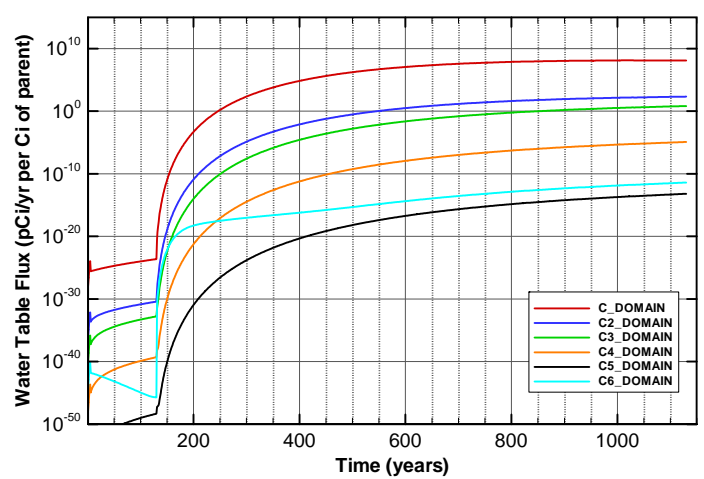

Figure A-312. Flux at water table for Case01n11_on Cm-248

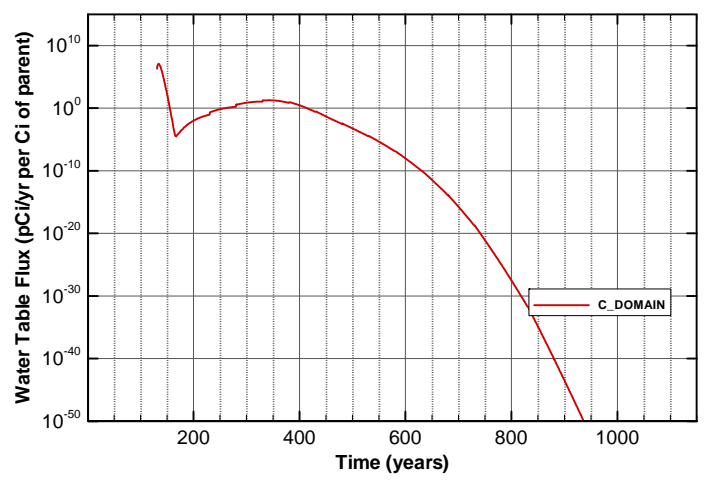

Figure A-314. Flux at water table for Case01n11_on H-3_ETF.Carbon 


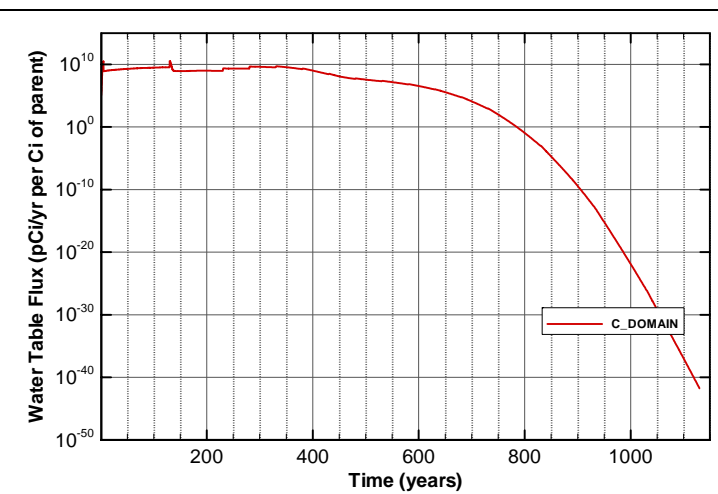

Figure A-315. Flux at water table for Case01n11_on I-129

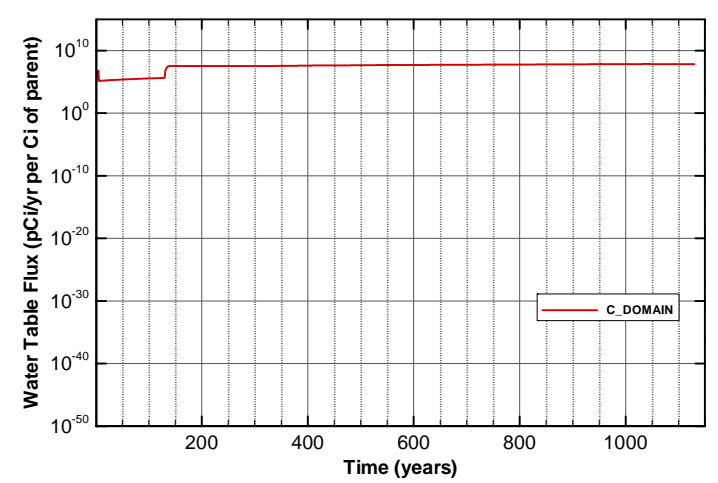

Figure A-317. Flux at water table for Case01n11_on I-129_ETF.GT.73

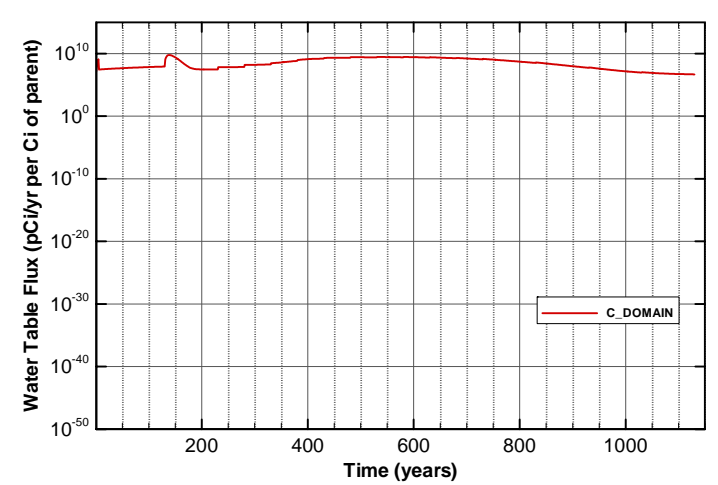

Figure A-319. Flux at water table for Case01n11_on I-129_F.CG.8

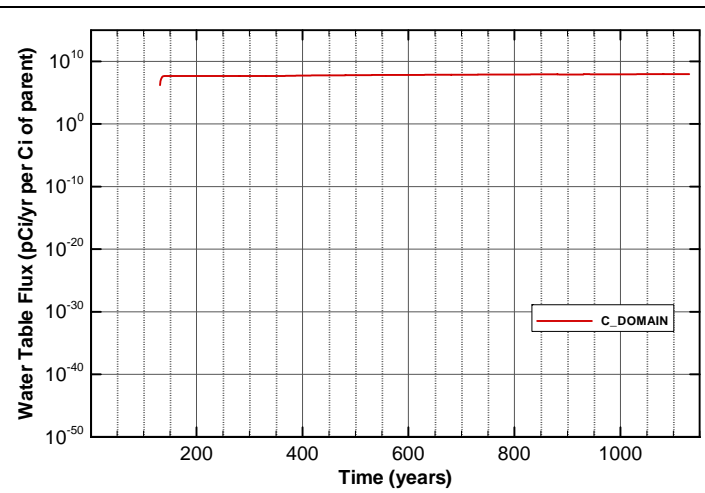

Figure A-316. Flux at water table for Case01n11_on I-129_ETF.Carbon

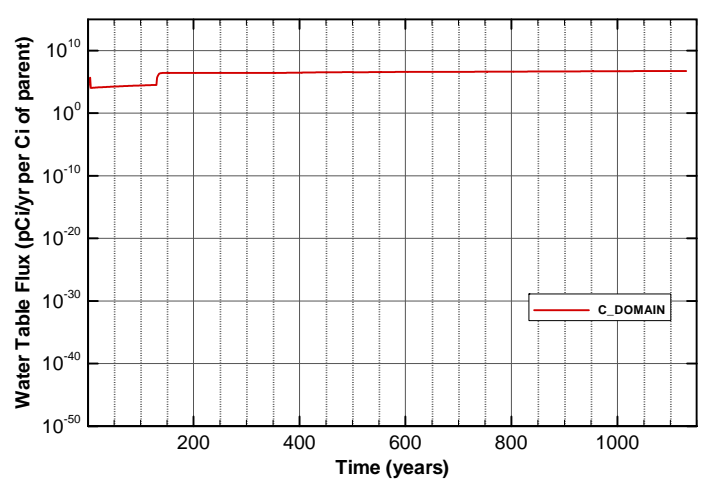

Figure A-318. Flux at water table for Case01n11_on I-129_F.Carbon

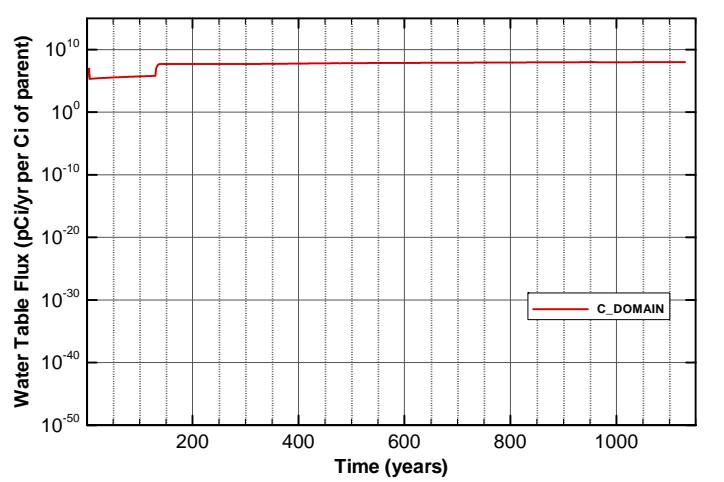

Figure A-320. Flux at water table for Case01n11_on I-129_F.Dowex.21K 


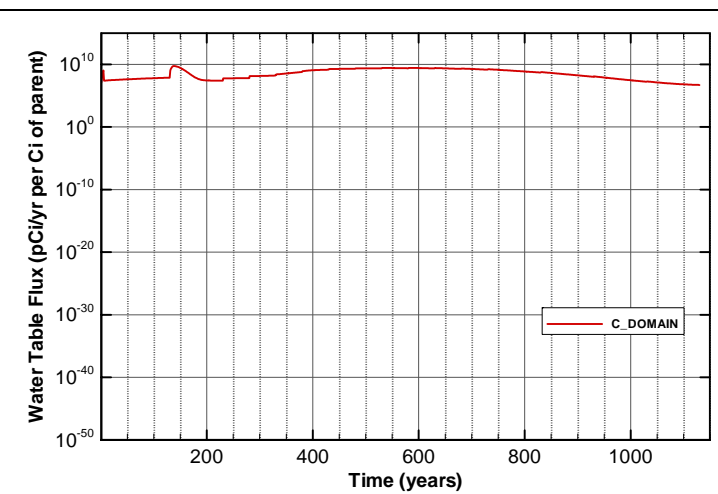

Figure A-321. Flux at water table for Case01n11_on I-129_F.Filtercake

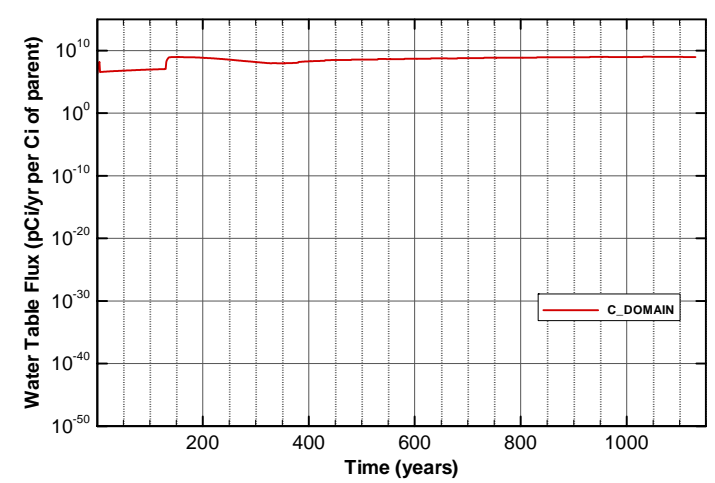

Figure A-323. Flux at water table for Case01n11_on I-129_H.CG.8

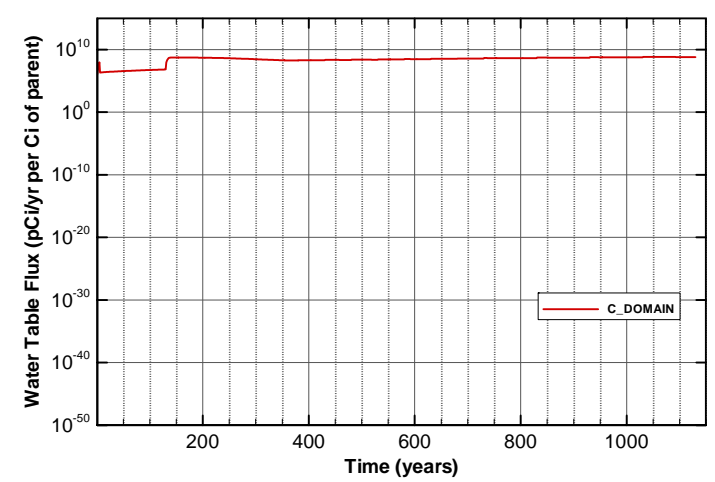

Figure A-325. Flux at water table for Case01n11_on I-129_H.Filtercake

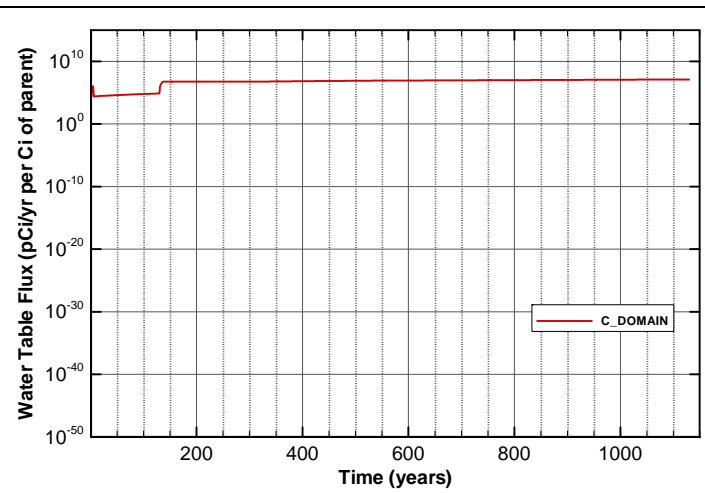

Figure A-322. Flux at water table for Case01n11_on I-129_H.Carbon

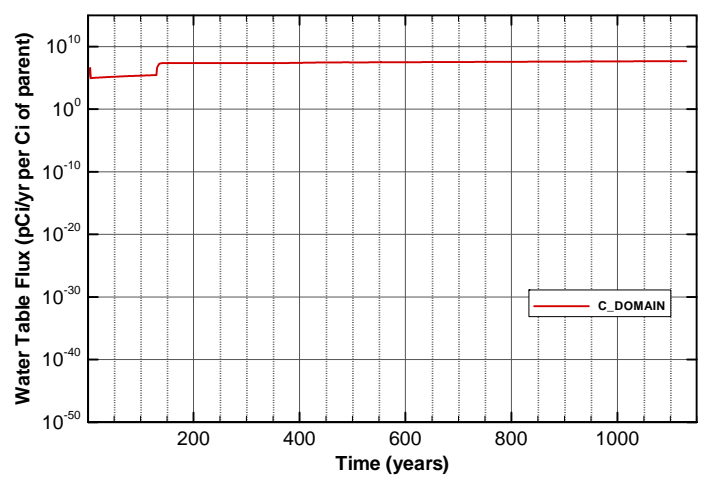

Figure A-324. Flux at water table for Case01n11_on I-129_H.Dowex.21K

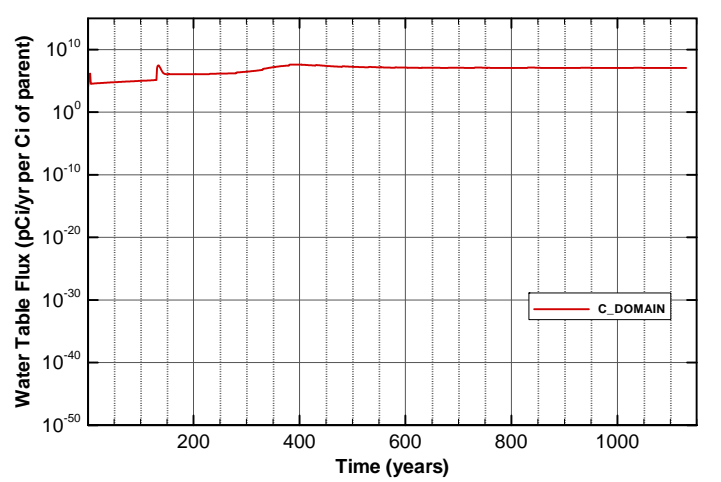

Figure A-326. Flux at water table for Case01n11_on I-129_Mk50A 


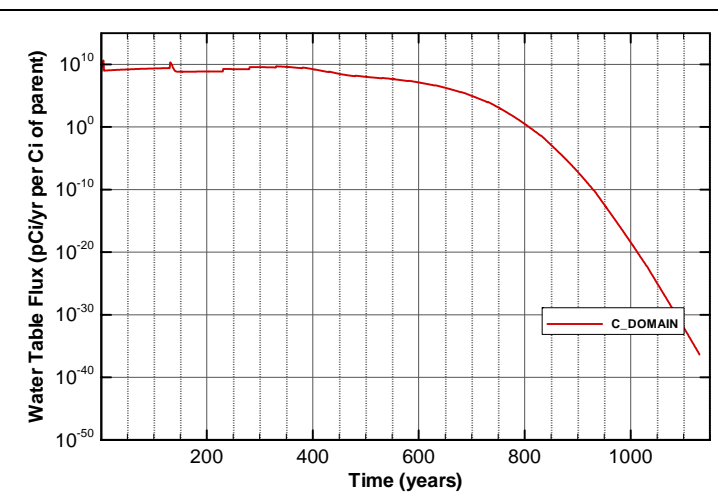

Figure A-327. Flux at water table for Case01n11_on K-40

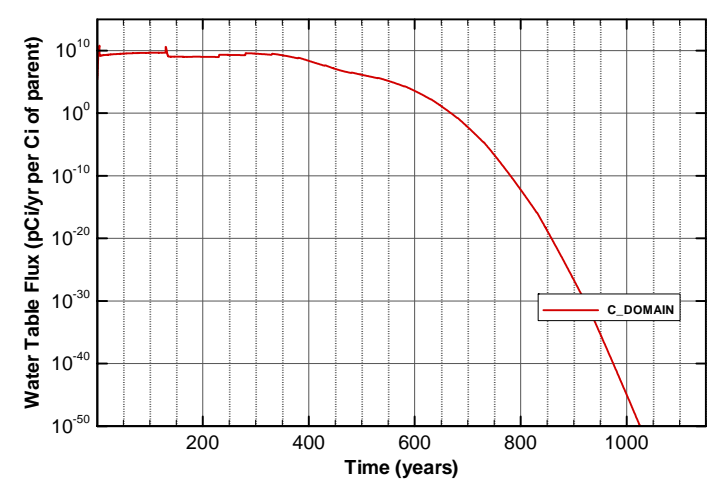

Figure A-329. Flux at water table for Case01n11_on Nb-94

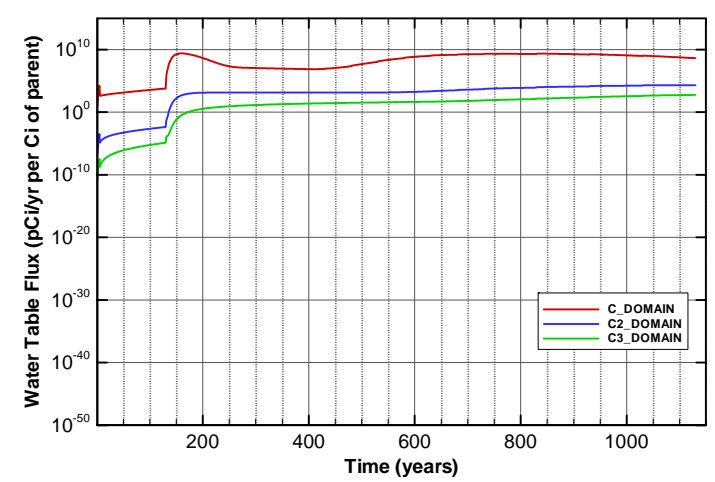

Figure A-331. Flux at water table for Case01n11_on Np-237

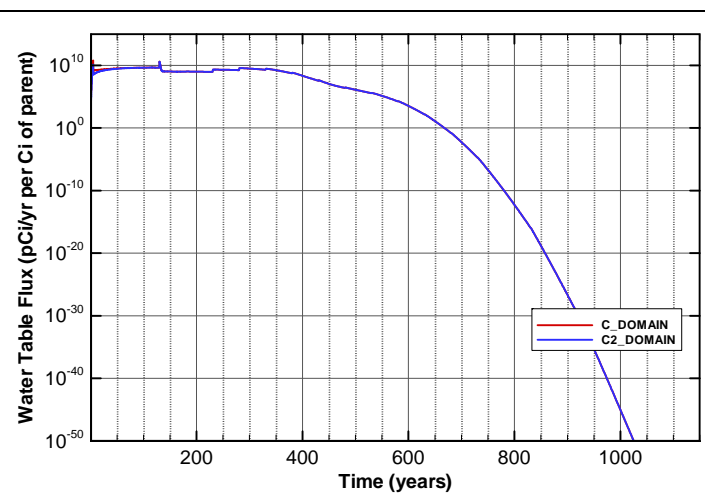

Figure A-328. Flux at water table for Case01n11_on Mo-93

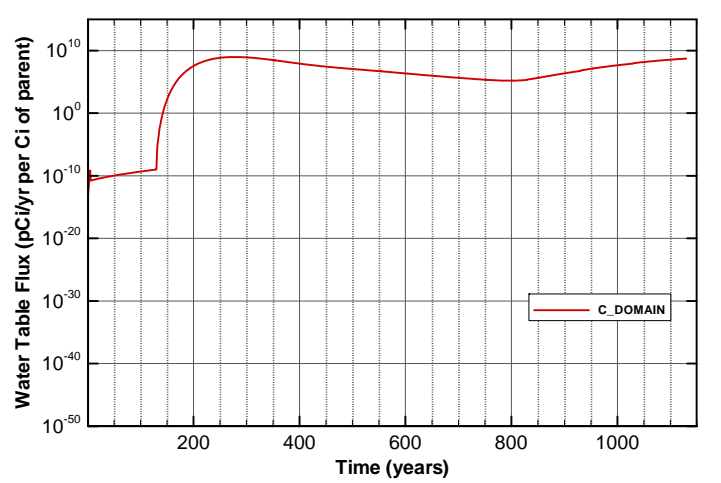

Figure A-330. Flux at water table for Case01n11_on Ni-59

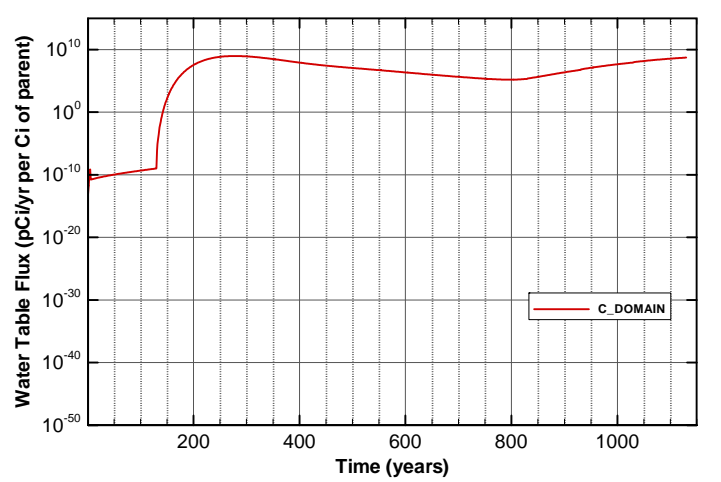

Figure A-332. Flux at water table for Case01n11_on Pd-107 
SRNL-STI-2008-00397, REVISION 0
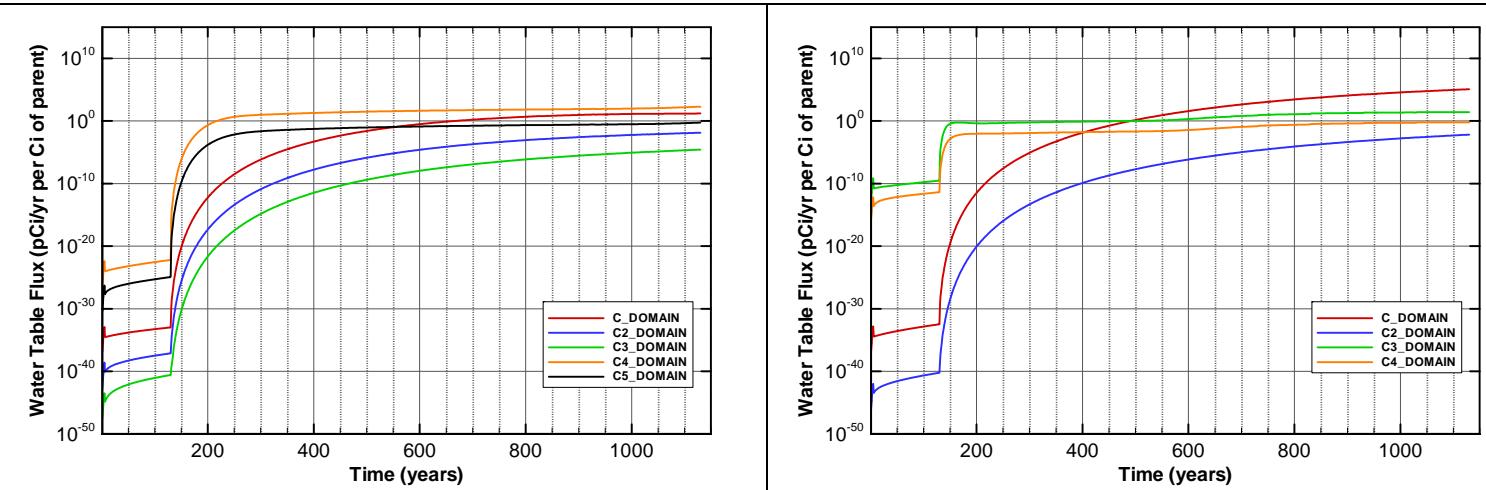

Figure A-333. Flux at water table for Case01n11_on Pu-238

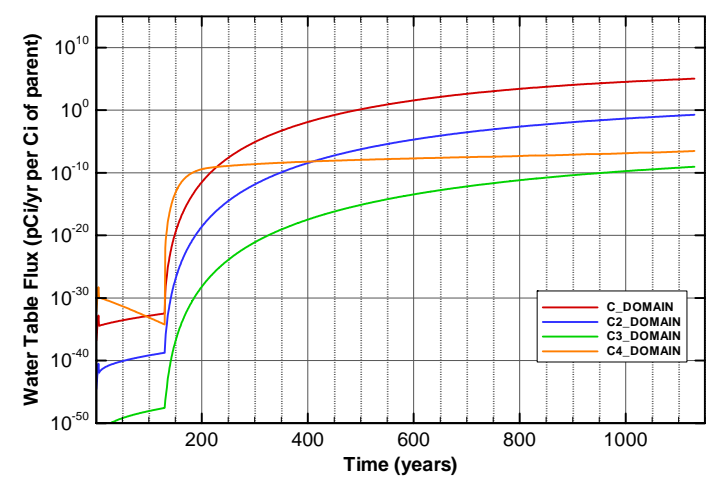

Figure A-335. Flux at water table for Case01n11_on Pu-240

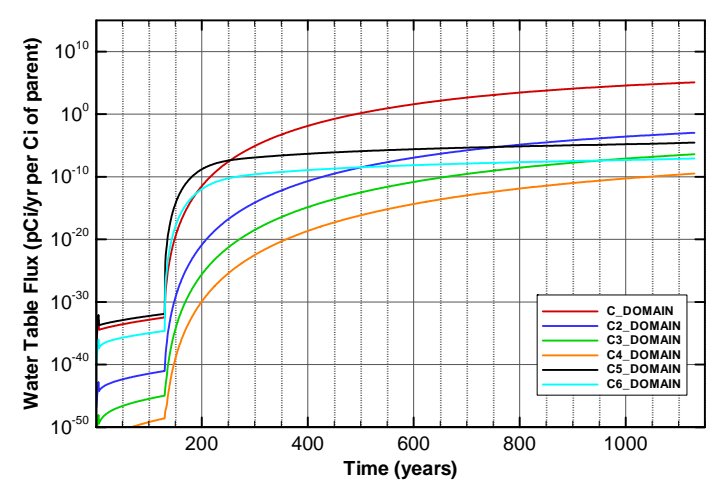

Figure A-337. Flux at water table for Case01n11_on Pu-242

Figure A-334. Flux at water table for Case01n11_on Pu-239

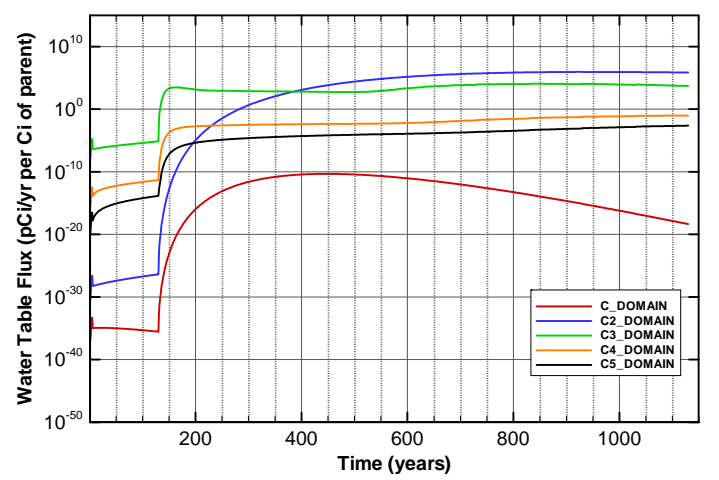

Figure A-336. Flux at water table for Case01n11_on Pu-241

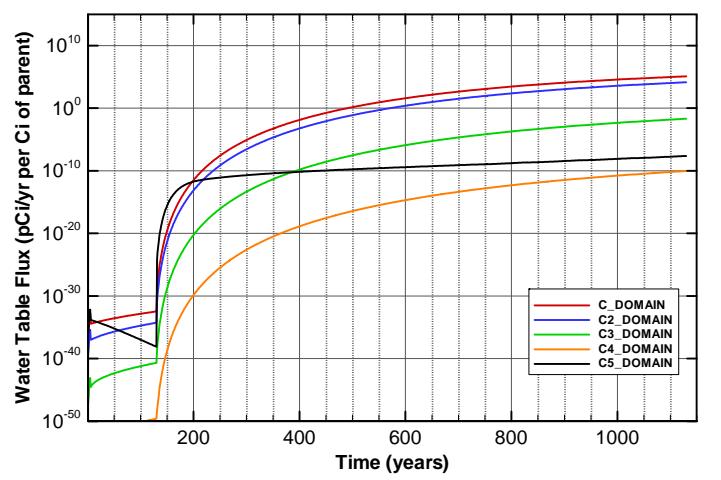

Figure A-338. Flux at water table for Case01n11_on Pu-244 


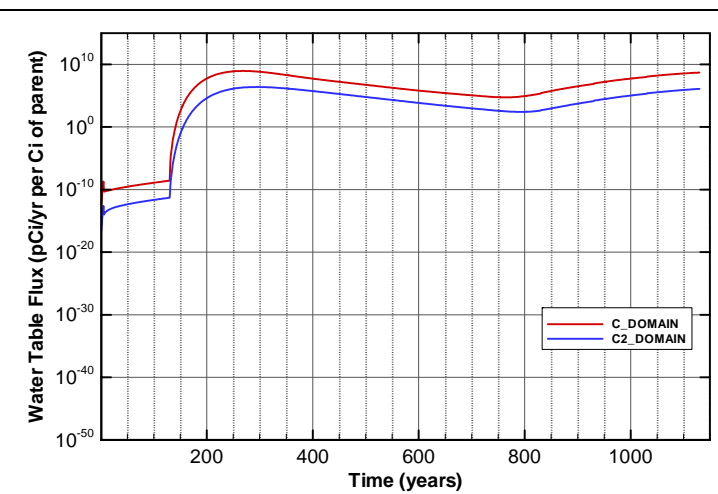

Figure A-339. Flux at water table for Case01n11_on Ra-226

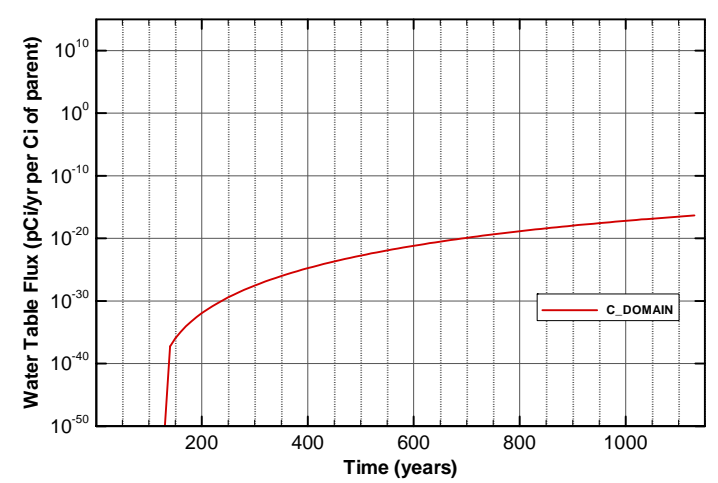

Figure A-341. Flux at water table for Case01n11_on Sn-126

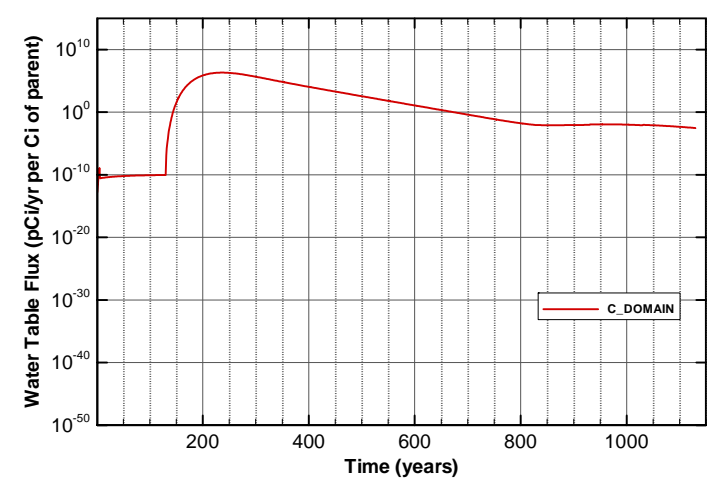

Figure A-343. Flux at water table for Case01n11_on Sr-90_Cask

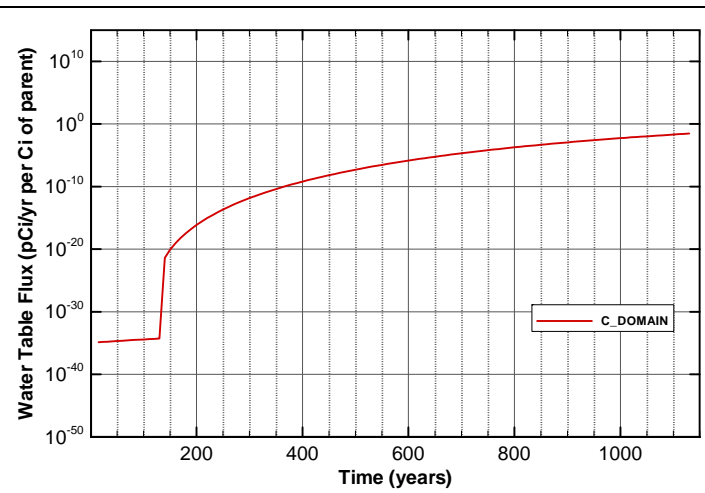

Figure A-340. Flux at water table for Case01n11_on Se-79

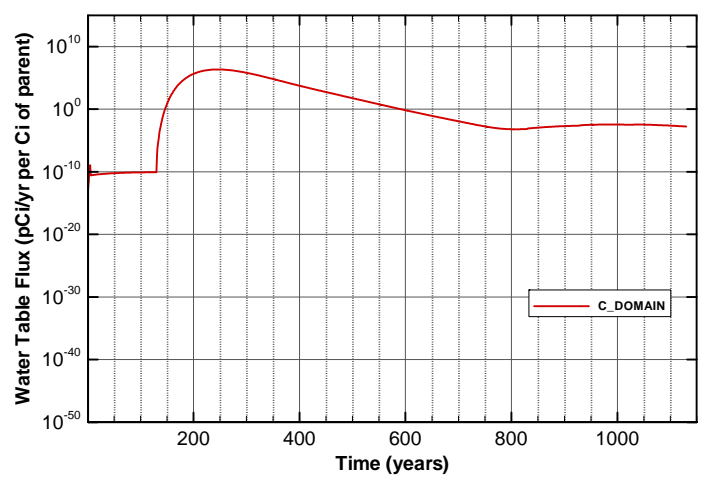

Figure A-342. Flux at water table for Case01n11_on Sr-90

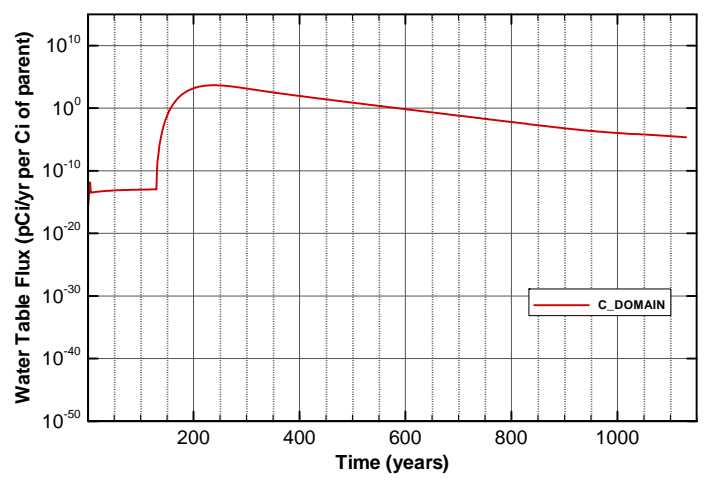

Figure A-344. Flux at water table for Case01n11_on Sr-90_Mk50A 


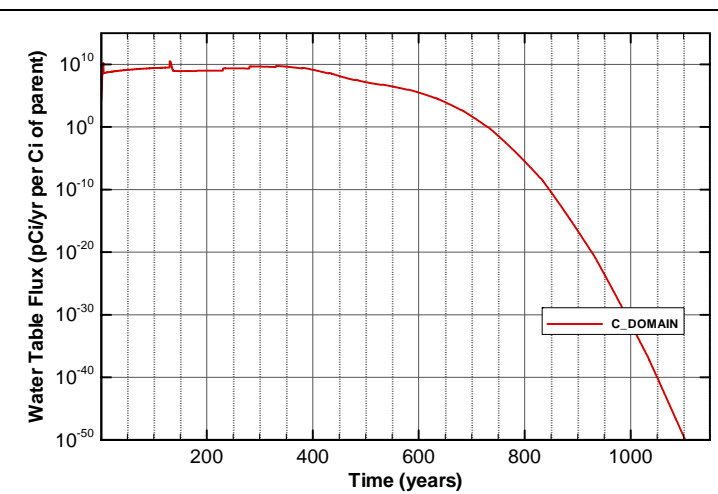

Figure A-345. Flux at water table for Case01n11_on Tc-99

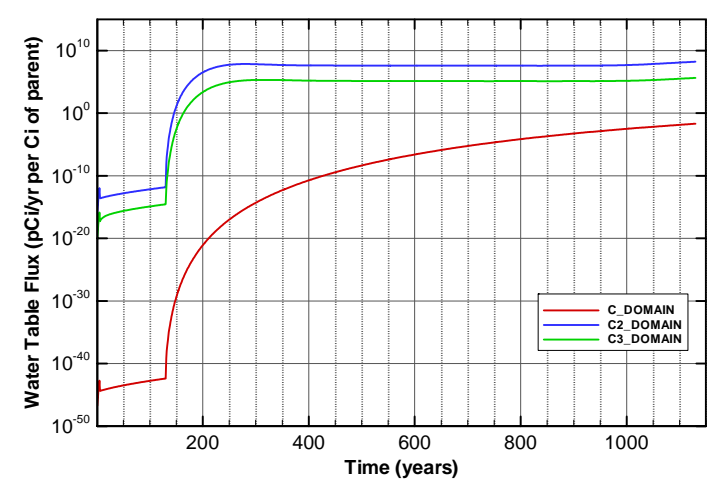

Figure A-347. Flux at water table for Case01n11_on Th-230

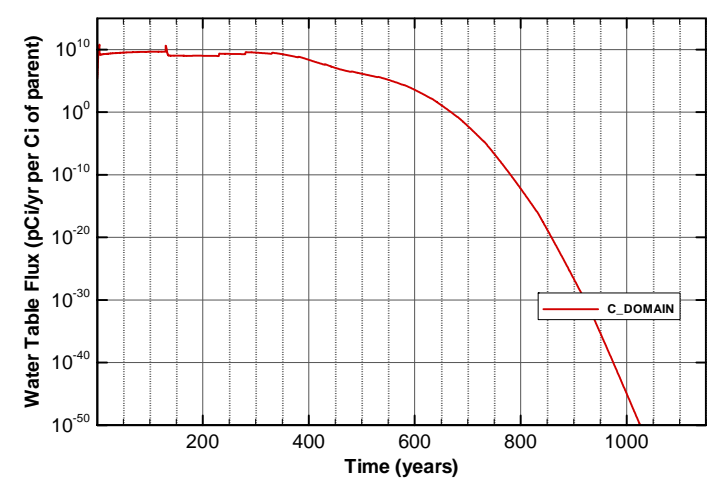

Figure A-349. Flux at water table for Case01n11_on Tracer

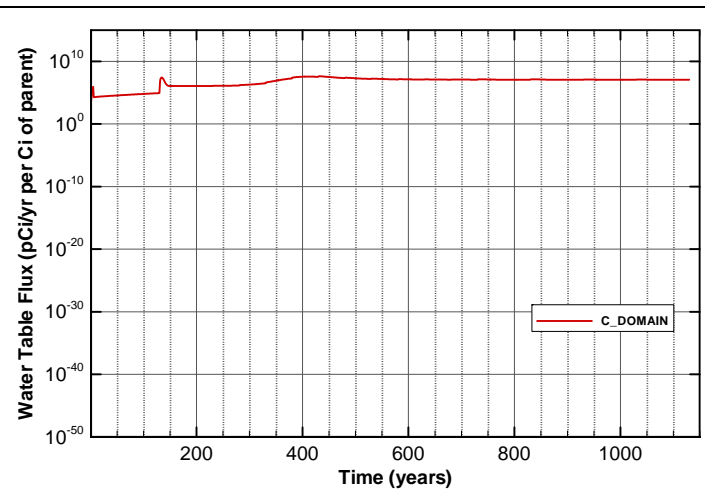

Figure A-346. Flux at water table for Case01n11_on Tc-99_Mk50A

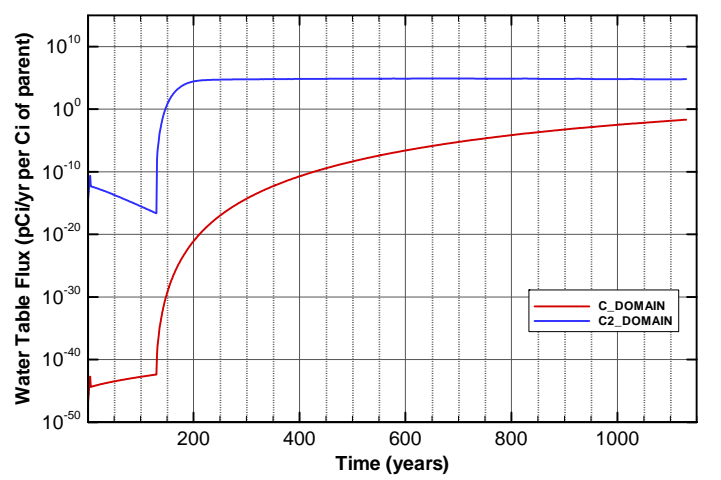

Figure A-348. Flux at water table for Case01n11_on Th-232

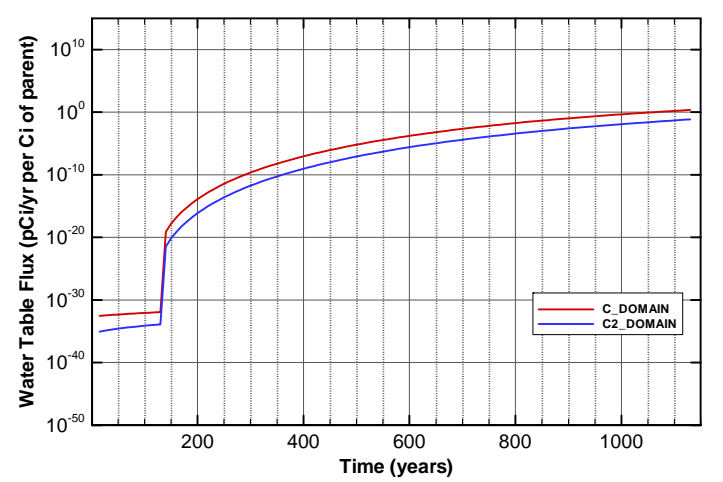

Figure A-350. Flux at water table for Case01n11_on U-233 


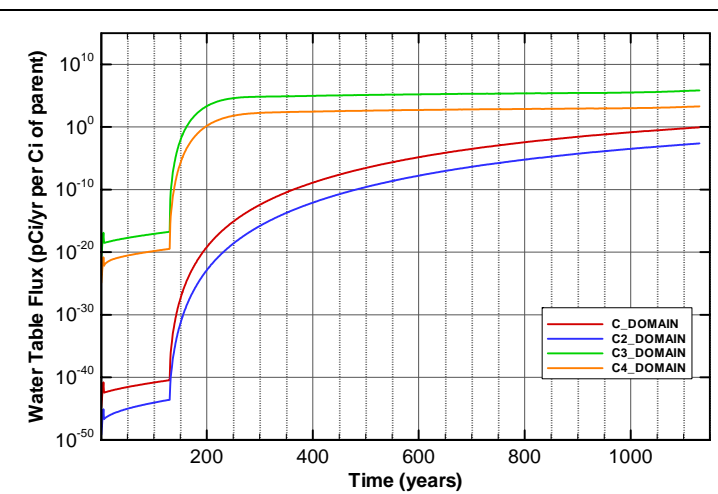

Figure A-351. Flux at water table for Case01n11_on U-234

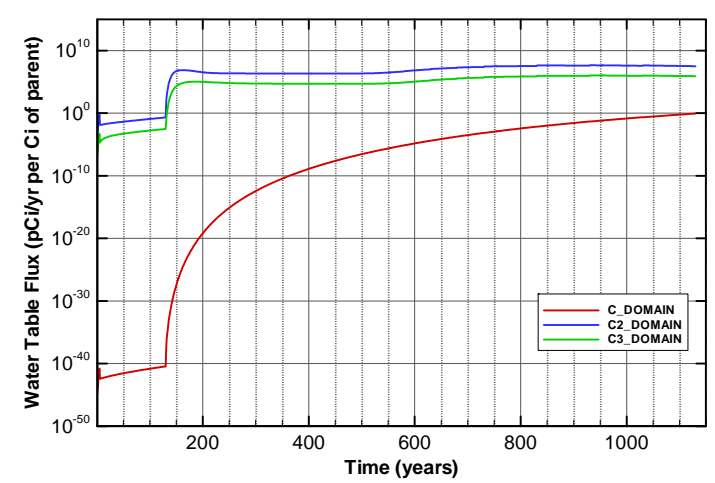

Figure A-353. Flux at water table for Case01n11_on U-235

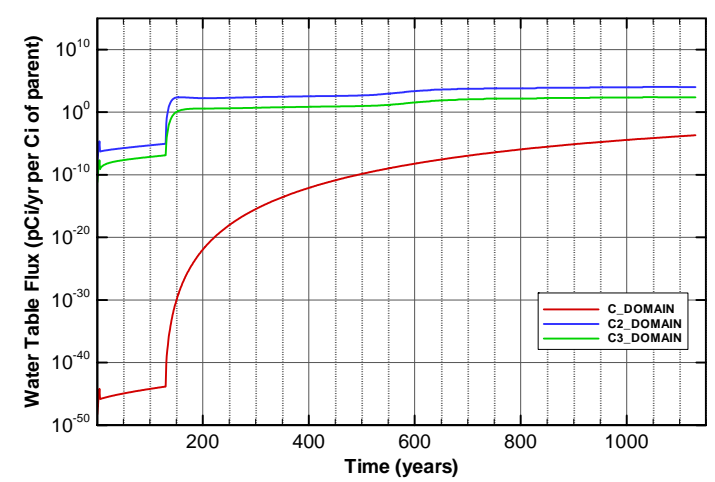

Figure A-355. Flux at water table for Case01n11_on U-235_Paducah.Cask

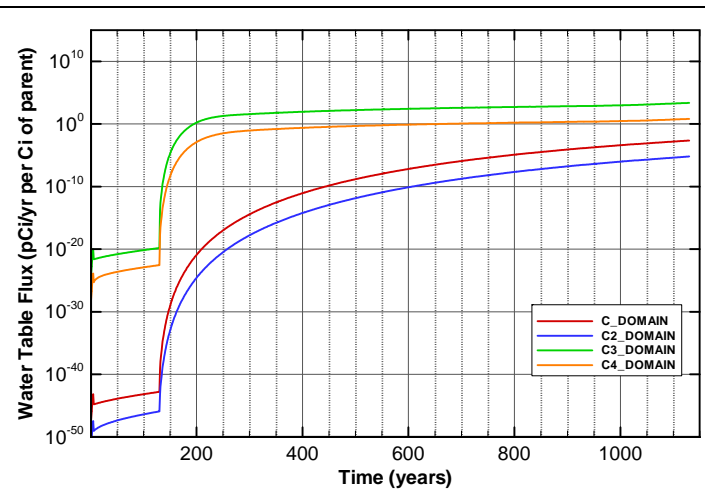

Figure A-352. Flux at water table for Case01n11_on U-234_Mglass

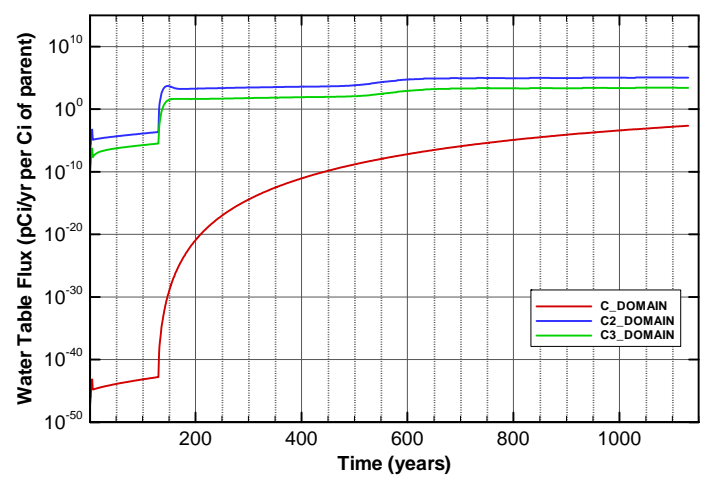

Figure A-354. Flux at water table for Case01n11_on U-235_Mglass

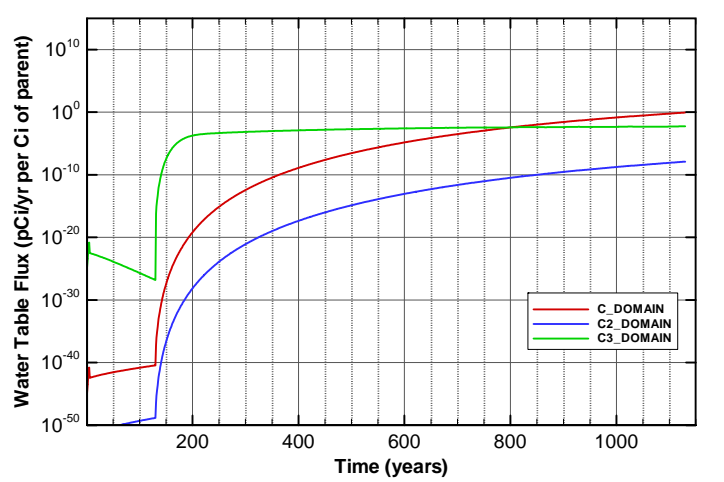

Figure A-356. Flux at water table for Case01n11_on U-236 


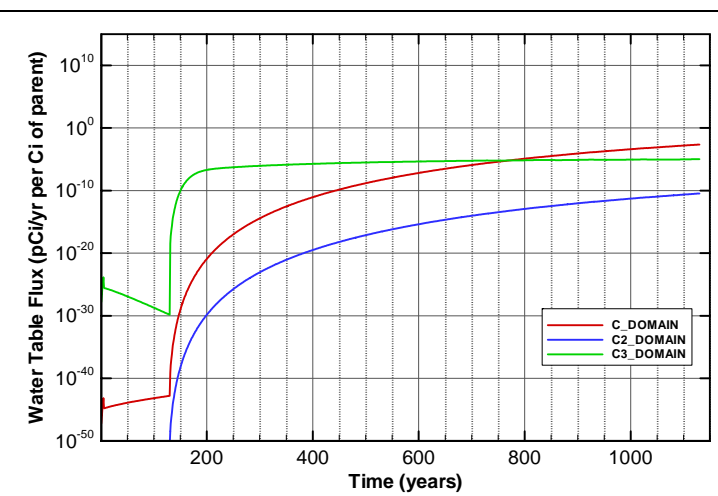

Figure A-357. Flux at water table for Case01n11_on U-236_Mglass

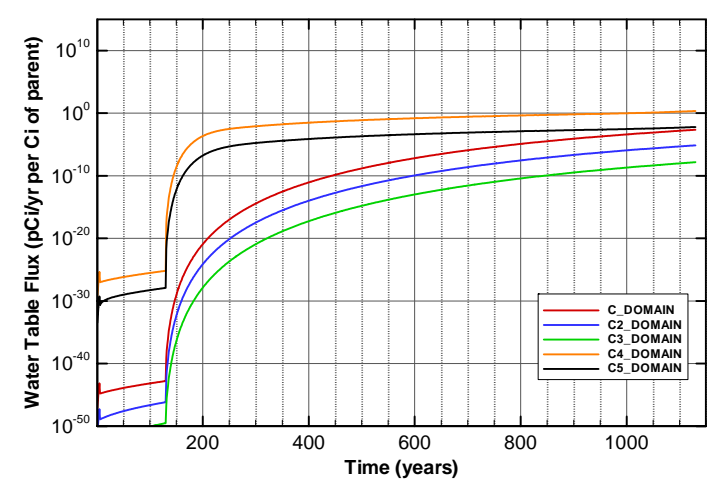

Figure A-359. Flux at water table for Case01n11_on U-238_Mglass

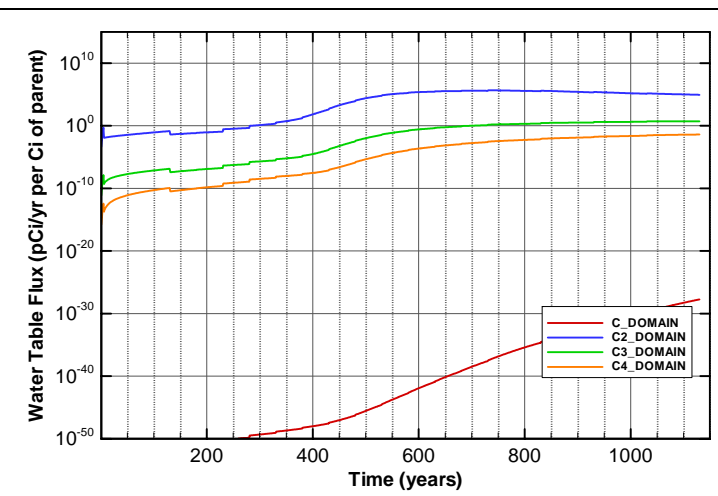

Figure A-361. Flux at water table for Case01_off Am-241

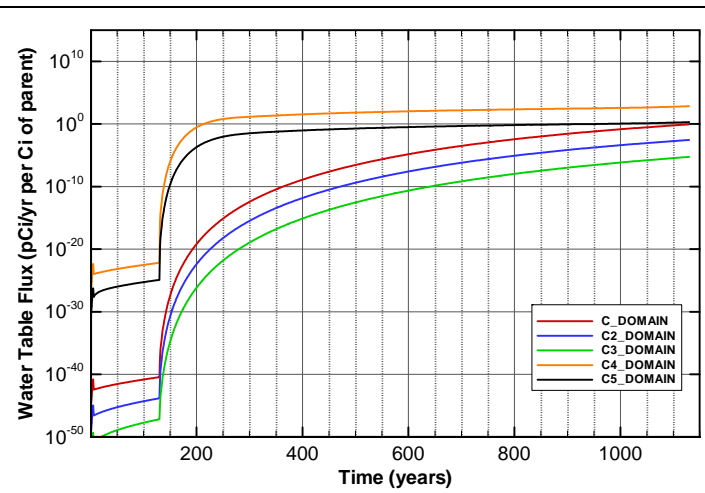

Figure A-358. Flux at water table for Case01n11_on U-238

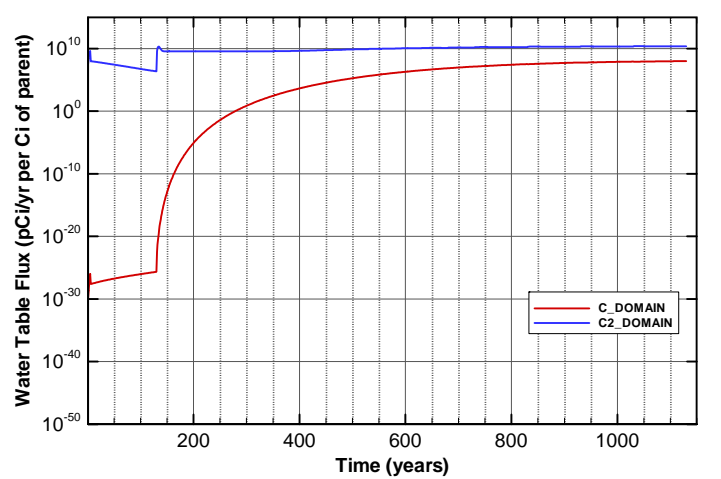

Figure A-360. Flux at water table for Case01n11_on Zr-93

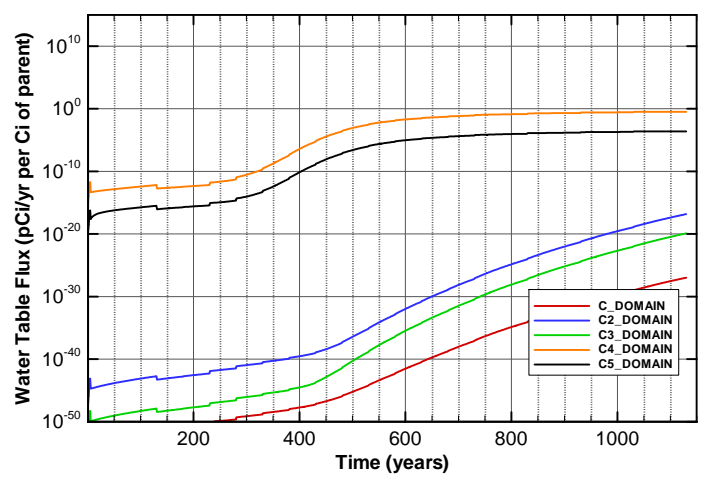

Figure A-362. Flux at water table for Case01_off Am-243 
SRNL-STI-2008-00397, REVISION 0
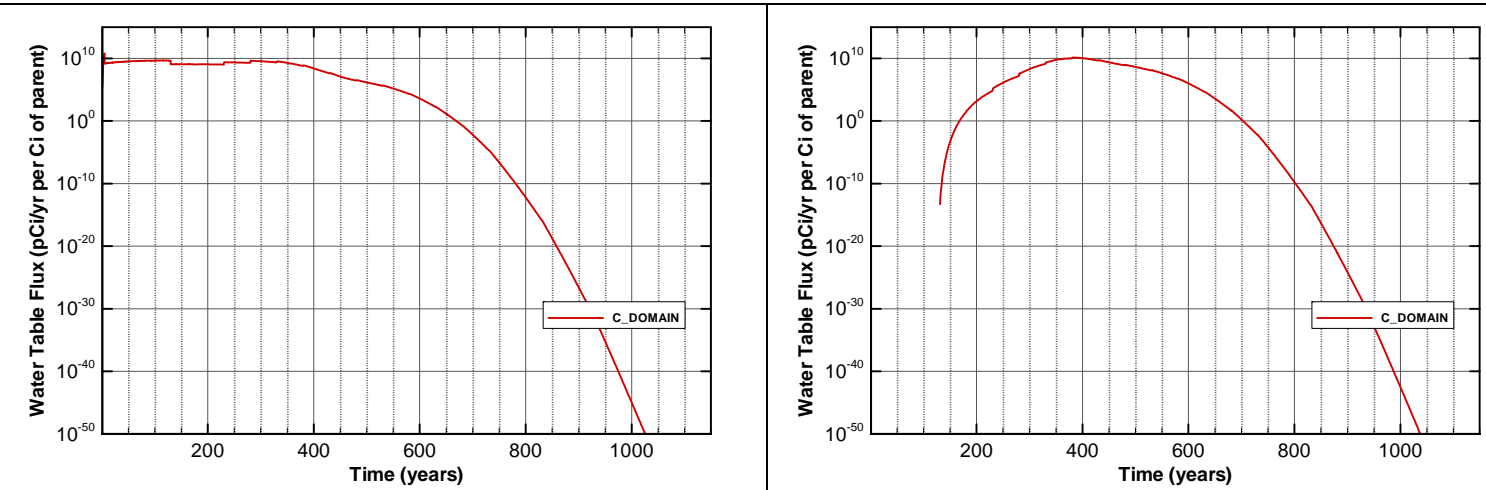

Figure A-363. Flux at water table for Case01_off C-14

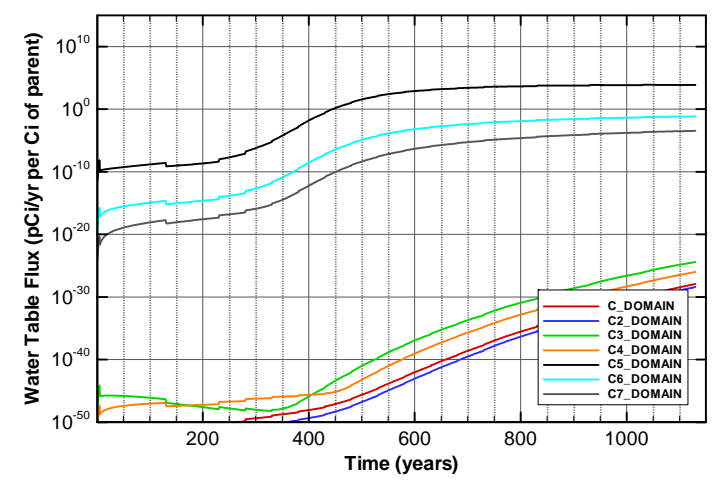

Figure A-365. Flux at water table for Case01_off Cf-249

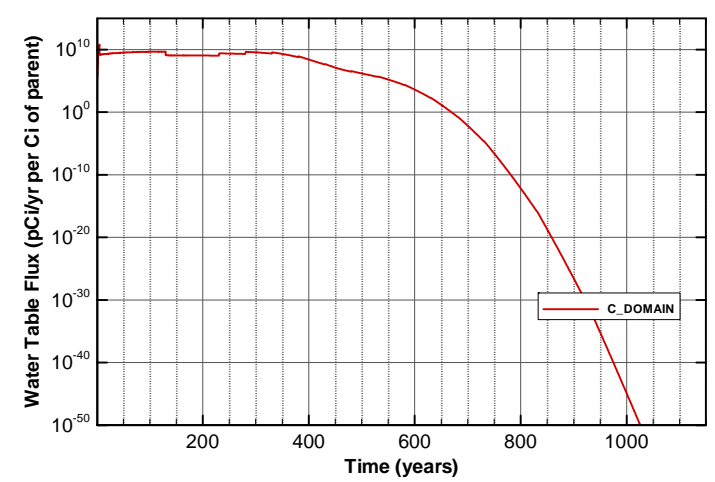

Figure A-367. Flux at water table for Case01_off Cl-36

Figure A-364. Flux at water table for Case01_off C-14_NR.Pump

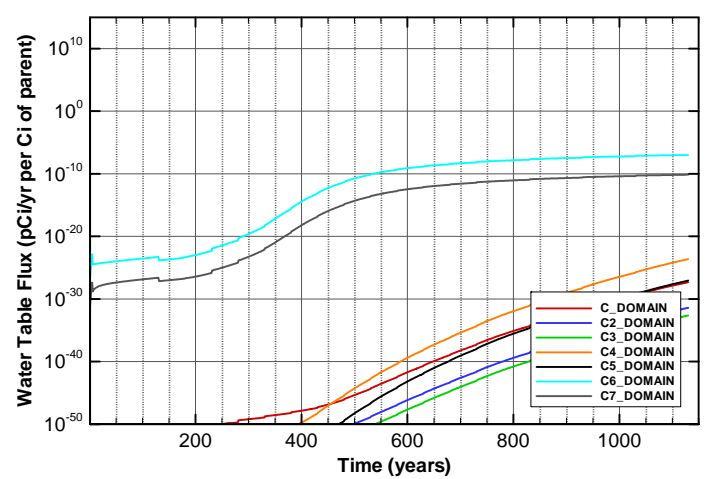

Figure A-366. Flux at water table for Case01_off Cf-251

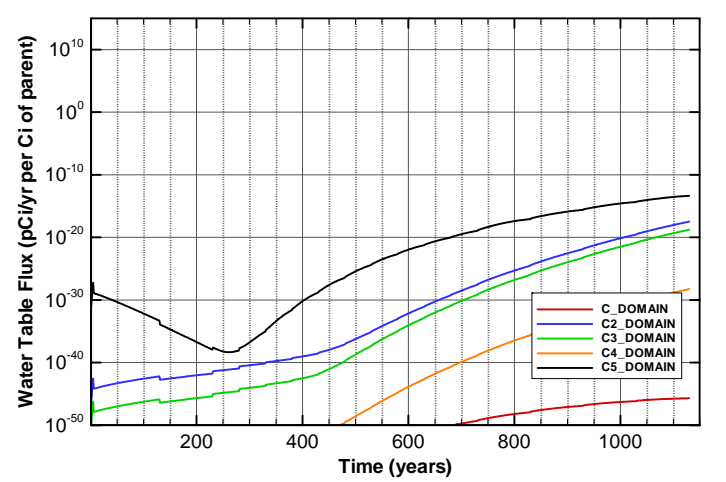

Figure A-368. Flux at water table for Case01_off Cm-244 
SRNL-STI-2008-00397, REVISION 0

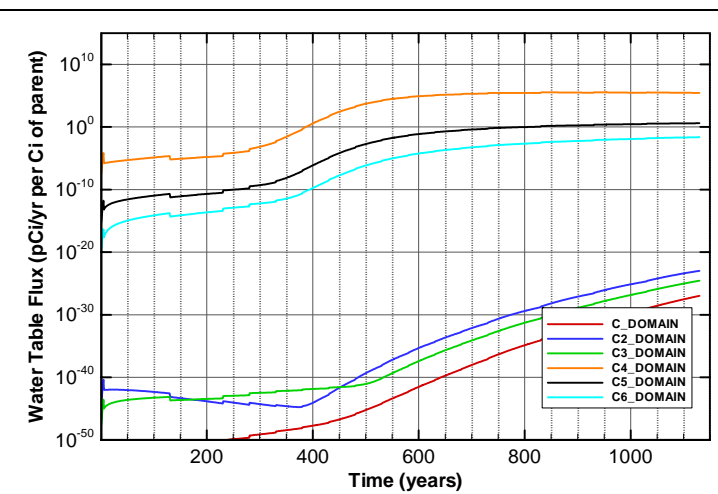

Figure A-369. Flux at water table for Case01_off Cm-245

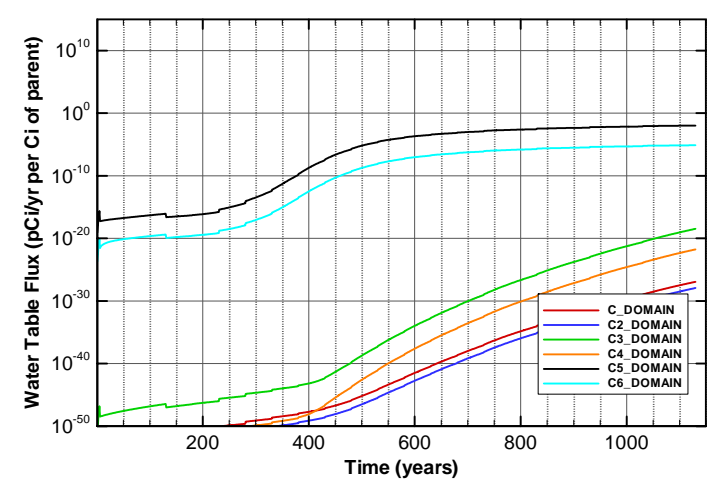

Figure A-371. Flux at water table for Case01_off Cm-247

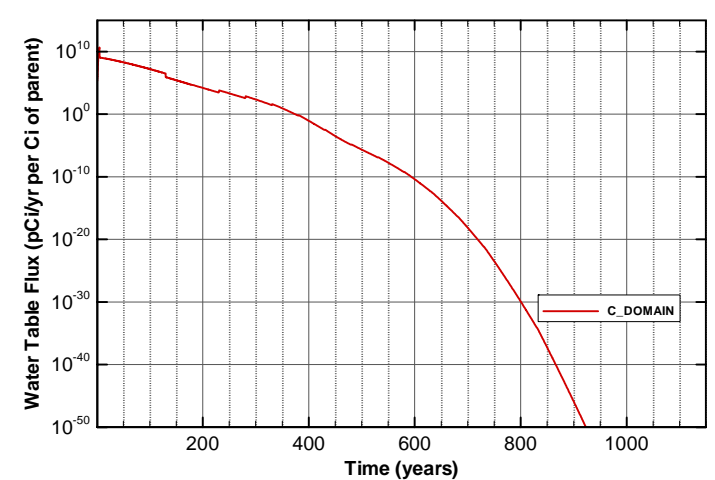

Figure A-373. Flux at water table for Case01_off H-3

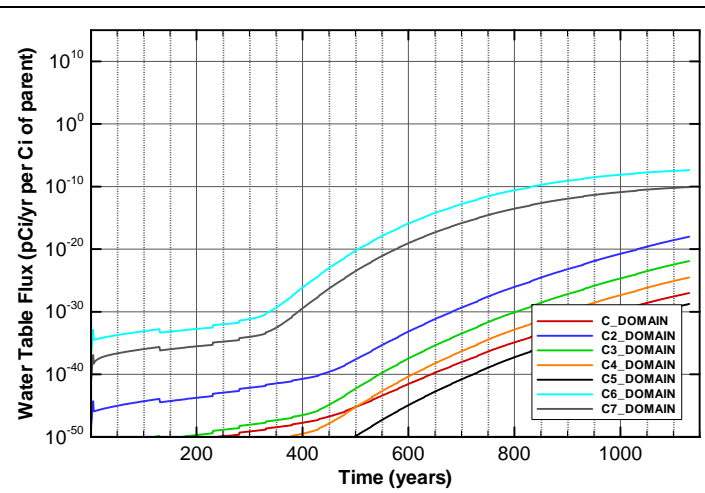

Figure A-370. Flux at water table for Case01_off Cm-246

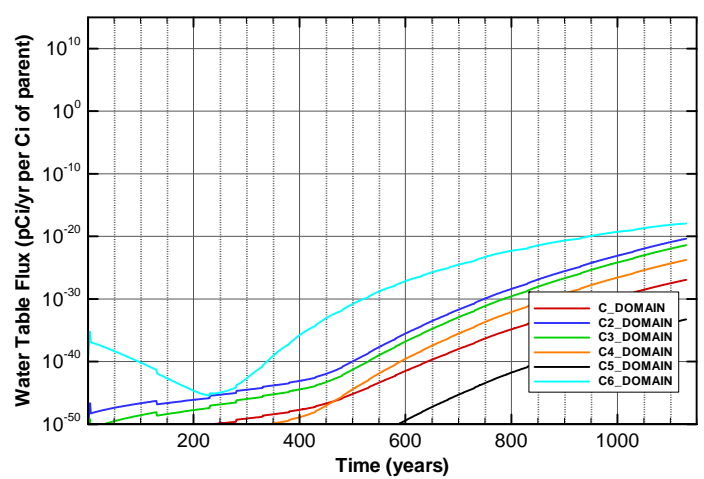

Figure A-372. Flux at water table for Case01_off Cm-248

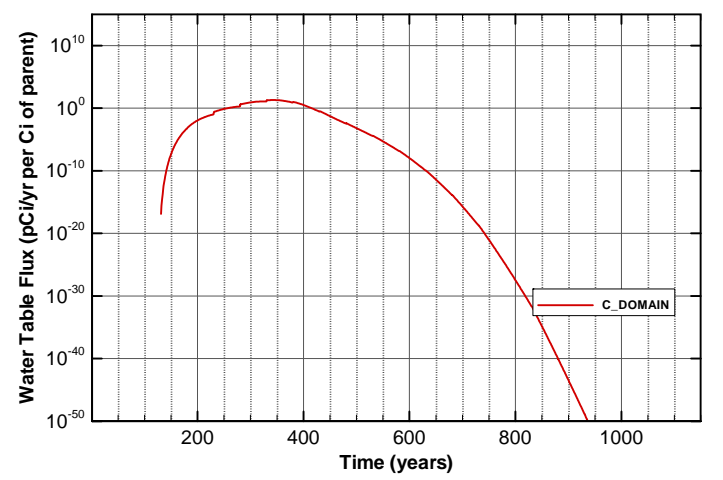

Figure A-374. Flux at water table for Case01_off H-3_ETF.Carbon 


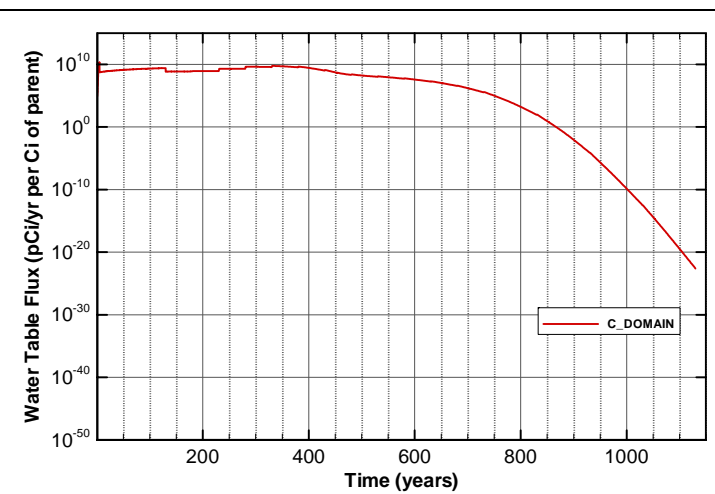

Figure A-375. Flux at water table for Case01_off I-129

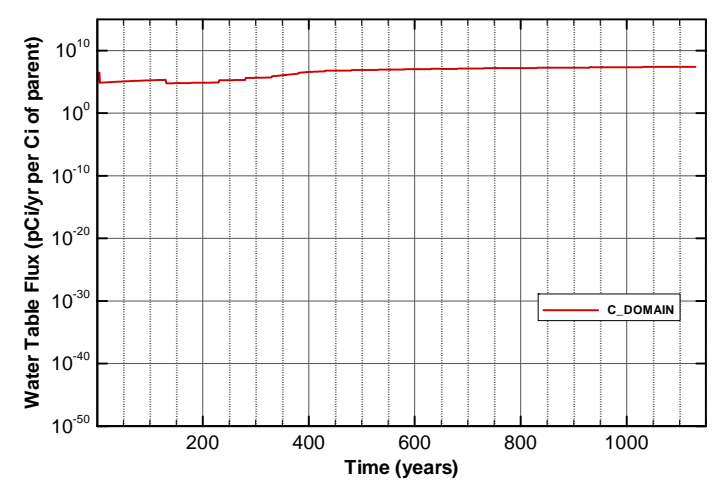

Figure A-377. Flux at water table for Case01_off I-129_ETF.GT.73

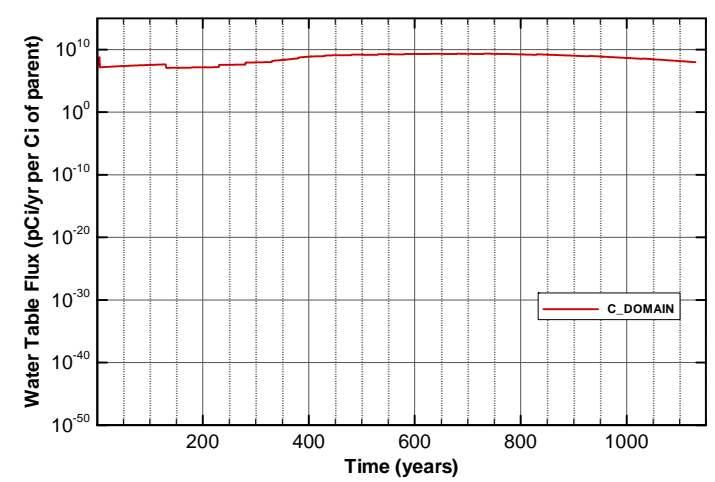

Figure A-379. Flux at water table for Case01_off I-129_F.CG.8

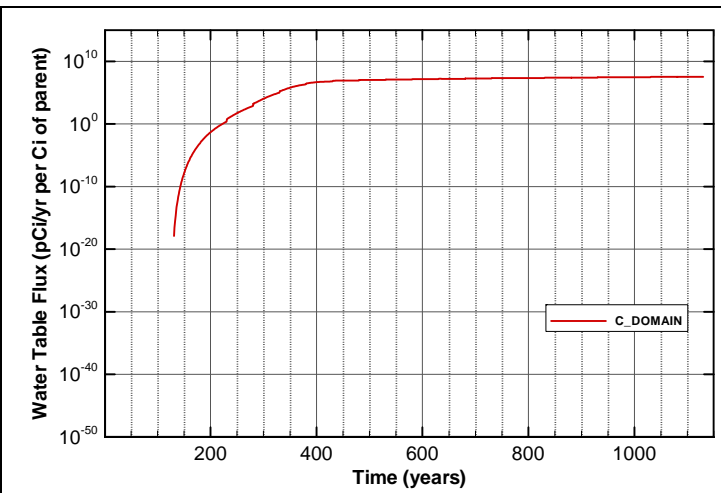

Figure A-376. Flux at water table for Case01_off I-129_ETF.Carbon

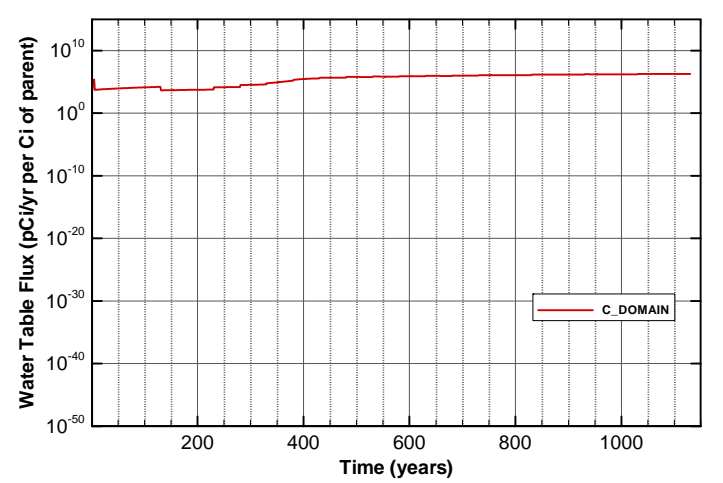

Figure A-378. Flux at water table for Case01_off I-129_F.Carbon

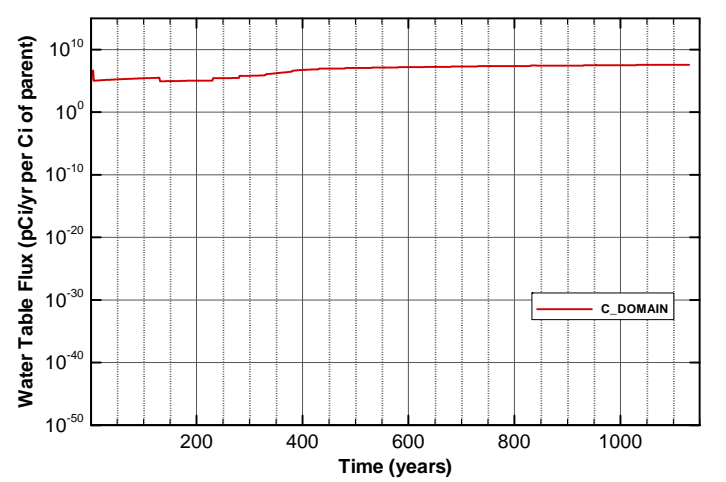

Figure A-380. Flux at water table for Case01_off I-129_F.Dowex.21K 


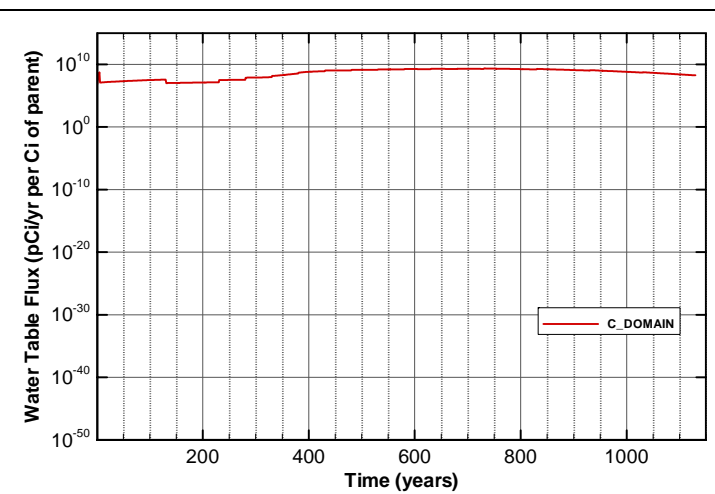

Figure A-381. Flux at water table for Case01_off I-129_F.Filtercake

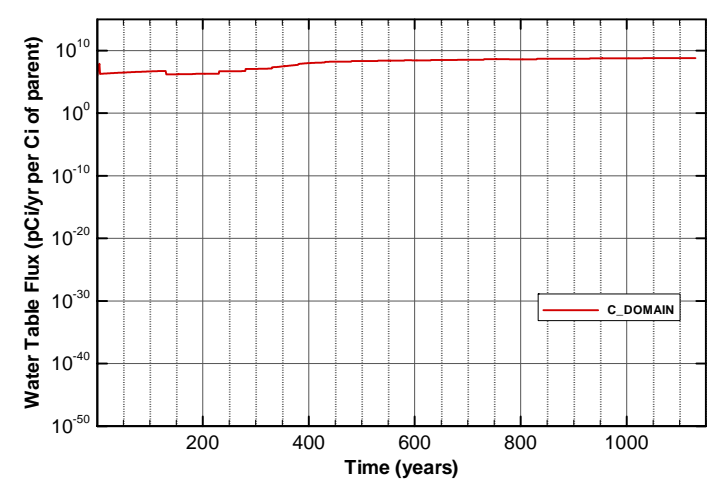

Figure A-383. Flux at water table for Case01_off I-129_H.CG.8

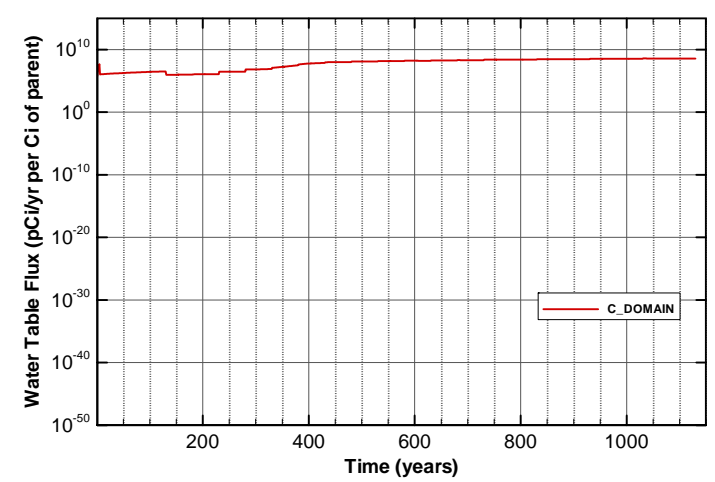

Figure A-385. Flux at water table for Case01_off I-129_H.Filtercake

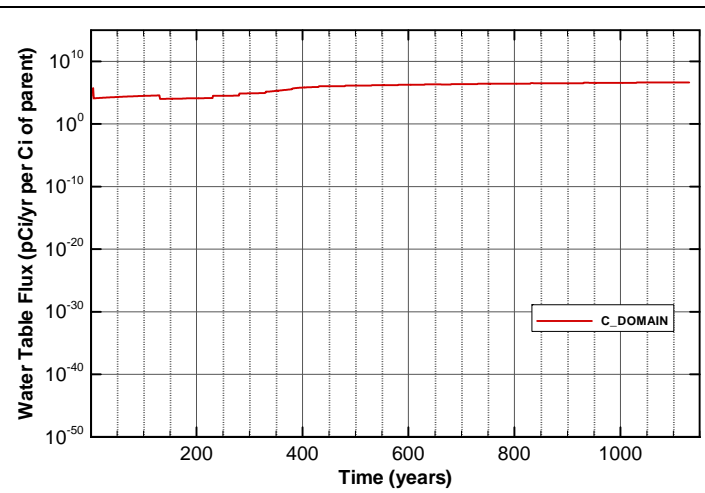

Figure A-382. Flux at water table for Case01_off I-129_H.Carbon

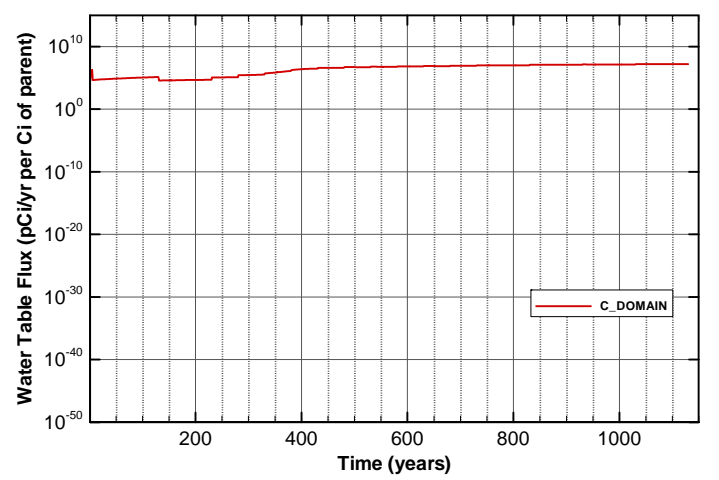

Figure A-384. Flux at water table for Case01_off I-129_H.Dowex.21K

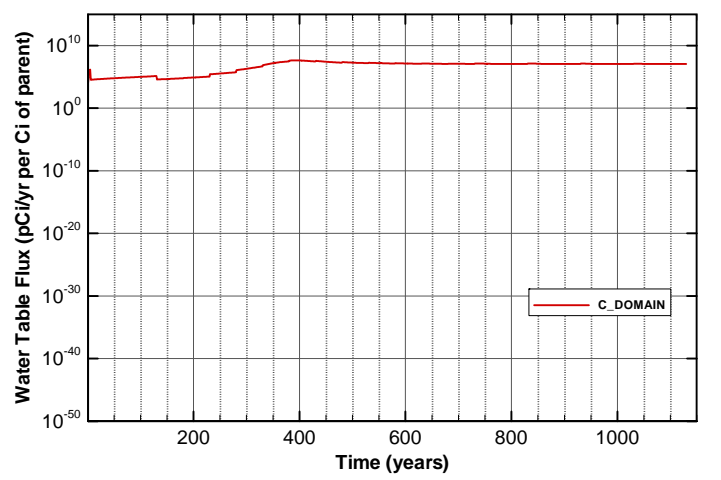

Figure A-386. Flux at water table for Case01_off I-129_Mk50A 


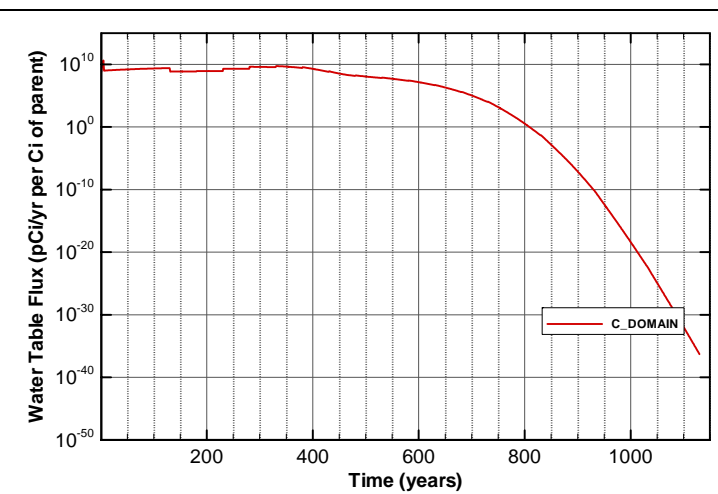

Figure A-387. Flux at water table for Case01_off K-40

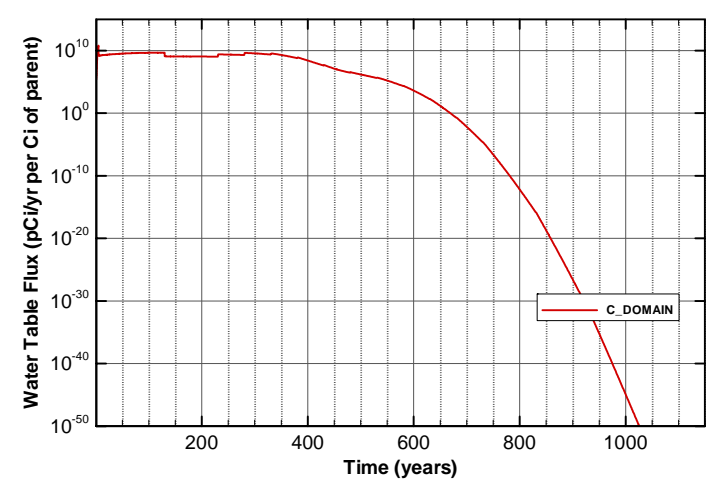

Figure A-389. Flux at water table for Case01_off Nb-94

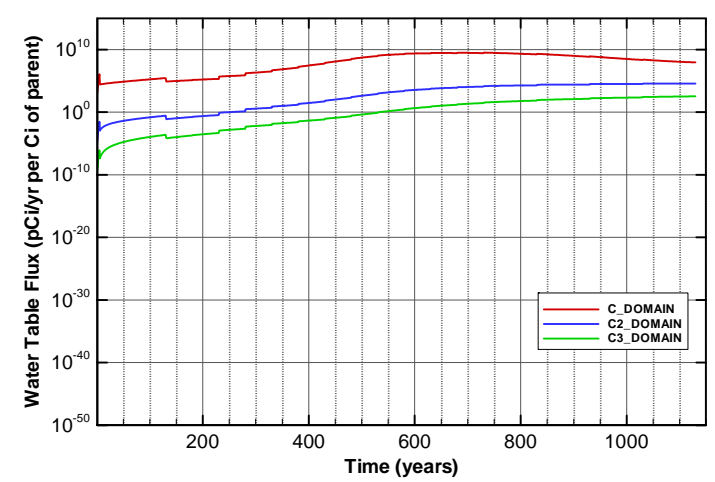

Figure A-391. Flux at water table for Case01_off Np-237

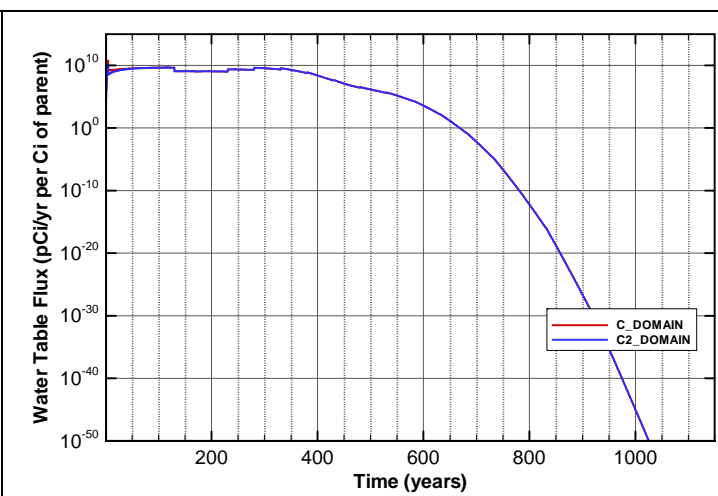

Figure A-388. Flux at water table for Case01_off Mo-93

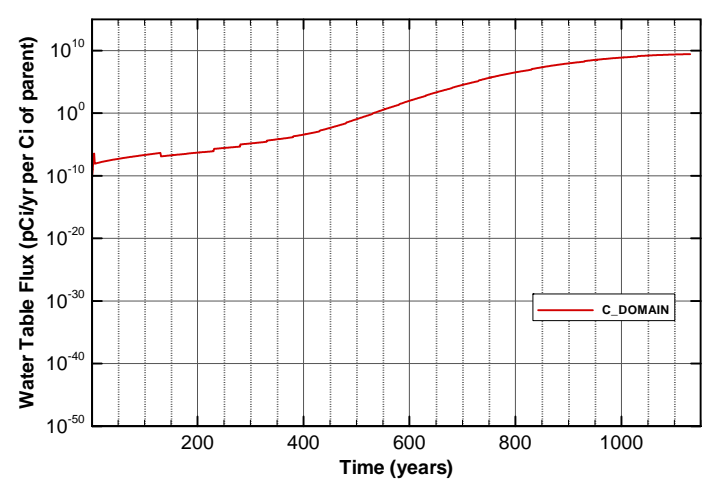

Figure A-390. Flux at water table for Case01_off Ni-59

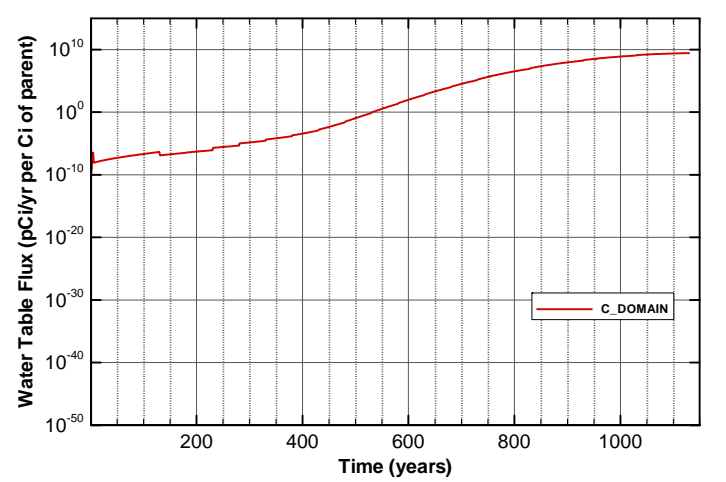

Figure A-392. Flux at water table for Case01_off Pd-107 
SRNL-STI-2008-00397, REVISION 0
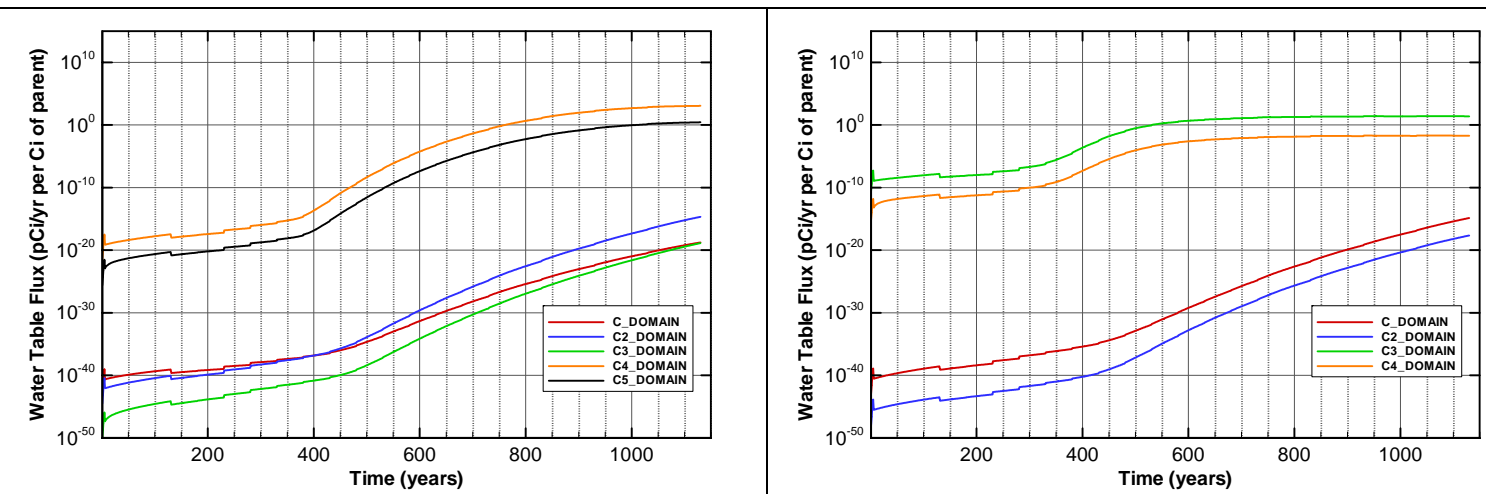

Figure A-393. Flux at water table for Case01_off Pu-238

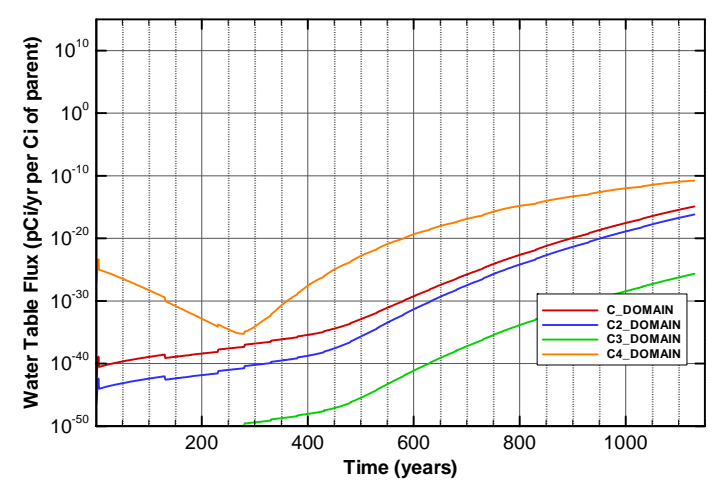

Figure A-395. Flux at water table for Case01_off Pu-240

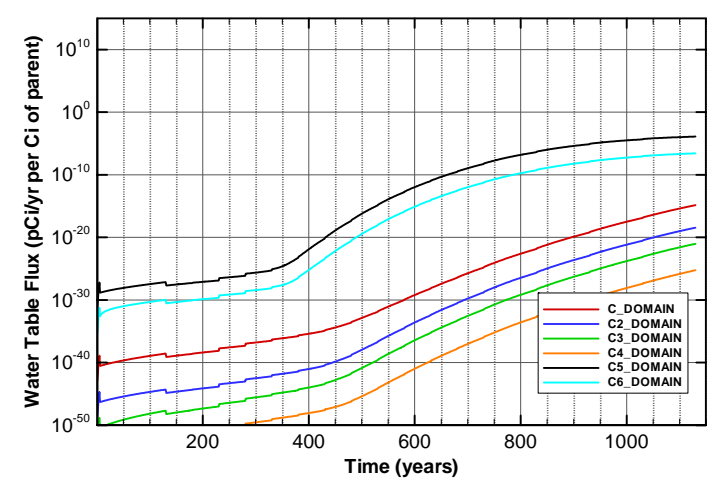

Figure A-397. Flux at water table for Case01_off Pu-242

Figure A-394. Flux at water table for Case01_off Pu-239

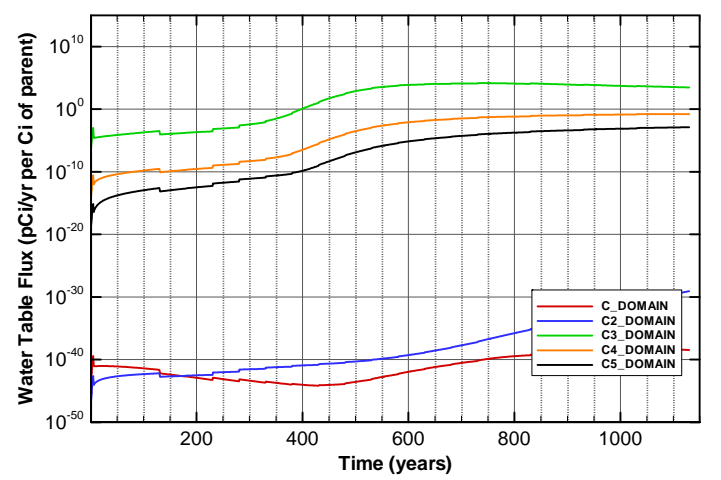

Figure A-396. Flux at water table for Case01_off Pu-241

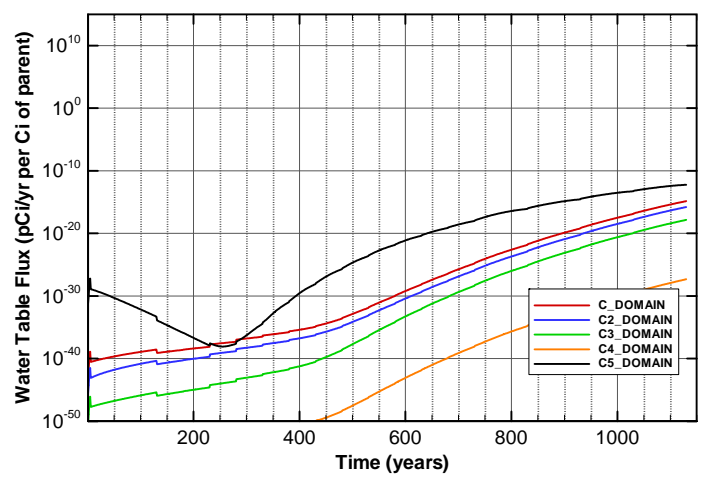

Figure A-398. Flux at water table for Case01_off Pu-244 
SRNL-STI-2008-00397, REVISION 0

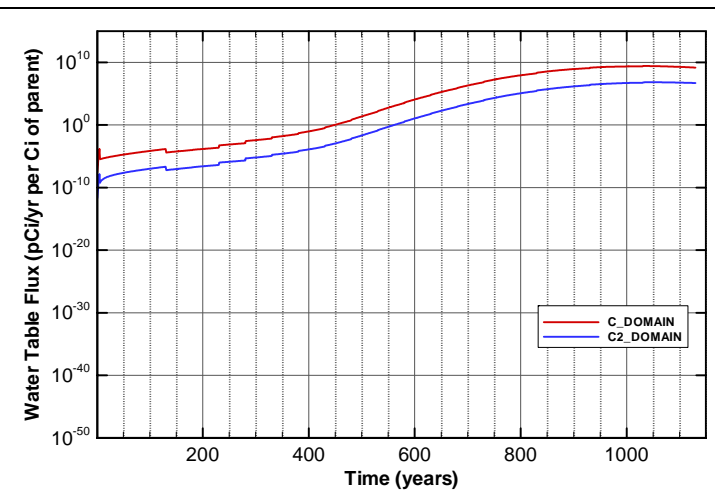

Figure A-399. Flux at water table for Case01_off Ra-226

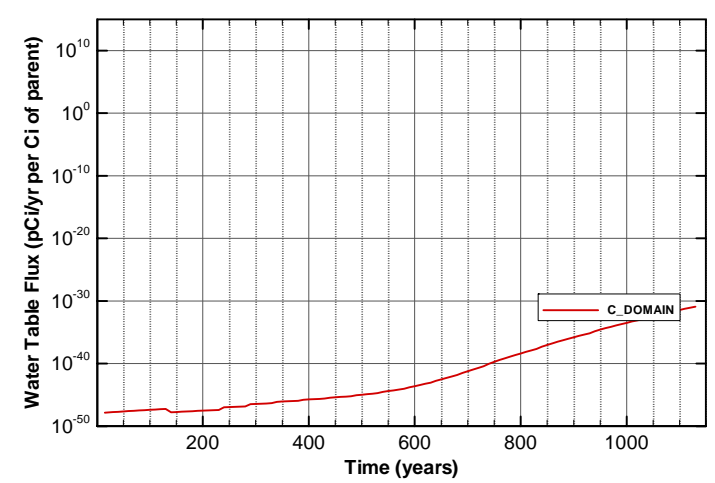

Figure A-401. Flux at water table for Case01_off Sn-126

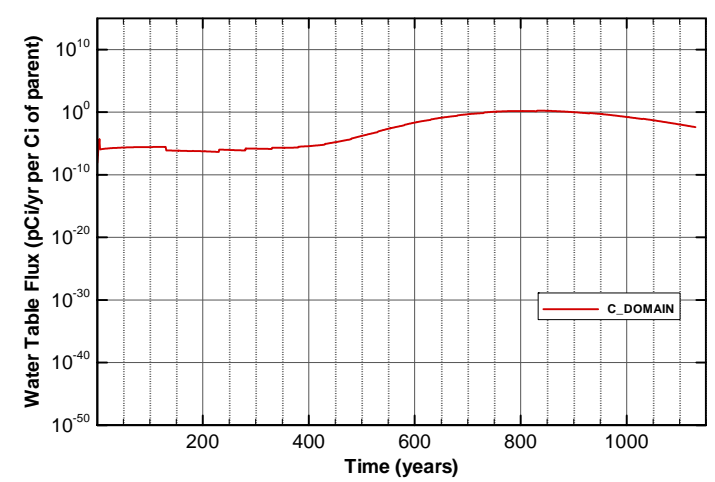

Figure A-403. Flux at water table for Case01_off Sr-90_Cask

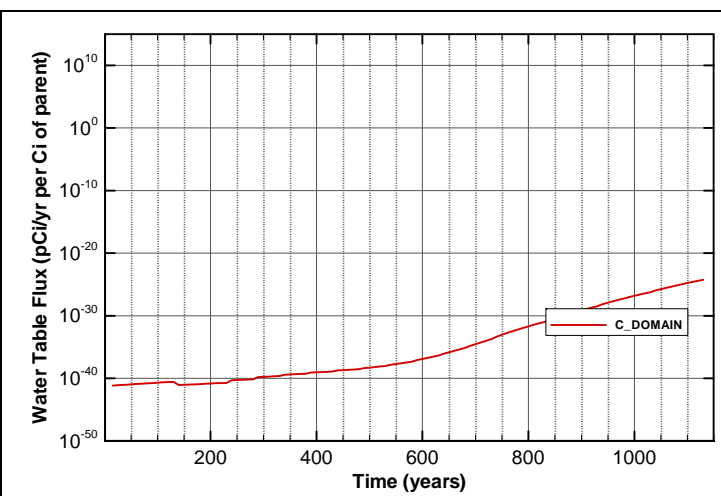

Figure A-400. Flux at water table for Case01_off Se-79

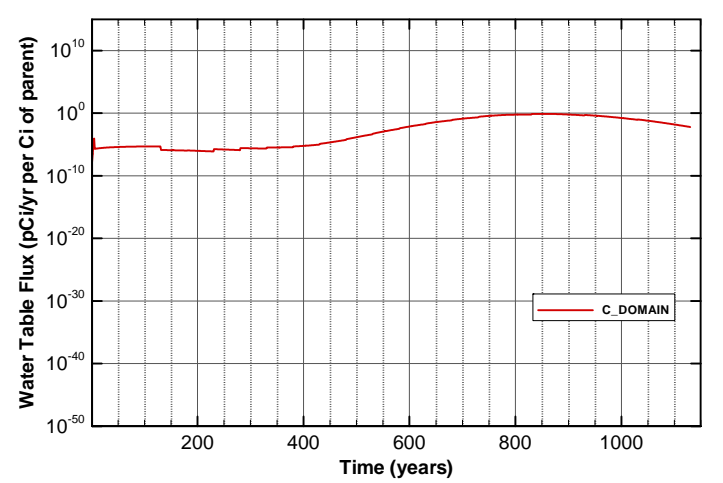

Figure A-402. Flux at water table for Case01_off Sr-90

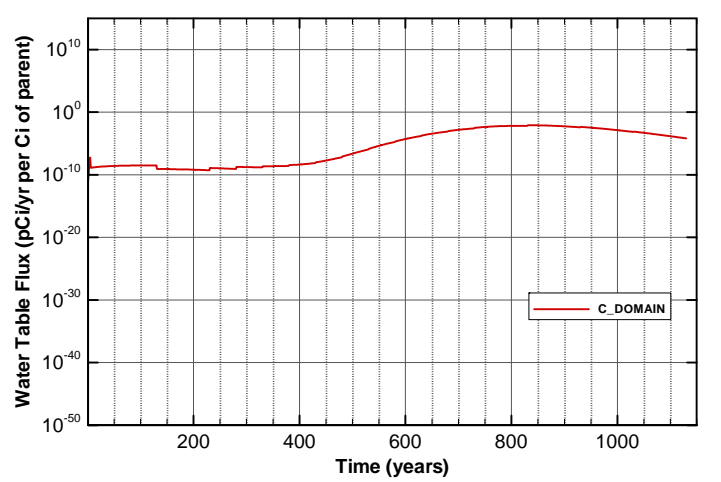

Figure A-404. Flux at water table for Case01_off Sr-90_Mk50A 


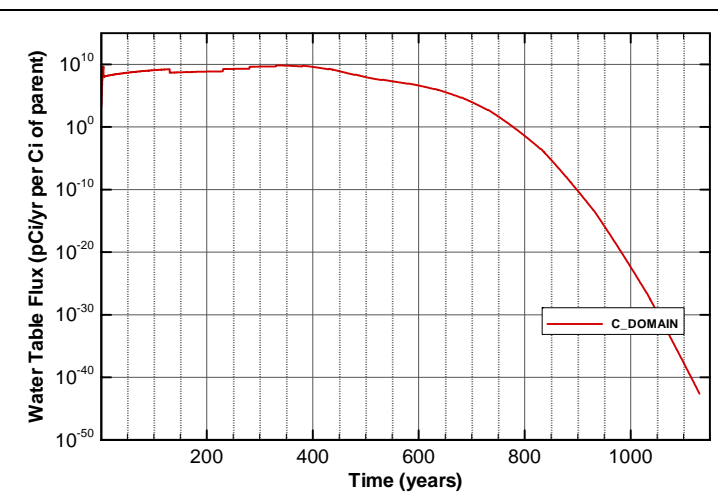

Figure A-405. Flux at water table for Case01_off Tc-99

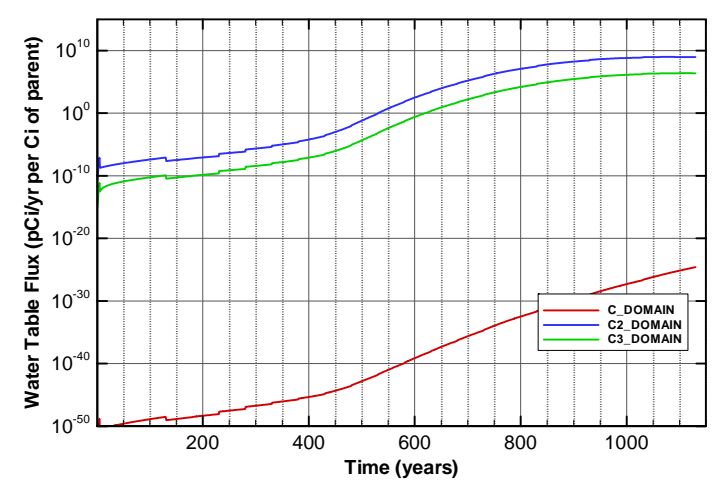

Figure A-407. Flux at water table for Case01_off Th-230

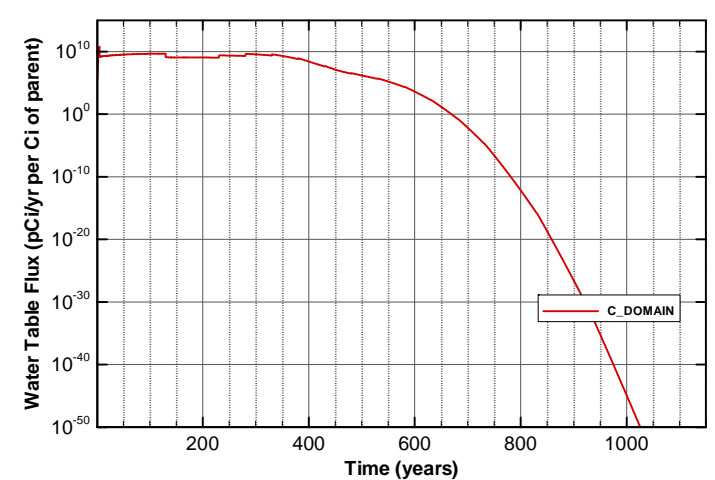

Figure A-409. Flux at water table for Case01_off Tracer

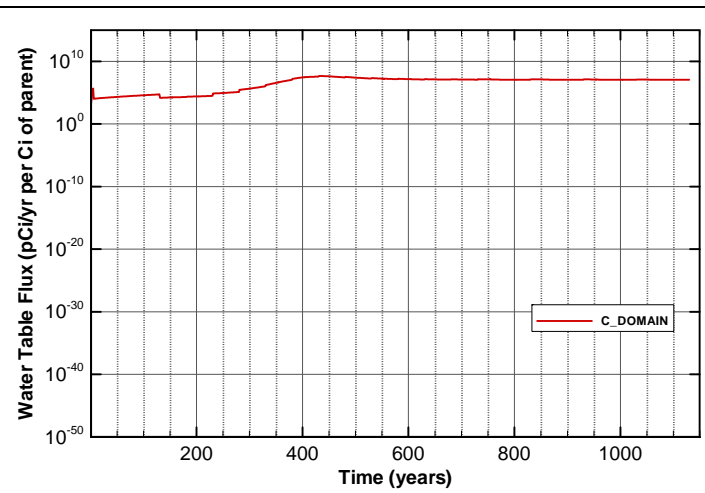

Figure A-406. Flux at water table for Case01_off Tc-99_Mk50A

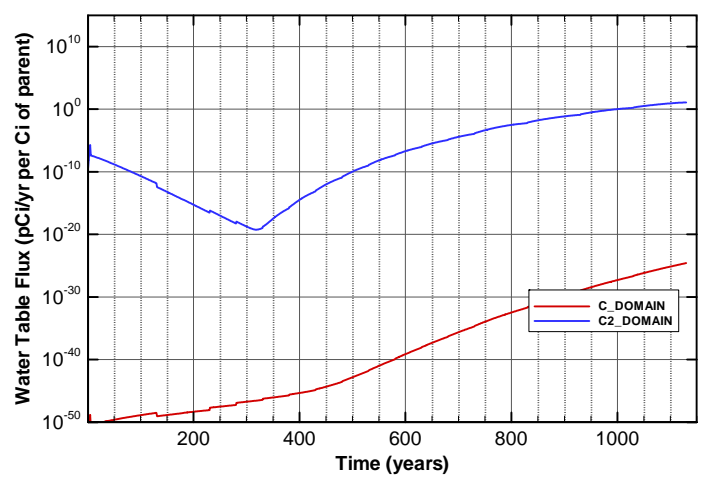

Figure A-408. Flux at water table for Case01_off Th-232

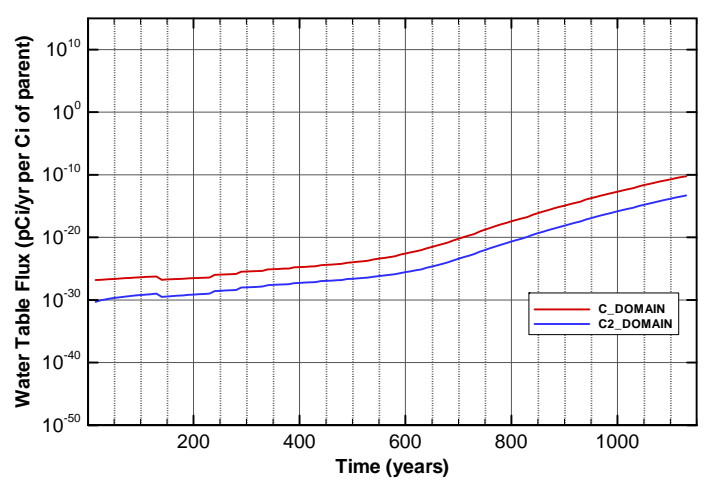

Figure A-410. Flux at water table for Case01_off U-233 
SRNL-STI-2008-00397, REVISION 0
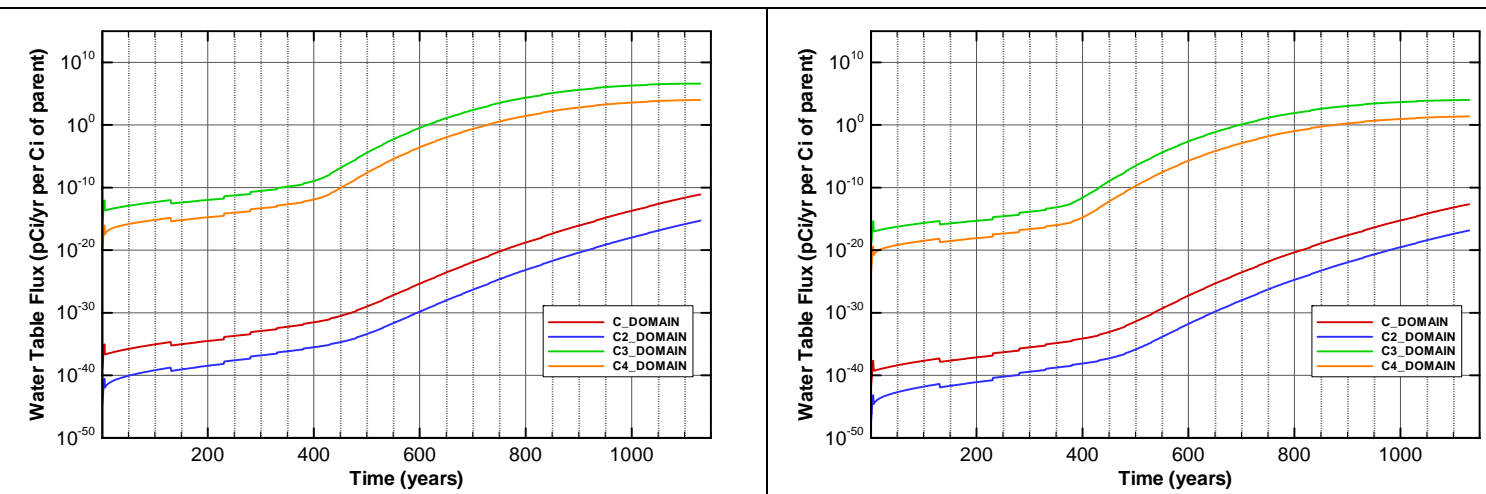

Figure A-411. Flux at water table for Case01_off U-234

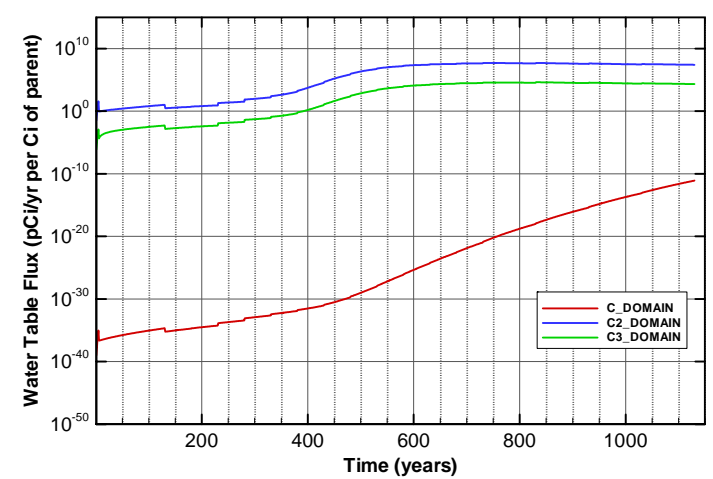

Figure A-413. Flux at water table for Case01_off U-235

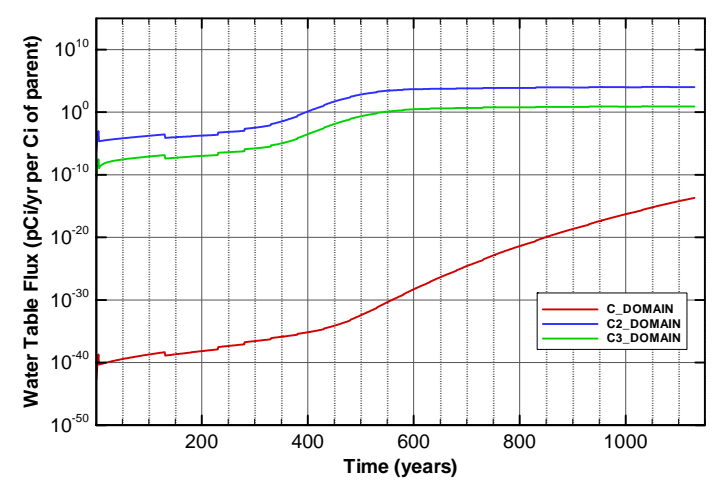

Figure A-415. Flux at water table for Case01_off U-235_Paducah.Cask

Figure A-412. Flux at water table for Case01_off U-234_Mglass

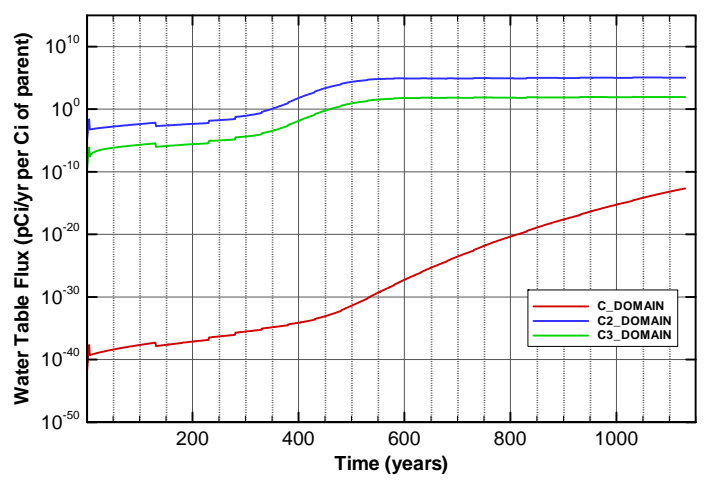

Figure A-414. Flux at water table for Case01_off U-235_Mglass

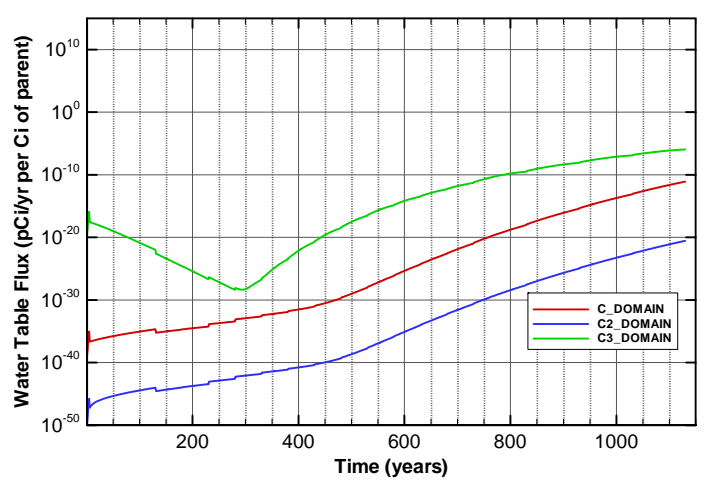

Figure A-416. Flux at water table for Case01_off U-236 
SRNL-STI-2008-00397, REVISION 0
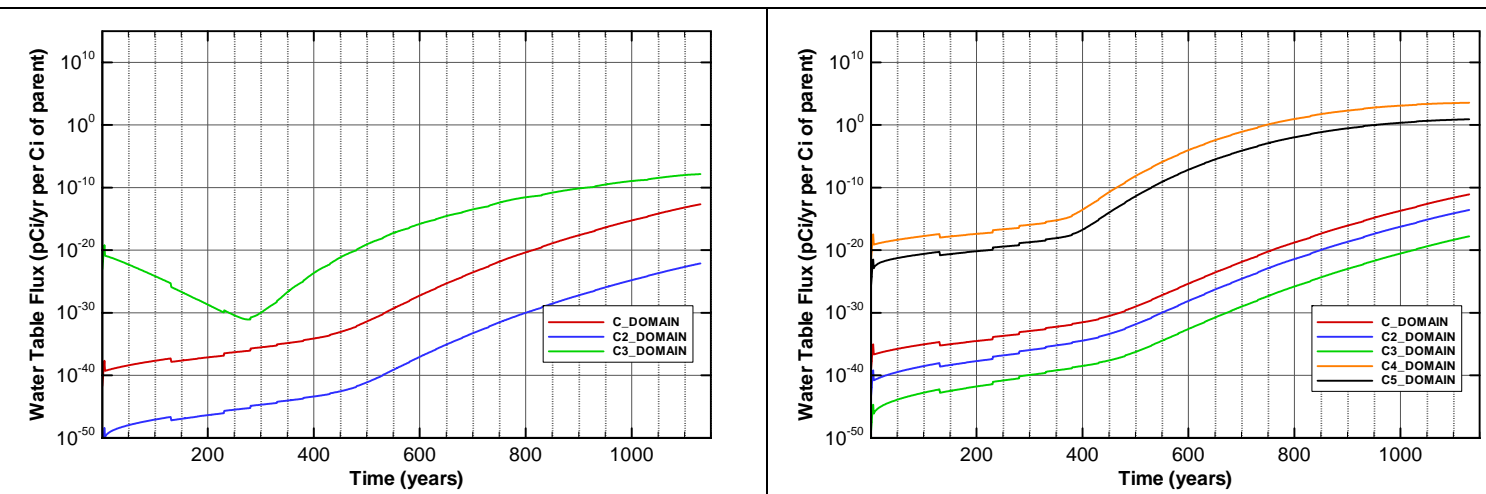

Figure A-417. Flux at water table for Case01_off U-236_Mglass

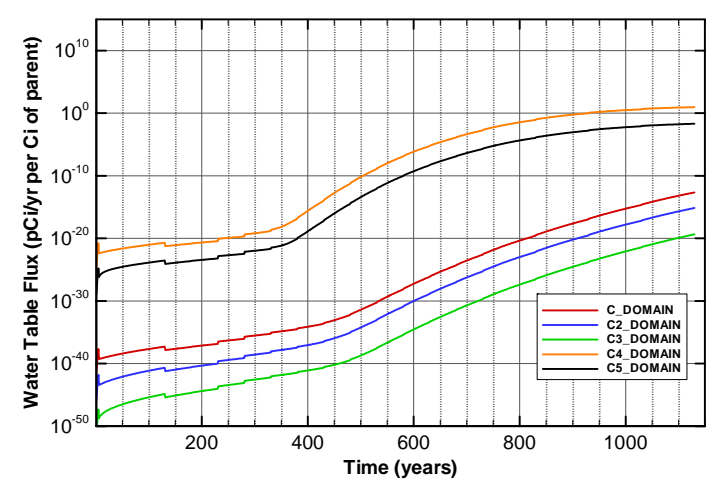

Figure A-419. Flux at water table for Case01_off U-238_Mglass

Figure A-418. Flux at water table for Case01_off U-238

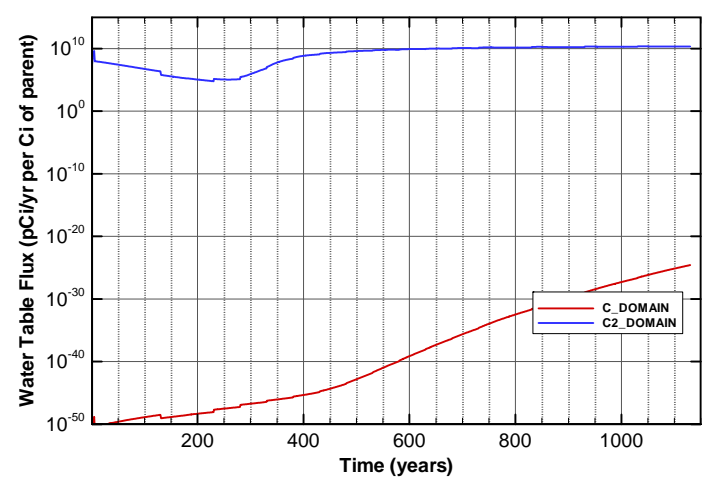

Figure A-420. Flux at water table for Case01_off Zr-93

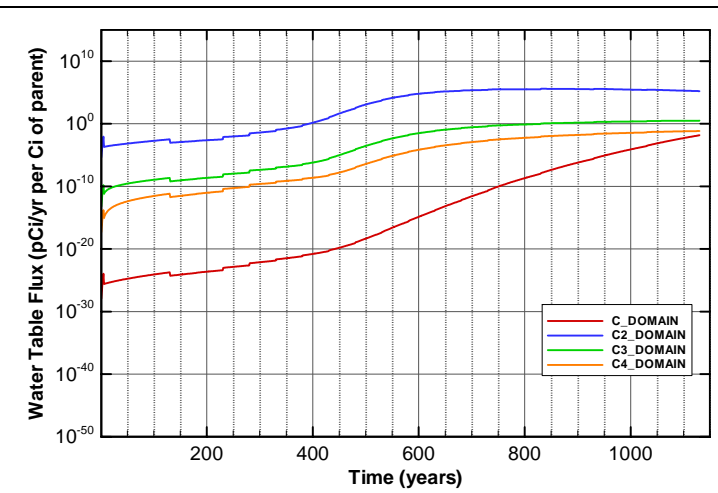

Figure A-421. Flux at water table for Case01_on Am-241

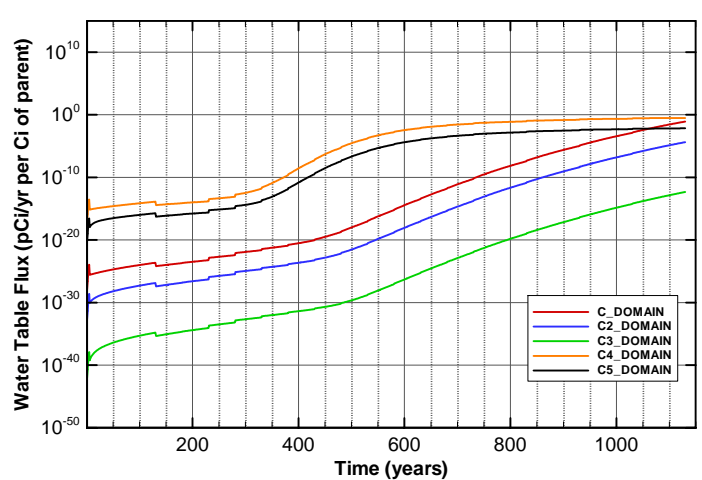

Figure A-422. Flux at water table for Case01_on Am-243 
SRNL-STI-2008-00397, REVISION 0
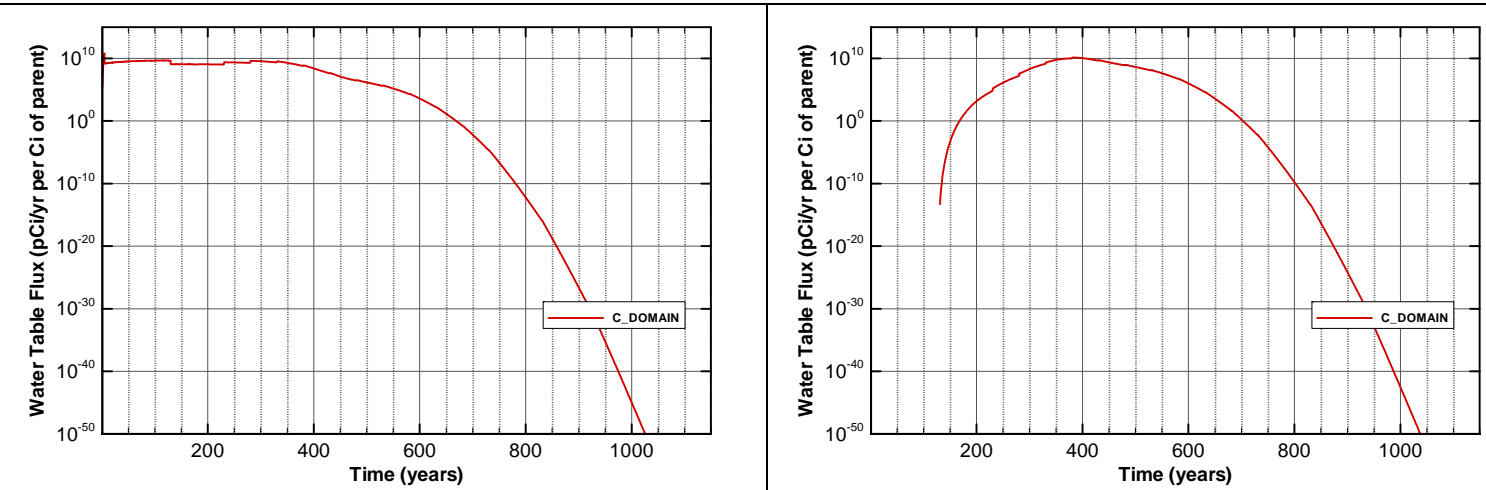

Figure A-423. Flux at water table for Case01_on C-14

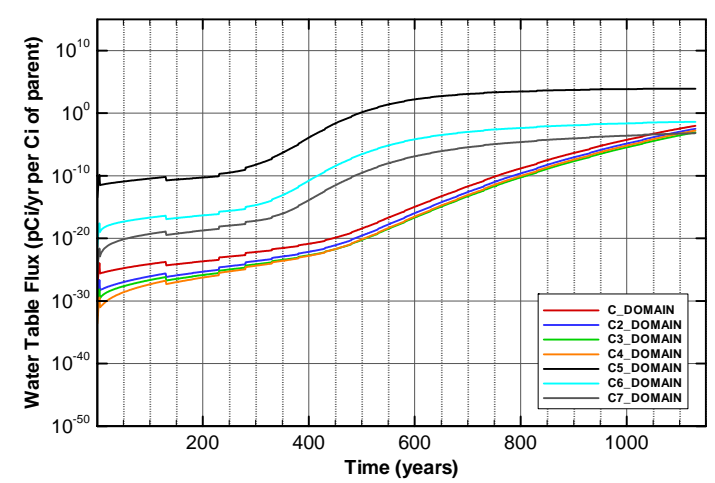

Figure A-425. Flux at water table for Case01_on Cf-249

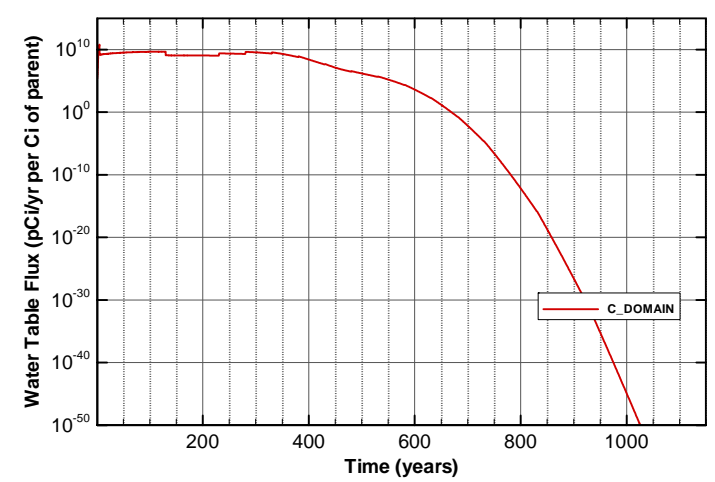

Figure A-427. Flux at water table for Case01_on Cl-36

Figure A-424. Flux at water table for Case01_on C-14_NR.Pump

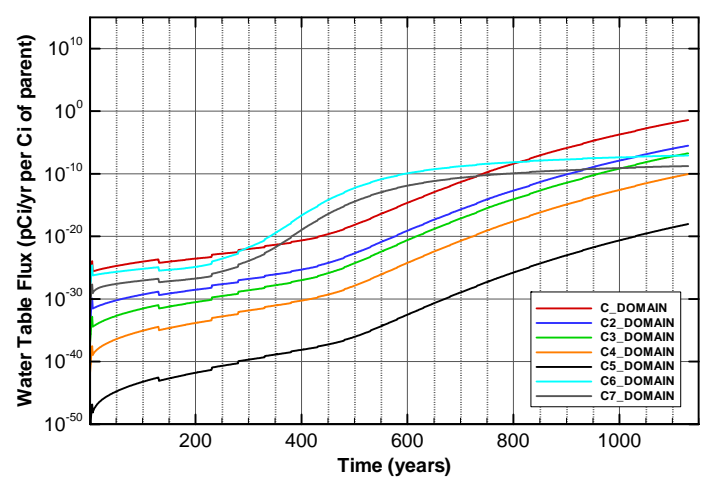

Figure A-426. Flux at water table for Case01_on Cf-251

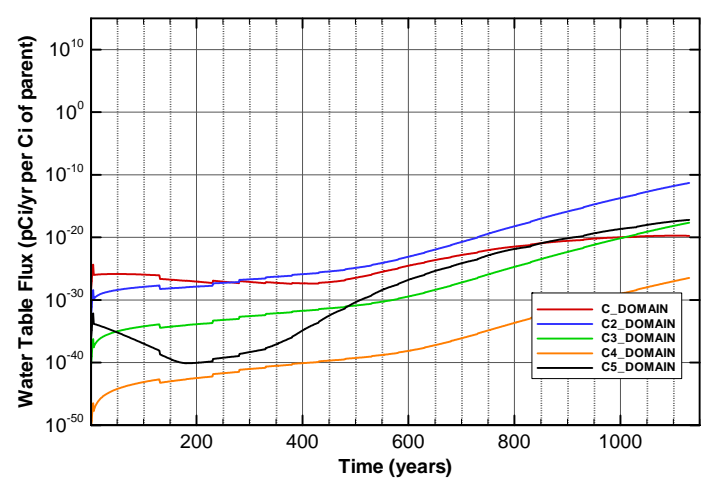

Figure A-428. Flux at water table for Case01_on Cm-244 
SRNL-STI-2008-00397, REVISION 0

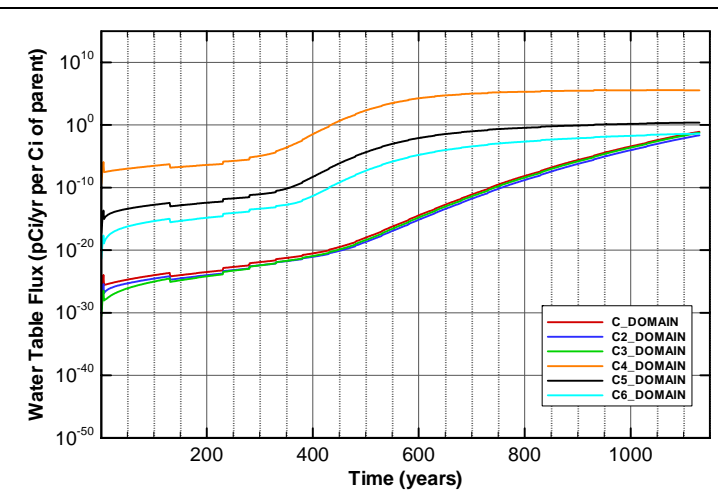

Figure A-429. Flux at water table for Case01_on Cm-245

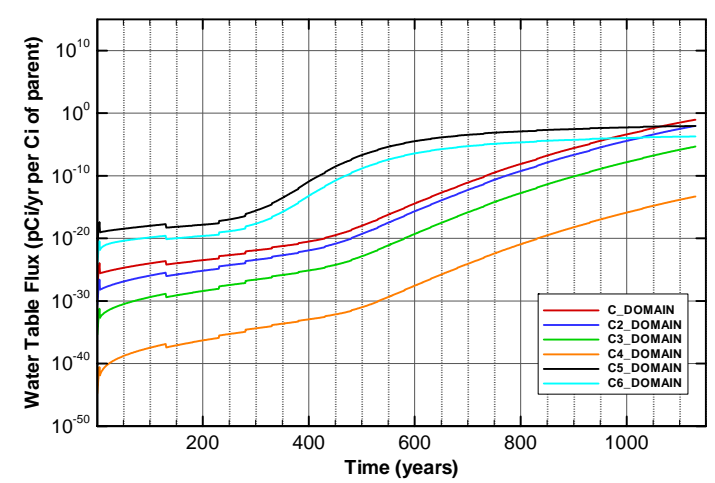

Figure A-431. Flux at water table for Case01_on Cm-247

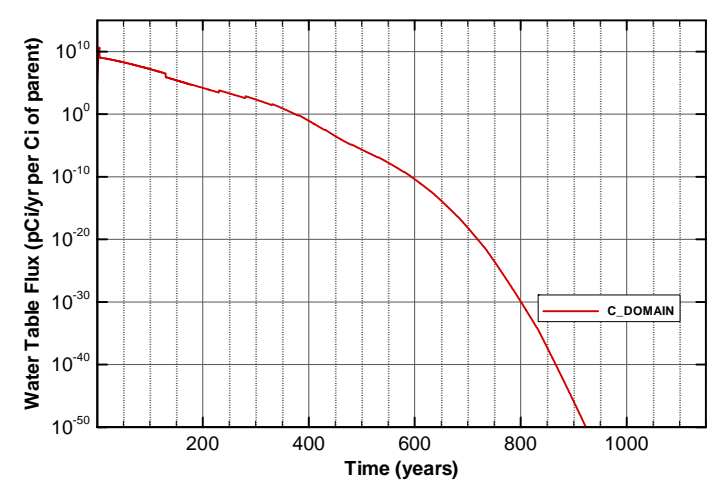

Figure A-433. Flux at water table for Case01_on H-3

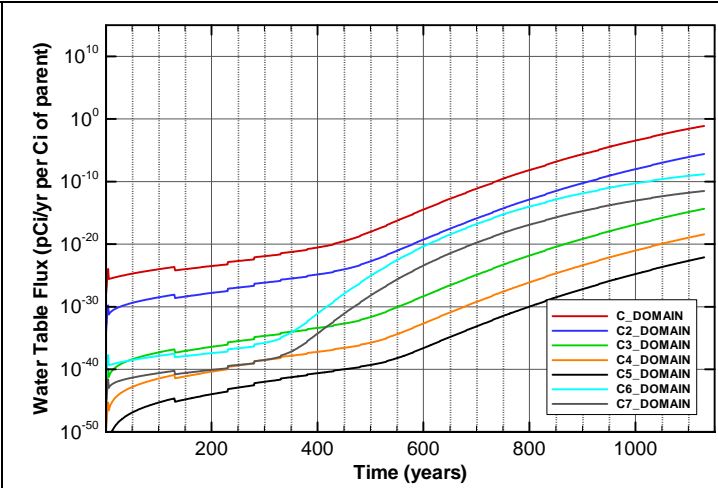

Figure A-430. Flux at water table for Case01_on Cm-246

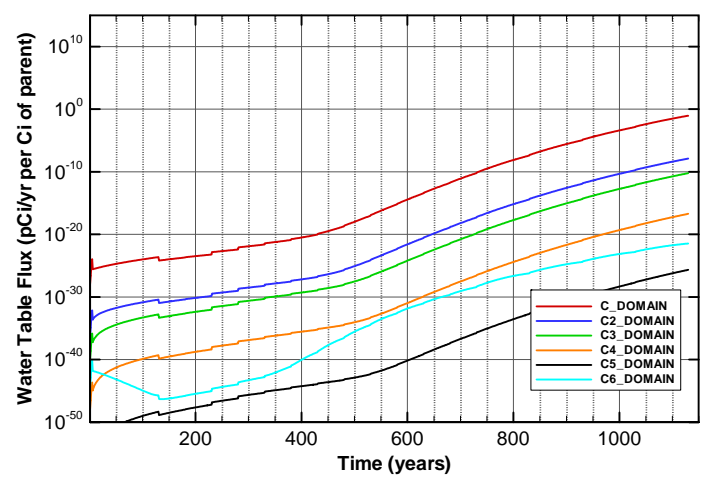

Figure A-432. Flux at water table for Case01_on Cm-248

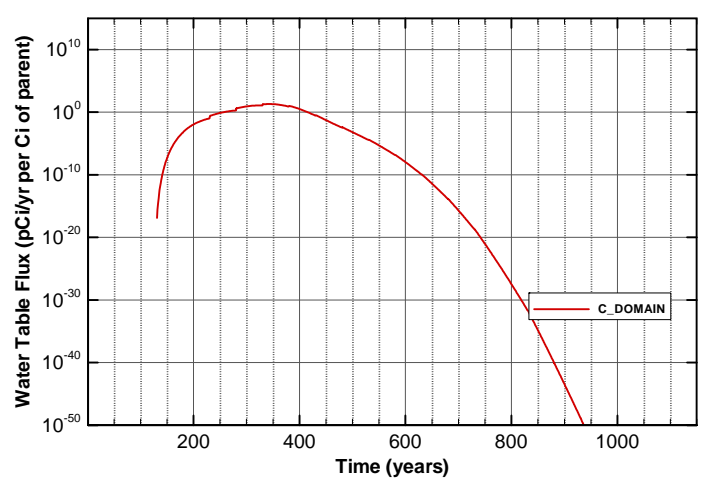

Figure A-434. Flux at water table for Case01_on H-3_ETF.Carbon 


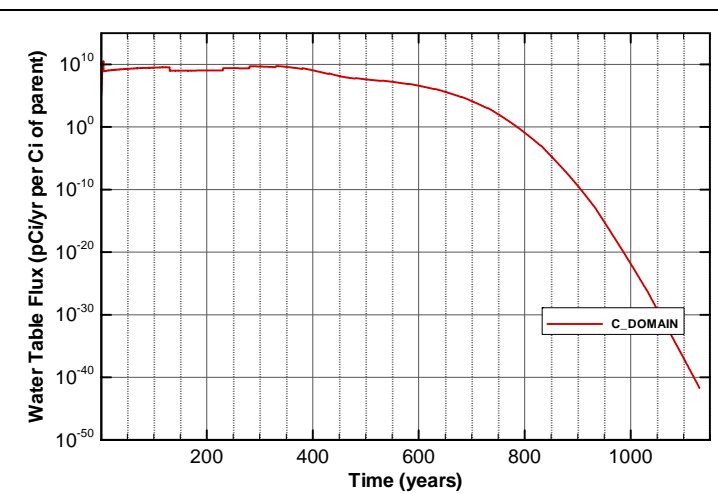

Figure A-435. Flux at water table for Case01_on I-129

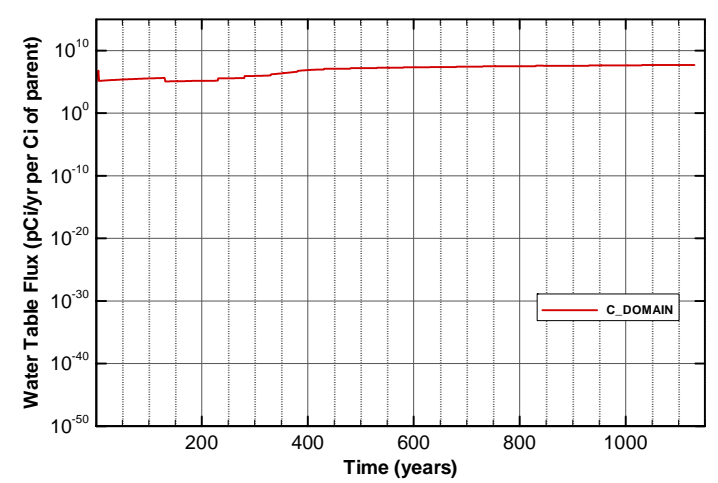

Figure A-437. Flux at water table for Case01_on I-129_ETF.GT.73

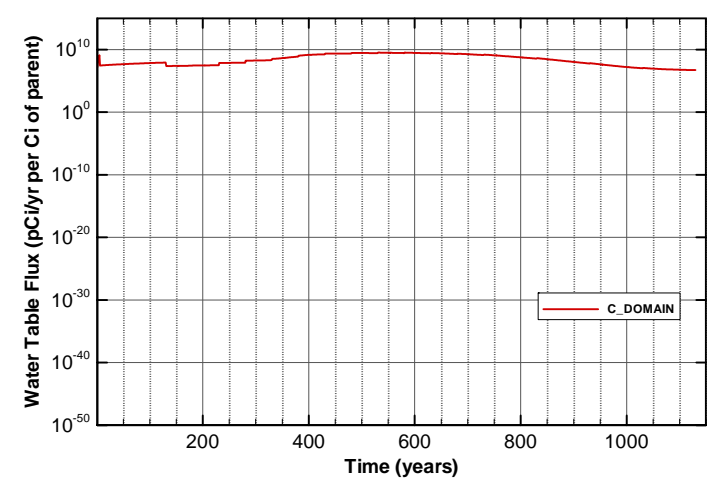

Figure A-439. Flux at water table for Case01_on I-129_F.CG.8

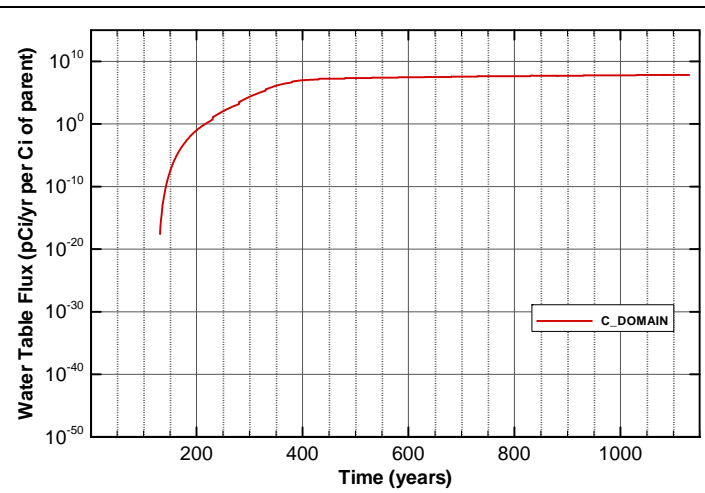

Figure A-436. Flux at water table for Case01_on I-129_ETF.Carbon

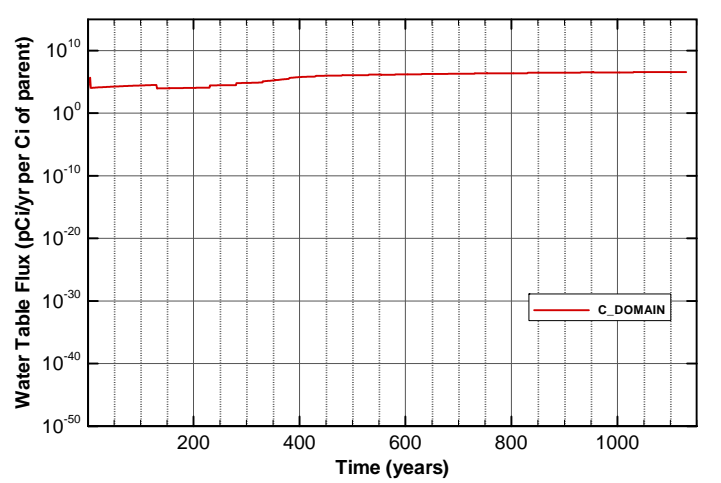

Figure A-438. Flux at water table for Case01_on I-129_F.Carbon

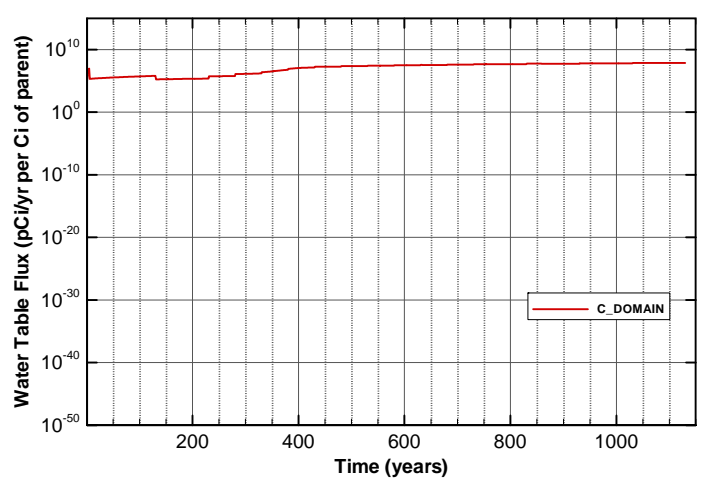

Figure A-440. Flux at water table for Case01_on I-129_F.Dowex.21K 


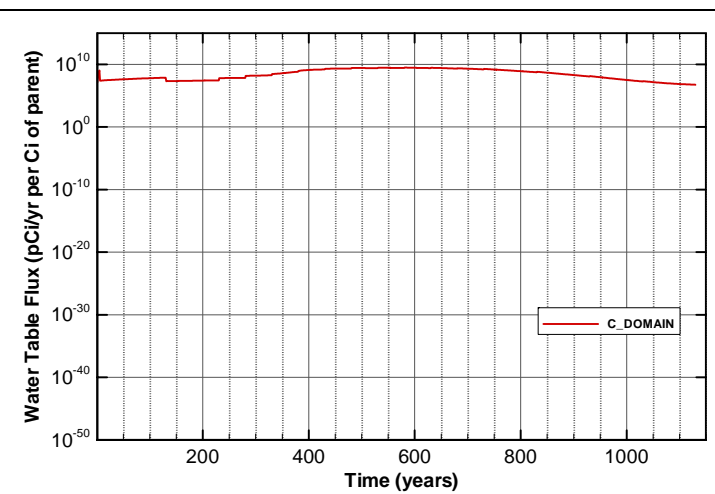

Figure A-441. Flux at water table for Case01_on I-129_F.Filtercake

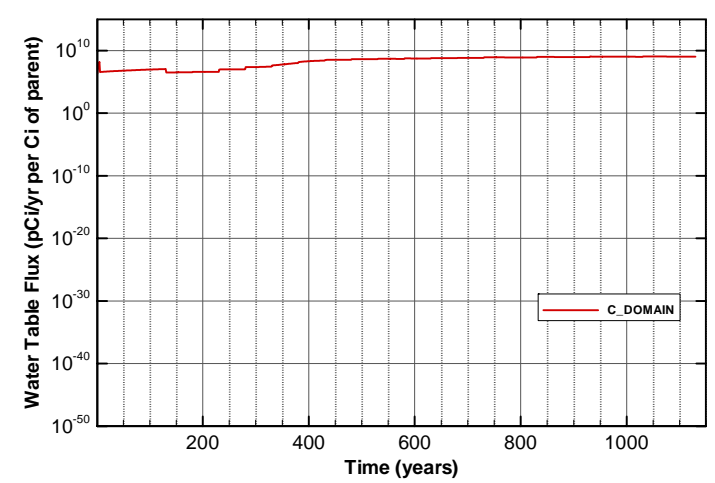

Figure A-443. Flux at water table for Case01_on I-129_H.CG.8

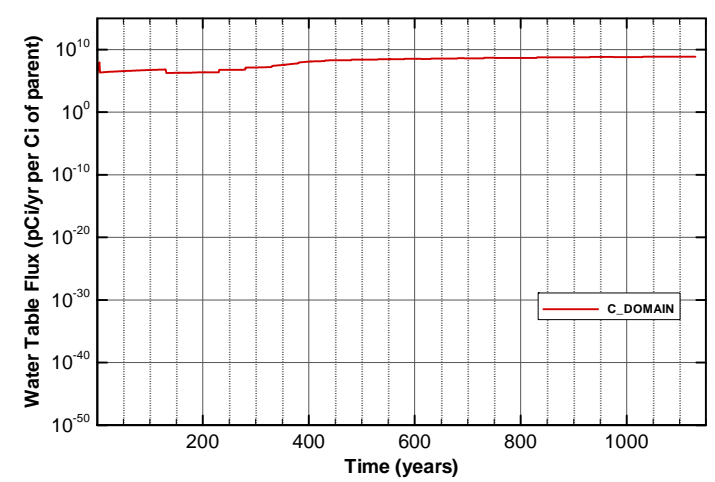

Figure A-445. Flux at water table for Case01_on I-129_H.Filtercake

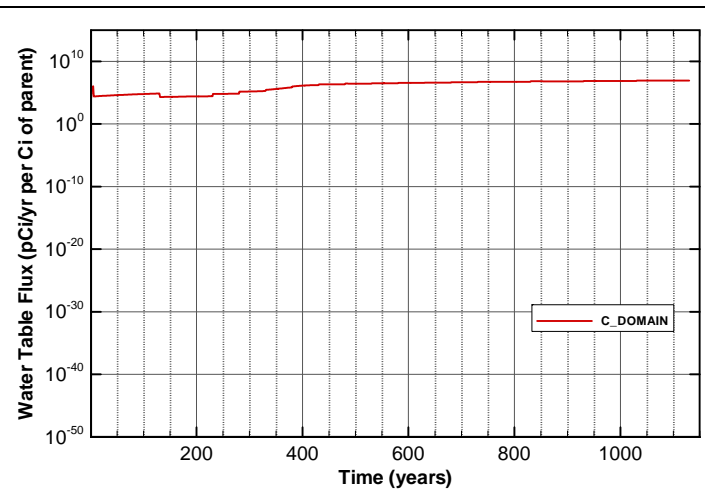

Figure A-442. Flux at water table for Case01_on I-129_H.Carbon

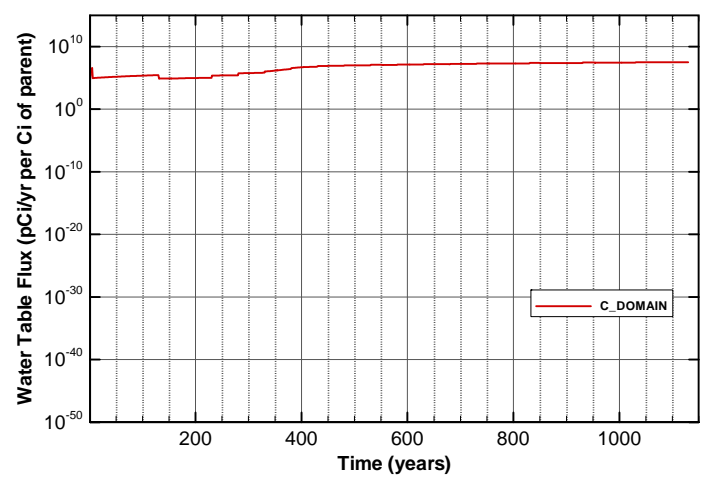

Figure A-444. Flux at water table for Case01_on I-129_H.Dowex.21K

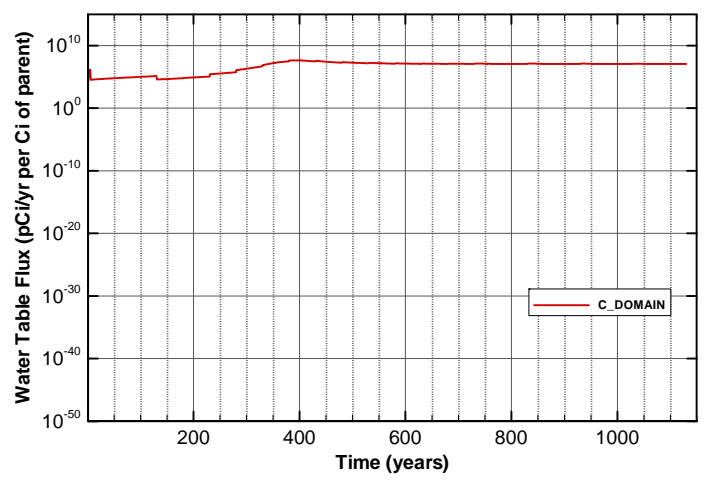

Figure A-446. Flux at water table for Case01_on I-129_Mk50A 


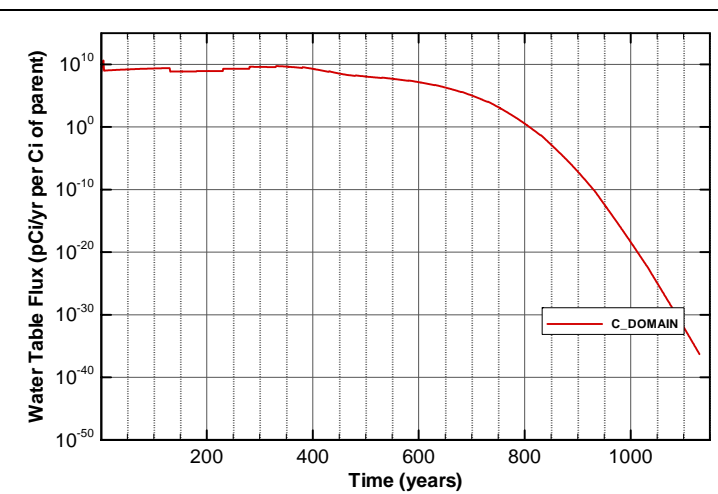

Figure A-447. Flux at water table for Case01_on K-40

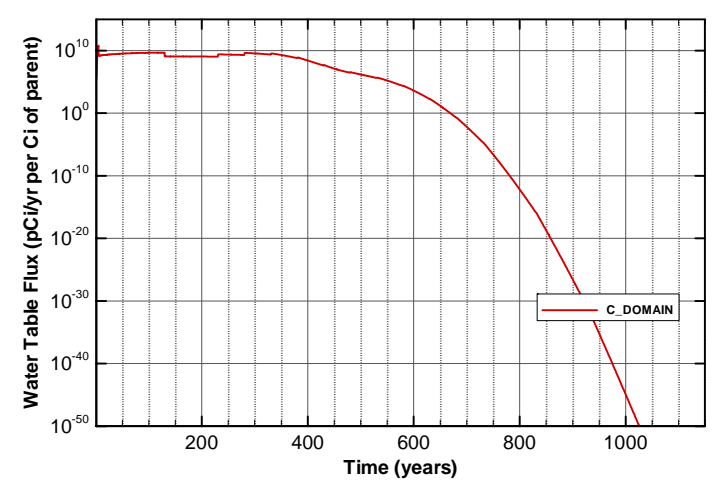

Figure A-449. Flux at water table for Case01_on Nb-94

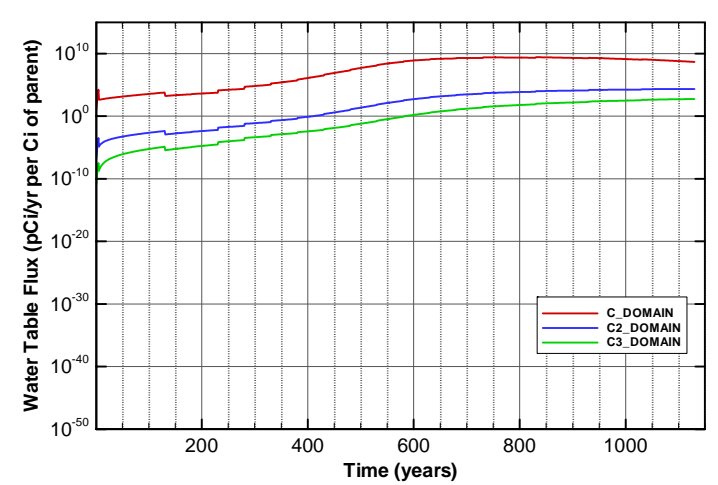

Figure A-451. Flux at water table for Case01_on Np-237

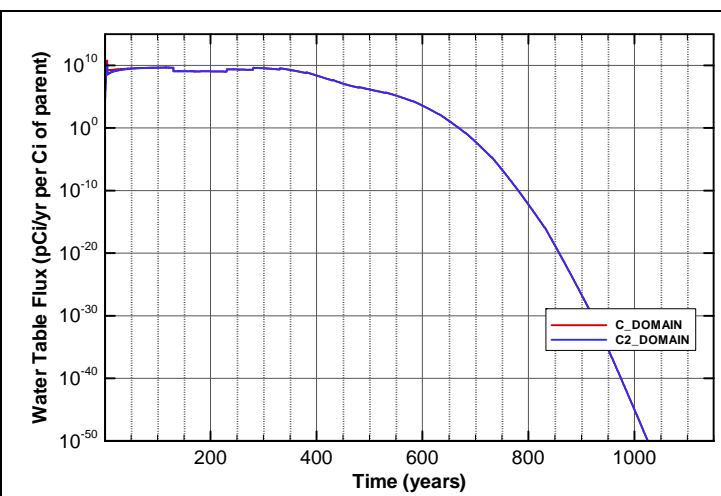

Figure A-448. Flux at water table for Case01_on Mo-93

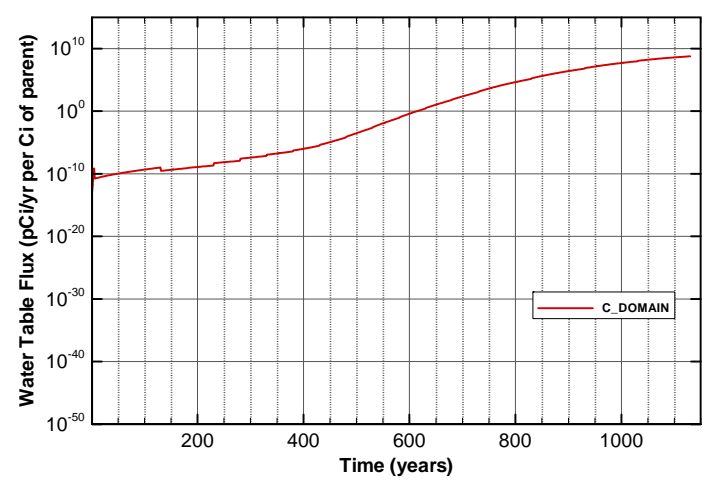

Figure A-450. Flux at water table for Case01_on Ni-59

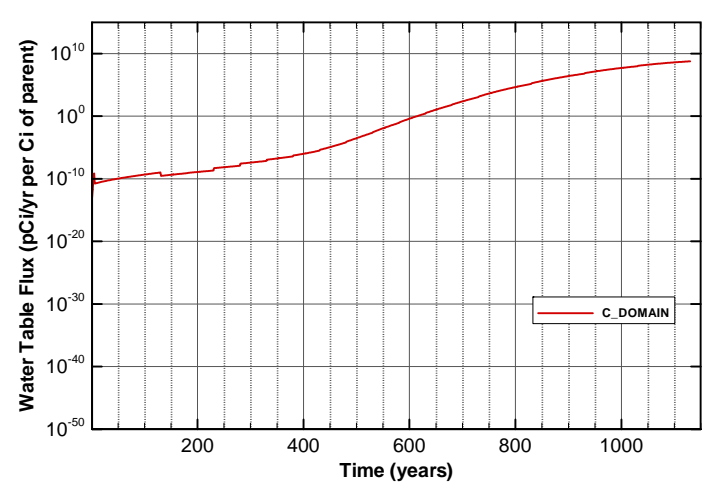

Figure A-452. Flux at water table for Case01_on Pd-107 
SRNL-STI-2008-00397, REVISION 0

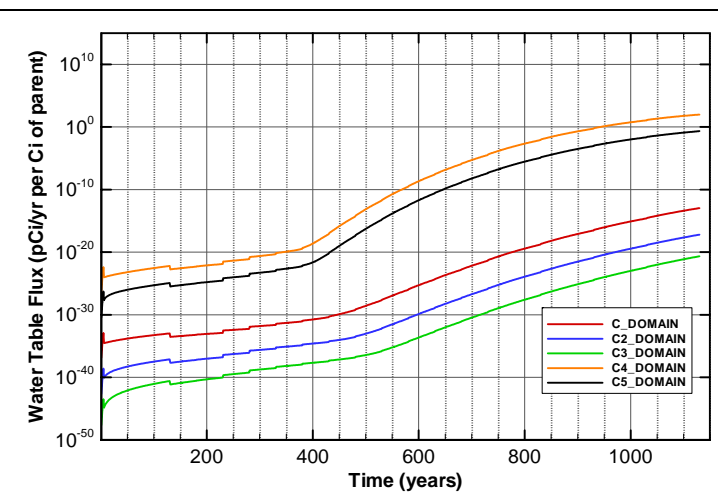

Figure A-453. Flux at water table for Case01_on Pu-238

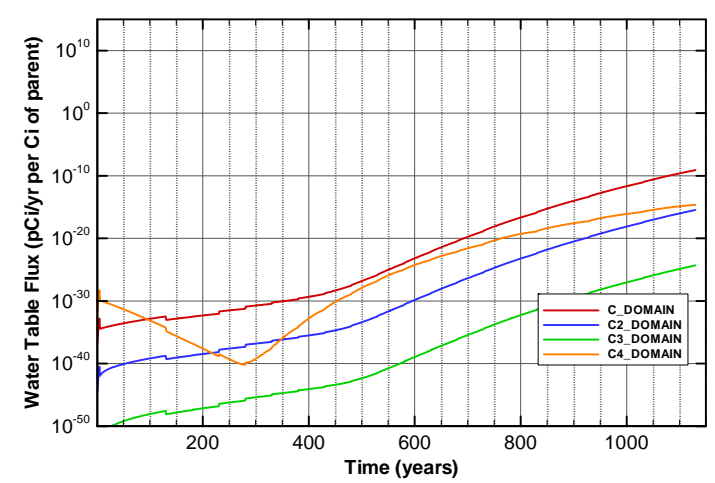

Figure A-455. Flux at water table for Case01_on Pu-240

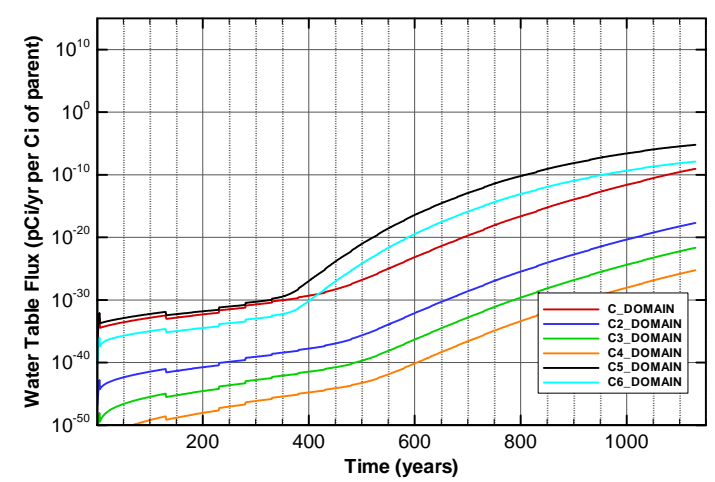

Figure A-457. Flux at water table for Case01_on Pu-242

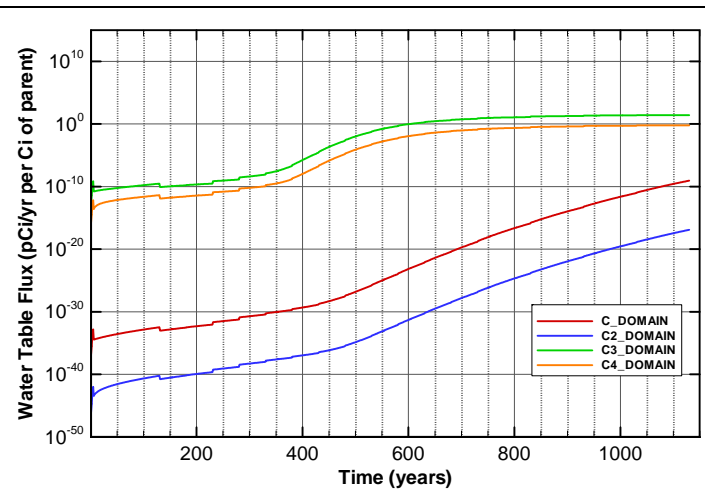

Figure A-454. Flux at water table for Case01_on Pu-239

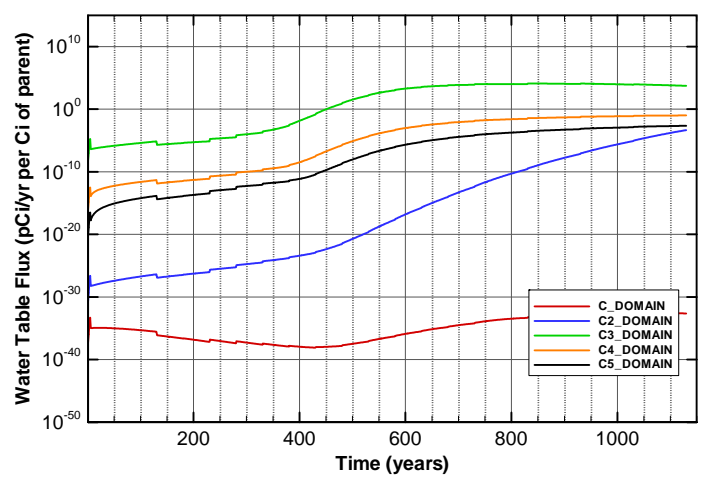

Figure A-456. Flux at water table for Case01_on Pu-241

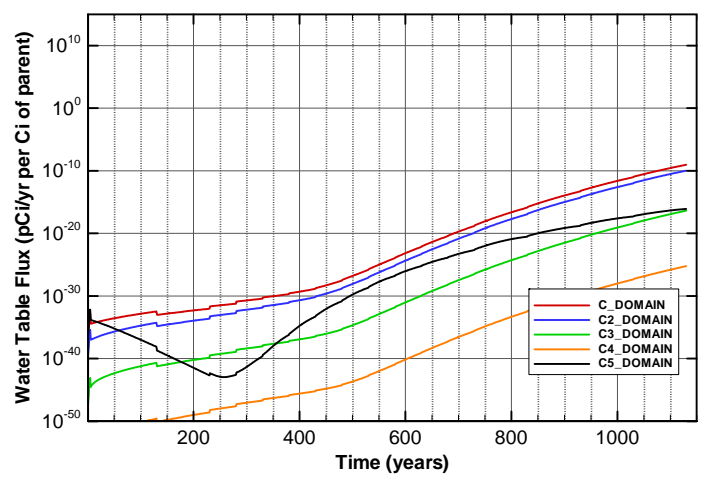

Figure A-458. Flux at water table for Case01_on Pu-244 
SRNL-STI-2008-00397, REVISION 0

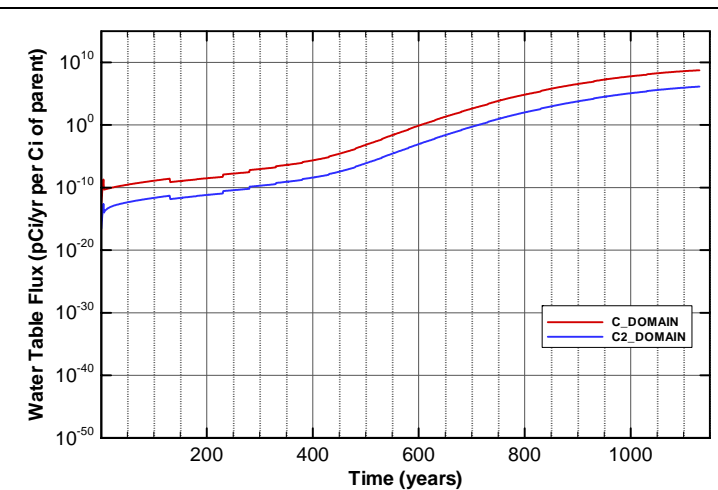

Figure A-459. Flux at water table for Case01_on Ra-226

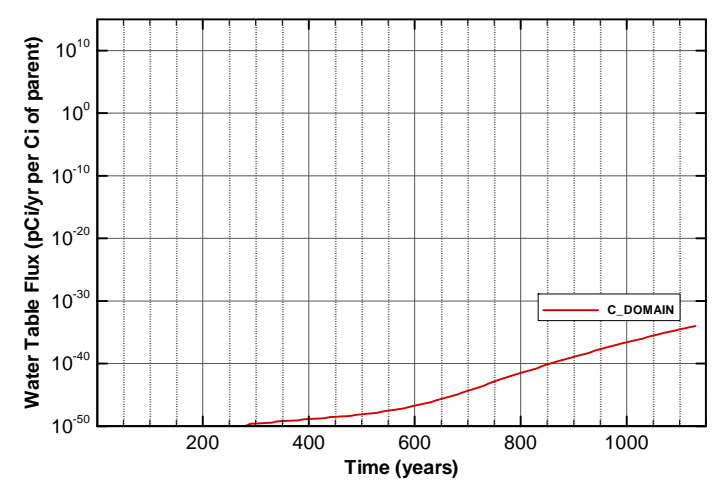

Figure A-461. Flux at water table for Case01_on Sn-126

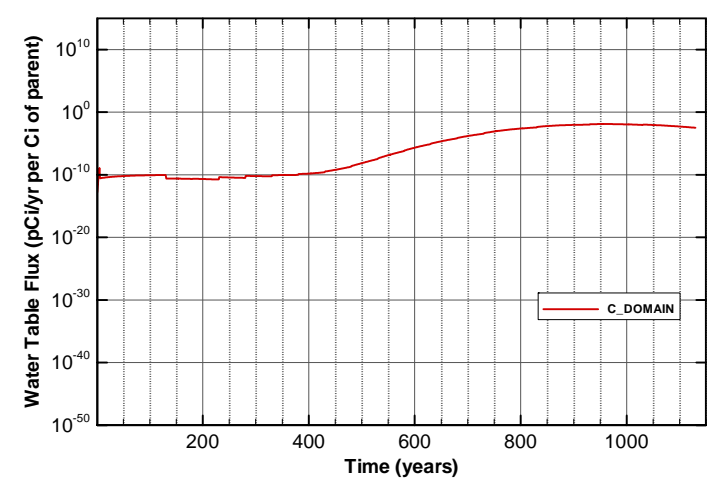

Figure A-463. Flux at water table for Case01_on Sr-90_Cask

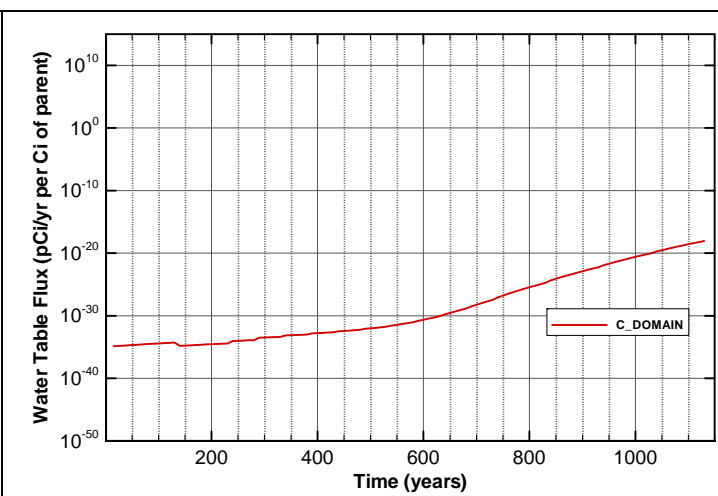

Figure A-460. Flux at water table for Case01_on Se-79

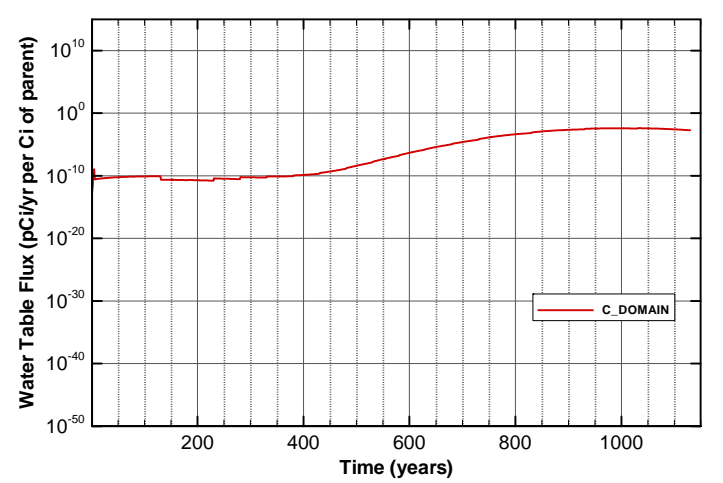

Figure A-462. Flux at water table for Case01_on Sr-90

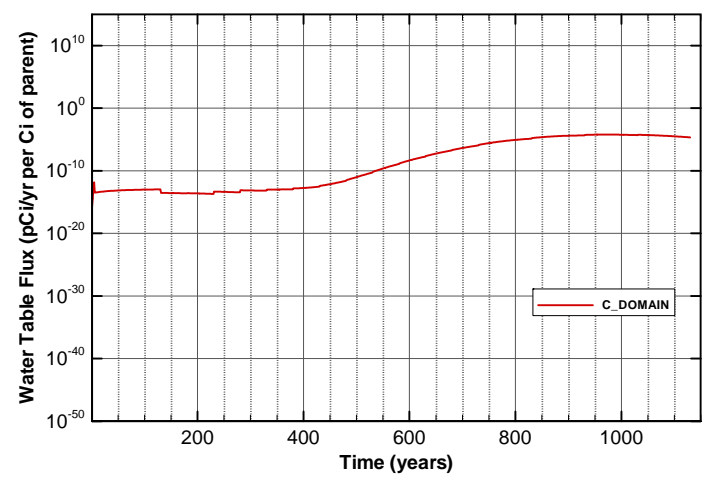

Figure A-464. Flux at water table for Case01_on Sr-90_Mk50A 


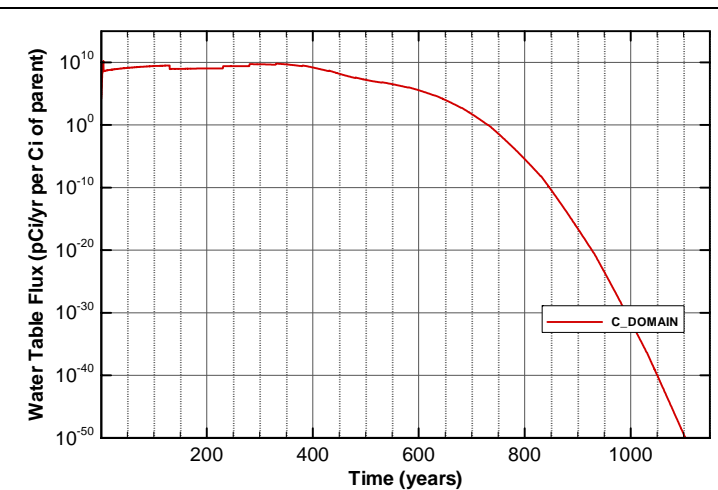

Figure A-465. Flux at water table for Case01_on Tc-99

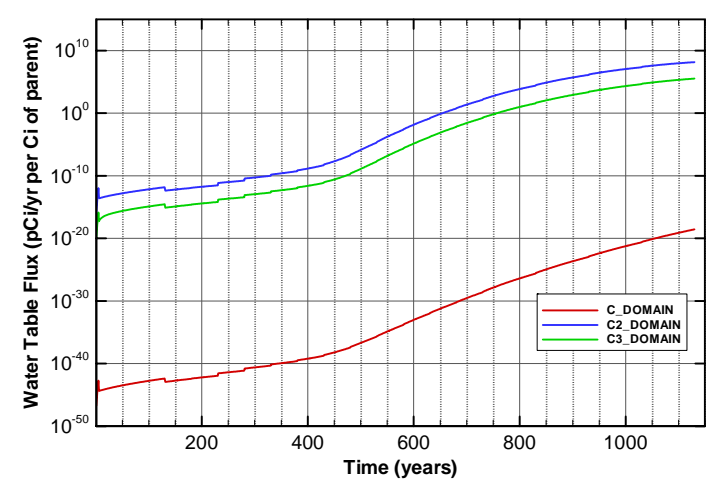

Figure A-467. Flux at water table for Case01_on Th-230

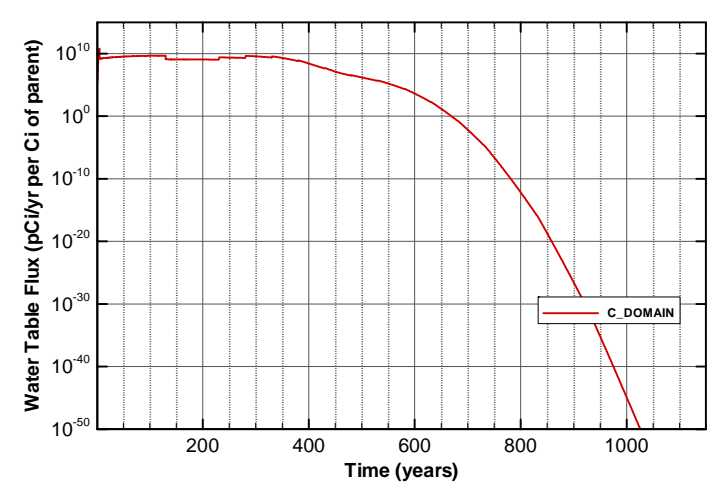

Figure A-469. Flux at water table for Case01_on Tracer

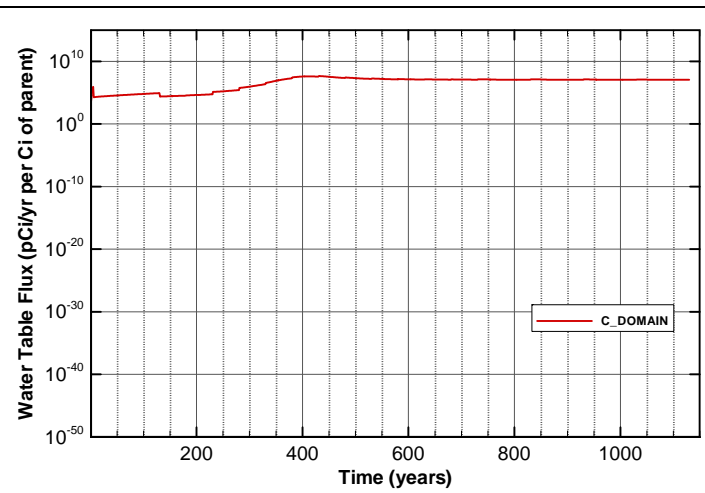

Figure A-466. Flux at water table for Case01_on Tc-99_Mk50A

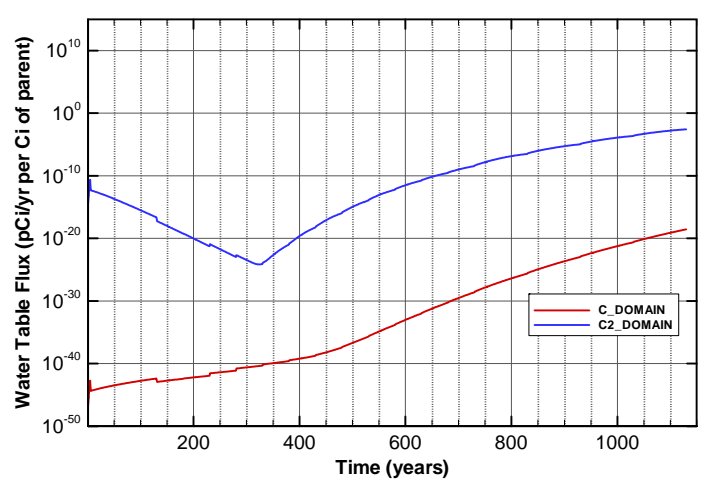

Figure A-468. Flux at water table for Case01_on Th-232

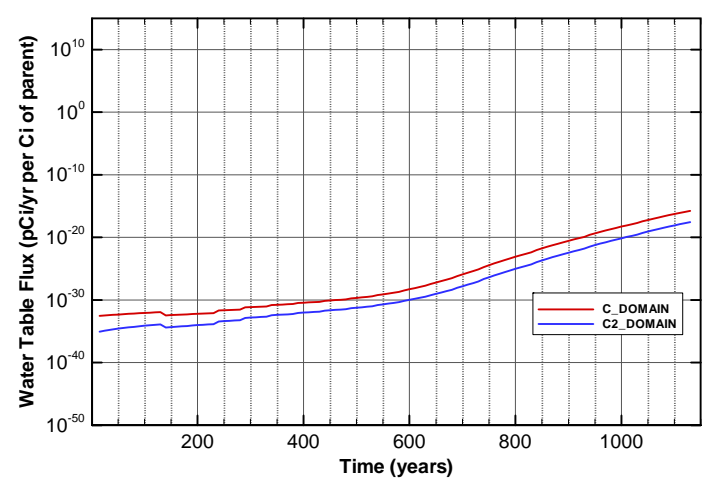

Figure A-470. Flux at water table for Case01_on U-233 
SRNL-STI-2008-00397, REVISION 0
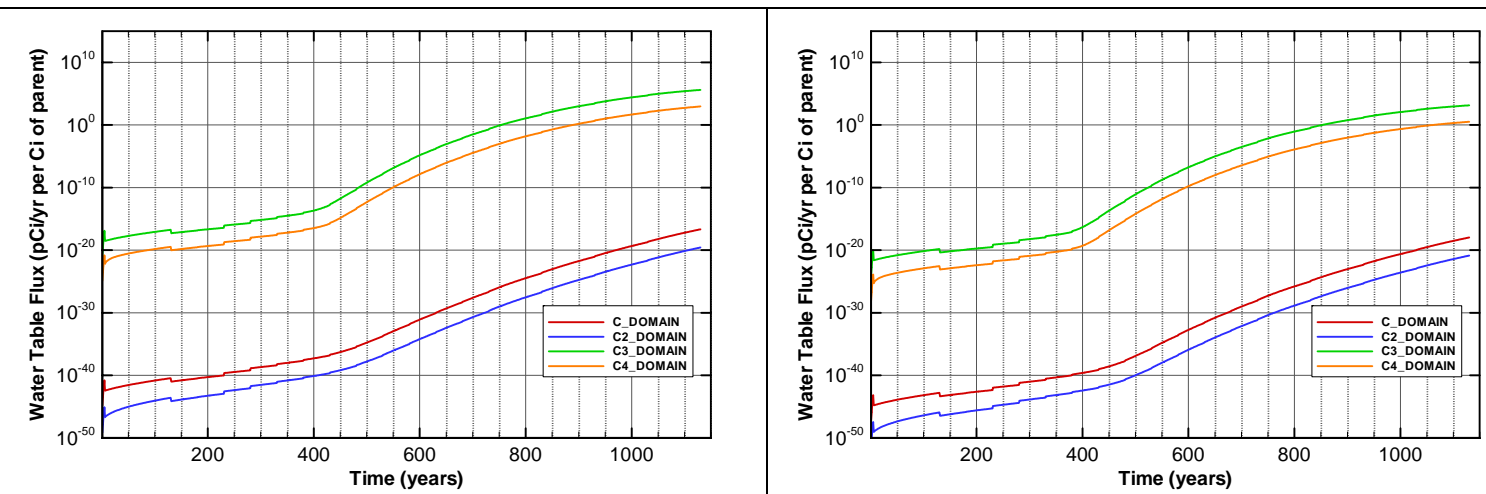

Figure A-471. Flux at water table for Case01_on U-234

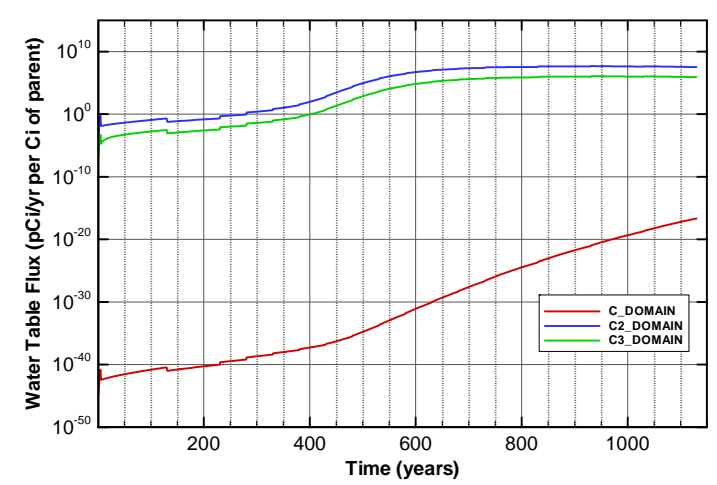

Figure A-473. Flux at water table for Case01_on U-235

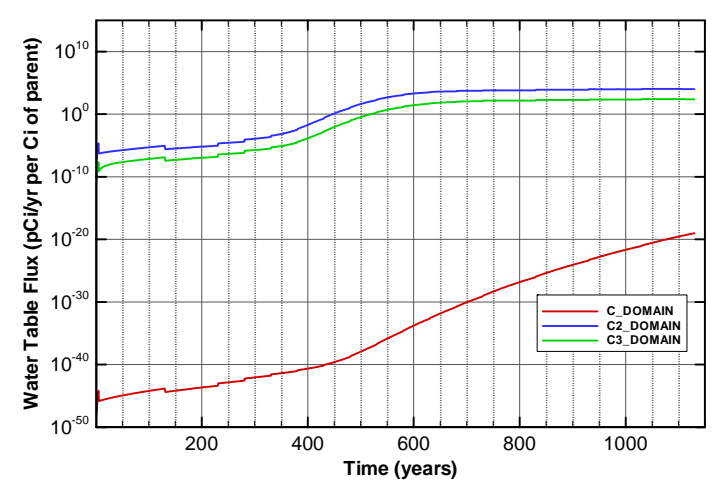

Figure A-475. Flux at water table for Case01_on U-235_Paducah.Cask

Figure A-472. Flux at water table for Case01_on U-234_Mglass

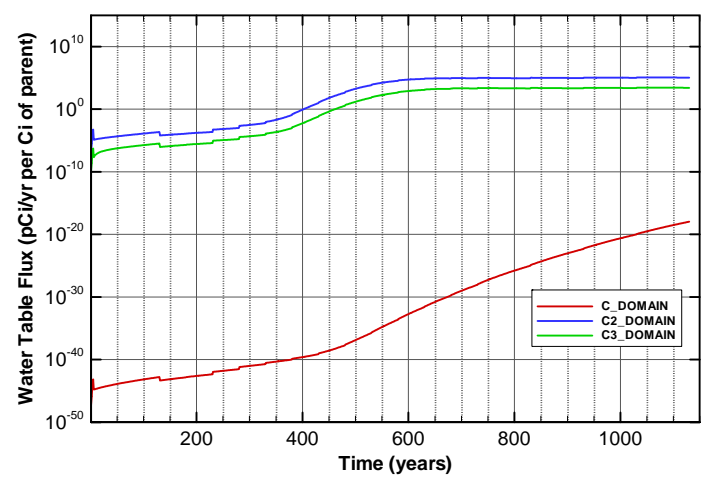

Figure A-474. Flux at water table for Case01_on U-235_Mglass

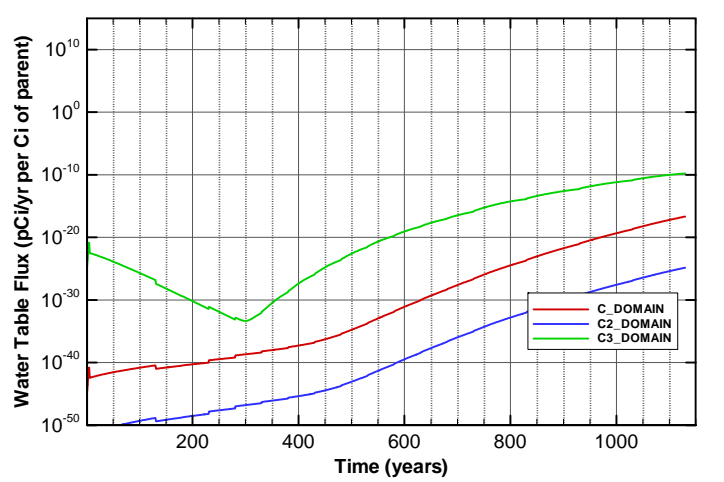

Figure A-476. Flux at water table for Case01_on U-236 


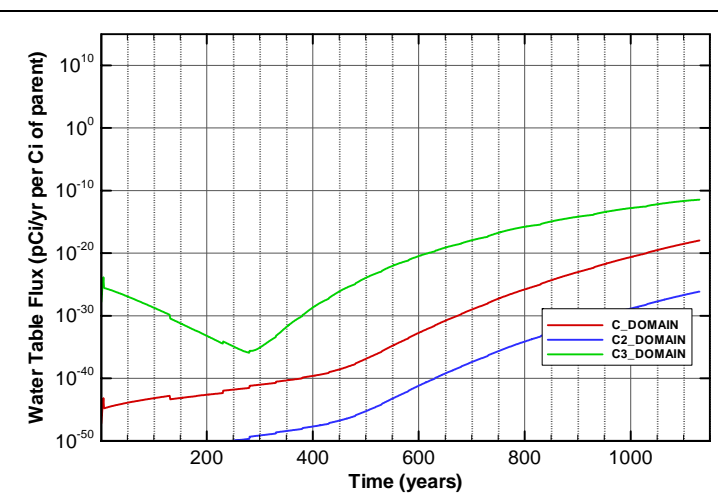

Figure A-477. Flux at water table for Case01_on U-236_Mglass

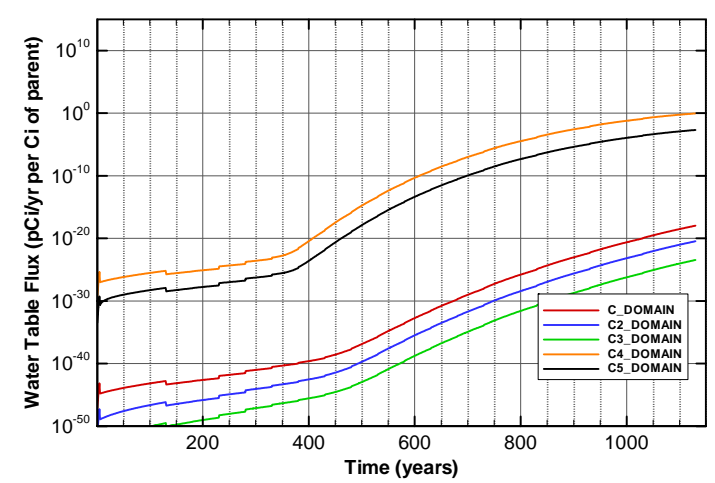

Figure A-479. Flux at water table for Case01_on U-238_Mglass

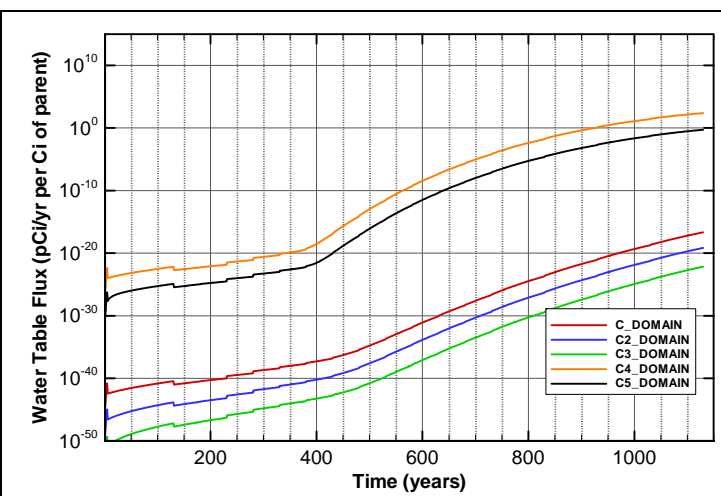

Figure A-478. Flux at water table for Case01_on U-238

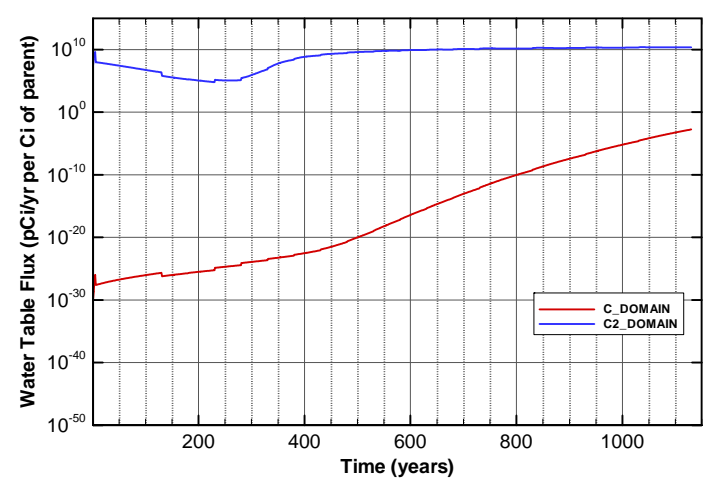

Figure A-480. Flux at water table for Case01_on Zr-93

\subsubsection{Center trench flux plots for 10 -year cover}

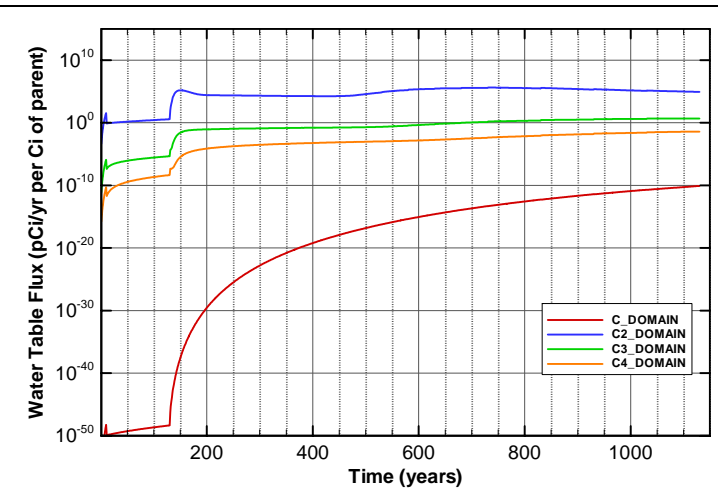

Figure A-481. Flux at water table for Case01n11_off Am-241

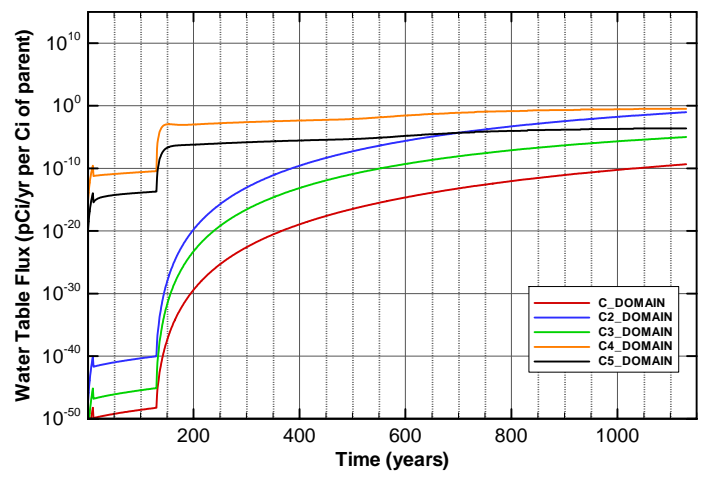

Figure A-482. Flux at water table for Case01n11_off Am-243 
SRNL-STI-2008-00397, REVISION 0
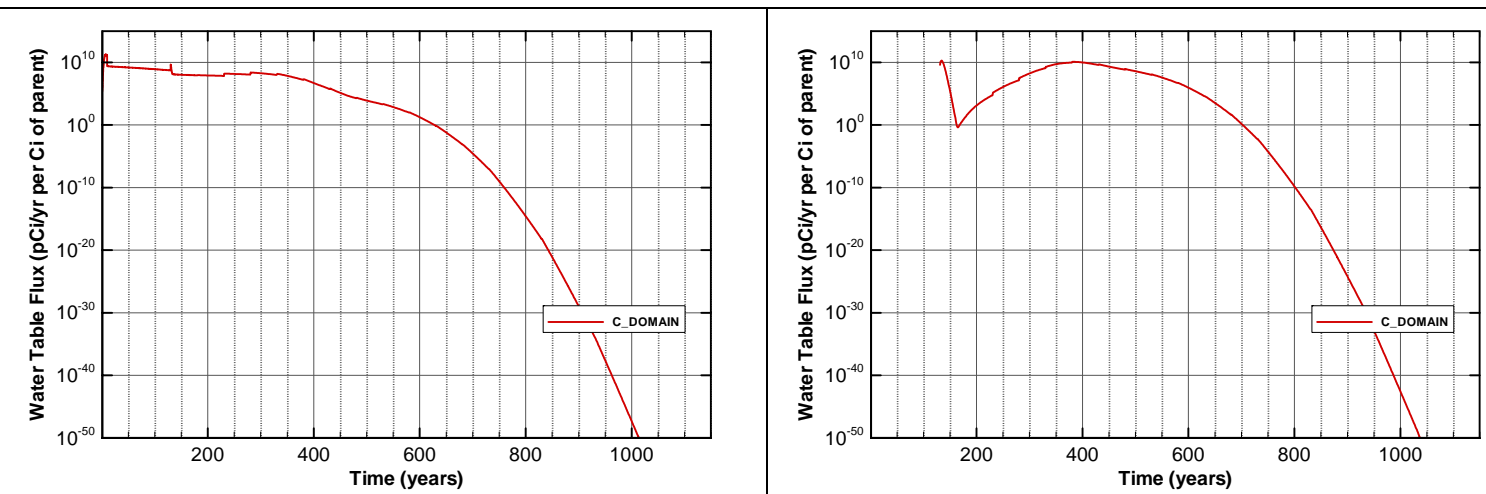

Figure A-483. Flux at water table for Case01n11_off C-14

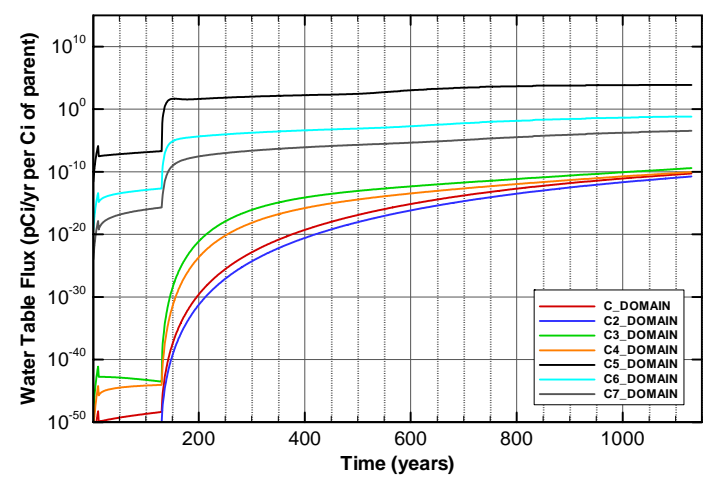

Figure A-485. Flux at water table for Case01n11_off Cf-249

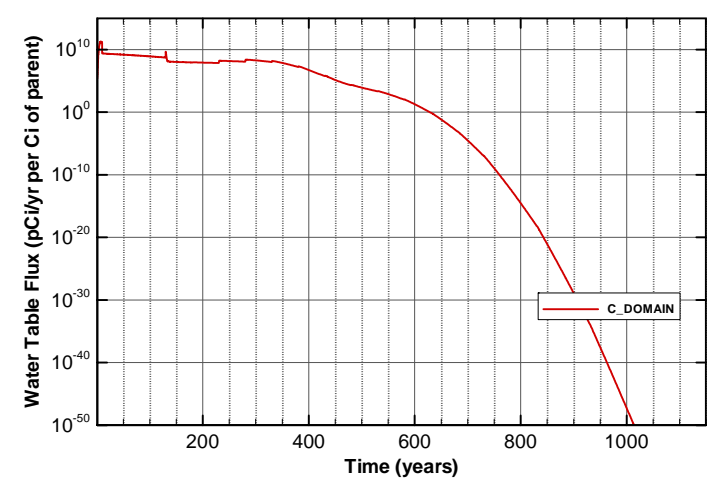

Figure A-487. Flux at water table for Case01n11_off Cl-36

Figure A-484. Flux at water table for Case01n11_off C-14_NR.Pump

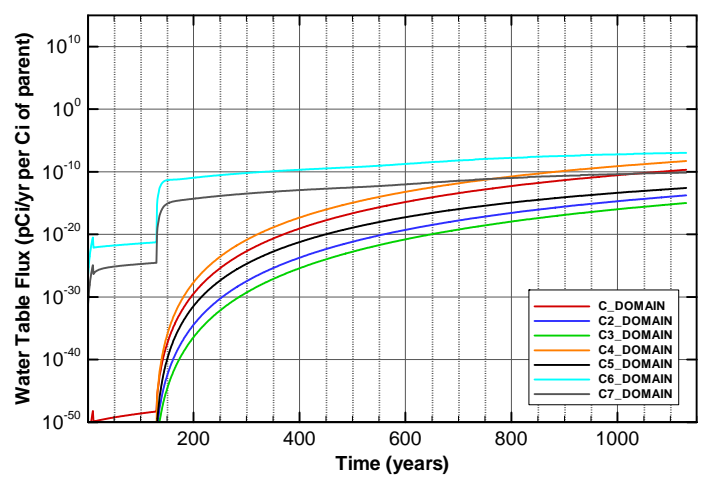

Figure A-486. Flux at water table for Case01n11_off Cf-251

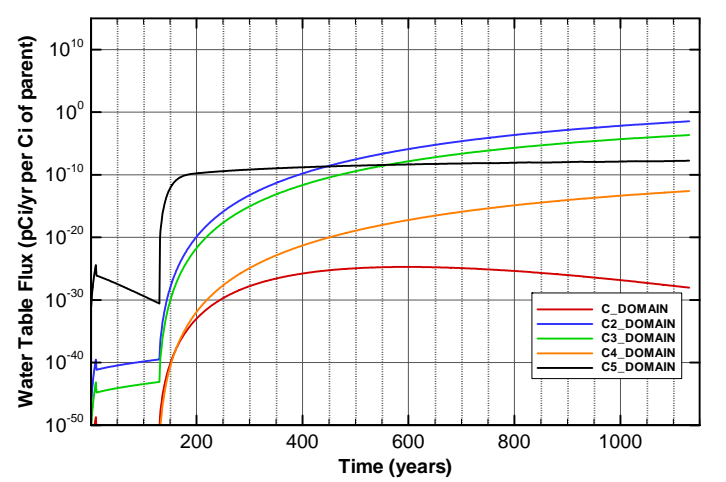

Figure A-488. Flux at water table for Case01n11_off Cm-244 
SRNL-STI-2008-00397, REVISION 0

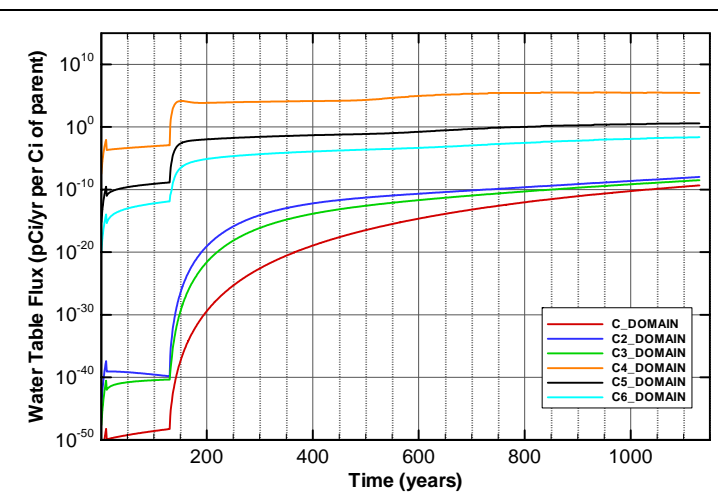

Figure A-489. Flux at water table for Case01n11_off Cm-245

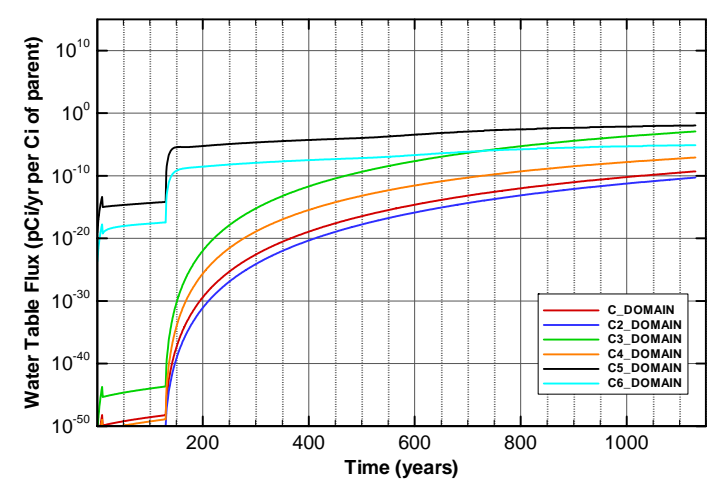

Figure A-491. Flux at water table for Case01n11_off Cm-247

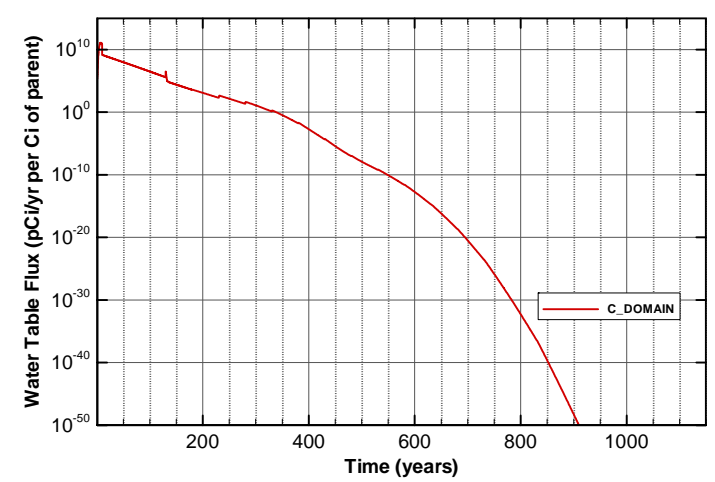

Figure A-493. Flux at water table for Case01n11_off H-3

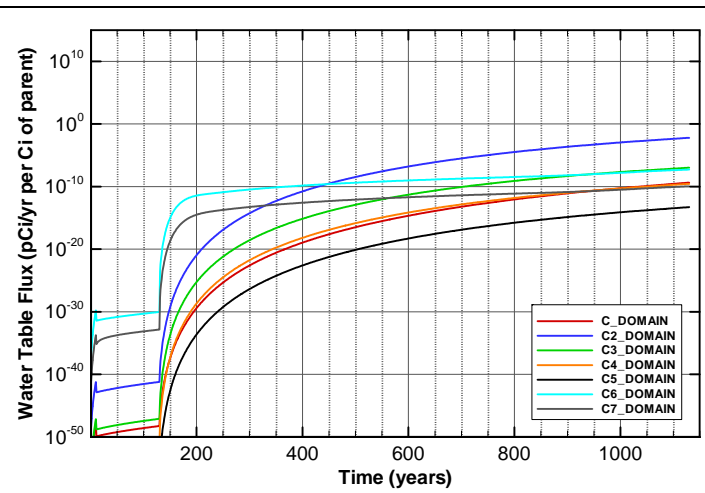

Figure A-490. Flux at water table for Case01n11_off Cm-246

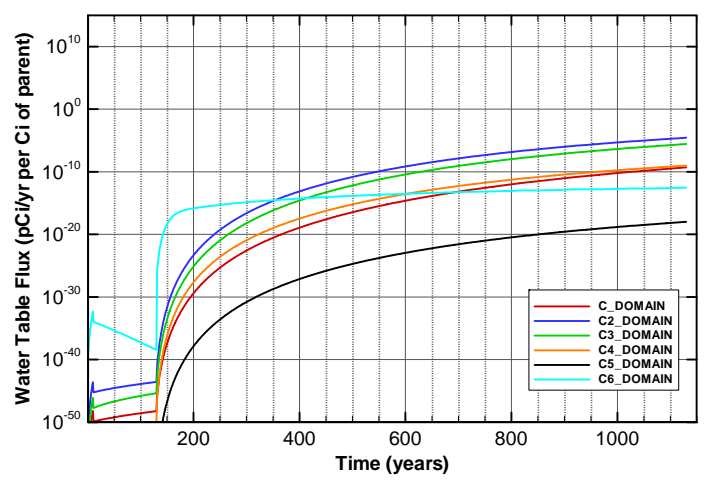

Figure A-492. Flux at water table for Case01n11_off Cm-248

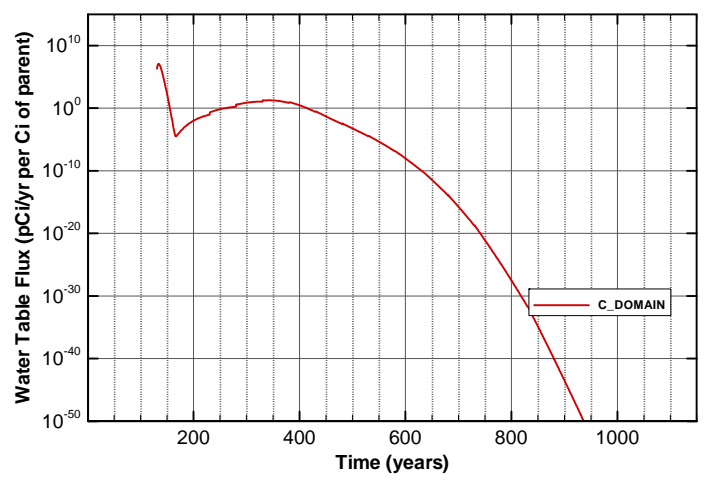

Figure A-494. Flux at water table for Case01n11_off H-3_ETF.Carbon 


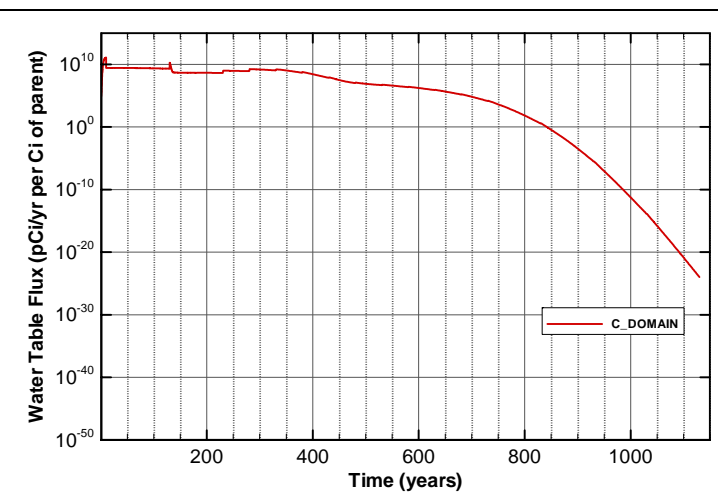

Figure A-495. Flux at water table for Case01n11_off I-129

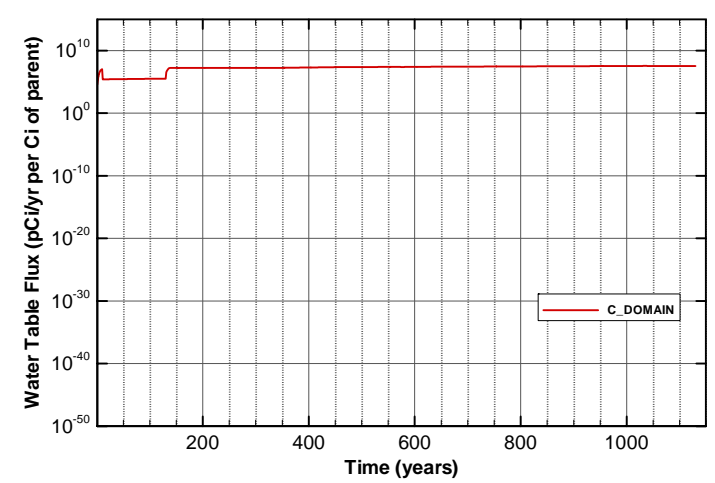

Figure A-497. Flux at water table for Case01n11_off I-129_ETF.GT.73

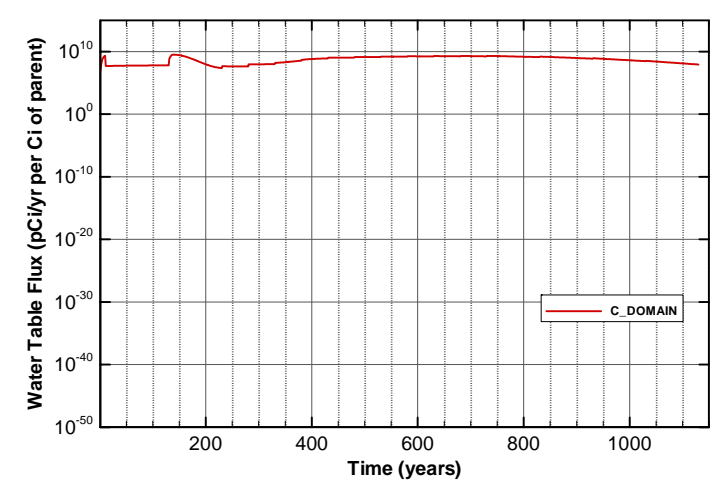

Figure A-499. Flux at water table for Case01n11_off I-129_F.CG.8

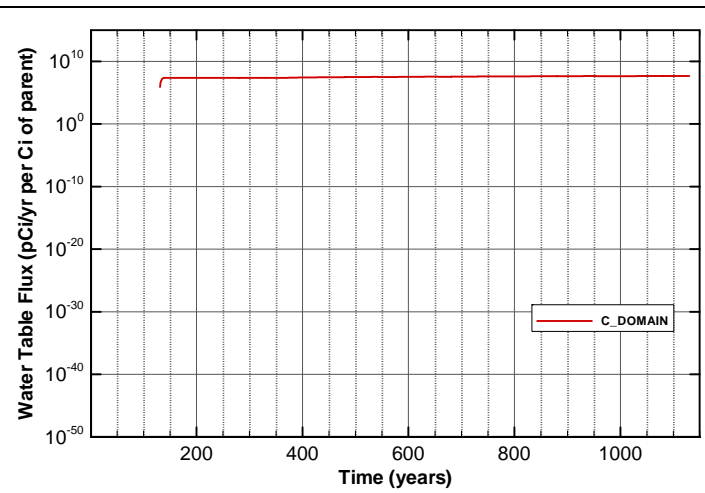

Figure A-496. Flux at water table for Case01n11_off I-129_ETF.Carbon

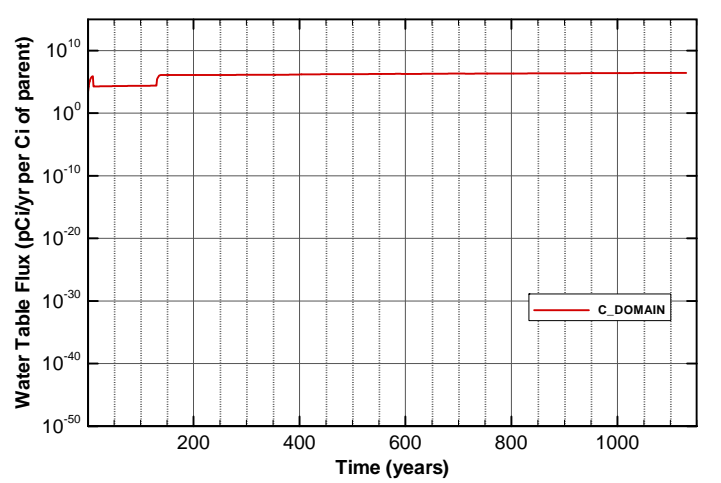

Figure A-498. Flux at water table for Case01n11_off I-129_F.Carbon

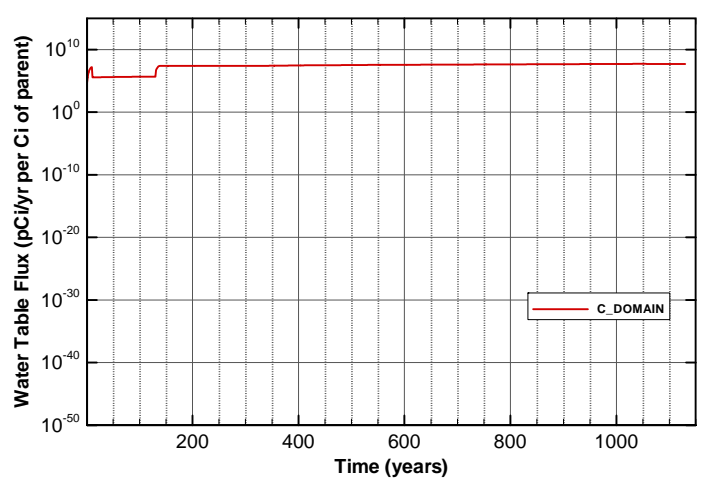

Figure A-500. Flux at water table for Case01n11_off I-129_F.Dowex.21K 


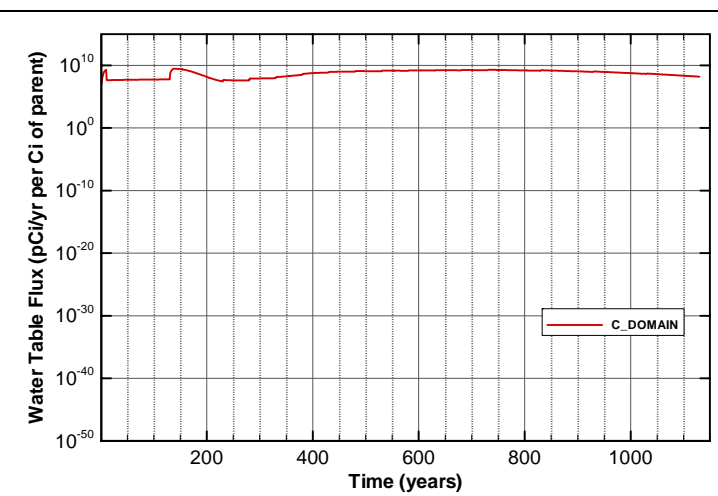

Figure A-501. Flux at water table for Case01n11_off I-129_F.Filtercake

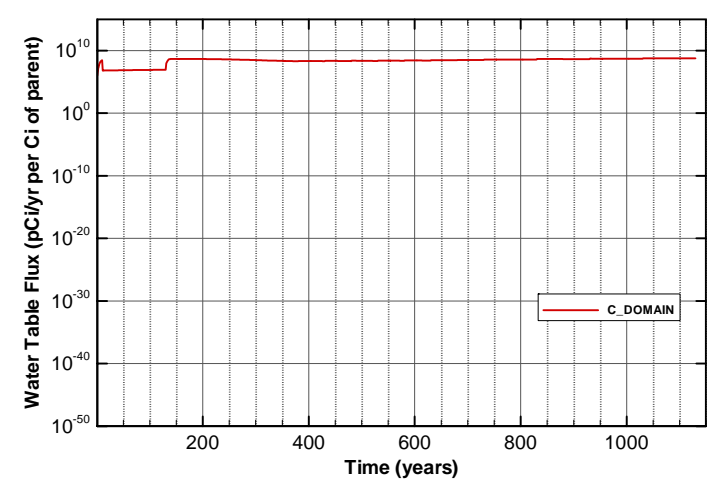

Figure A-503. Flux at water table for Case01n11_off I-129_H.CG.8

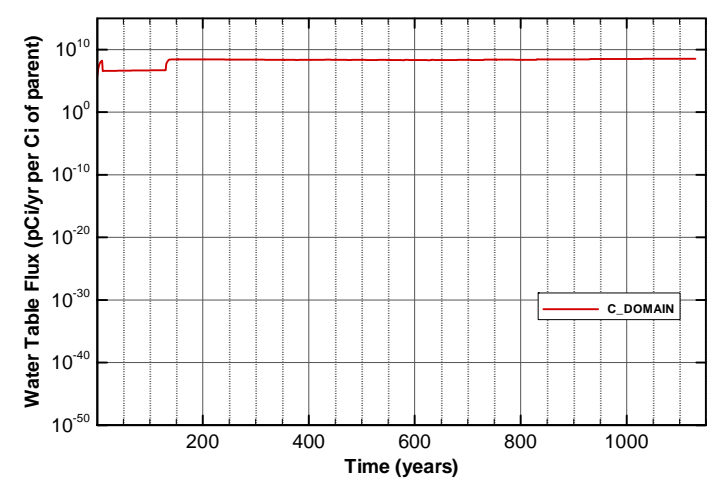

Figure A-505. Flux at water table for Case01n11_off I-129_H.Filtercake

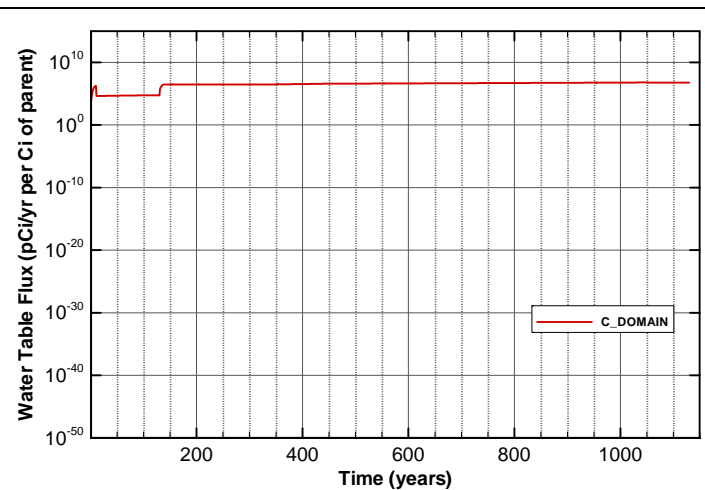

Figure A-502. Flux at water table for Case01n11_off I-129_H.Carbon

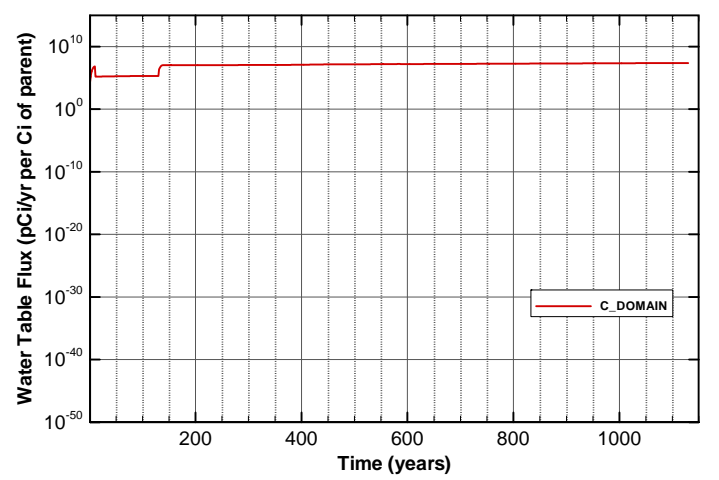

Figure A-504. Flux at water table for Case01n11_off I-129_H.Dowex.21K

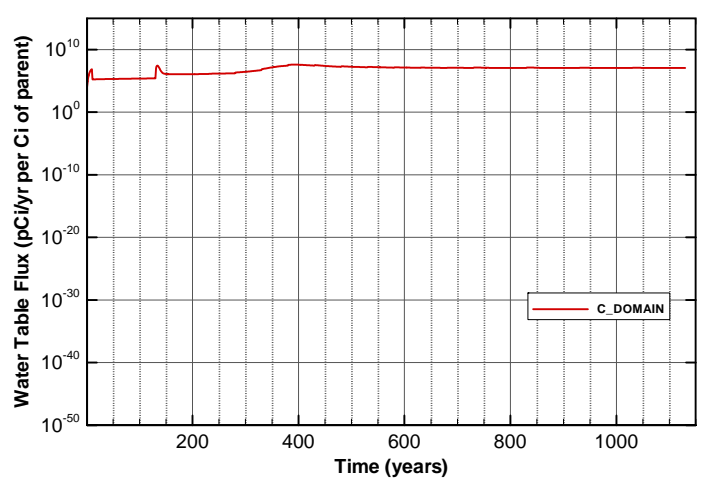

Figure A-506. Flux at water table for Case01n11_off I-129_Mk50A 


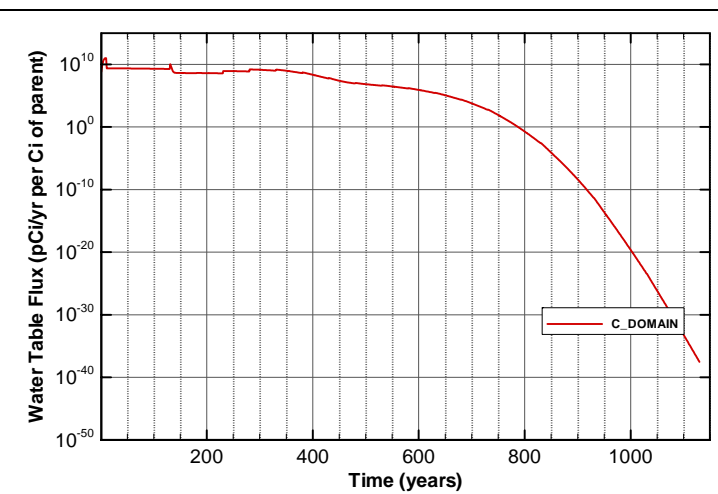

Figure A-507. Flux at water table for Case01n11_off K-40

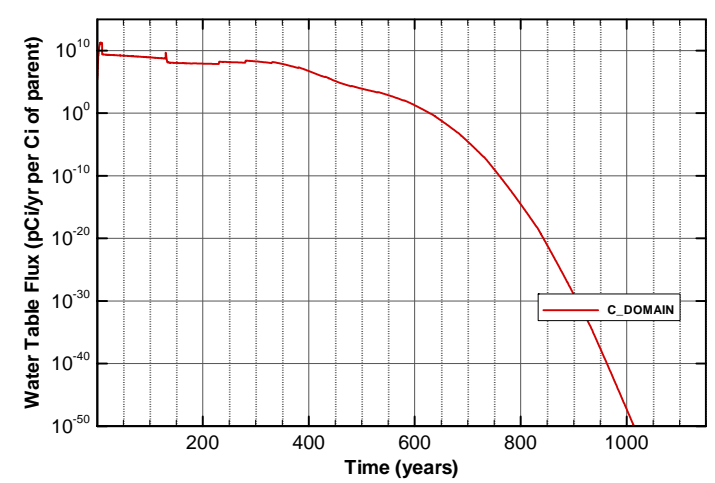

Figure A-509. Flux at water table for Case01n11_off Nb-94

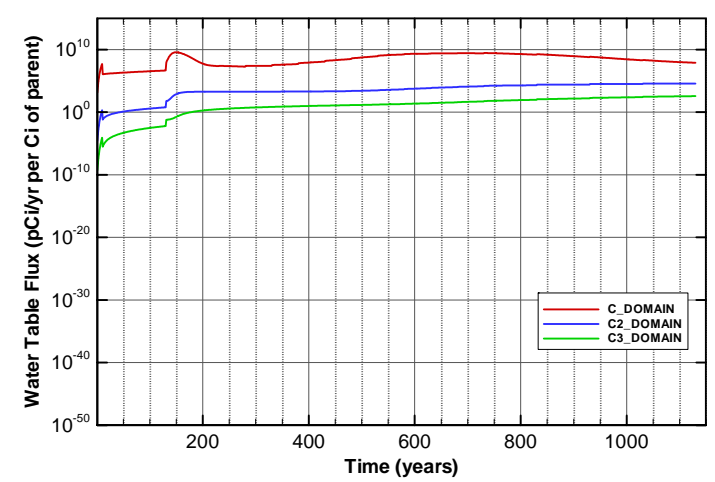

Figure A-511. Flux at water table for Case01n11_off Np-237

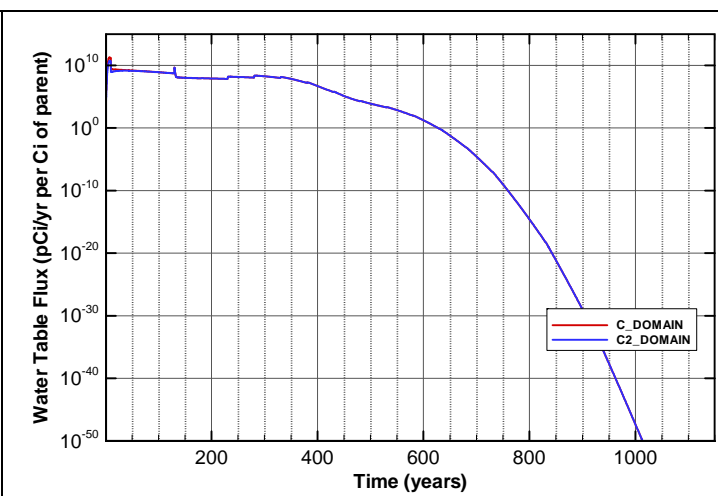

Figure A-508. Flux at water table for Case01n11_off Mo-93

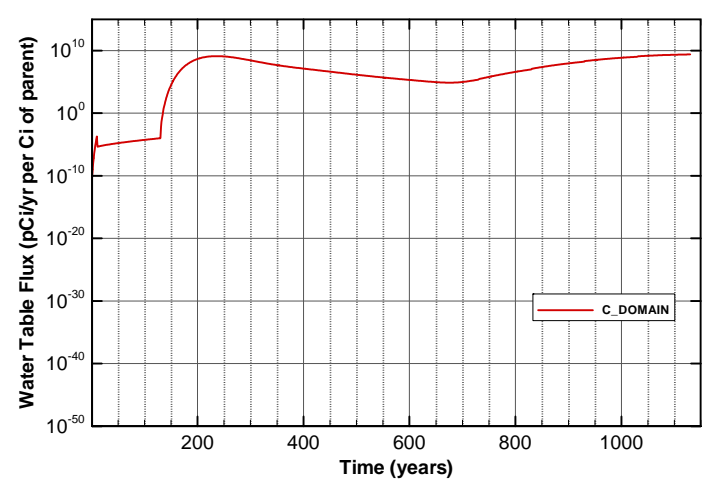

Figure A-510. Flux at water table for Case01n11_off Ni-59

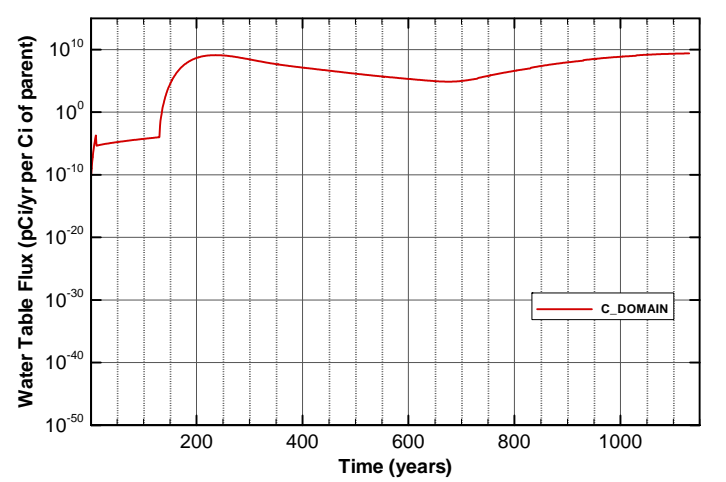

Figure A-512. Flux at water table for Case01n11_off Pd-107 
SRNL-STI-2008-00397, REVISION 0
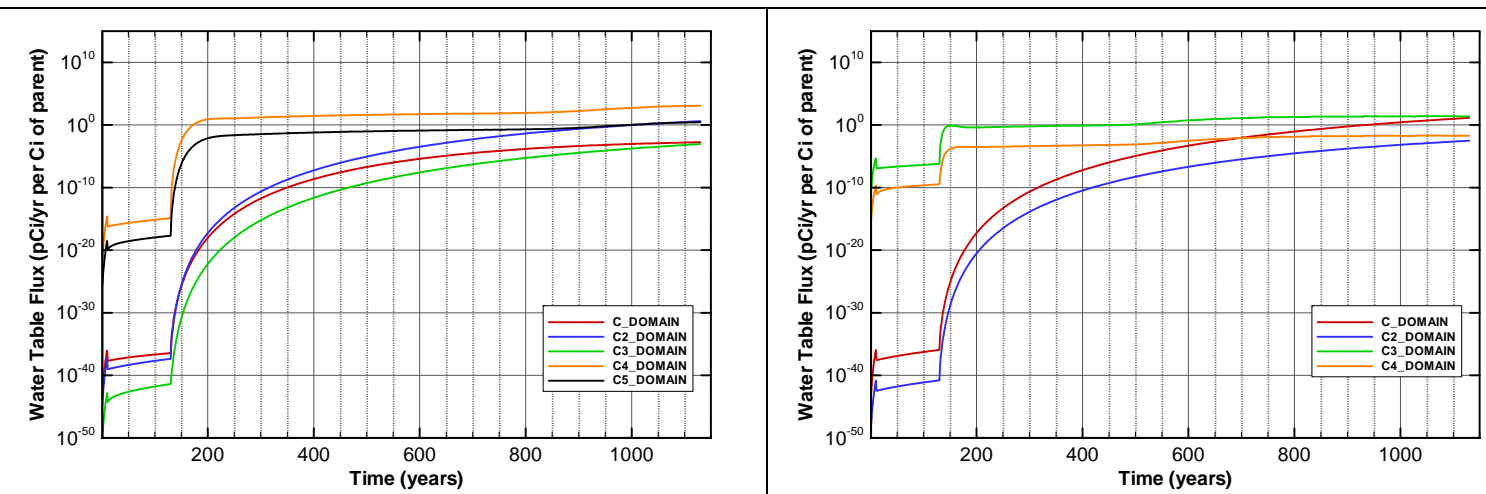

Figure A-513. Flux at water table for Case01n11_off Pu-238

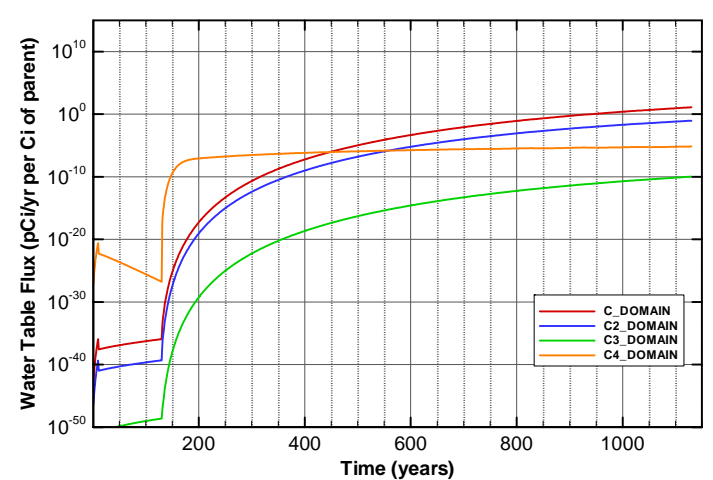

Figure A-515. Flux at water table for Case01n11_off Pu-240

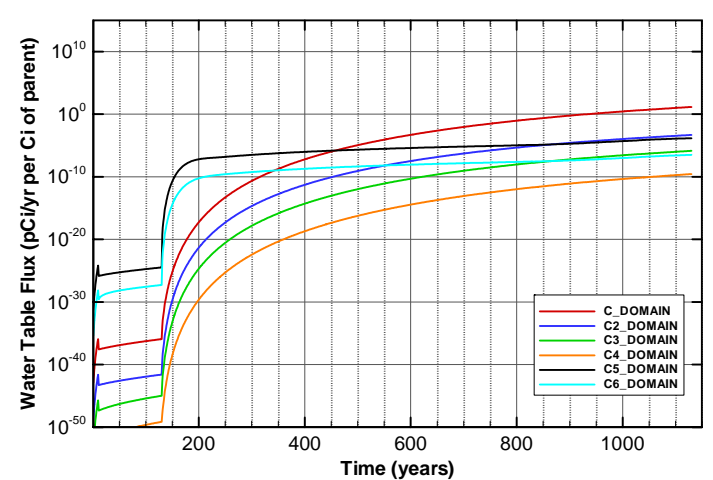

Figure A-517. Flux at water table for Case01n11_off Pu-242

Figure A-514. Flux at water table for Case01n11_off Pu-239

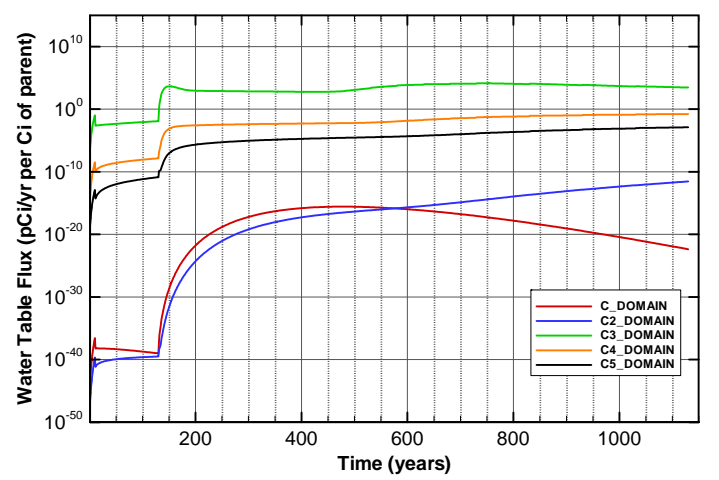

Figure A-516. Flux at water table for Case01n11_off Pu-241

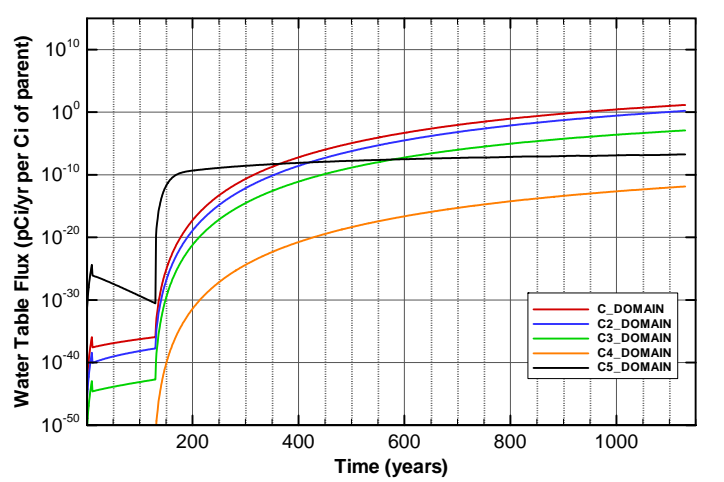

Figure A-518. Flux at water table for Case01n11_off Pu-244 
SRNL-STI-2008-00397, REVISION 0

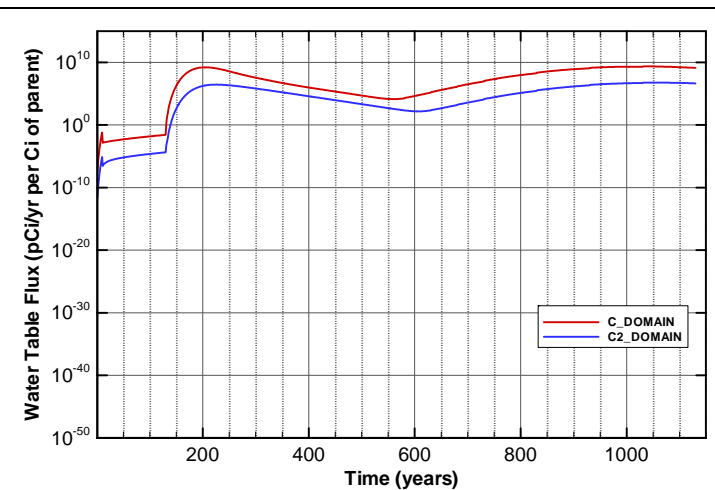

Figure A-519. Flux at water table for Case01n11_off Ra-226

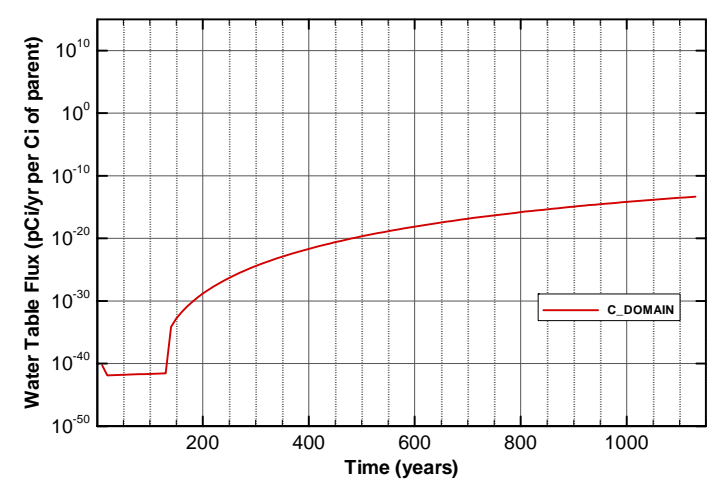

Figure A-521. Flux at water table for Case01n11_off Sn-126

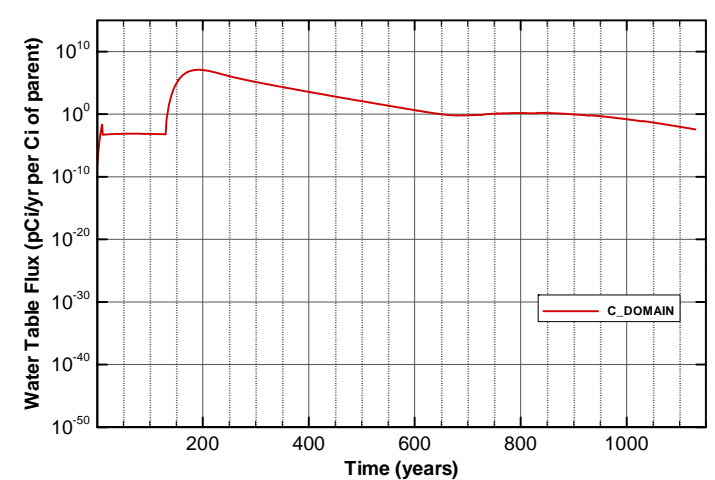

Figure A-523. Flux at water table for Case01n11_off Sr-90_Cask

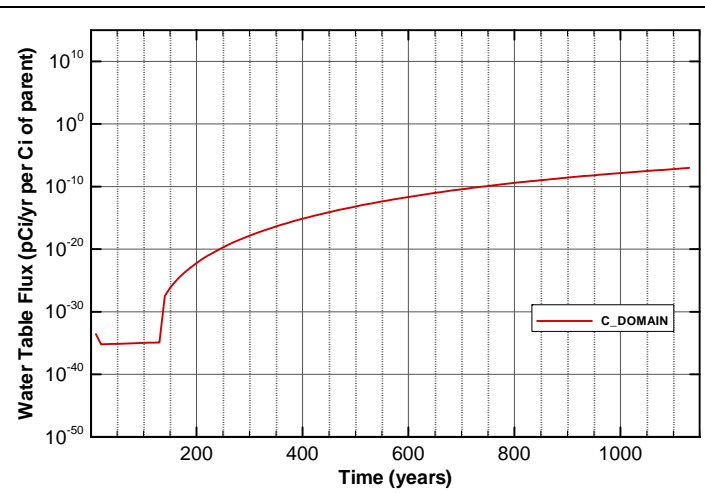

Figure A-520. Flux at water table for Case01n11_off Se-79

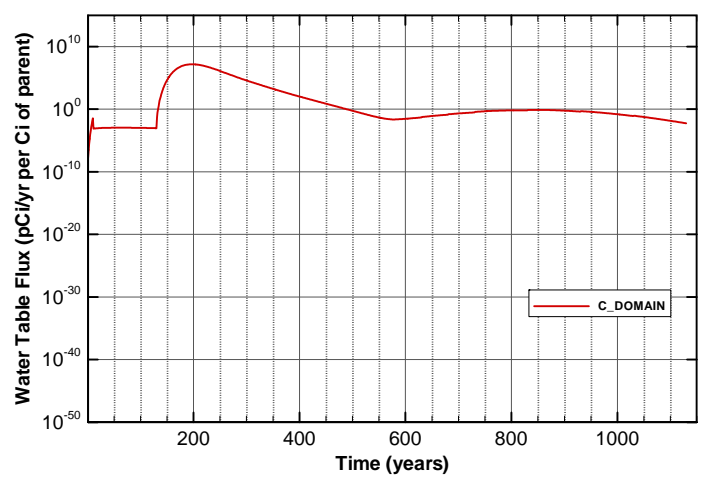

Figure A-522. Flux at water table for Case01n11_off Sr-90

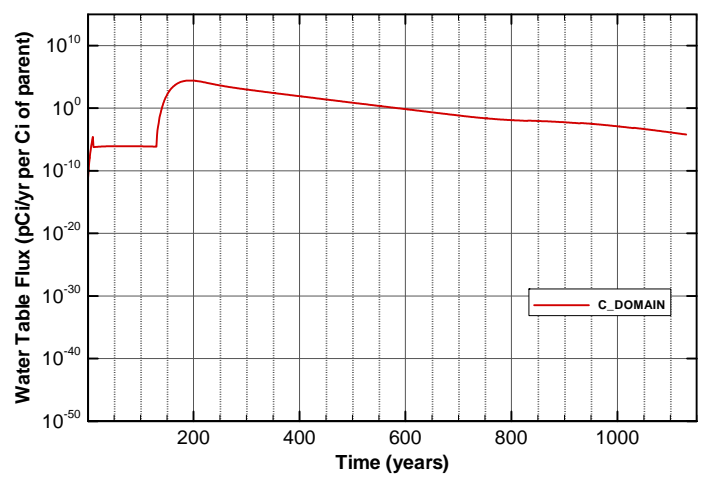

Figure A-524. Flux at water table for Case01n11_off Sr-90_Mk50A 


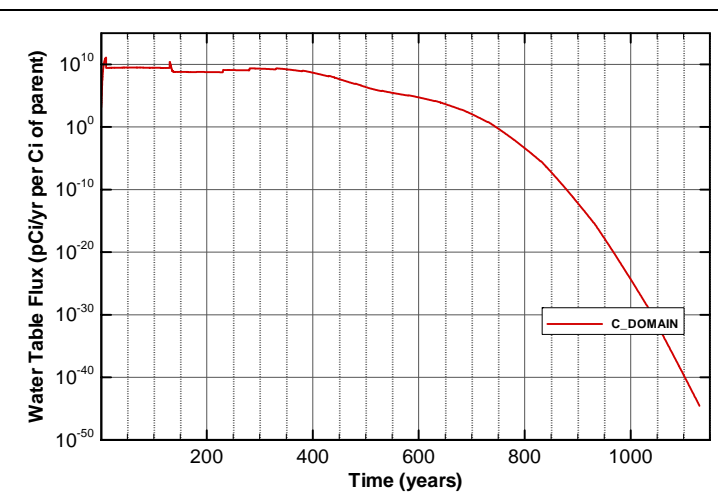

Figure A-525. Flux at water table for Case01n11_off Tc-99

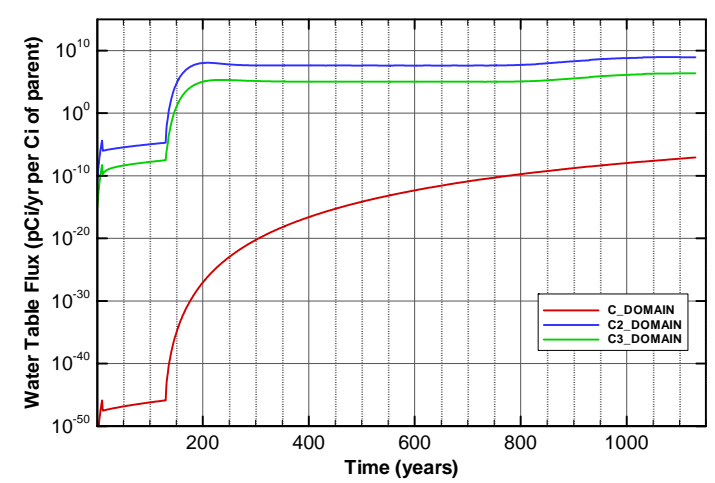

Figure A-527. Flux at water table for Case01n11_off Th-230

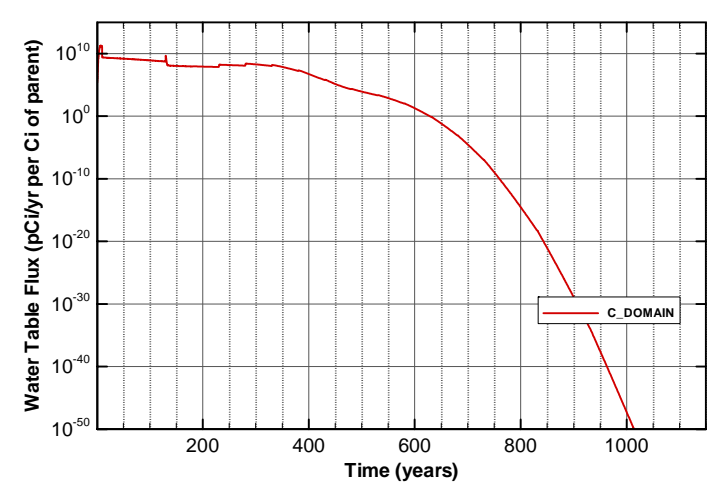

Figure A-529. Flux at water table for Case01n11_off Tracer

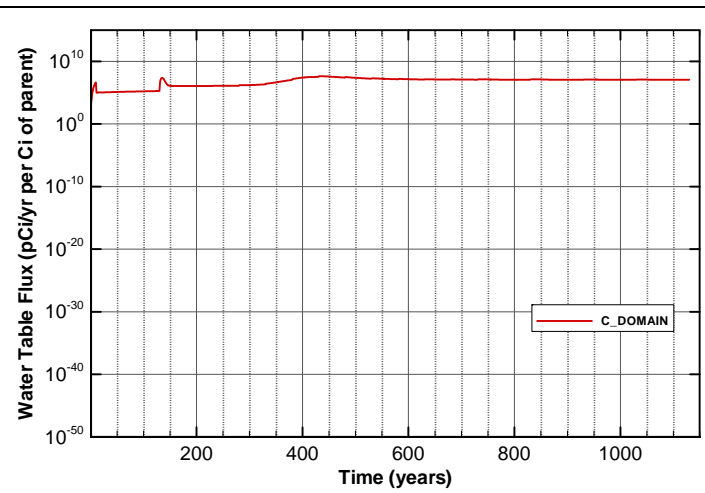

Figure A-526. Flux at water table for Case01n11_off Tc-99_Mk50A

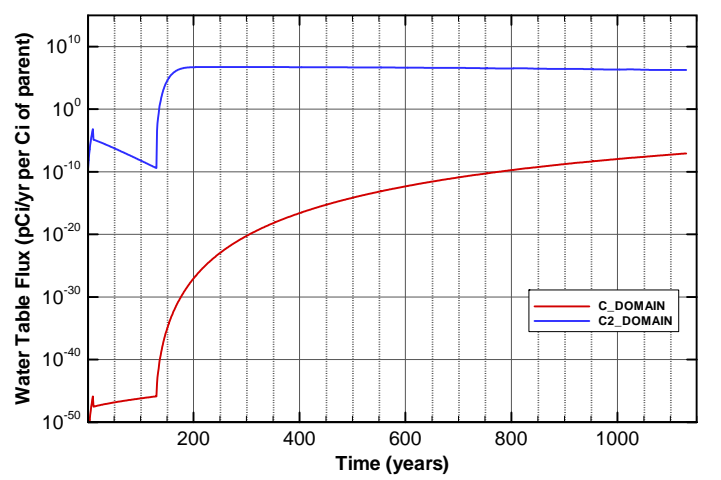

Figure A-528. Flux at water table for Case01n11_off Th-232

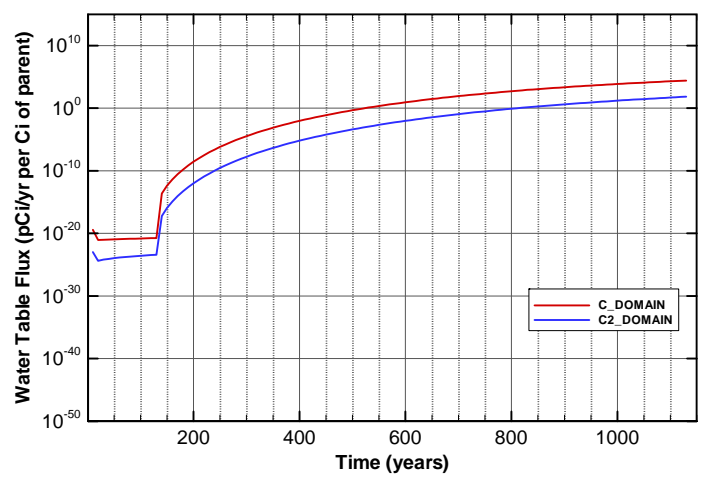

Figure A-530. Flux at water table for Case01n11_off U-233 


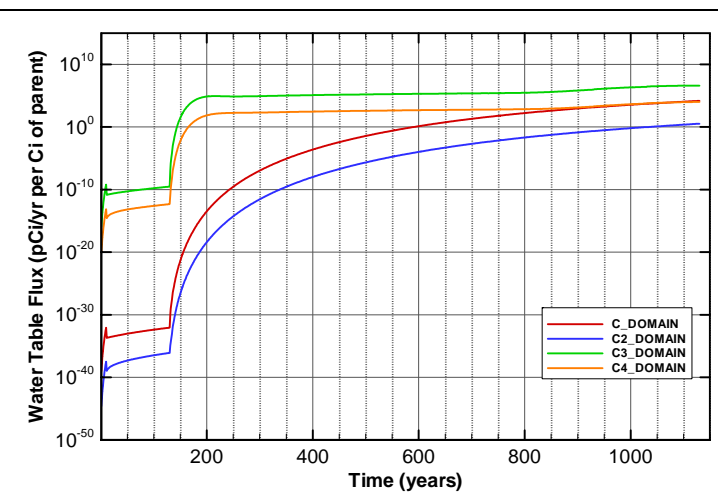

Figure A-531. Flux at water table for Case01n11_off U-234

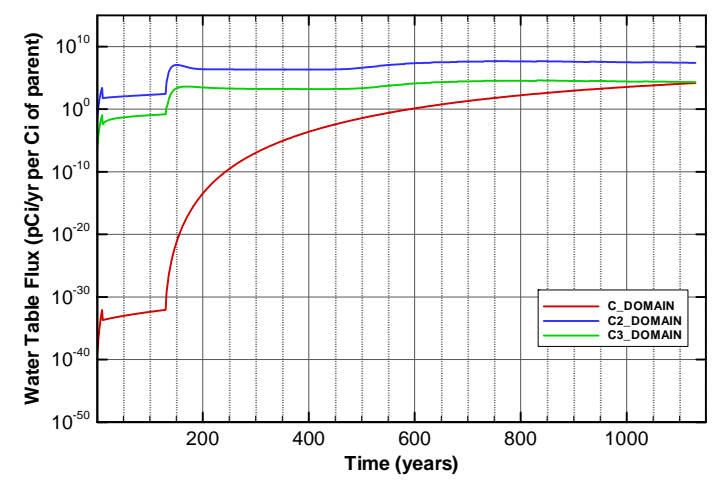

Figure A-533. Flux at water table for Case01n11_off U-235

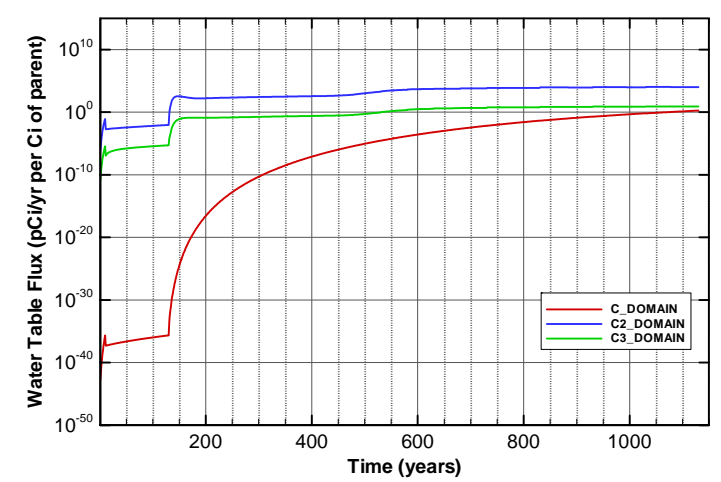

Figure A-535. Flux at water table for Case01n11_off U-235_Paducah.Cask

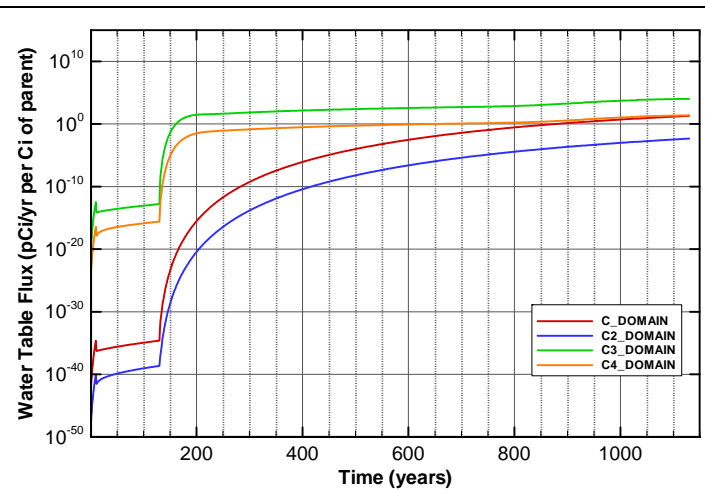

Figure A-532. Flux at water table for Case01n11_off U-234_Mglass

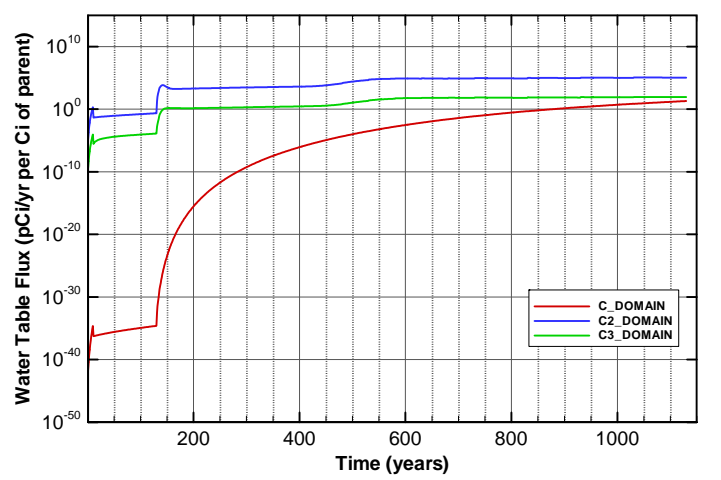

Figure A-534. Flux at water table for Case01n11_off U-235_Mglass

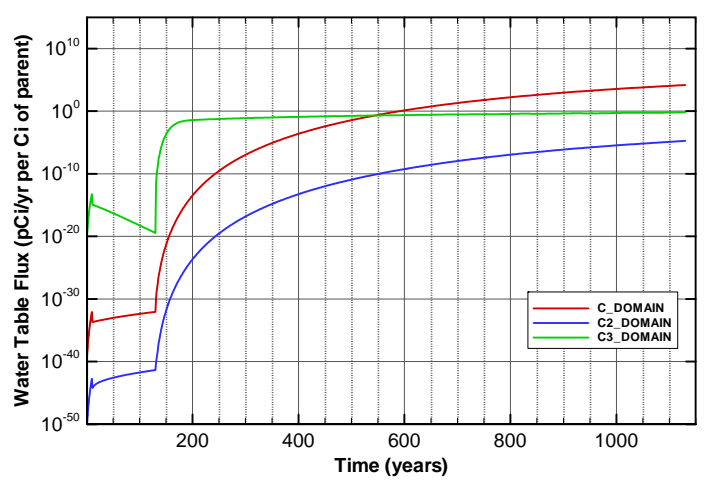

Figure A-536. Flux at water table for Case01n11_off U-236 


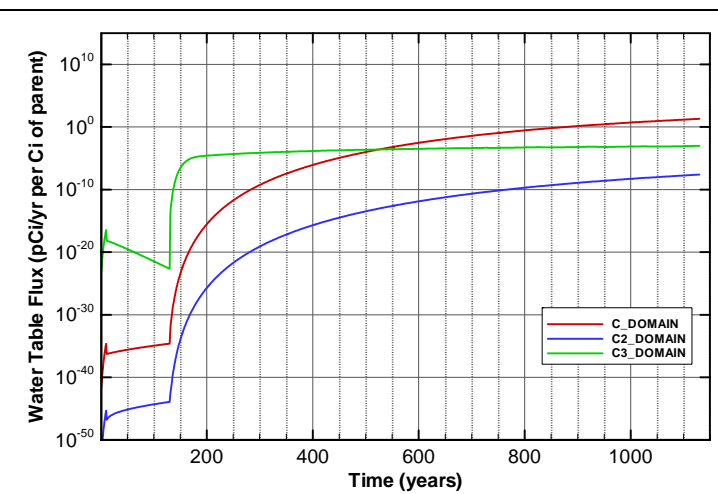

Figure A-537. Flux at water table for Case01n11_off U-236_Mglass

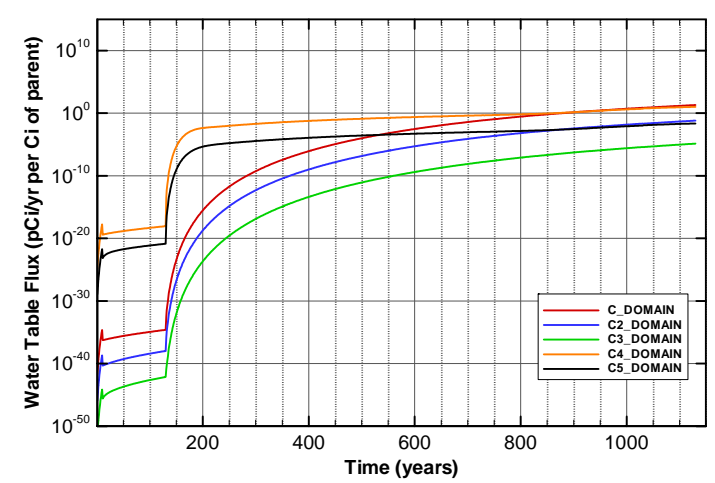

Figure A-539. Flux at water table for Case01n11_off U-238_Mglass

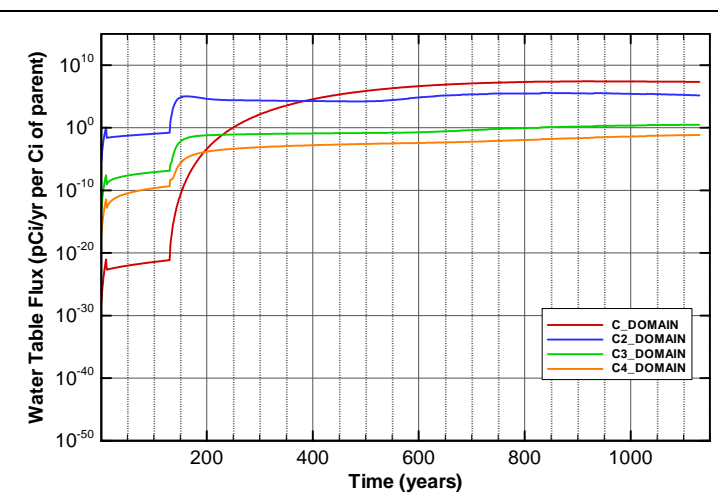

Figure A-541. Flux at water table for Case01n11_on Am-241

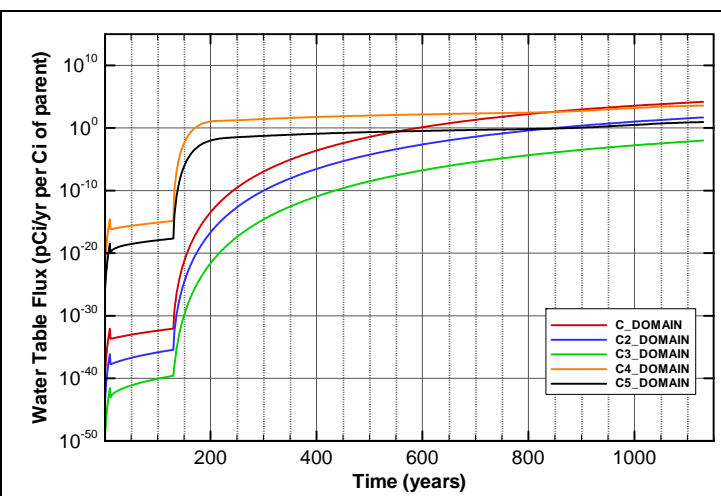

Figure A-538. Flux at water table for Case01n11_off U-238

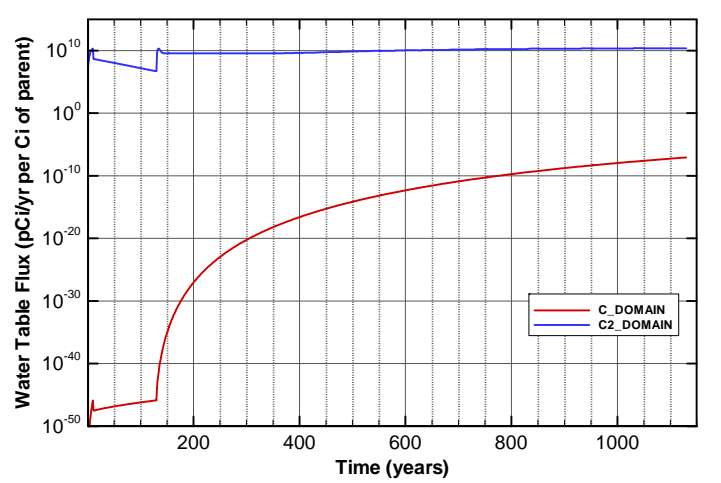

Figure A-540. Flux at water table for Case01n11_off Zr-93

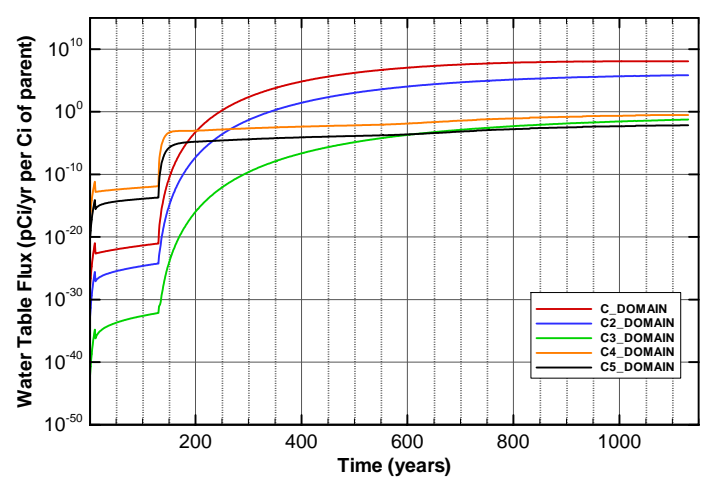

Figure A-542. Flux at water table for Case01n11_on Am-243 
SRNL-STI-2008-00397, REVISION 0

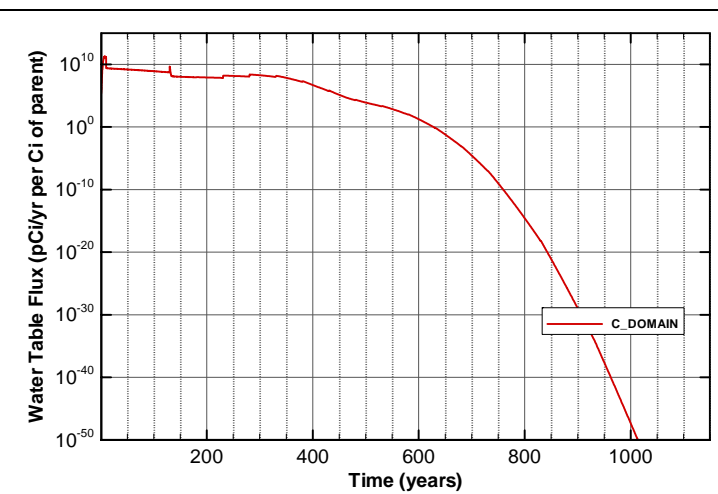

Figure A-543. Flux at water table for Case01n11_on C-14

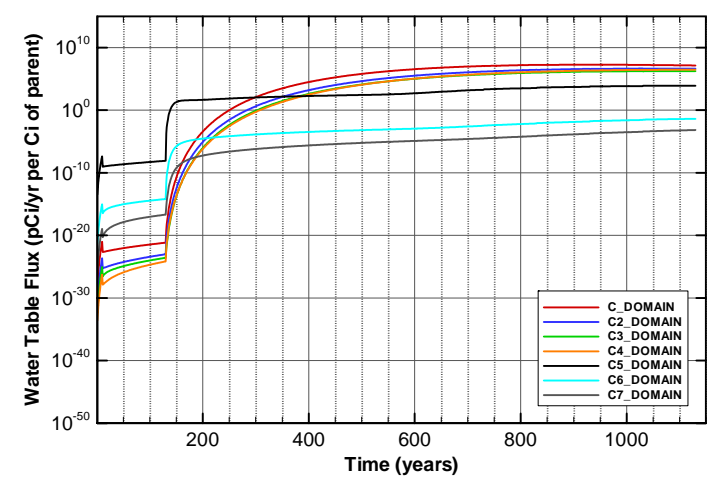

Figure A-545. Flux at water table for Case01n11_on Cf-249

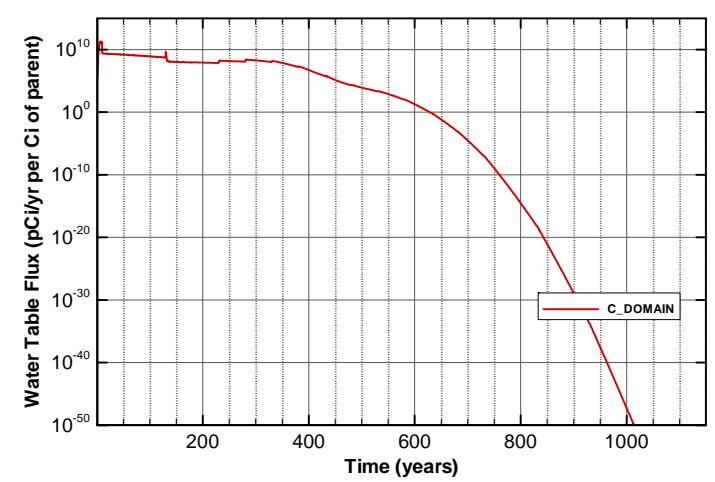

Figure A-547. Flux at water table for Case01n11_on Cl-36

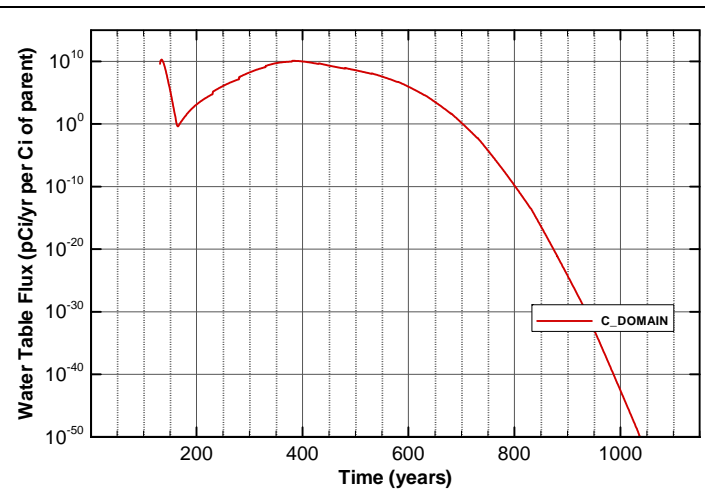

Figure A-544. Flux at water table for Case01n11_on C-14_NR.Pump

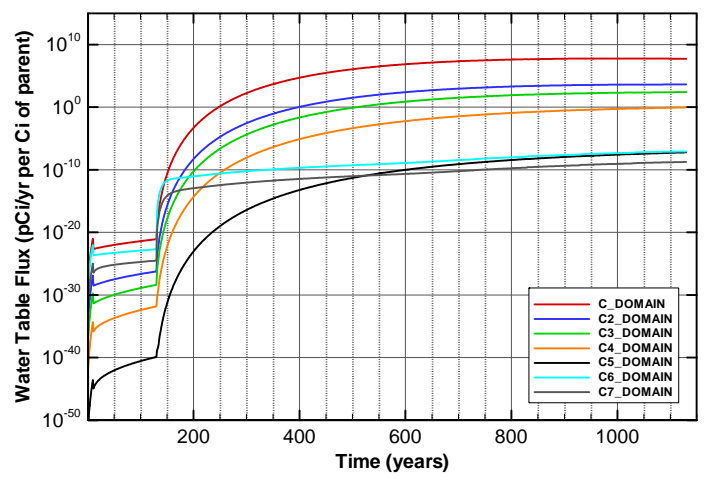

Figure A-546. Flux at water table for Case01n11_on Cf-251

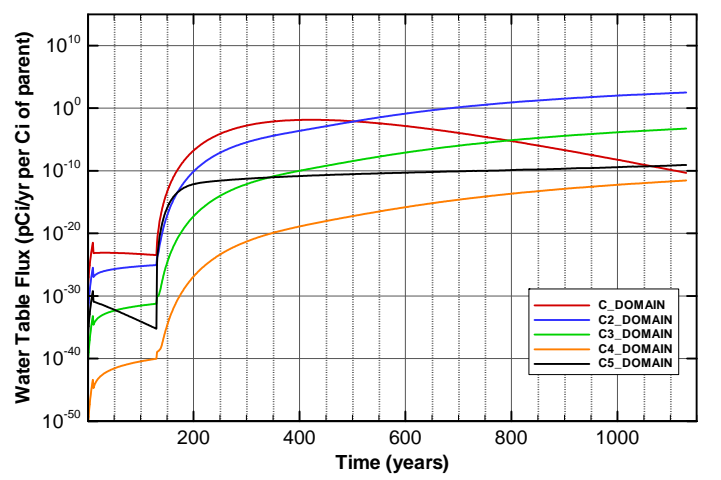

Figure A-548. Flux at water table for Case01n11_on Cm-244 


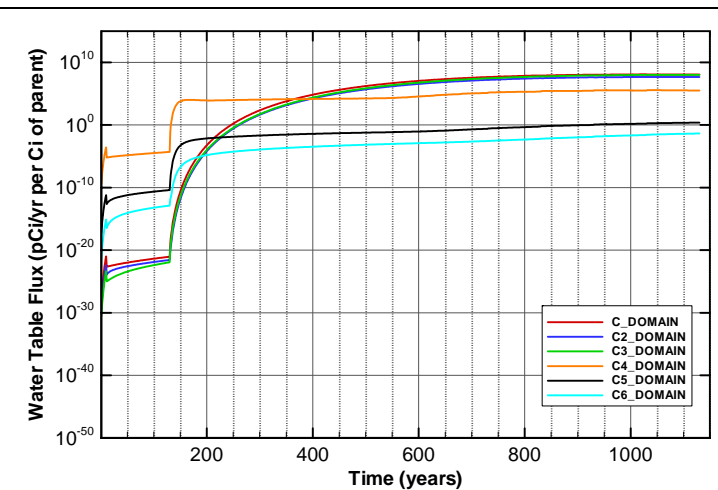

Figure A-549. Flux at water table for Case01n11_on Cm-245

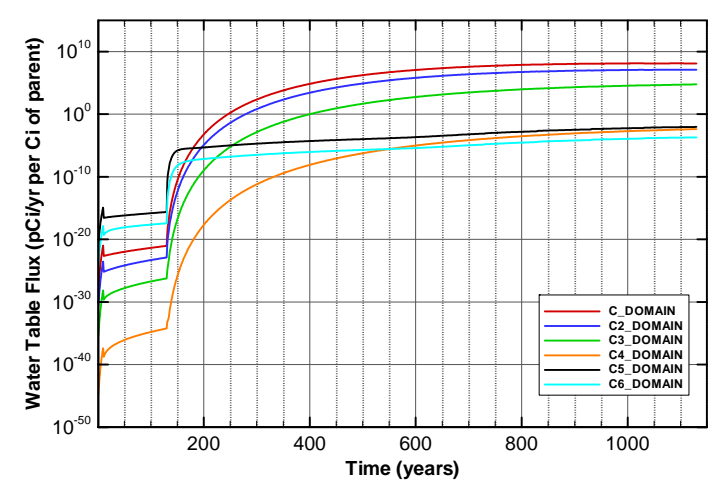

Figure A-551. Flux at water table for Case01n11_on Cm-247

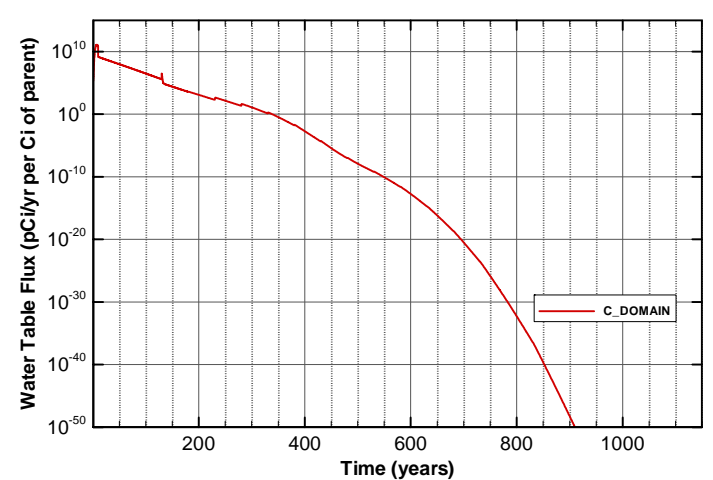

Figure A-553. Flux at water table for Case01n11_on H-3

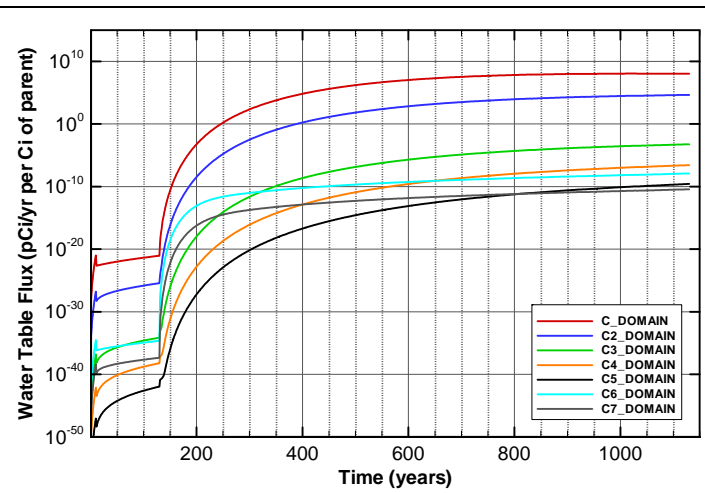

Figure A-550. Flux at water table for Case01n11_on Cm-246

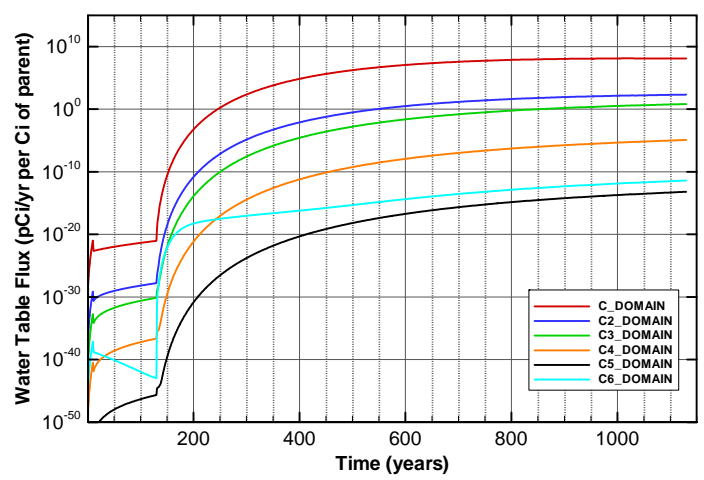

Figure A-552. Flux at water table for Case01n11_on Cm-248

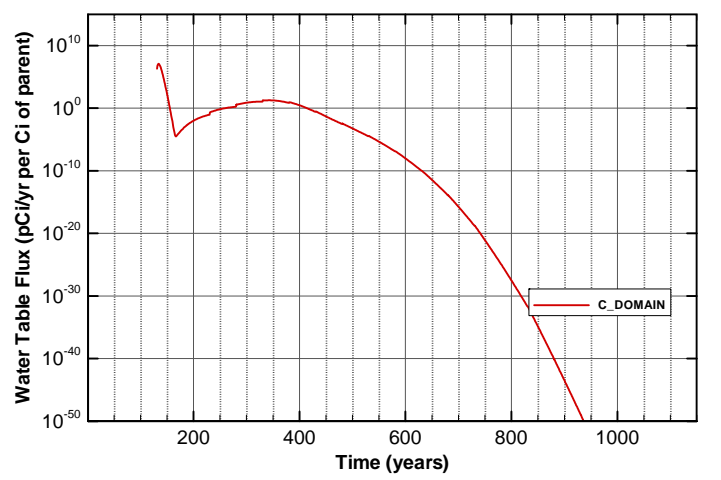

Figure A-554. Flux at water table for Case01n11_on H-3_ETF.Carbon 


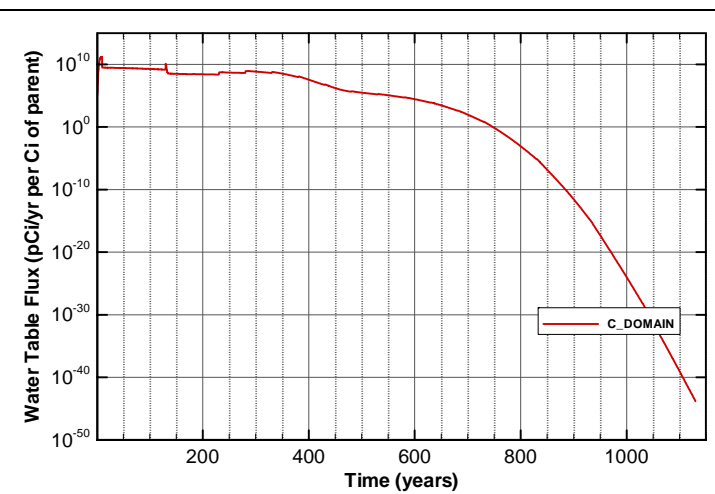

Figure A-555. Flux at water table for Case01n11_on I-129

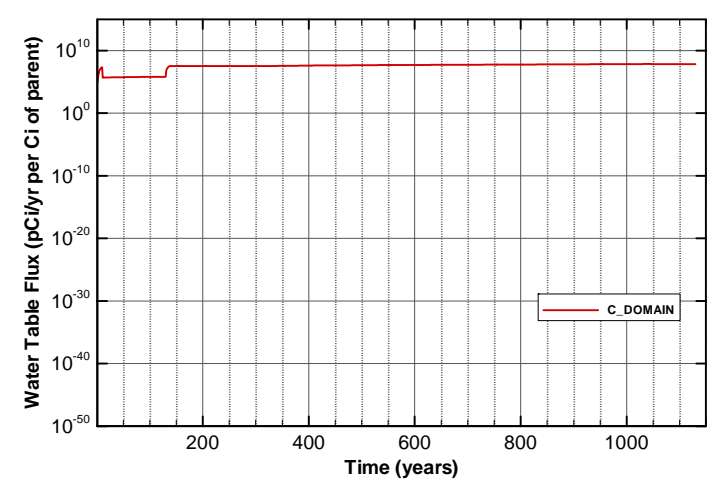

Figure A-557. Flux at water table for Case01n11_on I-129_ETF.GT.73

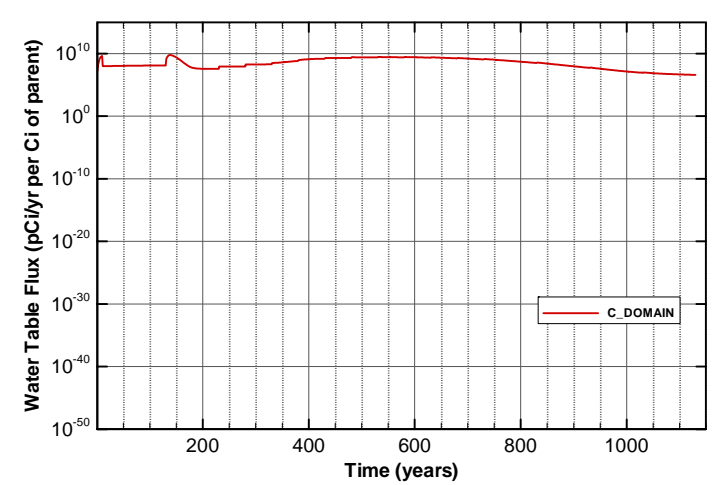

Figure A-559. Flux at water table for Case01n11_on I-129_F.CG.8

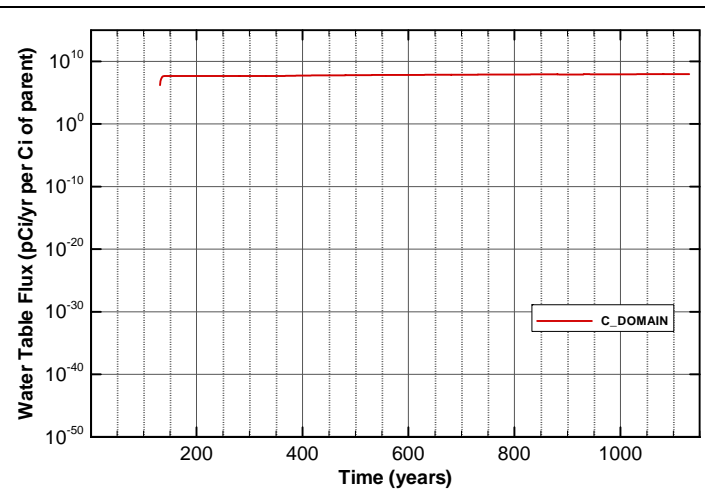

Figure A-556. Flux at water table for Case01n11_on I-129_ETF.Carbon

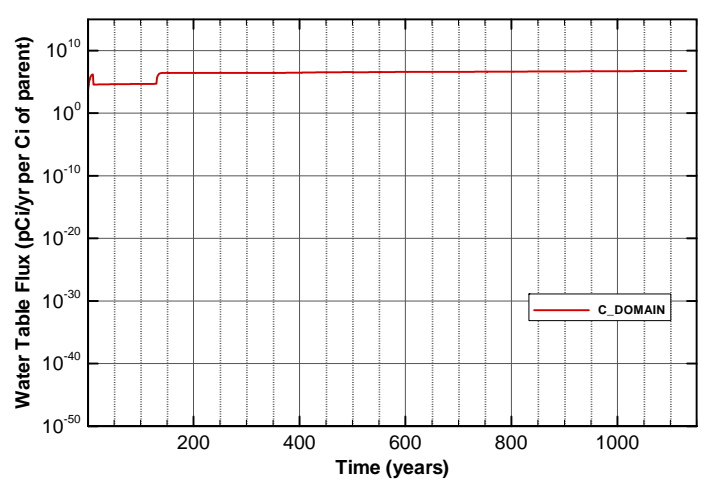

Figure A-558. Flux at water table for Case01n11_on I-129_F.Carbon

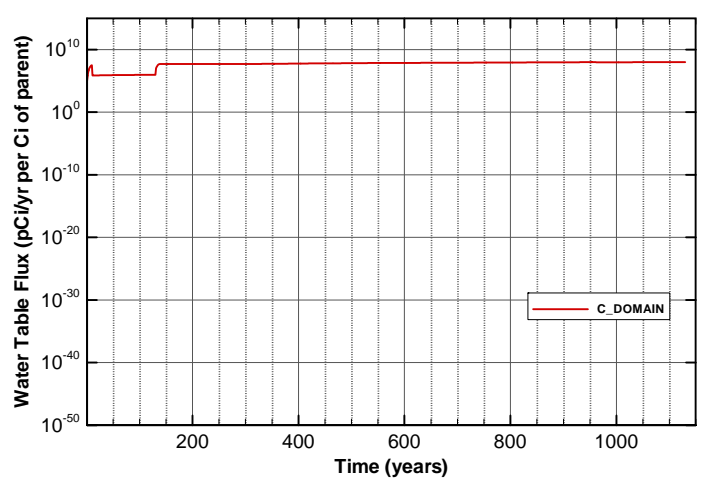

Figure A-560. Flux at water table for Case01n11_on I-129_F.Dowex.21K 


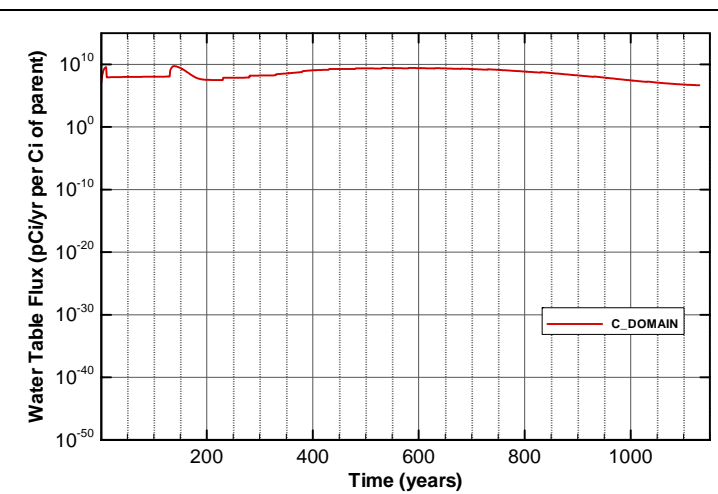

Figure A-561. Flux at water table for Case01n11_on I-129_F.Filtercake

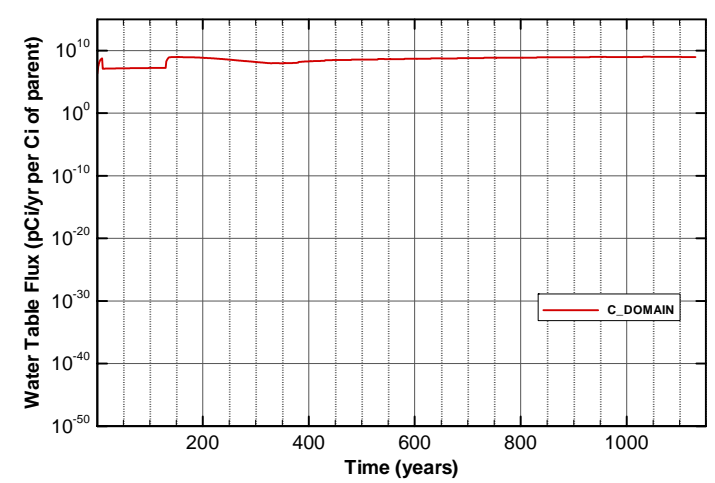

Figure A-563. Flux at water table for Case01n11_on I-129_H.CG.8

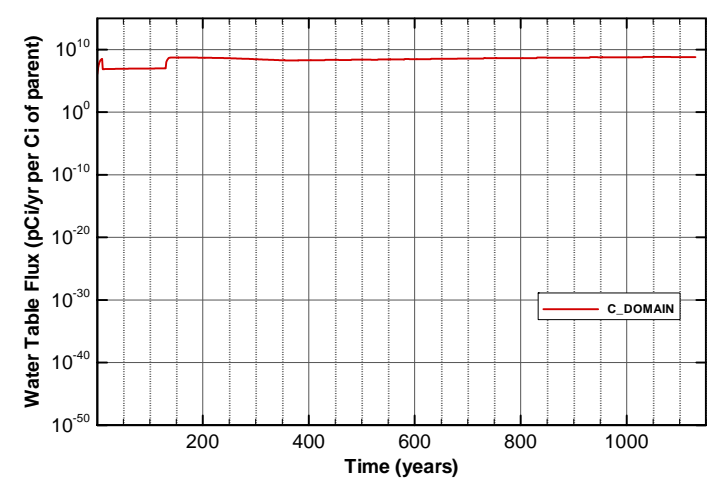

Figure A-565. Flux at water table for Case01n11_on I-129_H.Filtercake

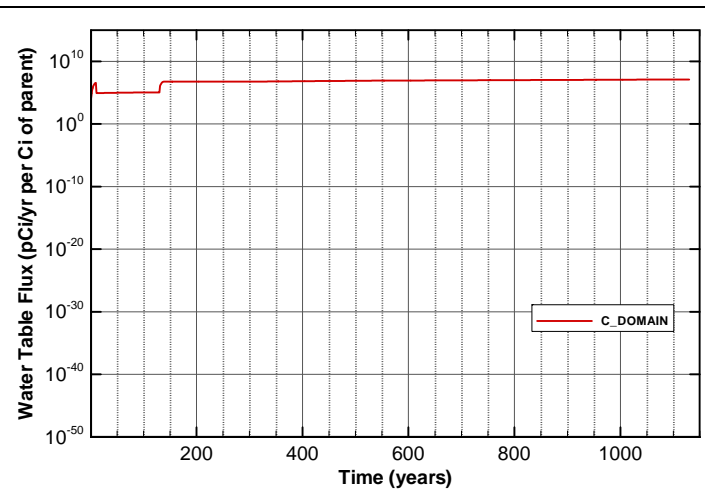

Figure A-562. Flux at water table for Case01n11_on I-129_H.Carbon

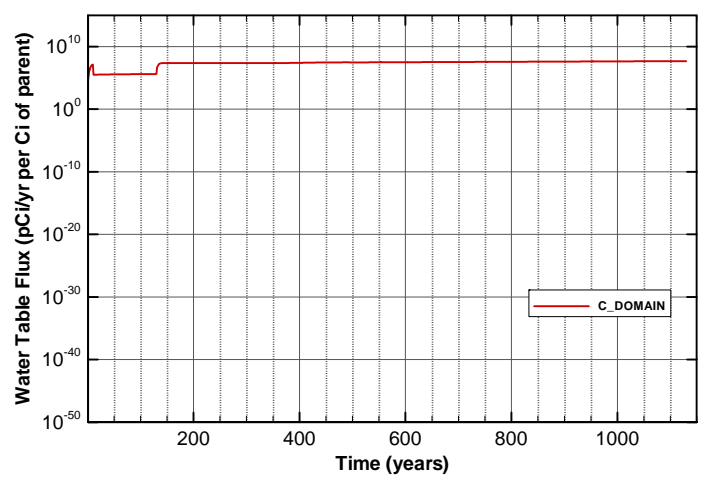

Figure A-564. Flux at water table for Case01n11_on I-129_H.Dowex.21K

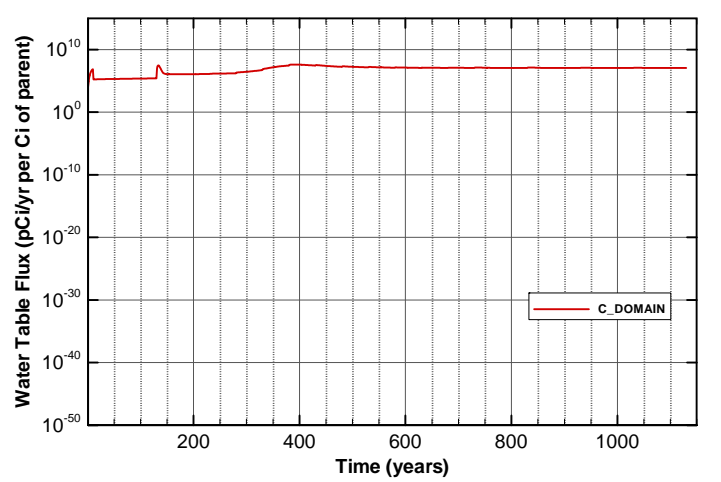

Figure A-566. Flux at water table for Case01n11_on I-129_Mk50A 


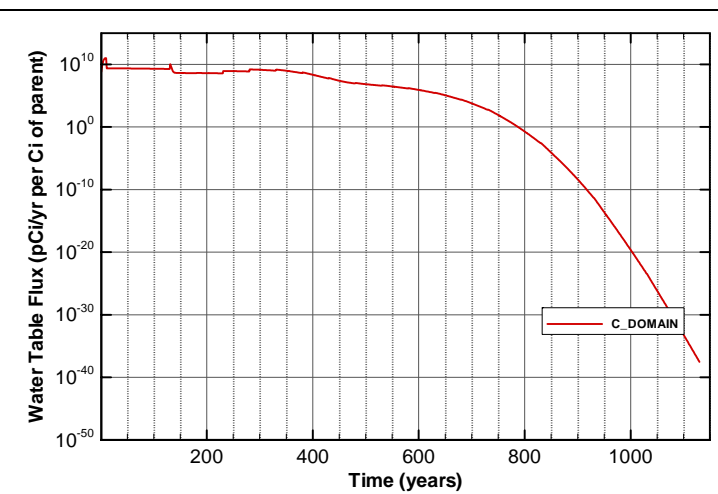

Figure A-567. Flux at water table for Case01n11_on K-40

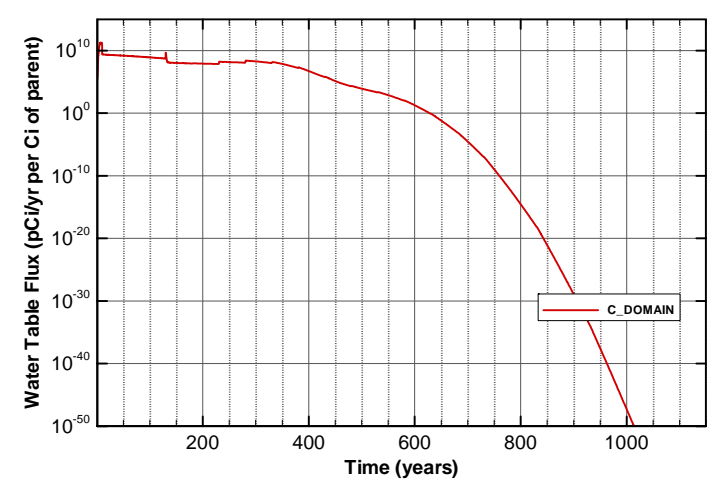

Figure A-569. Flux at water table for Case01n11_on Nb-94

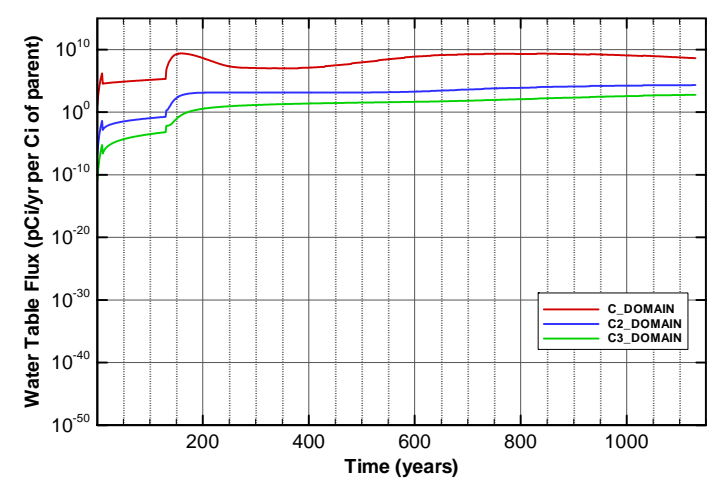

Figure A-571. Flux at water table for Case01n11_on Np-237

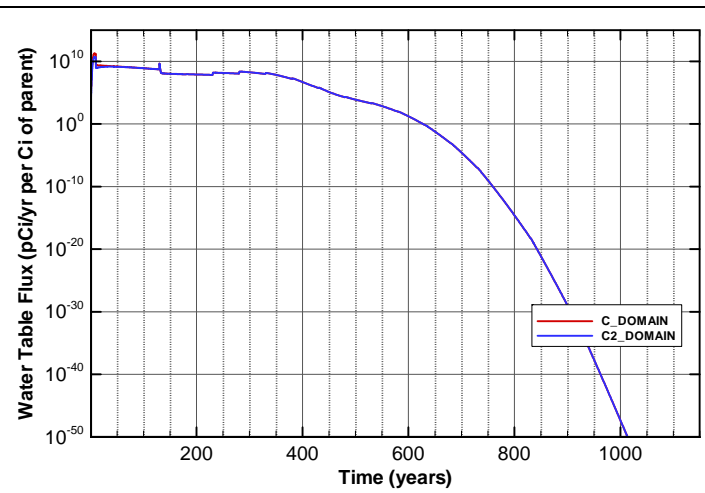

Figure A-568. Flux at water table for Case01n11_on Mo-93

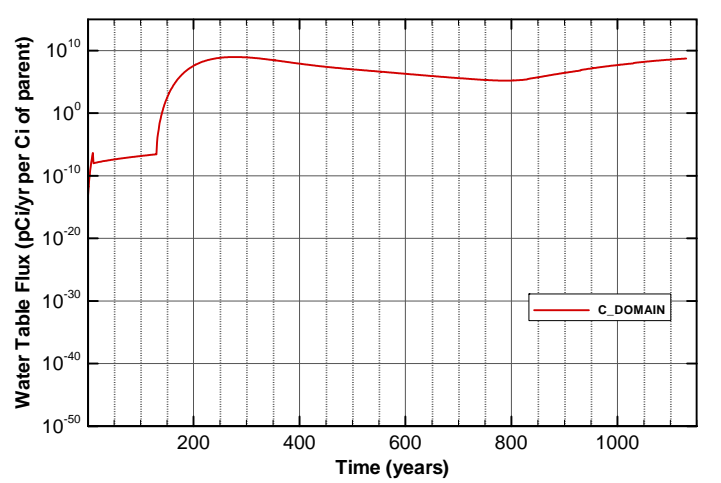

Figure A-570. Flux at water table for Case01n11_on Ni-59

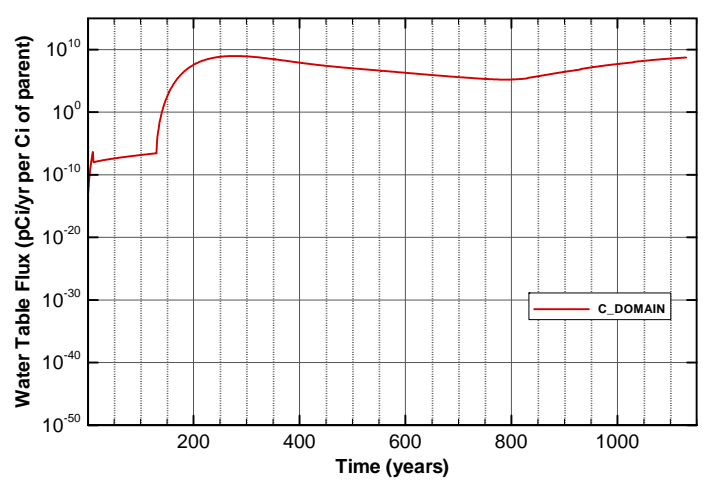

Figure A-572. Flux at water table for Case01n11_on Pd-107 
SRNL-STI-2008-00397, REVISION 0
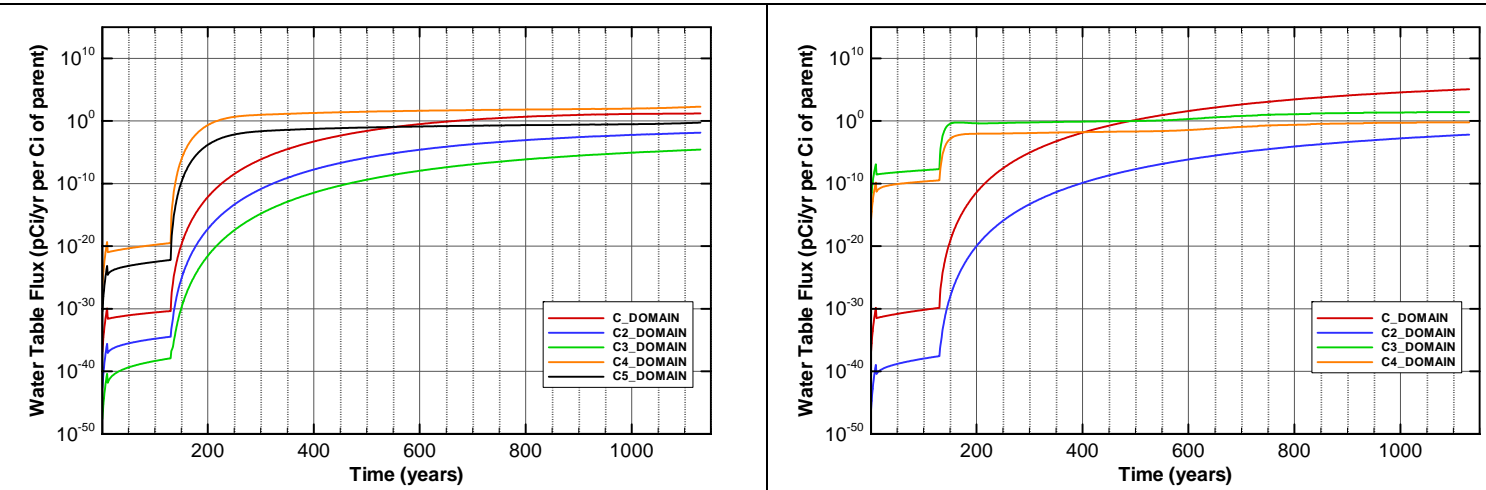

Figure A-573. Flux at water table for Case01n11_on Pu-238

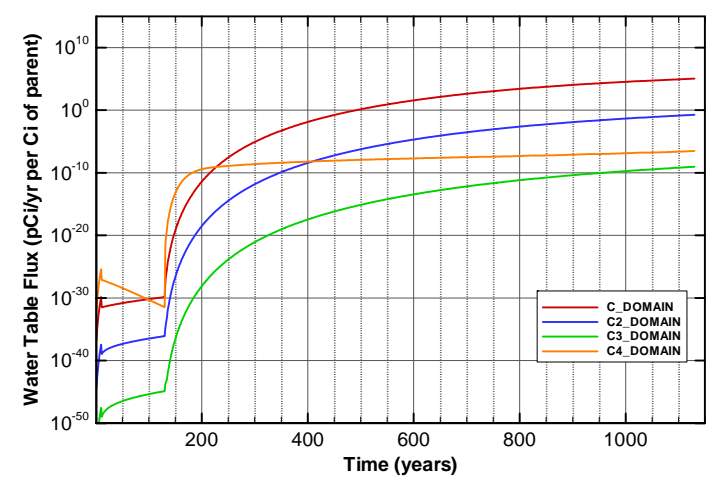

Figure A-575. Flux at water table for Case01n11_on Pu-240

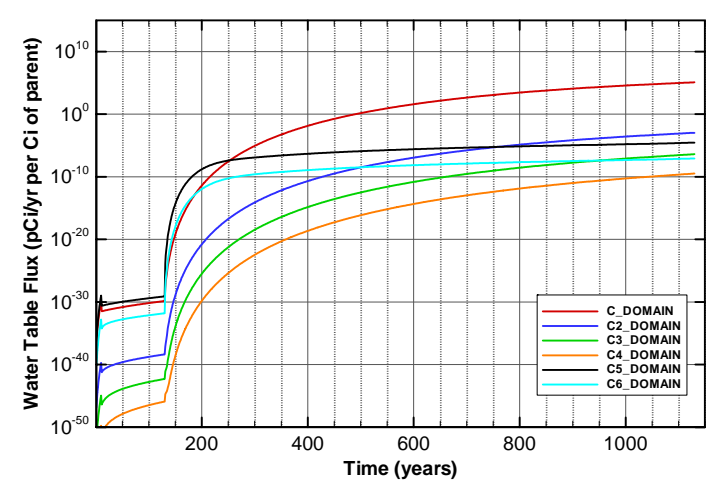

Figure A-577. Flux at water table for Case01n11_on Pu-242

Figure A-574. Flux at water table for Case01n11_on Pu-239

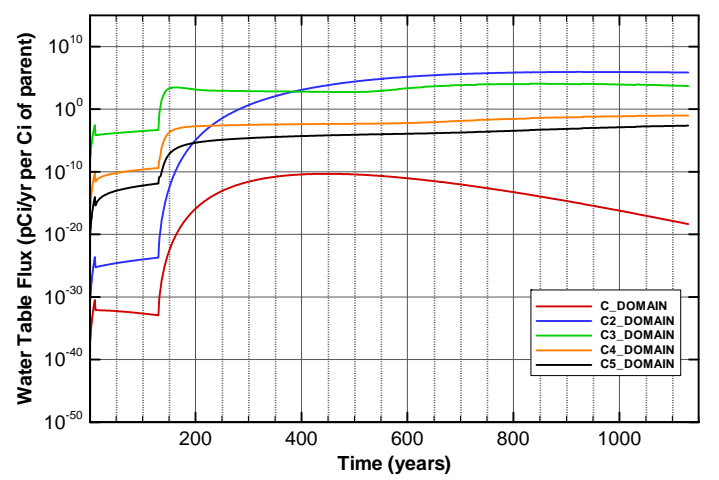

Figure A-576. Flux at water table for Case01n11_on Pu-241

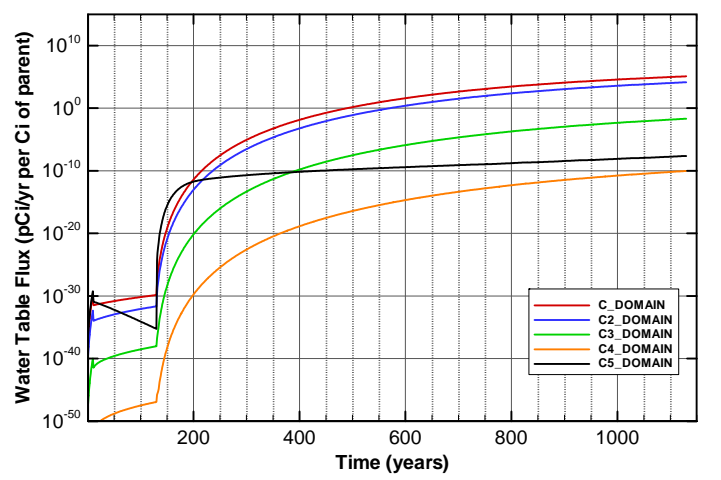

Figure A-578. Flux at water table for Case01n11_on Pu-244 


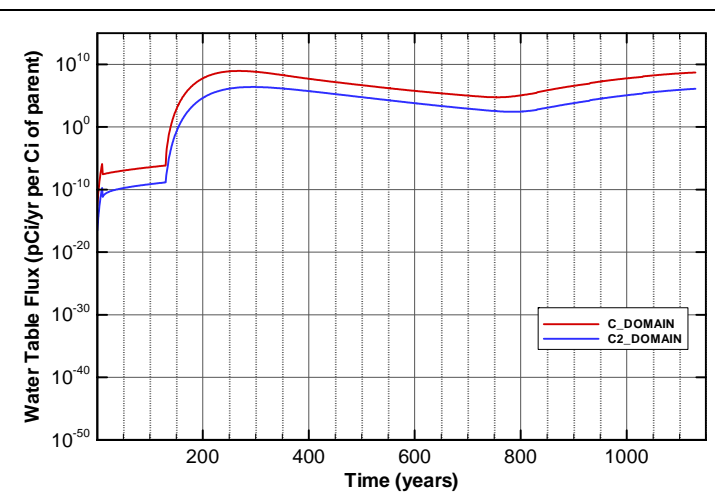

Figure A-579. Flux at water table for Case01n11_on Ra-226

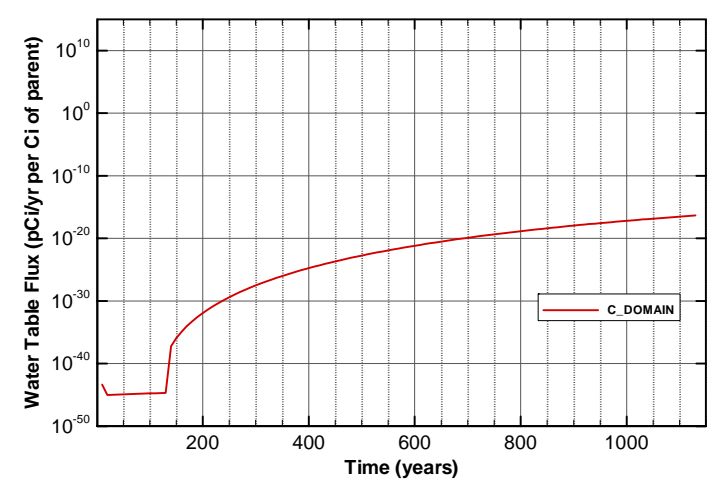

Figure A-581. Flux at water table for Case01n11_on Sn-126

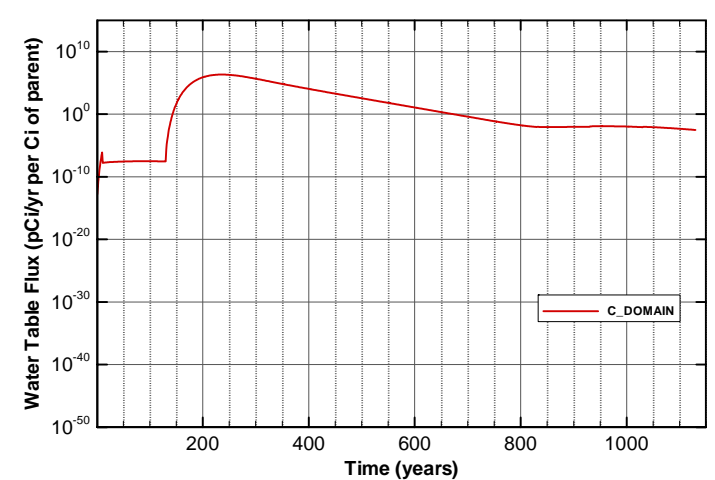

Figure A-583. Flux at water table for Case01n11_on Sr-90_Cask

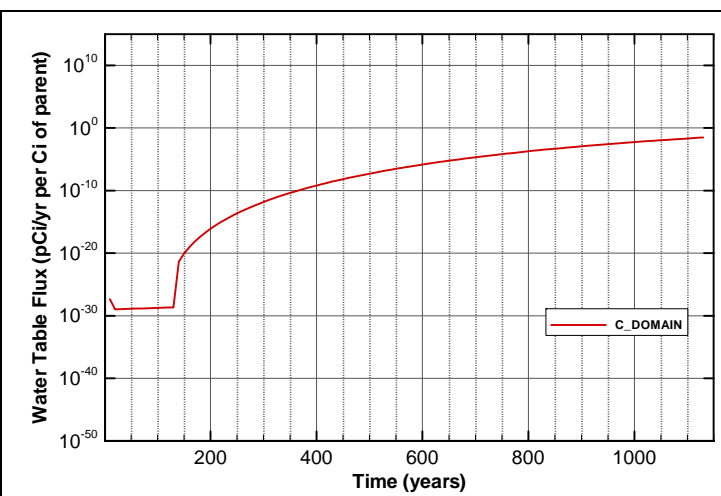

Figure A-580. Flux at water table for Case01n11_on Se-79

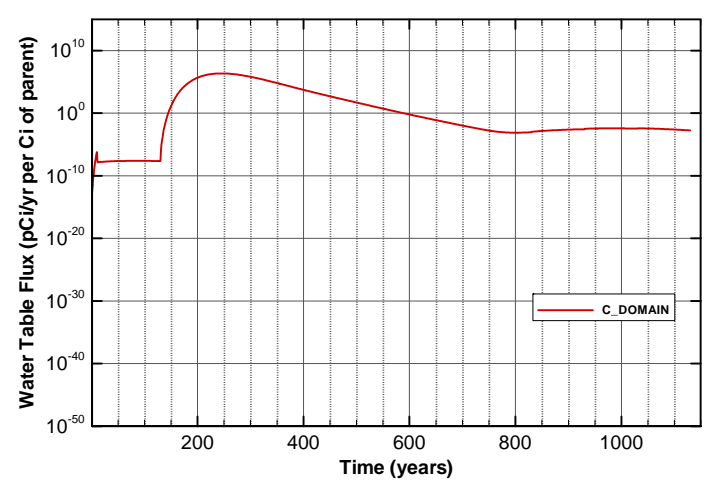

Figure A-582. Flux at water table for Case01n11_on Sr-90

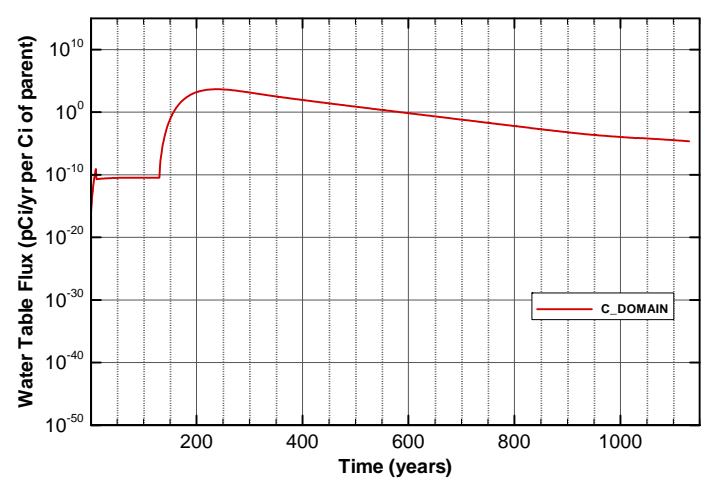

Figure A-584. Flux at water table for Case01n11_on Sr-90_Mk50A 


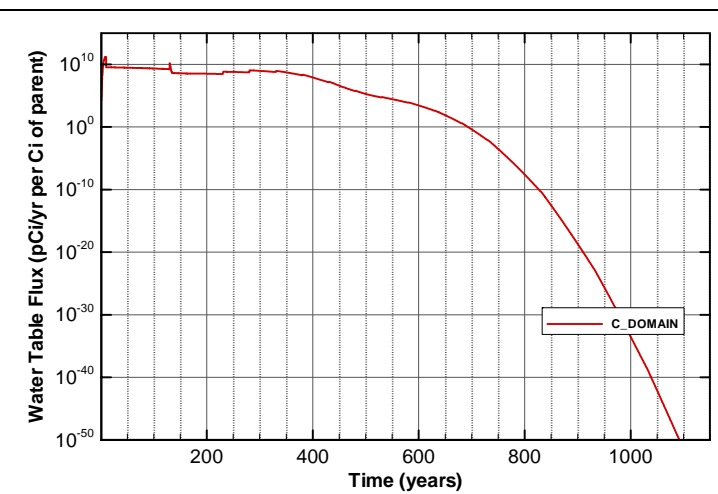

Figure A-585. Flux at water table for Case01n11_on Tc-99

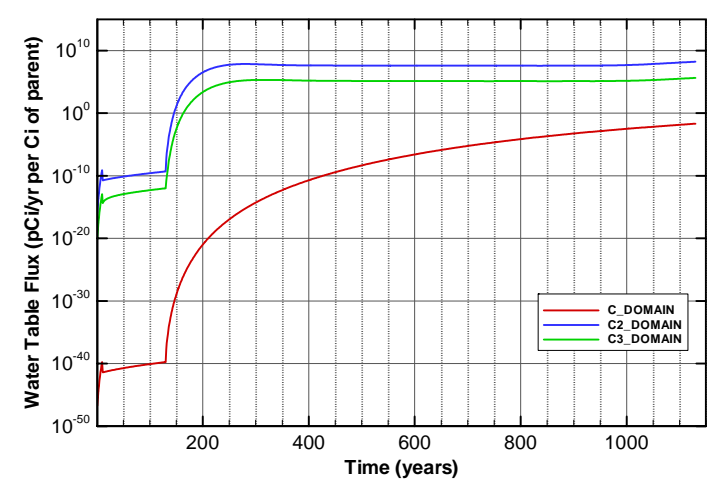

Figure A-587. Flux at water table for Case01n11_on Th-230

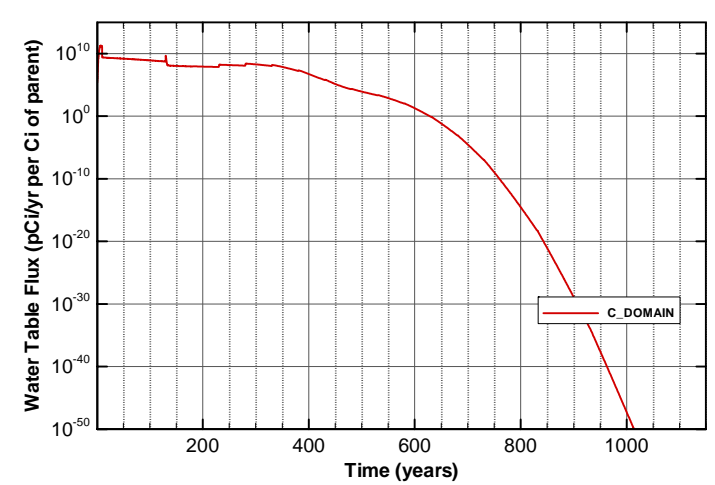

Figure A-589. Flux at water table for Case01n11_on Tracer

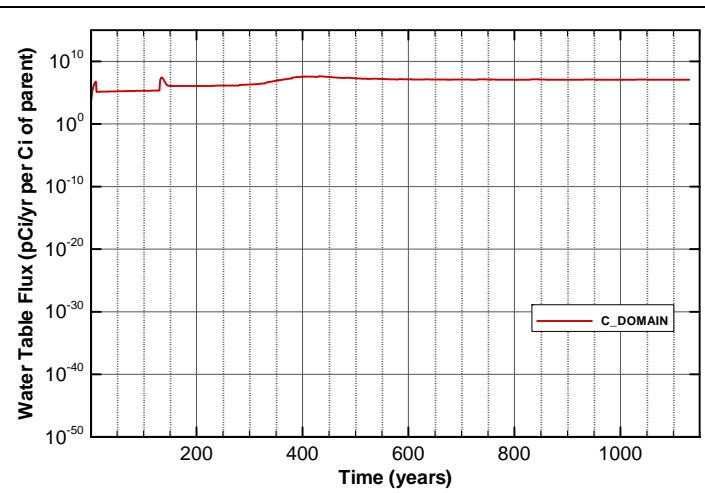

Figure A-586. Flux at water table for Case01n11_on Tc-99_Mk50A

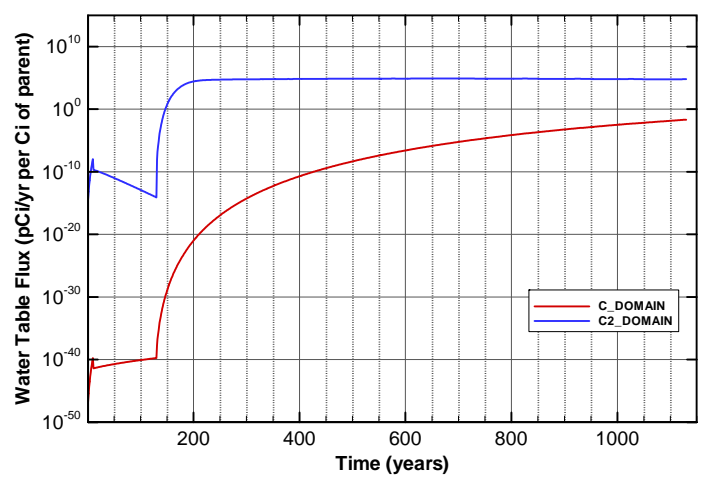

Figure A-588. Flux at water table for Case01n11_on Th-232

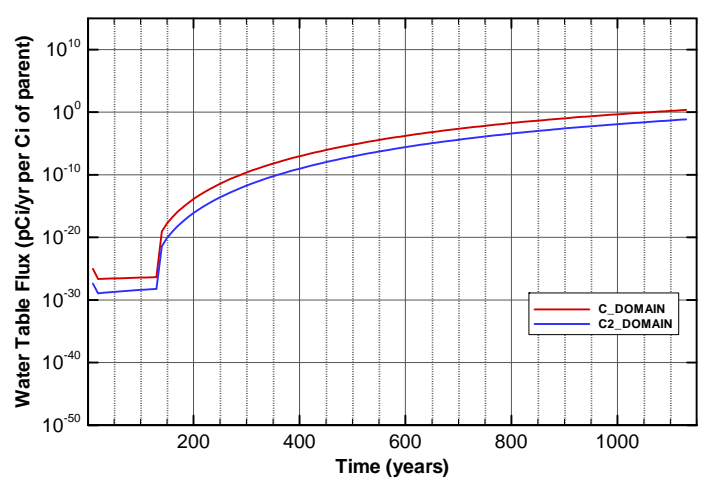

Figure A-590. Flux at water table for Case01n11_on U-233 


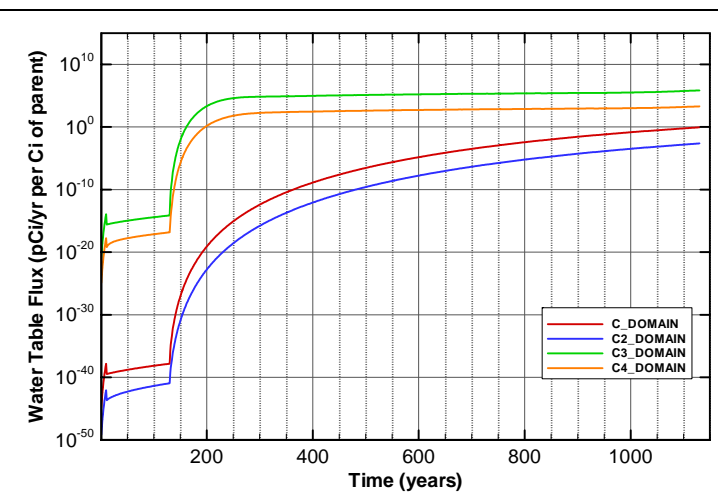

Figure A-591. Flux at water table for Case01n11_on U-234

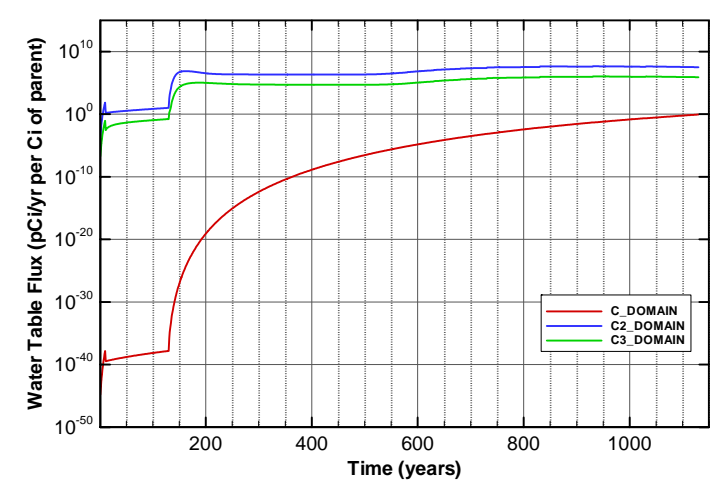

Figure A-593. Flux at water table for Case01n11_on U-235

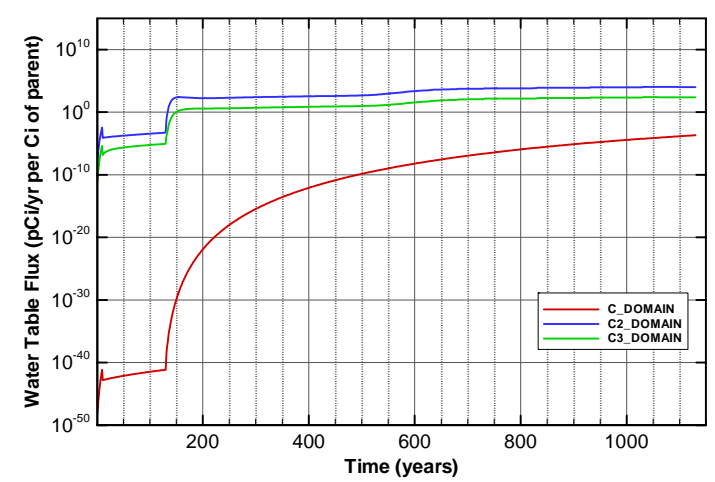

Figure A-595. Flux at water table for Case01n11_on U-235_Paducah.Cask

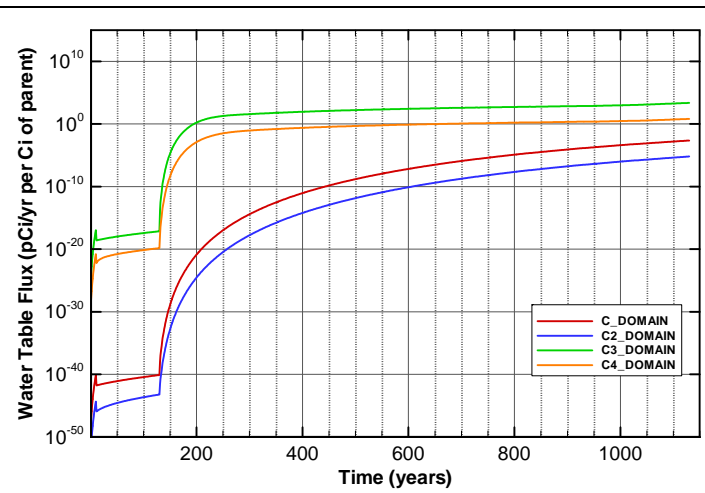

Figure A-592. Flux at water table for Case01n11_on U-234_Mglass

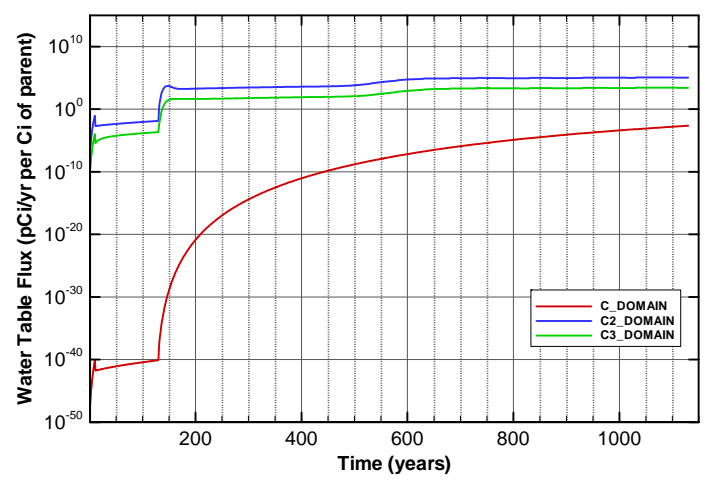

Figure A-594. Flux at water table for Case01n11_on U-235_Mglass

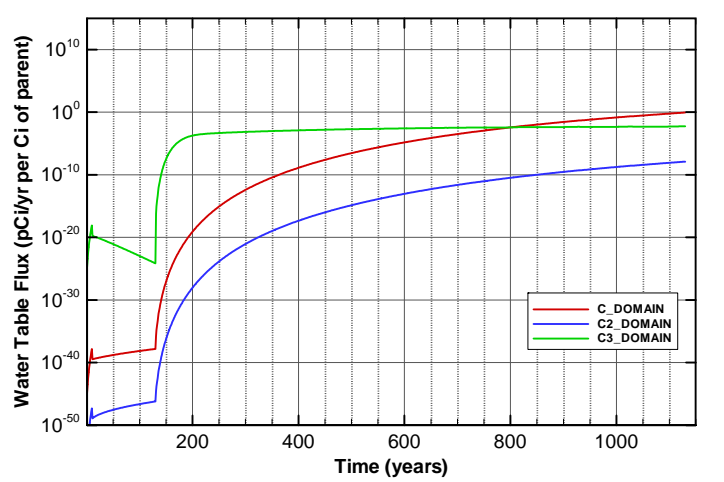

Figure A-596. Flux at water table for Case01n11_on U-236 


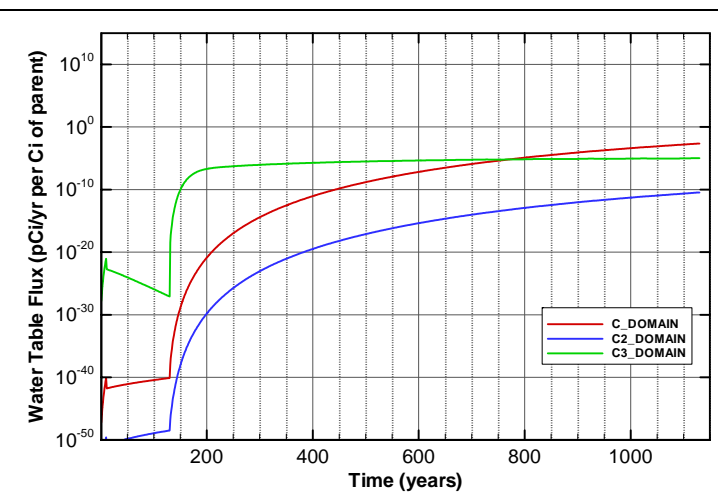

Figure A-597. Flux at water table for Case01n11_on U-236_Mglass

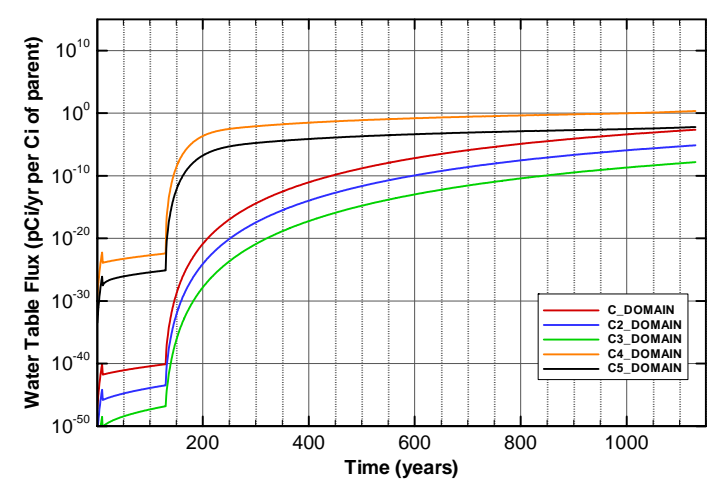

Figure A-599. Flux at water table for Case01n11_on U-238_Mglass

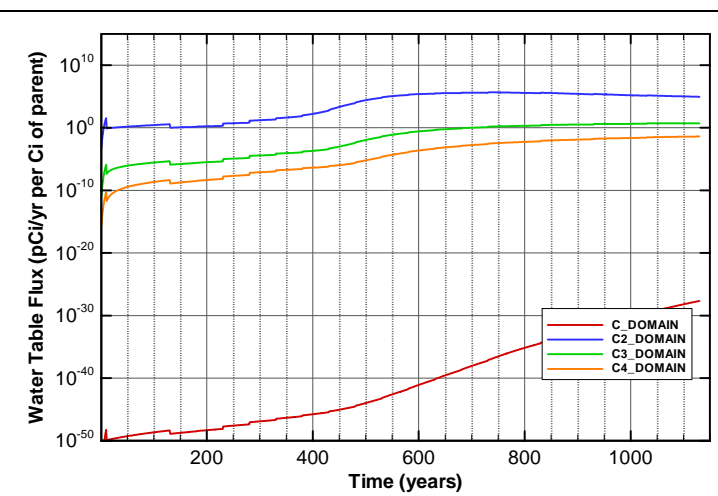

Figure A-601. Flux at water table for Case01_off Am-241

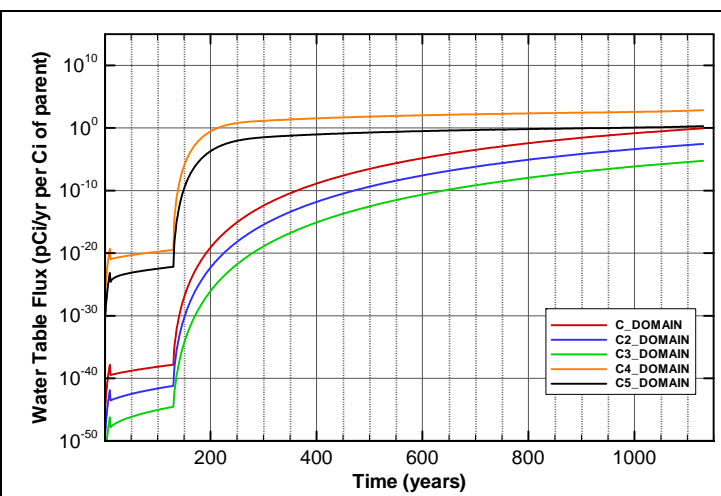

Figure A-598. Flux at water table for Case01n11_on U-238

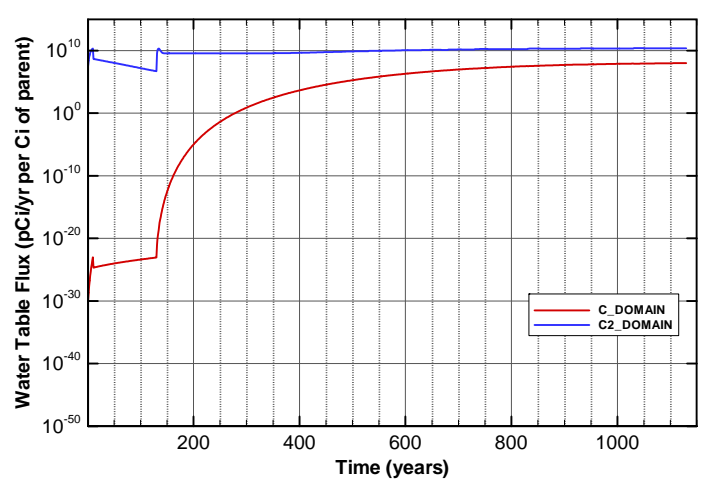

Figure A-600. Flux at water table for Case01n11_on Zr-93

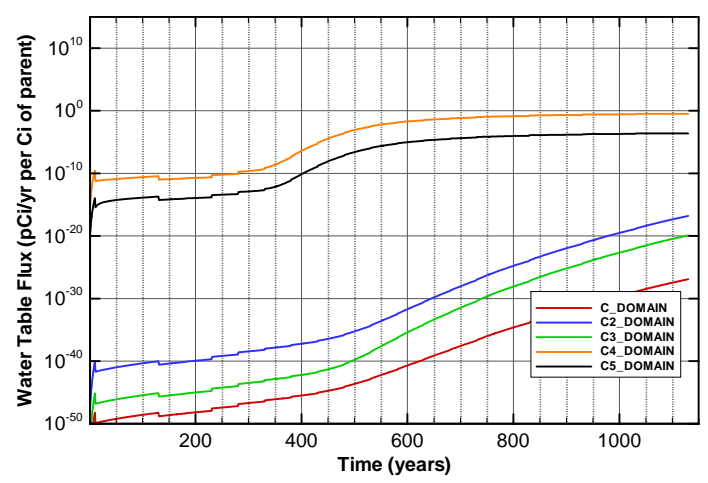

Figure A-602. Flux at water table for Case01_off Am-243 
SRNL-STI-2008-00397, REVISION 0
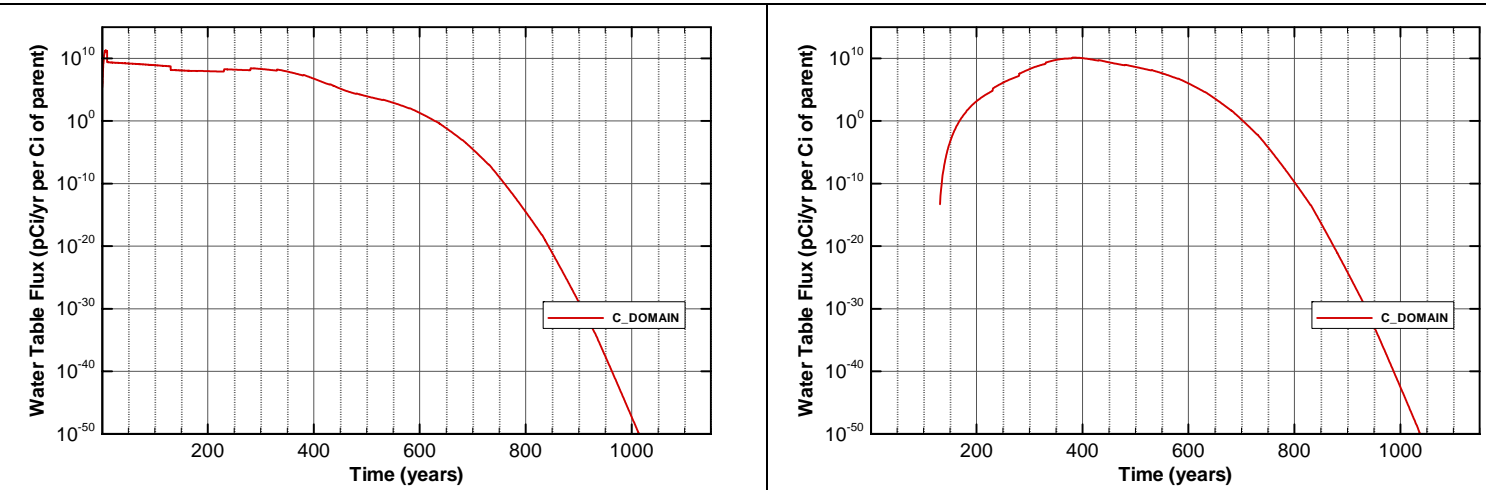

Figure A-603. Flux at water table for Case01_off C-14

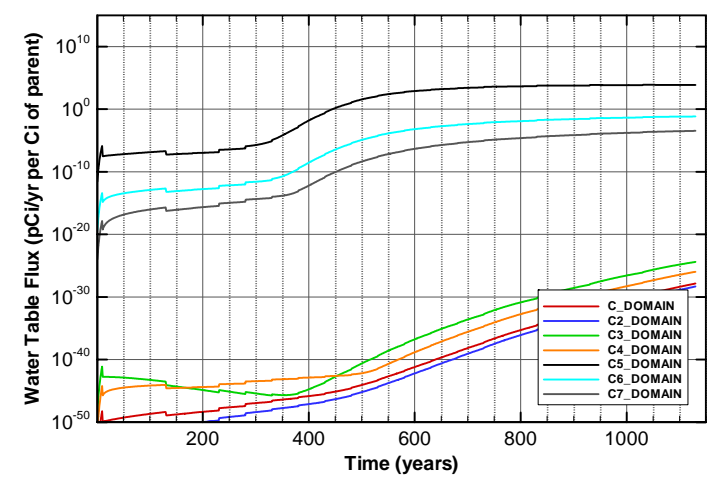

Figure A-605. Flux at water table for Case01_off Cf-249

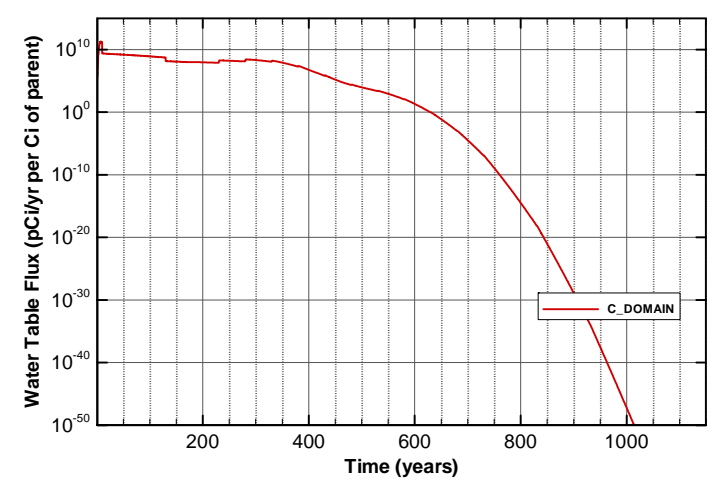

Figure A-607. Flux at water table for Case01_off Cl-36

Figure A-604. Flux at water table for Case01_off C-14_NR.Pump

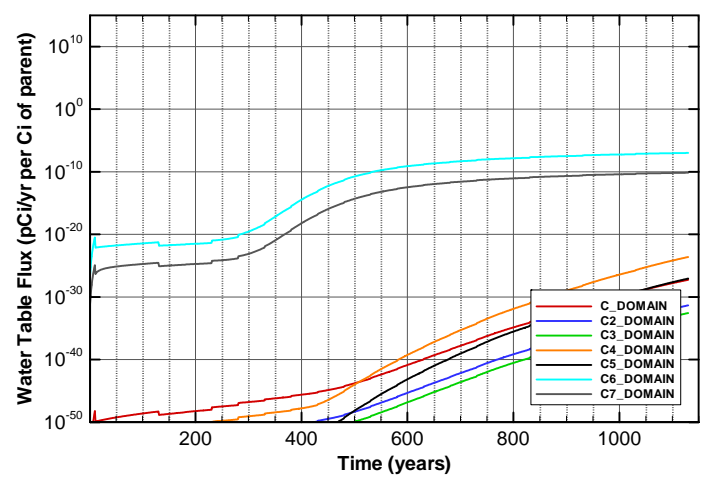

Figure A-606. Flux at water table for Case01_off Cf-251

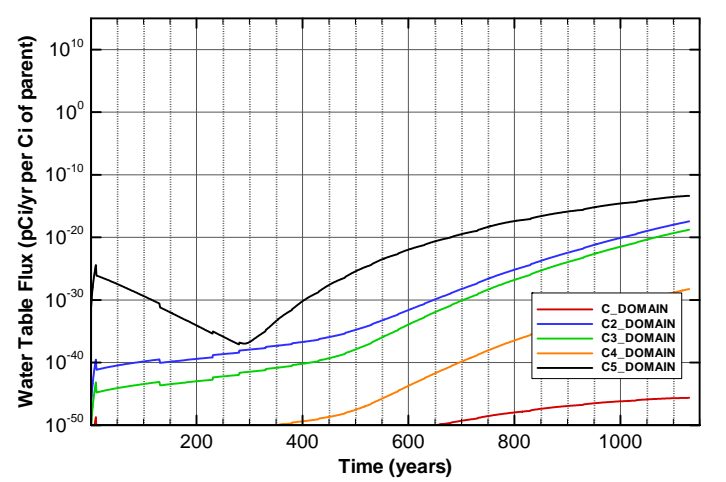

Figure A-608. Flux at water table for Case01_off Cm-244 
SRNL-STI-2008-00397, REVISION 0

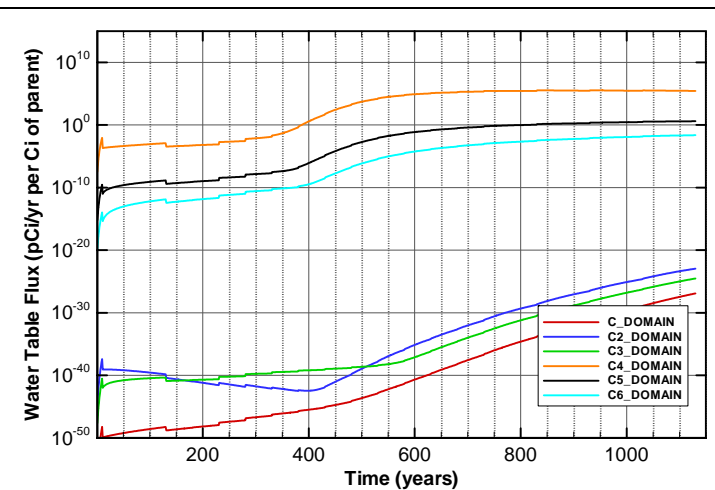

Figure A-609. Flux at water table for Case01_off Cm-245

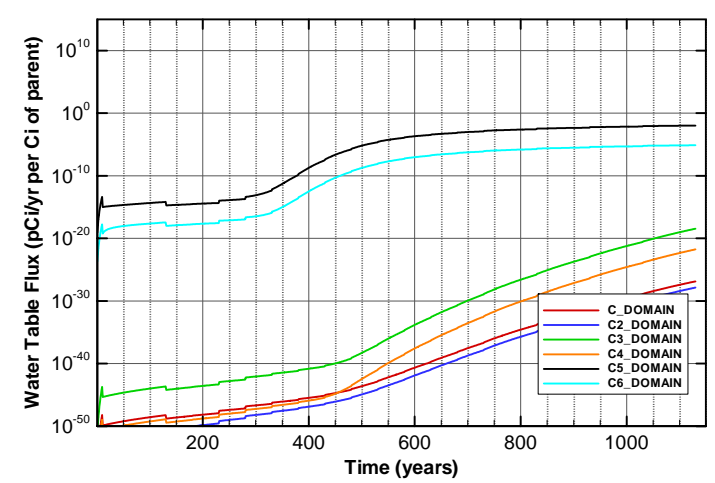

Figure A-611. Flux at water table for Case01_off Cm-247

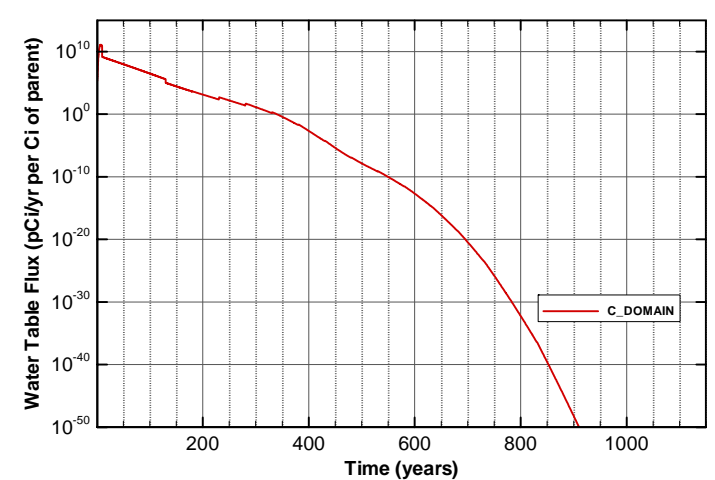

Figure A-613. Flux at water table for Case01_off H-3

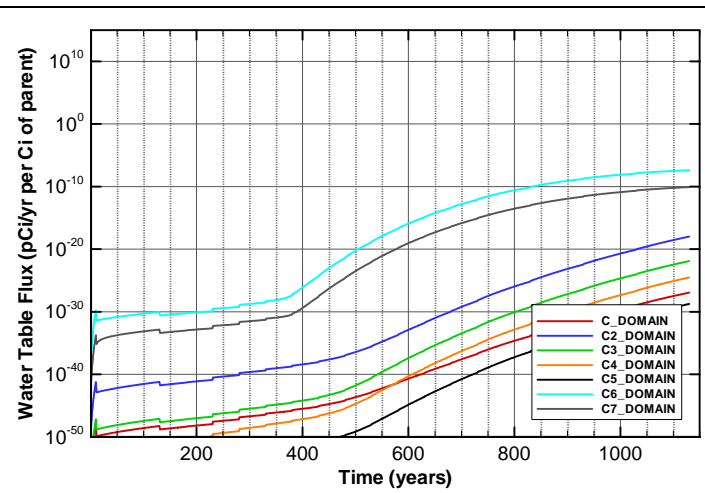

Figure A-610. Flux at water table for Case01_off Cm-246

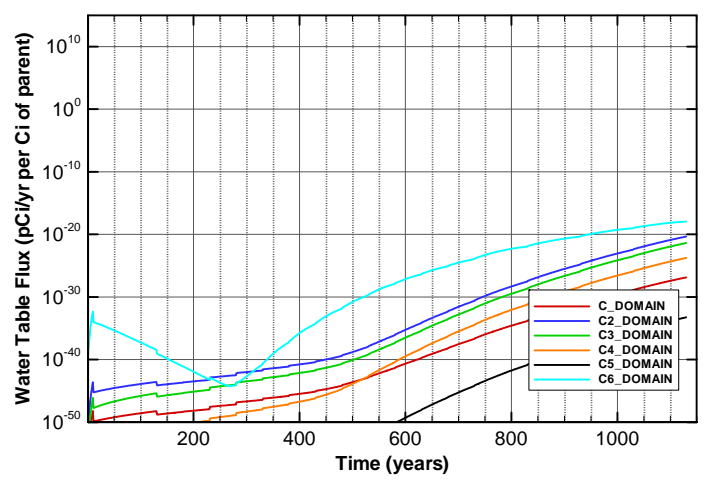

Figure A-612. Flux at water table for Case01_off Cm-248

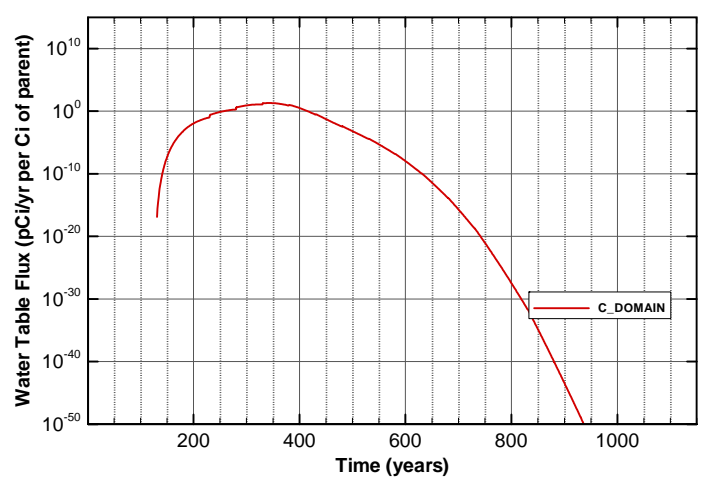

Figure A-614. Flux at water table for Case01_off H-3_ETF.Carbon 


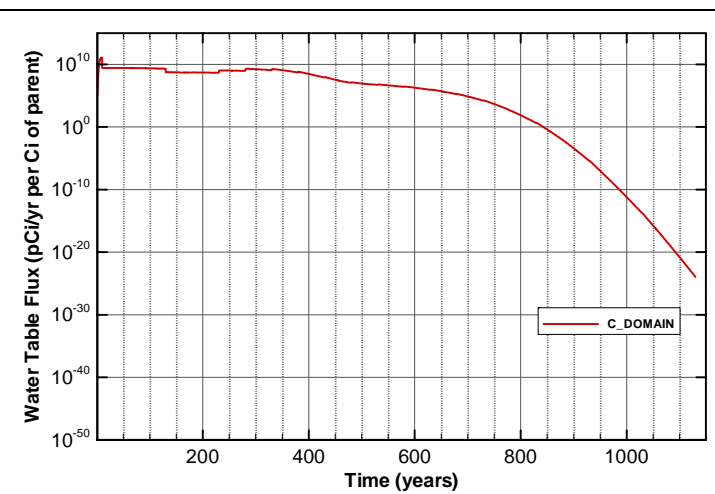

Figure A-615. Flux at water table for Case01_off I-129

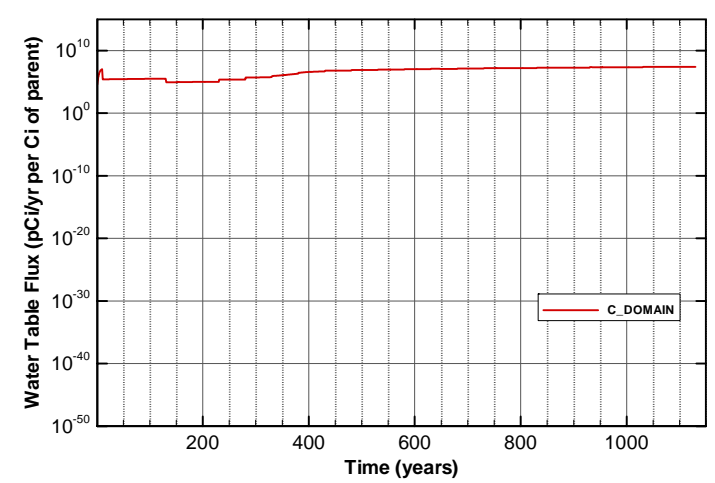

Figure A-617. Flux at water table for Case01_off I-129_ETF.GT.73

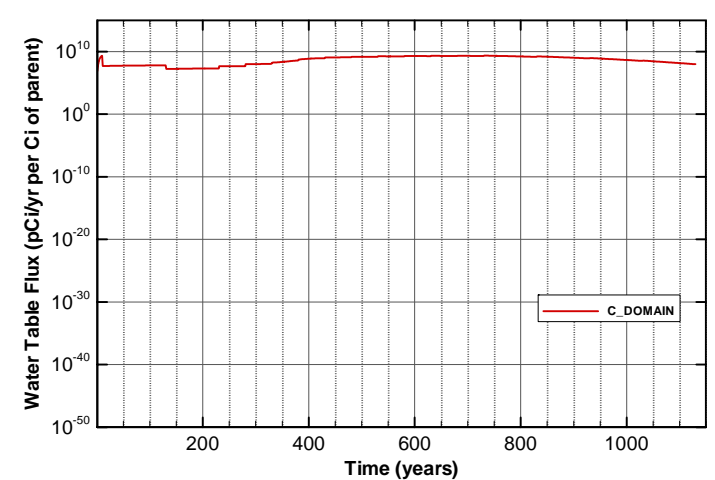

Figure A-619. Flux at water table for Case01_off I-129_F.CG.8

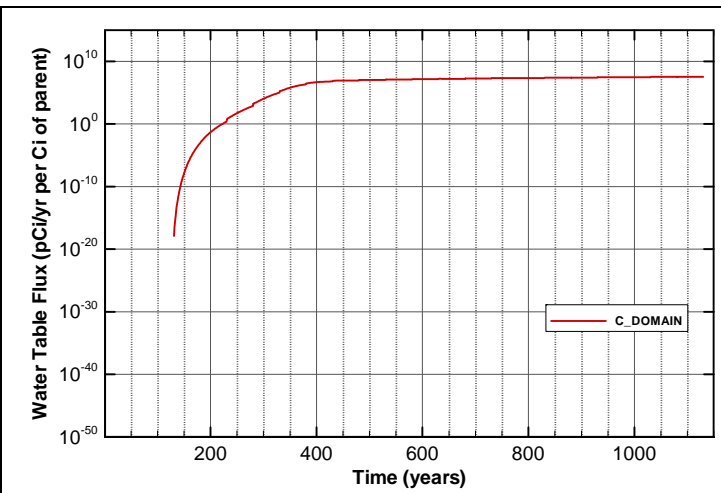

Figure A-616. Flux at water table for Case01_off I-129_ETF.Carbon

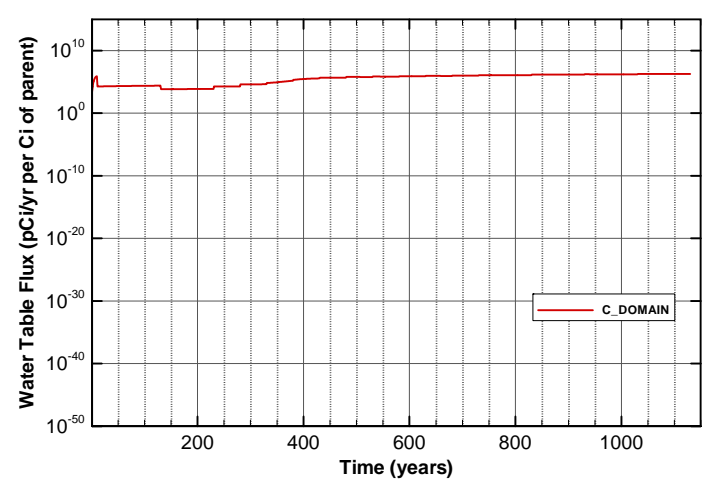

Figure A-618. Flux at water table for Case01_off I-129_F.Carbon

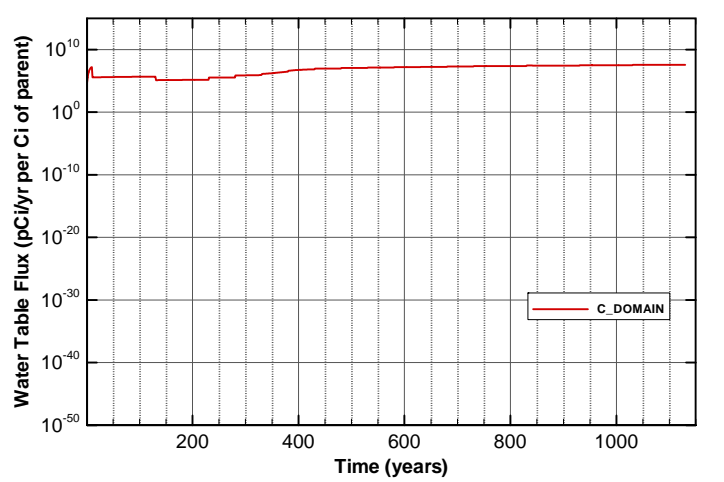

Figure A-620. Flux at water table for Case01_off I-129_F.Dowex.21K 


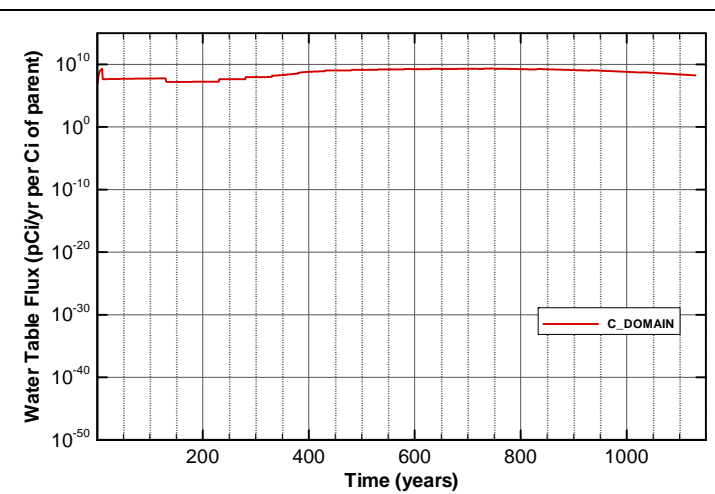

Figure A-621. Flux at water table for Case01_off I-129_F.Filtercake

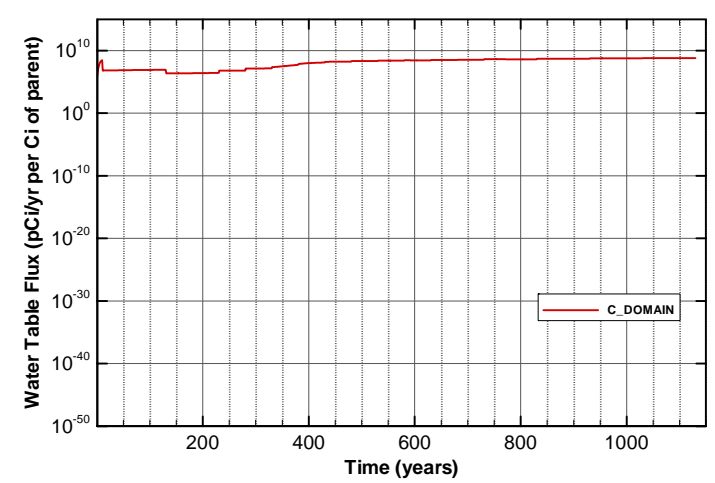

Figure A-623. Flux at water table for Case01_off I-129_H.CG.8

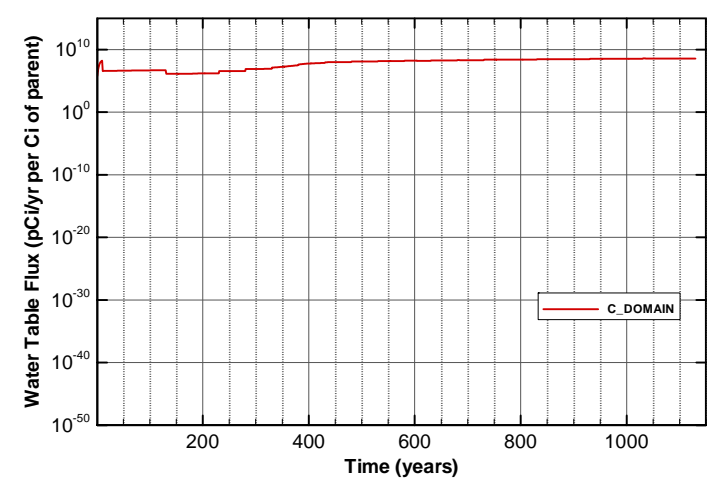

Figure A-625. Flux at water table for Case01_off I-129_H.Filtercake

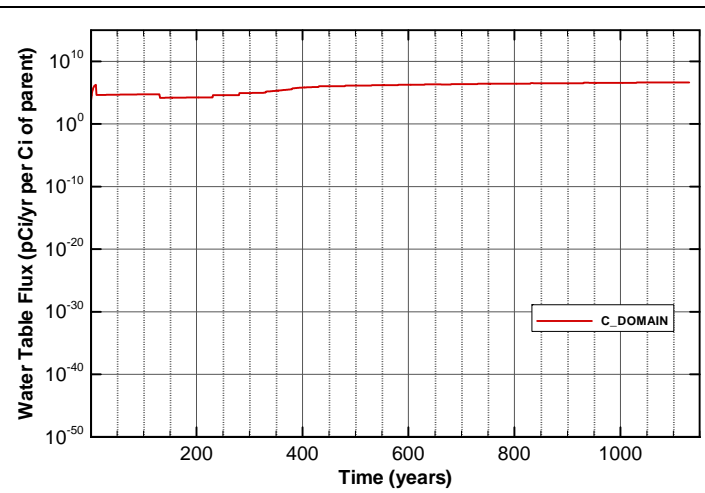

Figure A-622. Flux at water table for Case01_off I-129_H.Carbon

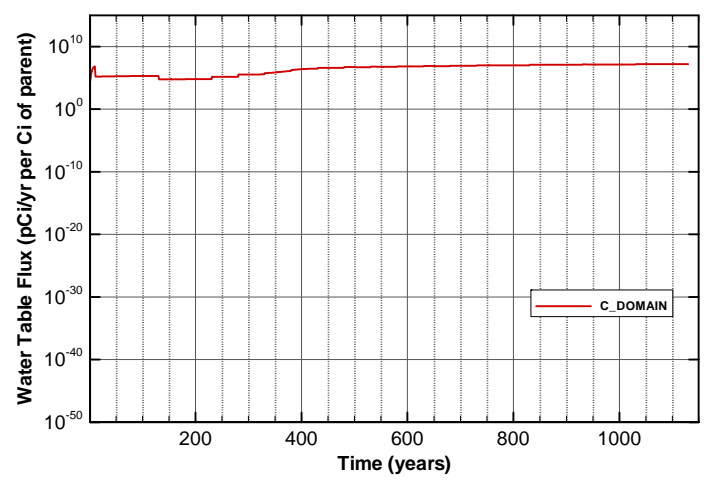

Figure A-624. Flux at water table for Case01_off I-129_H.Dowex.21K

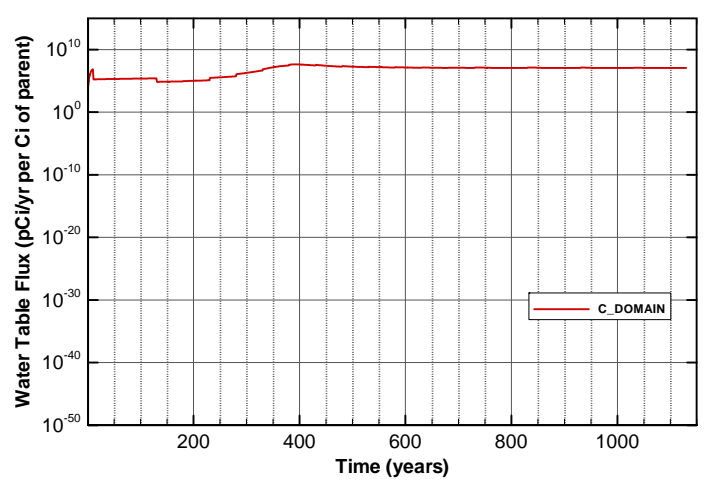

Figure A-626. Flux at water table for Case01_off I-129_Mk50A 


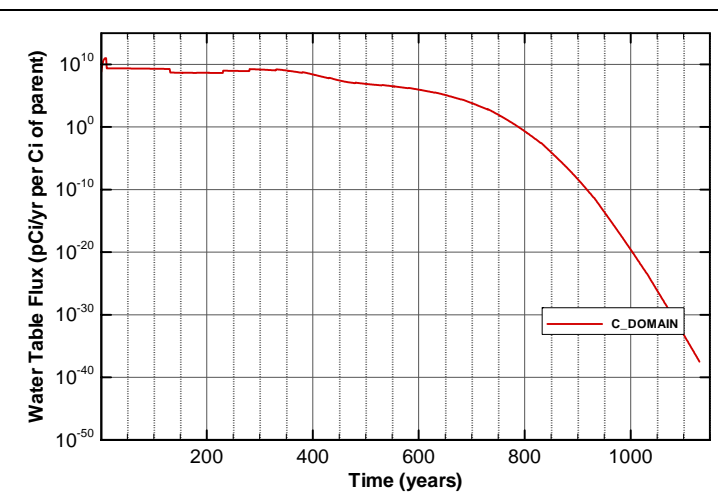

Figure A-627. Flux at water table for Case01_off K-40

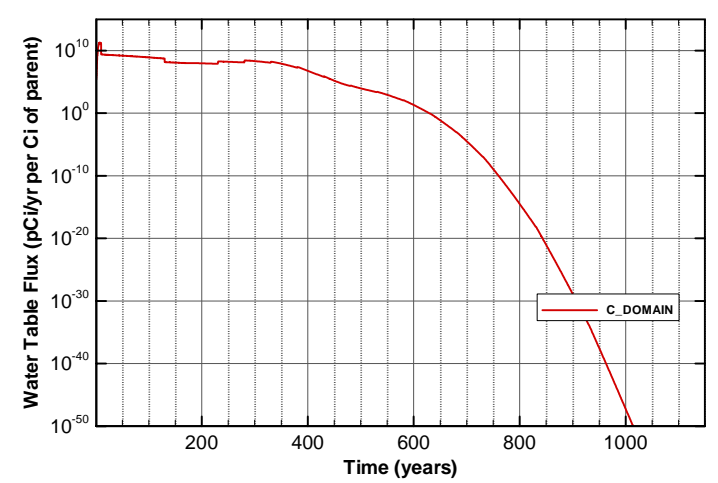

Figure A-629. Flux at water table for Case01_off Nb-94

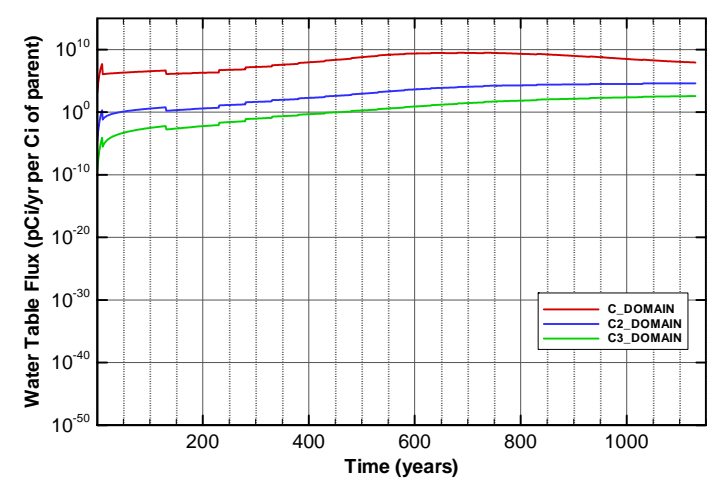

Figure A-631. Flux at water table for Case01_off Np-237

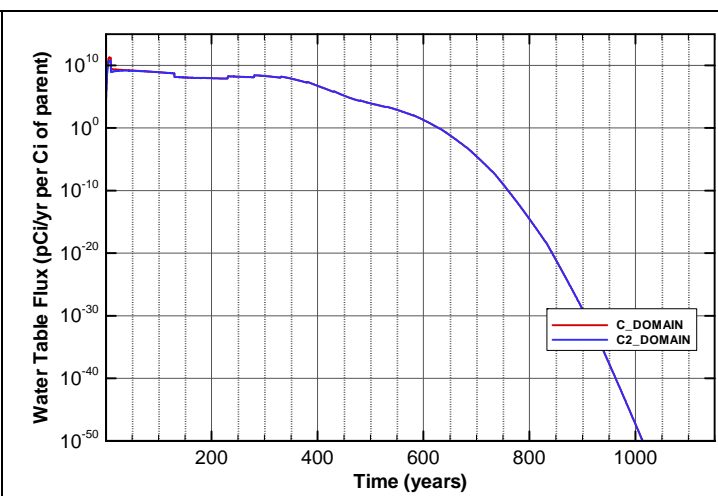

Figure A-628. Flux at water table for Case01_off Mo-93

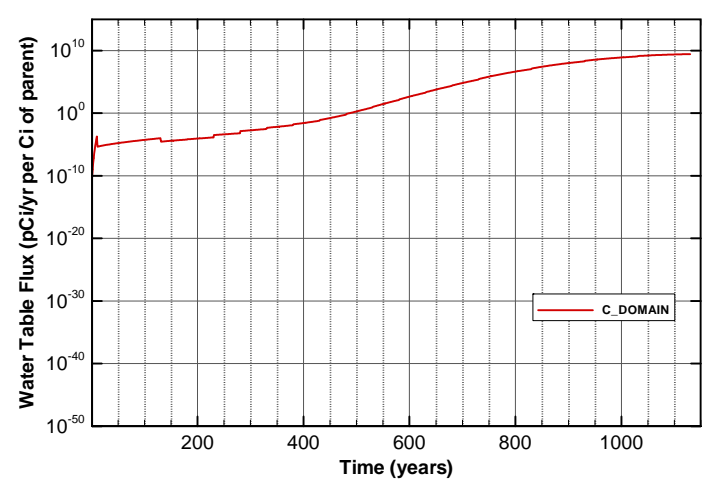

Figure A-630. Flux at water table for Case01_off Ni-59

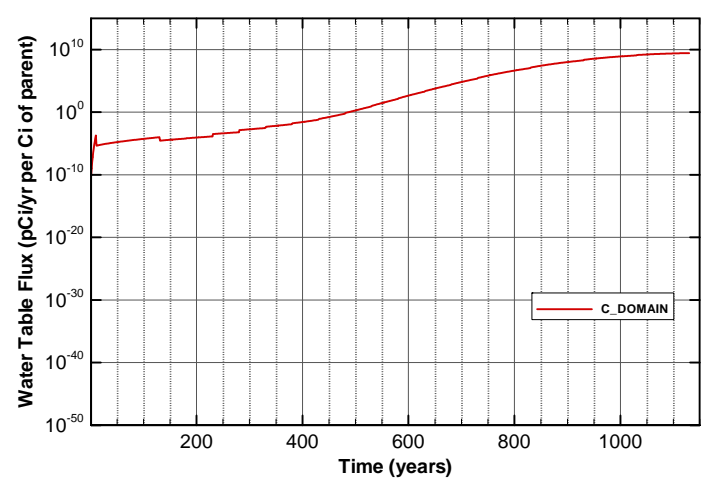

Figure A-632. Flux at water table for Case01_off Pd-107 
SRNL-STI-2008-00397, REVISION 0
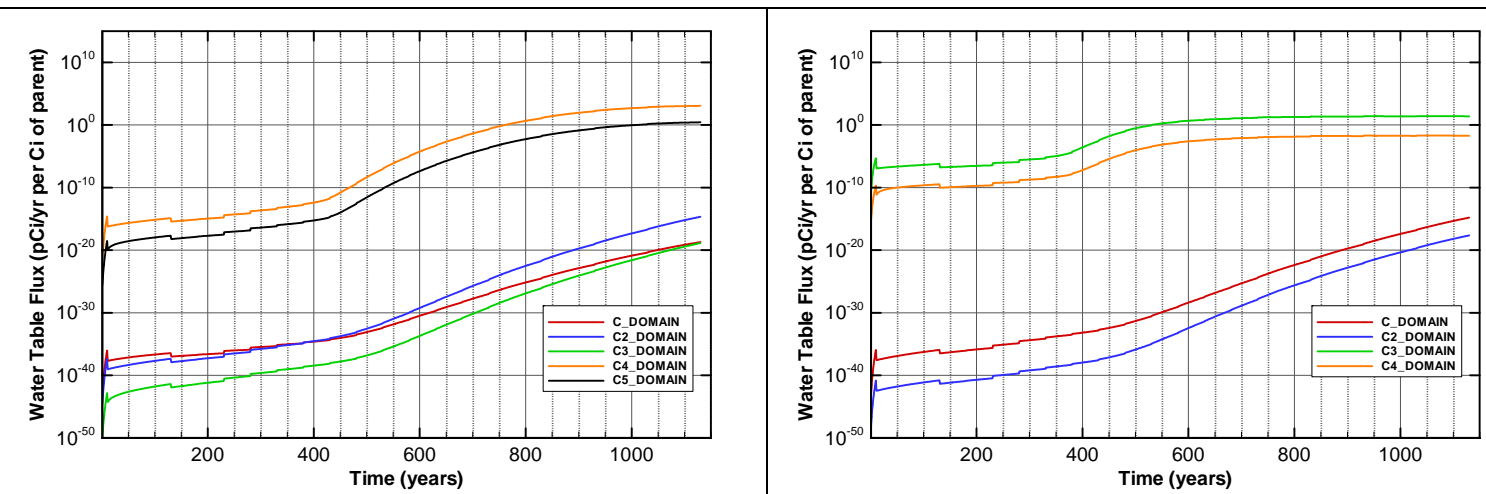

Figure A-633. Flux at water table for Case01_off Pu-238

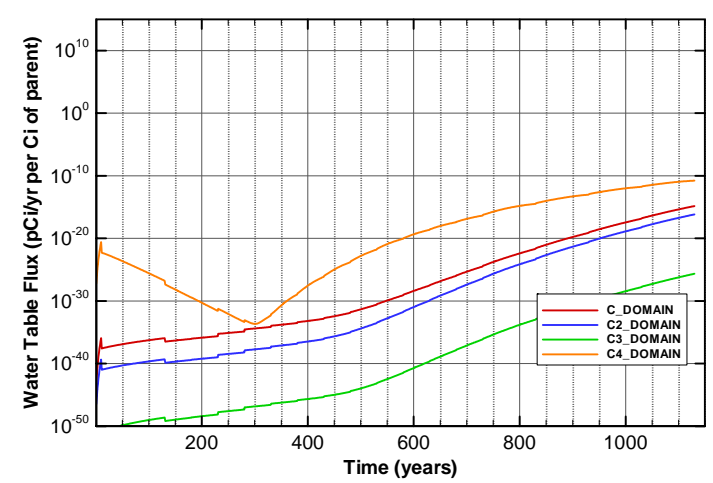

Figure A-635. Flux at water table for Case01_off Pu-240

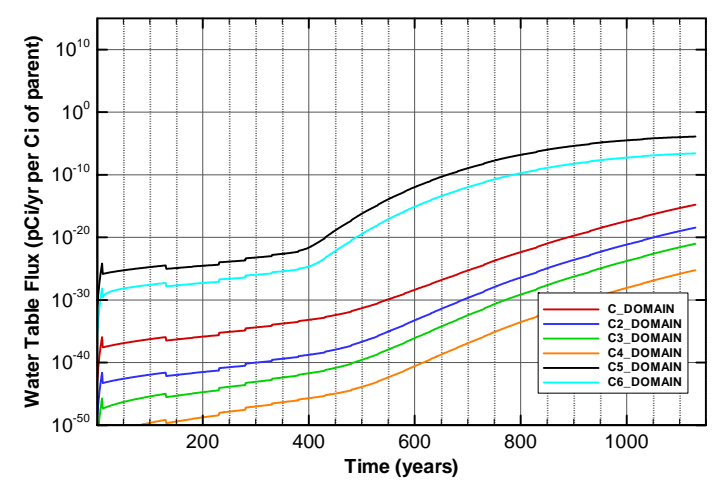

Figure A-637. Flux at water table for Case01_off Pu-242

Figure A-634. Flux at water table for Case01_off Pu-239

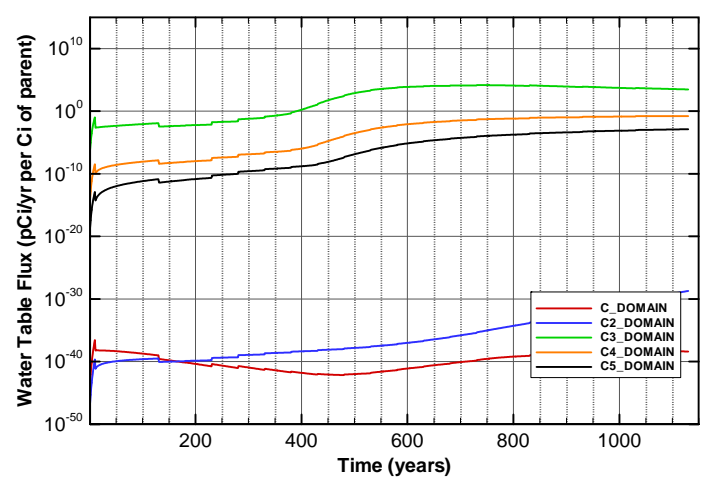

Figure A-636. Flux at water table for Case01_off Pu-241

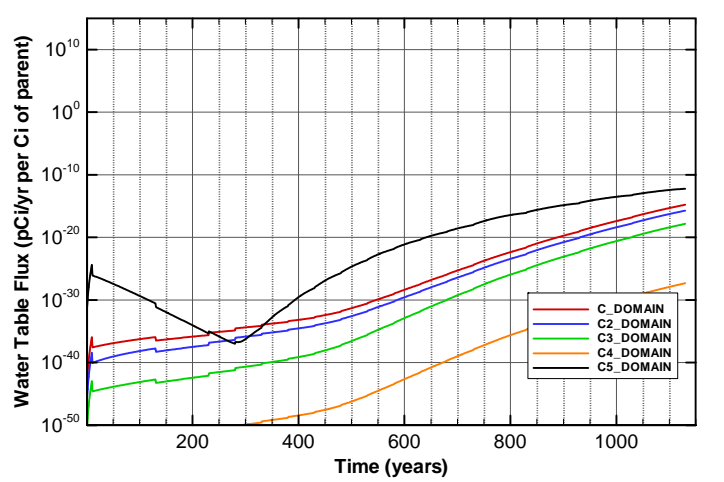

Figure A-638. Flux at water table for Case01_off Pu-244 
SRNL-STI-2008-00397, REVISION 0

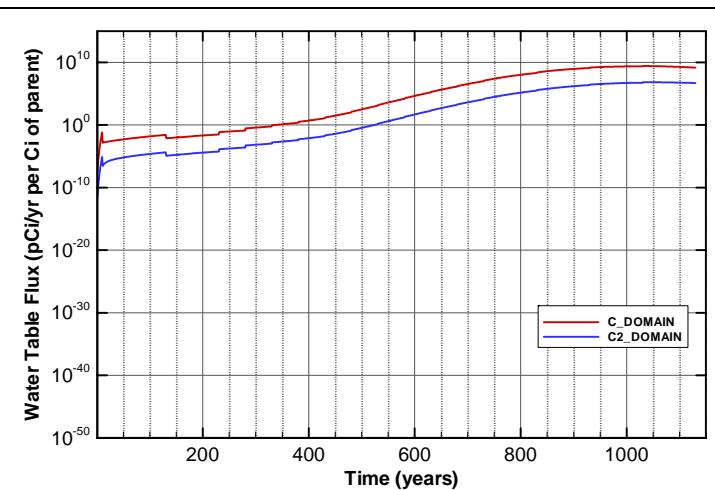

Figure A-639. Flux at water table for Case01_off Ra-226

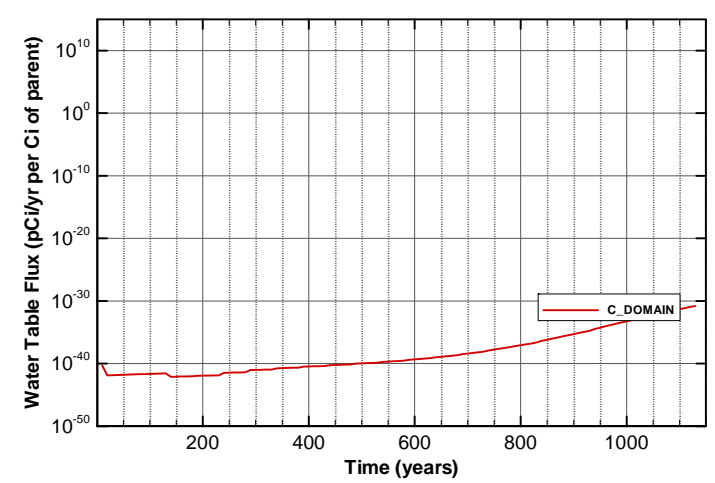

Figure A-641. Flux at water table for Case01_off Sn-126

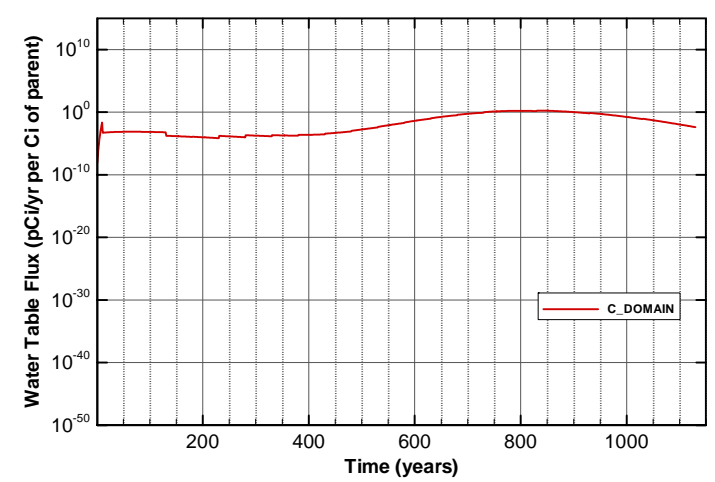

Figure A-643. Flux at water table for Case01_off Sr-90_Cask

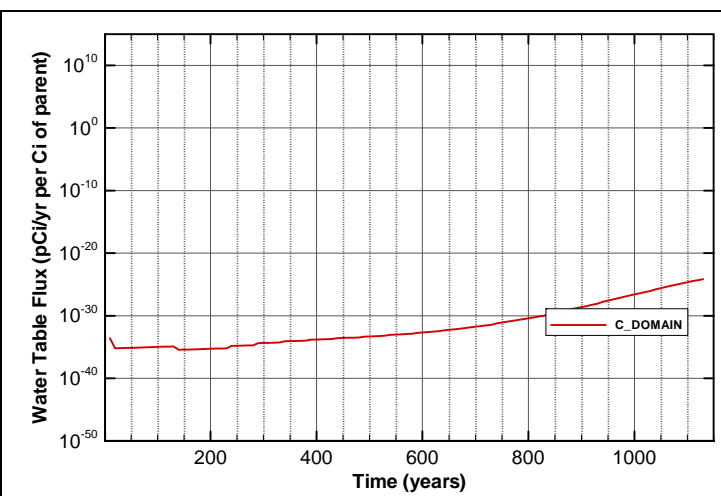

Figure A-640. Flux at water table for Case01_off Se-79

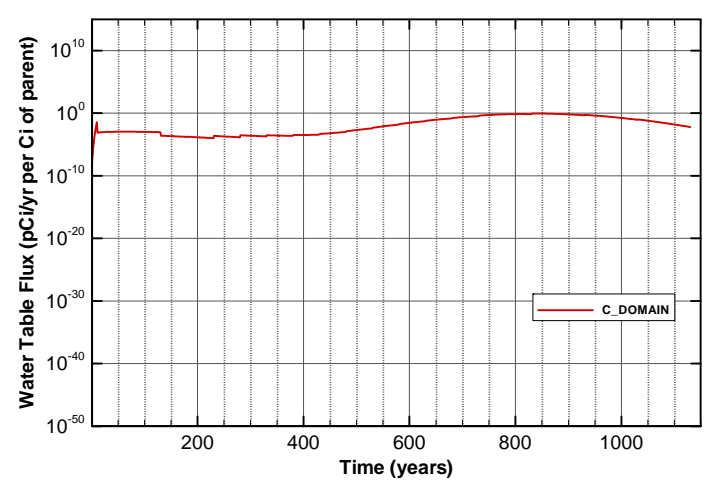

Figure A-642. Flux at water table for Case01_off Sr-90

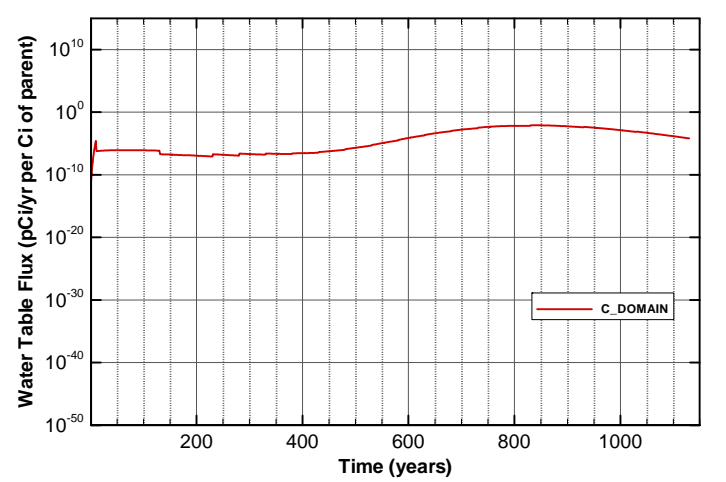

Figure A-644. Flux at water table for Case01_off Sr-90_Mk50A 


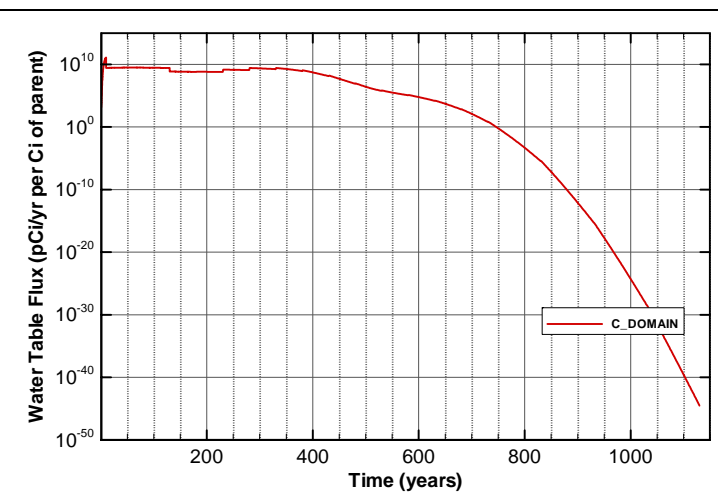

Figure A-645. Flux at water table for Case01_off Tc-99

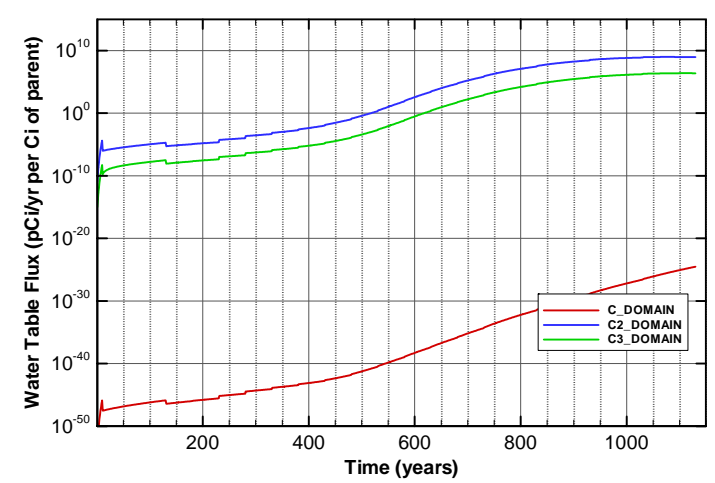

Figure A-647. Flux at water table for Case01_off Th-230

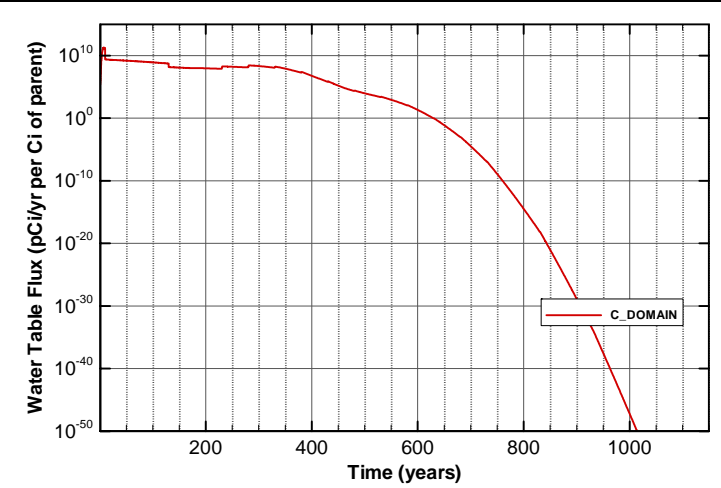

Figure A-649. Flux at water table for Case01_off Tracer

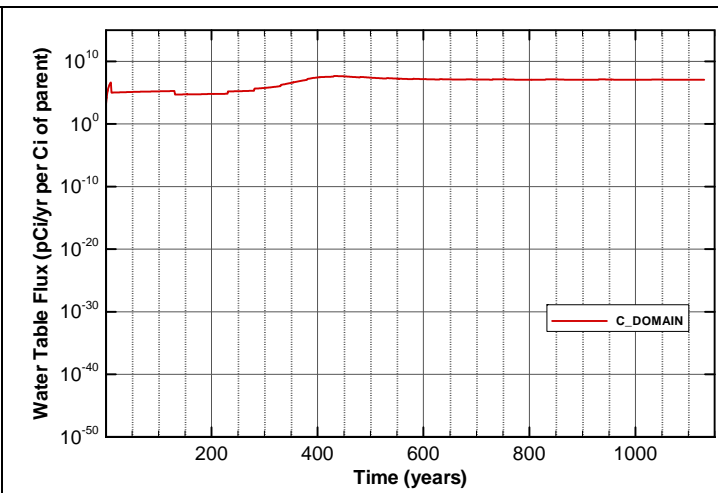

Figure A-646. Flux at water table for Case01_off Tc-99_Mk50A

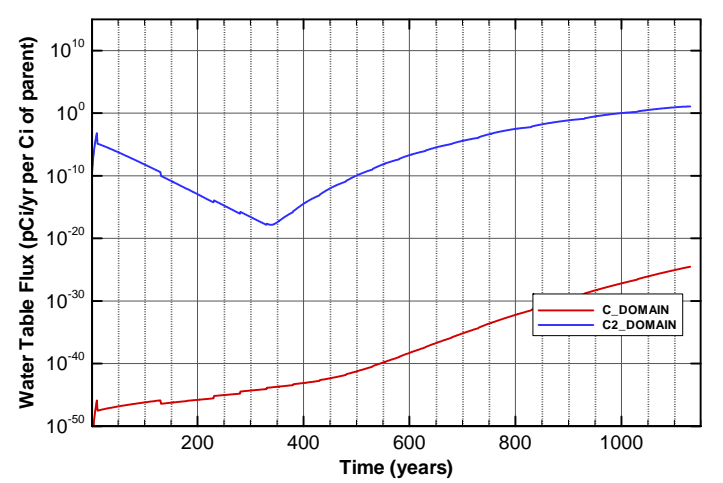

Figure A-648. Flux at water table for Case01_off Th-232

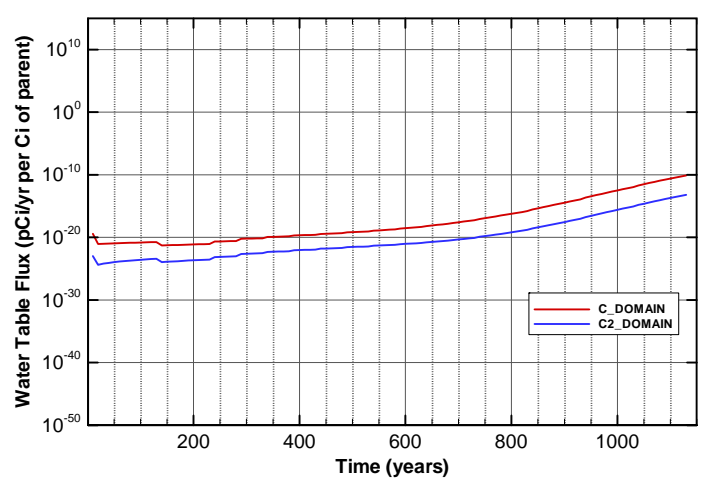

Figure A-650. Flux at water table for Case01_off U-233 
SRNL-STI-2008-00397, REVISION 0
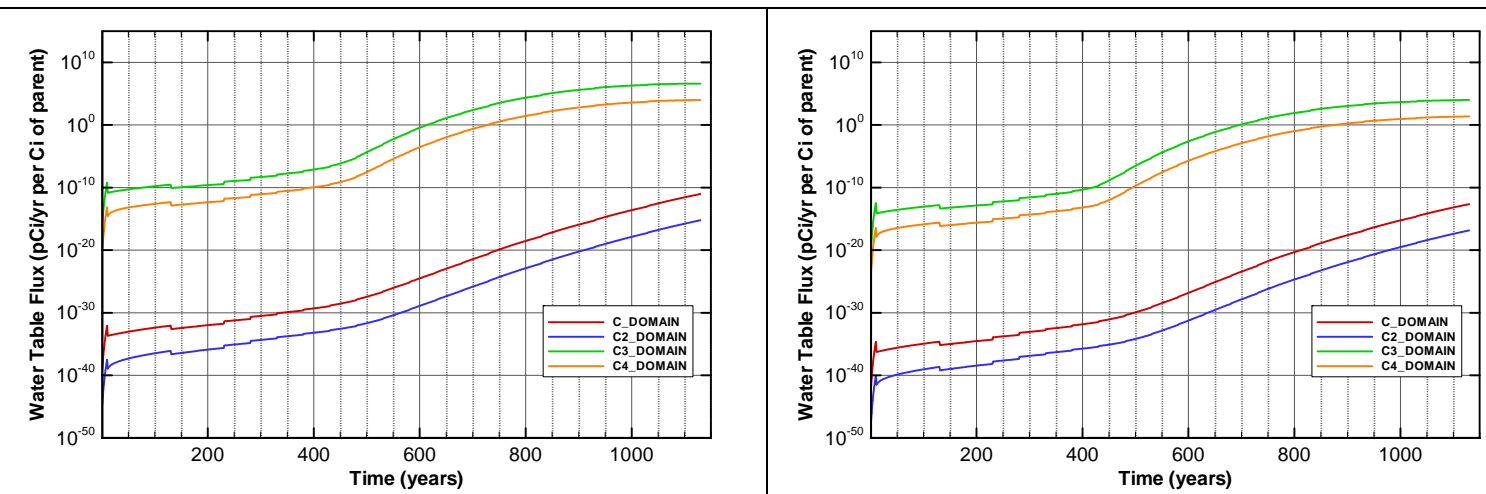

Figure A-651. Flux at water table for Case01_off U-234

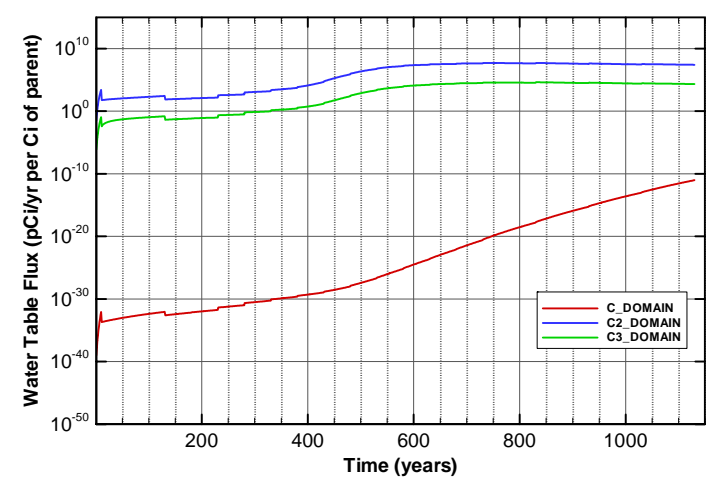

Figure A-653. Flux at water table for Case01_off U-235

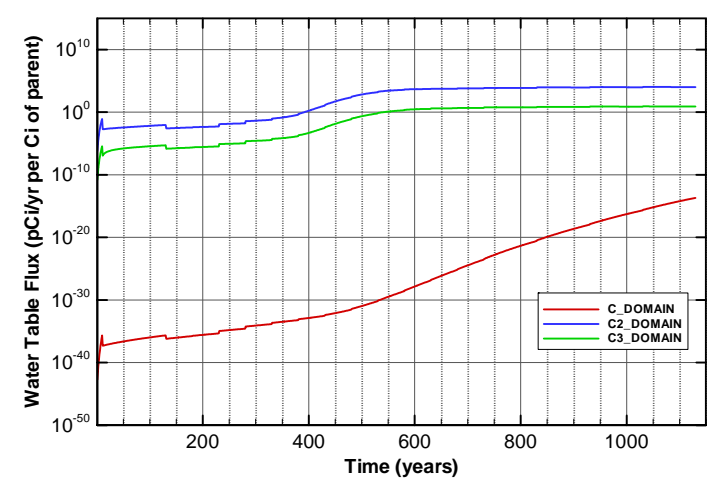

Figure A-655. Flux at water table for Case01_off U-235_Paducah.Cask

Figure A-652. Flux at water table for Case01_off U-234_Mglass

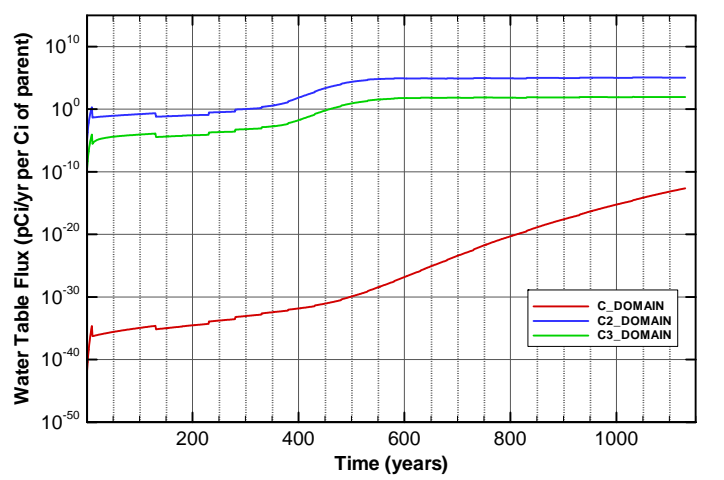

Figure A-654. Flux at water table for Case01_off U-235_Mglass

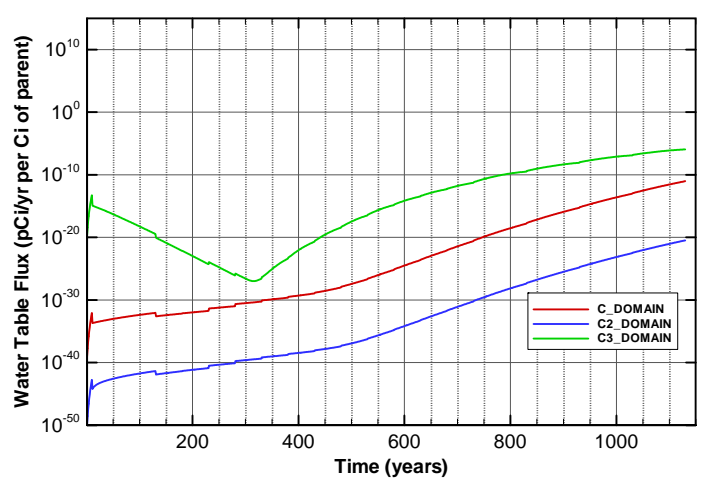

Figure A-656. Flux at water table for Case01_off U-236 
SRNL-STI-2008-00397, REVISION 0
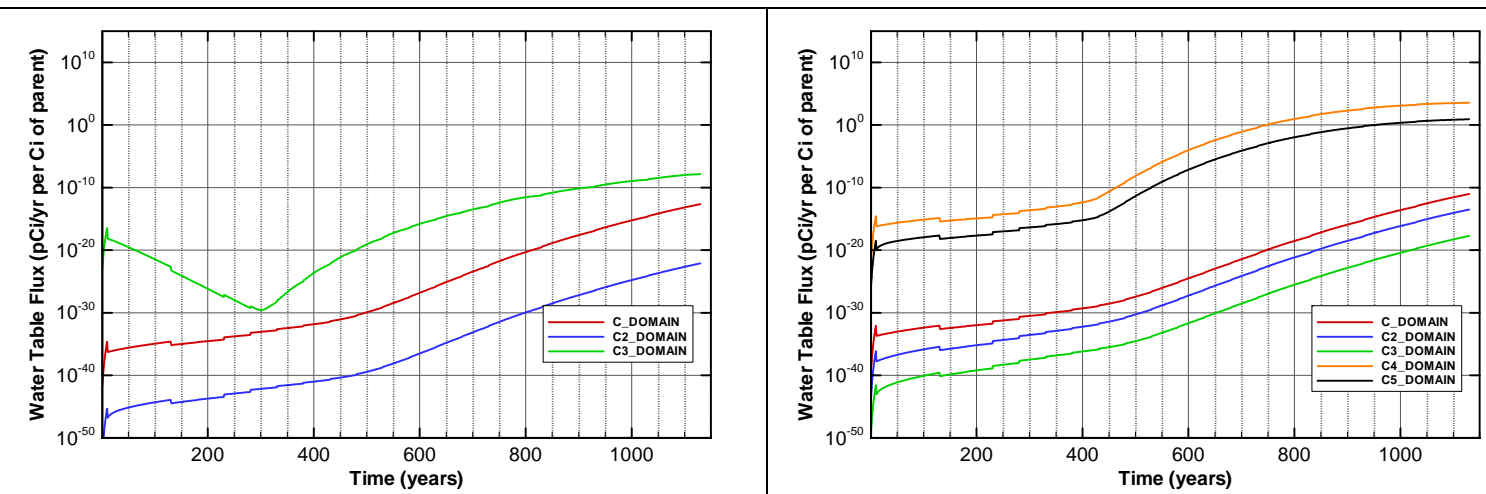

Figure A-657. Flux at water table for Case01_off U-236_Mglass

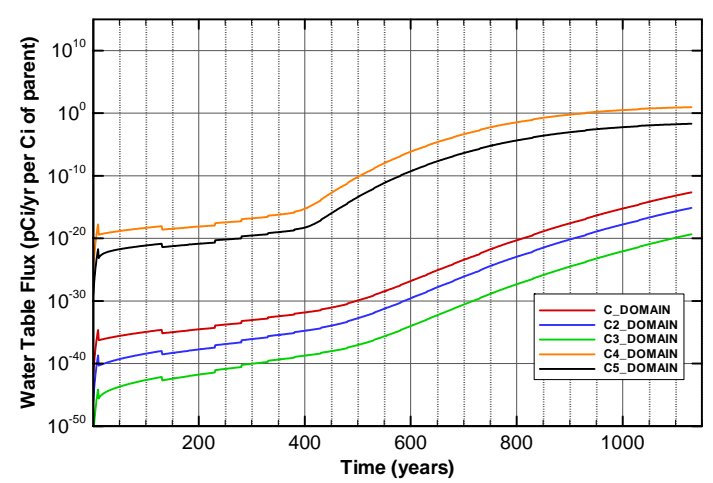

Figure A-659. Flux at water table for Case01_off U-238_Mglass

Figure A-658. Flux at water table for Case01_off U-238

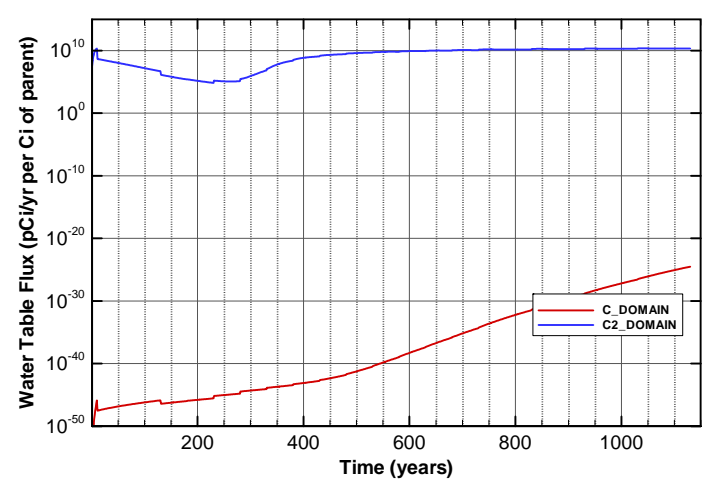

Figure A-660. Flux at water table for Case01_off Zr-93

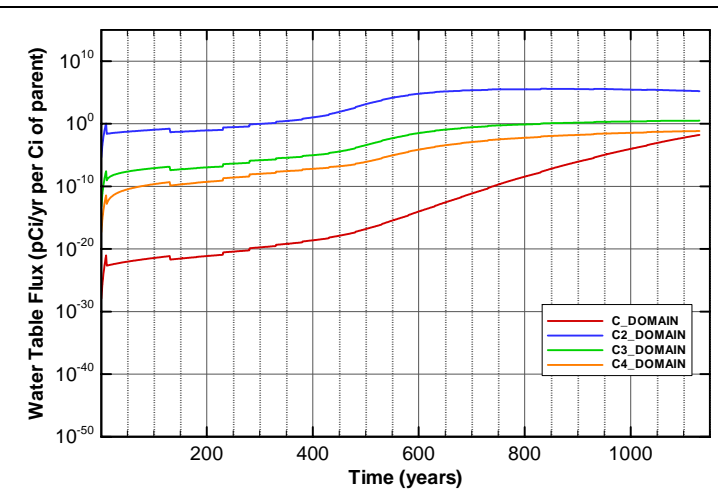

Figure A-661. Flux at water table for Case01_on Am-241

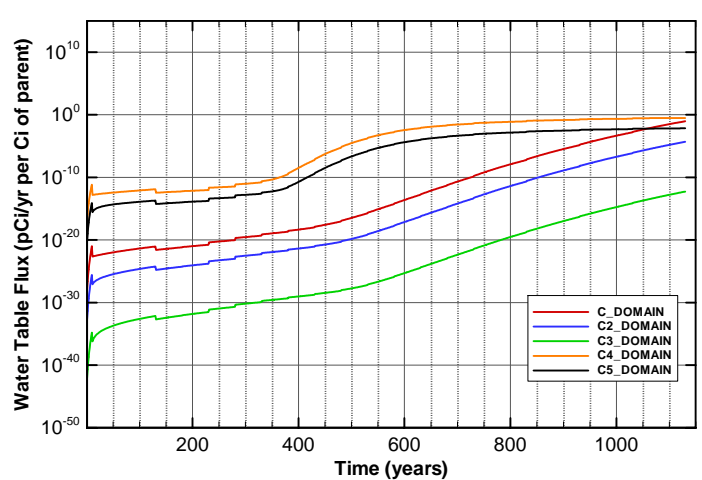

Figure A-662. Flux at water table for Case01_on Am-243 
SRNL-STI-2008-00397, REVISION 0
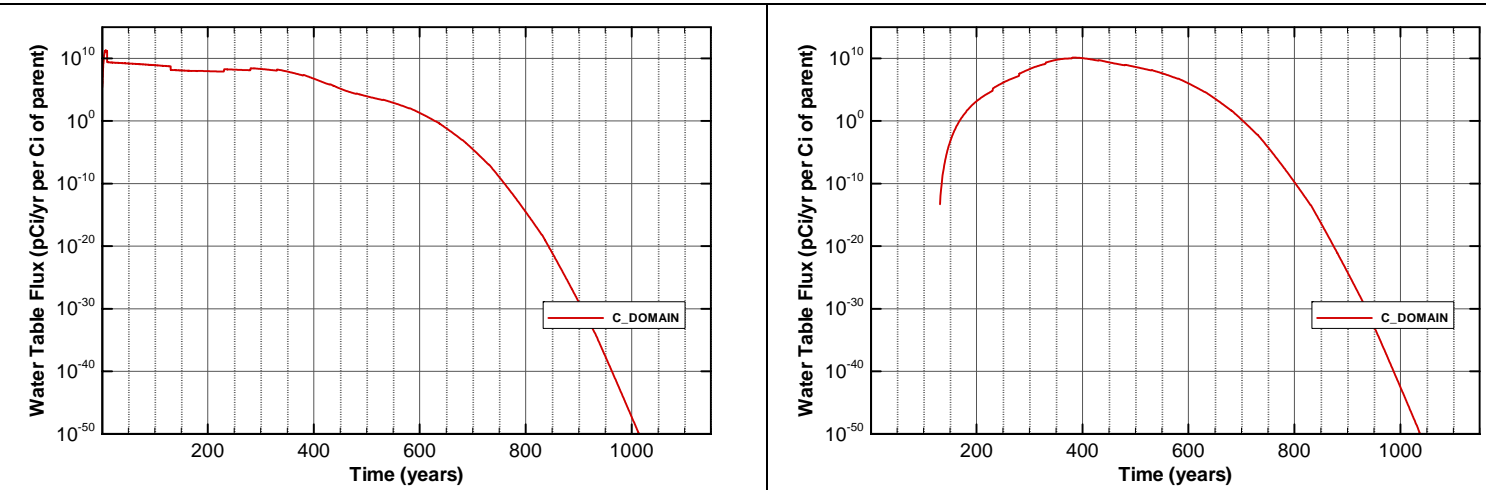

Figure A-663. Flux at water table for Case01_on C-14

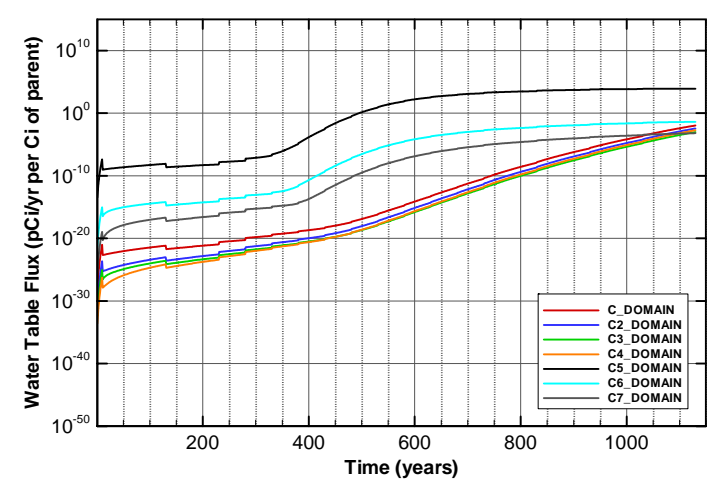

Figure A-665. Flux at water table for Case01_on Cf-249

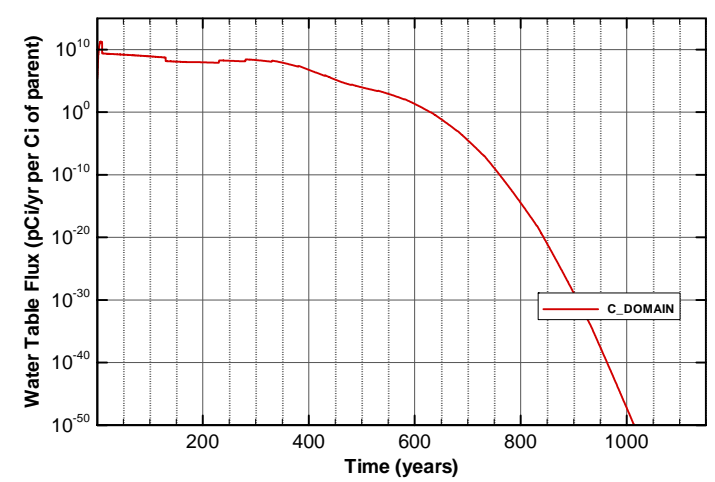

Figure A-667. Flux at water table for Case01_on Cl-36

Figure A-664. Flux at water table for Case01_on C-14_NR.Pump

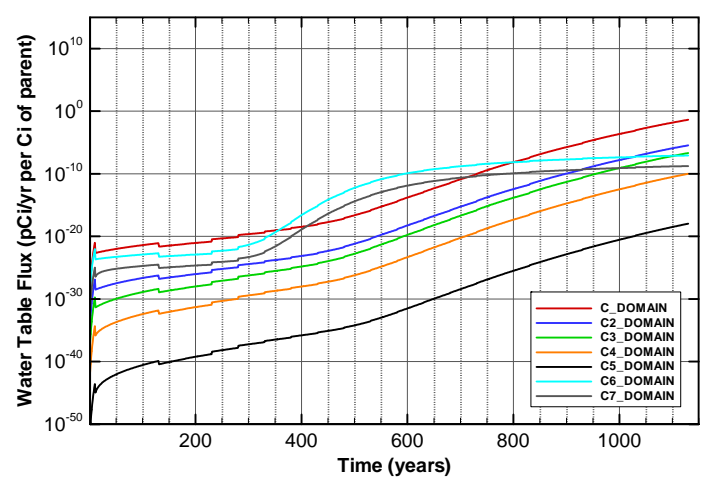

Figure A-666. Flux at water table for Case01_on Cf-251

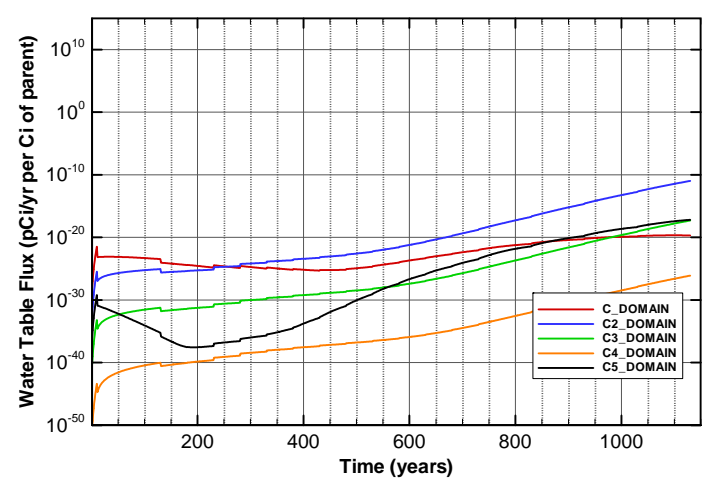

Figure A-668. Flux at water table for Case01_on Cm-244 
SRNL-STI-2008-00397, REVISION 0
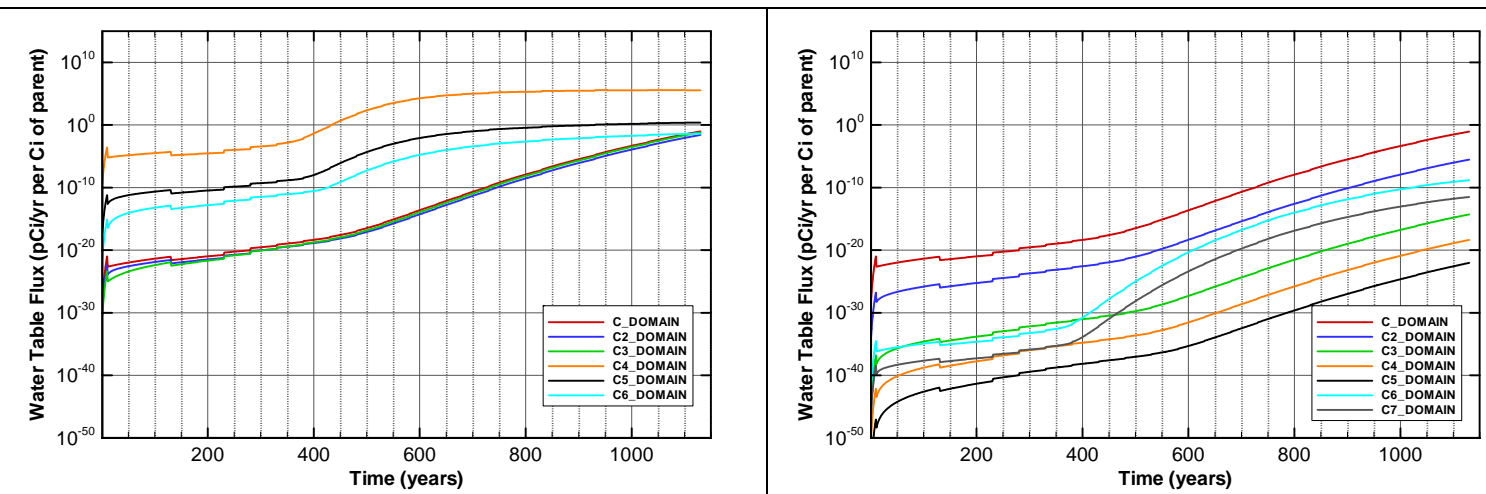

Figure A-669. Flux at water table for Case01_on Cm-245

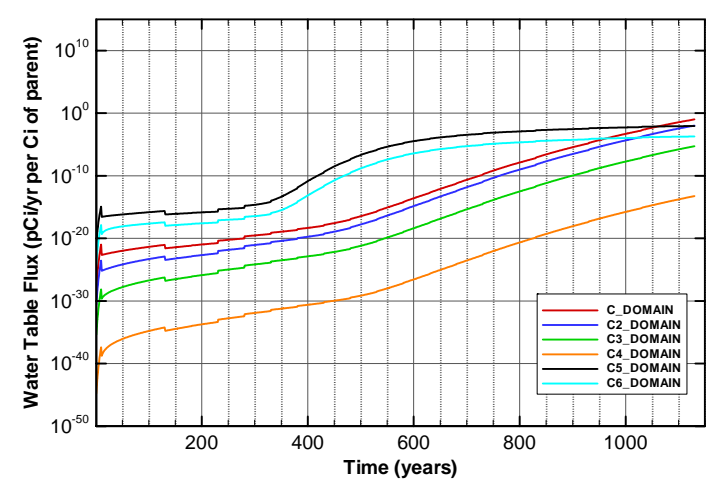

Figure A-671. Flux at water table for Case01_on Cm-247

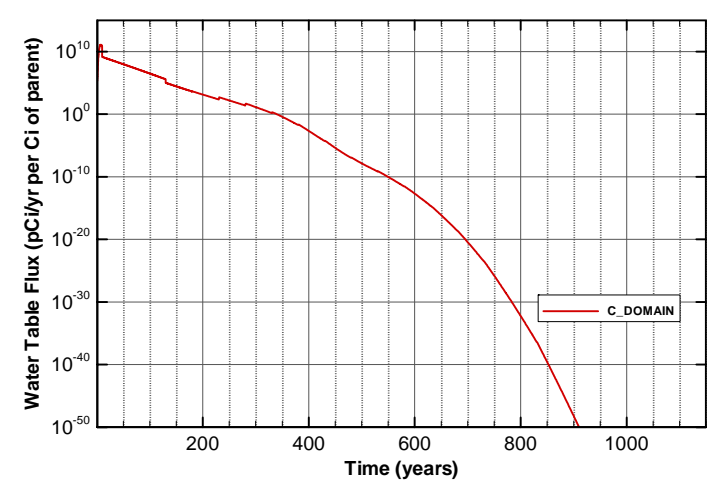

Figure A-673. Flux at water table for Case01_on H-3

Figure A-670. Flux at water table for Case01_on Cm-246

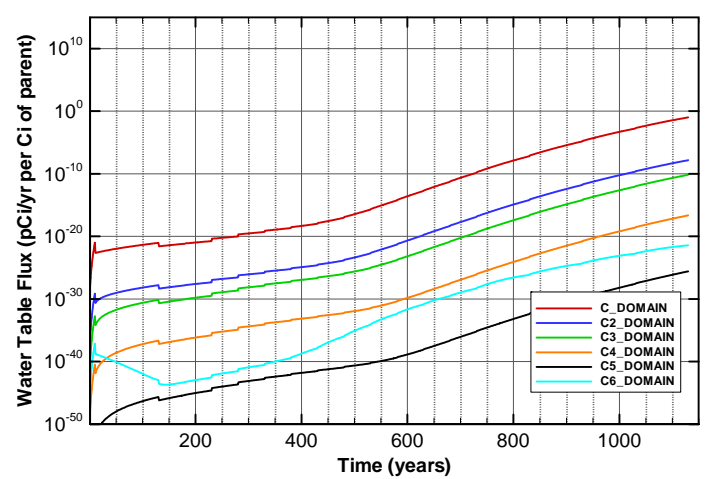

Figure A-672. Flux at water table for Case01_on Cm-248

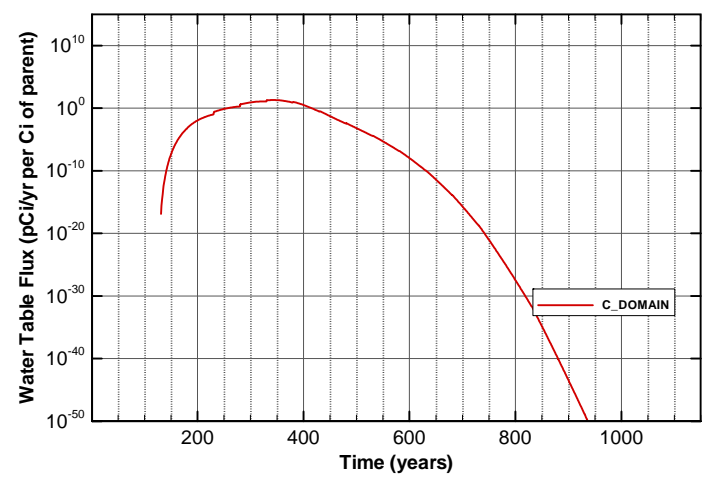

Figure A-674. Flux at water table for Case01_on H-3_ETF.Carbon 


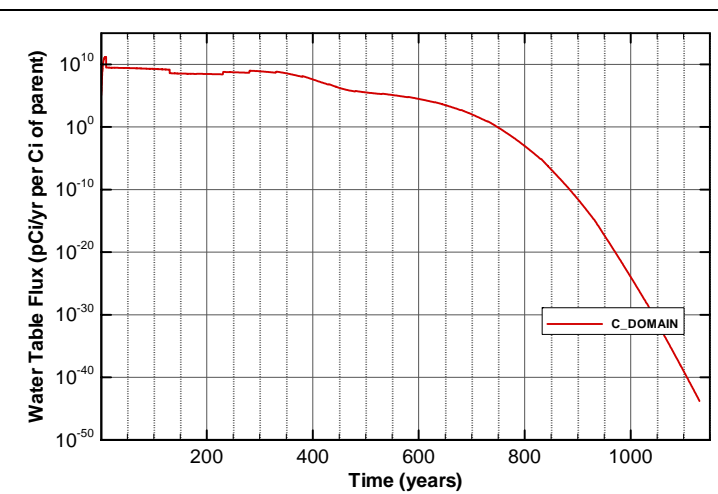

Figure A-675. Flux at water table for Case01_on I-129

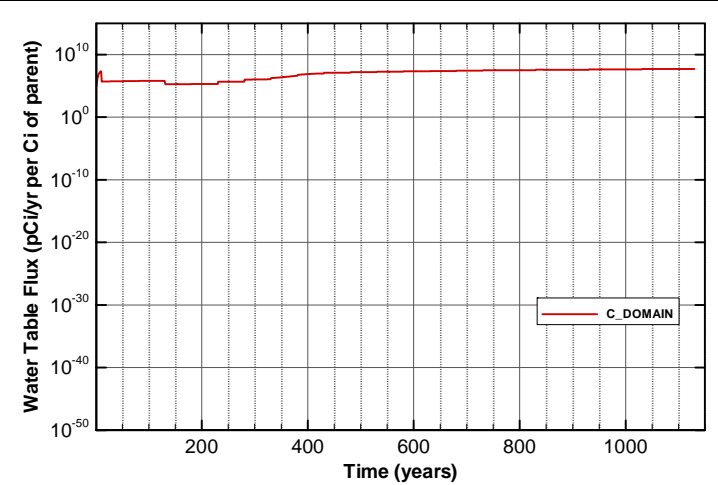

Figure A-677. Flux at water table for Case01_on I-129_ETF.GT.73

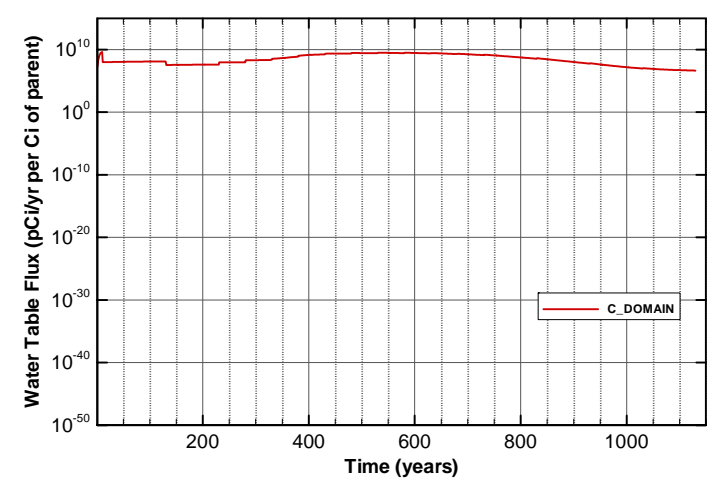

Figure A-679. Flux at water table for Case01_on I-129_F.CG.8

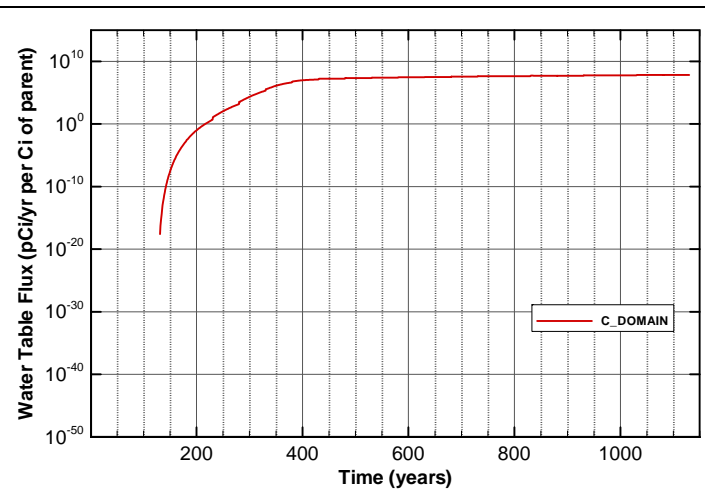

Figure A-676. Flux at water table for Case01_on I-129_ETF.Carbon

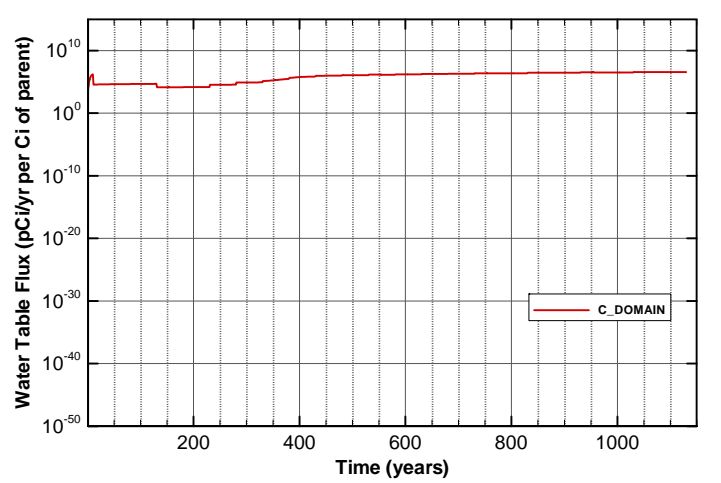

Figure A-678. Flux at water table for Case01_on I-129_F.Carbon

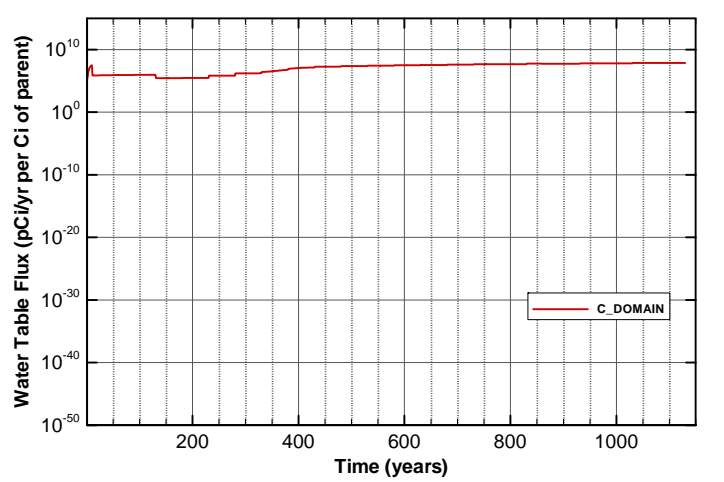

Figure A-680. Flux at water table for Case01_on I-129_F.Dowex.21K 


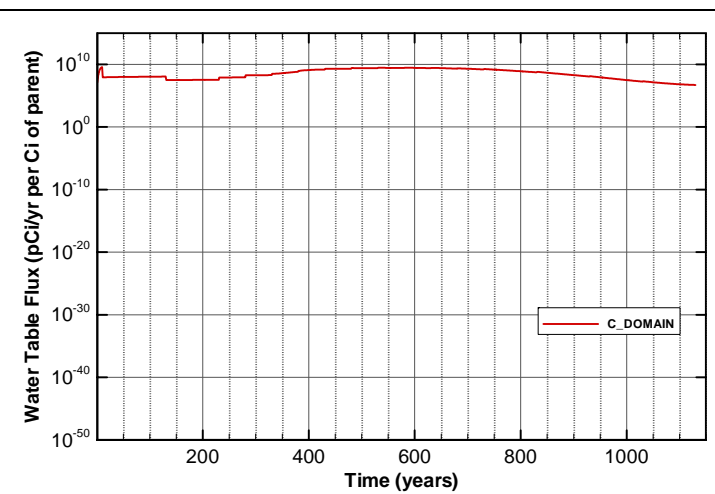

Figure A-681. Flux at water table for Case01_on I-129_F.Filtercake

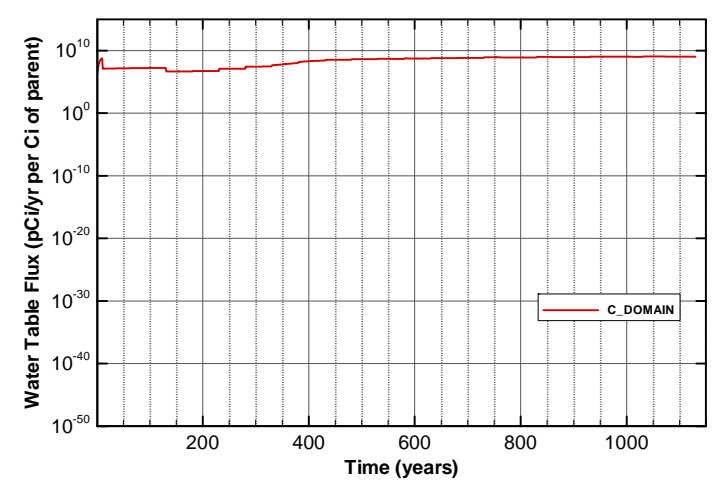

Figure A-683. Flux at water table for Case01_on I-129_H.CG.8

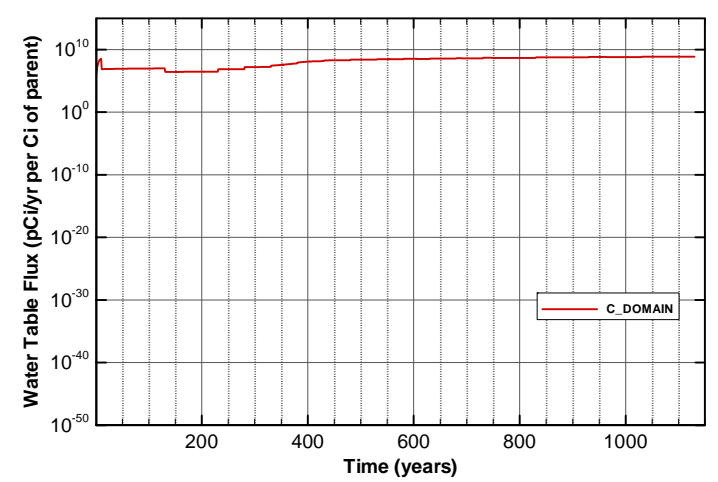

Figure A-685. Flux at water table for Case01_on I-129_H.Filtercake

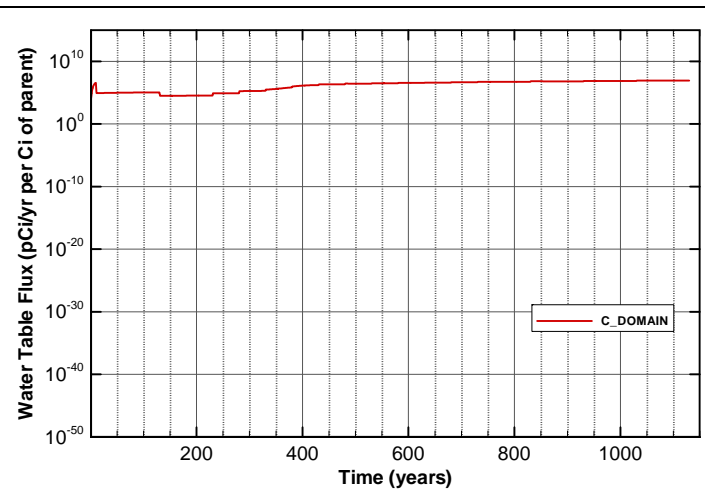

Figure A-682. Flux at water table for Case01_on I-129_H.Carbon

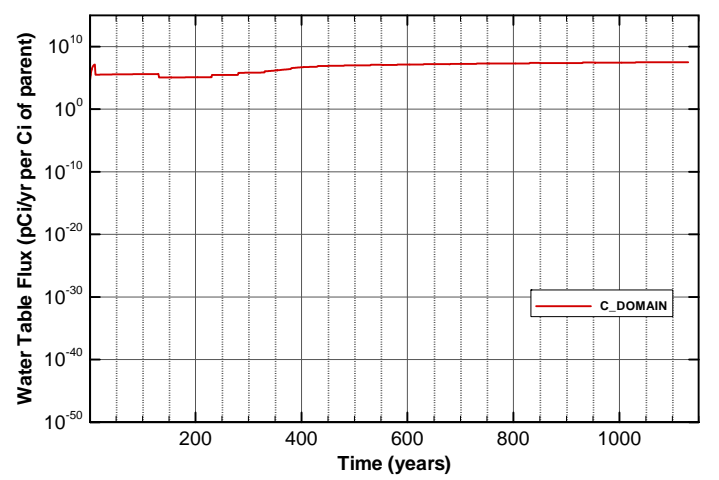

Figure A-684. Flux at water table for Case01_on I-129_H.Dowex.21K

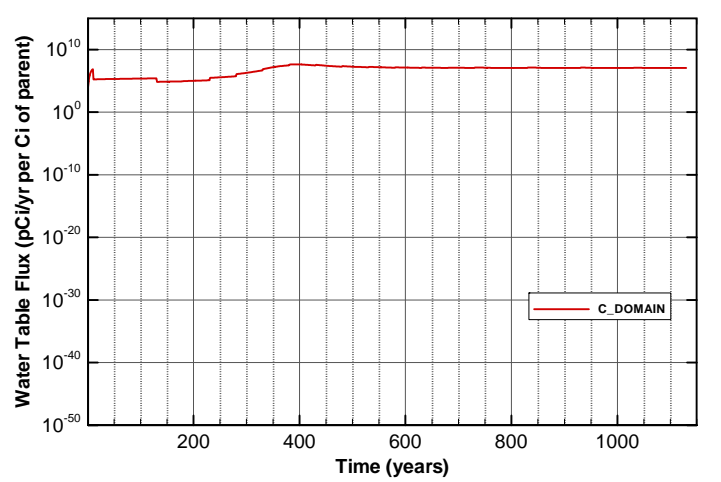

Figure A-686. Flux at water table for Case01_on I-129_Mk50A 


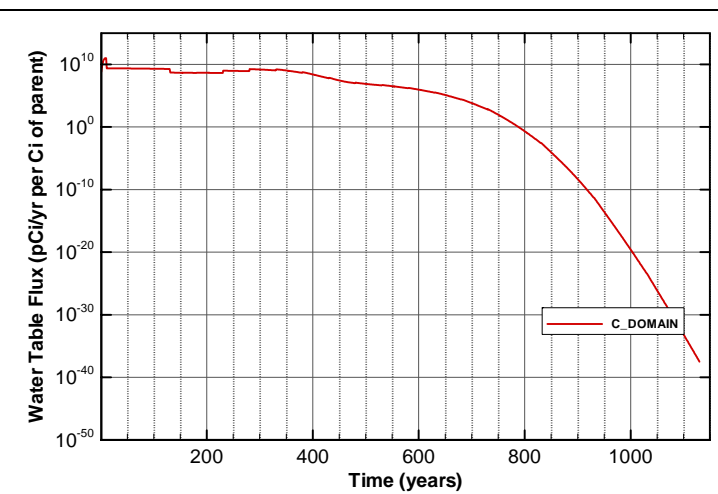

Figure A-687. Flux at water table for Case01_on K-40

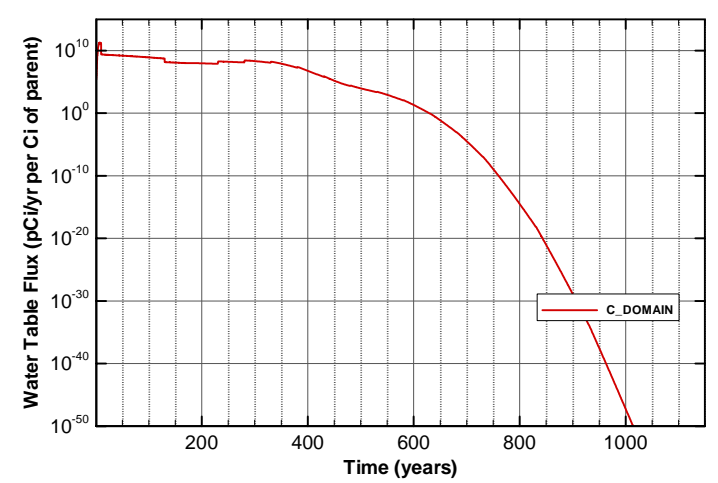

Figure A-689. Flux at water table for Case01_on Nb-94

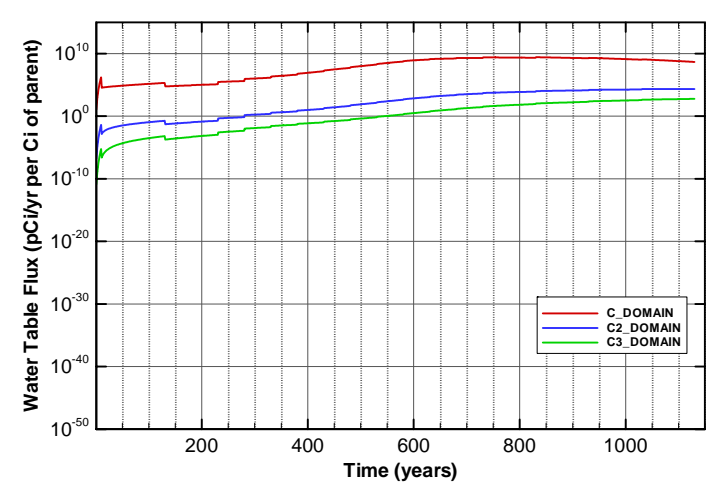

Figure A-691. Flux at water table for Case01_on Np-237

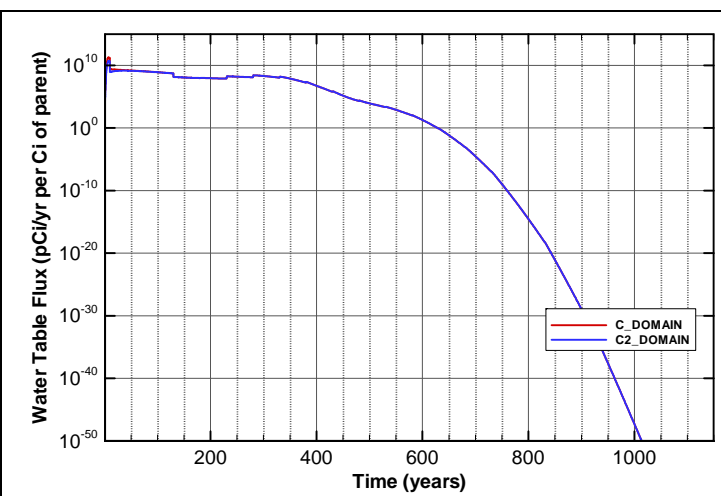

Figure A-688. Flux at water table for Case01_on Mo-93

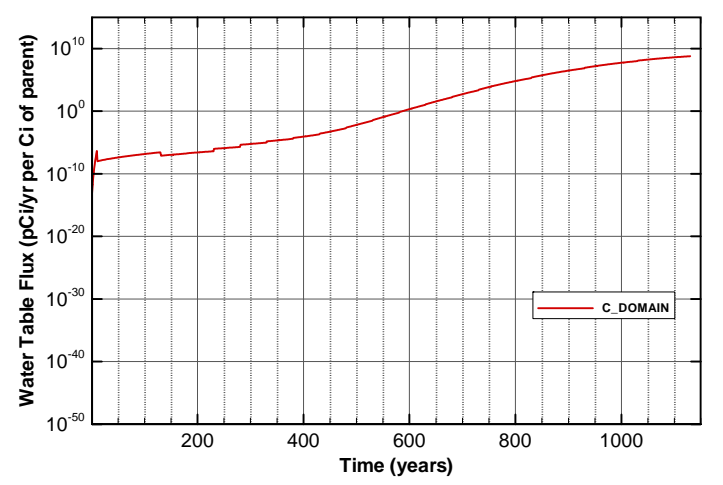

Figure A-690. Flux at water table for Case01_on Ni-59

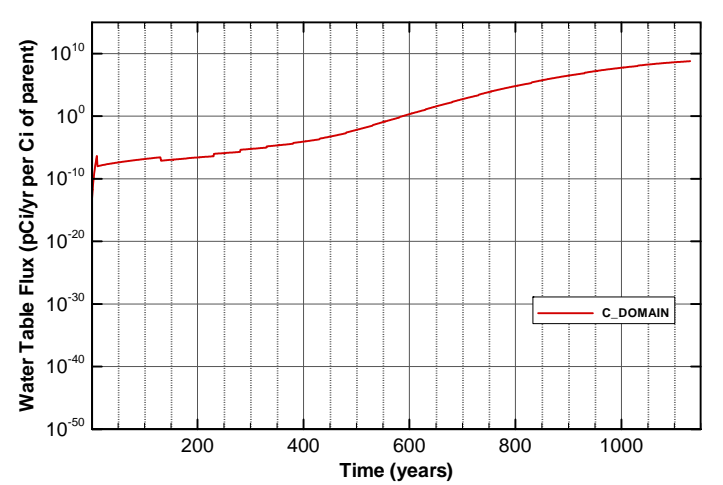

Figure A-692. Flux at water table for Case01_on Pd-107 
SRNL-STI-2008-00397, REVISION 0
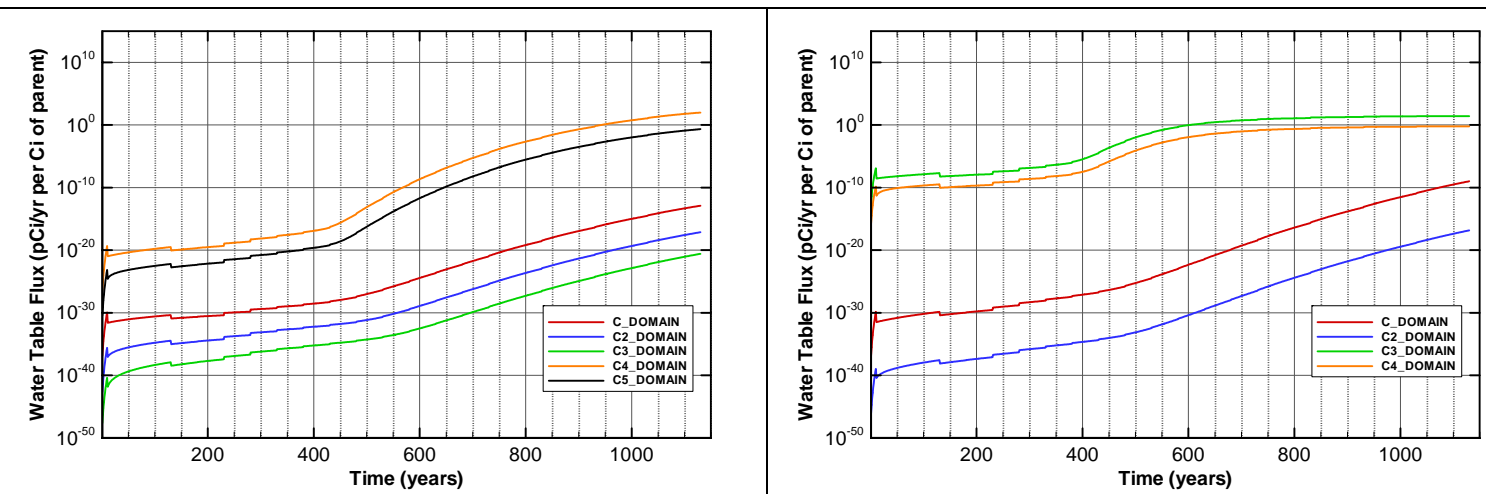

Figure A-693. Flux at water table for

Case01_on Pu-238

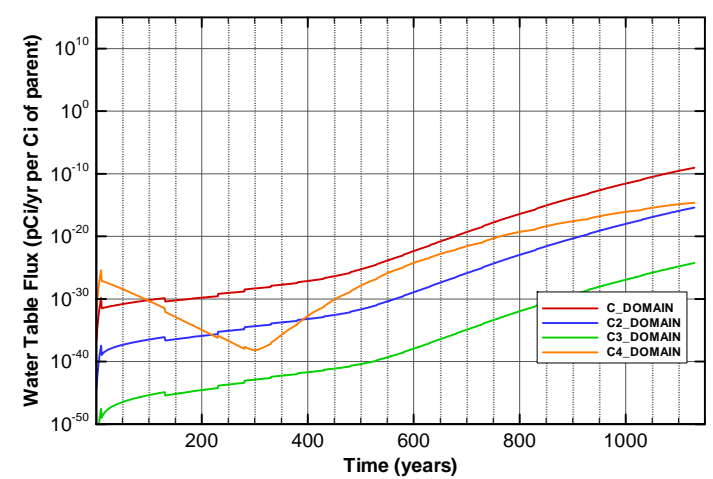

Figure A-695. Flux at water table for Case01_on Pu-240

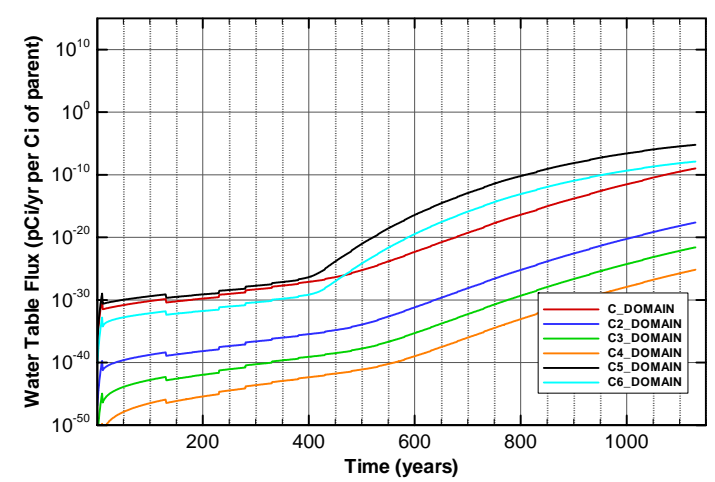

Figure A-697. Flux at water table for Case01_on Pu-242

Figure A-694. Flux at water table for Case01_on Pu-239

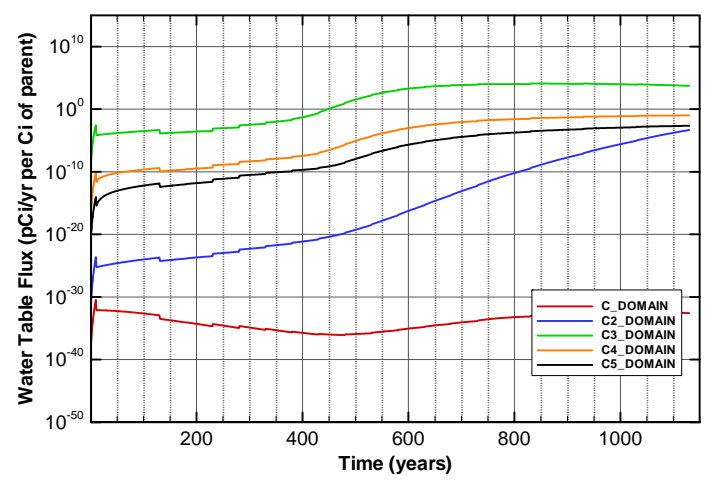

Figure A-696. Flux at water table for Case01_on Pu-241

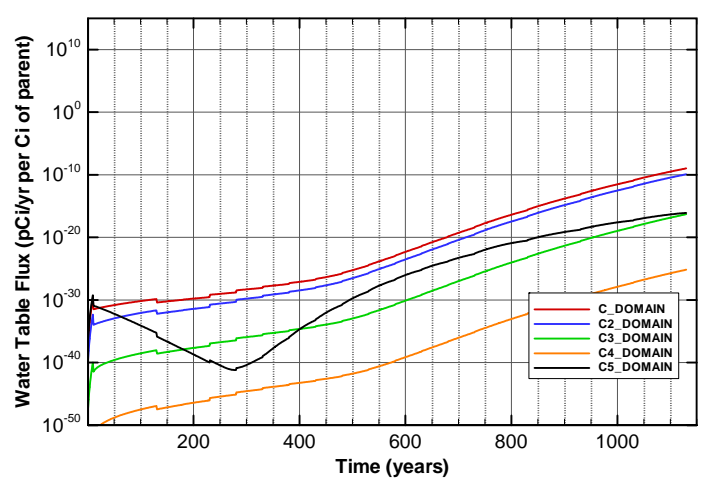

Figure A-698. Flux at water table for Case01_on Pu-244 
SRNL-STI-2008-00397, REVISION 0

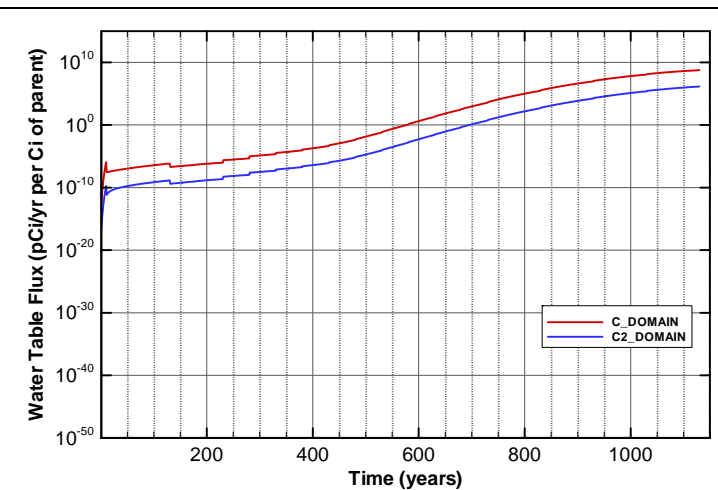

Figure A-699. Flux at water table for Case01_on Ra-226

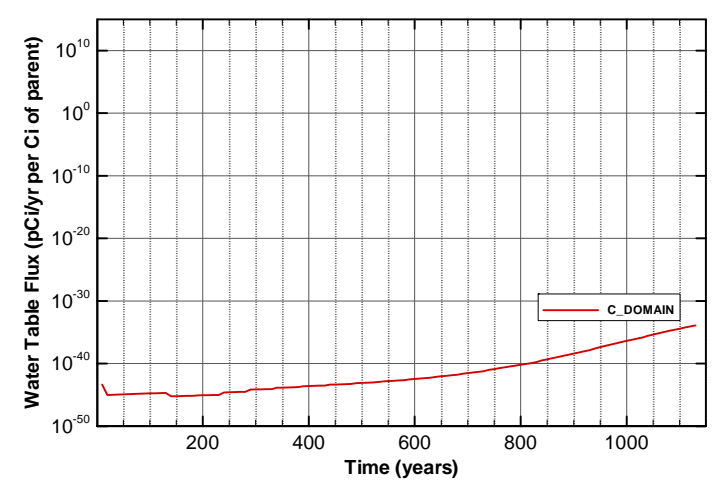

Figure A-701. Flux at water table for Case01_on Sn-126

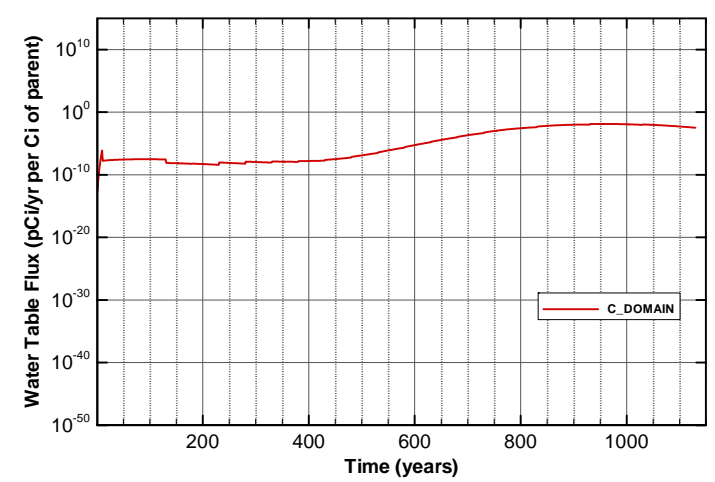

Figure A-703. Flux at water table for Case01_on Sr-90_Cask

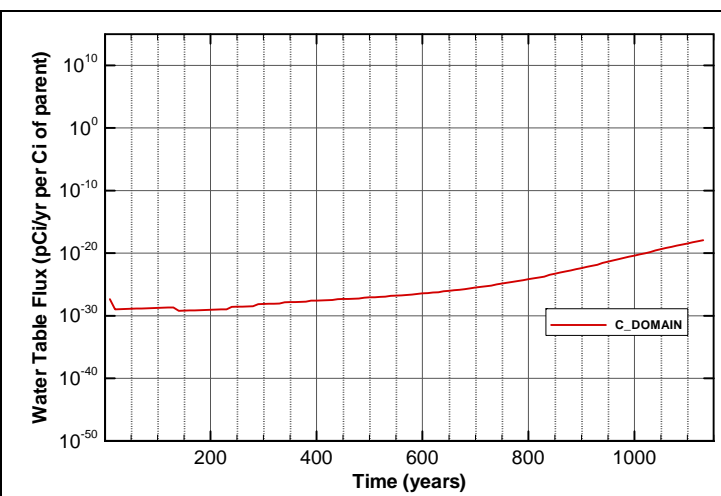

Figure A-700. Flux at water table for Case01_on Se-79

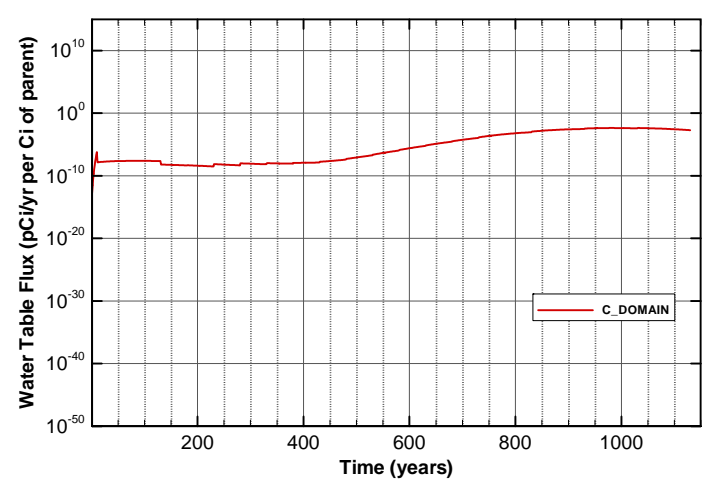

Figure A-702. Flux at water table for Case01_on Sr-90

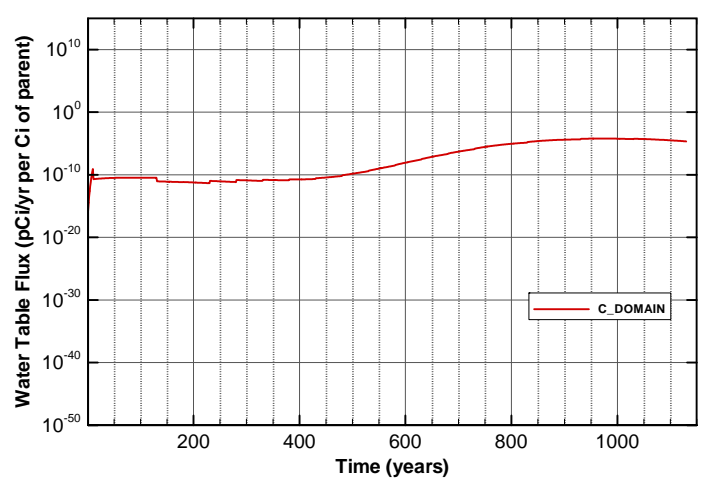

Figure A-704. Flux at water table for Case01_on Sr-90_Mk50A 


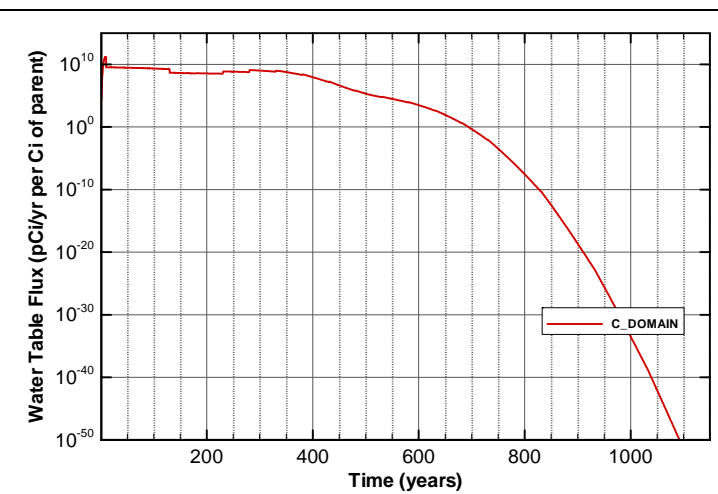

Figure A-705. Flux at water table for Case01_on Tc-99

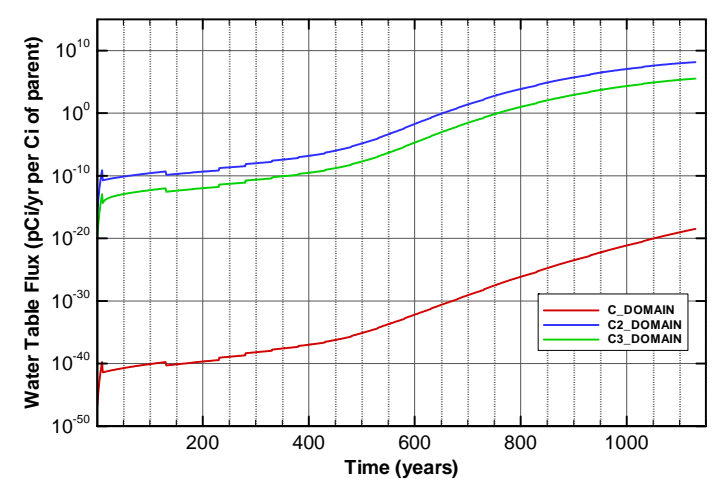

Figure A-707. Flux at water table for Case01_on Th-230

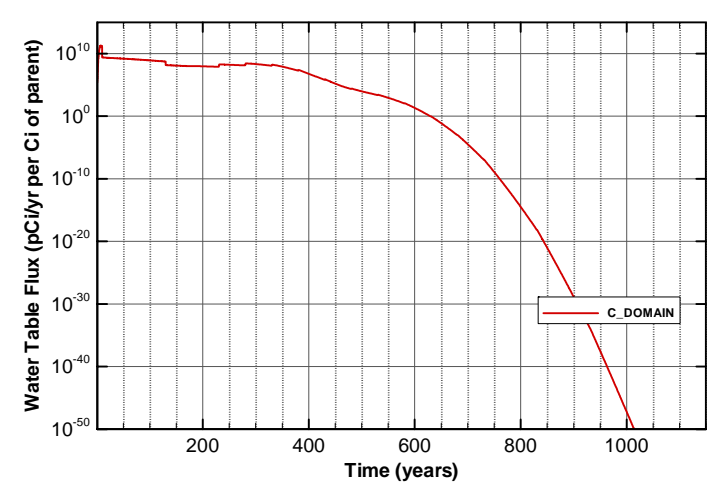

Figure A-709. Flux at water table for Case01_on Tracer

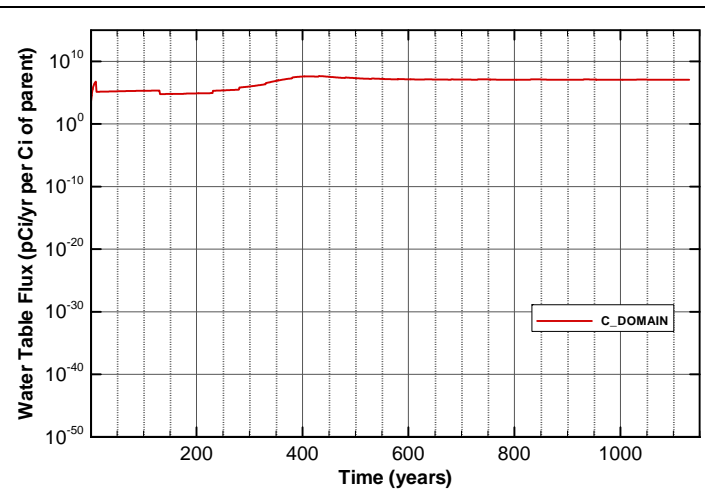

Figure A-706. Flux at water table for Case01_on Tc-99_Mk50A

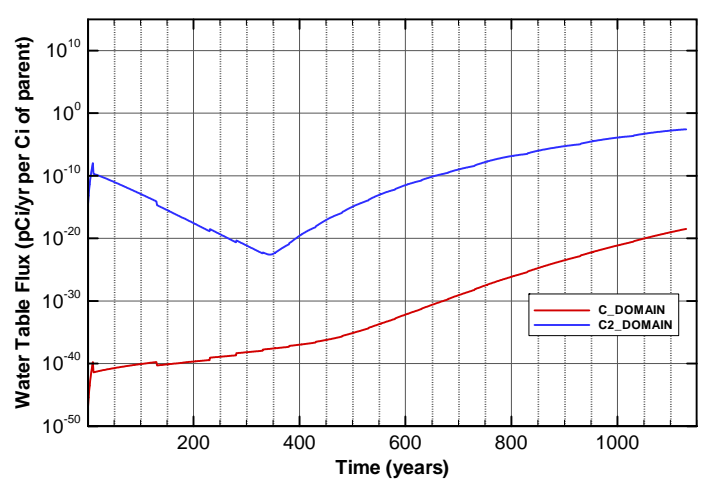

Figure A-708. Flux at water table for Case01_on Th-232

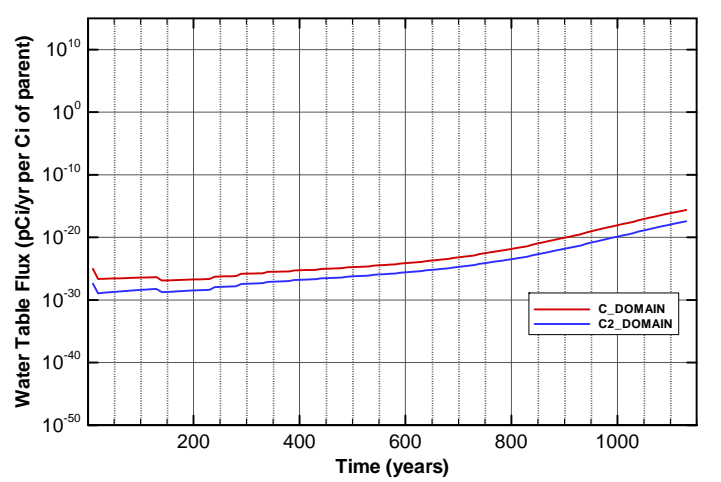

Figure A-710. Flux at water table for Case01_on U-233 
SRNL-STI-2008-00397, REVISION 0
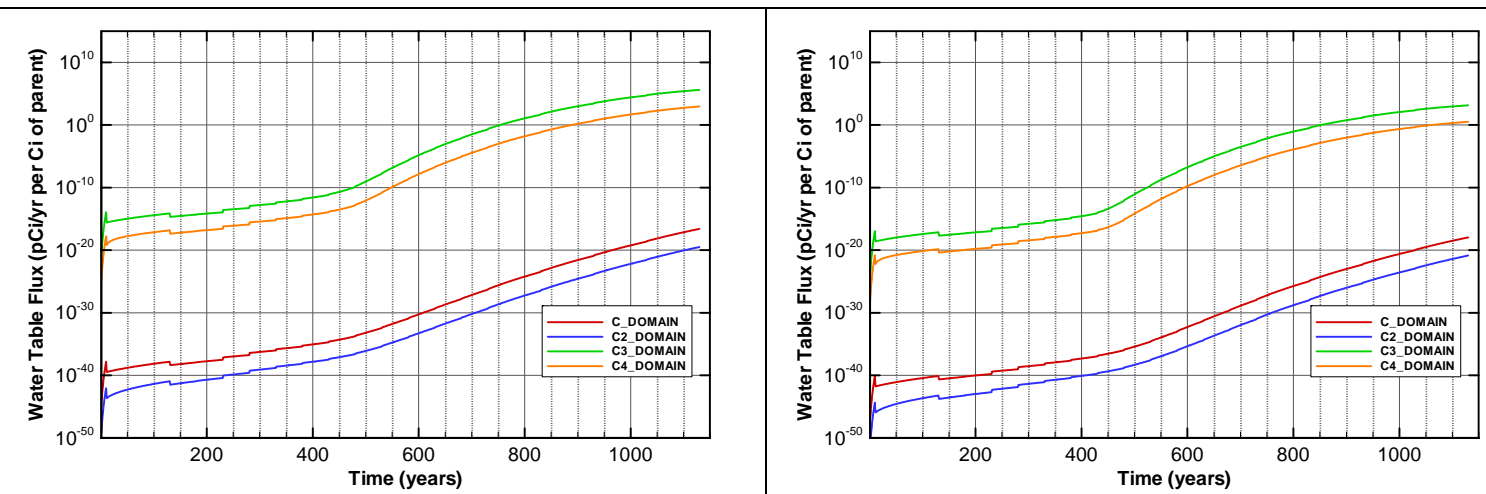

Figure A-711. Flux at water table for Case01_on U-234

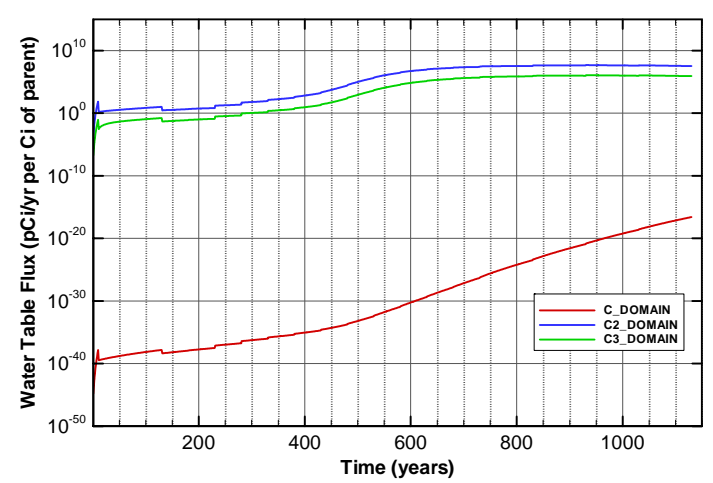

Figure A-713. Flux at water table for Case01_on U-235

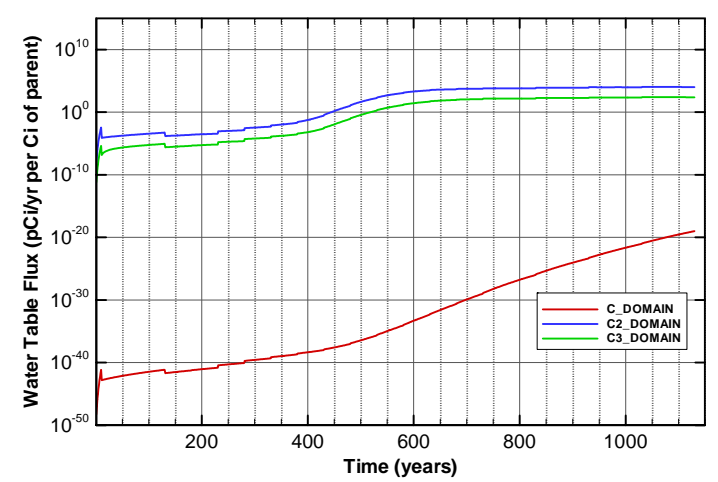

Figure A-715. Flux at water table for Case01_on U-235_Paducah.Cask

Figure A-712. Flux at water table for Case01_on U-234_Mglass

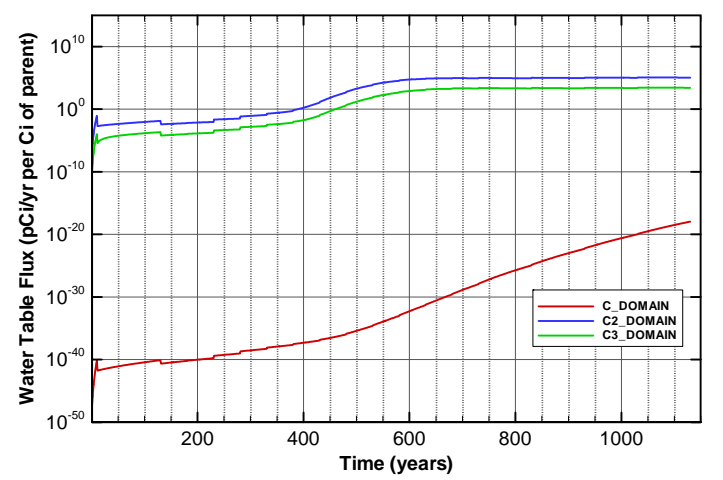

Figure A-714. Flux at water table for Case01_on U-235_Mglass

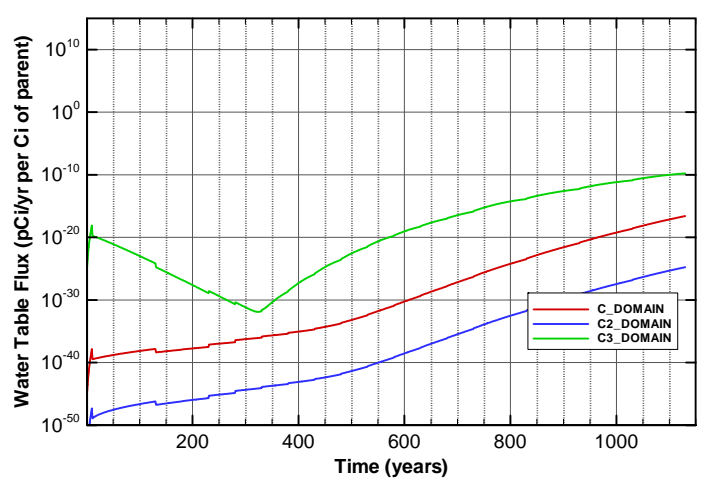

Figure A-716. Flux at water table for Case01_on U-236 
SRNL-STI-2008-00397, REVISION 0

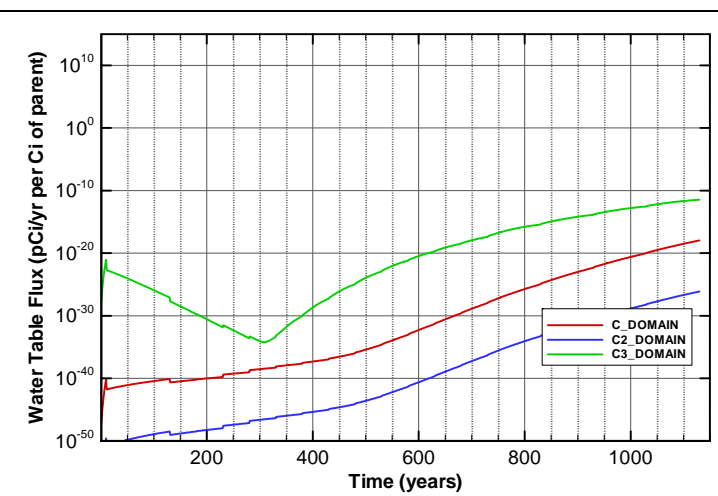

Figure A-717. Flux at water table for Case01_on U-236_Mglass

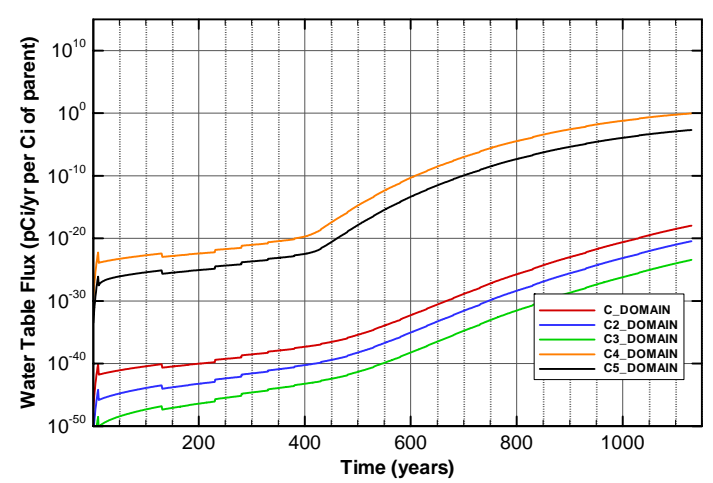

Figure A-719. Flux at water table for Case01_on U-238_Mglass

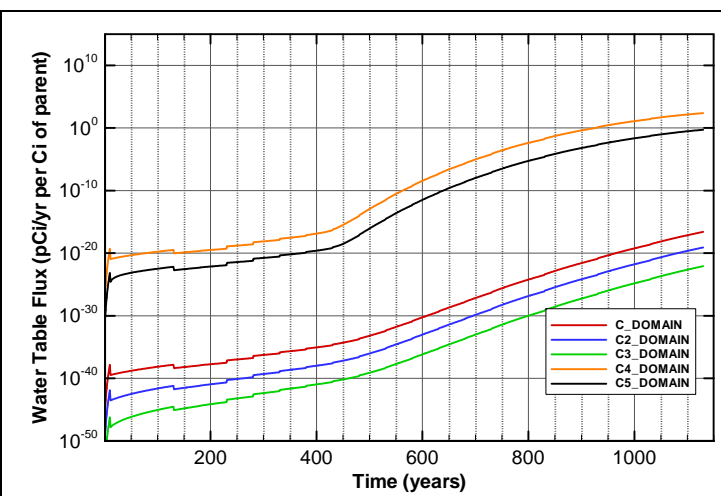

Figure A-718. Flux at water table for Case01_on U-238

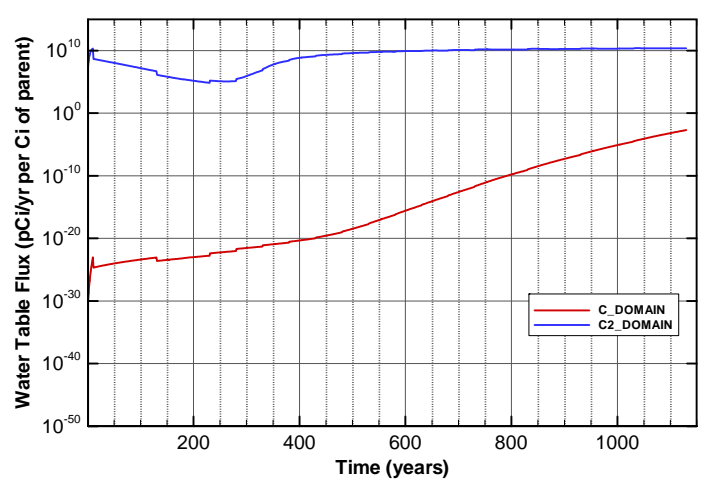

Figure A-720. Flux at water table for Case01_on Zr-93

\subsubsection{Edge trench flux plots for 15 -year cover}

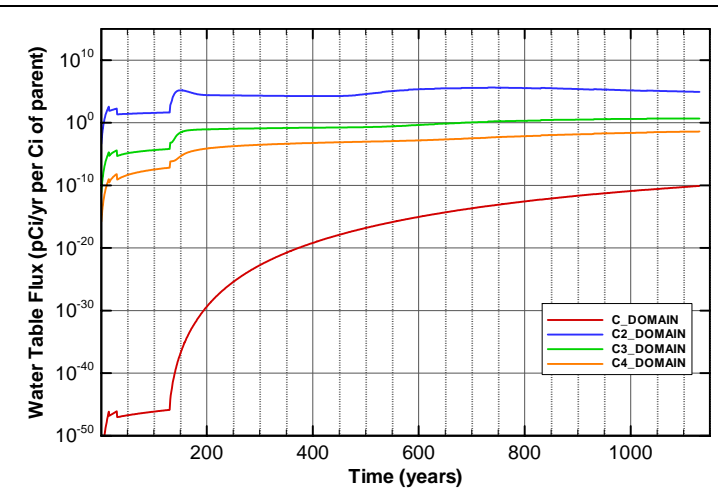

Figure A-721. Flux at water table for Case01n11_off Am-241

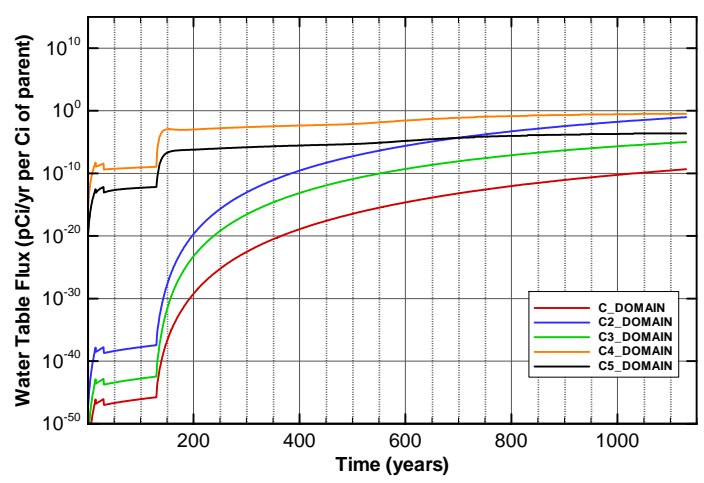

Figure A-722. Flux at water table for Case01n11_off Am-243 
SRNL-STI-2008-00397, REVISION 0
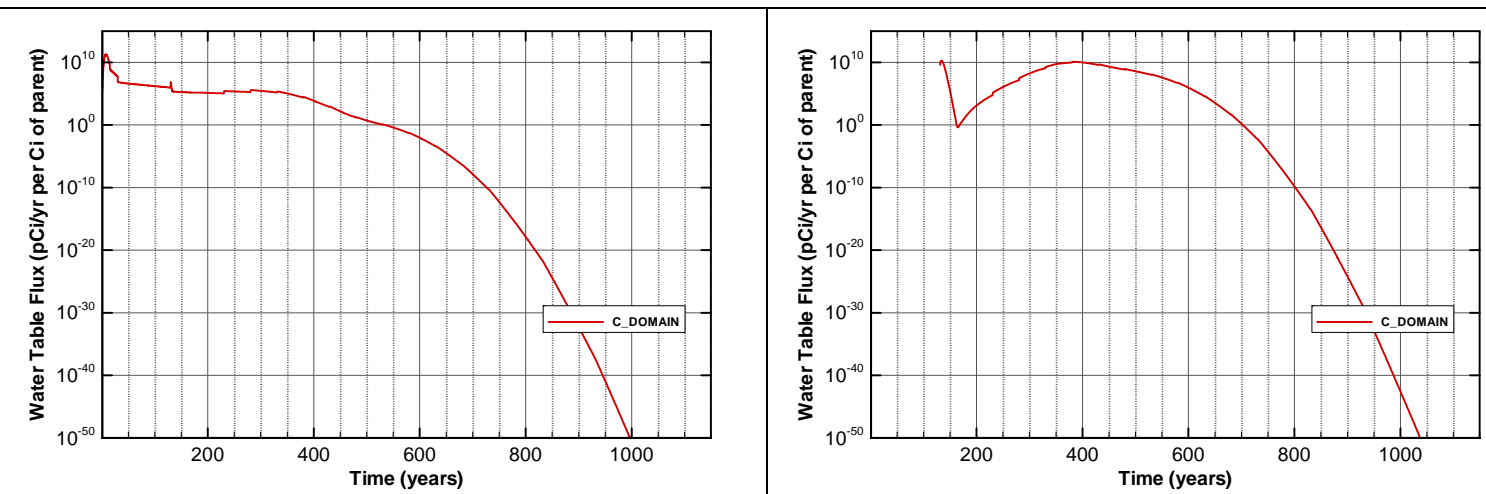

Figure A-723. Flux at water table for Case01n11_off C-14

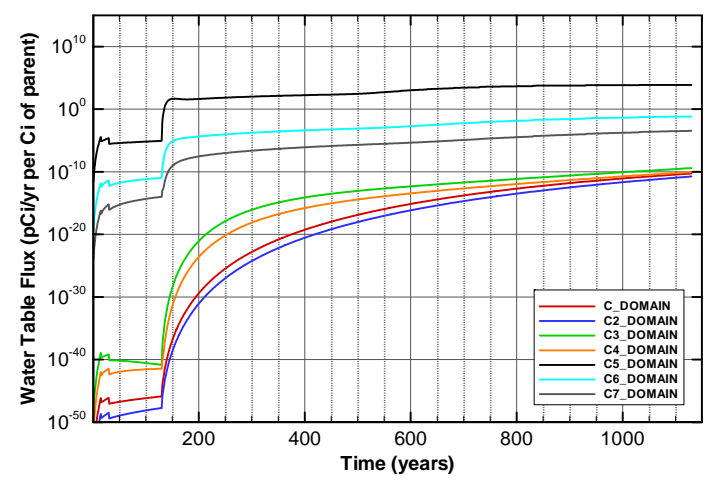

Figure A-725. Flux at water table for Case01n11_off Cf-249

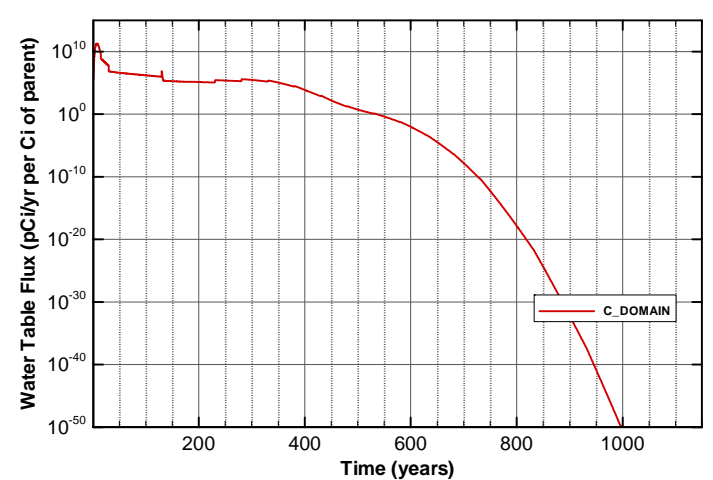

Figure A-727. Flux at water table for Case01n11_off Cl-36

Figure A-724. Flux at water table for Case01n11_off C-14_NR.Pump

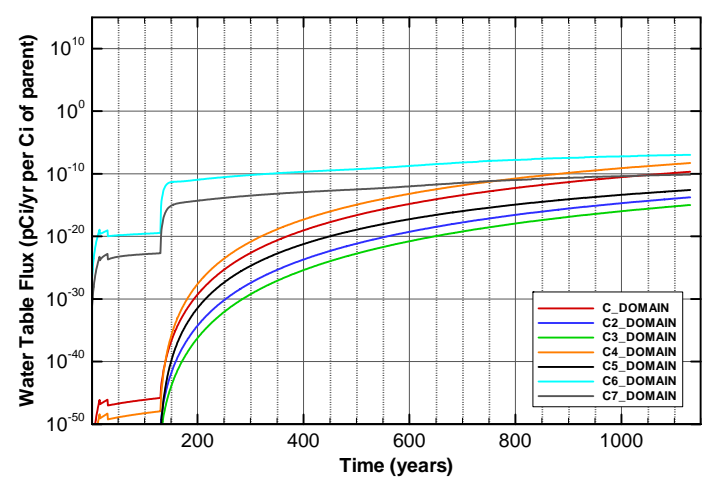

Figure A-726. Flux at water table for Case01n11_off Cf-251

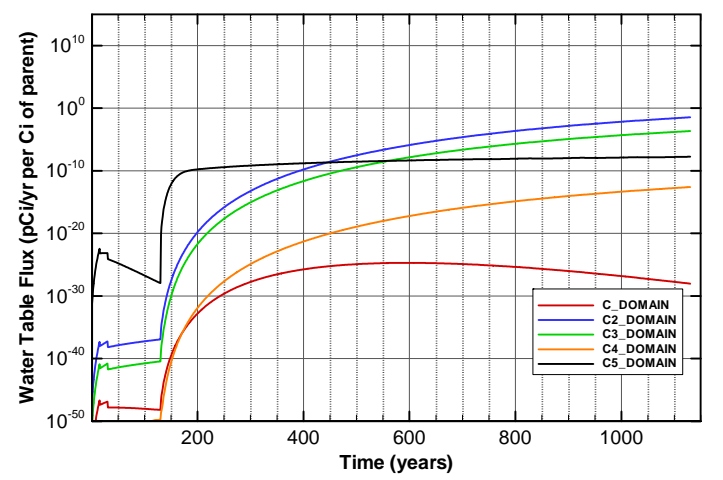

Figure A-728. Flux at water table for Case01n11_off Cm-244 
SRNL-STI-2008-00397, REVISION 0
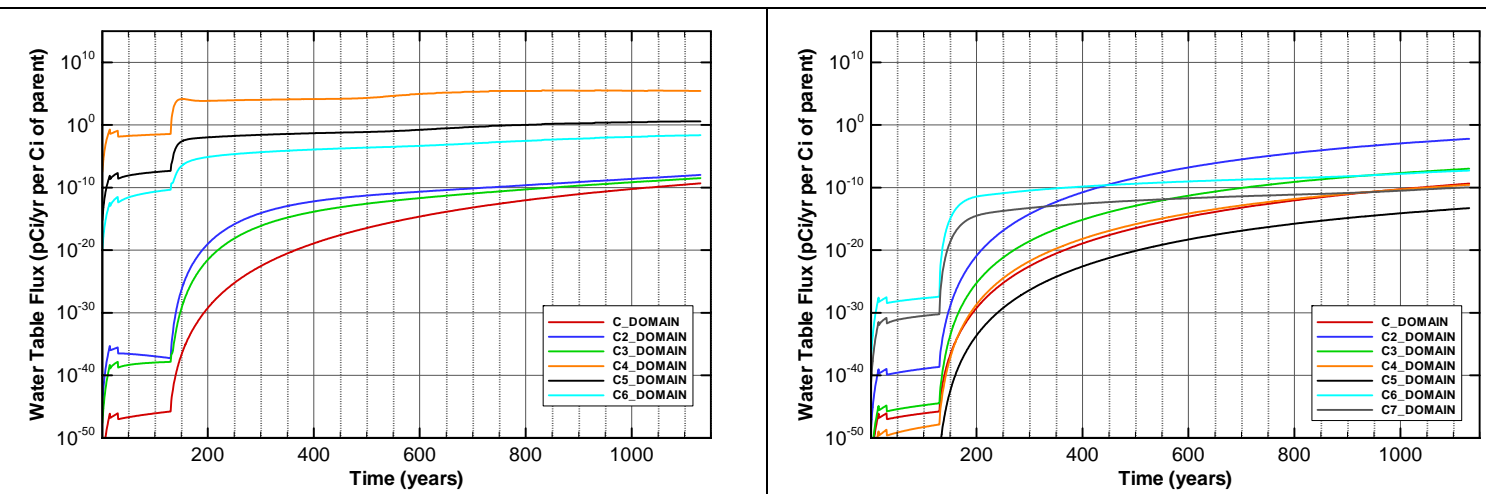

Figure A-729. Flux at water table for Case01n11_off Cm-245

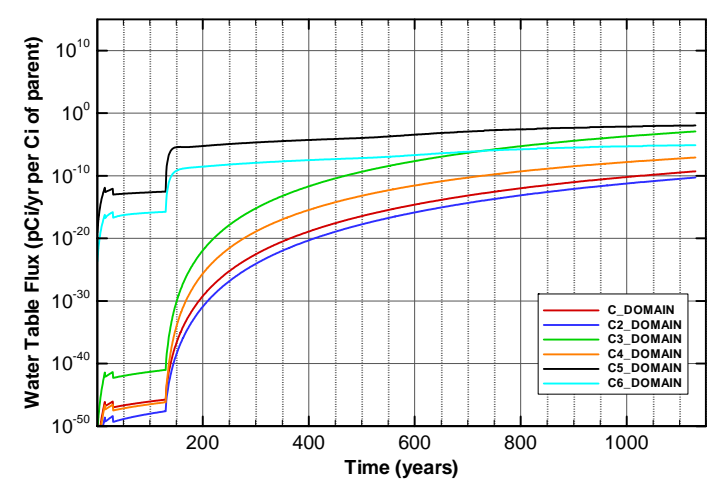

Figure A-731. Flux at water table for Case01n11_off Cm-247

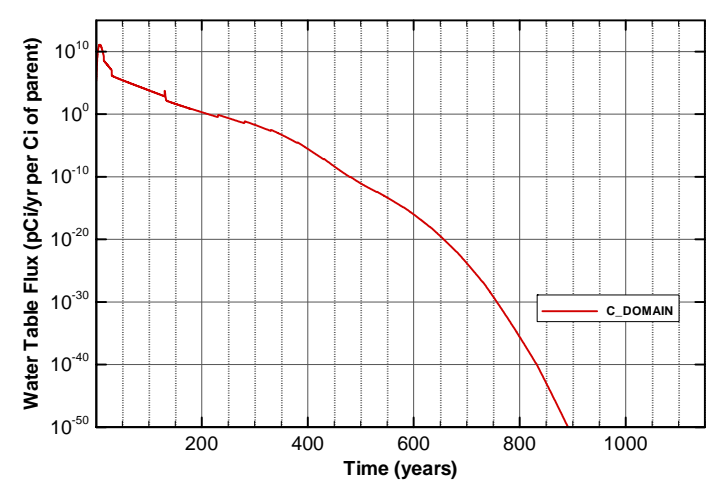

Figure A-733. Flux at water table for Case01n11_off H-3

Figure A-730. Flux at water table for Case01n11_off Cm-246

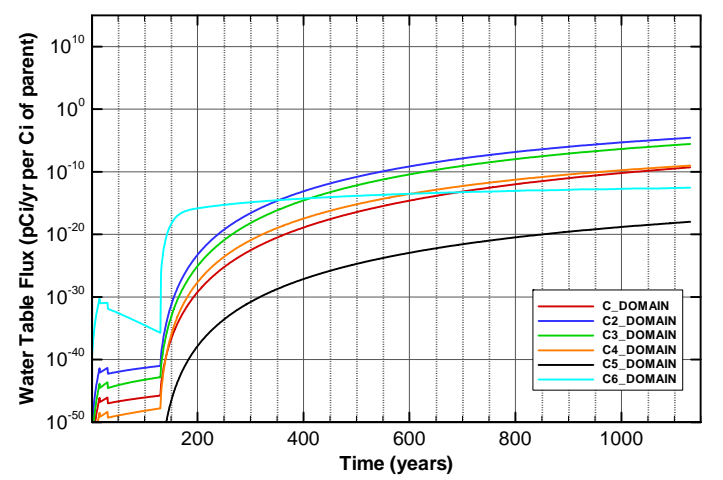

Figure A-732. Flux at water table for Case01n11_off Cm-248

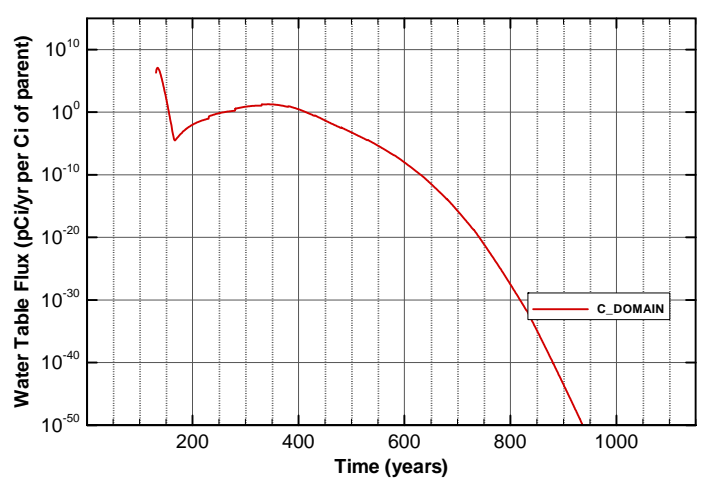

Figure A-734. Flux at water table for Case01n11_off H-3_ETF.Carbon 


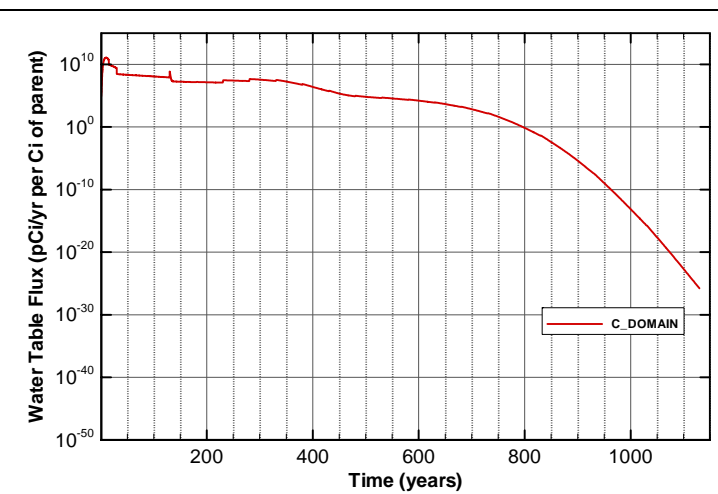

Figure A-735. Flux at water table for Case01n11_off I-129

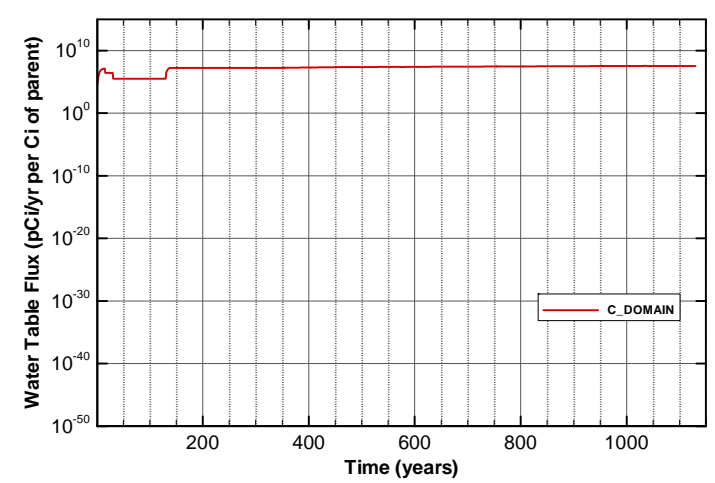

Figure A-737. Flux at water table for Case01n11_off I-129_ETF.GT.73

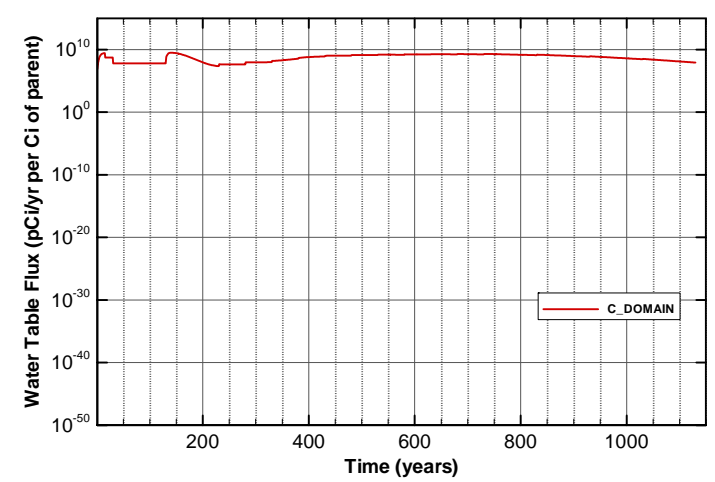

Figure A-739. Flux at water table for Case01n11_off I-129_F.CG.8

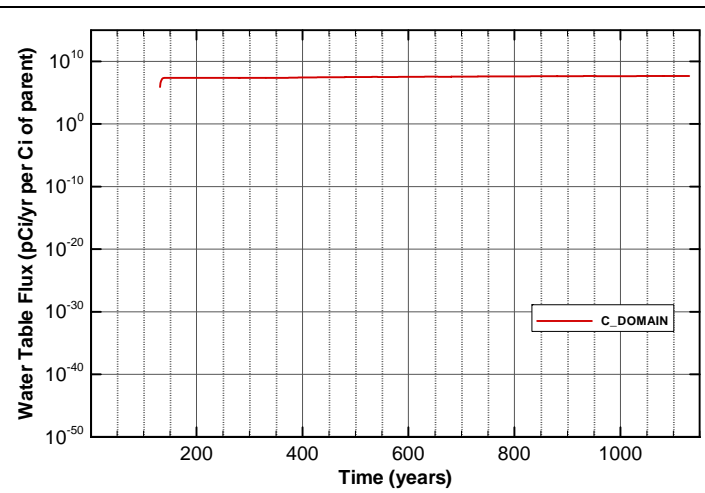

Figure A-736. Flux at water table for Case01n11_off I-129_ETF.Carbon

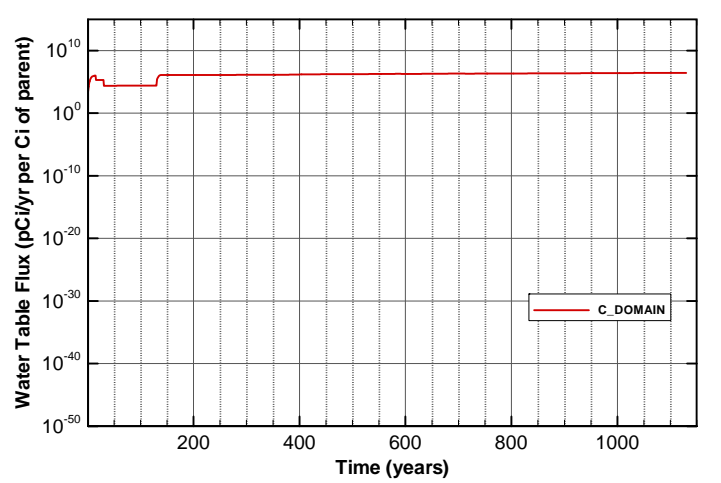

Figure A-738. Flux at water table for Case01n11_off I-129_F.Carbon

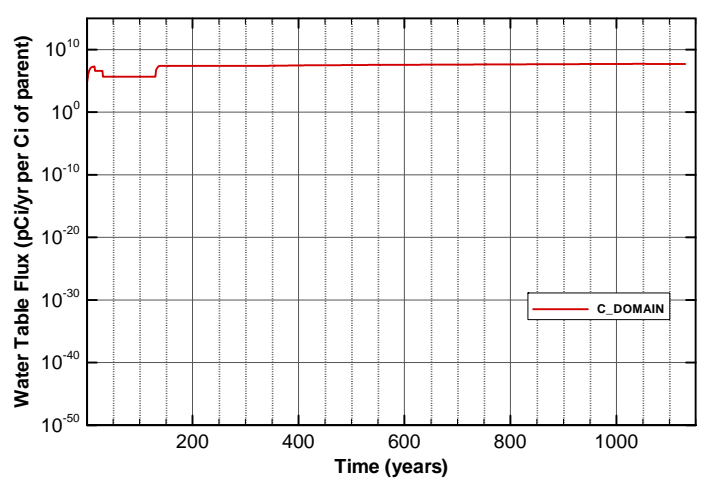

Figure A-740. Flux at water table for Case01n11_off I-129_F.Dowex.21K 


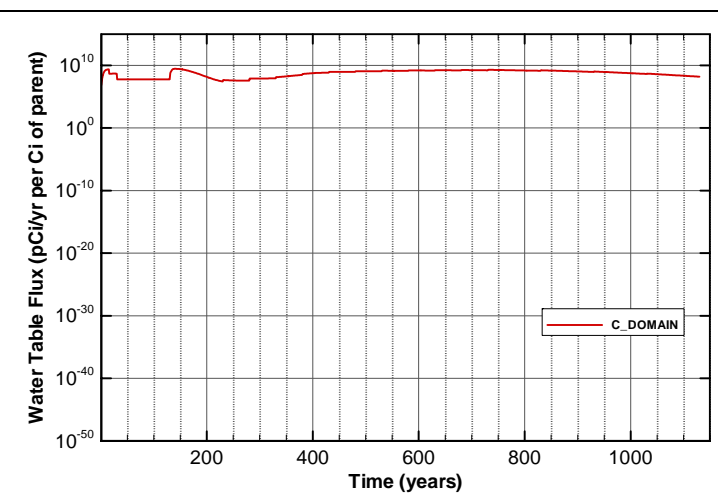

Figure A-741. Flux at water table for Case01n11_off I-129_F.Filtercake

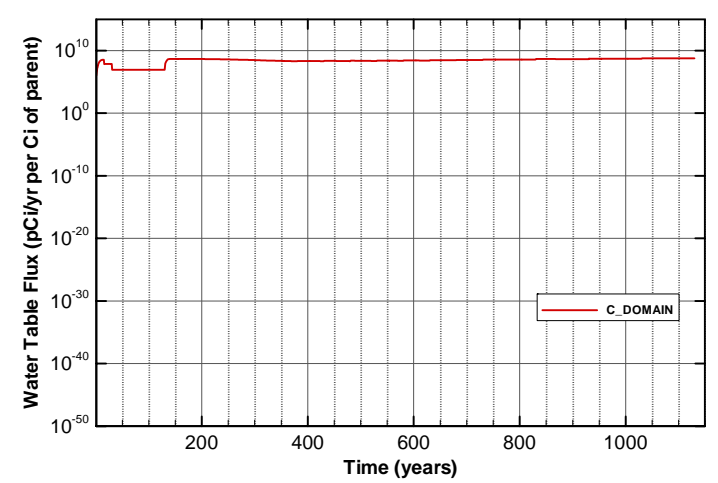

Figure A-743. Flux at water table for Case01n11_off I-129_H.CG.8

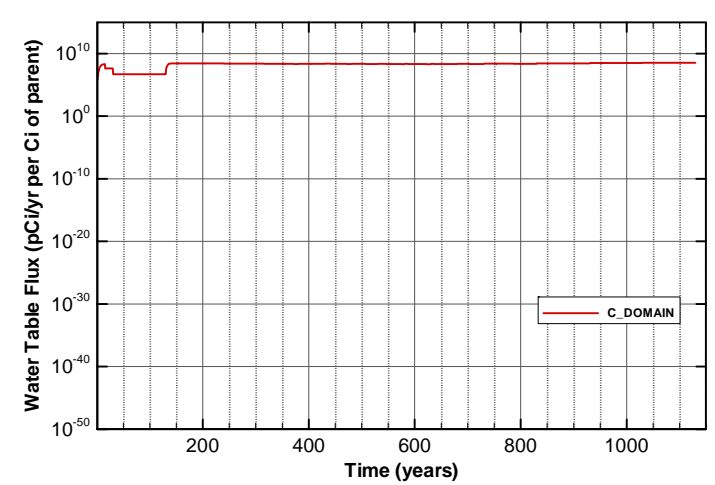

Figure A-745. Flux at water table for Case01n11_off I-129_H.Filtercake

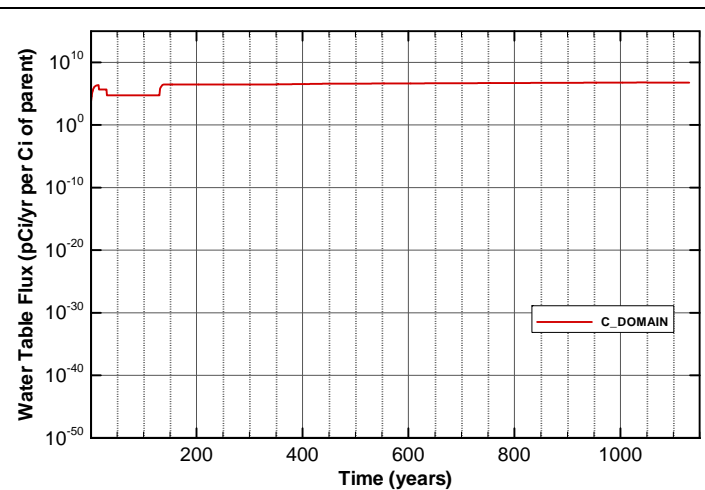

Figure A-742. Flux at water table for Case01n11_off I-129_H.Carbon

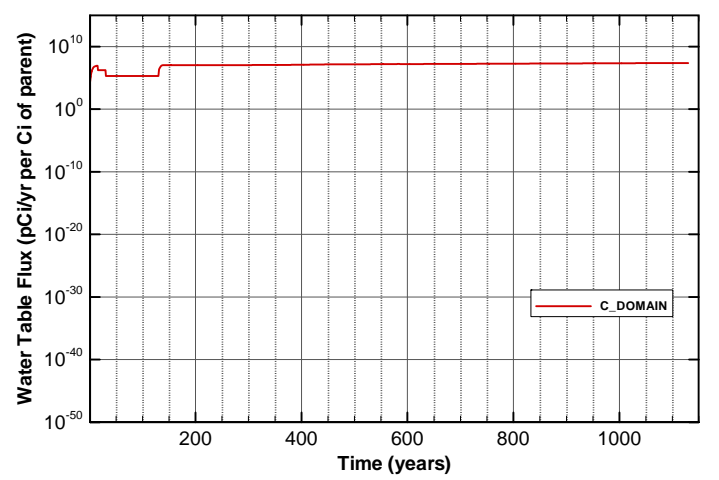

Figure A-744. Flux at water table for Case01n11_off I-129_H.Dowex.21K

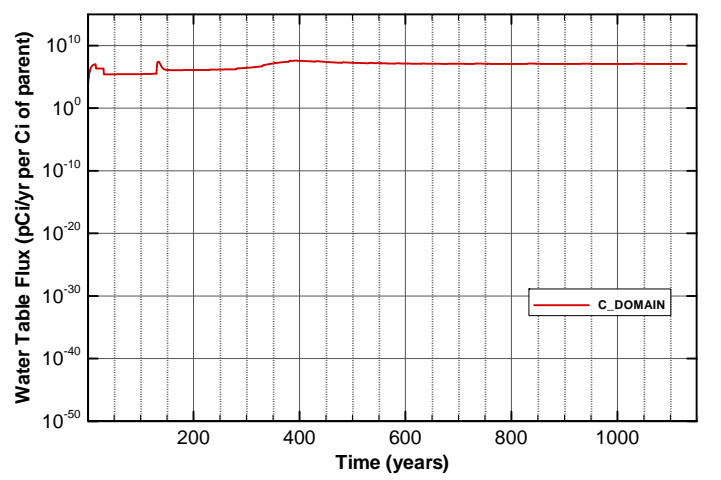

Figure A-746. Flux at water table for Case01n11_off I-129_Mk50A 


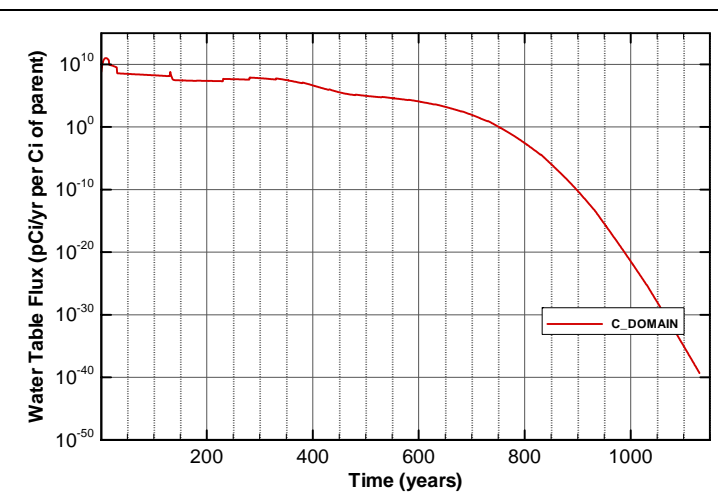

Figure A-747. Flux at water table for Case01n11_off K-40

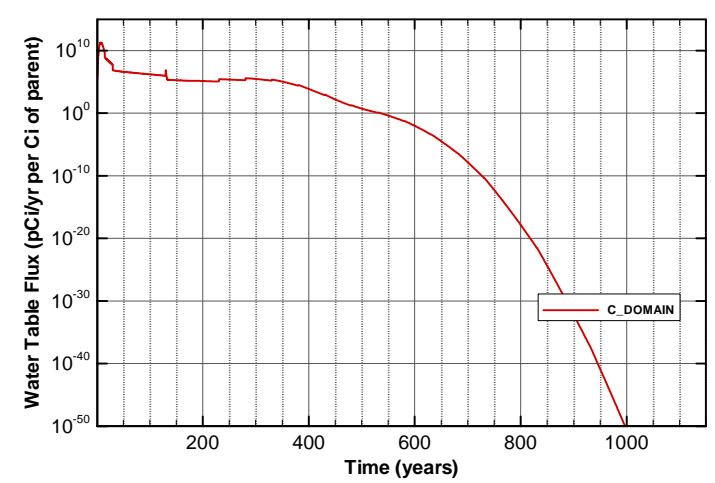

Figure A-749. Flux at water table for Case01n11_off Nb-94

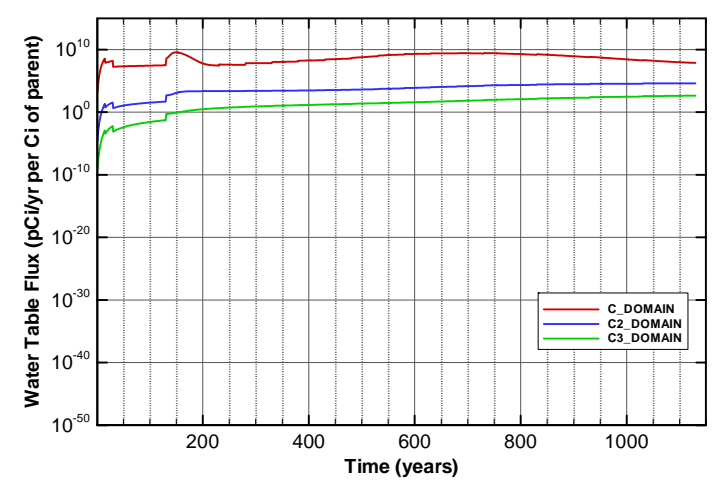

Figure A-751. Flux at water table for Case01n11_off Np-237

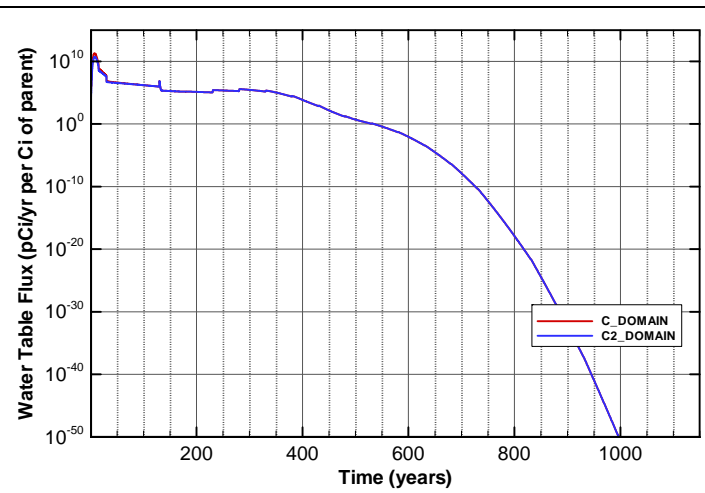

Figure A-748. Flux at water table for Case01n11_off Mo-93

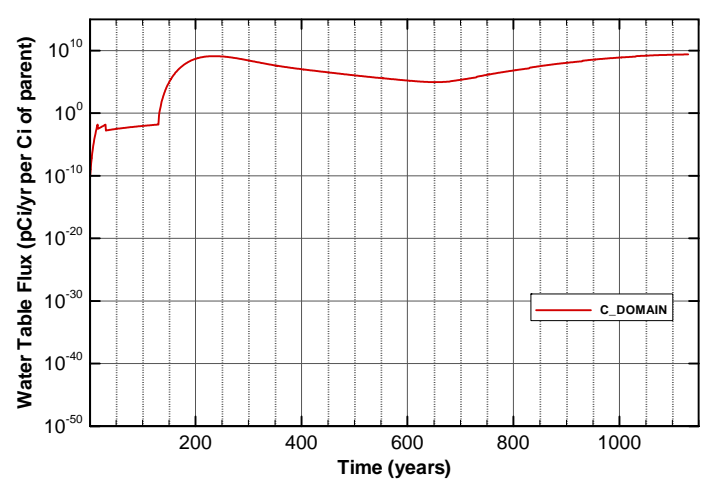

Figure A-750. Flux at water table for Case01n11_off Ni-59

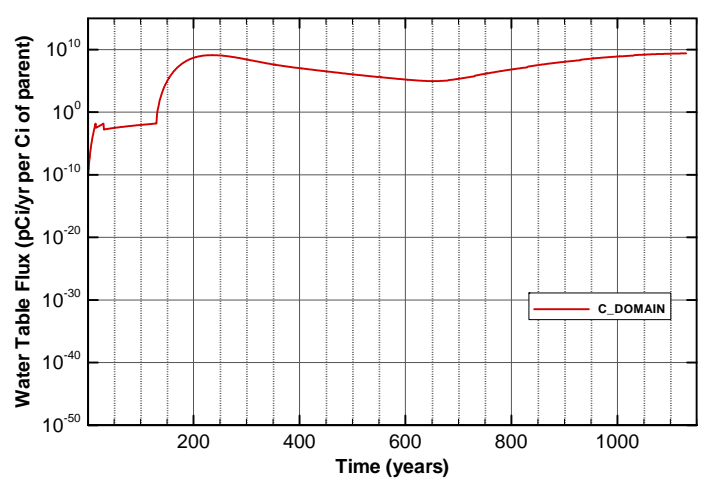

Figure A-752. Flux at water table for Case01n11_off Pd-107 
SRNL-STI-2008-00397, REVISION 0
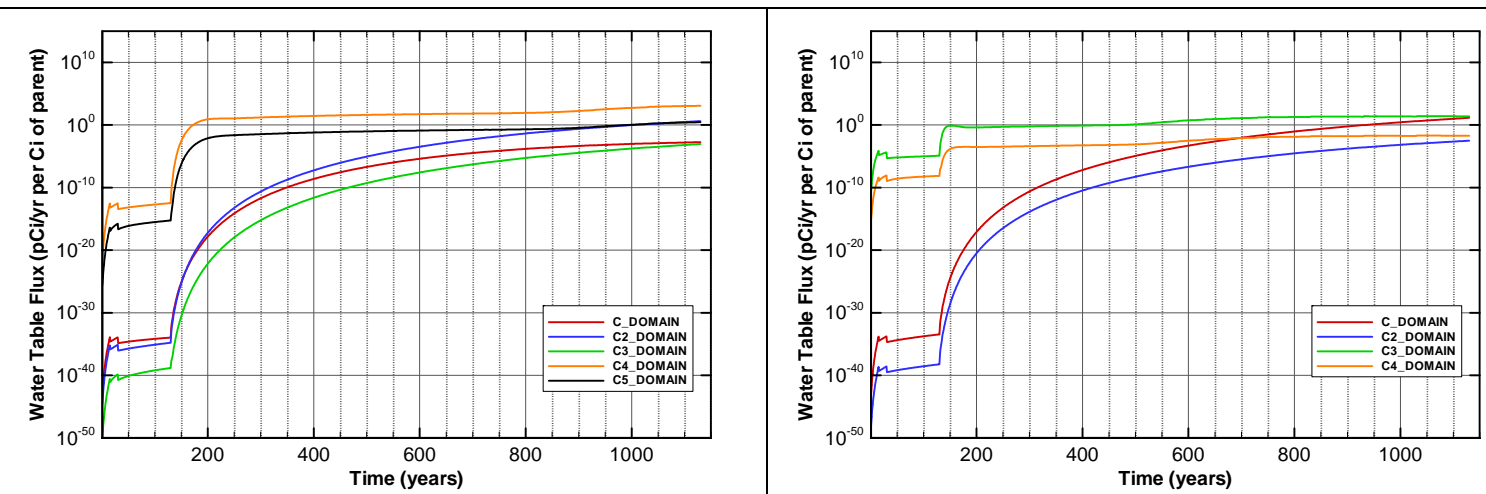

Figure A-753. Flux at water table for Case01n11_off Pu-238

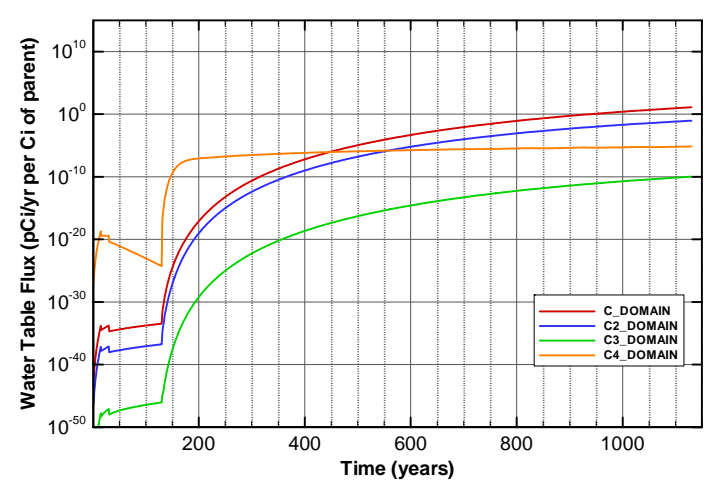

Figure A-755. Flux at water table for Case01n11_off Pu-240

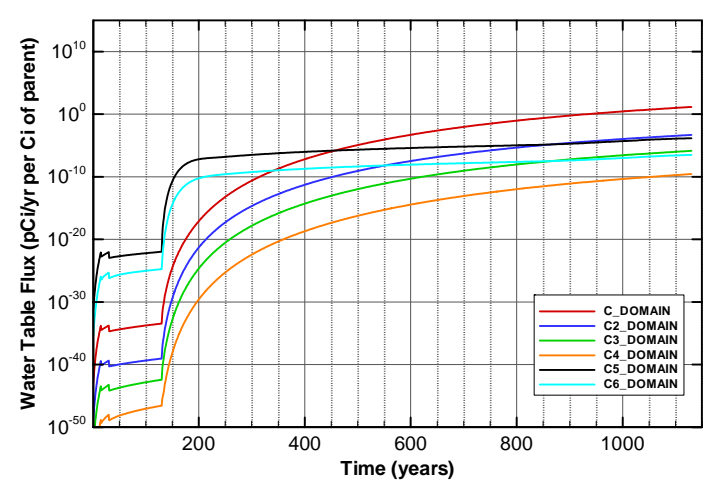

Figure A-757. Flux at water table for Case01n11_off Pu-242

Figure A-754. Flux at water table for Case01n11_off Pu-239

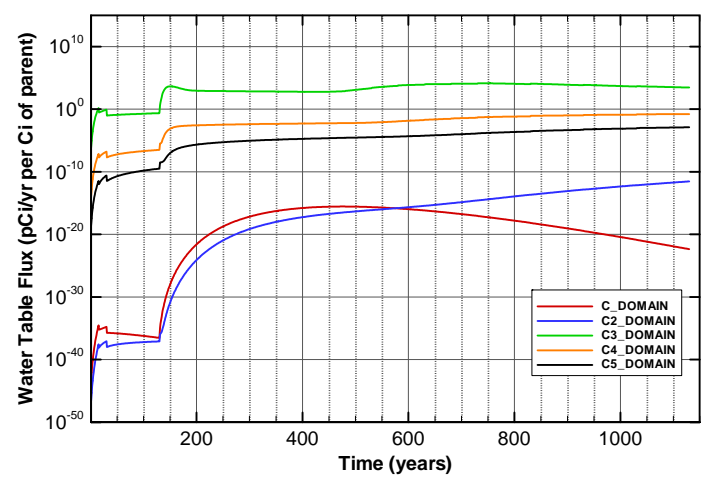

Figure A-756. Flux at water table for Case01n11_off Pu-241

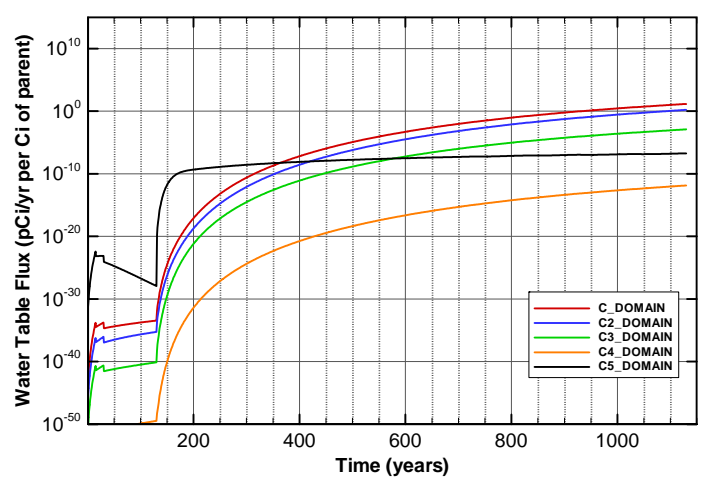

Figure A-758. Flux at water table for Case01n11_off Pu-244 
SRNL-STI-2008-00397, REVISION 0

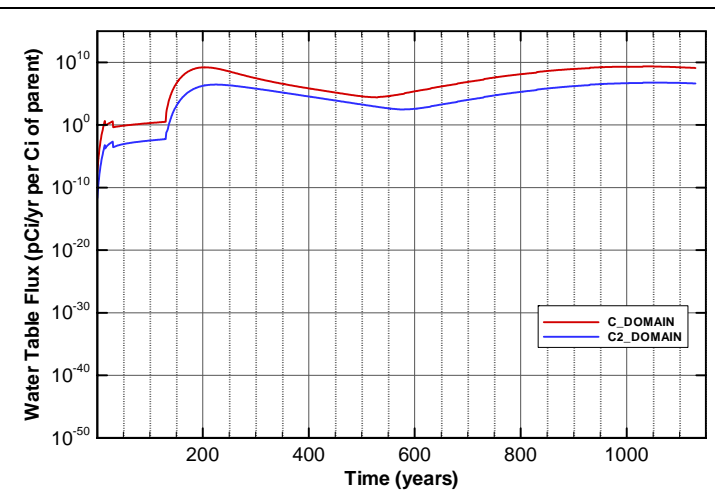

Figure A-759. Flux at water table for Case01n11_off Ra-226

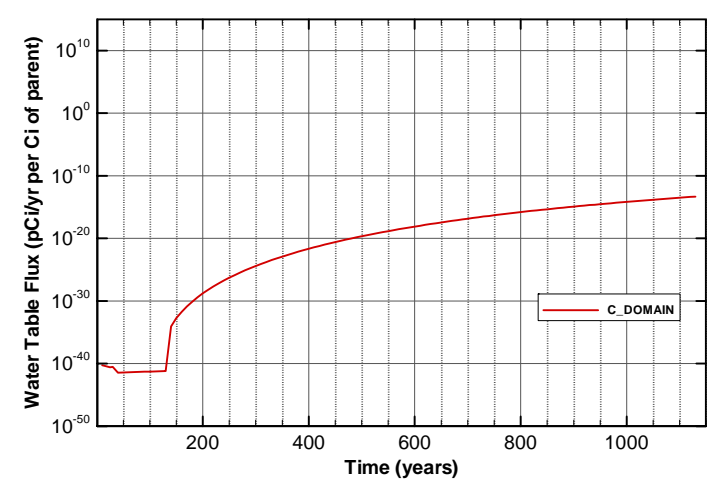

Figure A-761. Flux at water table for Case01n11_off Sn-126

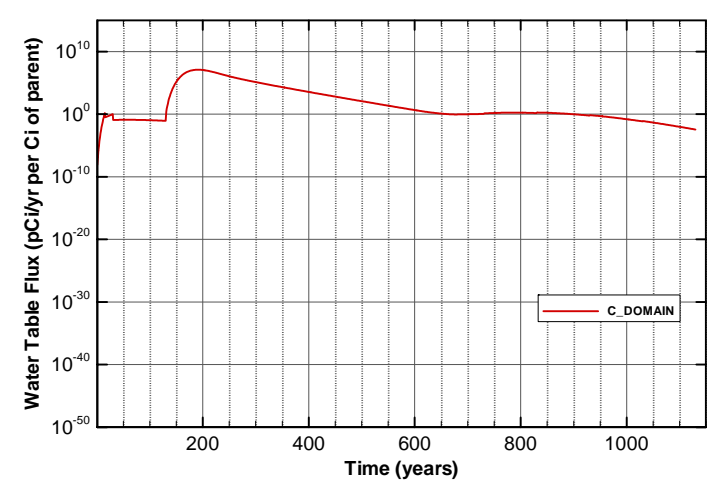

Figure A-763. Flux at water table for Case01n11_off Sr-90_Cask

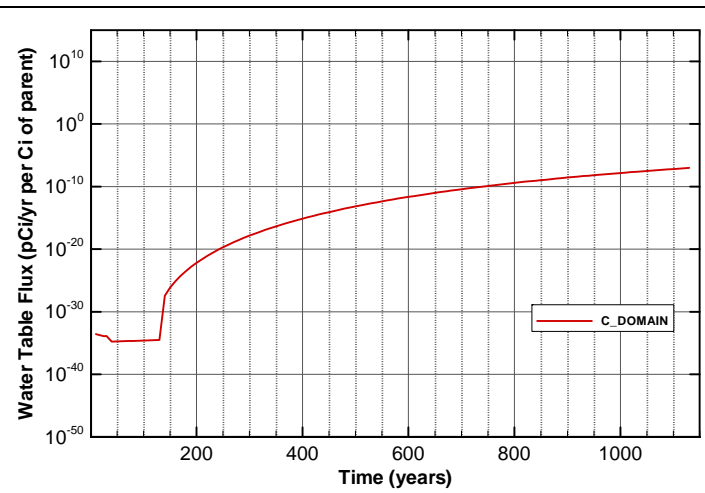

Figure A-760. Flux at water table for Case01n11_off Se-79

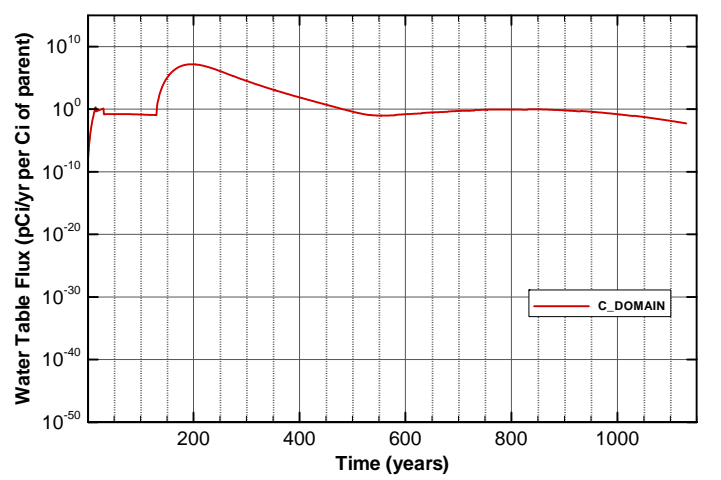

Figure A-762. Flux at water table for Case01n11_off Sr-90

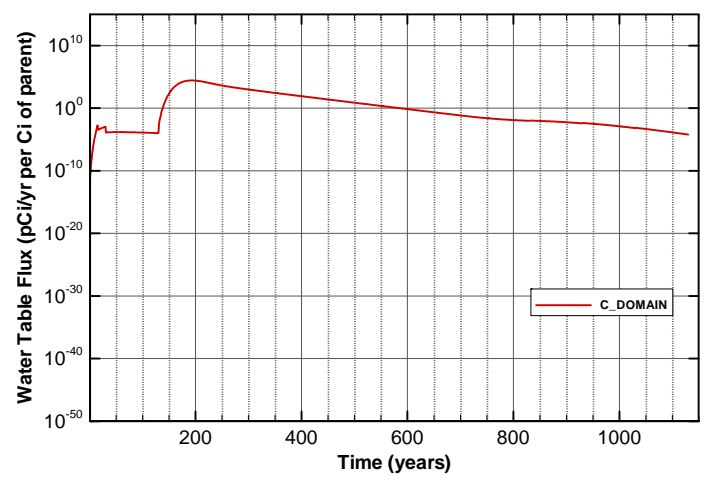

Figure A-764. Flux at water table for Case01n11_off Sr-90_Mk50A 


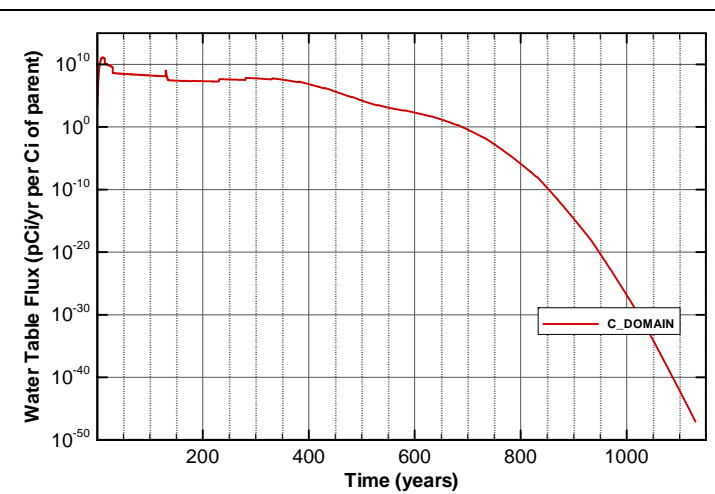

Figure A-765. Flux at water table for Case01n11_off Tc-99

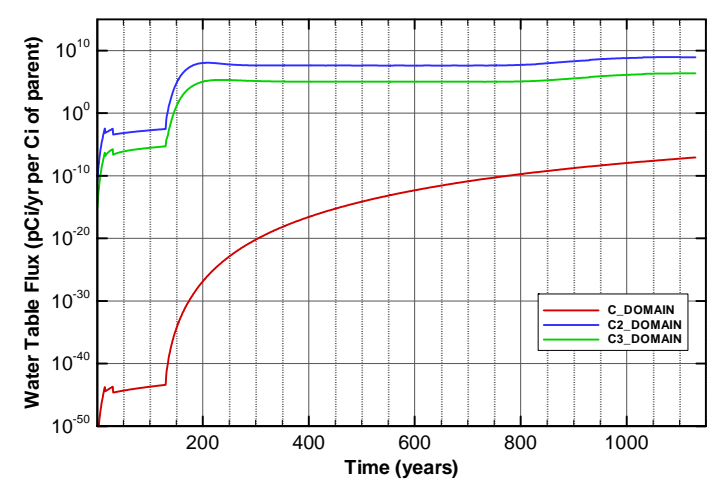

Figure A-767. Flux at water table for Case01n11_off Th-230

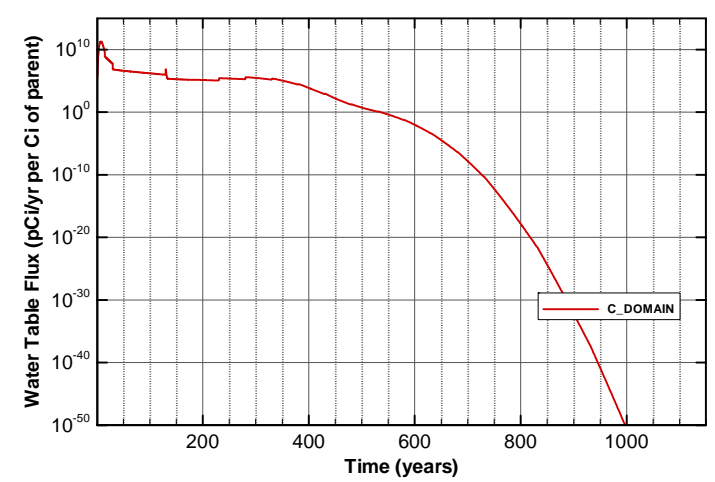

Figure A-769. Flux at water table for Case01n11_off Tracer

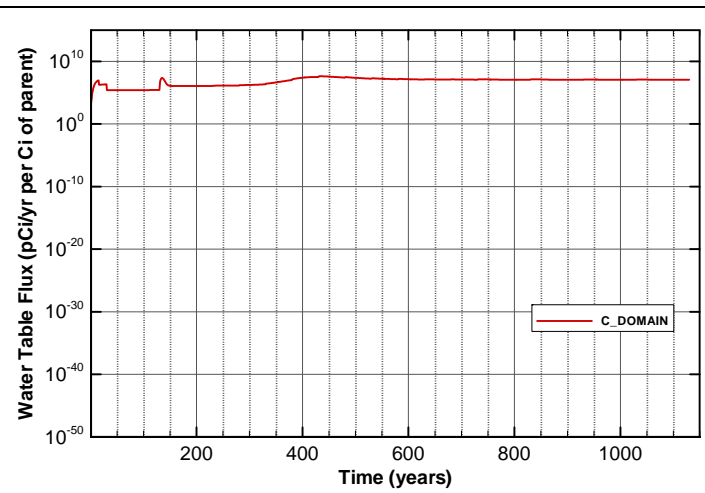

Figure A-766. Flux at water table for Case01n11_off Tc-99_Mk50A

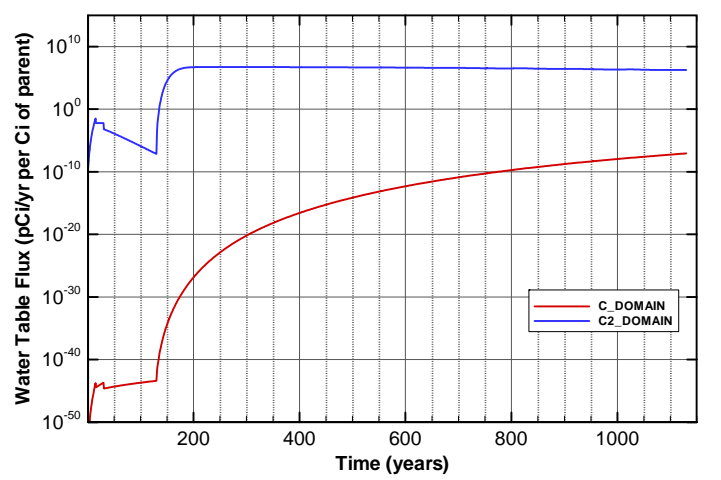

Figure A-768. Flux at water table for Case01n11_off Th-232

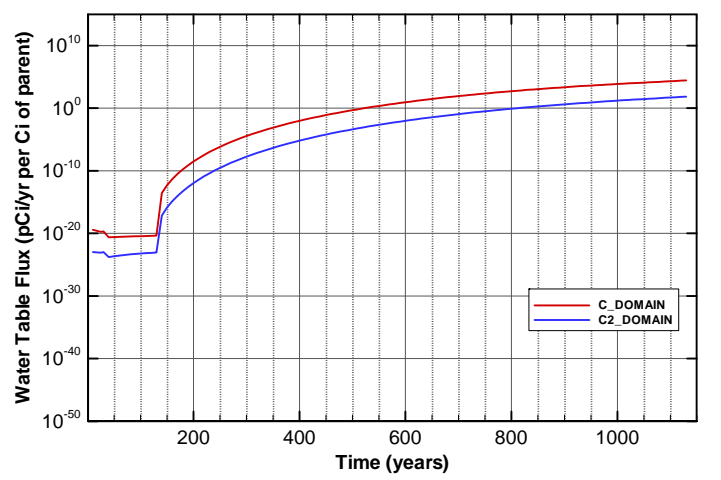

Figure A-770. Flux at water table for Case01n11_off U-233 


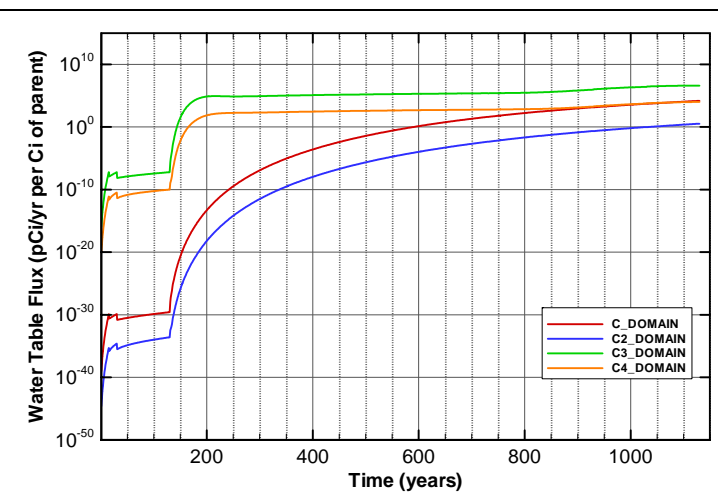

Figure A-771. Flux at water table for Case01n11_off U-234

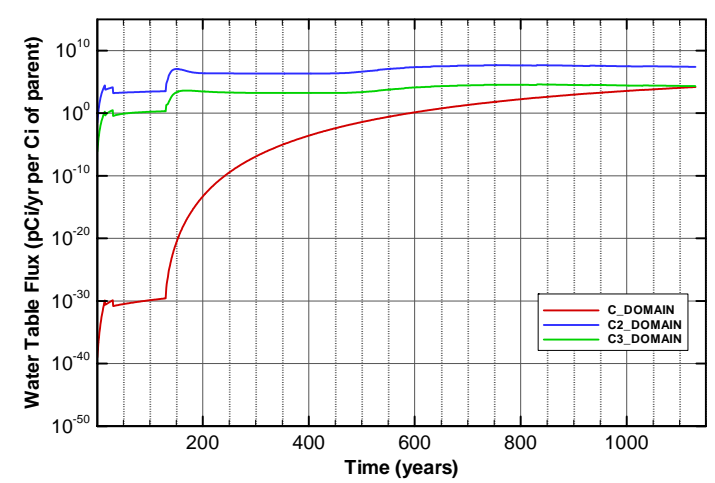

Figure A-773. Flux at water table for Case01n11_off U-235

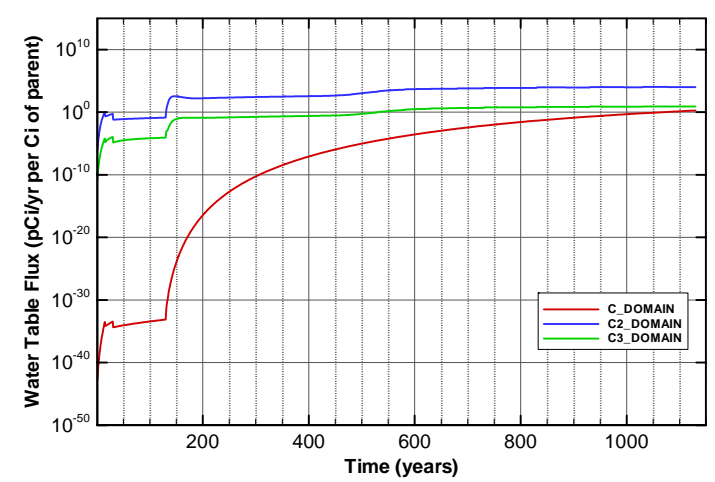

Figure A-775. Flux at water table for Case01n11_off U-235_Paducah.Cask

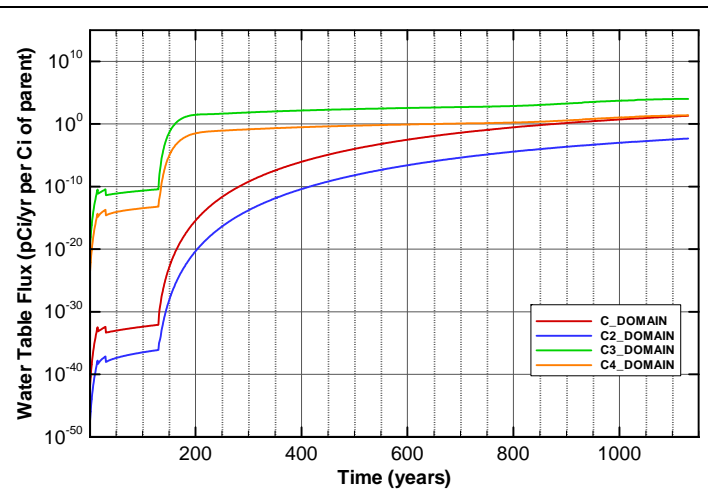

Figure A-772. Flux at water table for Case01n11_off U-234_Mglass

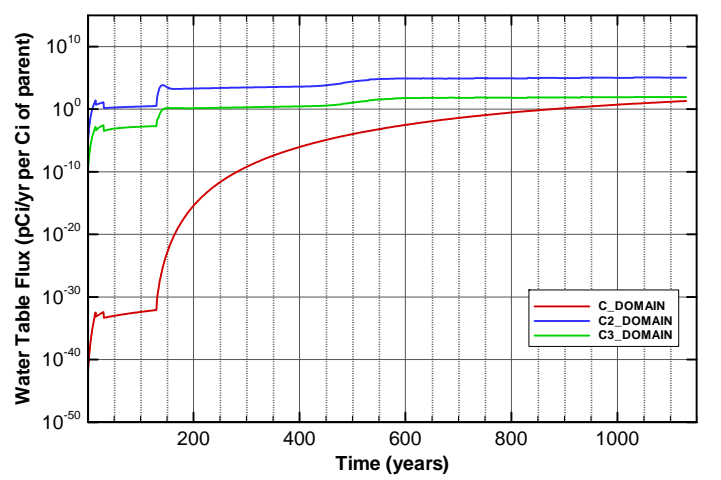

Figure A-774. Flux at water table for Case01n11_off U-235_Mglass

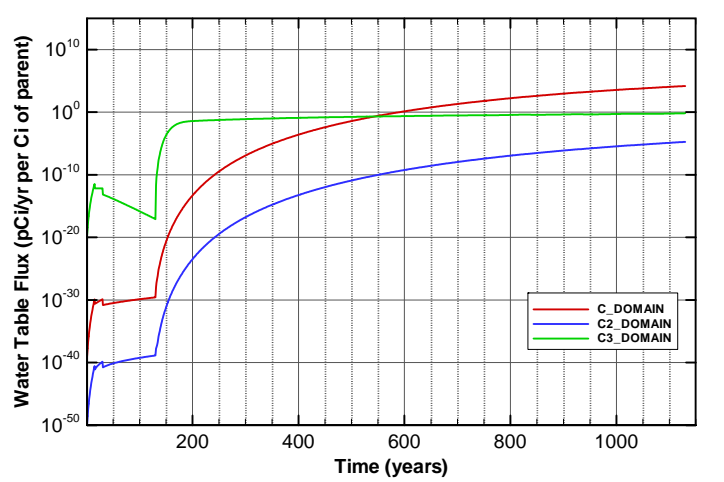

Figure A-776. Flux at water table for Case01n11_off U-236 


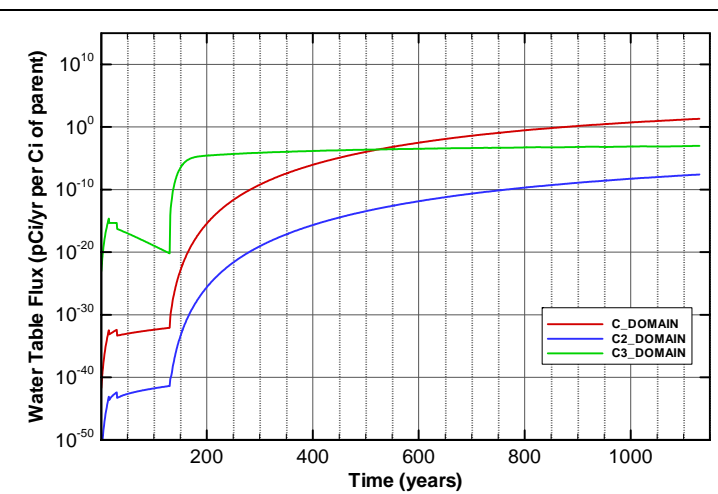

Figure A-777. Flux at water table for Case01n11_off U-236_Mglass

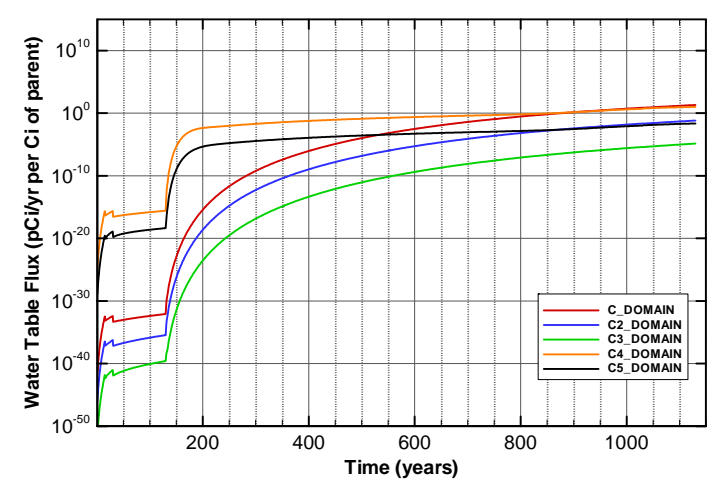

Figure A-779. Flux at water table for Case01n11_off U-238_Mglass

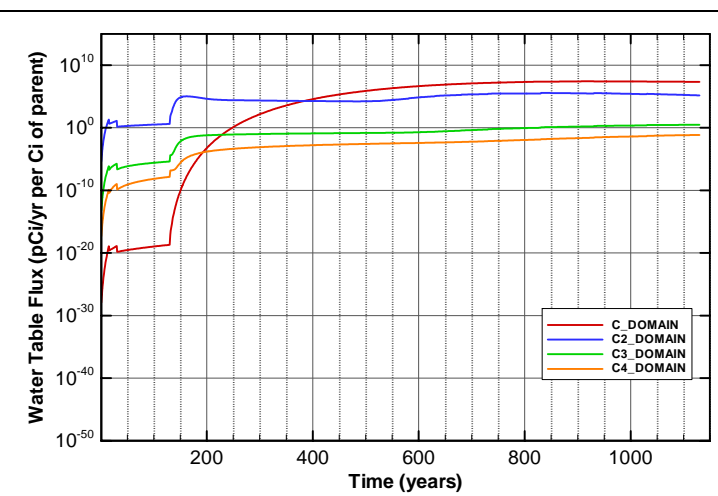

Figure A-781. Flux at water table for Case01n11_on Am-241

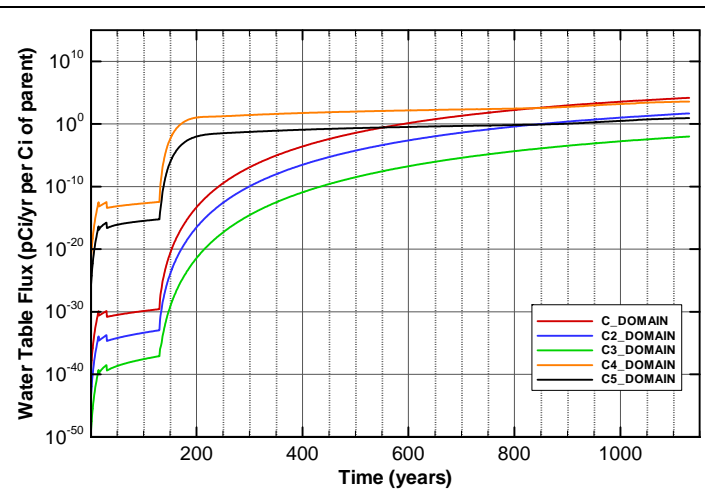

Figure A-778. Flux at water table for Case01n11_off U-238

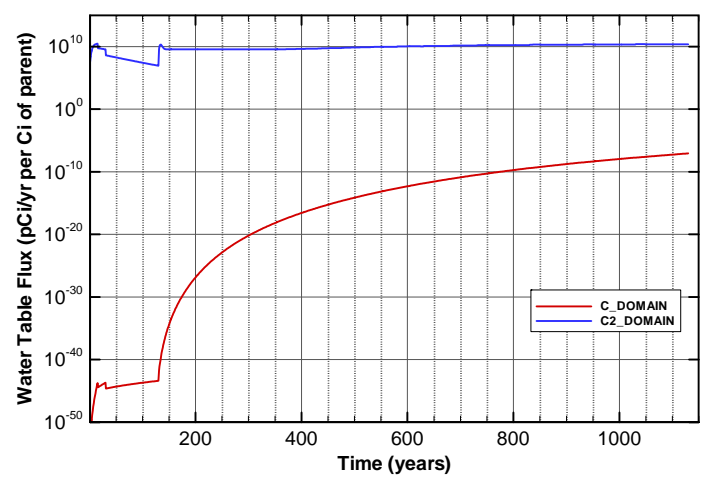

Figure A-780. Flux at water table for Case01n11_off Zr-93

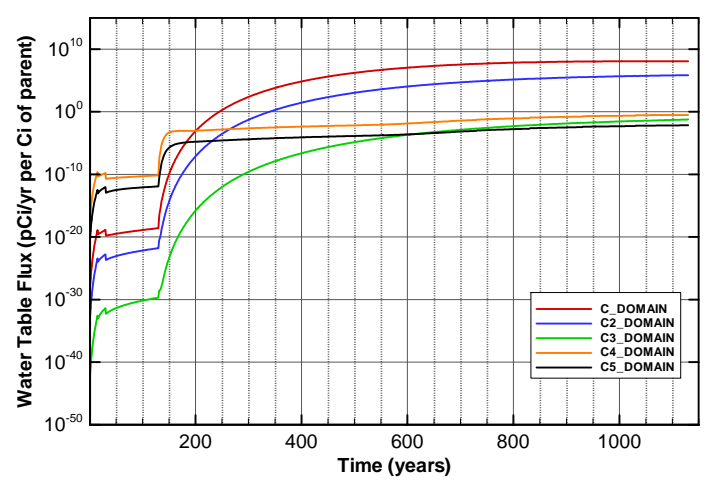

Figure A-782. Flux at water table for Case01n11_on Am-243 
SRNL-STI-2008-00397, REVISION 0
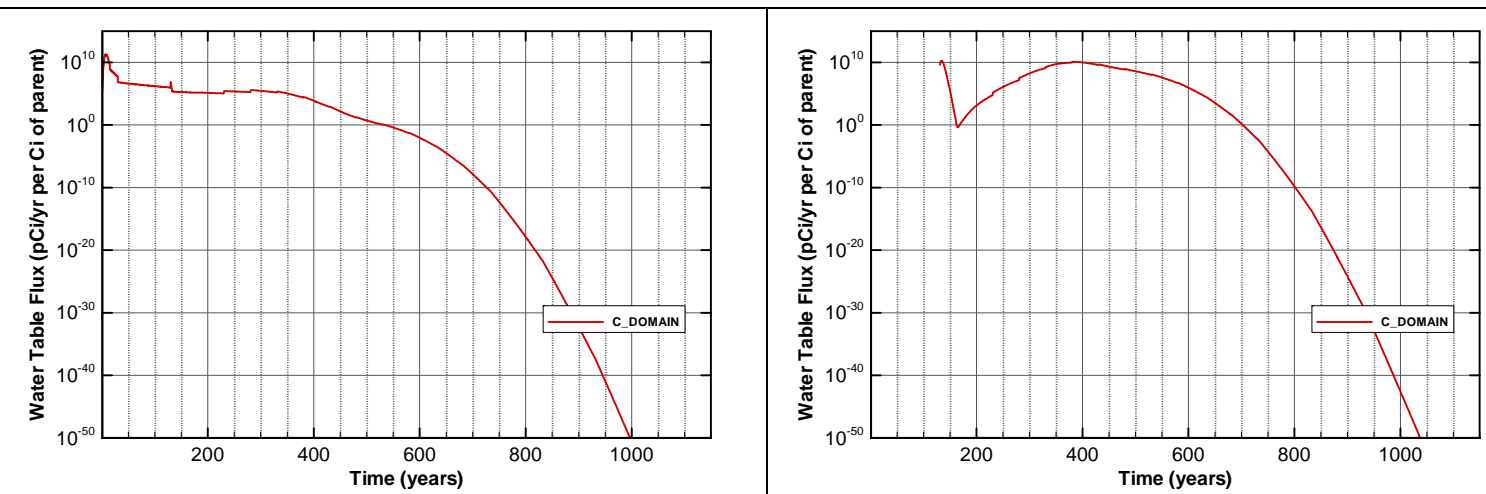

Figure A-783. Flux at water table for Case01n11_on C-14

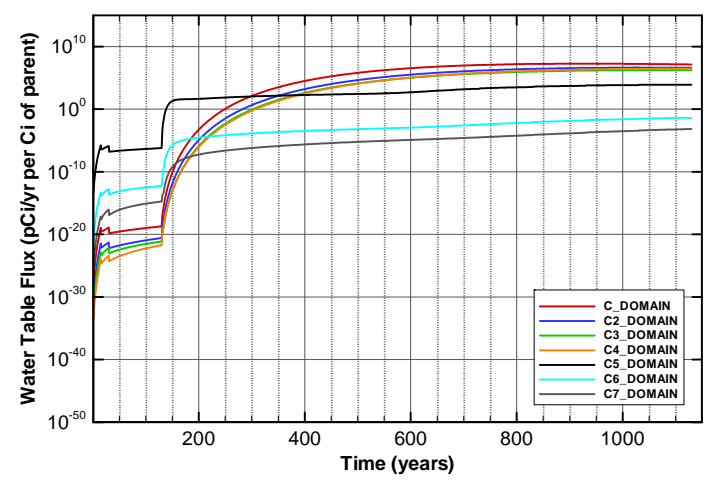

Figure A-785. Flux at water table for Case01n11_on Cf-249

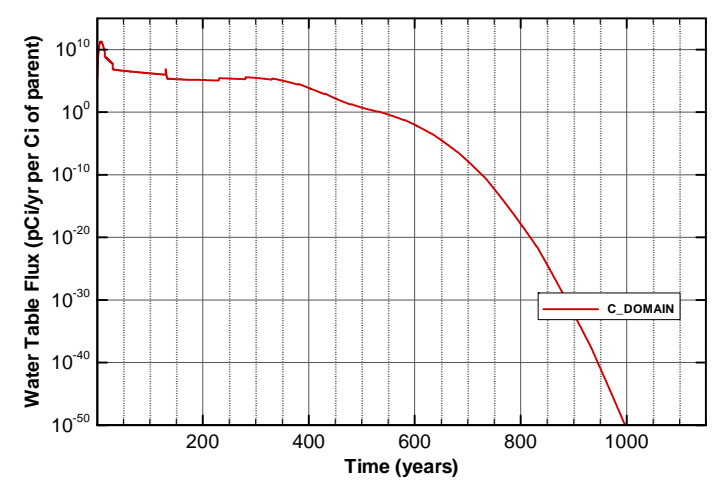

Figure A-787. Flux at water table for Case01n11_on Cl-36

Figure A-784. Flux at water table for Case01n11_on C-14_NR.Pump

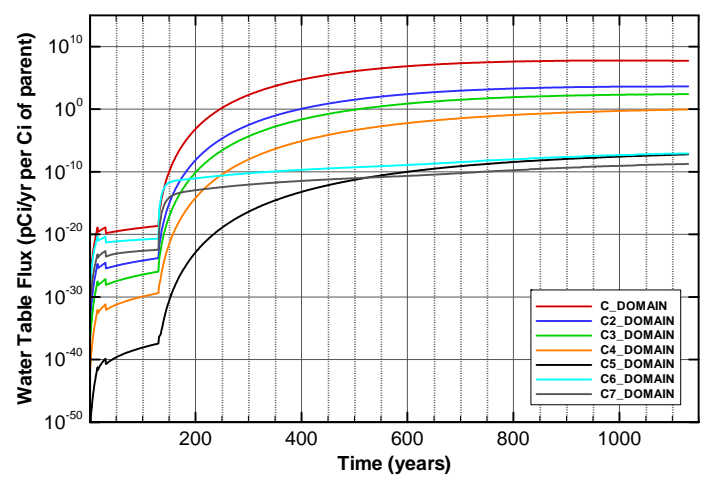

Figure A-786. Flux at water table for Case01n11_on Cf-251

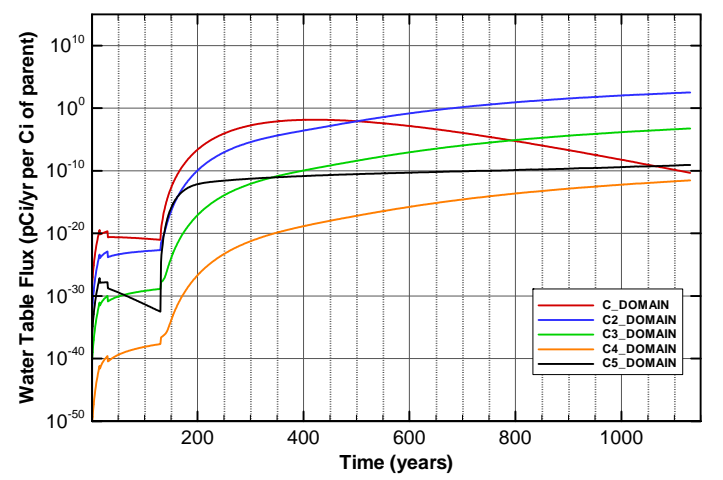

Figure A-788. Flux at water table for Case01n11_on Cm-244 
SRNL-STI-2008-00397, REVISION 0
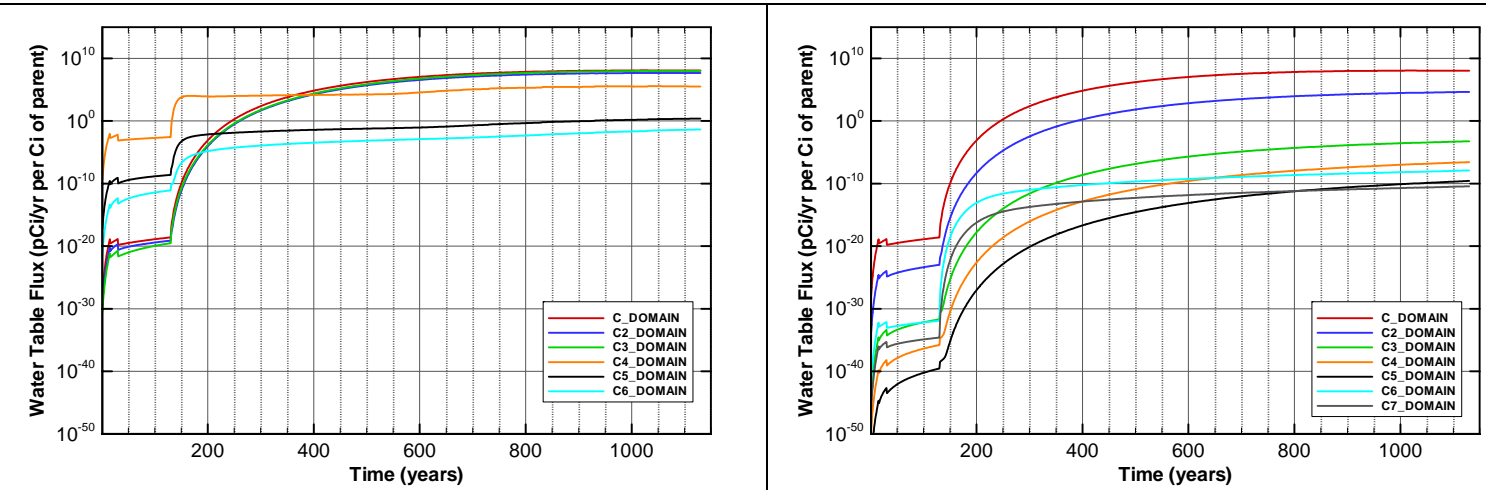

Figure A-789. Flux at water table for Case01n11_on Cm-245

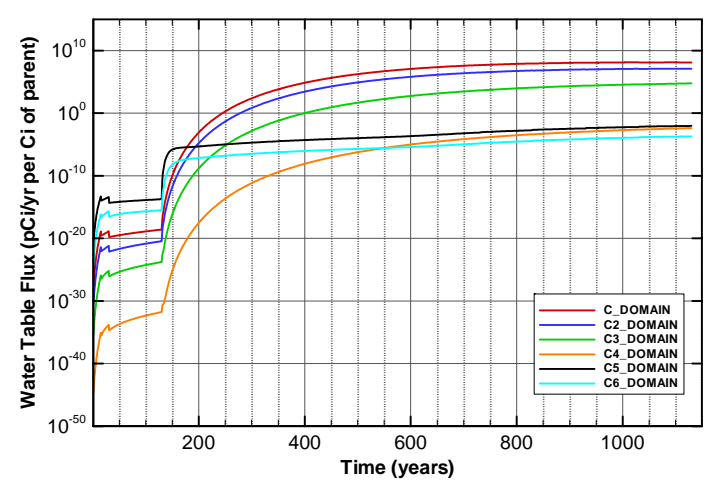

Figure A-791. Flux at water table for Case01n11_on Cm-247

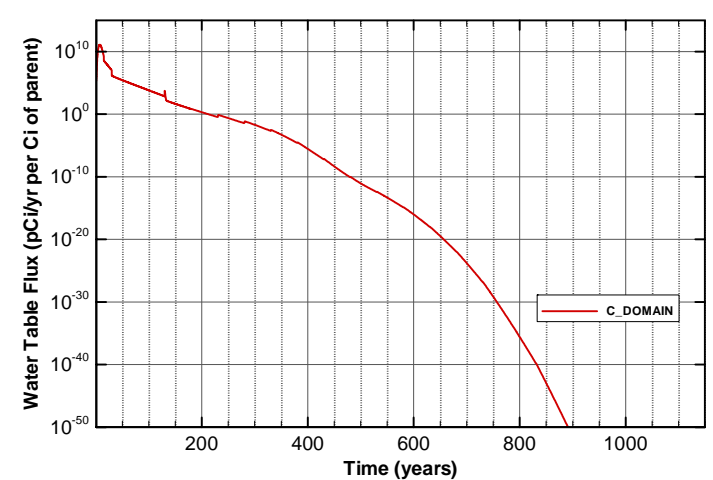

Figure A-793. Flux at water table for Case01n11_on H-3

Figure A-790. Flux at water table for Case01n11_on Cm-246

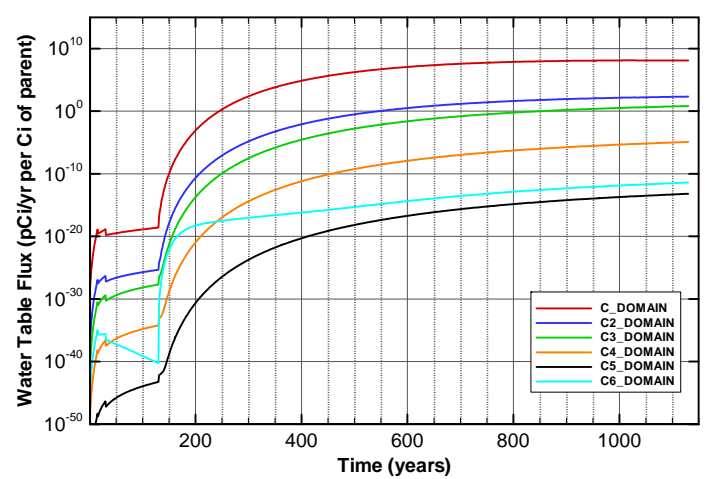

Figure A-792. Flux at water table for Case01n11_on Cm-248

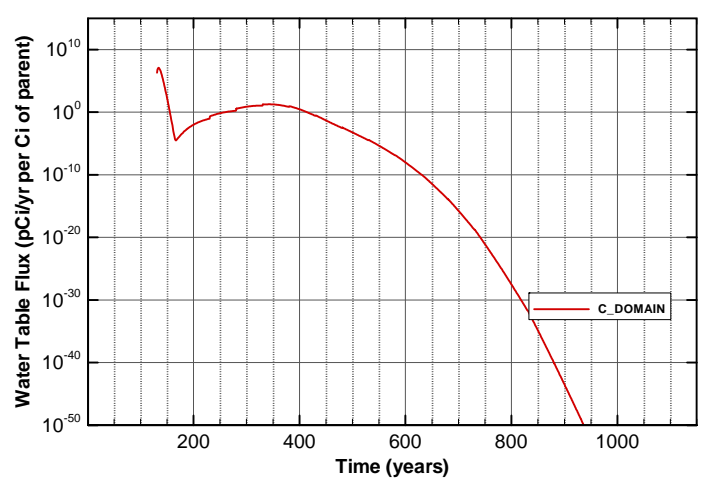

Figure A-794. Flux at water table for Case01n11_on H-3_ETF.Carbon 


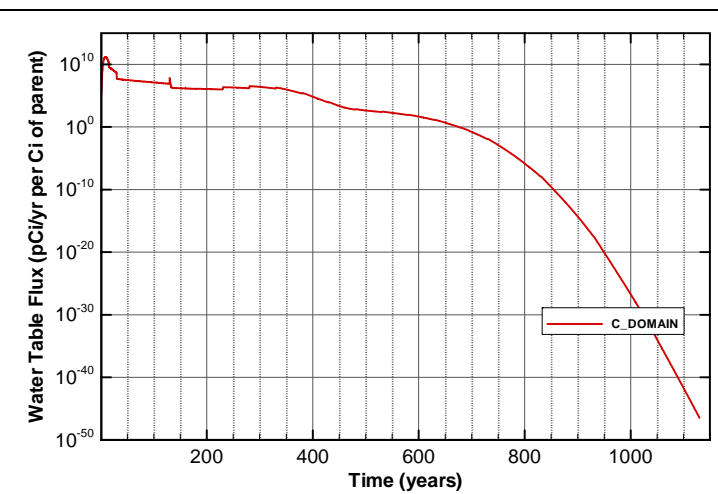

Figure A-795. Flux at water table for Case01n11_on I-129

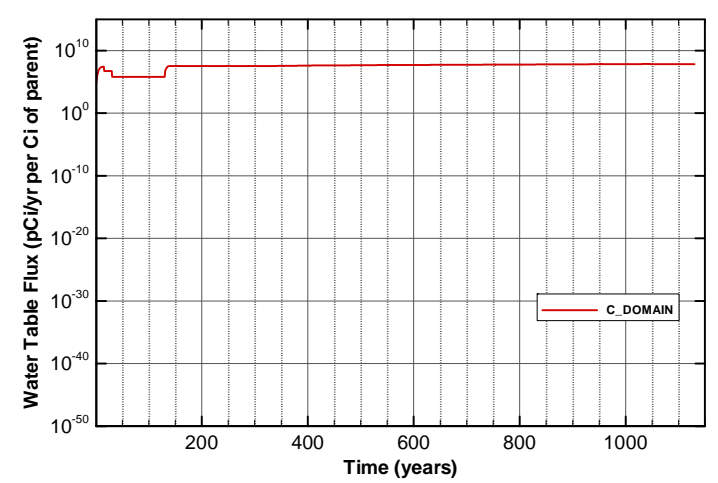

Figure A-797. Flux at water table for Case01n11_on I-129_ETF.GT.73

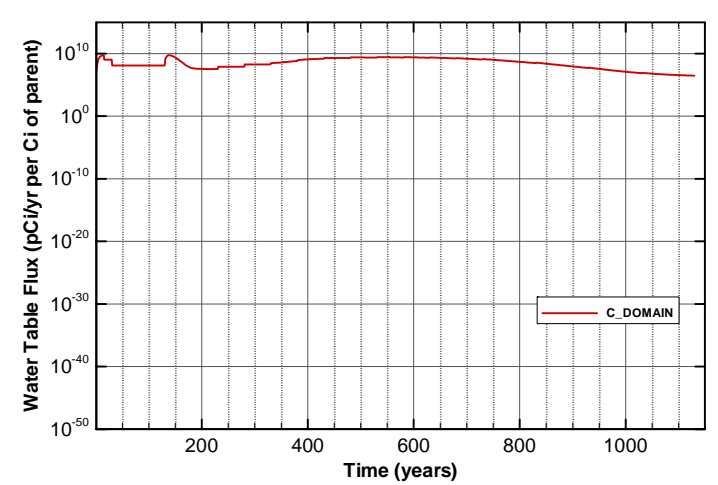

Figure A-799. Flux at water table for Case01n11_on I-129_F.CG.8

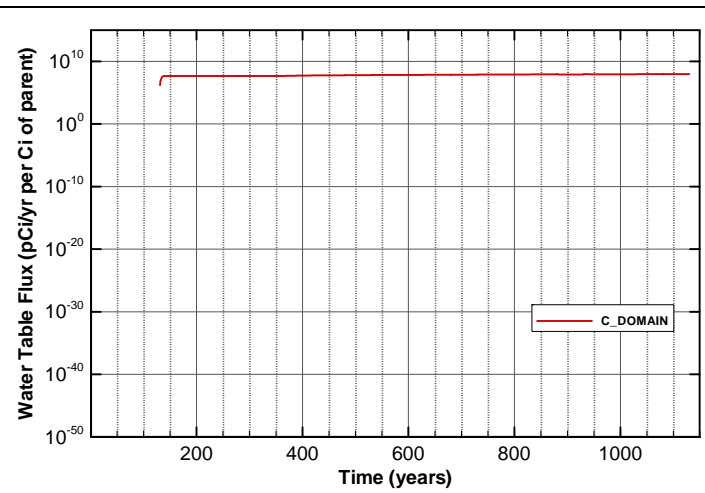

Figure A-796. Flux at water table for Case01n11_on I-129_ETF.Carbon

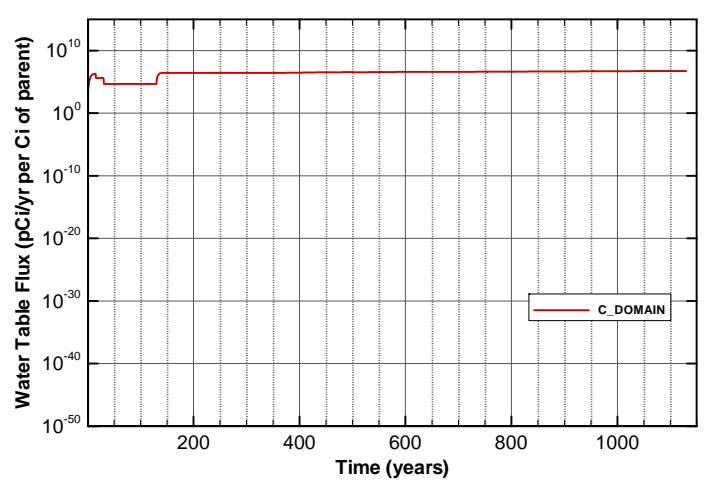

Figure A-798. Flux at water table for Case01n11_on I-129_F.Carbon

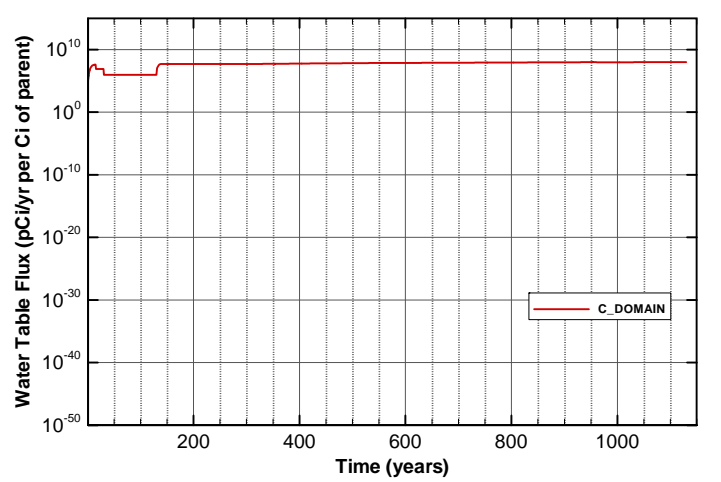

Figure A-800. Flux at water table for Case01n11_on I-129_F.Dowex.21K 


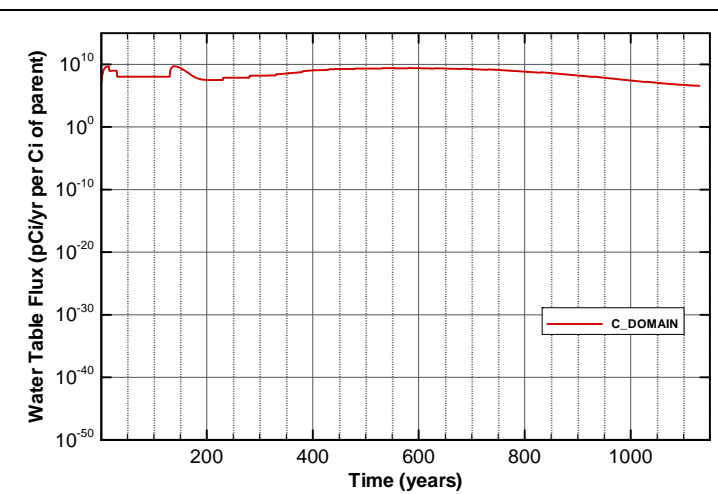

Figure A-801. Flux at water table for Case01n11_on I-129_F.Filtercake

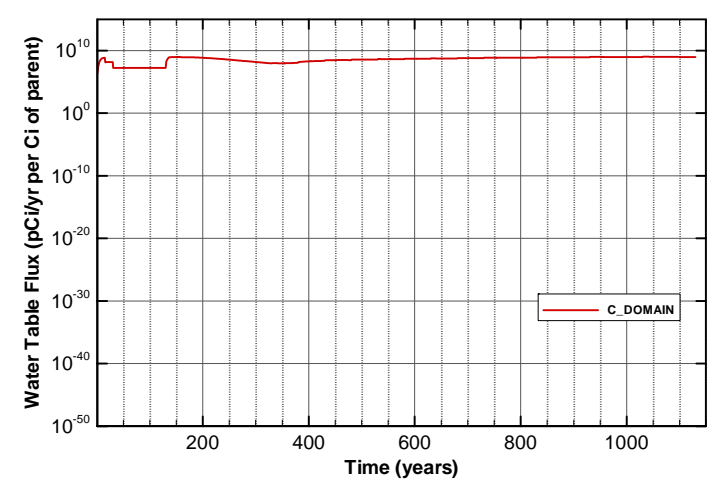

Figure A-803. Flux at water table for Case01n11_on I-129_H.CG.8

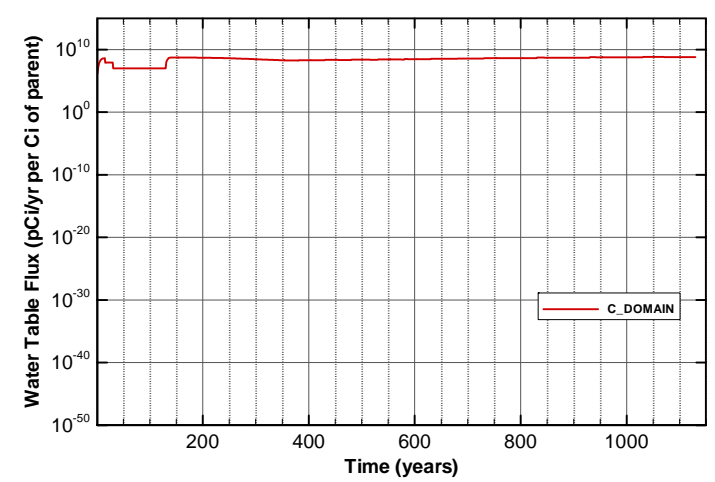

Figure A-805. Flux at water table for Case01n11_on I-129_H.Filtercake

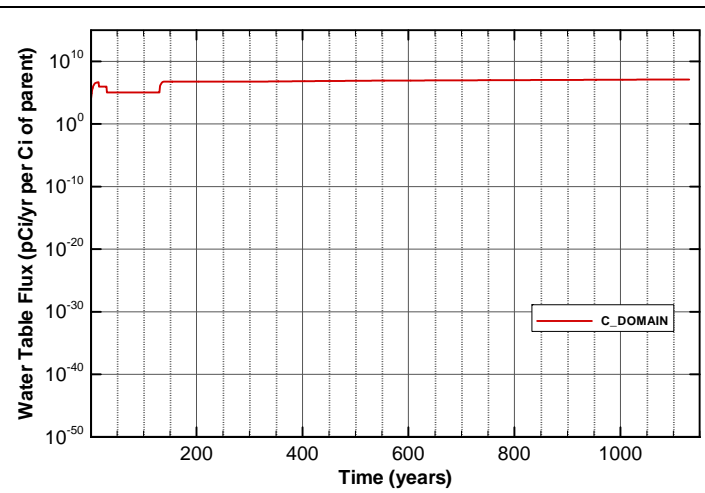

Figure A-802. Flux at water table for Case01n11_on I-129_H.Carbon

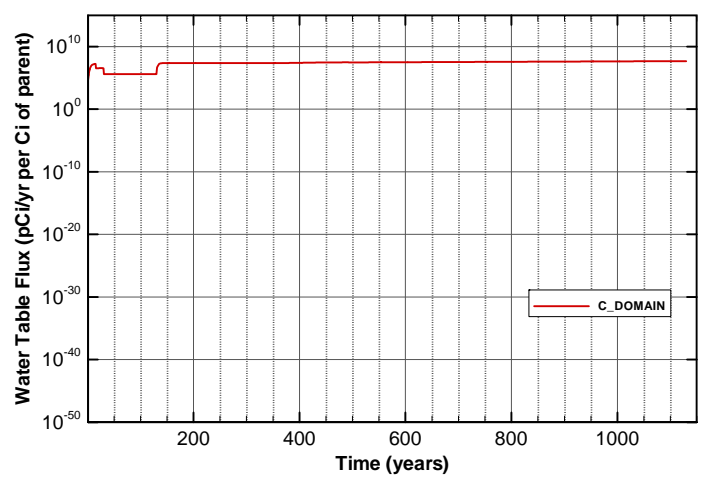

Figure A-804. Flux at water table for Case01n11_on I-129_H.Dowex.21K

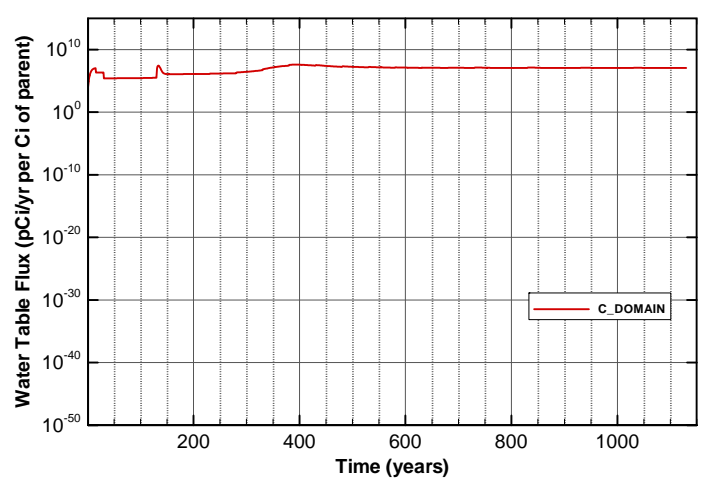

Figure A-806. Flux at water table for Case01n11_on I-129_Mk50A 


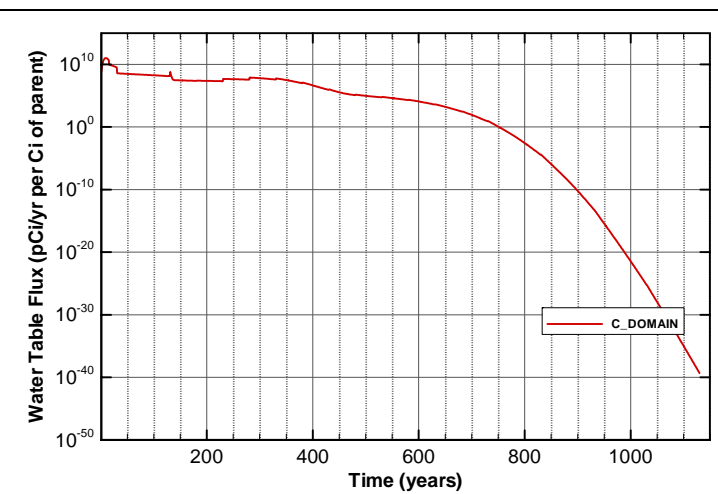

Figure A-807. Flux at water table for Case01n11_on K-40

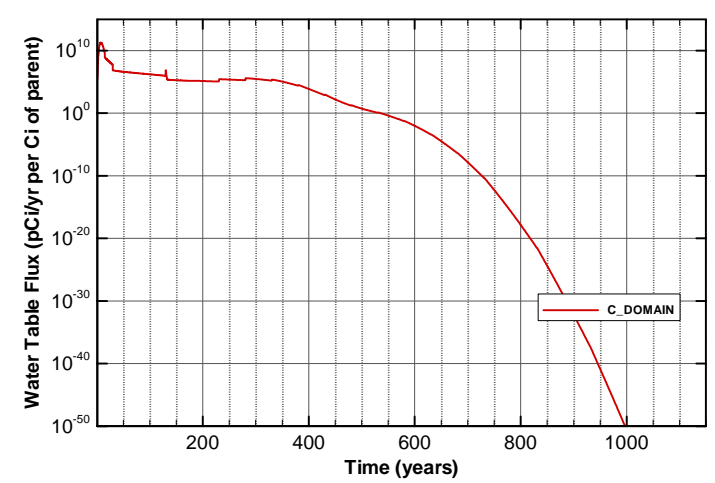

Figure A-809. Flux at water table for Case01n11_on Nb-94

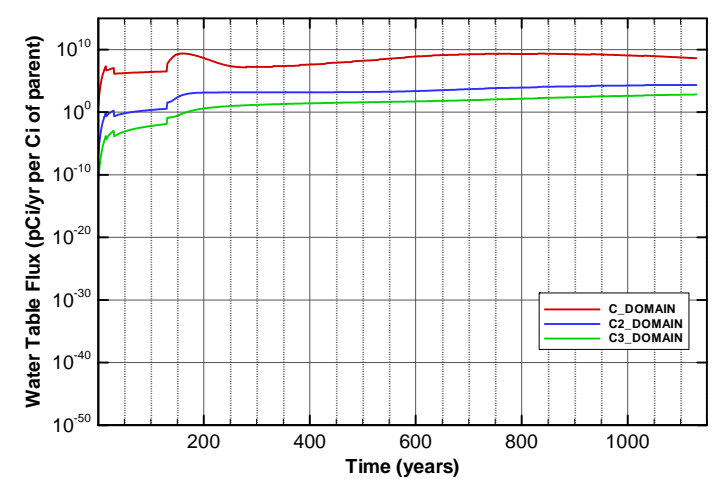

Figure A-811. Flux at water table for Case01n11_on Np-237

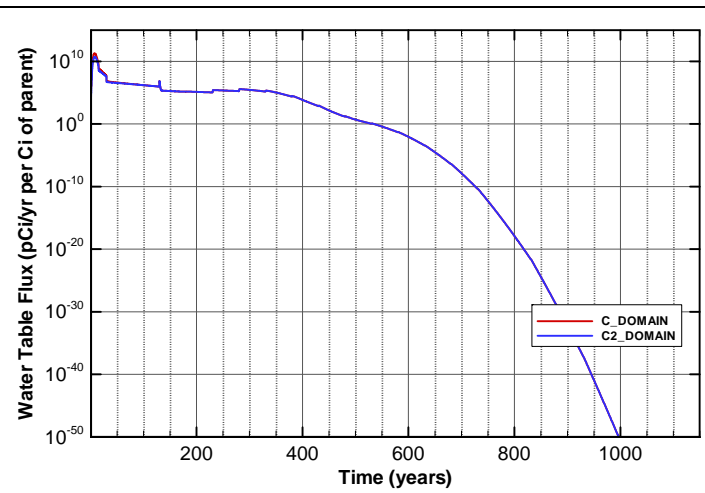

Figure A-808. Flux at water table for Case01n11_on Mo-93

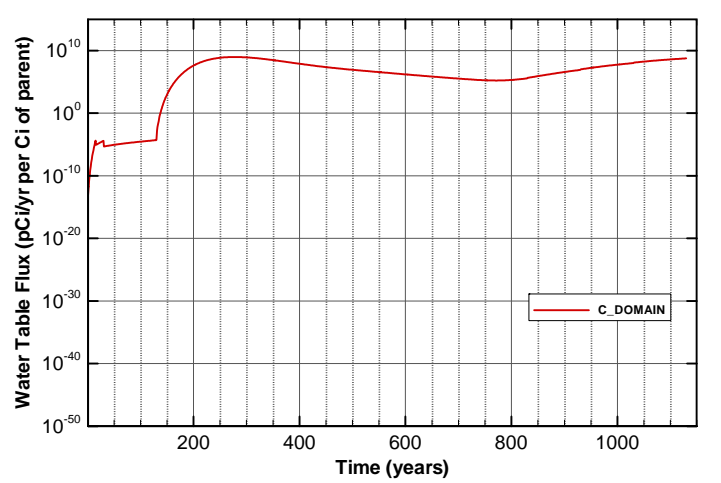

Figure A-810. Flux at water table for Case01n11_on Ni-59

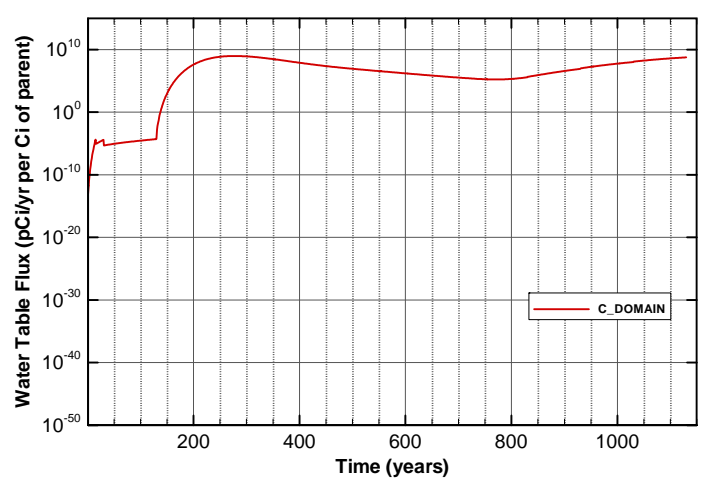

Figure A-812. Flux at water table for Case01n11_on Pd-107 
SRNL-STI-2008-00397, REVISION 0
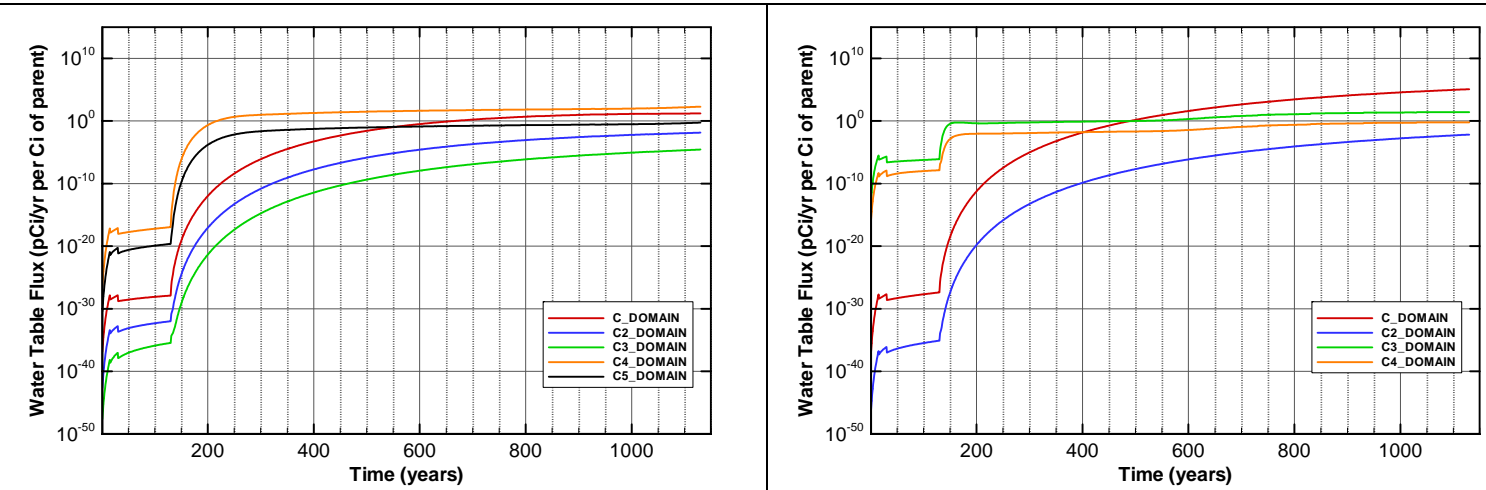

Figure A-813. Flux at water table for Case01n11_on Pu-238

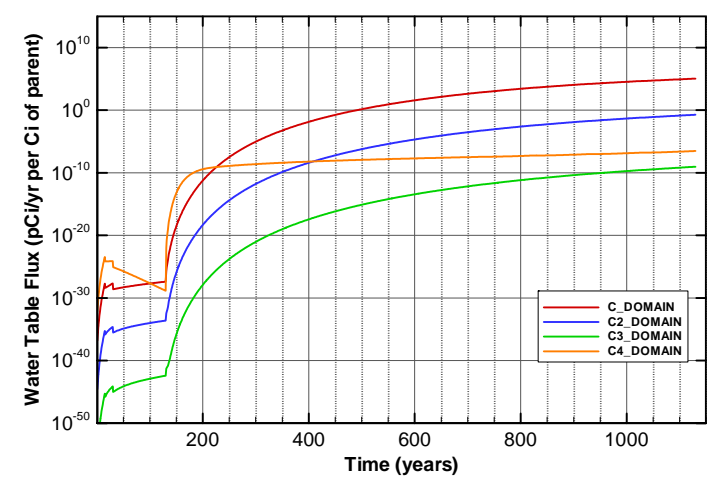

Figure A-815. Flux at water table for Case01n11_on Pu-240

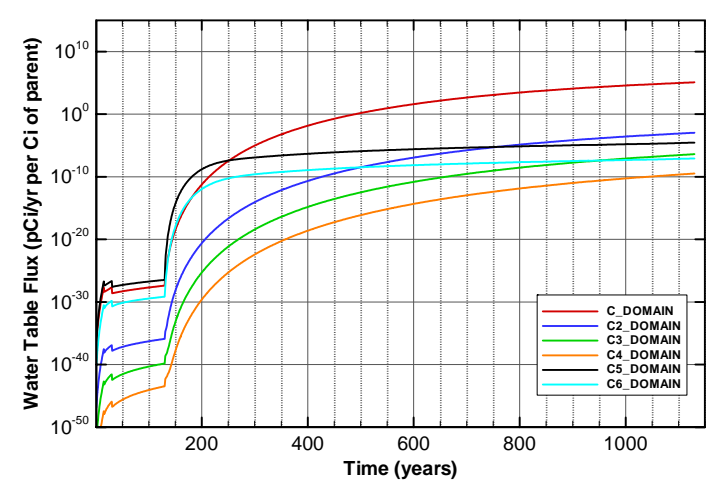

Figure A-817. Flux at water table for Case01n11_on Pu-242

Figure A-814. Flux at water table for Case01n11_on Pu-239

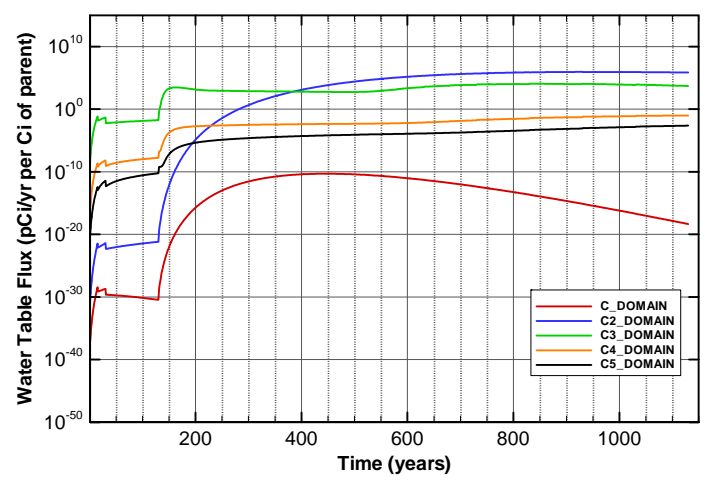

Figure A-816. Flux at water table for Case01n11_on Pu-241

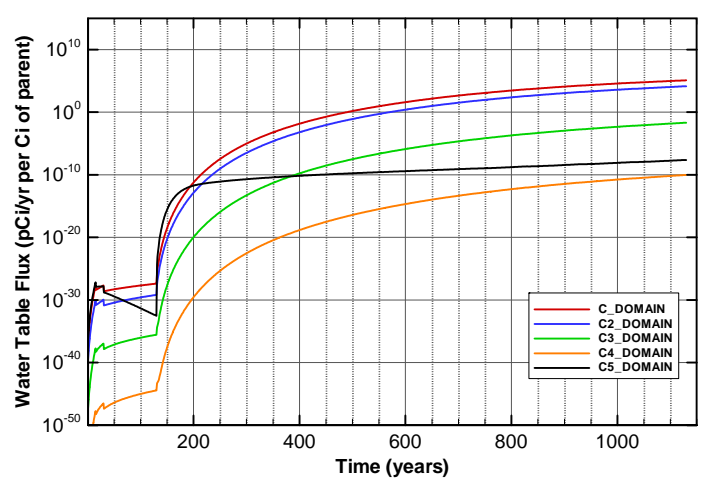

Figure A-818. Flux at water table for Case01n11_on Pu-244 


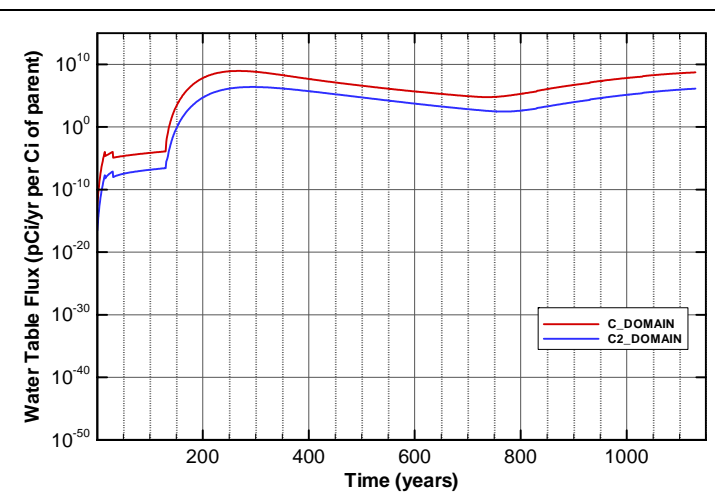

Figure A-819. Flux at water table for Case01n11_on Ra-226

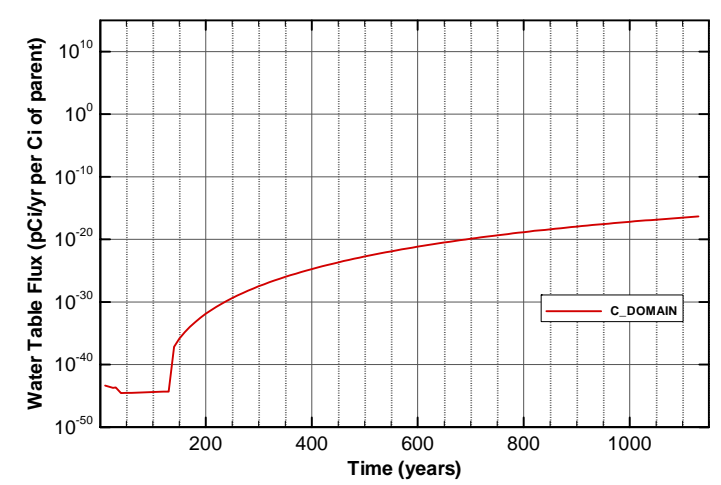

Figure A-821. Flux at water table for Case01n11_on Sn-126

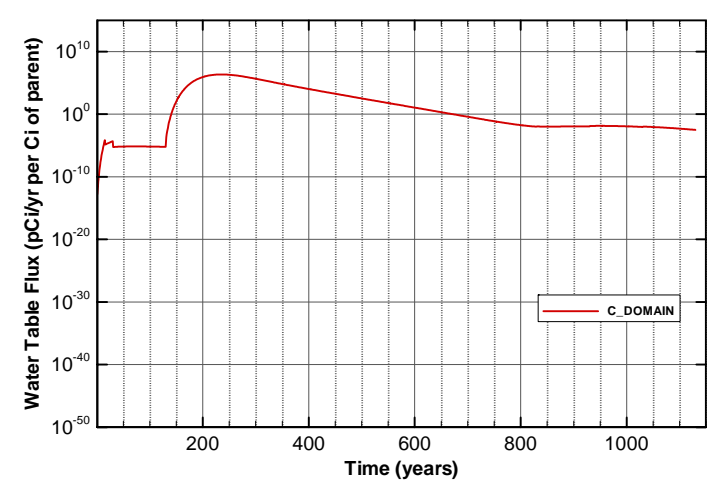

Figure A-823. Flux at water table for Case01n11_on Sr-90_Cask

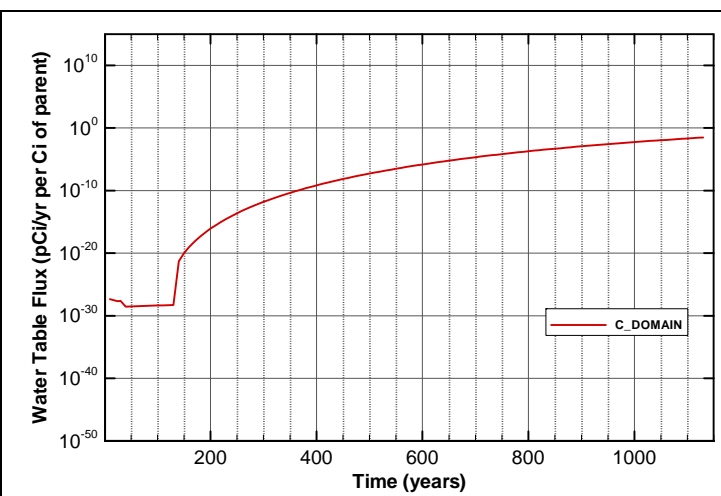

Figure A-820. Flux at water table for Case01n11_on Se-79

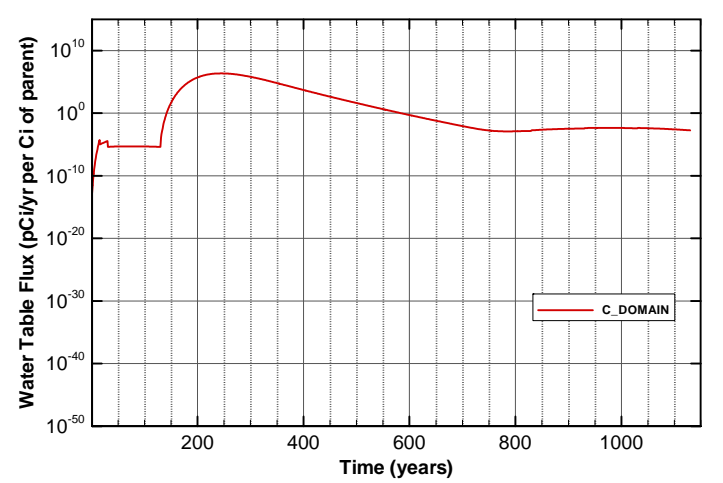

Figure A-822. Flux at water table for Case01n11_on Sr-90

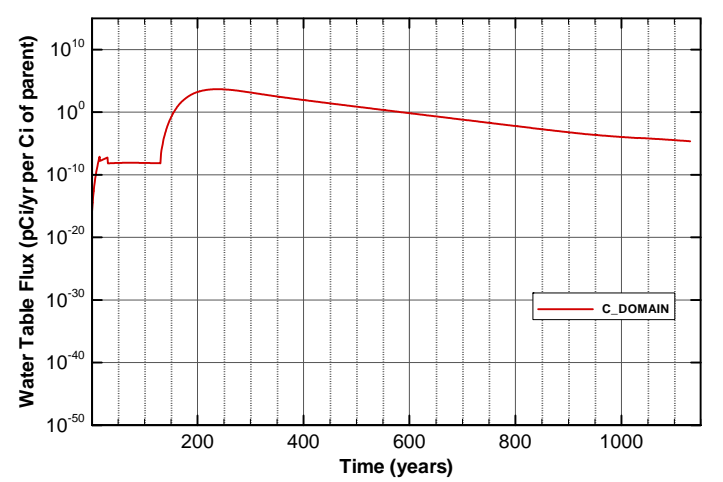

Figure A-824. Flux at water table for Case01n11_on Sr-90_Mk50A 


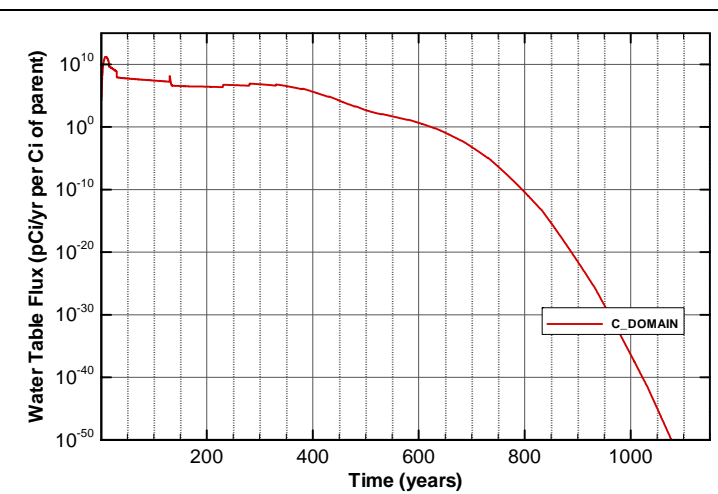

Figure A-825. Flux at water table for Case01n11_on Tc-99

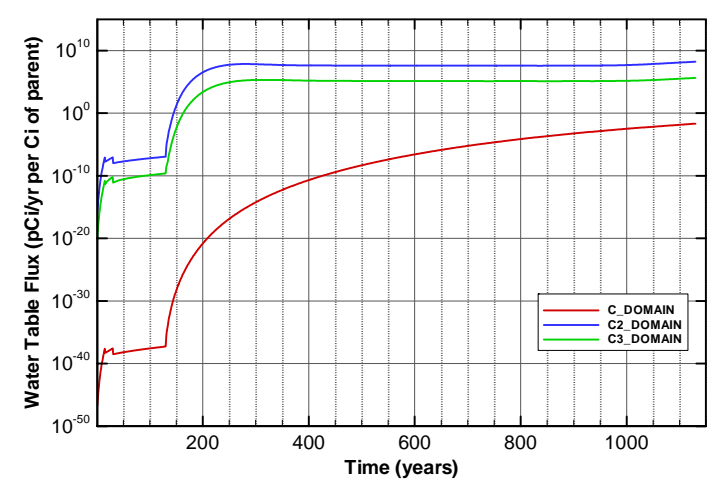

Figure A-827. Flux at water table for Case01n11_on Th-230

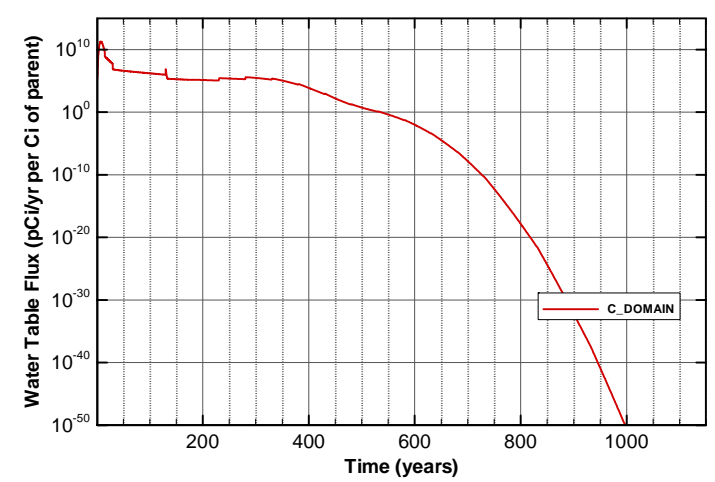

Figure A-829. Flux at water table for Case01n11_on Tracer

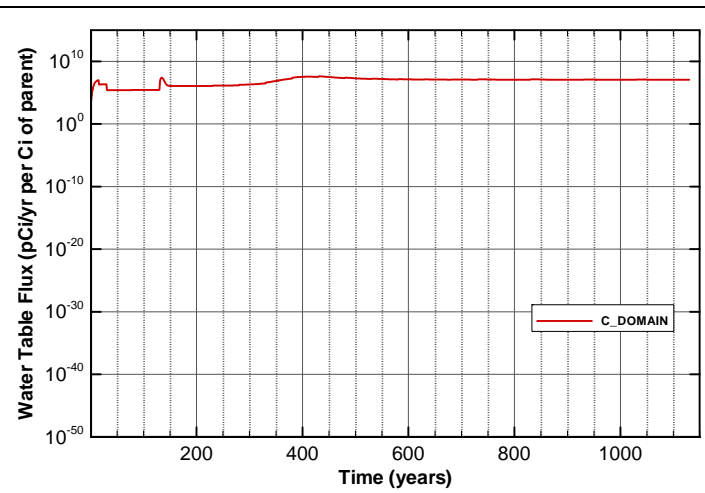

Figure A-826. Flux at water table for Case01n11_on Tc-99_Mk50A

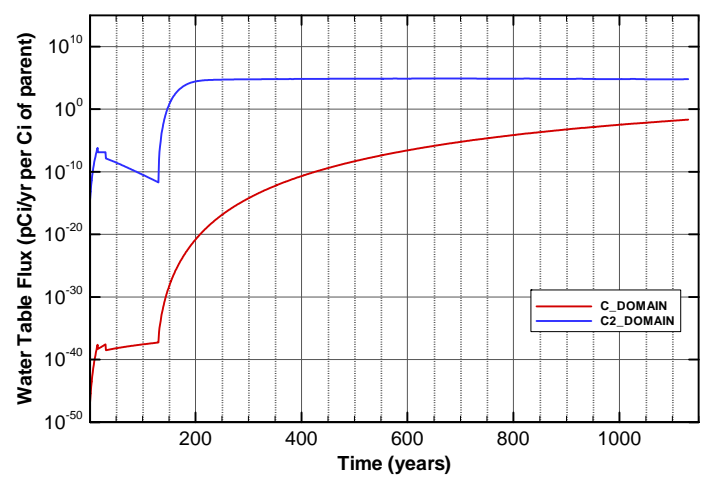

Figure A-828. Flux at water table for Case01n11_on Th-232

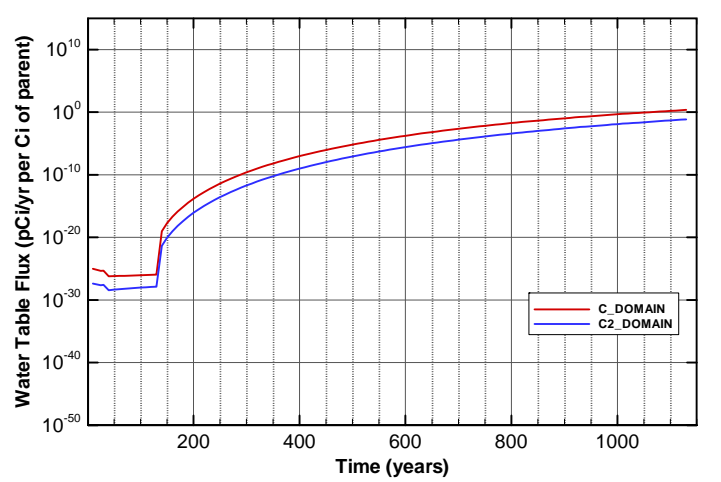

Figure A-830. Flux at water table for Case01n11_on U-233 


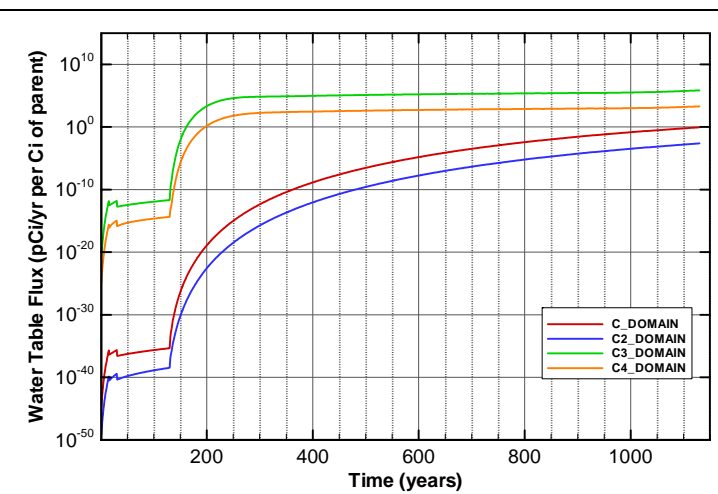

Figure A-831. Flux at water table for Case01n11_on U-234

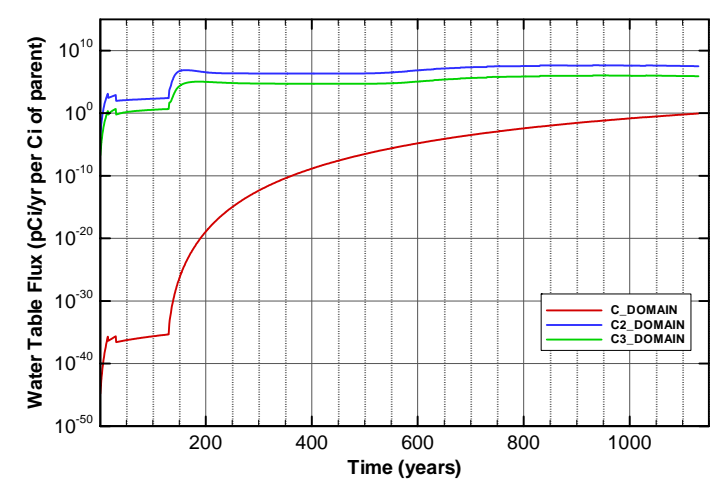

Figure A-833. Flux at water table for Case01n11_on U-235

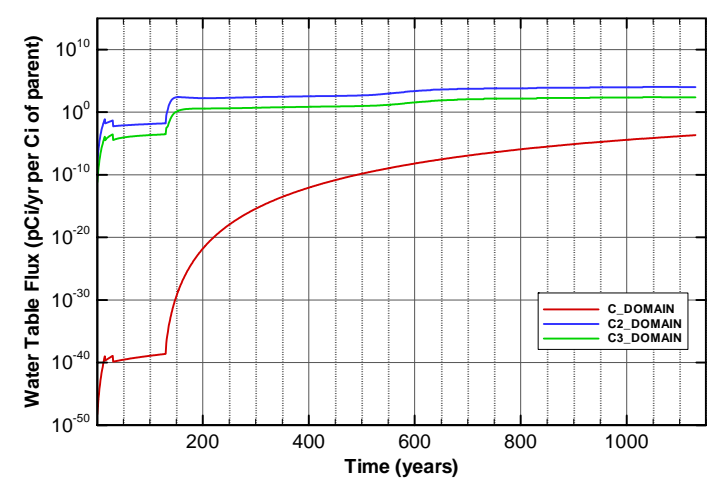

Figure A-835. Flux at water table for Case01n11_on U-235_Paducah.Cask

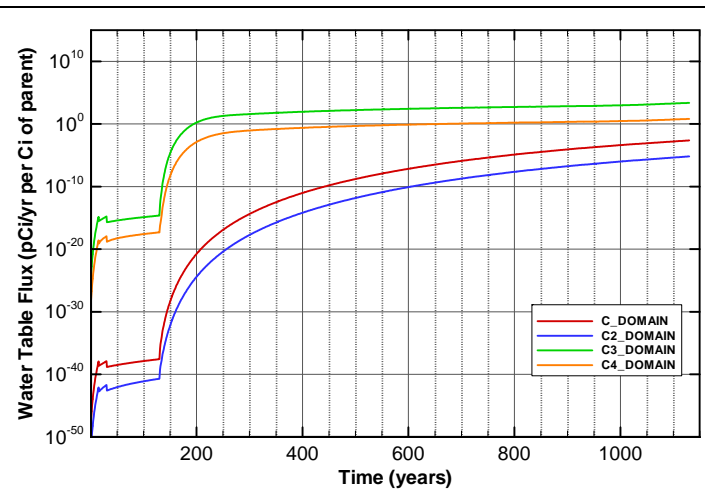

Figure A-832. Flux at water table for Case01n11_on U-234_Mglass

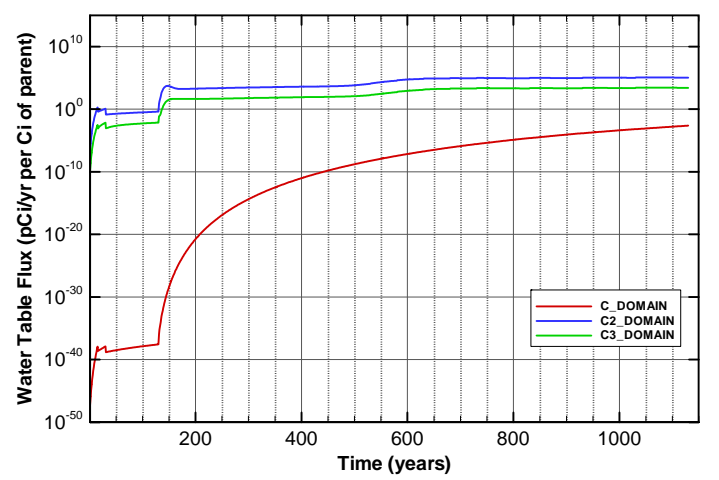

Figure A-834. Flux at water table for Case01n11_on U-235_Mglass

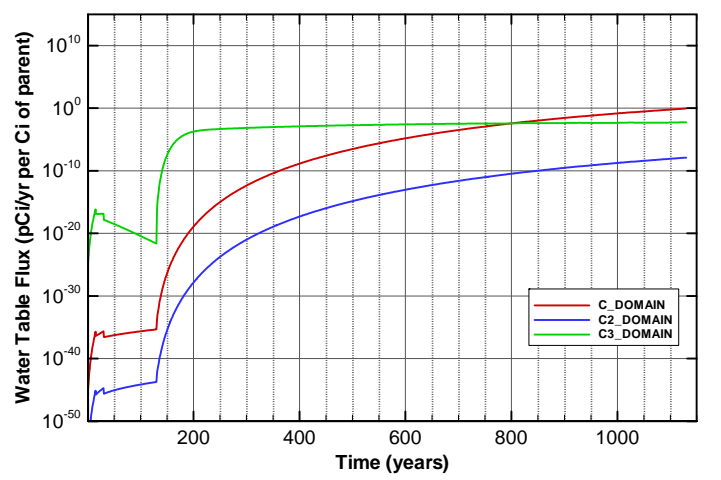

Figure A-836. Flux at water table for Case01n11_on U-236 


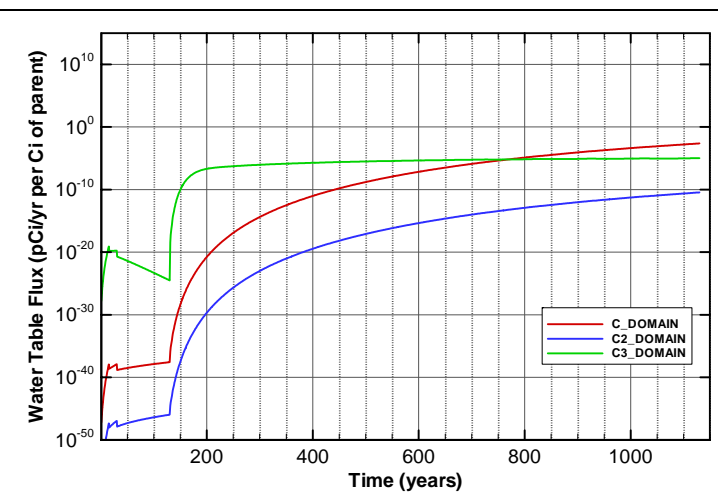

Figure A-837. Flux at water table for Case01n11_on U-236_Mglass

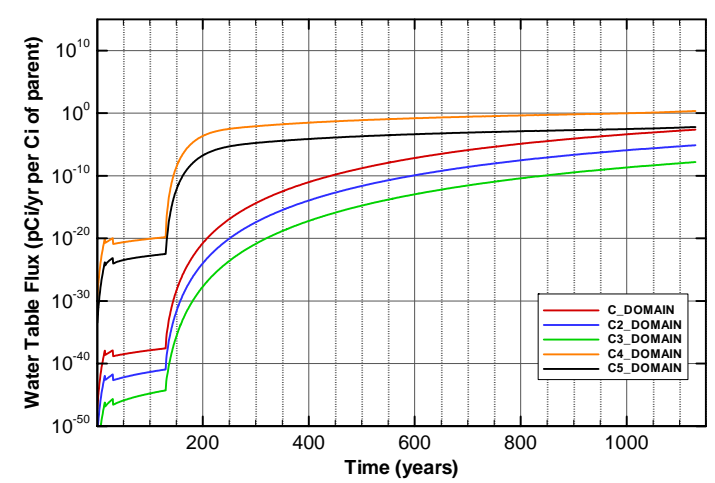

Figure A-839. Flux at water table for Case01n11_on U-238_Mglass

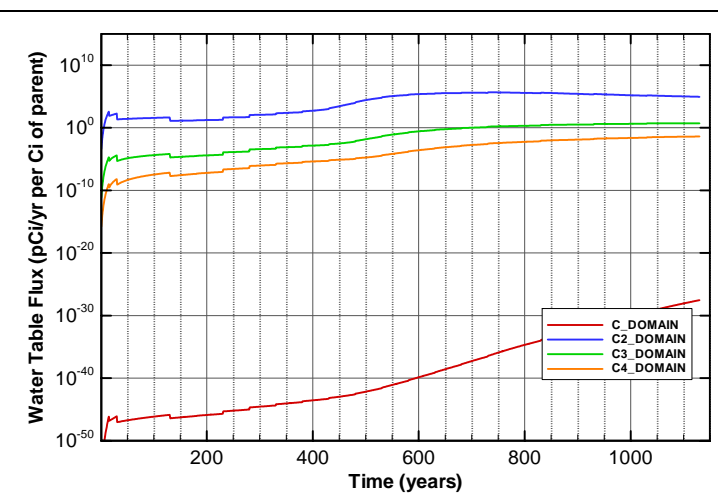

Figure A-841. Flux at water table for Case01_off Am-241

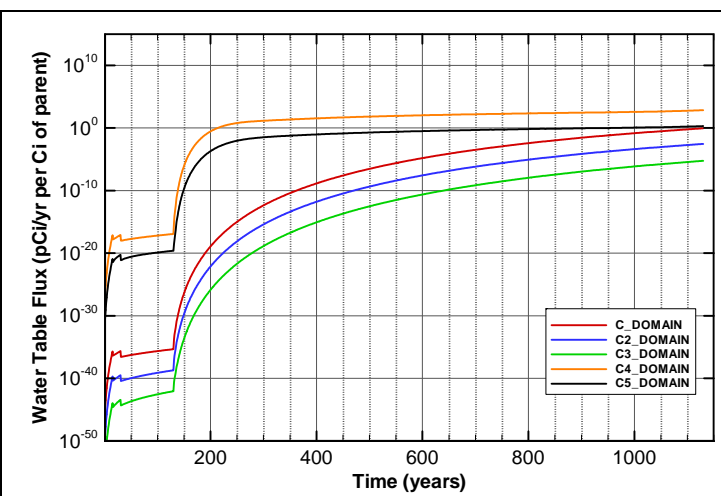

Figure A-838. Flux at water table for Case01n11_on U-238

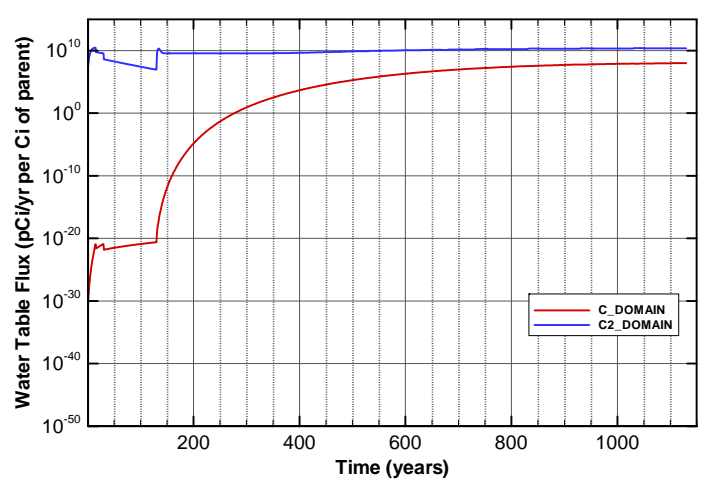

Figure A-840. Flux at water table for Case01n11_on Zr-93

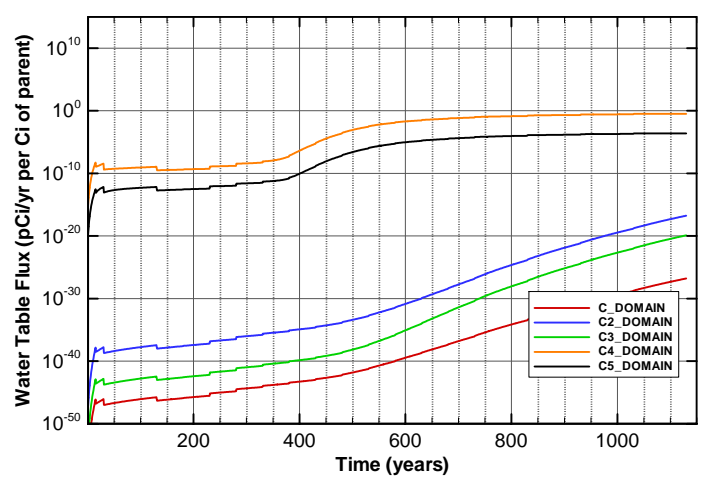

Figure A-842. Flux at water table for Case01_off Am-243 
SRNL-STI-2008-00397, REVISION 0
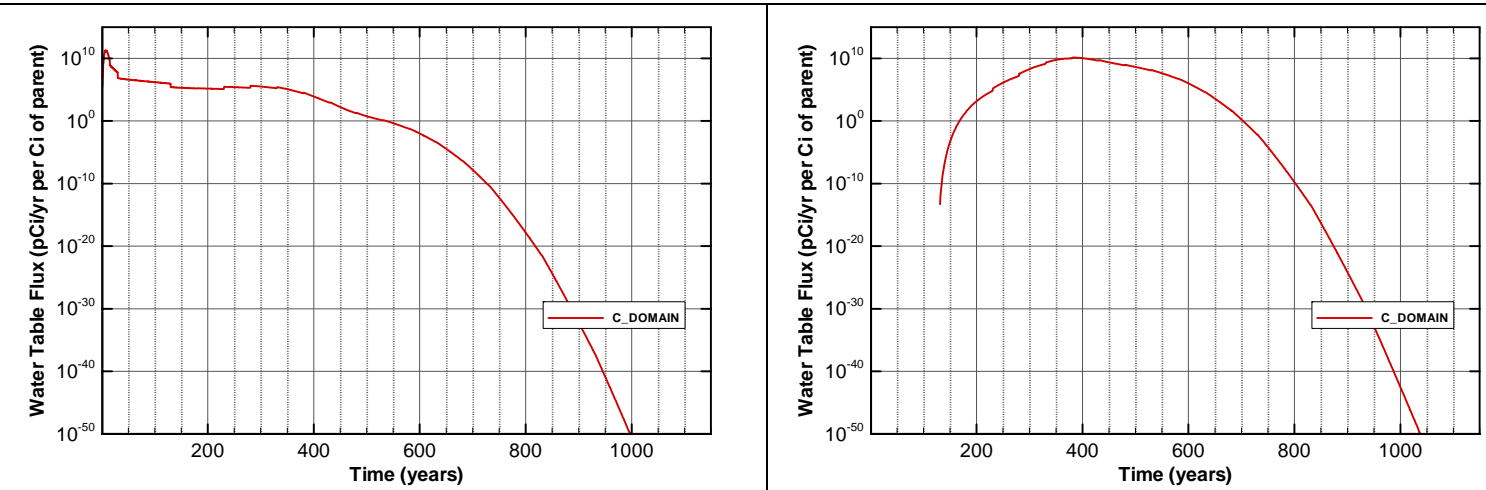

Figure A-843. Flux at water table for Case01_off C-14

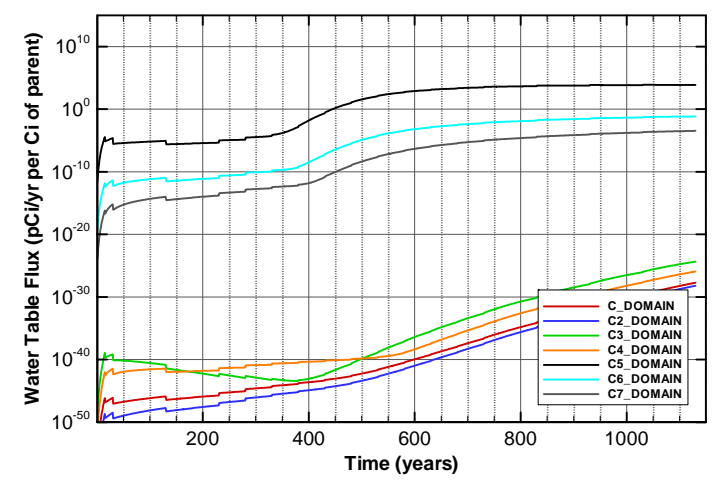

Figure A-845. Flux at water table for Case01_off Cf-249

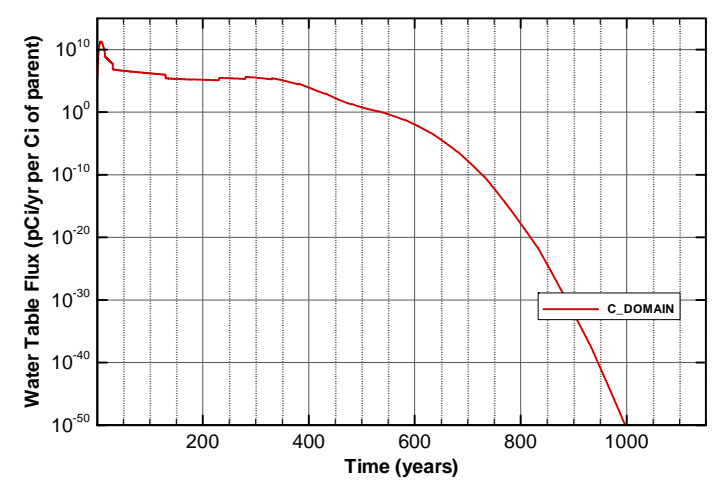

Figure A-847. Flux at water table for Case01_off Cl-36

Figure A-844. Flux at water table for Case01_off C-14_NR.Pump

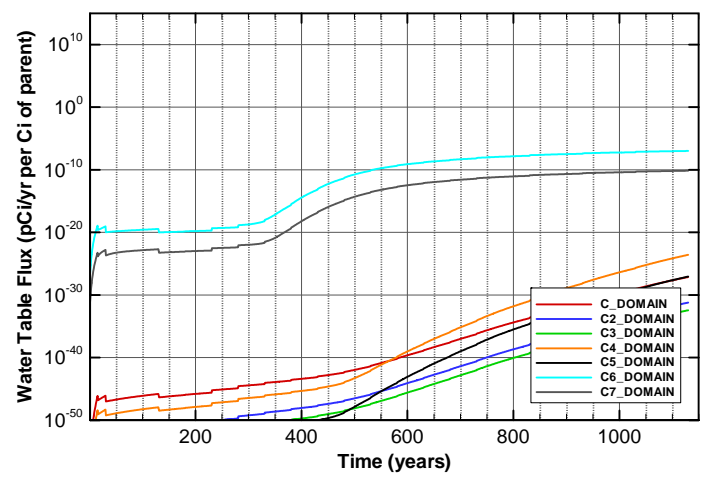

Figure A-846. Flux at water table for Case01_off Cf-251

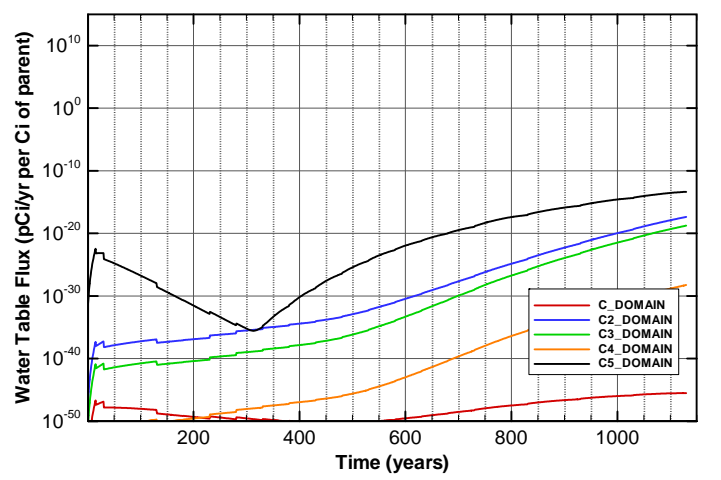

Figure A-848. Flux at water table for Case01_off Cm-244 
SRNL-STI-2008-00397, REVISION 0

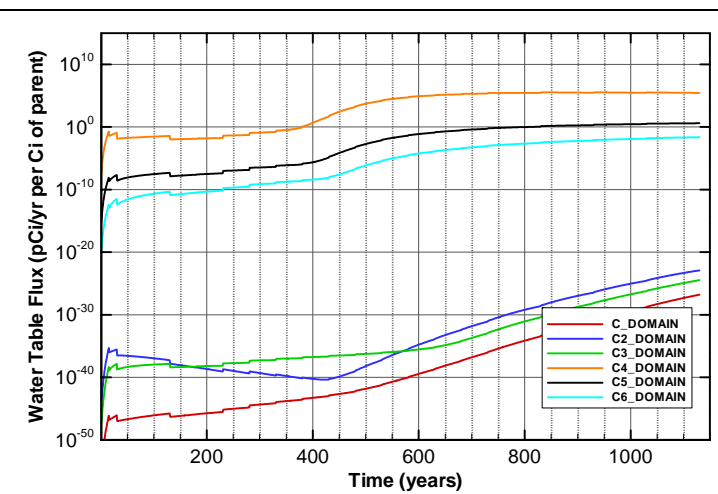

Figure A-849. Flux at water table for Case01_off Cm-245

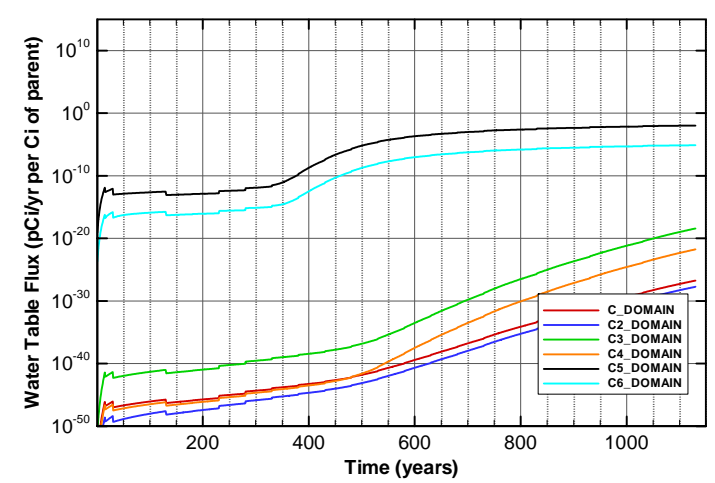

Figure A-851. Flux at water table for Case01_off Cm-247

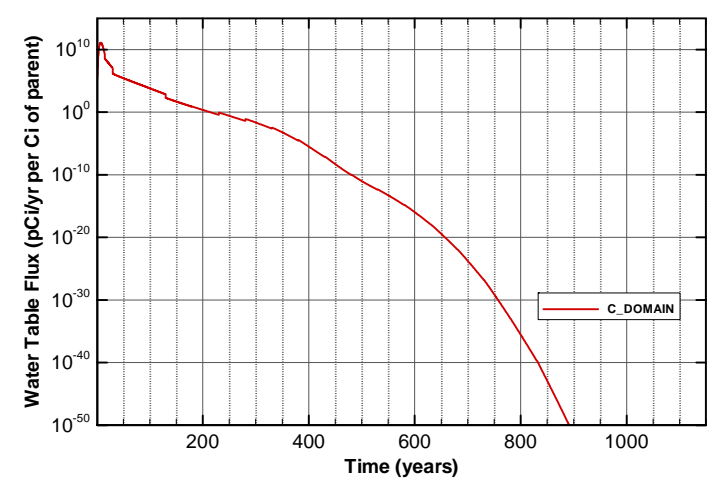

Figure A-853. Flux at water table for Case01_off H-3

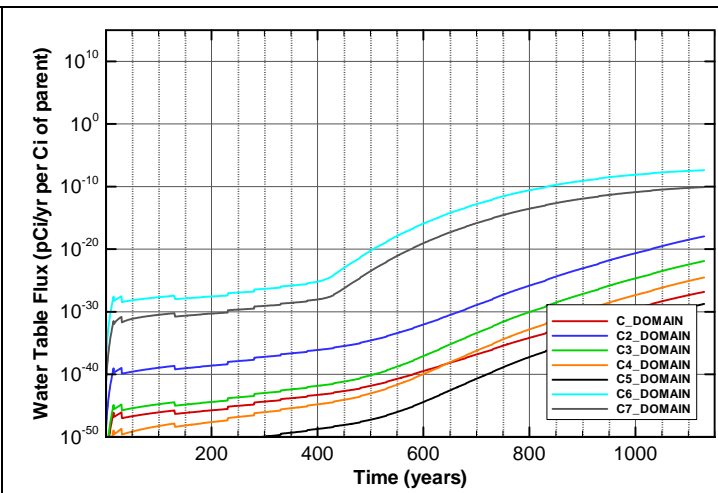

Figure A-850. Flux at water table for Case01_off Cm-246

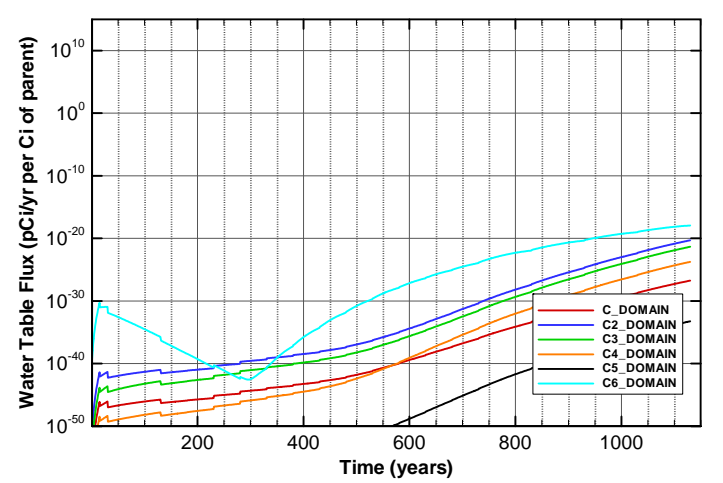

Figure A-852. Flux at water table for Case01_off Cm-248

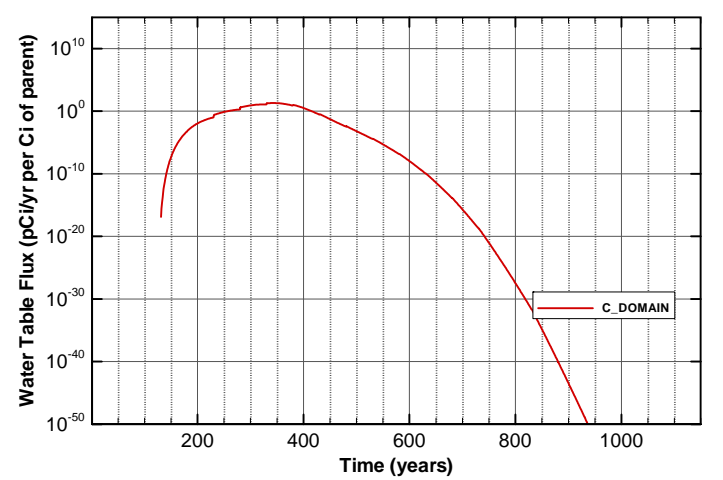

Figure A-854. Flux at water table for Case01_off H-3_ETF.Carbon 


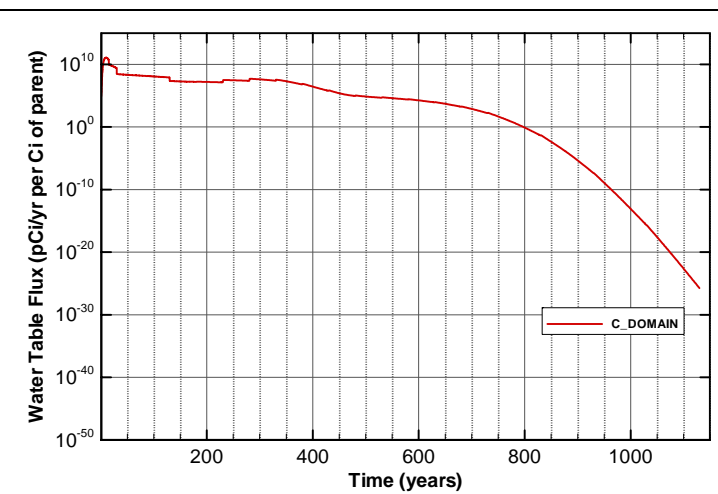

Figure A-855. Flux at water table for Case01_off I-129

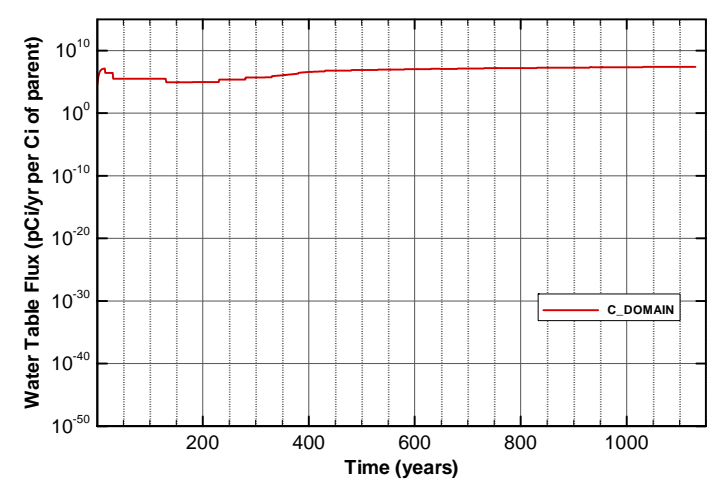

Figure A-857. Flux at water table for Case01_off I-129_ETF.GT.73

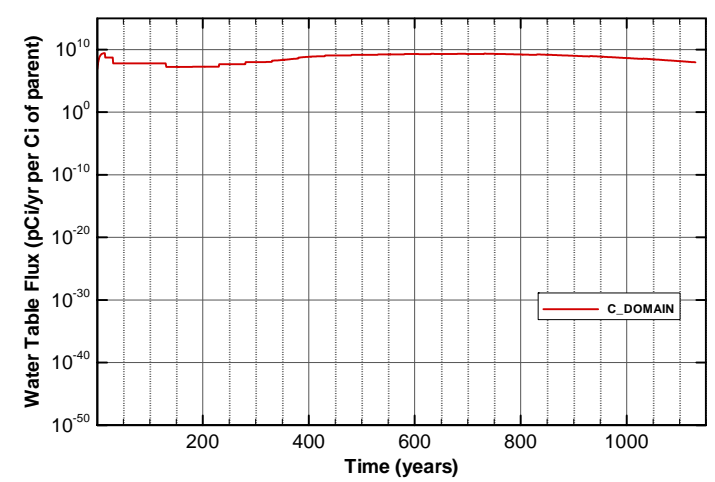

Figure A-859. Flux at water table for Case01_off I-129_F.CG.8

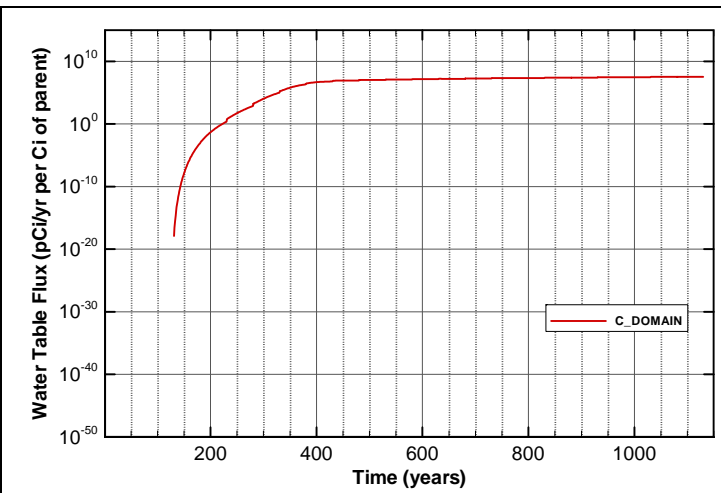

Figure A-856. Flux at water table for Case01_off I-129_ETF.Carbon

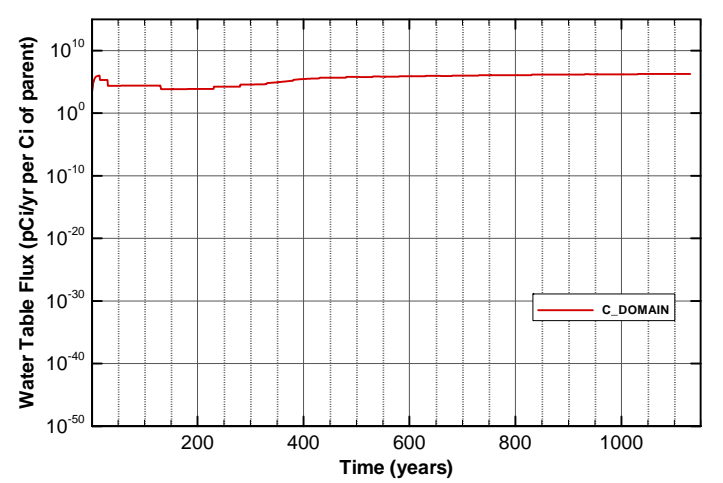

Figure A-858. Flux at water table for Case01_off I-129_F.Carbon

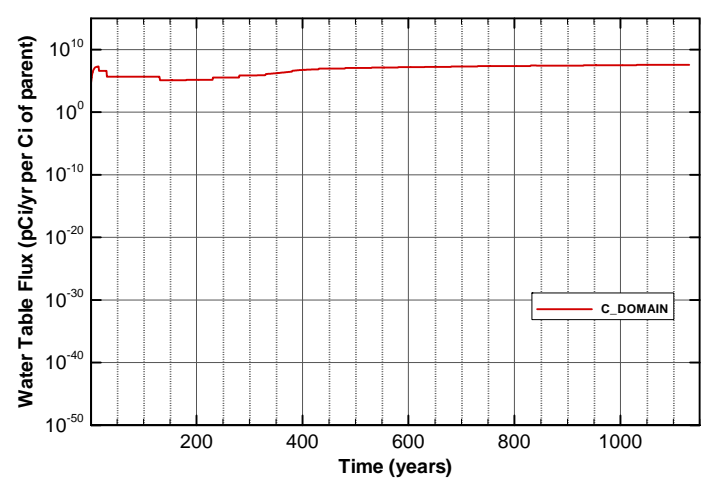

Figure A-860. Flux at water table for Case01_off I-129_F.Dowex.21K 


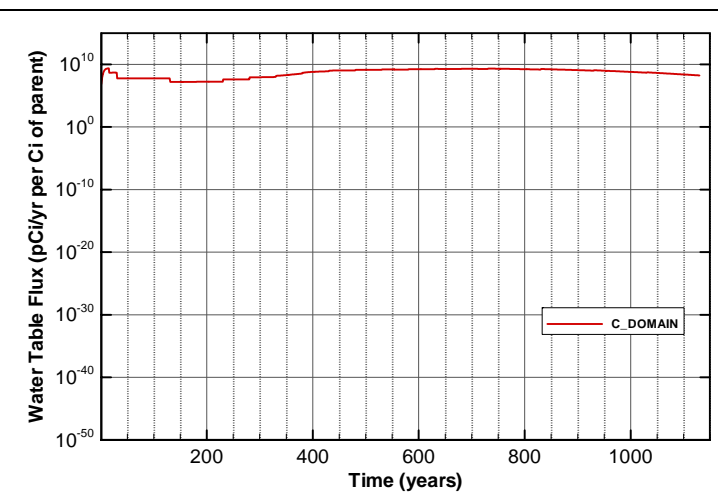

Figure A-861. Flux at water table for Case01_off I-129_F.Filtercake

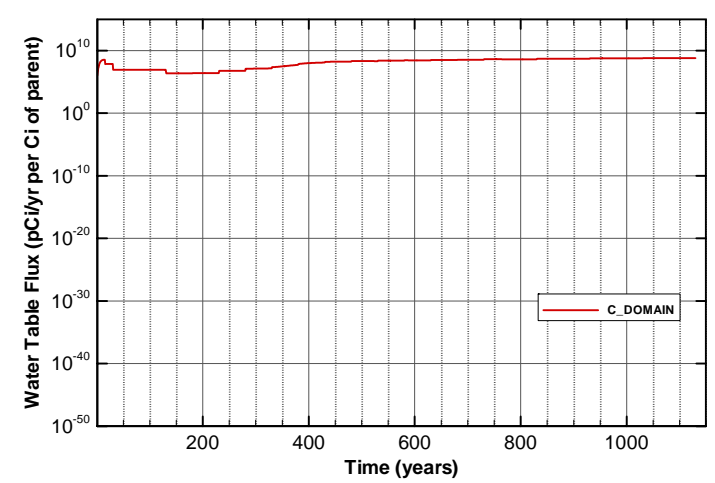

Figure A-863. Flux at water table for Case01_off I-129_H.CG.8

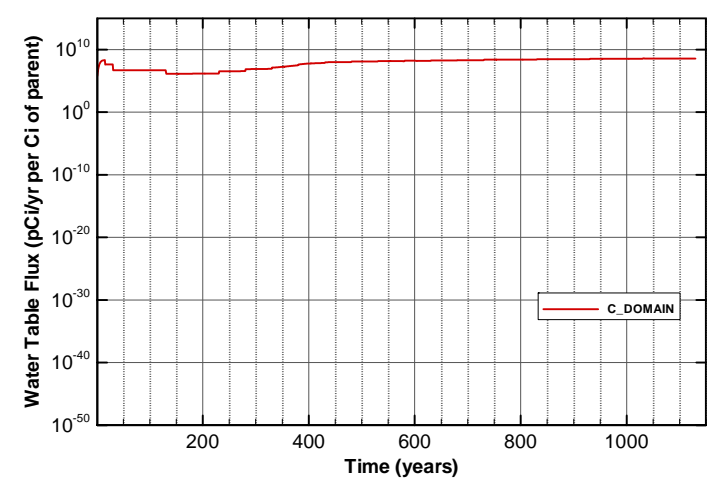

Figure A-865. Flux at water table for Case01_off I-129_H.Filtercake

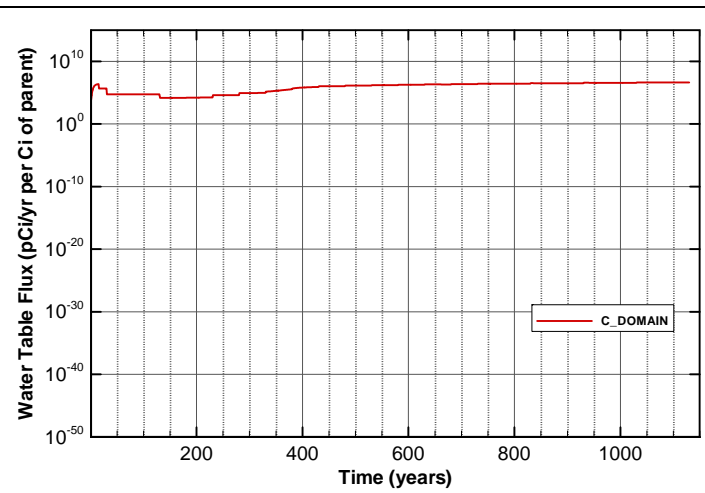

Figure A-862. Flux at water table for Case01_off I-129_H.Carbon

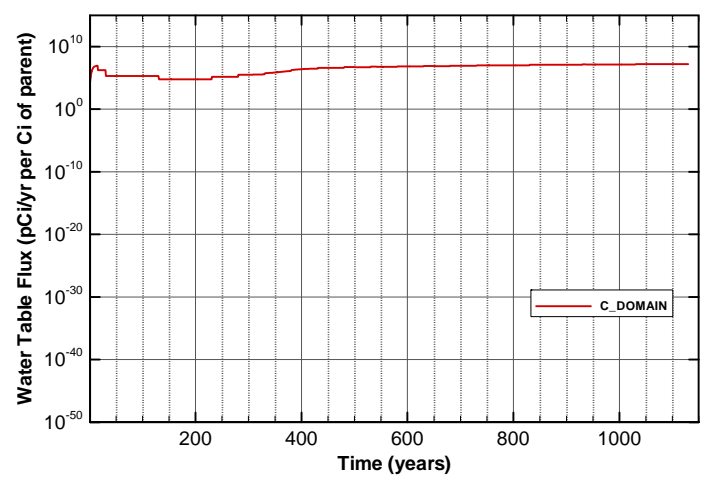

Figure A-864. Flux at water table for Case01_off I-129_H.Dowex.21K

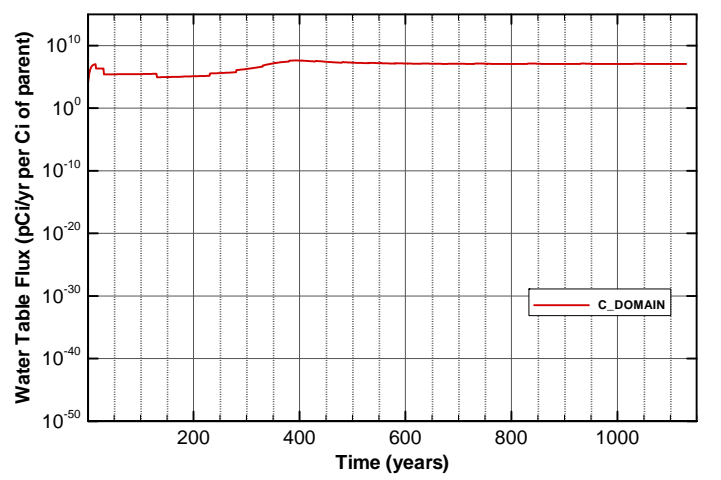

Figure A-866. Flux at water table for Case01_off I-129_Mk50A 


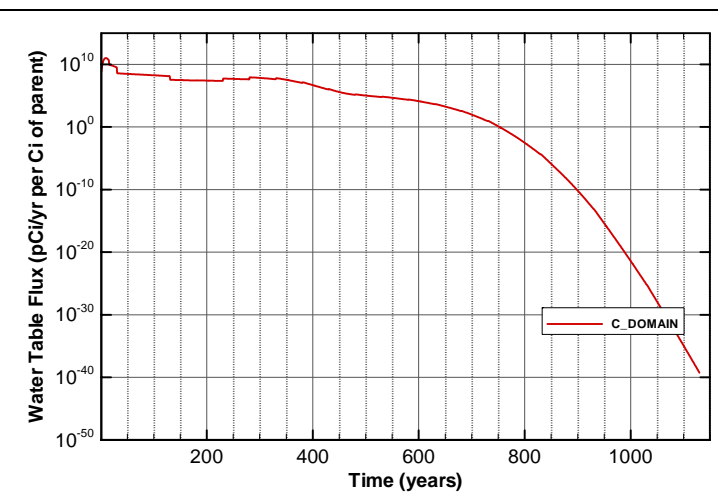

Figure A-867. Flux at water table for Case01_off K-40

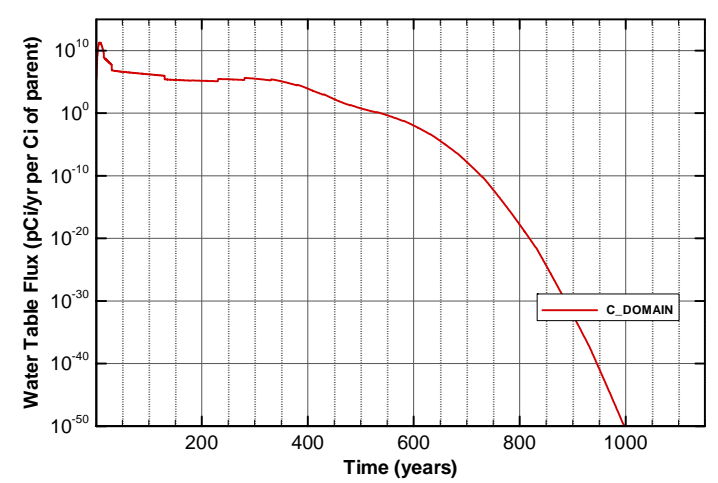

Figure A-869. Flux at water table for Case01_off Nb-94

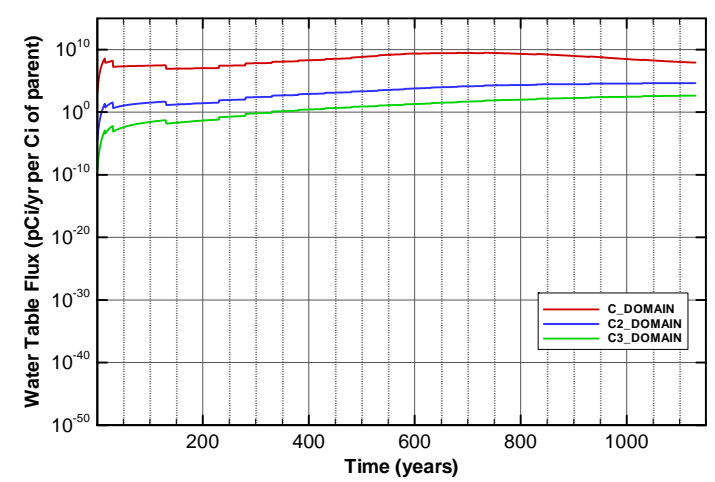

Figure A-871. Flux at water table for Case01_off Np-237

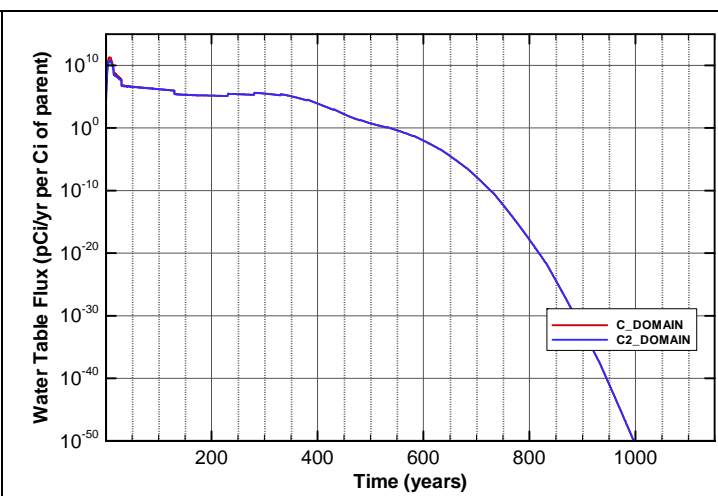

Figure A-868. Flux at water table for Case01_off Mo-93

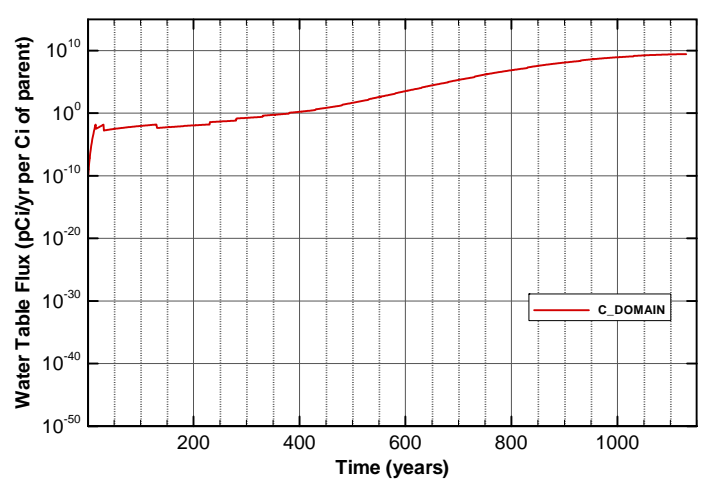

Figure A-870. Flux at water table for Case01_off Ni-59

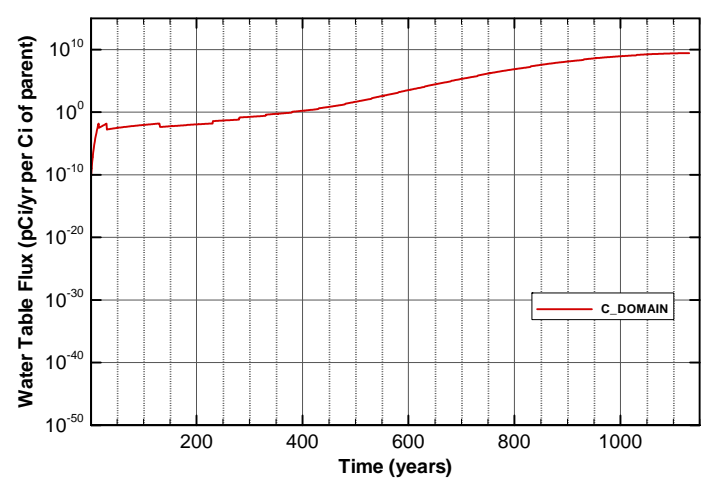

Figure A-872. Flux at water table for Case01_off Pd-107 
SRNL-STI-2008-00397, REVISION 0
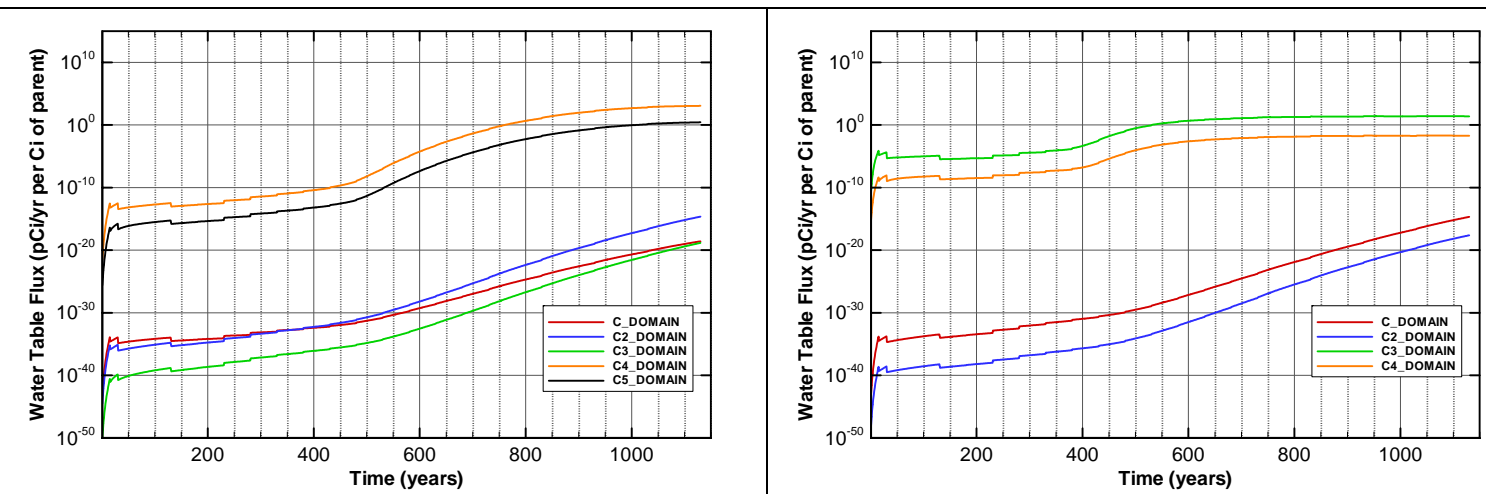

Figure A-873. Flux at water table for Case01_off Pu-238

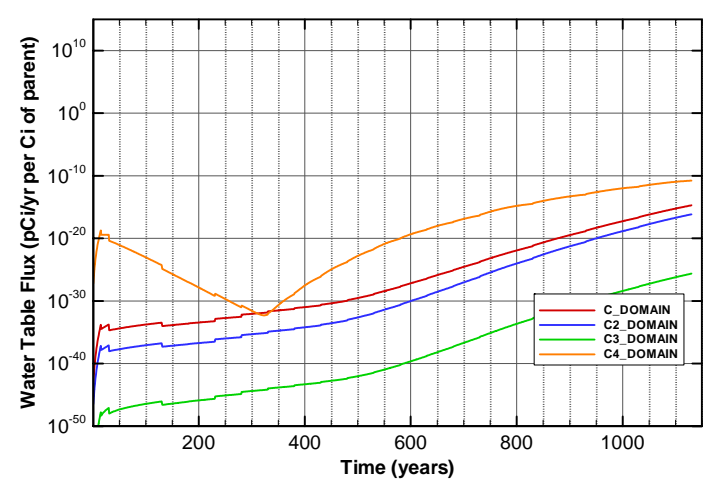

Figure A-875. Flux at water table for Case01_off Pu-240

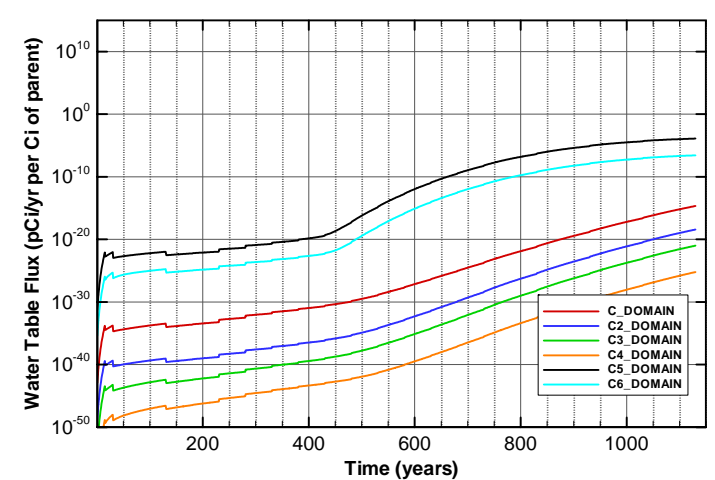

Figure A-877. Flux at water table for Case01_off Pu-242

Figure A-874. Flux at water table for Case01_off Pu-239

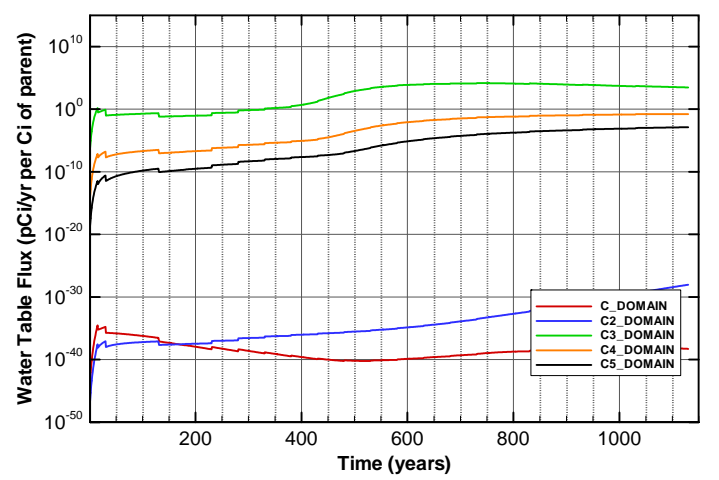

Figure A-876. Flux at water table for Case01_off Pu-241

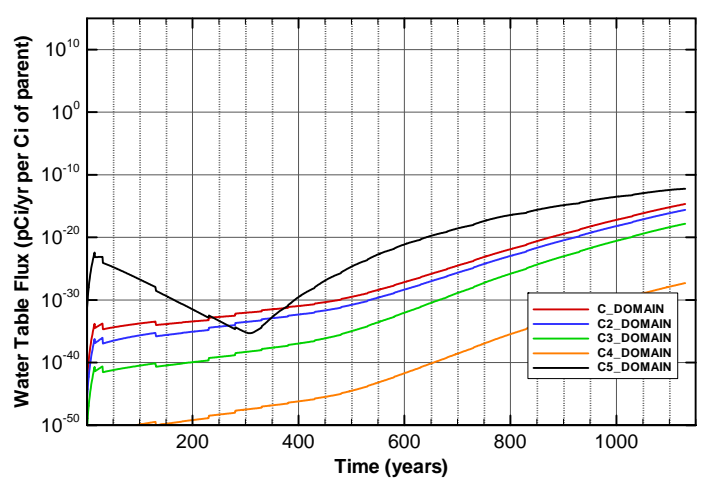

Figure A-878. Flux at water table for Case01_off Pu-244 
SRNL-STI-2008-00397, REVISION 0

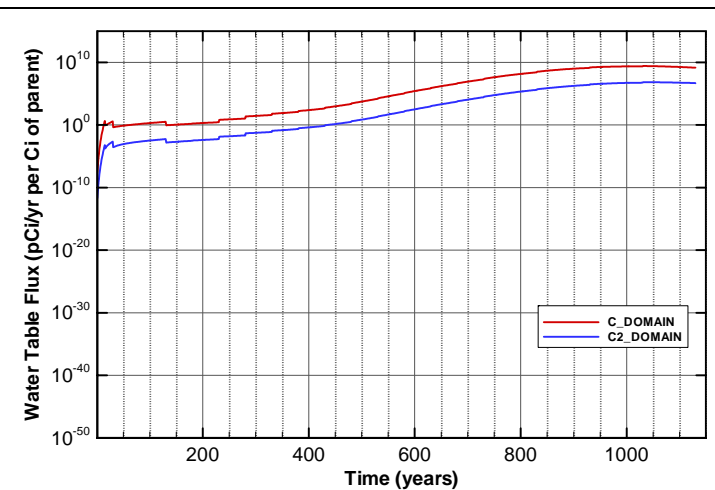

Figure A-879. Flux at water table for Case01_off Ra-226

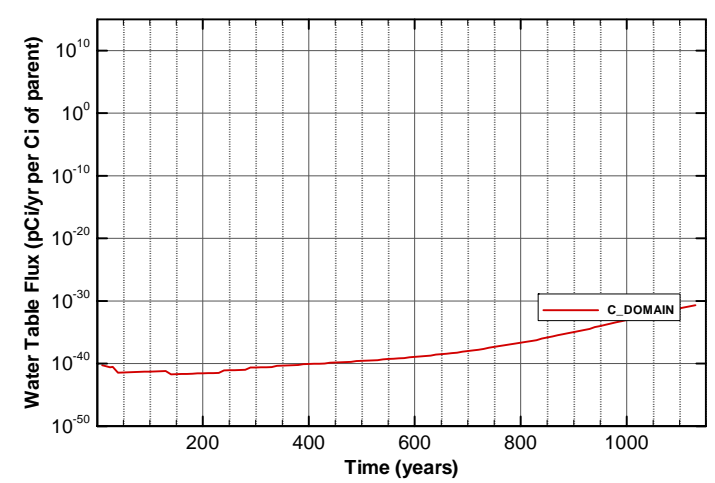

Figure A-881. Flux at water table for Case01_off Sn-126

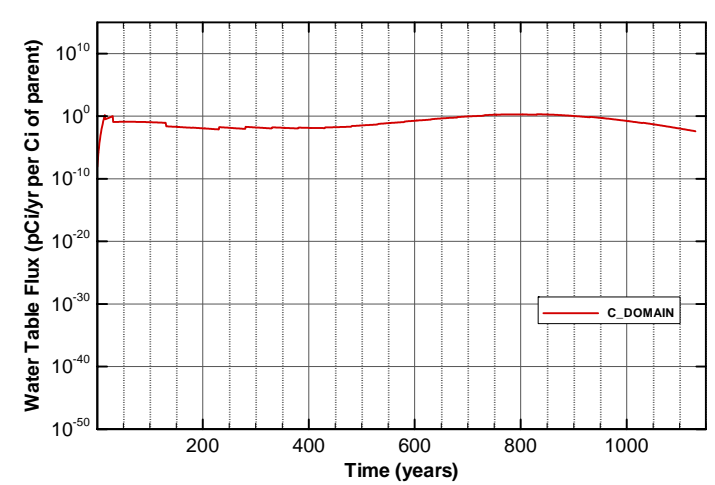

Figure A-883. Flux at water table for Case01_off Sr-90_Cask

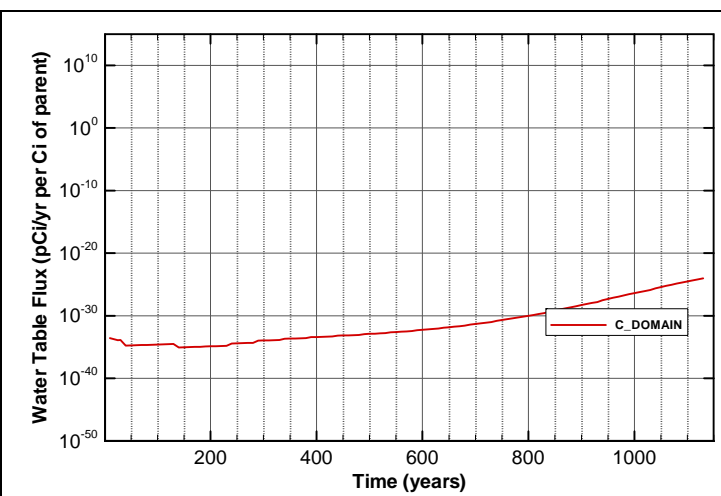

Figure A-880. Flux at water table for Case01_off Se-79

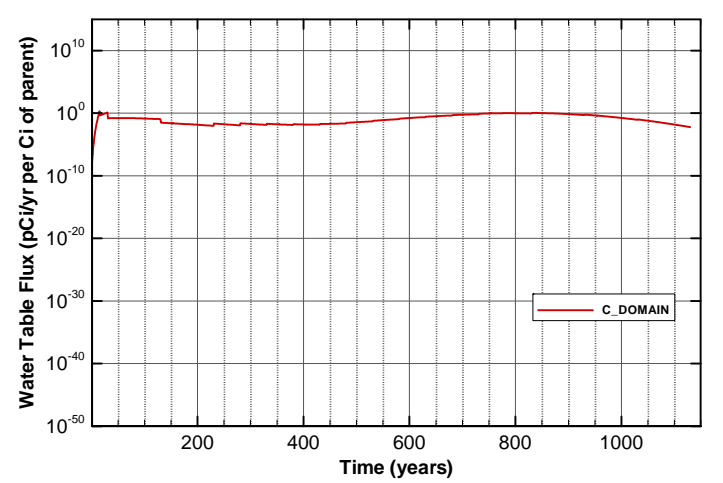

Figure A-882. Flux at water table for Case01_off Sr-90

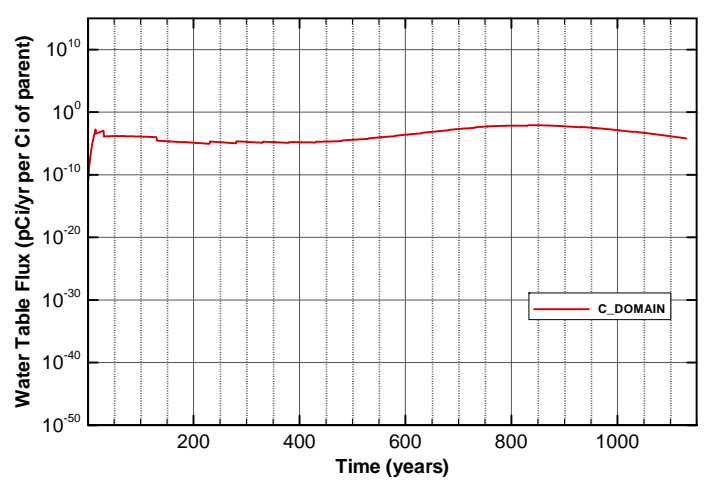

Figure A-884. Flux at water table for Case01_off Sr-90_Mk50A 


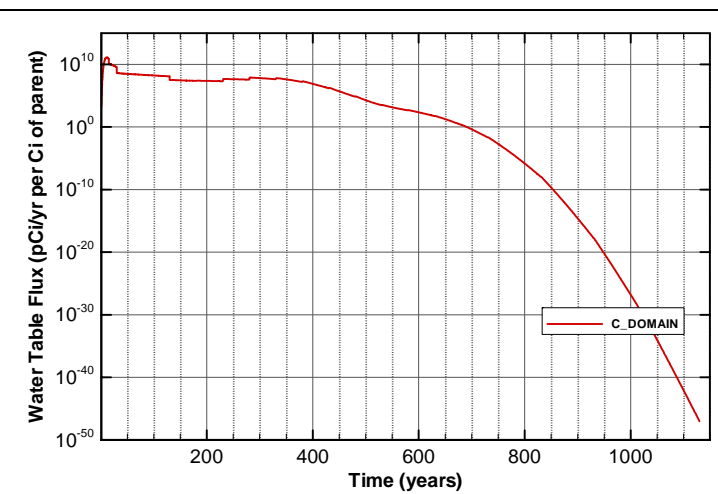

Figure A-885. Flux at water table for Case01_off Tc-99

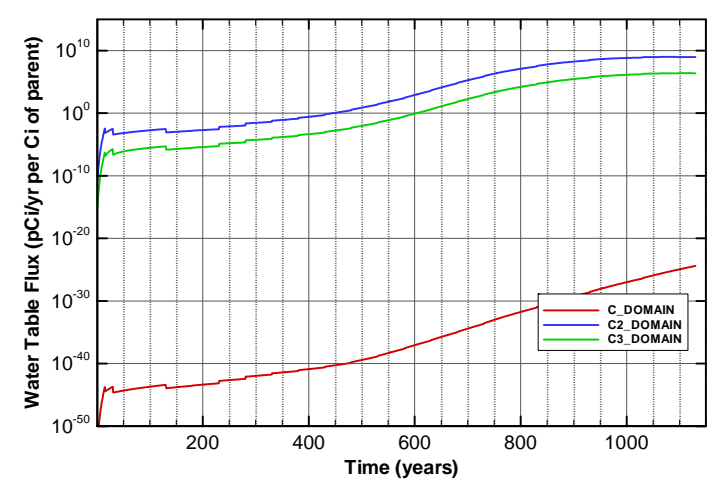

Figure A-887. Flux at water table for Case01_off Th-230

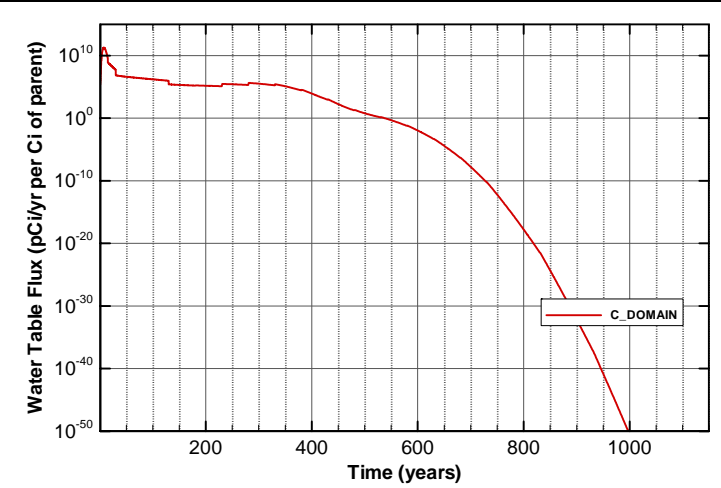

Figure A-889. Flux at water table for Case01_off Tracer

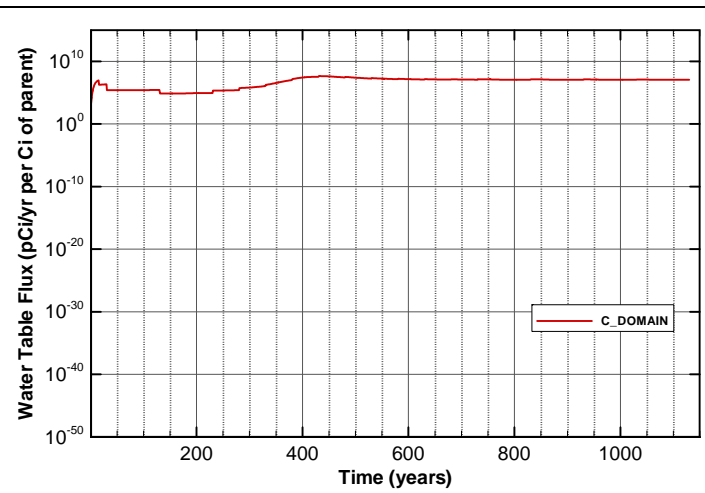

Figure A-886. Flux at water table for Case01_off Tc-99_Mk50A

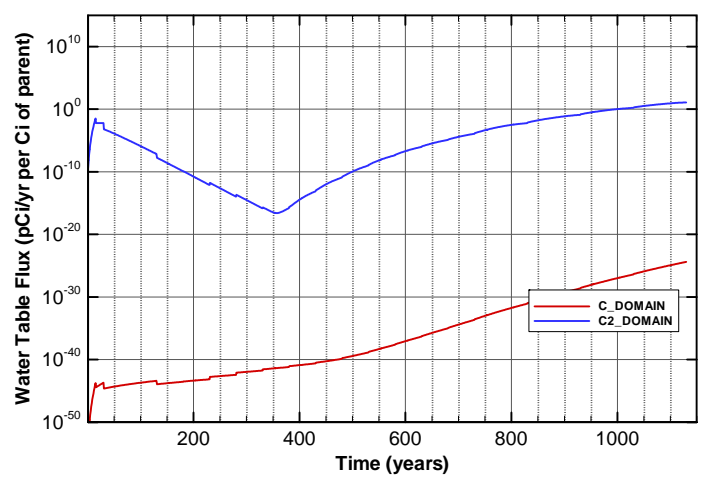

Figure A-888. Flux at water table for Case01_off Th-232

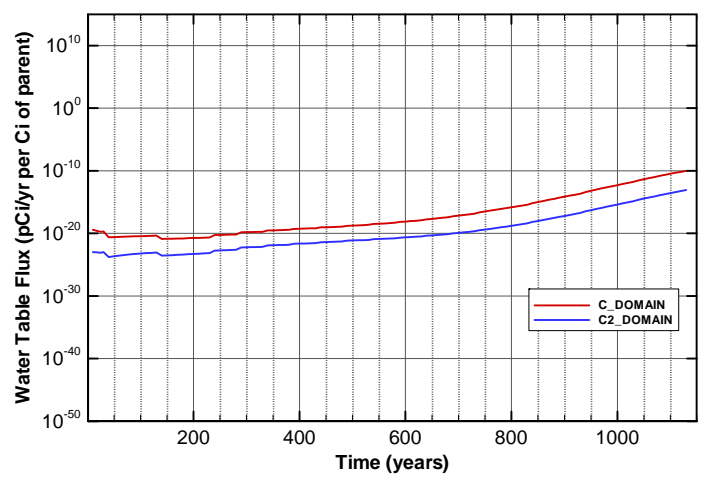

Figure A-890. Flux at water table for Case01_off U-233 
SRNL-STI-2008-00397, REVISION 0
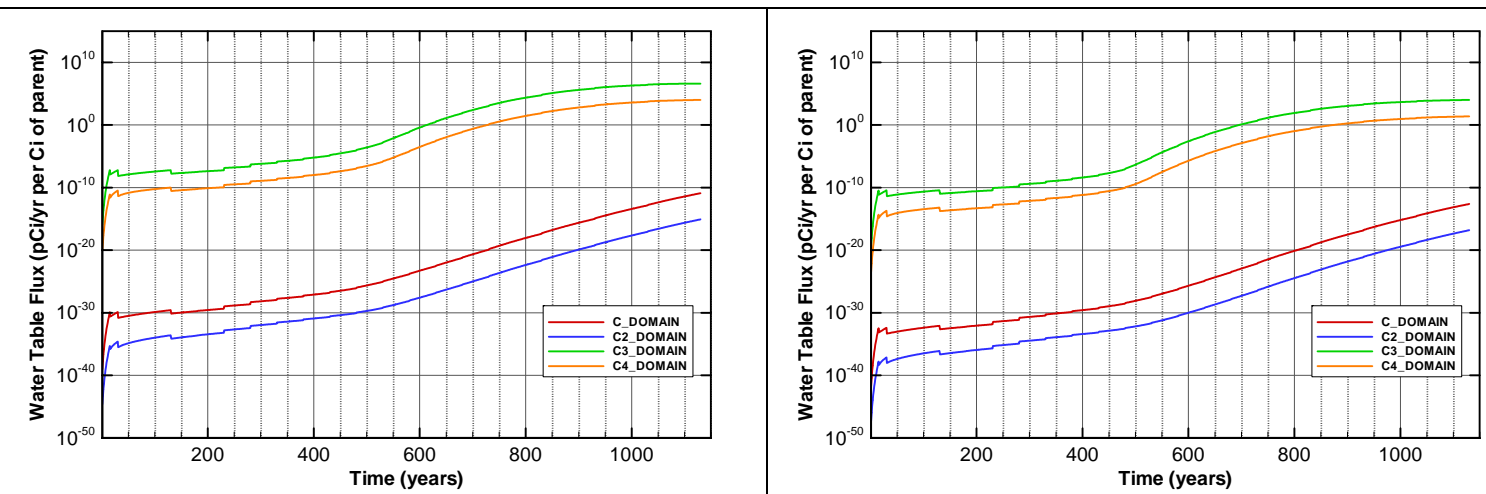

Figure A-891. Flux at water table for Case01_off U-234

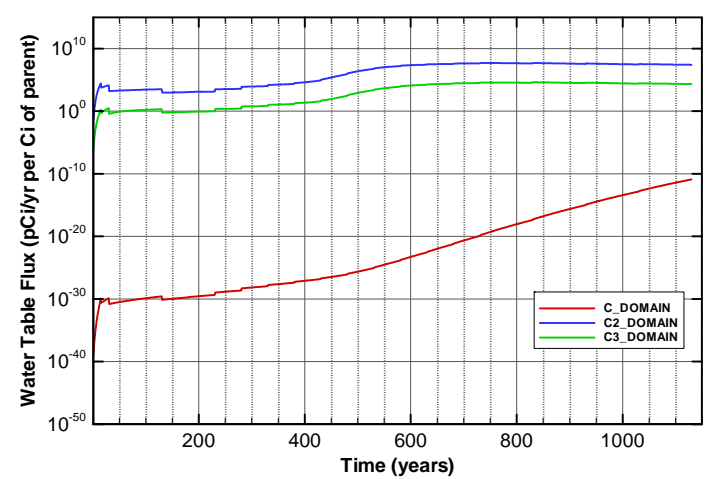

Figure A-893. Flux at water table for Case01_off U-235

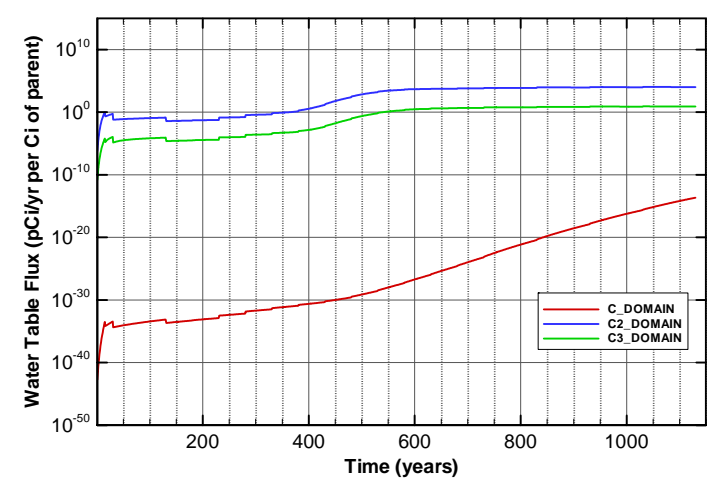

Figure A-895. Flux at water table for Case01_off U-235_Paducah.Cask

Figure A-892. Flux at water table for Case01_off U-234_Mglass

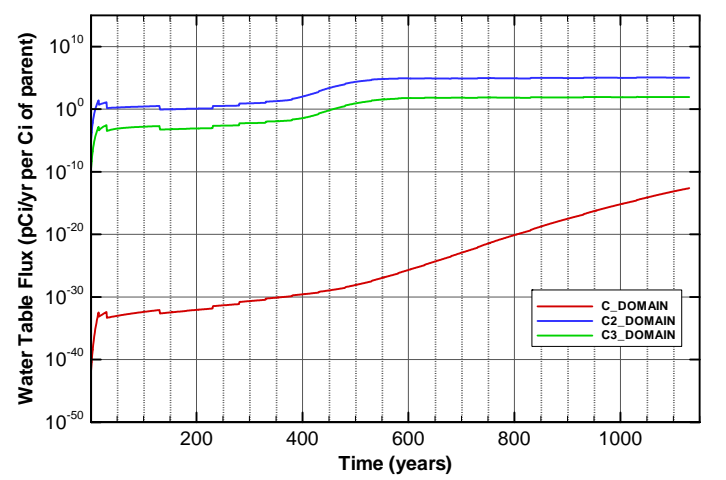

Figure A-894. Flux at water table for Case01_off U-235_Mglass

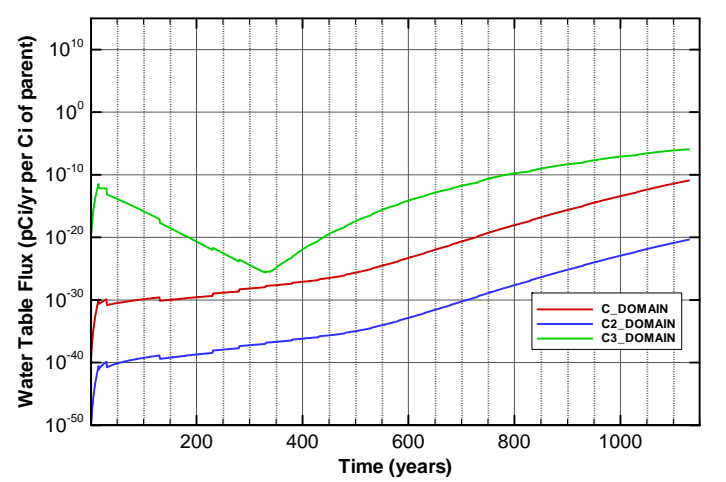

Figure A-896. Flux at water table for Case01_off U-236 
SRNL-STI-2008-00397, REVISION 0
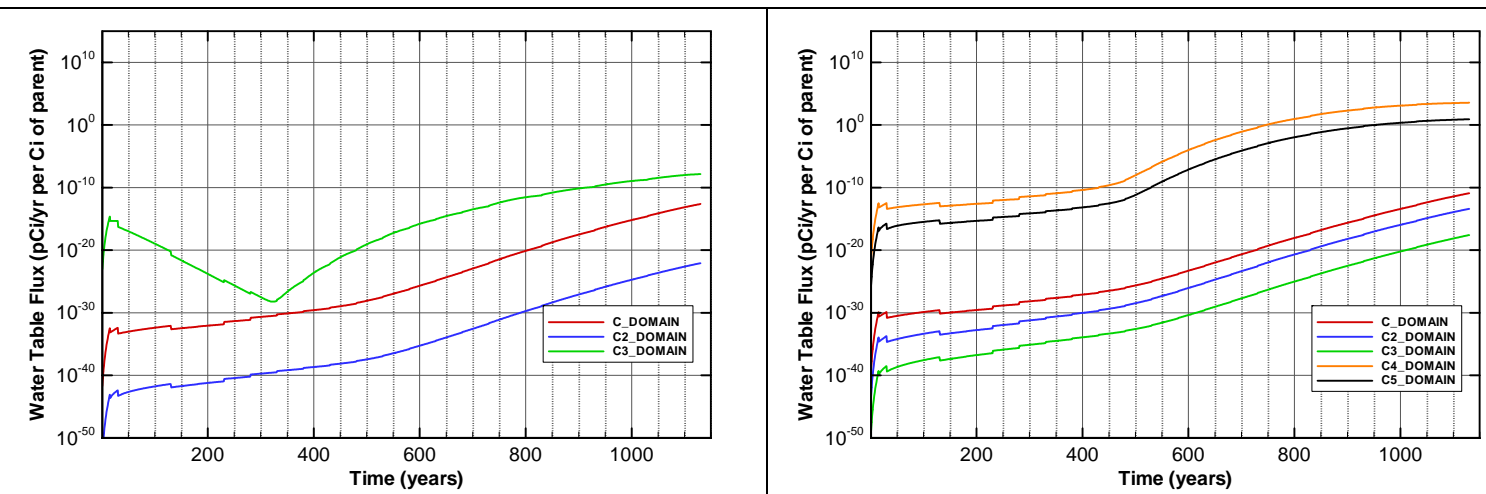

Figure A-897. Flux at water table for Case01_off U-236_Mglass

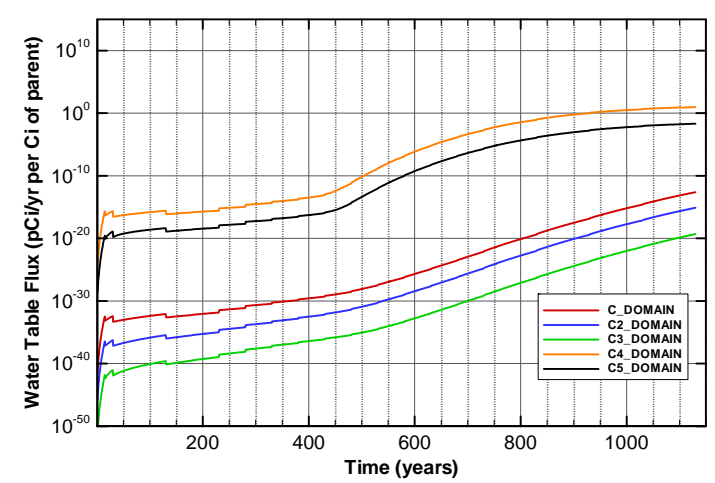

Figure A-899. Flux at water table for Case01_off U-238_Mglass

Figure A-898. Flux at water table for Case01_off U-238

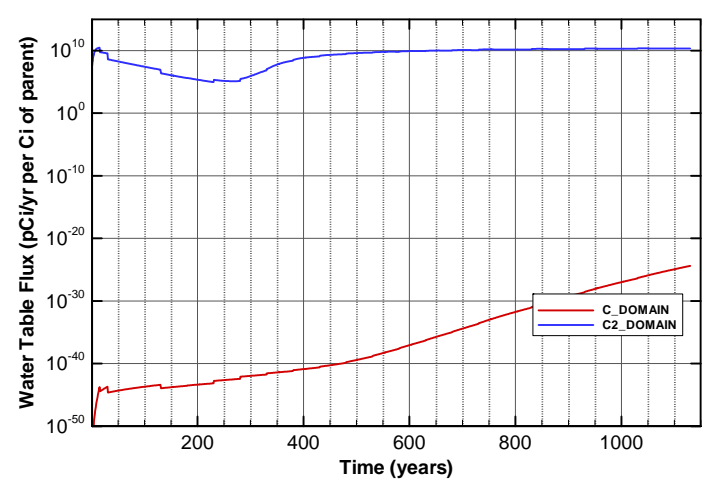

Figure A-900. Flux at water table for Case01_off Zr-93

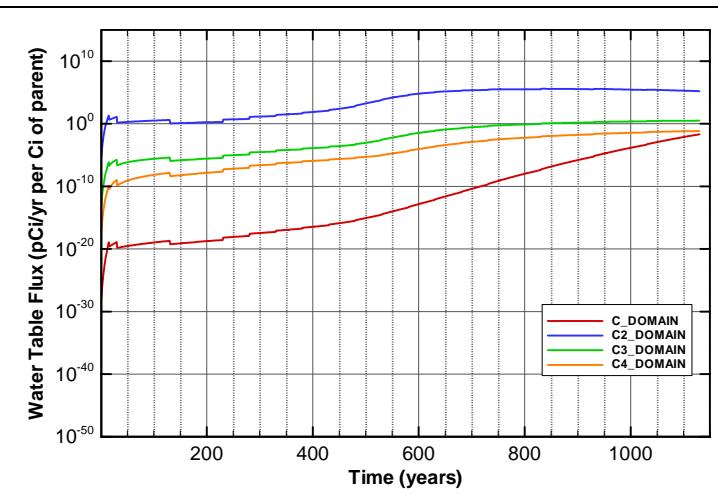

Figure A-901. Flux at water table for Case01_on Am-241

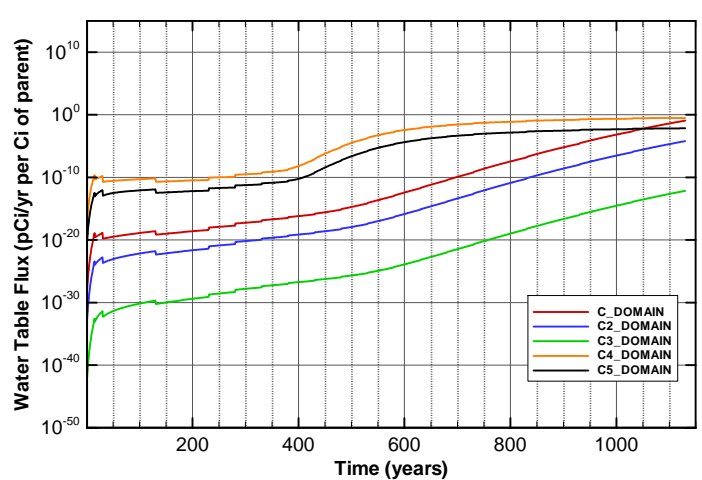

Figure A-902. Flux at water table for Case01_on Am-243 
SRNL-STI-2008-00397, REVISION 0
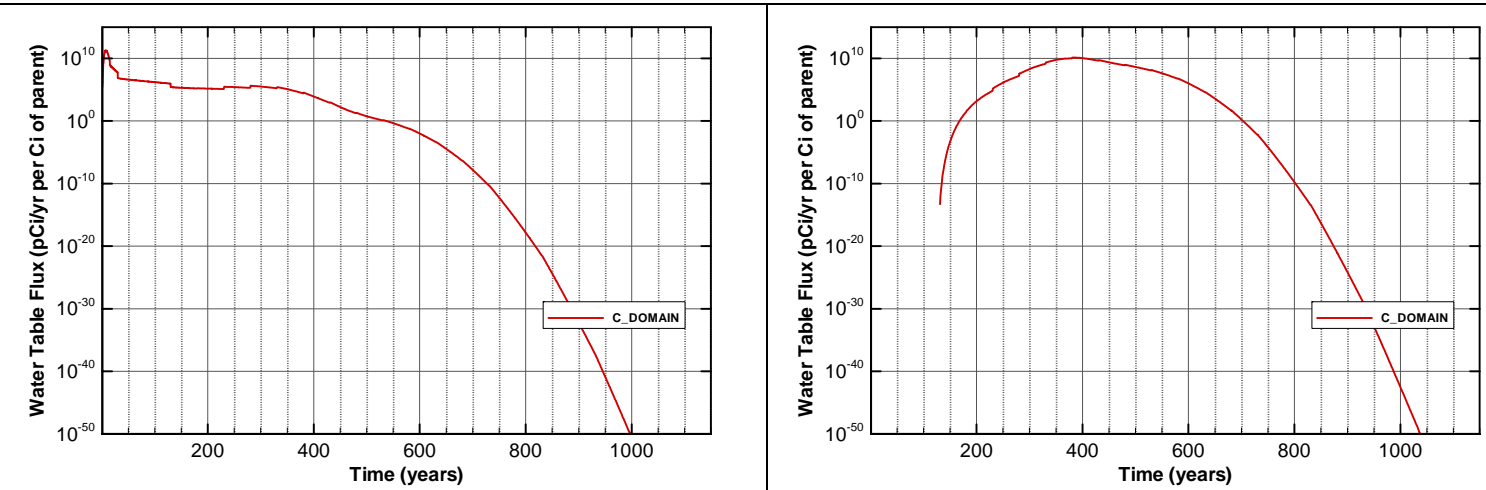

Figure A-903. Flux at water table for Case01_on C-14

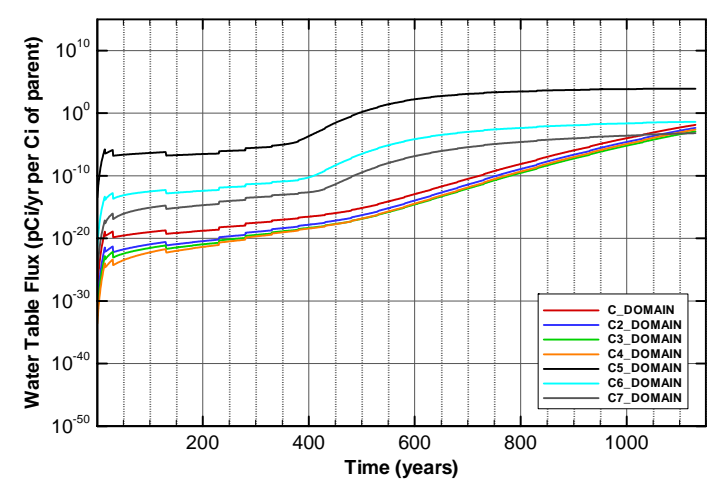

Figure A-905. Flux at water table for Case01_on Cf-249

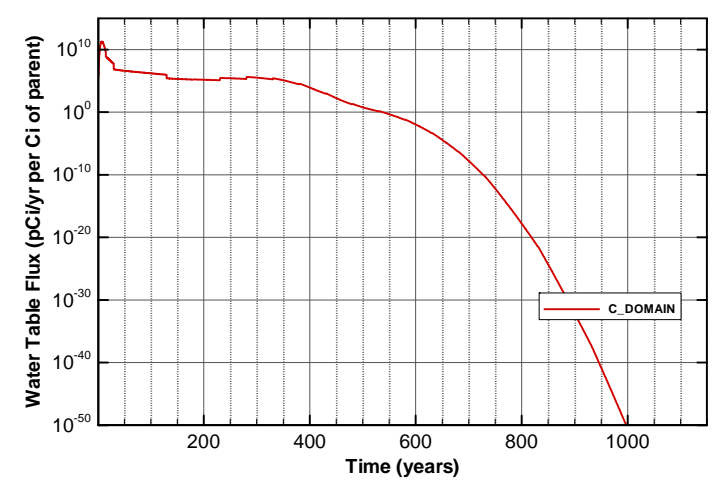

Figure A-907. Flux at water table for Case01_on Cl-36

Figure A-904. Flux at water table for Case01_on C-14_NR.Pump

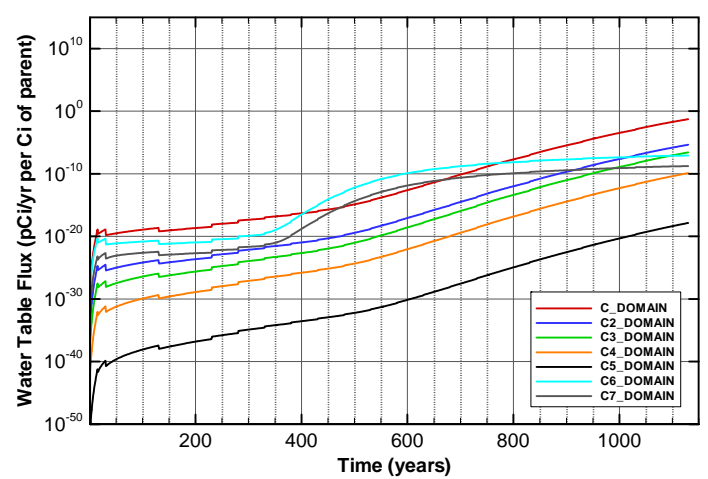

Figure A-906. Flux at water table for Case01_on Cf-251

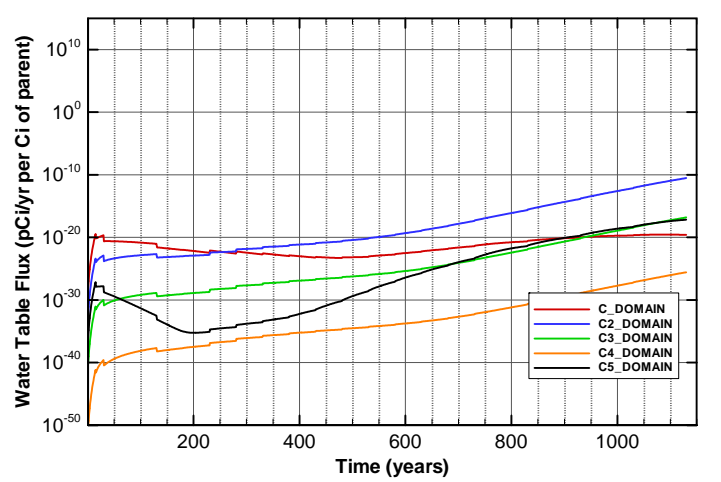

Figure A-908. Flux at water table for Case01_on Cm-244 
SRNL-STI-2008-00397, REVISION 0
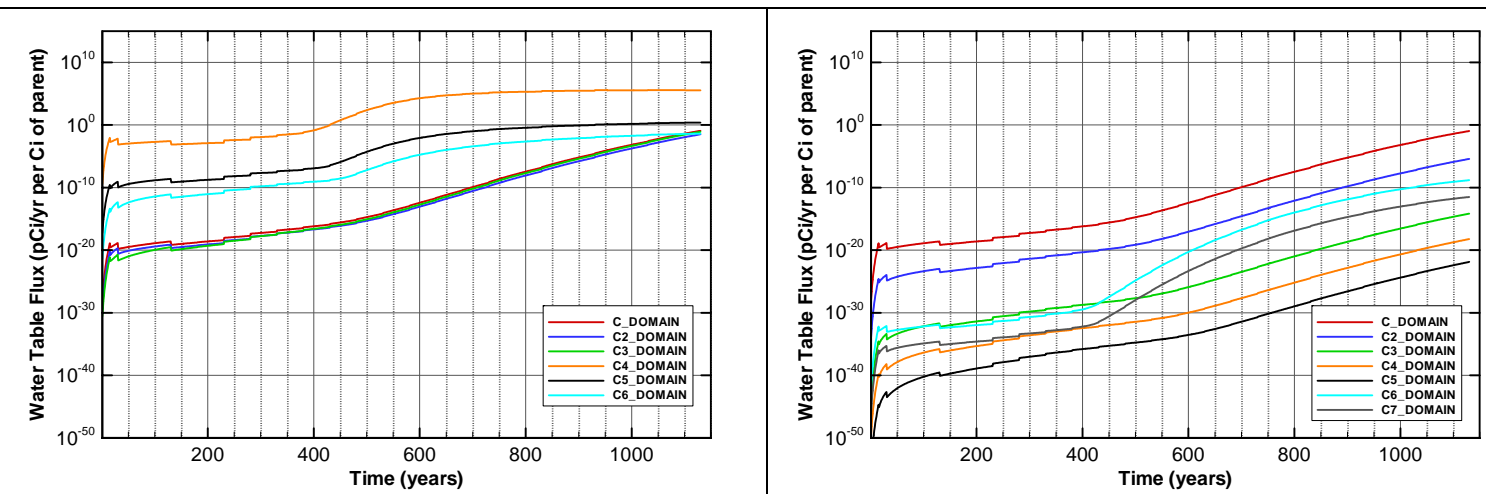

Figure A-909. Flux at water table for Case01_on Cm-245

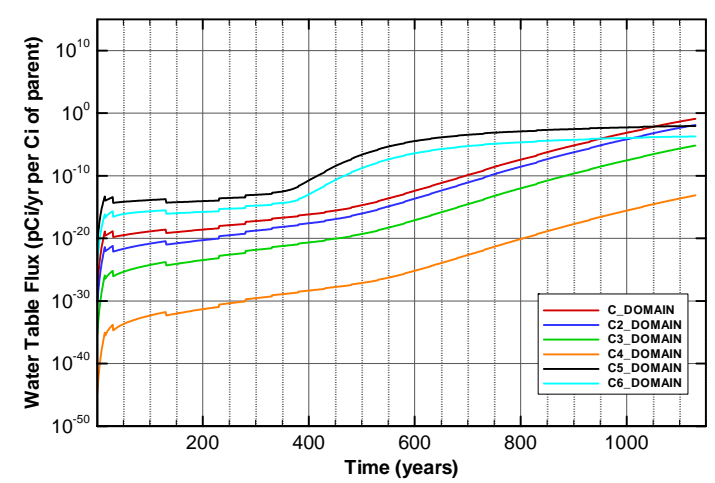

Figure A-911. Flux at water table for Case01_on Cm-247

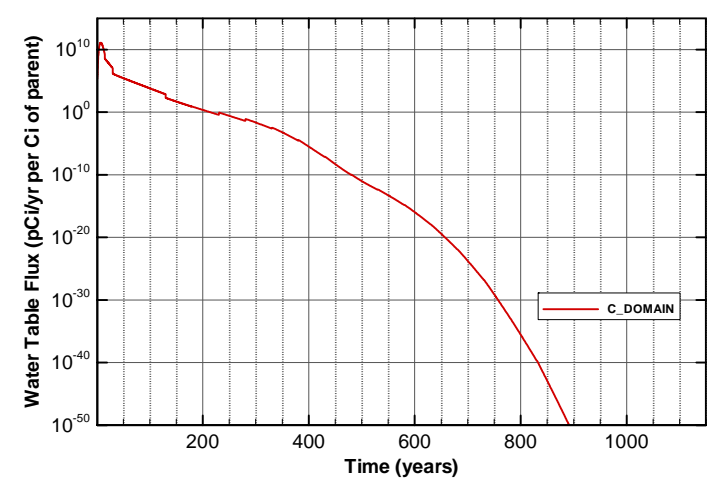

Figure A-913. Flux at water table for Case01_on H-3

Figure A-910. Flux at water table for Case01_on Cm-246

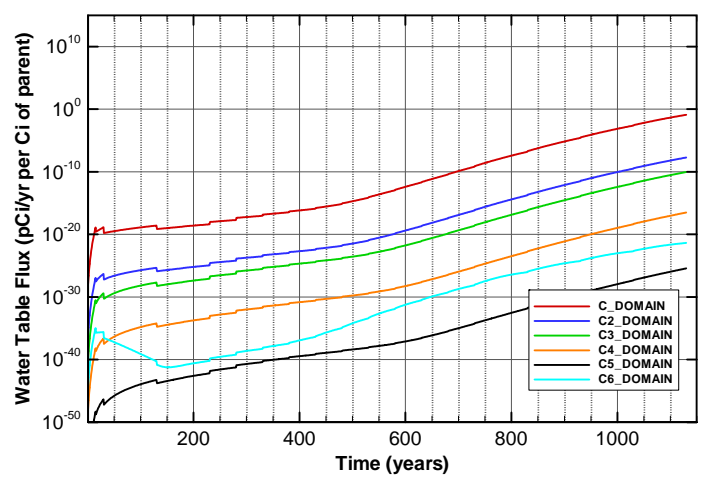

Figure A-912. Flux at water table for Case01_on Cm-248

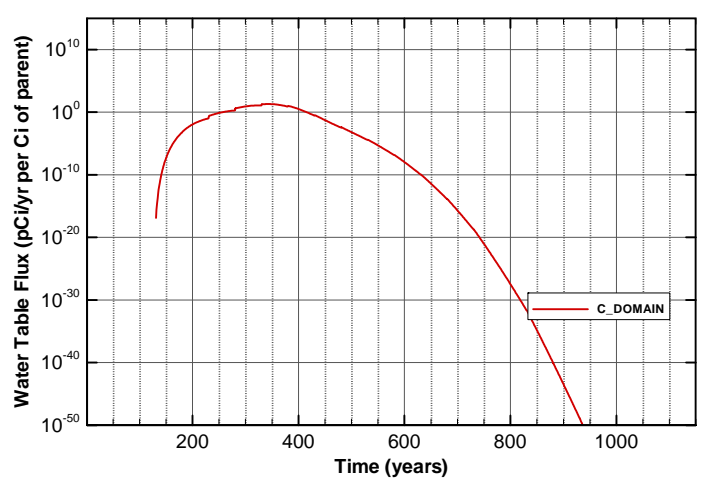

Figure A-914. Flux at water table for Case01_on H-3_ETF.Carbon 


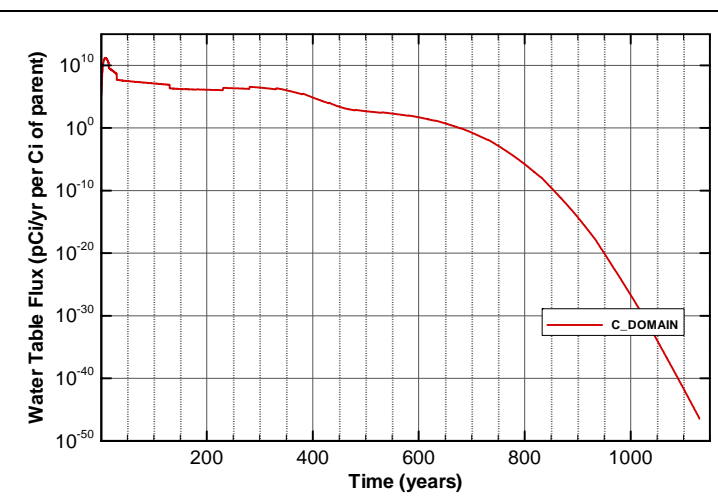

Figure A-915. Flux at water table for Case01_on I-129

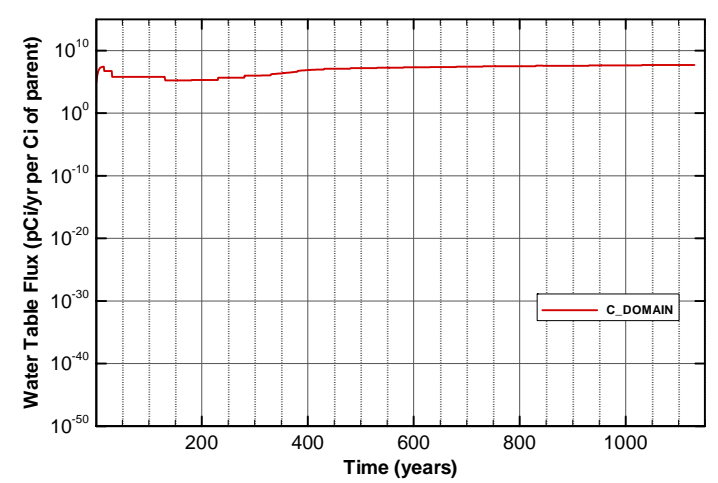

Figure A-917. Flux at water table for Case01_on I-129_ETF.GT.73

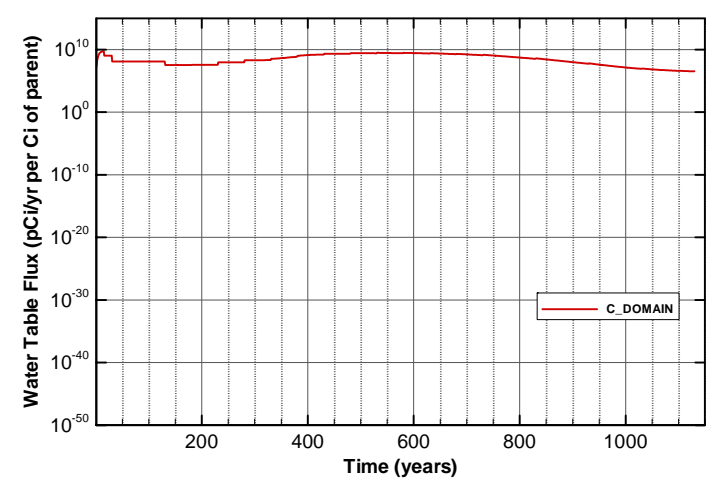

Figure A-919. Flux at water table for Case01_on I-129_F.CG.8

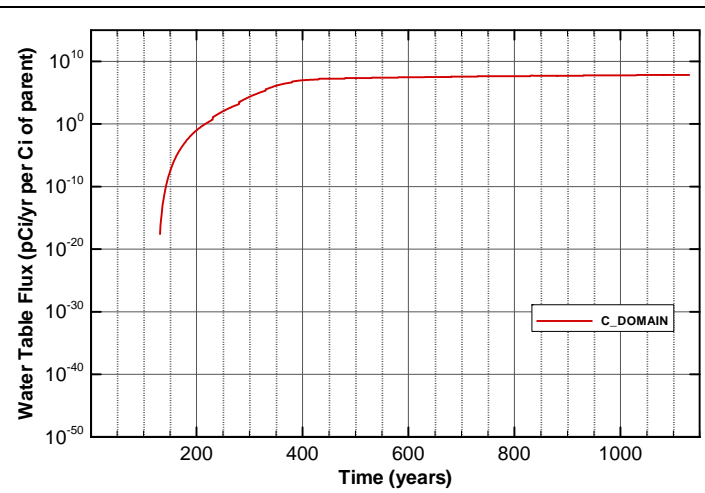

Figure A-916. Flux at water table for Case01_on I-129_ETF.Carbon

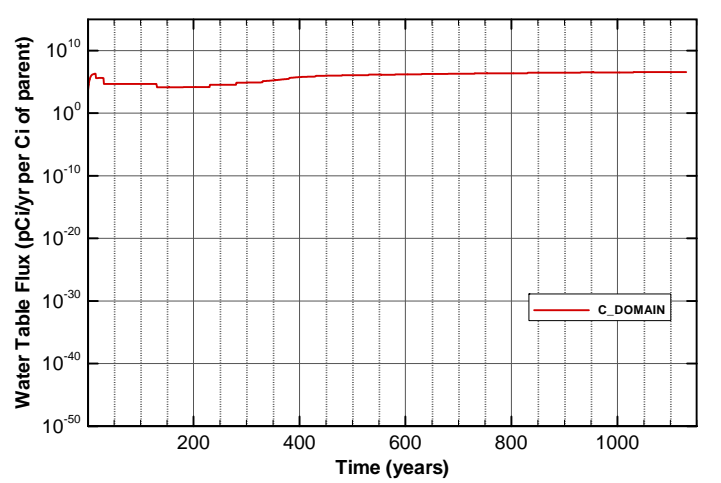

Figure A-918. Flux at water table for Case01_on I-129_F.Carbon

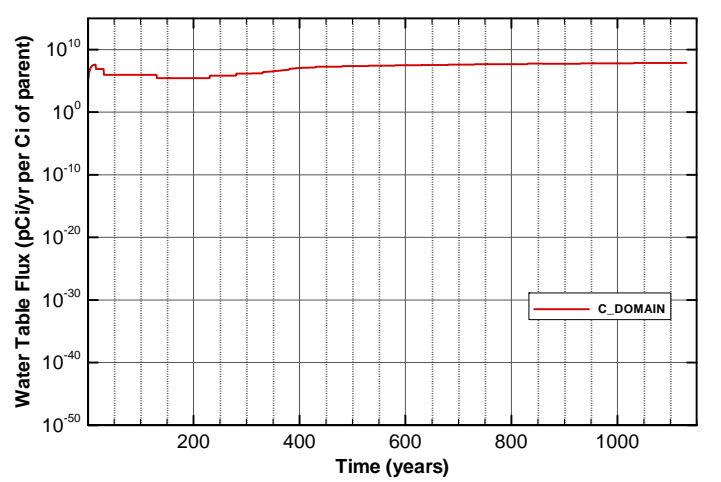

Figure A-920. Flux at water table for Case01_on I-129_F.Dowex.21K 


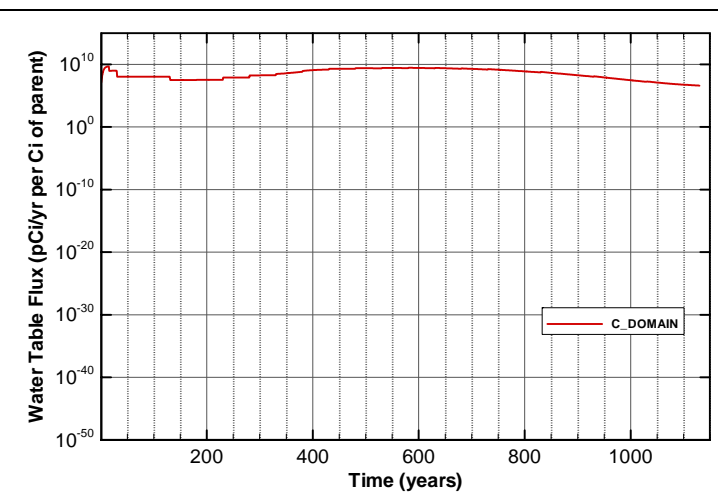

Figure A-921. Flux at water table for Case01_on I-129_F.Filtercake

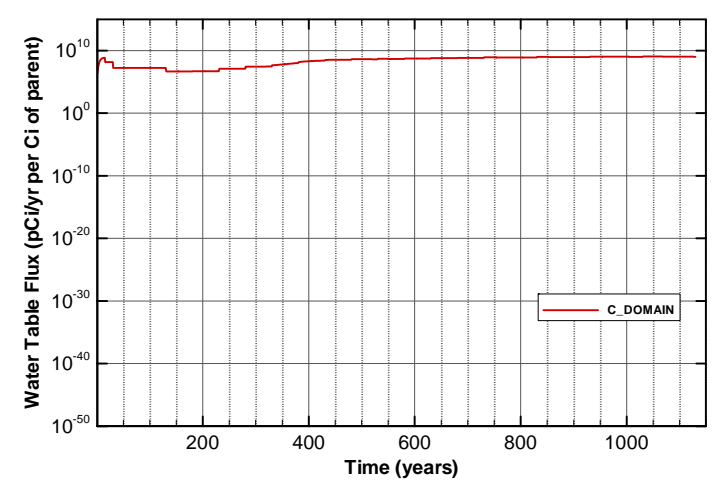

Figure A-923. Flux at water table for Case01_on I-129_H.CG.8

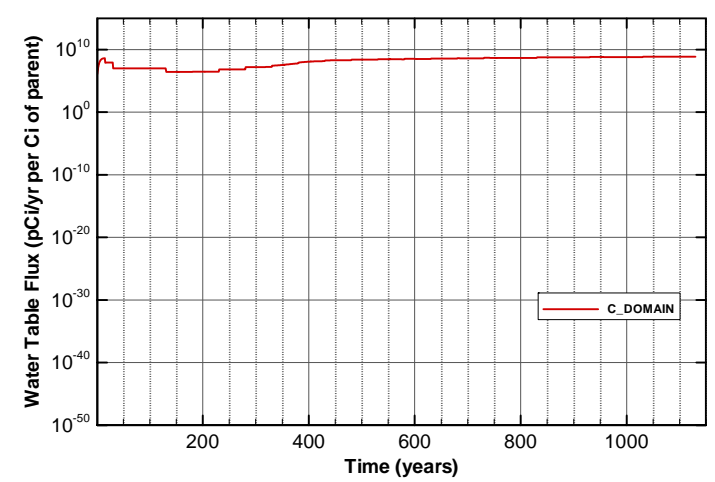

Figure A-925. Flux at water table for Case01_on I-129_H.Filtercake

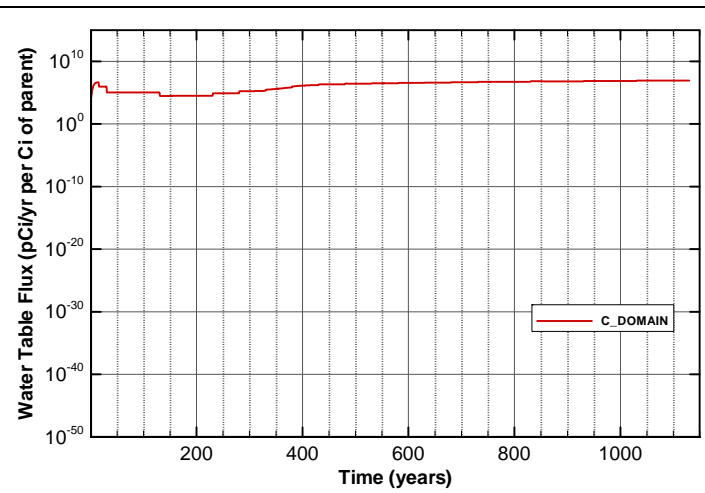

Figure A-922. Flux at water table for Case01_on I-129_H.Carbon

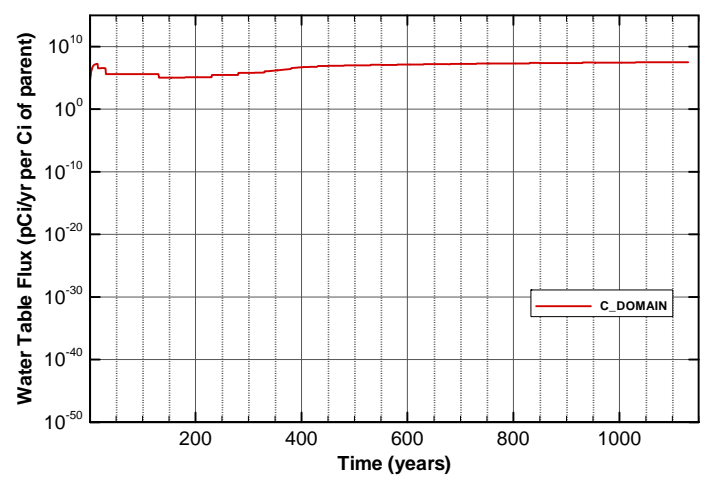

Figure A-924. Flux at water table for Case01_on I-129_H.Dowex.21K

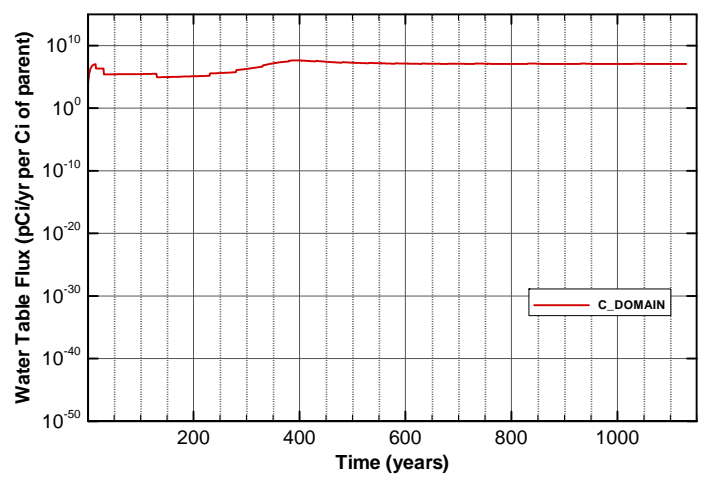

Figure A-926. Flux at water table for Case01_on I-129_Mk50A 


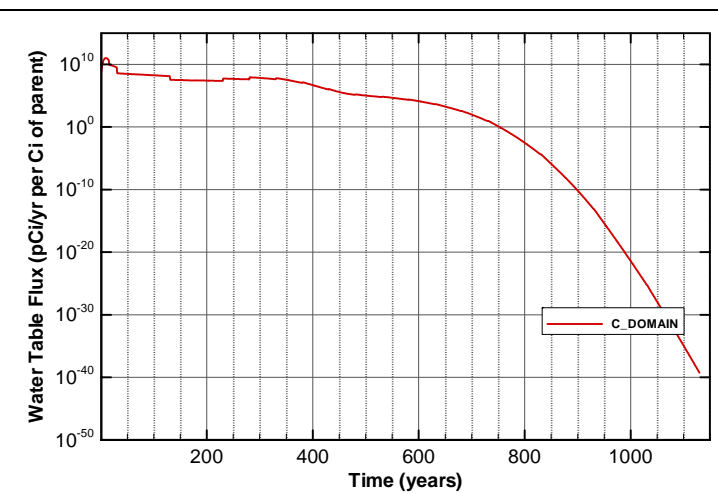

Figure A-927. Flux at water table for Case01_on K-40

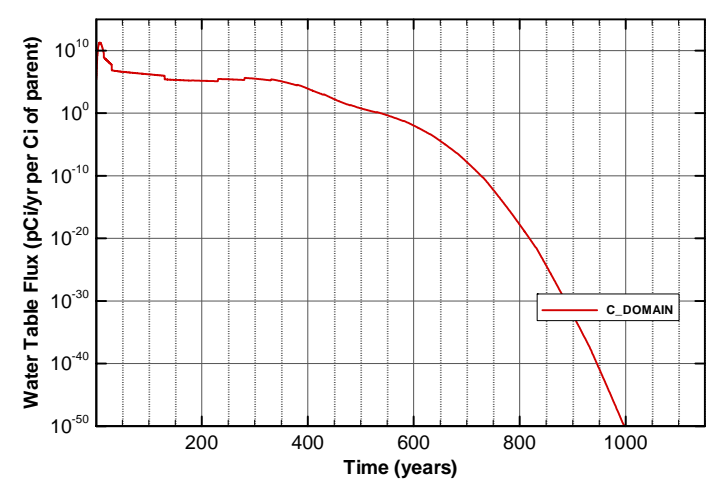

Figure A-929. Flux at water table for Case01_on Nb-94

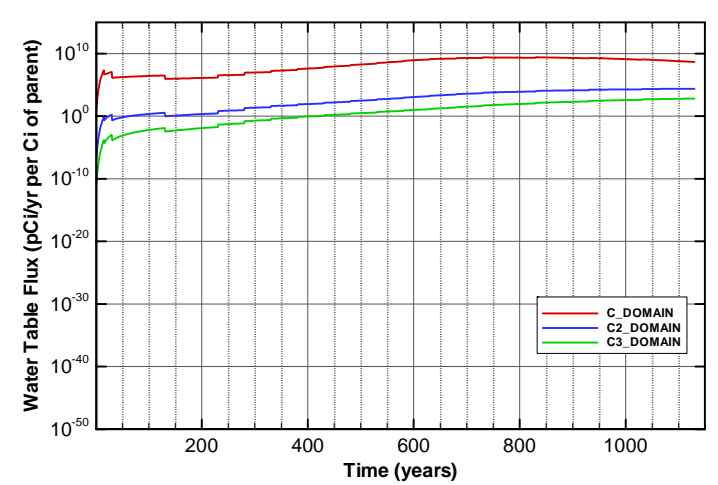

Figure A-931. Flux at water table for Case01_on Np-237

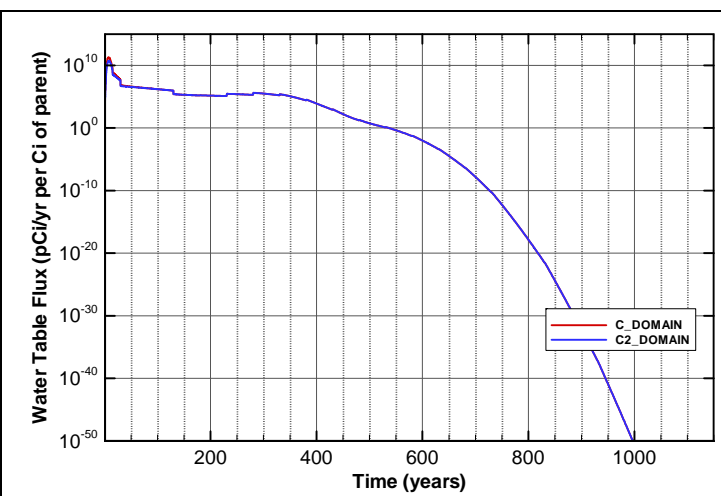

Figure A-928. Flux at water table for Case01_on Mo-93

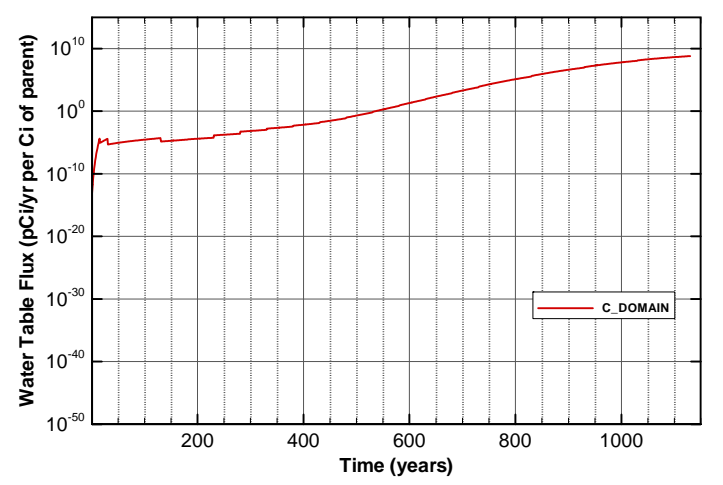

Figure A-930. Flux at water table for Case01_on Ni-59

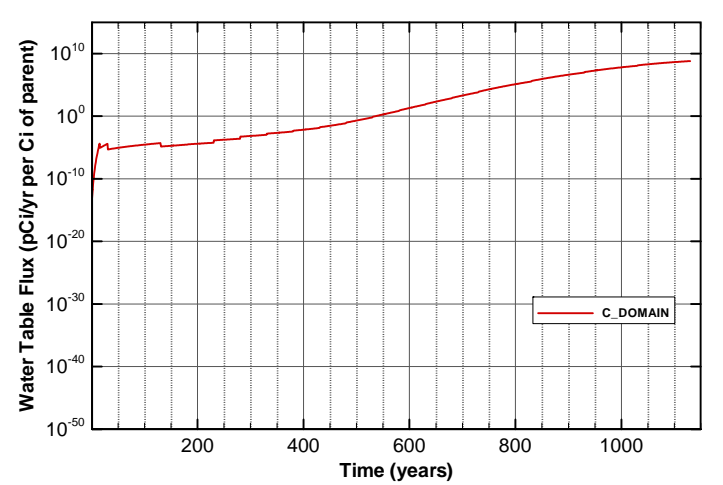

Figure A-932. Flux at water table for Case01_on Pd-107 
SRNL-STI-2008-00397, REVISION 0
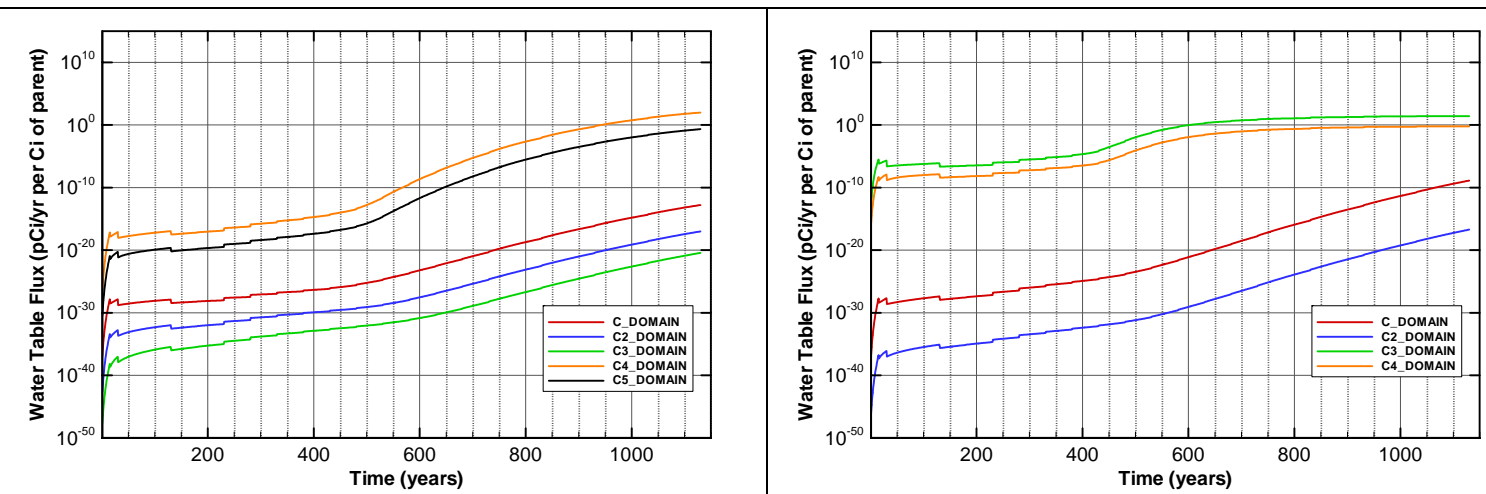

Figure A-933. Flux at water table for

Case01_on Pu-238

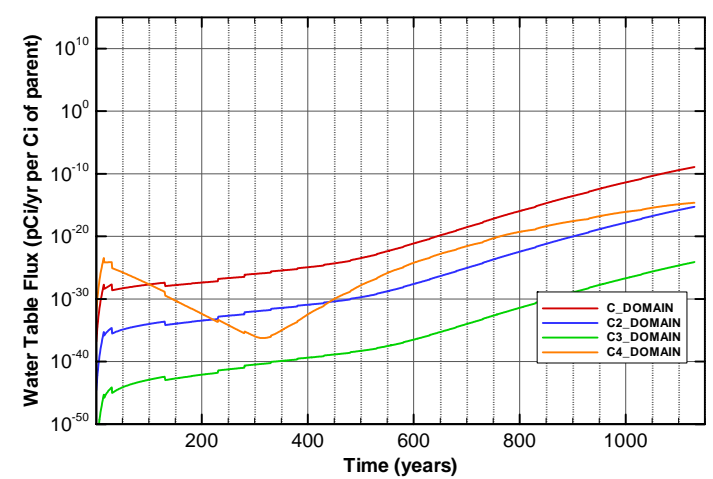

Figure A-935. Flux at water table for Case01_on Pu-240

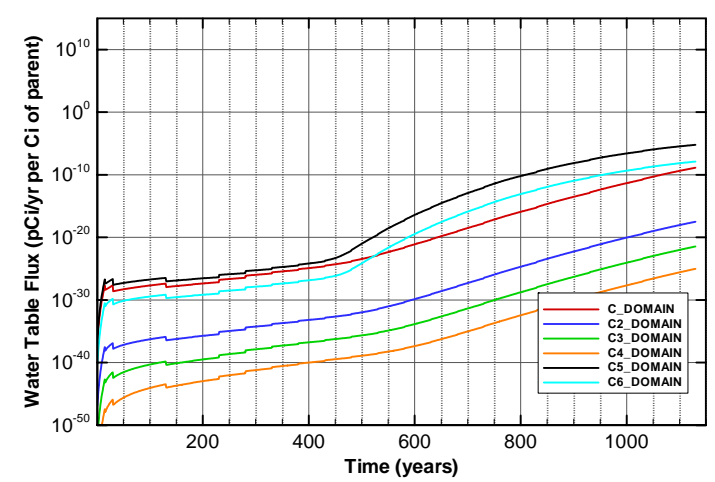

Figure A-937. Flux at water table for Case01_on Pu-242

Figure A-934. Flux at water table for Case01_on Pu-239

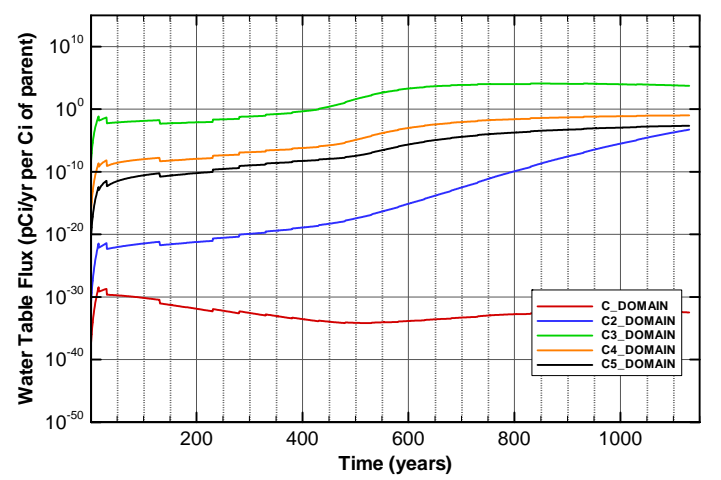

Figure A-936. Flux at water table for Case01_on Pu-241

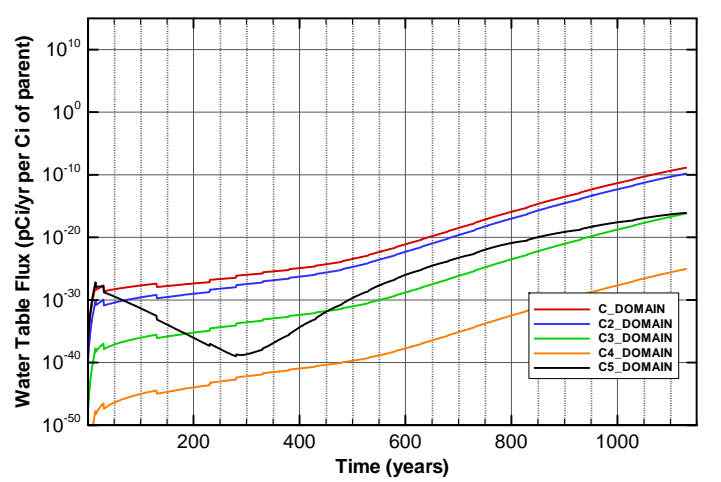

Figure A-938. Flux at water table for Case01_on Pu-244 
SRNL-STI-2008-00397, REVISION 0

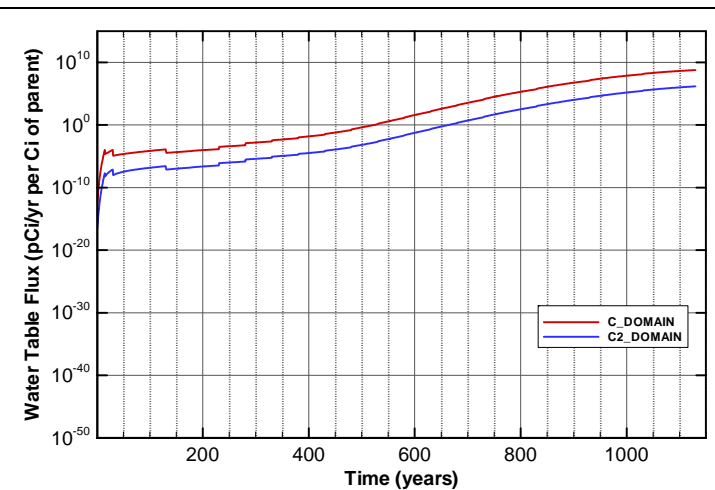

Figure A-939. Flux at water table for Case01_on Ra-226

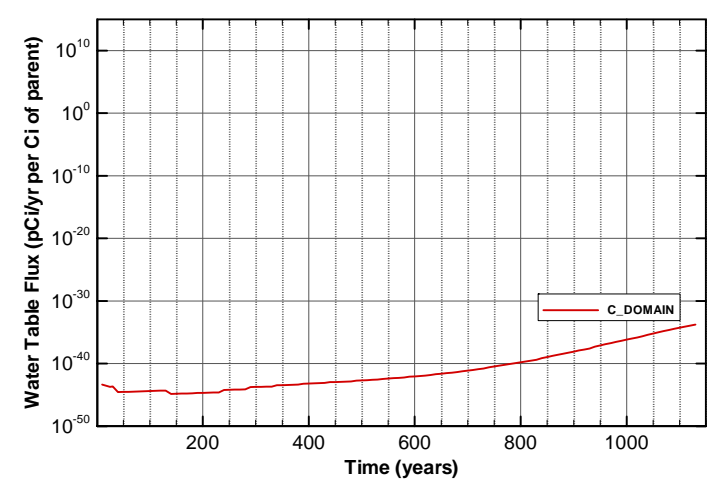

Figure A-941. Flux at water table for Case01_on Sn-126

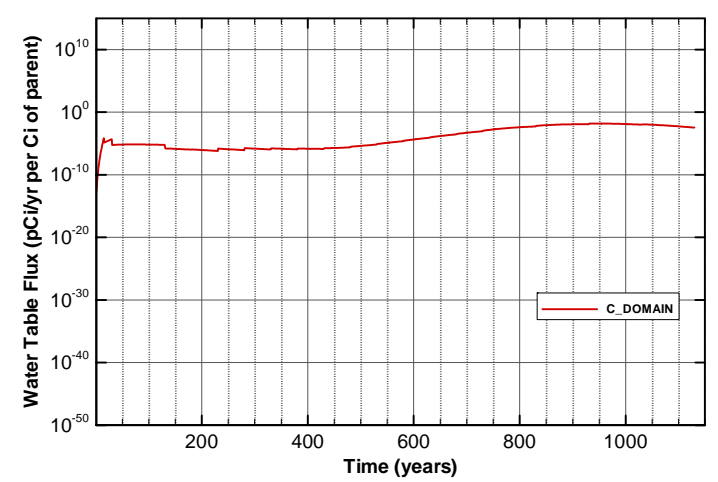

Figure A-943. Flux at water table for Case01_on Sr-90_Cask

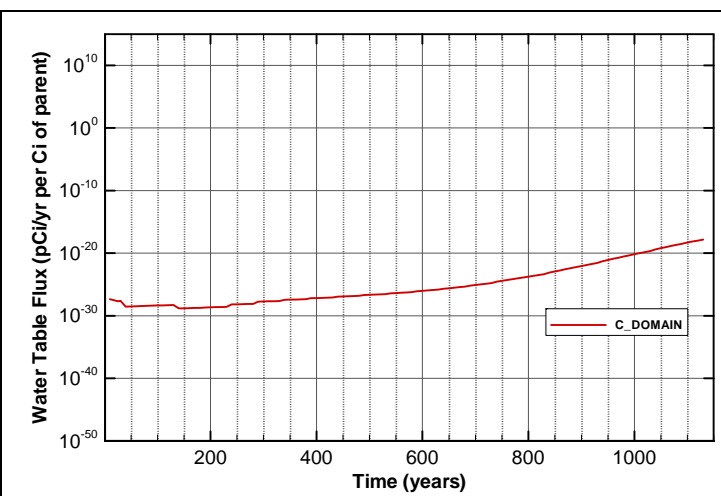

Figure A-940. Flux at water table for Case01_on Se-79

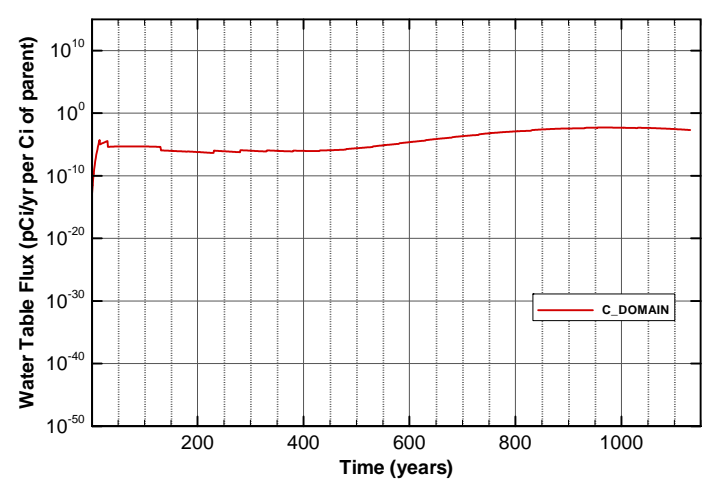

Figure A-942. Flux at water table for Case01_on Sr-90

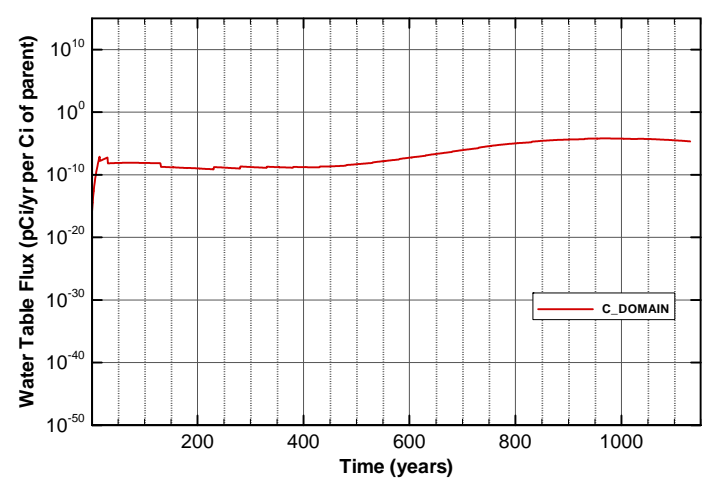

Figure A-944. Flux at water table for Case01_on Sr-90_Mk50A 


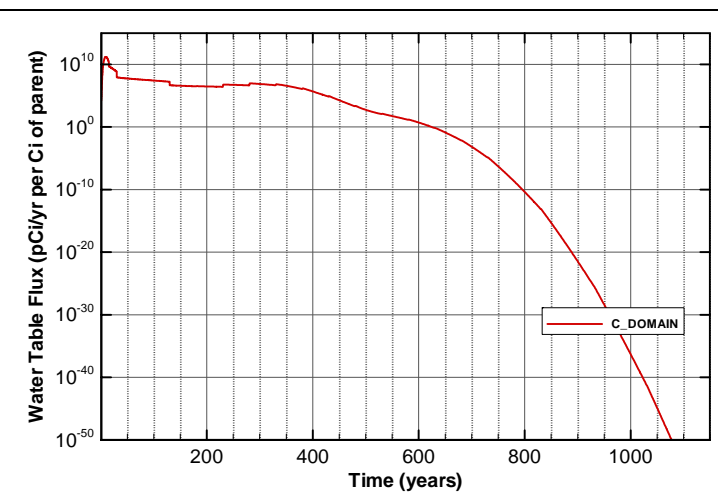

Figure A-945. Flux at water table for Case01_on Tc-99

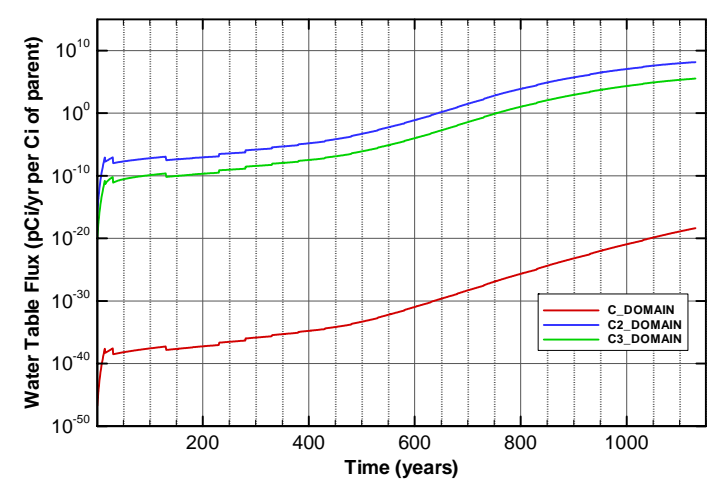

Figure A-947. Flux at water table for Case01_on Th-230

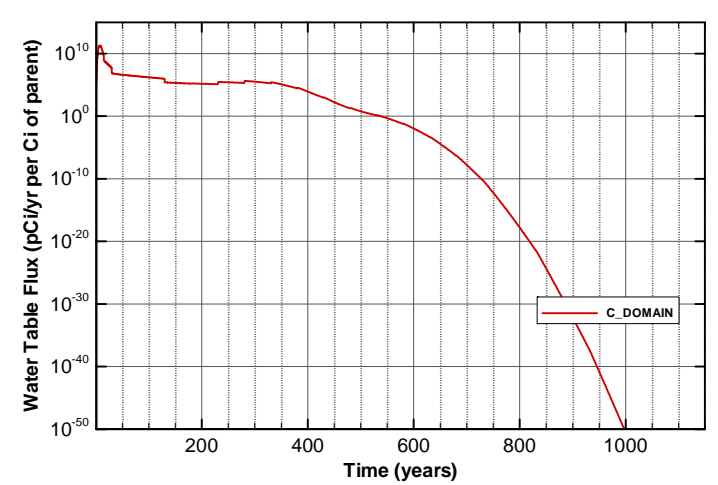

Figure A-949. Flux at water table for Case01_on Tracer

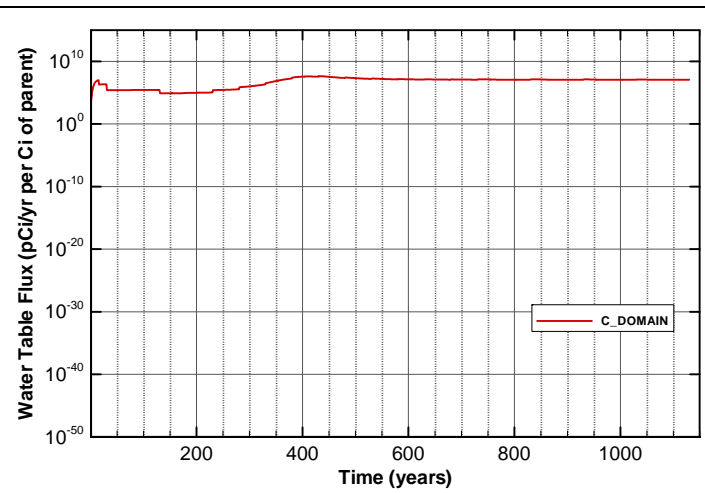

Figure A-946. Flux at water table for Case01_on Tc-99_Mk50A

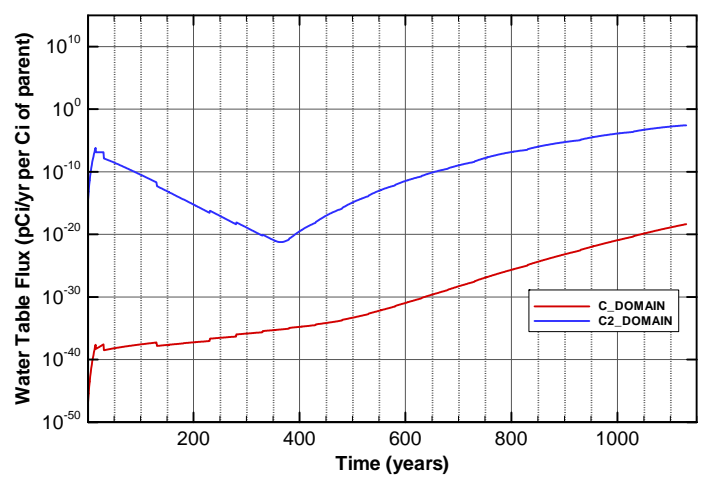

Figure A-948. Flux at water table for Case01_on Th-232

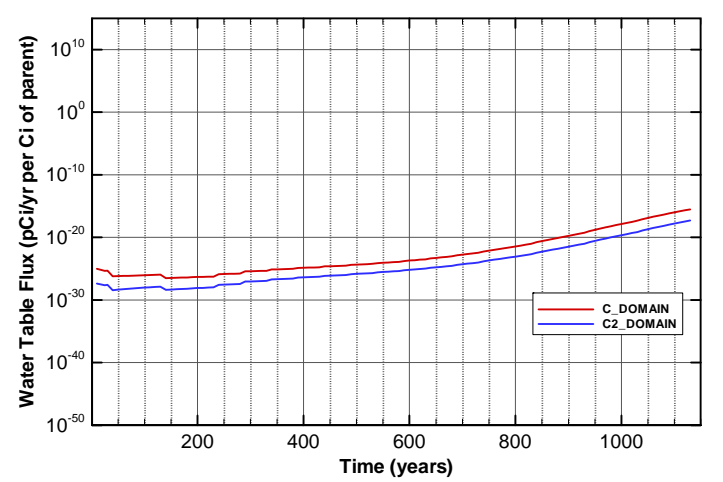

Figure A-950. Flux at water table for Case01_on U-233 
SRNL-STI-2008-00397, REVISION 0
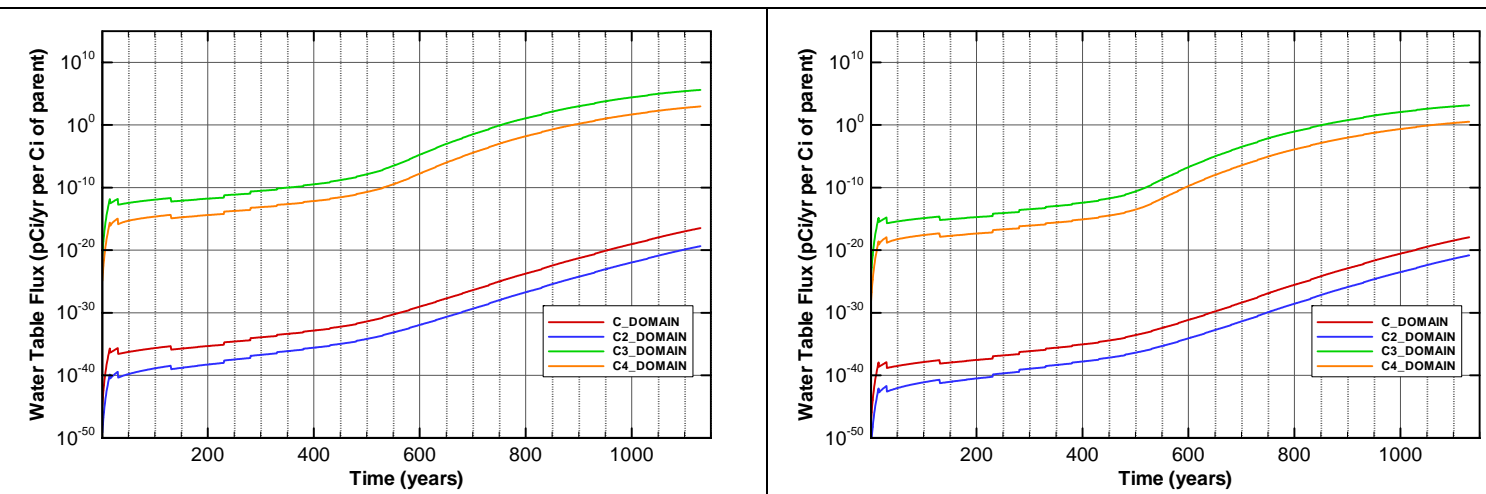

Figure A-951. Flux at water table for Case01_on U-234

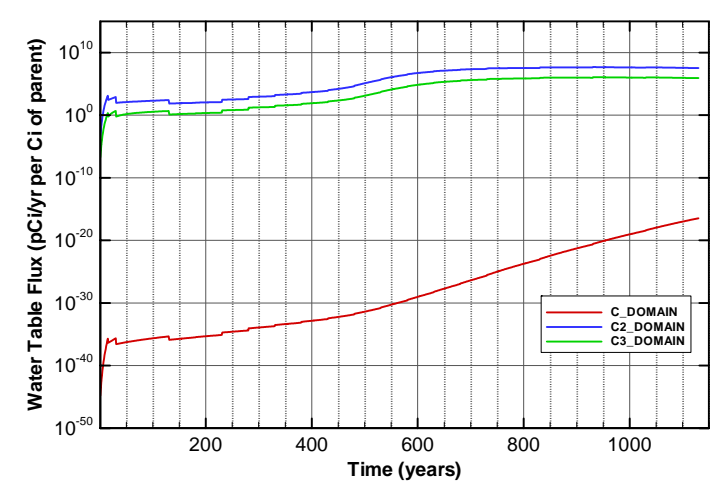

Figure A-953. Flux at water table for Case01_on U-235

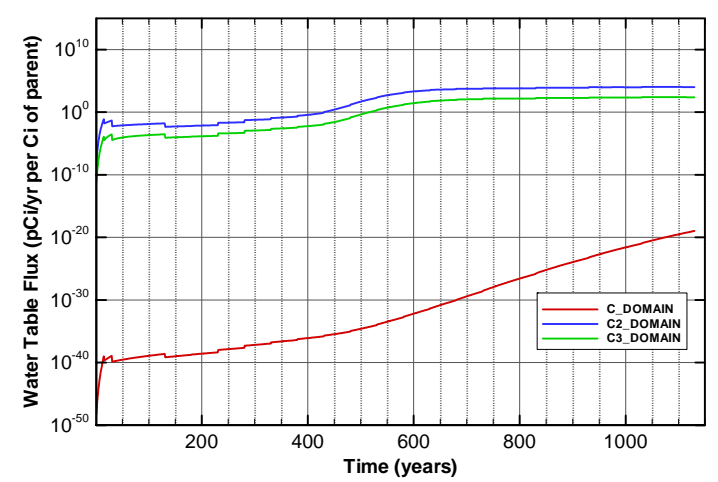

Figure A-955. Flux at water table for Case01_on U-235_Paducah.Cask

Figure A-952. Flux at water table for Case01_on U-234_Mglass

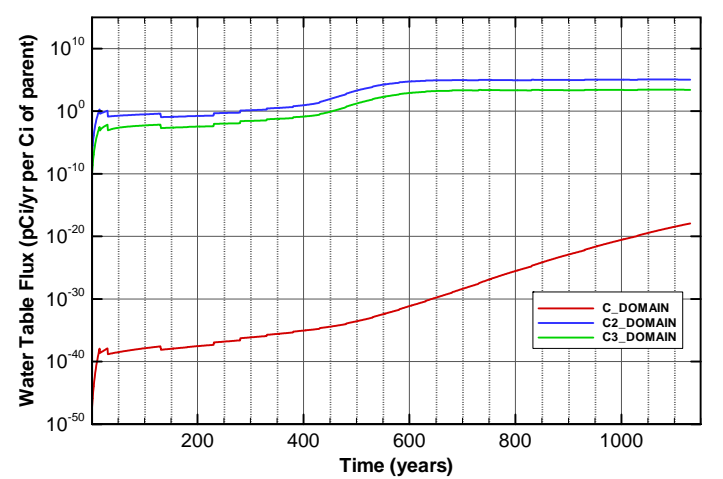

Figure A-954. Flux at water table for Case01_on U-235_Mglass

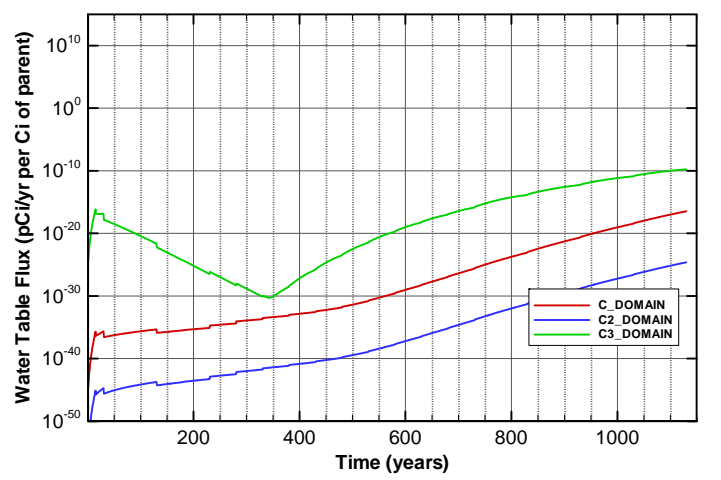

Figure A-956. Flux at water table for Case01_on U-236 
SRNL-STI-2008-00397, REVISION 0

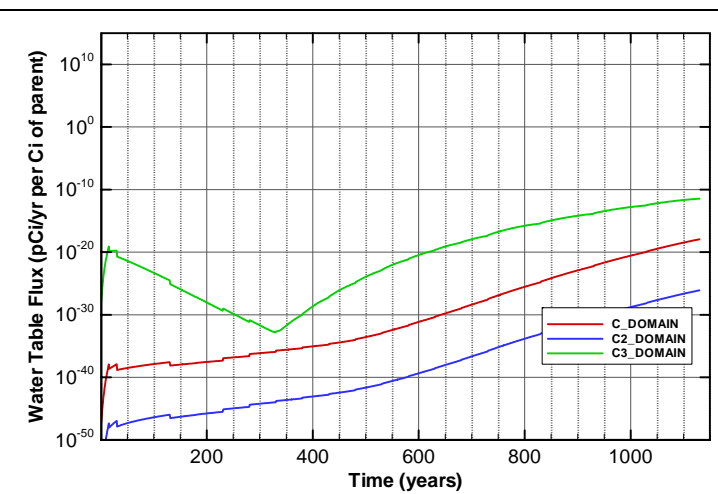

Figure A-957. Flux at water table for Case01_on U-236_Mglass

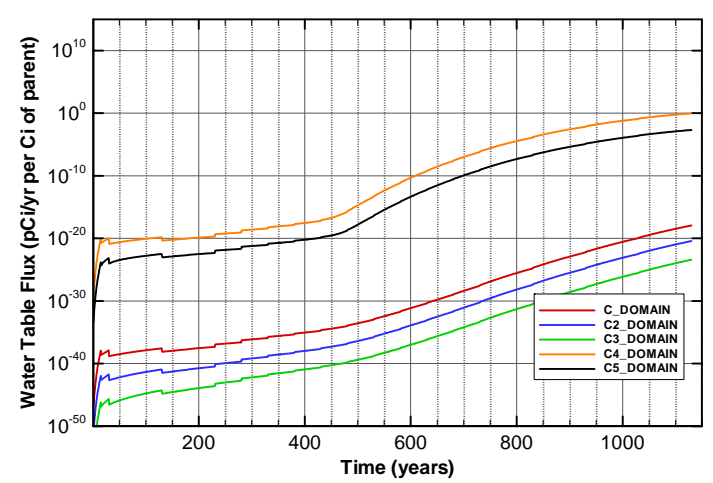

Figure A-959. Flux at water table for Case01_on U-238_Mglass

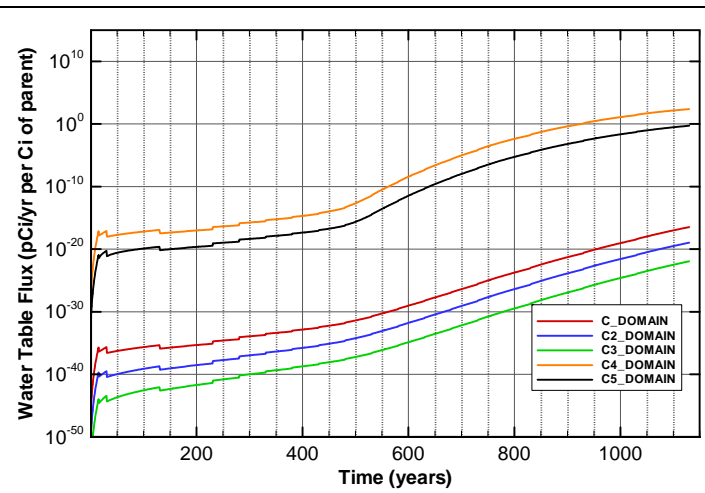

Figure A-958. Flux at water table for Case01_on U-238

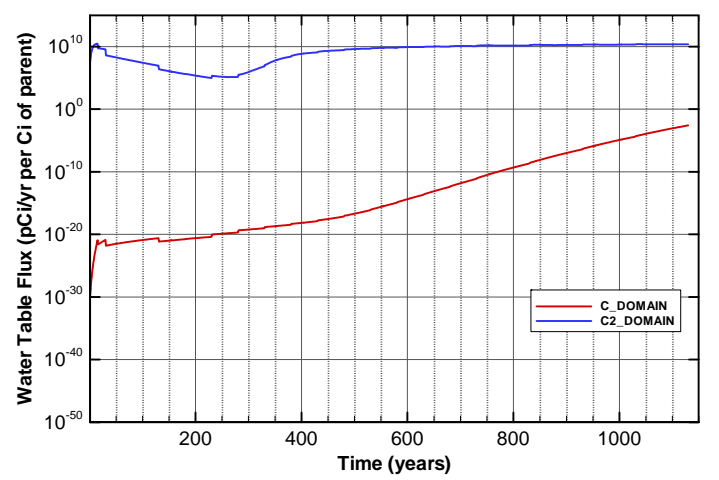

Figure A-960. Flux at water table for Case01_on Zr-93

\subsubsection{Edge trench flux plots for 5-year cover}

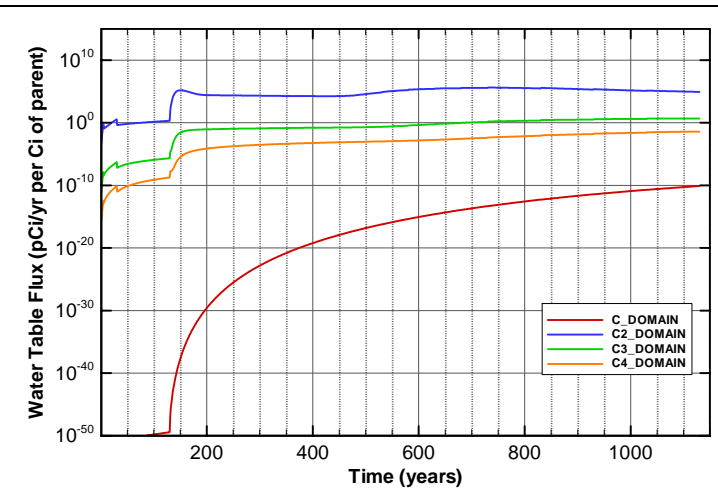

Figure A-961. Flux at water table for Case01n11_off Am-241

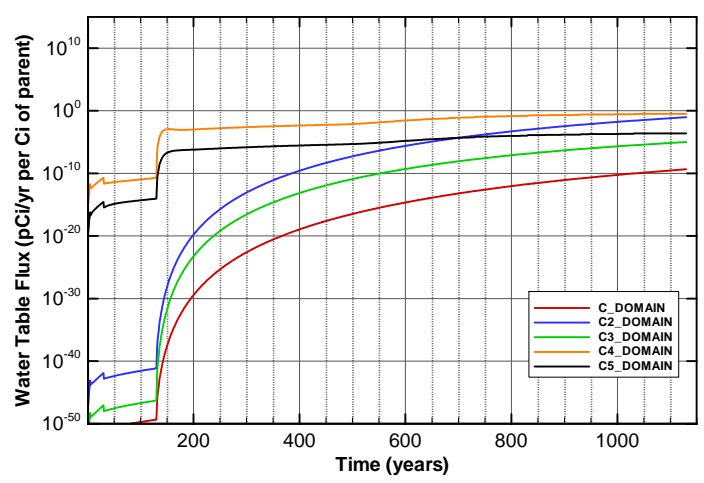

Figure A-962. Flux at water table for Case01n11_off Am-243 
SRNL-STI-2008-00397, REVISION 0

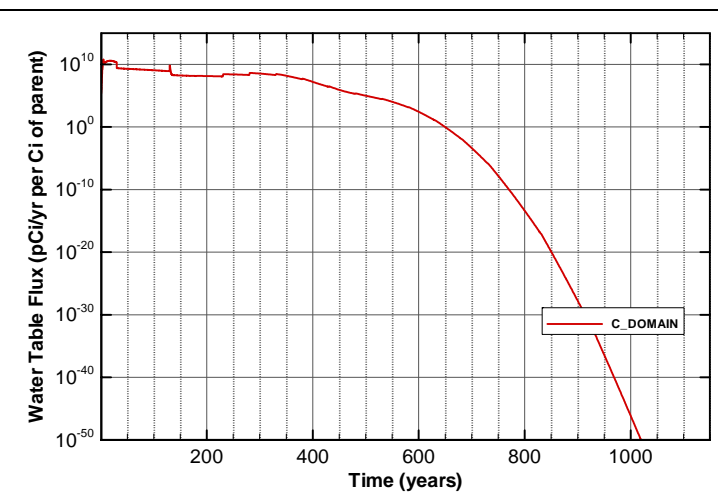

Figure A-963. Flux at water table for Case01n11_off C-14

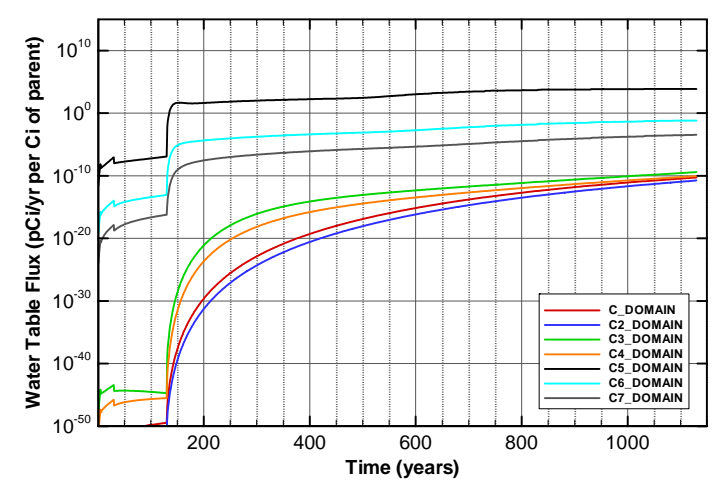

Figure A-965. Flux at water table for Case01n11_off Cf-249

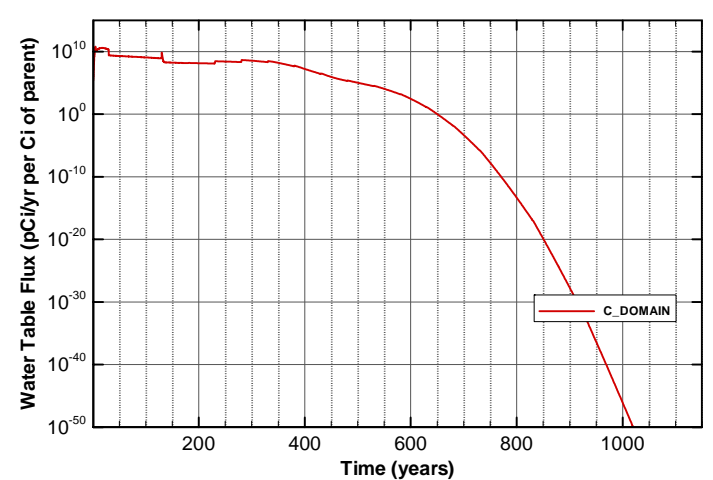

Figure A-967. Flux at water table for Case01n11_off Cl-36

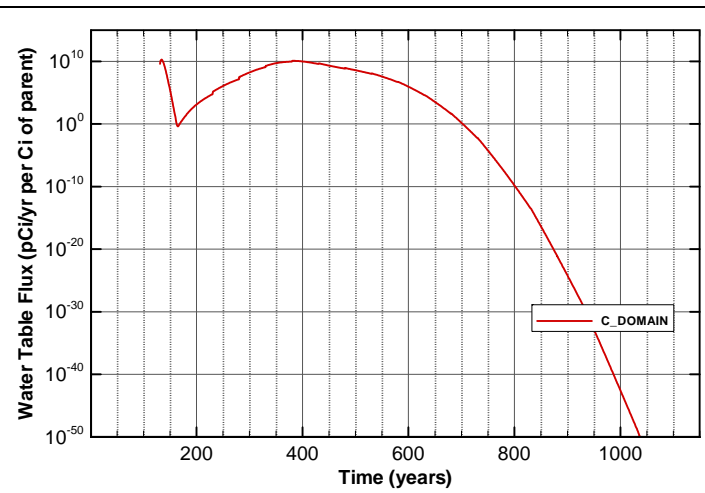

Figure A-964. Flux at water table for Case01n11_off C-14_NR.Pump

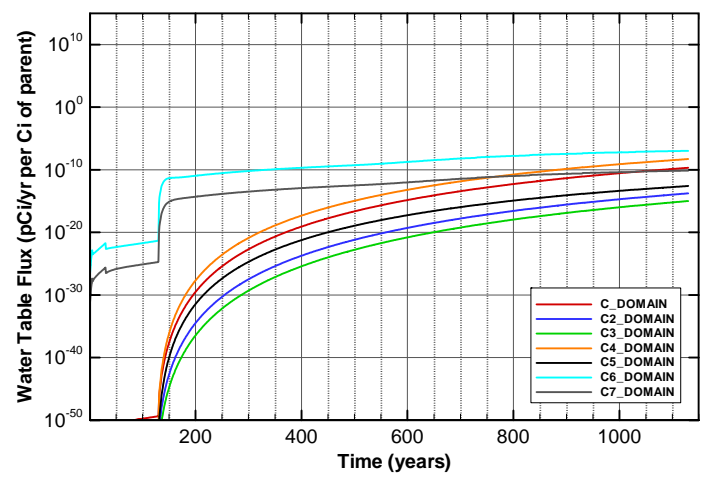

Figure A-966. Flux at water table for Case01n11_off Cf-251

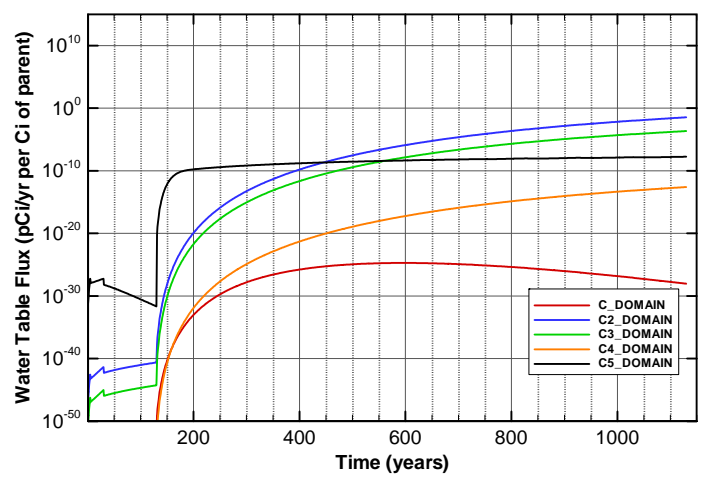

Figure A-968. Flux at water table for Case01n11_off Cm-244 
SRNL-STI-2008-00397, REVISION 0
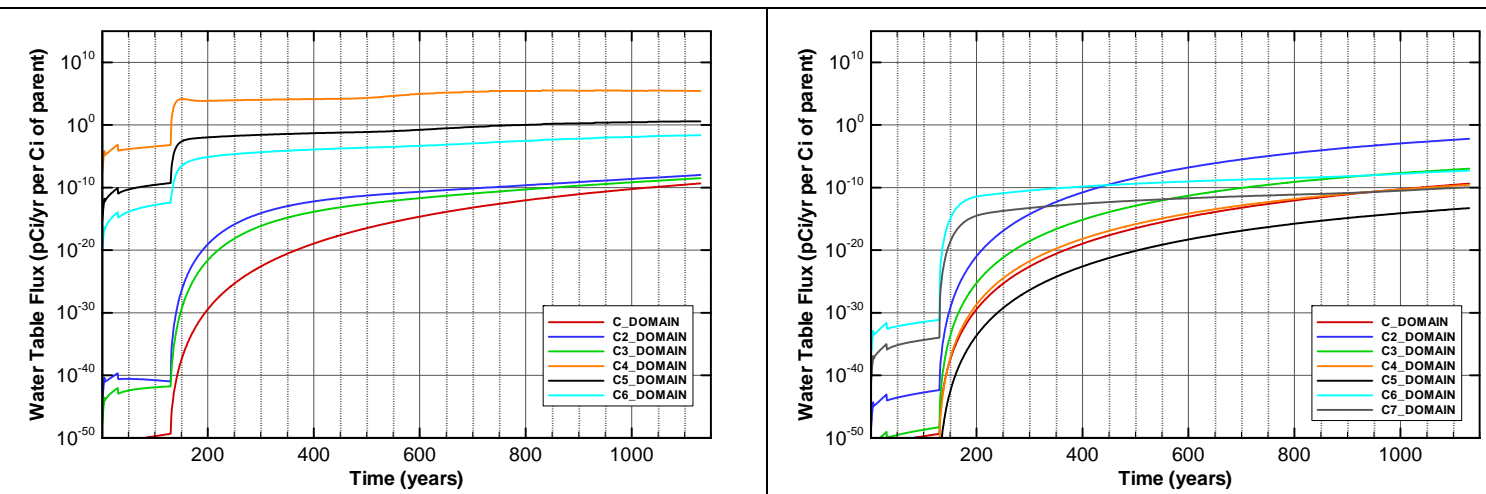

Figure A-969. Flux at water table for Case01n11_off Cm-245

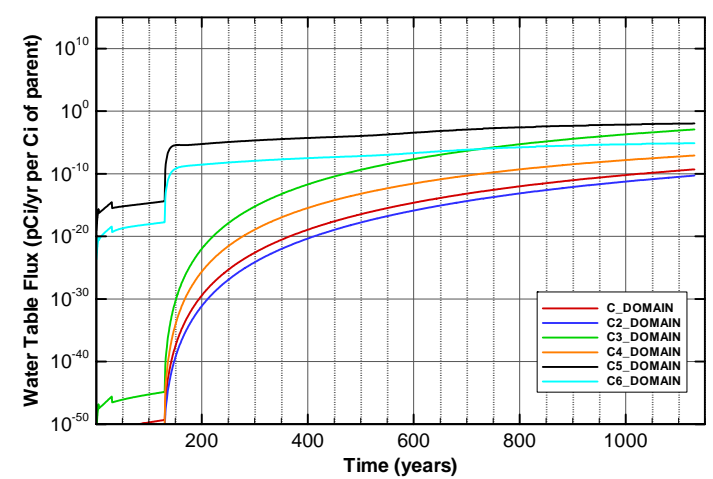

Figure A-971. Flux at water table for Case01n11_off Cm-247

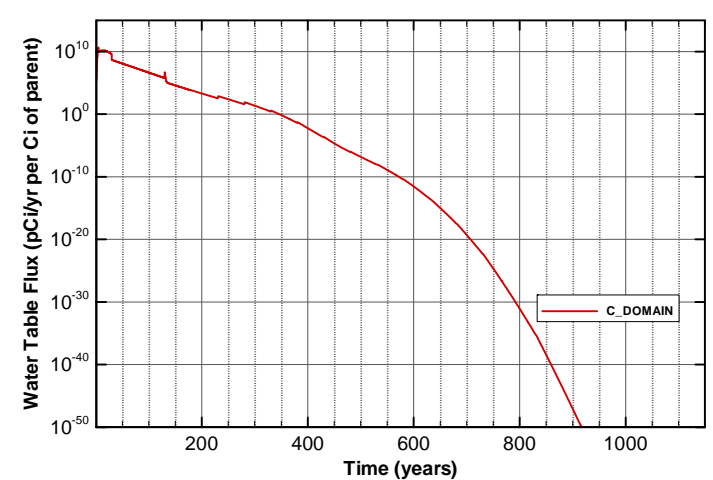

Figure A-973. Flux at water table for Case01n11_off H-3

Figure A-970. Flux at water table for Case01n11_off Cm-246

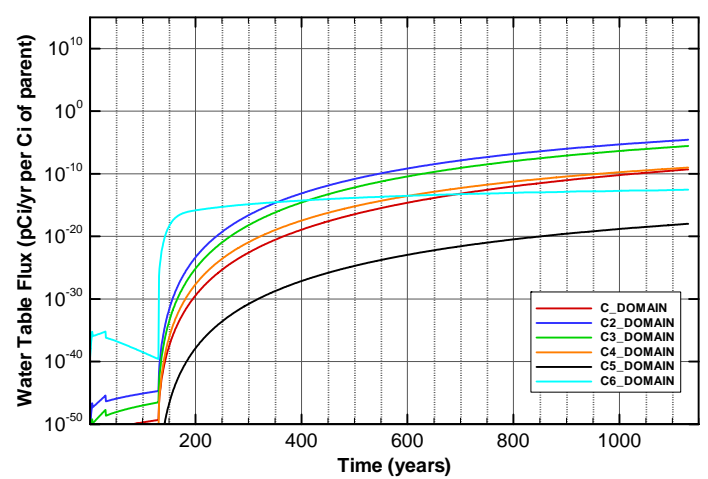

Figure A-972. Flux at water table for Case01n11_off Cm-248

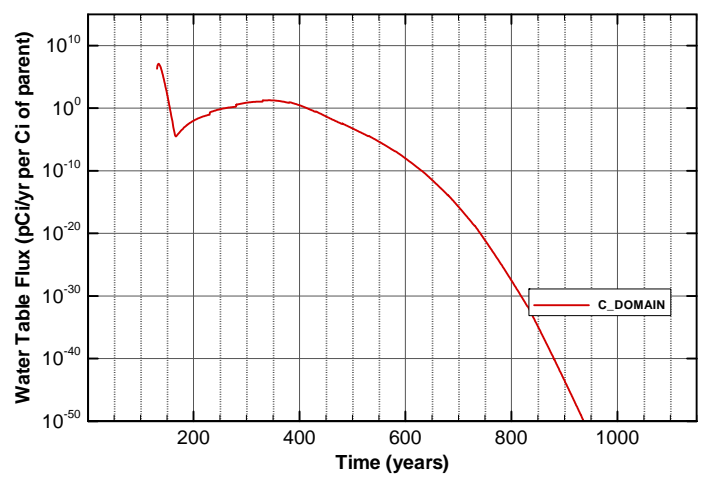

Figure A-974. Flux at water table for Case01n11_off H-3_ETF.Carbon 


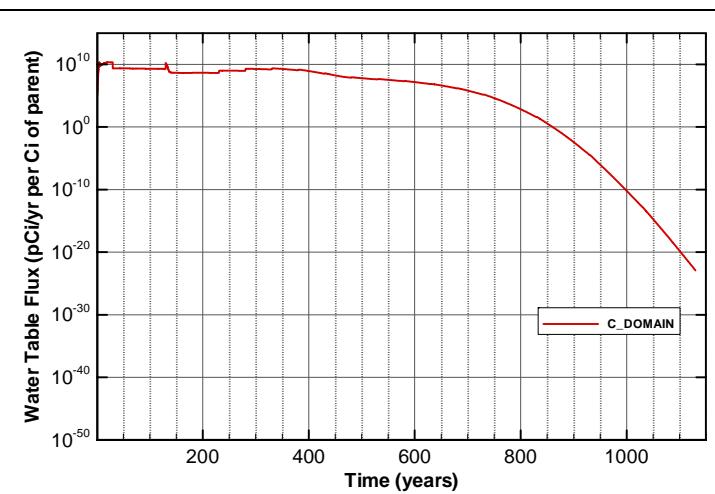

Figure A-975. Flux at water table for Case01n11_off I-129

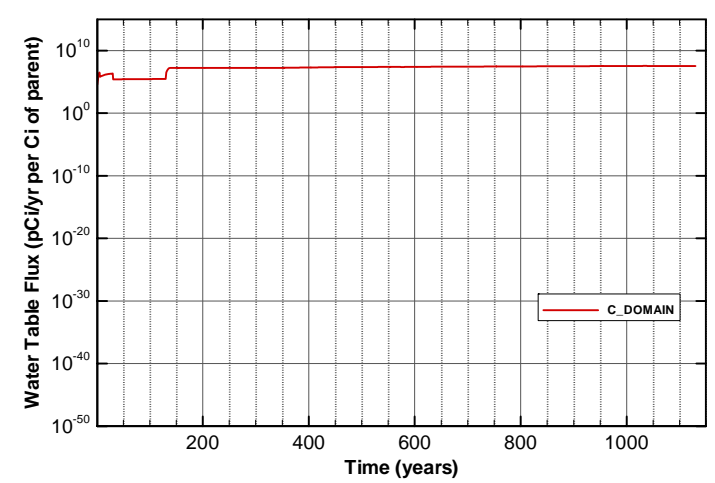

Figure A-977. Flux at water table for Case01n11_off I-129_ETF.GT.73

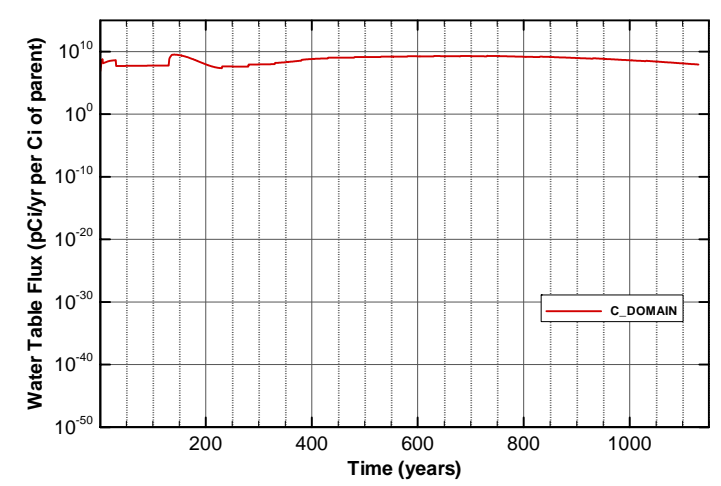

Figure A-979. Flux at water table for Case01n11_off I-129_F.CG.8

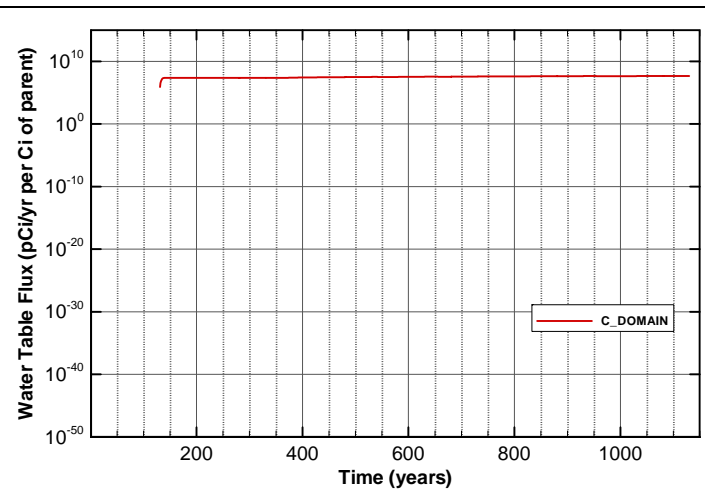

Figure A-976. Flux at water table for Case01n11_off I-129_ETF.Carbon

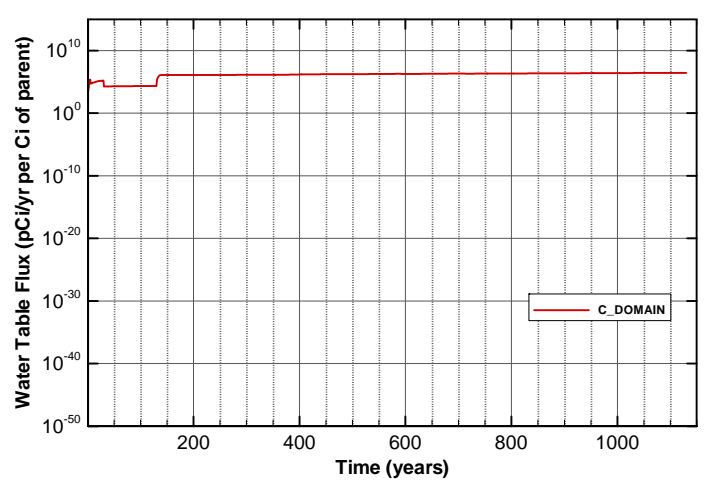

Figure A-978. Flux at water table for Case01n11_off I-129_F.Carbon

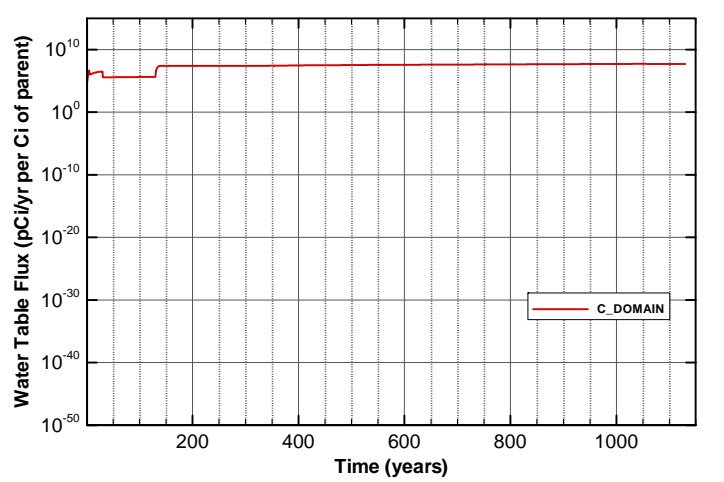

Figure A-980. Flux at water table for Case01n11_off I-129_F.Dowex.21K 


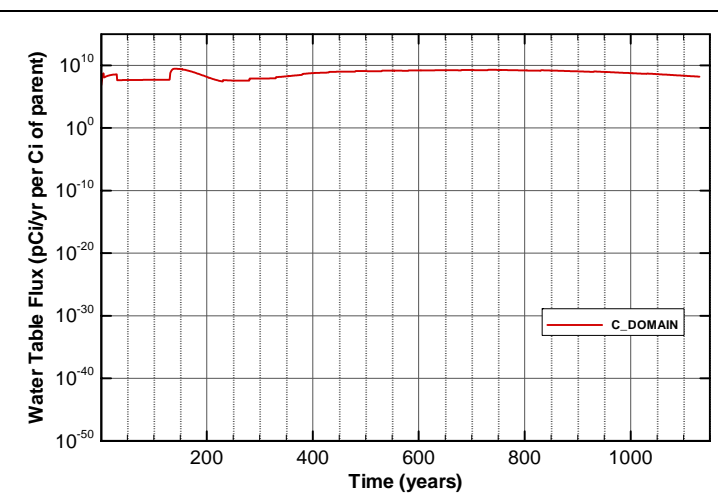

Figure A-981. Flux at water table for Case01n11_off I-129_F.Filtercake

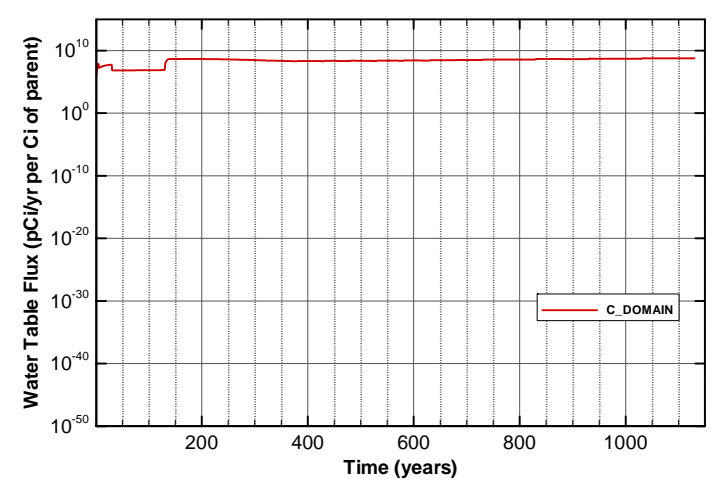

Figure A-983. Flux at water table for Case01n11_off I-129_H.CG.8

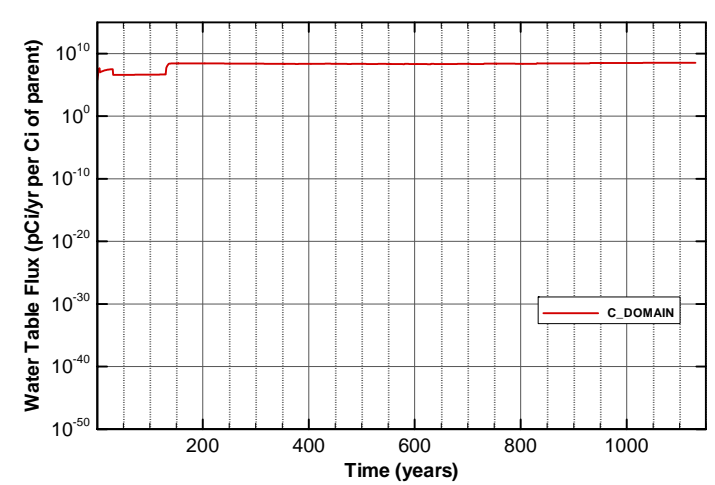

Figure A-985. Flux at water table for Case01n11_off I-129_H.Filtercake

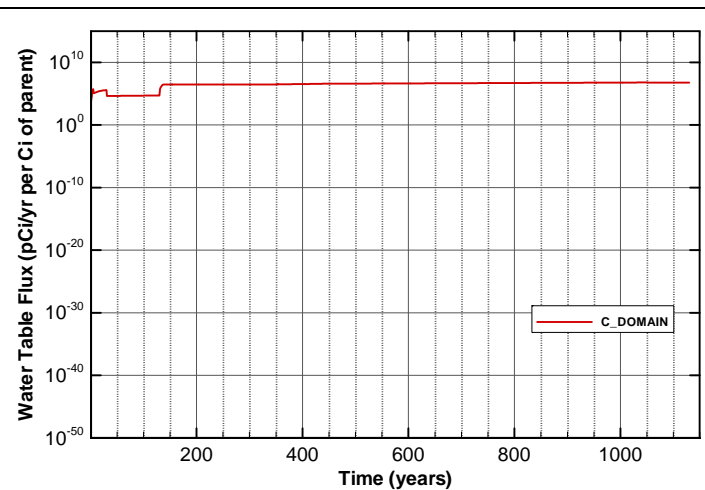

Figure A-982. Flux at water table for Case01n11_off I-129_H.Carbon

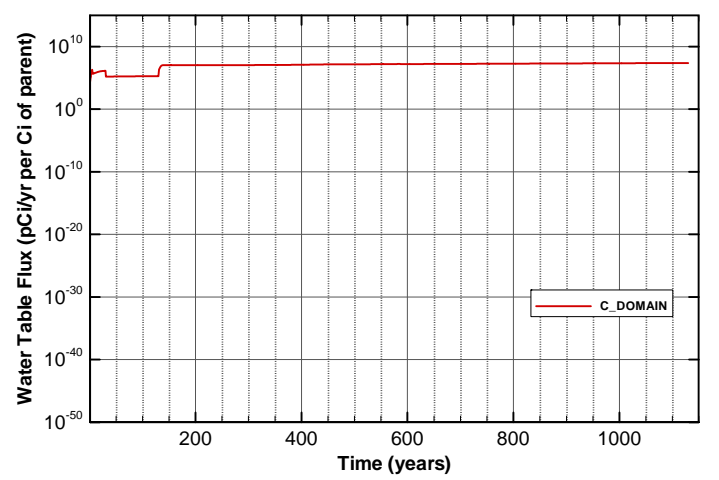

Figure A-984. Flux at water table for Case01n11_off I-129_H.Dowex.21K

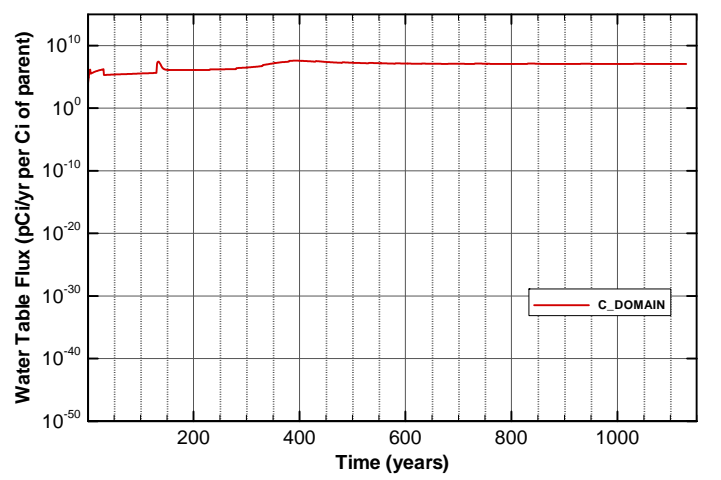

Figure A-986. Flux at water table for Case01n11_off I-129_Mk50A 


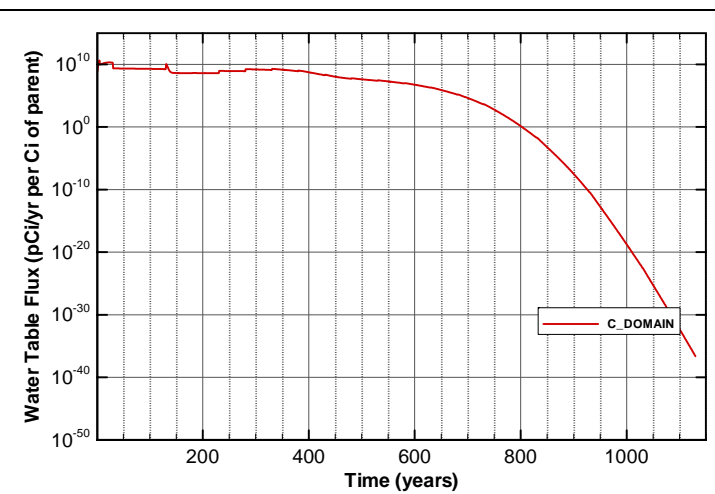

Figure A-987. Flux at water table for Case01n11_off K-40

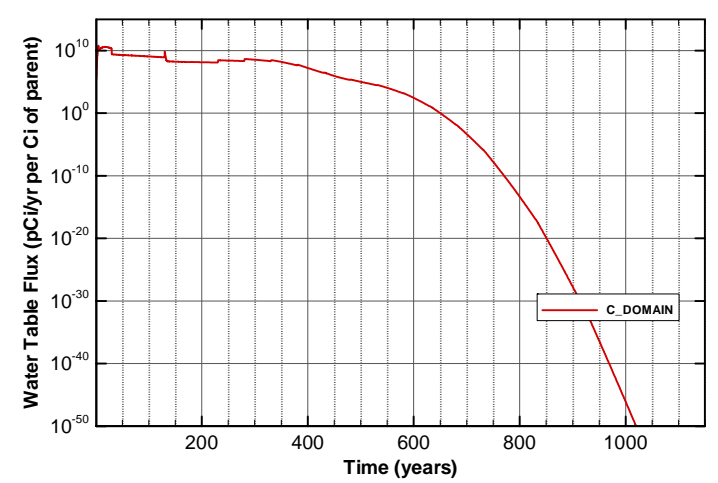

Figure A-989. Flux at water table for Case01n11_off Nb-94

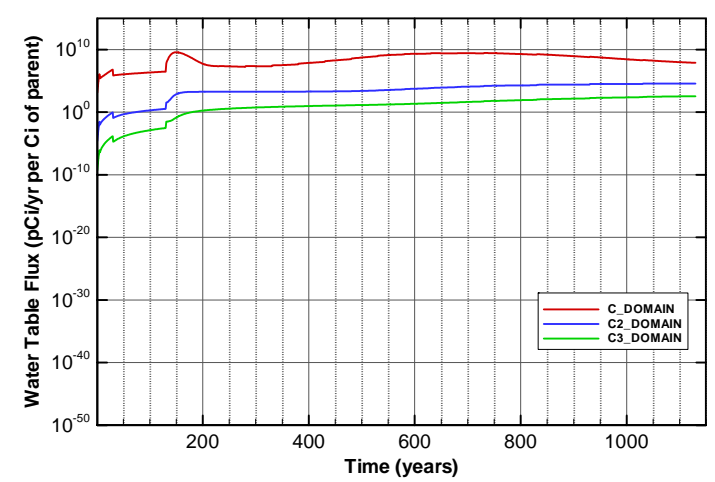

Figure A-991. Flux at water table for Case01n11_off Np-237

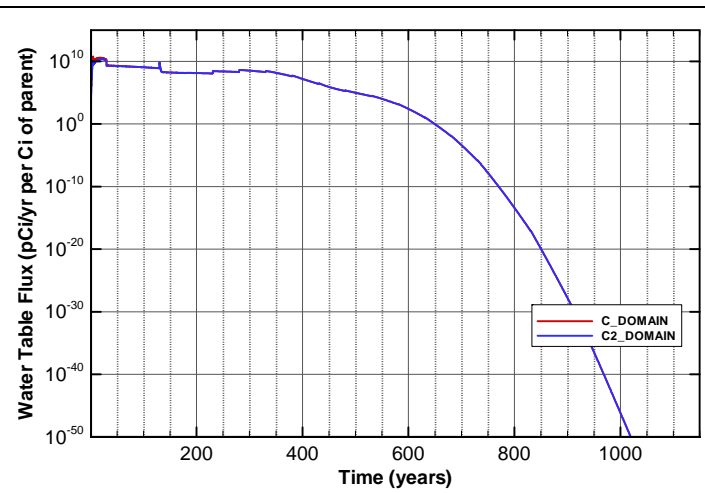

Figure A-988. Flux at water table for Case01n11_off Mo-93

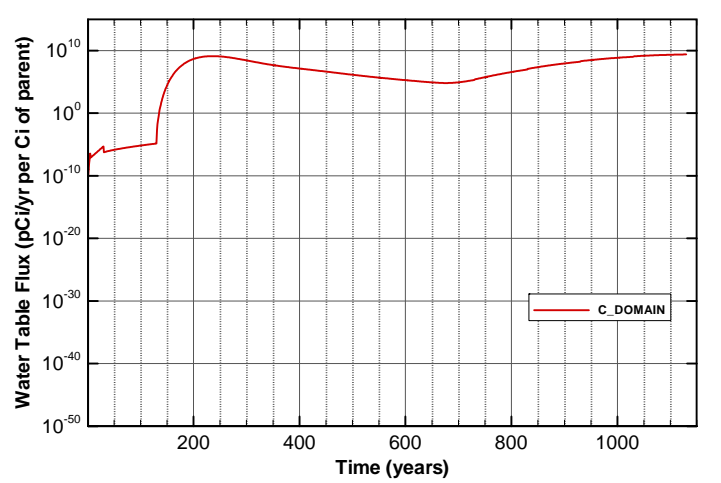

Figure A-990. Flux at water table for Case01n11_off Ni-59

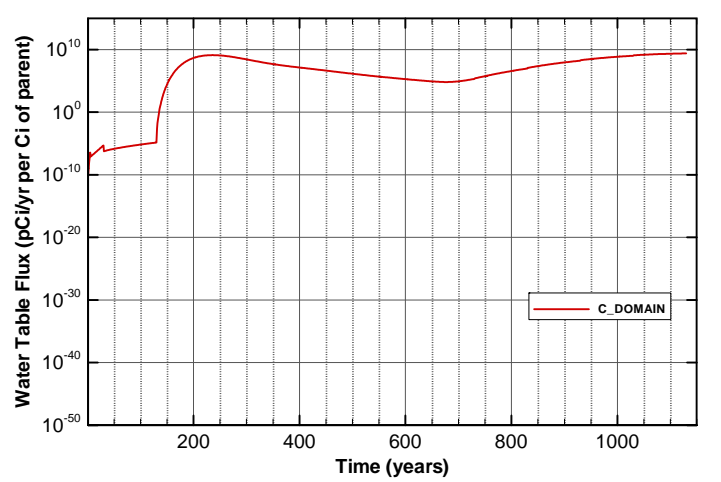

Figure A-992. Flux at water table for Case01n11_off Pd-107 
SRNL-STI-2008-00397, REVISION 0
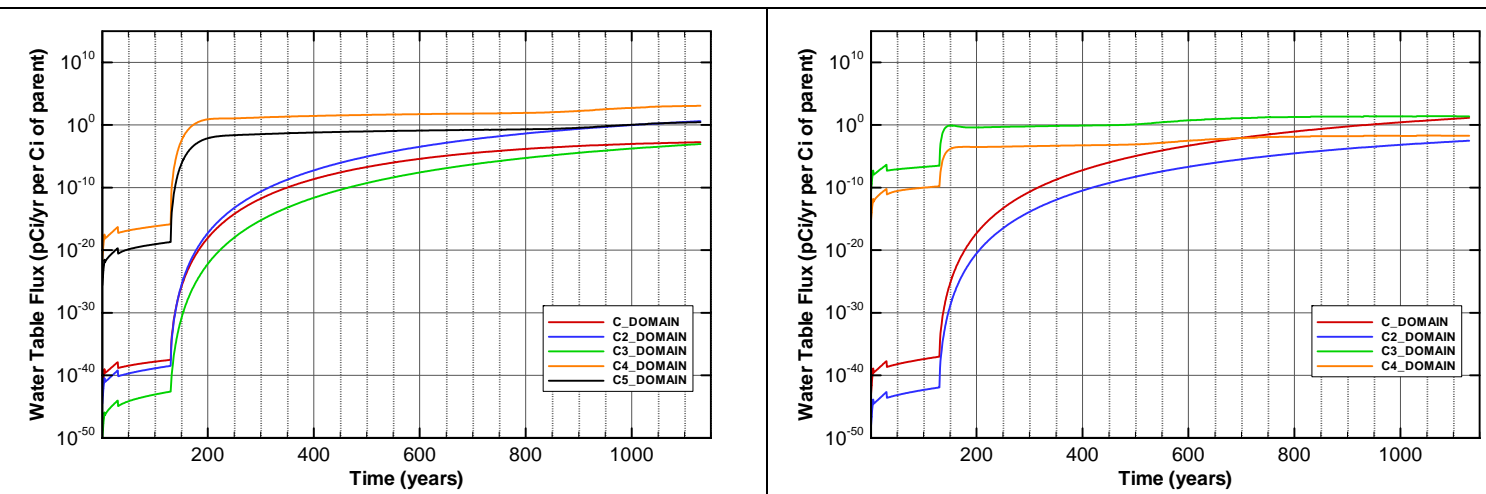

Figure A-993. Flux at water table for Case01n11_off Pu-238

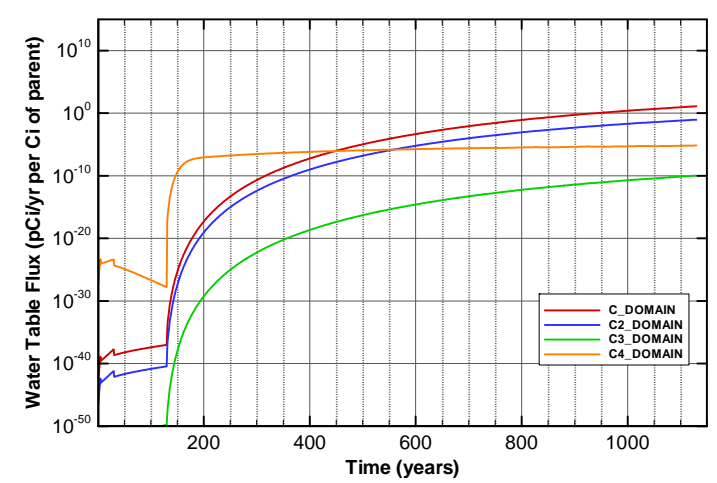

Figure A-995. Flux at water table for Case01n11_off Pu-240

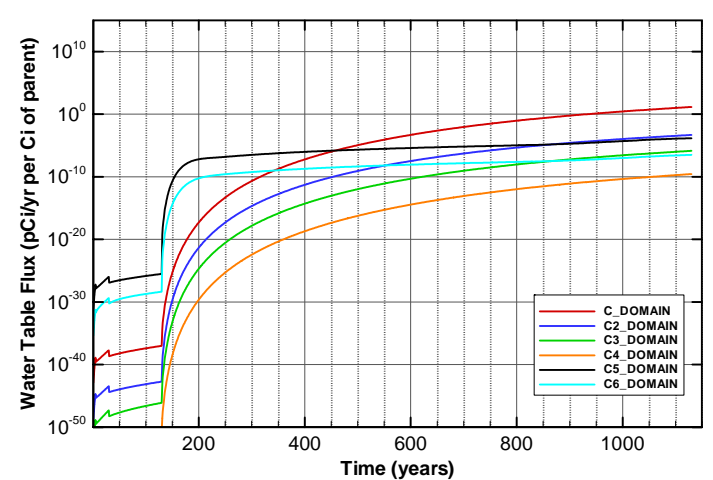

Figure A-997. Flux at water table for Case01n11_off Pu-242

Figure A-994. Flux at water table for Case01n11_off Pu-239

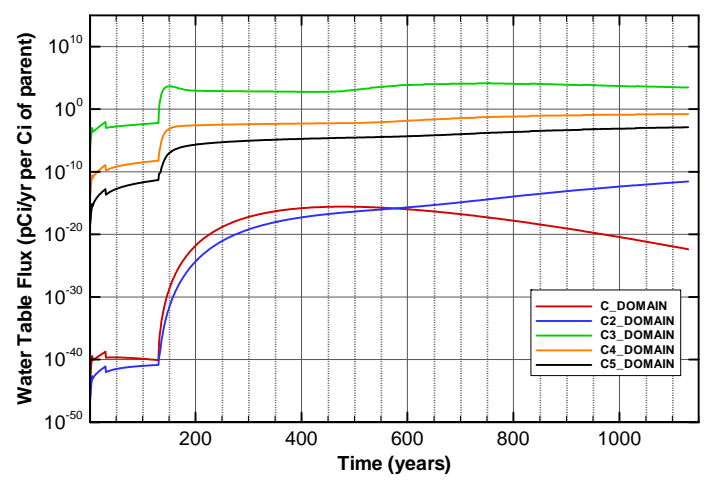

Figure A-996. Flux at water table for Case01n11_off Pu-241

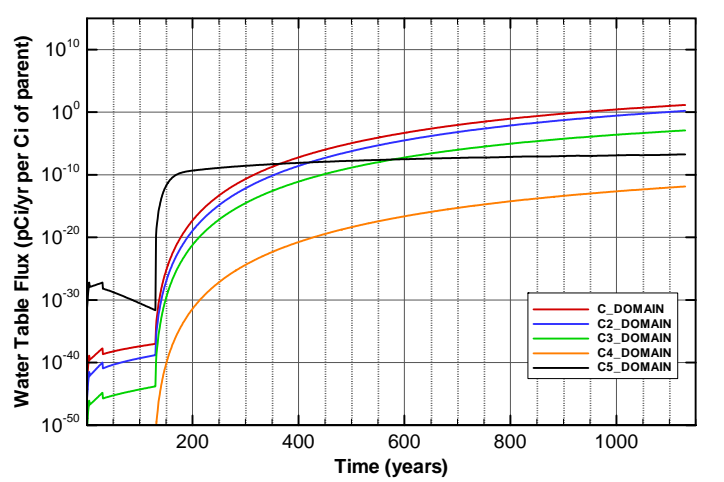

Figure A-998. Flux at water table for Case01n11_off Pu-244 


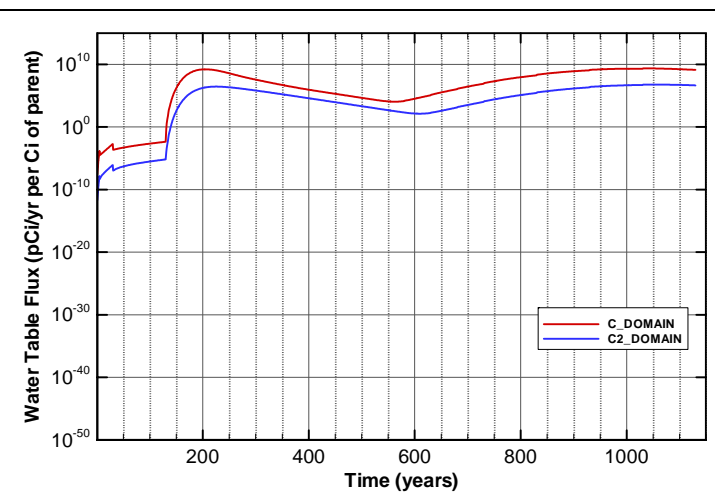

Figure A-999. Flux at water table for Case01n11_off Ra-226

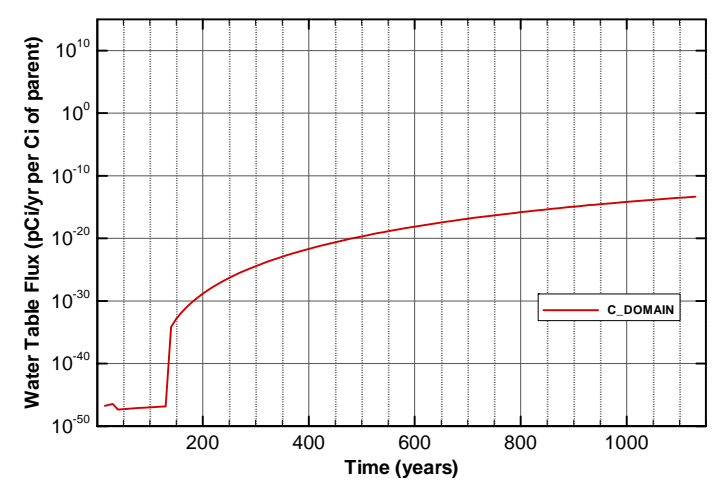

Figure A-1001. Flux at water table for Case01n11_off Sn-126

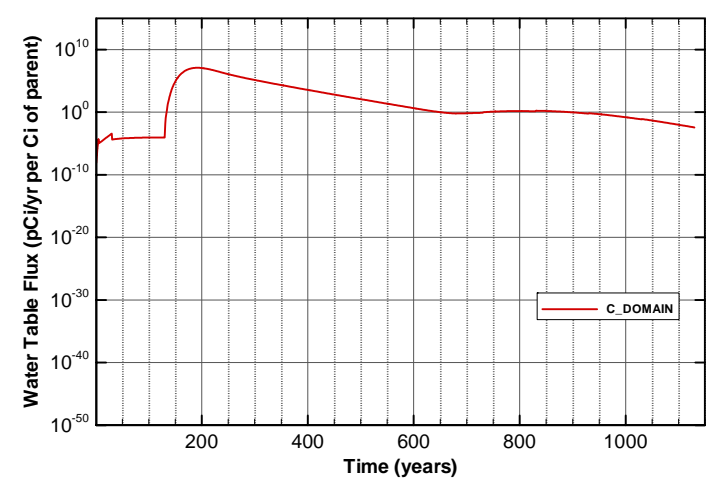

Figure A-1003. Flux at water table for Case01n11_off Sr-90_Cask

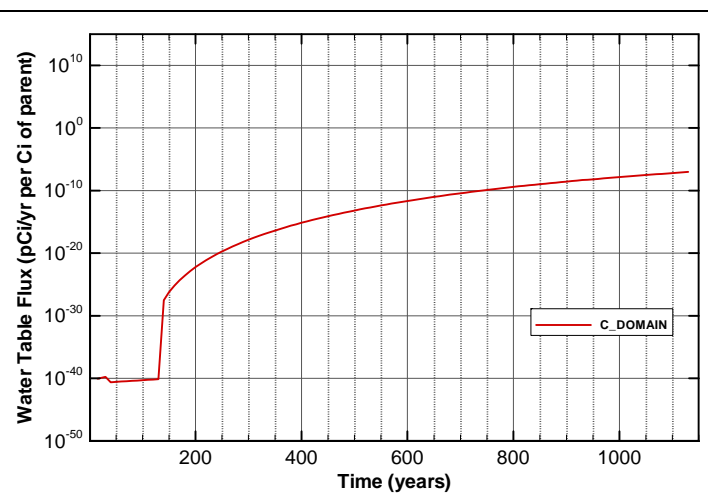

Figure A-1000. Flux at water table for Case01n11_off Se-79

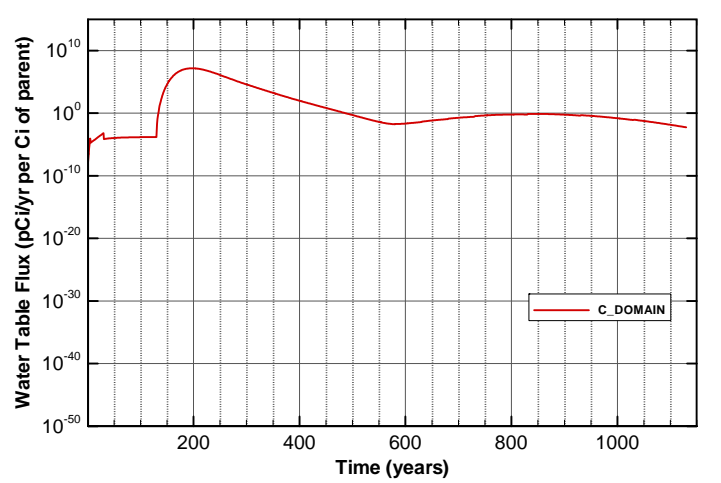

Figure A-1002. Flux at water table for Case01n11_off Sr-90

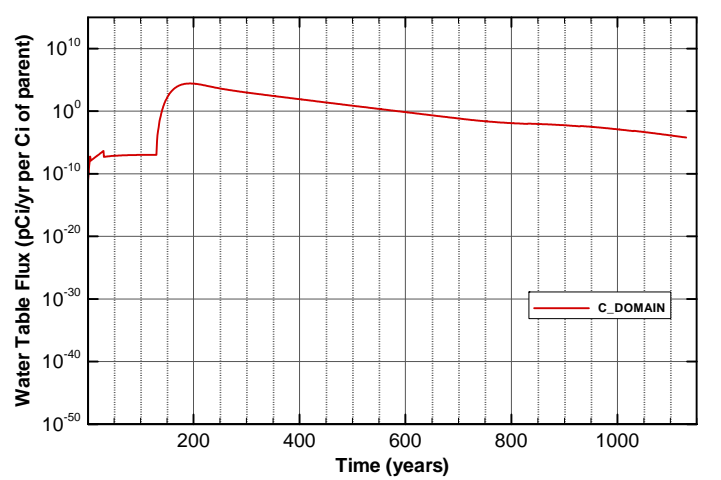

Figure A-1004. Flux at water table for Case01n11_off Sr-90_Mk50A 


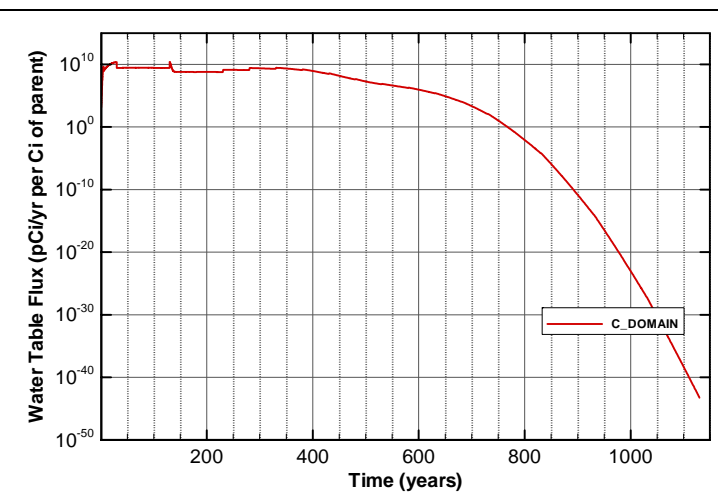

Figure A-1005. Flux at water table for Case01n11_off Tc-99

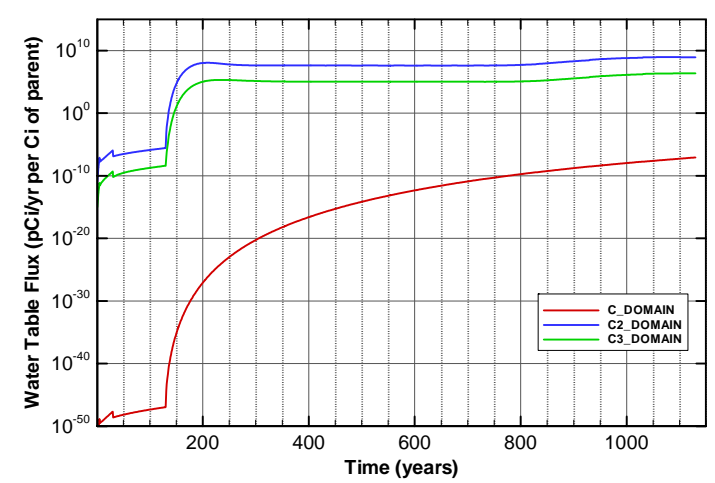

Figure A-1007. Flux at water table for Case01n11_off Th-230

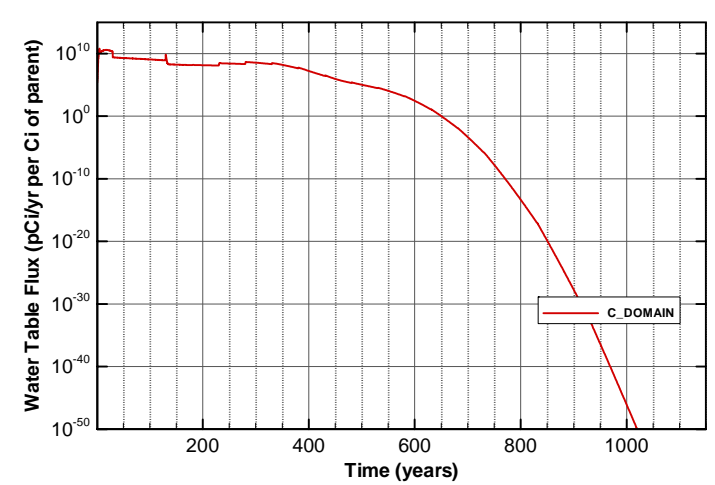

Figure A-1009. Flux at water table for Case01n11_off Tracer

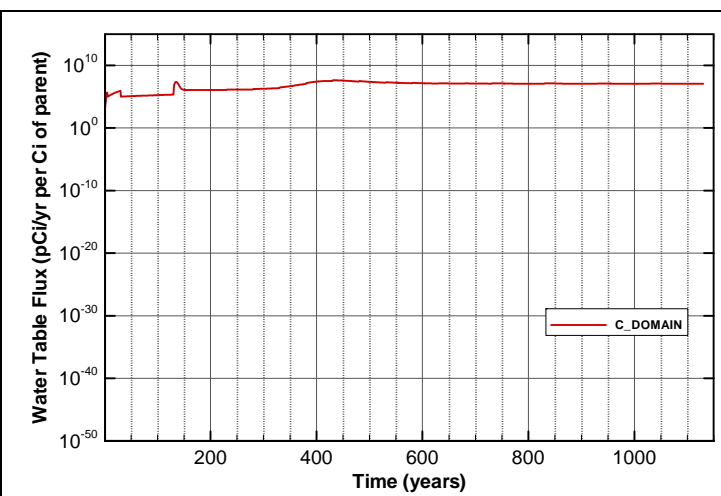

Figure A-1006. Flux at water table for Case01n11_off Tc-99_Mk50A

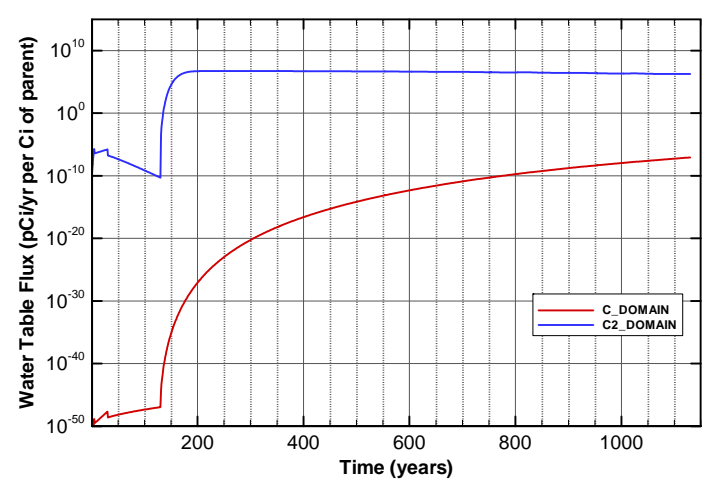

Figure A-1008. Flux at water table for Case01n11_off Th-232

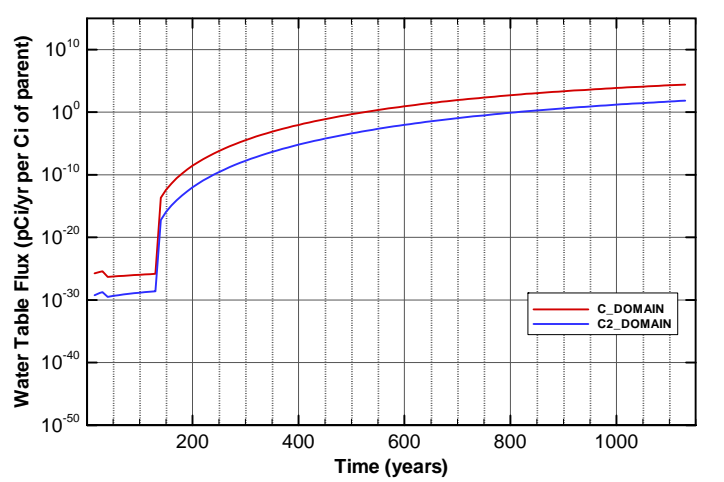

Figure A-1010. Flux at water table for Case01n11_off U-233 


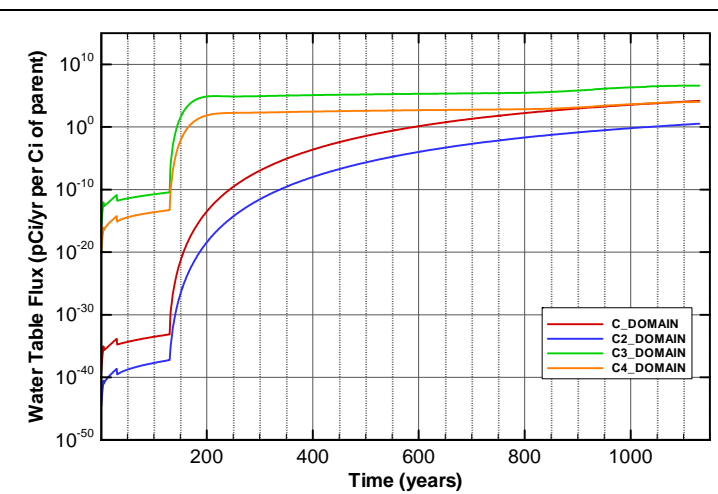

Figure A-1011. Flux at water table for Case01n11_off U-234

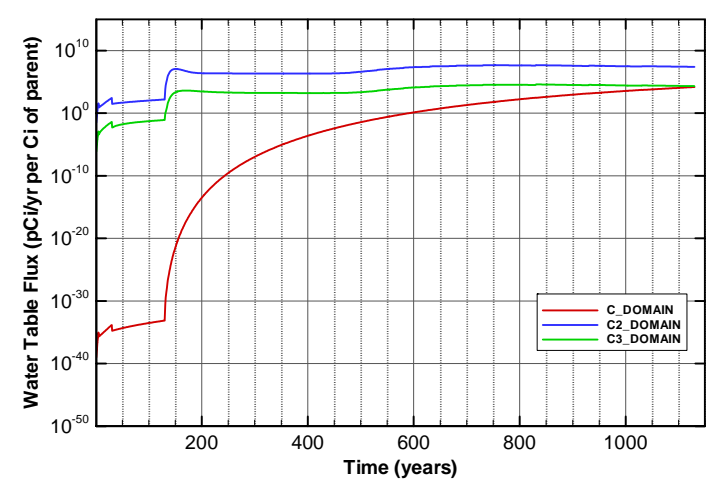

Figure A-1013. Flux at water table for Case01n11_off U-235

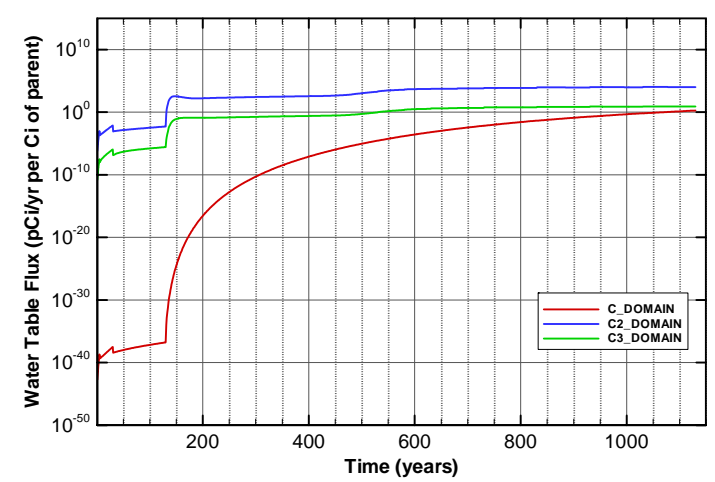

Figure A-1015. Flux at water table for Case01n11_off U-235_Paducah.Cask

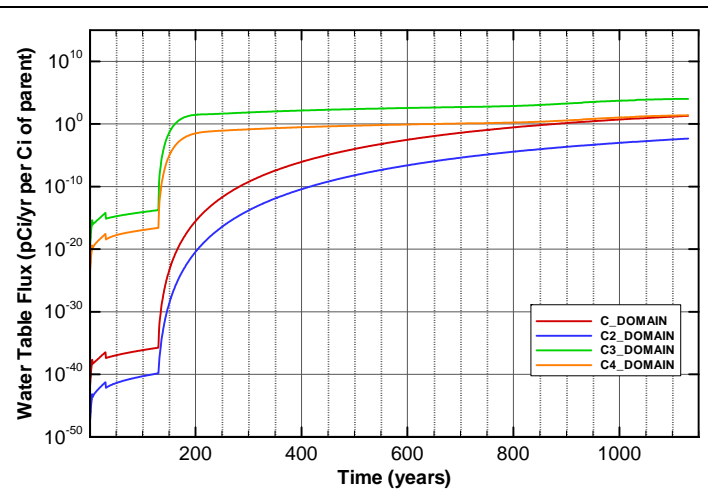

Figure A-1012. Flux at water table for Case01n11_off U-234_Mglass

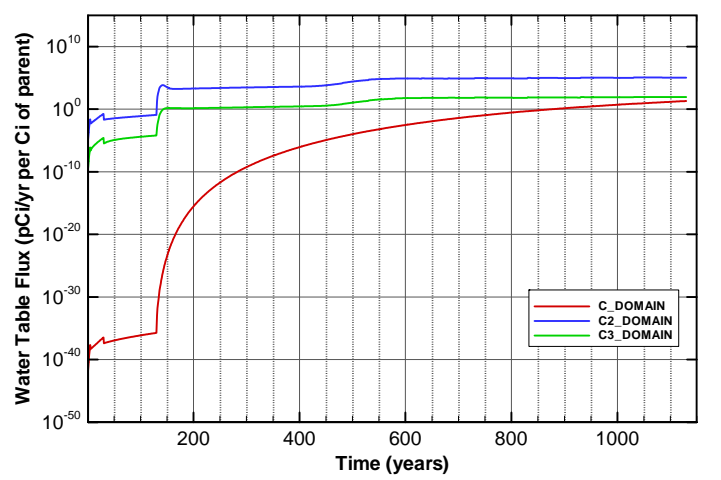

Figure A-1014. Flux at water table for Case01n11_off U-235_Mglass

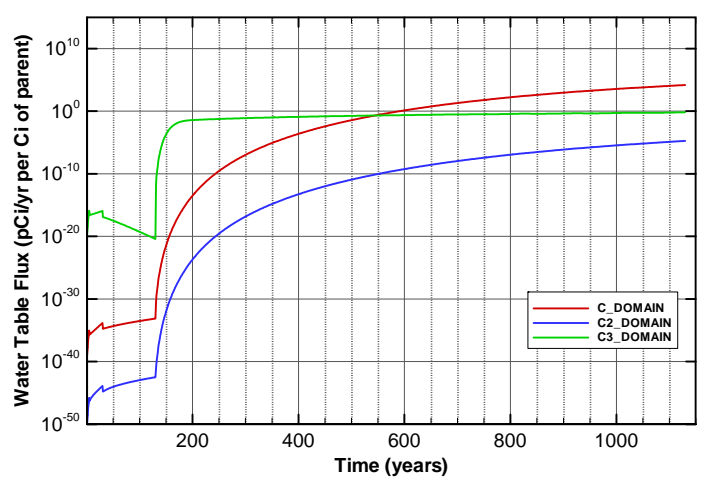

Figure A-1016. Flux at water table for Case01n11_off U-236 


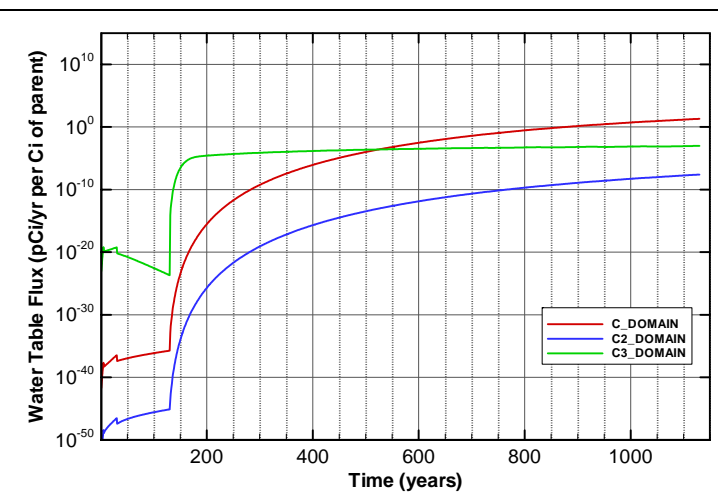

Figure A-1017. Flux at water table for Case01n11_off U-236_Mglass

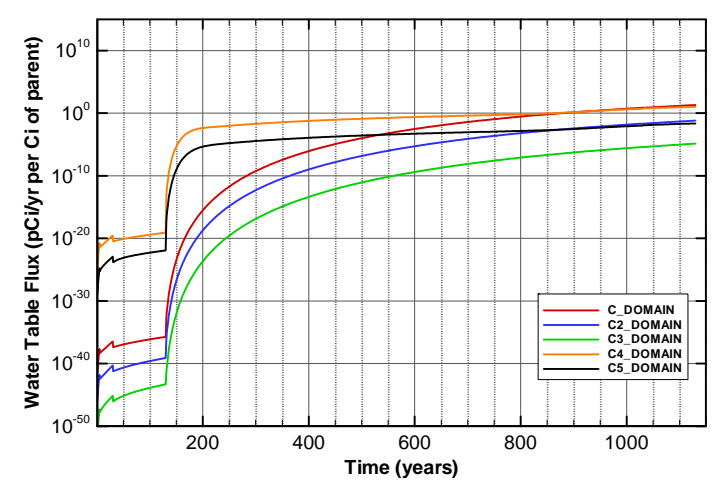

Figure A-1019. Flux at water table for Case01n11_off U-238_Mglass

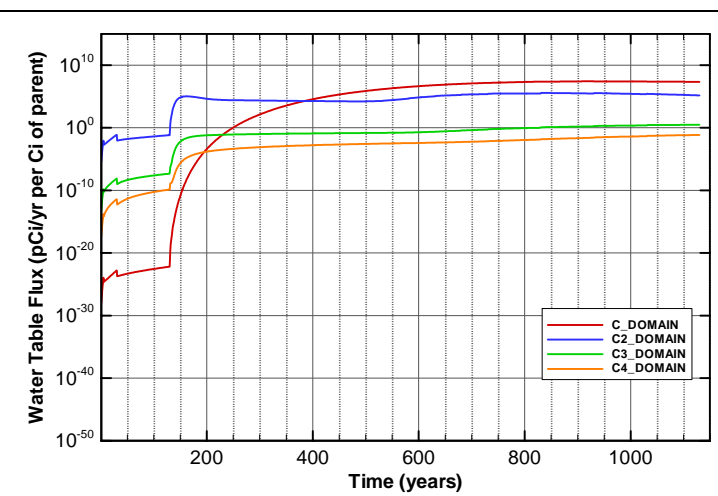

Figure A-1021. Flux at water table for Case01n11_on Am-241

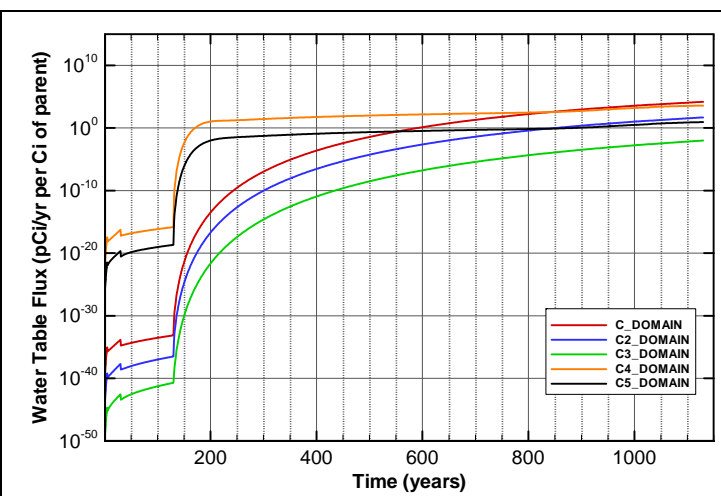

Figure A-1018. Flux at water table for Case01n11_off U-238

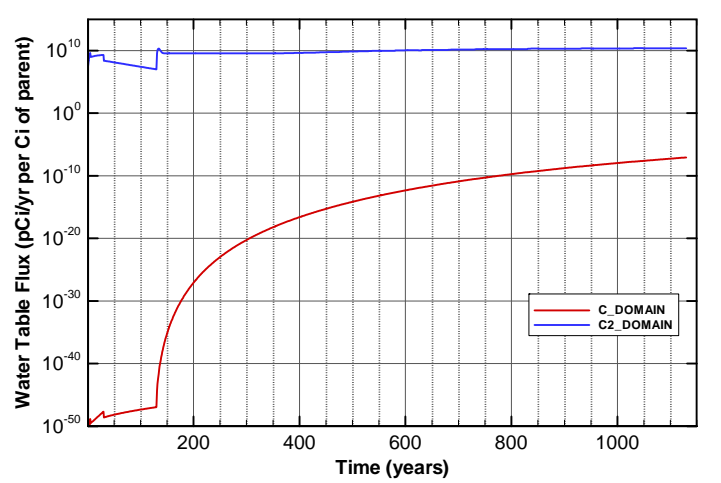

Figure A-1020. Flux at water table for Case01n11_off Zr-93

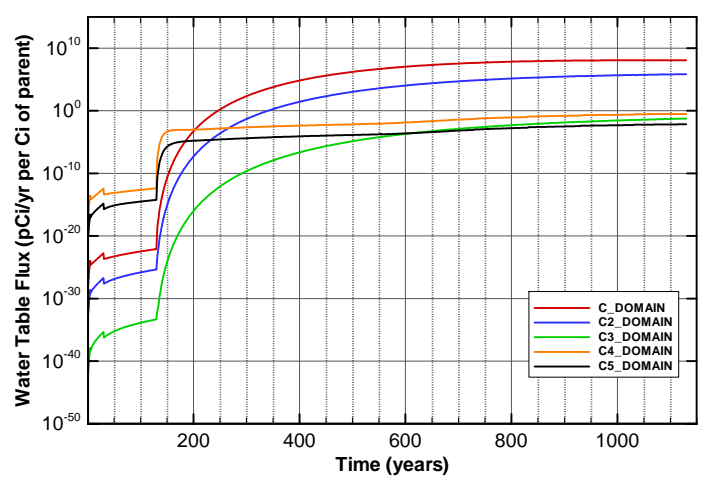

Figure A-1022. Flux at water table for Case01n11_on Am-243 
SRNL-STI-2008-00397, REVISION 0

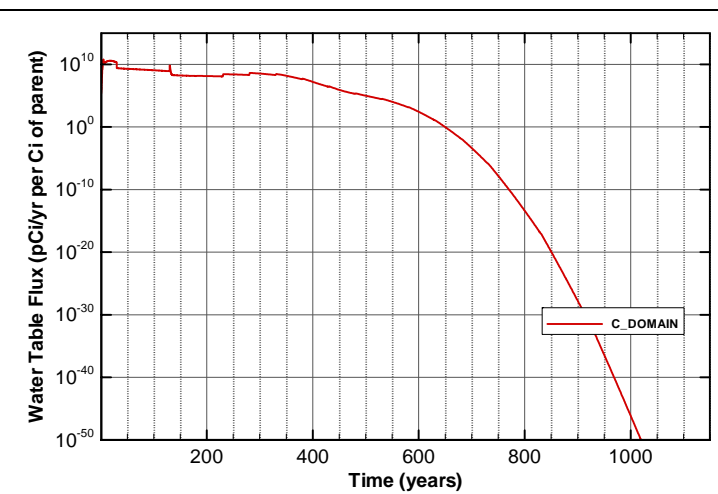

Figure A-1023. Flux at water table for Case01n11_on C-14

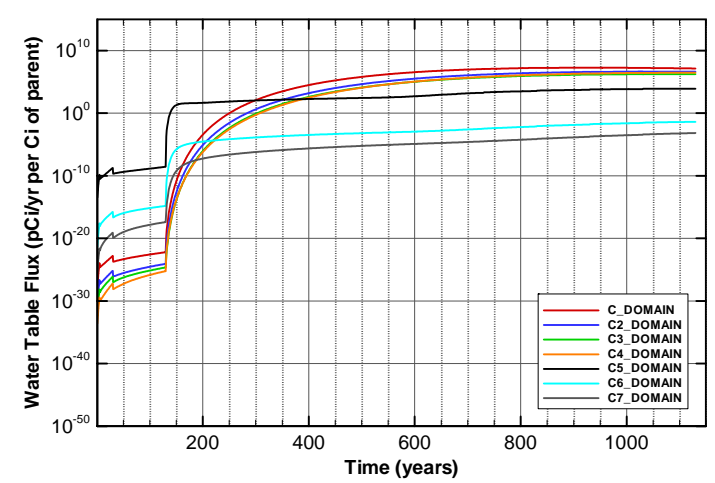

Figure A-1025. Flux at water table for Case01n11_on Cf-249

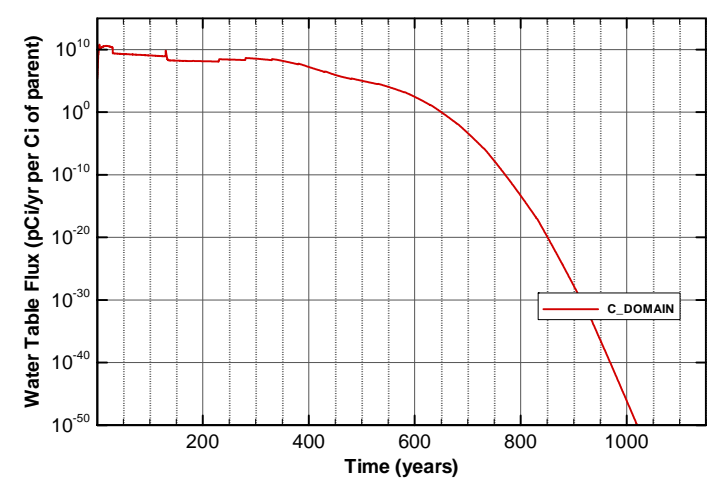

Figure A-1027. Flux at water table for Case01n11_on Cl-36

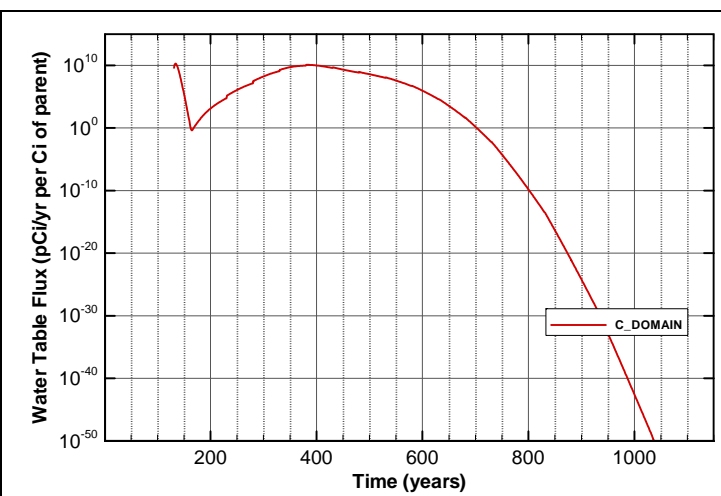

Figure A-1024. Flux at water table for Case01n11_on C-14_NR.Pump

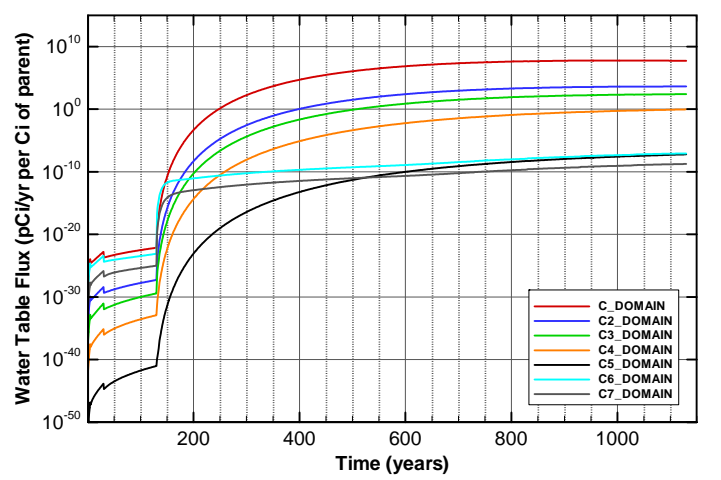

Figure A-1026. Flux at water table for Case01n11_on Cf-251

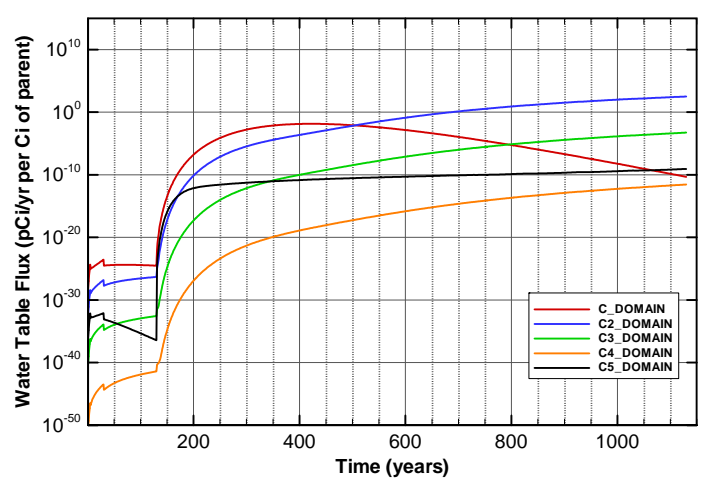

Figure A-1028. Flux at water table for Case01n11_on Cm-244 


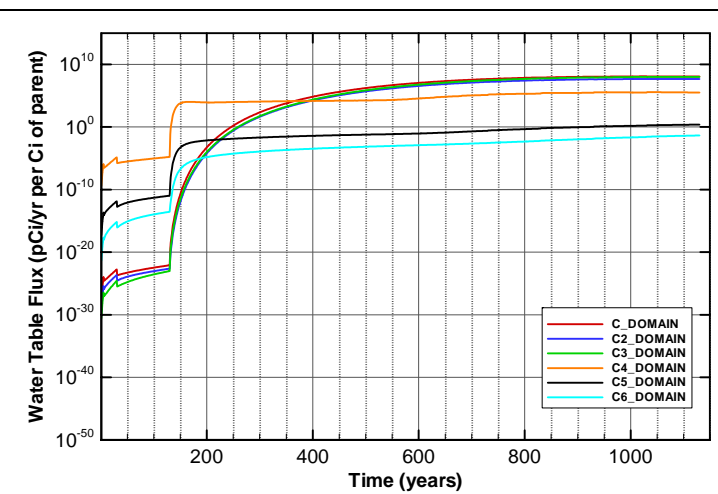

Figure A-1029. Flux at water table for Case01n11_on Cm-245

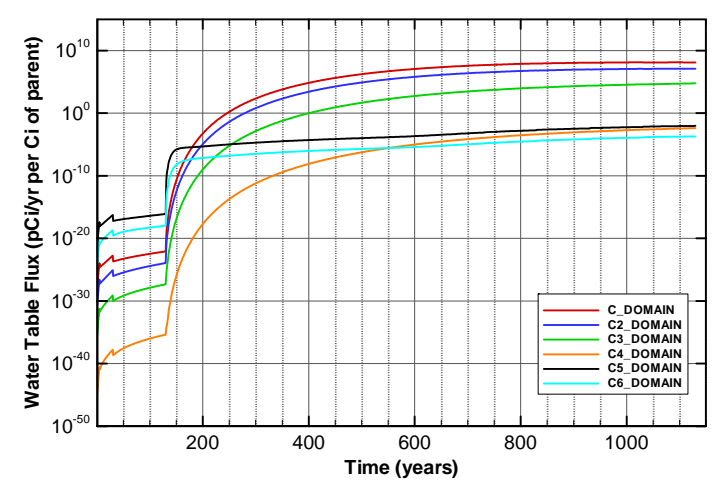

Figure A-1031. Flux at water table for Case01n11_on Cm-247

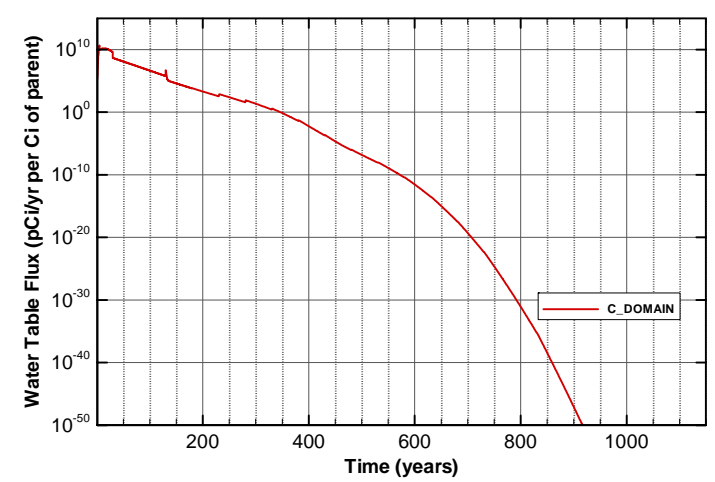

Figure A-1033. Flux at water table for Case01n11_on H-3

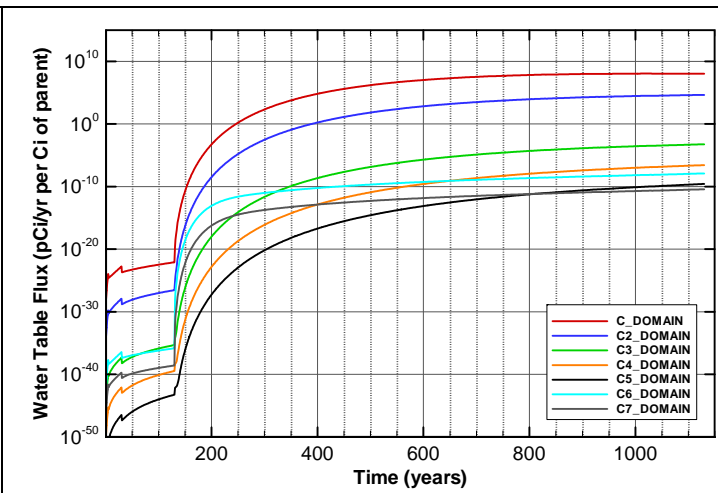

Figure A-1030. Flux at water table for Case01n11_on Cm-246

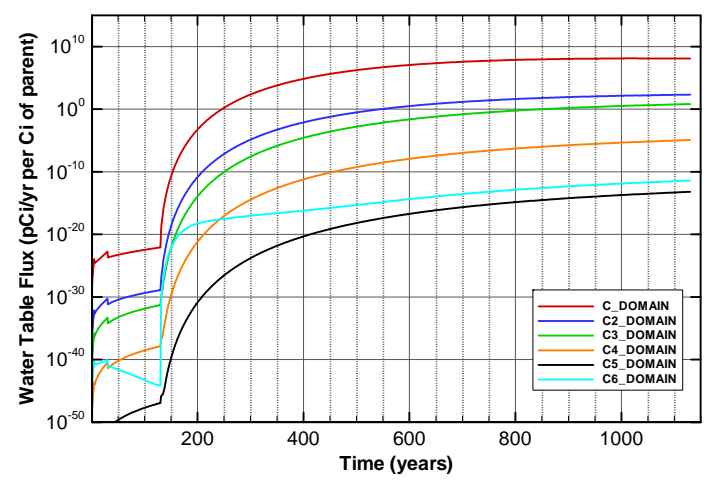

Figure A-1032. Flux at water table for Case01n11_on Cm-248

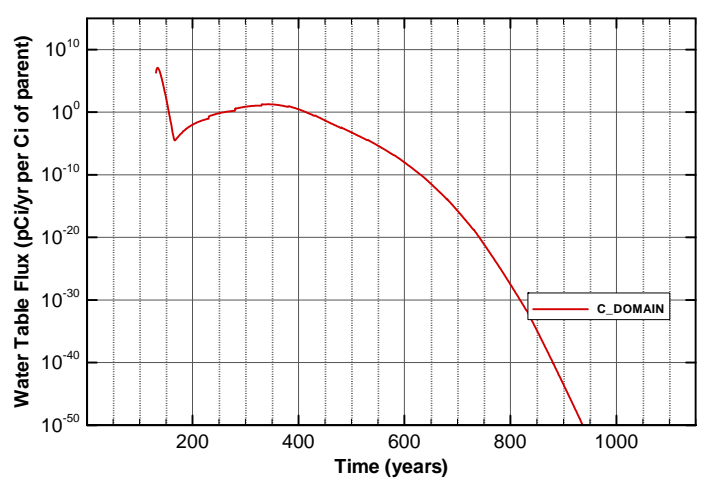

Figure A-1034. Flux at water table for Case01n11_on H-3_ETF.Carbon 


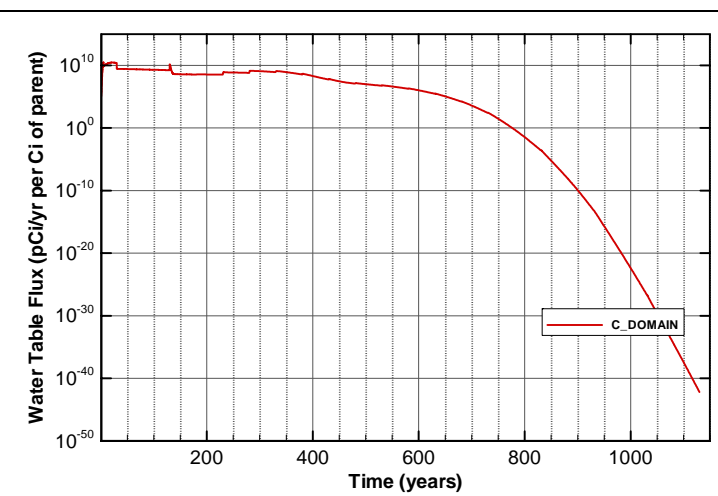

Figure A-1035. Flux at water table for Case01n11_on I-129

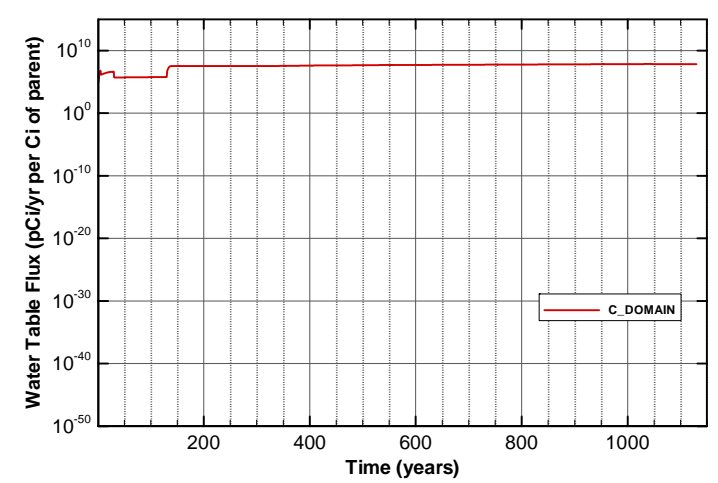

Figure A-1037. Flux at water table for Case01n11_on I-129_ETF.GT.73

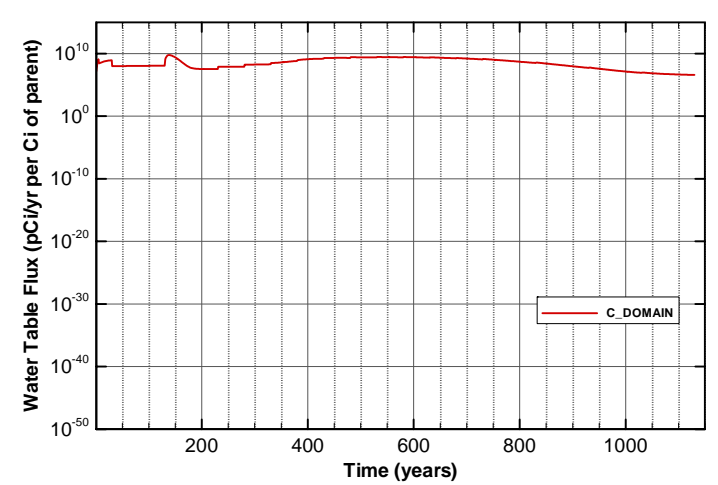

Figure A-1039. Flux at water table for Case01n11_on I-129_F.CG.8

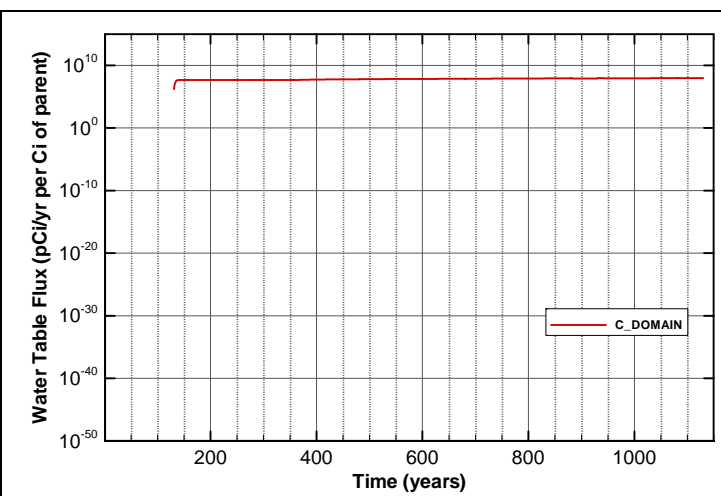

Figure A-1036. Flux at water table for Case01n11_on I-129_ETF.Carbon

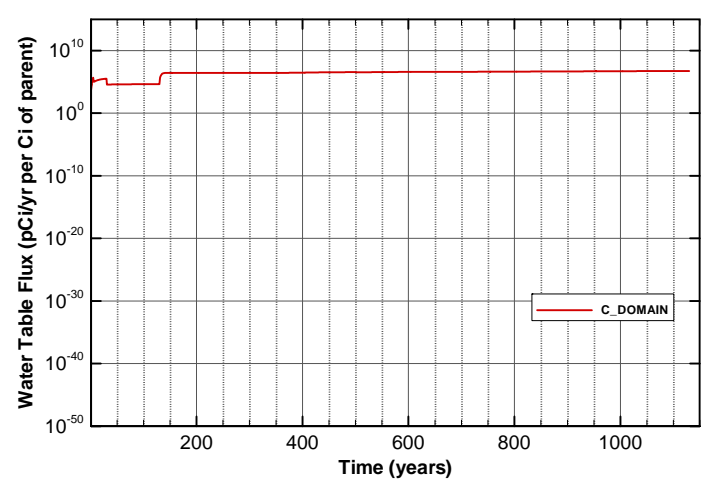

Figure A-1038. Flux at water table for Case01n11_on I-129_F.Carbon

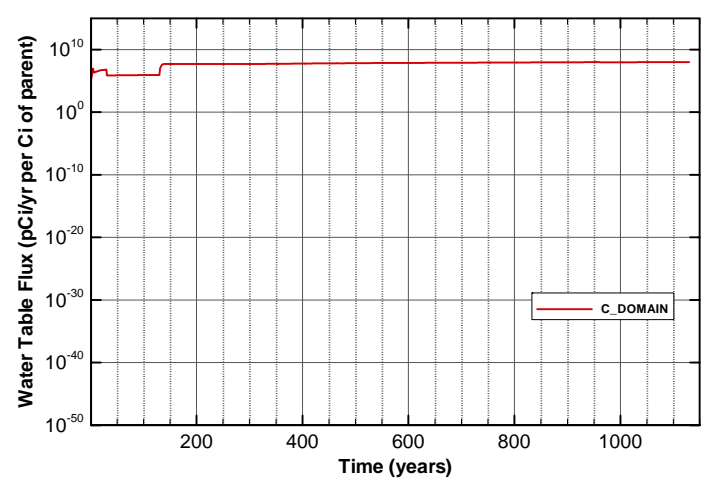

Figure A-1040. Flux at water table for Case01n11_on I-129_F.Dowex.21K 


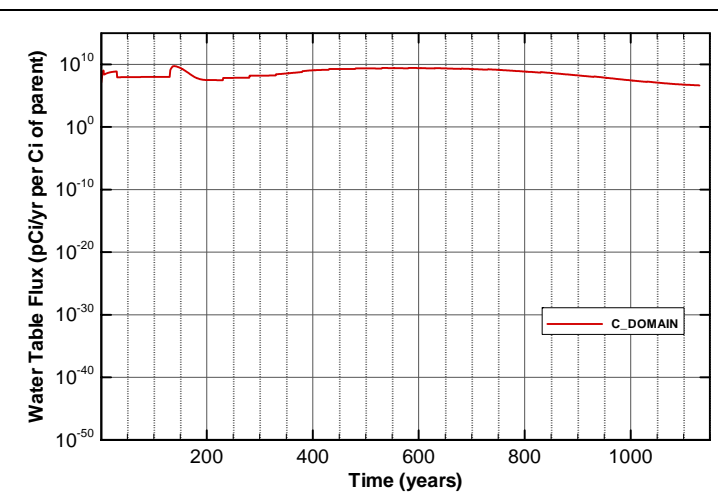

Figure A-1041. Flux at water table for Case01n11_on I-129_F.Filtercake

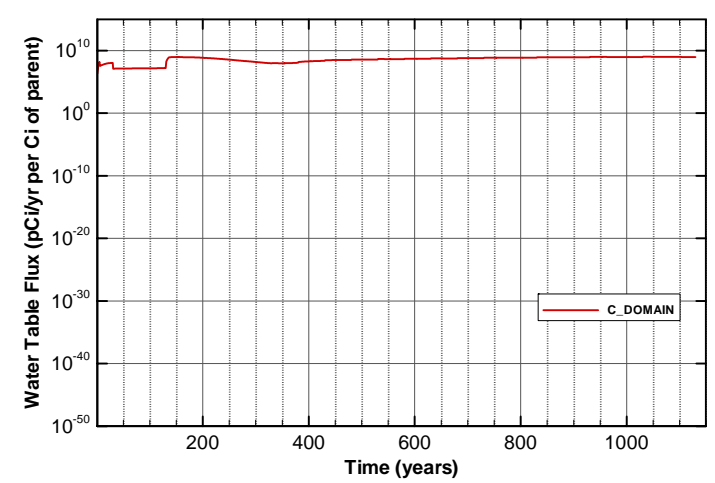

Figure A-1043. Flux at water table for Case01n11_on I-129_H.CG.8

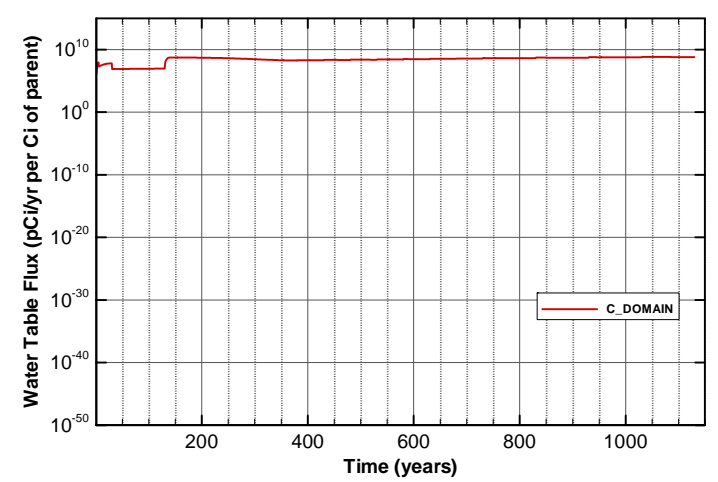

Figure A-1045. Flux at water table for Case01n11_on I-129_H.Filtercake

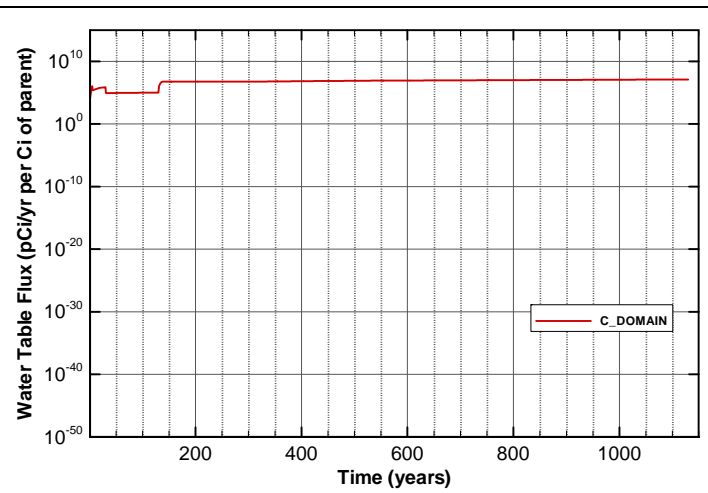

Figure A-1042. Flux at water table for Case01n11_on I-129_H.Carbon

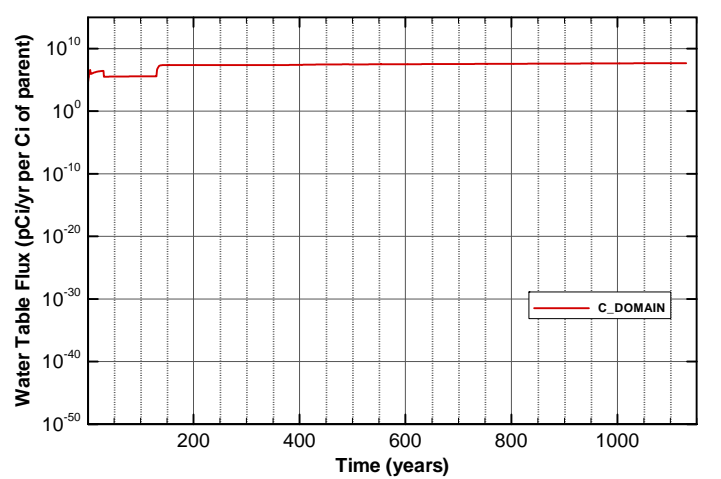

Figure A-1044. Flux at water table for Case01n11_on I-129_H.Dowex.21K

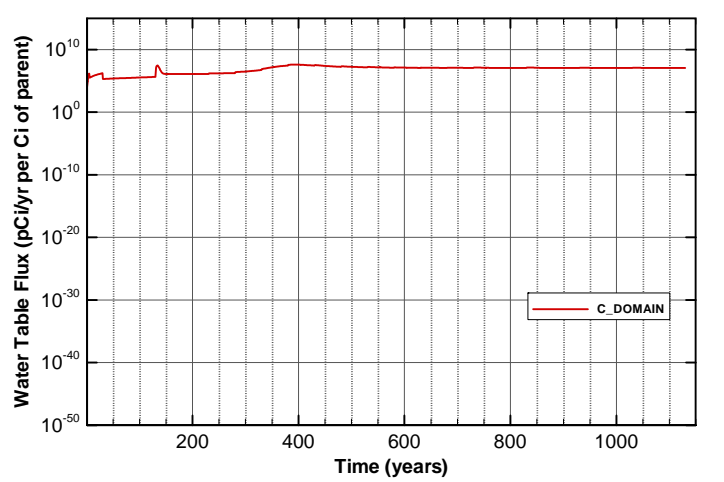

Figure A-1046. Flux at water table for Case01n11_on I-129_Mk50A 


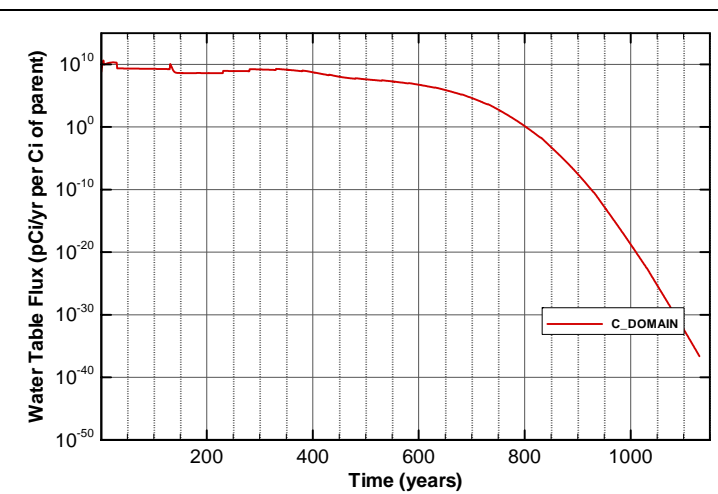

Figure A-1047. Flux at water table for Case01n11_on K-40

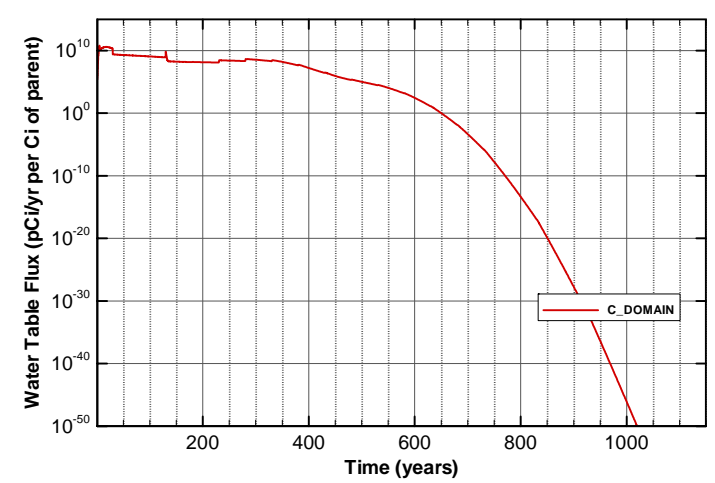

Figure A-1049. Flux at water table for Case01n11_on Nb-94

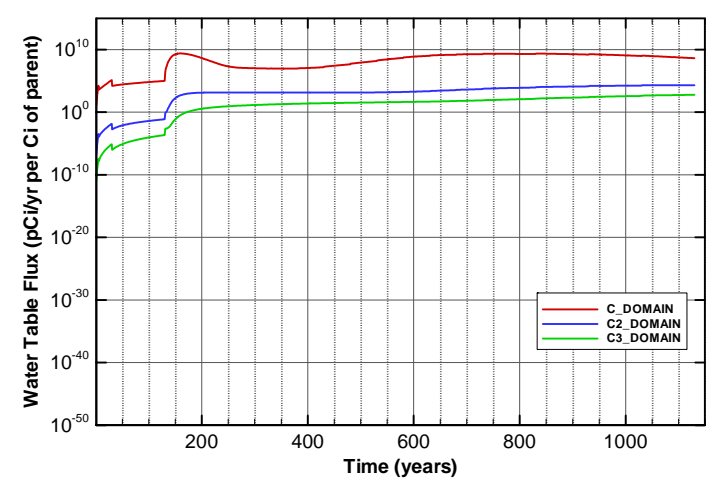

Figure A-1051. Flux at water table for Case01n11_on Np-237

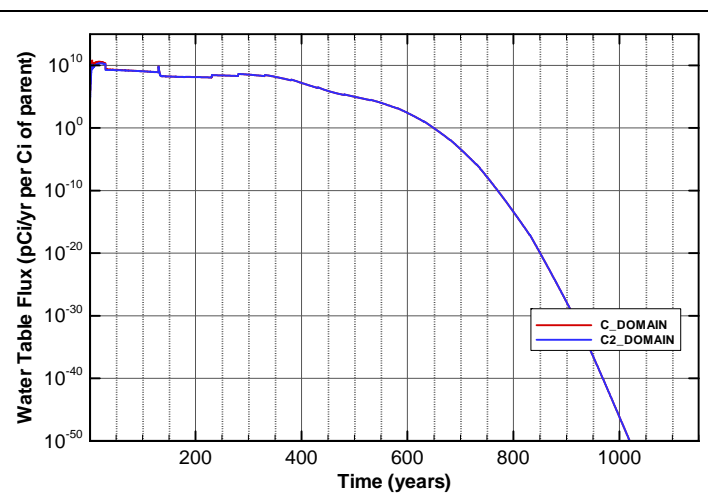

Figure A-1048. Flux at water table for Case01n11_on Mo-93

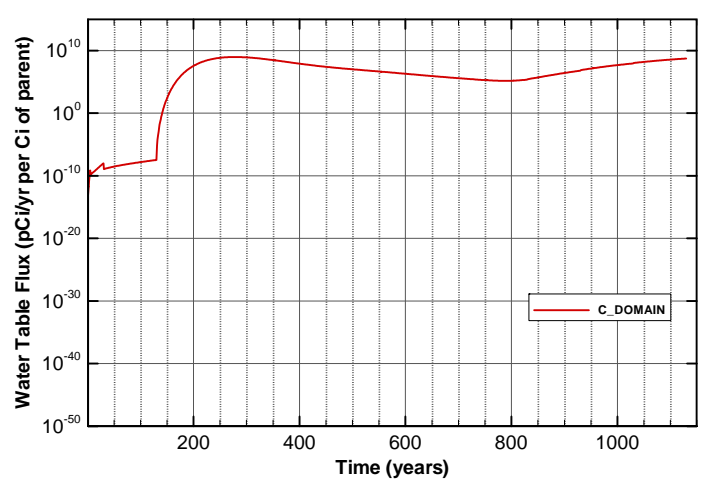

Figure A-1050. Flux at water table for Case01n11_on Ni-59

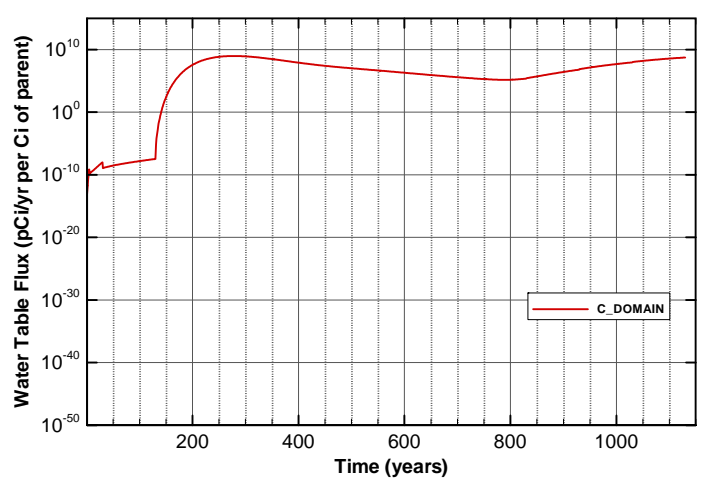

Figure A-1052. Flux at water table for Case01n11_on Pd-107 
SRNL-STI-2008-00397, REVISION 0

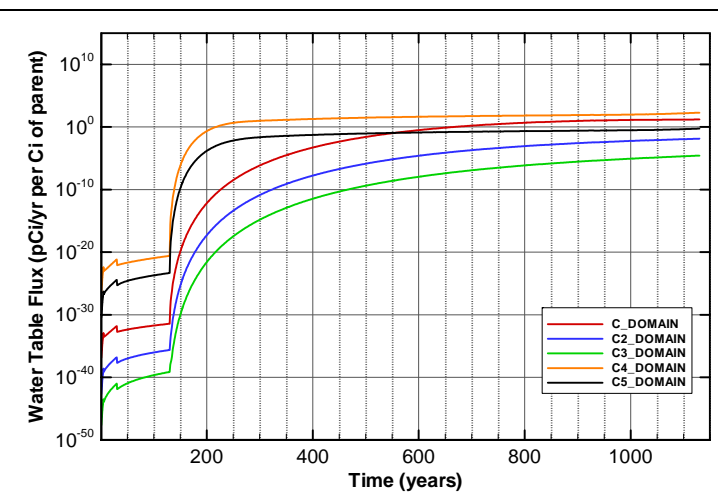

Figure A-1053. Flux at water table for Case01n11_on Pu-238

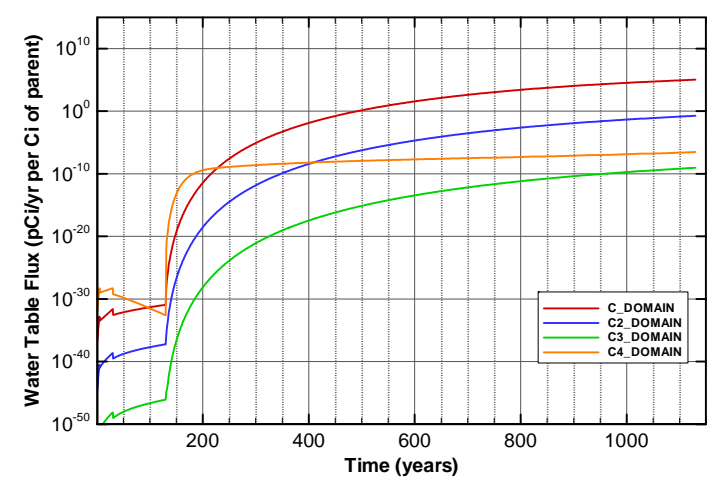

Figure A-1055. Flux at water table for Case01n11_on Pu-240

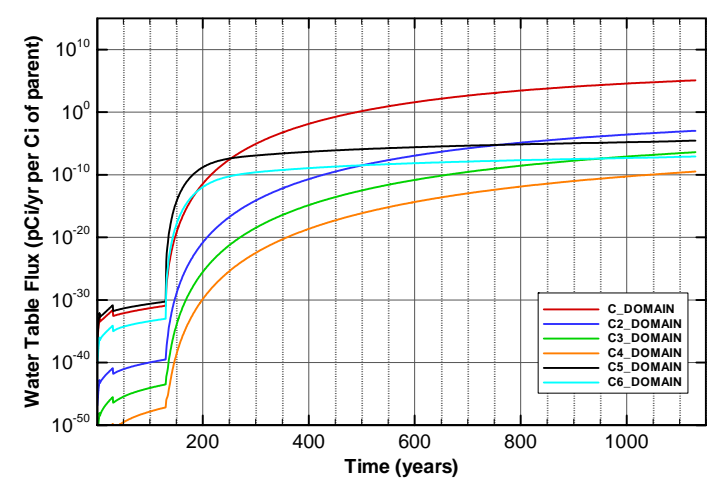

Figure A-1057. Flux at water table for Case01n11_on Pu-242

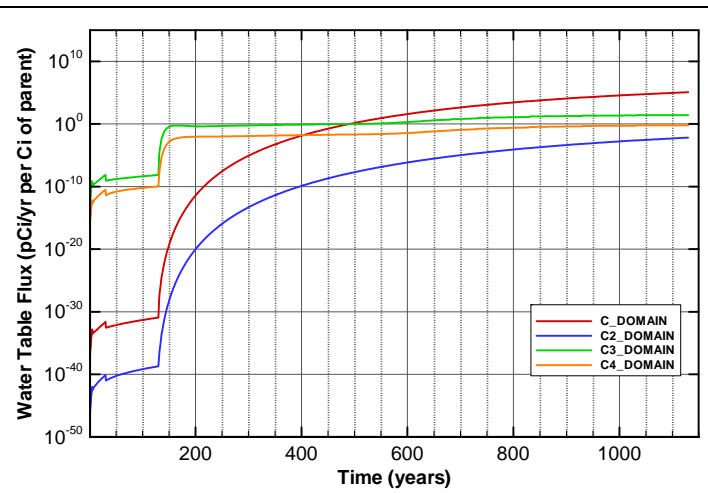

Figure A-1054. Flux at water table for Case01n11_on Pu-239

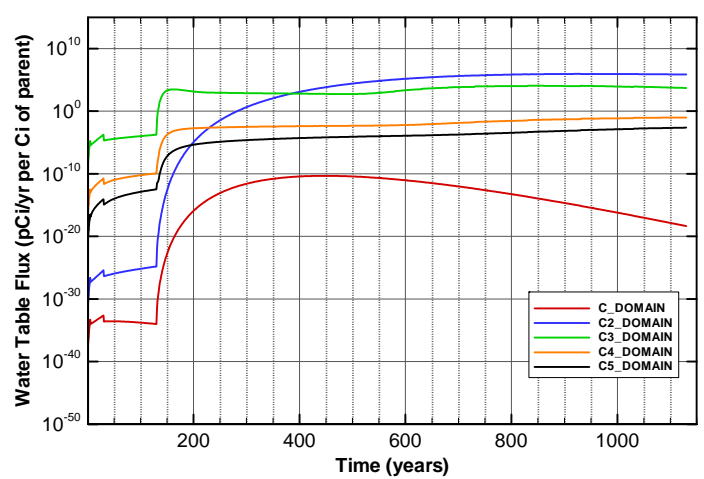

Figure A-1056. Flux at water table for Case01n11_on Pu-241

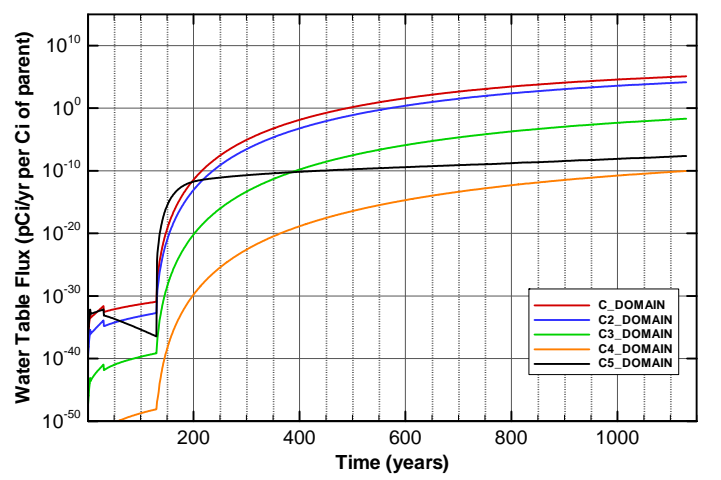

Figure A-1058. Flux at water table for Case01n11_on Pu-244 


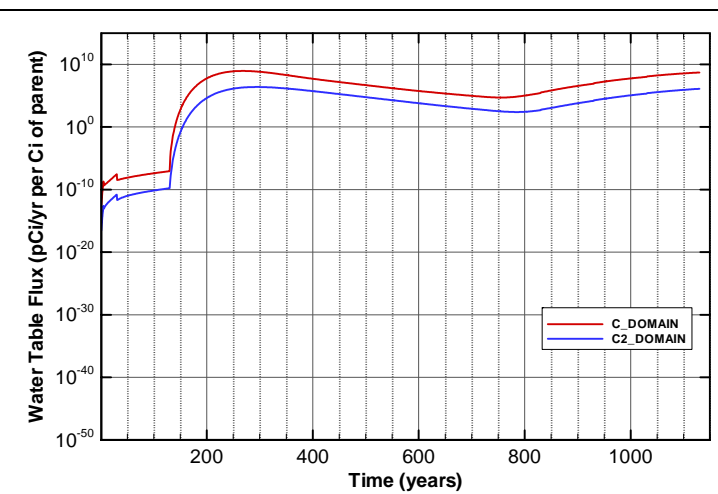

Figure A-1059. Flux at water table for Case01n11_on Ra-226

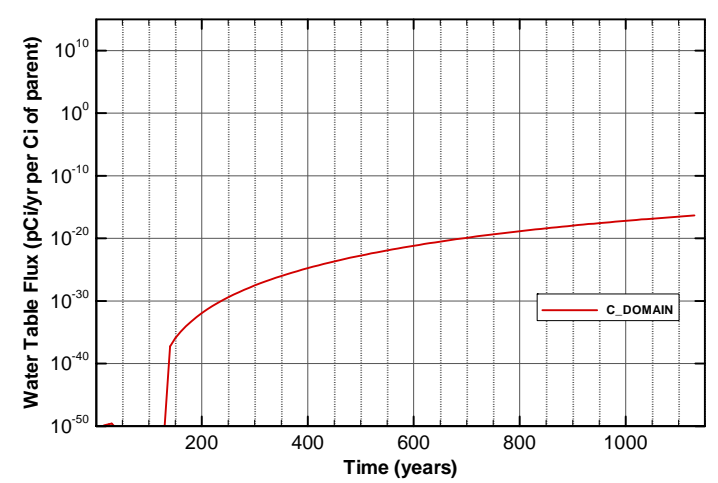

Figure A-1061. Flux at water table for Case01n11_on Sn-126

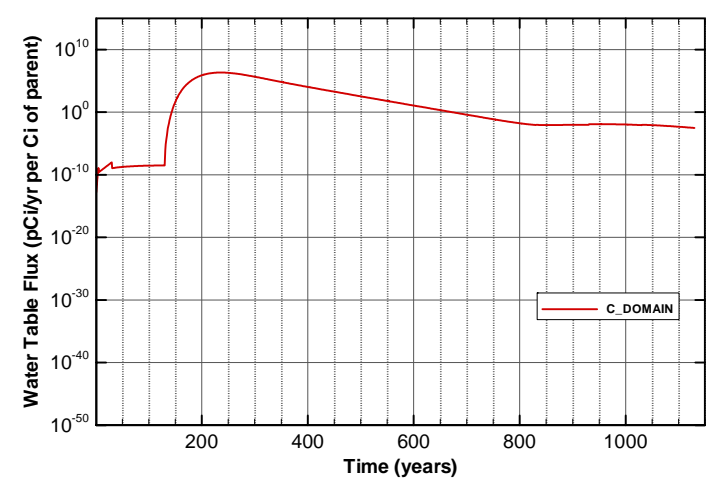

Figure A-1063. Flux at water table for Case01n11_on Sr-90_Cask

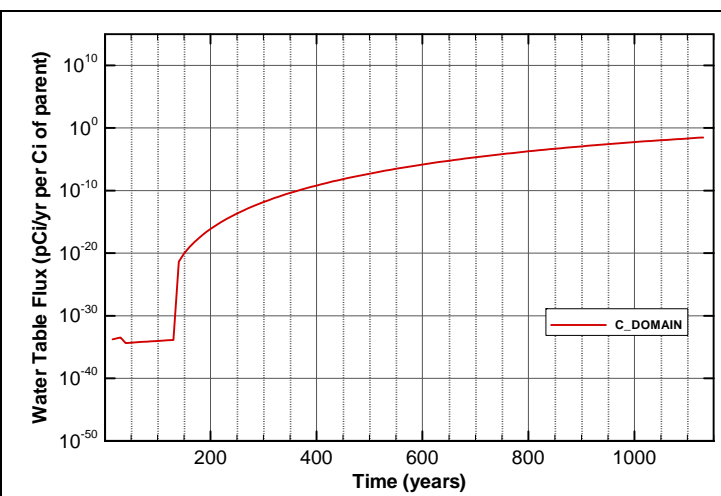

Figure A-1060. Flux at water table for Case01n11_on Se-79

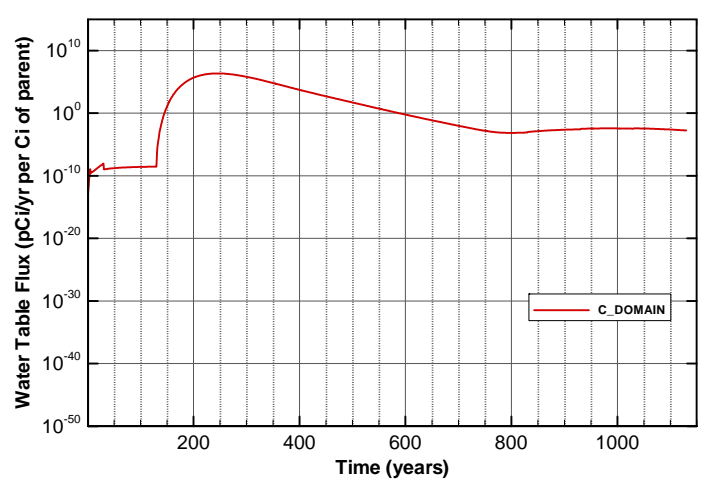

Figure A-1062. Flux at water table for Case01n11_on Sr-90

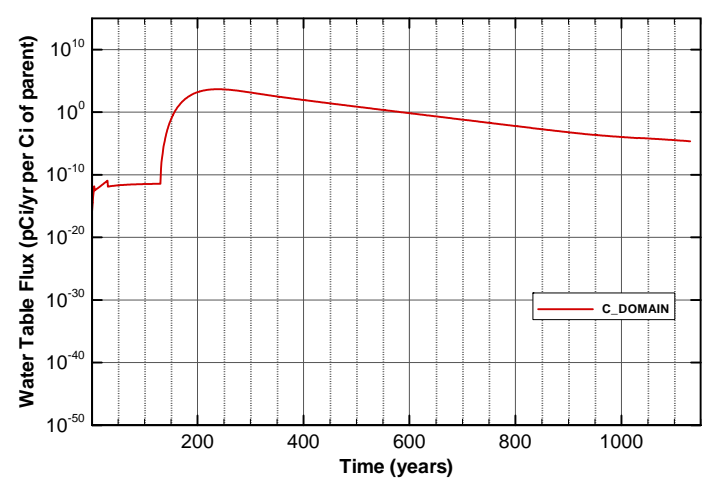

Figure A-1064. Flux at water table for Case01n11_on Sr-90_Mk50A 


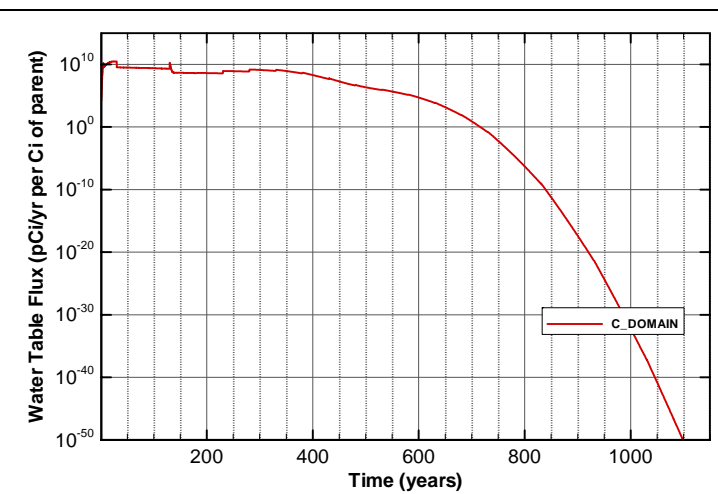

Figure A-1065. Flux at water table for Case01n11_on Tc-99

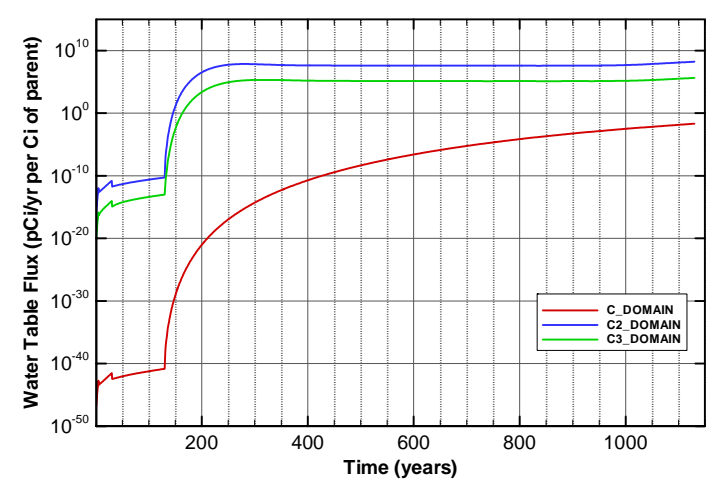

Figure A-1067. Flux at water table for Case01n11_on Th-230

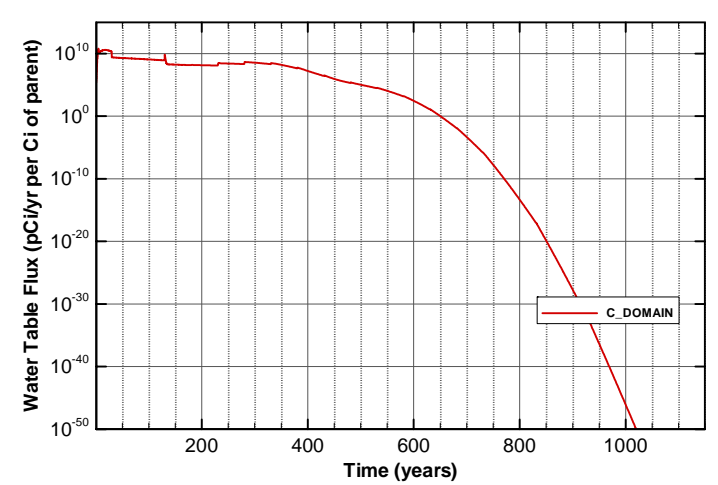

Figure A-1069. Flux at water table for Case01n11_on Tracer

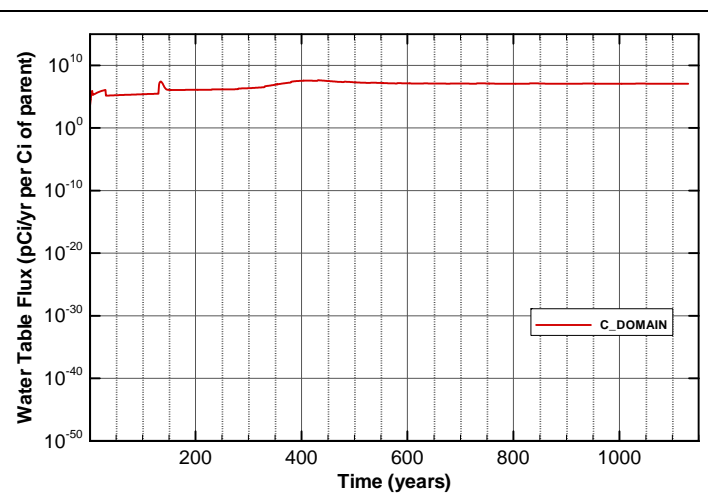

Figure A-1066. Flux at water table for Case01n11_on Tc-99_Mk50A

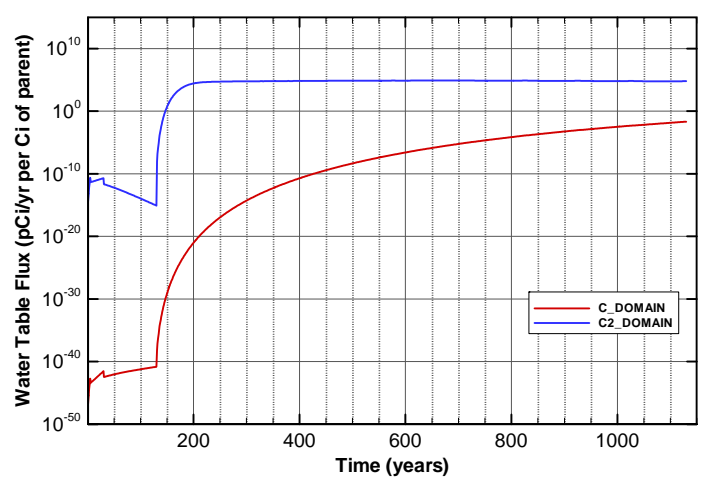

Figure A-1068. Flux at water table for Case01n11_on Th-232

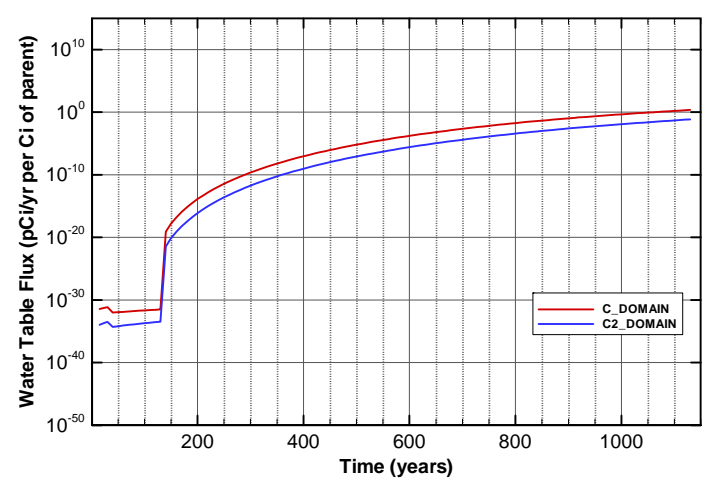

Figure A-1070. Flux at water table for Case01n11_on U-233 


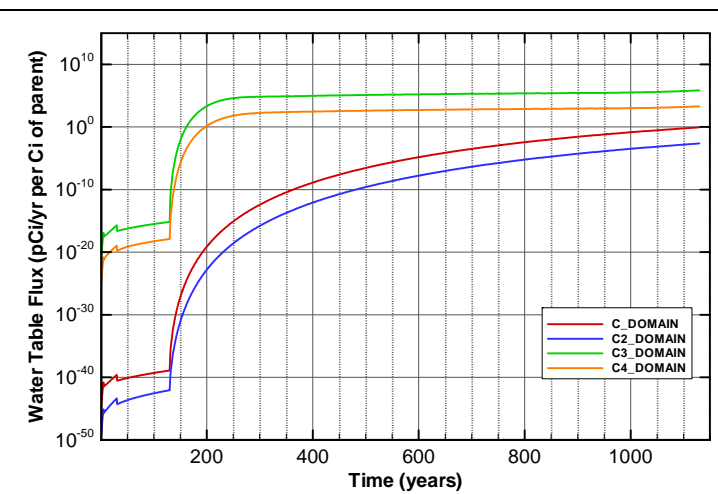

Figure A-1071. Flux at water table for Case01n11_on U-234

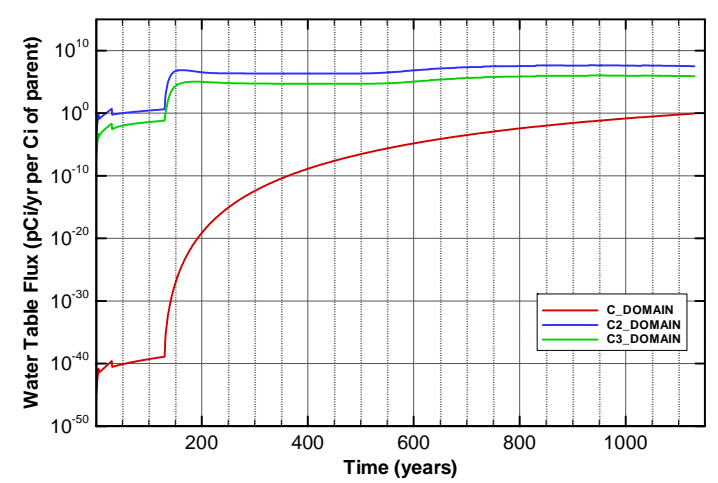

Figure A-1073. Flux at water table for Case01n11_on U-235

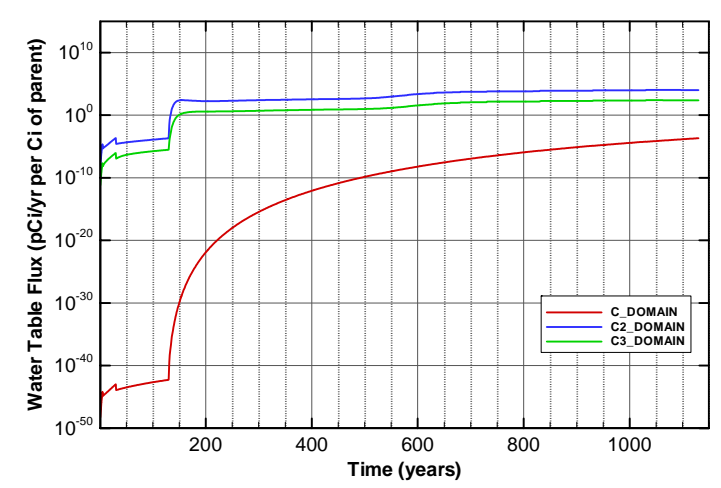

Figure A-1075. Flux at water table for Case01n11_on U-235_Paducah.Cask

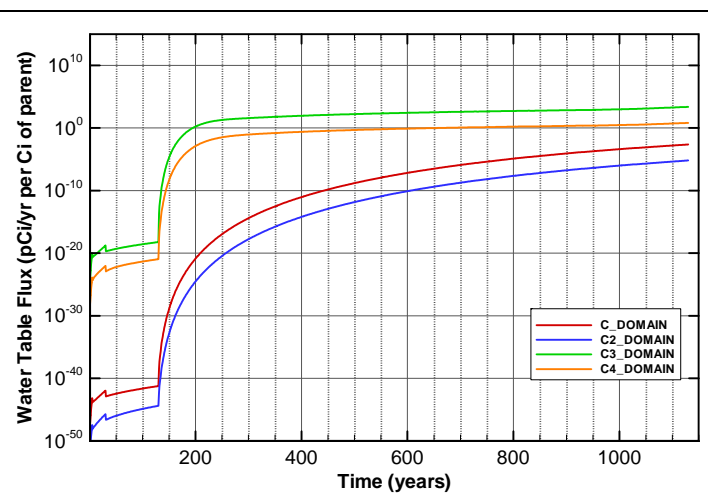

Figure A-1072. Flux at water table for Case01n11_on U-234_Mglass

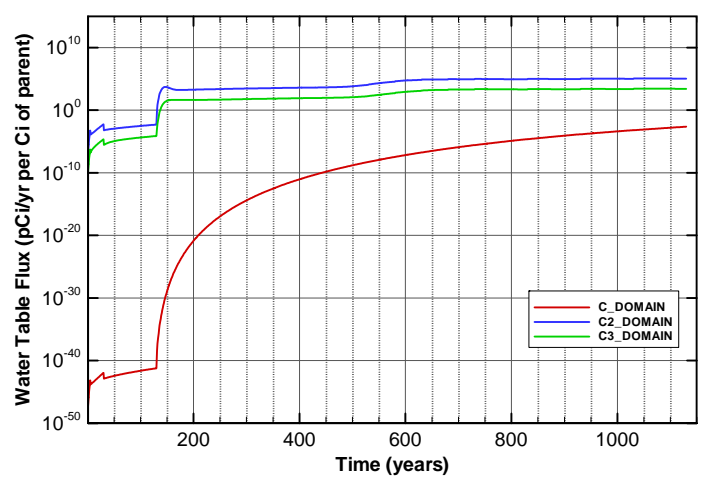

Figure A-1074. Flux at water table for Case01n11_on U-235_Mglass

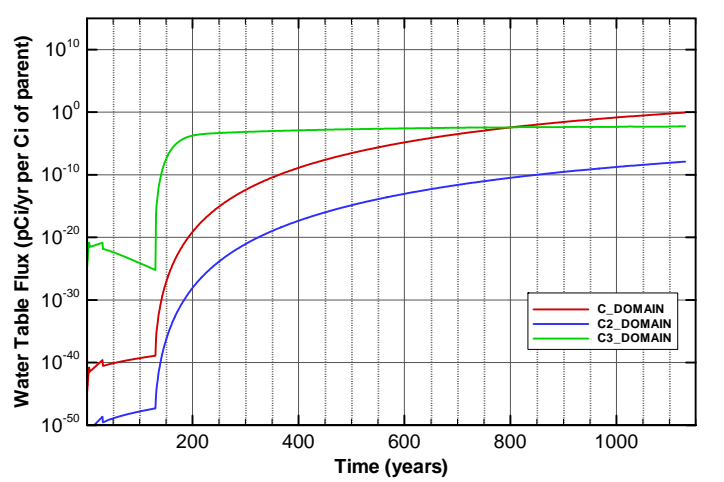

Figure A-1076. Flux at water table for Case01n11_on U-236 


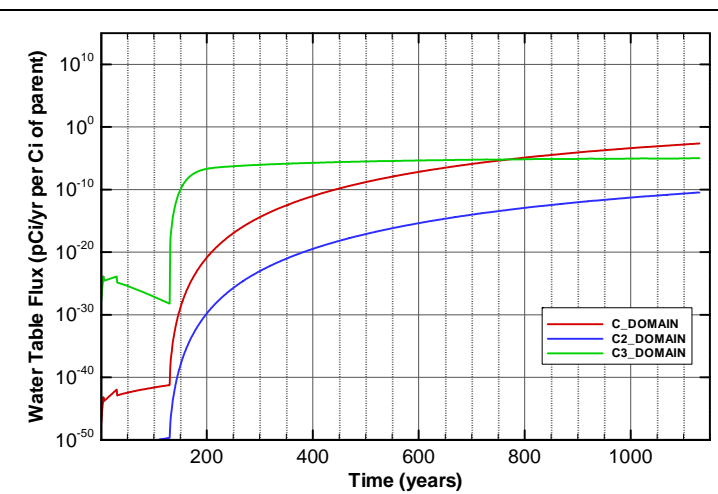

Figure A-1077. Flux at water table for Case01n11_on U-236_Mglass

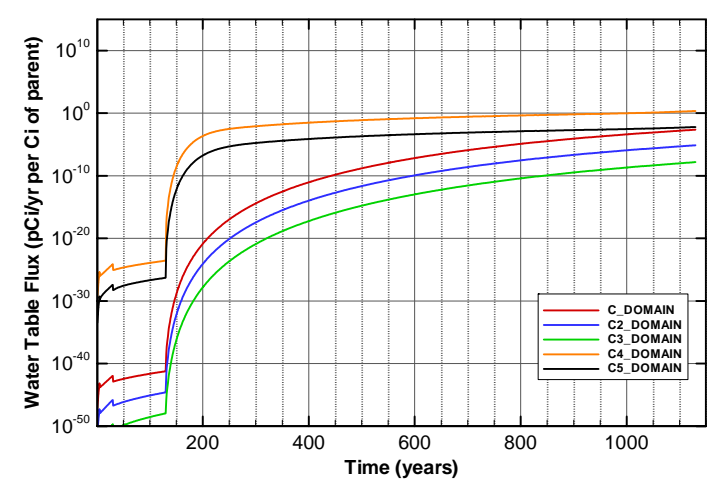

Figure A-1079. Flux at water table for Case01n11_on U-238_Mglass

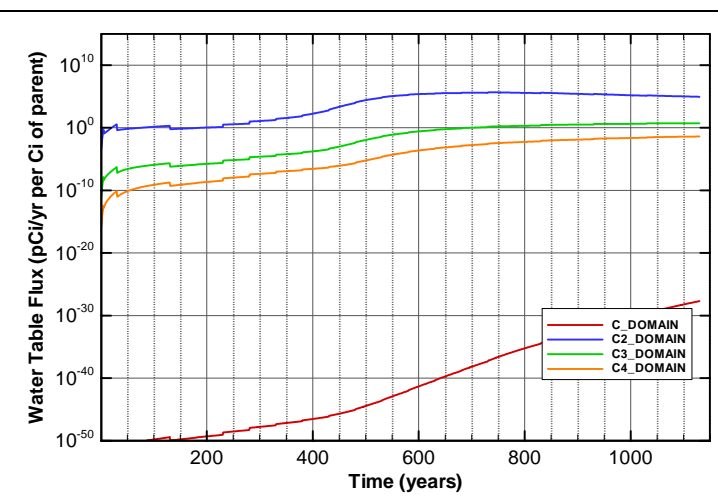

Figure A-1081. Flux at water table for Case01_off Am-241

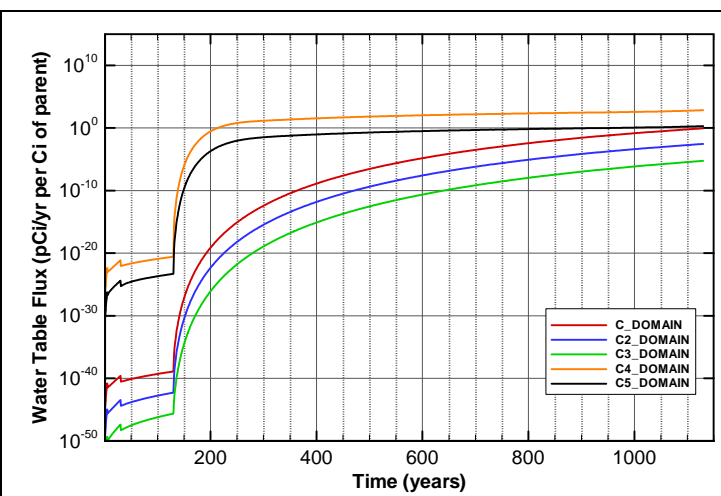

Figure A-1078. Flux at water table for Case01n11_on U-238

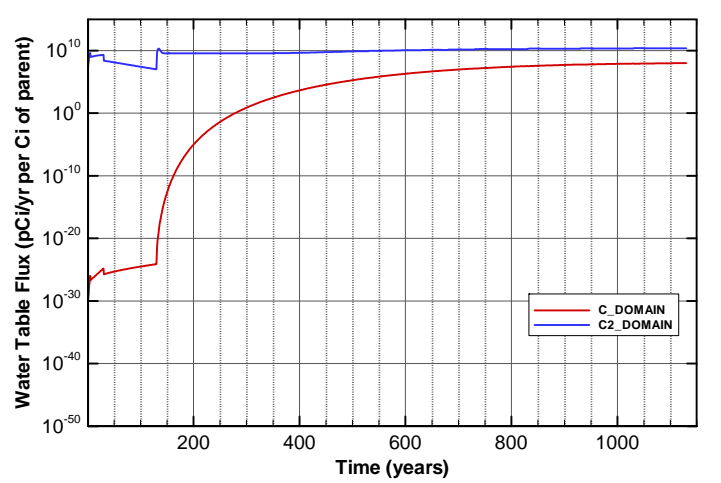

Figure A-1080. Flux at water table for Case01n11_on Zr-93

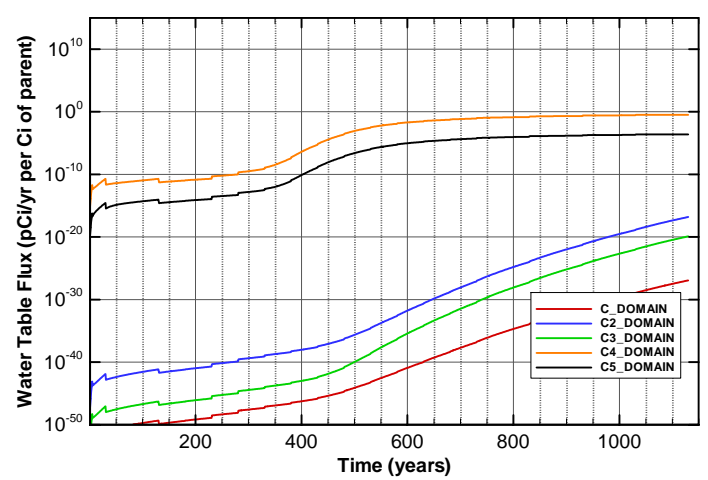

Figure A-1082. Flux at water table for Case01_off Am-243 
SRNL-STI-2008-00397, REVISION 0

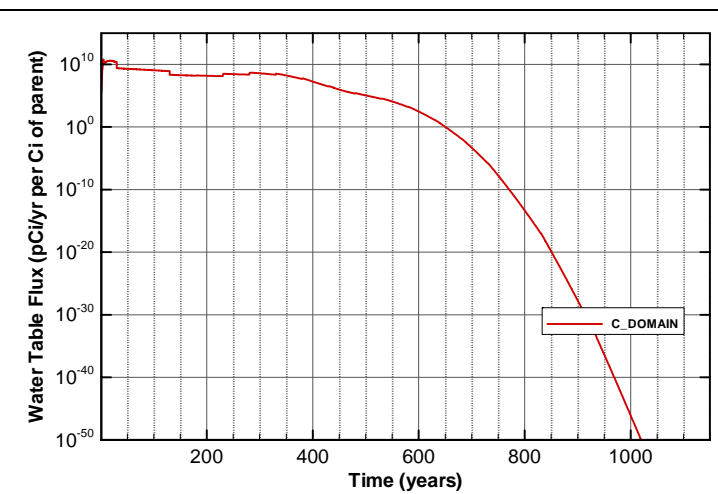

Figure A-1083. Flux at water table for Case01_off C-14

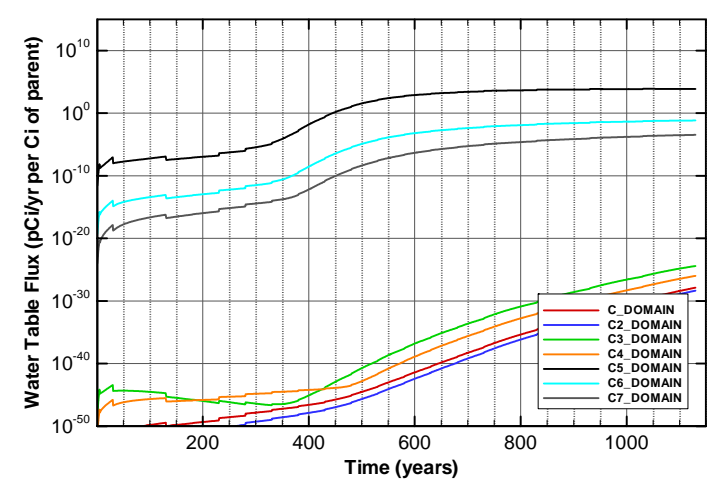

Figure A-1085. Flux at water table for Case01_off Cf-249

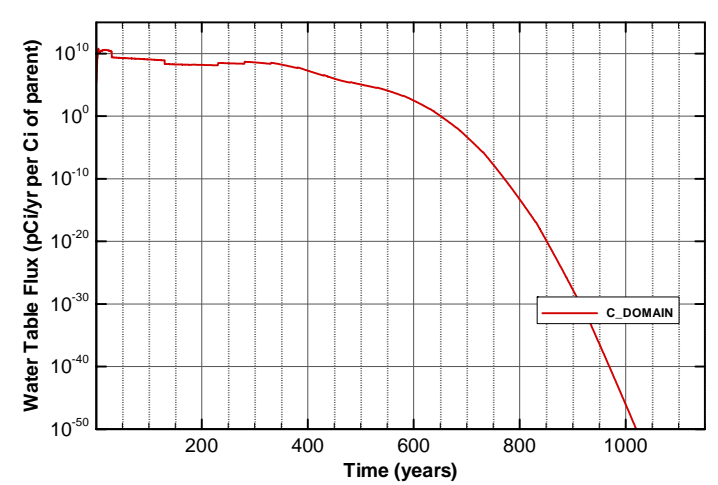

Figure A-1087. Flux at water table for Case01_off Cl-36

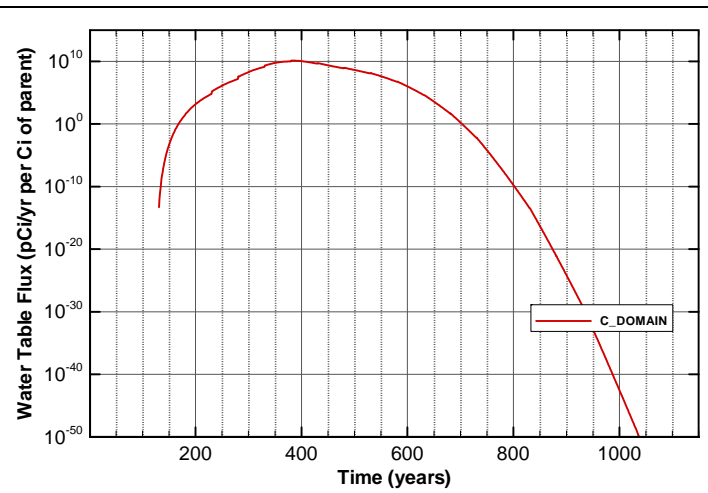

Figure A-1084. Flux at water table for Case01_off C-14_NR.Pump

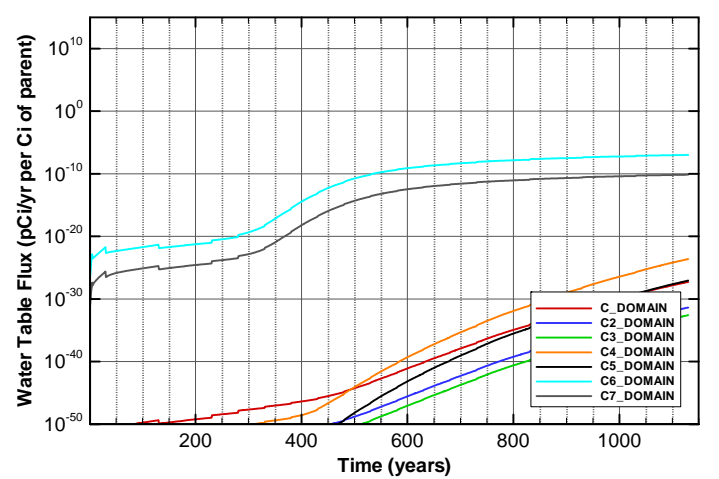

Figure A-1086. Flux at water table for Case01_off Cf-251

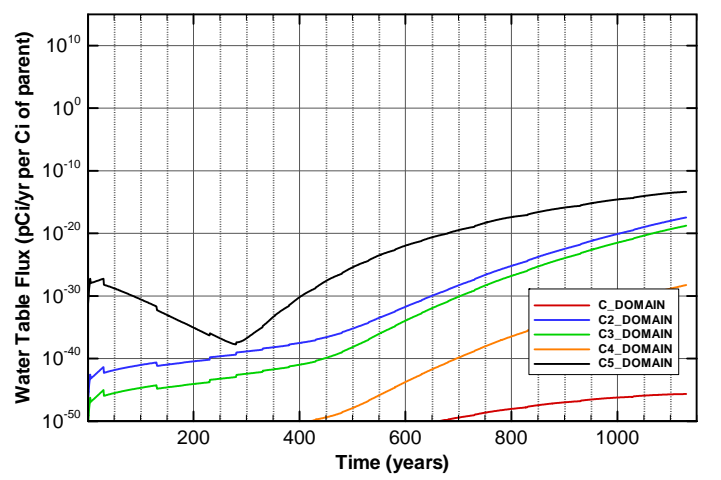

Figure A-1088. Flux at water table for Case01_off Cm-244 
SRNL-STI-2008-00397, REVISION 0

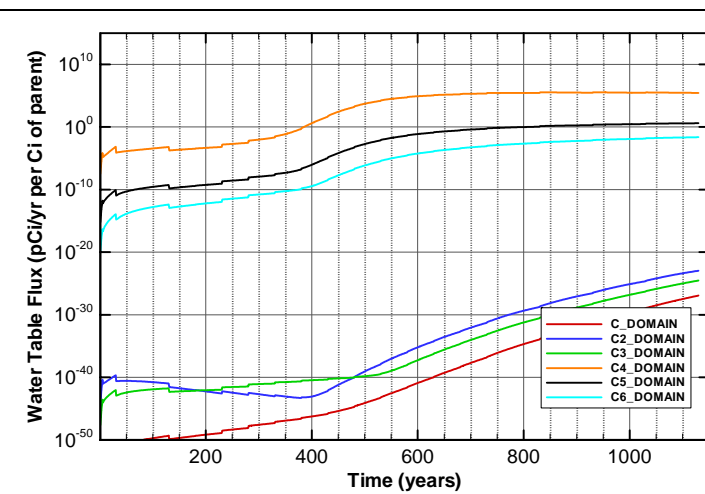

Figure A-1089. Flux at water table for Case01_off Cm-245

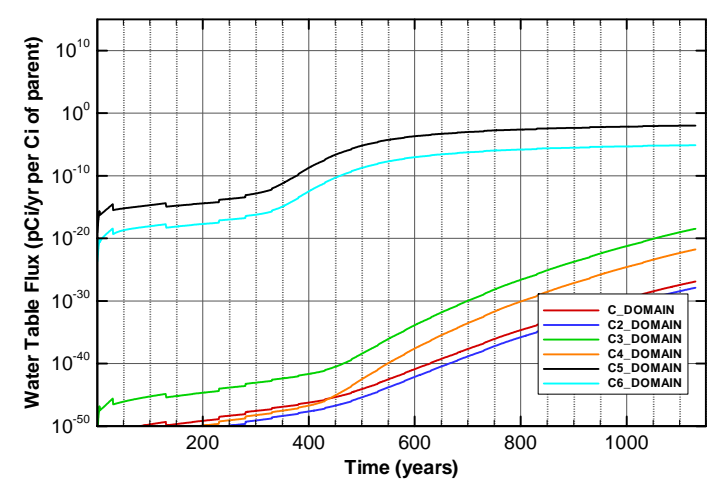

Figure A-1091. Flux at water table for Case01_off Cm-247

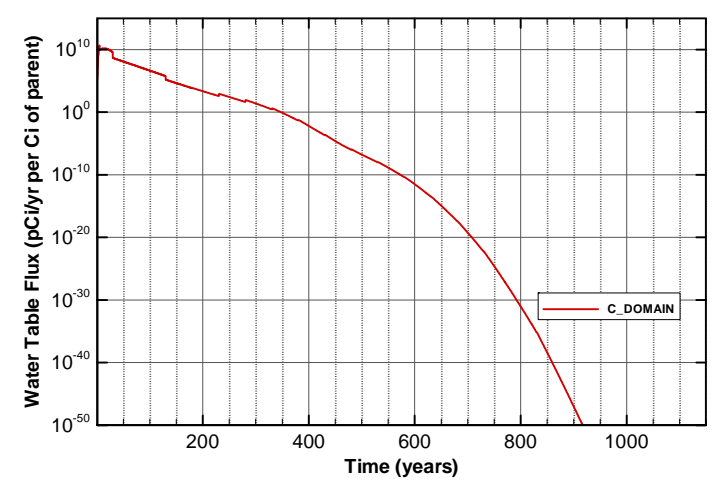

Figure A-1093. Flux at water table for Case01_off H-3

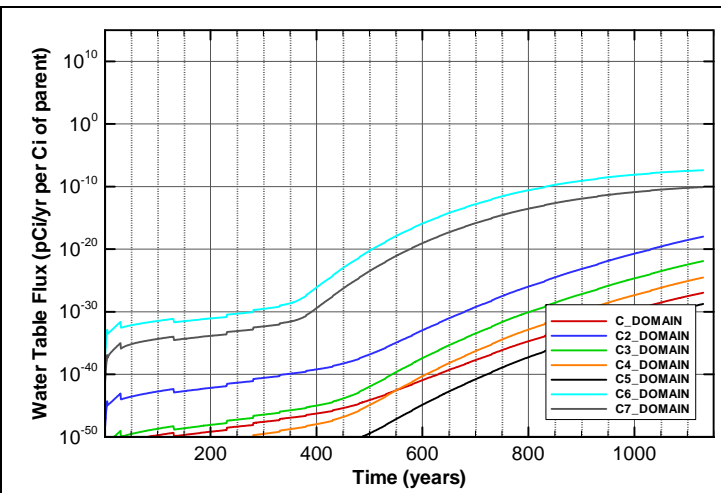

Figure A-1090. Flux at water table for Case01_off Cm-246

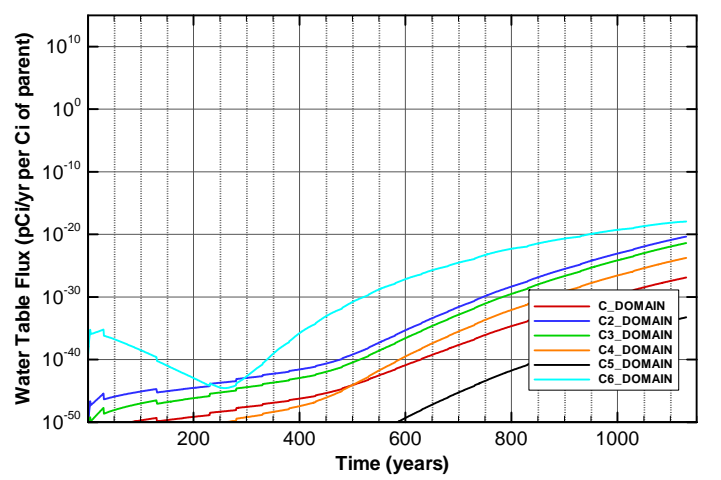

Figure A-1092. Flux at water table for Case01_off Cm-248

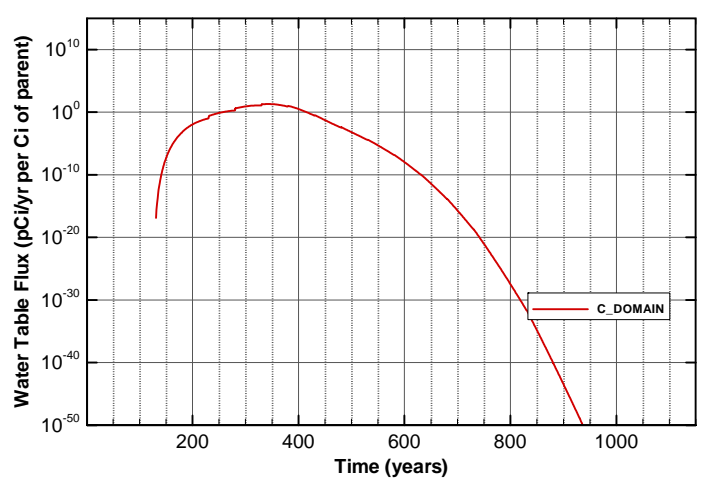

Figure A-1094. Flux at water table for Case01_off H-3_ETF.Carbon 


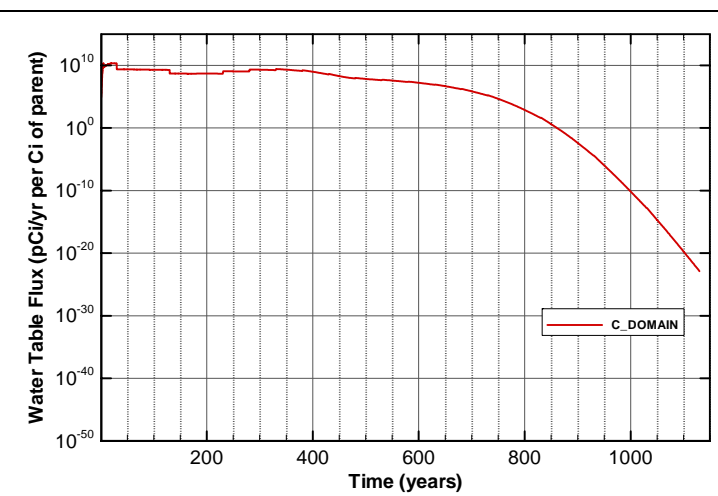

Figure A-1095. Flux at water table for Case01_off I-129

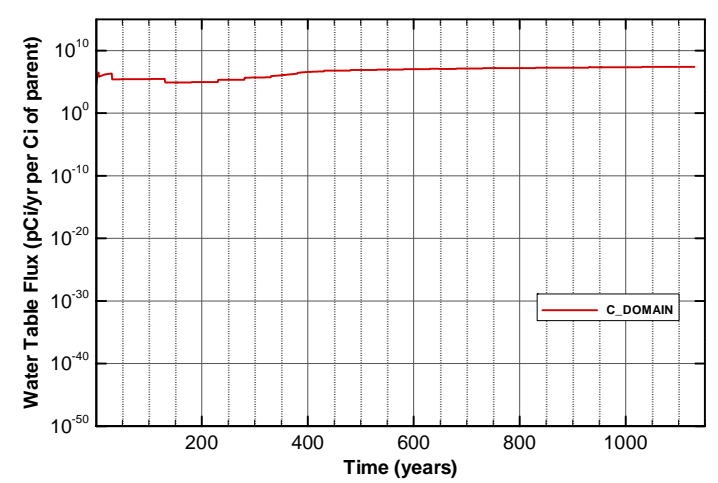

Figure A-1097. Flux at water table for Case01_off I-129_ETF.GT.73

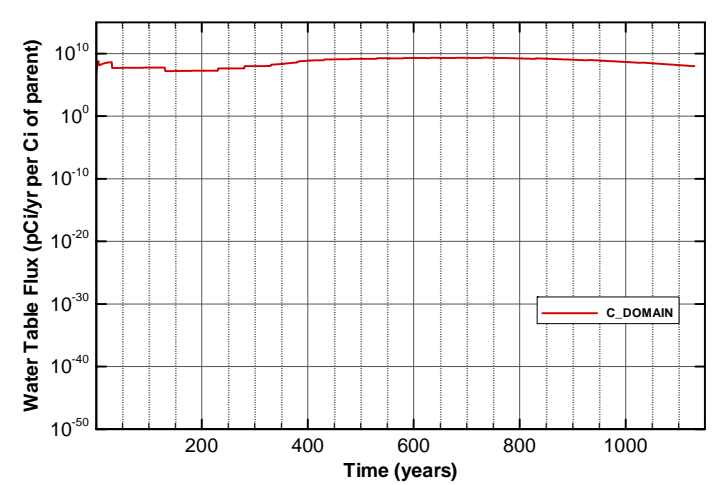

Figure A-1099. Flux at water table for Case01_off I-129_F.CG.8

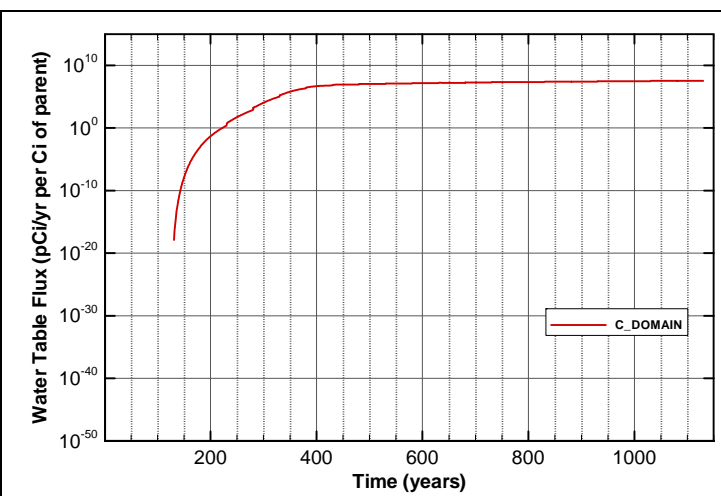

Figure A-1096. Flux at water table for Case01_off I-129_ETF.Carbon

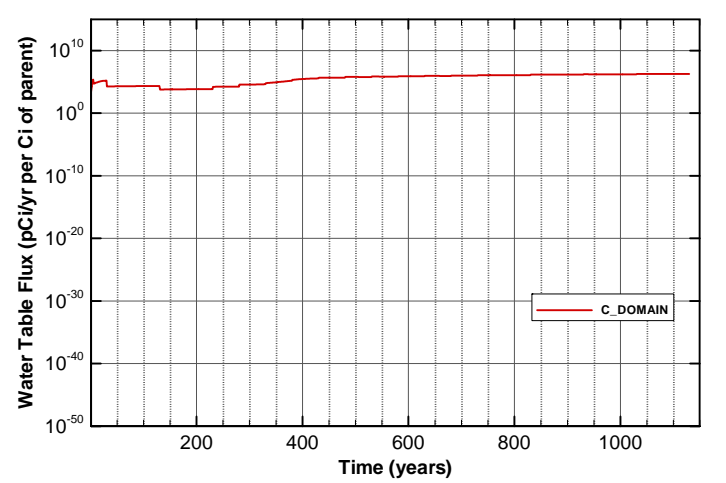

Figure A-1098. Flux at water table for Case01_off I-129_F.Carbon

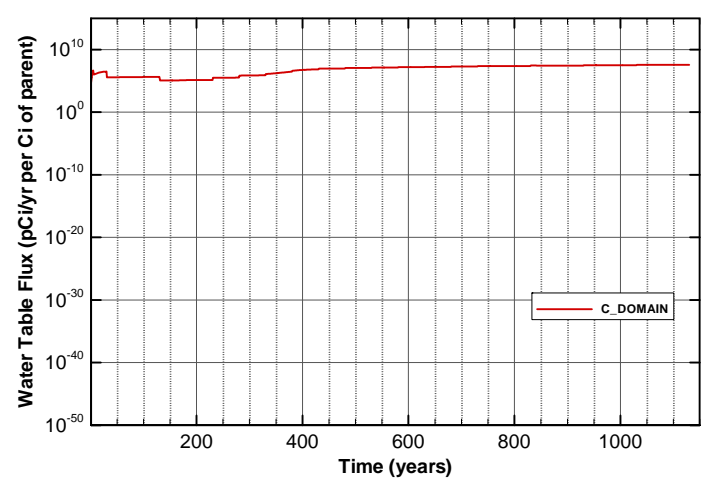

Figure A-1100. Flux at water table for Case01_off I-129_F.Dowex.21K 


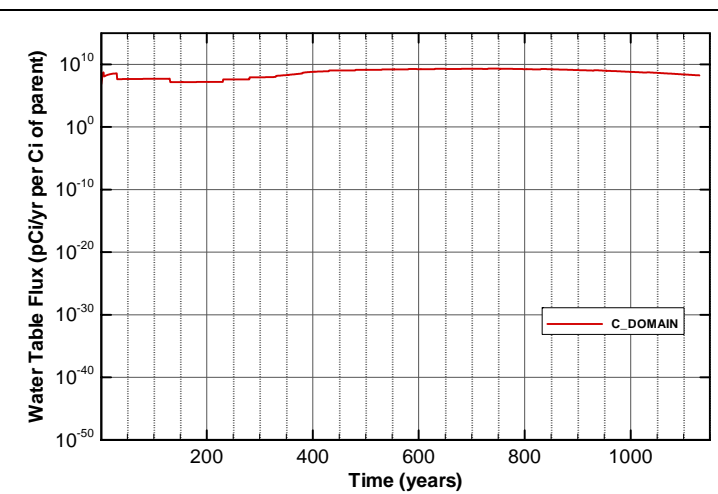

Figure A-1101. Flux at water table for Case01_off I-129_F.Filtercake

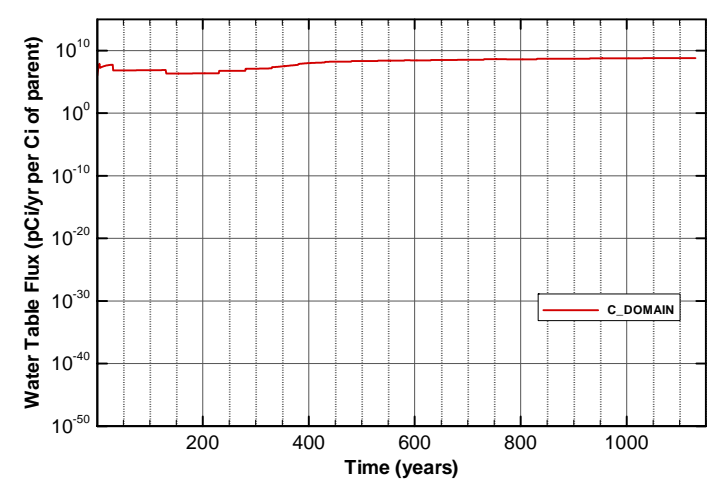

Figure A-1103. Flux at water table for Case01_off I-129_H.CG.8

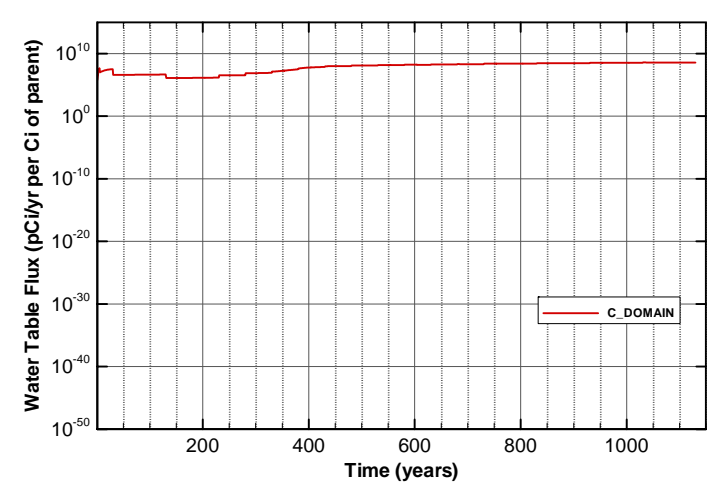

Figure A-1105. Flux at water table for Case01_off I-129_H.Filtercake

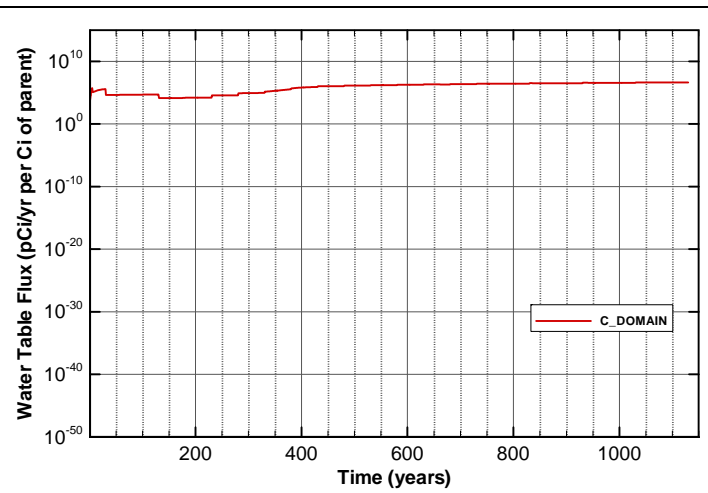

Figure A-1102. Flux at water table for Case01_off I-129_H.Carbon

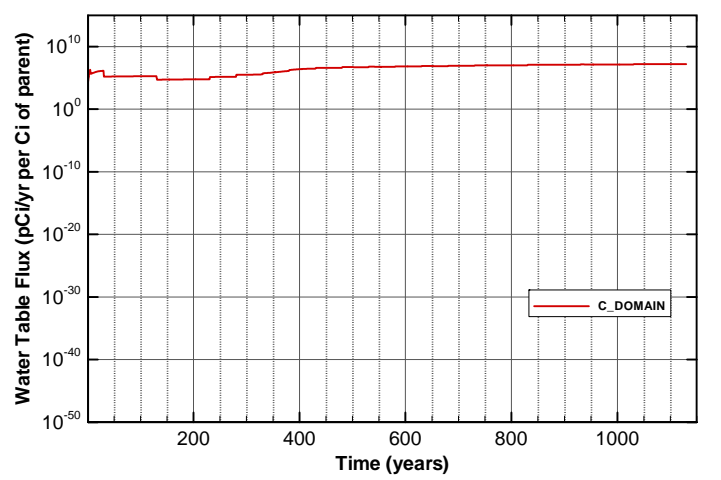

Figure A-1104. Flux at water table for Case01_off I-129_H.Dowex.21K

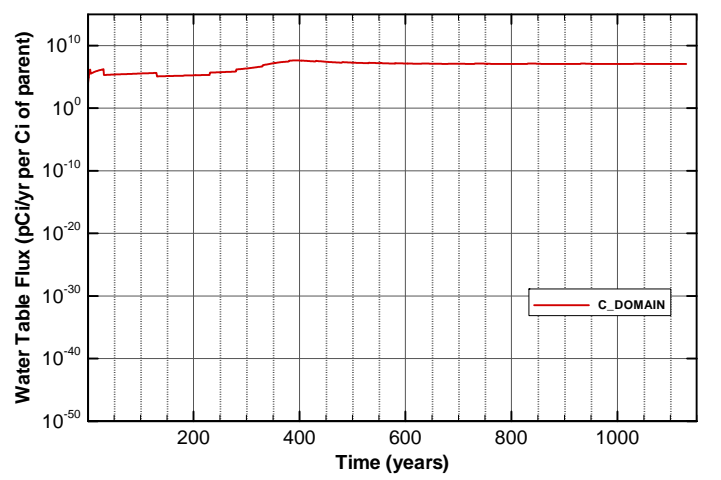

Figure A-1106. Flux at water table for Case01_off I-129_Mk50A 


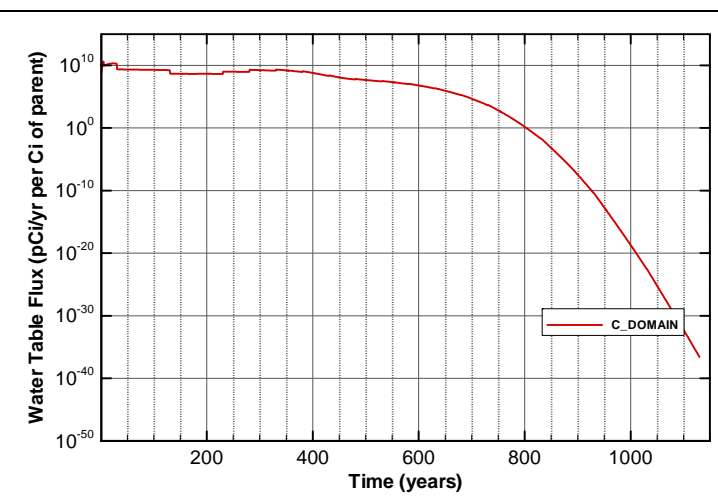

Figure A-1107. Flux at water table for Case01_off K-40

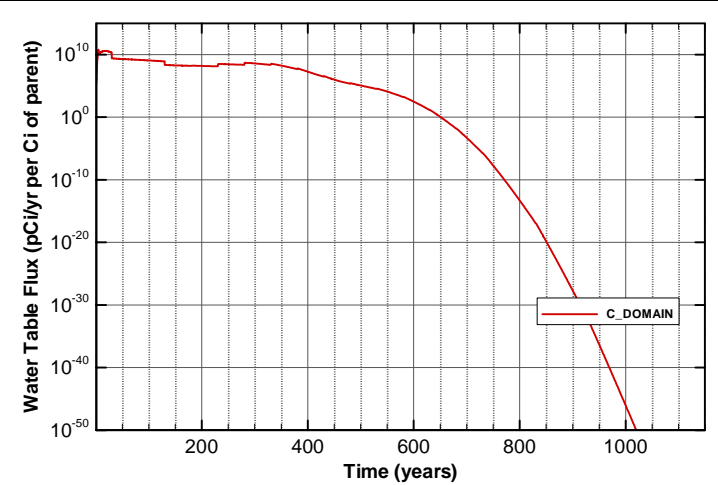

Figure A-1109. Flux at water table for Case01_off Nb-94

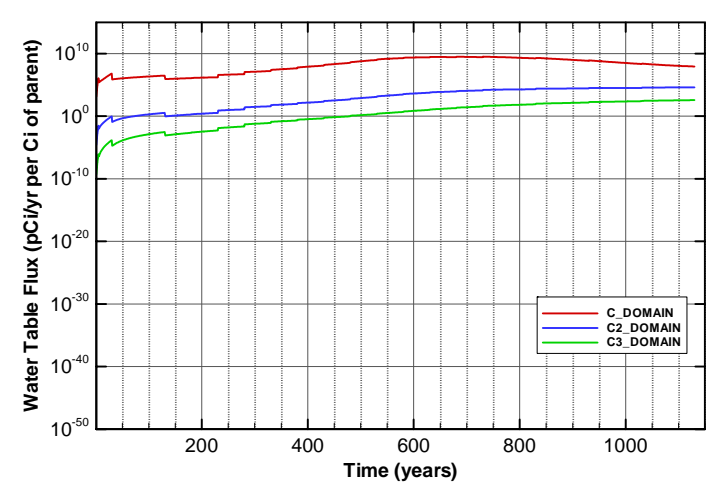

Figure A-1111. Flux at water table for Case01_off Np-237

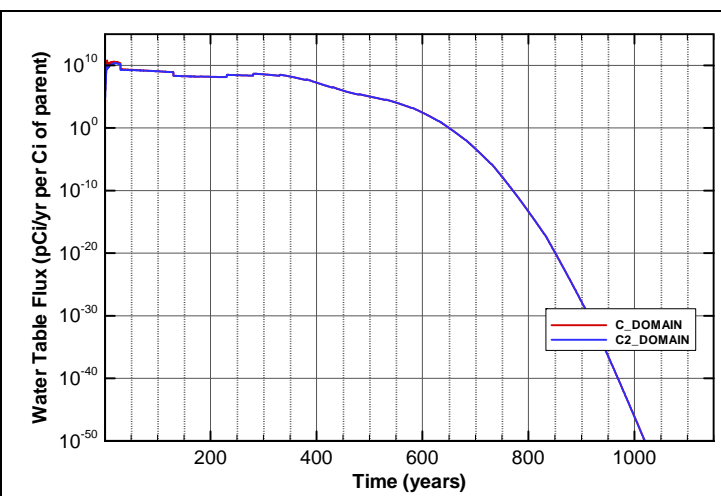

Figure A-1108. Flux at water table for Case01_off Mo-93

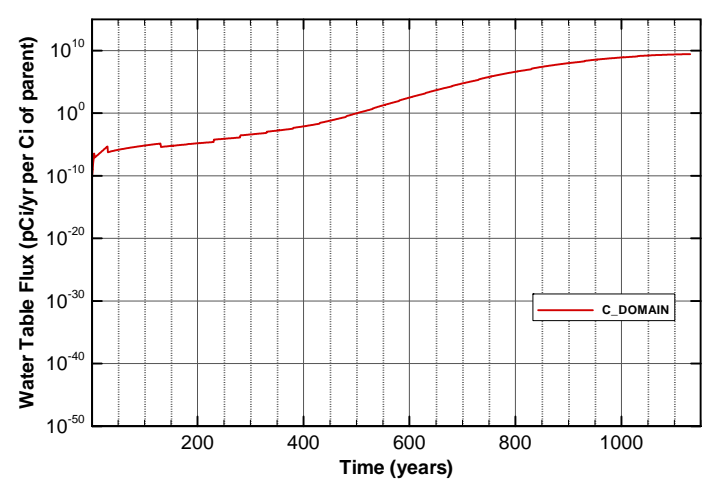

Figure A-1110. Flux at water table for Case01_off Ni-59

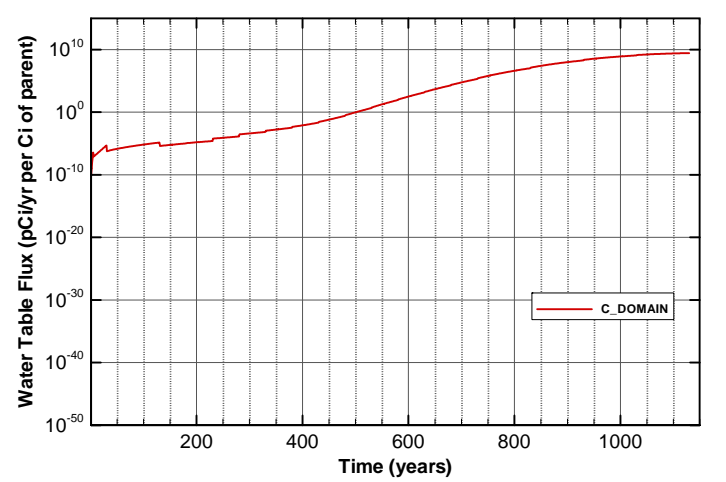

Figure A-1112. Flux at water table for Case01_off Pd-107 
SRNL-STI-2008-00397, REVISION 0

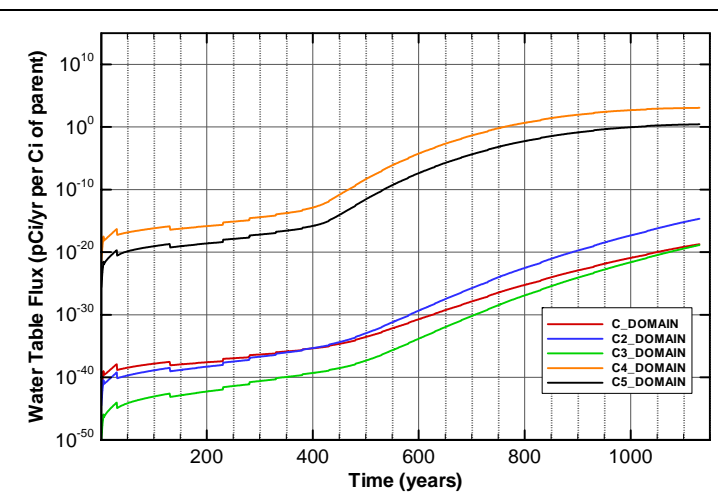

Figure A-1113. Flux at water table for Case01_off Pu-238

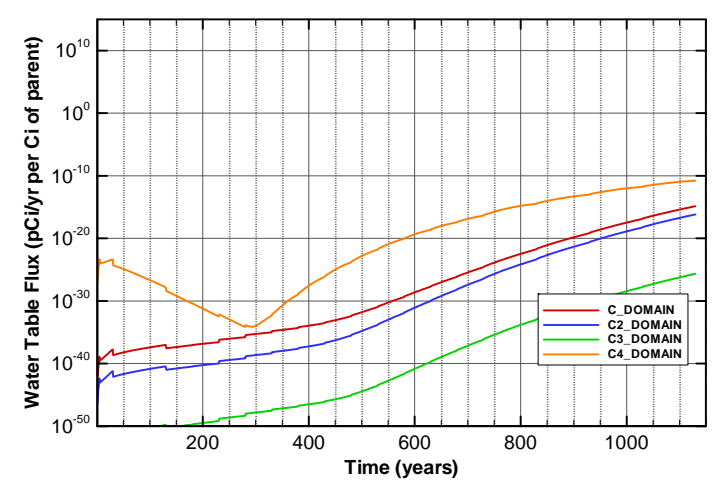

Figure A-1115. Flux at water table for Case01_off Pu-240

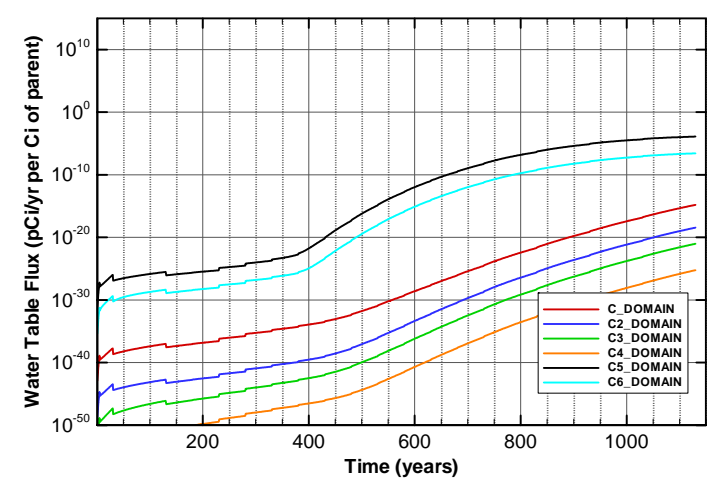

Figure A-1117. Flux at water table for Case01_off Pu-242

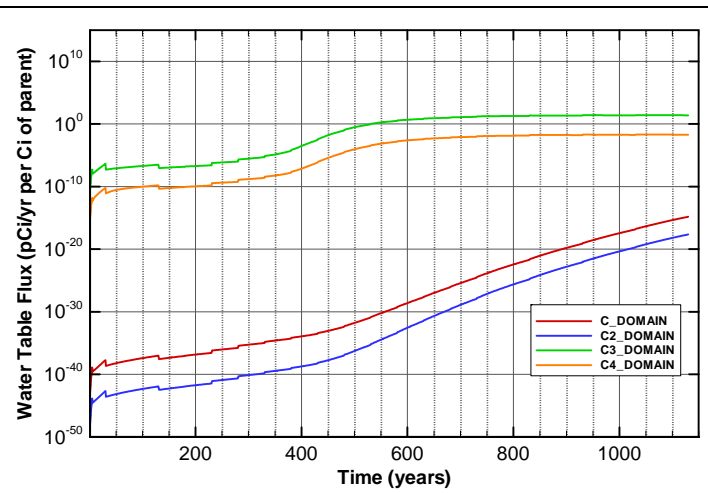

Figure A-1114. Flux at water table for Case01_off Pu-239

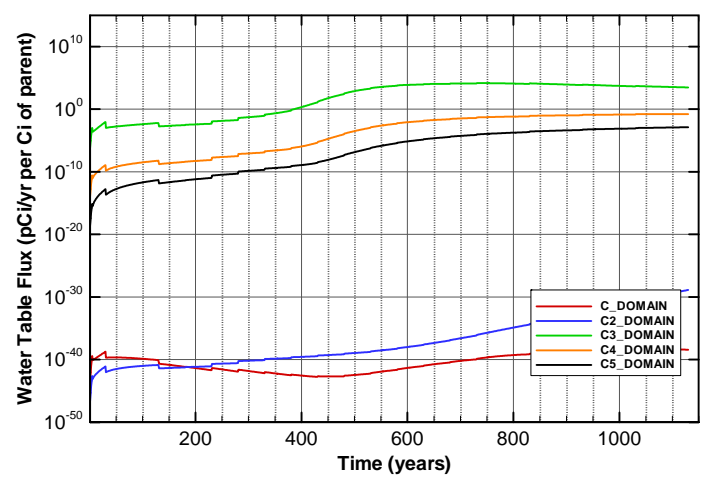

Figure A-1116. Flux at water table for Case01_off Pu-241

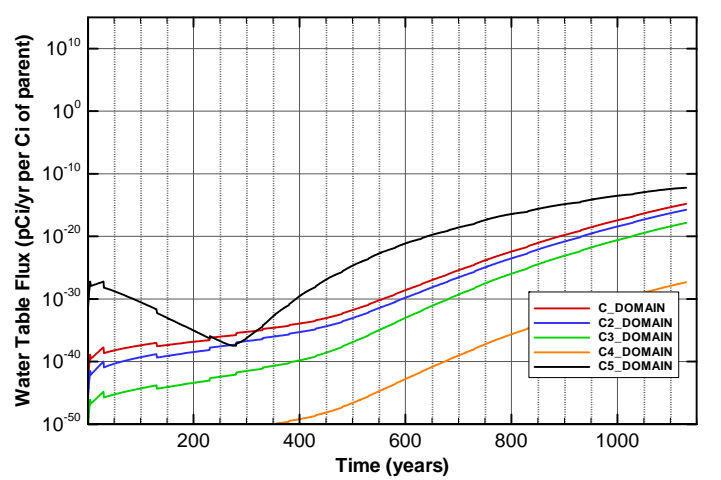

Figure A-1118. Flux at water table for Case01_off Pu-244 


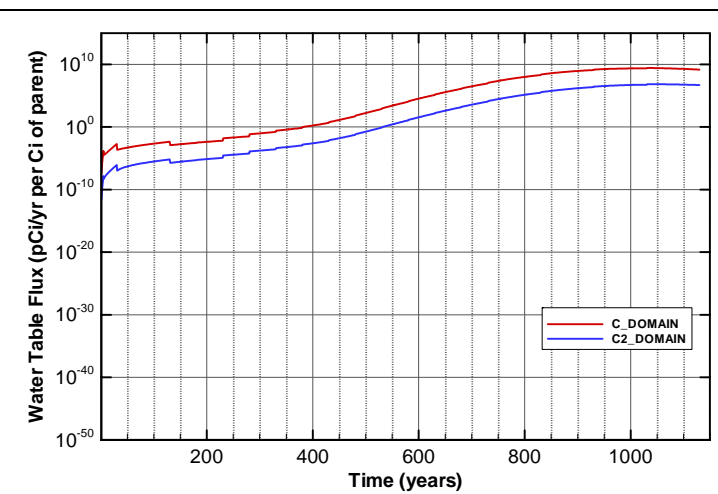

Figure A-1119. Flux at water table for Case01_off Ra-226

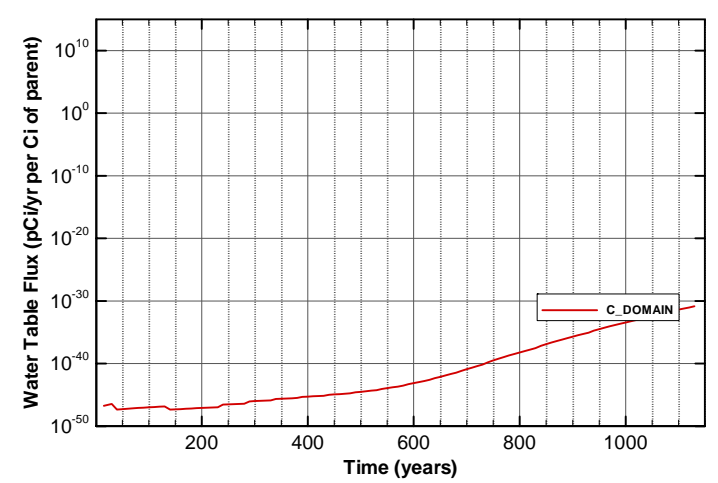

Figure A-1121. Flux at water table for Case01_off Sn-126

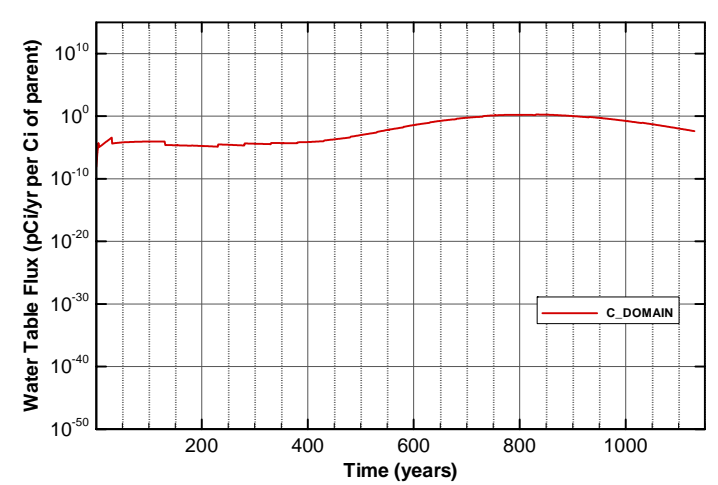

Figure A-1123. Flux at water table for Case01_off Sr-90_Cask

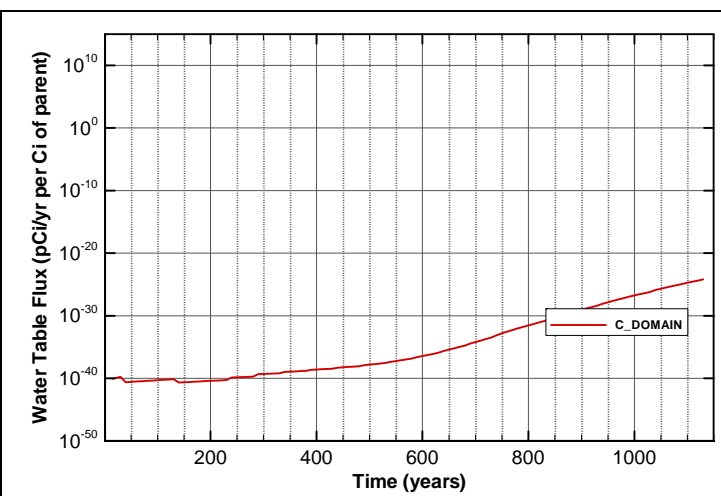

Figure A-1120. Flux at water table for Case01_off Se-79

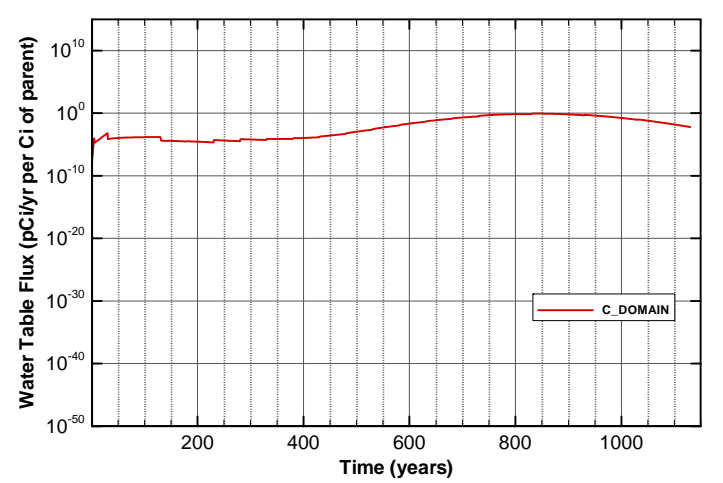

Figure A-1122. Flux at water table for Case01_off Sr-90

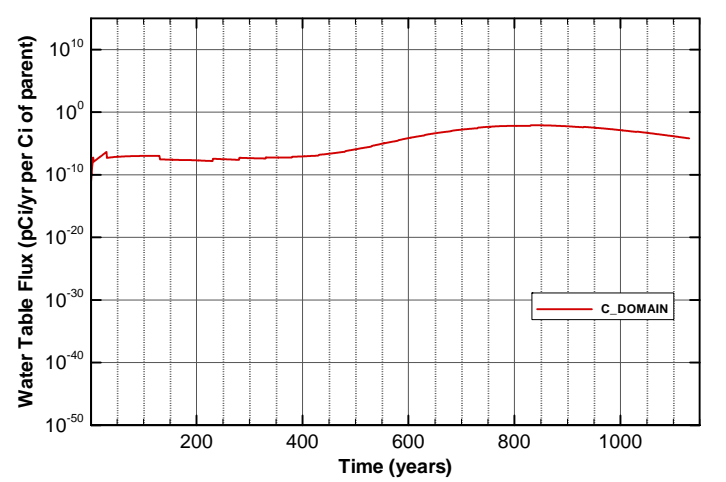

Figure A-1124. Flux at water table for Case01_off Sr-90_Mk50A 


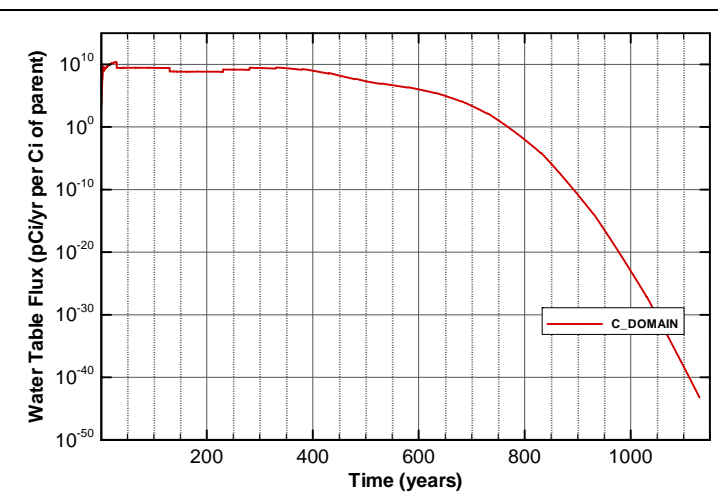

Figure A-1125. Flux at water table for Case01_off Tc-99

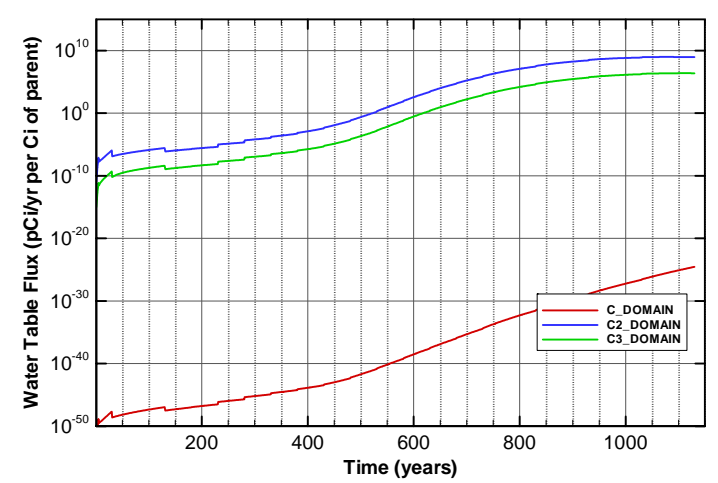

Figure A-1127. Flux at water table for Case01_off Th-230

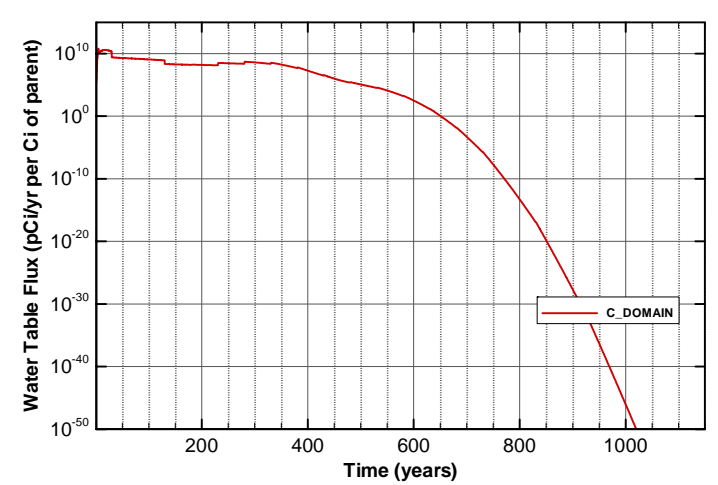

Figure A-1129. Flux at water table for Case01_off Tracer

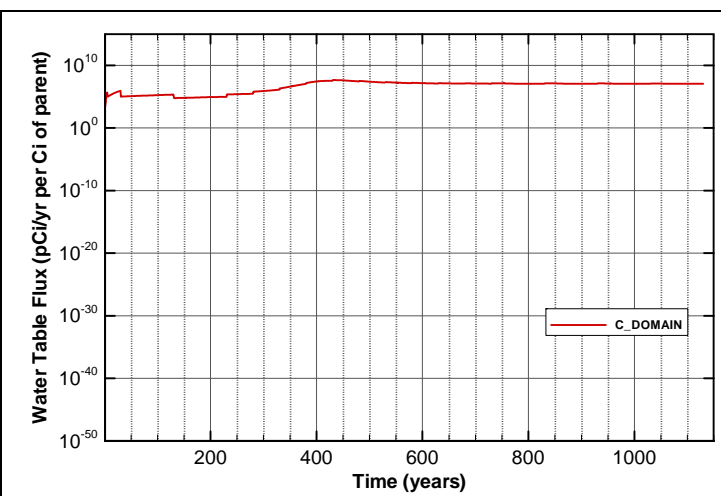

Figure A-1126. Flux at water table for Case01_off Tc-99_Mk50A

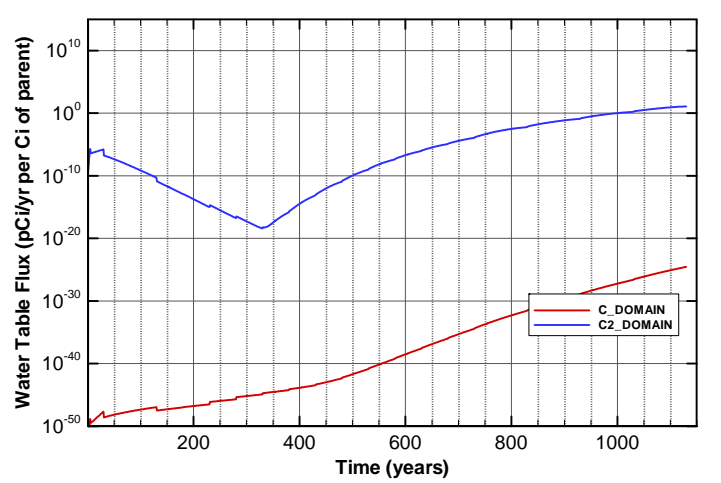

Figure A-1128. Flux at water table for Case01_off Th-232

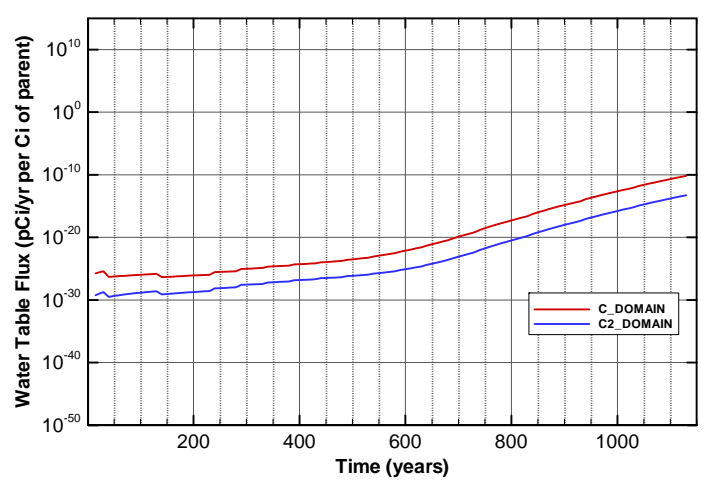

Figure A-1130. Flux at water table for Case01_off U-233 
SRNL-STI-2008-00397, REVISION 0

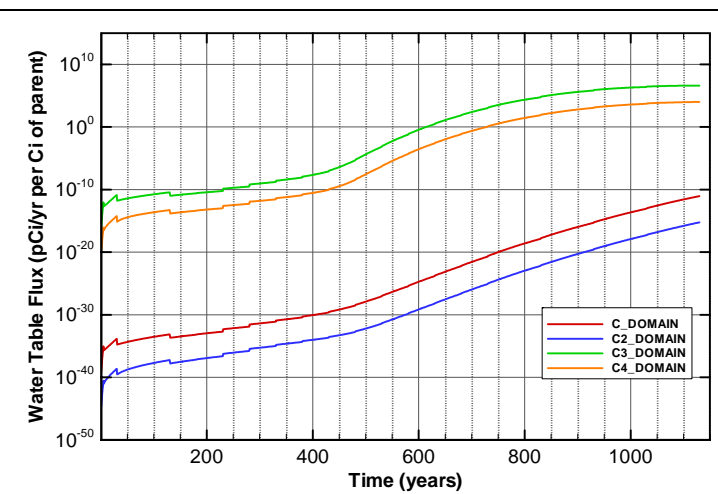

Figure A-1131. Flux at water table for Case01_off U-234

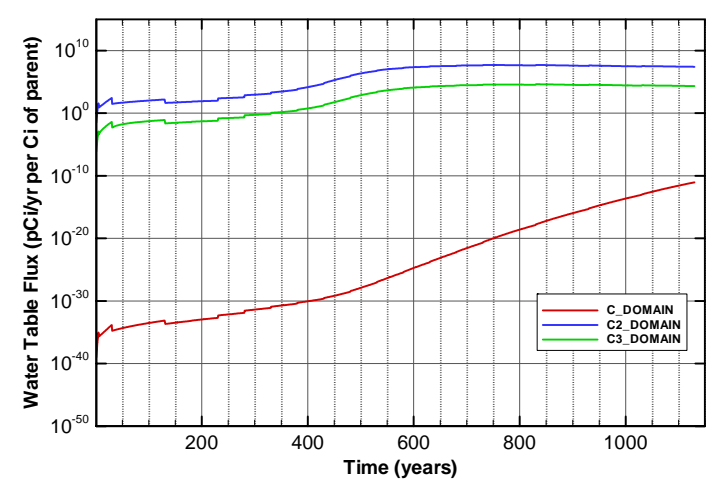

Figure A-1133. Flux at water table for Case01_off U-235

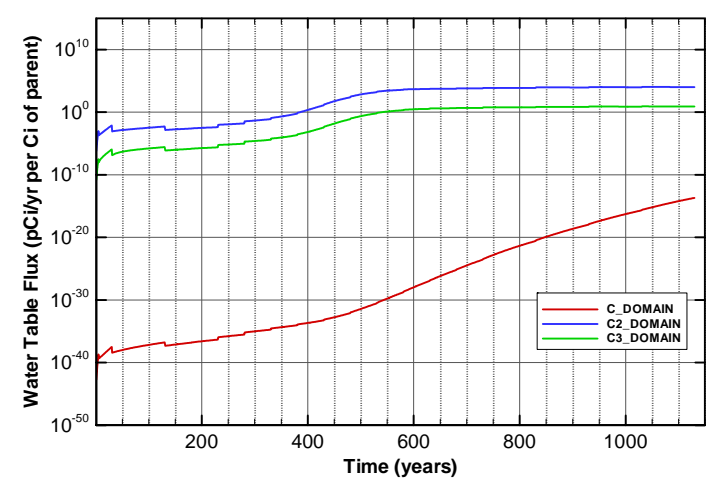

Figure A-1135. Flux at water table for Case01_off U-235_Paducah.Cask

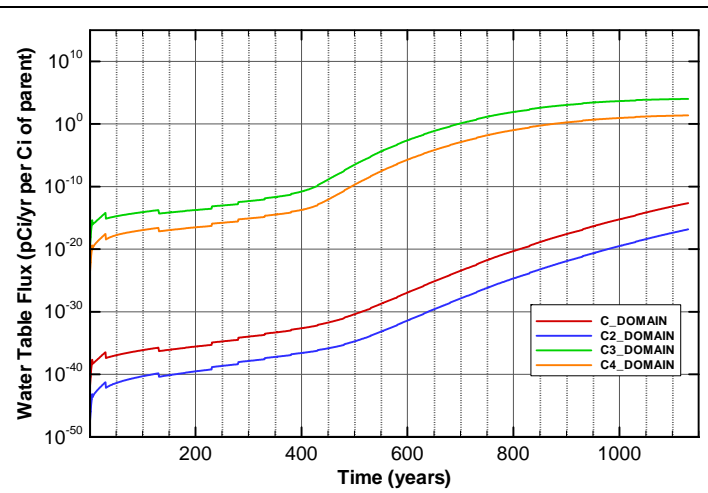

Figure A-1132. Flux at water table for Case01_off U-234_Mglass

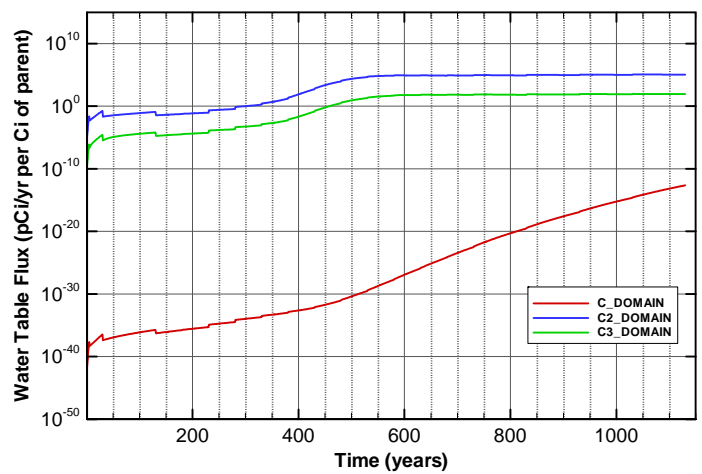

Figure A-1134. Flux at water table for Case01_off U-235_Mglass

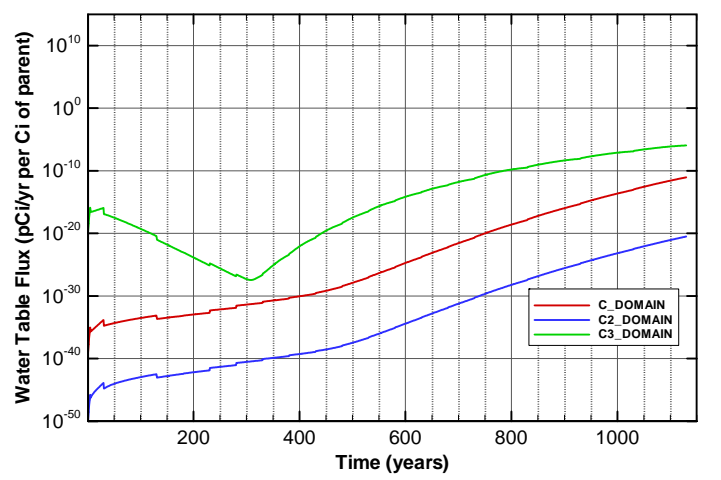

Figure A-1136. Flux at water table for Case01_off U-236 
SRNL-STI-2008-00397, REVISION 0
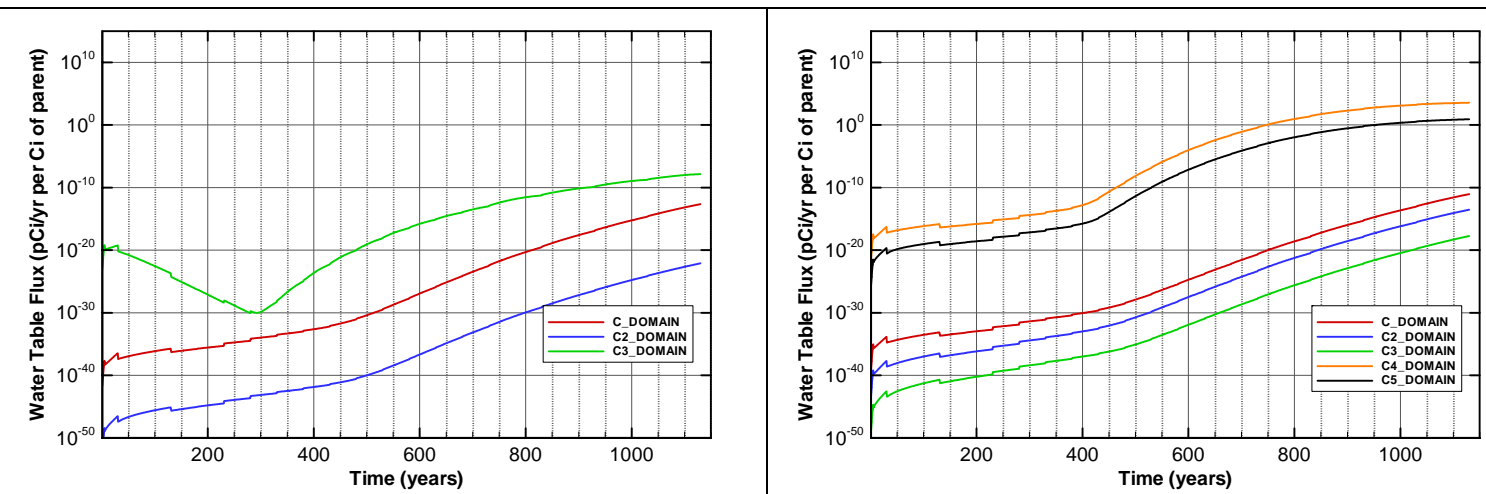

Figure A-1137. Flux at water table for Case01_off U-236_Mglass

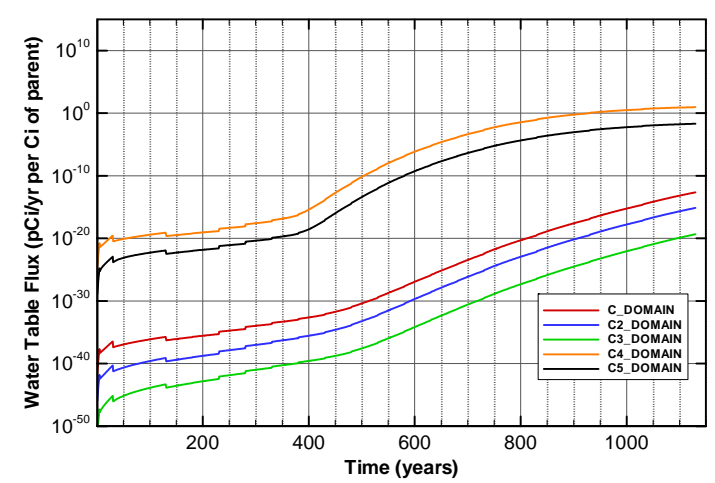

Figure A-1139. Flux at water table for Case01_off U-238_Mglass

Figure A-1138. Flux at water table for Case01_off U-238

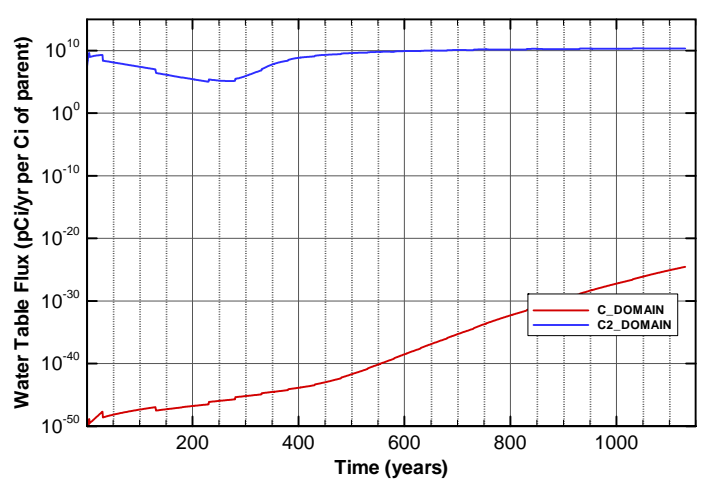

Figure A-1140. Flux at water table for Case01_off Zr-93

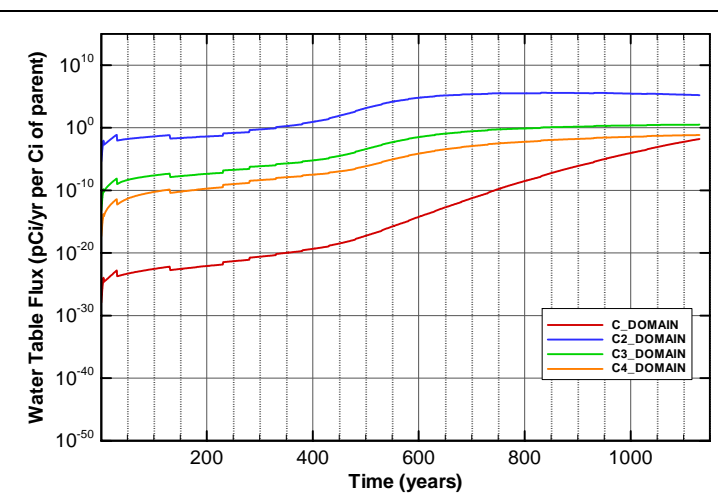

Figure A-1141. Flux at water table for Case01_on Am-241

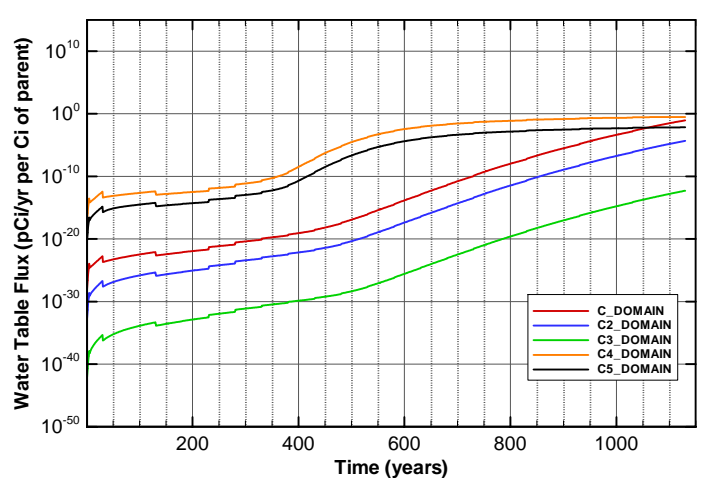

Figure A-1142. Flux at water table for Case01_on Am-243 
SRNL-STI-2008-00397, REVISION 0

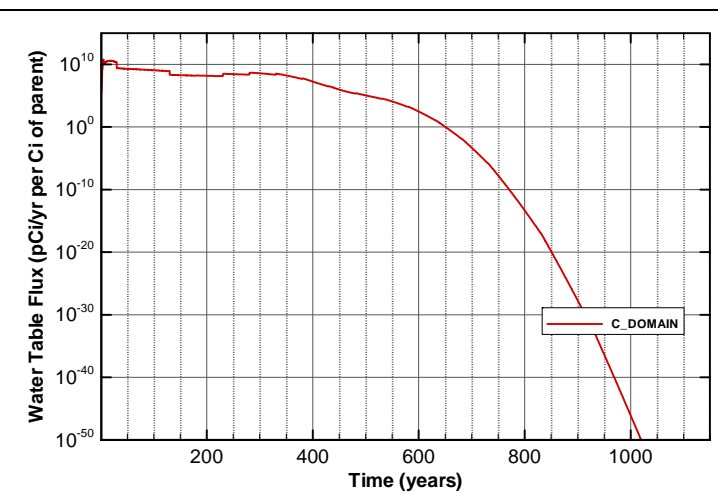

Figure A-1143. Flux at water table for Case01_on C-14

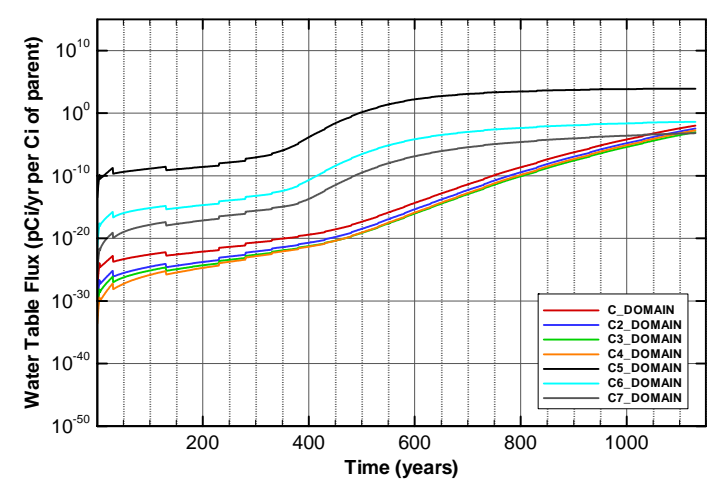

Figure A-1145. Flux at water table for Case01_on Cf-249

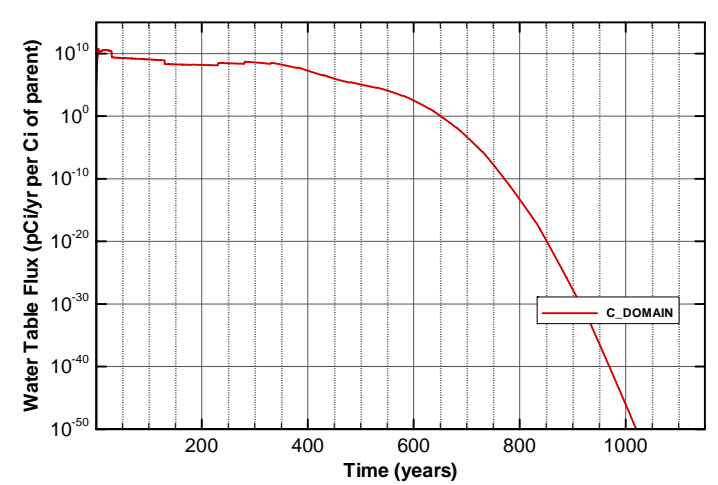

Figure A-1147. Flux at water table for Case01_on Cl-36

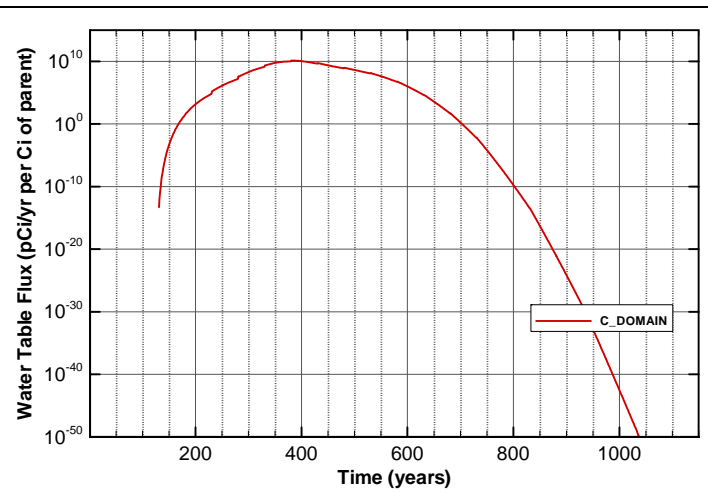

Figure A-1144. Flux at water table for Case01_on C-14_NR.Pump

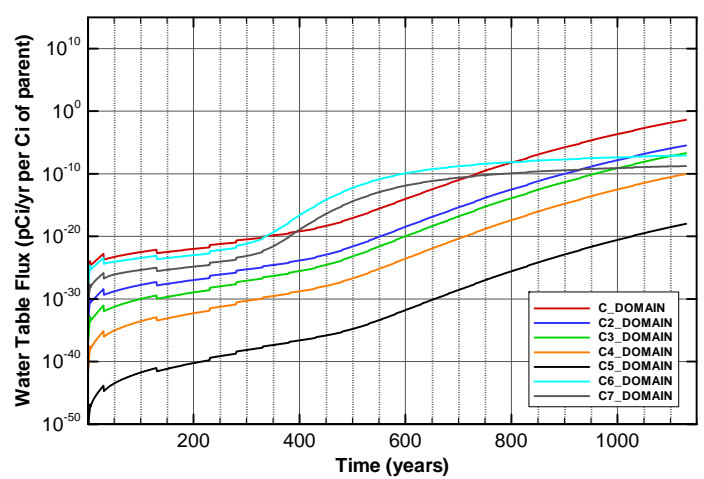

Figure A-1146. Flux at water table for Case01_on Cf-251

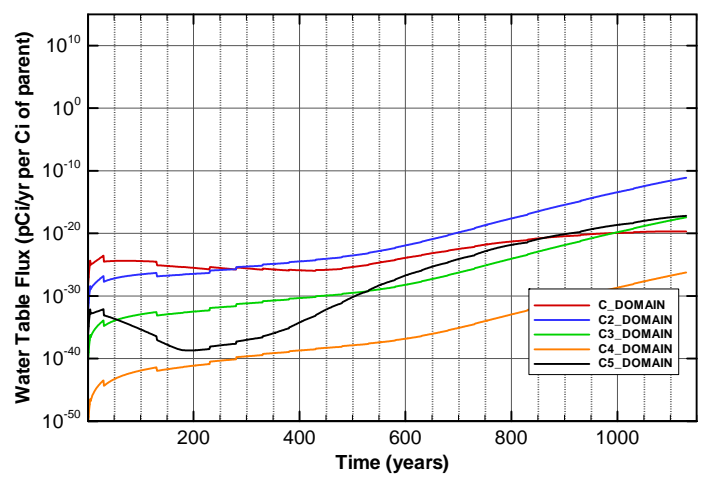

Figure A-1148. Flux at water table for Case01_on Cm-244 
SRNL-STI-2008-00397, REVISION 0

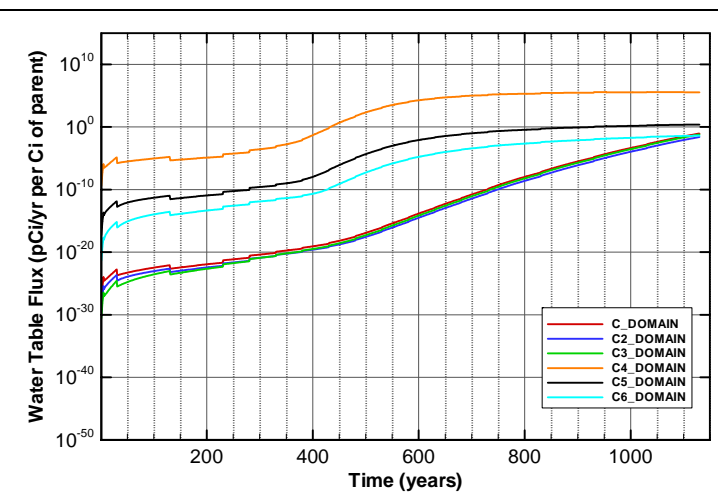

Figure A-1149. Flux at water table for Case01_on Cm-245

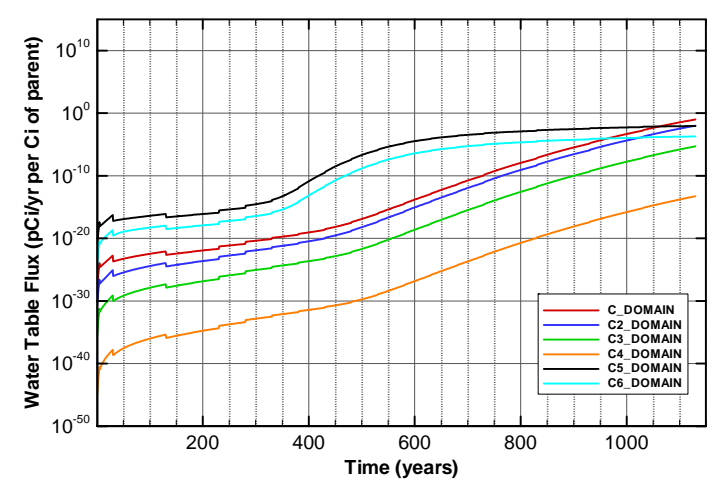

Figure A-1151. Flux at water table for Case01_on Cm-247

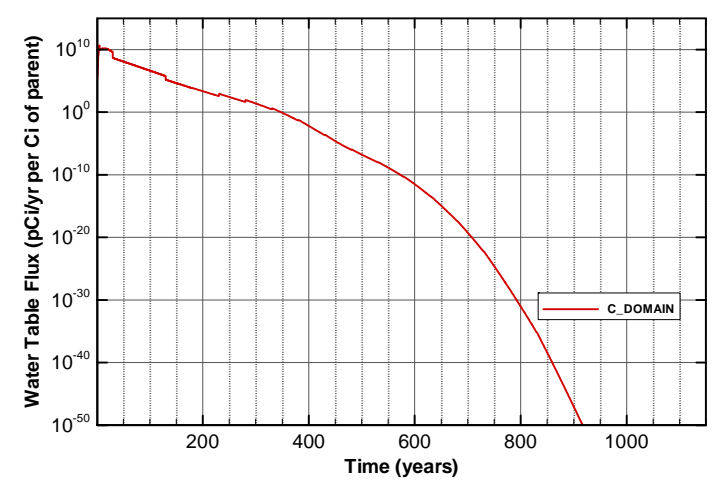

Figure A-1153. Flux at water table for Case01_on H-3

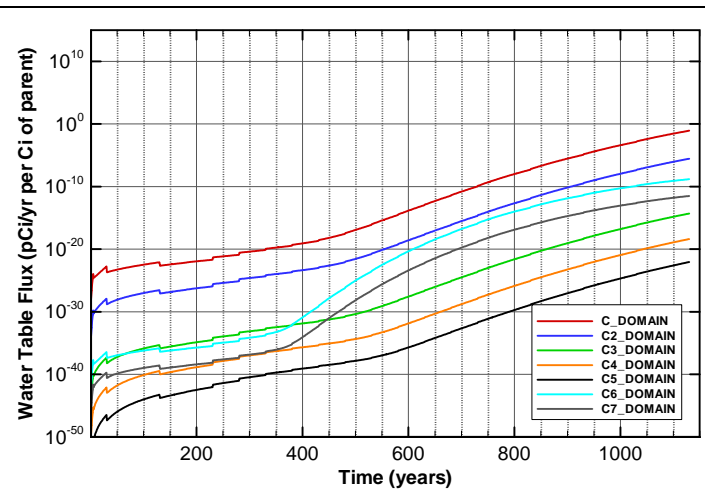

Figure A-1150. Flux at water table for Case01_on Cm-246

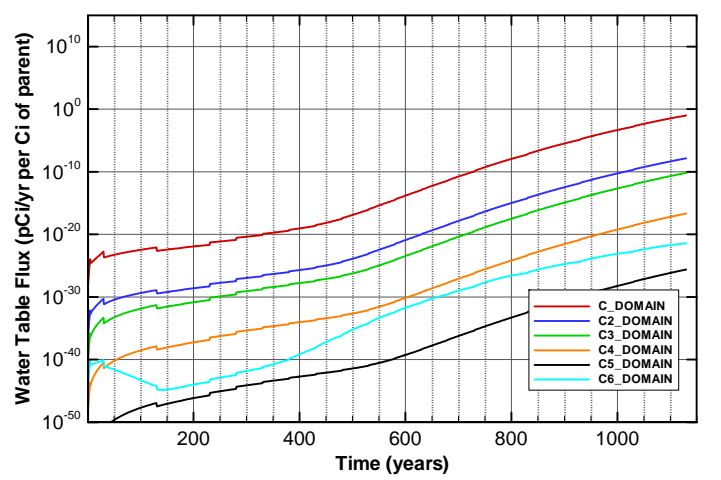

Figure A-1152. Flux at water table for Case01_on Cm-248

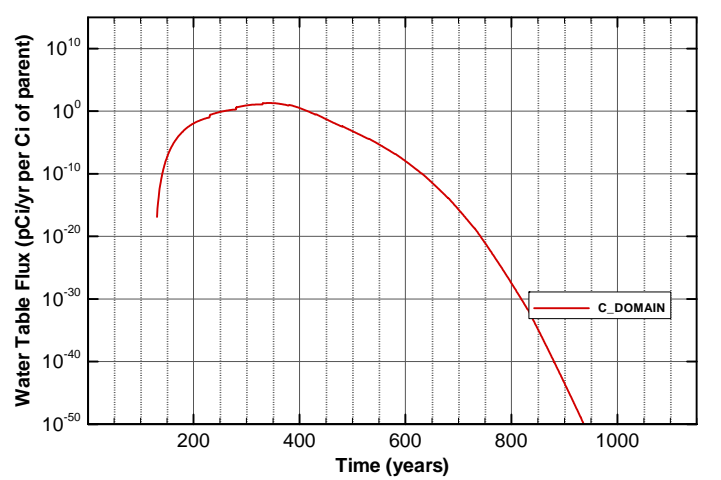

Figure A-1154. Flux at water table for Case01_on H-3_ETF.Carbon 


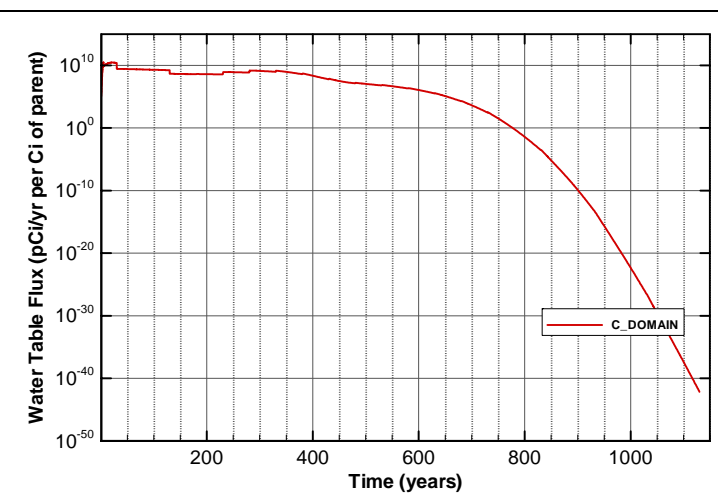

Figure A-1155. Flux at water table for Case01_on I-129

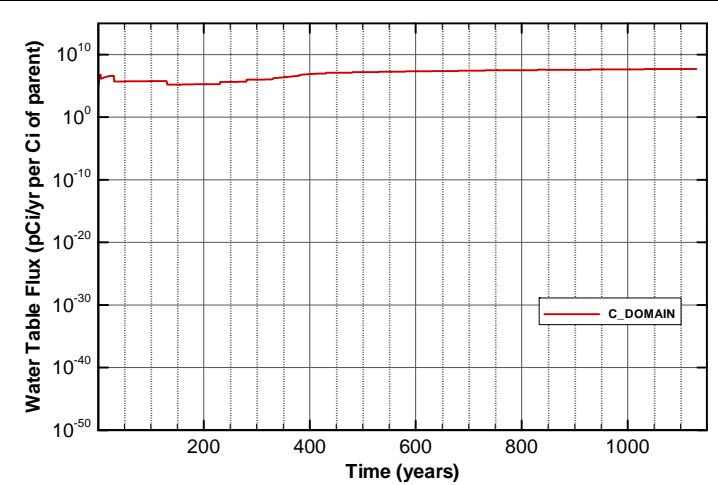

Figure A-1157. Flux at water table for Case01_on I-129_ETF.GT.73

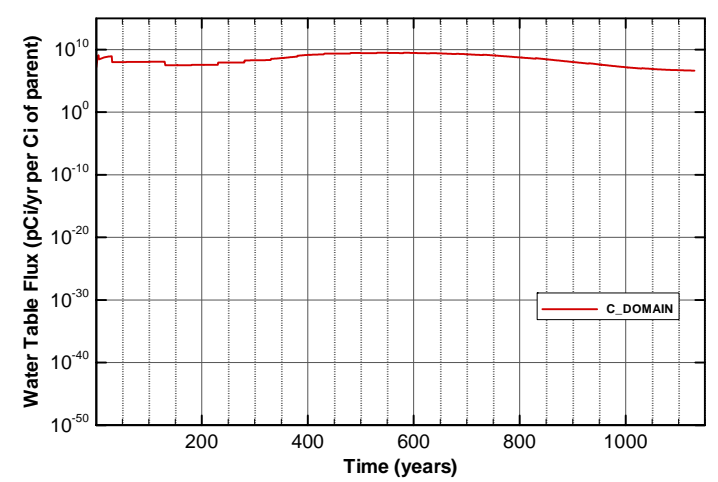

Figure A-1159. Flux at water table for Case01_on I-129_F.CG.8

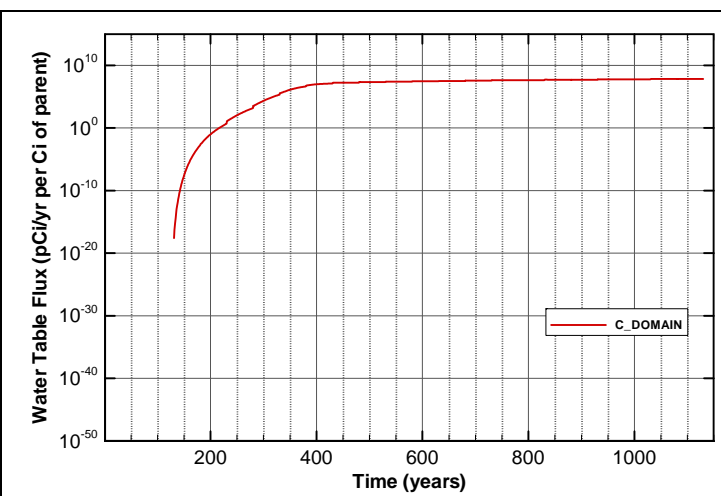

Figure A-1156. Flux at water table for Case01_on I-129_ETF.Carbon

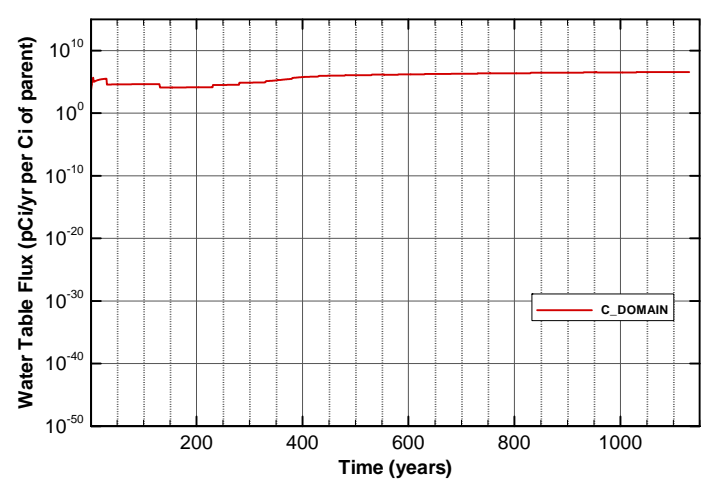

Figure A-1158. Flux at water table for Case01_on I-129_F.Carbon

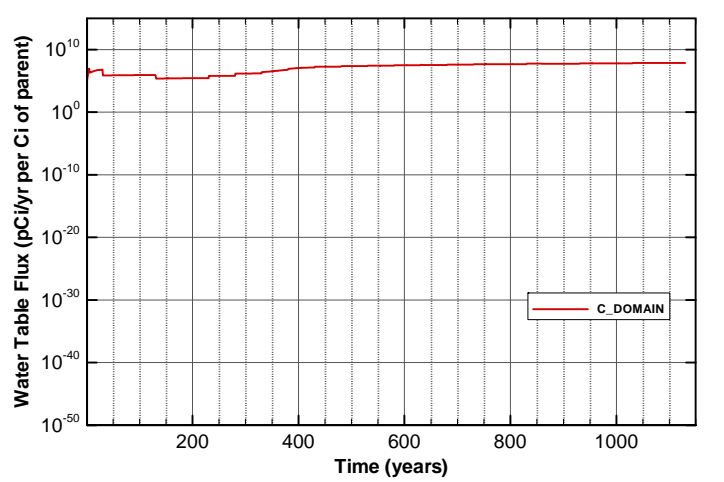

Figure A-1160. Flux at water table for Case01_on I-129_F.Dowex.21K 


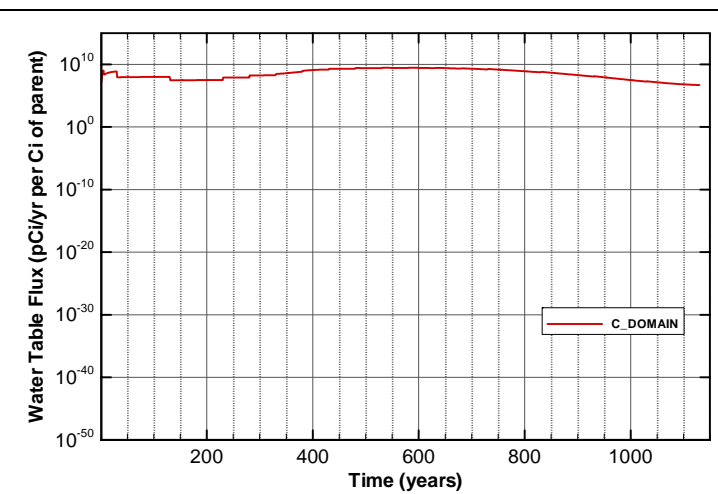

Figure A-1161. Flux at water table for Case01_on I-129_F.Filtercake

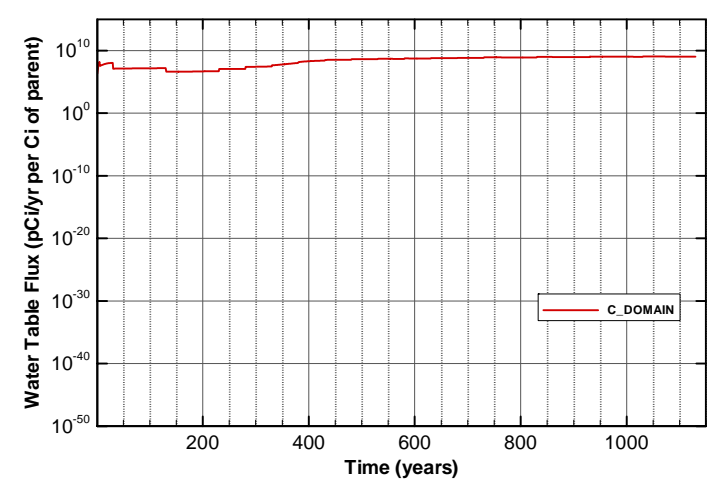

Figure A-1163. Flux at water table for Case01_on I-129_H.CG.8

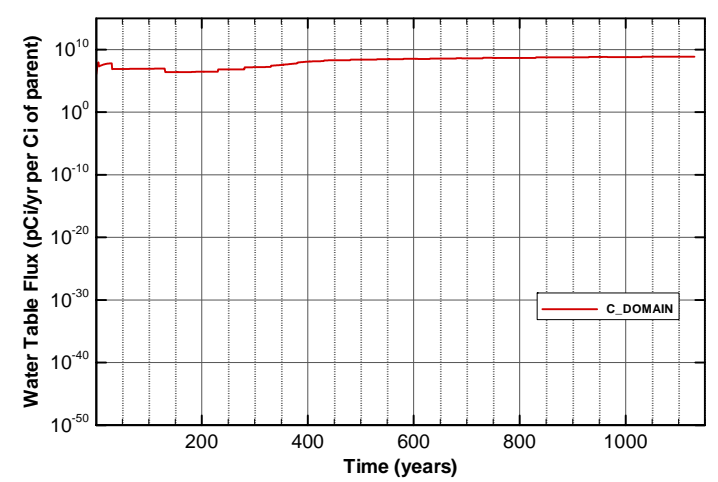

Figure A-1165. Flux at water table for Case01_on I-129_H.Filtercake

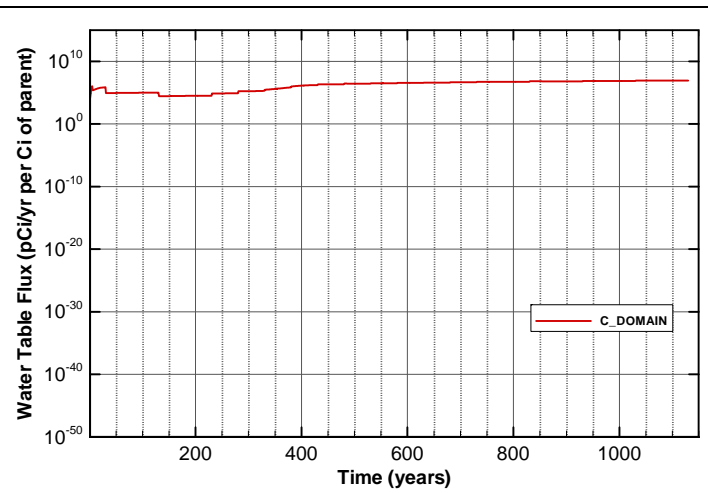

Figure A-1162. Flux at water table for Case01_on I-129_H.Carbon

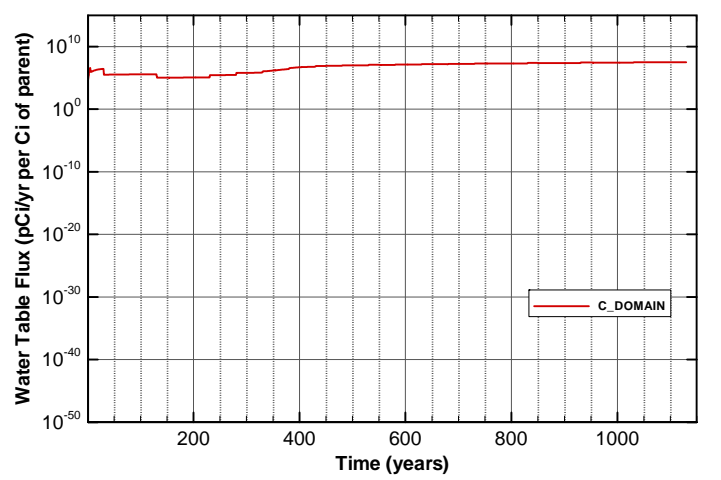

Figure A-1164. Flux at water table for Case01_on I-129_H.Dowex.21K

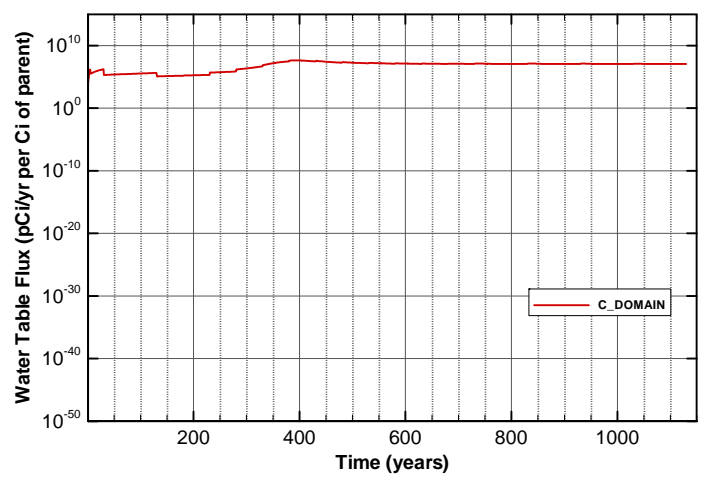

Figure A-1166. Flux at water table for Case01_on I-129_Mk50A 


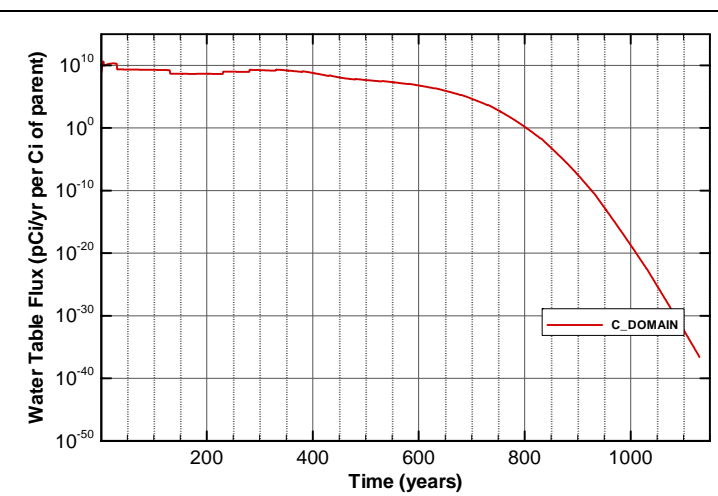

Figure A-1167. Flux at water table for Case01_on K-40

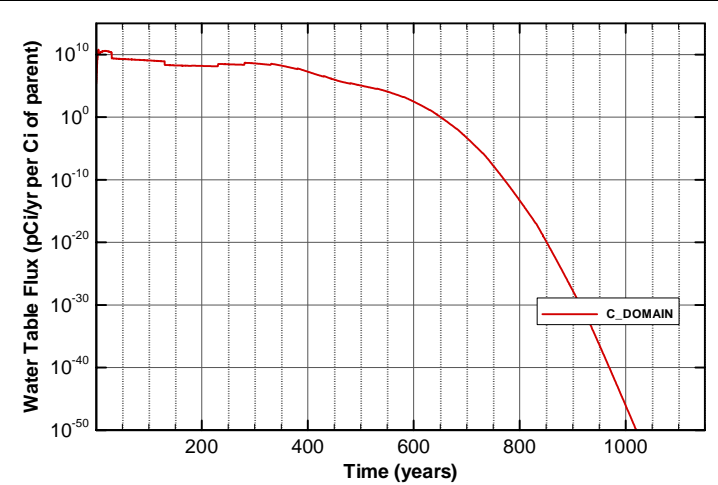

Figure A-1169. Flux at water table for Case01_on Nb-94

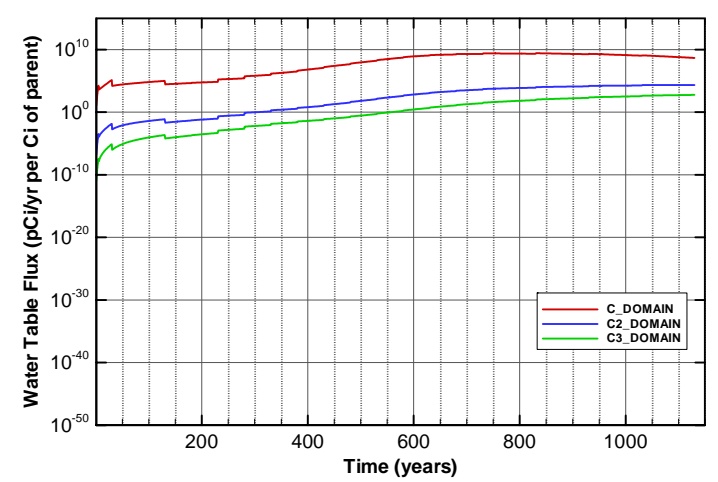

Figure A-1171. Flux at water table for Case01_on Np-237

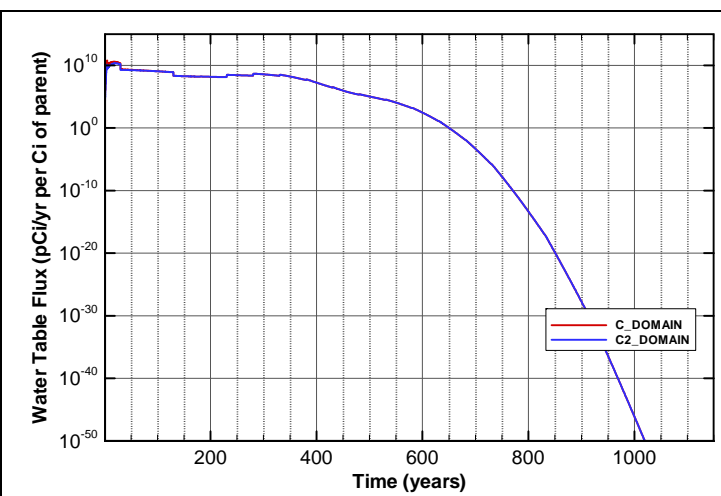

Figure A-1168. Flux at water table for Case01_on Mo-93

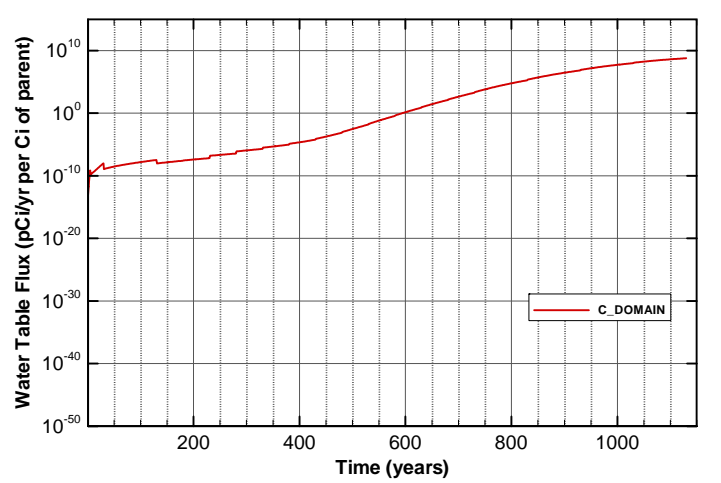

Figure A-1170. Flux at water table for Case01_on Ni-59

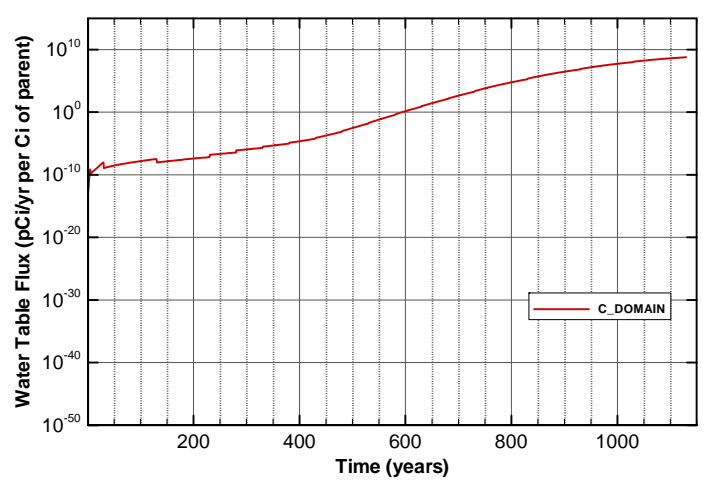

Figure A-1172. Flux at water table for Case01_on Pd-107 
SRNL-STI-2008-00397, REVISION 0

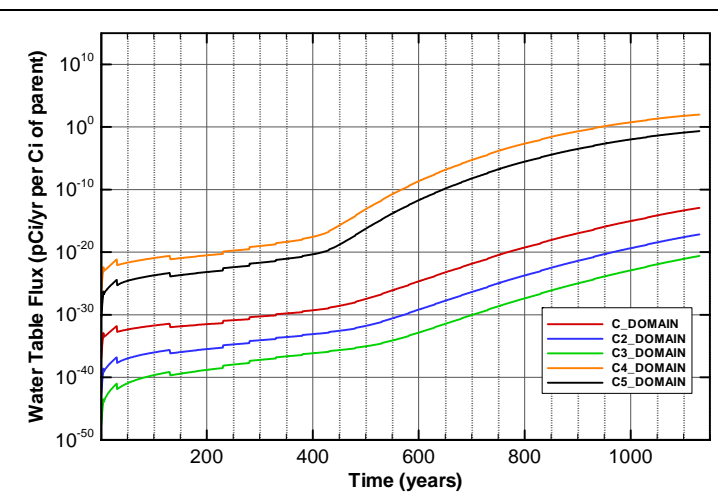

Figure A-1173. Flux at water table for Case01_on Pu-238

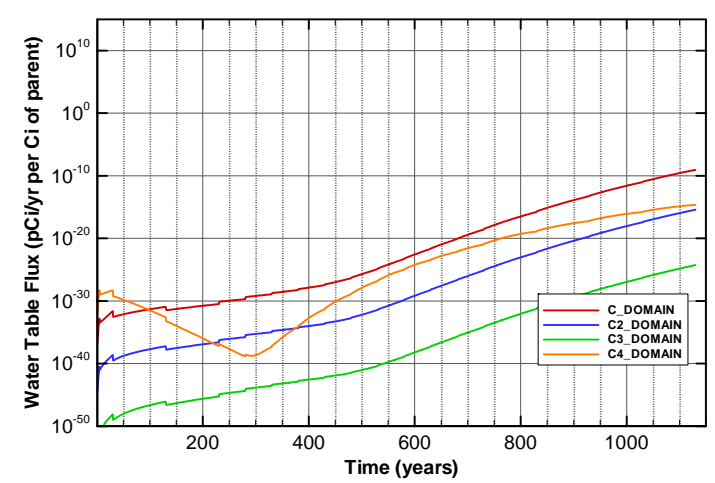

Figure A-1175. Flux at water table for Case01_on Pu-240

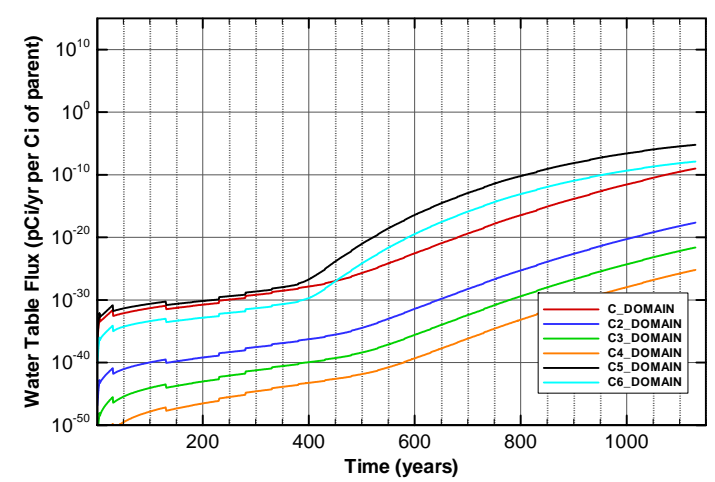

Figure A-1177. Flux at water table for Case01_on Pu-242

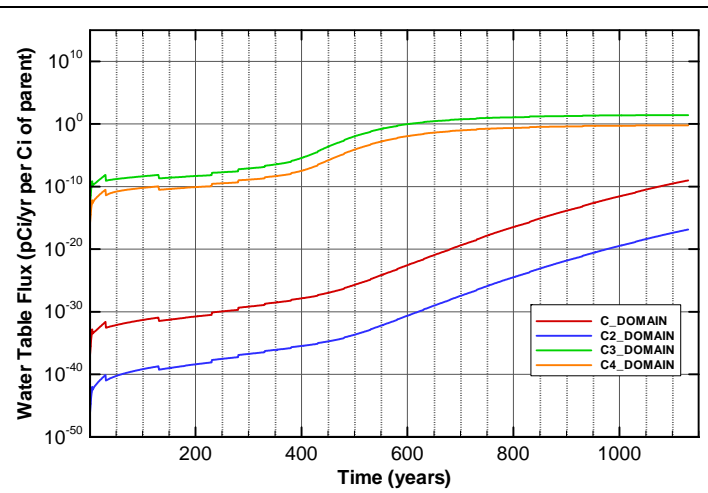

Figure A-1174. Flux at water table for Case01_on Pu-239

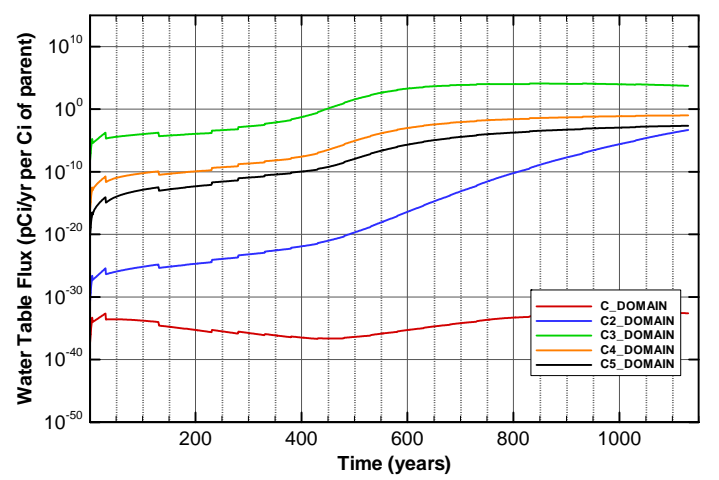

Figure A-1176. Flux at water table for Case01_on Pu-241

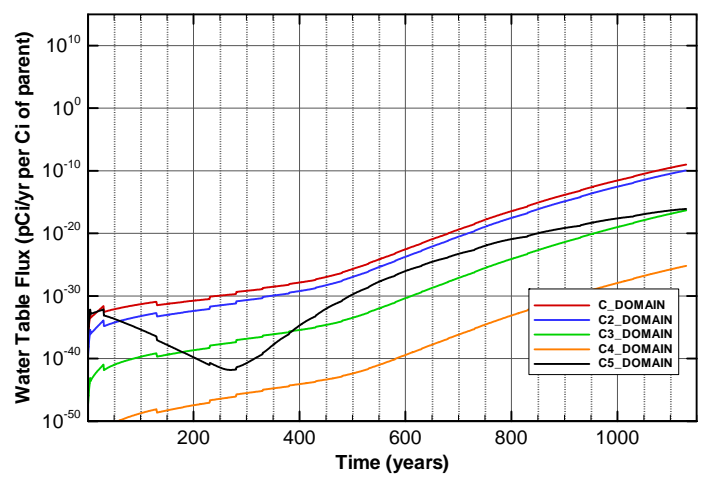

Figure A-1178. Flux at water table for Case01_on Pu-244 


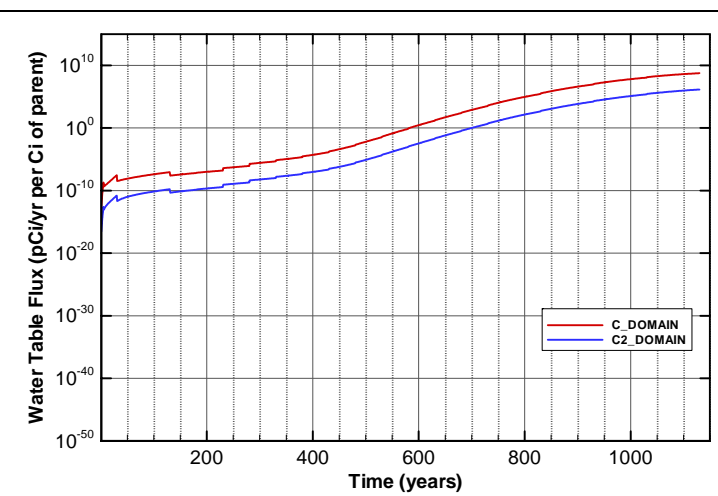

Figure A-1179. Flux at water table for Case01_on Ra-226

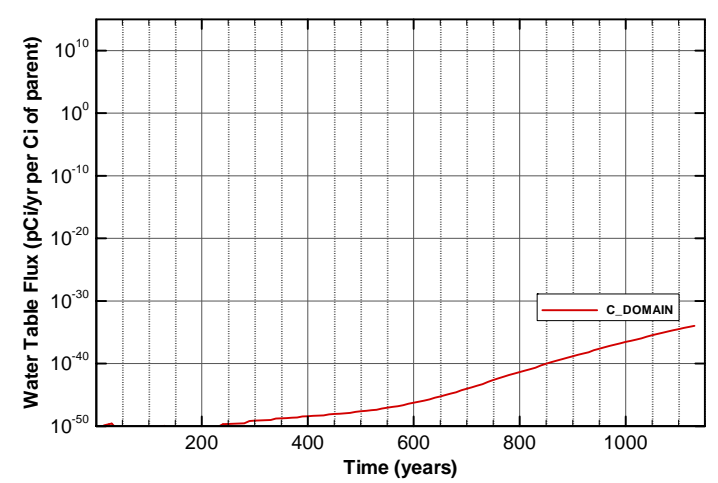

Figure A-1181. Flux at water table for Case01_on Sn-126

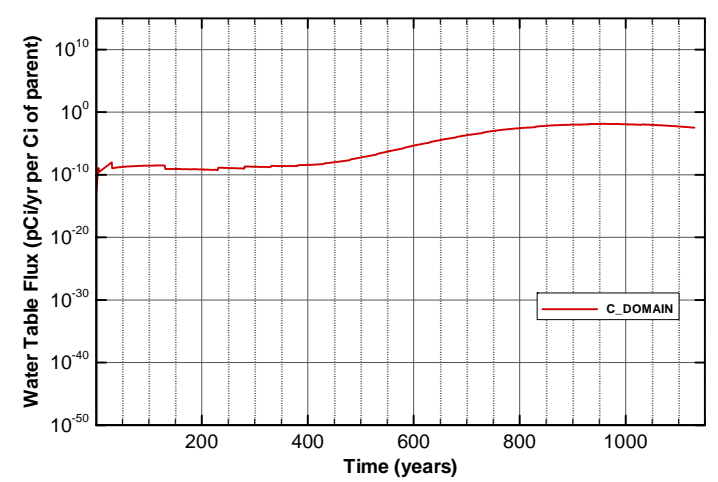

Figure A-1183. Flux at water table for Case01_on Sr-90_Cask

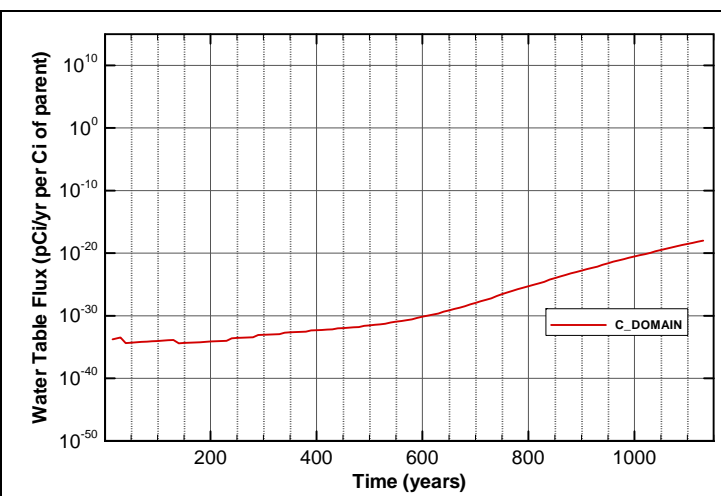

Figure A-1180. Flux at water table for Case01_on Se-79

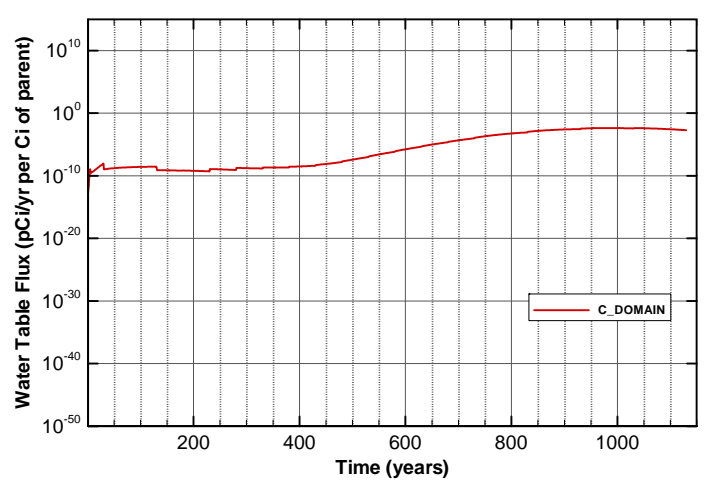

Figure A-1182. Flux at water table for Case01_on Sr-90

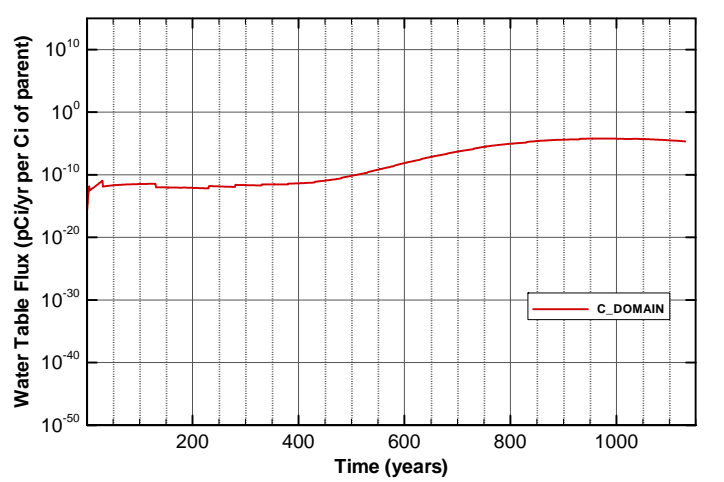

Figure A-1184. Flux at water table for Case01_on Sr-90_Mk50A 


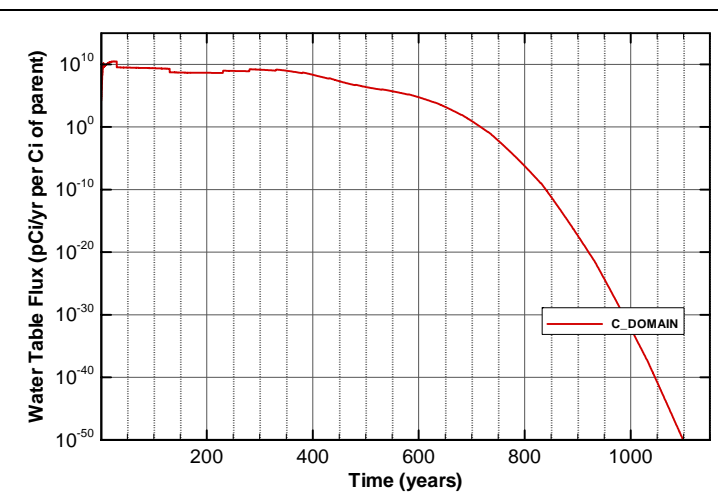

Figure A-1185. Flux at water table for Case01_on Tc-99

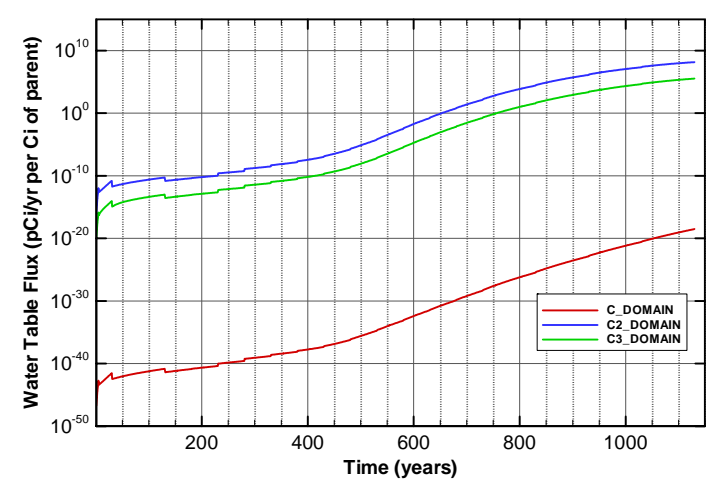

Figure A-1187. Flux at water table for Case01_on Th-230

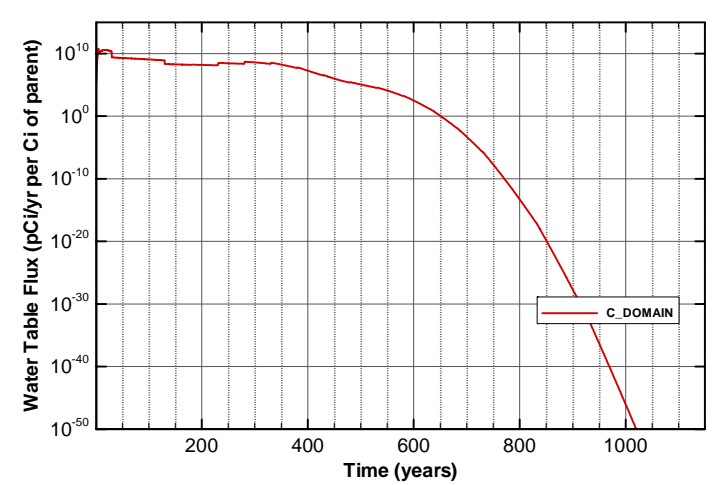

Figure A-1189. Flux at water table for Case01_on Tracer

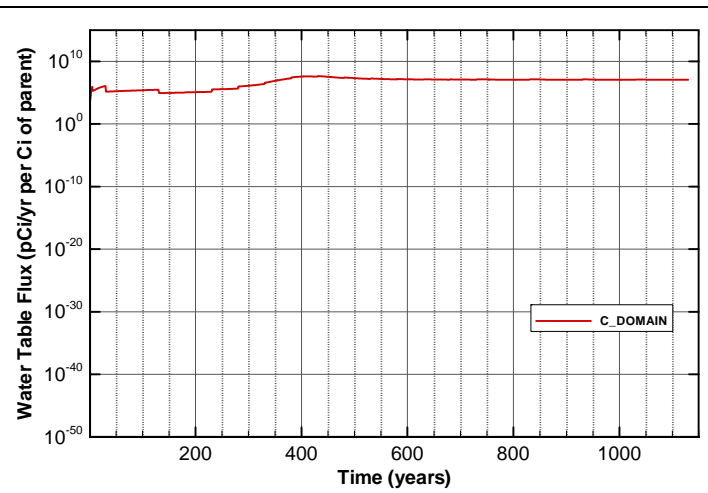

Figure A-1186. Flux at water table for Case01_on Tc-99_Mk50A

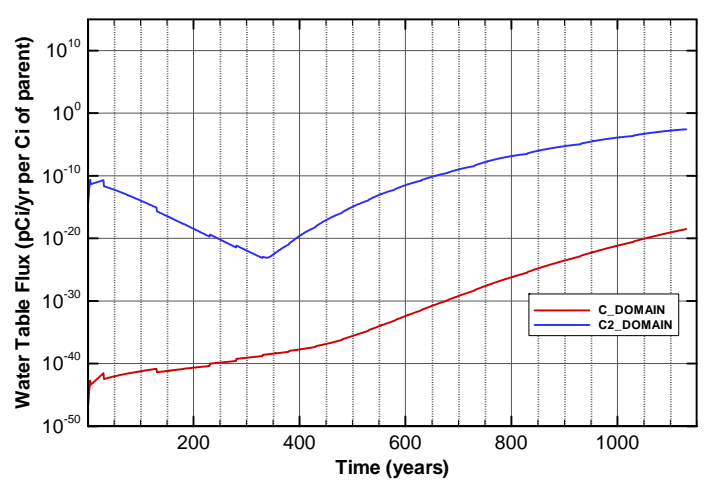

Figure A-1188. Flux at water table for Case01_on Th-232

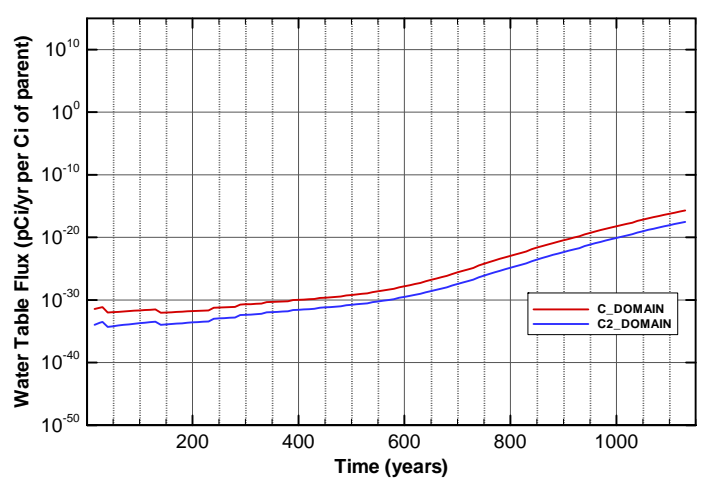

Figure A-1190. Flux at water table for Case01_on U-233 
SRNL-STI-2008-00397, REVISION 0

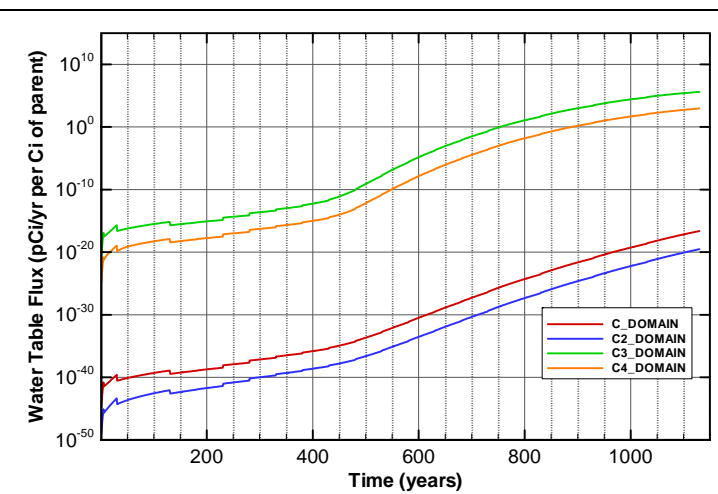

Figure A-1191. Flux at water table for Case01_on U-234

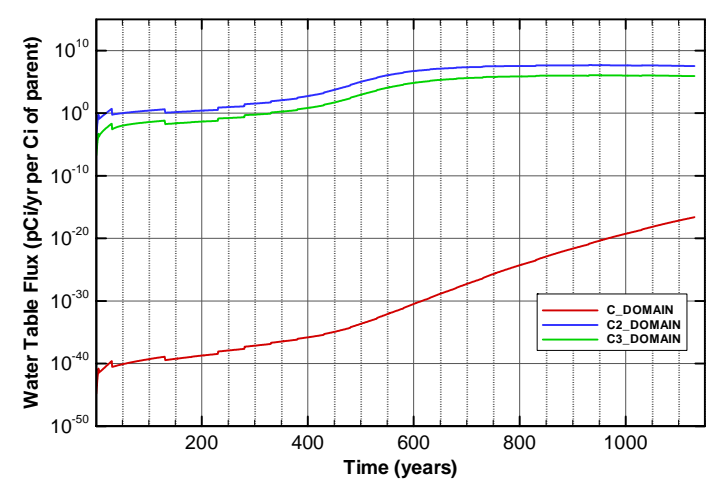

Figure A-1193. Flux at water table for Case01_on U-235

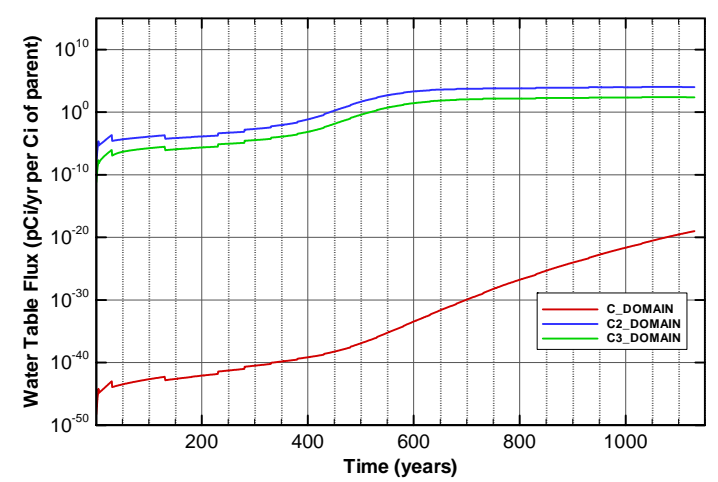

Figure A-1195. Flux at water table for Case01_on U-235_Paducah.Cask

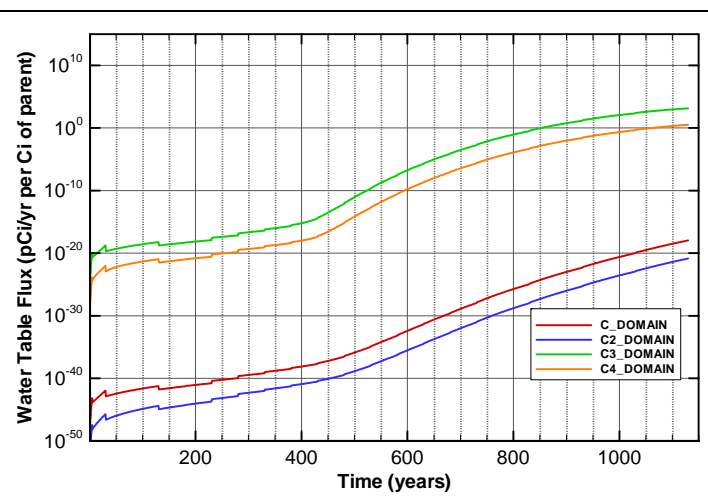

Figure A-1192. Flux at water table for Case01_on U-234_Mglass

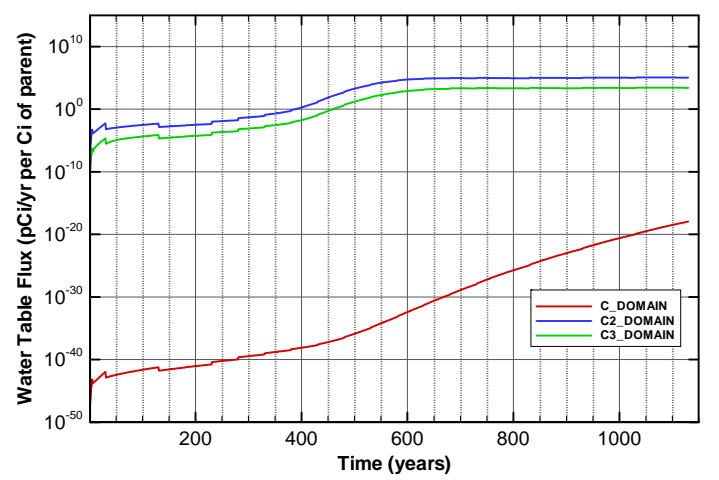

Figure A-1194. Flux at water table for Case01_on U-235_Mglass

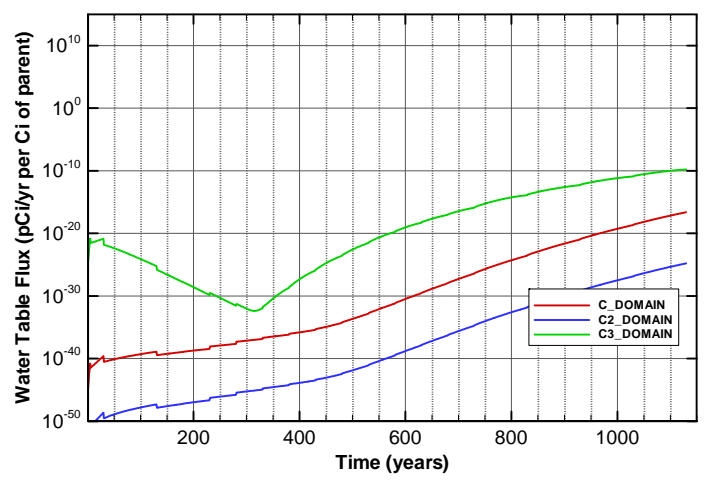

Figure A-1196. Flux at water table for Case01_on U-236 
SRNL-STI-2008-00397, REVISION 0

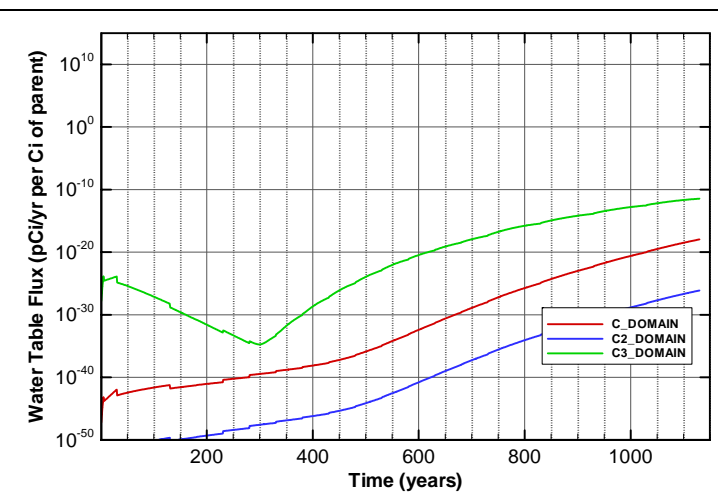

Figure A-1197. Flux at water table for Case01_on U-236_Mglass

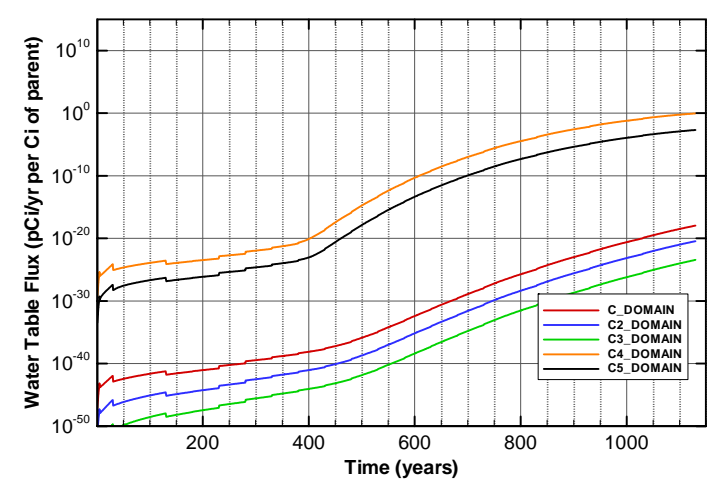

Figure A-1199. Flux at water table for Case01_on U-238_Mglass

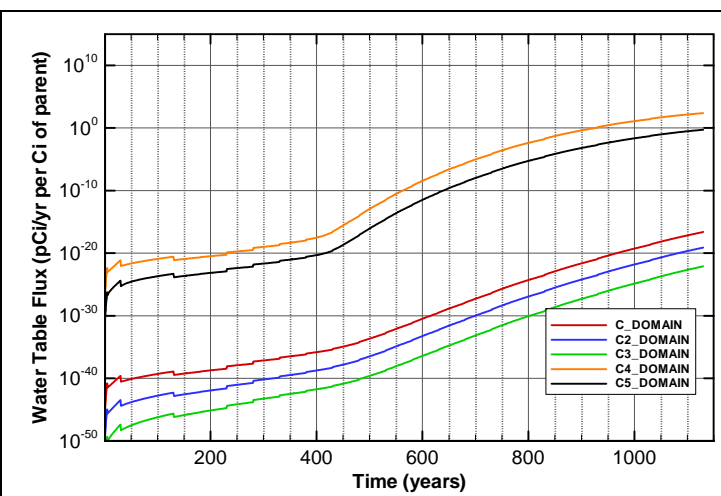

Figure A-1198. Flux at water table for Case01_on U-238

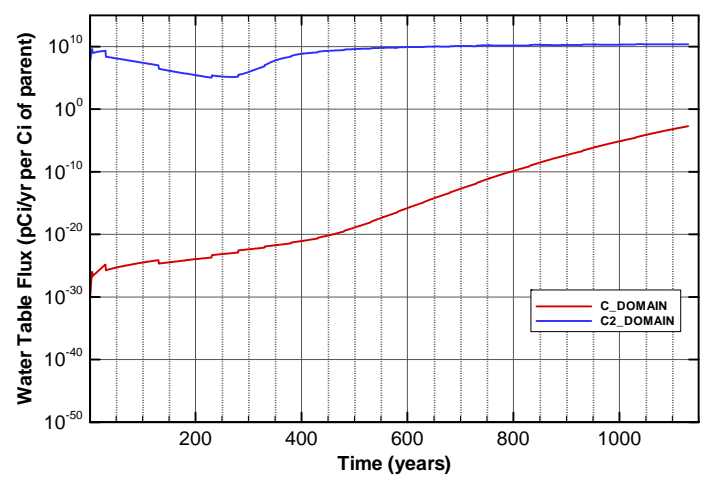

Figure A-1200. Flux at water table for Case01_on Zr-93

\subsubsection{Edge trench flux plots for 10 -year cover}

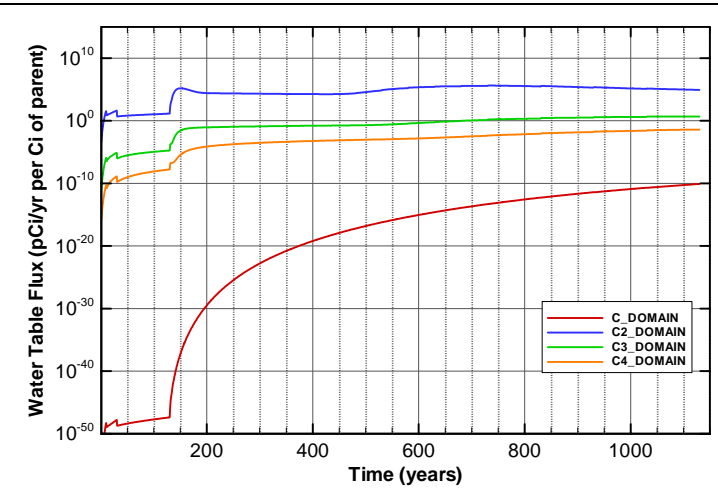

Figure A-1201. Flux at water table for Case01n11_off Am-241

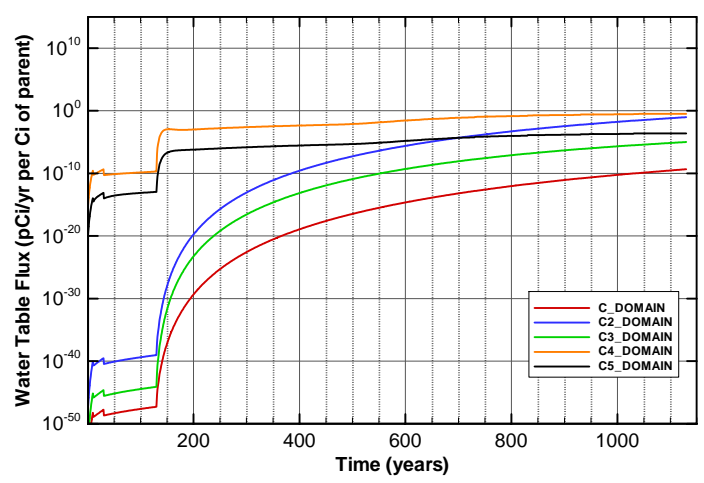

Figure A-1202. Flux at water table for Case01n11_off Am-243 
SRNL-STI-2008-00397, REVISION 0

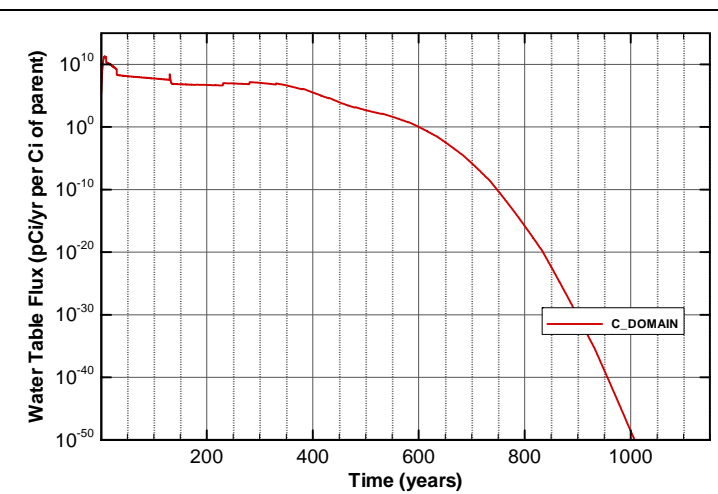

Figure A-1203. Flux at water table for Case01n11_off C-14

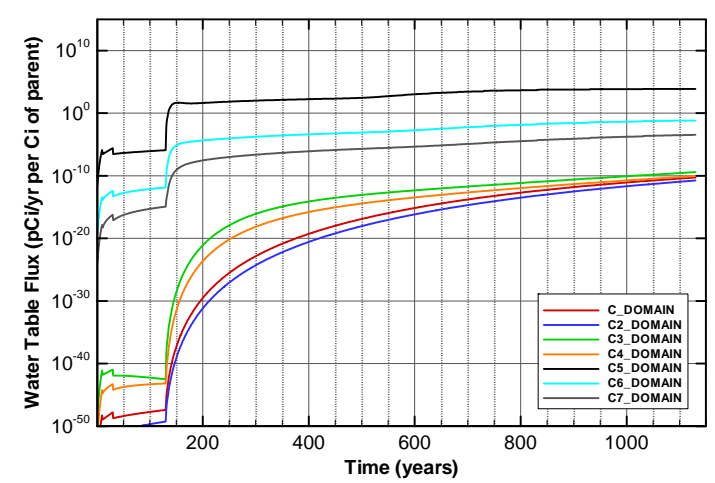

Figure A-1205. Flux at water table for Case01n11_off Cf-249

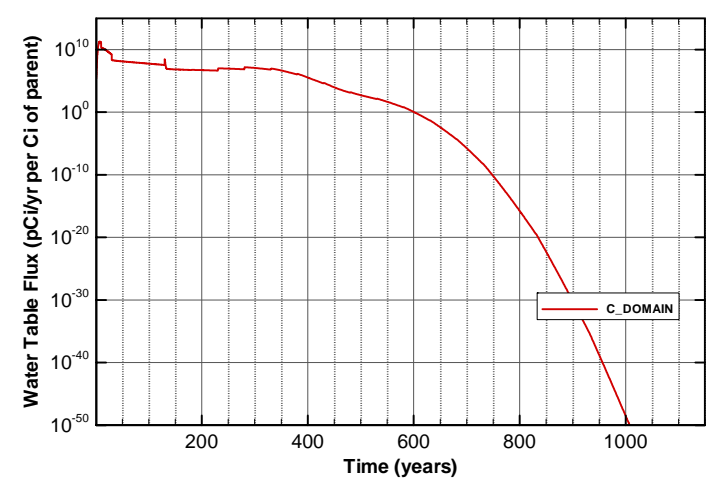

Figure A-1207. Flux at water table for Case01n11_off Cl-36

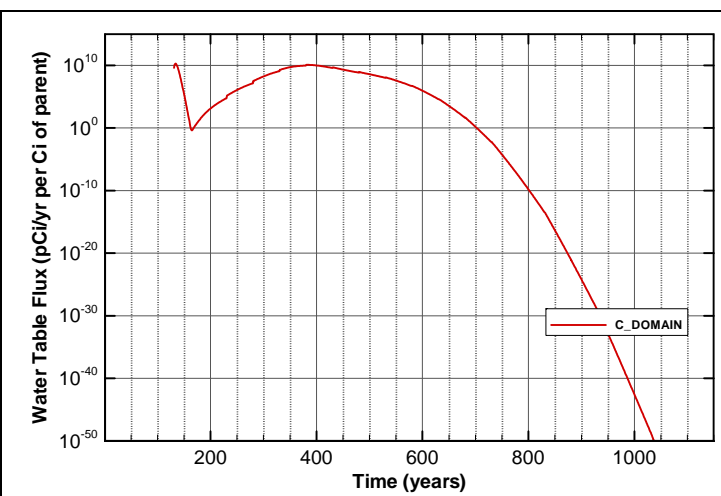

Figure A-1204. Flux at water table for Case01n11_off C-14_NR.Pump

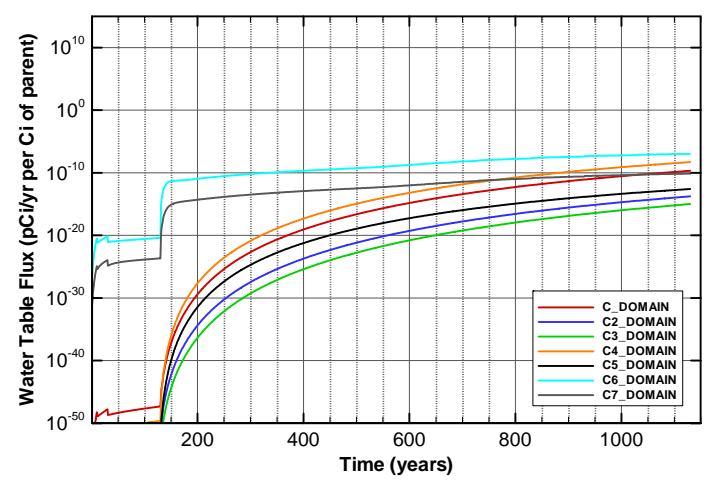

Figure A-1206. Flux at water table for Case01n11_off Cf-251

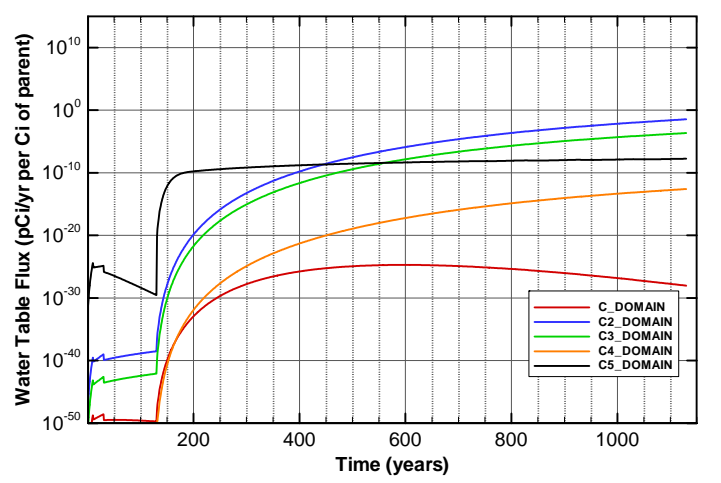

Figure A-1208. Flux at water table for Case01n11_off Cm-244 


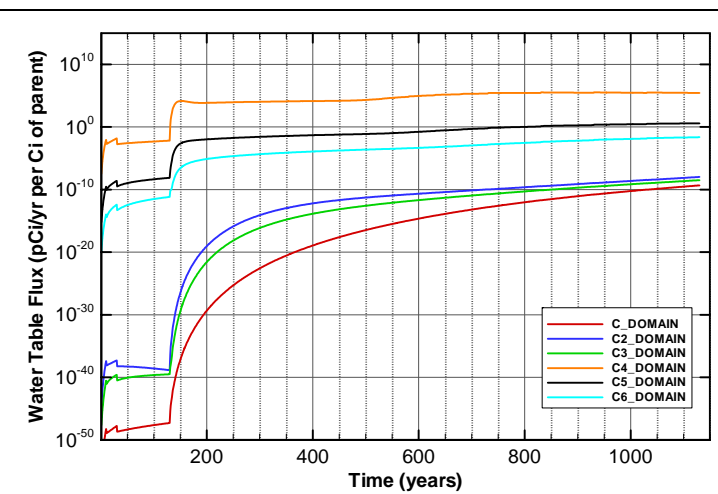

Figure A-1209. Flux at water table for Case01n11_off Cm-245

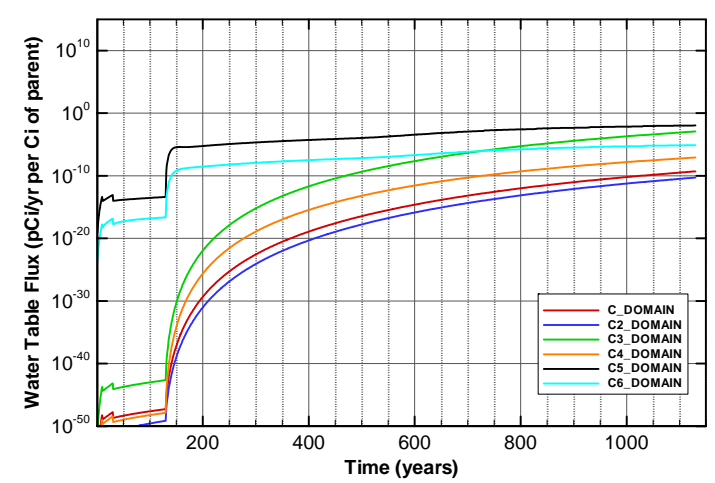

Figure A-1211. Flux at water table for Case01n11_off Cm-247

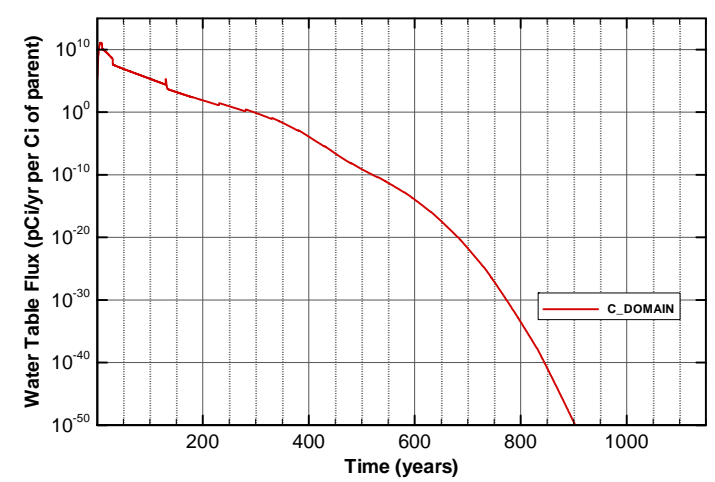

Figure A-1213. Flux at water table for Case01n11_off H-3

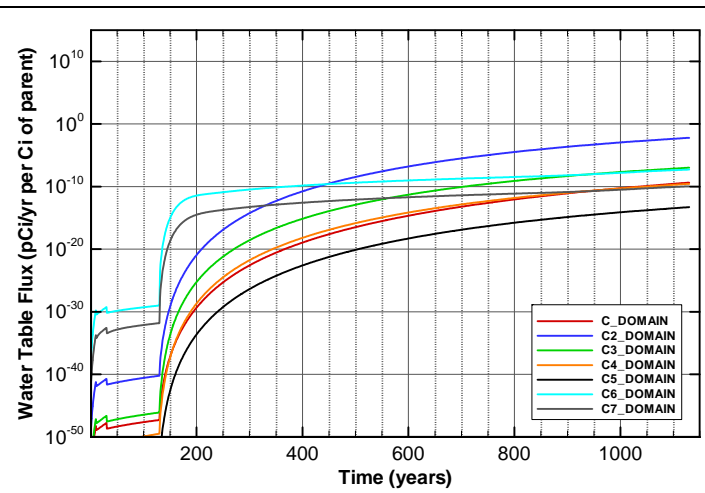

Figure A-1210. Flux at water table for Case01n11_off Cm-246

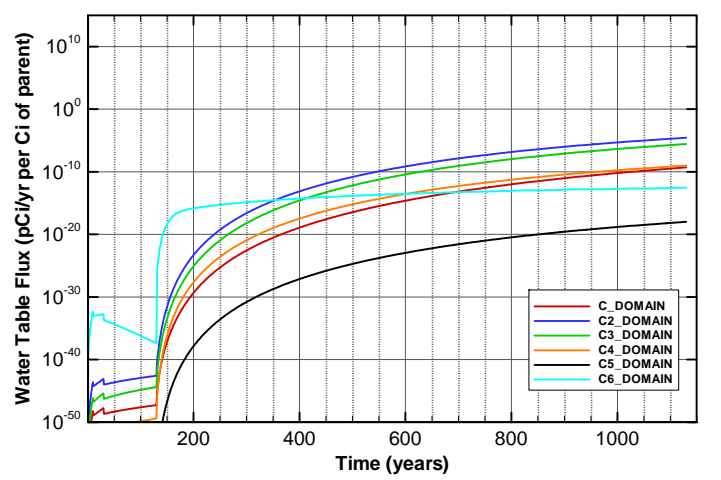

Figure A-1212. Flux at water table for Case01n11_off Cm-248

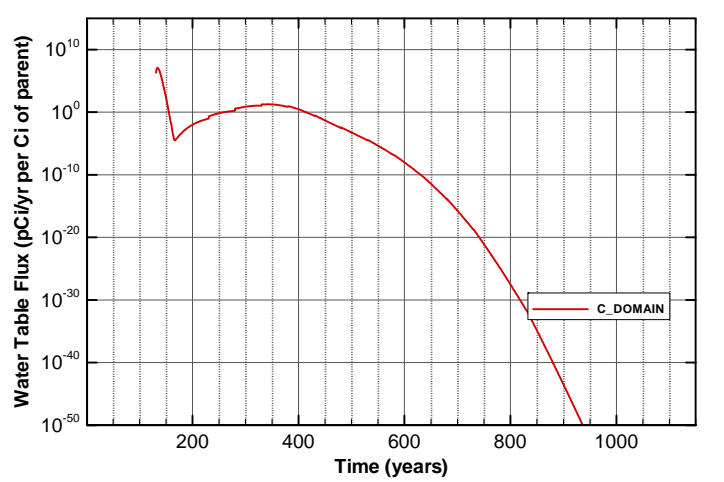

Figure A-1214. Flux at water table for Case01n11_off H-3_ETF.Carbon 


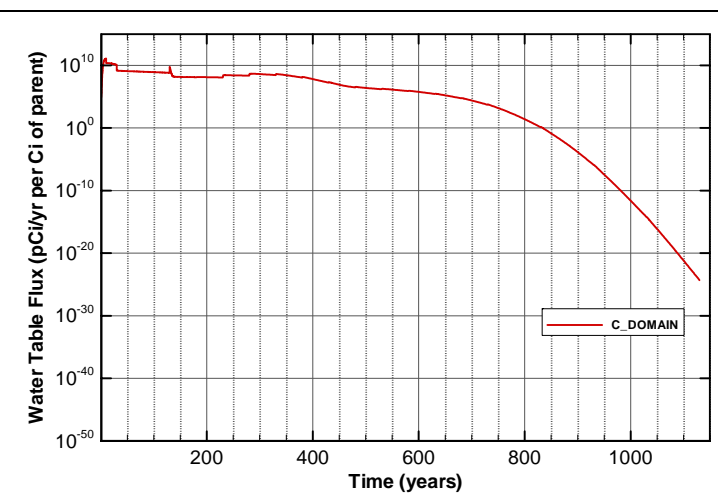

Figure A-1215. Flux at water table for Case01n11_off I-129

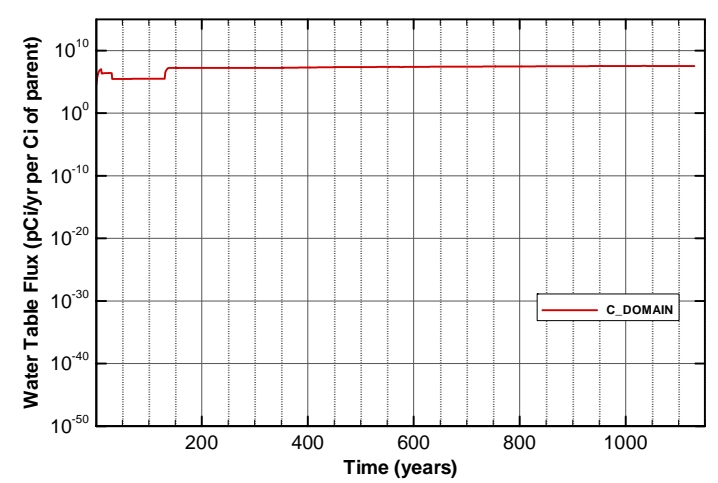

Figure A-1217. Flux at water table for Case01n11_off I-129_ETF.GT.73

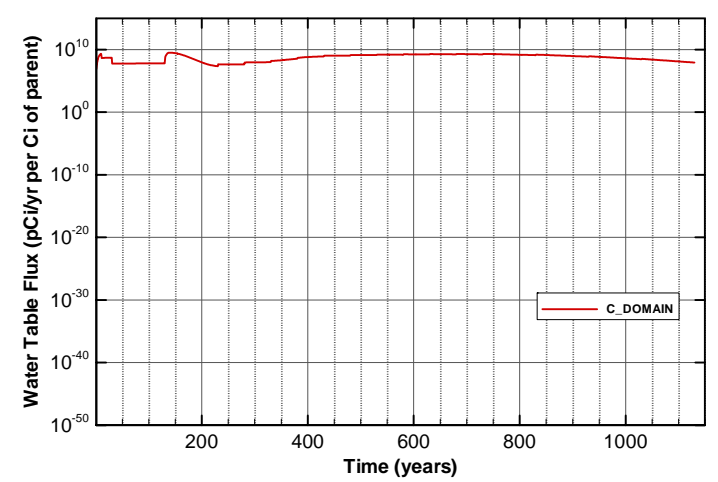

Figure A-1219. Flux at water table for Case01n11_off I-129_F.CG.8

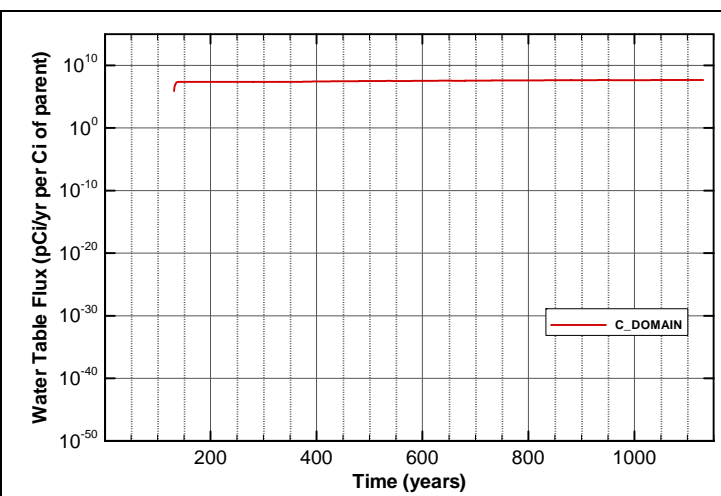

Figure A-1216. Flux at water table for Case01n11_off I-129_ETF.Carbon

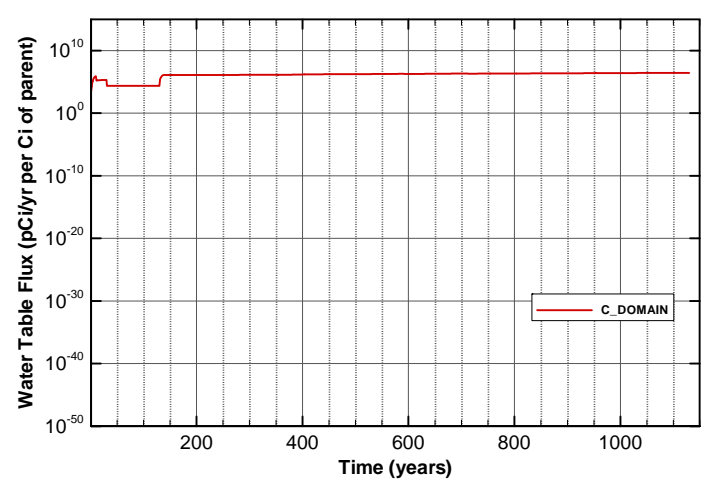

Figure A-1218. Flux at water table for Case01n11_off I-129_F.Carbon

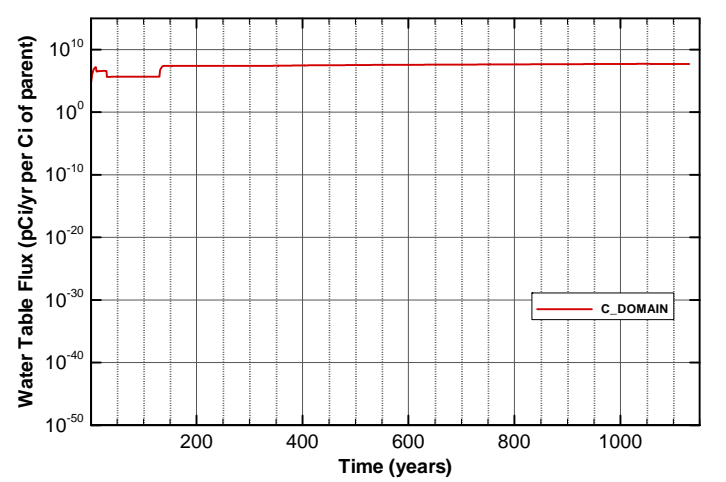

Figure A-1220. Flux at water table for Case01n11_off I-129_F.Dowex.21K 


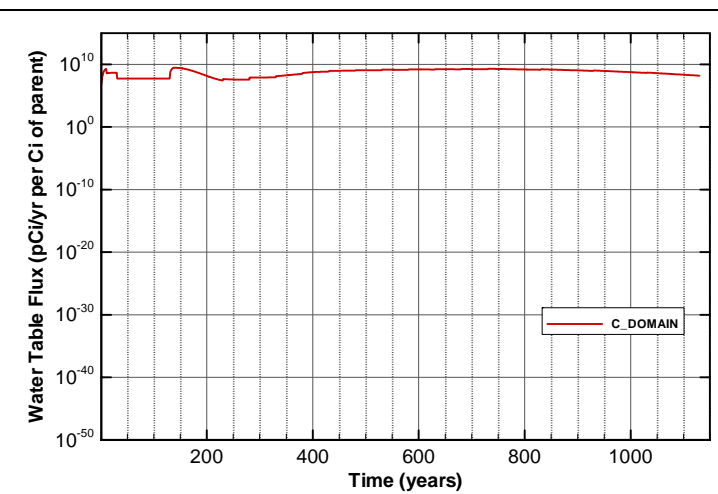

Figure A-1221. Flux at water table for Case01n11_off I-129_F.Filtercake

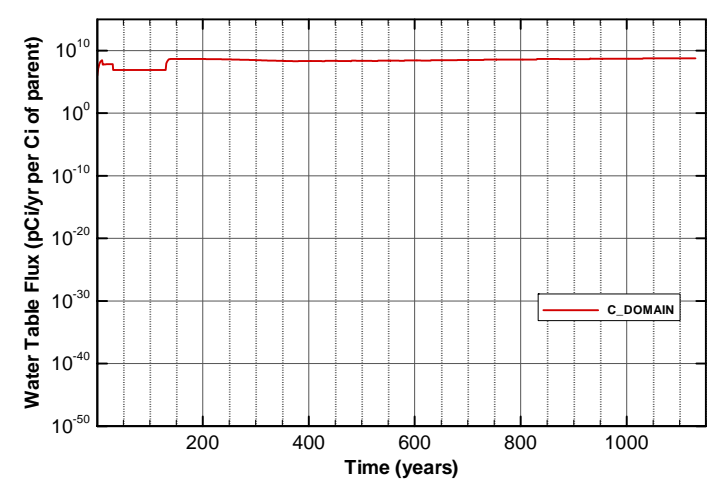

Figure A-1223. Flux at water table for Case01n11_off I-129_H.CG.8

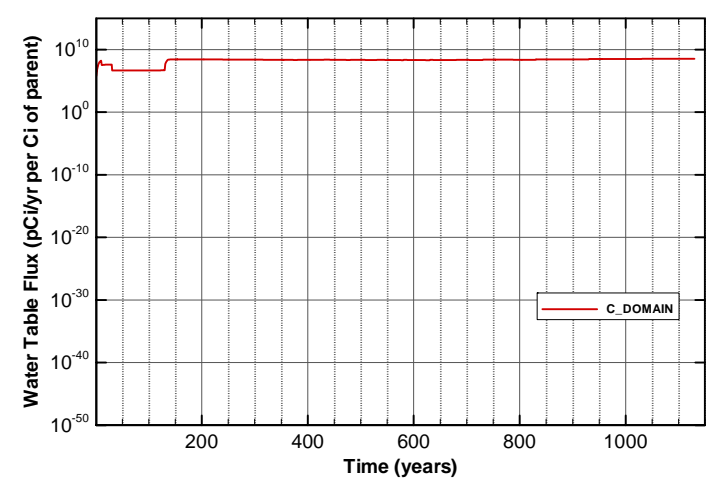

Figure A-1225. Flux at water table for Case01n11_off I-129_H.Filtercake

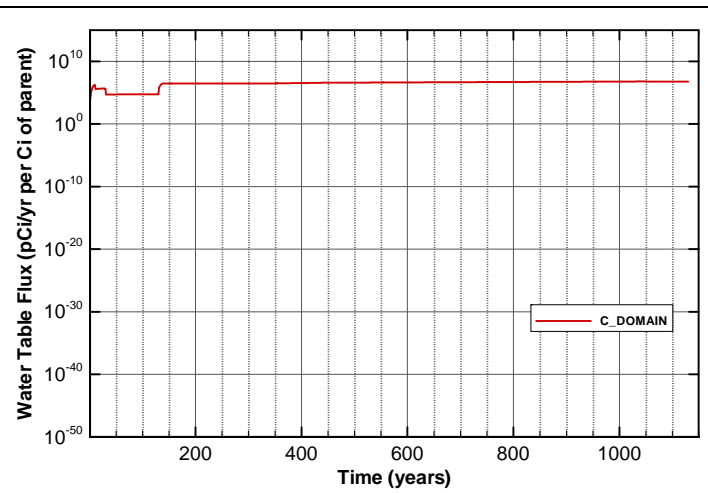

Figure A-1222. Flux at water table for Case01n11_off I-129_H.Carbon

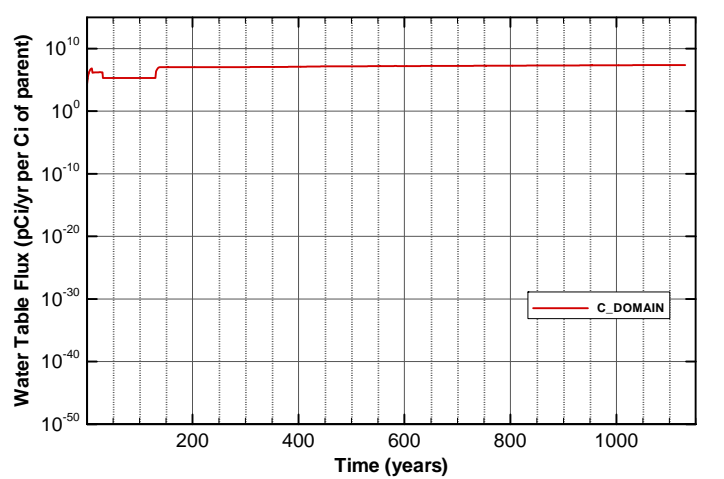

Figure A-1224. Flux at water table for Case01n11_off I-129_H.Dowex.21K

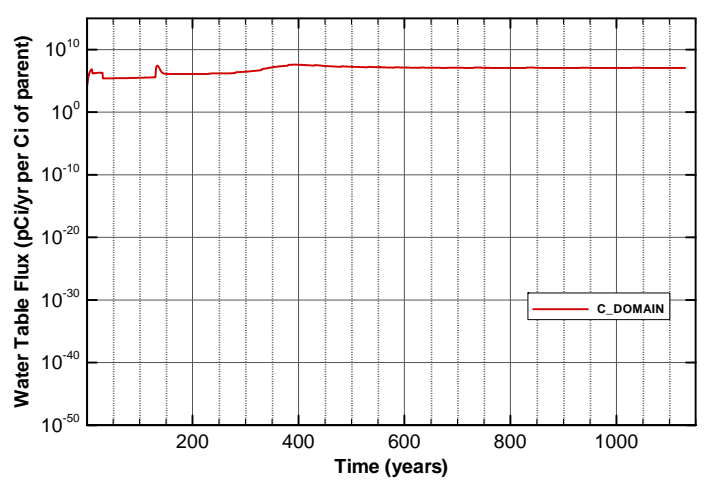

Figure A-1226. Flux at water table for Case01n11_off I-129_Mk50A 


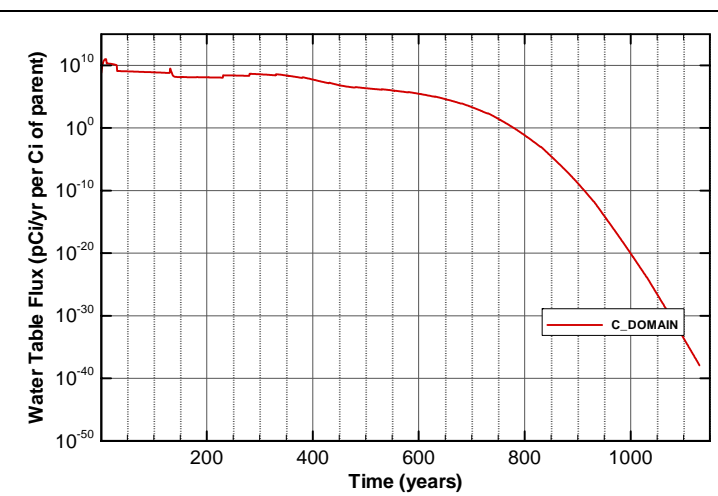

Figure A-1227. Flux at water table for Case01n11_off K-40

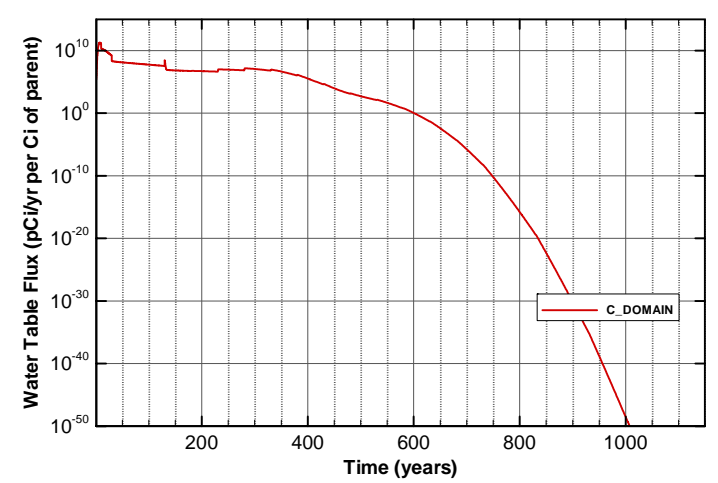

Figure A-1229. Flux at water table for Case01n11_off Nb-94

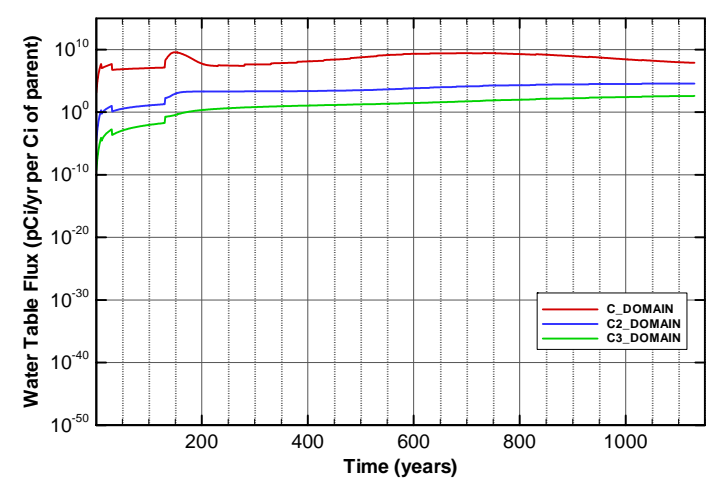

Figure A-1231. Flux at water table for Case01n11_off Np-237

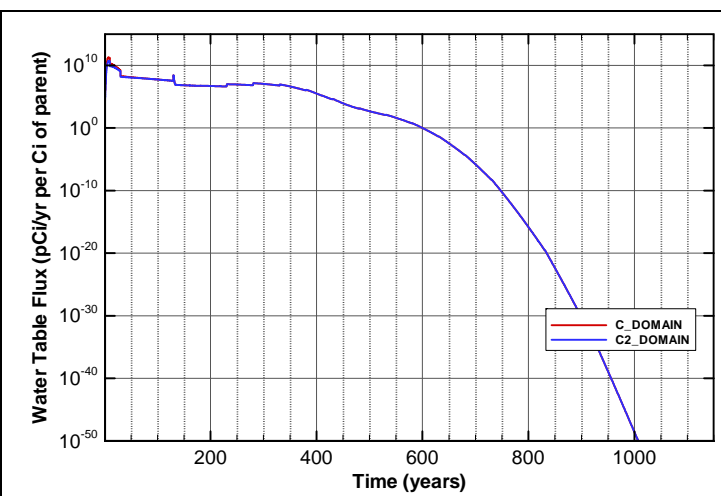

Figure A-1228. Flux at water table for Case01n11_off Mo-93

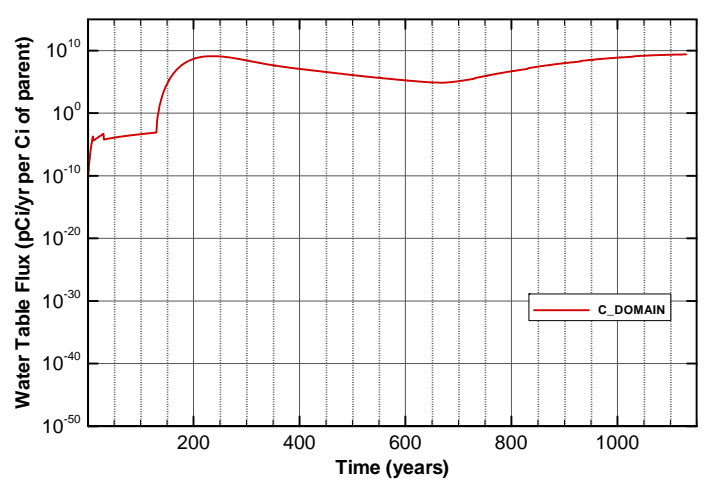

Figure A-1230. Flux at water table for Case01n11_off Ni-59

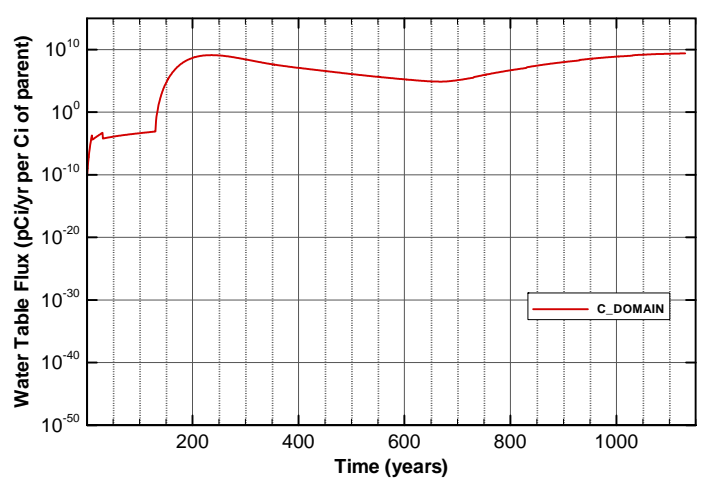

Figure A-1232. Flux at water table for Case01n11_off Pd-107 
SRNL-STI-2008-00397, REVISION 0
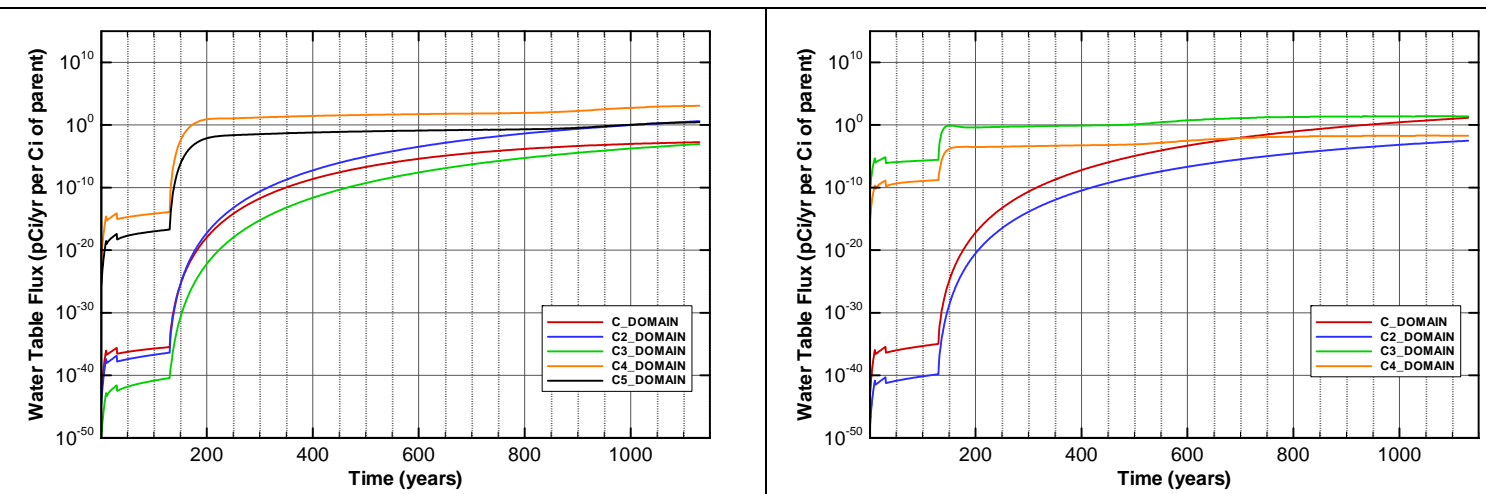

Figure A-1233. Flux at water table for Case01n11_off Pu-238

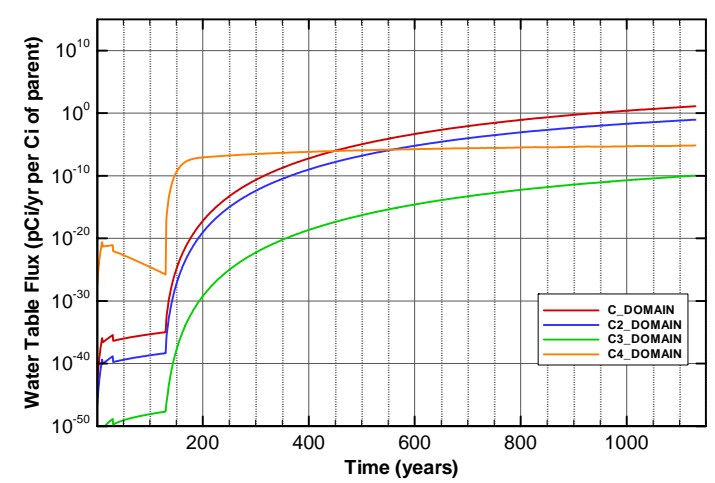

Figure A-1235. Flux at water table for Case01n11_off Pu-240

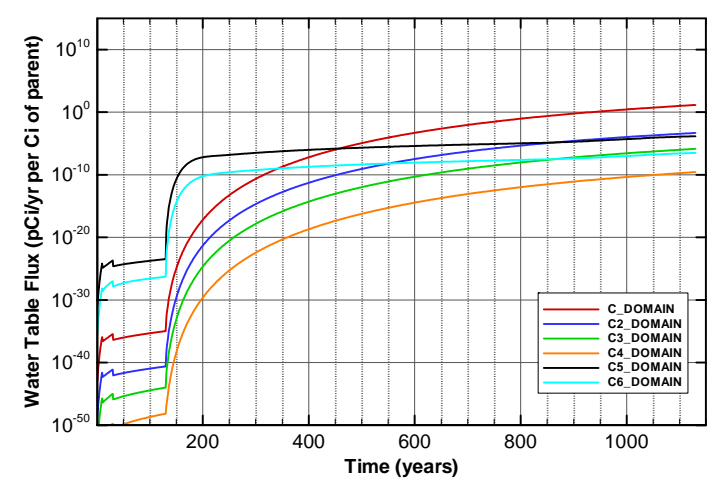

Figure A-1237. Flux at water table for Case01n11_off Pu-242

Figure A-1234. Flux at water table for Case01n11_off Pu-239

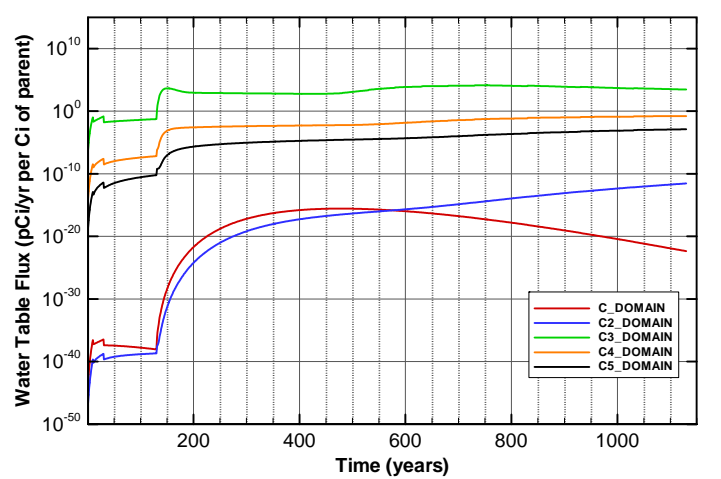

Figure A-1236. Flux at water table for Case01n11_off Pu-241

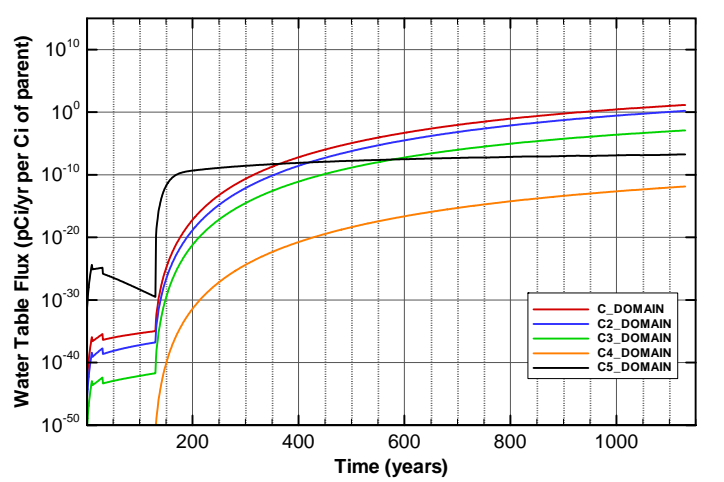

Figure A-1238. Flux at water table for Case01n11_off Pu-244 


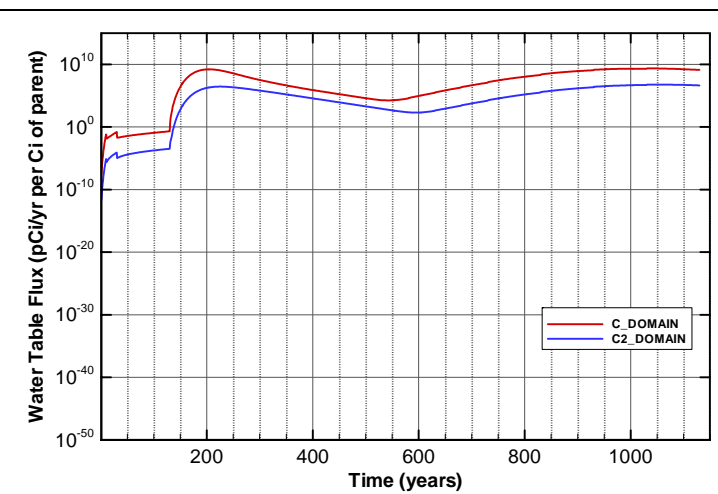

Figure A-1239. Flux at water table for Case01n11_off Ra-226

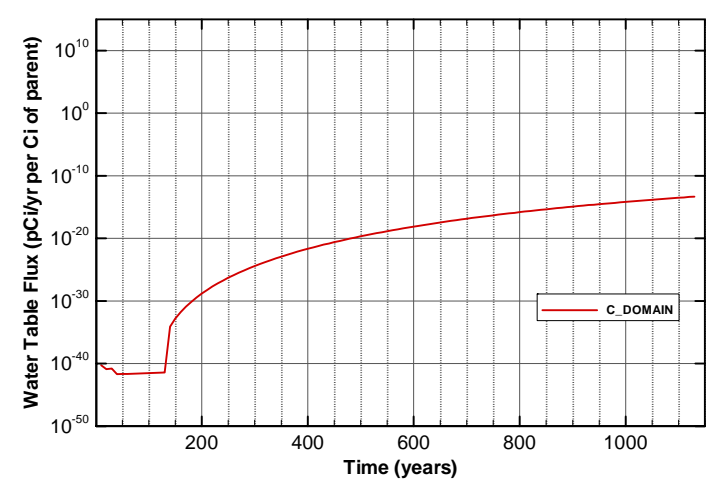

Figure A-1241. Flux at water table for Case01n11_off Sn-126

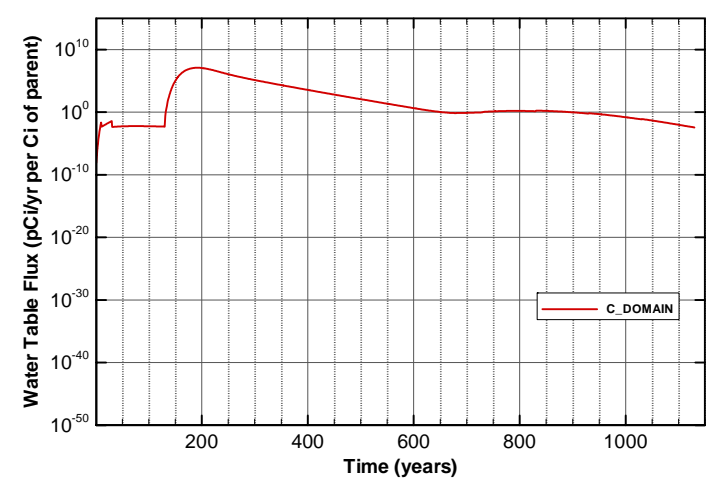

Figure A-1243. Flux at water table for Case01n11_off Sr-90_Cask

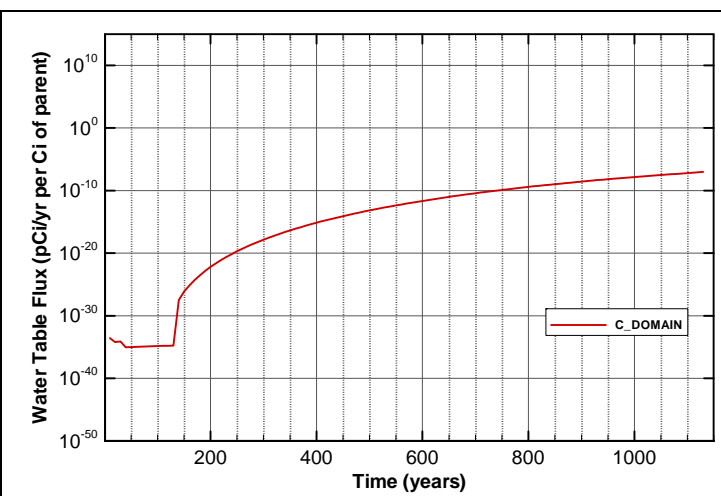

Figure A-1240. Flux at water table for Case01n11_off Se-79

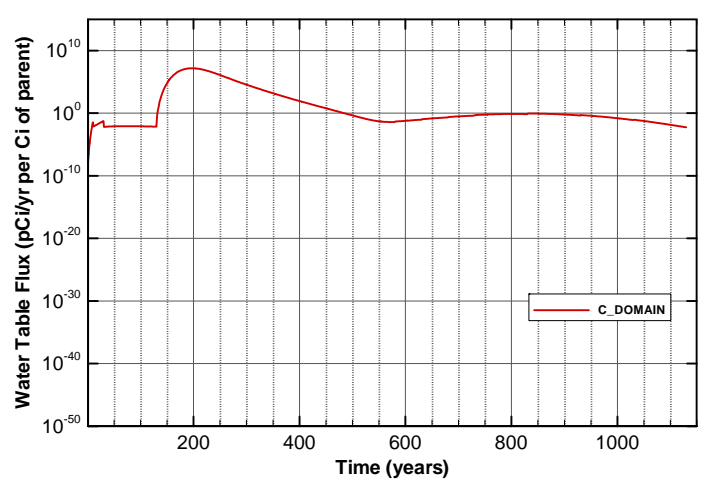

Figure A-1242. Flux at water table for Case01n11_off Sr-90

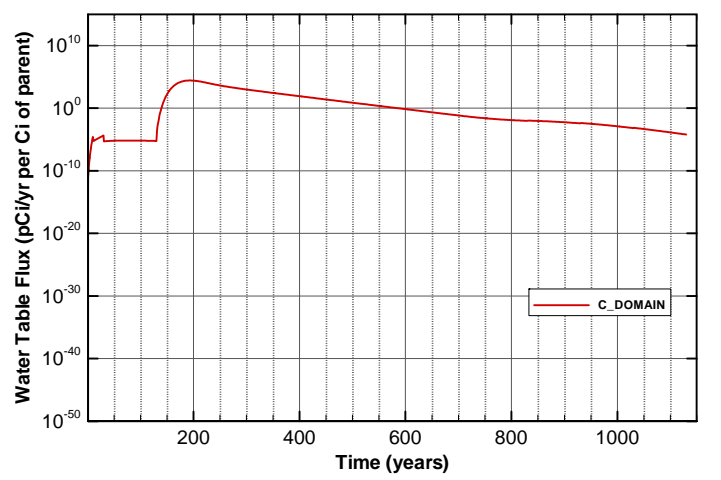

Figure A-1244. Flux at water table for Case01n11_off Sr-90_Mk50A 


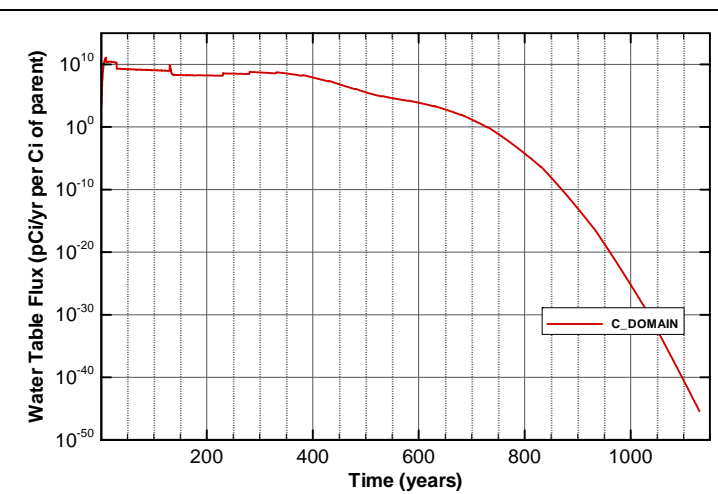

Figure A-1245. Flux at water table for Case01n11_off Tc-99

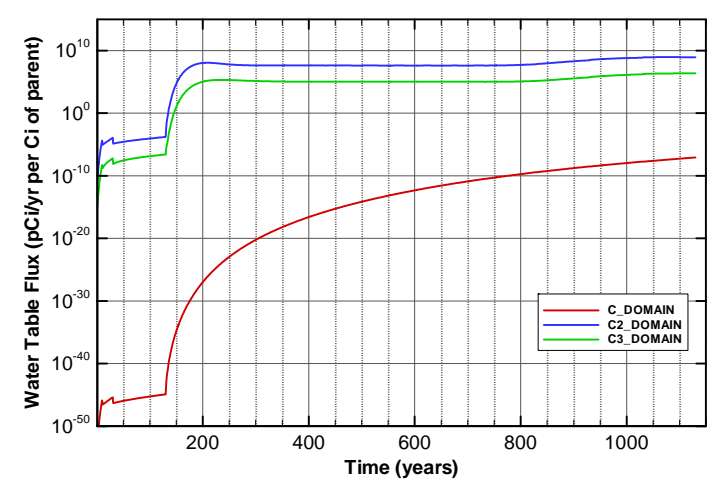

Figure A-1247. Flux at water table for Case01n11_off Th-230

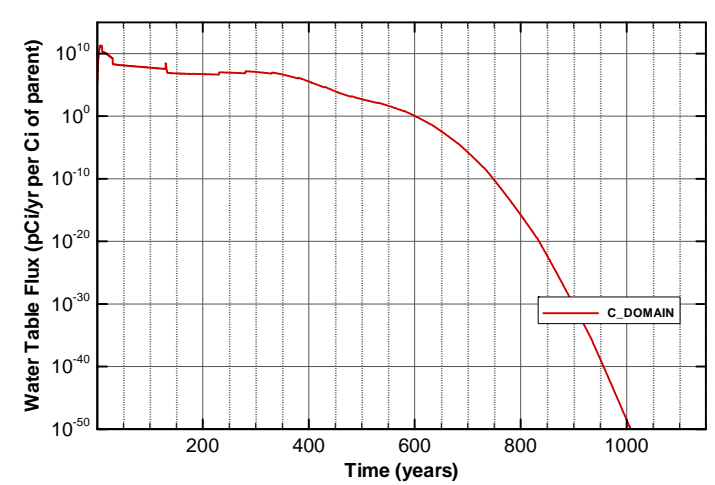

Figure A-1249. Flux at water table for Case01n11_off Tracer

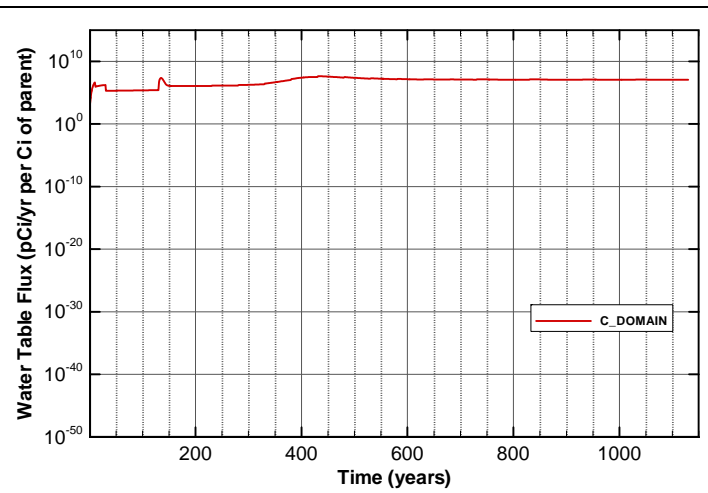

Figure A-1246. Flux at water table for Case01n11_off Tc-99_Mk50A

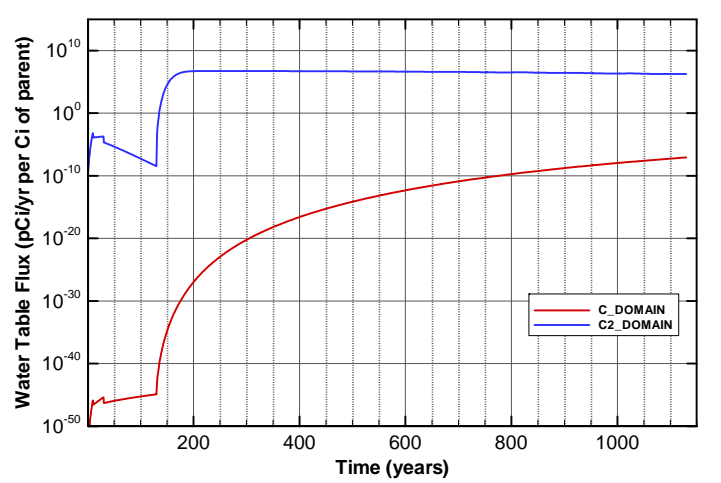

Figure A-1248. Flux at water table for Case01n11_off Th-232

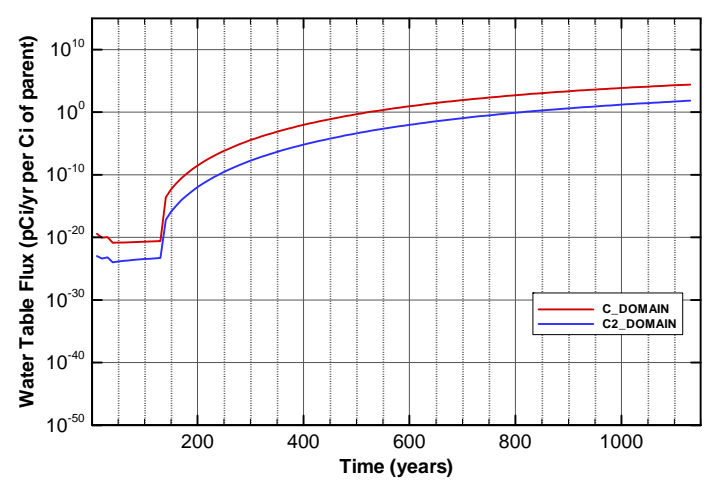

Figure A-1250. Flux at water table for Case01n11_off U-233 


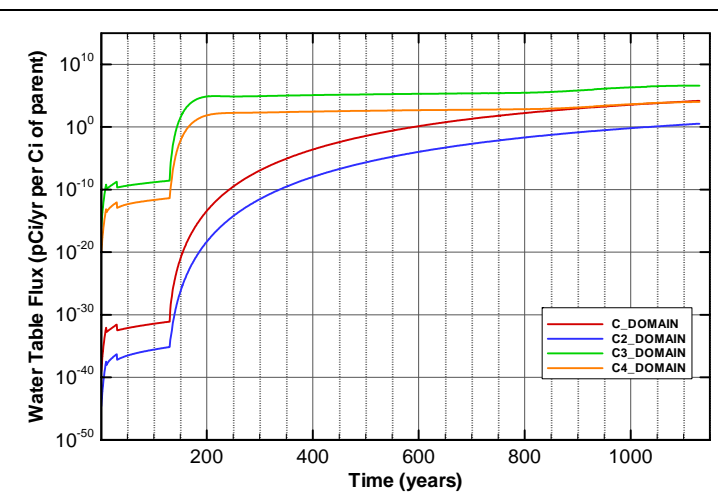

Figure A-1251. Flux at water table for Case01n11_off U-234

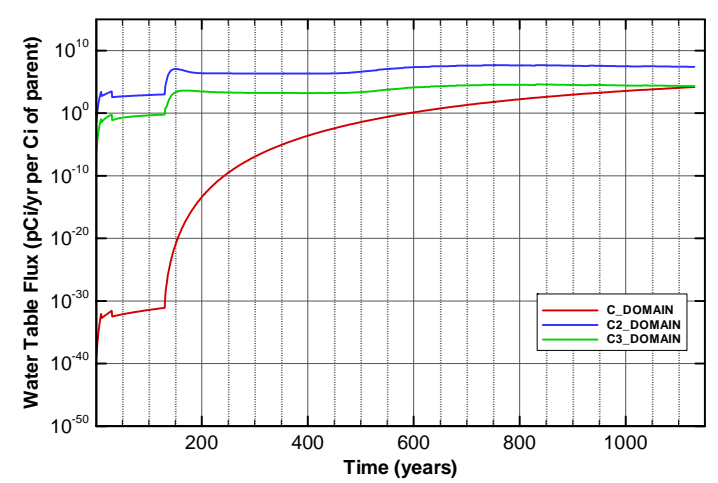

Figure A-1253. Flux at water table for Case01n11_off U-235

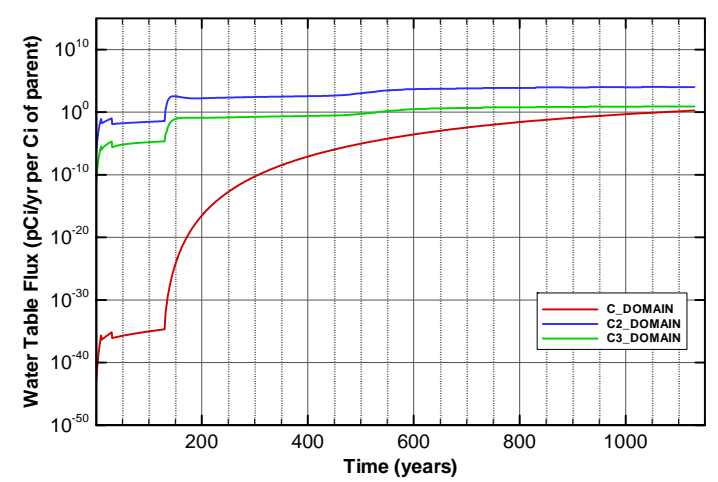

Figure A-1255. Flux at water table for Case01n11_off U-235_Paducah.Cask

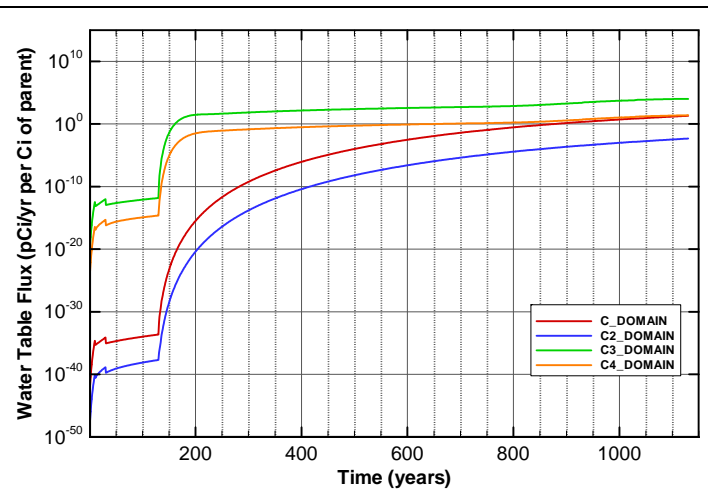

Figure A-1252. Flux at water table for Case01n11_off U-234_Mglass

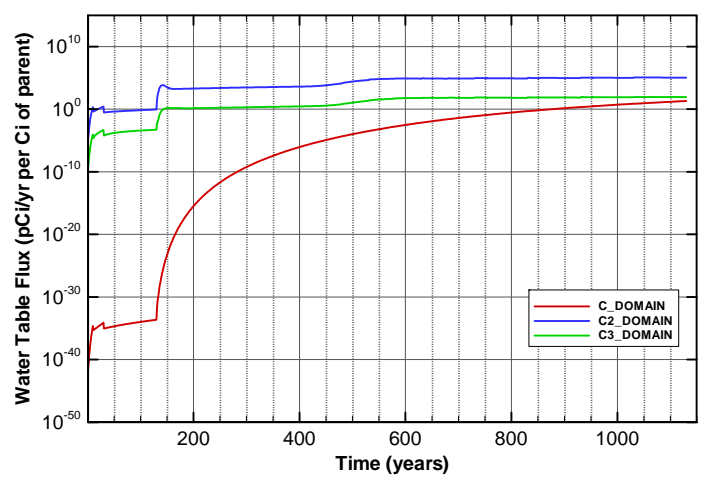

Figure A-1254. Flux at water table for Case01n11_off U-235_Mglass

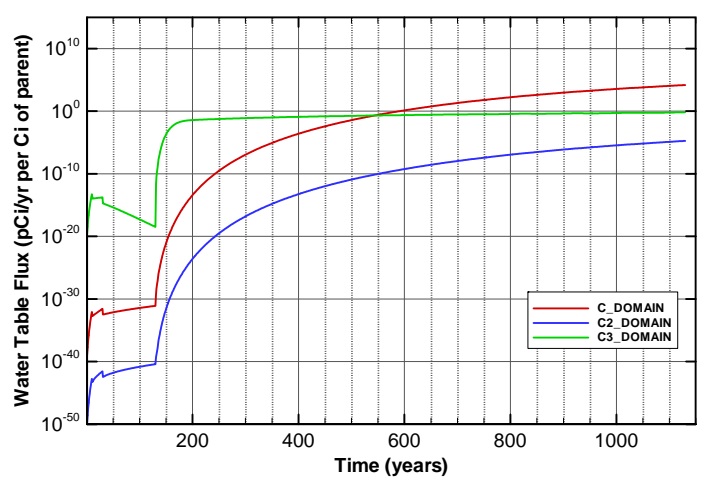

Figure A-1256. Flux at water table for Case01n11_off U-236 


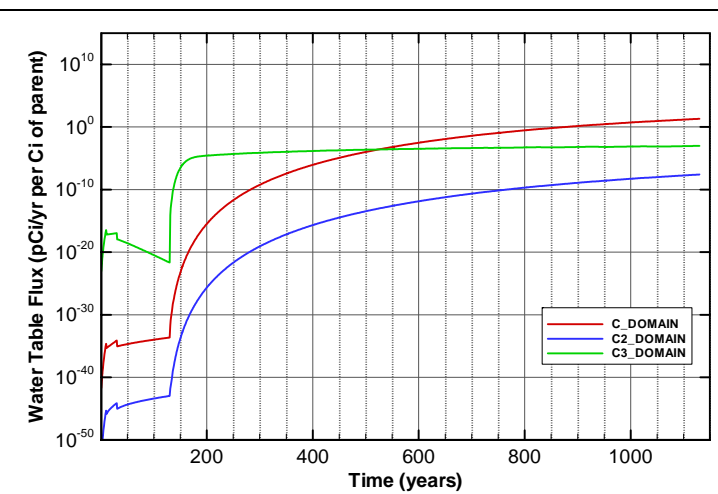

Figure A-1257. Flux at water table for Case01n11_off U-236_Mglass

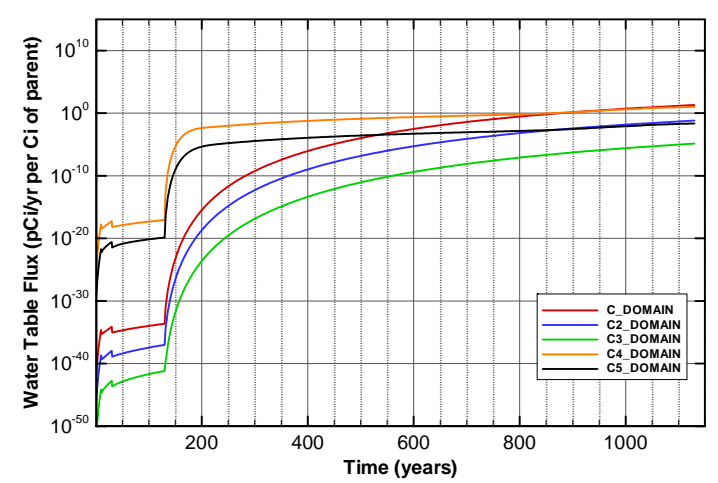

Figure A-1259. Flux at water table for Case01n11_off U-238_Mglass

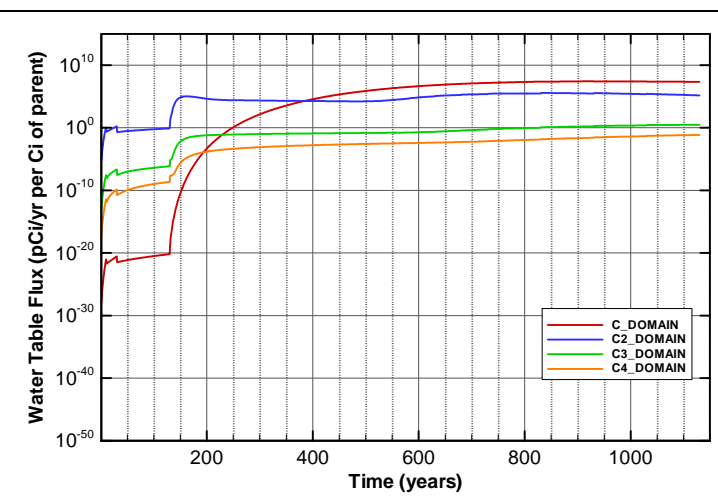

Figure A-1261. Flux at water table for Case01n11_on Am-241

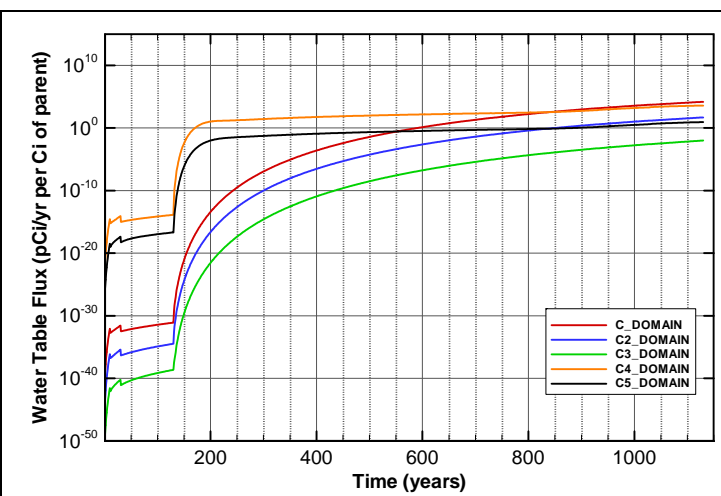

Figure A-1258. Flux at water table for Case01n11_off U-238

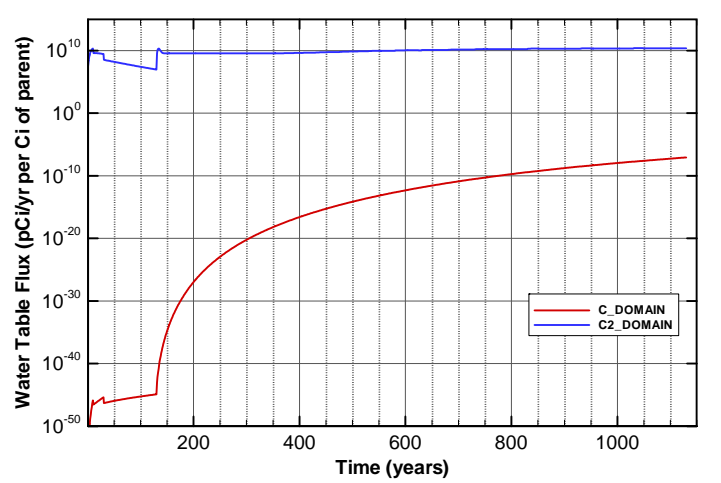

Figure A-1260. Flux at water table for Case01n11_off Zr-93

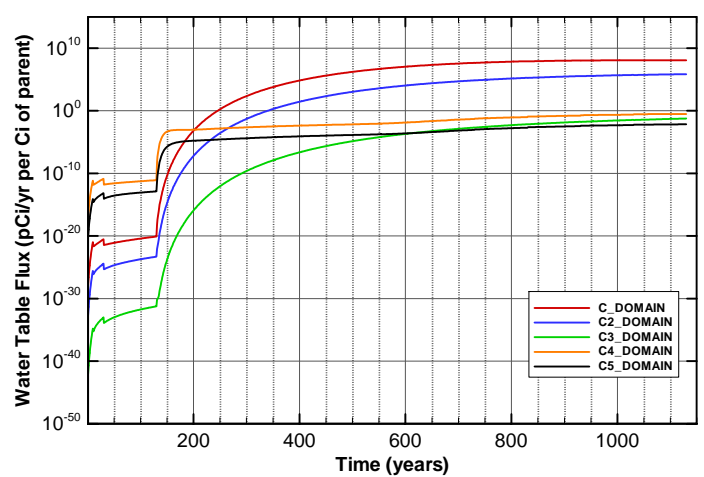

Figure A-1262. Flux at water table for Case01n11_on Am-243 
SRNL-STI-2008-00397, REVISION 0

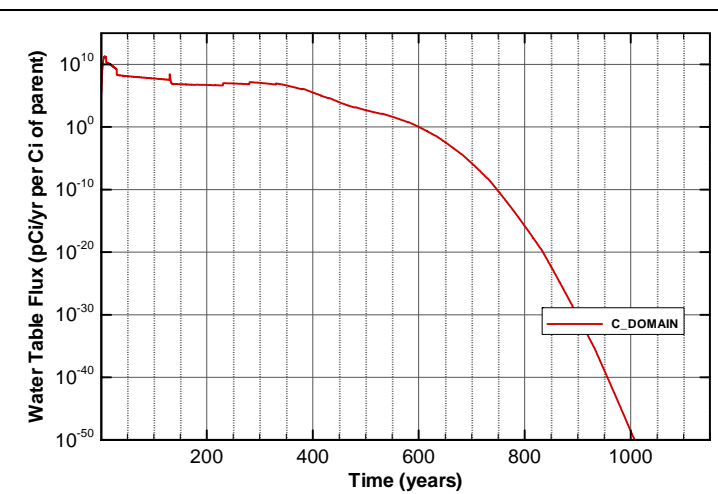

Figure A-1263. Flux at water table for Case01n11_on C-14

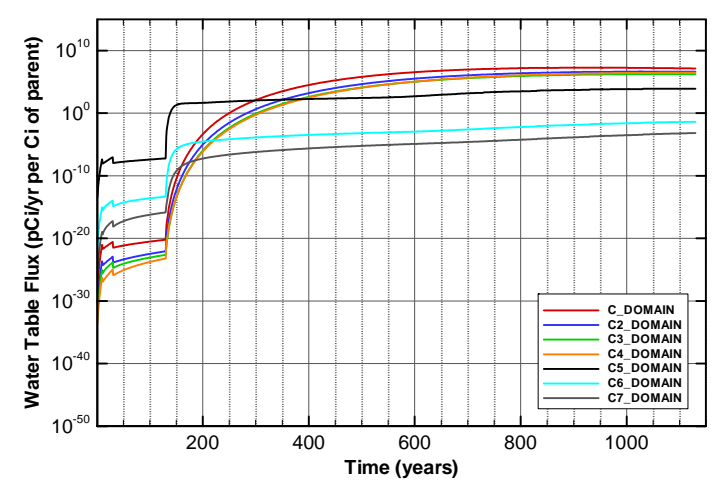

Figure A-1265. Flux at water table for Case01n11_on Cf-249

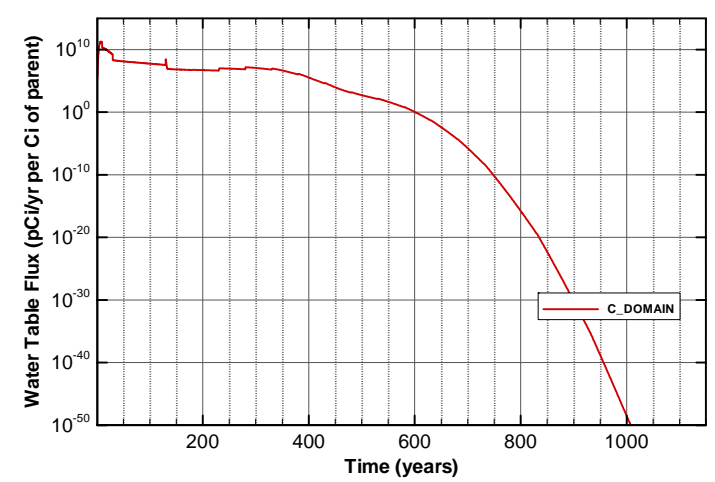

Figure A-1267. Flux at water table for Case01n11_on Cl-36

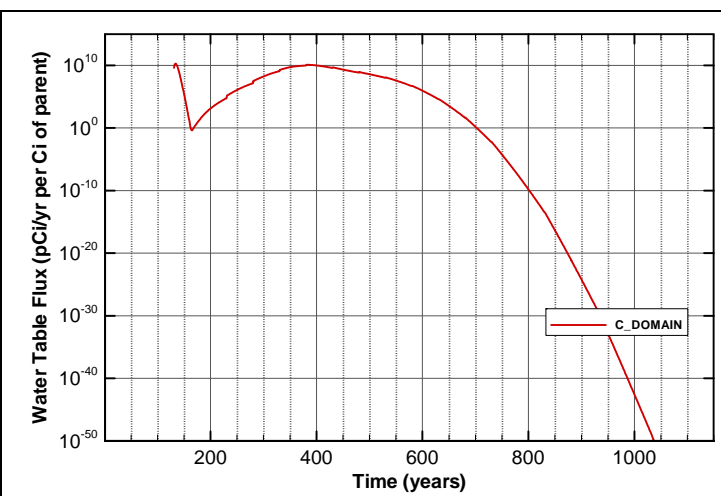

Figure A-1264. Flux at water table for Case01n11_on C-14_NR.Pump

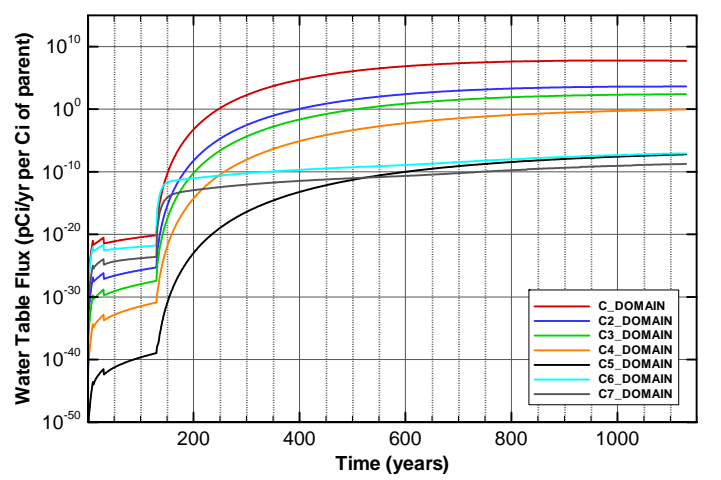

Figure A-1266. Flux at water table for Case01n11_on Cf-251

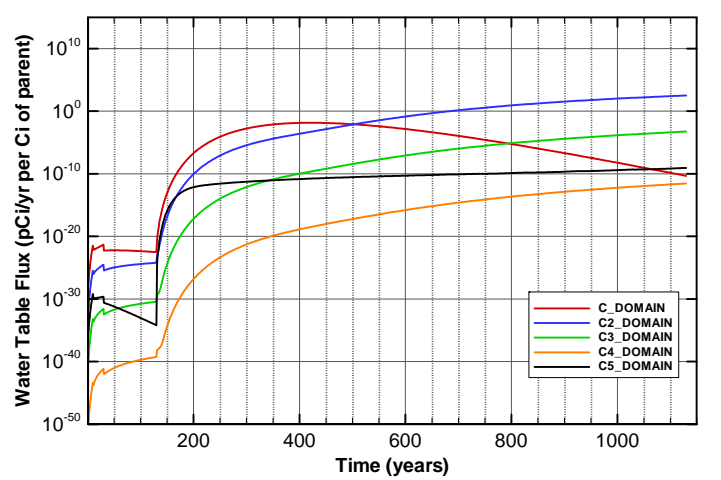

Figure A-1268. Flux at water table for Case01n11_on Cm-244 


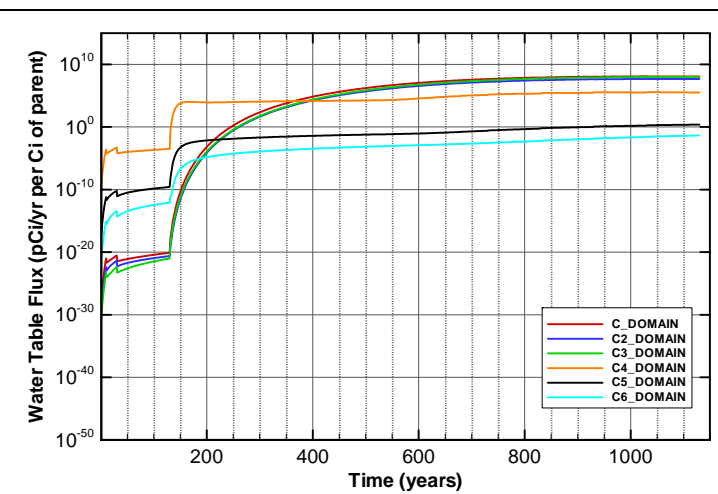

Figure A-1269. Flux at water table for Case01n11_on Cm-245

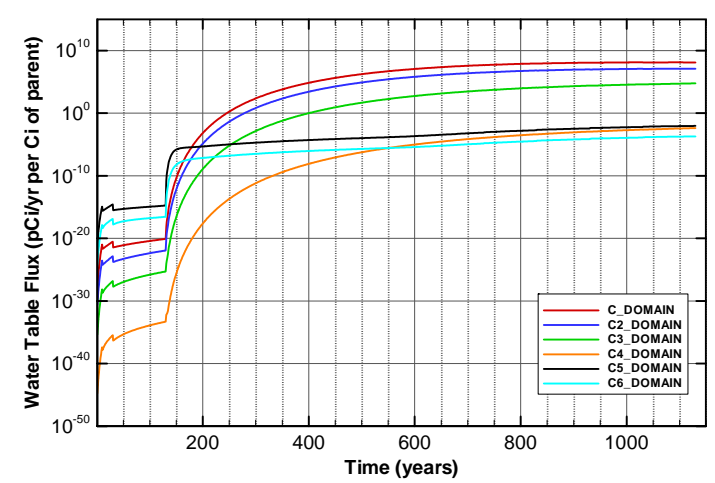

Figure A-1271. Flux at water table for Case01n11_on Cm-247

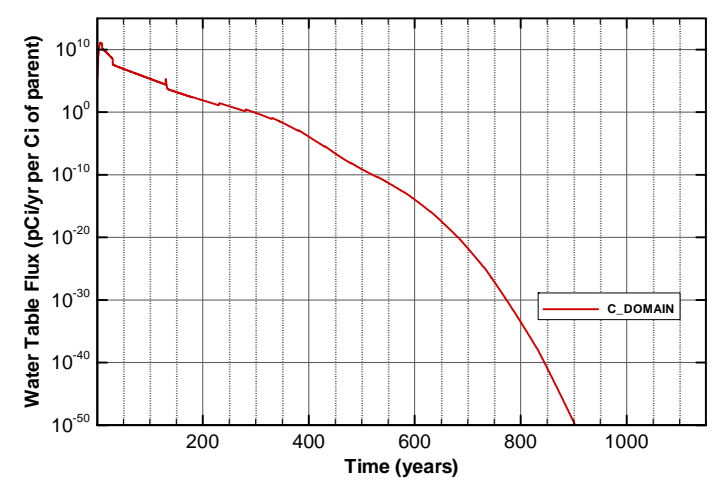

Figure A-1273. Flux at water table for Case01n11_on H-3

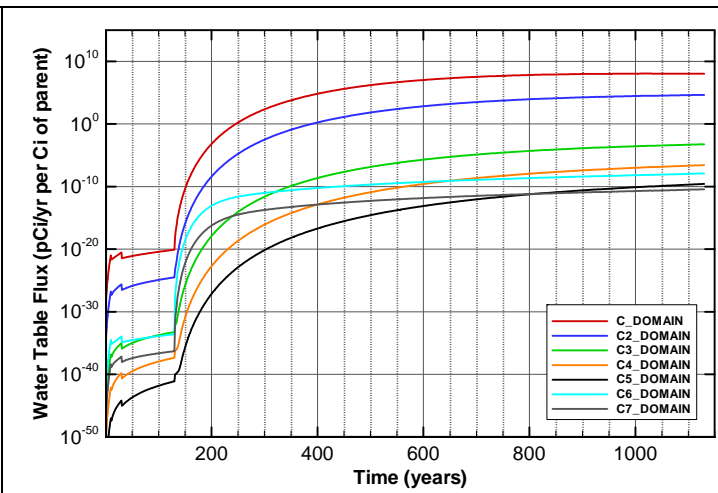

Figure A-1270. Flux at water table for Case01n11_on Cm-246

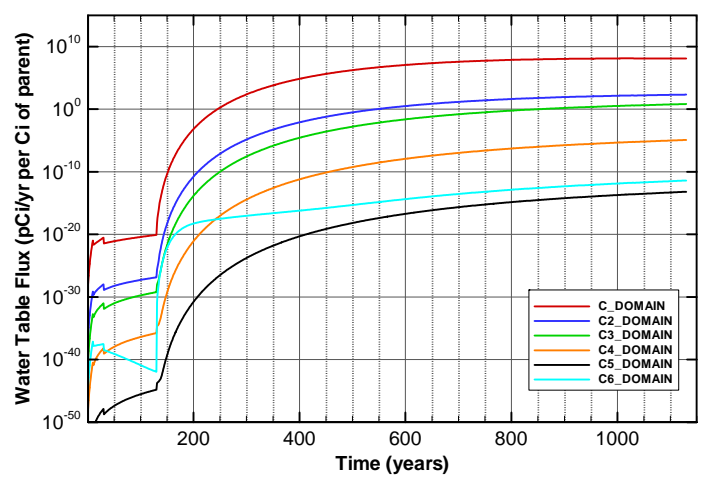

Figure A-1272. Flux at water table for Case01n11_on Cm-248

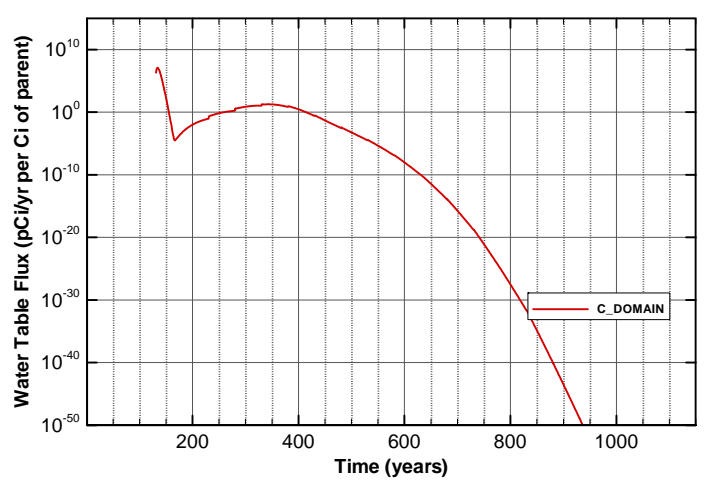

Figure A-1274. Flux at water table for Case01n11_on H-3_ETF.Carbon 


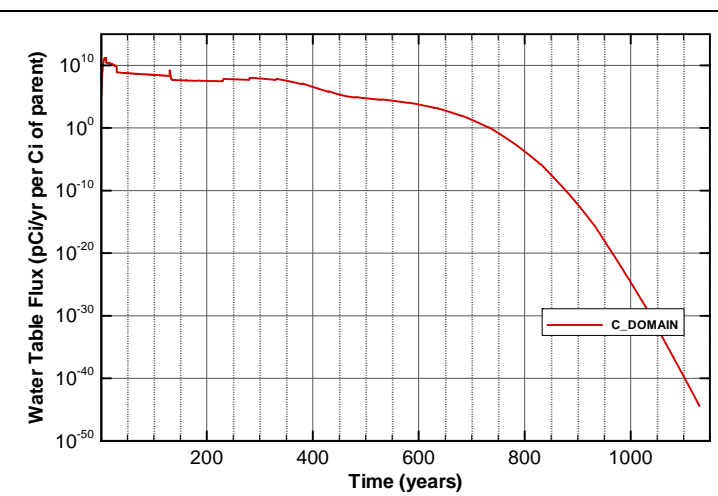

Figure A-1275. Flux at water table for Case01n11_on I-129

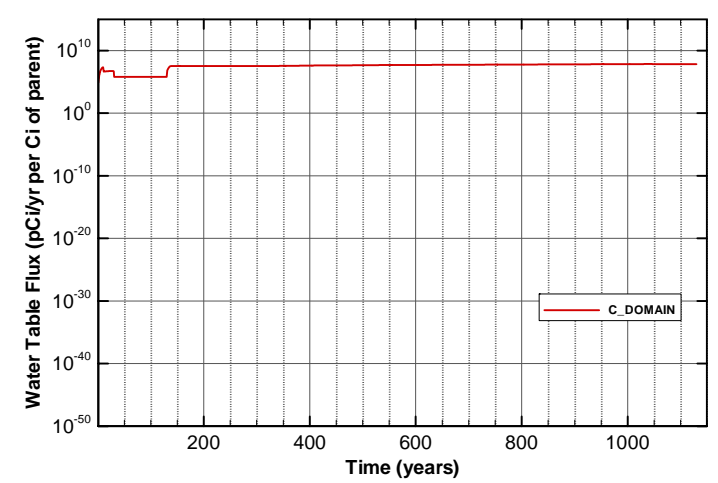

Figure A-1277. Flux at water table for Case01n11_on I-129_ETF.GT.73

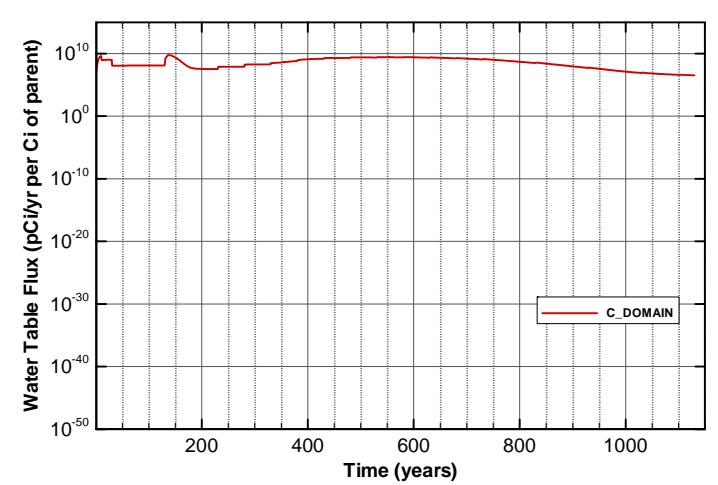

Figure A-1279. Flux at water table for Case01n11_on I-129_F.CG.8

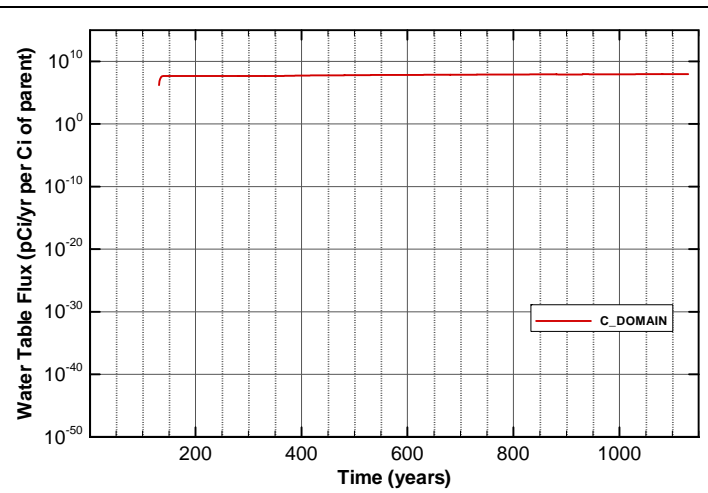

Figure A-1276. Flux at water table for Case01n11_on I-129_ETF.Carbon

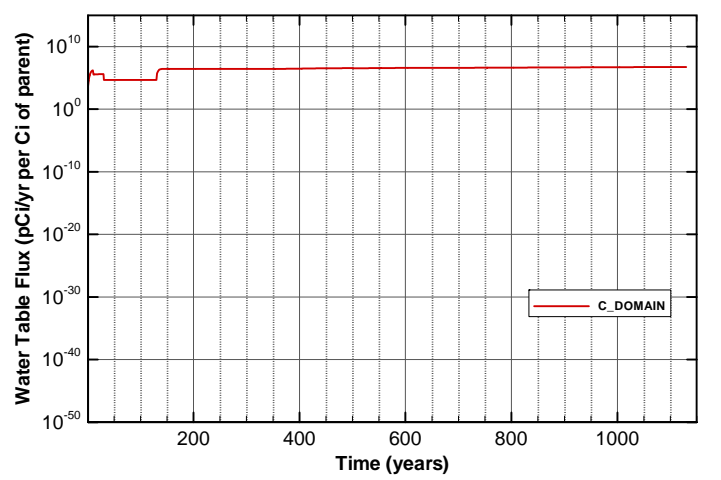

Figure A-1278. Flux at water table for Case01n11_on I-129_F.Carbon

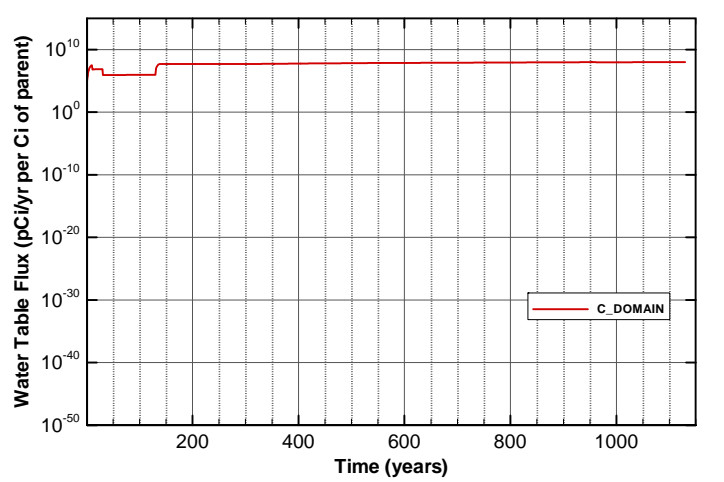

Figure A-1280. Flux at water table for Case01n11_on I-129_F.Dowex.21K 


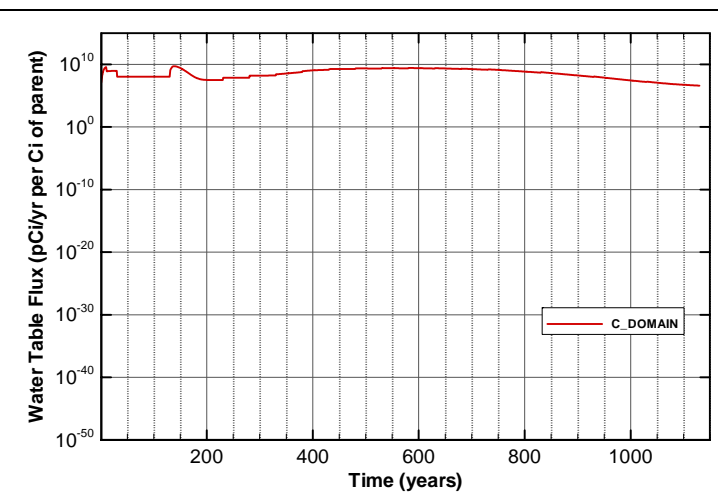

Figure A-1281. Flux at water table for Case01n11_on I-129_F.Filtercake

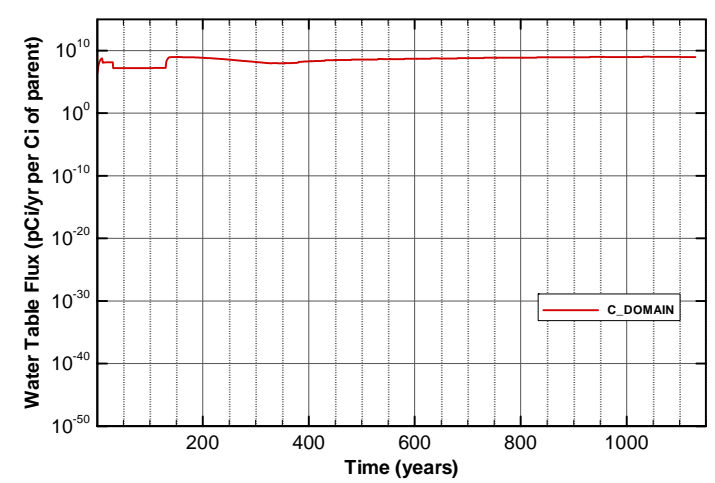

Figure A-1283. Flux at water table for Case01n11_on I-129_H.CG.8

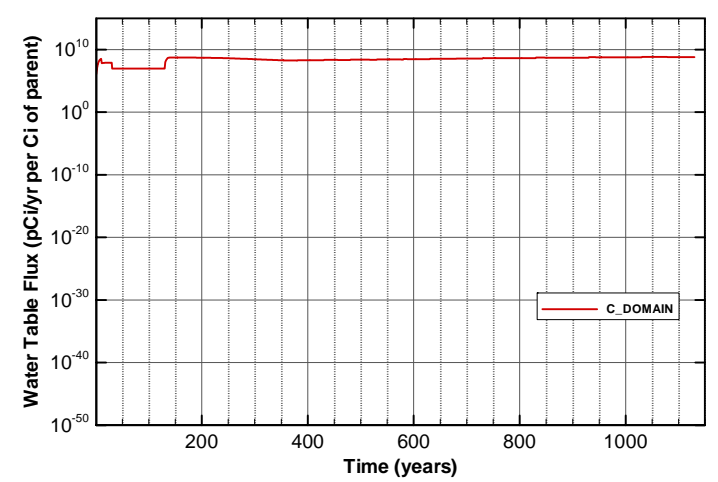

Figure A-1285. Flux at water table for Case01n11_on I-129_H.Filtercake

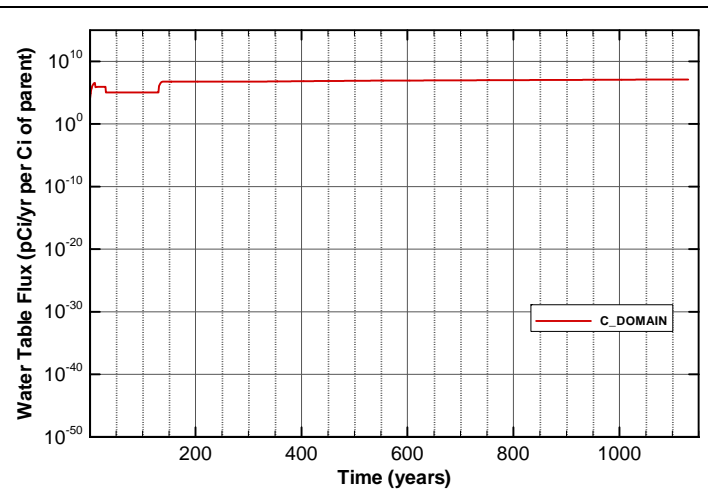

Figure A-1282. Flux at water table for Case01n11_on I-129_H.Carbon

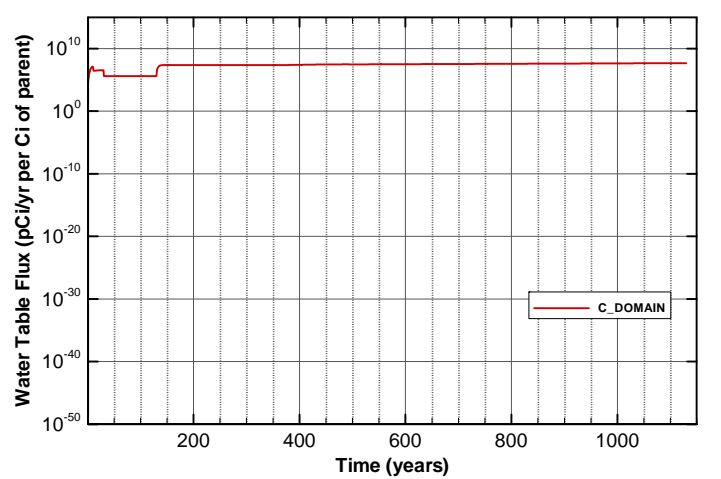

Figure A-1284. Flux at water table for Case01n11_on I-129_H.Dowex.21K

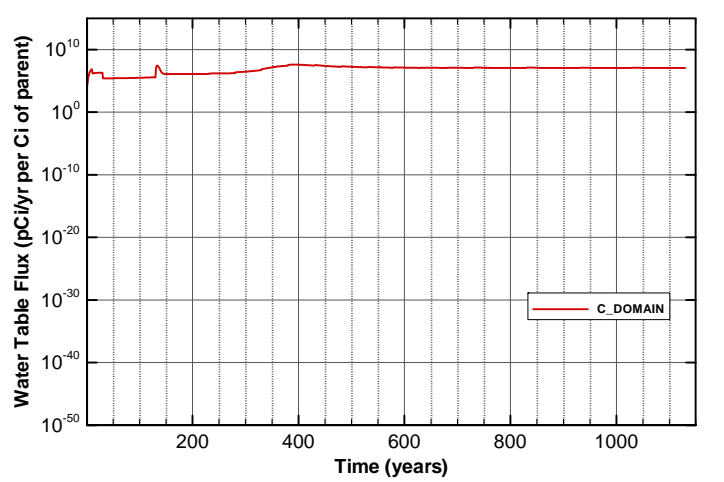

Figure A-1286. Flux at water table for Case01n11_on I-129_Mk50A 


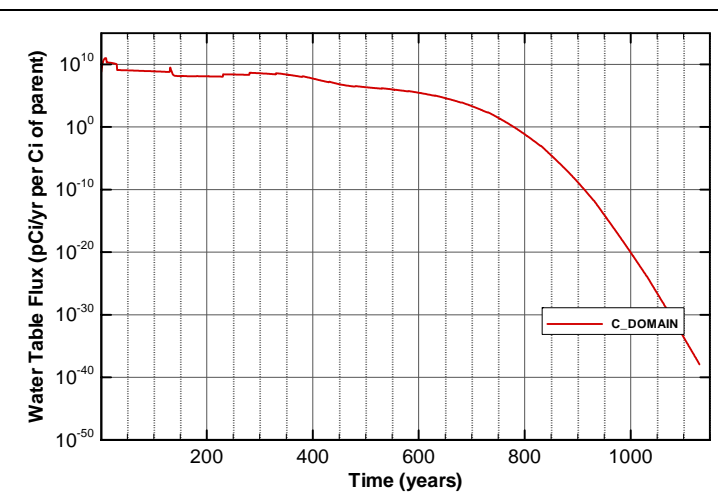

Figure A-1287. Flux at water table for Case01n11_on K-40

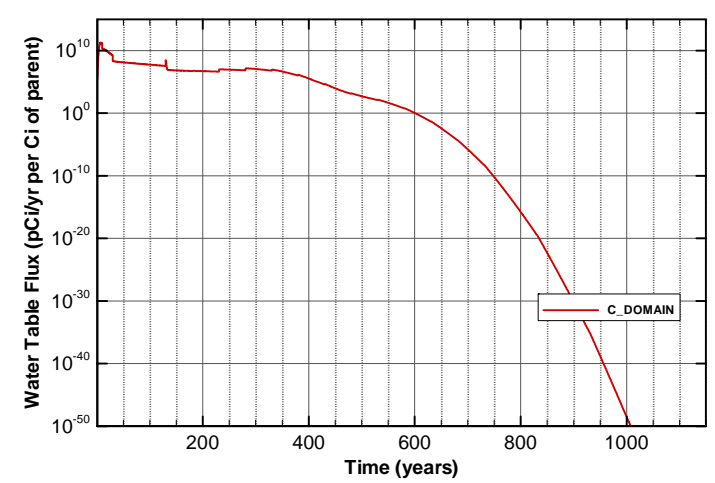

Figure A-1289. Flux at water table for Case01n11_on Nb-94

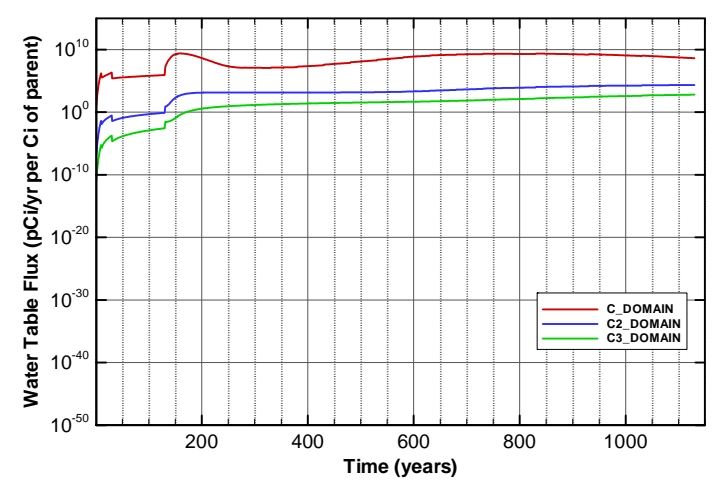

Figure A-1291. Flux at water table for Case01n11_on Np-237

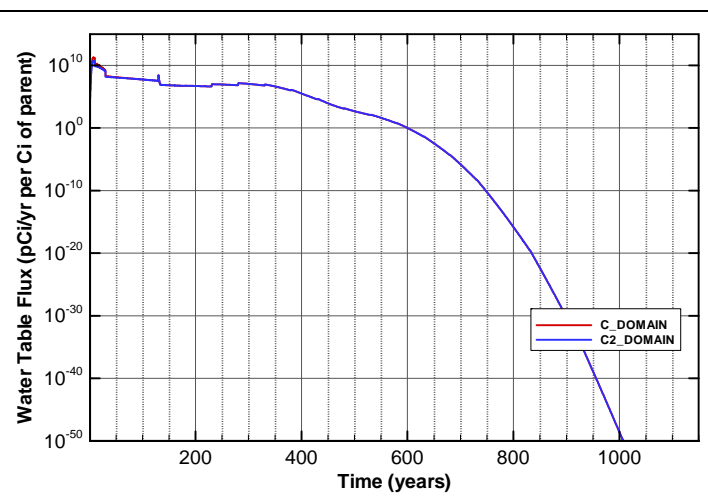

Figure A-1288. Flux at water table for Case01n11_on Mo-93

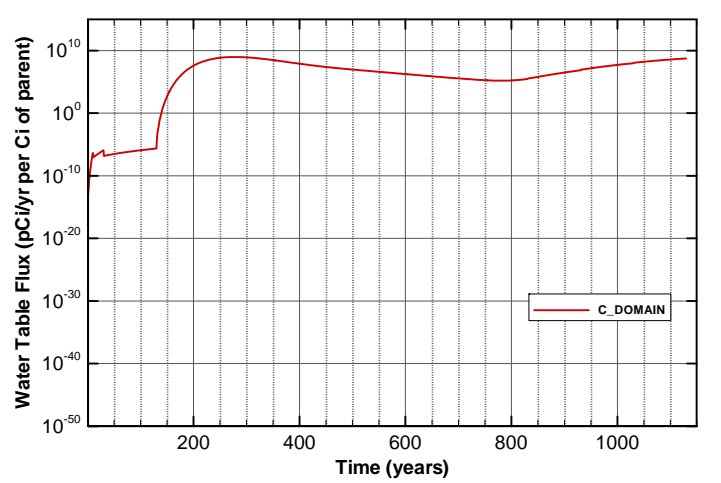

Figure A-1290. Flux at water table for Case01n11_on Ni-59

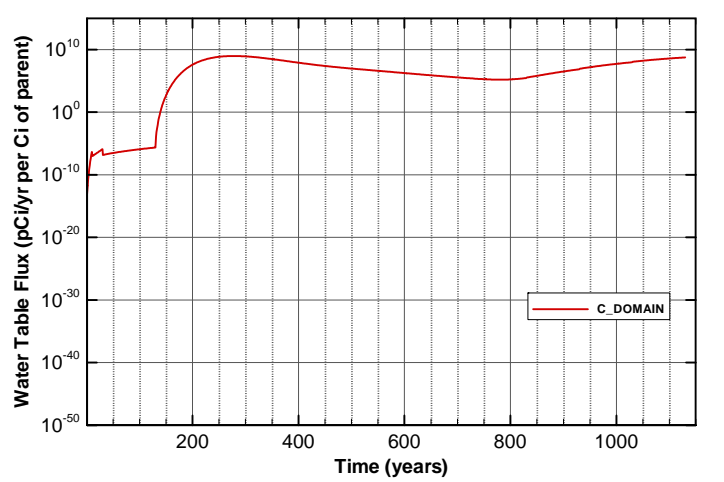

Figure A-1292. Flux at water table for Case01n11_on Pd-107 
SRNL-STI-2008-00397, REVISION 0
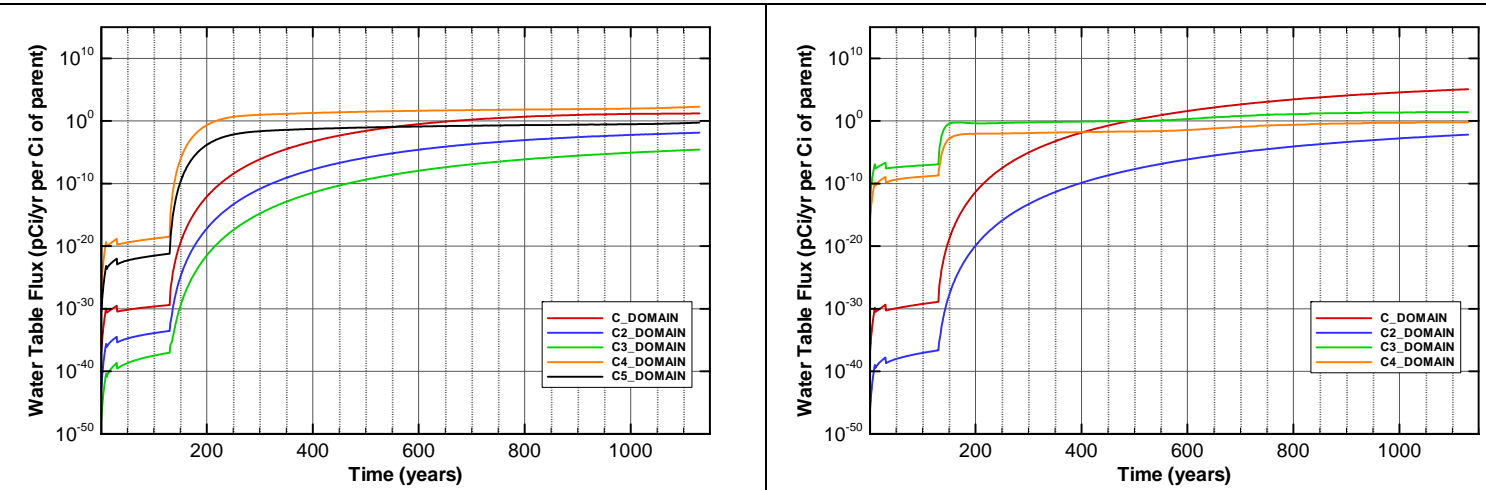

Figure A-1293. Flux at water table for Case01n11_on Pu-238

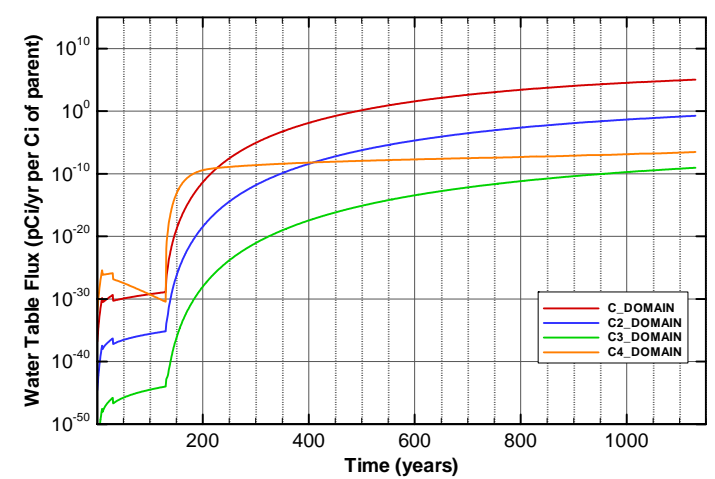

Figure A-1295. Flux at water table for Case01n11_on Pu-240

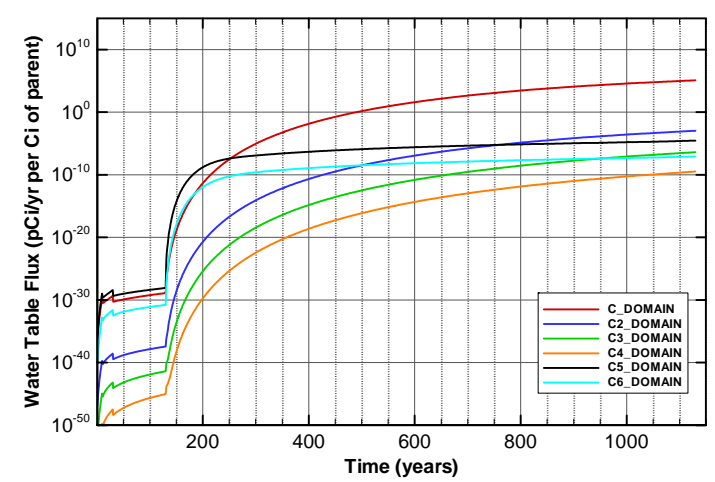

Figure A-1297. Flux at water table for Case01n11_on Pu-242

Figure A-1294. Flux at water table for Case01n11_on Pu-239

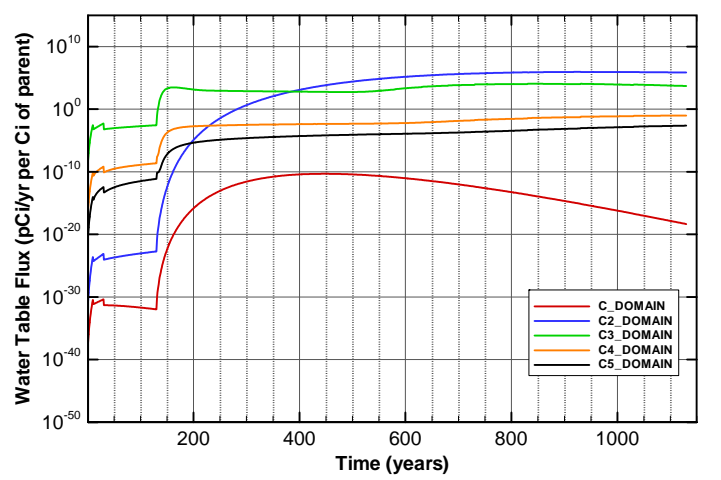

Figure A-1296. Flux at water table for Case01n11_on Pu-241

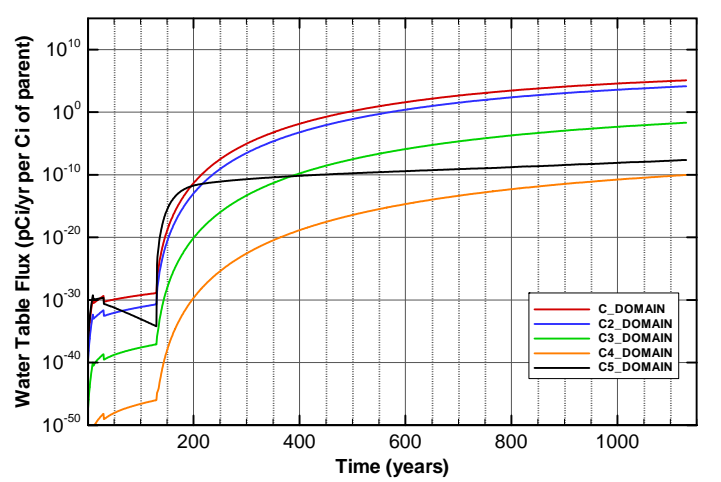

Figure A-1298. Flux at water table for Case01n11_on Pu-244 


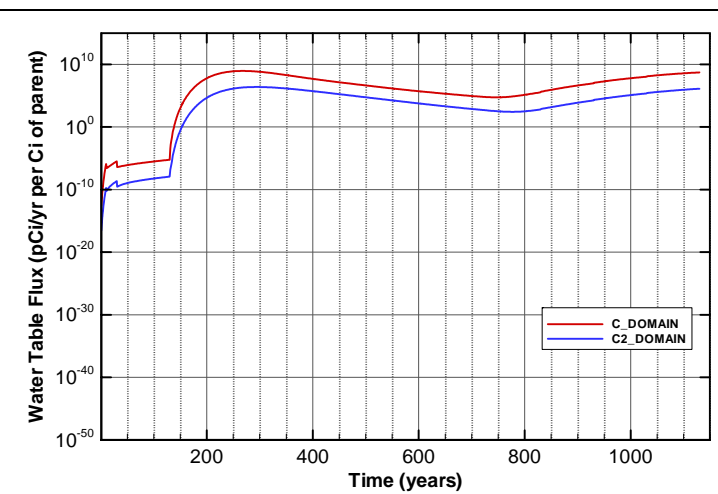

Figure A-1299. Flux at water table for Case01n11_on Ra-226

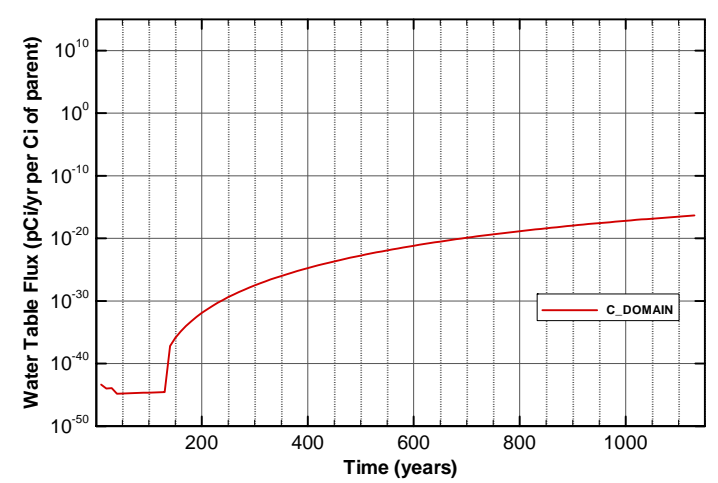

Figure A-1301. Flux at water table for Case01n11_on Sn-126

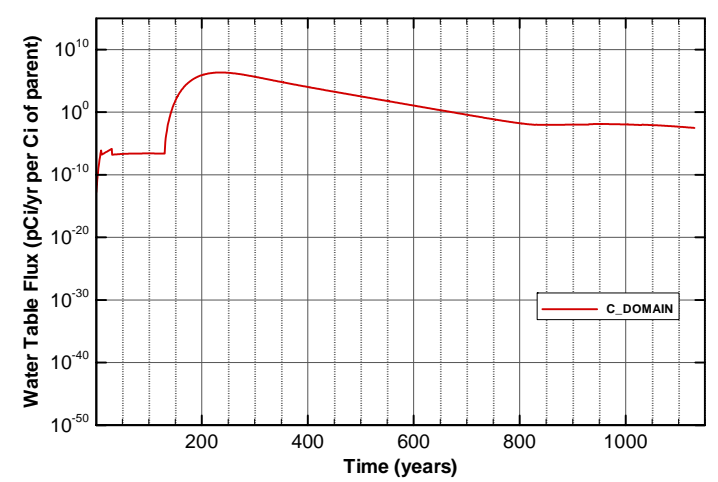

Figure A-1303. Flux at water table for Case01n11_on Sr-90_Cask

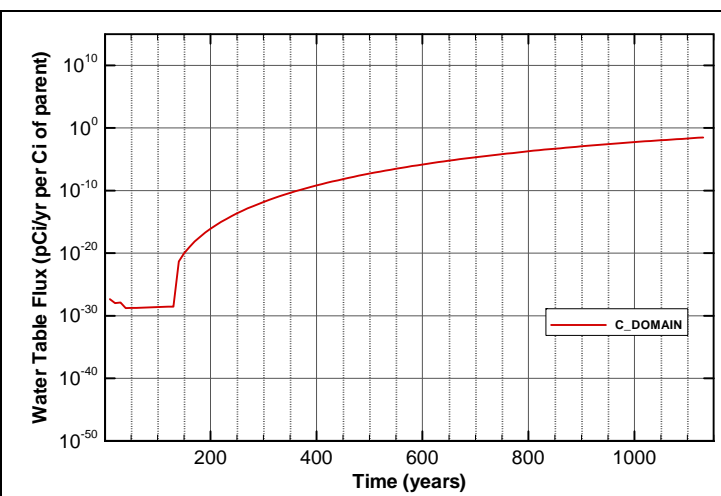

Figure A-1300. Flux at water table for Case01n11_on Se-79

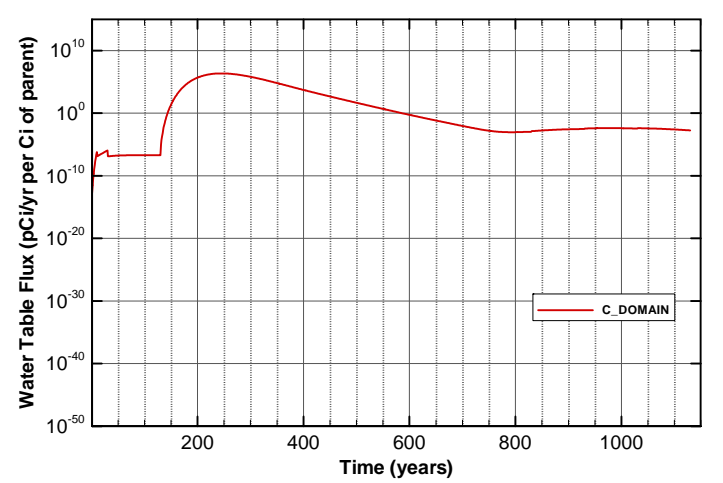

Figure A-1302. Flux at water table for Case01n11_on Sr-90

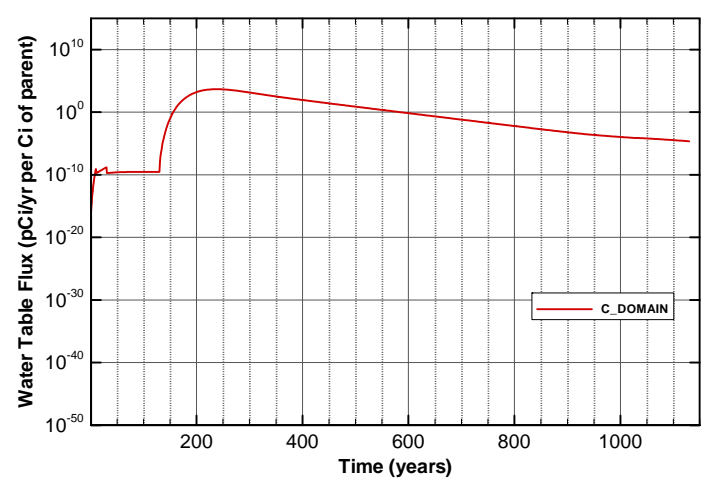

Figure A-1304. Flux at water table for Case01n11_on Sr-90_Mk50A 


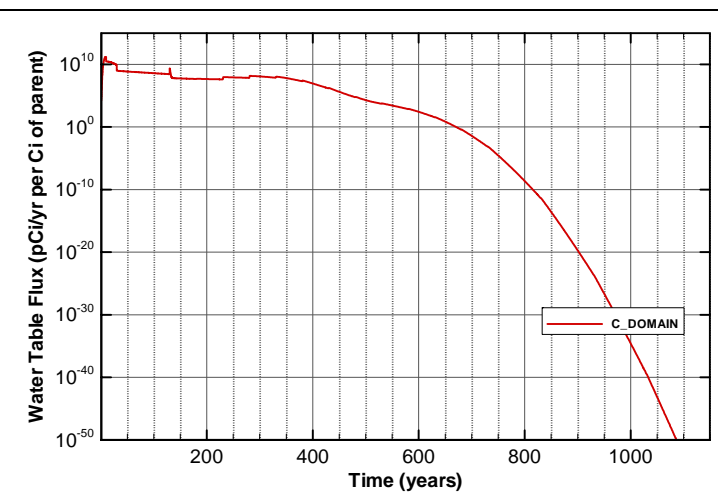

Figure A-1305. Flux at water table for Case01n11_on Tc-99

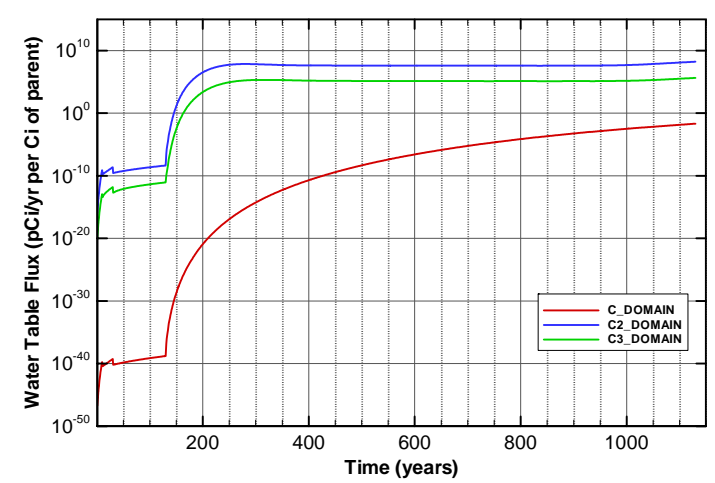

Figure A-1307. Flux at water table for Case01n11_on Th-230

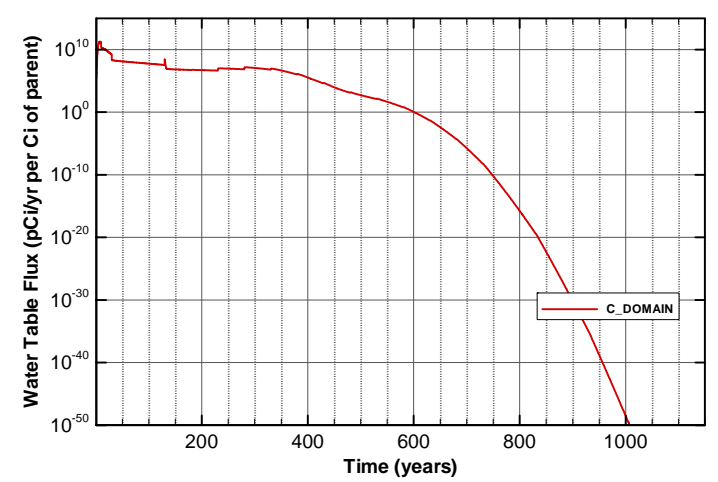

Figure A-1309. Flux at water table for Case01n11_on Tracer

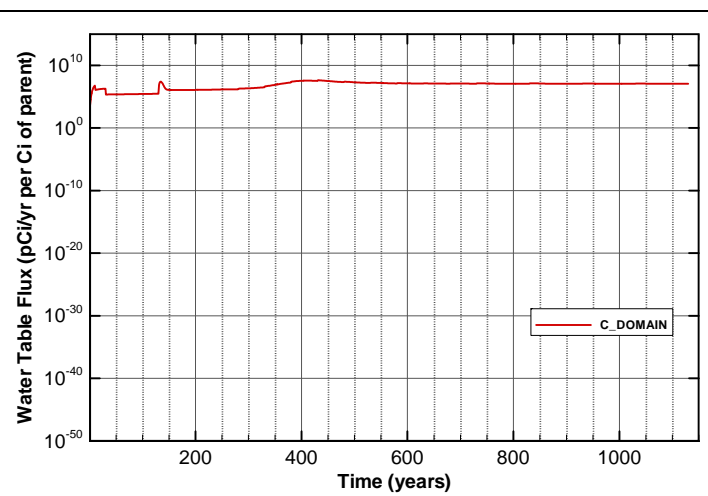

Figure A-1306. Flux at water table for Case01n11_on Tc-99_Mk50A

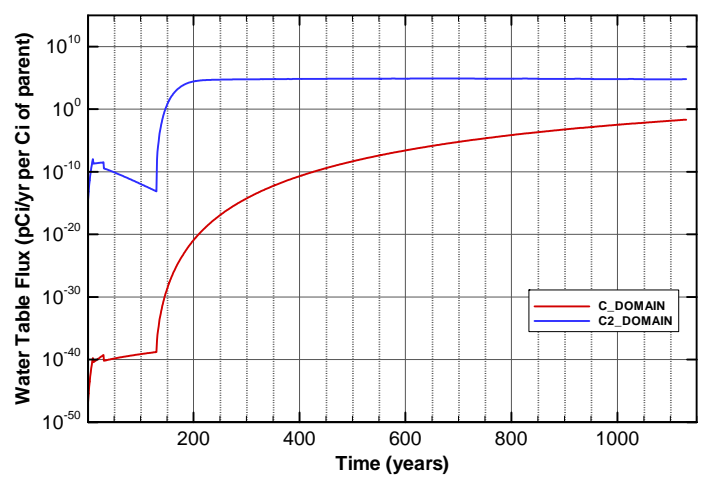

Figure A-1308. Flux at water table for Case01n11_on Th-232

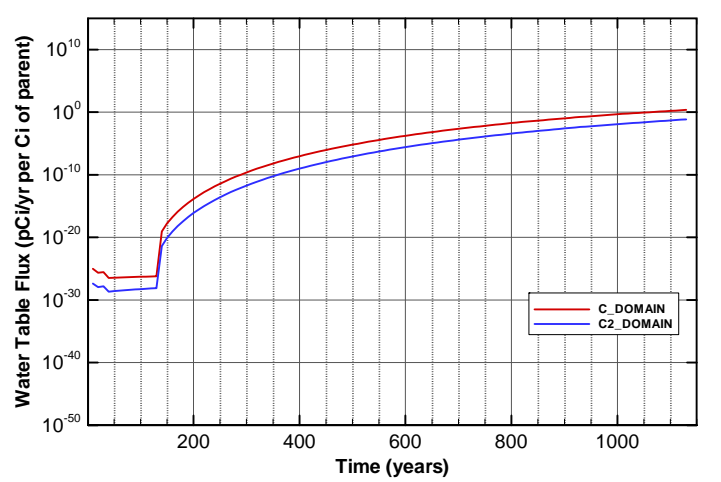

Figure A-1310. Flux at water table for Case01n11_on U-233 


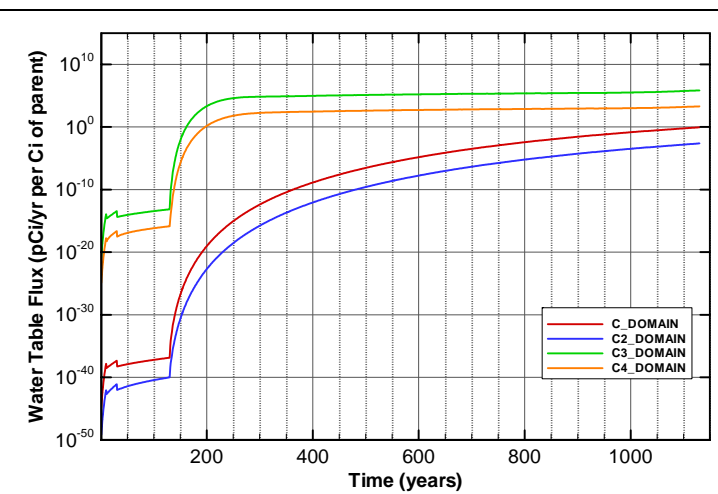

Figure A-1311. Flux at water table for Case01n11_on U-234

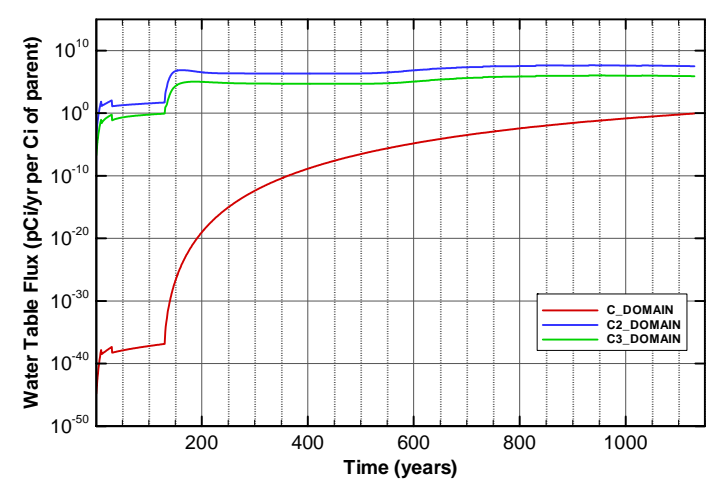

Figure A-1313. Flux at water table for Case01n11_on U-235

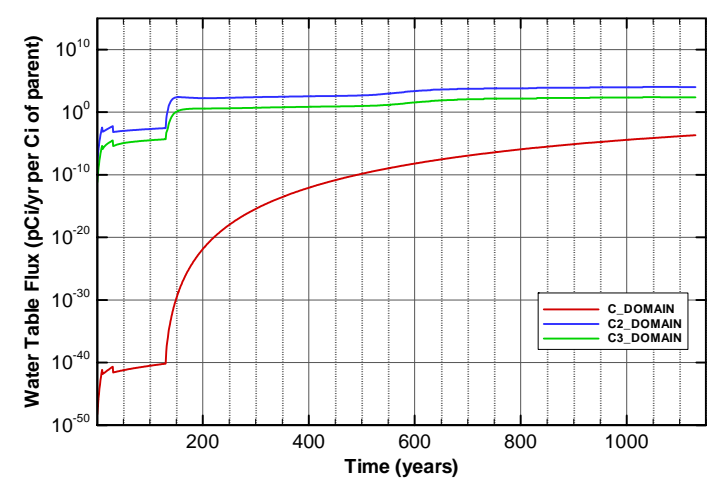

Figure A-1315. Flux at water table for Case01n11_on U-235_Paducah.Cask

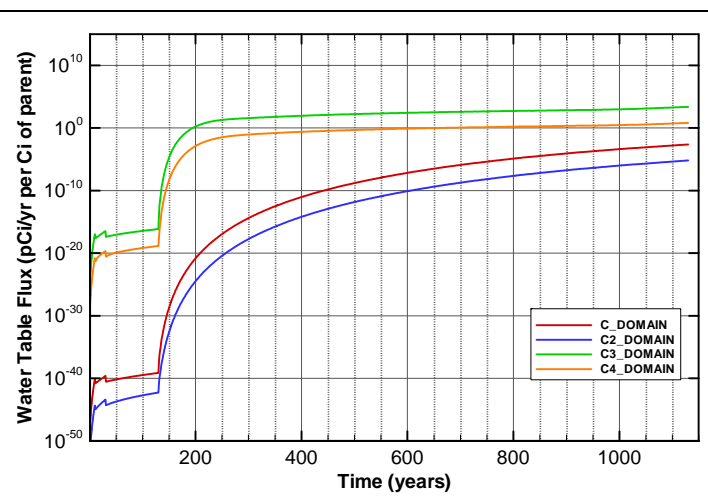

Figure A-1312. Flux at water table for Case01n11_on U-234_Mglass

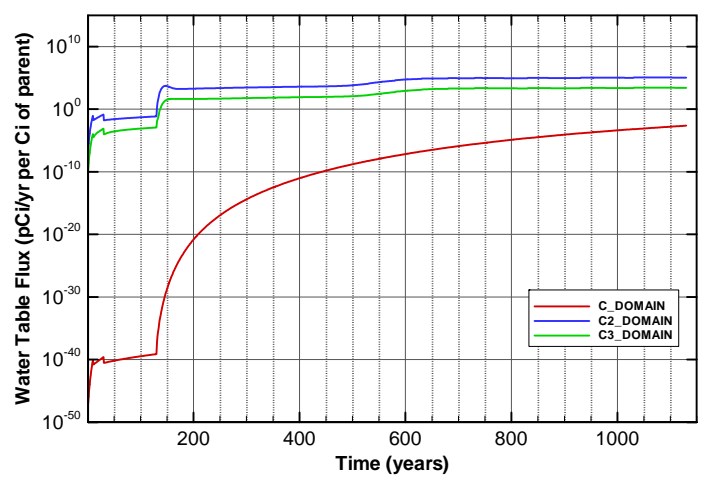

Figure A-1314. Flux at water table for Case01n11_on U-235_Mglass

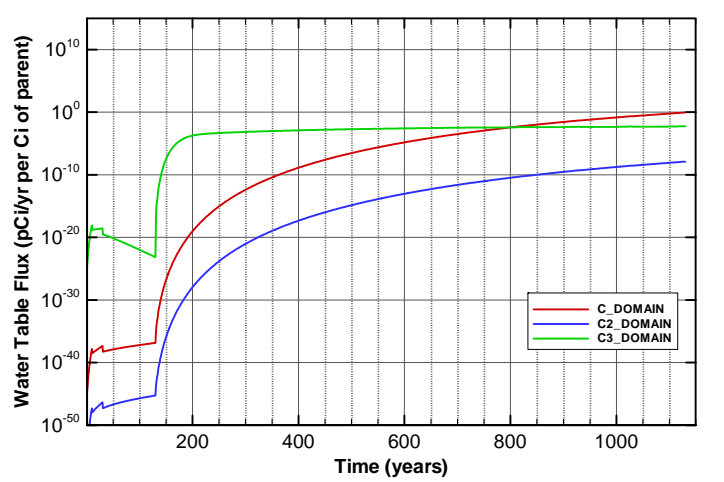

Figure A-1316. Flux at water table for Case01n11_on U-236 


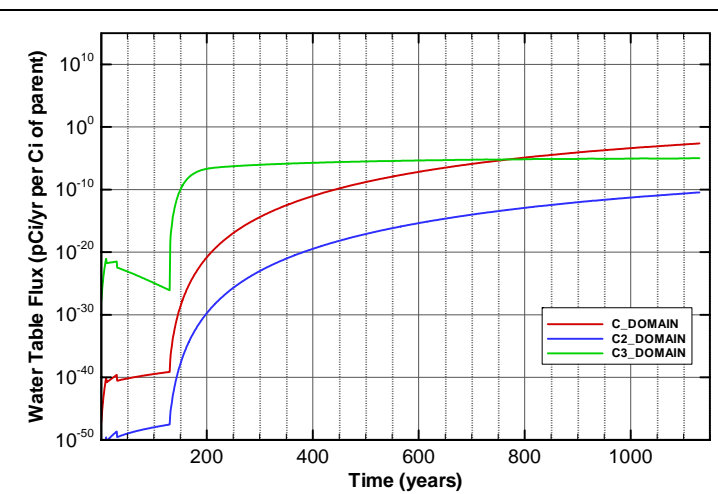

Figure A-1317. Flux at water table for Case01n11_on U-236_Mglass

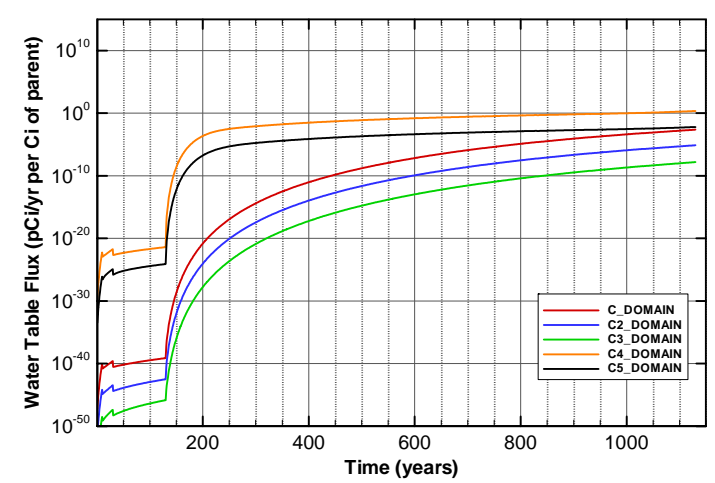

Figure A-1319. Flux at water table for Case01n11_on U-238_Mglass

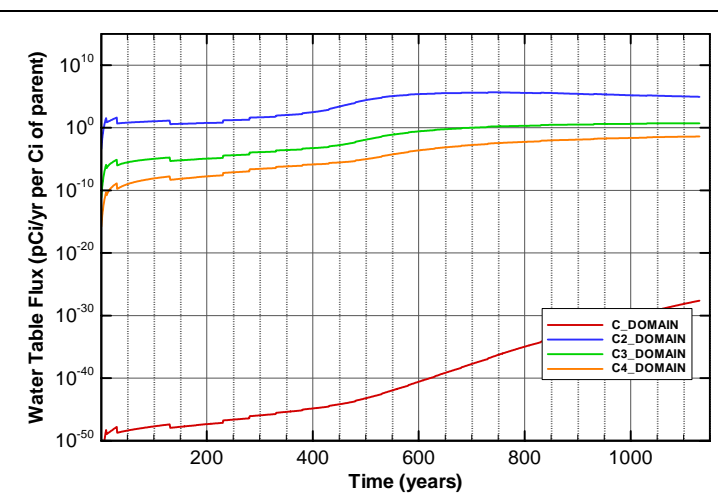

Figure A-1321. Flux at water table for Case01_off Am-241

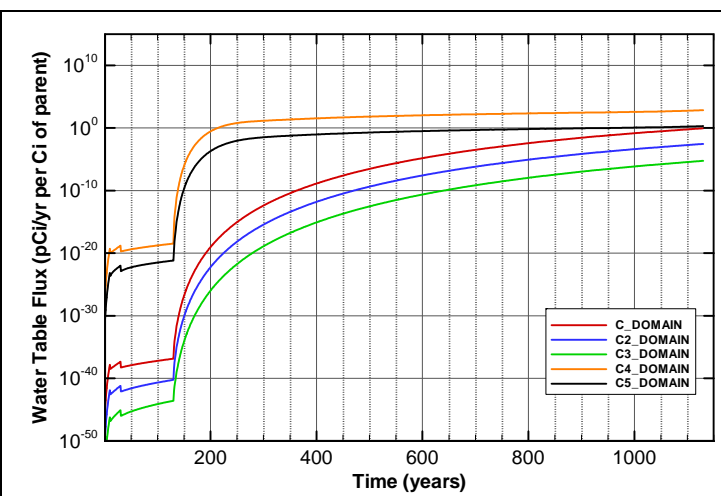

Figure A-1318. Flux at water table for Case01n11_on U-238

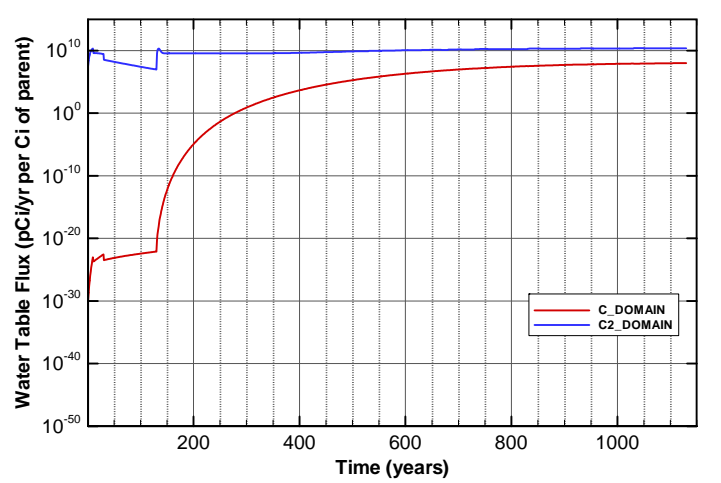

Figure A-1320. Flux at water table for Case01n11_on Zr-93

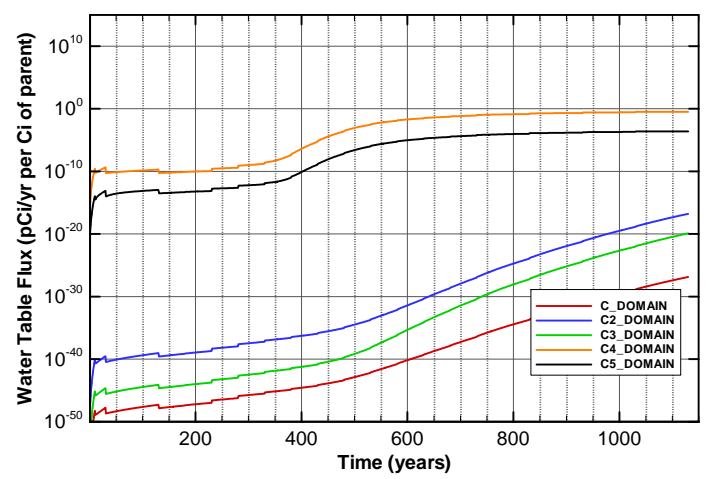

Figure A-1322. Flux at water table for Case01_off Am-243 
SRNL-STI-2008-00397, REVISION 0

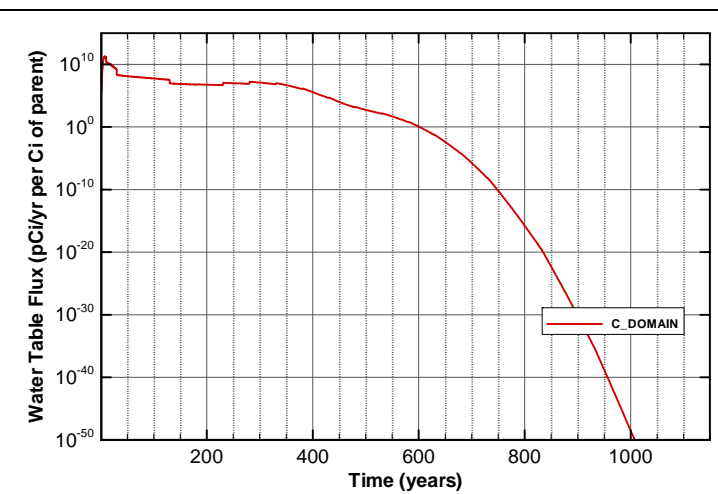

Figure A-1323. Flux at water table for Case01_off C-14

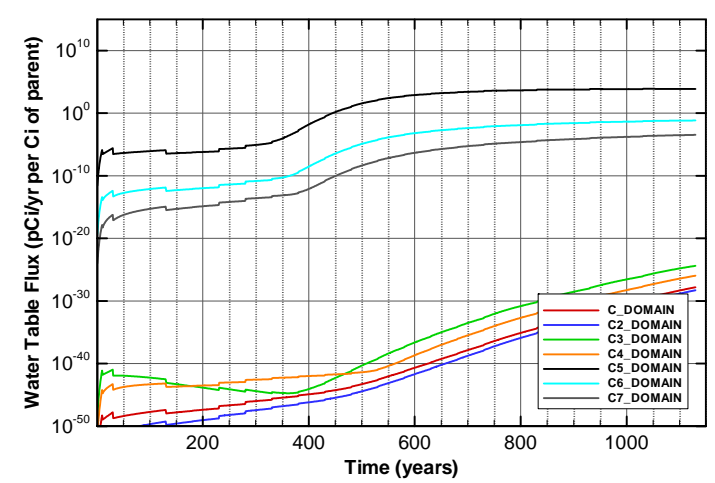

Figure A-1325. Flux at water table for Case01_off Cf-249

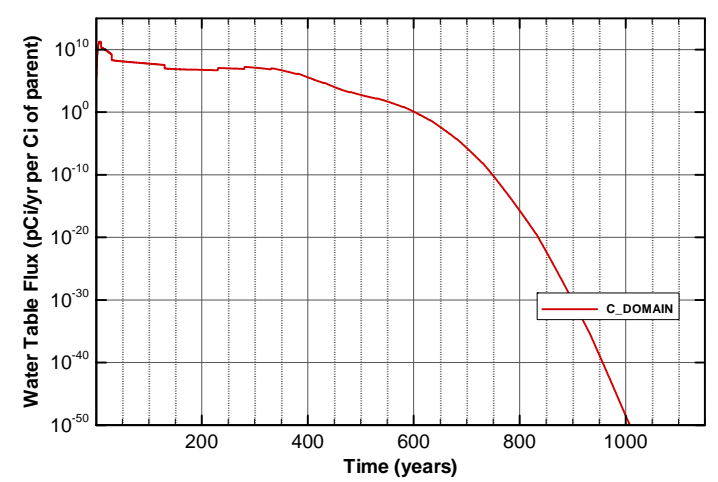

Figure A-1327. Flux at water table for Case01_off Cl-36

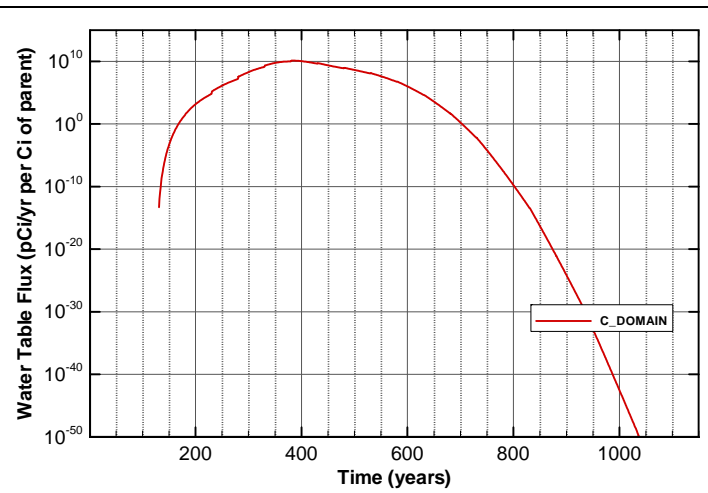

Figure A-1324. Flux at water table for Case01_off C-14_NR.Pump

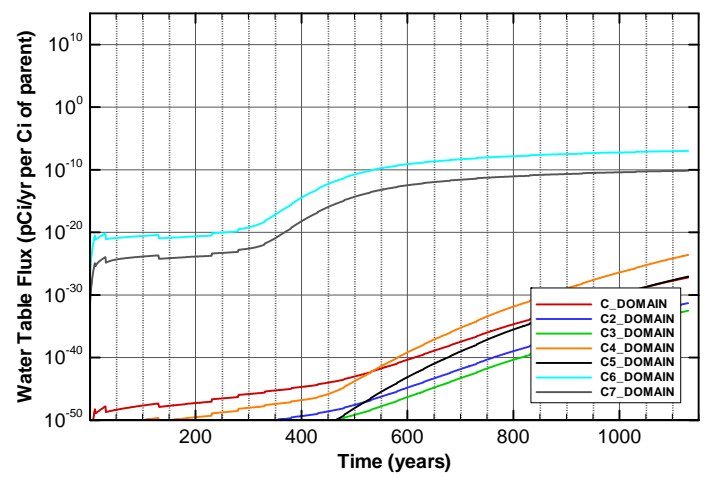

Figure A-1326. Flux at water table for Case01_off Cf-251

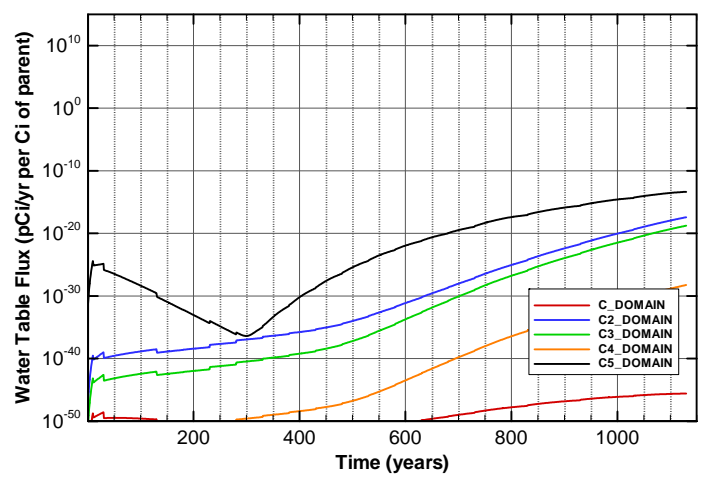

Figure A-1328. Flux at water table for Case01_off Cm-244 
SRNL-STI-2008-00397, REVISION 0

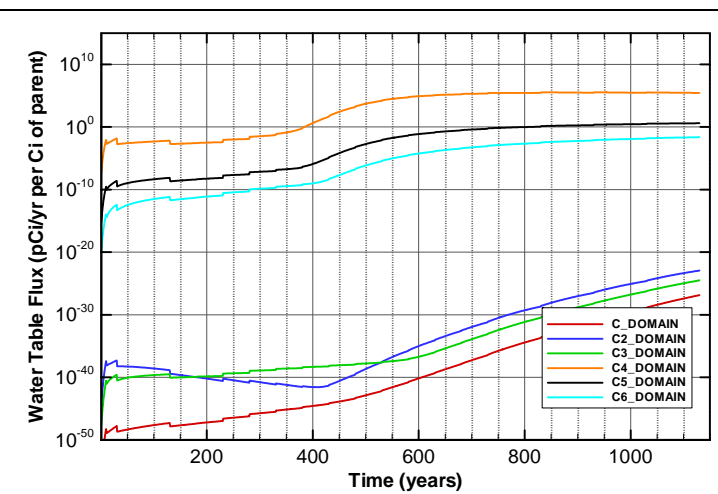

Figure A-1329. Flux at water table for Case01_off Cm-245

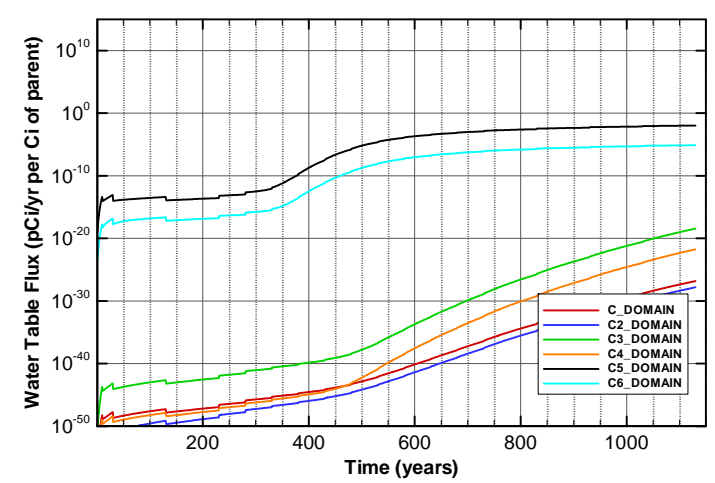

Figure A-1331. Flux at water table for Case01_off Cm-247

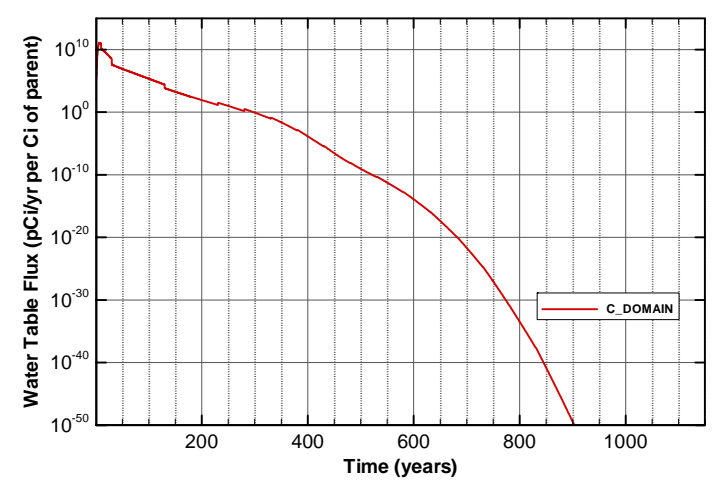

Figure A-1333. Flux at water table for Case01_off H-3

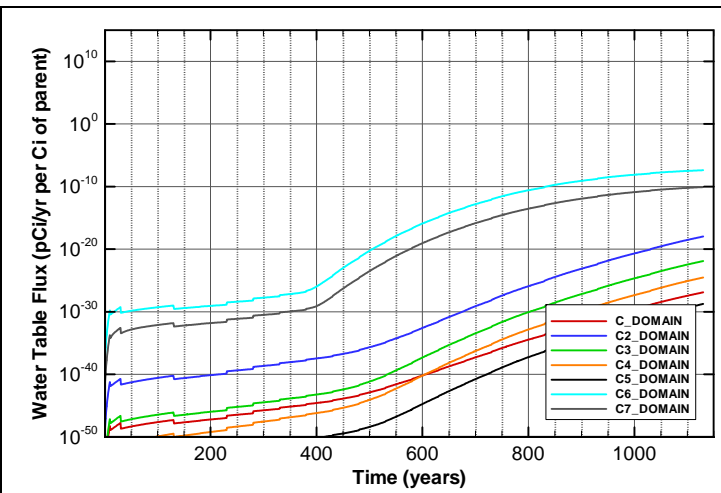

Figure A-1330. Flux at water table for Case01_off Cm-246

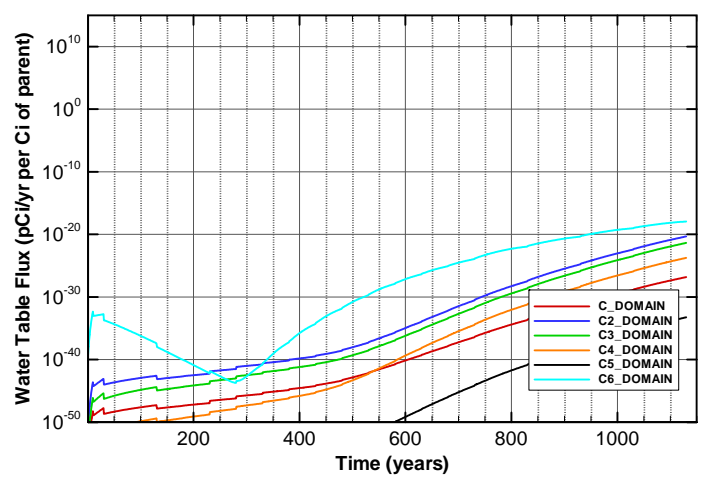

Figure A-1332. Flux at water table for Case01_off Cm-248

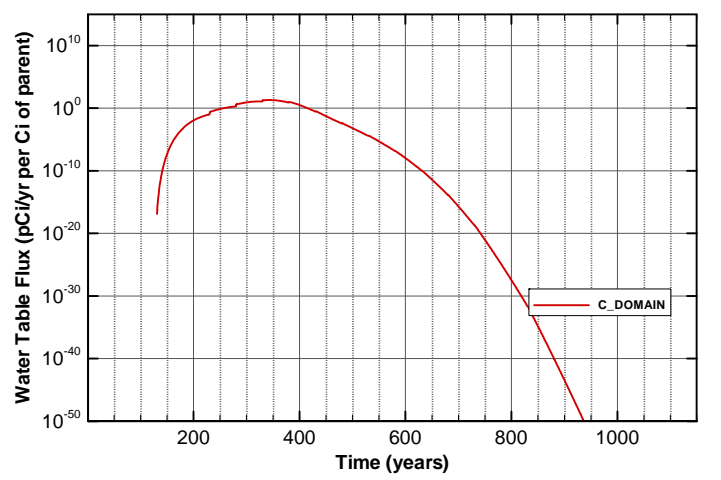

Figure A-1334. Flux at water table for Case01_off H-3_ETF.Carbon 


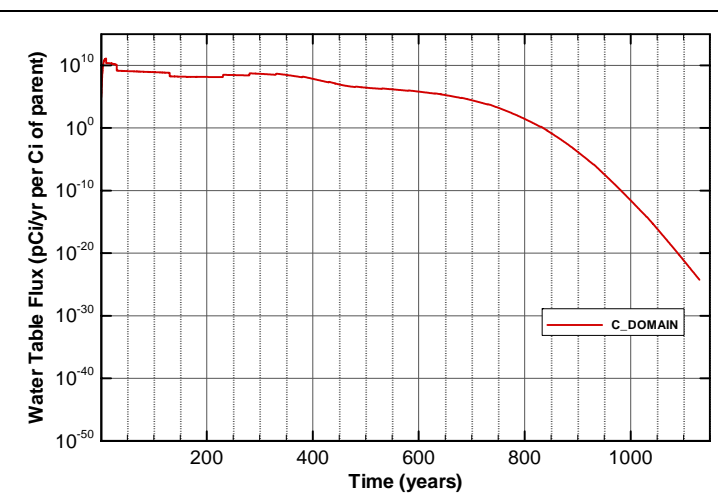

Figure A-1335. Flux at water table for Case01_off I-129

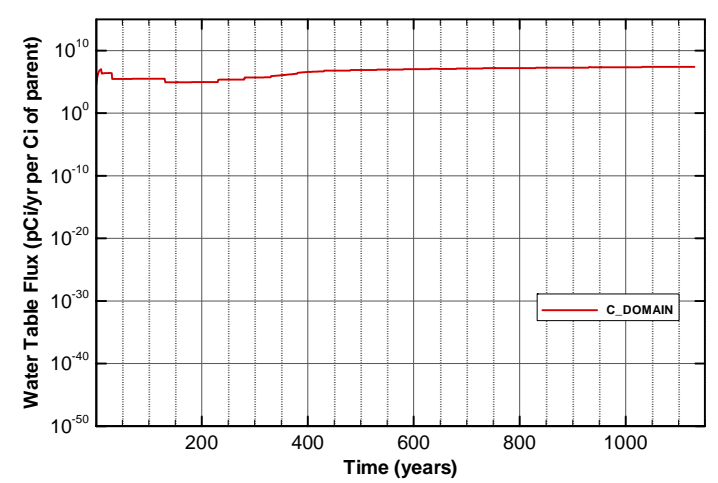

Figure A-1337. Flux at water table for Case01_off I-129_ETF.GT.73

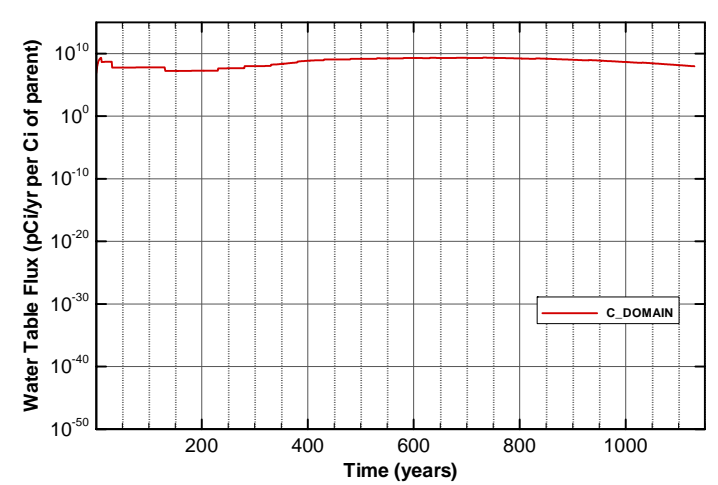

Figure A-1339. Flux at water table for Case01_off I-129_F.CG.8

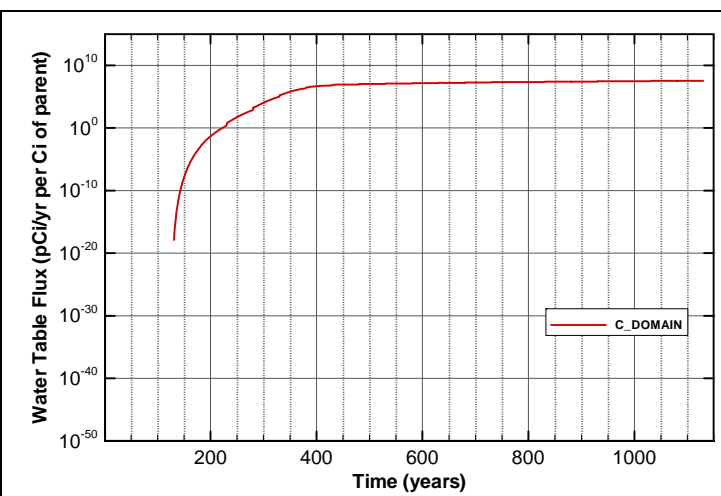

Figure A-1336. Flux at water table for Case01_off I-129_ETF.Carbon

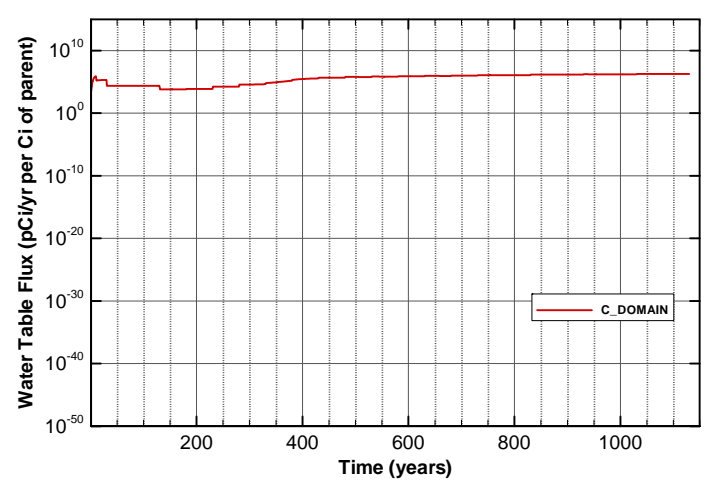

Figure A-1338. Flux at water table for Case01_off I-129_F.Carbon

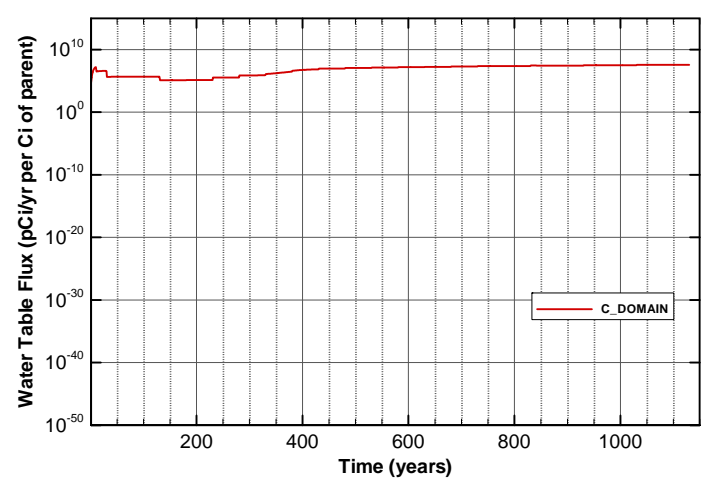

Figure A-1340. Flux at water table for Case01_off I-129_F.Dowex.21K 


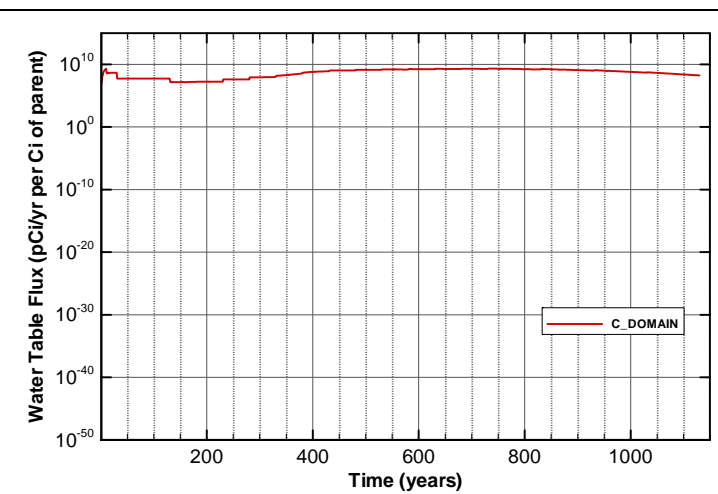

Figure A-1341. Flux at water table for Case01_off I-129_F.Filtercake

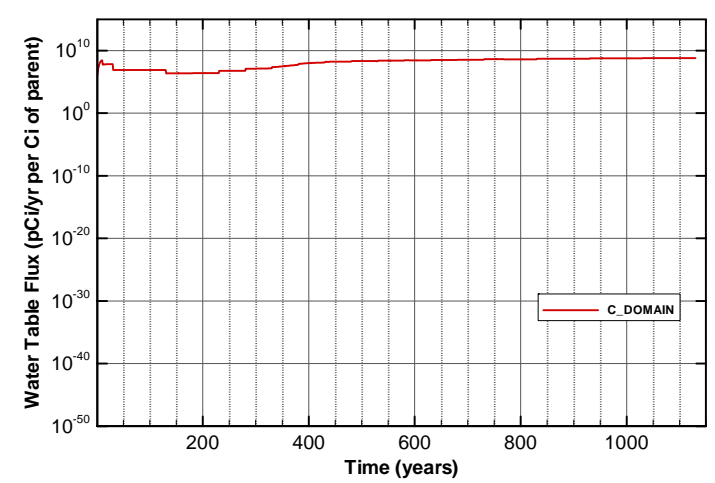

Figure A-1343. Flux at water table for Case01_off I-129_H.CG.8

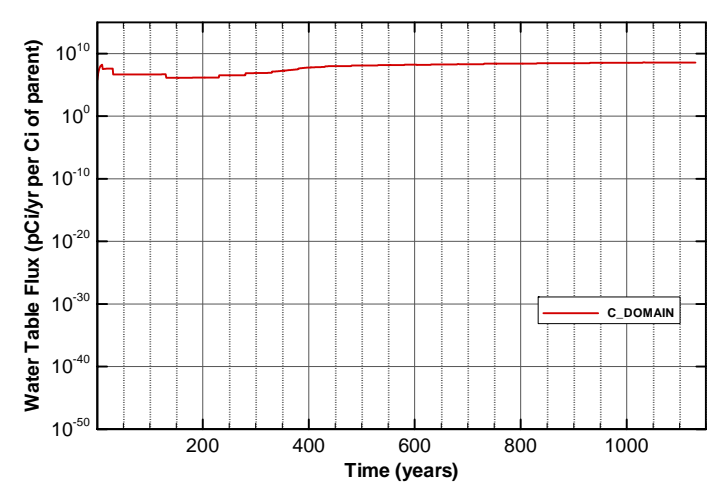

Figure A-1345. Flux at water table for Case01_off I-129_H.Filtercake

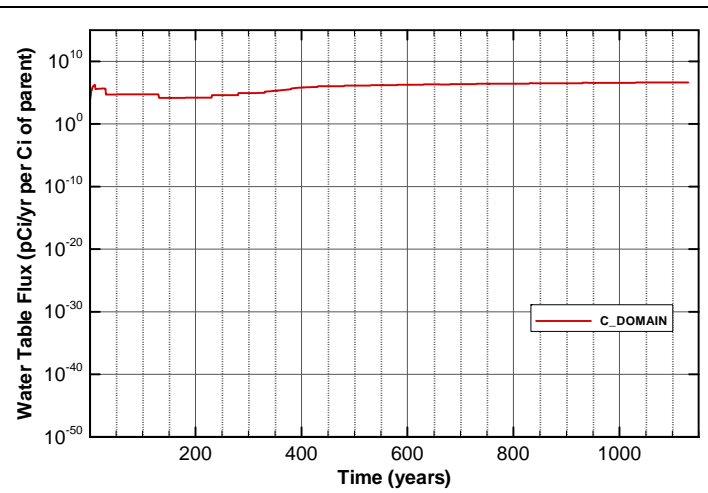

Figure A-1342. Flux at water table for Case01_off I-129_H.Carbon

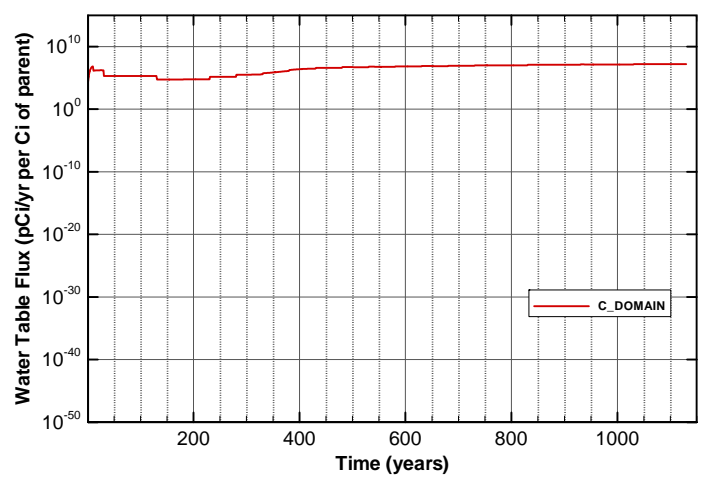

Figure A-1344. Flux at water table for Case01_off I-129_H.Dowex.21K

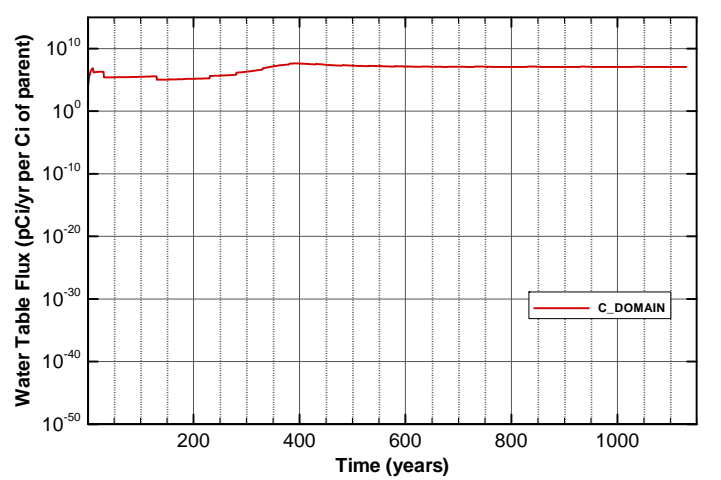

Figure A-1346. Flux at water table for Case01_off I-129_Mk50A 


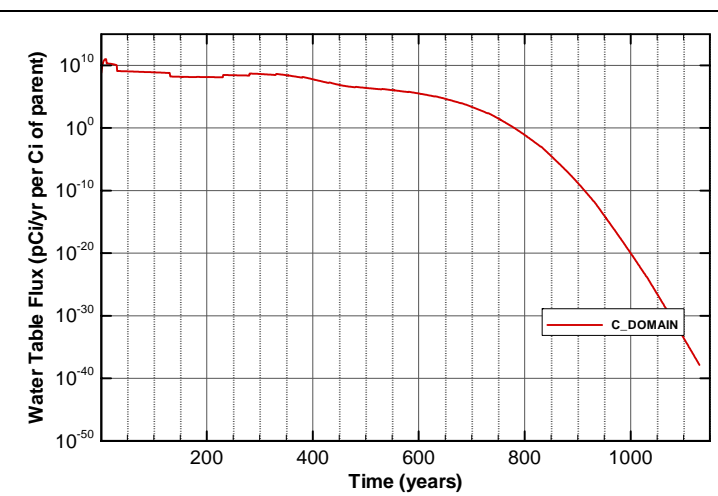

Figure A-1347. Flux at water table for Case01_off K-40

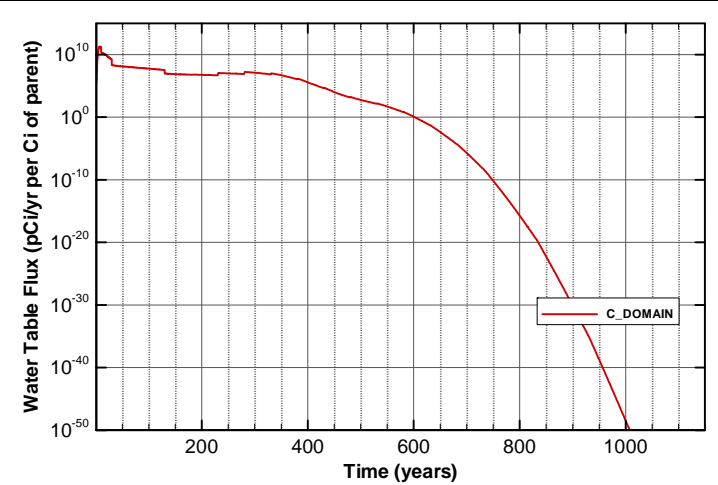

Figure A-1349. Flux at water table for Case01_off Nb-94

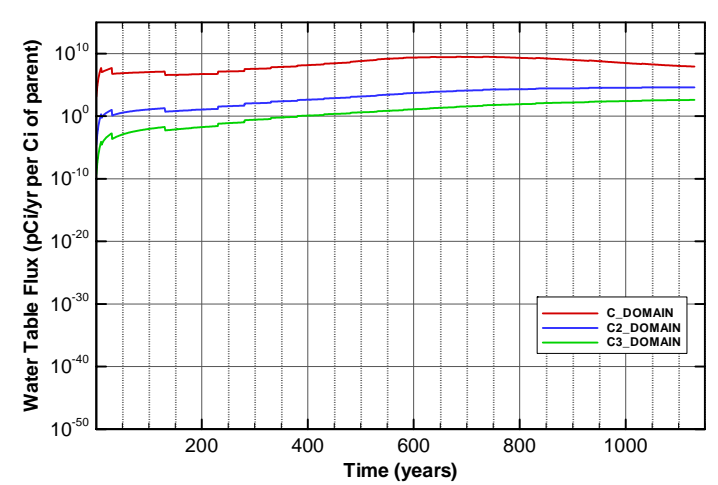

Figure A-1351. Flux at water table for Case01_off Np-237

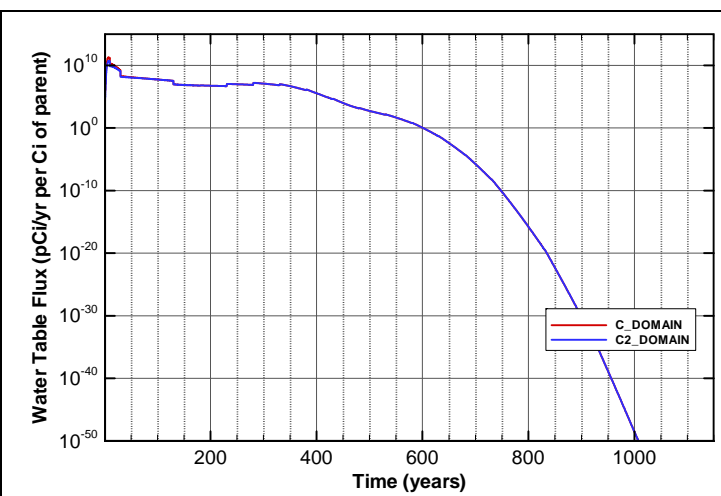

Figure A-1348. Flux at water table for Case01_off Mo-93

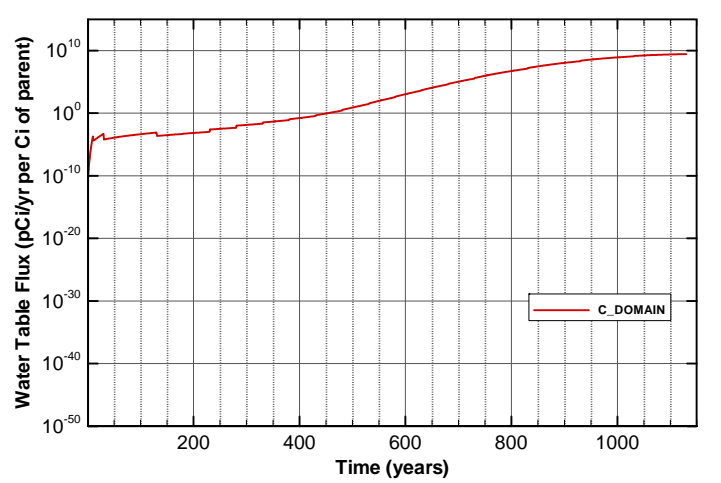

Figure A-1350. Flux at water table for Case01_off Ni-59

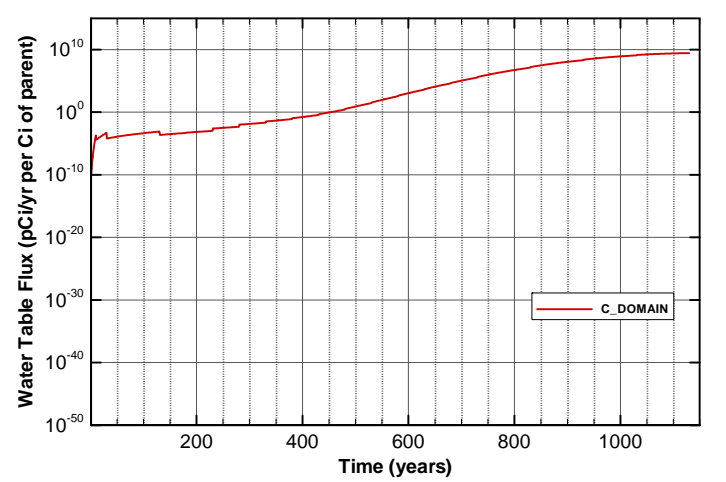

Figure A-1352. Flux at water table for Case01_off Pd-107 
SRNL-STI-2008-00397, REVISION 0
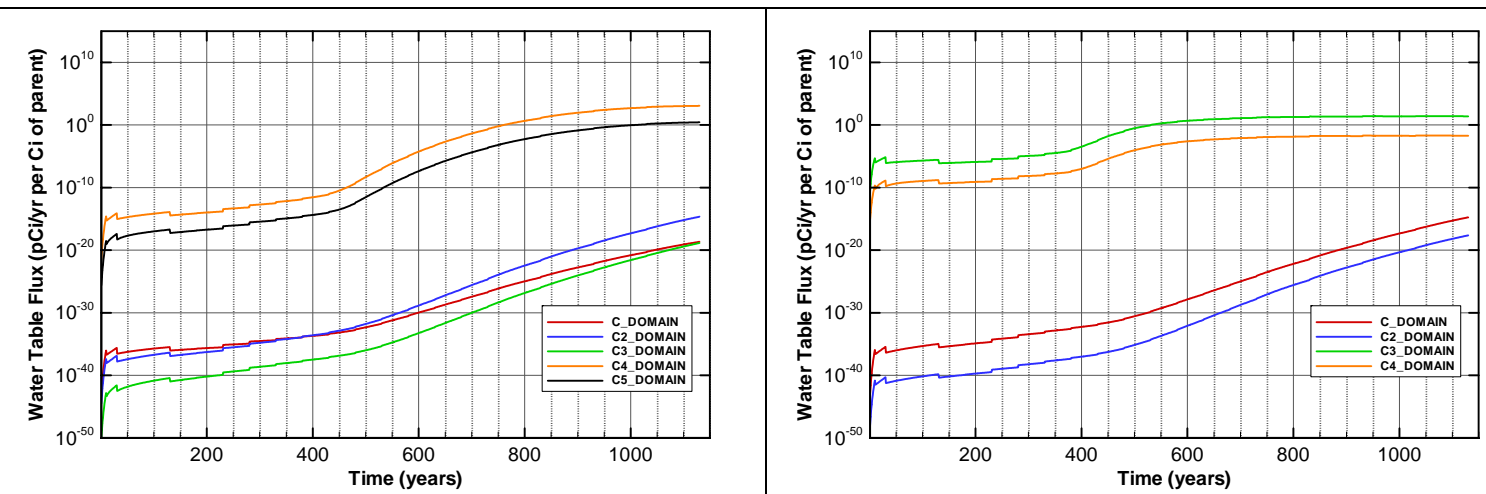

Figure A-1353. Flux at water table for Case01_off Pu-238

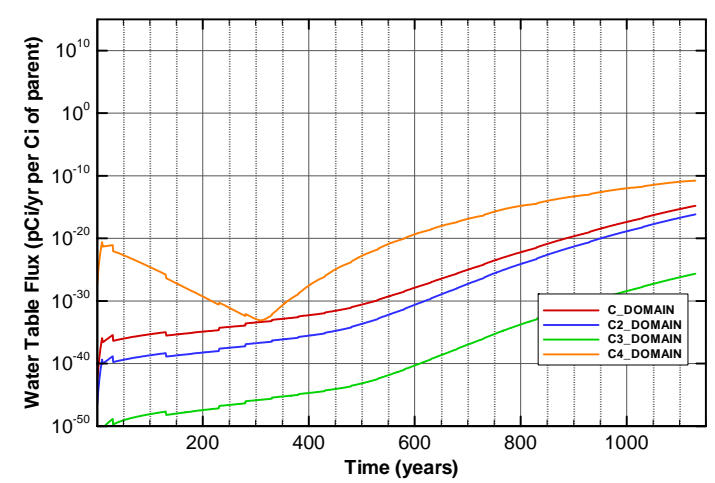

Figure A-1355. Flux at water table for Case01_off Pu-240

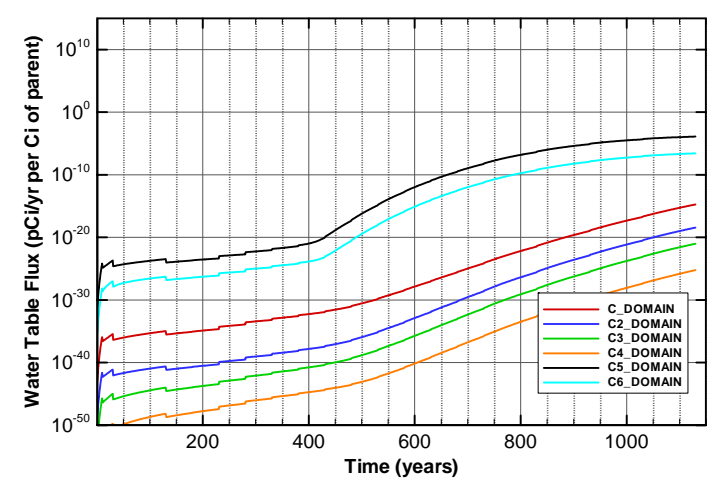

Figure A-1357. Flux at water table for Case01_off Pu-242

Figure A-1354. Flux at water table for Case01_off Pu-239

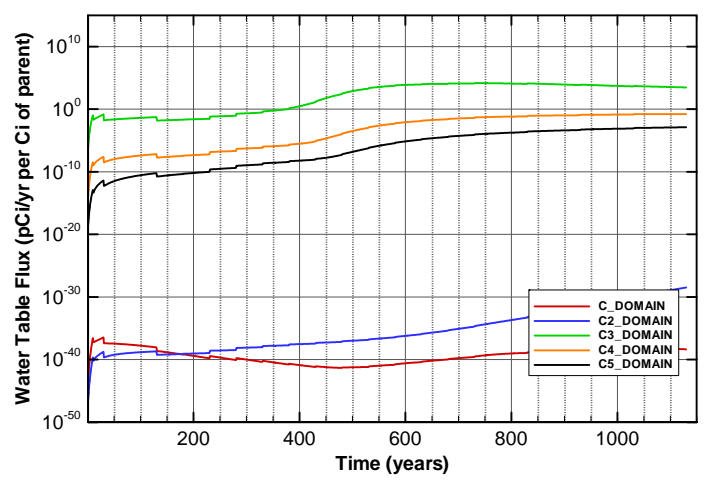

Figure A-1356. Flux at water table for Case01_off Pu-241

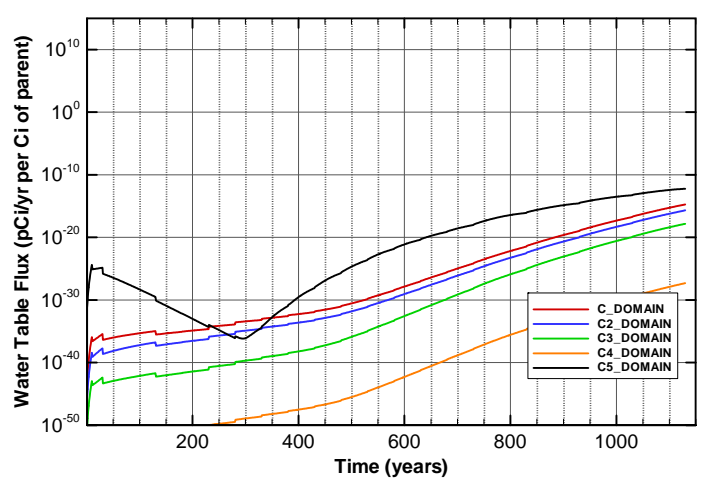

Figure A-1358. Flux at water table for Case01_off Pu-244 


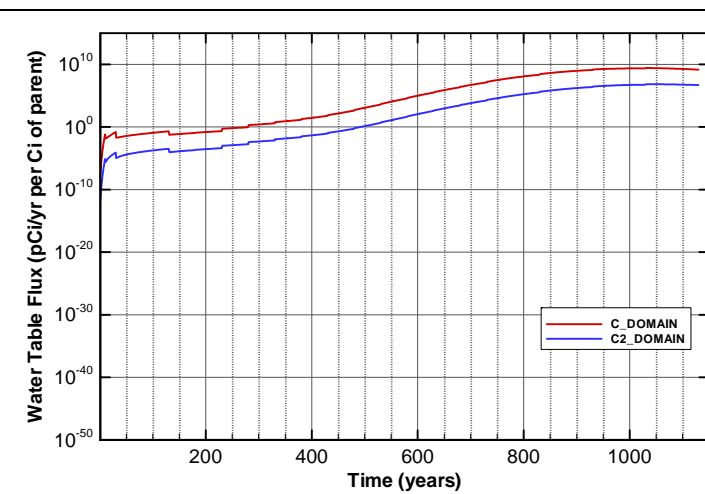

Figure A-1359. Flux at water table for Case01_off Ra-226

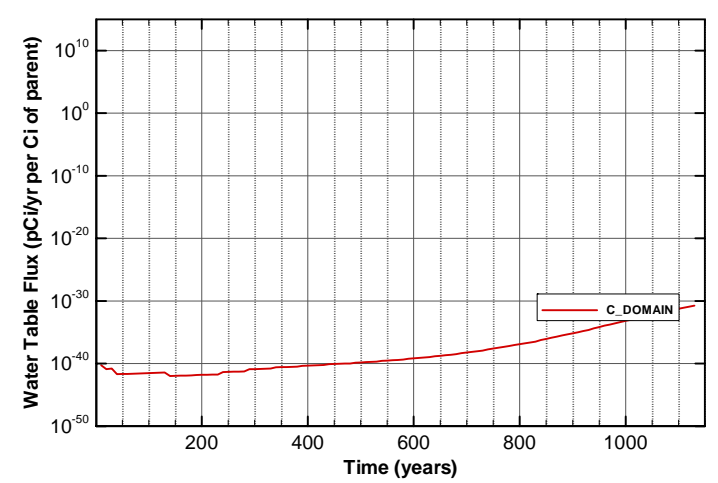

Figure A-1361. Flux at water table for Case01_off Sn-126

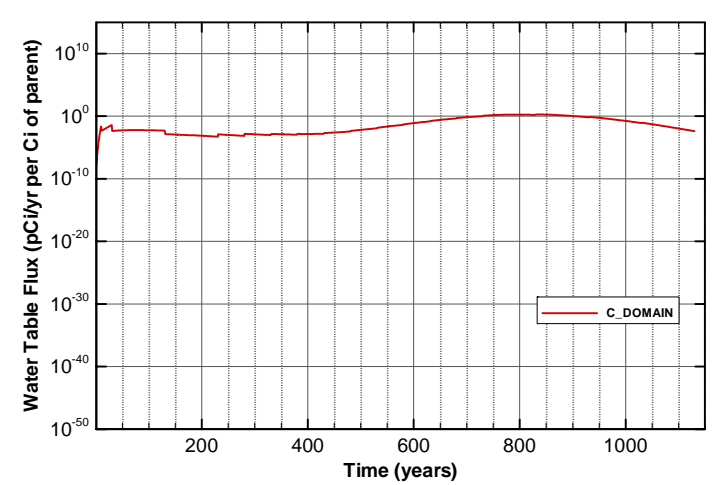

Figure A-1363. Flux at water table for Case01_off Sr-90_Cask

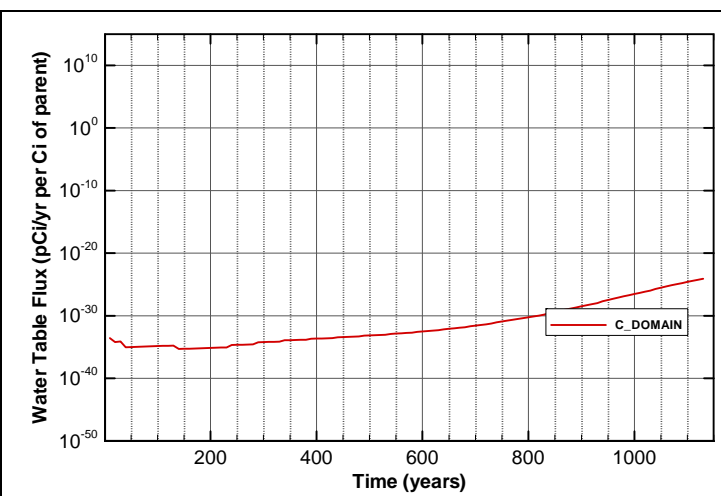

Figure A-1360. Flux at water table for Case01_off Se-79

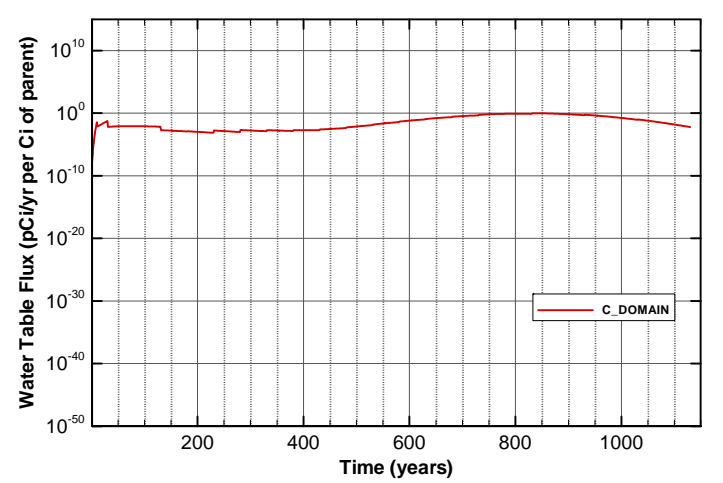

Figure A-1362. Flux at water table for Case01_off Sr-90

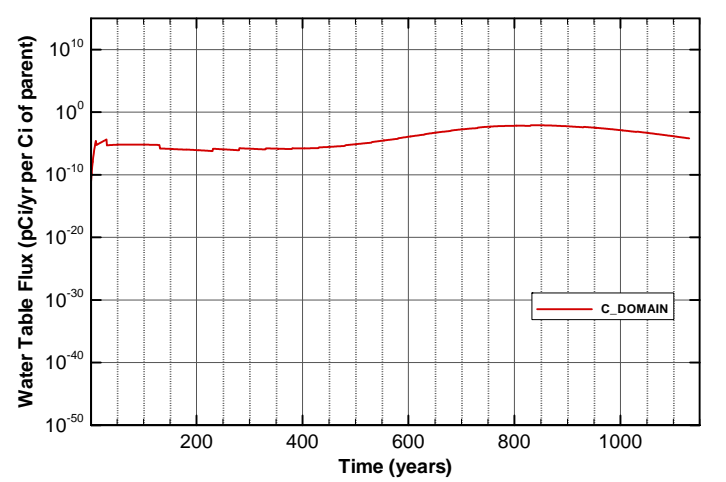

Figure A-1364. Flux at water table for Case01_off Sr-90_Mk50A 


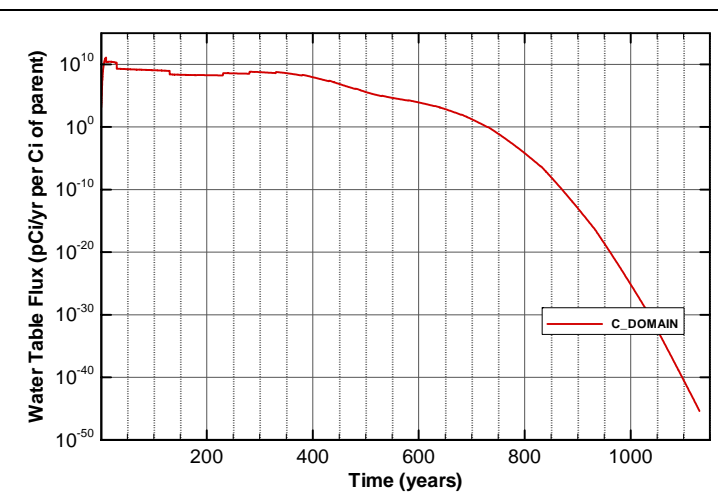

Figure A-1365. Flux at water table for Case01_off Tc-99

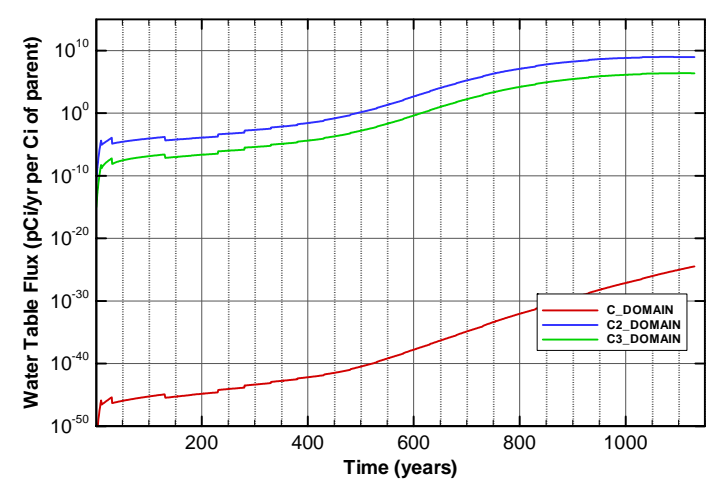

Figure A-1367. Flux at water table for Case01_off Th-230

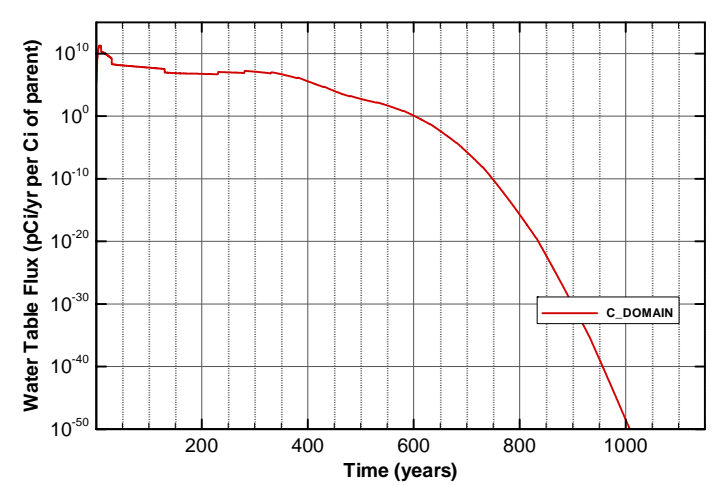

Figure A-1369. Flux at water table for Case01_off Tracer

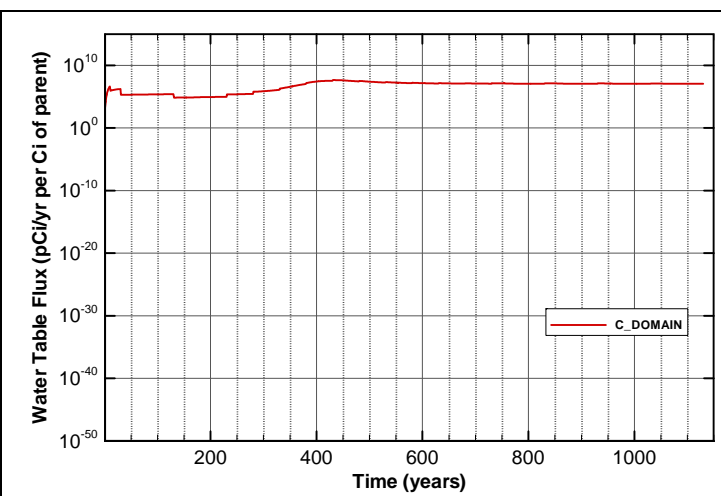

Figure A-1366. Flux at water table for Case01_off Tc-99_Mk50A

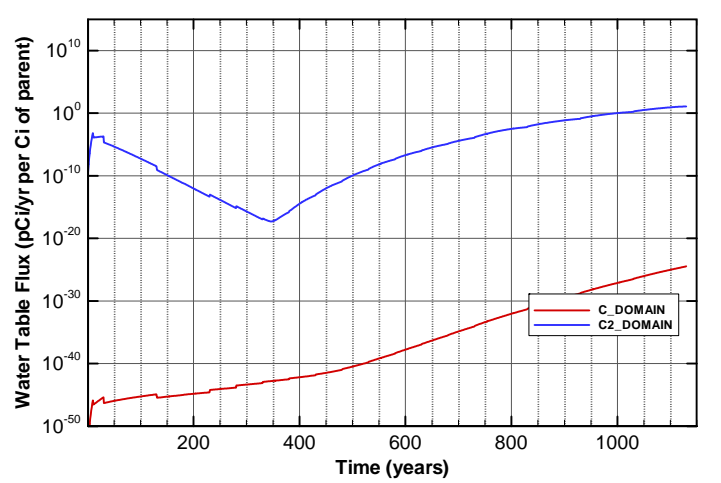

Figure A-1368. Flux at water table for Case01_off Th-232

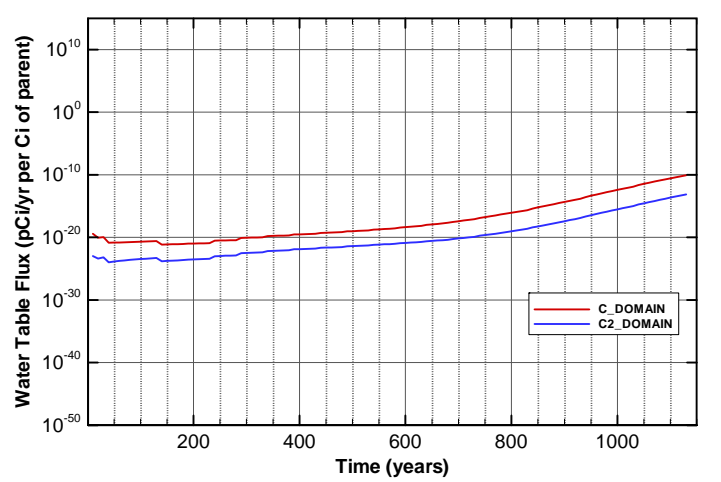

Figure A-1370. Flux at water table for Case01_off U-233 
SRNL-STI-2008-00397, REVISION 0

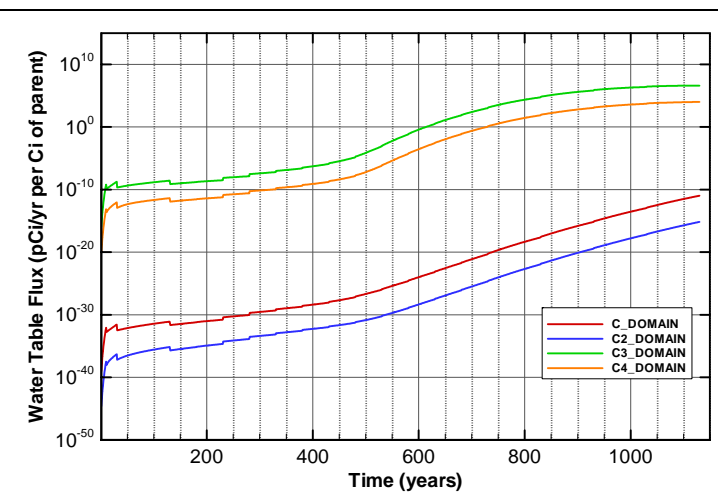

Figure A-1371. Flux at water table for Case01_off U-234

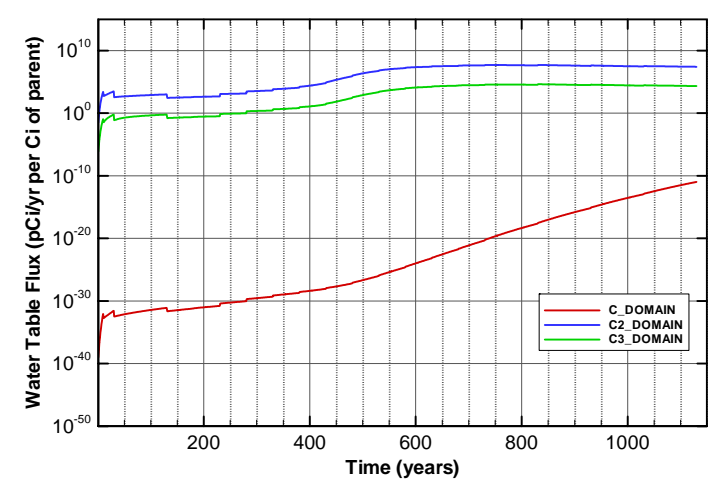

Figure A-1373. Flux at water table for Case01_off U-235

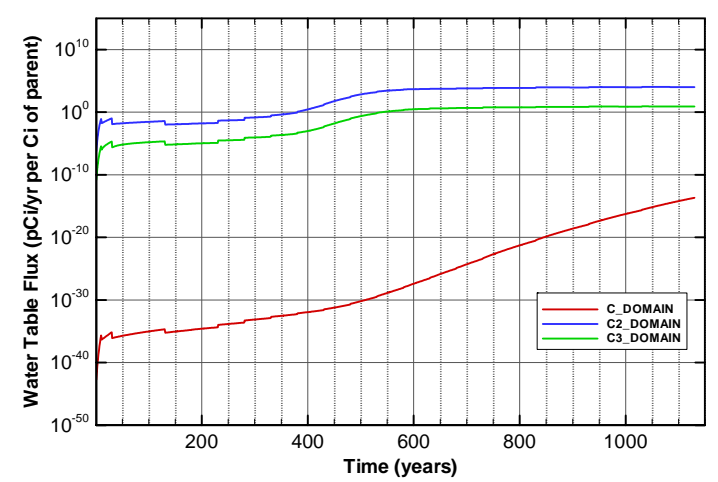

Figure A-1375. Flux at water table for Case01_off U-235_Paducah.Cask

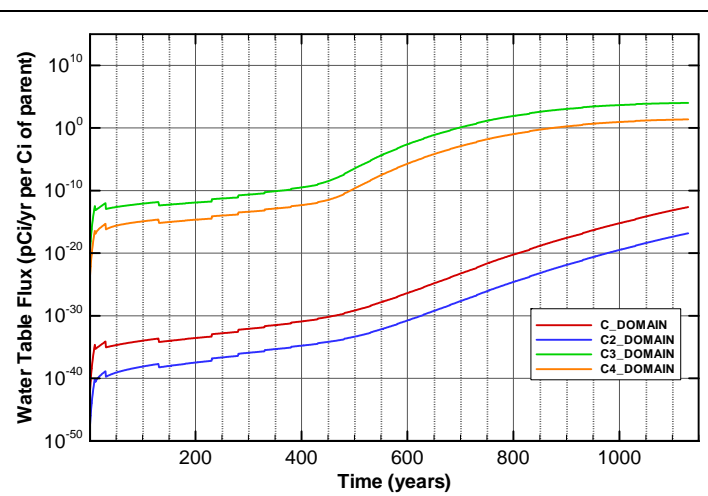

Figure A-1372. Flux at water table for Case01_off U-234_Mglass

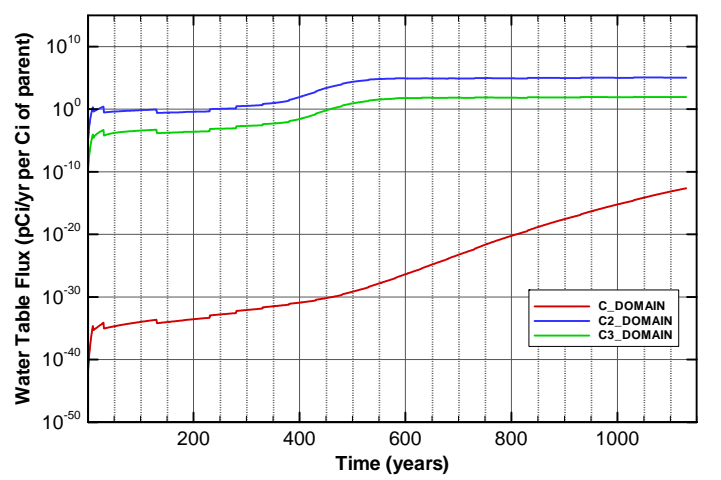

Figure A-1374. Flux at water table for Case01_off U-235_Mglass

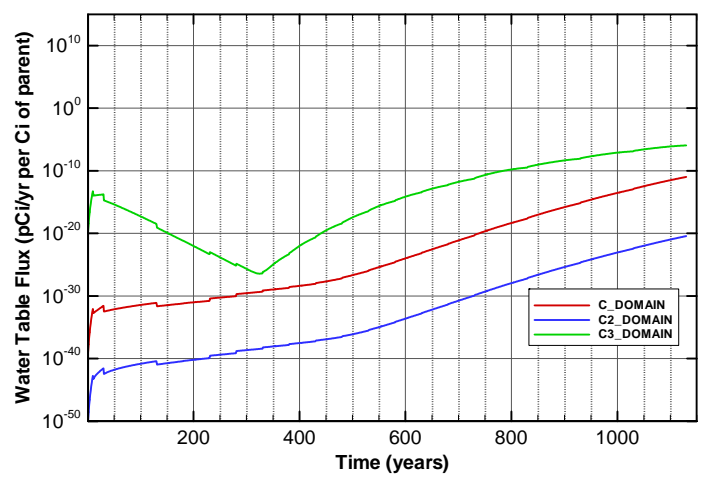

Figure A-1376. Flux at water table for Case01_off U-236 
SRNL-STI-2008-00397, REVISION 0
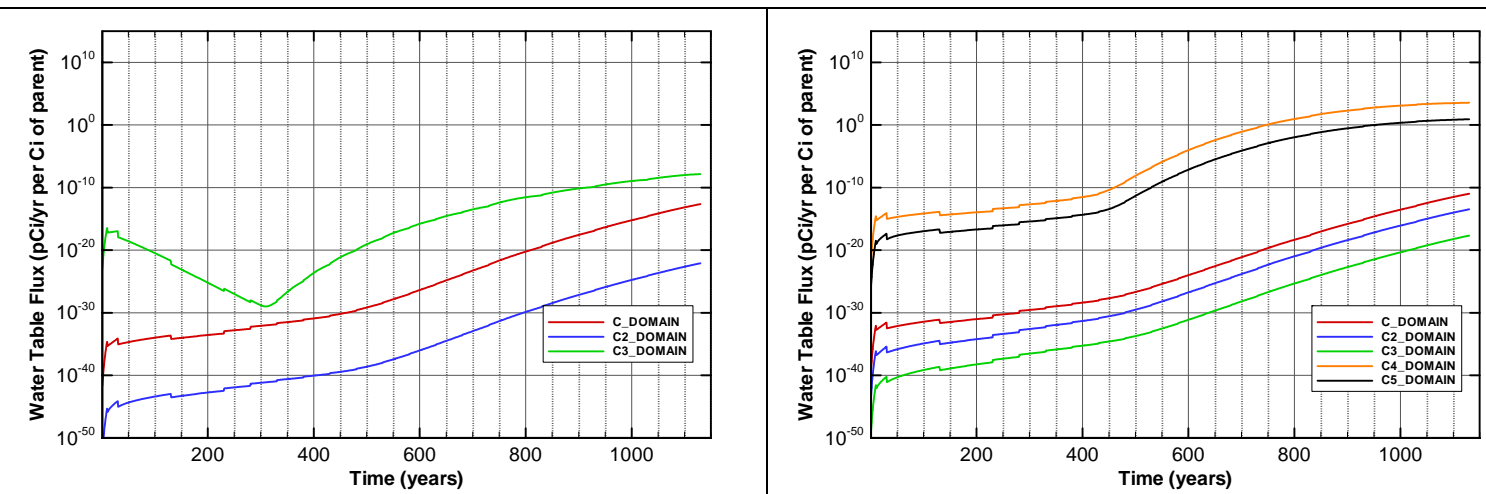

Figure A-1377. Flux at water table for Case01_off U-236_Mglass

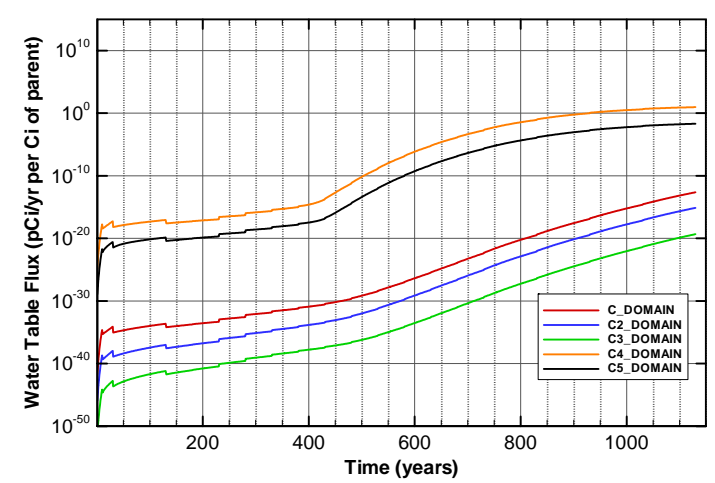

Figure A-1379. Flux at water table for Case01_off U-238_Mglass

Figure A-1378. Flux at water table for Case01_off U-238

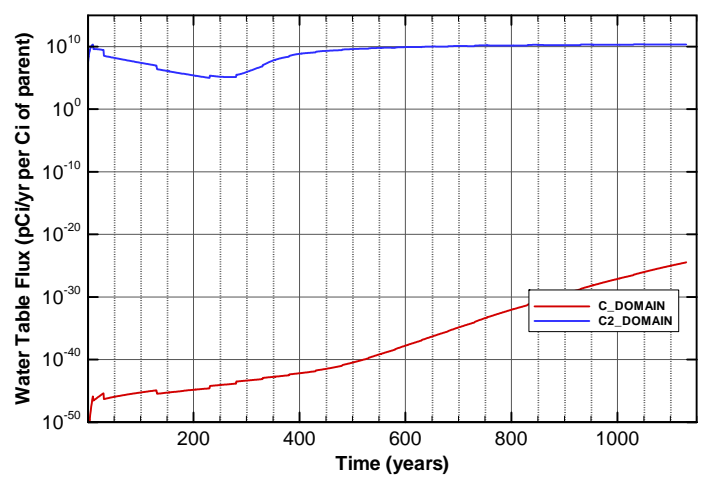

Figure A-1380. Flux at water table for Case01_off Zr-93

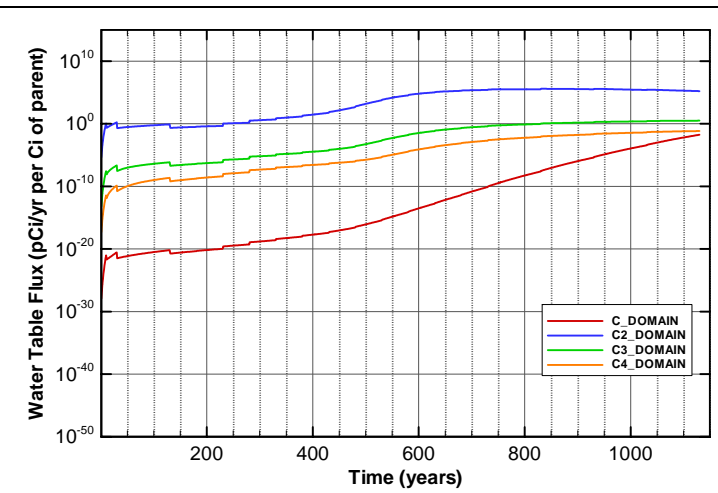

Figure A-1381. Flux at water table for Case01_on Am-241

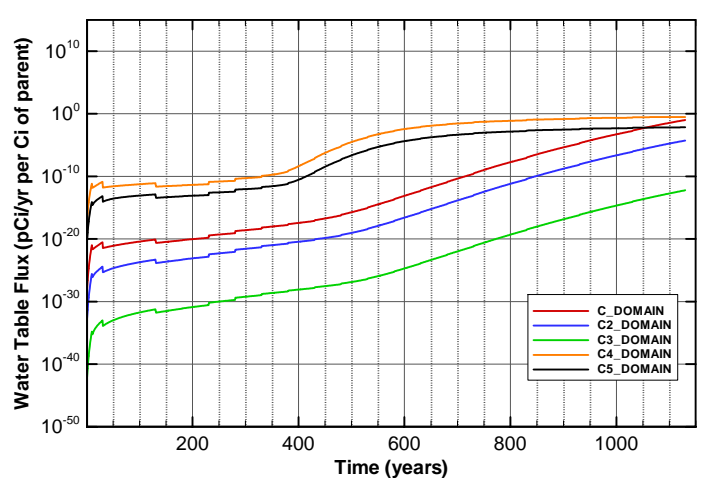

Figure A-1382. Flux at water table for Case01_on Am-243 
SRNL-STI-2008-00397, REVISION 0

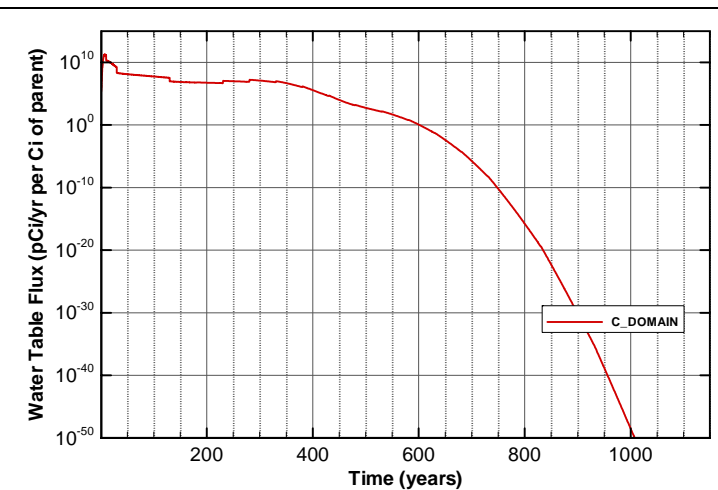

Figure A-1383. Flux at water table for Case01_on C-14

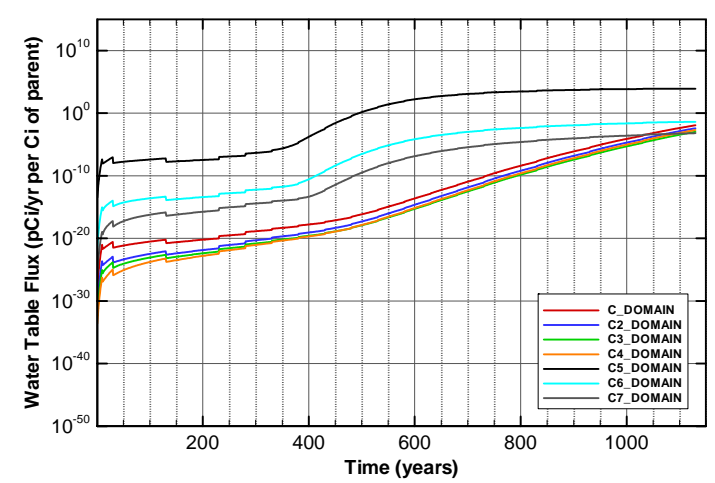

Figure A-1385. Flux at water table for Case01_on Cf-249

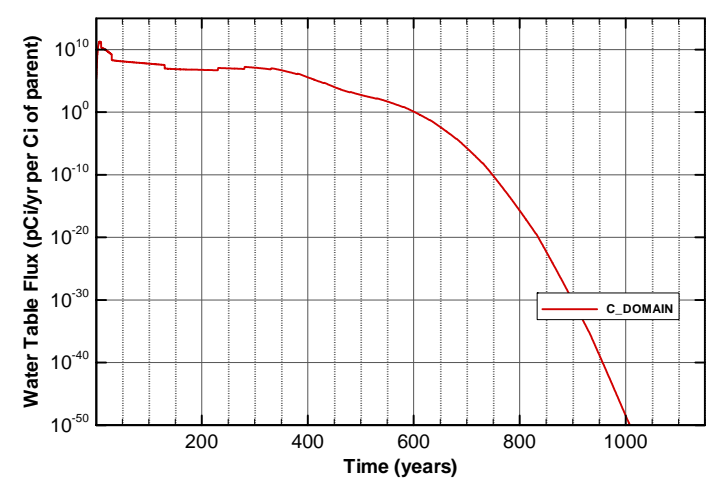

Figure A-1387. Flux at water table for Case01_on Cl-36

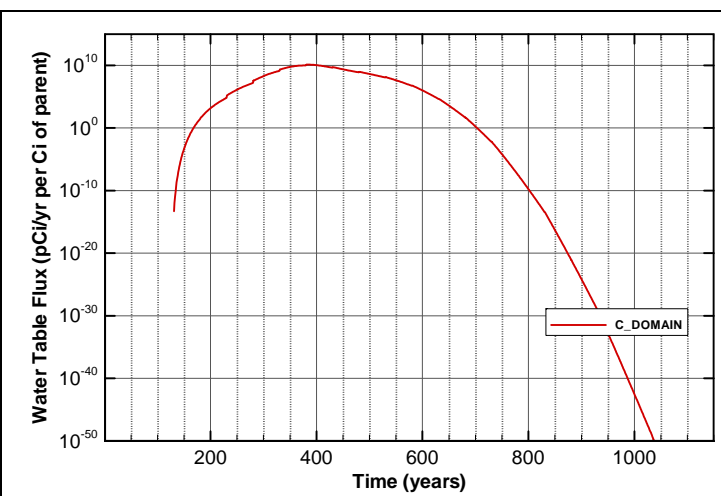

Figure A-1384. Flux at water table for Case01_on C-14_NR.Pump

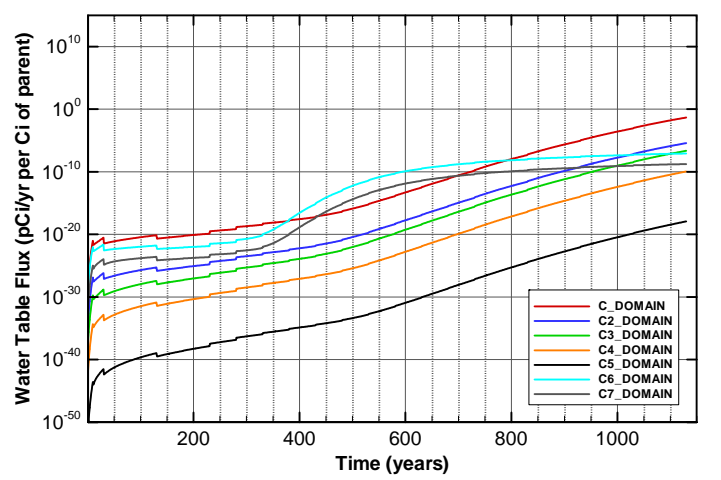

Figure A-1386. Flux at water table for Case01_on Cf-251

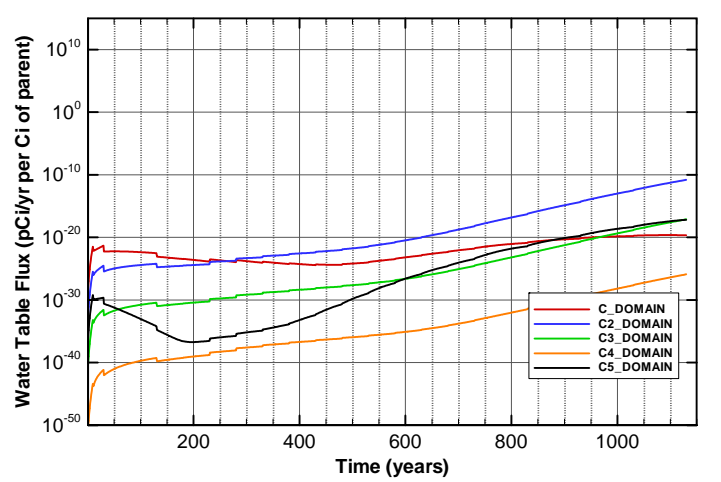

Figure A-1388. Flux at water table for Case01_on Cm-244 
SRNL-STI-2008-00397, REVISION 0

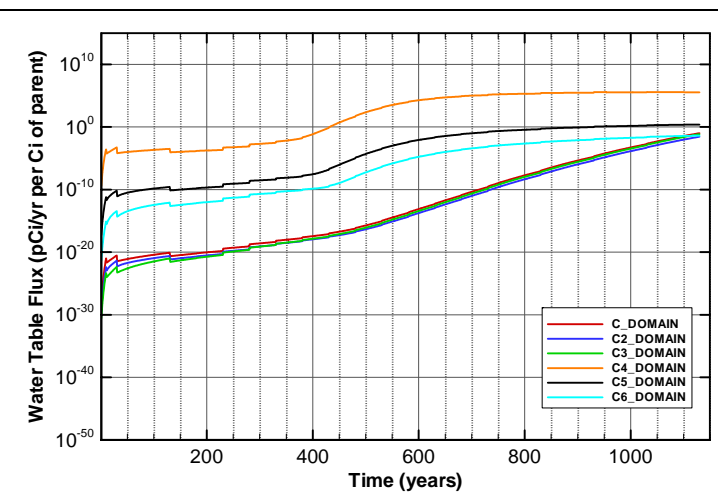

Figure A-1389. Flux at water table for Case01_on Cm-245

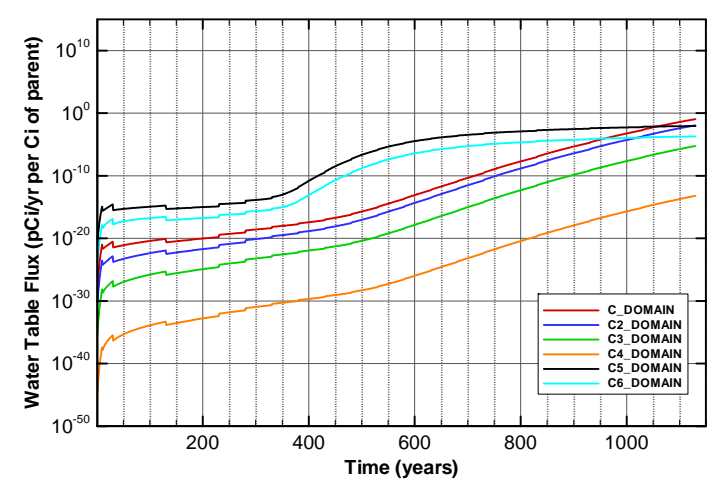

Figure A-1391. Flux at water table for Case01_on Cm-247

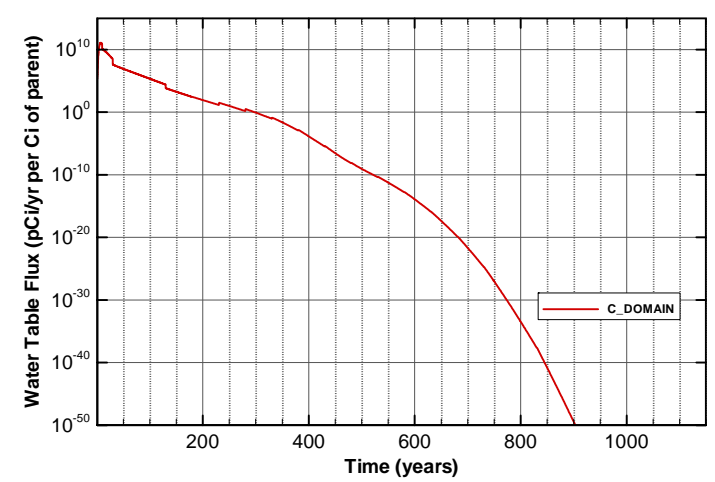

Figure A-1393. Flux at water table for Case01_on H-3

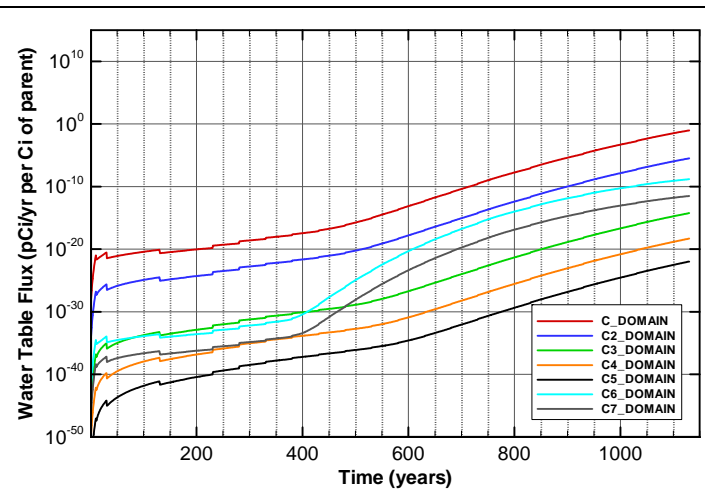

Figure A-1390. Flux at water table for Case01_on Cm-246

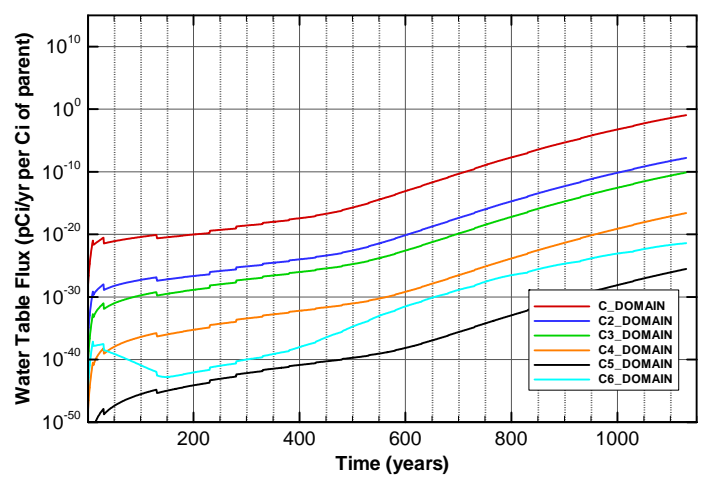

Figure A-1392. Flux at water table for Case01_on Cm-248

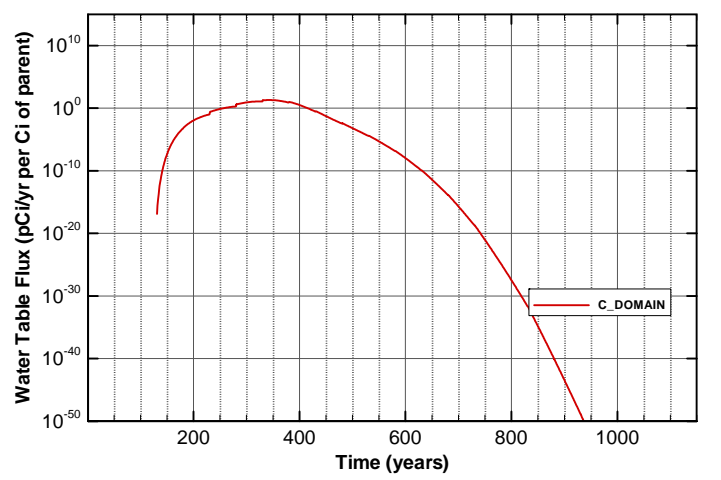

Figure A-1394. Flux at water table for Case01_on H-3_ETF.Carbon 


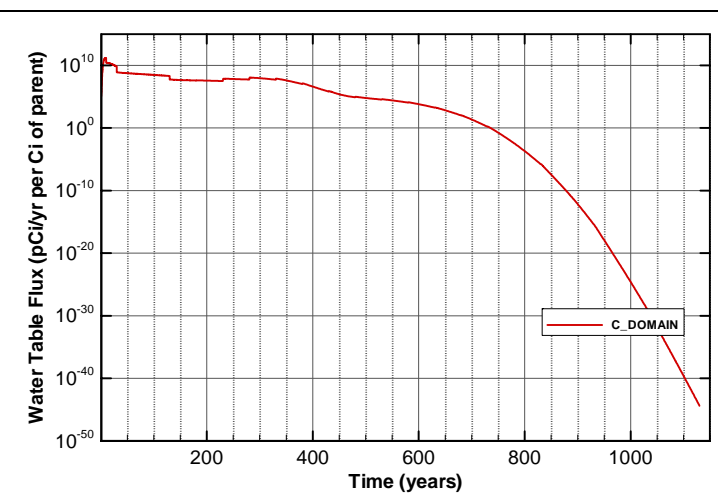

Figure A-1395. Flux at water table for Case01_on I-129

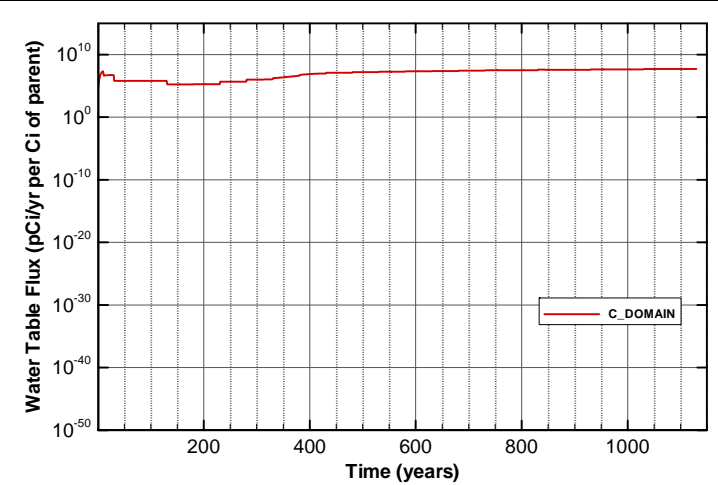

Figure A-1397. Flux at water table for Case01_on I-129_ETF.GT.73

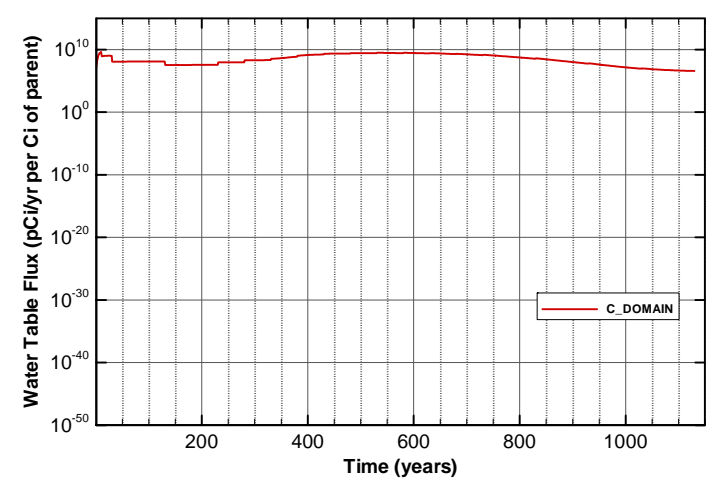

Figure A-1399. Flux at water table for Case01_on I-129_F.CG.8

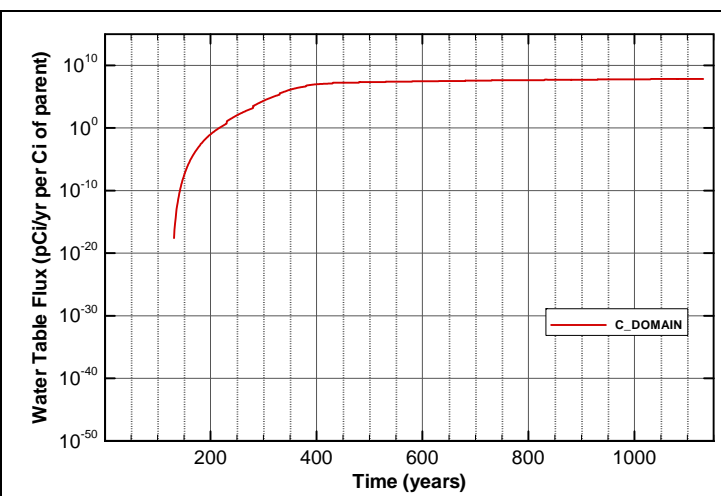

Figure A-1396. Flux at water table for Case01_on I-129_ETF.Carbon

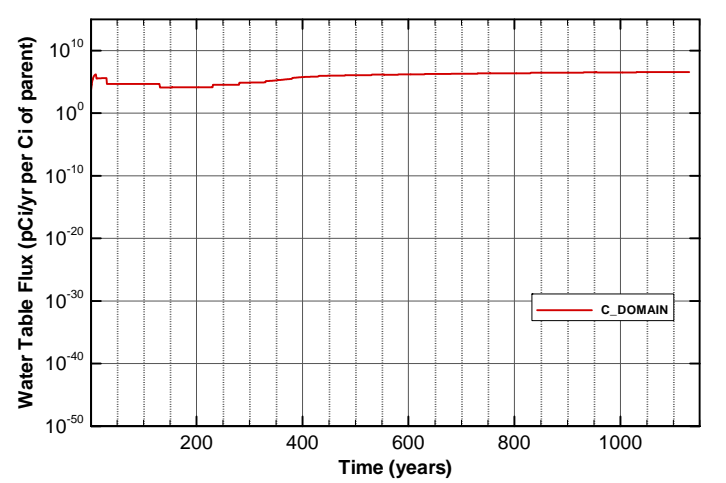

Figure A-1398. Flux at water table for Case01_on I-129_F.Carbon

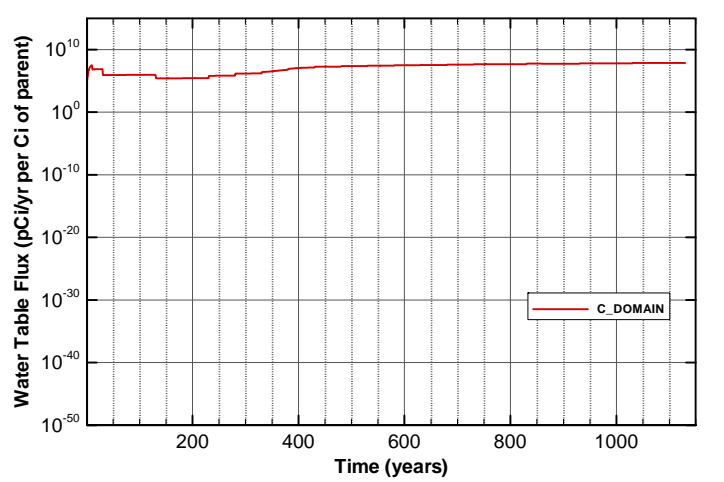

Figure A-1400. Flux at water table for Case01_on I-129_F.Dowex.21K 


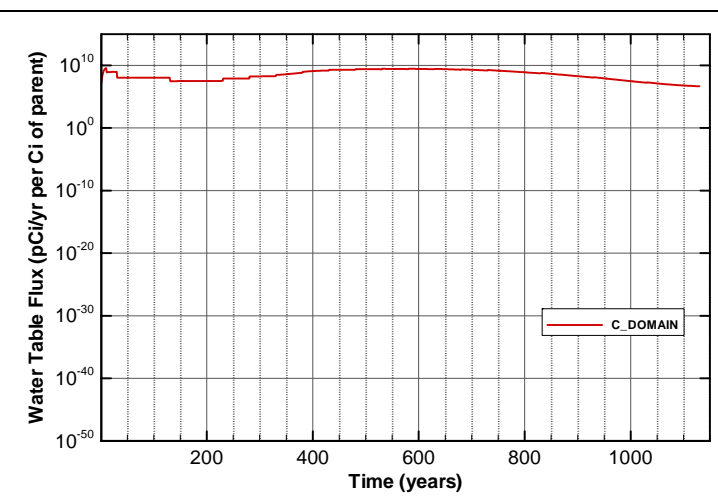

Figure A-1401. Flux at water table for Case01_on I-129_F.Filtercake

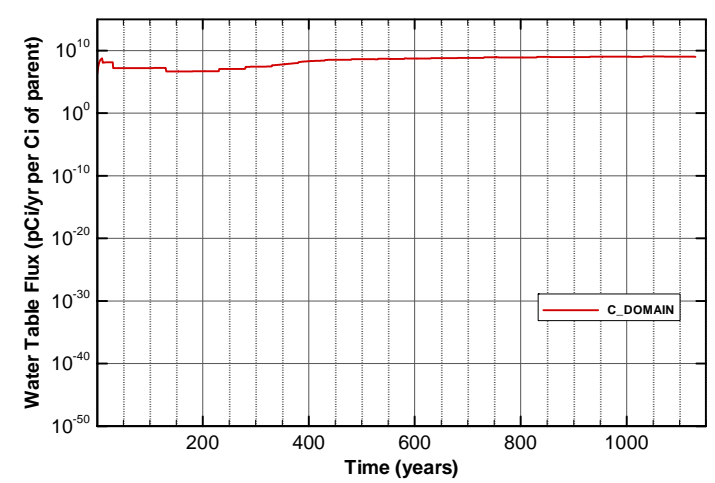

Figure A-1403. Flux at water table for Case01_on I-129_H.CG.8

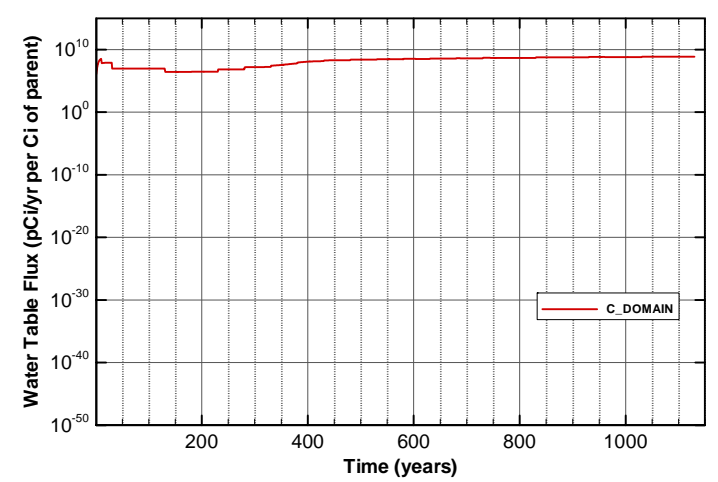

Figure A-1405. Flux at water table for Case01_on I-129_H.Filtercake

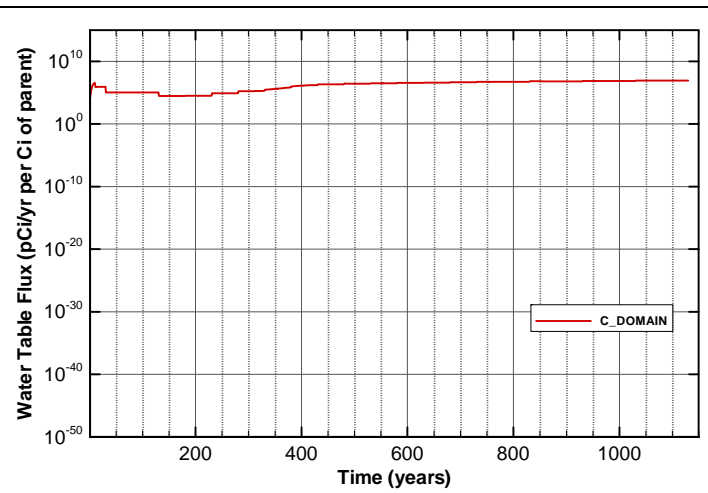

Figure A-1402. Flux at water table for Case01_on I-129_H.Carbon

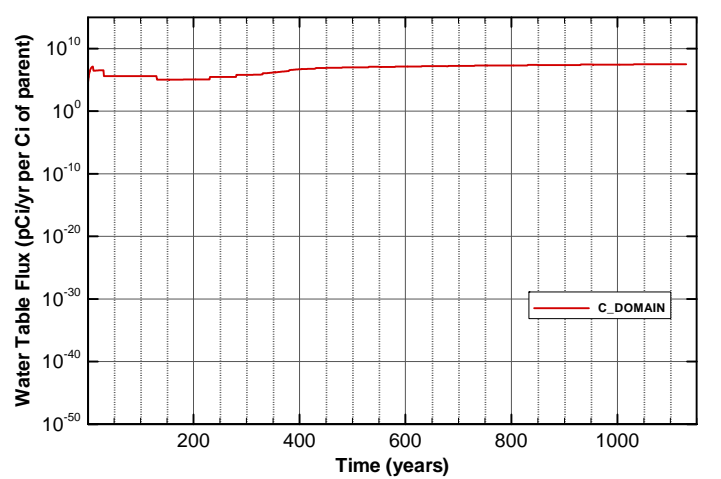

Figure A-1404. Flux at water table for Case01_on I-129_H.Dowex.21K

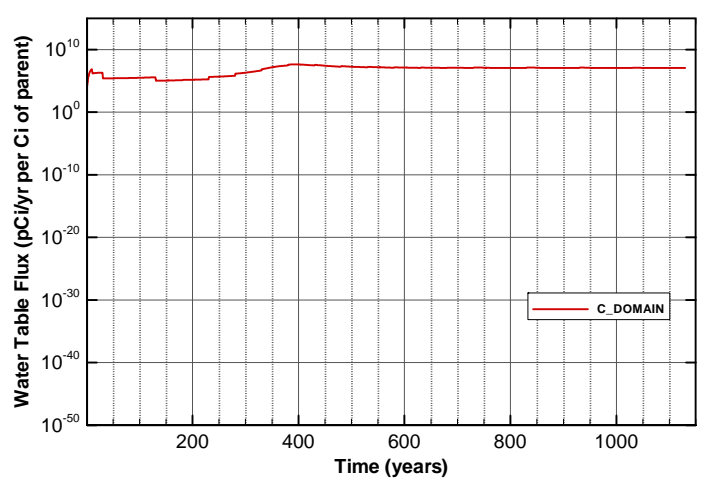

Figure A-1406. Flux at water table for Case01_on I-129_Mk50A 


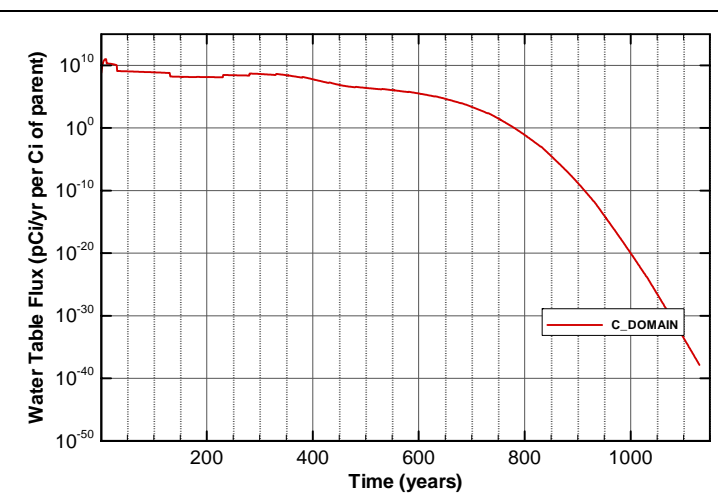

Figure A-1407. Flux at water table for Case01_on K-40

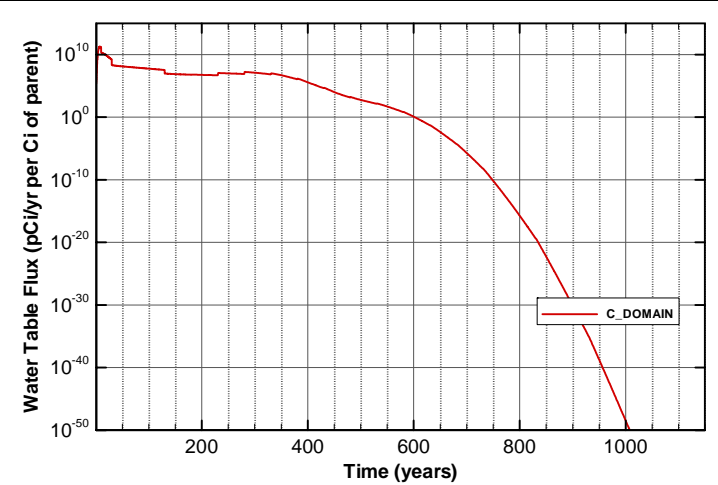

Figure A-1409. Flux at water table for Case01_on Nb-94

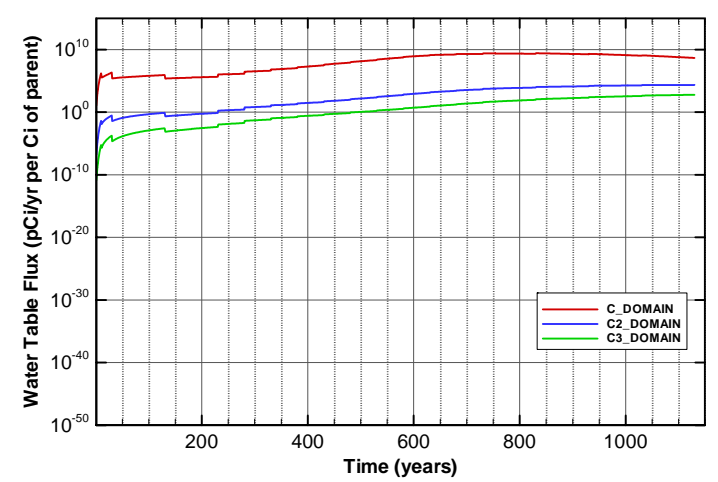

Figure A-1411. Flux at water table for Case01_on Np-237

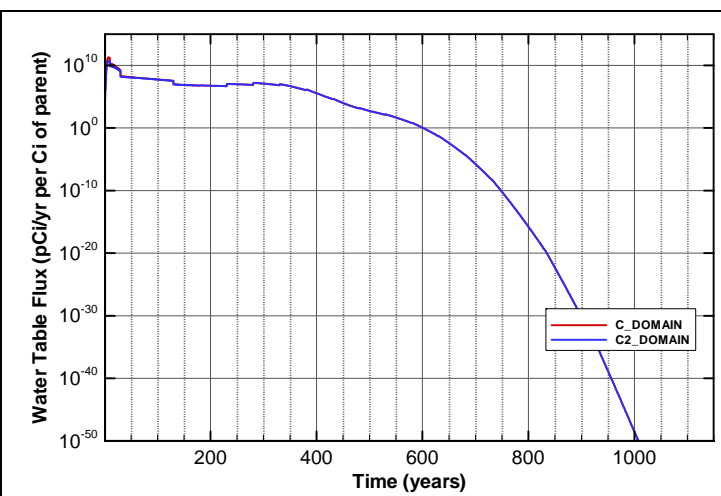

Figure A-1408. Flux at water table for Case01_on Mo-93

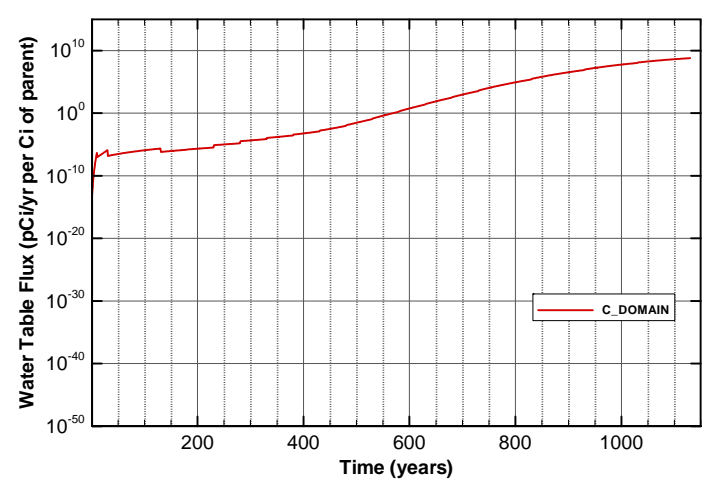

Figure A-1410. Flux at water table for Case01_on Ni-59

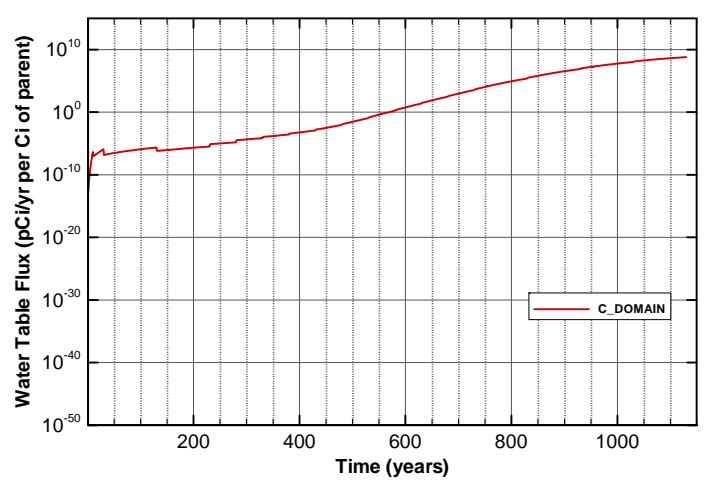

Figure A-1412. Flux at water table for Case01_on Pd-107 
SRNL-STI-2008-00397, REVISION 0

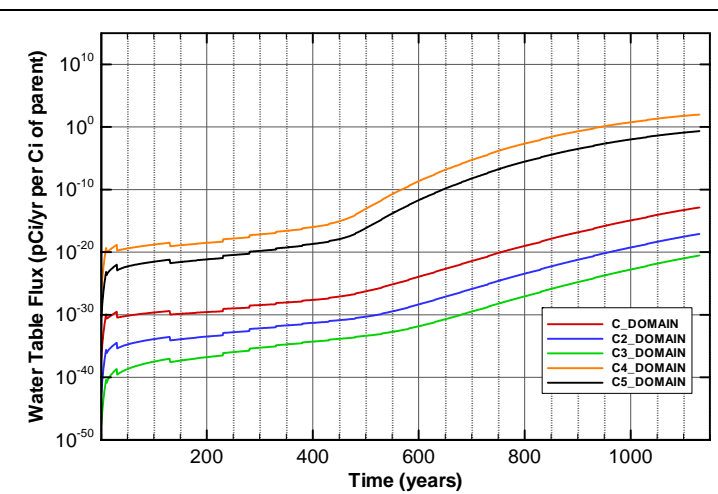

Figure A-1413. Flux at water table for Case01_on Pu-238

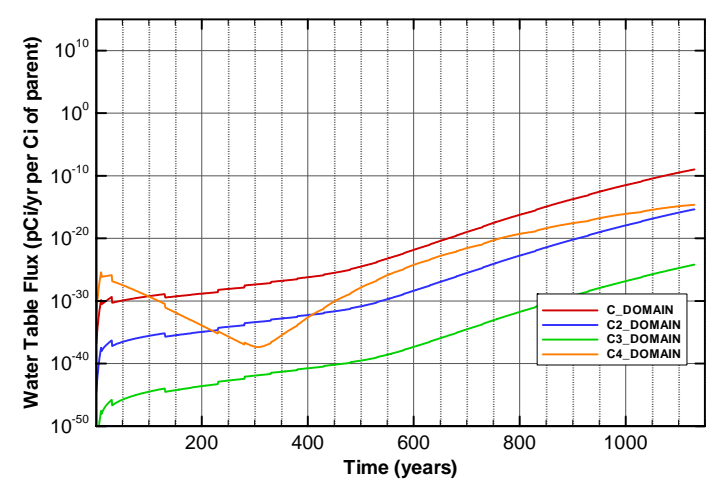

Figure A-1415. Flux at water table for Case01_on Pu-240

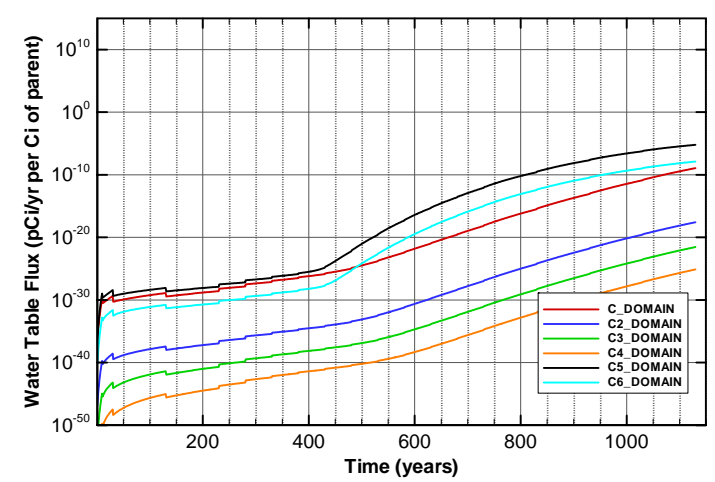

Figure A-1417. Flux at water table for Case01_on Pu-242

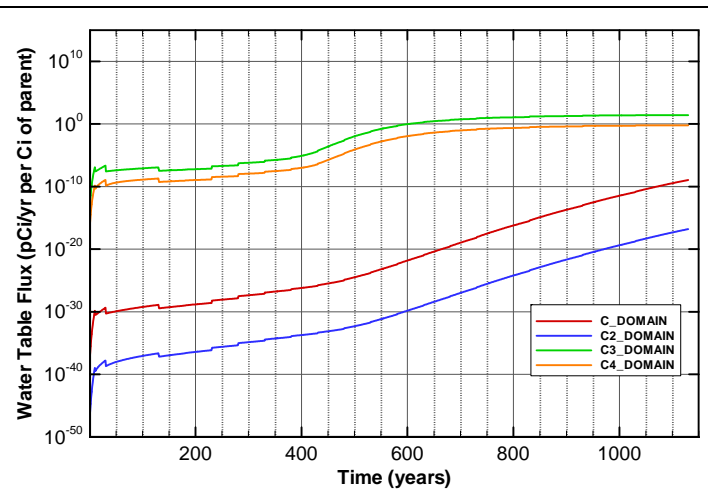

Figure A-1414. Flux at water table for Case01_on Pu-239

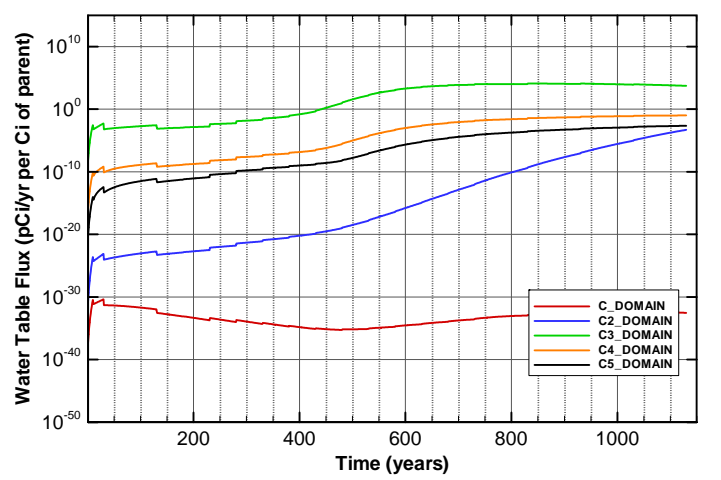

Figure A-1416. Flux at water table for Case01_on Pu-241

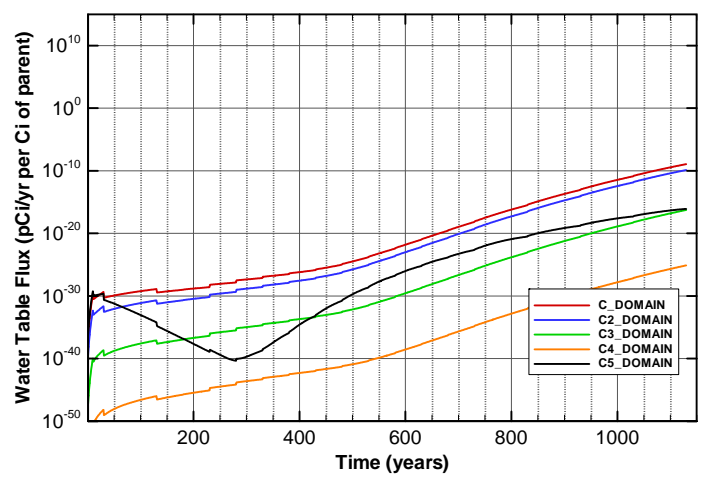

Figure A-1418. Flux at water table for Case01_on Pu-244 
SRNL-STI-2008-00397, REVISION 0

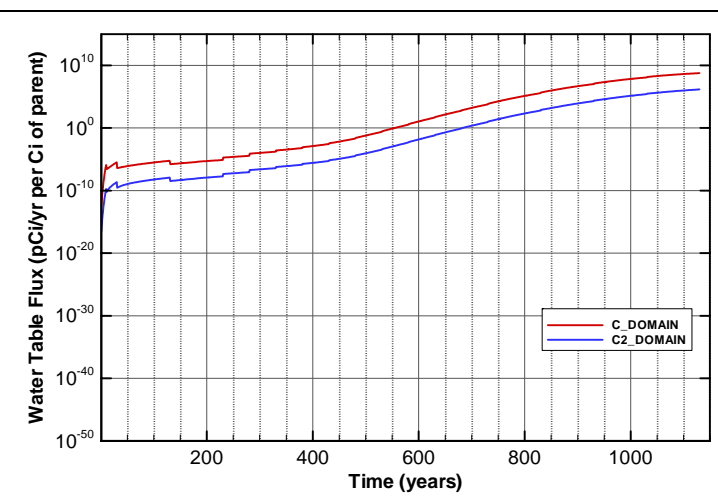

Figure A-1419. Flux at water table for Case01_on Ra-226

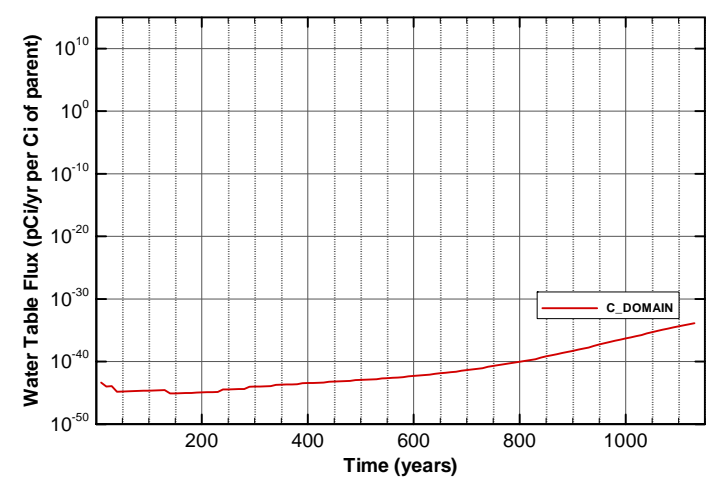

Figure A-1421. Flux at water table for Case01_on Sn-126

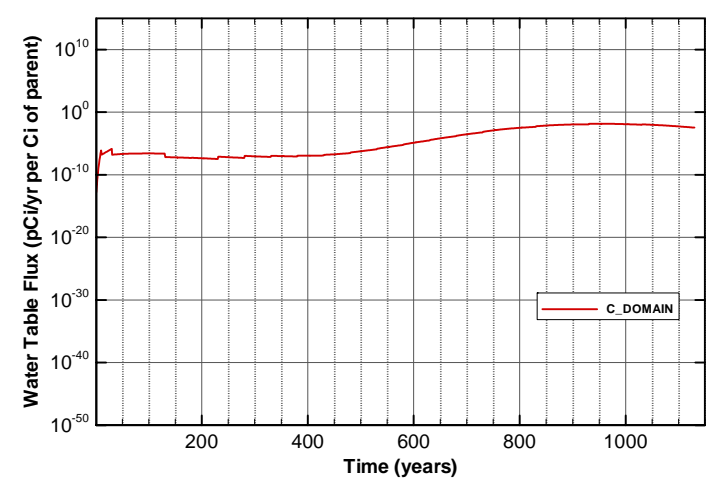

Figure A-1423. Flux at water table for Case01_on Sr-90_Cask

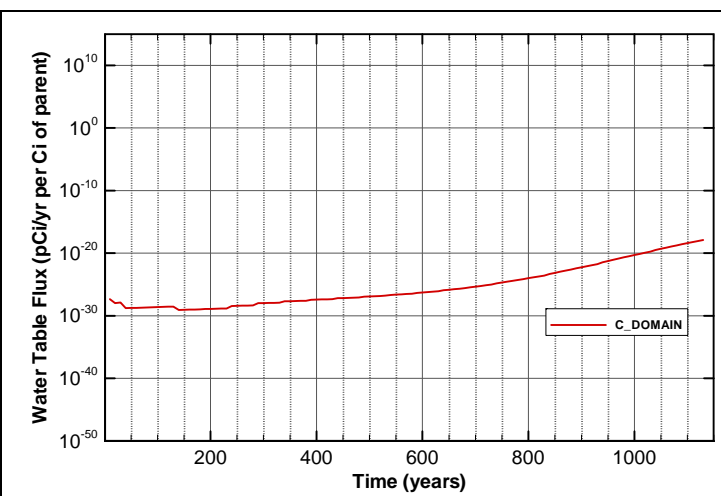

Figure A-1420. Flux at water table for Case01_on Se-79

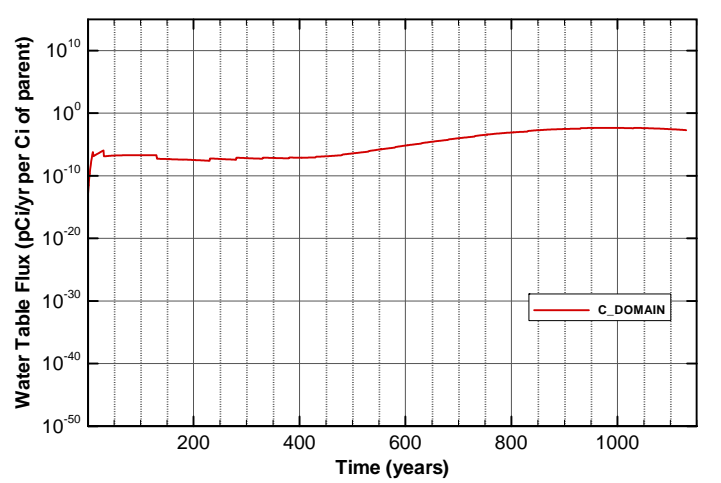

Figure A-1422. Flux at water table for Case01_on Sr-90

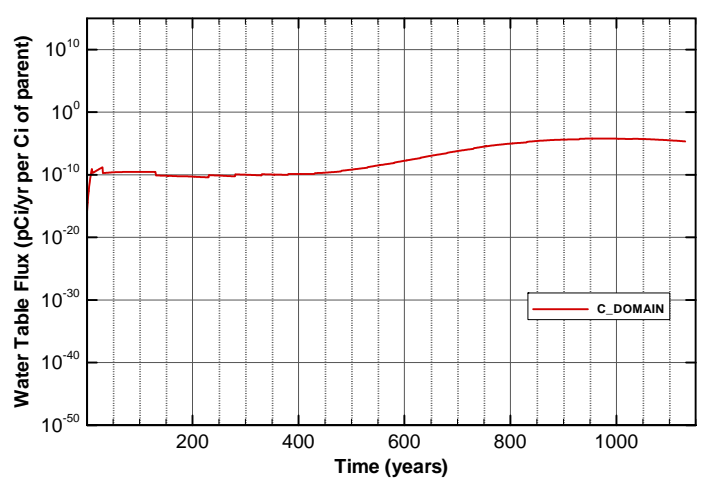

Figure A-1424. Flux at water table for Case01_on Sr-90_Mk50A 


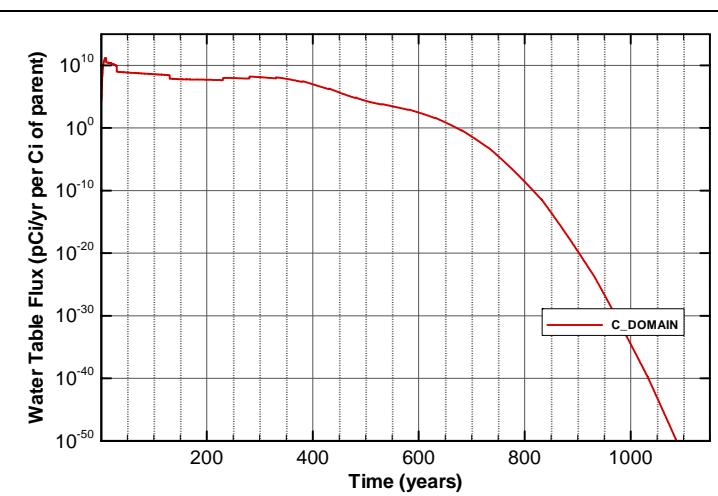

Figure A-1425. Flux at water table for Case01_on Tc-99

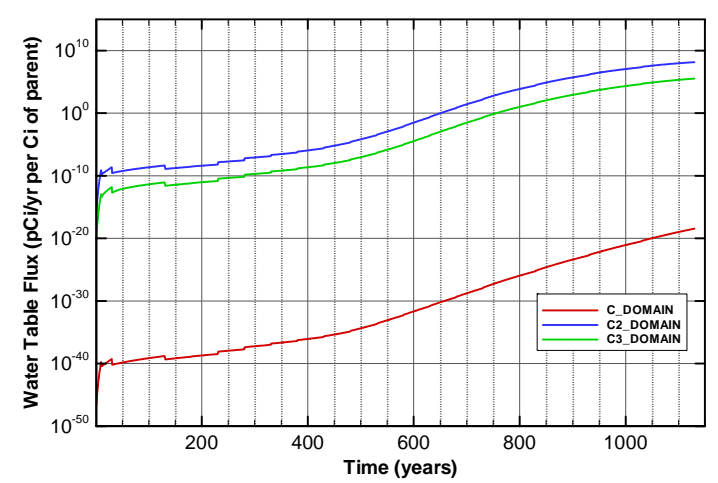

Figure A-1427. Flux at water table for Case01_on Th-230

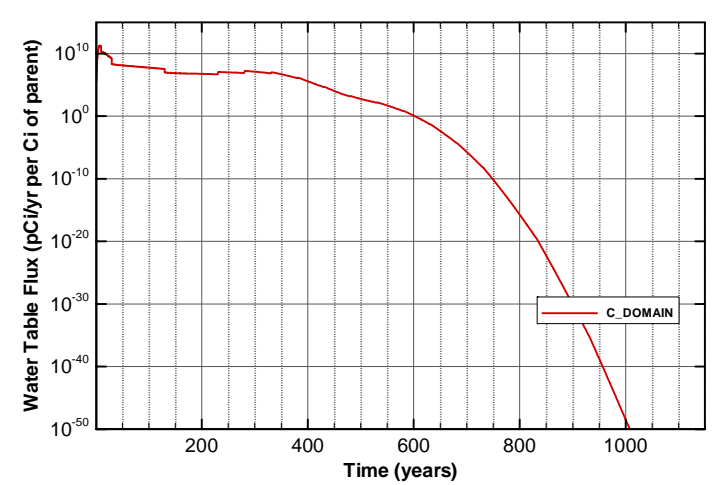

Figure A-1429. Flux at water table for Case01_on Tracer

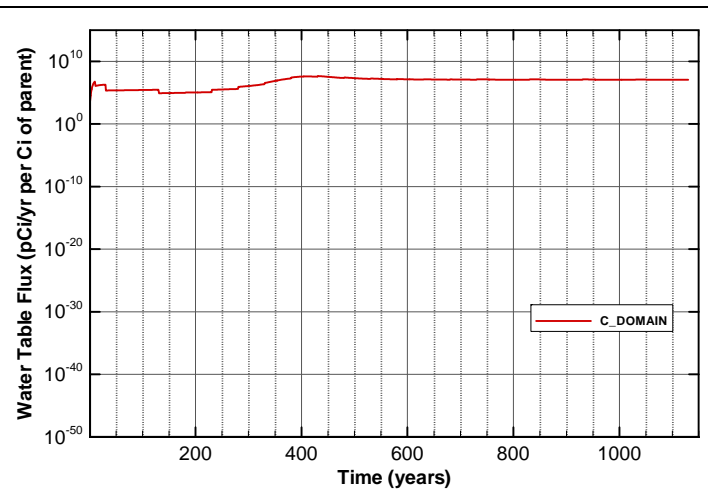

Figure A-1426. Flux at water table for Case01_on Tc-99_Mk50A

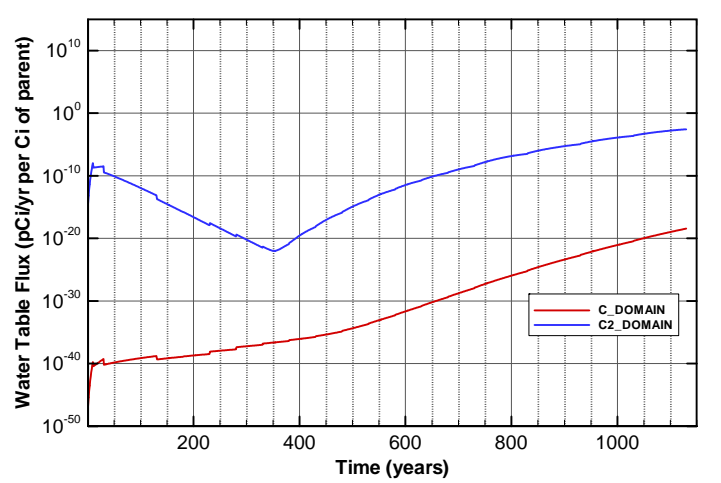

Figure A-1428. Flux at water table for Case01_on Th-232

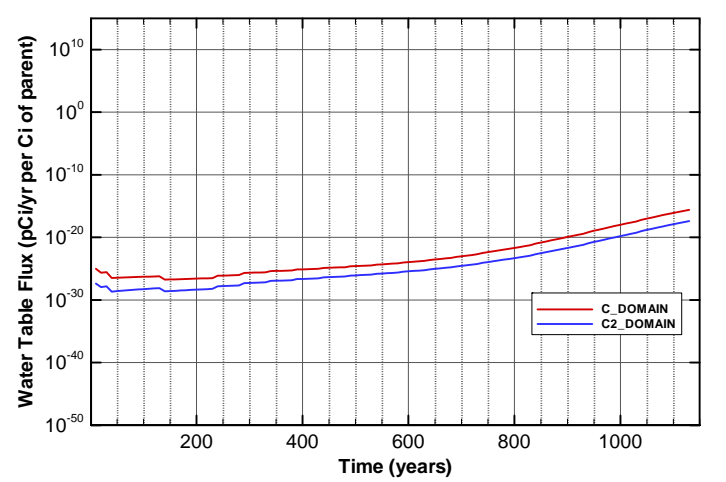

Figure A-1430. Flux at water table for Case01_on U-233 
SRNL-STI-2008-00397, REVISION 0

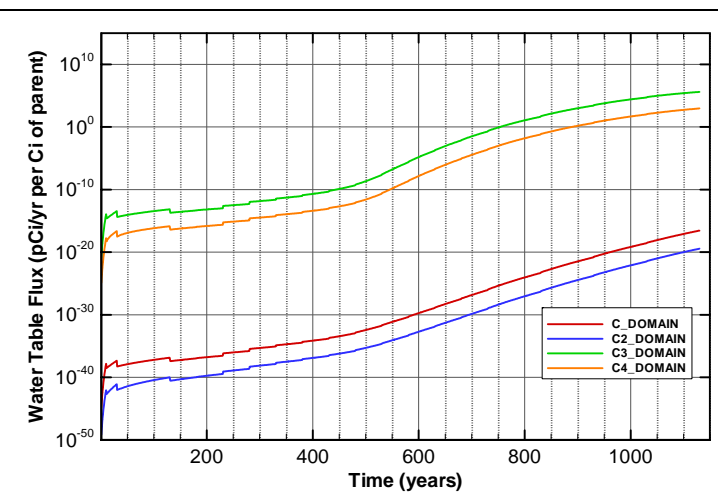

Figure A-1431. Flux at water table for Case01_on U-234

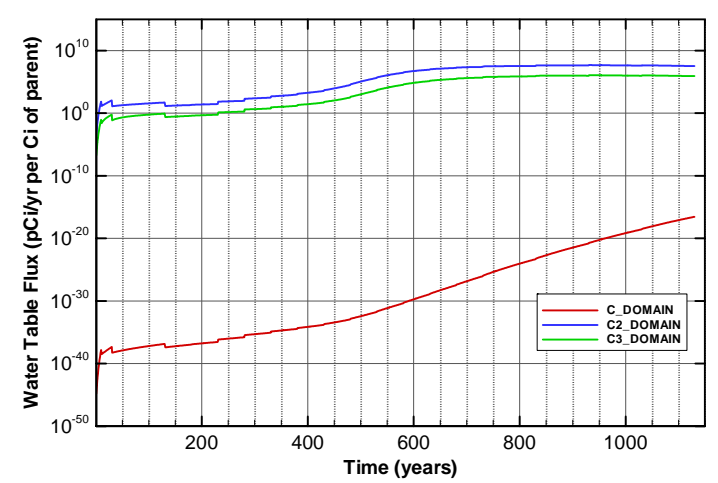

Figure A-1433. Flux at water table for Case01_on U-235

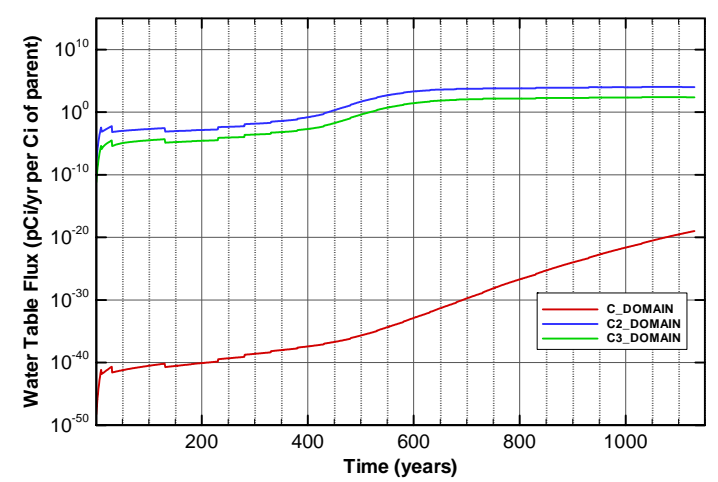

Figure A-1435. Flux at water table for Case01_on U-235_Paducah.Cask

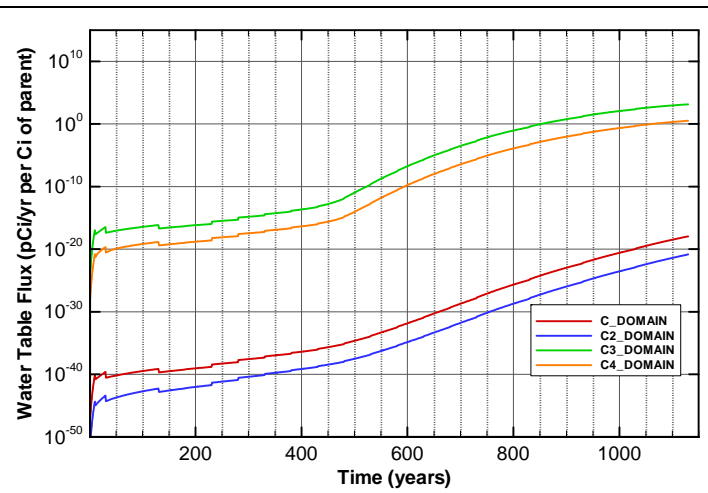

Figure A-1432. Flux at water table for Case01_on U-234_Mglass

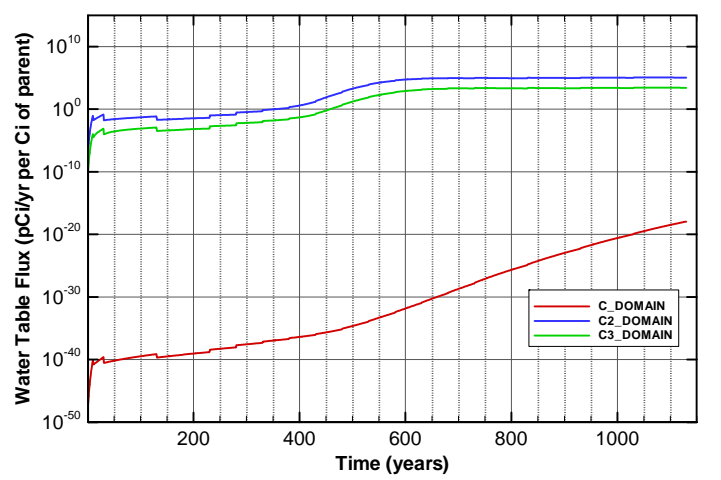

Figure A-1434. Flux at water table for Case01_on U-235_Mglass

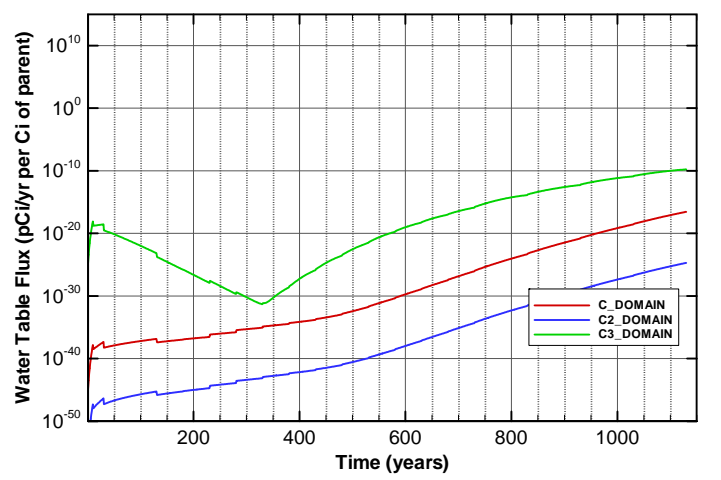

Figure A-1436. Flux at water table for Case01_on U-236 
SRNL-STI-2008-00397, REVISION 0

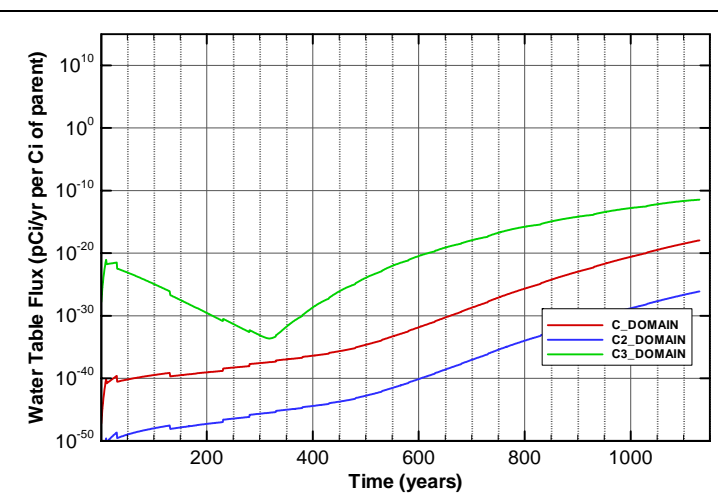

Figure A-1437. Flux at water table for Case01_on U-236_Mglass

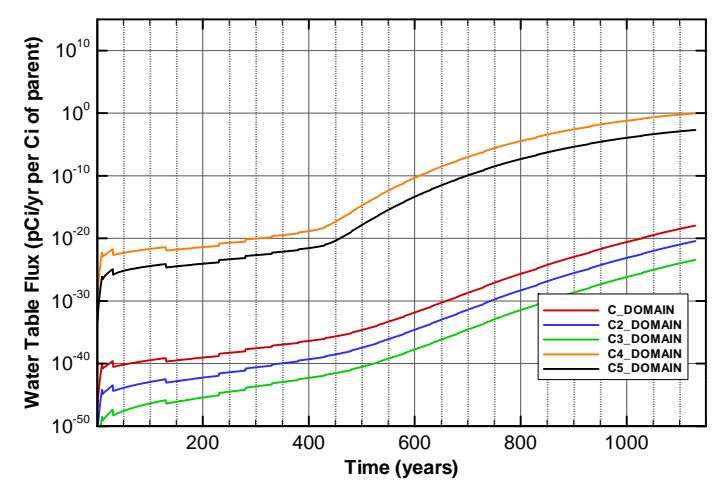

Figure A-1439. Flux at water table for Case01_on U-238_Mglass

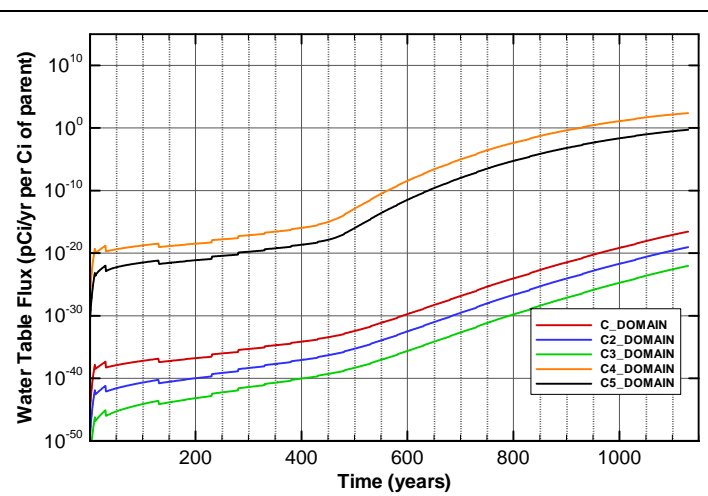

Figure A-1438. Flux at water table for Case01_on U-238

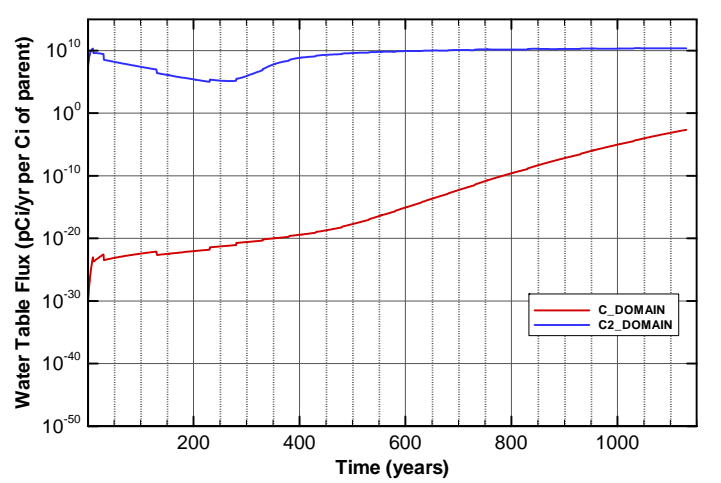

Figure A-1440. Flux at water table for Case01_on Zr-93 


\subsection{PLOTS OF CONCENTRATIONS AT A HYPOTHETICAL 100-M WELL}

Plots of concentrations at a hypothetical well are presented in sections. All well concentration plots are per g-mole of parent disposed. Because the fluxes at the water table from the center and edge trenches are combined in the aquifer models, the major sections presented above for the vadose zone do not apply to the aquifer. However, the aquifer model cases match the vadose zone model cases as described in Table A- 1.

Five aquifer scenarios were analyzed as follows:

\begin{tabular}{|l|l|}
\hline $\begin{array}{l}\text { Time of cover } \\
(\mathrm{yr})\end{array}$ & $\begin{array}{l}\text { Number of covers over } \\
\text { ST1 to ST4 }\end{array}$ \\
\hline 15 & 1 \\
\hline 5 & 1 \\
\hline 15 & 2 \\
\hline 5 & 2 \\
\hline 10 & 2 \\
\hline
\end{tabular}

Because results for 2 covers (one cover over ST1 and ST2 and one cover over ST3 and ST4) varied little from results for 1 cover, only results from two covers are presented below.

\subsubsection{Concentration plots for 15-year cover}

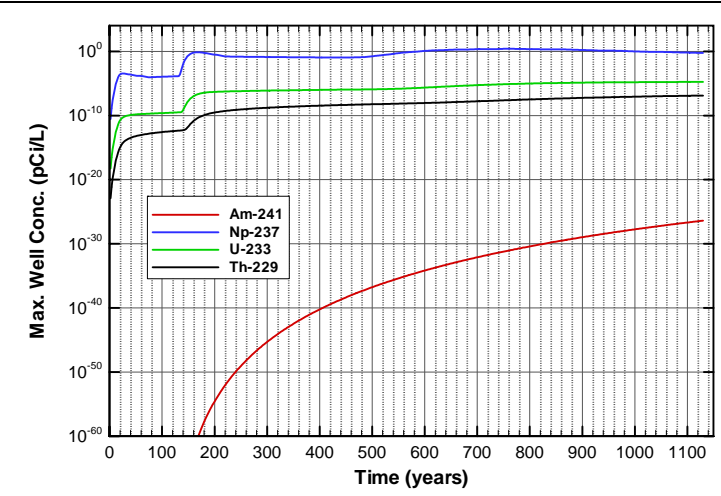

Figure A-1441. Well concentrations for Case01n11_off Am-241

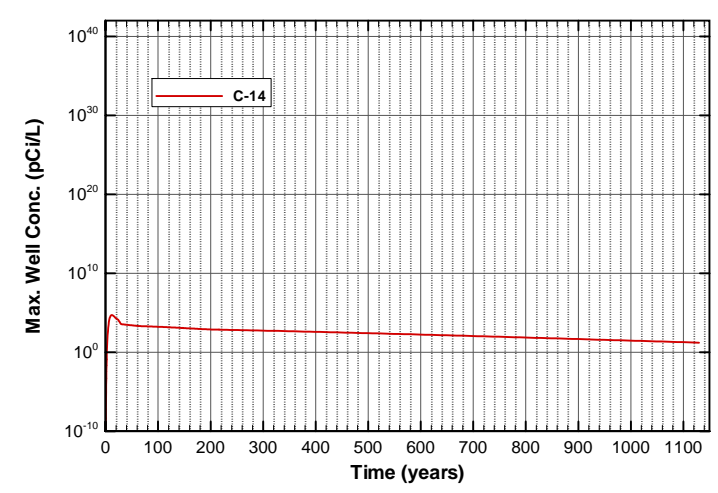

Figure A-1443. Well concentrations for Case01n11_off C-14

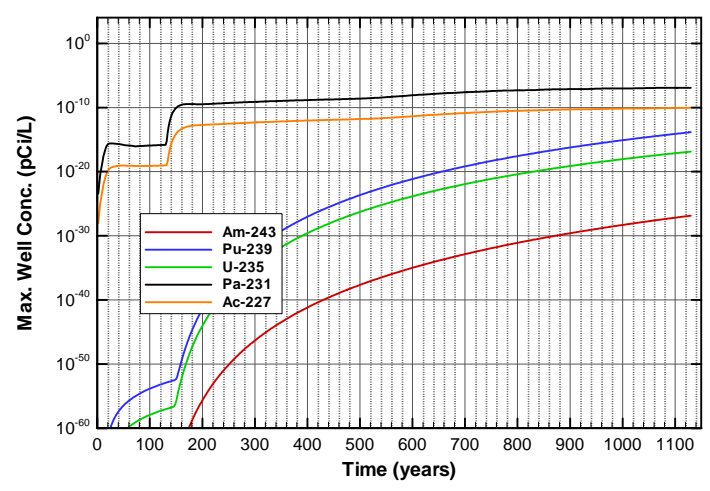

Figure A-1442. Well concentrations for Case01n11_off Am-243

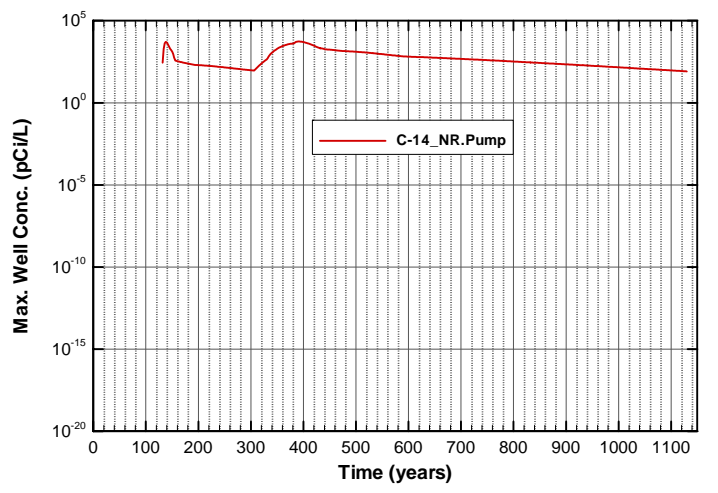

Figure A-1444. Well concentrations for Case01n11_off C-14_NR.Pump 
SRNL-STI-2008-00397, REVISION 0

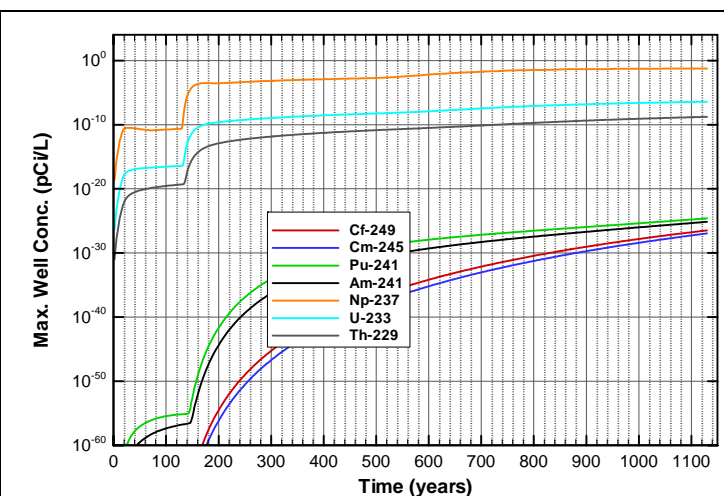

Figure A-1445. Well concentrations for Case01n11_off Cf-249

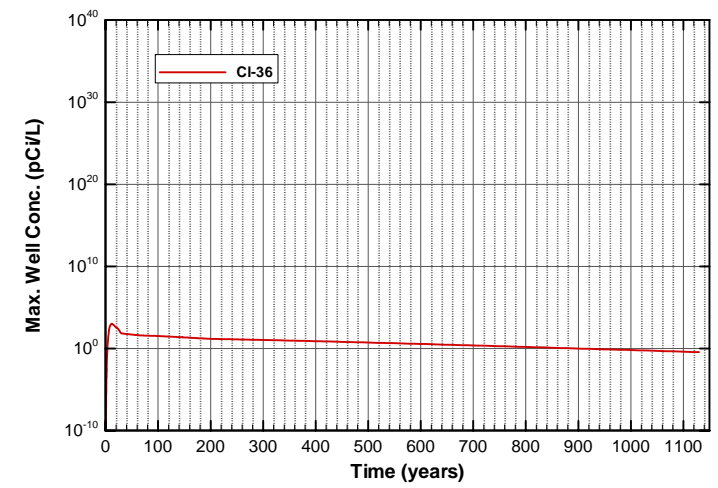

Figure A-1447. Well concentrations for Case01n11_off Cl-36

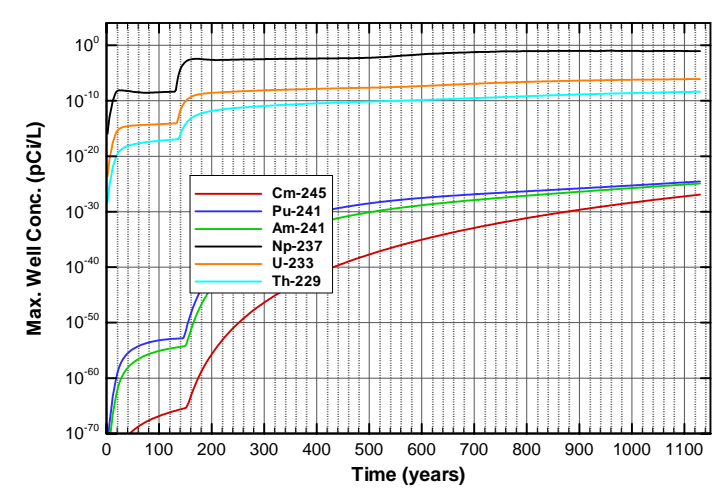

Figure A-1449. Well concentrations for Case01n11_off Cm-245

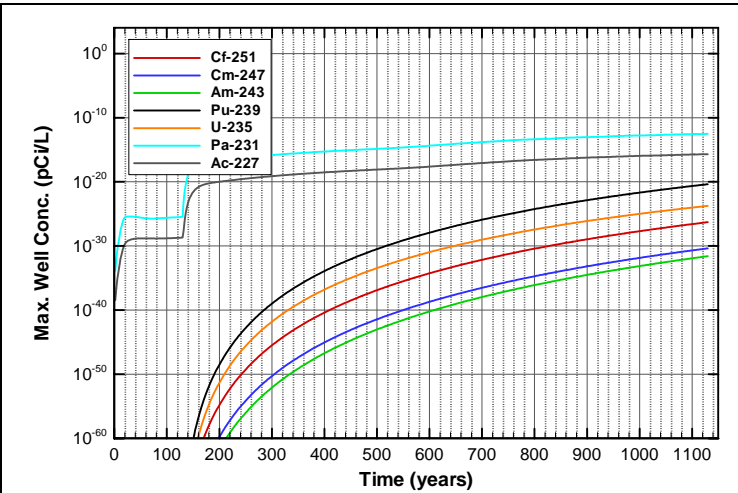

Figure A-1446. Well concentrations for Case01n11_off Cf-251

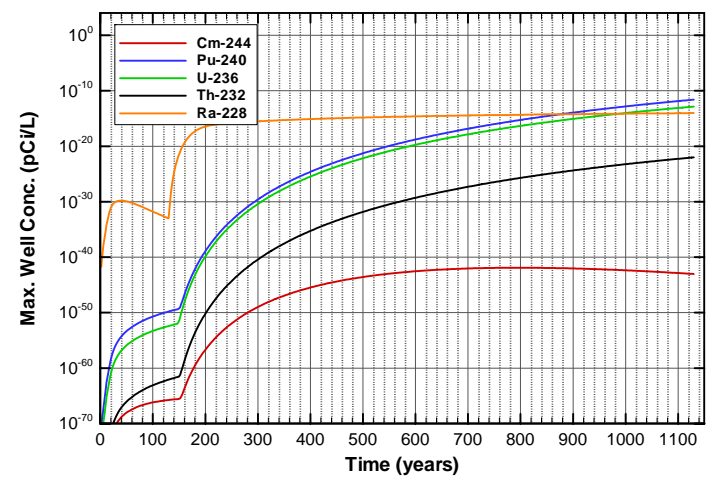

Figure A-1448. Well concentrations for Case01n11_off Cm-244

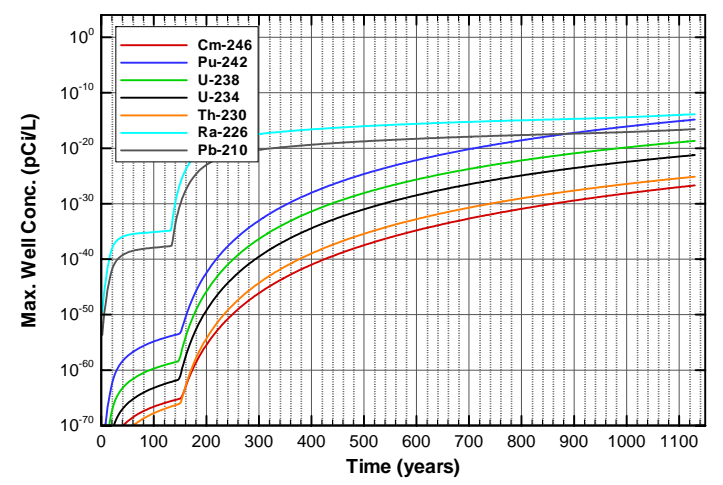

Figure A-1450. Well concentrations for Case01n11_off Cm-246 
SRNL-STI-2008-00397, REVISION 0

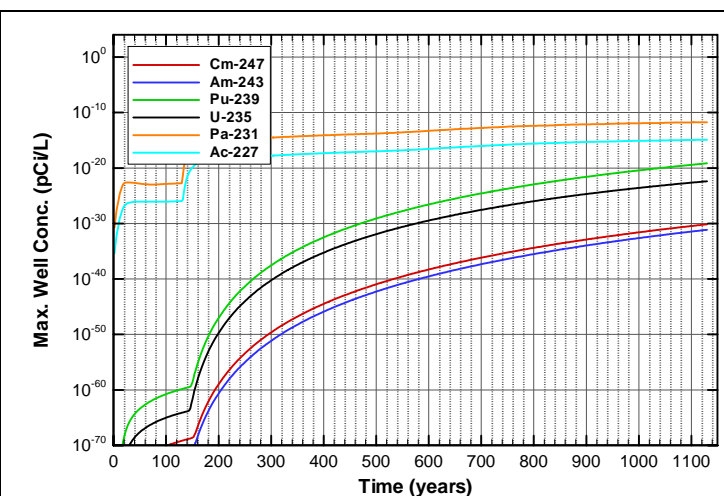

Figure A-1451. Well concentrations for Case01n11_off Cm-247

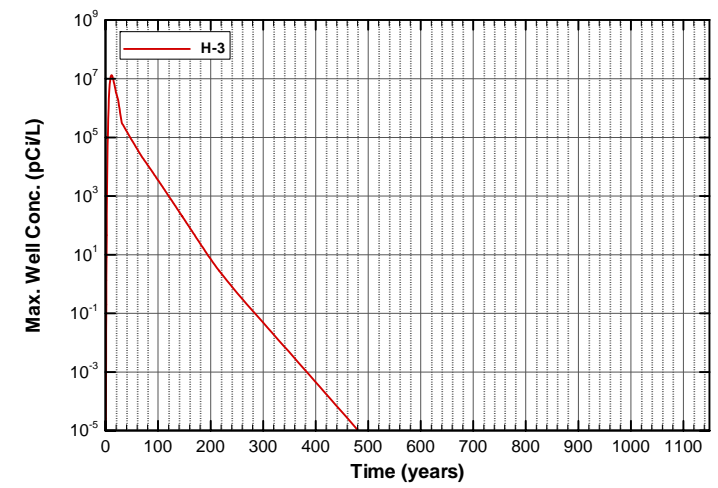

Figure A-1453. Well concentrations for Case01n11_off H-3

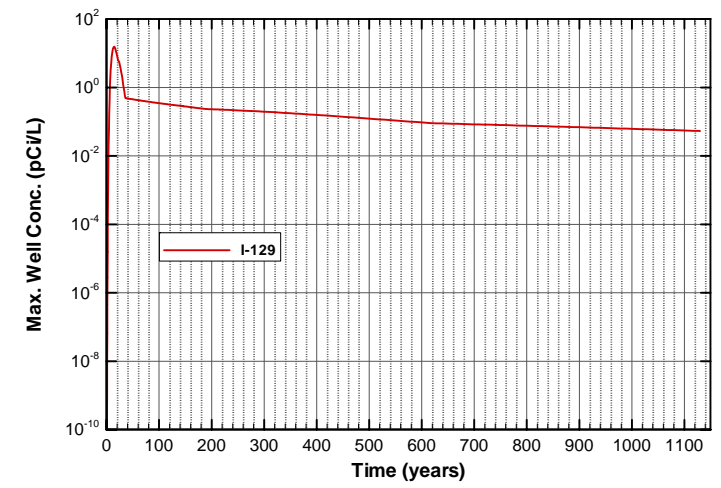

Figure A-1455. Well concentrations for Case01n11_off I-129

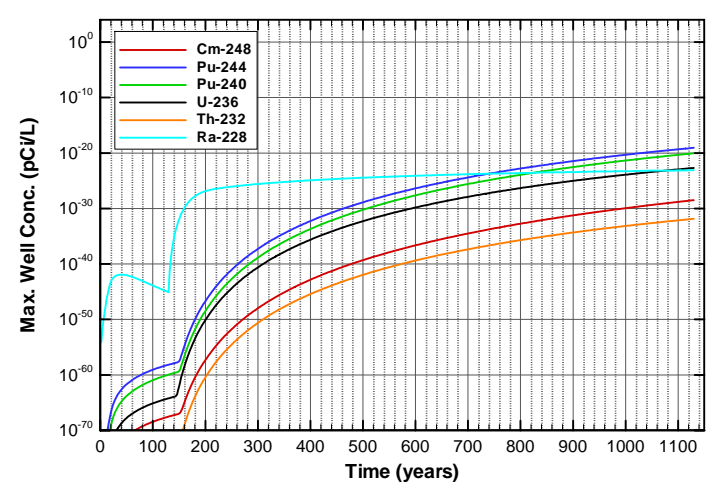

Figure A-1452. Well concentrations for Case01n11_off Cm-248

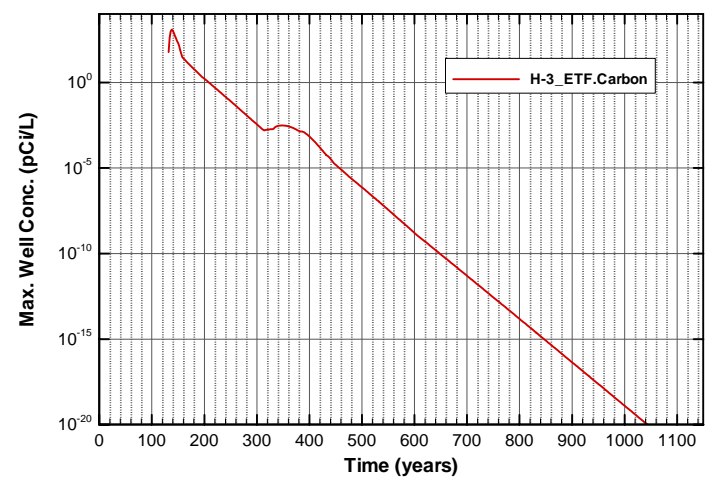

Figure A-1454. Well concentrations for Case01n11_off H-3_ETF.Carbon

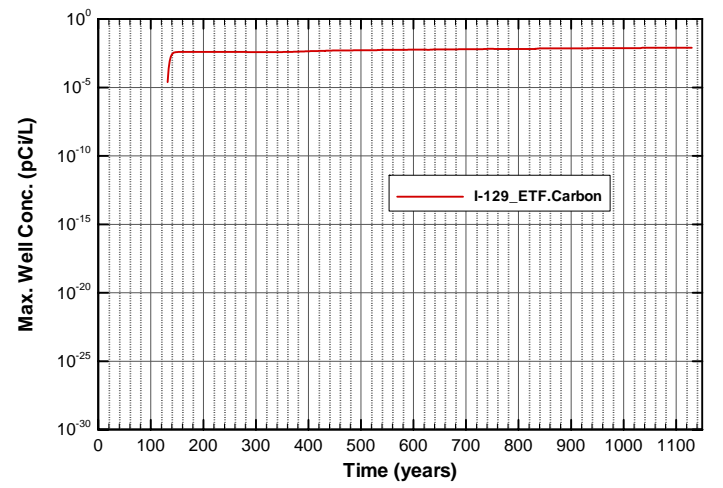

Figure A-1456. Well concentrations for Case01n11_off I-129_ETF.Carbon 
SRNL-STI-2008-00397, REVISION 0

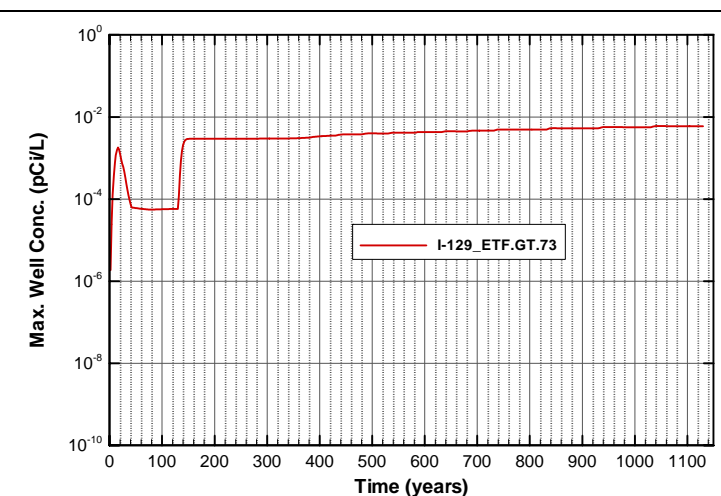

Figure A-1457. Well concentrations for Case01n11_off I-129_ETF.GT.73

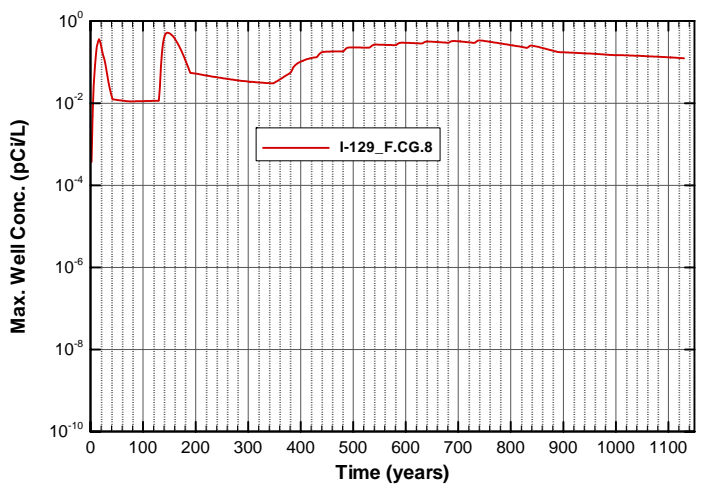

Figure A-1459. Well concentrations for Case01n11_off I-129_F.CG.8

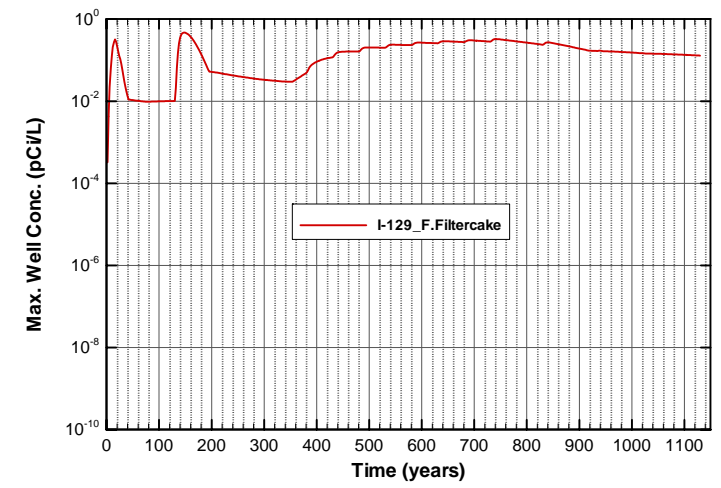

Figure A-1461. Well concentrations for Case01n11_off I-129_F.Filtercake

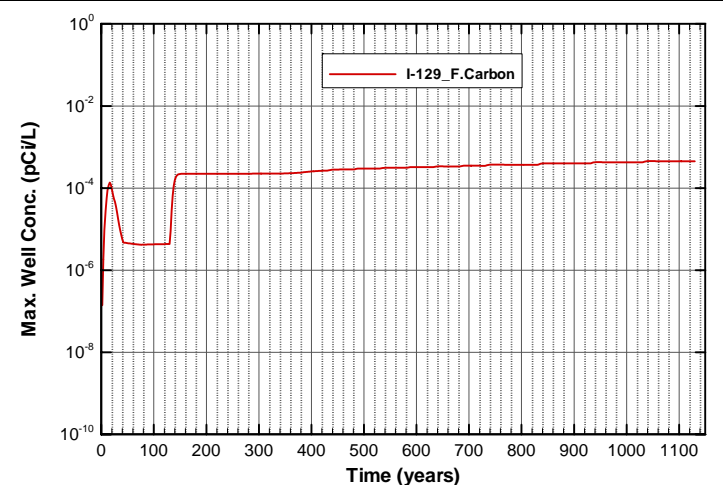

Figure A-1458. Well concentrations for Case01n11_off I-129_F.Carbon

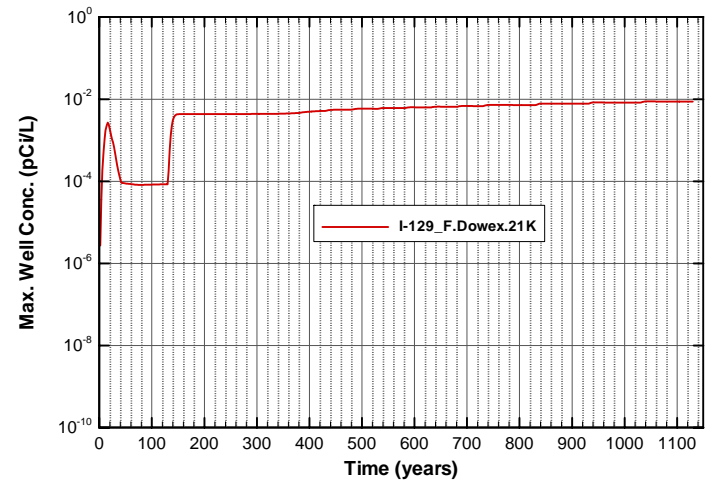

Figure A-1460. Well concentrations for Case01n11_off I-129_F.Dowex.21K

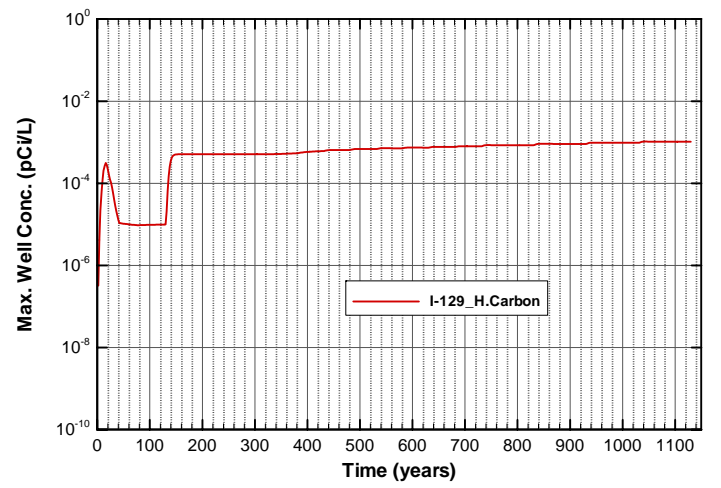

Figure A-1462. Well concentrations for Case01n11_off I-129_H.Carbon 


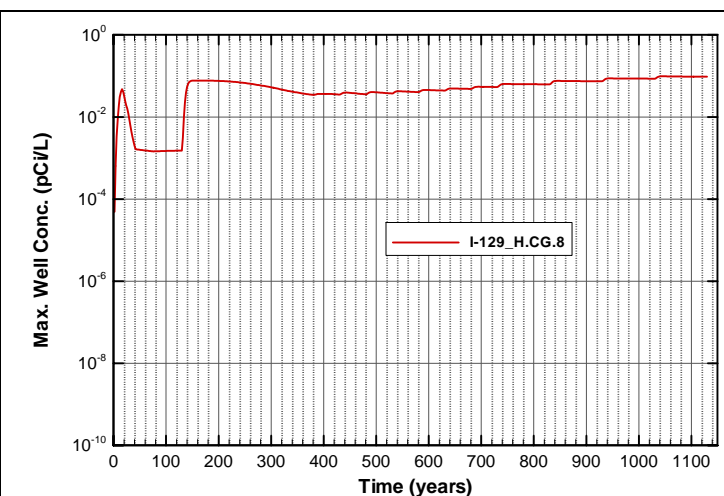

Figure A-1463. Well concentrations for Case01n11_off I-129_H.CG.8

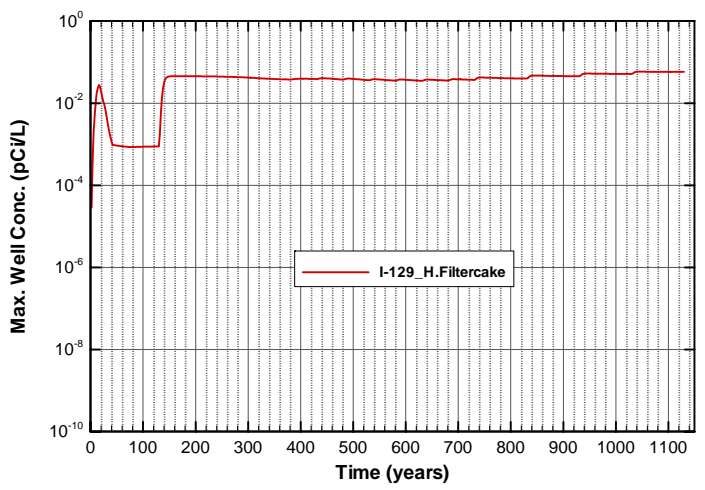

Figure A-1465. Well concentrations for Case01n11_off I-129_H.Filtercake

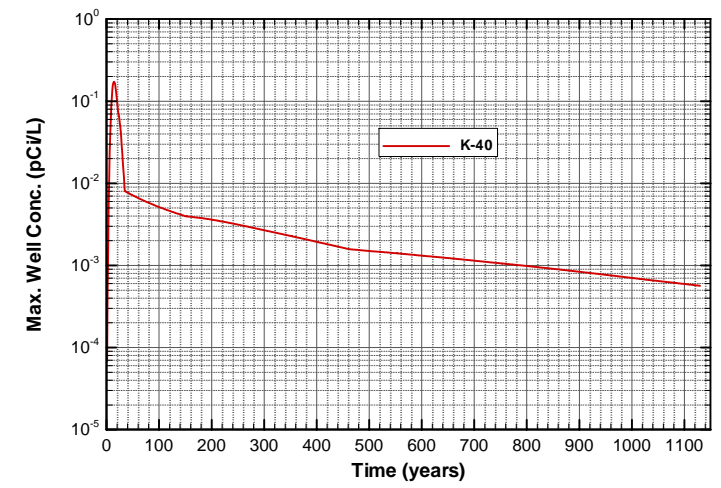

Figure A-1467. Well concentrations for Case01n11_off K-40

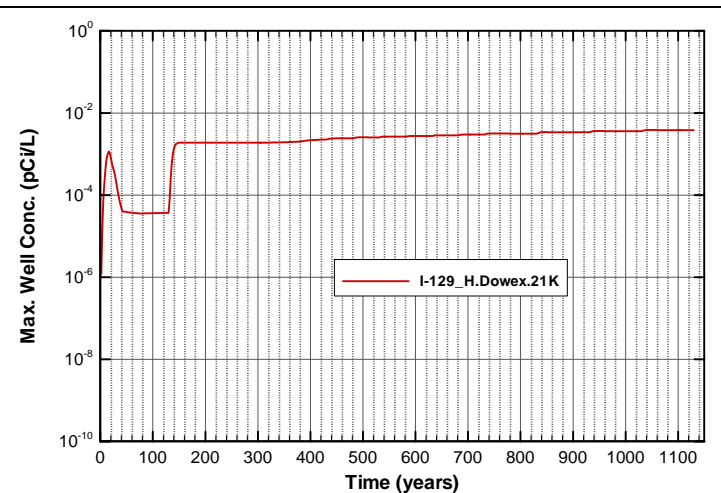

Figure A-1464. Well concentrations for Case01n11_off I-129_H.Dowex.21K

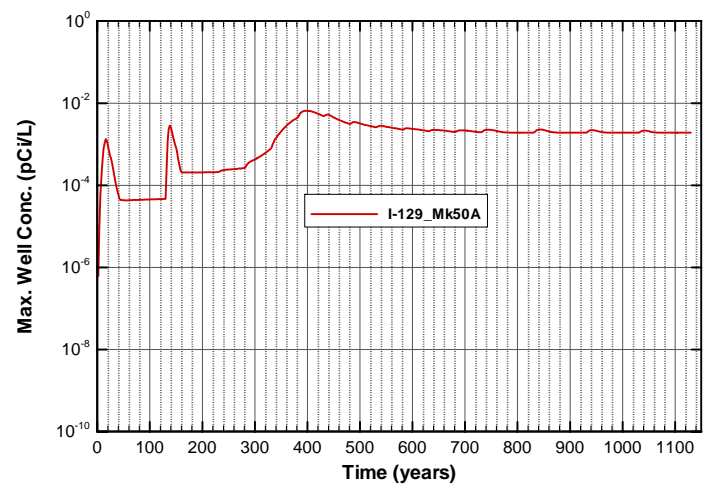

Figure A-1466. Well concentrations for Case01n11_off I-129_Mk50A

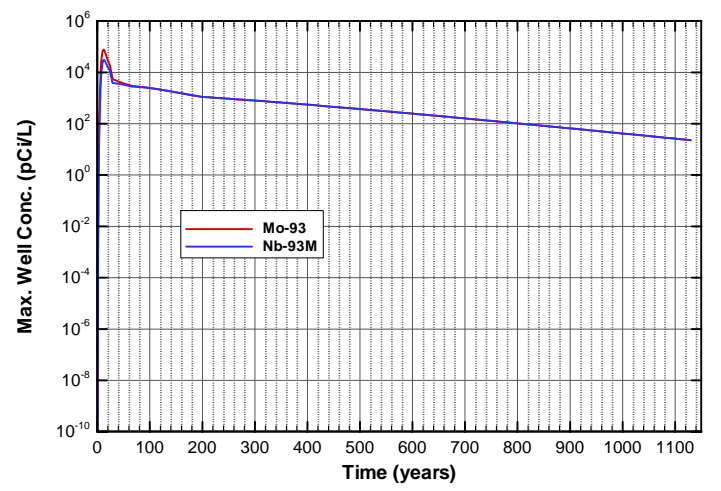

Figure A-1468. Well concentrations for Case01n11_off Mo-93 
SRNL-STI-2008-00397, REVISION 0

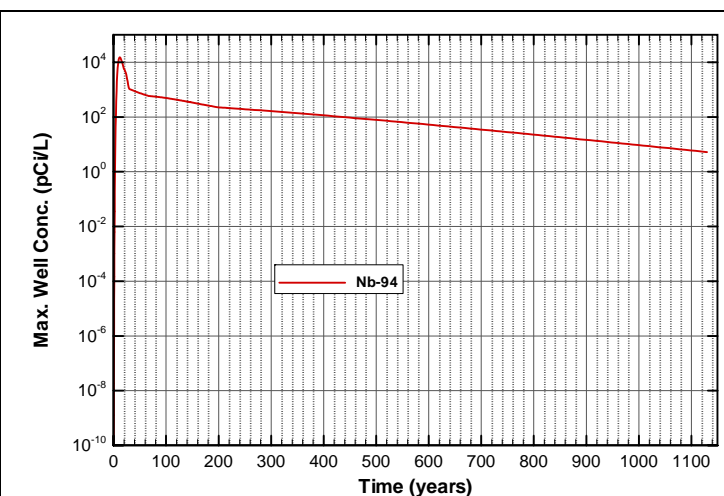

Figure A-1469. Well concentrations for Case01n11_off Nb-94

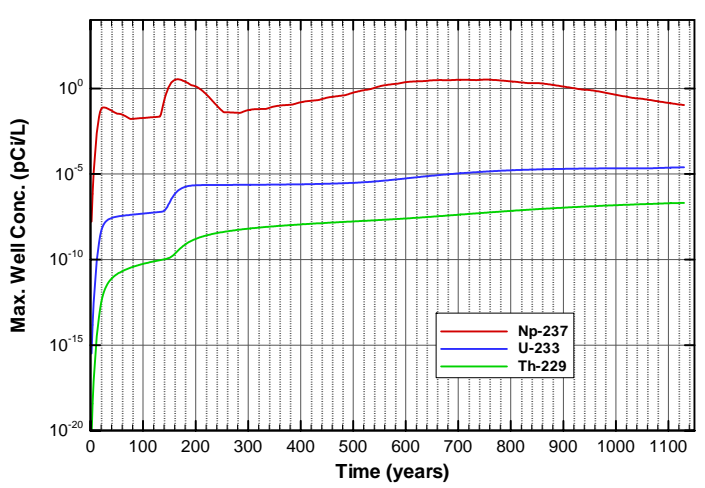

Figure A-1471. Well concentrations for Case01n11_off Np-237

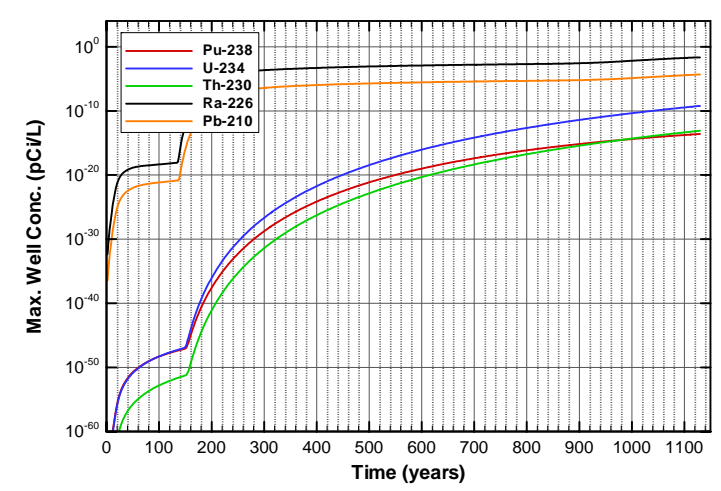

Figure A-1473. Well concentrations for Case01n11_off Pu-238

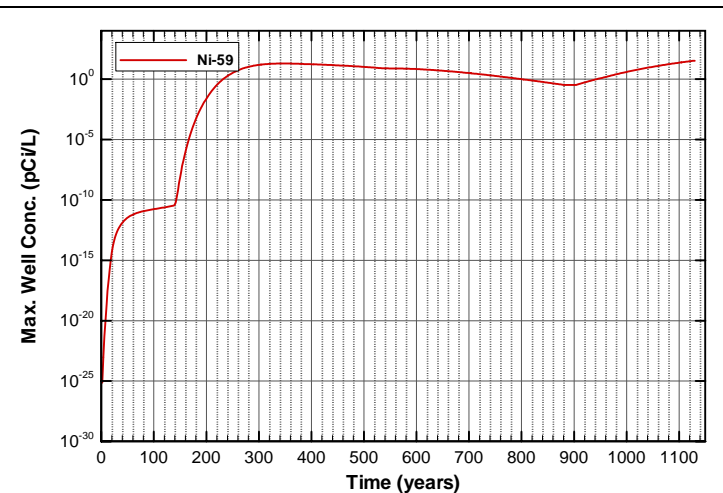

Figure A-1470. Well concentrations for Case01n11_off Ni-59

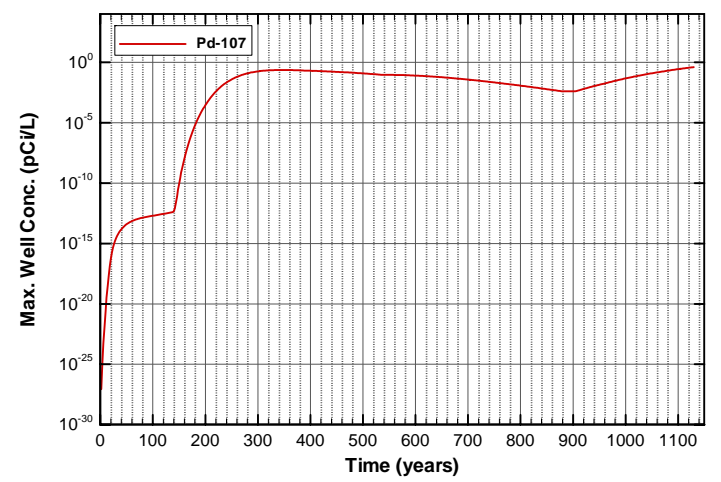

Figure A-1472. Well concentrations for Case01n11_off Pd-107

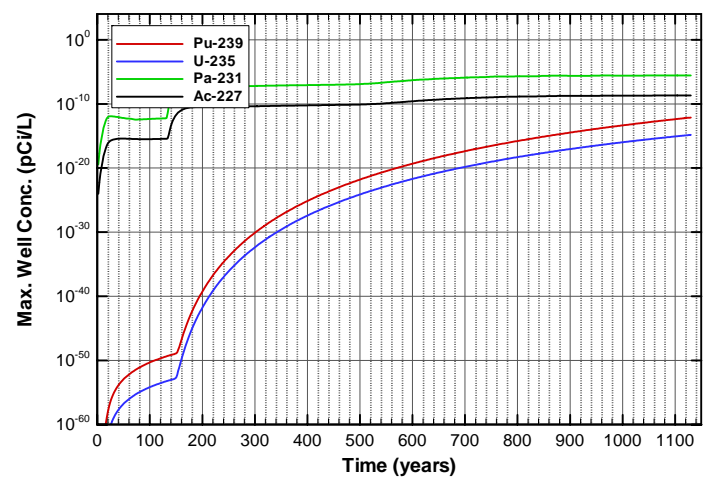

Figure A-1474. Well concentrations for Case01n11_off Pu-239 
SRNL-STI-2008-00397, REVISION 0

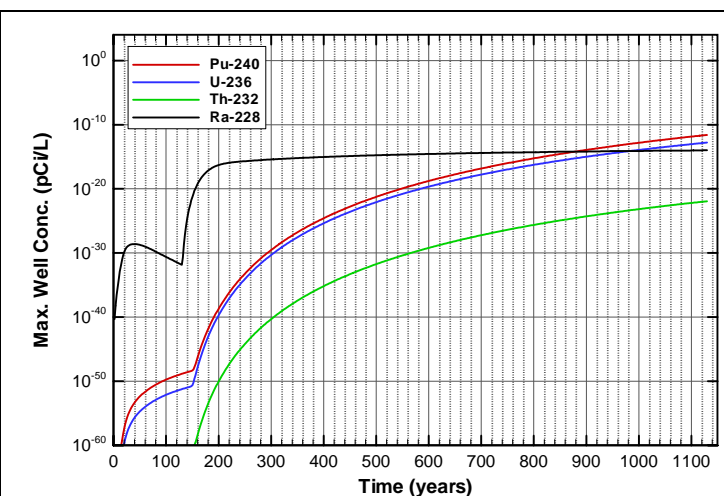

Figure A-1475. Well concentrations for Case01n11_off Pu-240

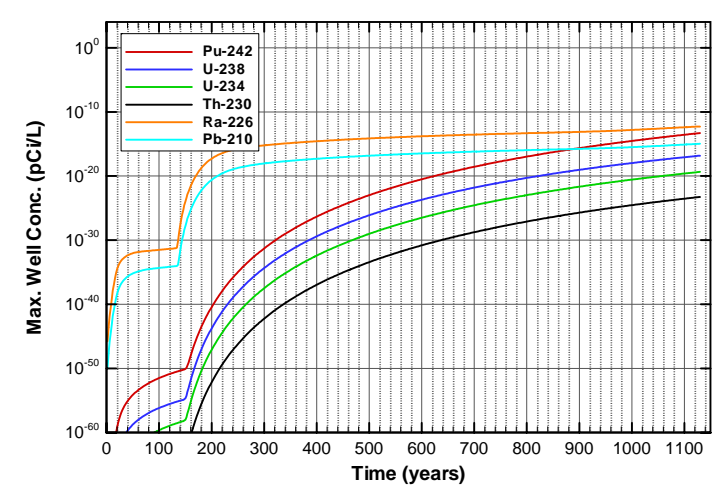

Figure A-1477. Well concentrations for Case01n11_off Pu-242

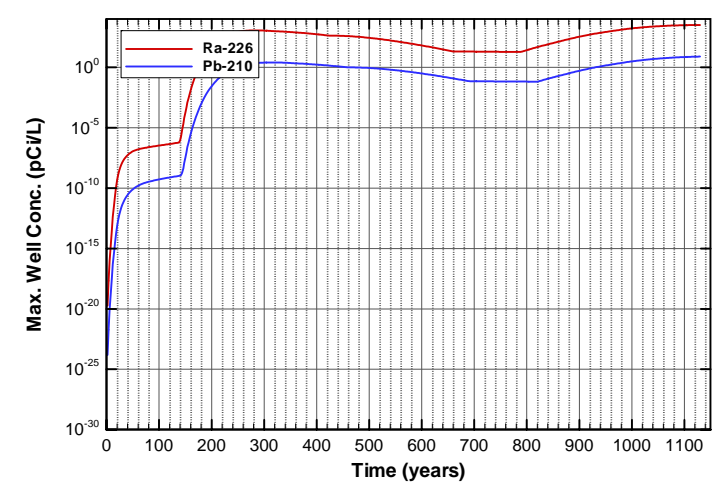

Figure A-1479. Well concentrations for Case01n11_off Ra-226

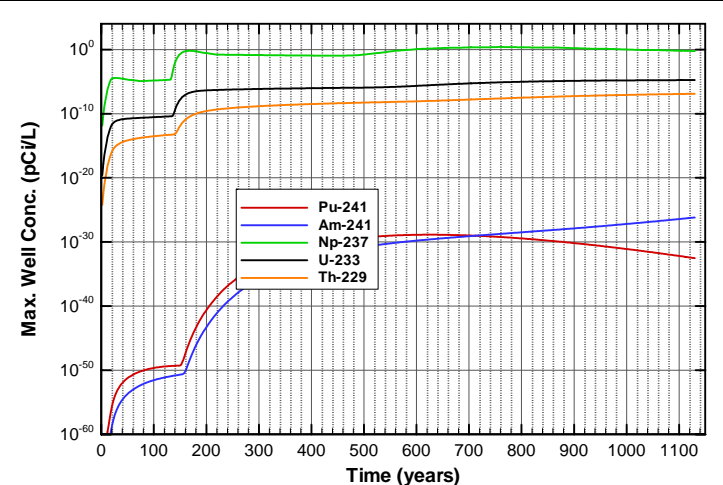

Figure A-1476. Well concentrations for Case01n11_off Pu-241

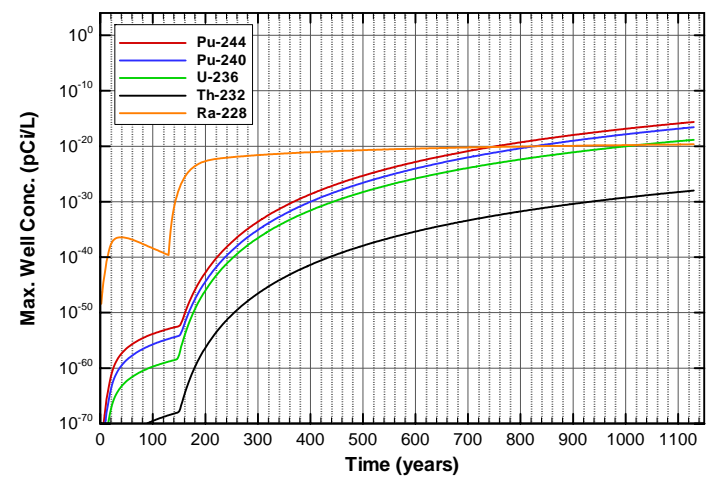

Figure A-1478. Well concentrations for Case01n11_off Pu-244

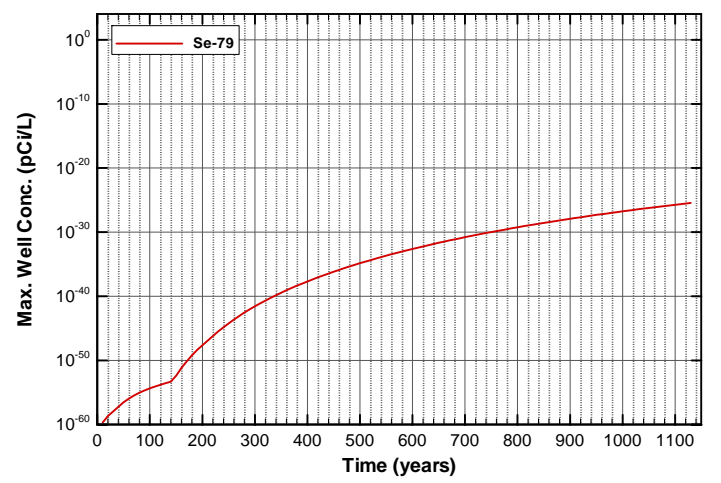

Figure A-1480. Well concentrations for Case01n11_off Se-79 
SRNL-STI-2008-00397, REVISION 0

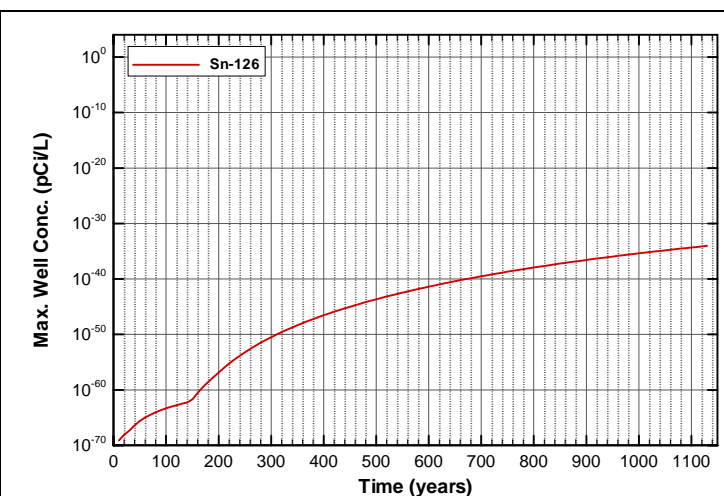

Figure A-1481. Well concentrations for Case01n11_off Sn-126

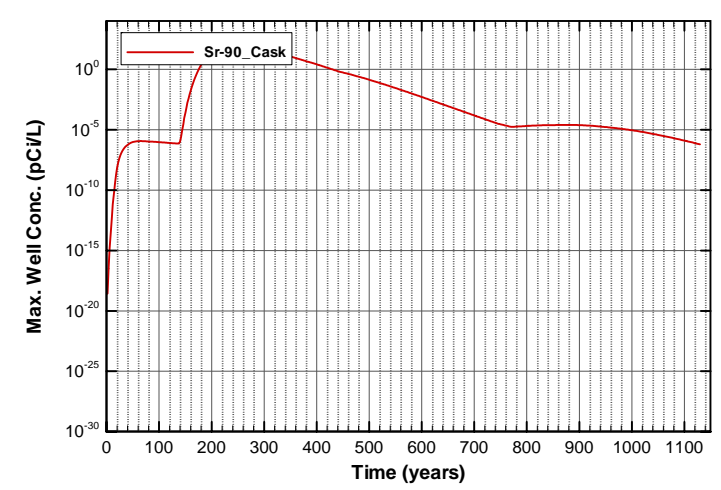

Figure A-1483. Well concentrations for Case01n11_off Sr-90_Cask

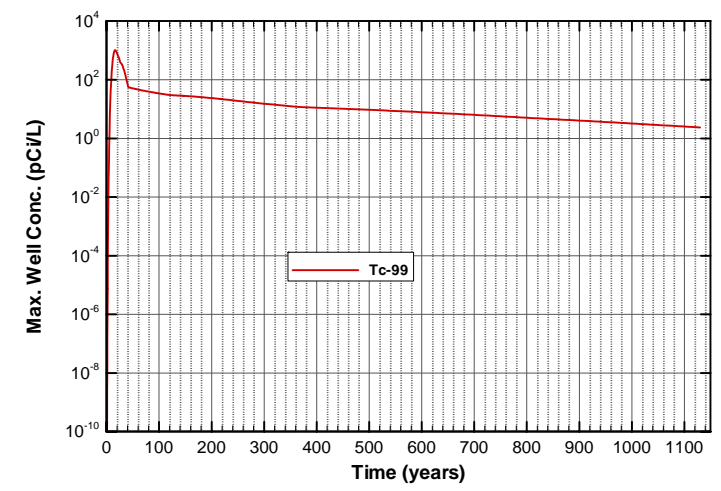

Figure A-1485. Well concentrations for Case01n11_off Tc-99

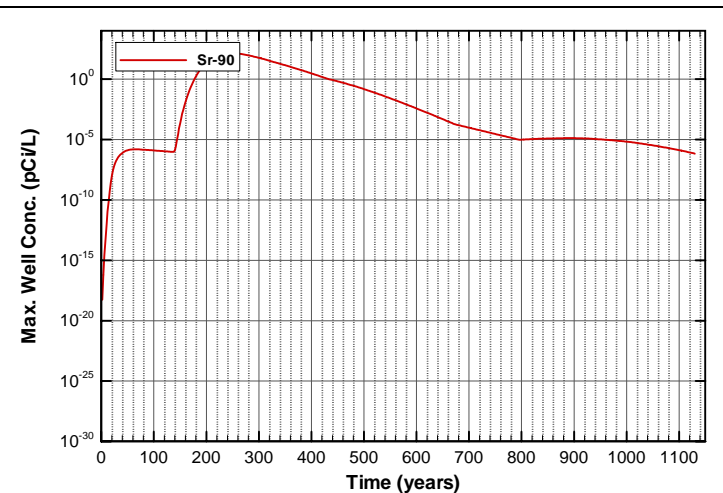

Figure A-1482. Well concentrations for Case01n11_off Sr-90

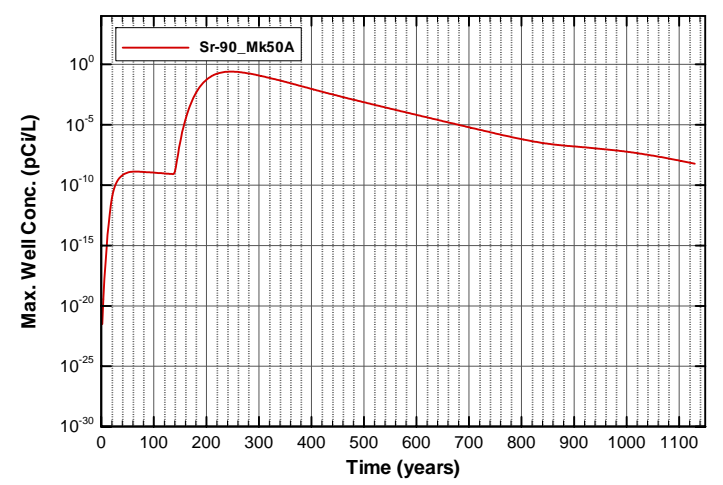

Figure A-1484. Well concentrations for Case01n11_off Sr-90_Mk50A

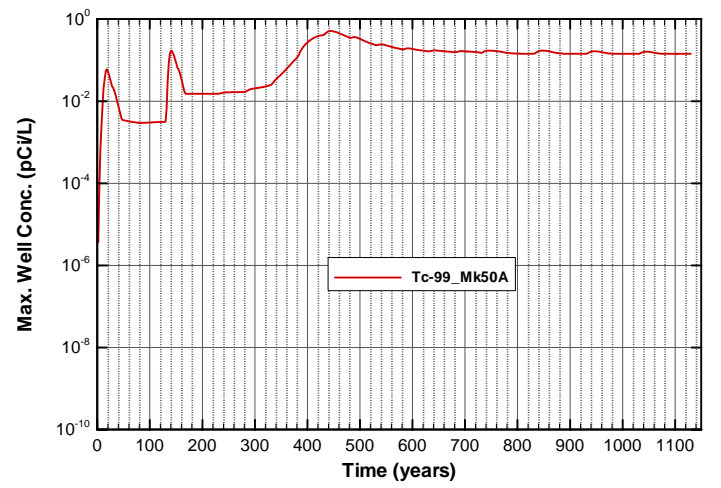

Figure A-1486. Well concentrations for Case01n11_off Tc-99_Mk50A 
SRNL-STI-2008-00397, REVISION 0

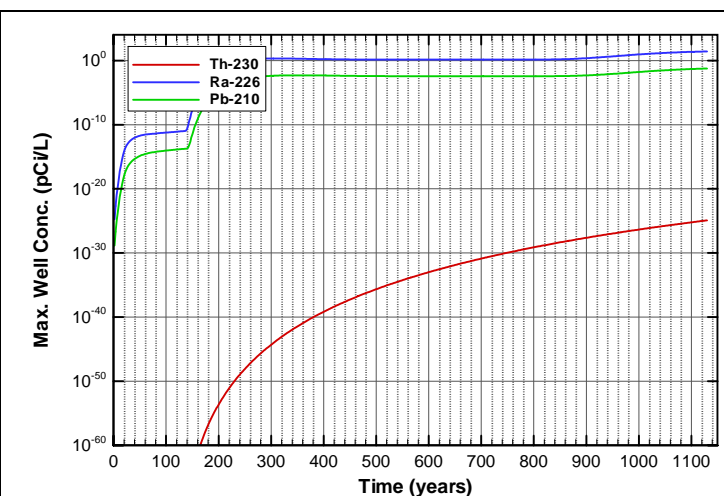

Figure A-1487. Well concentrations for Case01n11_off Th-230

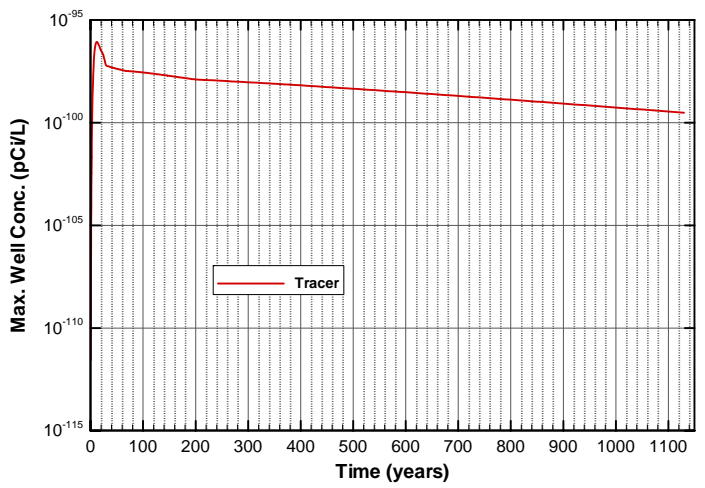

Figure A-1489. Well concentrations for Case01n11_off Tracer

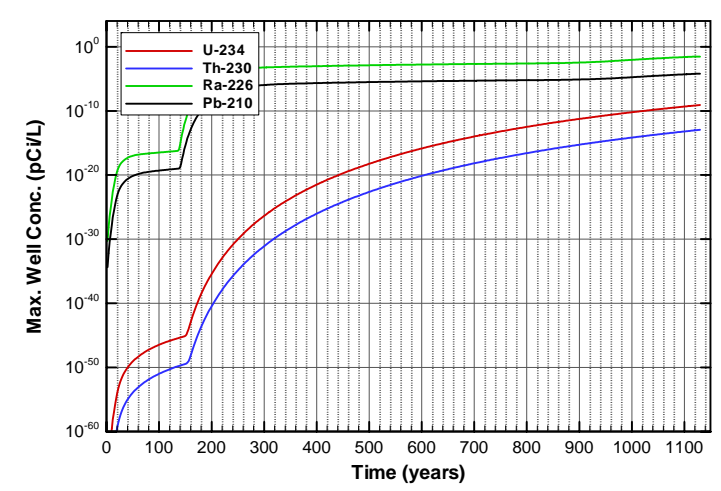

Figure A-1491. Well concentrations for Case01n11_off U-234

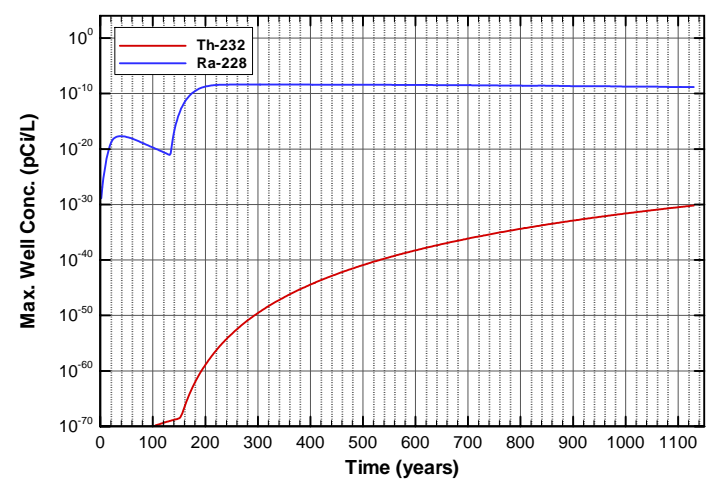

Figure A-1488. Well concentrations for Case01n11_off Th-232

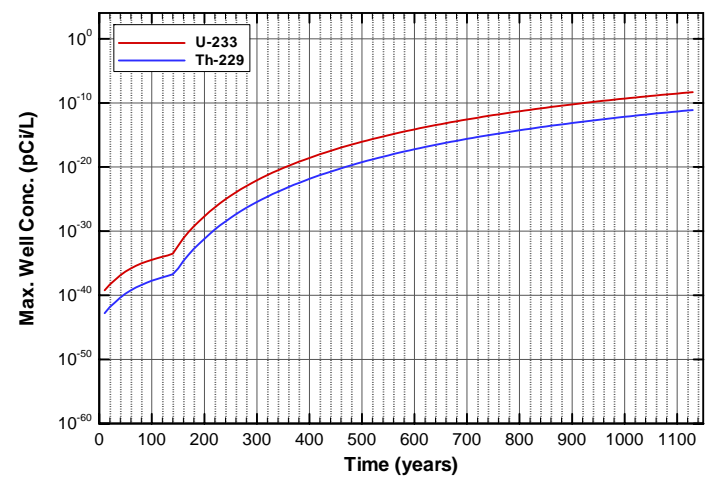

Figure A-1490. Well concentrations for Case01n11_off U-233

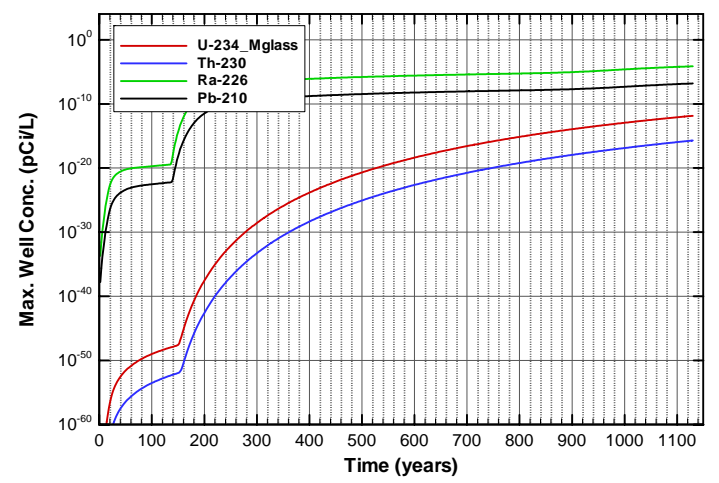

Figure A-1492. Well concentrations for Case01n11_off U-234_Mglass 
SRNL-STI-2008-00397, REVISION 0

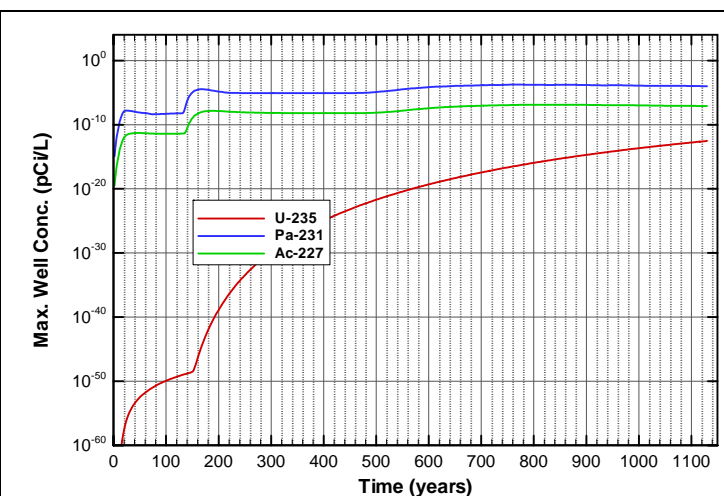

Figure A-1493. Well concentrations for Case01n11_off U-235

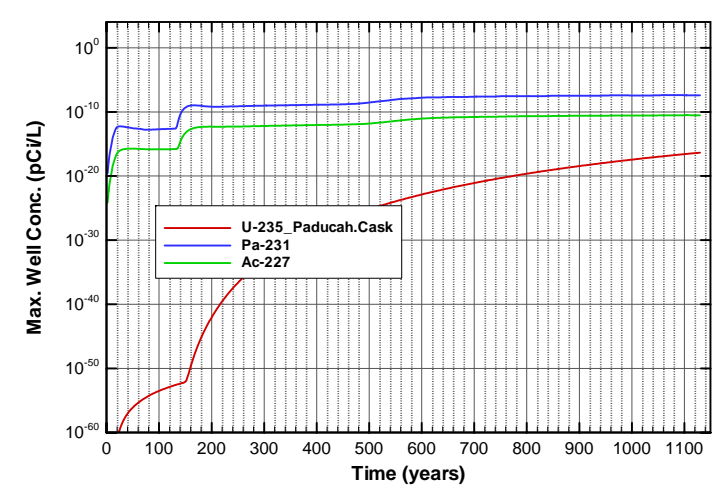

Figure A-1495. Well concentrations for Case01n11_off U-235_Paducah.Cask

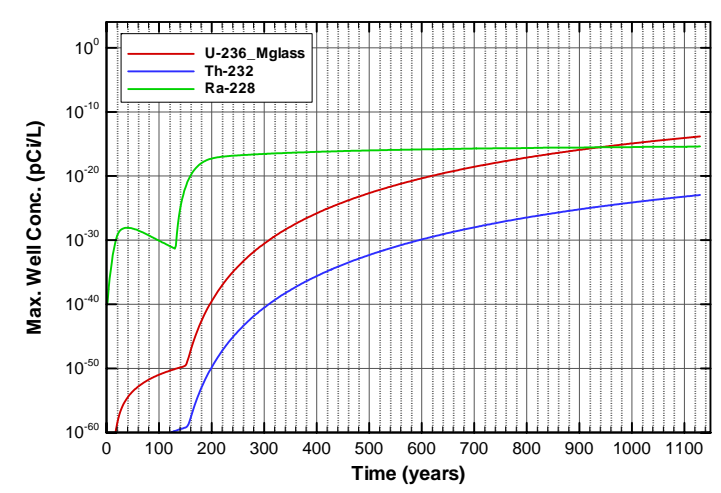

Figure A-1497. Well concentrations for Case01n11_off U-236_Mglass

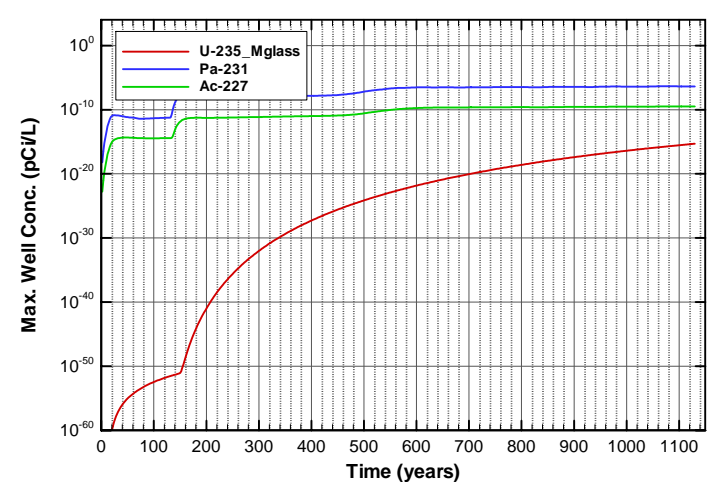

Figure A-1494. Well concentrations for Case01n11_off U-235_Mglass

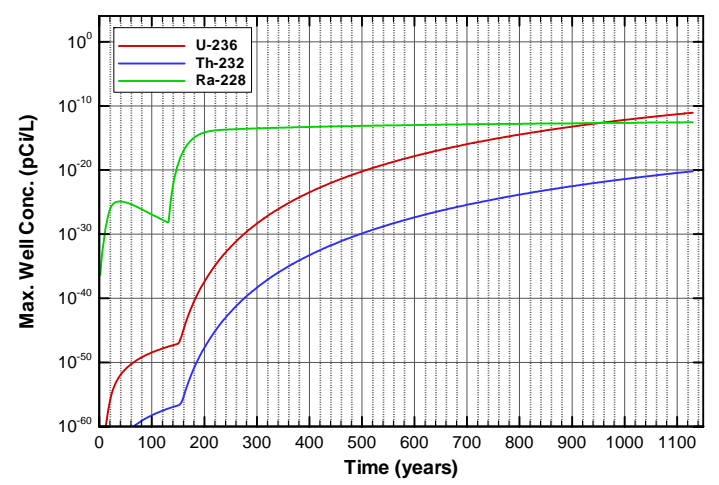

Figure A-1496. Well concentrations for Case01n11_off U-236

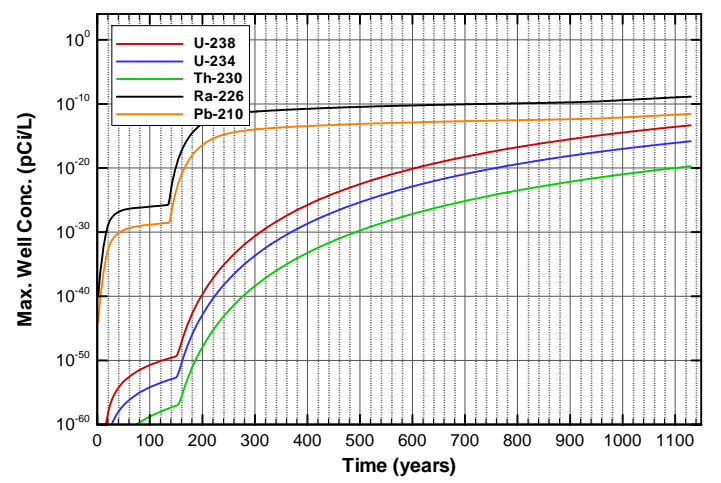

Figure A-1498. Well concentrations for Case01n11_off U-238 


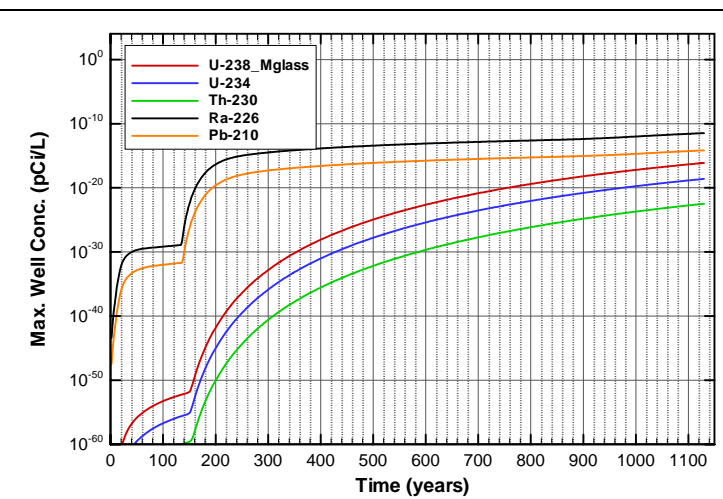

Figure A-1499. Well concentrations for Case01n11_off U-238_Mglass

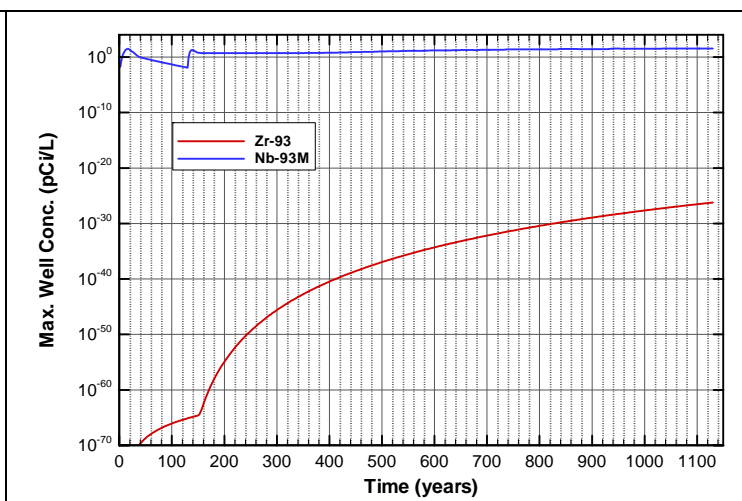

Figure A-1500. Well concentrations for Case01n11_off Zr-93

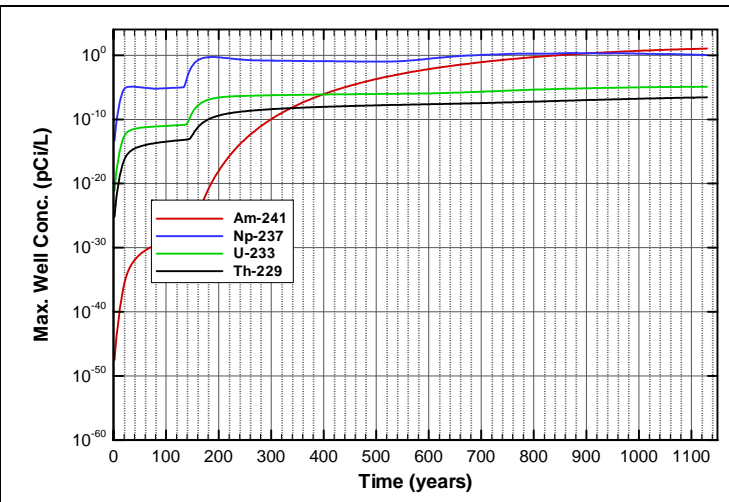

Figure A-1501. Well concentrations for Case01n11_on Am-241

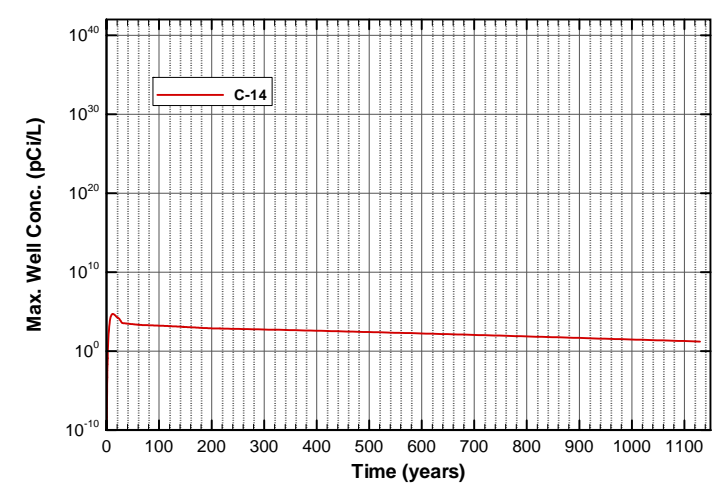

Figure A-1503. Well concentrations for Case01n11_on C-14

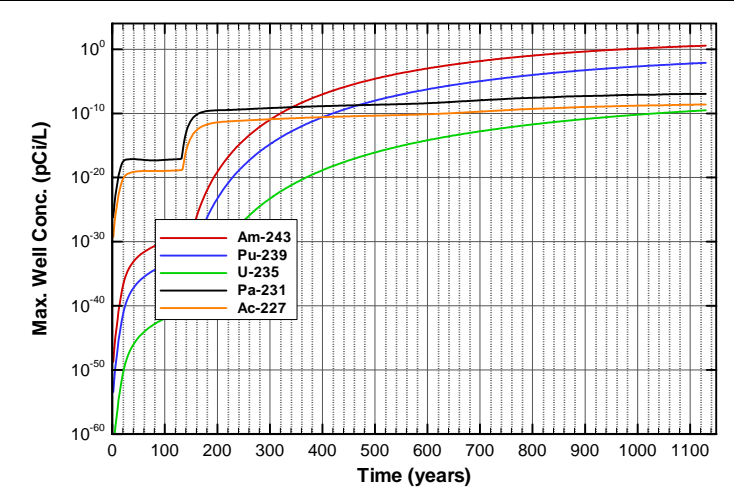

Figure A-1502. Well concentrations for Case01n11_on Am-243

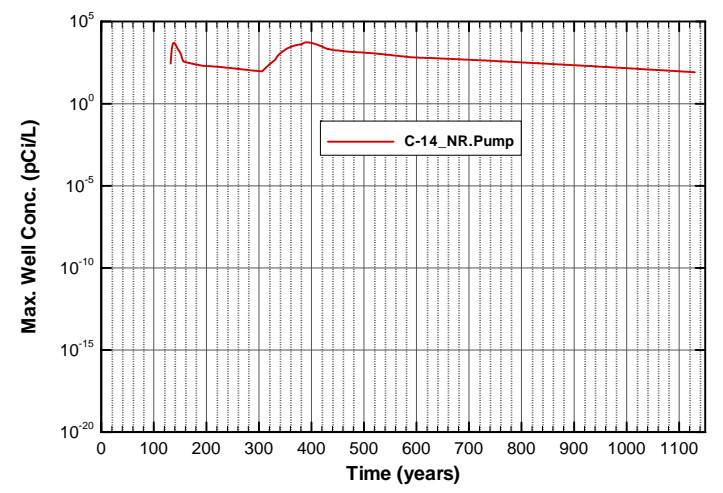

Figure A-1504. Well concentrations for Case01n11_on C-14_NR.Pump 
SRNL-STI-2008-00397, REVISION 0

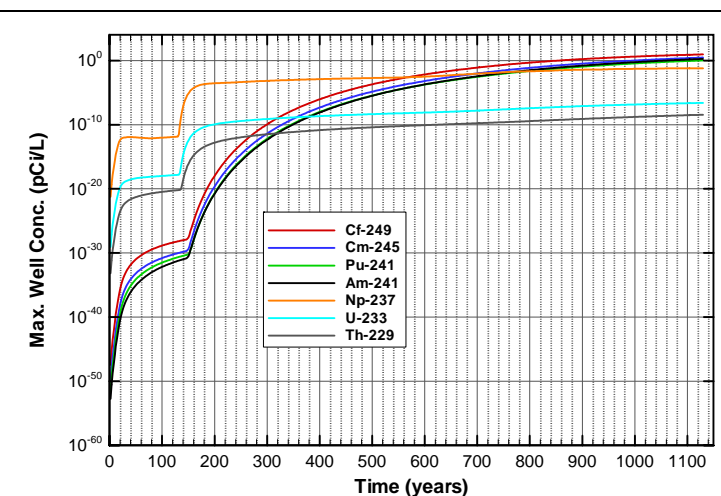

Figure A-1505. Well concentrations for Case01n11_on Cf-249

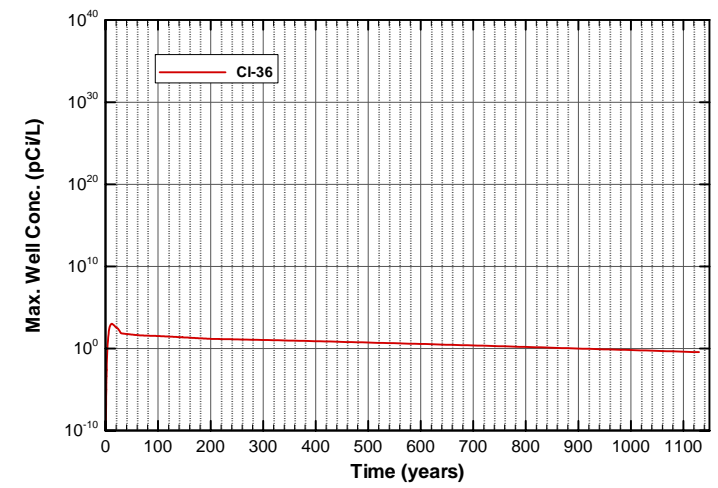

Figure A-1507. Well concentrations for Case01n11_on Cl-36

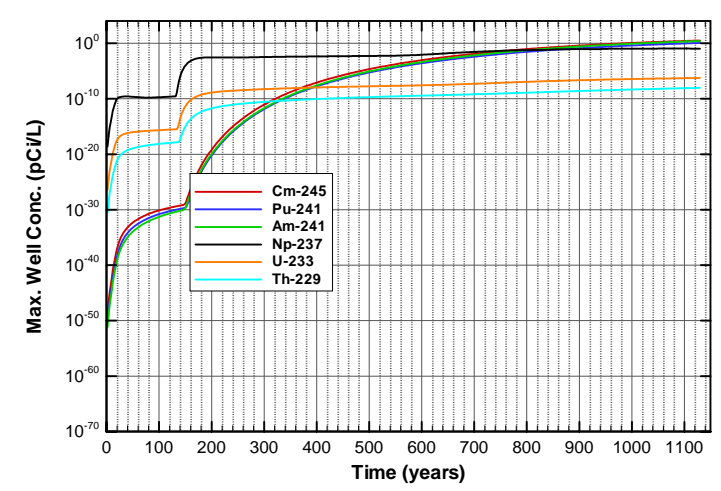

Figure A-1509. Well concentrations for Case01n11_on Cm-245

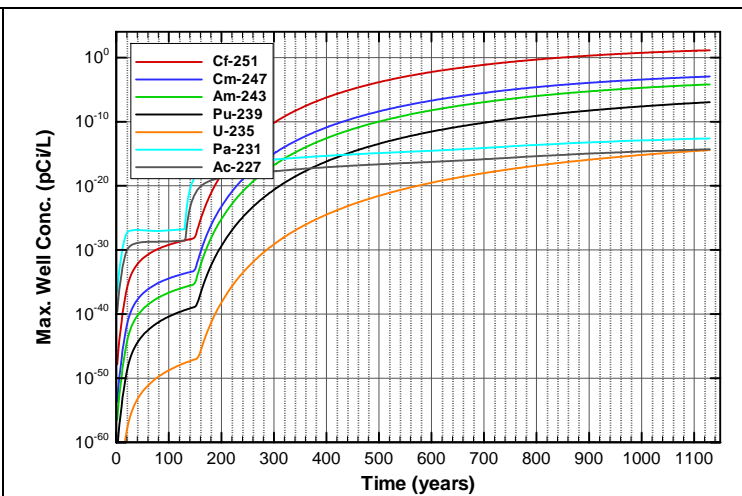

Figure A-1506. Well concentrations for Case01n11_on Cf-251

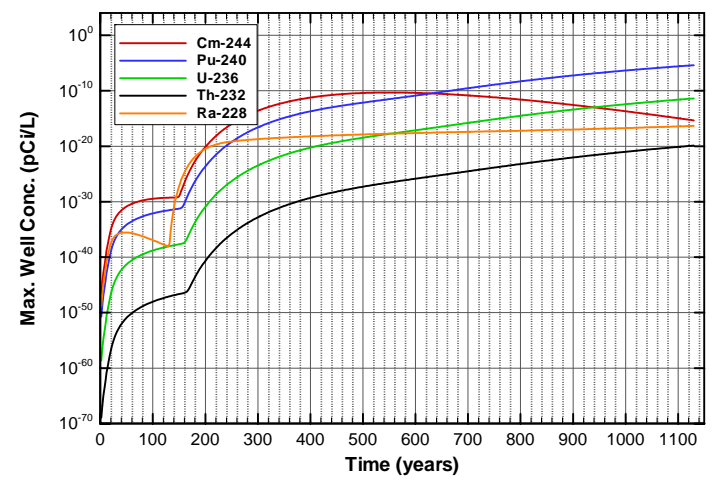

Figure A-1508. Well concentrations for Case01n11_on Cm-244

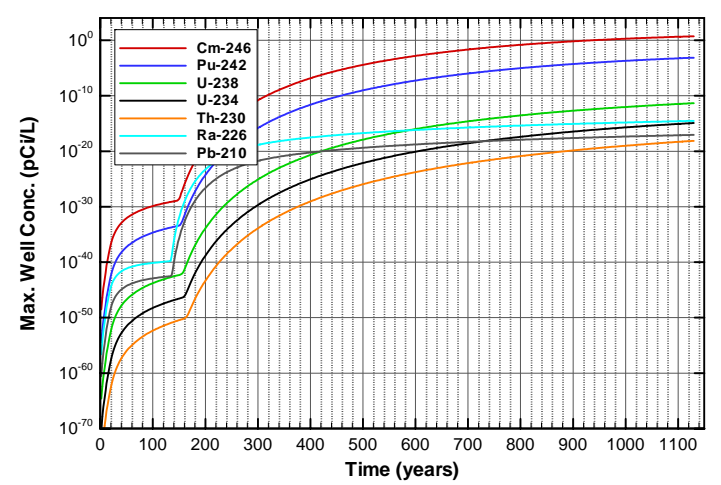

Figure A-1510. Well concentrations for Case01n11_on Cm-246 


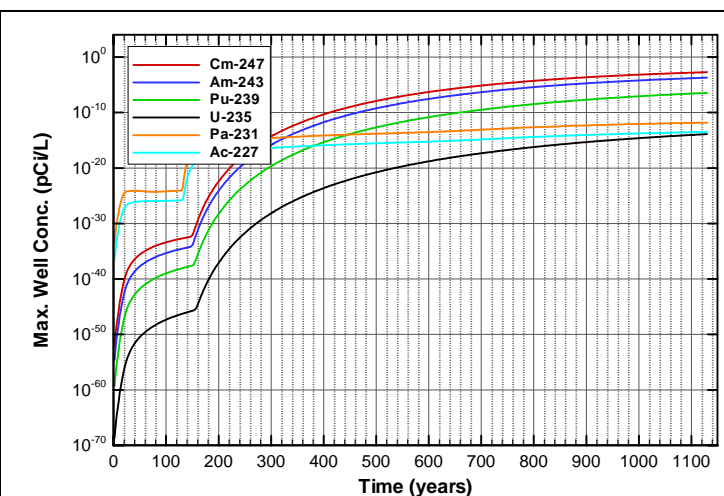

Figure A-1511. Well concentrations for Case01n11_on Cm-247

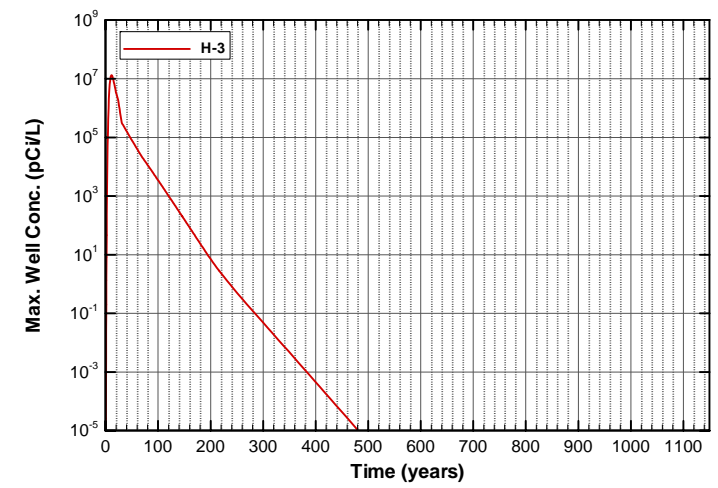

Figure A-1513. Well concentrations for Case01n11_on H-3

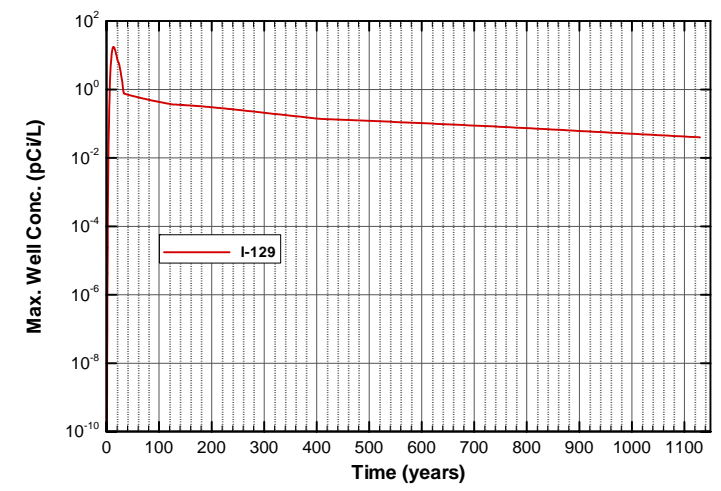

Figure A-1515. Well concentrations for Case01n11_on I-129

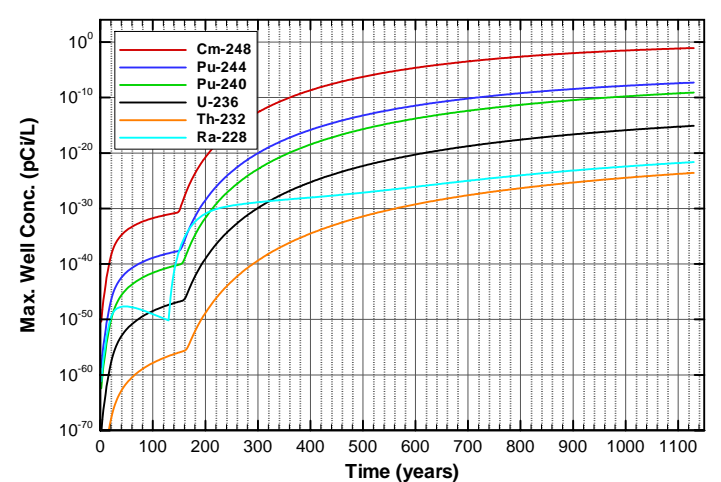

Figure A-1512. Well concentrations for Case01n11_on Cm-248

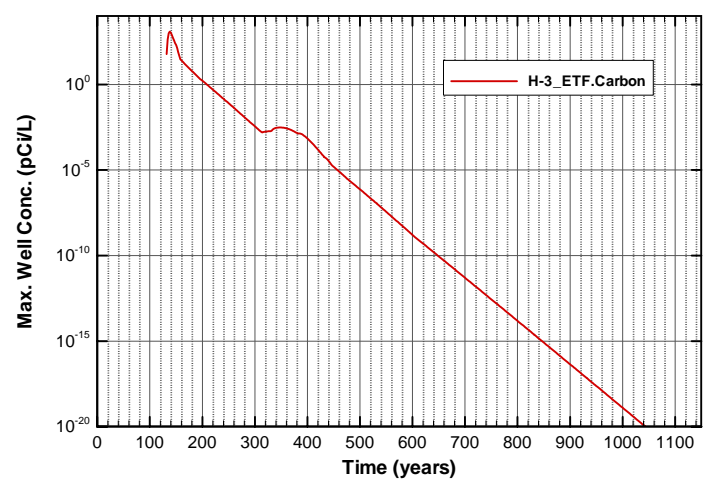

Figure A-1514. Well concentrations for Case01n11_on H-3_ETF.Carbon

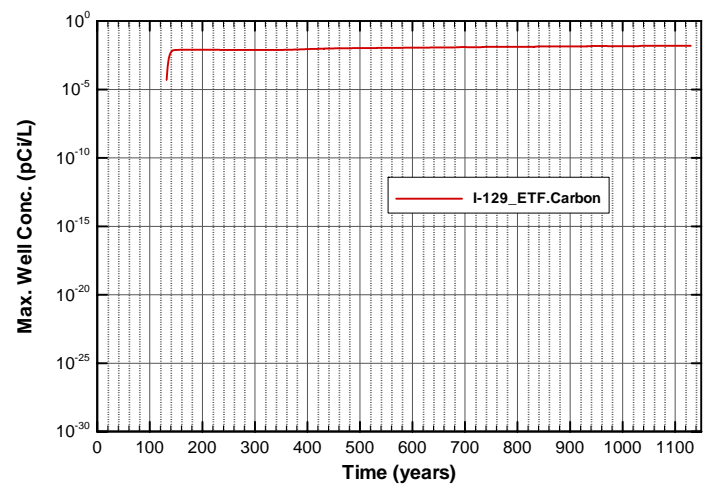

Figure A-1516. Well concentrations for Case01n11_on I-129_ETF.Carbon 
SRNL-STI-2008-00397, REVISION 0

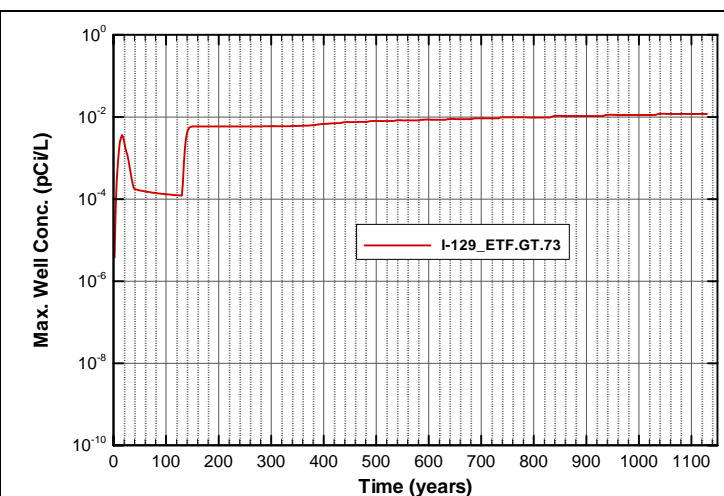

Figure A-1517. Well concentrations for Case01n11_on I-129_ETF.GT.73

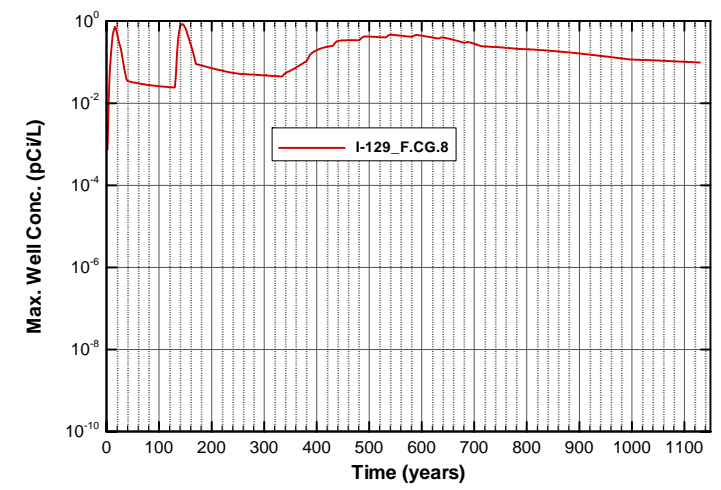

Figure A-1519. Well concentrations for Case01n11_on I-129_F.CG.8

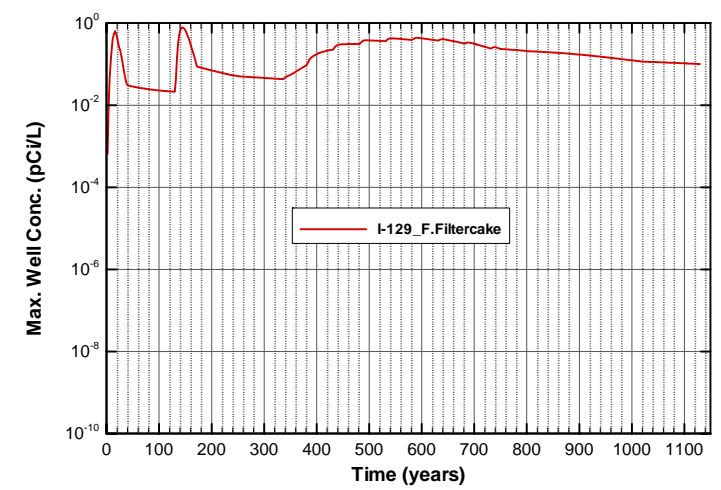

Figure A-1521. Well concentrations for Case01n11_on I-129_F.Filtercake

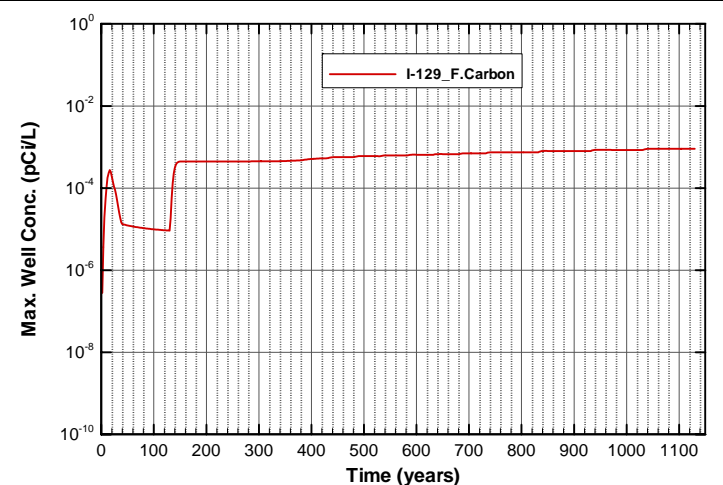

Figure A-1518. Well concentrations for Case01n11_on I-129_F.Carbon

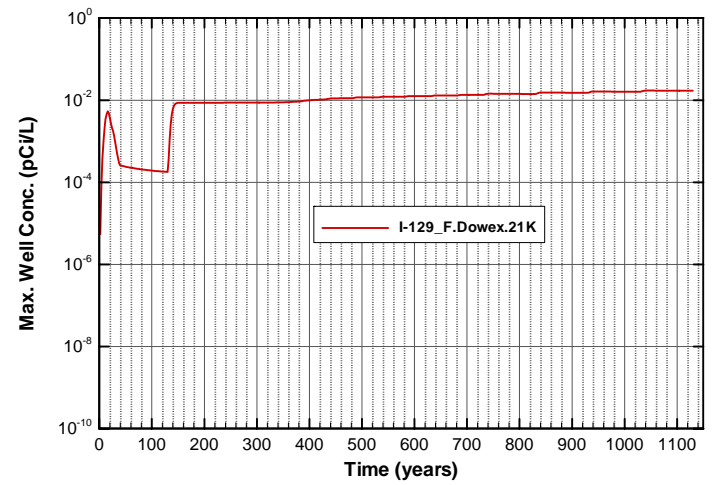

Figure A-1520. Well concentrations for Case01n11_on I-129_F.Dowex.21K

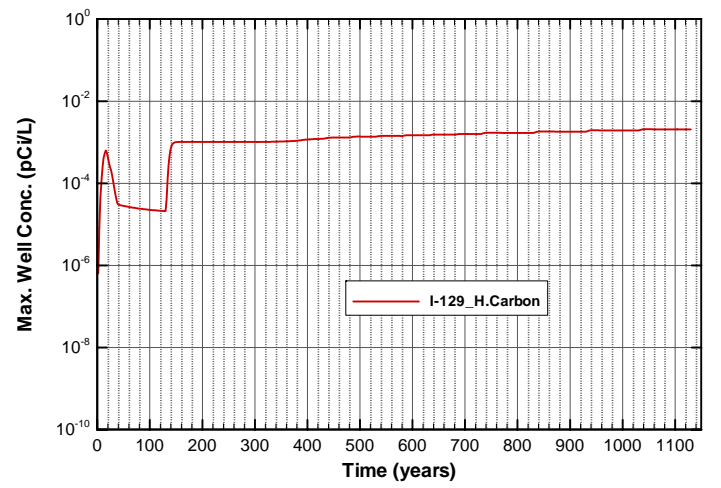

Figure A-1522. Well concentrations for Case01n11_on I-129_H.Carbon 
SRNL-STI-2008-00397, REVISION 0

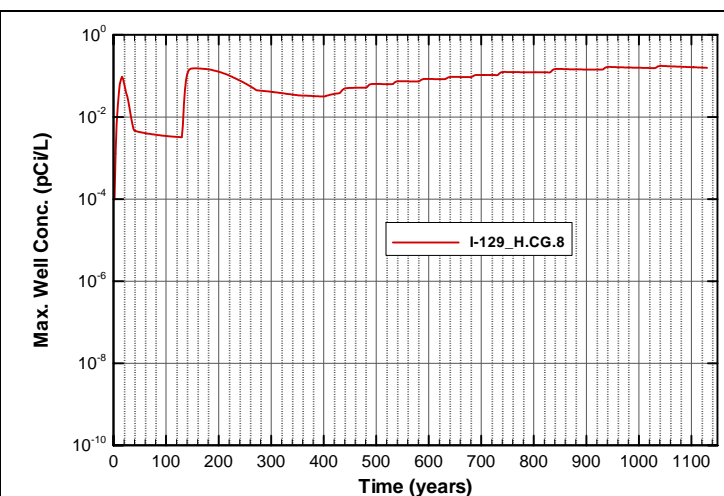

Figure A-1523. Well concentrations for Case01n11_on I-129_H.CG.8

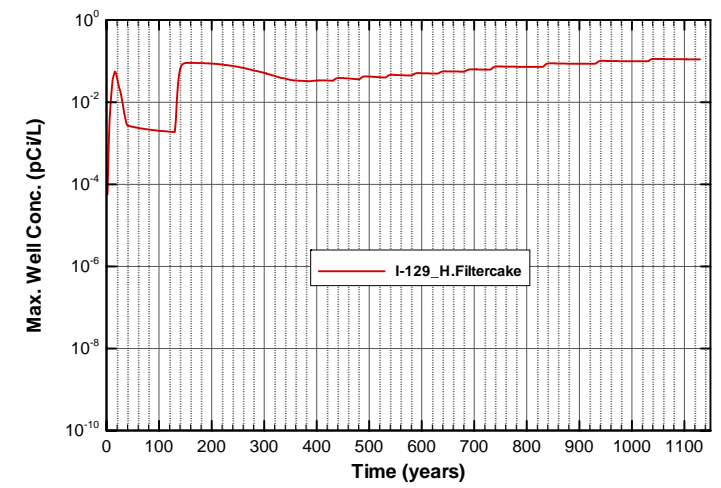

Figure A-1525. Well concentrations for Case01n11_on I-129_H.Filtercake

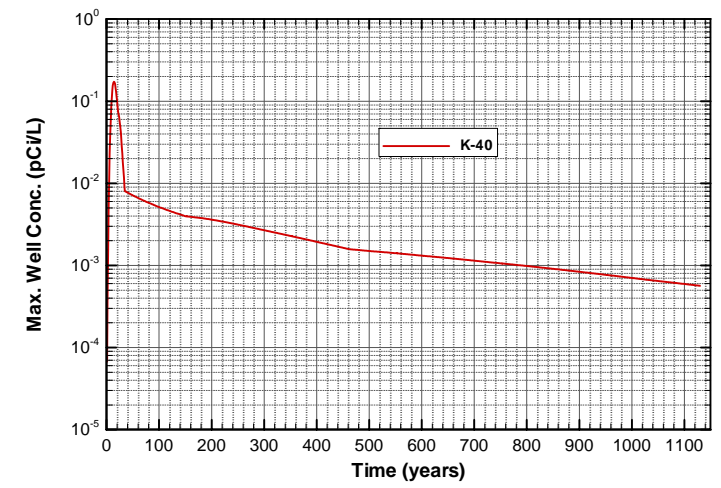

Figure A-1527. Well concentrations for Case01n11_on K-40

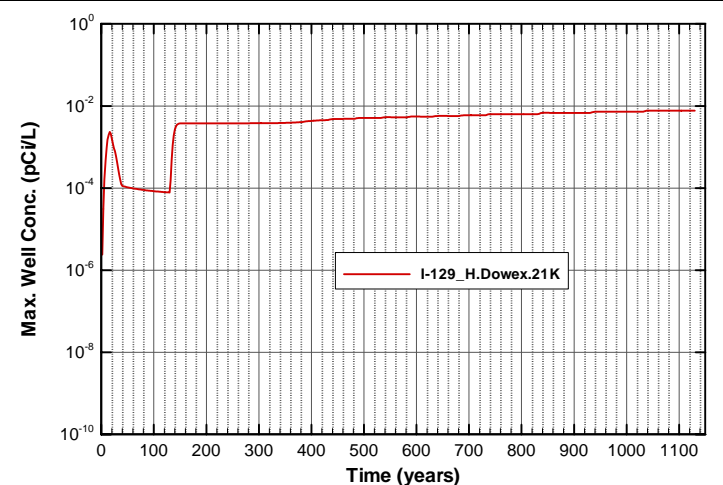

Figure A-1524. Well concentrations for Case01n11_on I-129_H.Dowex.21K

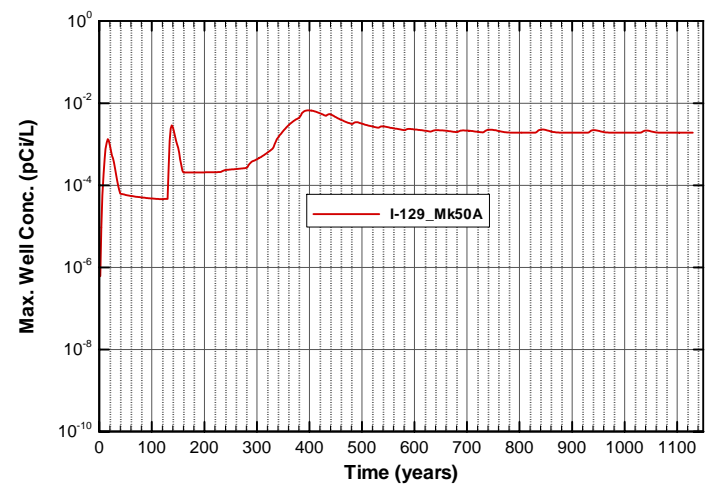

Figure A-1526. Well concentrations for Case01n11_on I-129_Mk50A

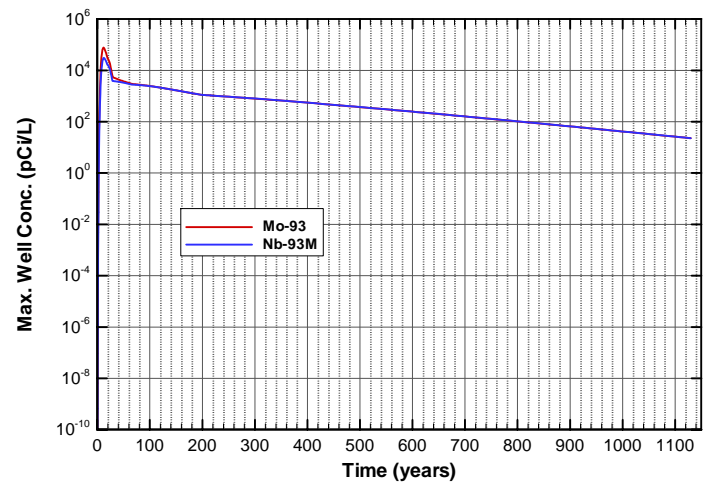

Figure A-1528. Well concentrations for Case01n11_on Mo-93 
SRNL-STI-2008-00397, REVISION 0

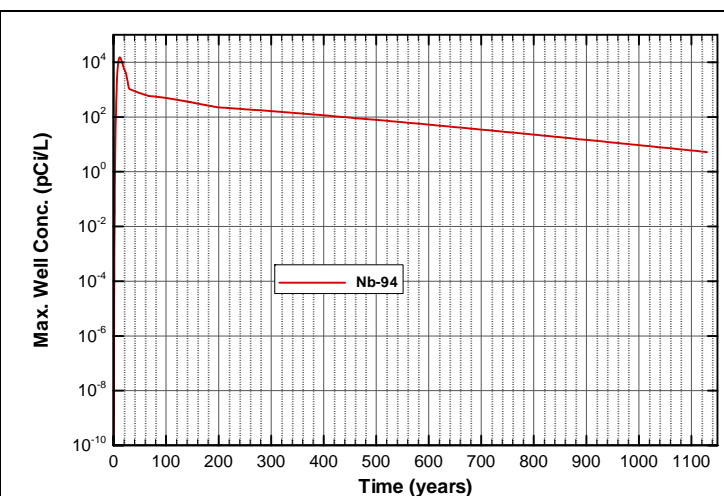

Figure A-1529. Well concentrations for Case01n11_on Nb-94

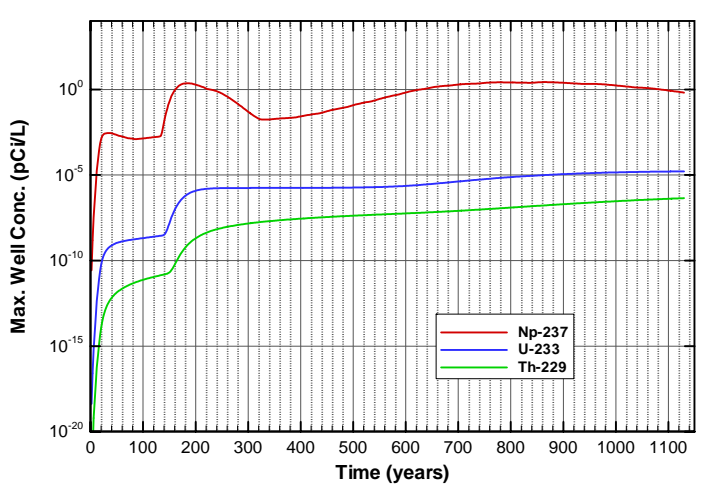

Figure A-1531. Well concentrations for Case01n11_on Np-237

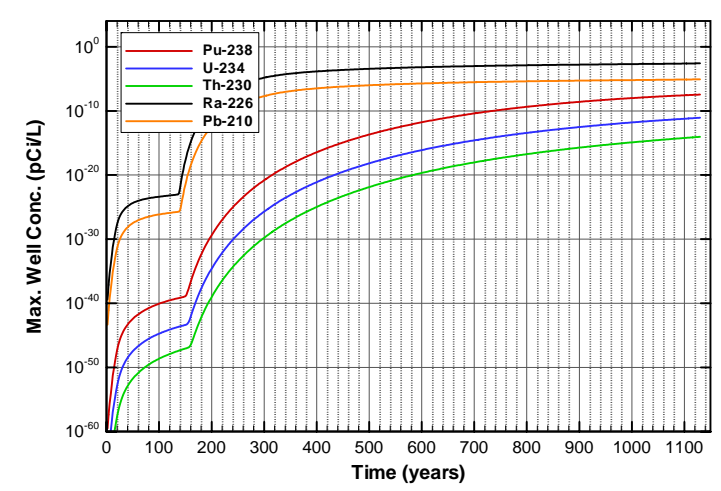

Figure A-1533. Well concentrations for Case01n11_on Pu-238

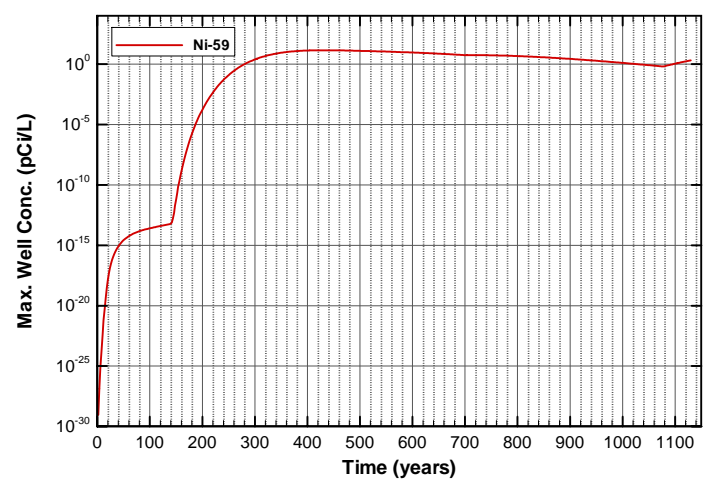

Figure A-1530. Well concentrations for Case01n11_on Ni-59

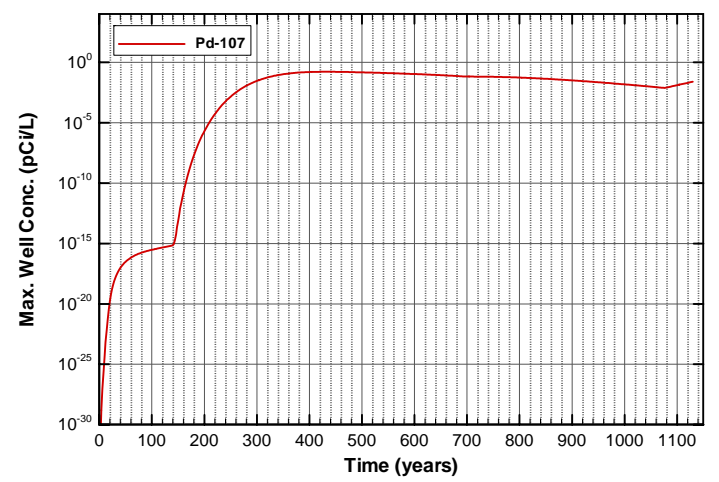

Figure A-1532. Well concentrations for Case01n11_on Pd-107

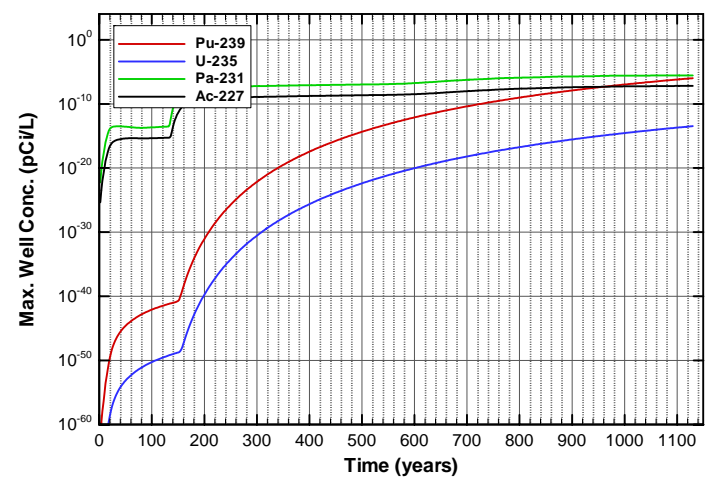

Figure A-1534. Well concentrations for Case01n11_on Pu-239 
SRNL-STI-2008-00397, REVISION 0

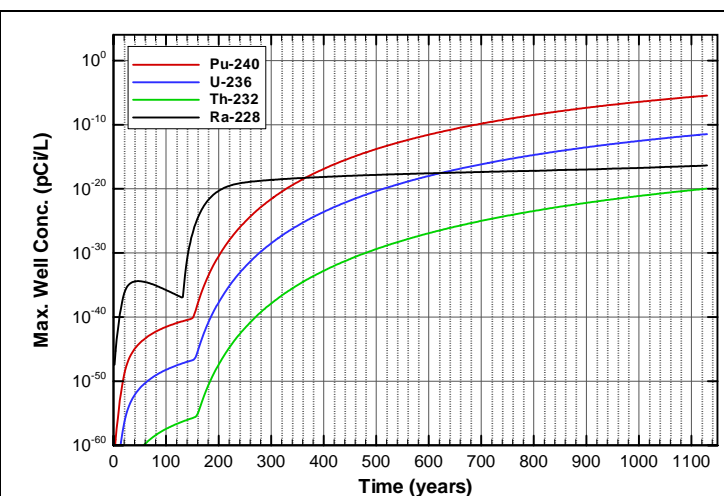

Figure A-1535. Well concentrations for Case01n11_on Pu-240

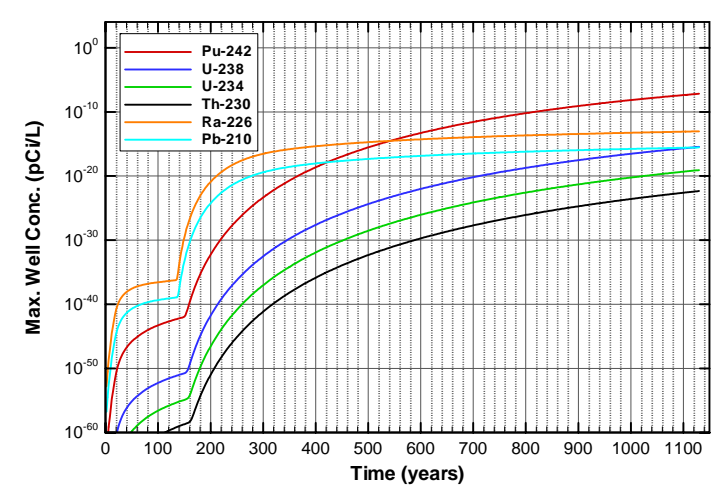

Figure A-1537. Well concentrations for Case01n11_on Pu-242

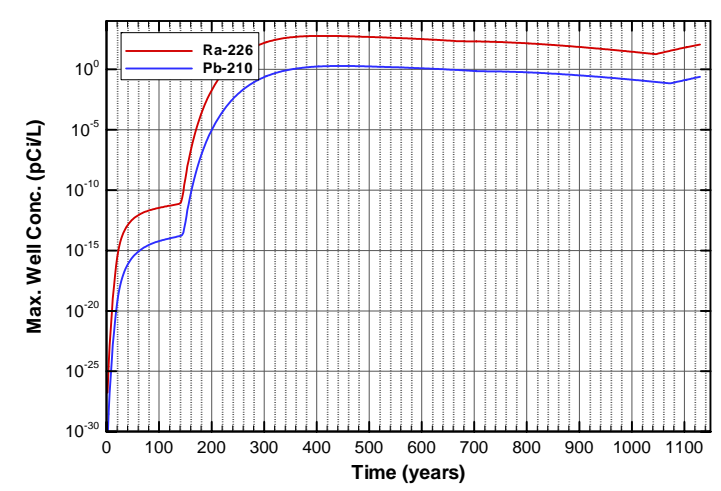

Figure A-1539. Well concentrations for Case01n11_on Ra-226

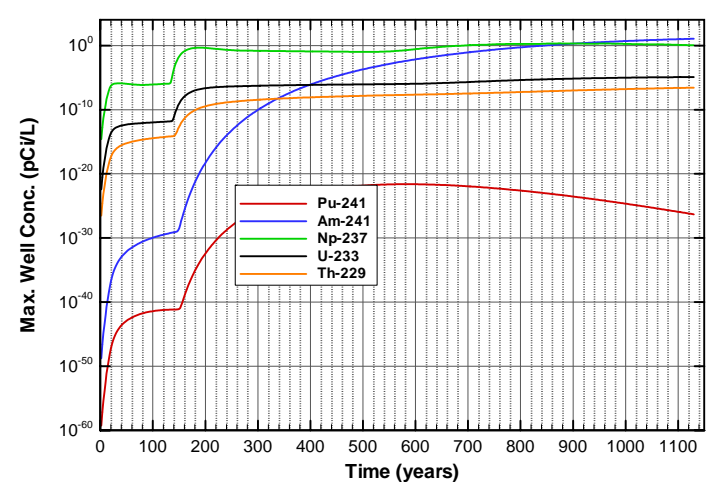

Figure A-1536. Well concentrations for Case01n11_on Pu-241

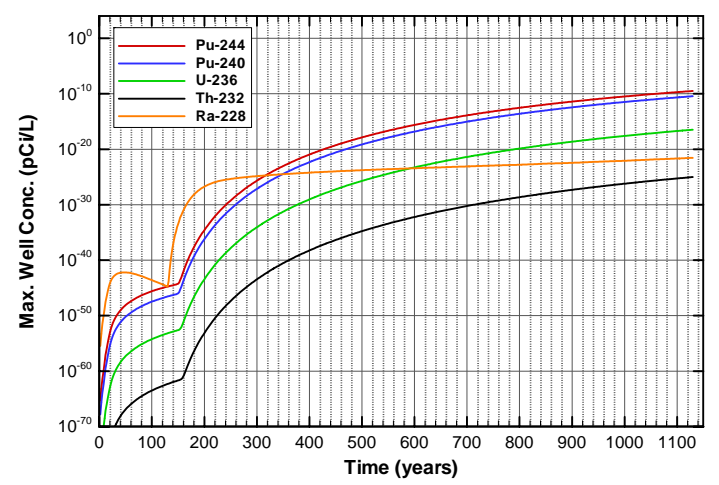

Figure A-1538. Well concentrations for Case01n11_on Pu-244

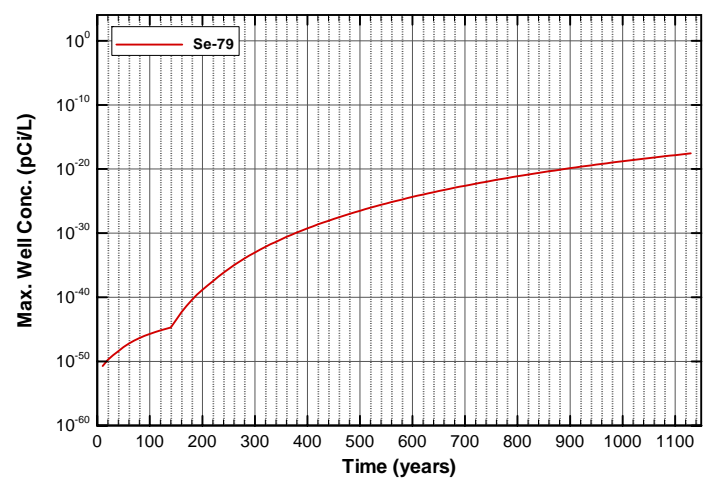

Figure A-1540. Well concentrations for Case01n11_on Se-79 
SRNL-STI-2008-00397, REVISION 0

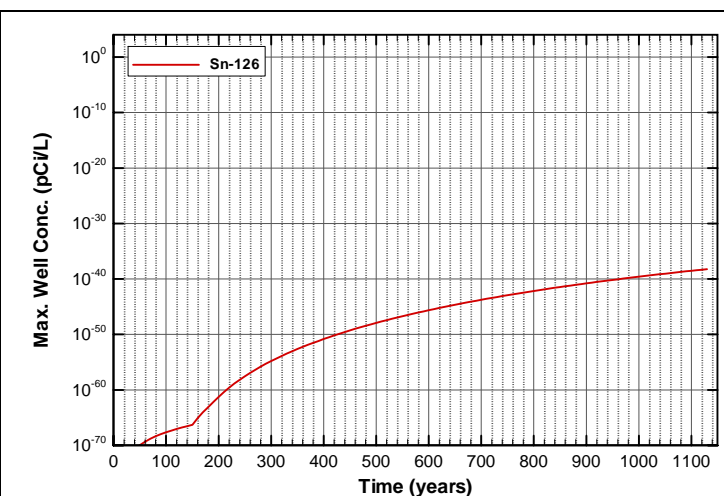

Figure A-1541. Well concentrations for Case01n11_on Sn-126

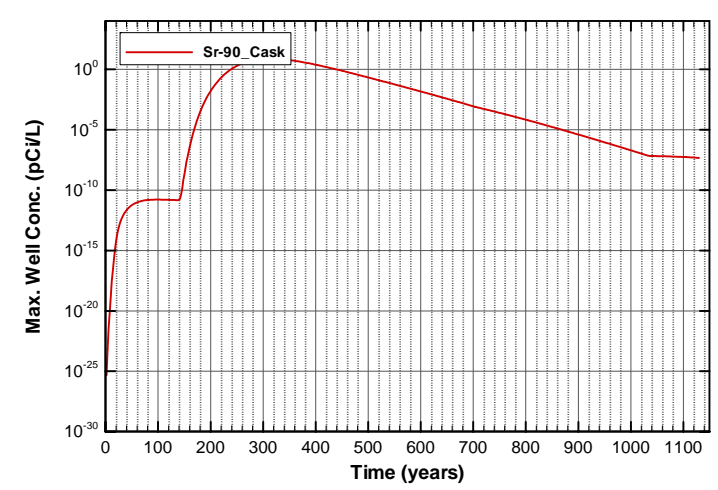

Figure A-1543. Well concentrations for Case01n11_on Sr-90_Cask

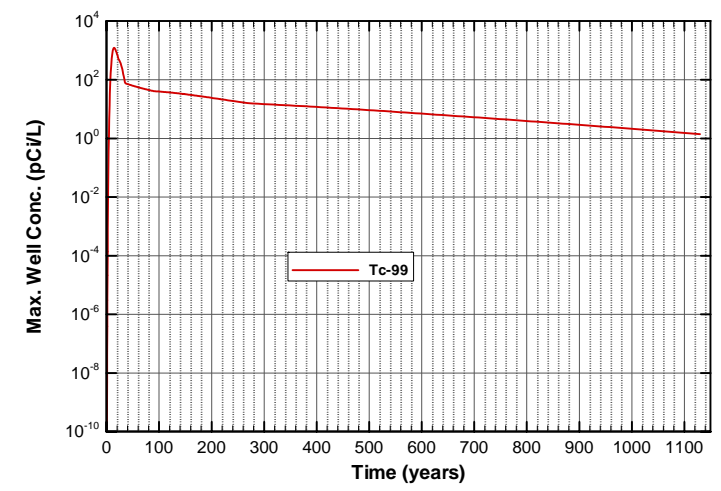

Figure A-1545. Well concentrations for Case01n11_on Tc-99

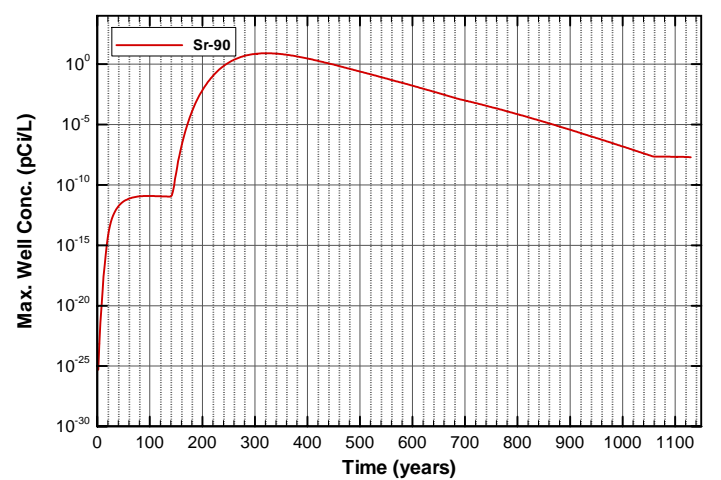

Figure A-1542. Well concentrations for Case01n11_on Sr-90

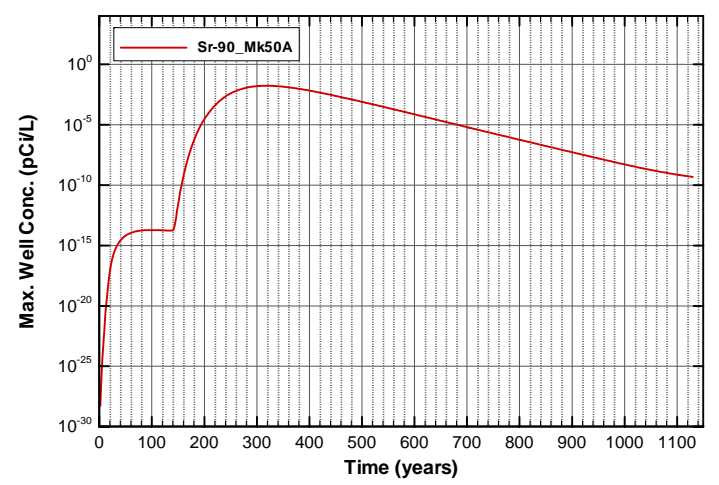

Figure A-1544. Well concentrations for Case01n11_on Sr-90_Mk50A

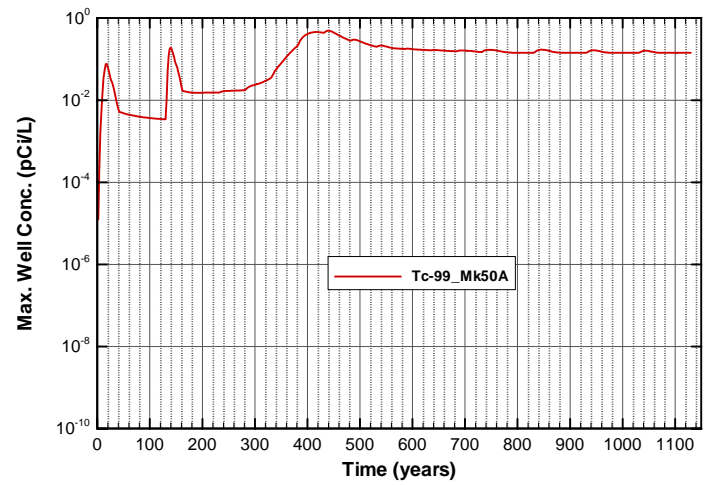

Figure A-1546. Well concentrations for Case01n11_on Tc-99_Mk50A 
SRNL-STI-2008-00397, REVISION 0

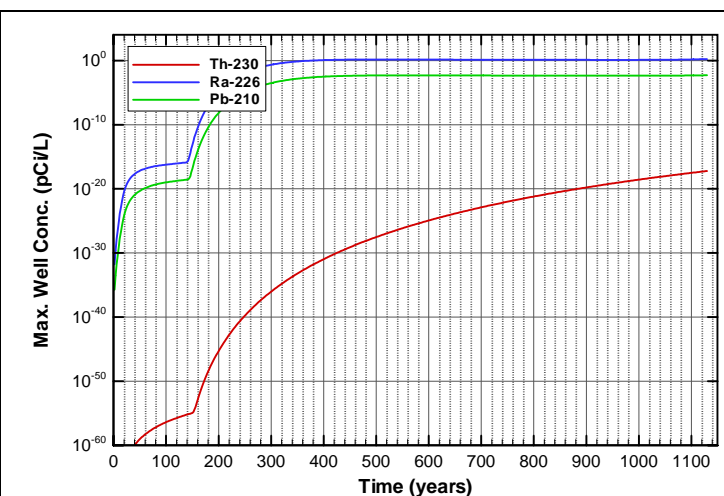

Figure A-1547. Well concentrations for Case01n11_on Th-230

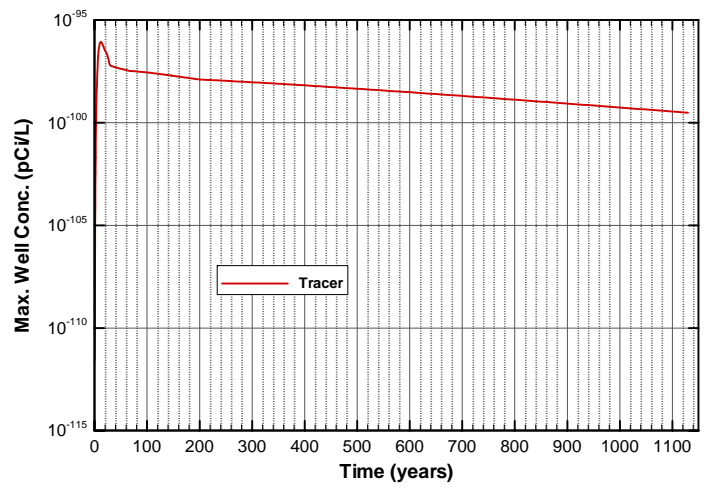

Figure A-1549. Well concentrations for Case01n11_on Tracer

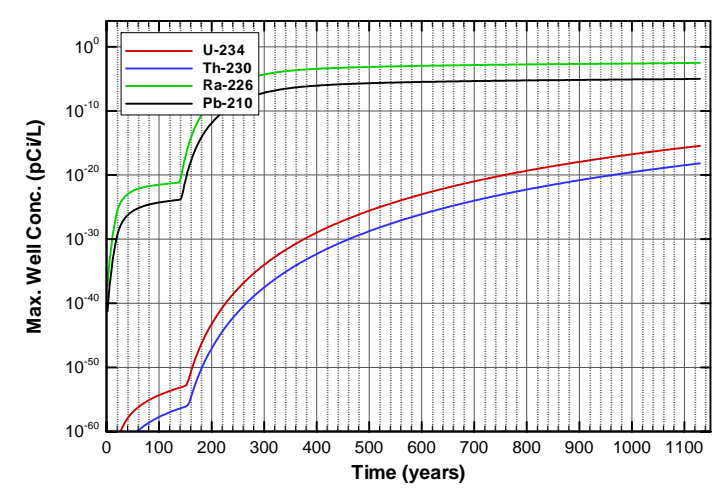

Figure A-1551. Well concentrations for Case01n11_on U-234

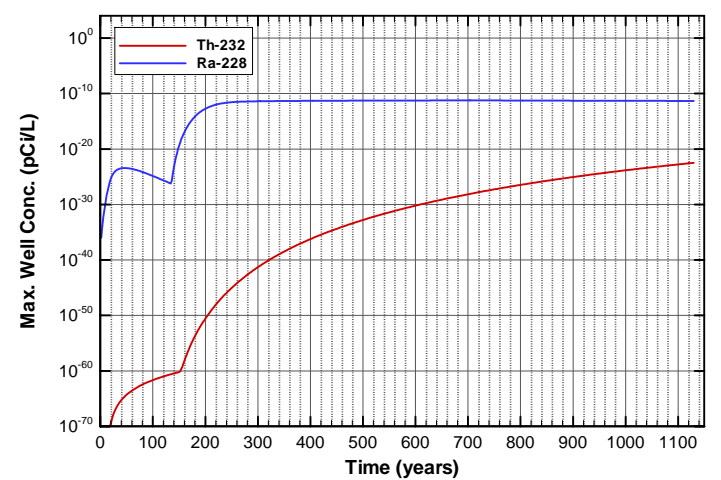

Figure A-1548. Well concentrations for Case01n11_on Th-232

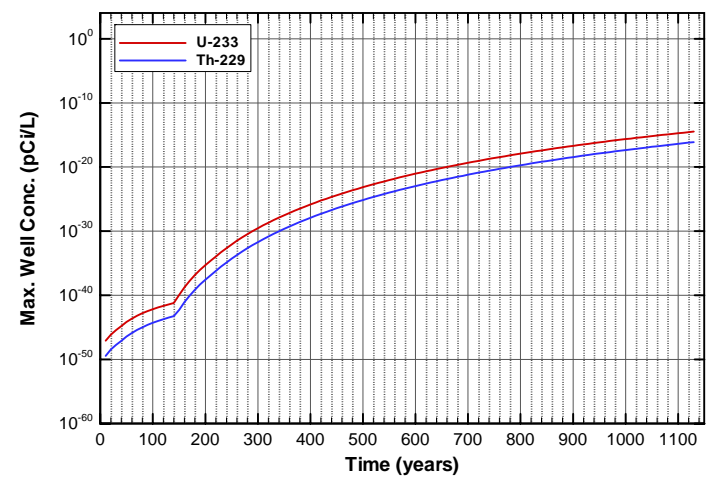

Figure A-1550. Well concentrations for Case01n11_on U-233

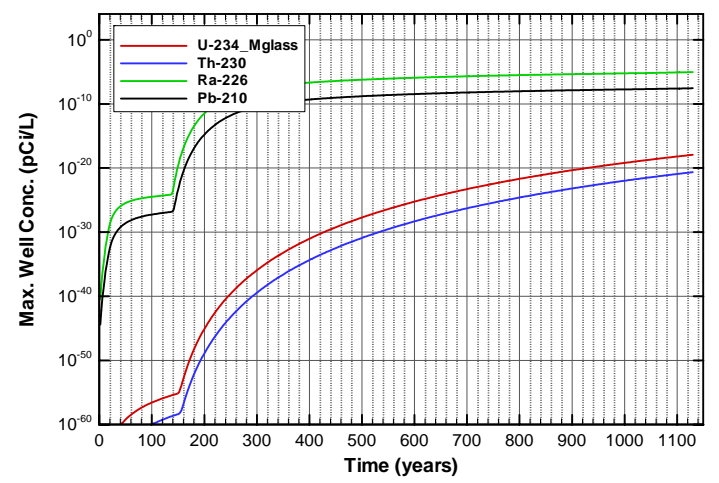

Figure A-1552. Well concentrations for Case01n11_on U-234_Mglass 


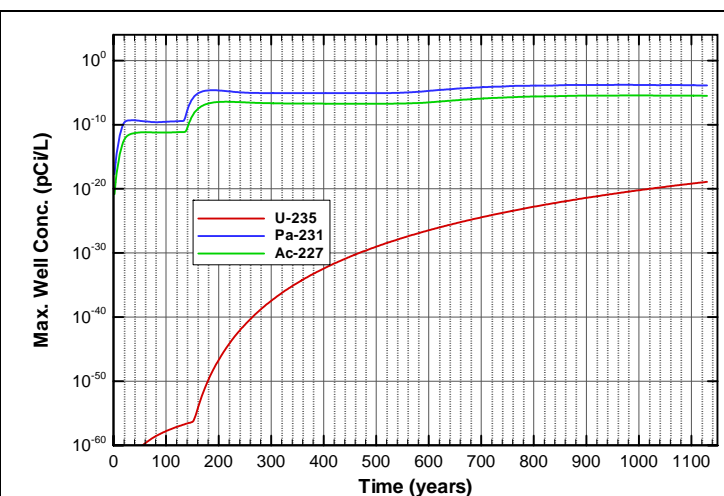

Figure A-1553. Well concentrations for Case01n11_on U-235

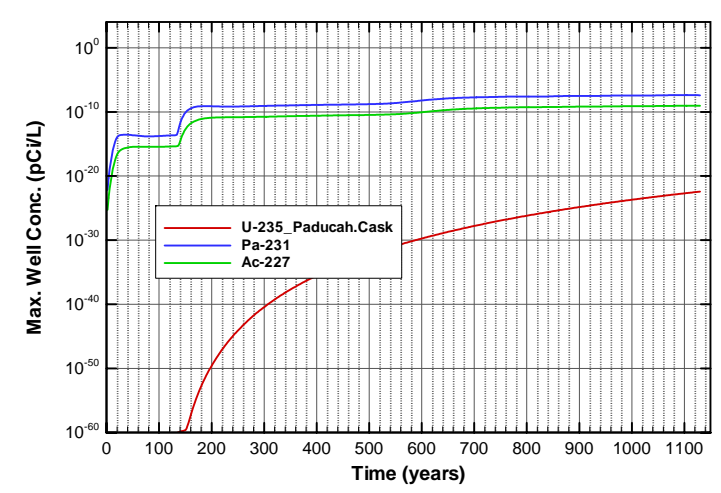

Figure A-1555. Well concentrations for Case01n11_on U-235_Paducah.Cask

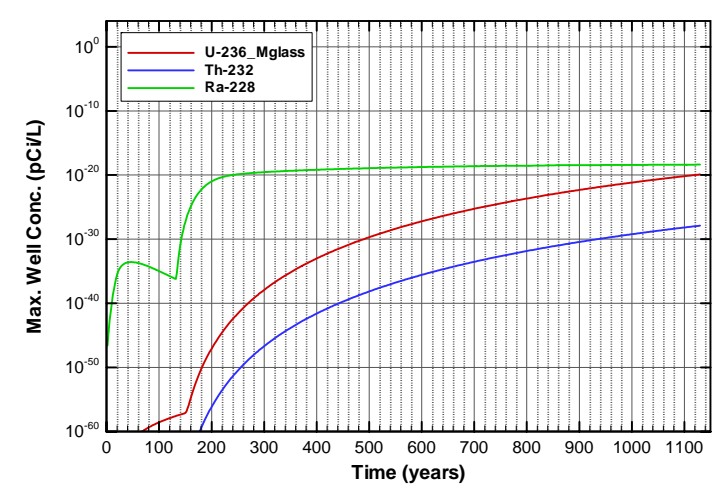

Figure A-1557. Well concentrations for Case01n11_on U-236_Mglass

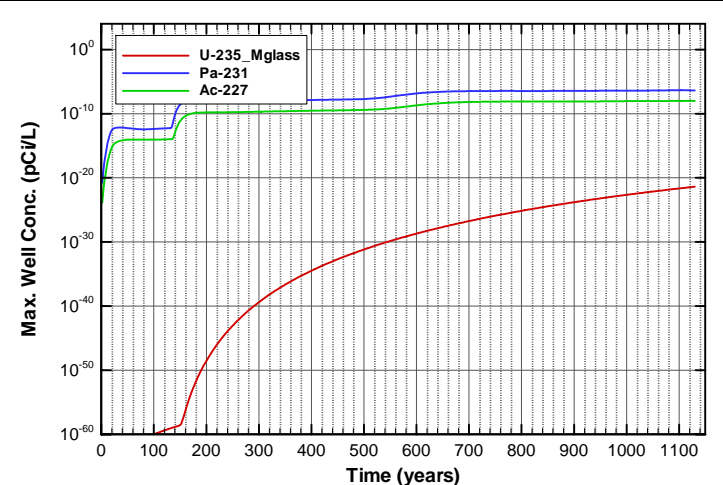

Figure A-1554. Well concentrations for Case01n11_on U-235_Mglass

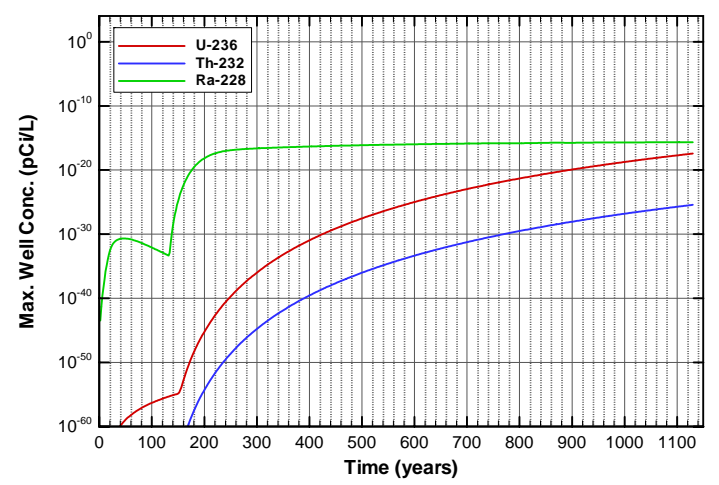

Figure A-1556. Well concentrations for Case01n11_on U-236

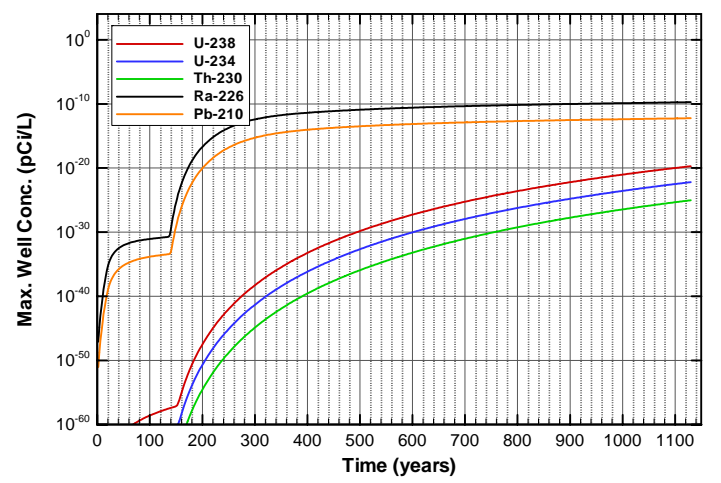

Figure A-1558. Well concentrations for Case01n11_on U-238 


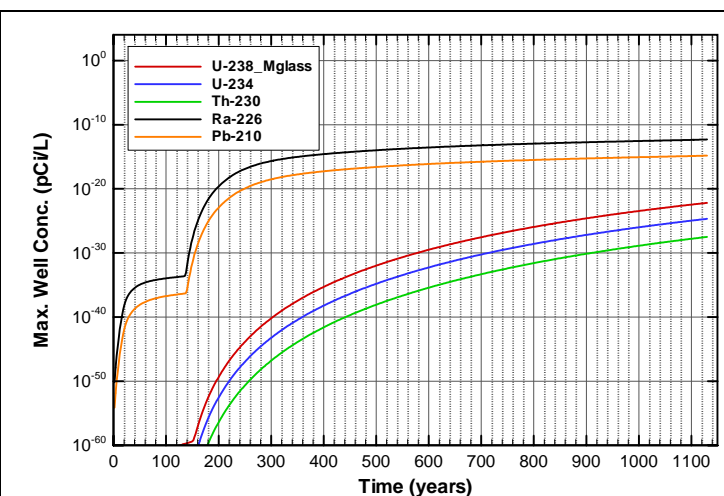

Figure A-1559. Well concentrations for Case01n11_on U-238_Mglass

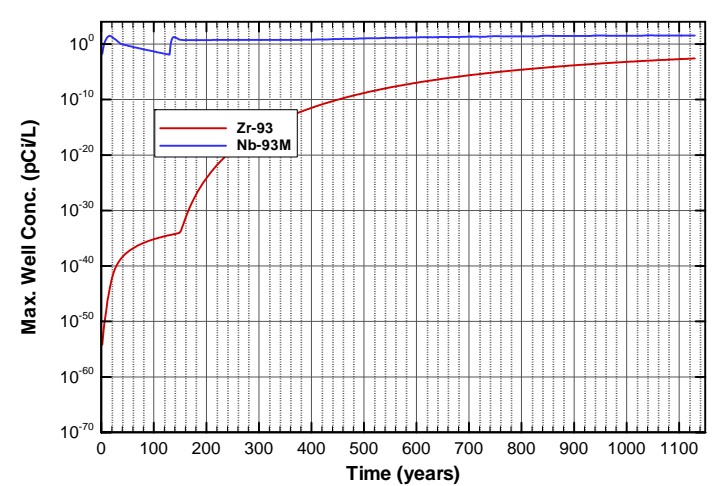

Figure A-1560. Well concentrations for Case01n11_on Zr-93

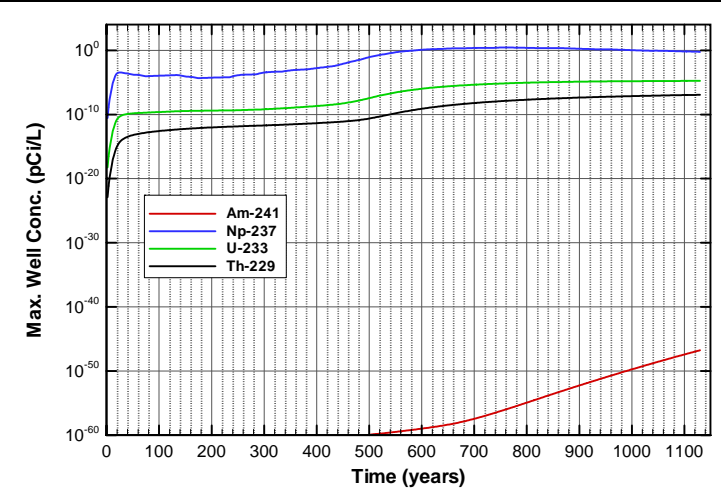

Figure A-1561. Well concentrations for Case01_off Am-241

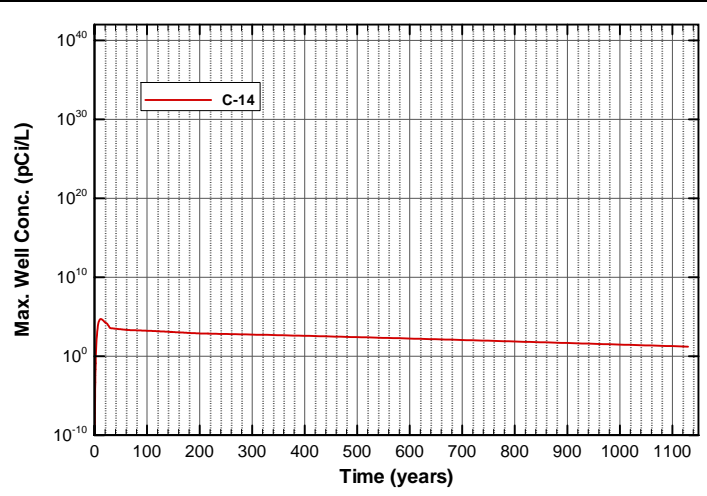

Figure A-1563. Well concentrations for Case01_off C-14

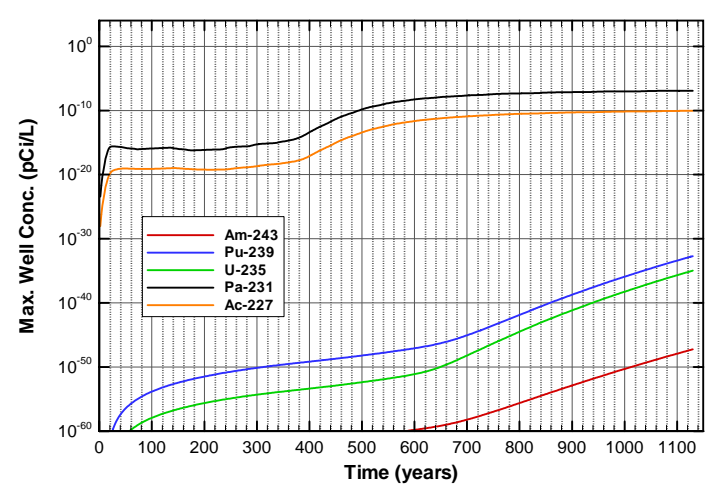

Figure A-1562. Well concentrations for Case01_off Am-243

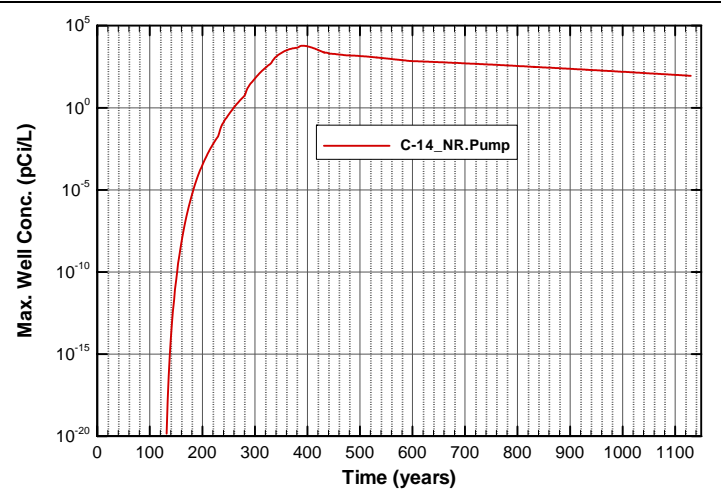

Figure A-1564. Well concentrations for Case01_off C-14_NR.Pump 
SRNL-STI-2008-00397, REVISION 0

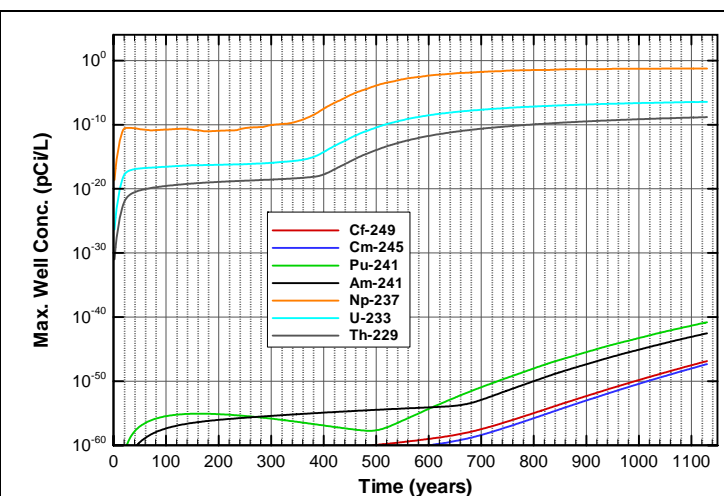

Figure A-1565. Well concentrations for Case01_off Cf-249

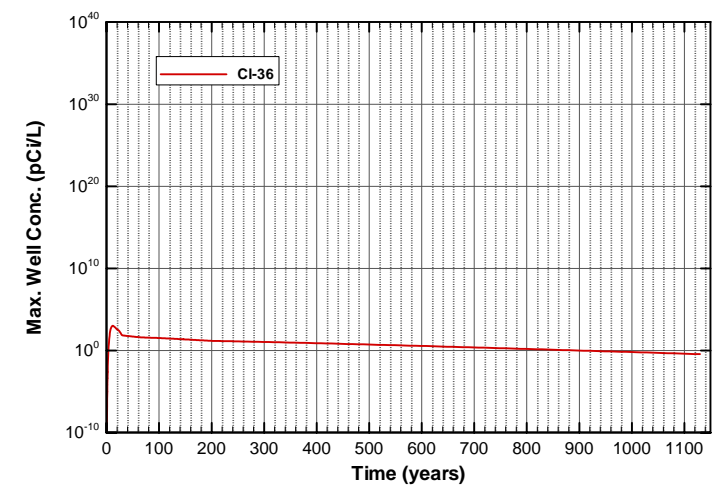

Figure A-1567. Well concentrations for Case01_off Cl-36

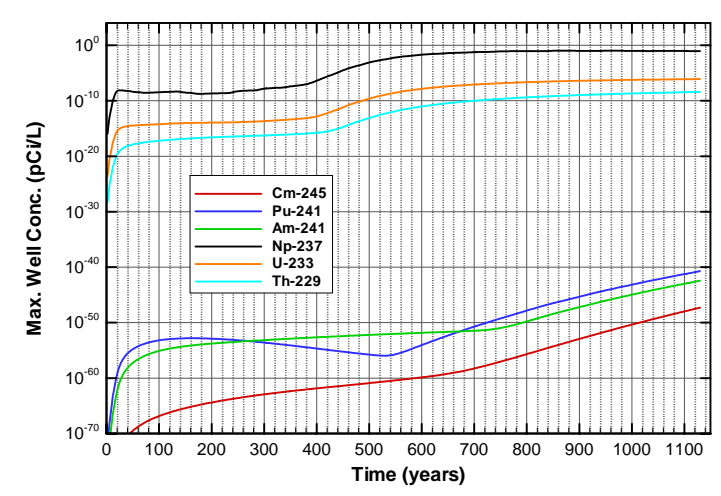

Figure A-1569. Well concentrations for Case01_off Cm-245

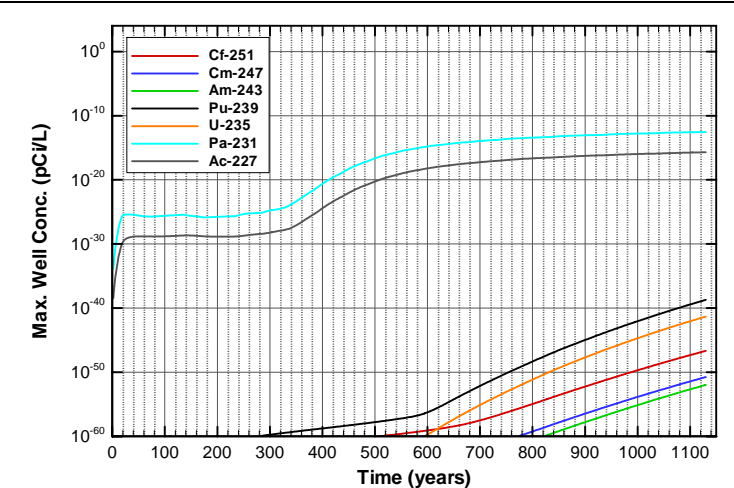

Figure A-1566. Well concentrations for Case01_off Cf-251

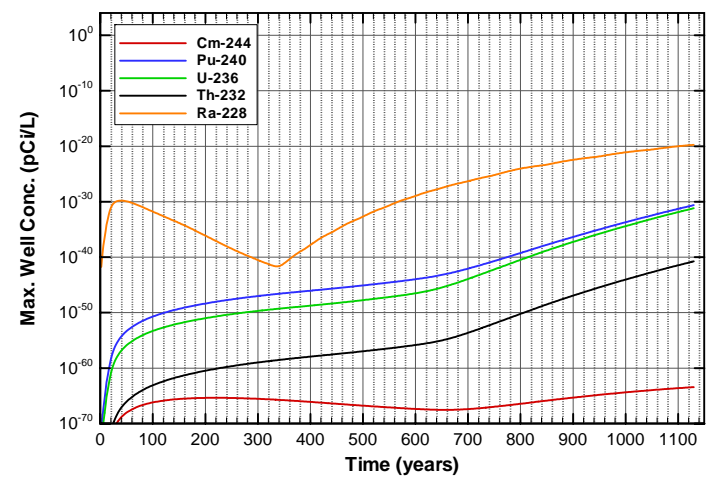

Figure A-1568. Well concentrations for Case01_off Cm-244

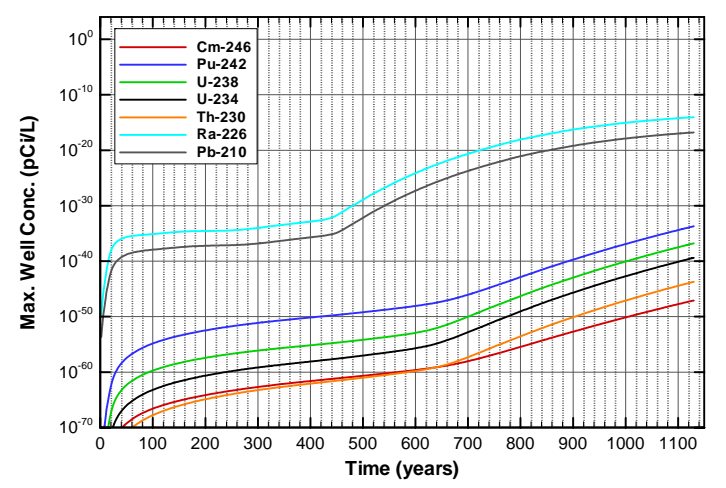

Figure A-1570. Well concentrations for Case01_off Cm-246 
SRNL-STI-2008-00397, REVISION 0

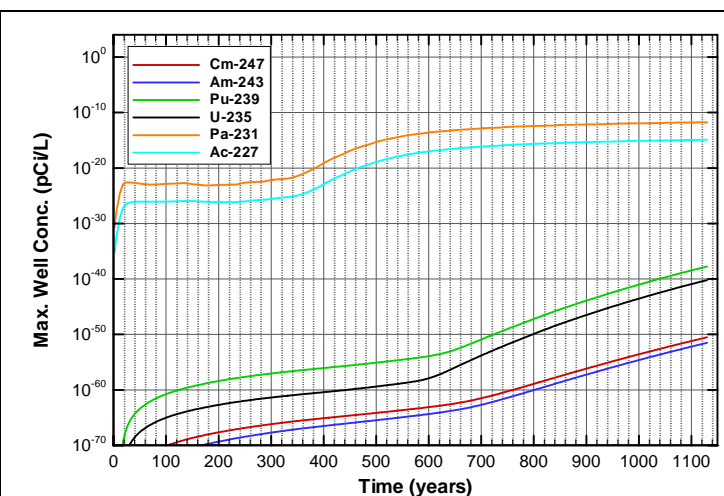

Figure A-1571. Well concentrations for Case01_off Cm-247

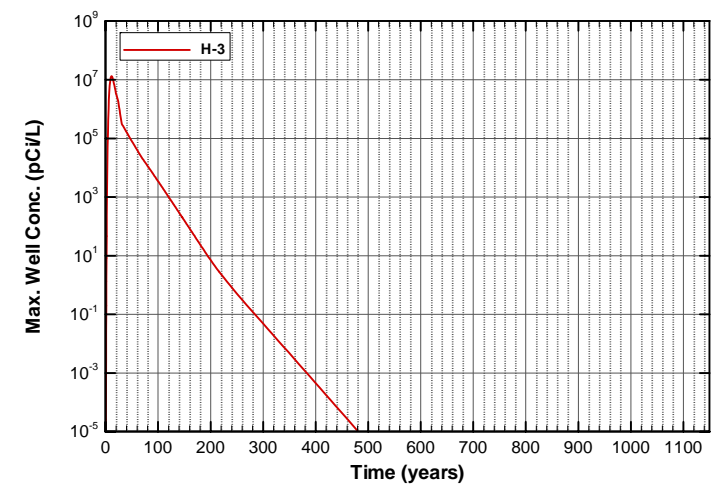

Figure A-1573. Well concentrations for Case01_off H-3

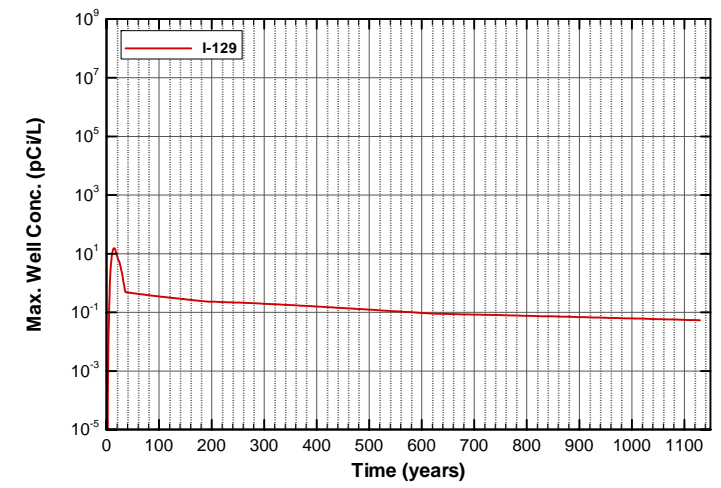

Figure A-1575. Well concentrations for Case01_off I-129

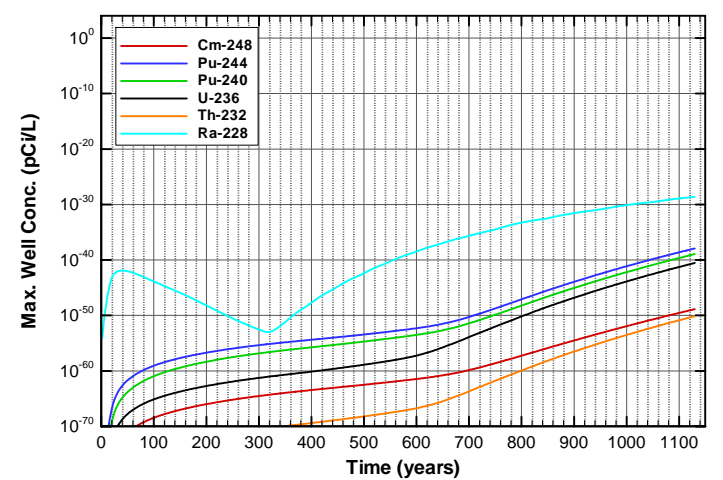

Figure A-1572. Well concentrations for Case01_off Cm-248

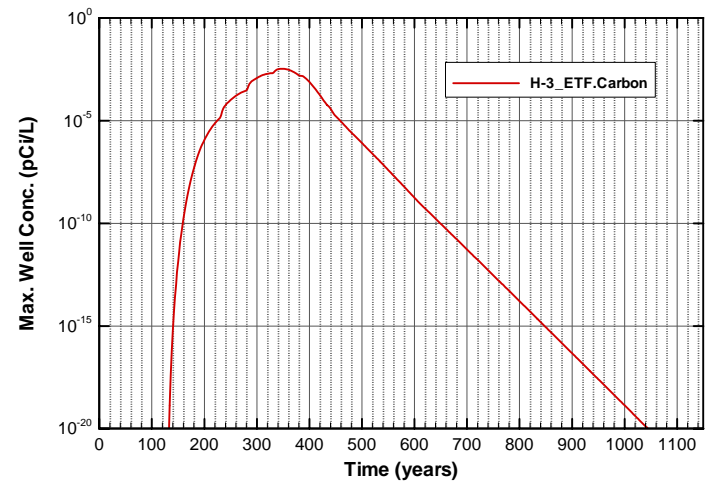

Figure A-1574. Well concentrations for Case01_off H-3_ETF.Carbon

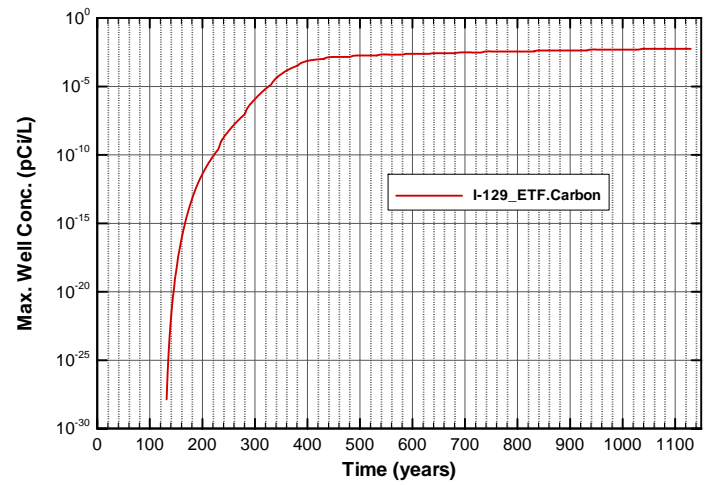

Figure A-1576. Well concentrations for Case01_off I-129_ETF.Carbon 
SRNL-STI-2008-00397, REVISION 0

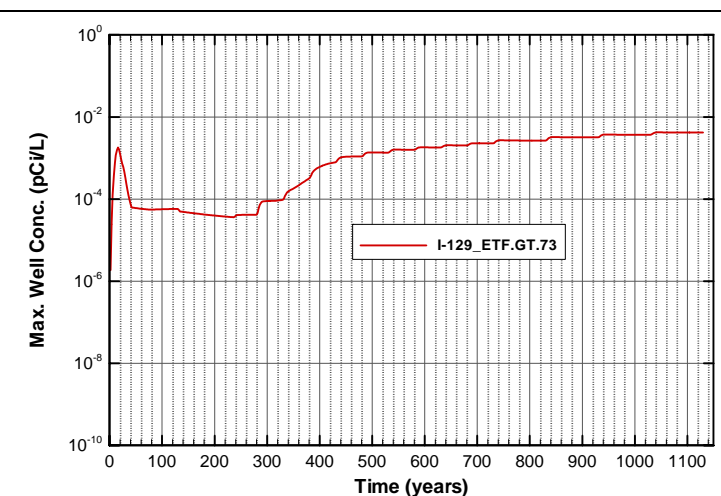

Figure A-1577. Well concentrations for Case01_off I-129_ETF.GT.73

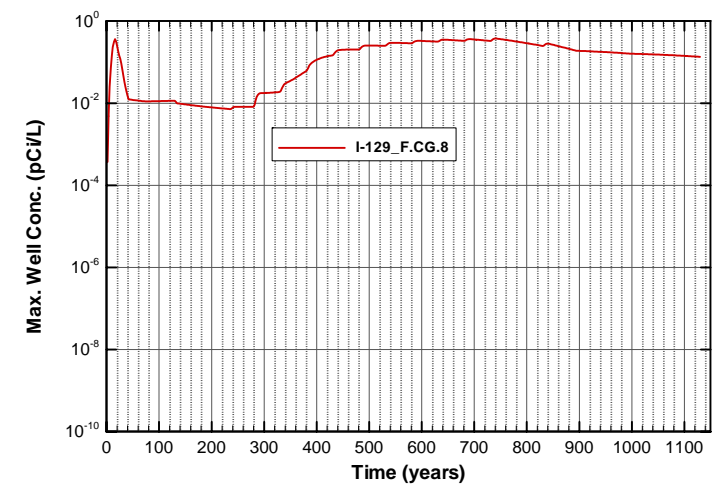

Figure A-1579. Well concentrations for Case01_off I-129_F.CG.8

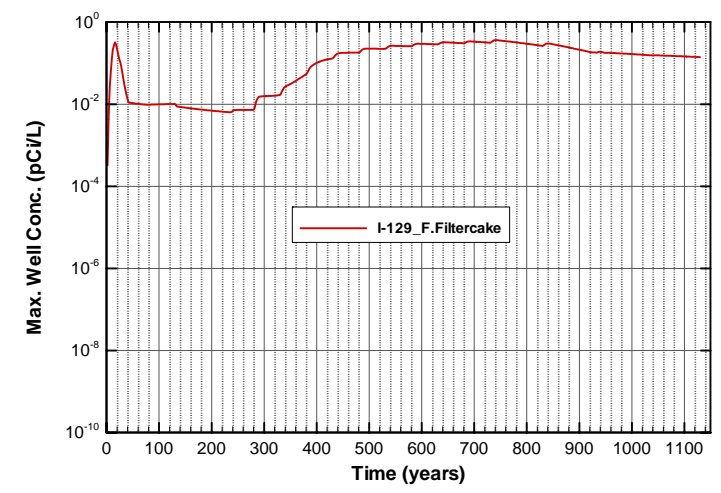

Figure A-1581. Well concentrations for Case01_off I-129_F.Filtercake

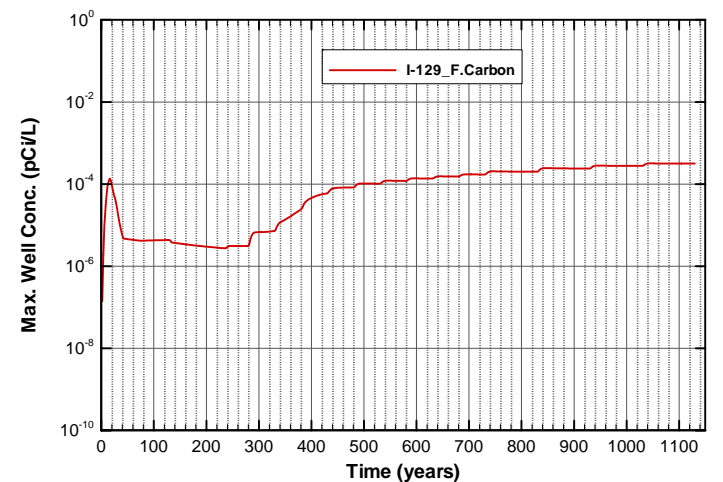

Figure A-1578. Well concentrations for Case01_off I-129_F.Carbon

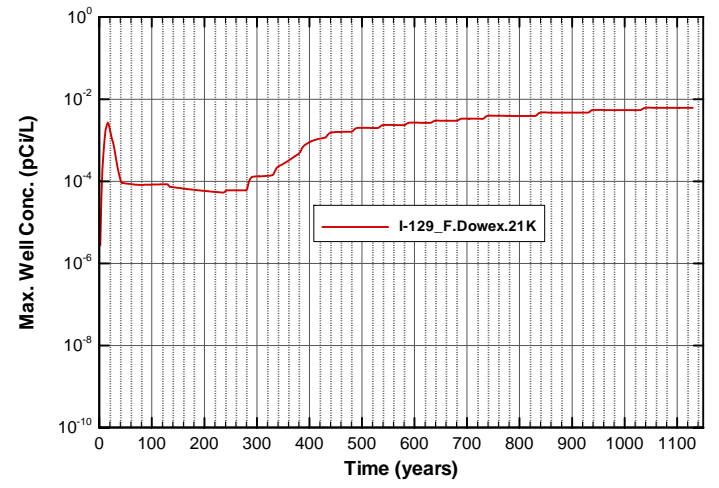

Figure A-1580. Well concentrations for Case01_off I-129_F.Dowex.21K

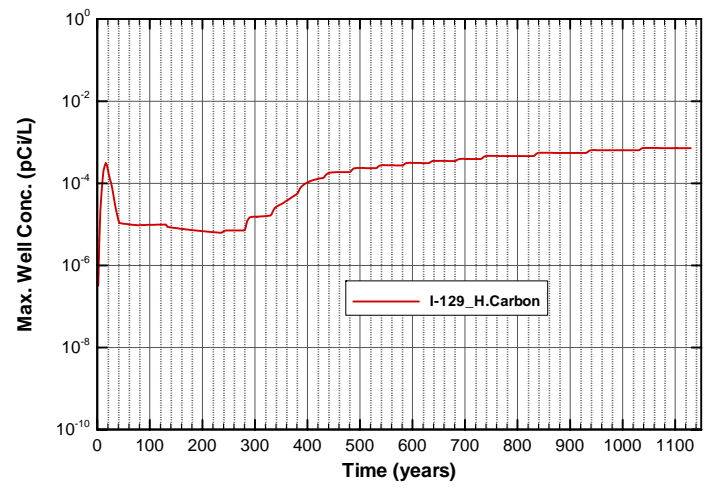

Figure A-1582. Well concentrations for Case01_off I-129_H.Carbon 
SRNL-STI-2008-00397, REVISION 0

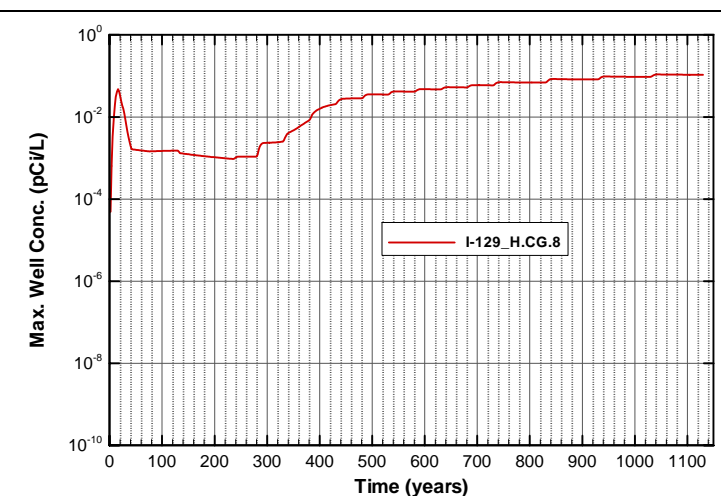

Figure A-1583. Well concentrations for Case01_off I-129_H.CG.8

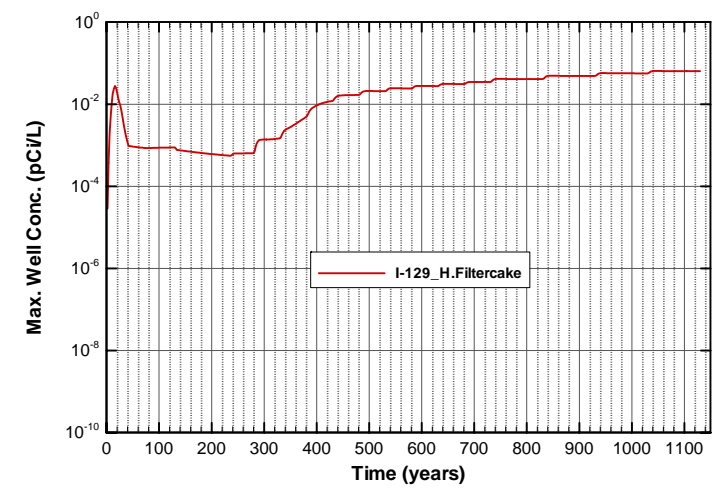

Figure A-1585. Well concentrations for Case01_off I-129_H.Filtercake

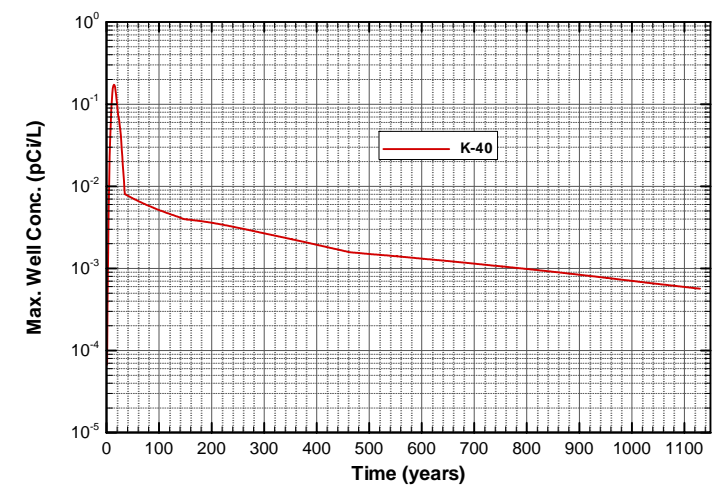

Figure A-1587. Well concentrations for Case01_off K-40

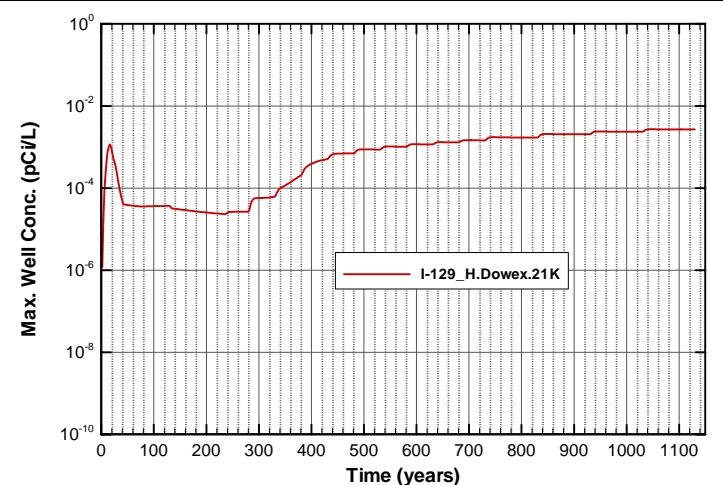

Figure A-1584. Well concentrations for Case01_off I-129_H.Dowex.21K

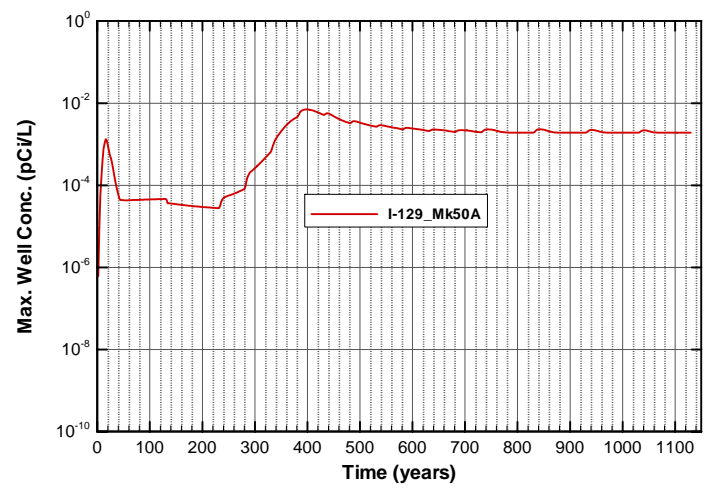

Figure A-1586. Well concentrations for Case01_off I-129_Mk50A

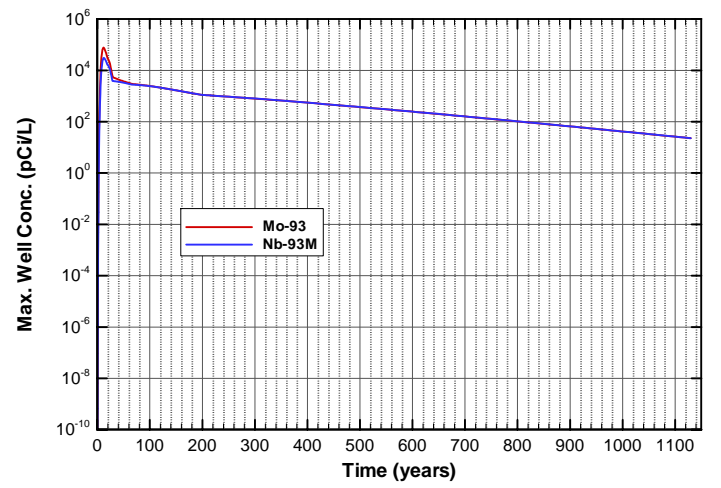

Figure A-1588. Well concentrations for Case01_off Mo-93 
SRNL-STI-2008-00397, REVISION 0

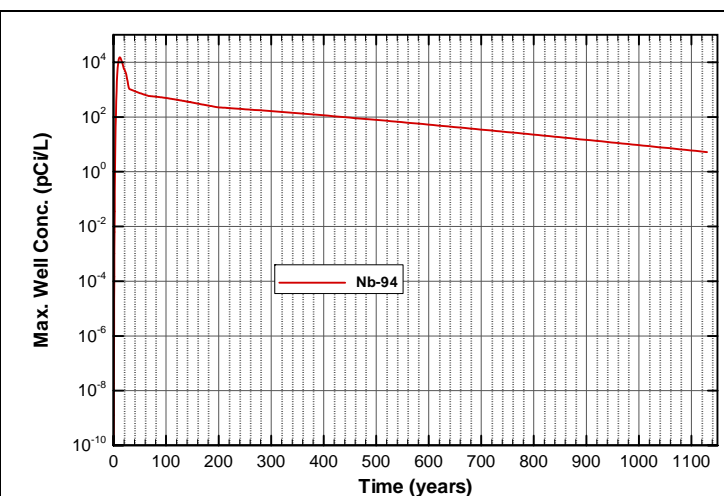

Figure A-1589. Well concentrations for Case01_off Nb-94

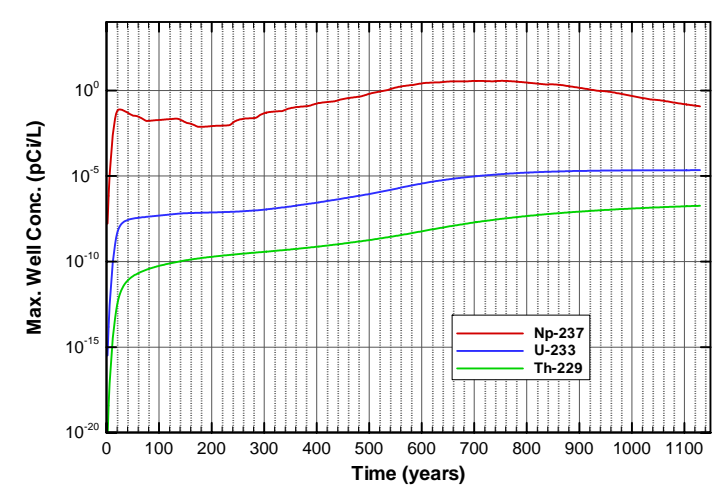

Figure A-1591. Well concentrations for Case01_off Np-237

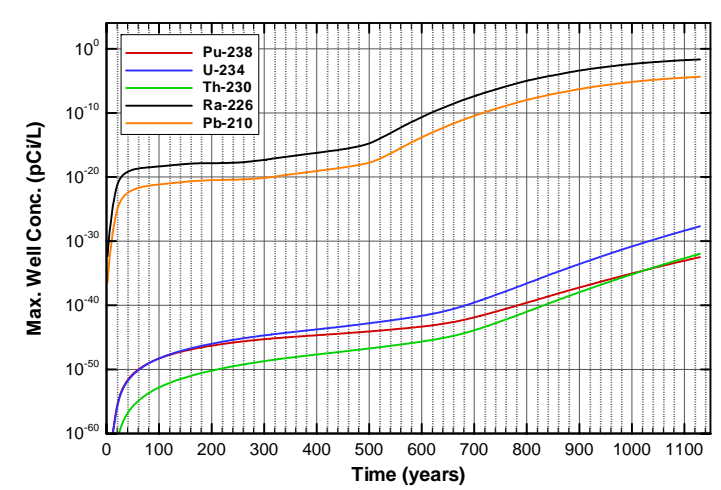

Figure A-1593. Well concentrations for Case01_off Pu-238

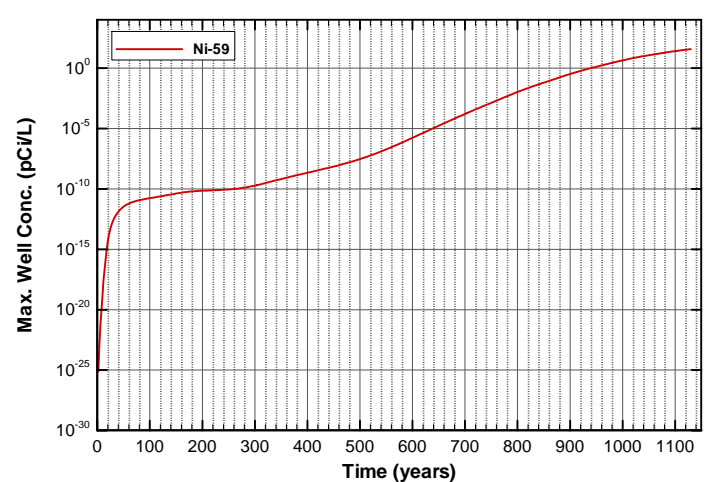

Figure A-1590. Well concentrations for Case01_off Ni-59

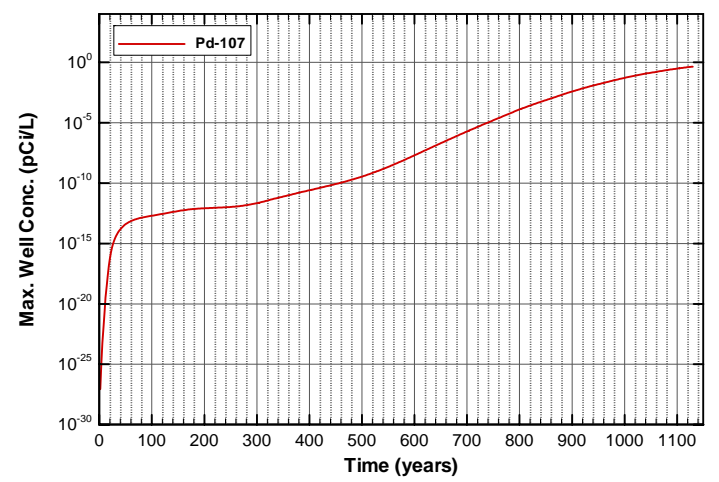

Figure A-1592. Well concentrations for Case01_off Pd-107

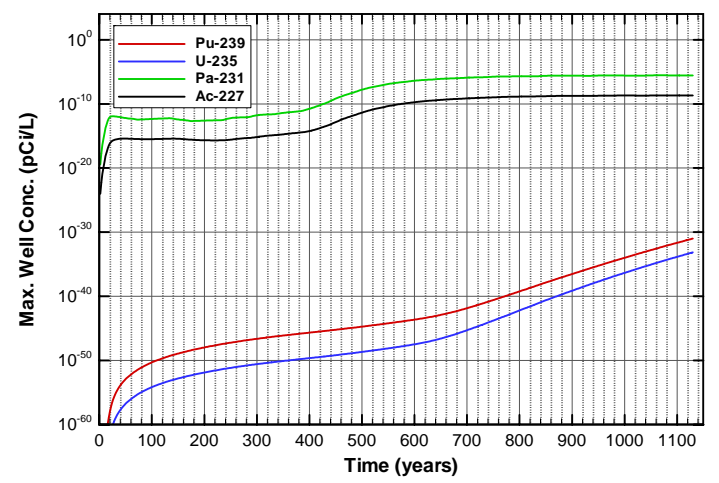

Figure A-1594. Well concentrations for Case01_off Pu-239 
SRNL-STI-2008-00397, REVISION 0

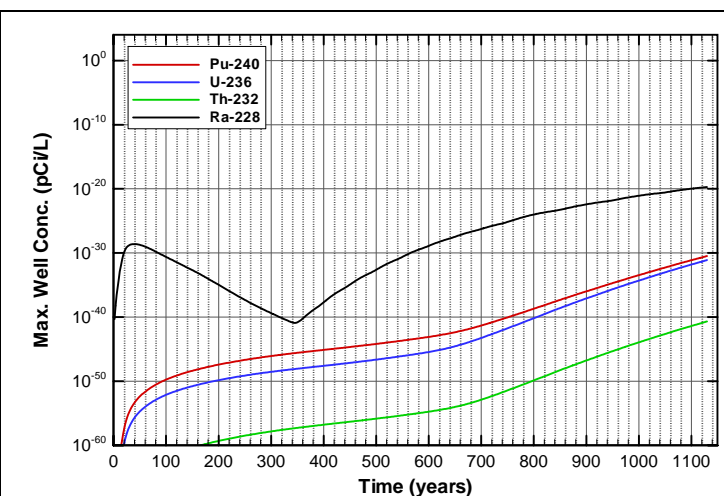

Figure A-1595. Well concentrations for Case01_off Pu-240

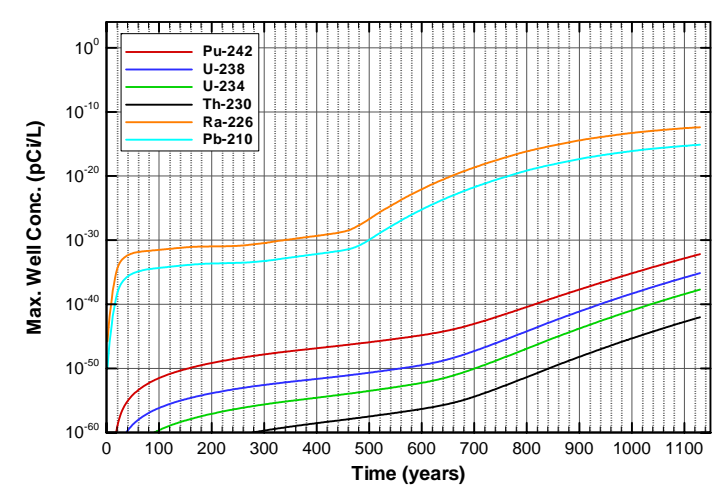

Figure A-1597. Well concentrations for Case01_off Pu-242

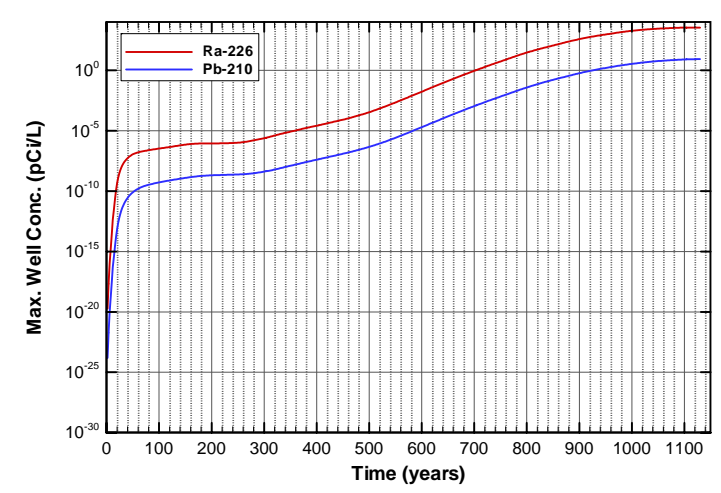

Figure A-1599. Well concentrations for Case01_off Ra-226

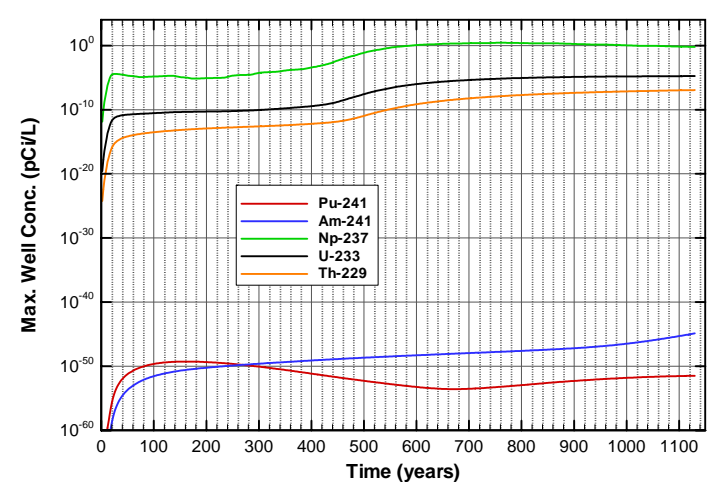

Figure A-1596. Well concentrations for Case01_off Pu-241

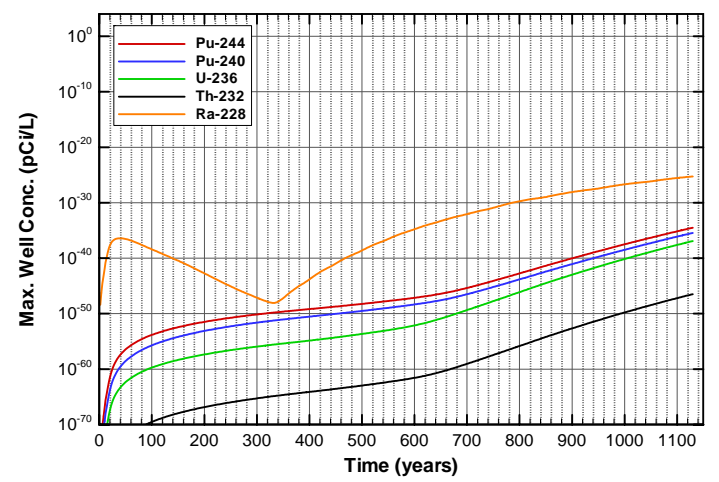

Figure A-1598. Well concentrations for Case01_off Pu-244

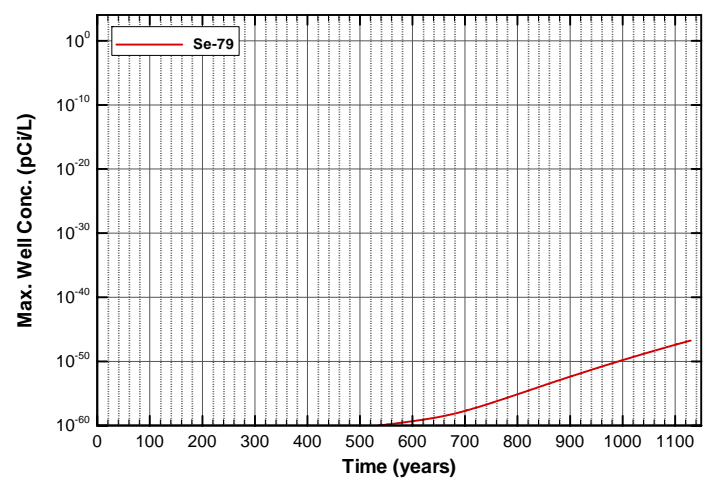

Figure A-1600. Well concentrations for Case01_off Se-79 
SRNL-STI-2008-00397, REVISION 0

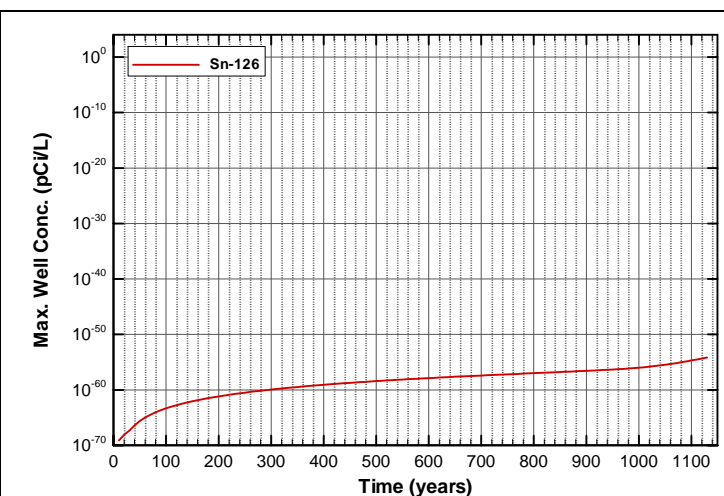

Figure A-1601. Well concentrations for Case01_off Sn-126

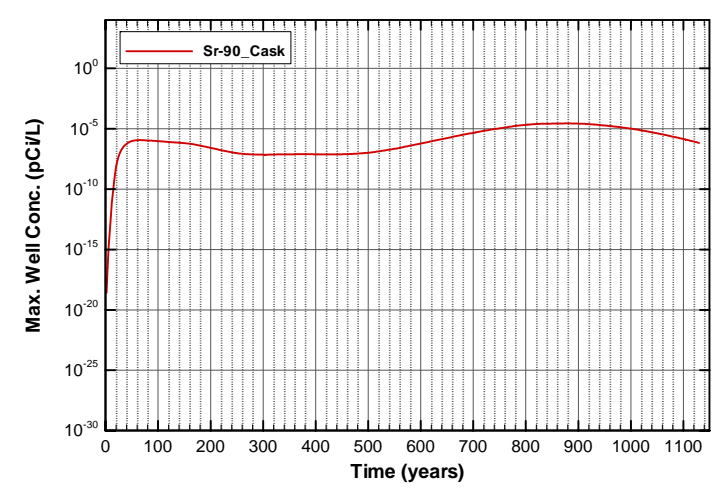

Figure A-1603. Well concentrations for Case01_off Sr-90_Cask

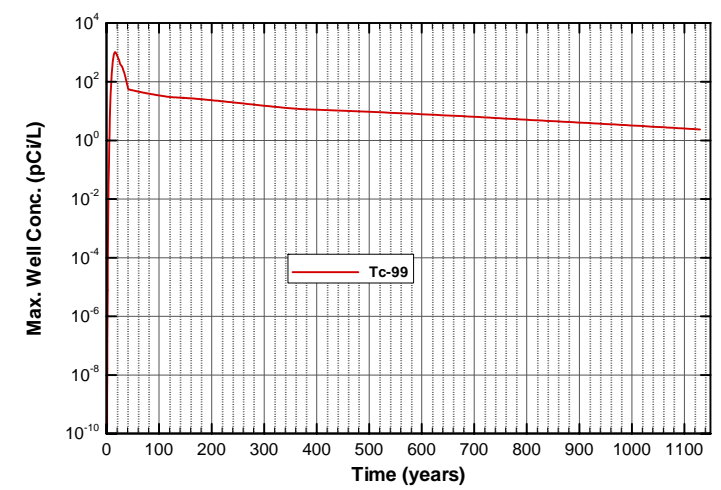

Figure A-1605. Well concentrations for Case01_off Tc-99

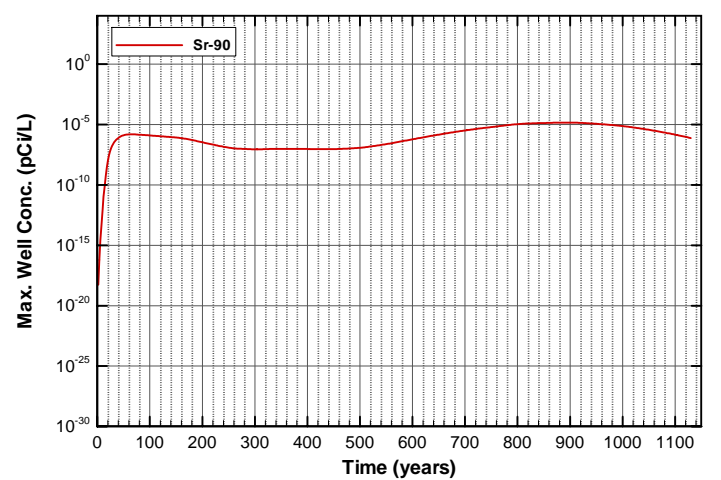

Figure A-1602. Well concentrations for Case01_off Sr-90

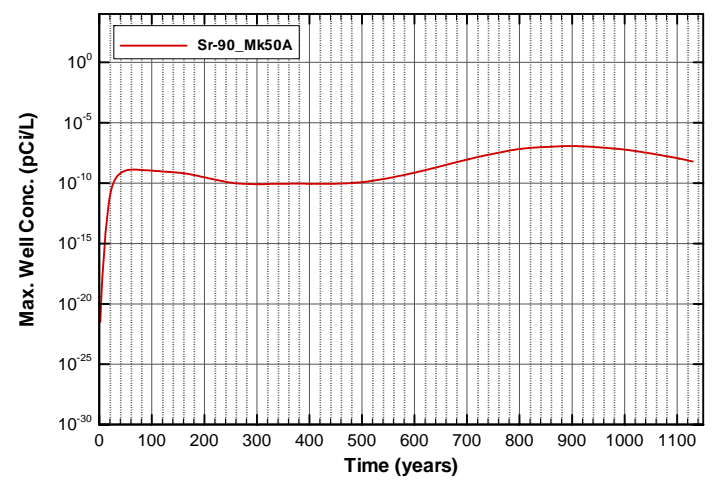

Figure A-1604. Well concentrations for Case01_off Sr-90_Mk50A

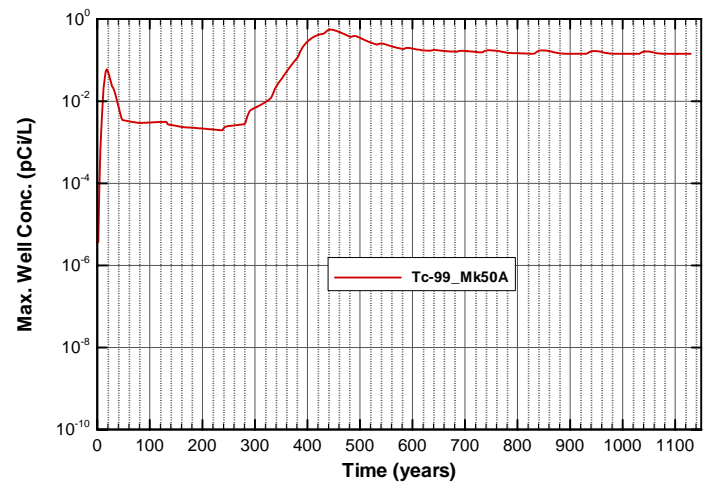

Figure A-1606. Well concentrations for Case01_off Tc-99_Mk50A 


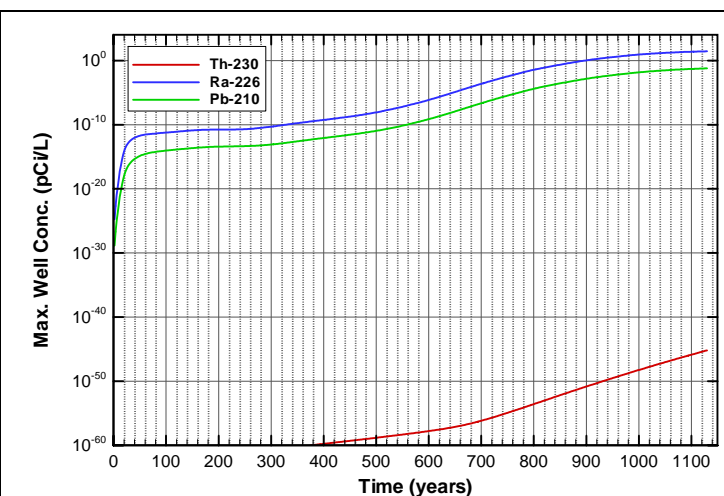

Figure A-1607. Well concentrations for Case01_off Th-230

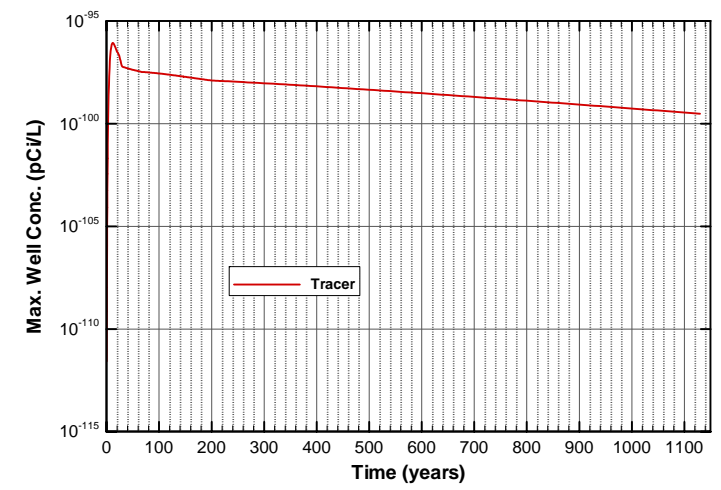

Figure A-1609. Well concentrations for Case01_off Tracer

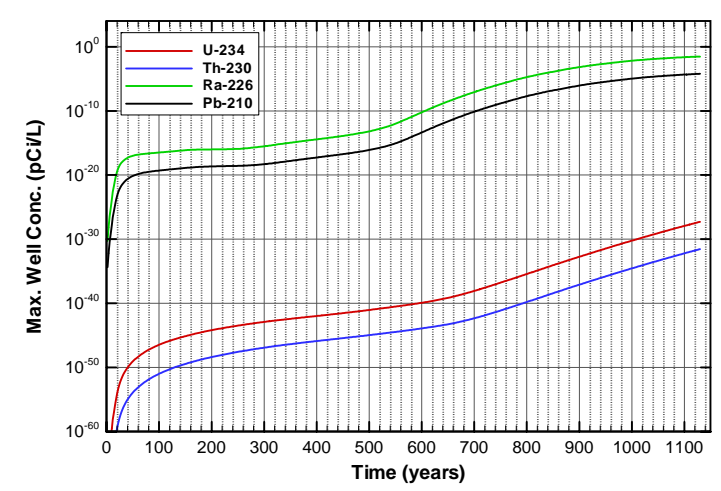

Figure A-1611. Well concentrations for Case01_off U-234

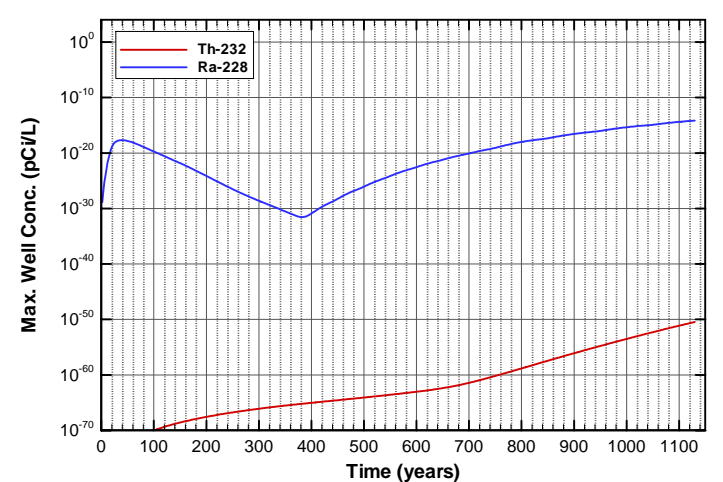

Figure A-1608. Well concentrations for Case01_off Th-232

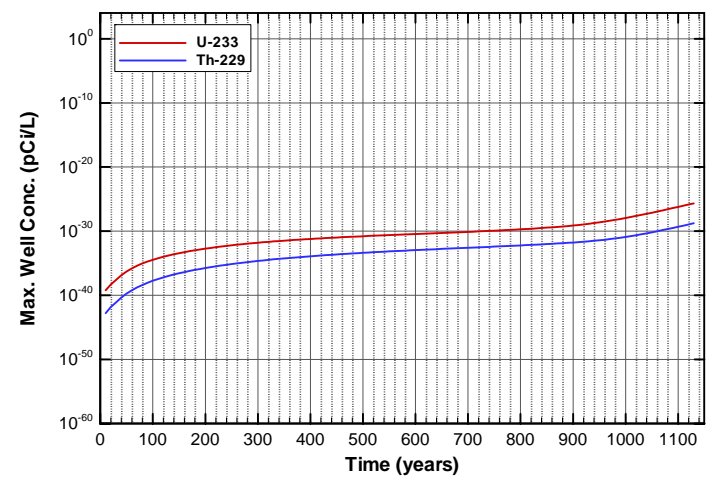

Figure A-1610. Well concentrations for Case01_off U-233

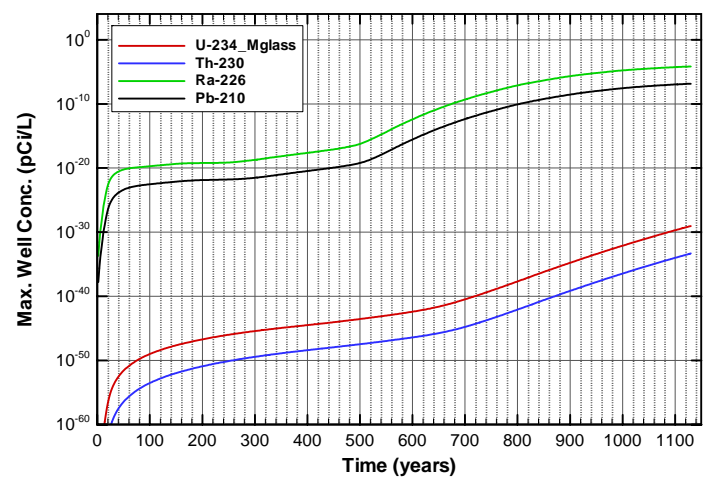

Figure A-1612. Well concentrations for Case01_off U-234_Mglass 


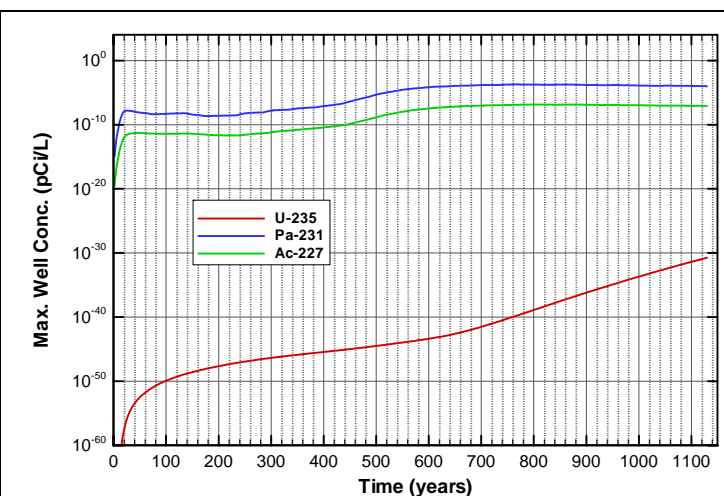

Figure A-1613. Well concentrations for Case01_off U-235

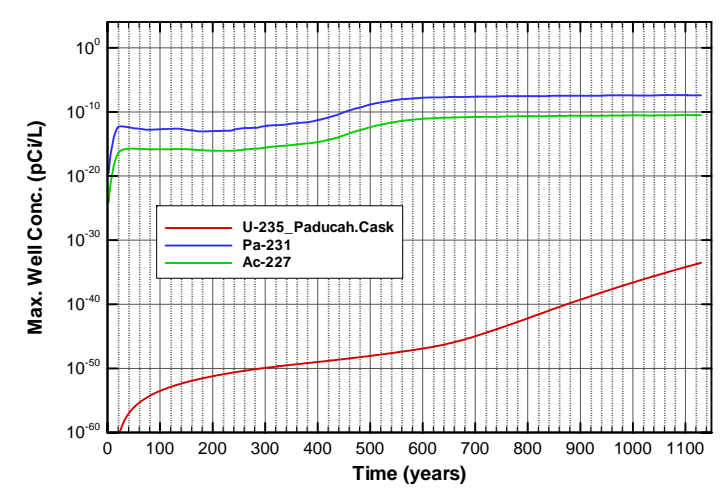

Figure A-1615. Well concentrations for Case01_off U-235_Paducah.Cask

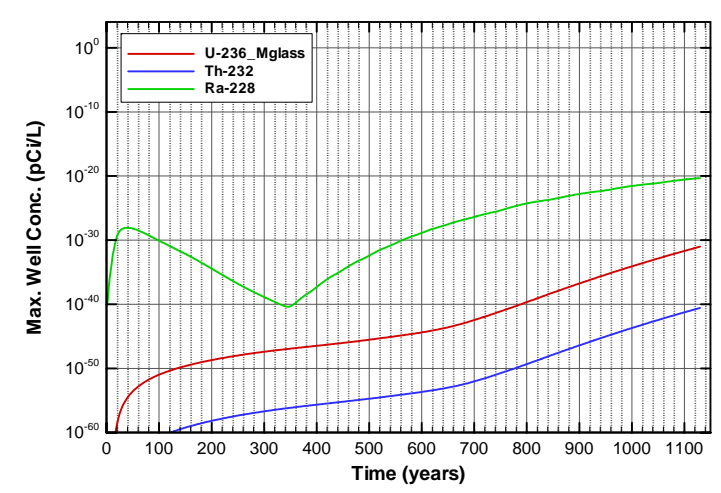

Figure A-1617. Well concentrations for Case01_off U-236_Mglass

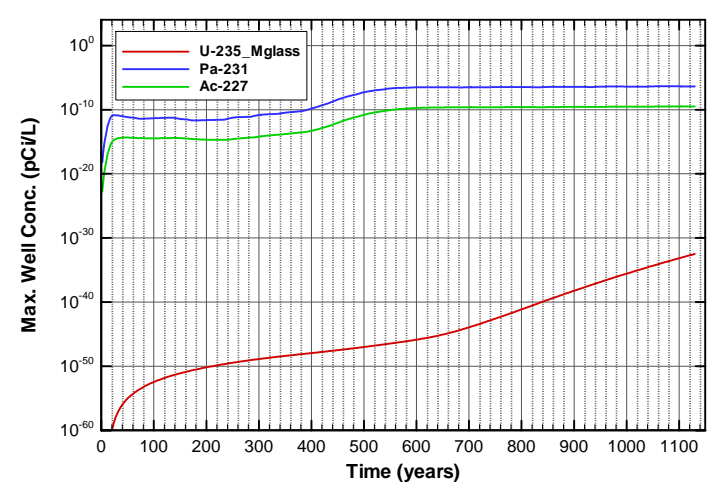

Figure A-1614. Well concentrations for Case01_off U-235_Mglass

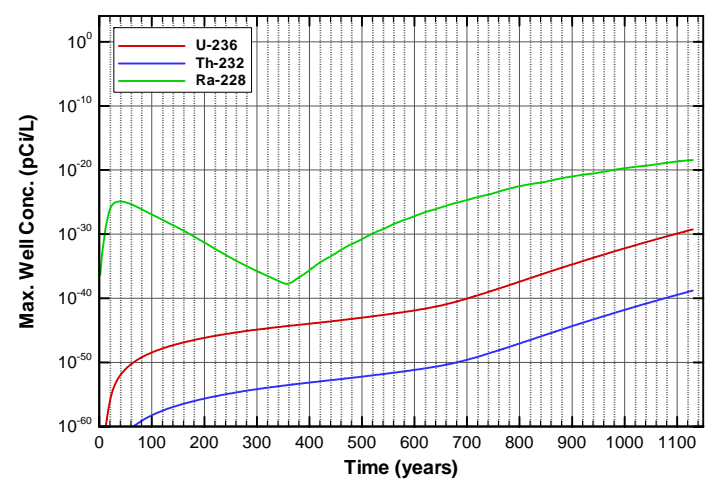

Figure A-1616. Well concentrations for Case01_off U-236

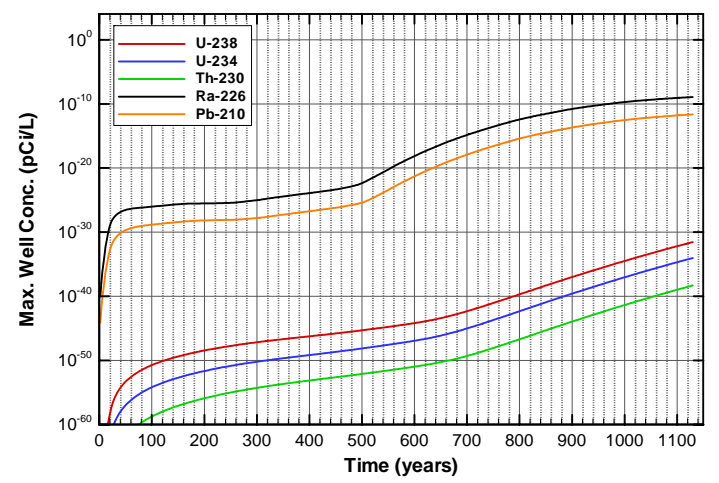

Figure A-1618. Well concentrations for Case01_off U-238 


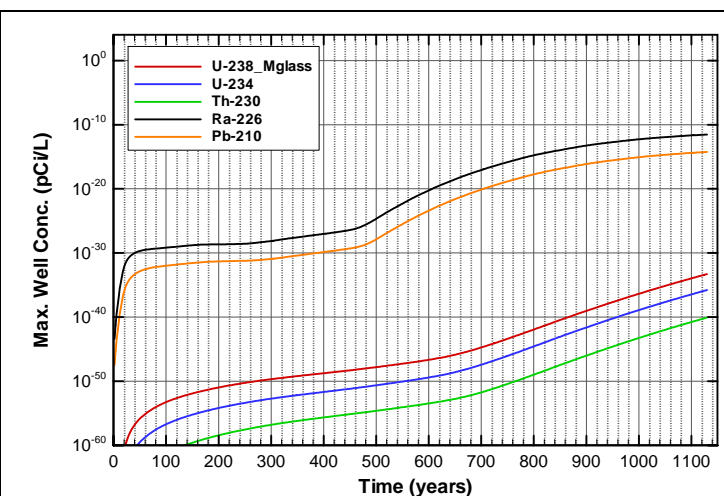

Figure A-1619. Well concentrations for Case01_off U-238_Mglass

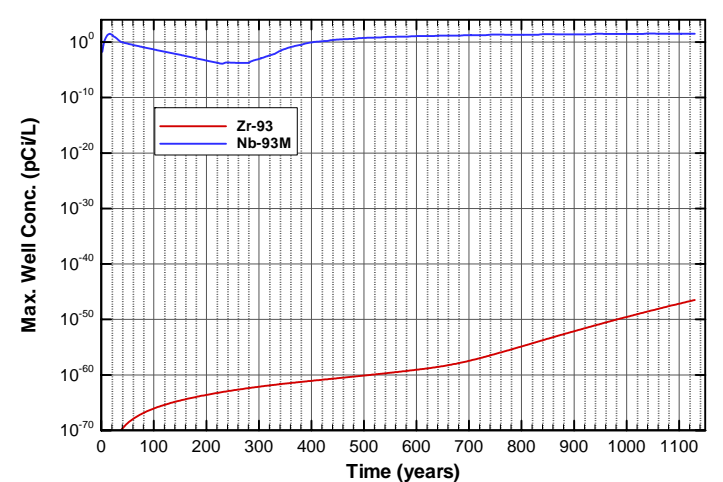

Figure A-1620. Well concentrations for Case01_off Zr-93

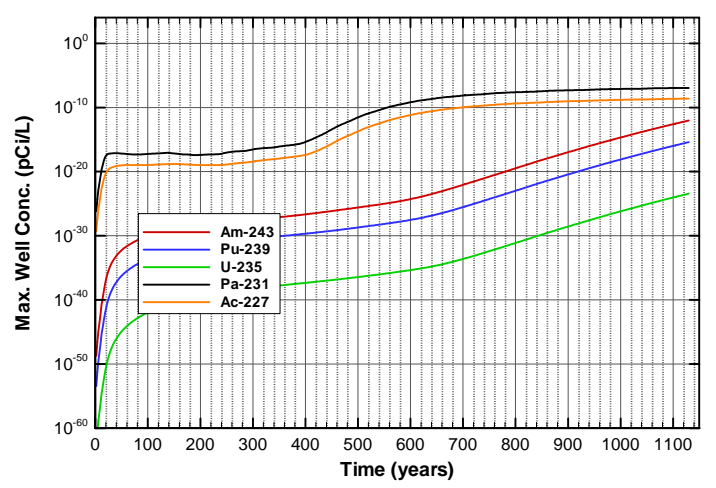

Figure A-1622. Well concentrations for Case01_on Am-243

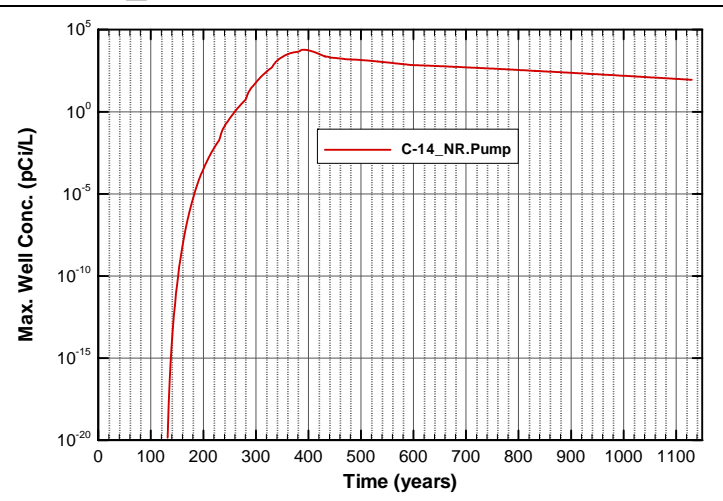

Figure A-1624. Well concentrations for Case01_on C-14_NR.Pump 
SRNL-STI-2008-00397, REVISION 0

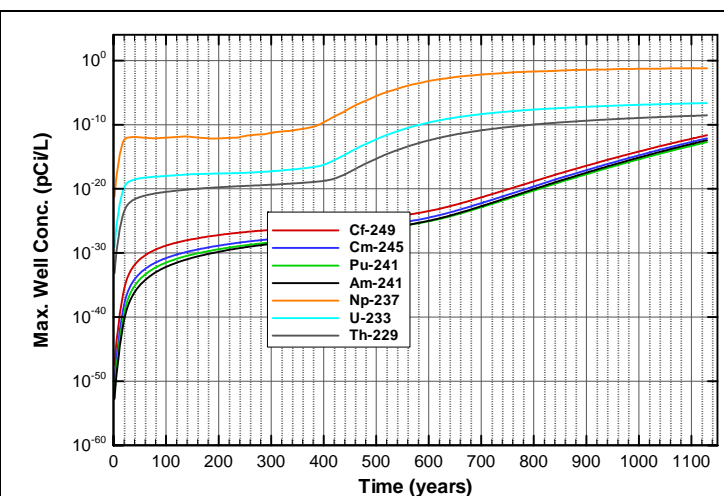

Figure A-1625. Well concentrations for Case01_on Cf-249

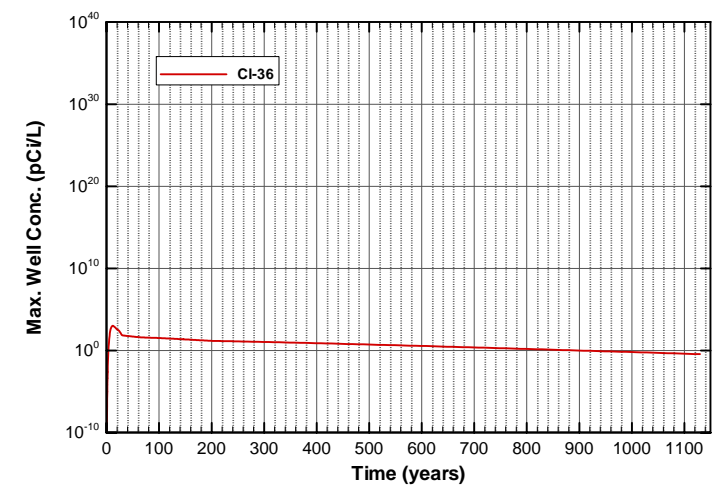

Figure A-1627. Well concentrations for Case01_on Cl-36

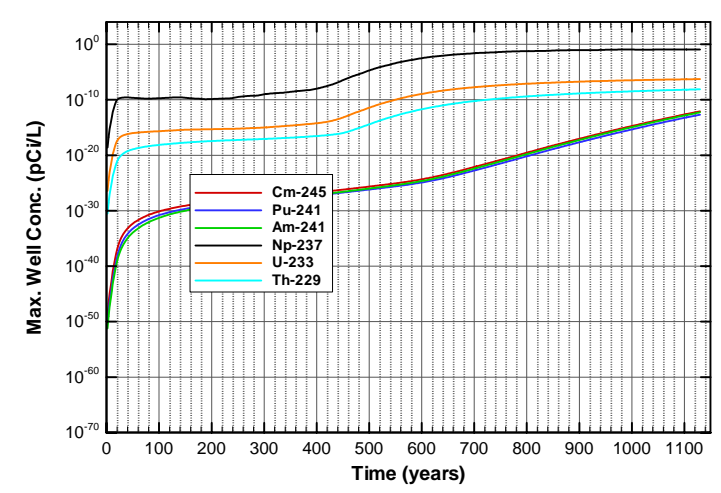

Figure A-1629. Well concentrations for Case01_on Cm-245

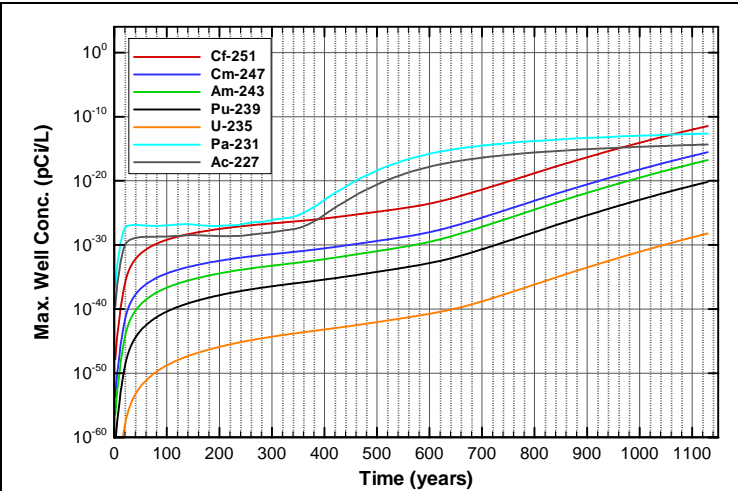

Figure A-1626. Well concentrations for Case01_on Cf-251

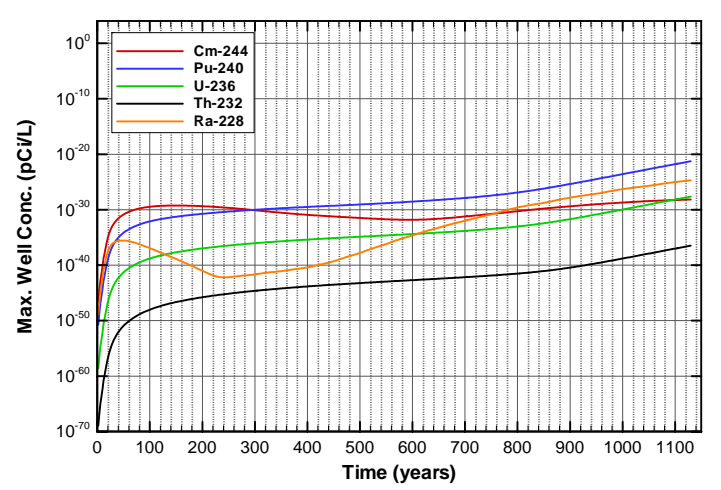

Figure A-1628. Well concentrations for Case01_on Cm-244

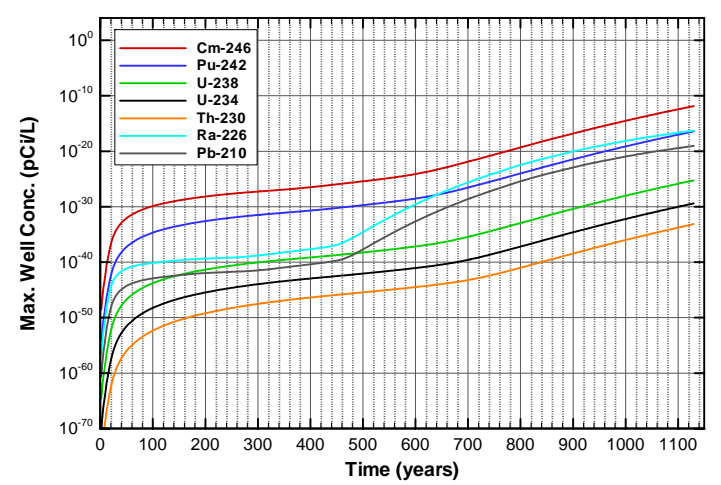

Figure A-1630. Well concentrations for Case01_on Cm-246 
SRNL-STI-2008-00397, REVISION 0

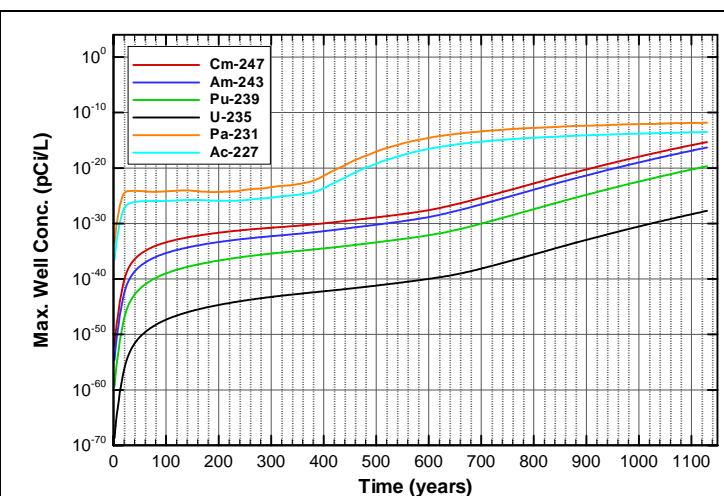

Figure A-1631. Well concentrations for Case01_on Cm-247

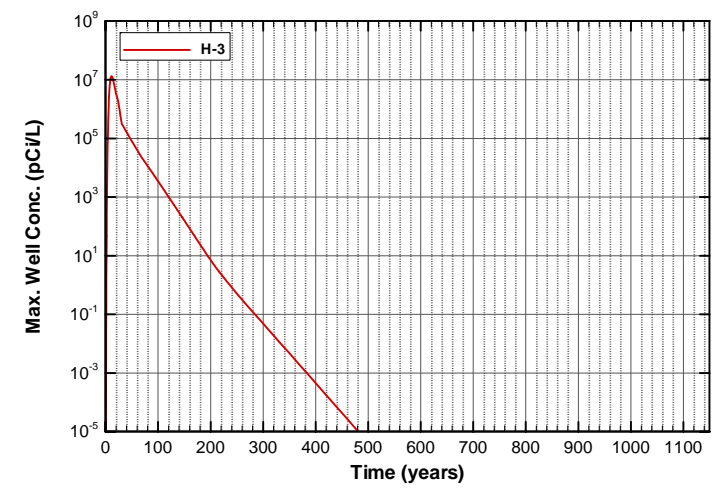

Figure A-1633. Well concentrations for Case01_on H-3

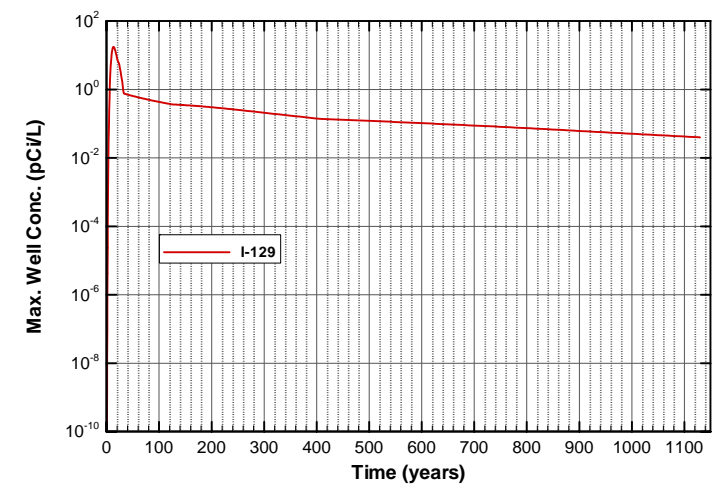

Figure A-1635. Well concentrations for Case01_on I-129

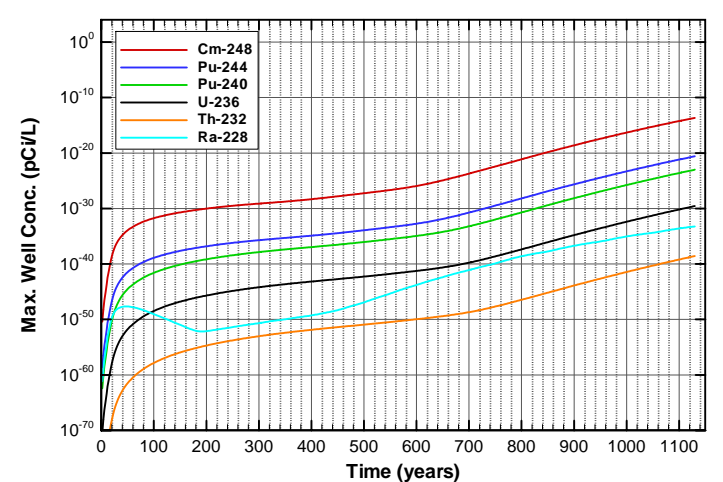

Figure A-1632. Well concentrations for Case01_on Cm-248

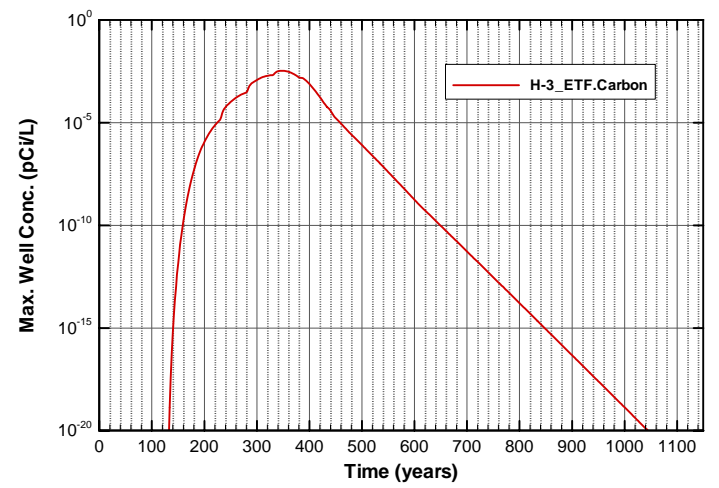

Figure A-1634. Well concentrations for Case01_on H-3_ETF.Carbon

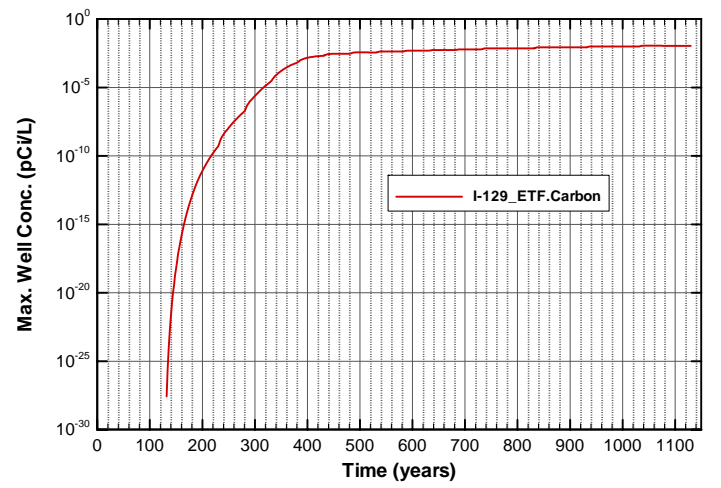

Figure A-1636. Well concentrations for Case01_on I-129_ETF.Carbon 
SRNL-STI-2008-00397, REVISION 0

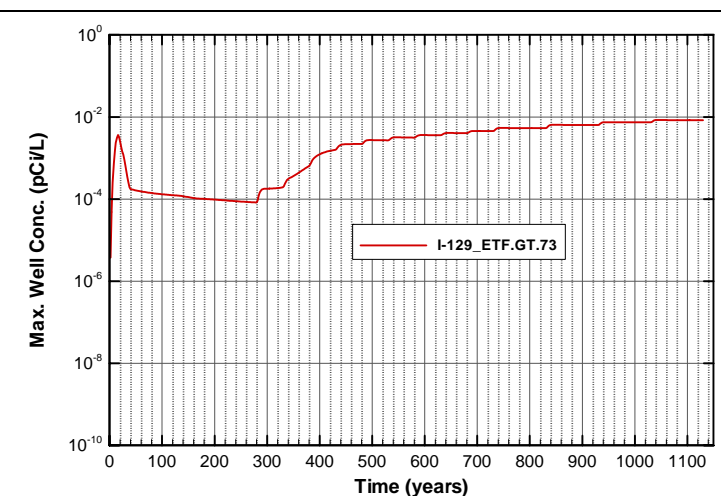

Figure A-1637. Well concentrations for Case01_on I-129_ETF.GT.73

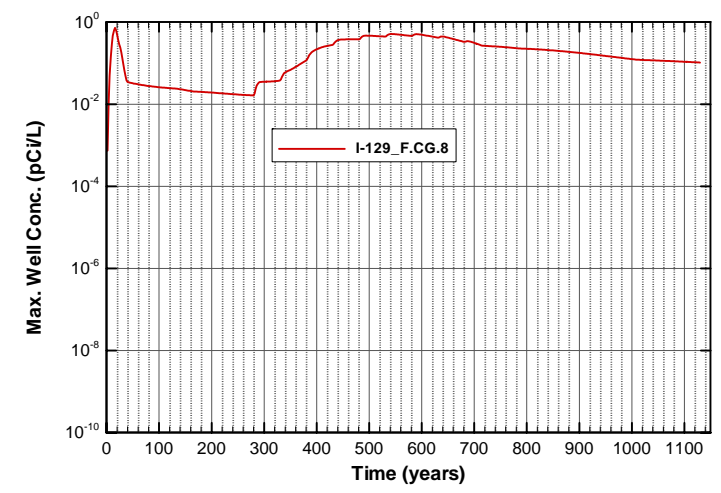

Figure A-1639. Well concentrations for Case01_on I-129_F.CG.8

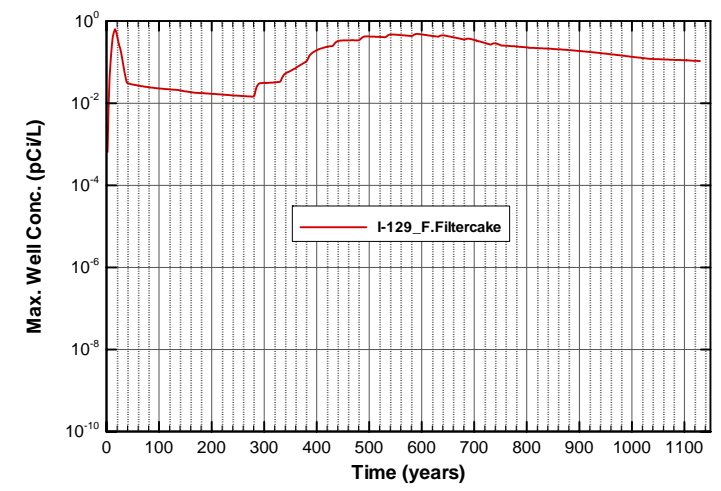

Figure A-1641. Well concentrations for Case01_on I-129_F.Filtercake

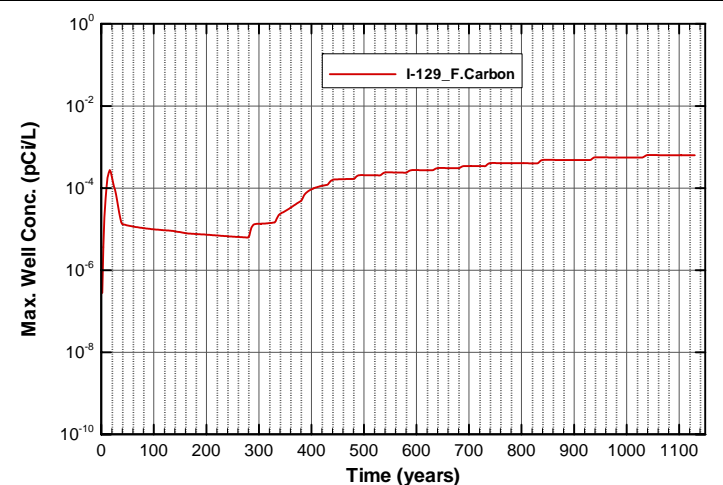

Figure A-1638. Well concentrations for Case01_on I-129_F.Carbon

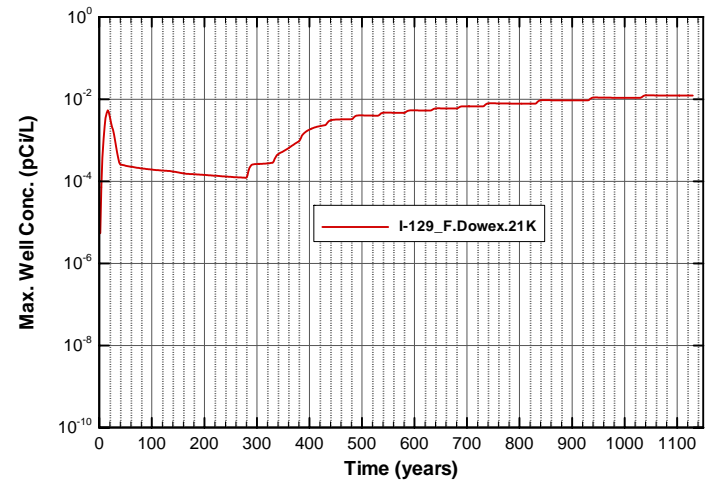

Figure A-1640. Well concentrations for Case01_on I-129_F.Dowex.21K

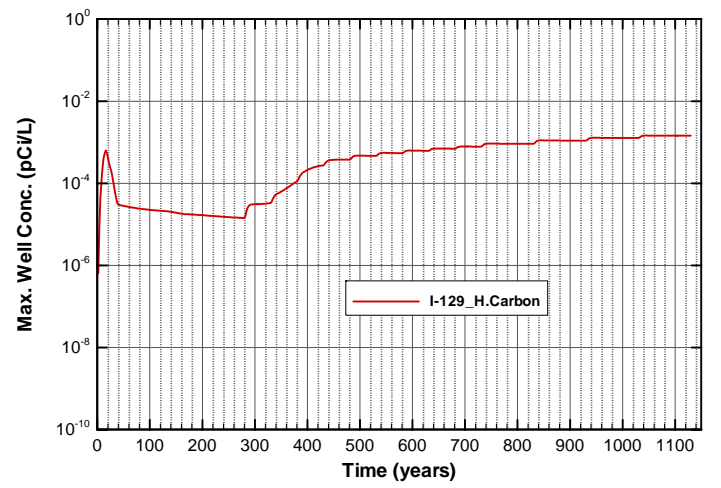

Figure A-1642. Well concentrations for Case01_on I-129_H.Carbon 
SRNL-STI-2008-00397, REVISION 0

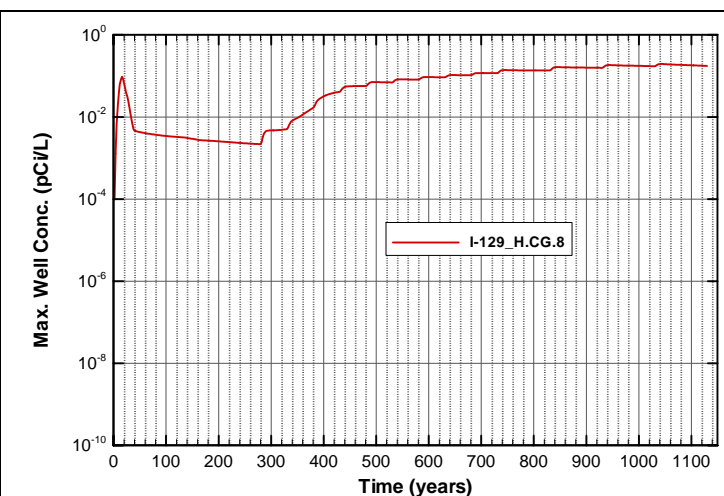

Figure A-1643. Well concentrations for Case01_on I-129_H.CG.8

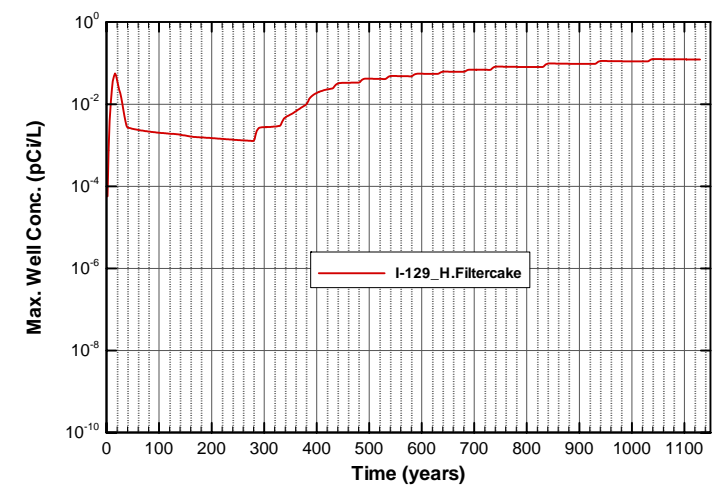

Figure A-1645. Well concentrations for Case01_on I-129_H.Filtercake

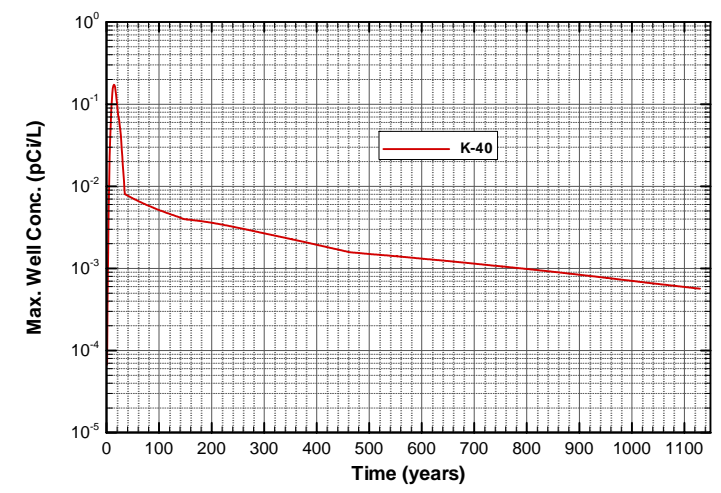

Figure A-1647. Well concentrations for Case01_on K-40

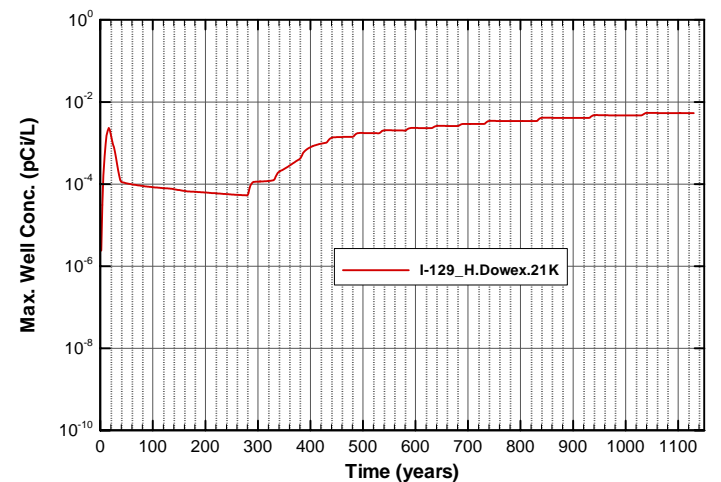

Figure A-1644. Well concentrations for Case01_on I-129_H.Dowex.21K

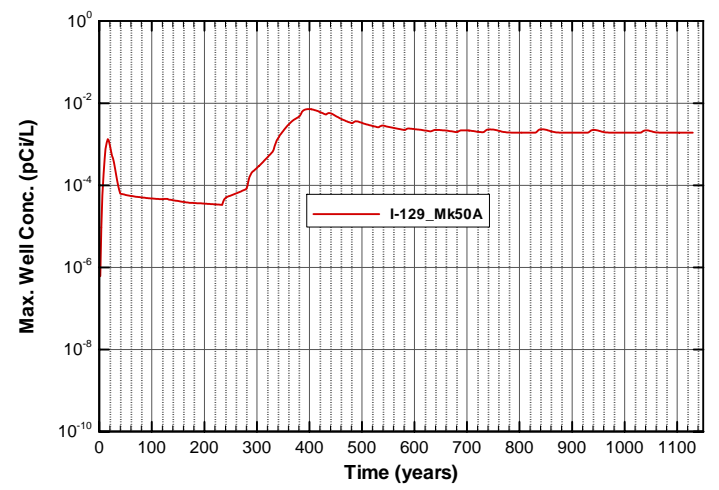

Figure A-1646. Well concentrations for Case01_on I-129_Mk50A

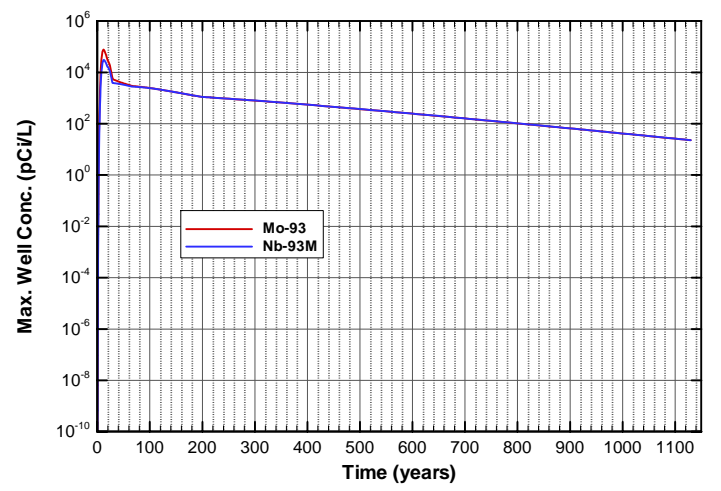

Figure A-1648. Well concentrations for Case01_on Mo-93 
SRNL-STI-2008-00397, REVISION 0

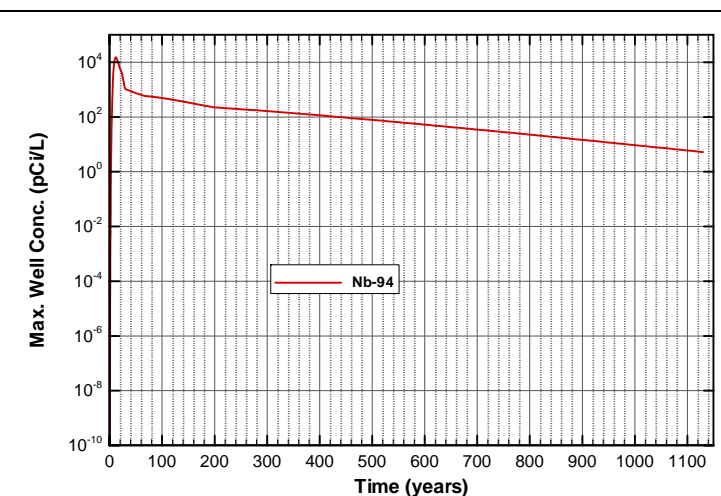

Figure A-1649. Well concentrations for Case01_on Nb-94

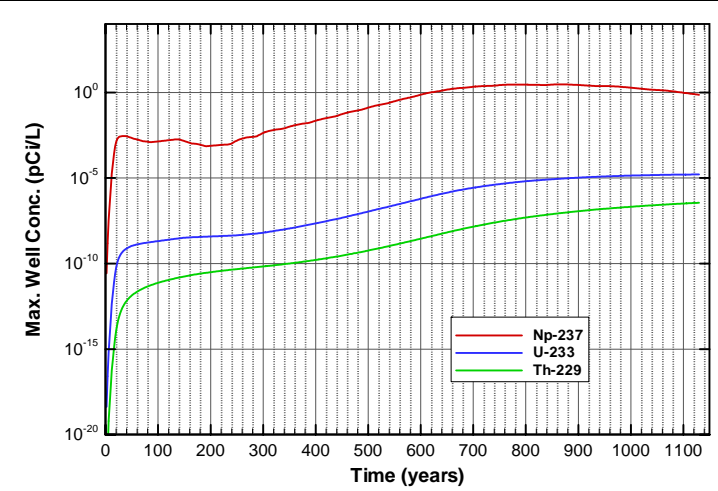

Figure A-1651. Well concentrations for Case01_on Np-237

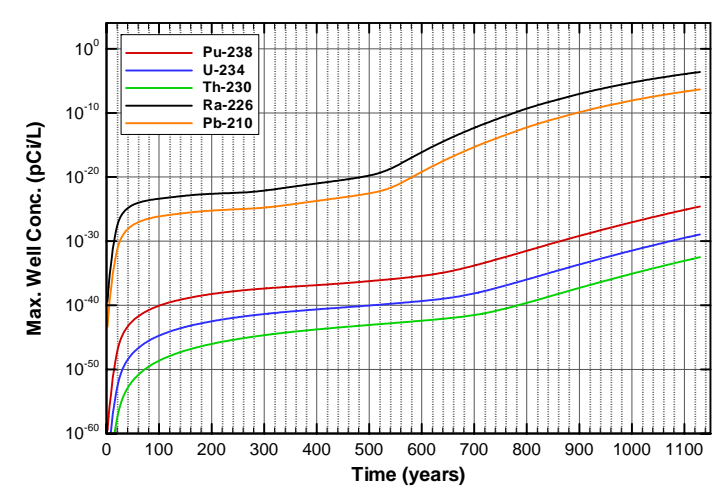

Figure A-1653. Well concentrations for Case01_on Pu-238

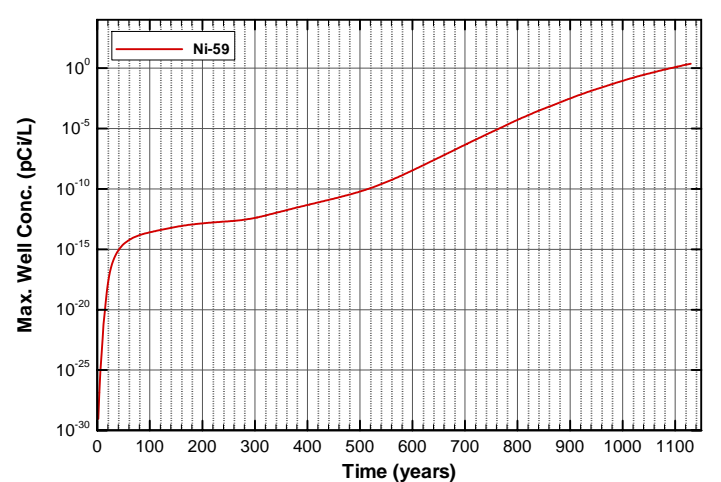

Figure A-1650. Well concentrations for Case01_on Ni-59

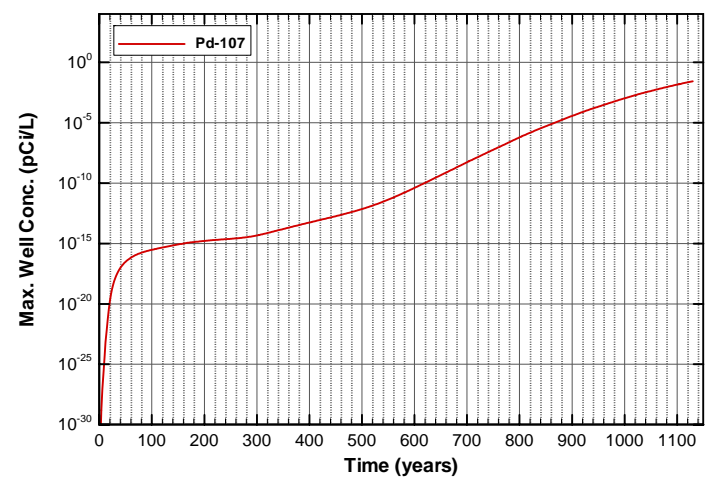

Figure A-1652. Well concentrations for Case01_on Pd-107

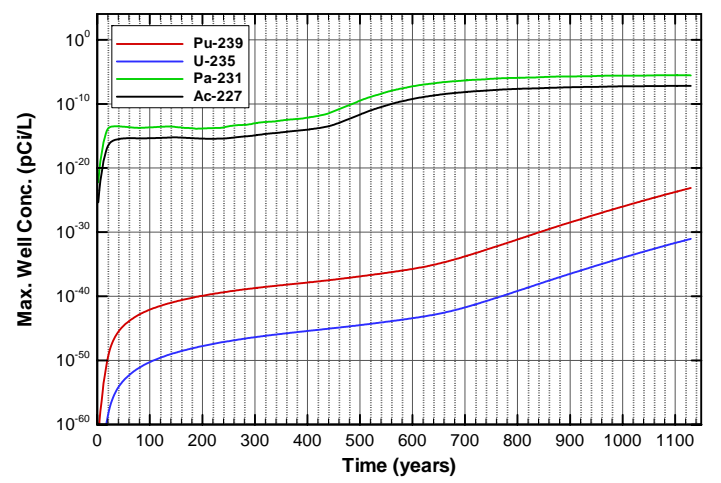

Figure A-1654. Well concentrations for Case01_on Pu-239 
SRNL-STI-2008-00397, REVISION 0

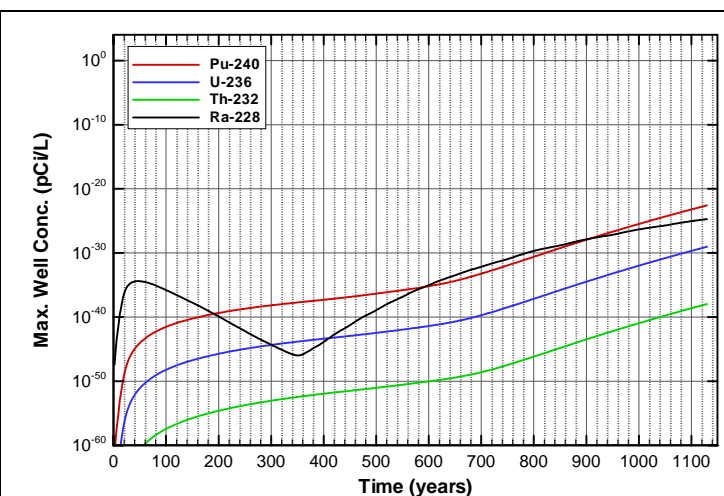

Figure A-1655. Well concentrations for Case01_on Pu-240

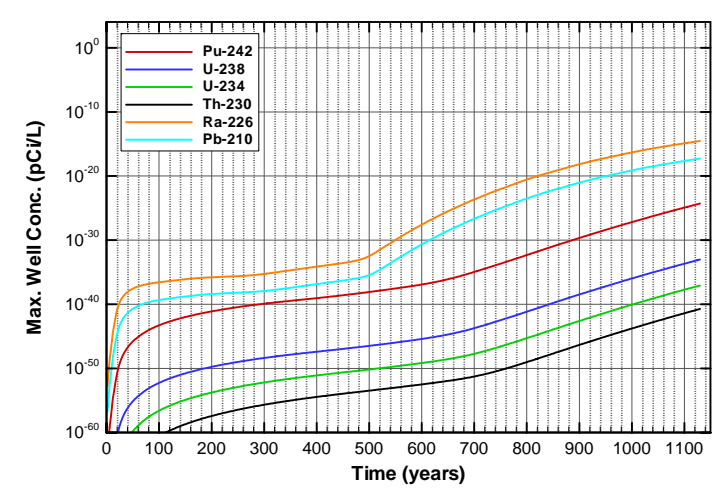

Figure A-1657. Well concentrations for Case01_on Pu-242

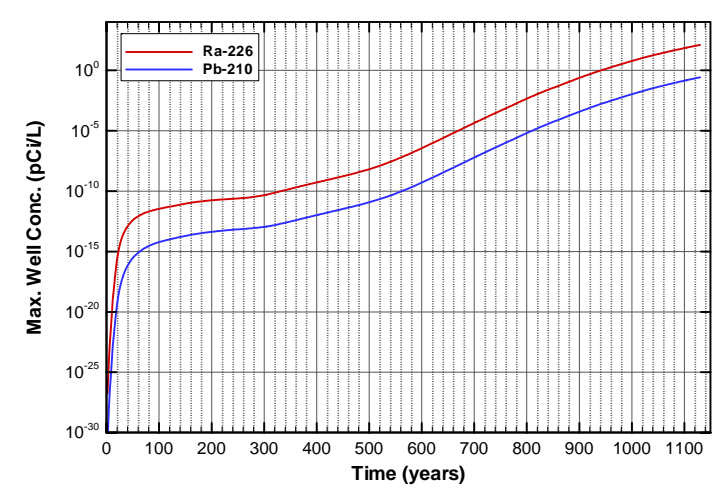

Figure A-1659. Well concentrations for Case01_on Ra-226

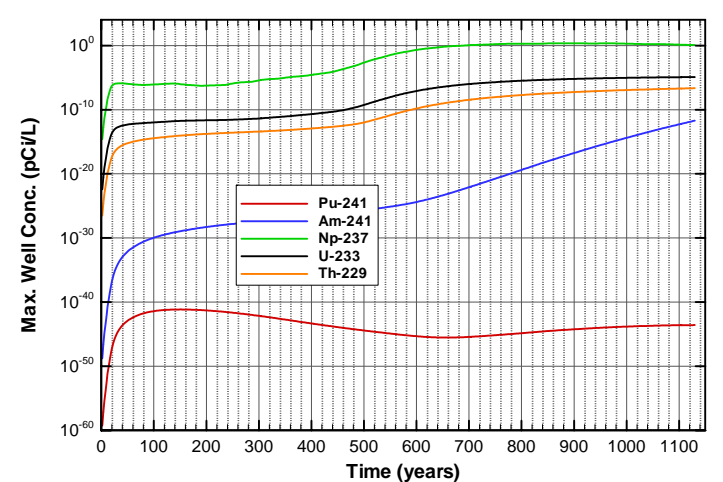

Figure A-1656. Well concentrations for Case01_on Pu-241

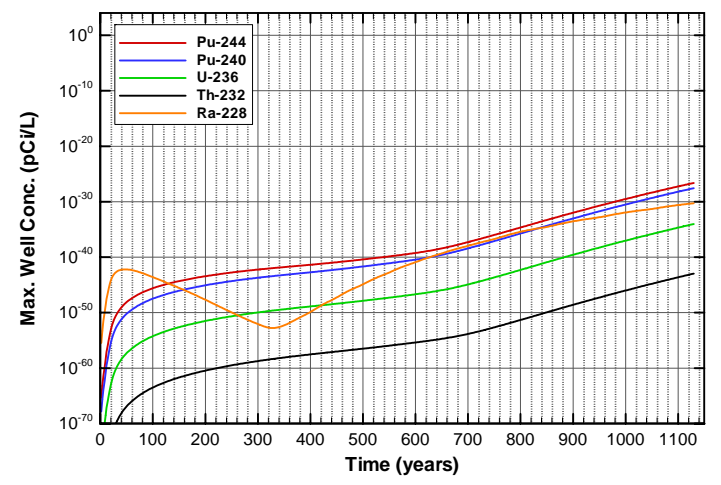

Figure A-1658. Well concentrations for Case01_on Pu-244

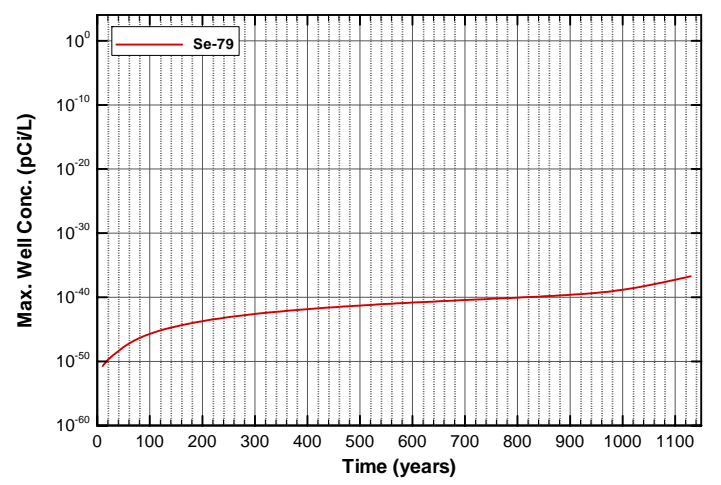

Figure A-1660. Well concentrations for Case01_on Se-79 
SRNL-STI-2008-00397, REVISION 0

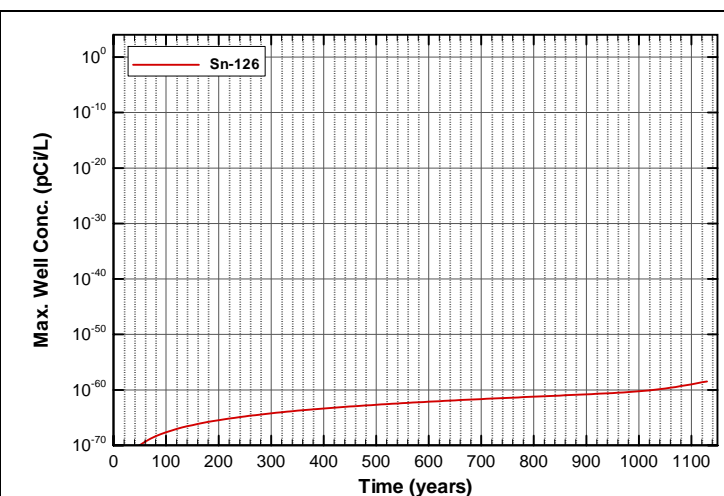

Figure A-1661. Well concentrations for Case01_on Sn-126

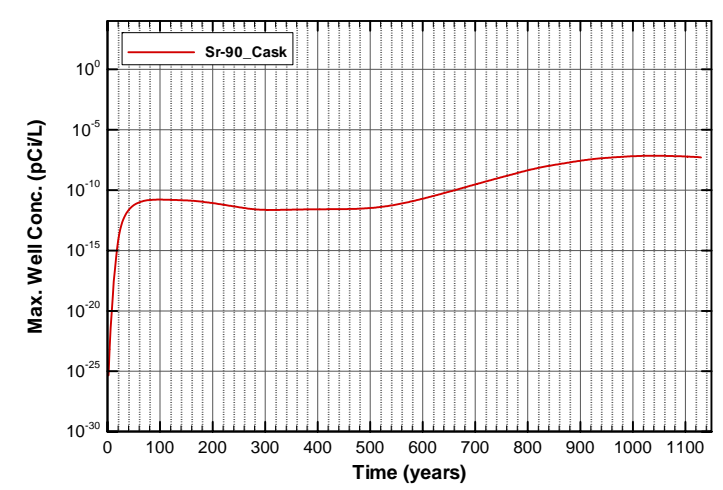

Figure A-1663. Well concentrations for Case01_on Sr-90_Cask

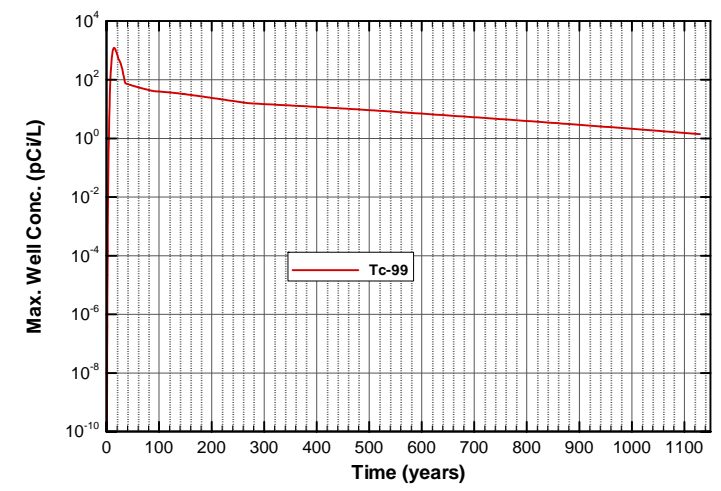

Figure A-1665. Well concentrations for Case01_on Tc-99

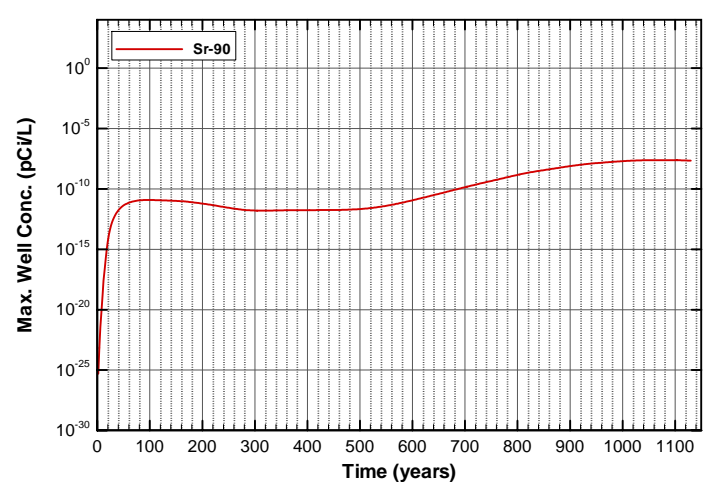

Figure A-1662. Well concentrations for Case01_on Sr-90

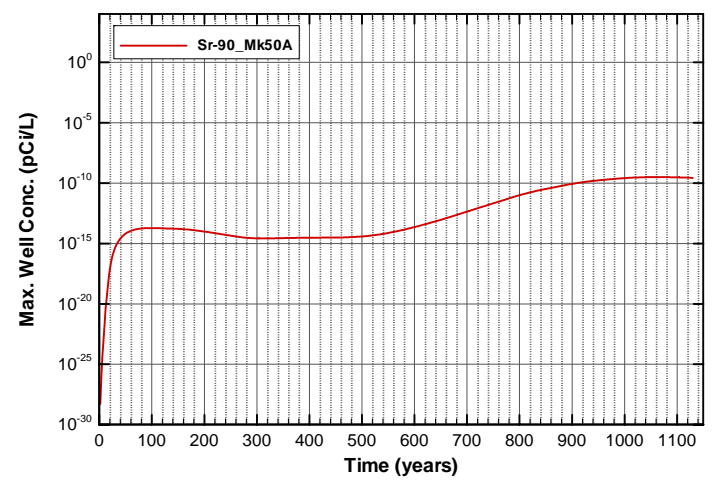

Figure A-1664. Well concentrations for Case01_on Sr-90_Mk50A

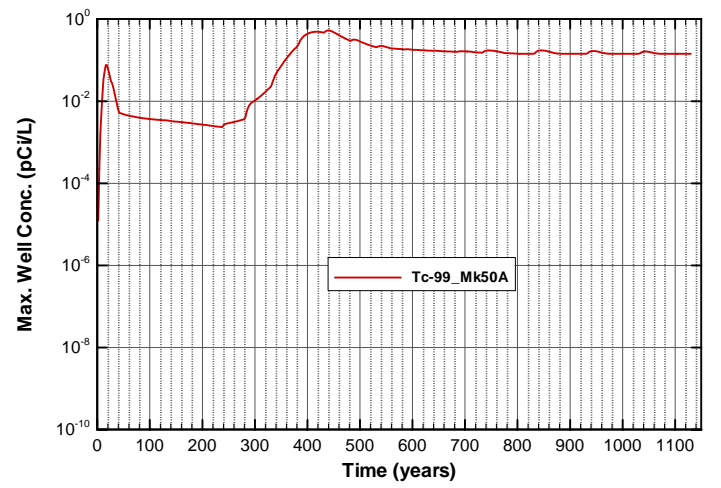

Figure A-1666. Well concentrations for Case01_on Tc-99_Mk50A 
SRNL-STI-2008-00397, REVISION 0

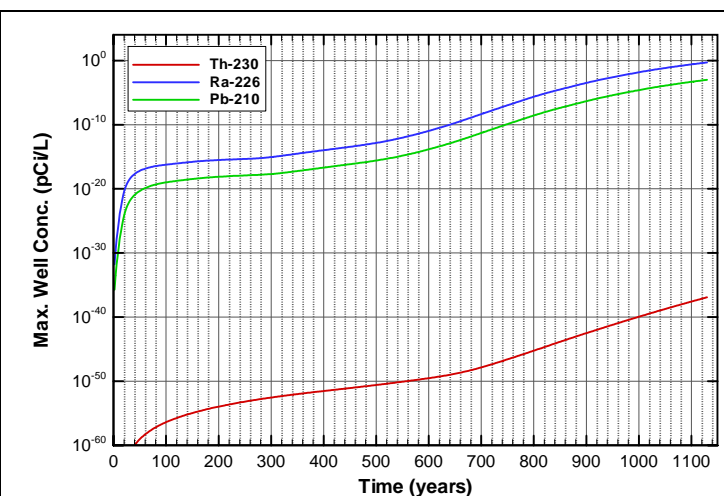

Figure A-1667. Well concentrations for Case01_on Th-230

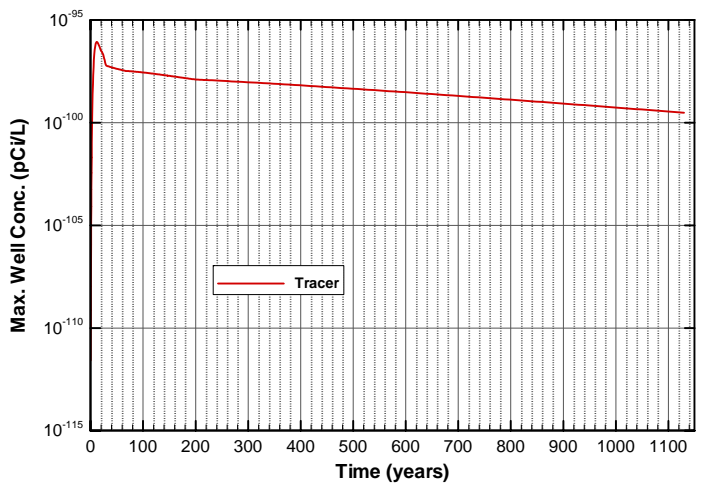

Figure A-1669. Well concentrations for Case01_on Tracer

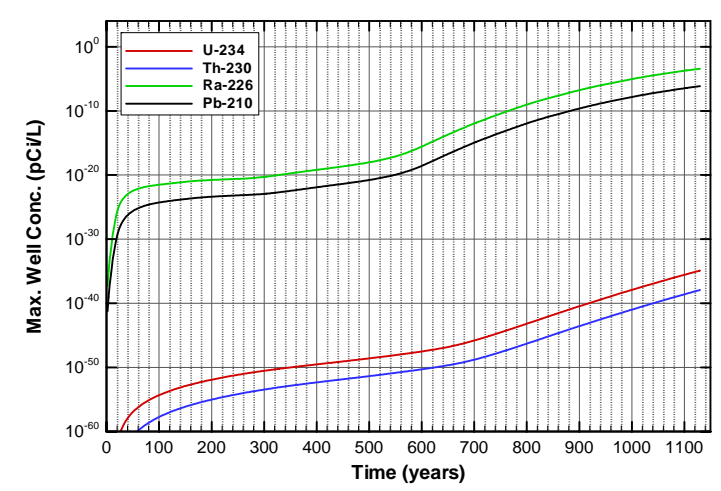

Figure A-1671. Well concentrations for Case01_on U-234

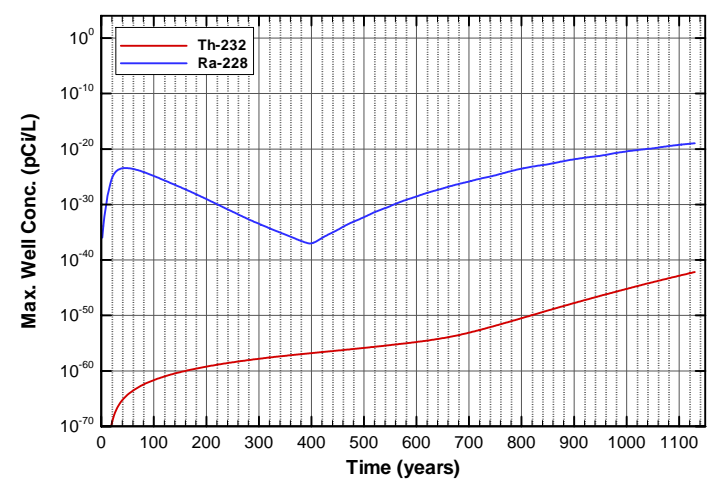

Figure A-1668. Well concentrations for Case01_on Th-232

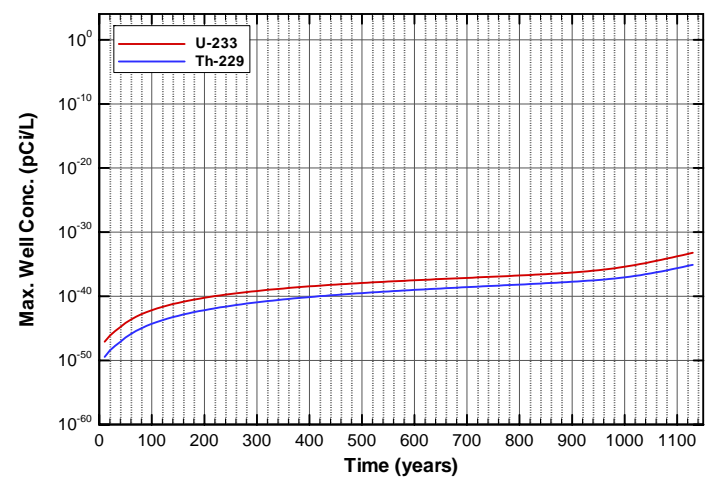

Figure A-1670. Well concentrations for Case01_on U-233

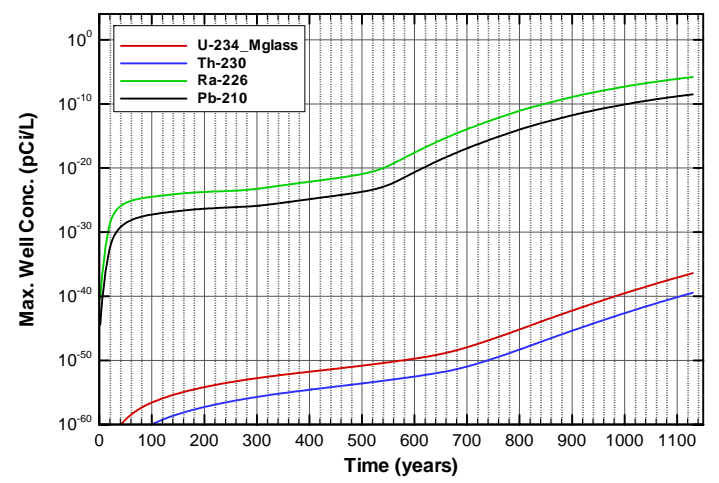

Figure A-1672. Well concentrations for Case01_on U-234_Mglass 


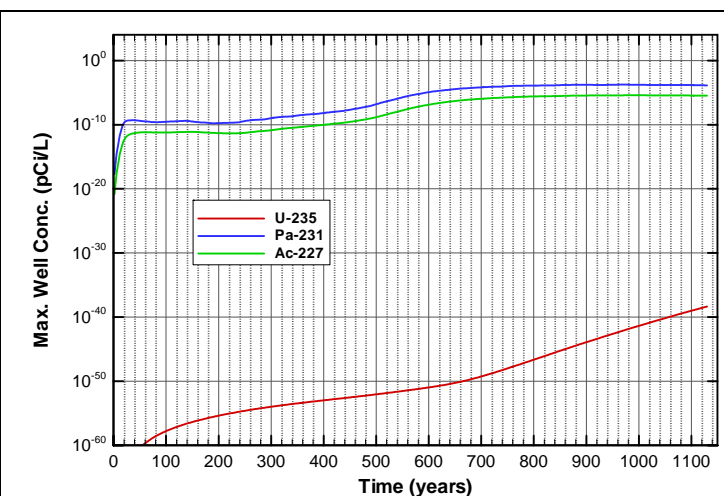

Figure A-1673. Well concentrations for Case01_on U-235

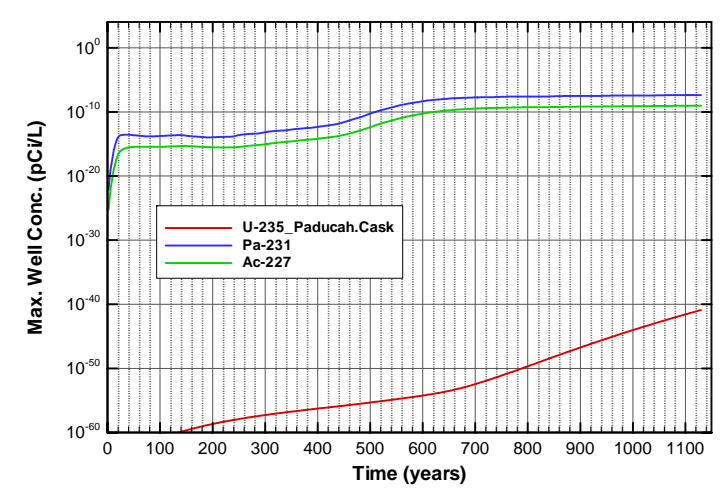

Figure A-1675. Well concentrations for Case01_on U-235_Paducah.Cask

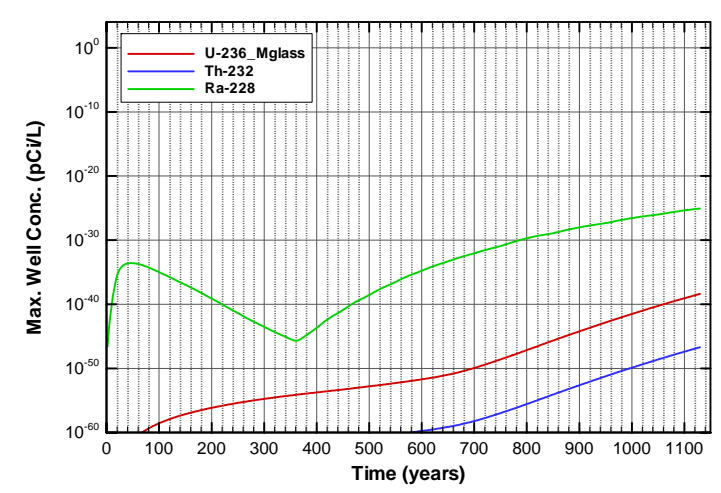

Figure A-1677. Well concentrations for Case01_on U-236_Mglass

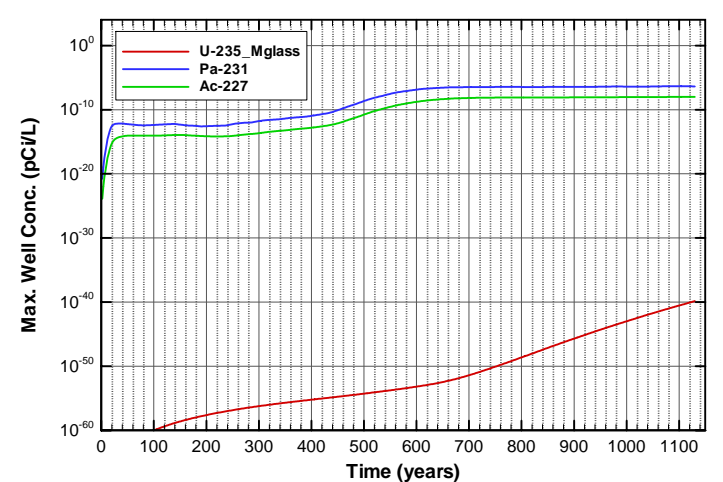

Figure A-1674. Well concentrations for Case01_on U-235_Mglass

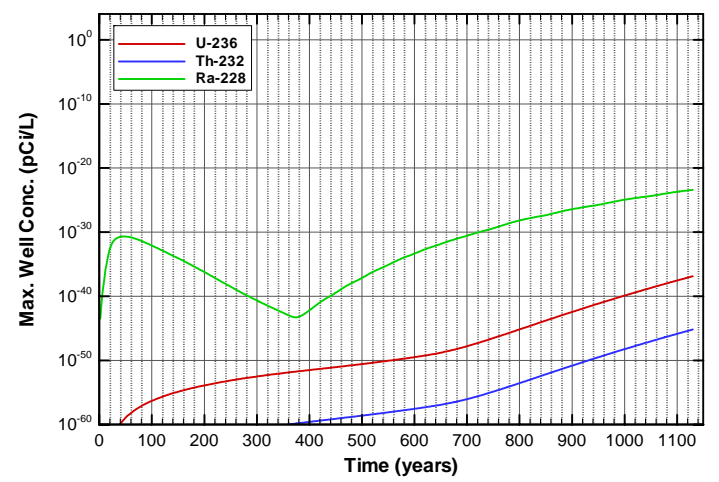

Figure A-1676. Well concentrations for Case01_on U-236

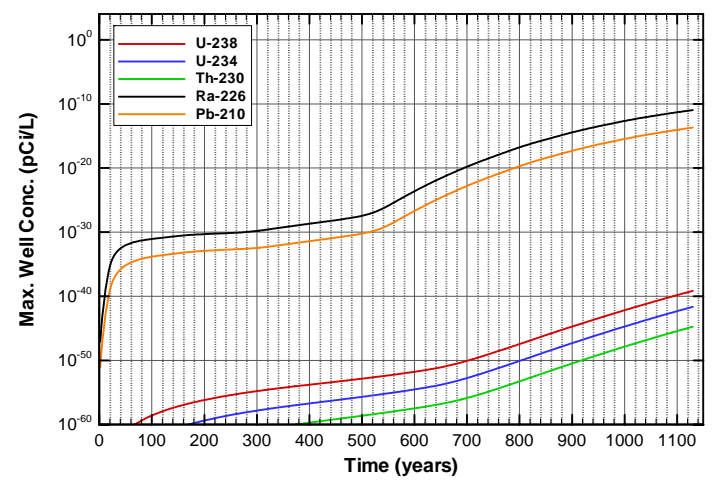

Figure A-1678. Well concentrations for Case01_on U-238 


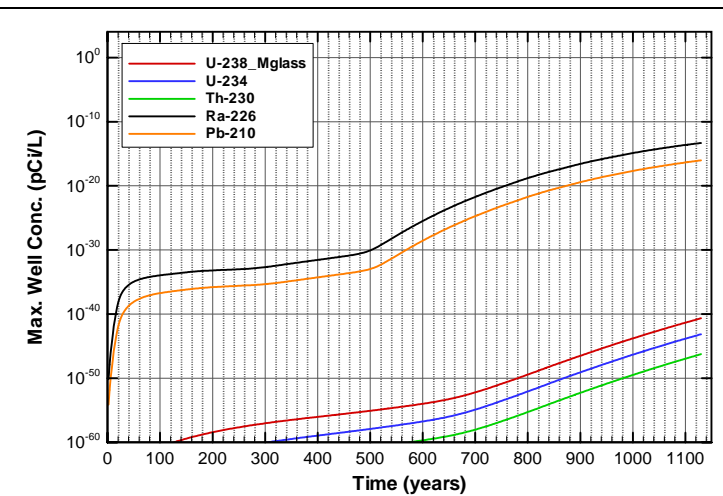

Figure A-1679. Well concentrations for Case01_on U-238_Mglass

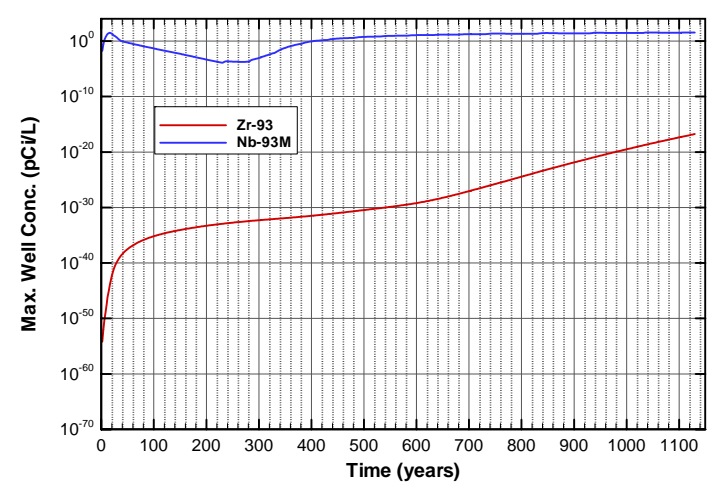

Figure A-1680. Well concentrations for Case01_on Zr-93

\subsubsection{Concentration plots for 5-year cover}

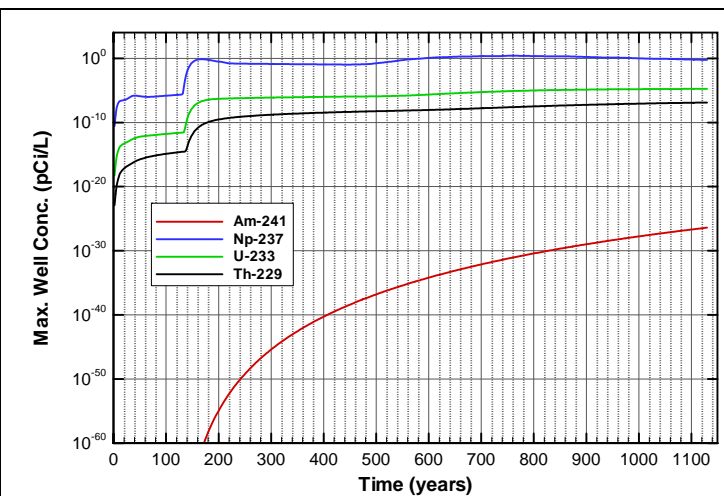

Figure A-1681. Well concentrations for Case01n11_off Am-241

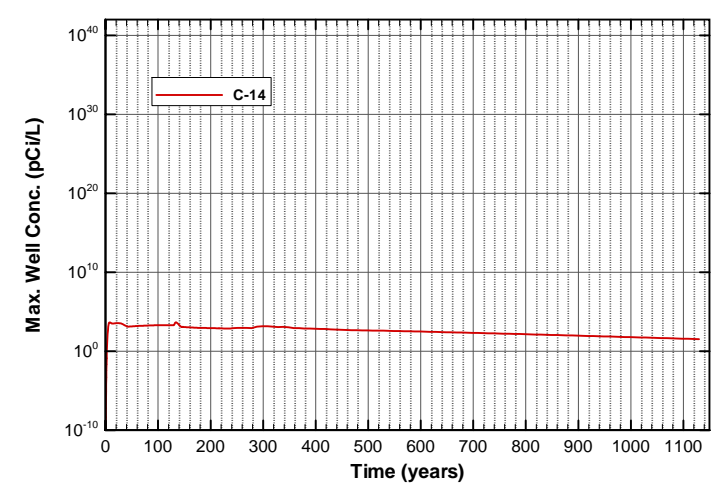

Figure A-1683. Well concentrations for Case01n11_off C-14

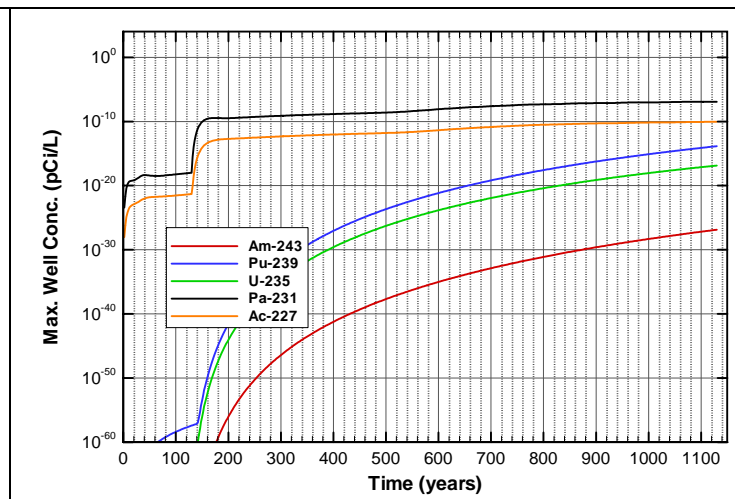

Figure A-1682. Well concentrations for Case01n11_off Am-243

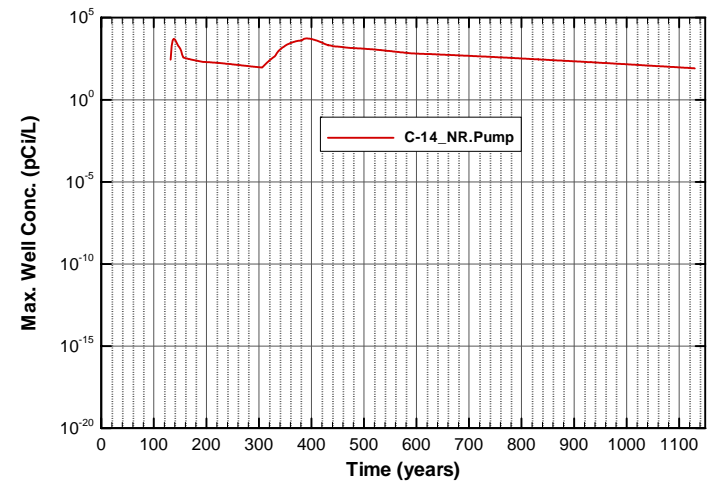

Figure A-1684. Well concentrations for Case01n11_off C-14_NR.Pump 
SRNL-STI-2008-00397, REVISION 0

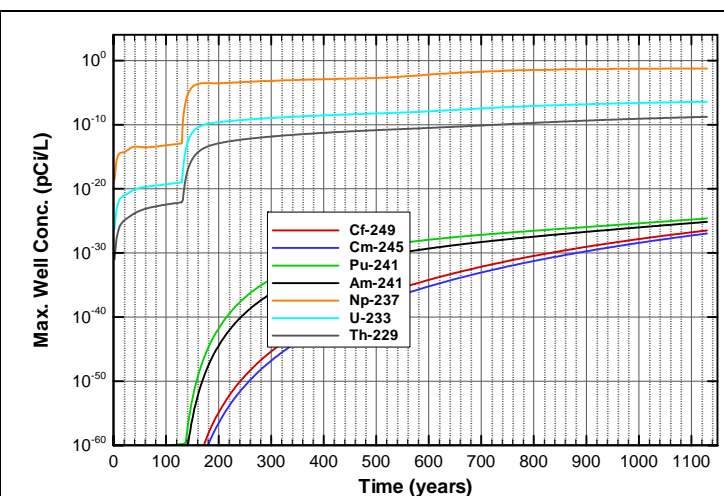

Figure A-1685. Well concentrations for Case01n11_off Cf-249

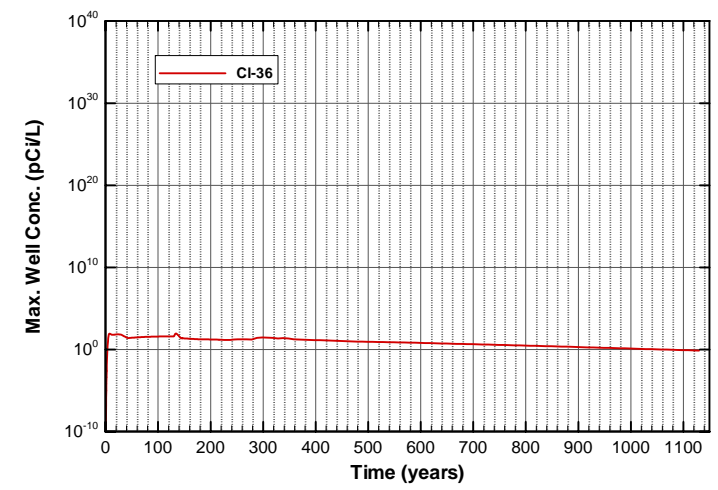

Figure A-1687. Well concentrations for Case01n11_off Cl-36

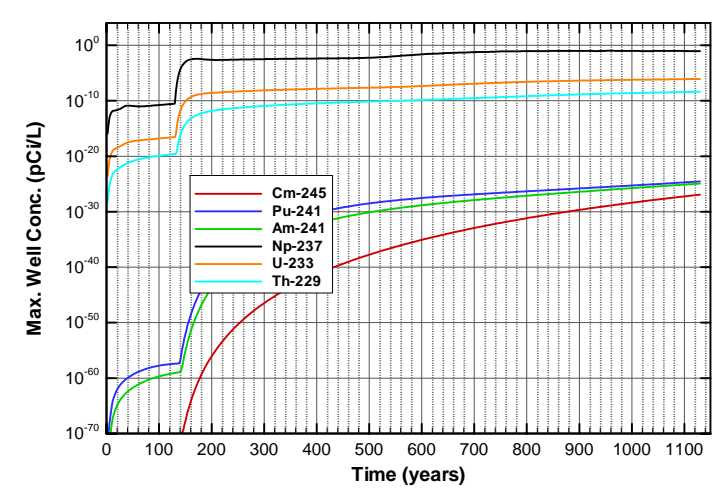

Figure A-1689. Well concentrations for Case01n11_off Cm-245

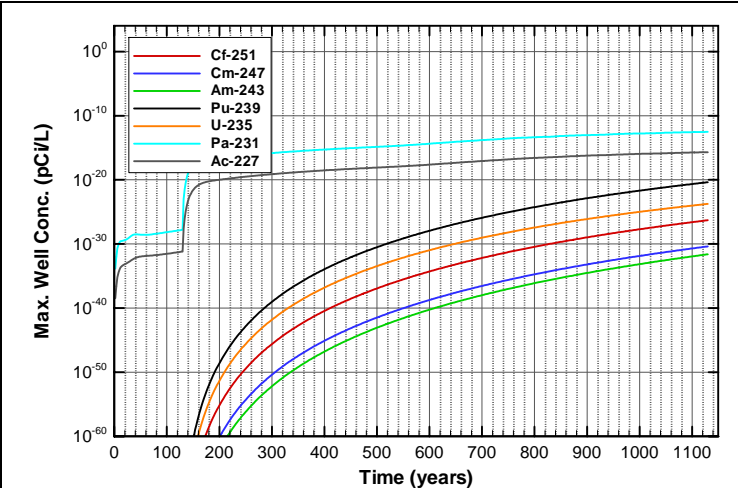

Figure A-1686. Well concentrations for Case01n11_off Cf-251

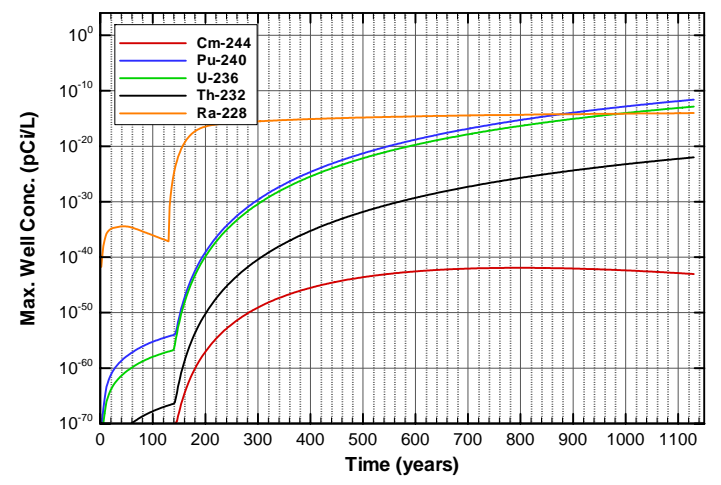

Figure A-1688. Well concentrations for Case01n11_off Cm-244

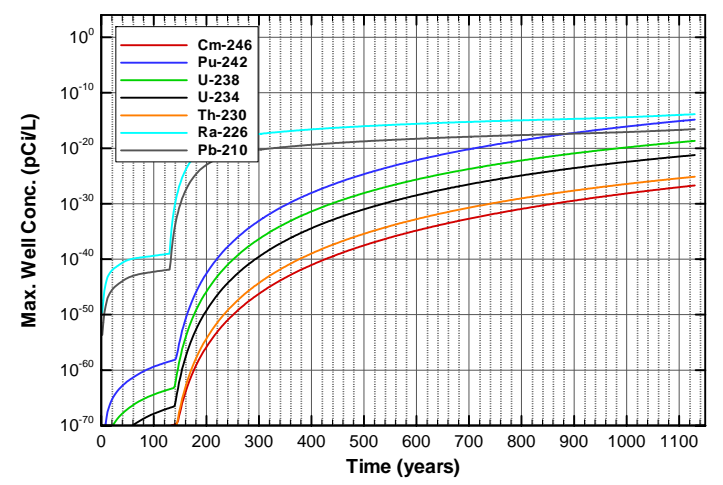

Figure A-1690. Well concentrations for Case01n11_off Cm-246 
SRNL-STI-2008-00397, REVISION 0

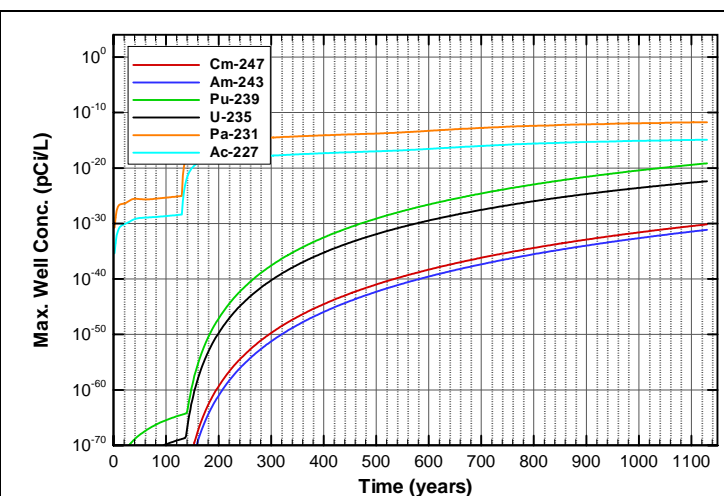

Figure A-1691. Well concentrations for Case01n11_off Cm-247

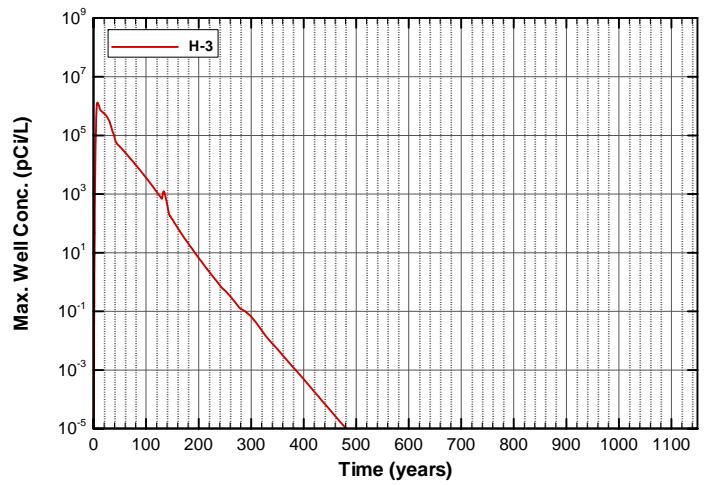

Figure A-1693. Well concentrations for Case01n11_off H-3

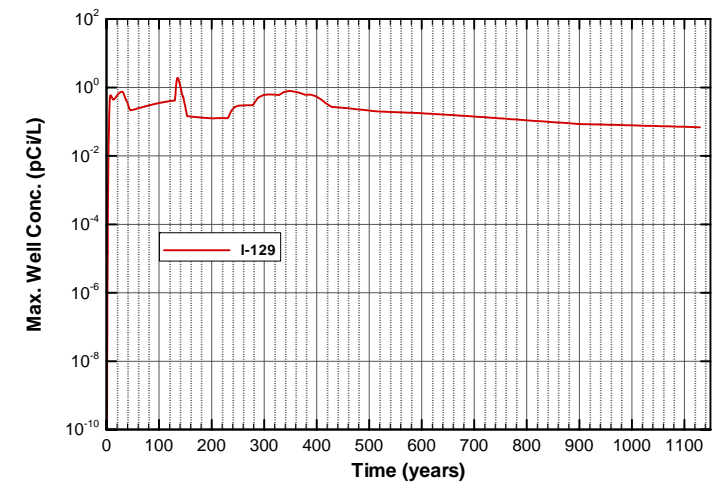

Figure A-1695. Well concentrations for Case01n11_off I-129

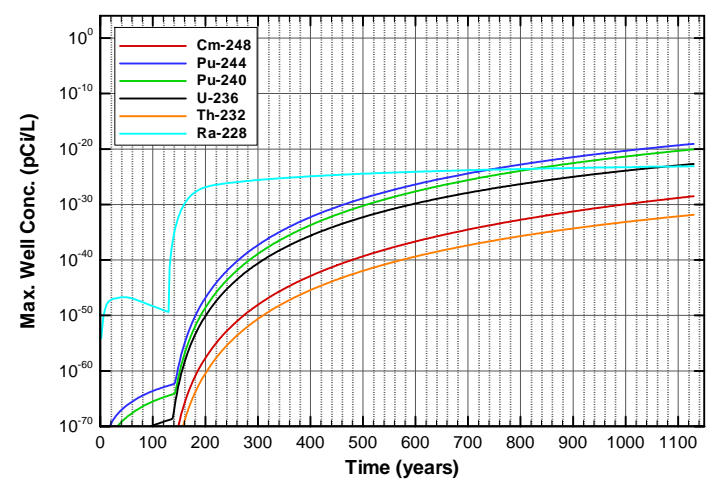

Figure A-1692. Well concentrations for Case01n11_off Cm-248

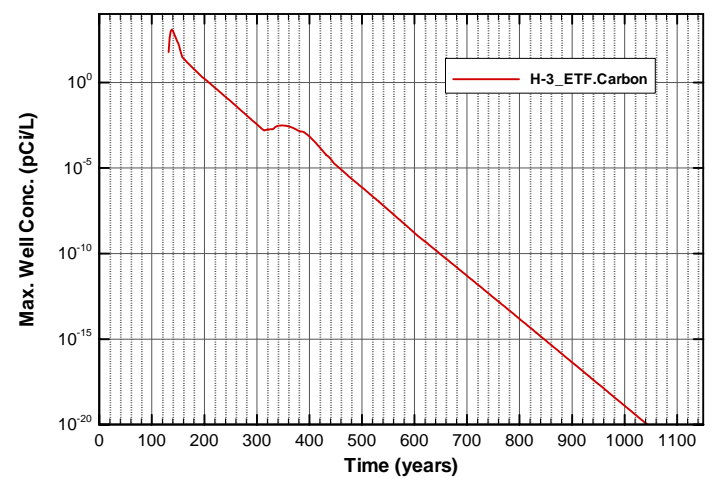

Figure A-1694. Well concentrations for Case01n11_off H-3_ETF.Carbon

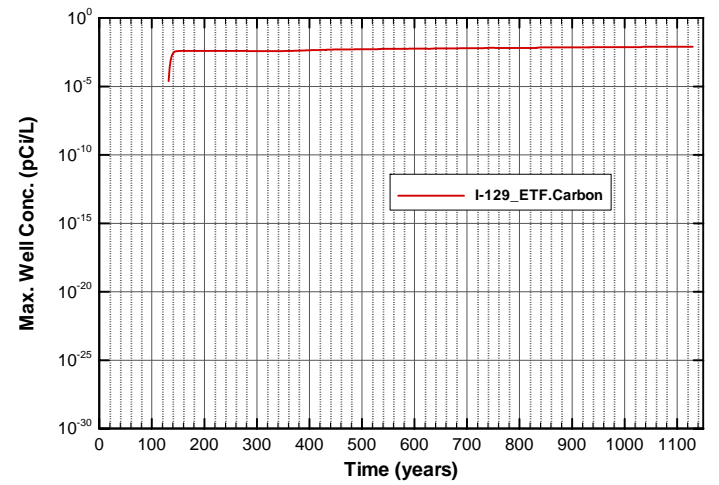

Figure A-1696. Well concentrations for Case01n11_off I-129_ETF.Carbon 
SRNL-STI-2008-00397, REVISION 0

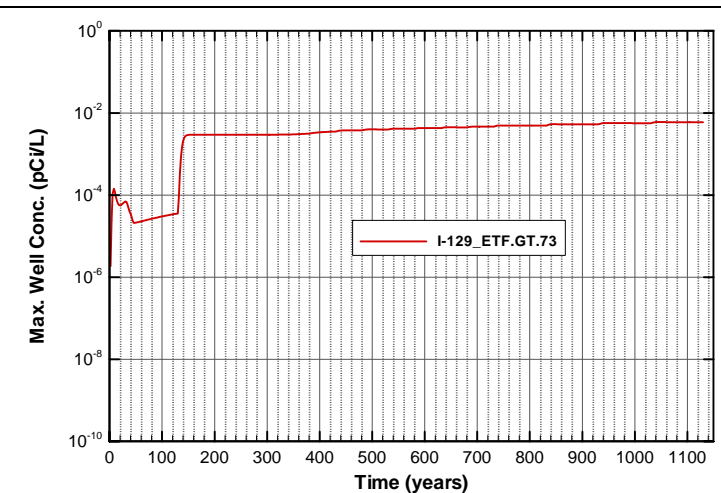

Figure A-1697. Well concentrations for Case01n11_off I-129_ETF.GT.73

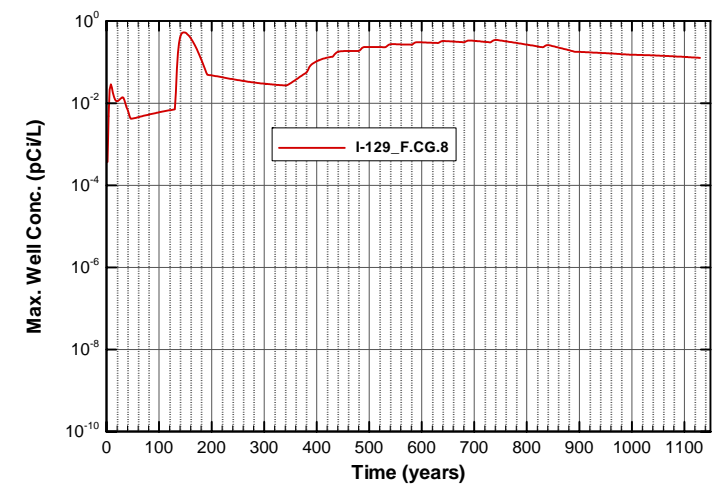

Figure A-1699. Well concentrations for Case01n11_off I-129_F.CG.8

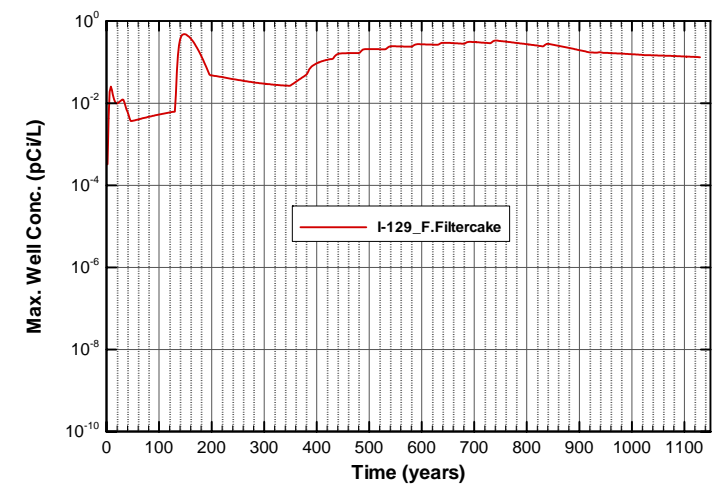

Figure A-1701. Well concentrations for Case01n11_off I-129_F.Filtercake

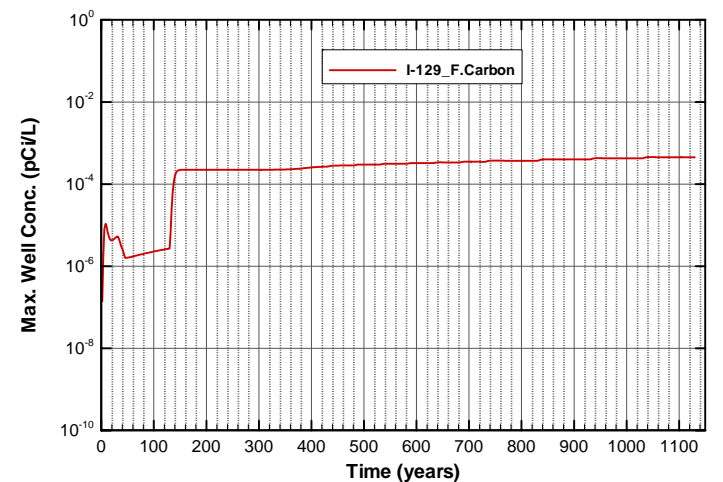

Figure A-1698. Well concentrations for Case01n11_off I-129_F.Carbon

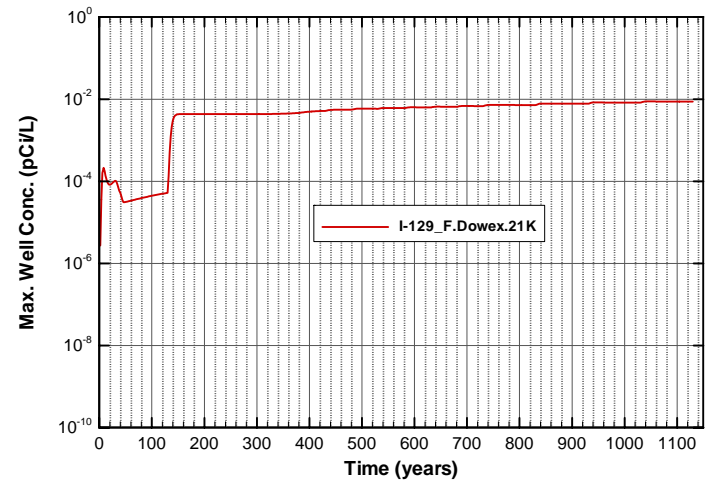

Figure A-1700. Well concentrations for Case01n11_off I-129_F.Dowex.21K

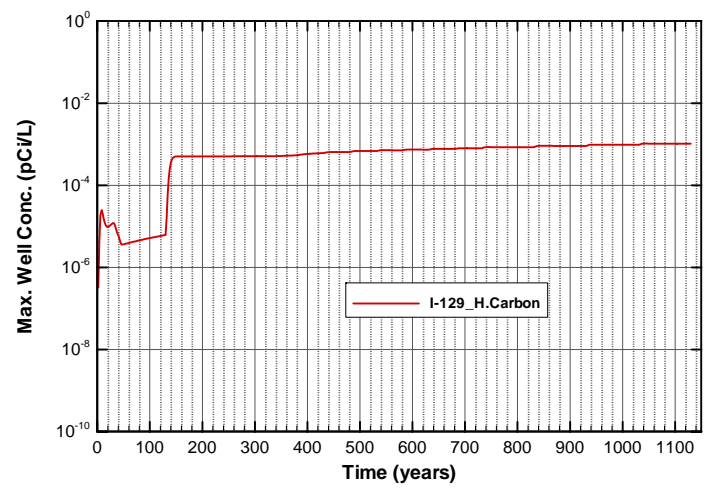

Figure A-1702. Well concentrations for Case01n11_off I-129_H.Carbon 
SRNL-STI-2008-00397, REVISION 0

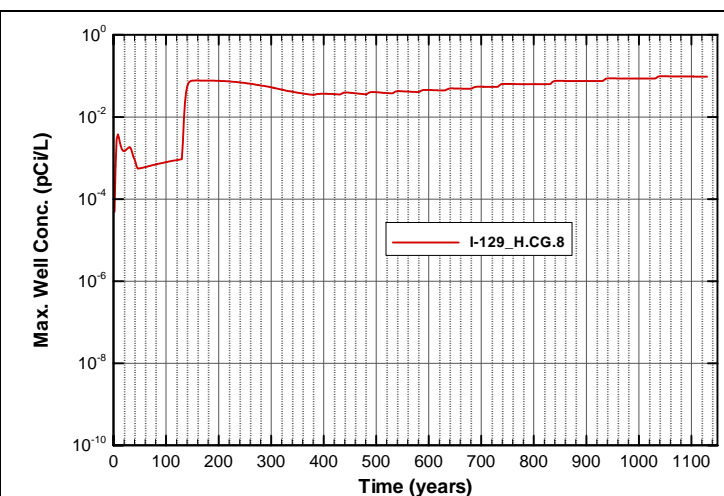

Figure A-1703. Well concentrations for Case01n11_off I-129_H.CG.8

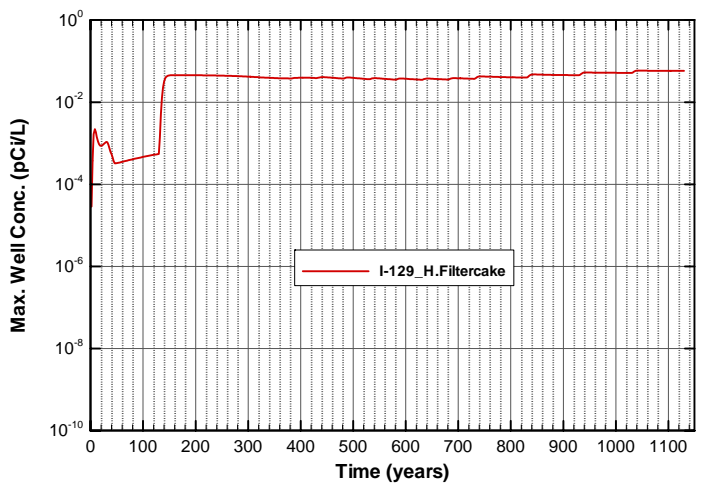

Figure A-1705. Well concentrations for Case01n11_off I-129_H.Filtercake

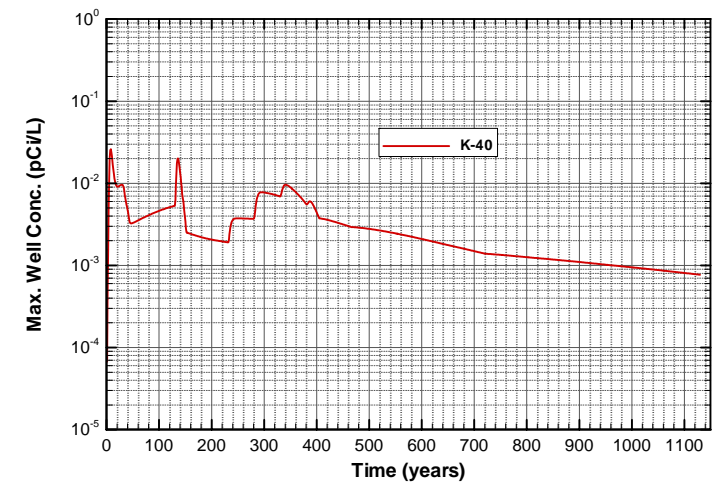

Figure A-1707. Well concentrations for Case01n11_off K-40

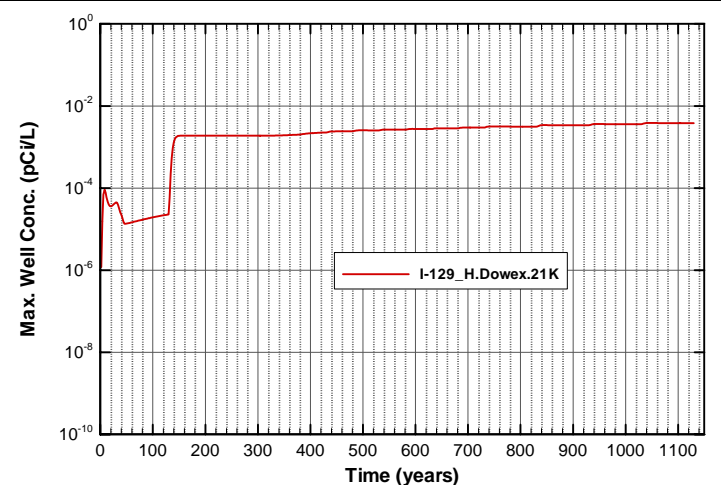

Figure A-1704. Well concentrations for Case01n11_off I-129_H.Dowex.21K

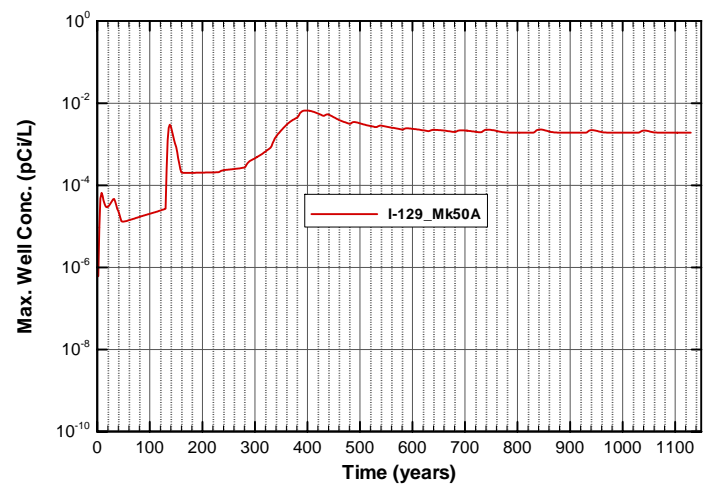

Figure A-1706. Well concentrations for Case01n11_off I-129_Mk50A

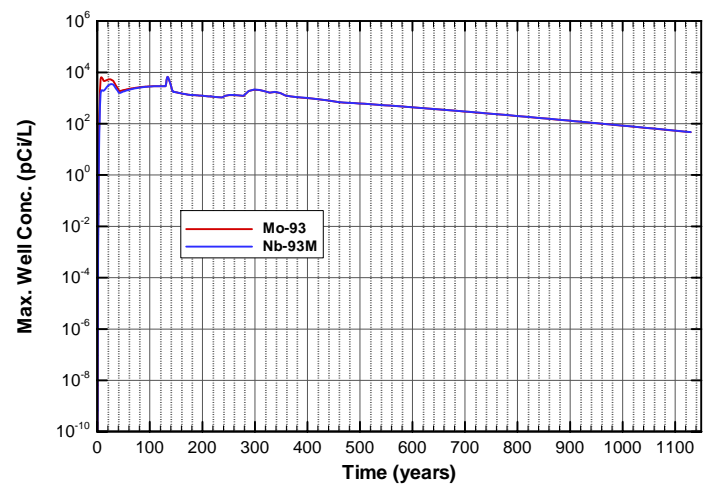

Figure A-1708. Well concentrations for Case01n11_off Mo-93 
SRNL-STI-2008-00397, REVISION 0

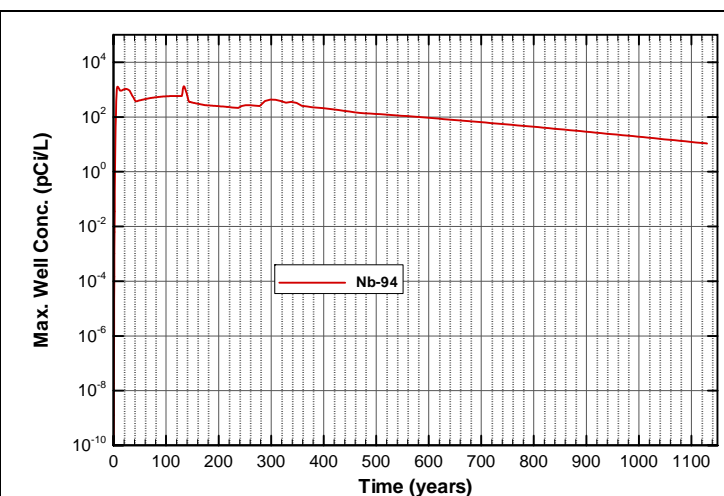

Figure A-1709. Well concentrations for Case01n11_off Nb-94

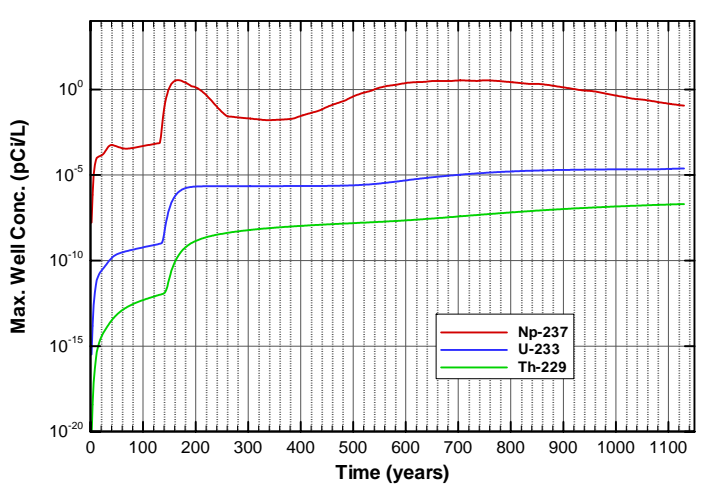

Figure A-1711. Well concentrations for Case01n11_off Np-237

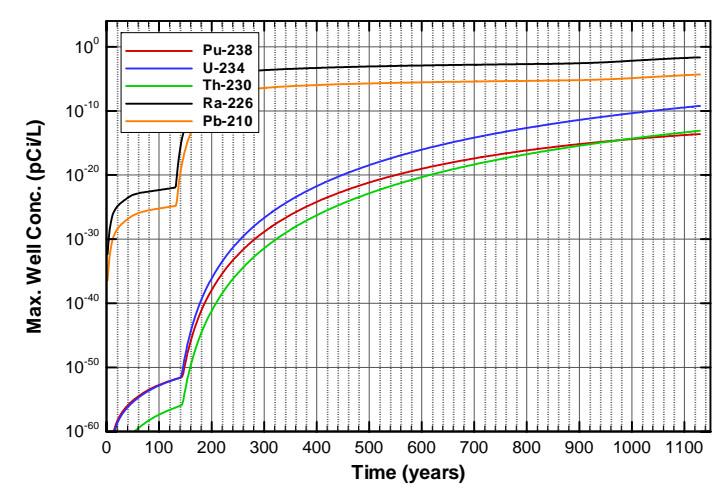

Figure A-1713. Well concentrations for Case01n11_off Pu-238

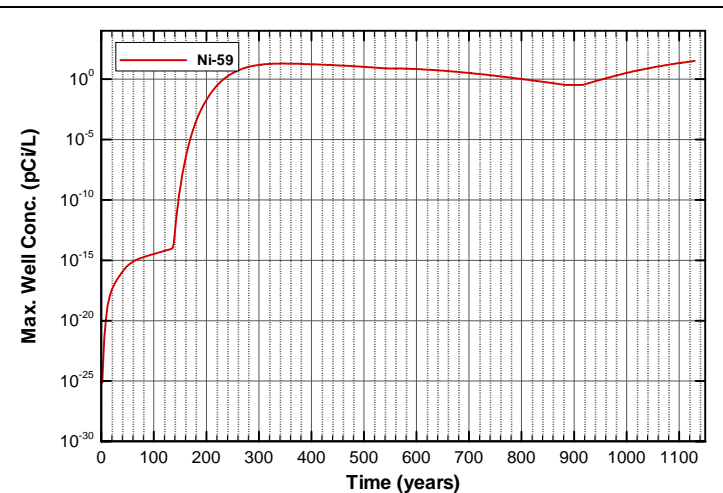

Figure A-1710. Well concentrations for Case01n11_off Ni-59

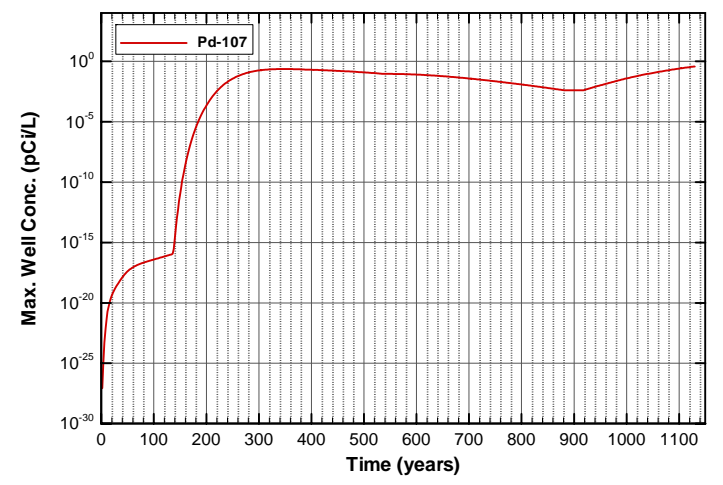

Figure A-1712. Well concentrations for Case01n11_off Pd-107

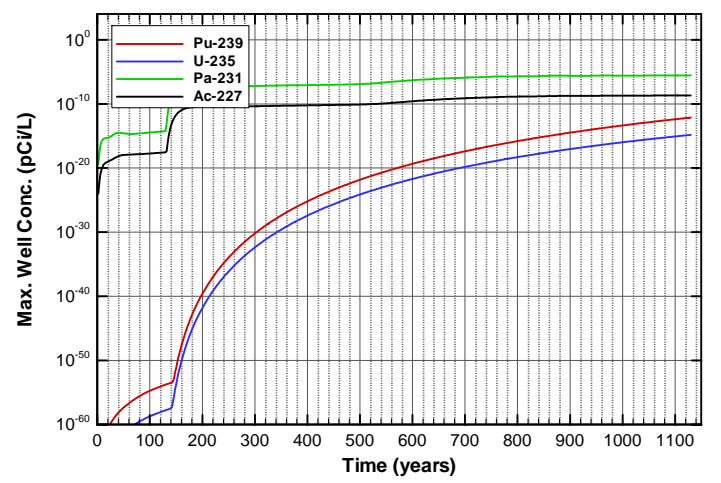

Figure A-1714. Well concentrations for Case01n11_off Pu-239 
SRNL-STI-2008-00397, REVISION 0

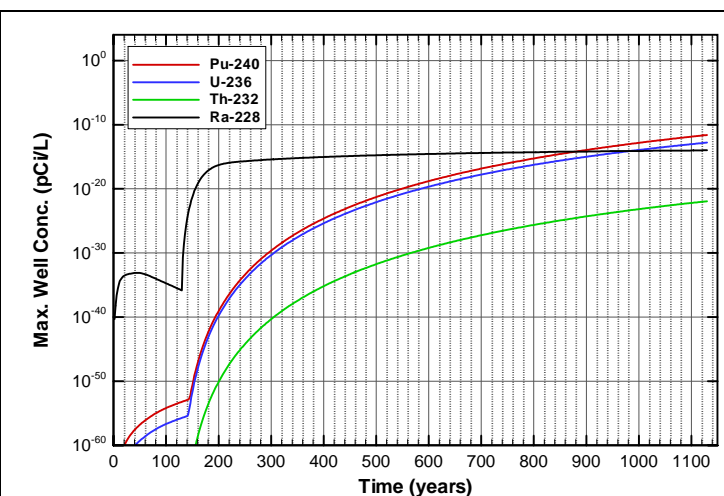

Figure A-1715. Well concentrations for Case01n11_off Pu-240

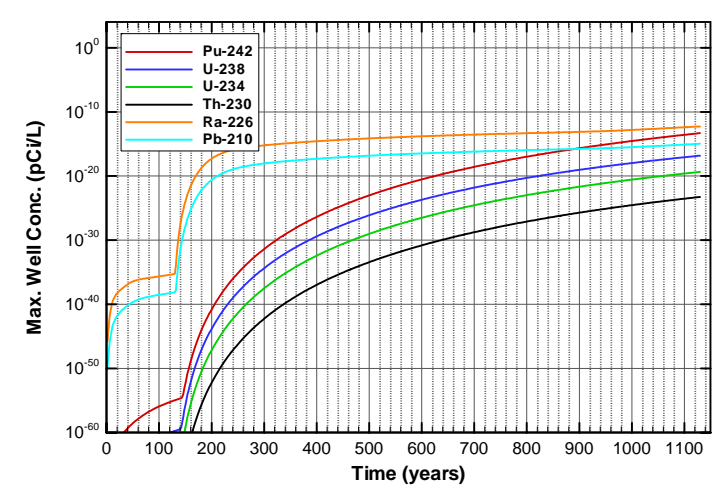

Figure A-1717. Well concentrations for Case01n11_off Pu-242

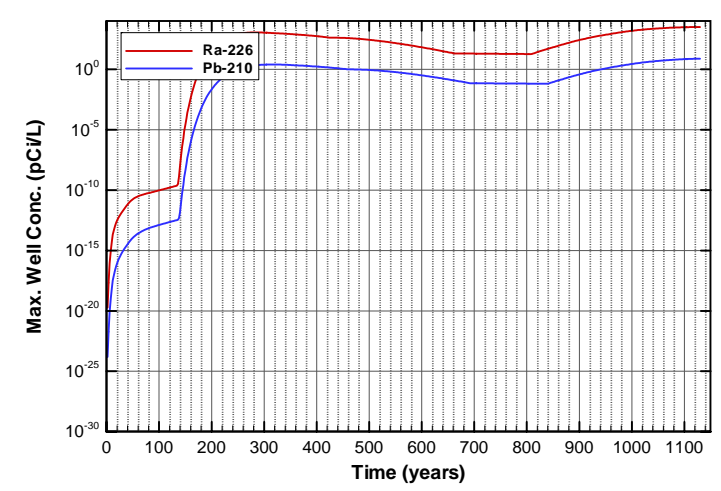

Figure A-1719. Well concentrations for Case01n11_off Ra-226

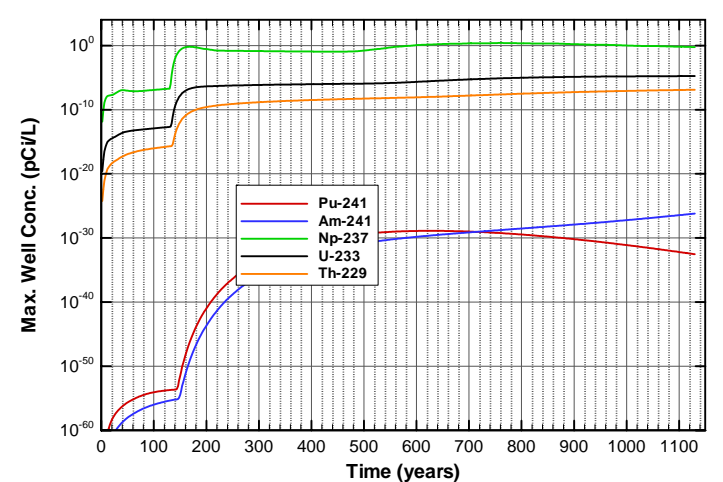

Figure A-1716. Well concentrations for Case01n11_off Pu-241

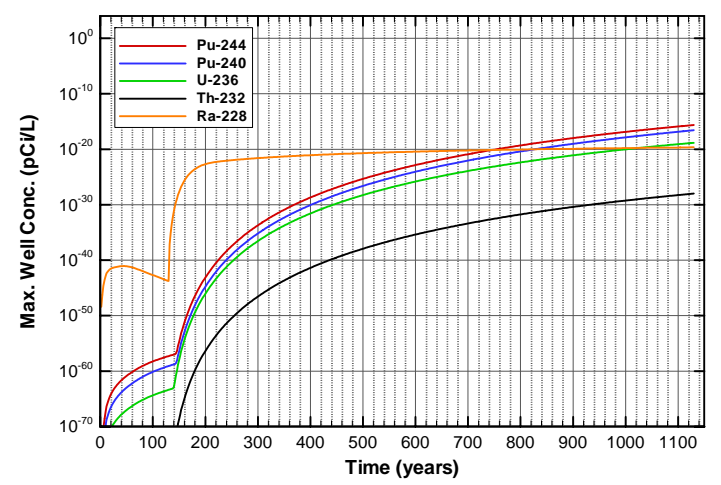

Figure A-1718. Well concentrations for Case01n11_off Pu-244

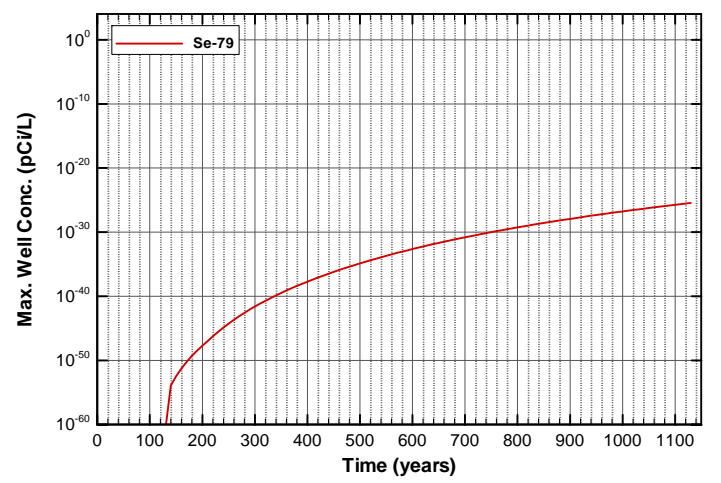

Figure A-1720. Well concentrations for Case01n11_off Se-79 
SRNL-STI-2008-00397, REVISION 0

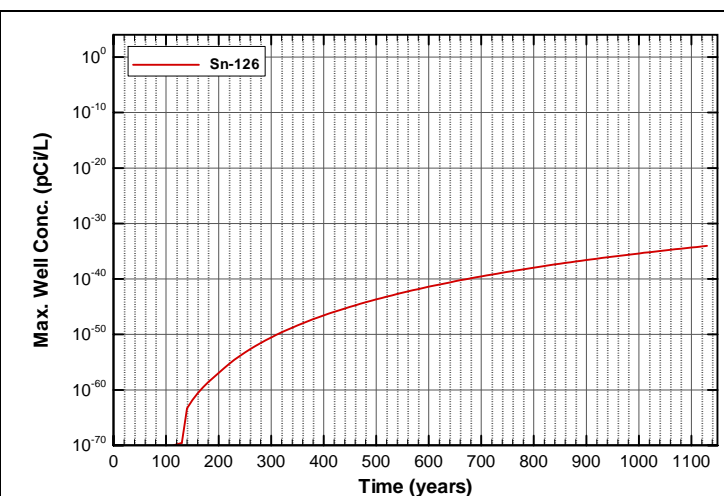

Figure A-1721. Well concentrations for Case01n11_off Sn-126

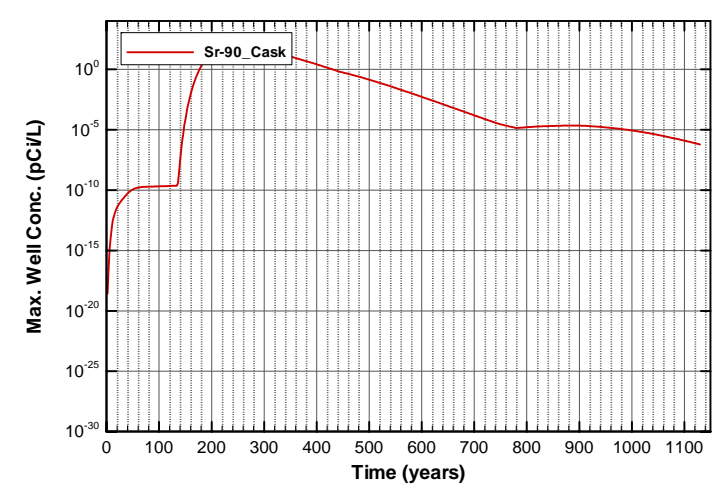

Figure A-1723. Well concentrations for Case01n11_off Sr-90_Cask

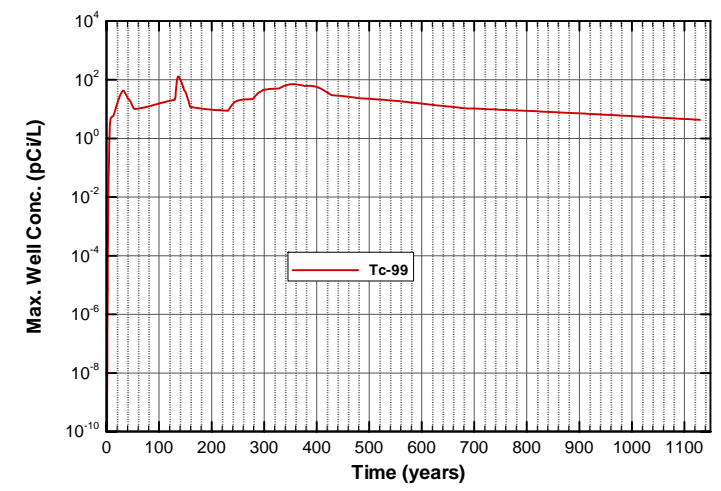

Figure A-1725. Well concentrations for Case01n11_off Tc-99

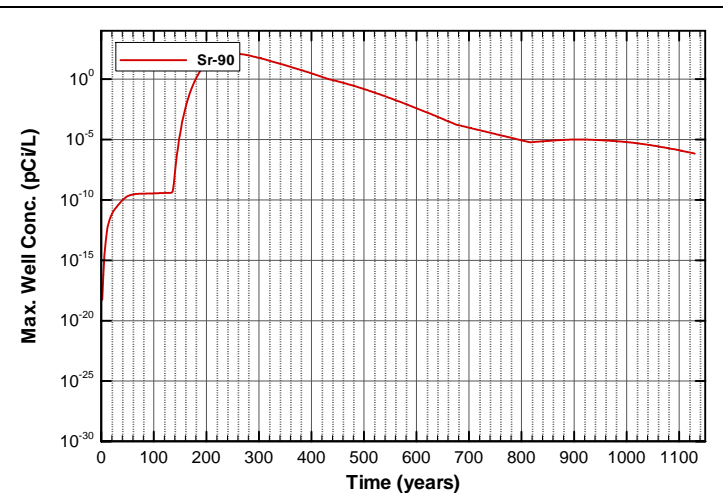

Figure A-1722. Well concentrations for Case01n11_off Sr-90

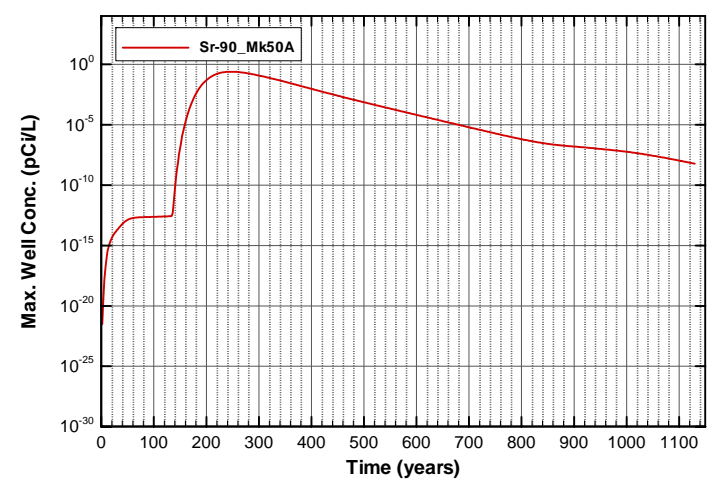

Figure A-1724. Well concentrations for Case01n11_off Sr-90_Mk50A

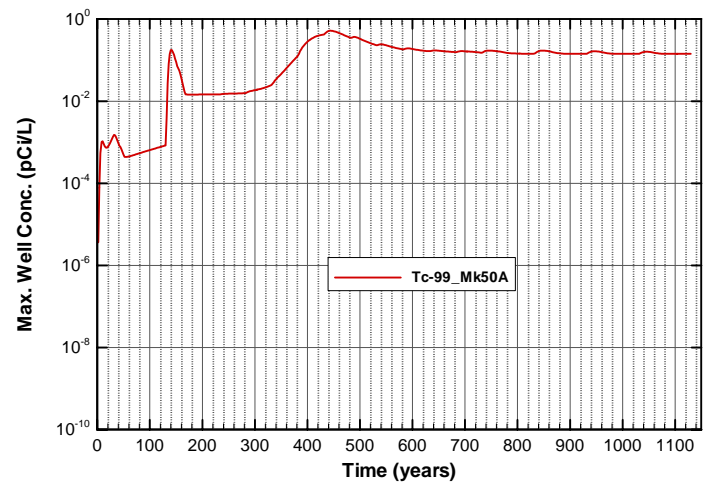

Figure A-1726. Well concentrations for Case01n11_off Tc-99_Mk50A 


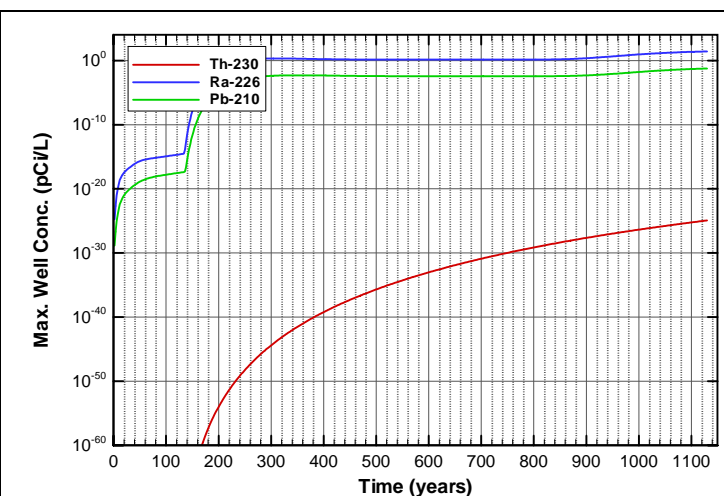

Figure A-1727. Well concentrations for Case01n11_off Th-230

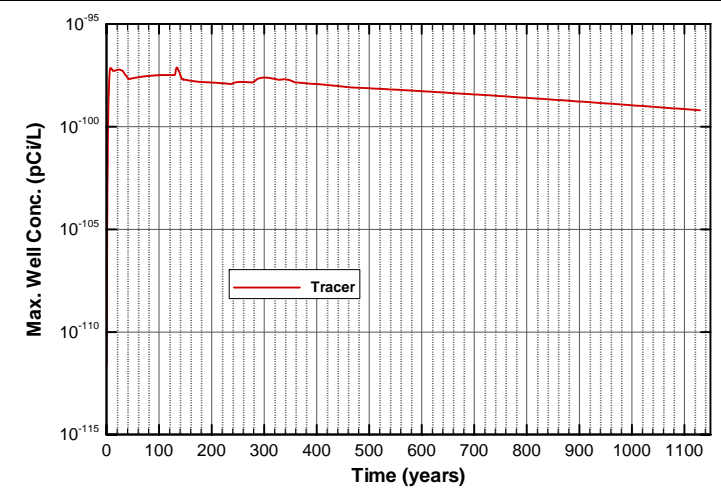

Figure A-1729. Well concentrations for Case01n11_off Tracer

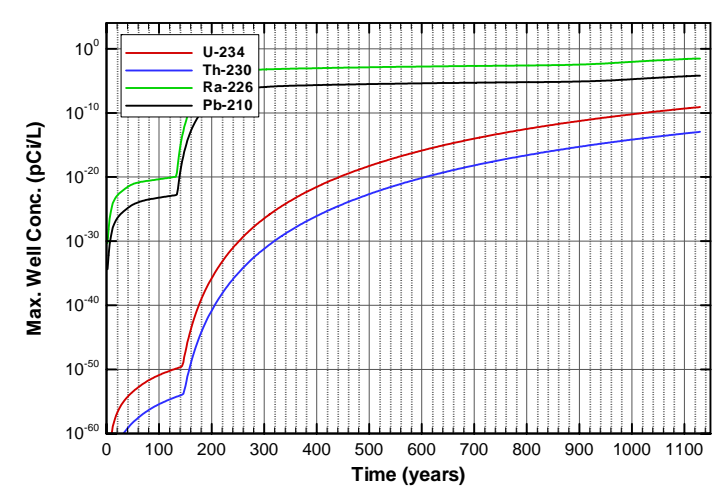

Figure A-1731. Well concentrations for Case01n11_off U-234

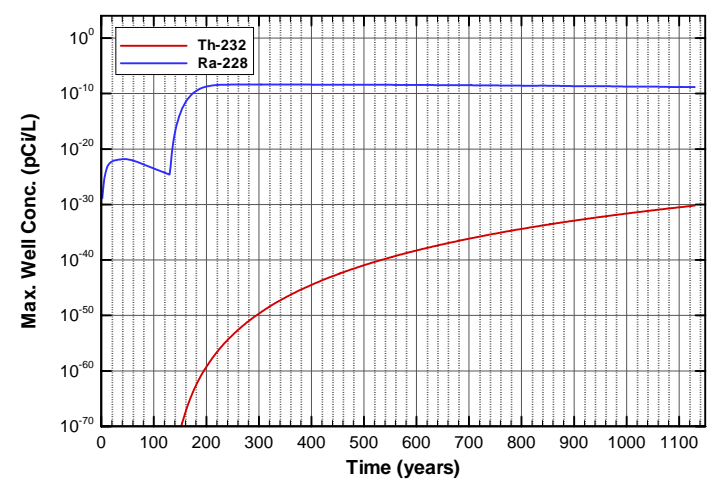

Figure A-1728. Well concentrations for Case01n11_off Th-232

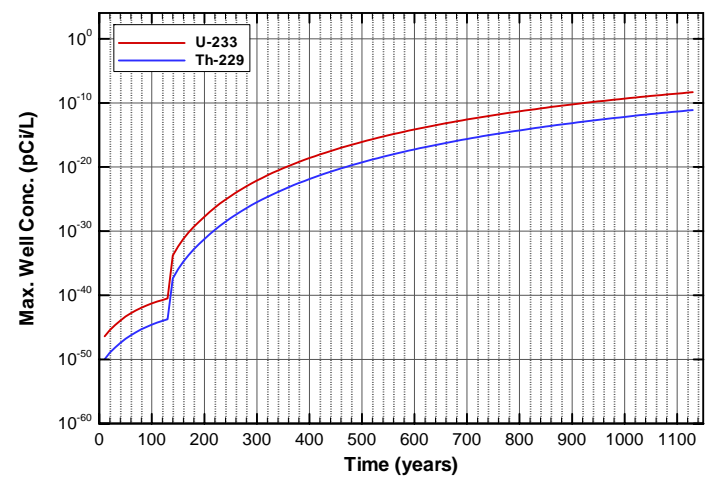

Figure A-1730. Well concentrations for Case01n11_off U-233

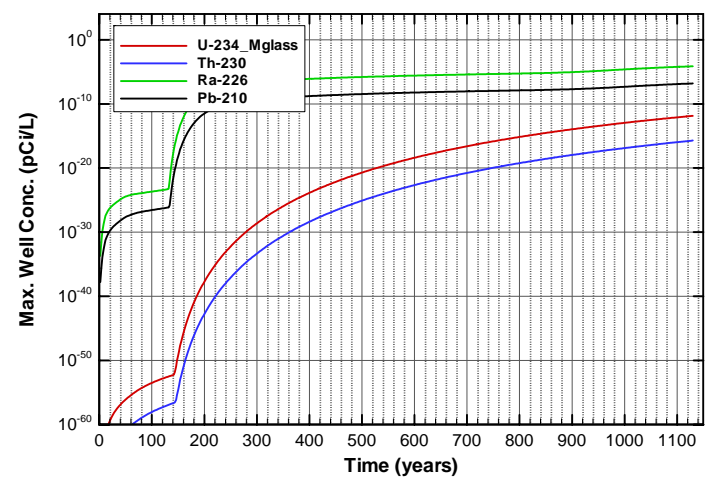

Figure A-1732. Well concentrations for Case01n11_off U-234_Mglass 


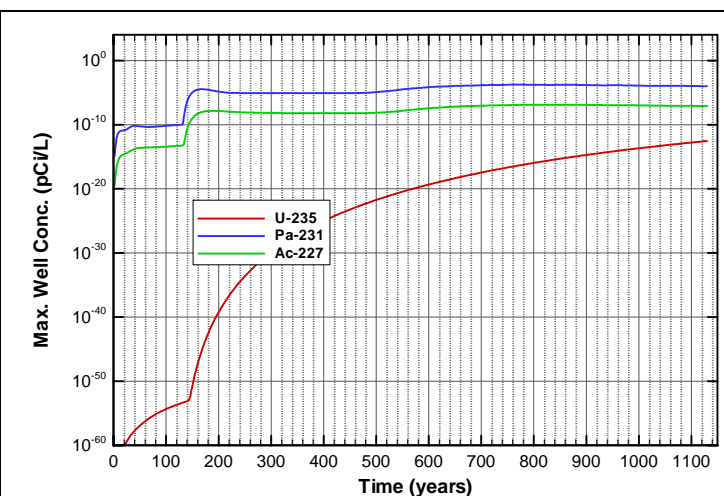

Figure A-1733. Well concentrations for Case01n11_off U-235

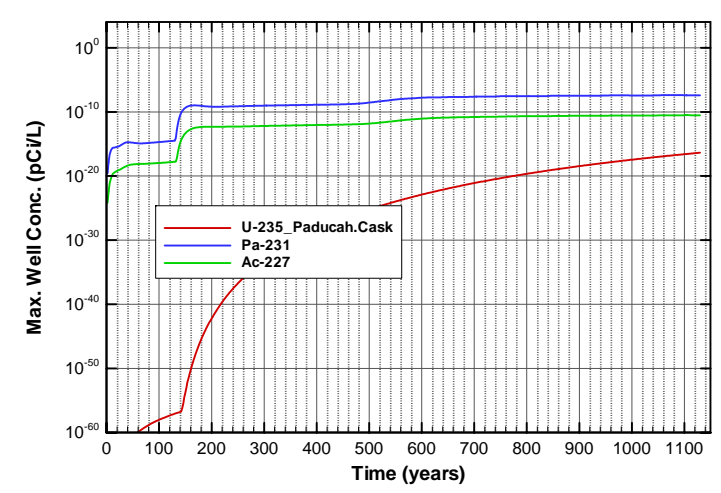

Figure A-1735. Well concentrations for Case01n11_off U-235_Paducah.Cask

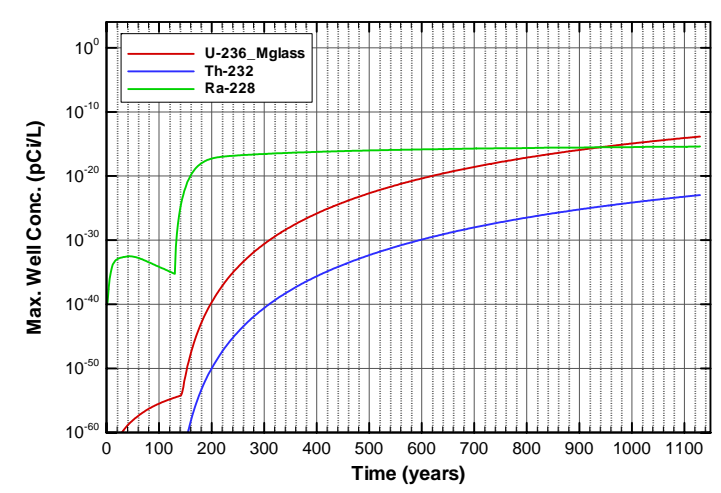

Figure A-1737. Well concentrations for Case01n11_off U-236_Mglass

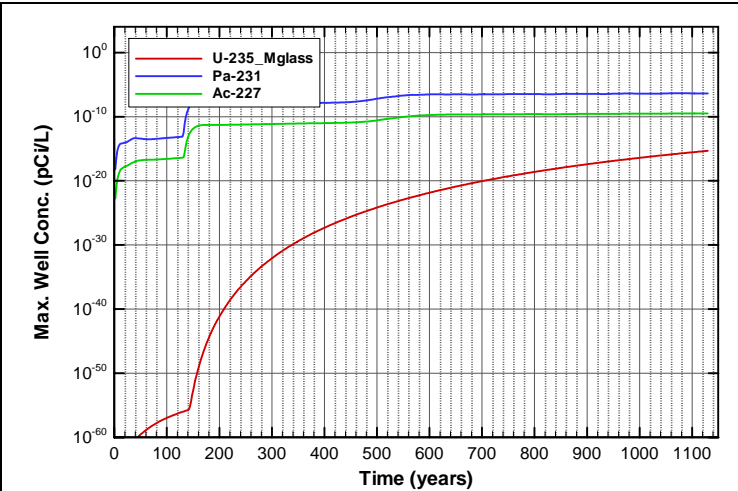

Figure A-1734. Well concentrations for Case01n11_off U-235_Mglass

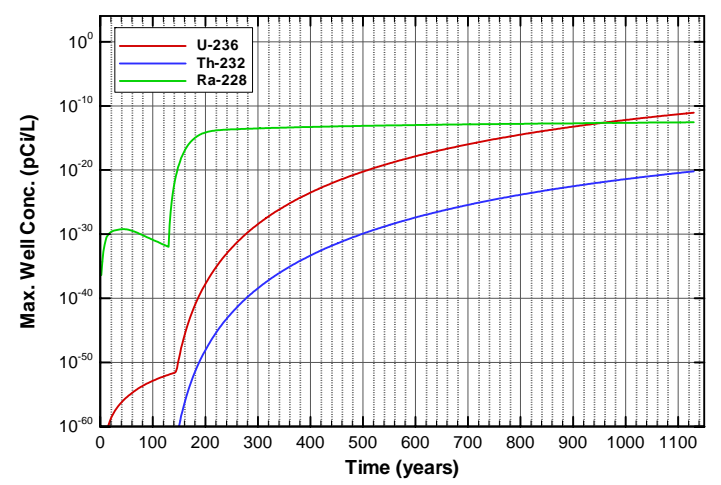

Figure A-1736. Well concentrations for Case01n11_off U-236

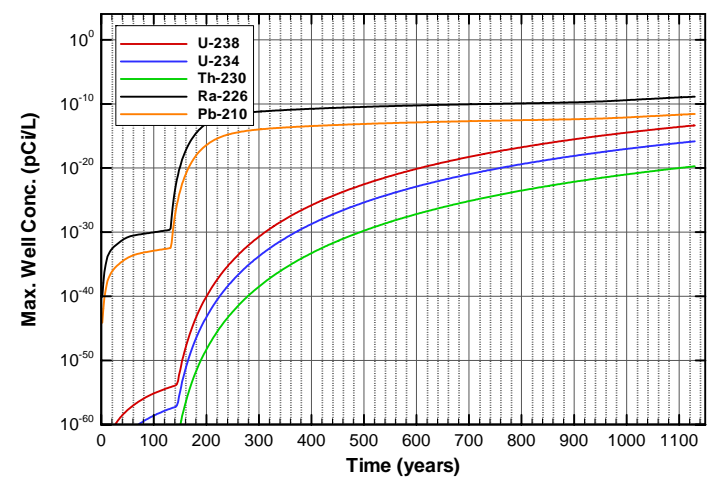

Figure A-1738. Well concentrations for Case01n11_off U-238 


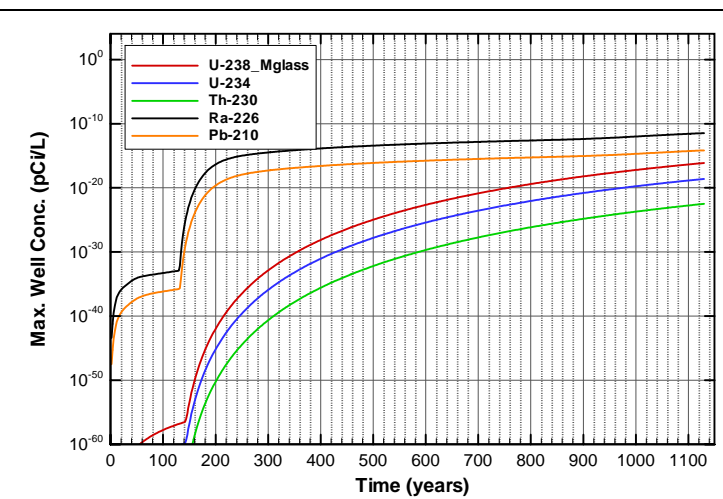

Figure A-1739. Well concentrations for Case01n11_off U-238_Mglass

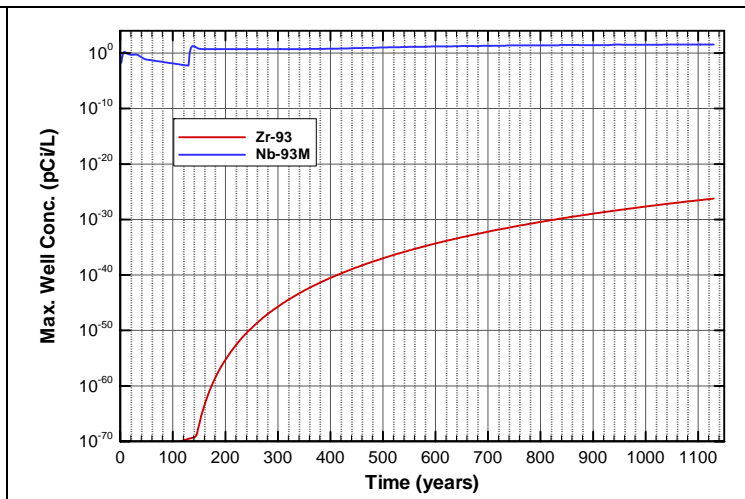

Figure A-1740. Well concentrations for Case01n11_off Zr-93

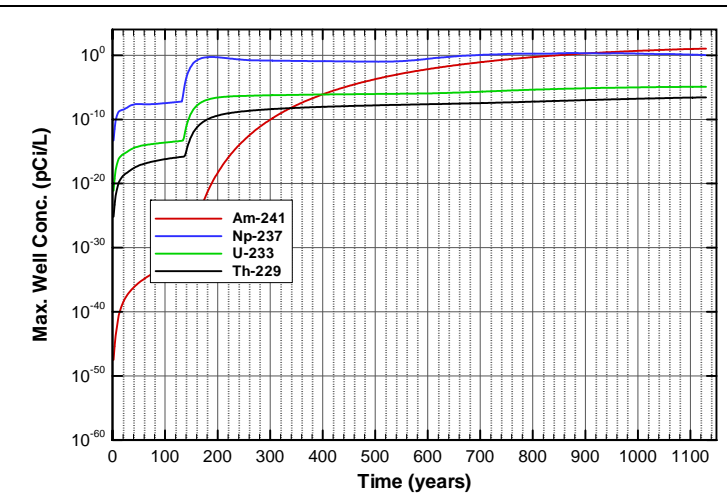

Figure A-1741. Well concentrations for Case01n11_on Am-241

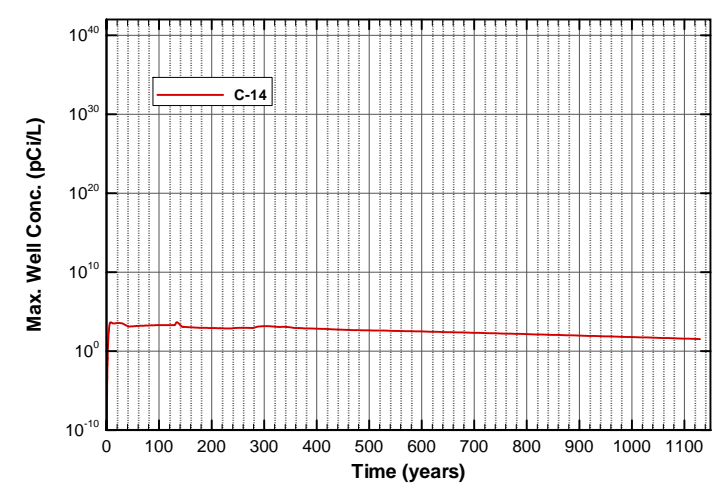

Figure A-1743. Well concentrations for Case01n11_on C-14

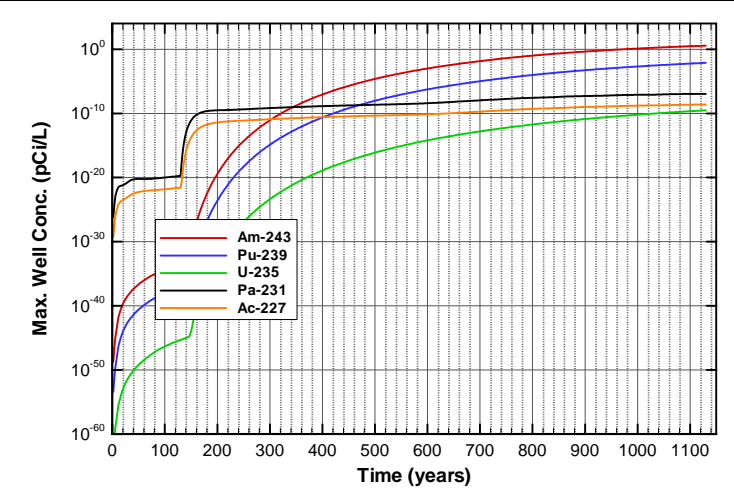

Figure A-1742. Well concentrations for Case01n11_on Am-243

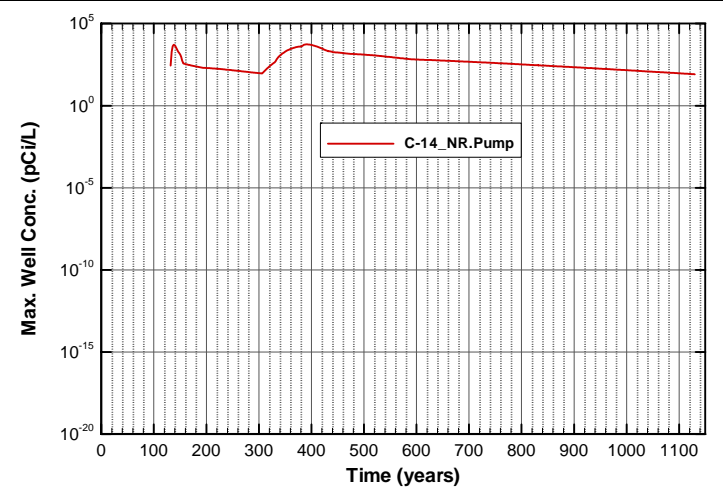

Figure A-1744. Well concentrations for Case01n11_on C-14_NR.Pump 
SRNL-STI-2008-00397, REVISION 0

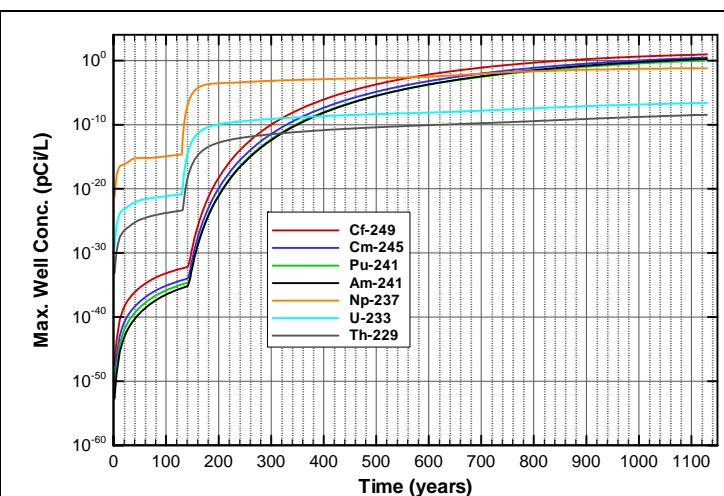

Figure A-1745. Well concentrations for Case01n11_on Cf-249

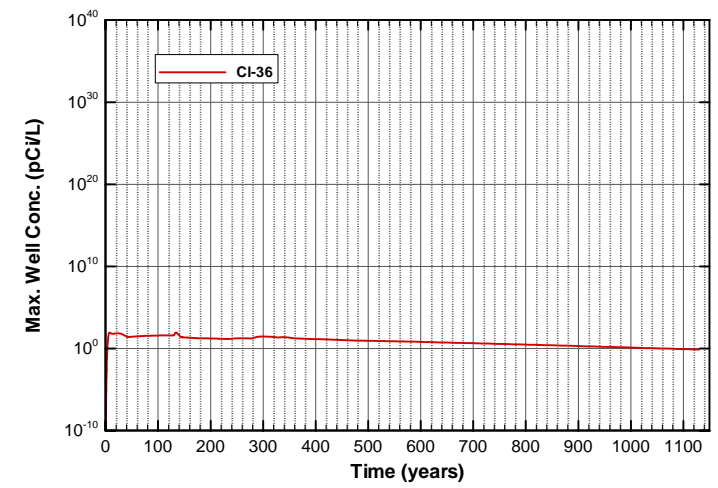

Figure A-1747. Well concentrations for Case01n11_on Cl-36

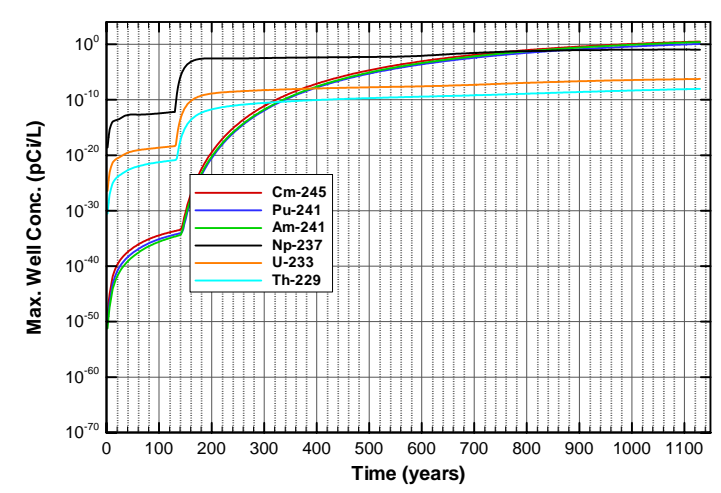

Figure A-1749. Well concentrations for Case01n11_on Cm-245

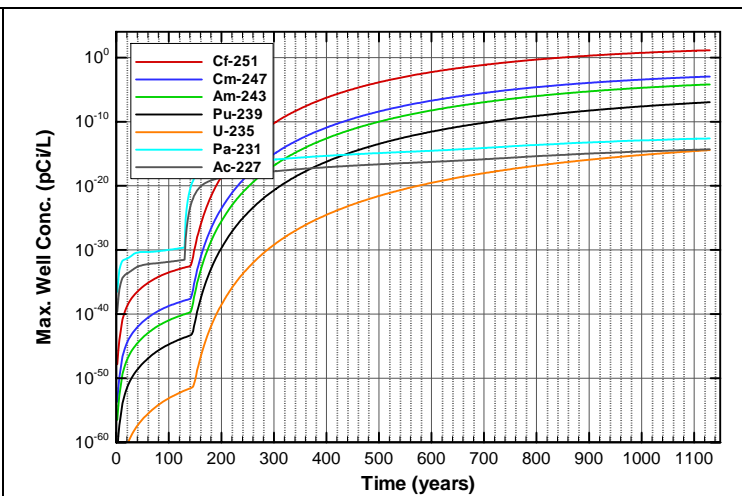

Figure A-1746. Well concentrations for Case01n11_on Cf-251

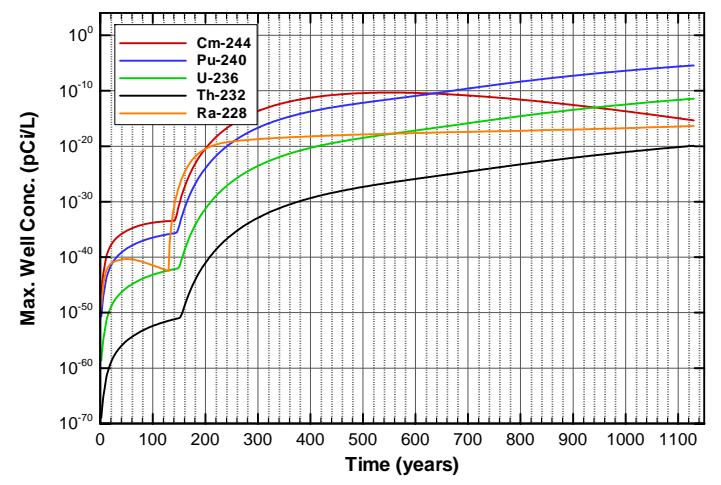

Figure A-1748. Well concentrations for Case01n11_on Cm-244

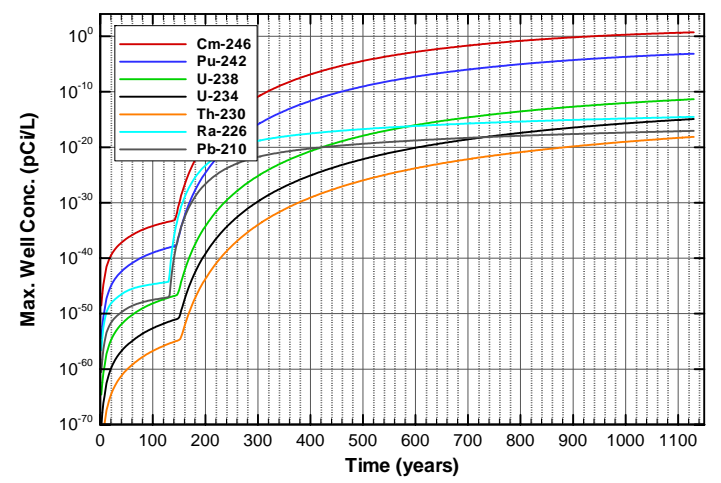

Figure A-1750. Well concentrations for Case01n11_on Cm-246 


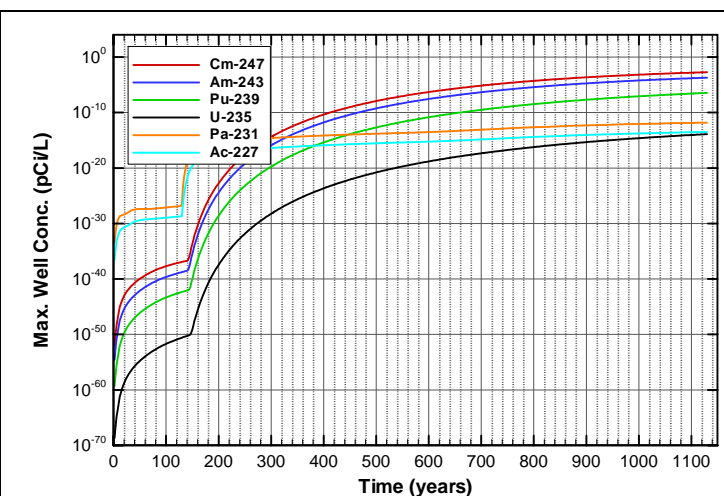

Figure A-1751. Well concentrations for Case01n11_on Cm-247

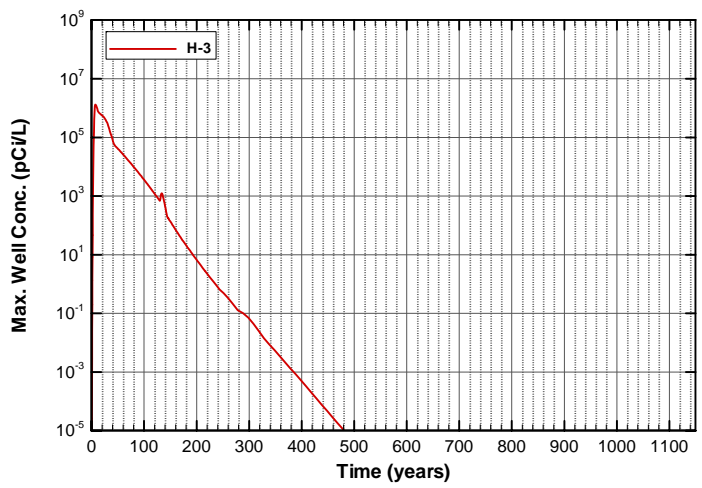

Figure A-1753. Well concentrations for Case01n11_on H-3

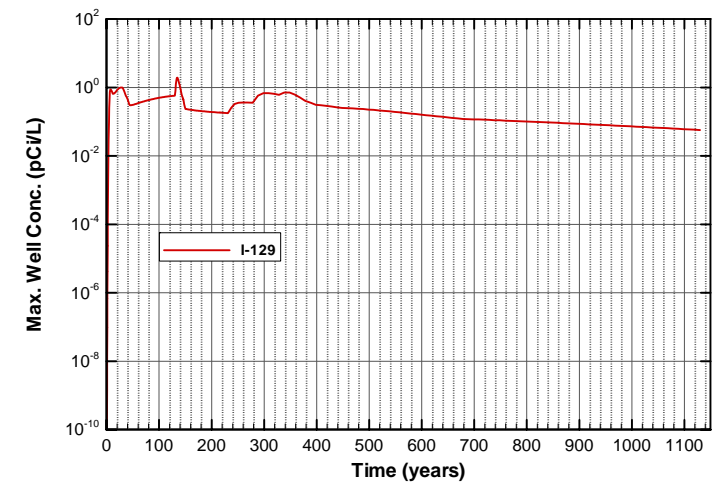

Figure A-1755. Well concentrations for Case01n11_on I-129

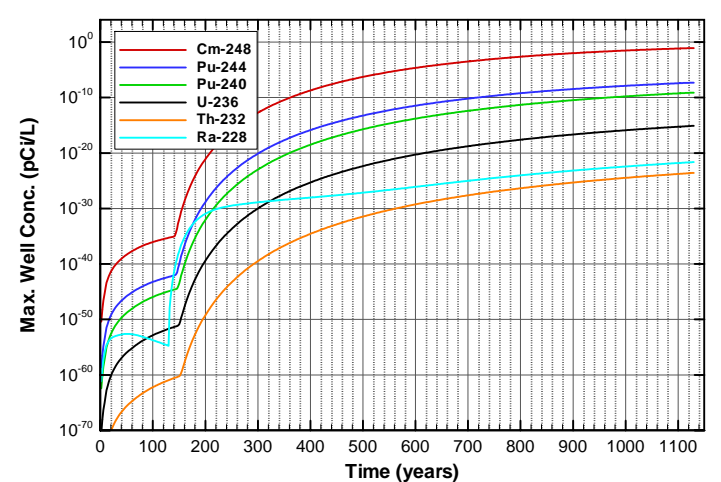

Figure A-1752. Well concentrations for Case01n11_on Cm-248

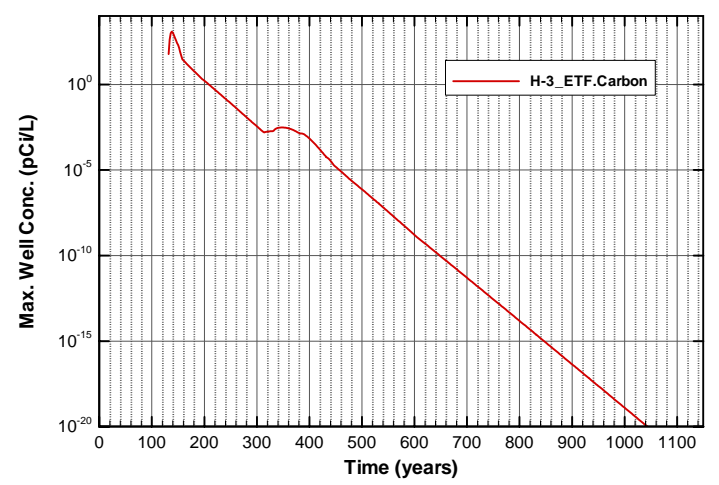

Figure A-1754. Well concentrations for Case01n11_on H-3_ETF.Carbon

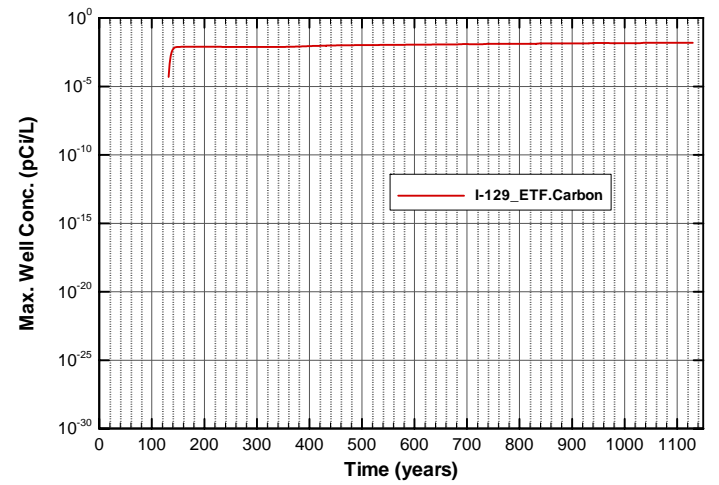

Figure A-1756. Well concentrations for Case01n11_on I-129_ETF.Carbon 
SRNL-STI-2008-00397, REVISION 0

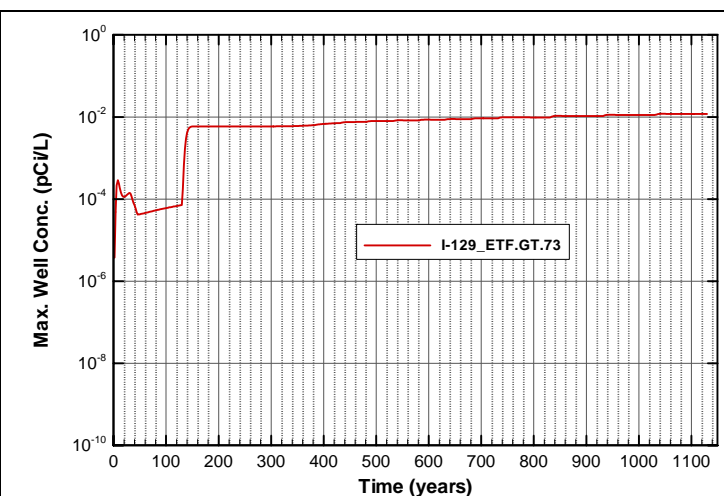

Figure A-1757. Well concentrations for Case01n11_on I-129_ETF.GT.73

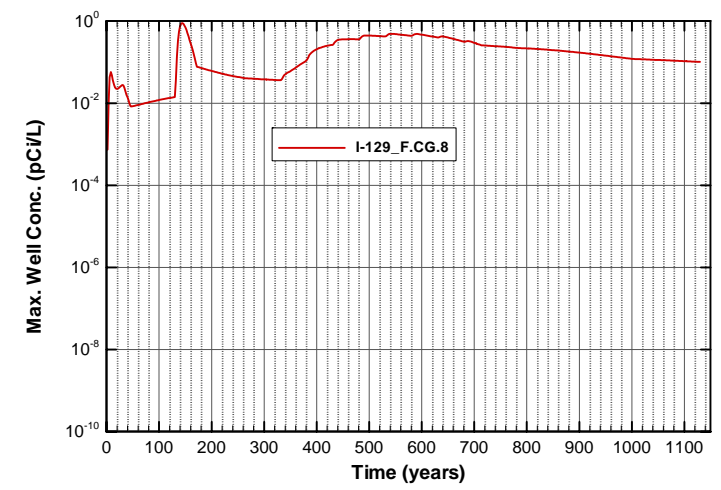

Figure A-1759. Well concentrations for Case01n11_on I-129_F.CG.8

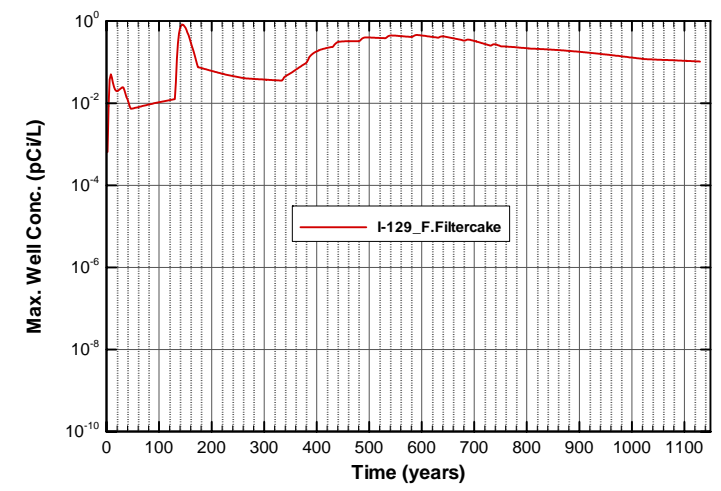

Figure A-1761. Well concentrations for Case01n11_on I-129_F.Filtercake

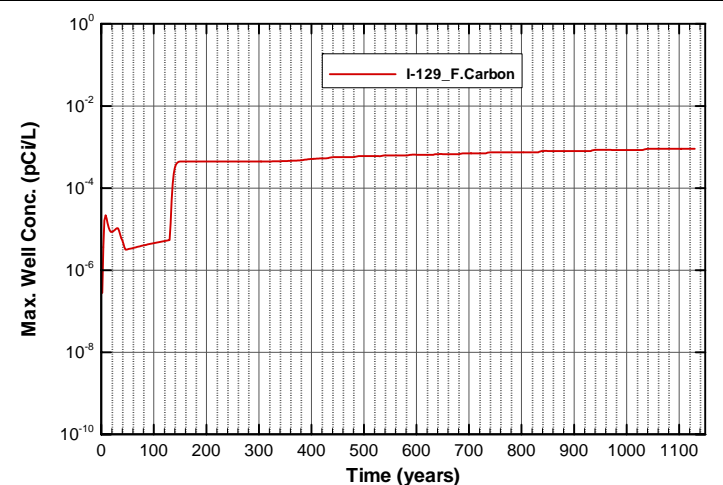

Figure A-1758. Well concentrations for Case01n11_on I-129_F.Carbon

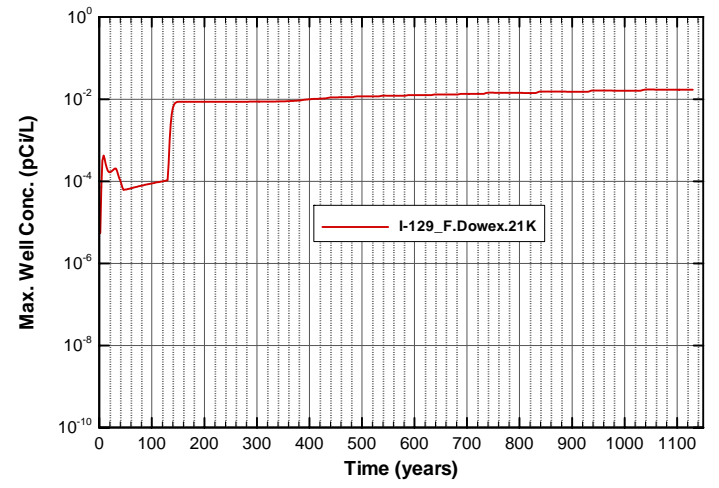

Figure A-1760. Well concentrations for Case01n11_on I-129_F.Dowex.21K

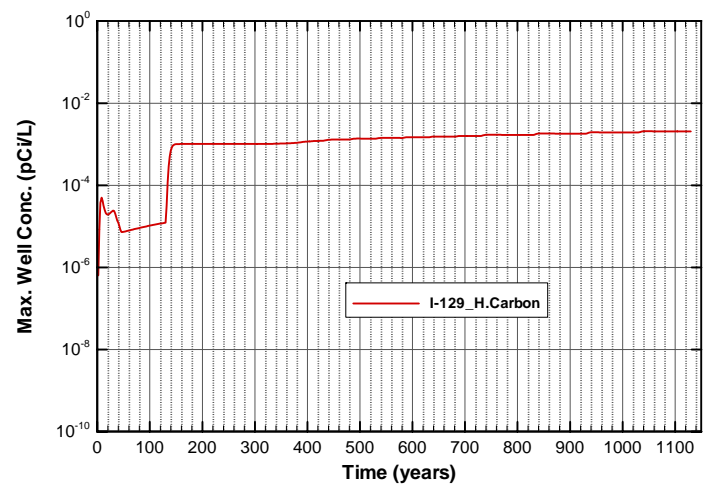

Figure A-1762. Well concentrations for Case01n11_on I-129_H.Carbon 
SRNL-STI-2008-00397, REVISION 0

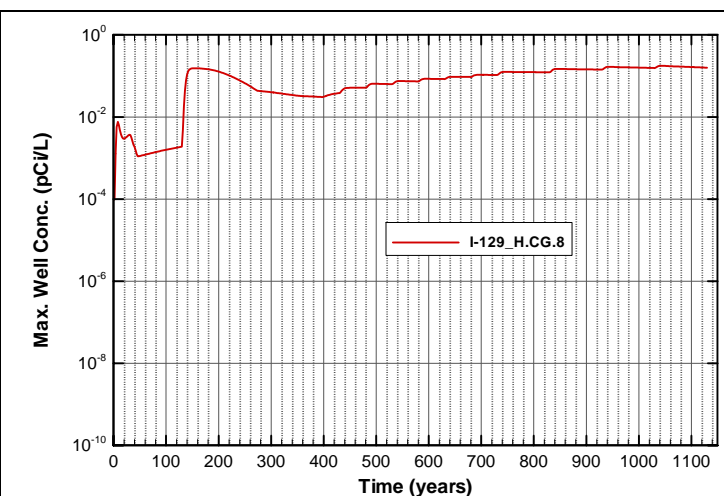

Figure A-1763. Well concentrations for Case01n11_on I-129_H.CG.8

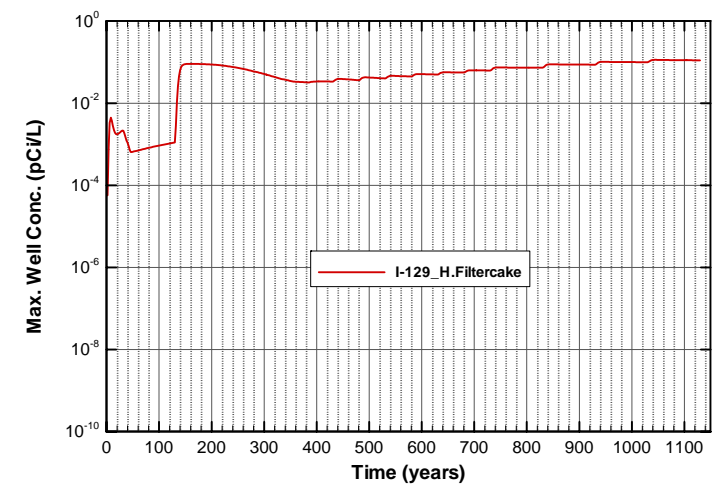

Figure A-1765. Well concentrations for Case01n11_on I-129_H.Filtercake

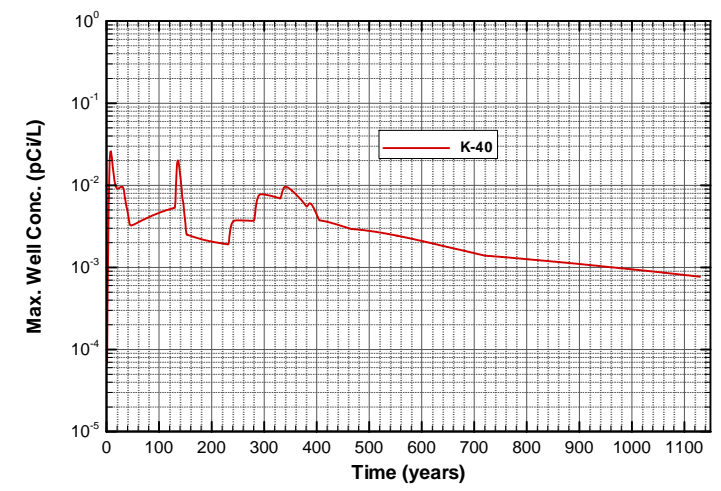

Figure A-1767. Well concentrations for Case01n11_on K-40

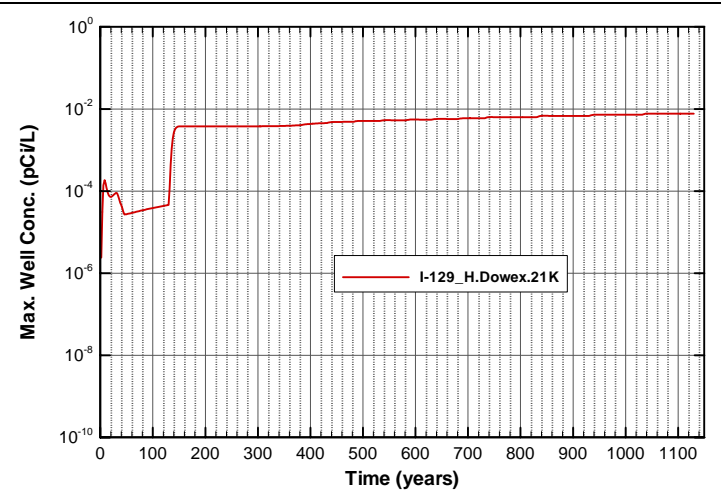

Figure A-1764. Well concentrations for Case01n11_on I-129_H.Dowex.21K

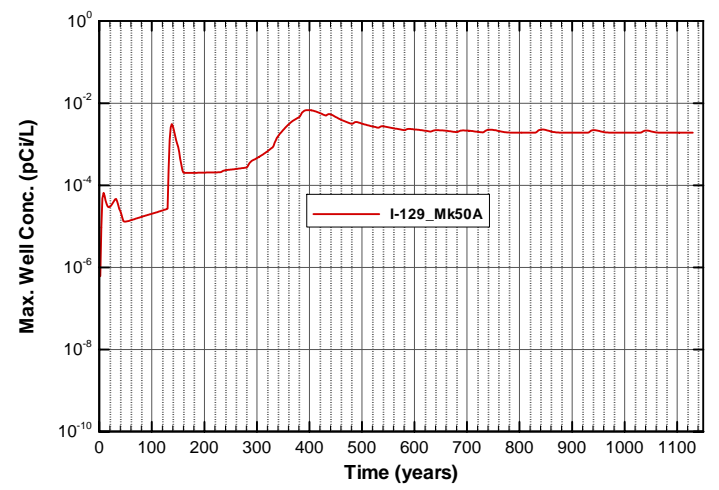

Figure A-1766. Well concentrations for Case01n11_on I-129_Mk50A

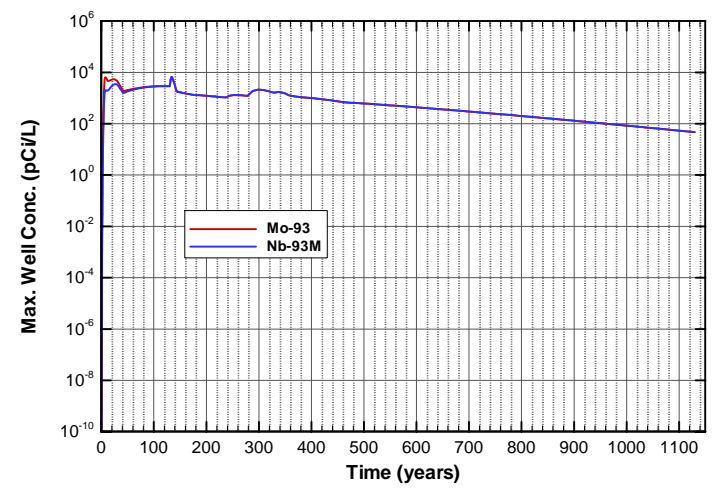

Figure A-1768. Well concentrations for Case01n11_on Mo-93 
SRNL-STI-2008-00397, REVISION 0

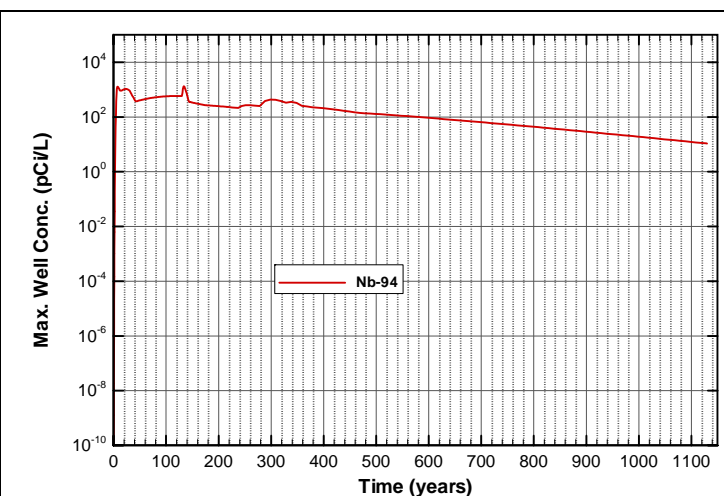

Figure A-1769. Well concentrations for Case01n11_on Nb-94

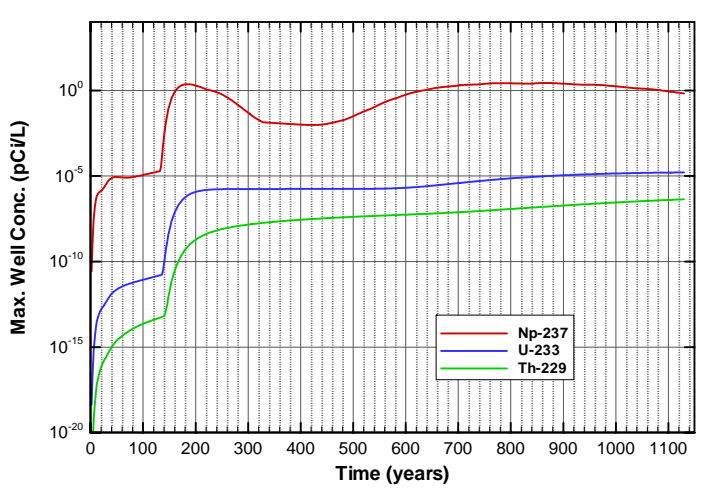

Figure A-1771. Well concentrations for Case01n11_on Np-237

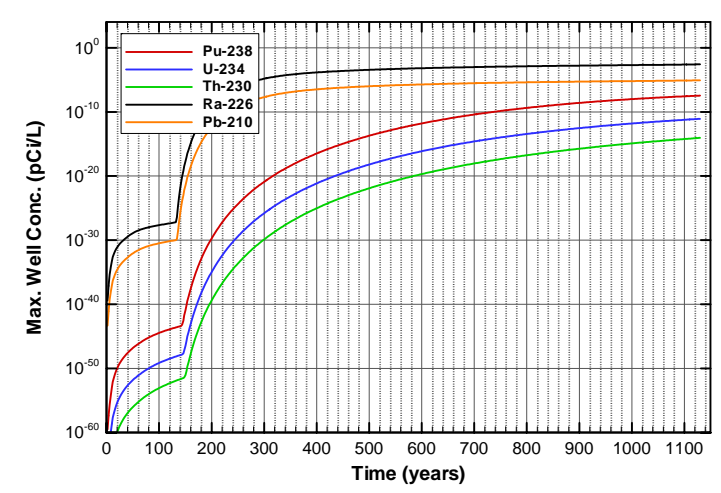

Figure A-1773. Well concentrations for Case01n11_on Pu-238

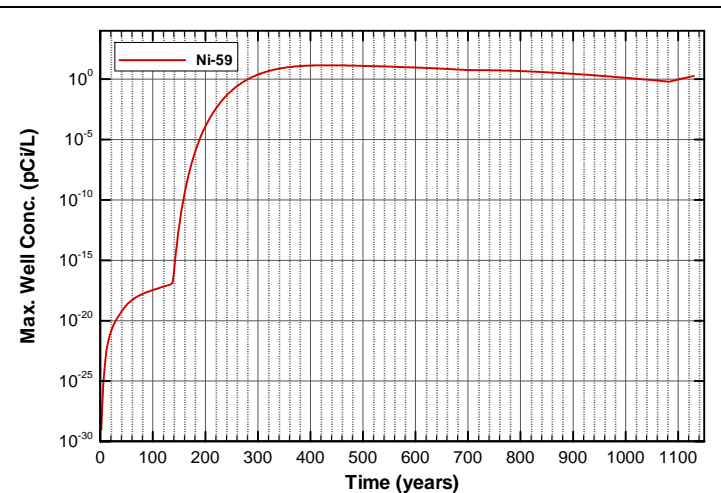

Figure A-1770. Well concentrations for Case01n11_on Ni-59

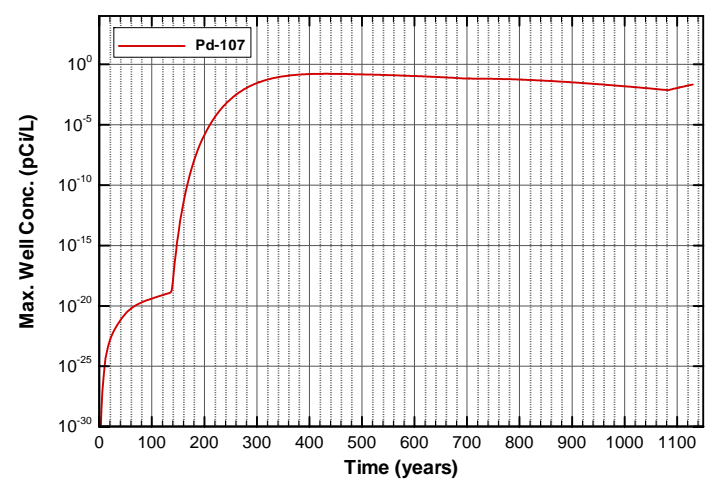

Figure A-1772. Well concentrations for Case01n11_on Pd-107

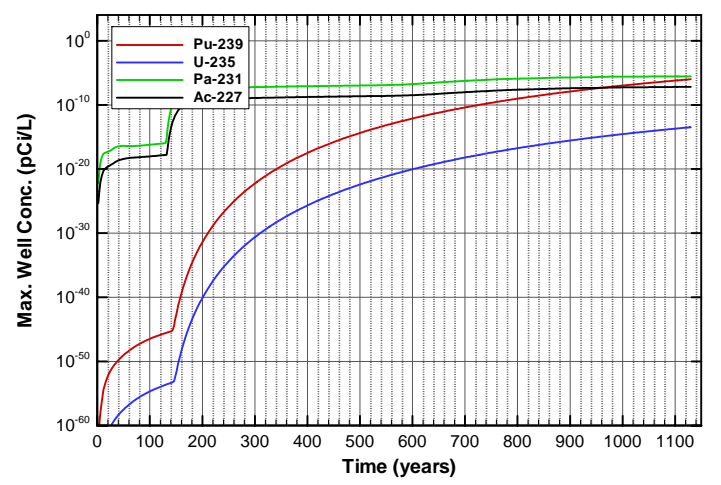

Figure A-1774. Well concentrations for Case01n11_on Pu-239 
SRNL-STI-2008-00397, REVISION 0

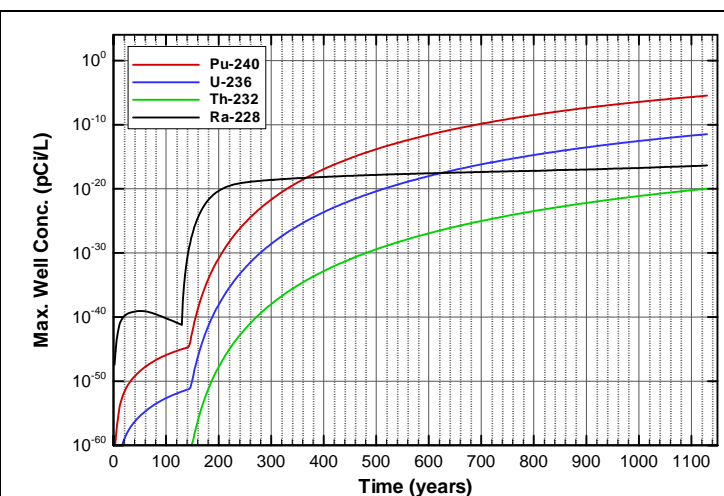

Figure A-1775. Well concentrations for Case01n11_on Pu-240

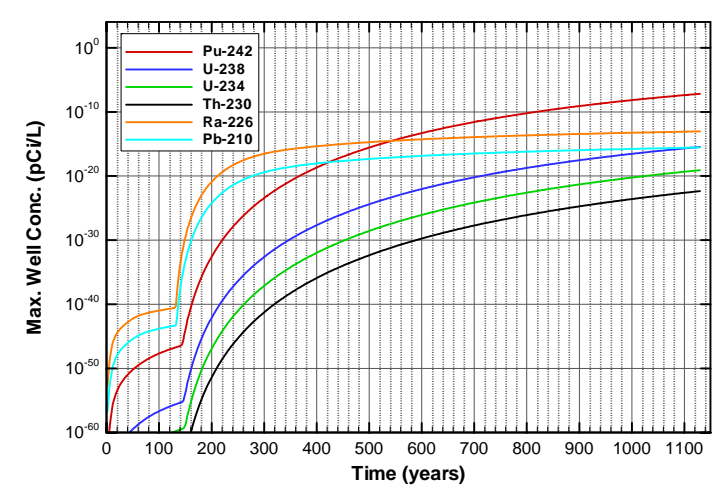

Figure A-1777. Well concentrations for Case01n11_on Pu-242

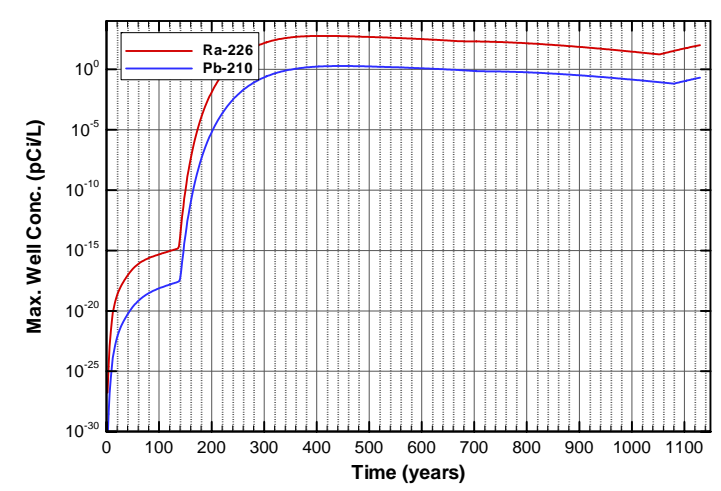

Figure A-1779. Well concentrations for Case01n11_on Ra-226

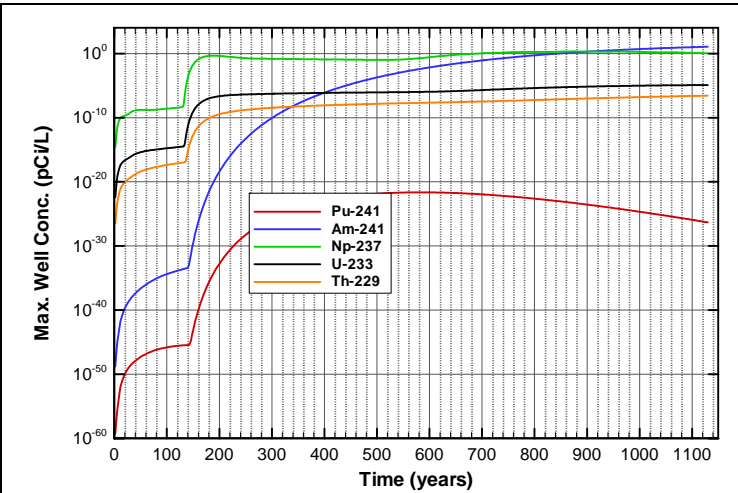

Figure A-1776. Well concentrations for Case01n11_on Pu-241

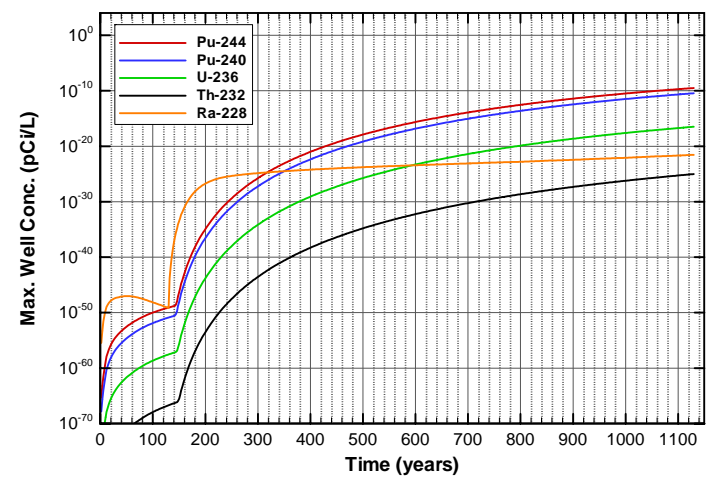

Figure A-1778. Well concentrations for Case01n11_on Pu-244

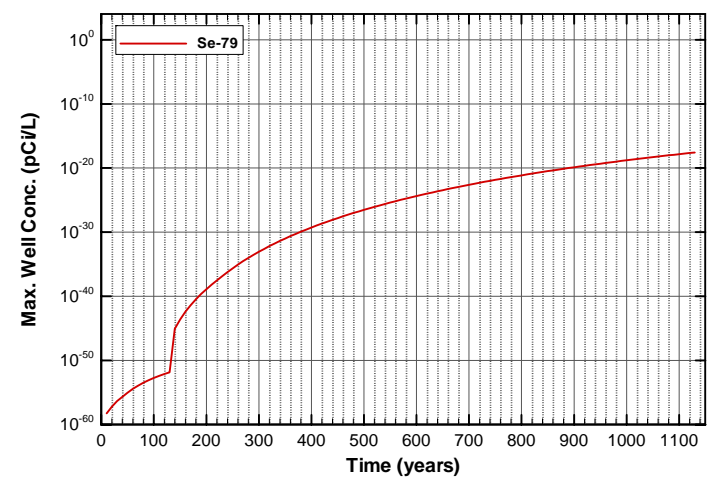

Figure A-1780. Well concentrations for Case01n11_on Se-79 
SRNL-STI-2008-00397, REVISION 0

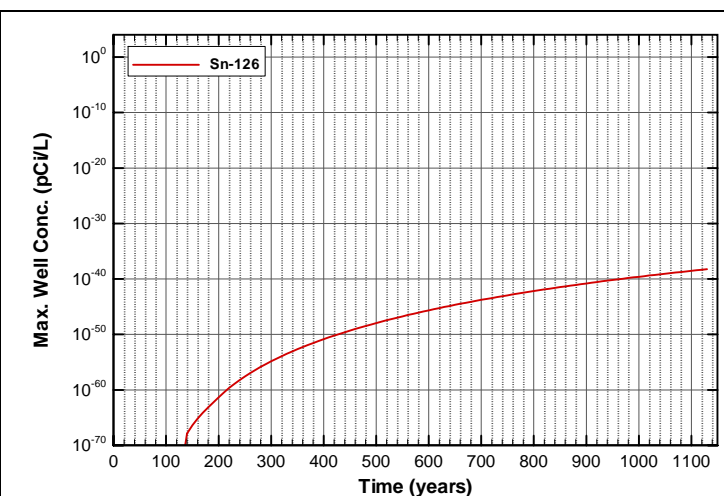

Figure A-1781. Well concentrations for Case01n11_on Sn-126

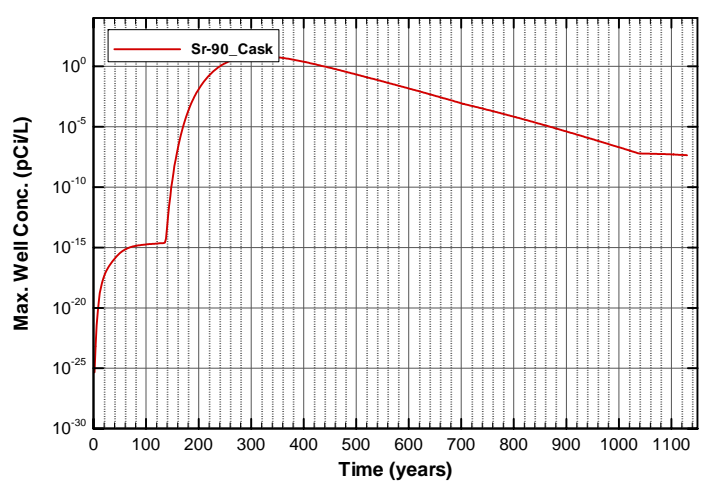

Figure A-1783. Well concentrations for Case01n11_on Sr-90_Cask

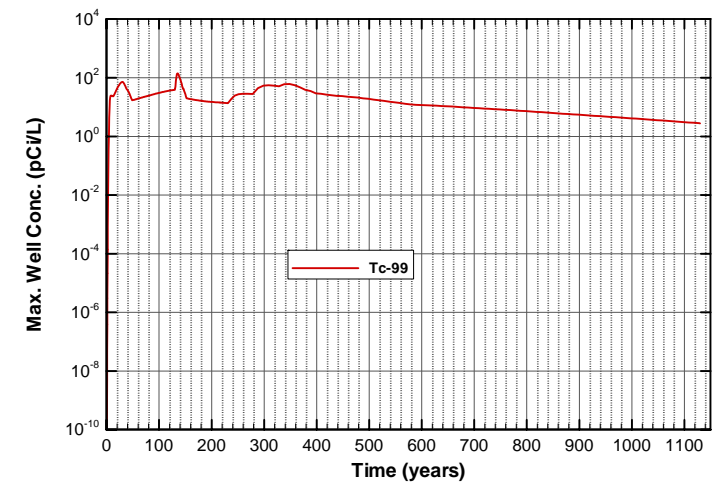

Figure A-1785. Well concentrations for Case01n11_on Tc-99

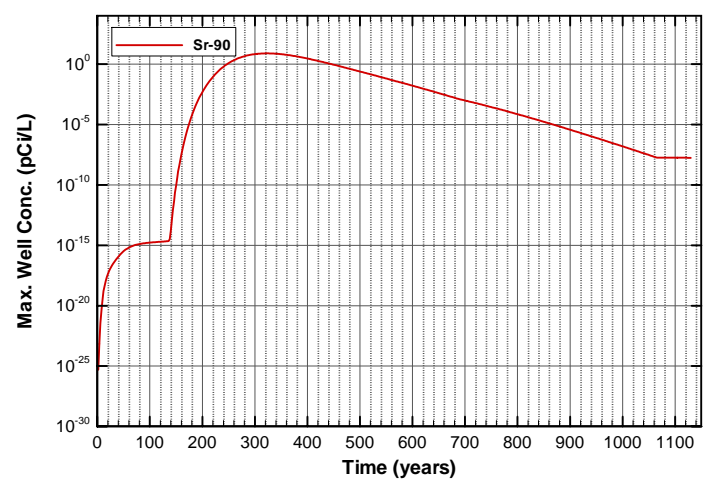

Figure A-1782. Well concentrations for Case01n11_on Sr-90

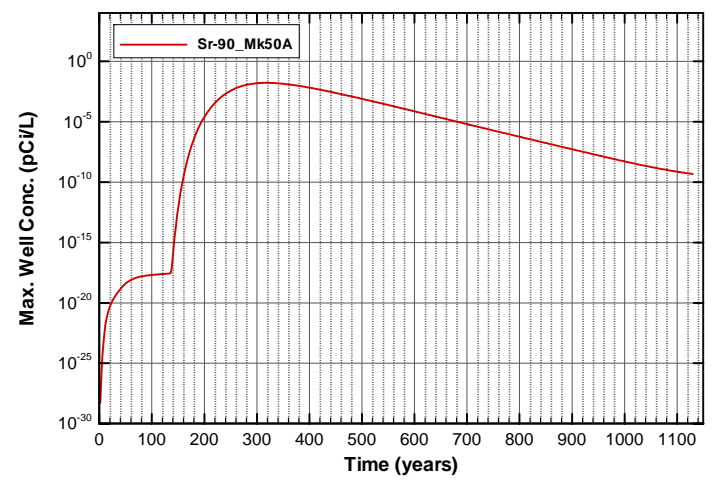

Figure A-1784. Well concentrations for Case01n11_on Sr-90_Mk50A

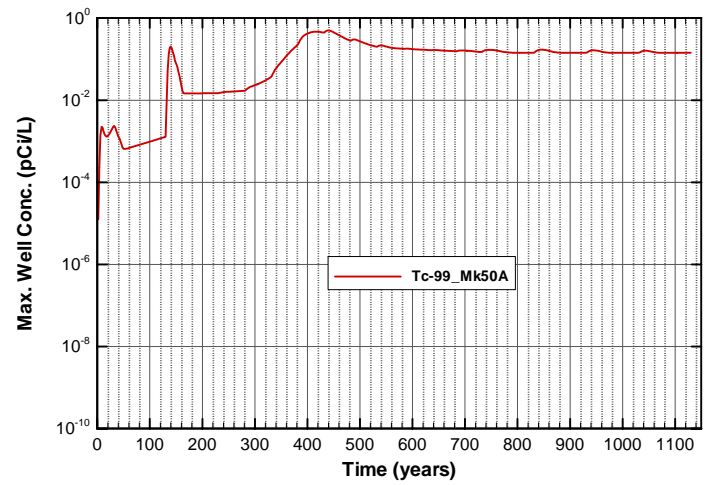

Figure A-1786. Well concentrations for Case01n11_on Tc-99_Mk50A 


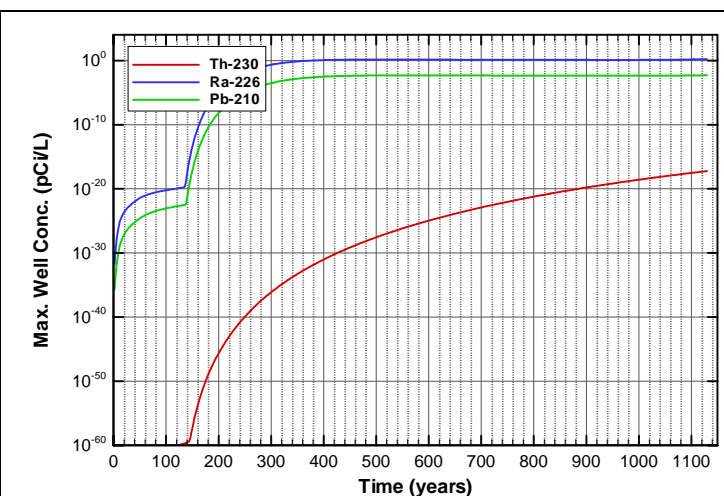

Figure A-1787. Well concentrations for Case01n11_on Th-230

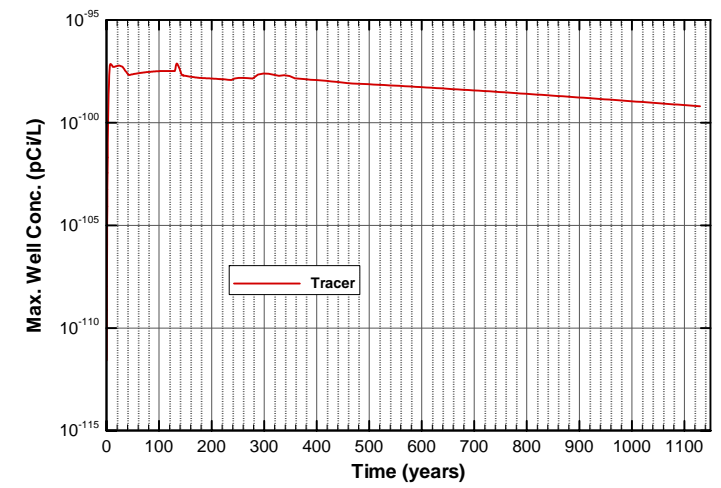

Figure A-1789. Well concentrations for Case01n11_on Tracer

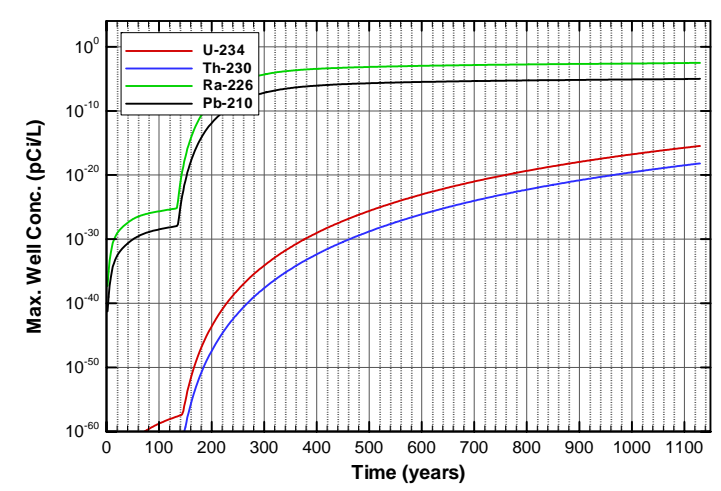

Figure A-1791. Well concentrations for Case01n11_on U-234

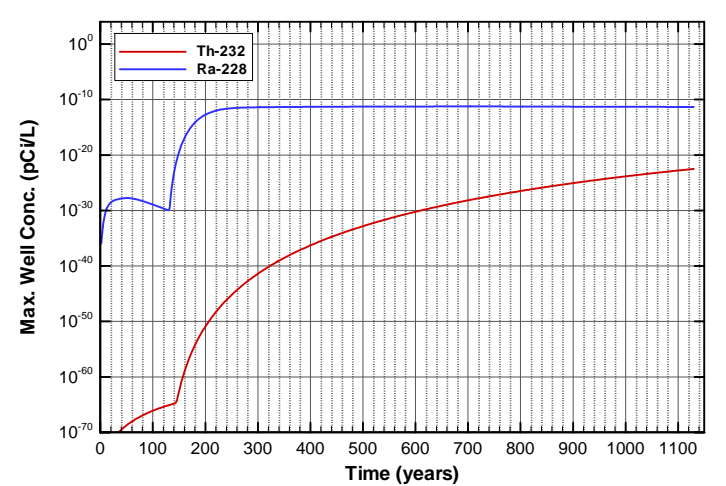

Figure A-1788. Well concentrations for Case01n11_on Th-232

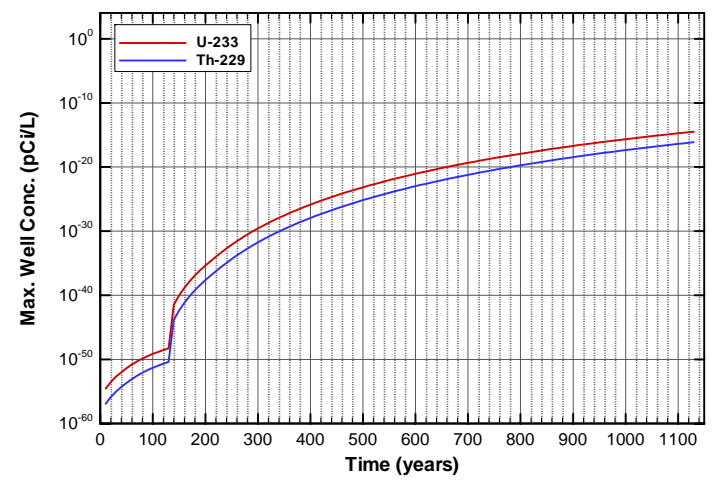

Figure A-1790. Well concentrations for Case01n11_on U-233

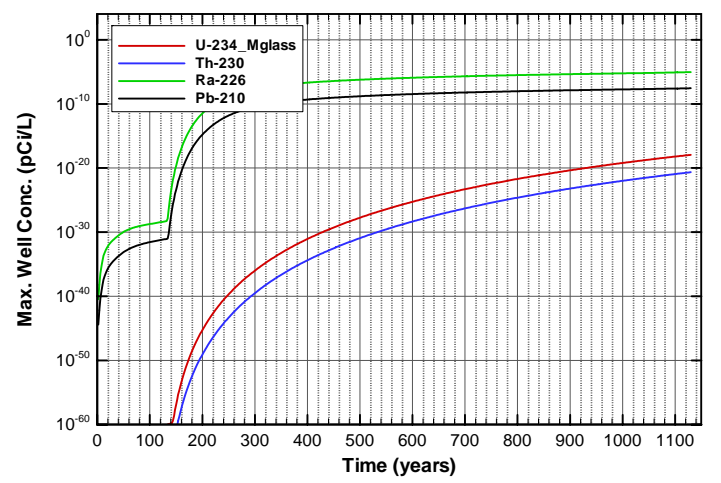

Figure A-1792. Well concentrations for Case01n11_on U-234_Mglass 


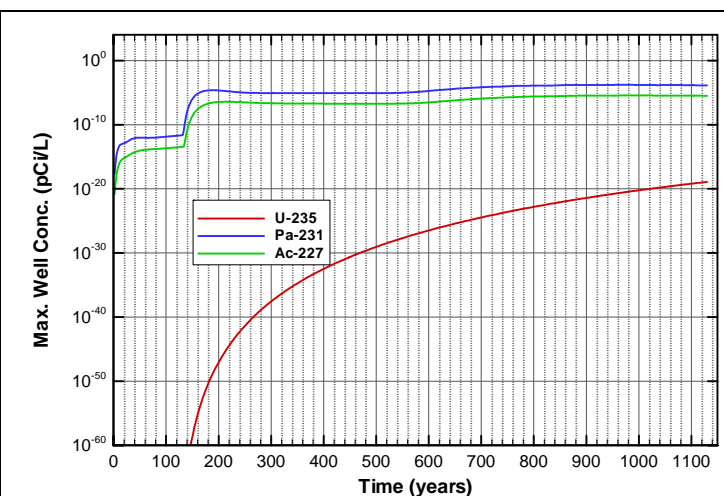

Figure A-1793. Well concentrations for Case01n11_on U-235

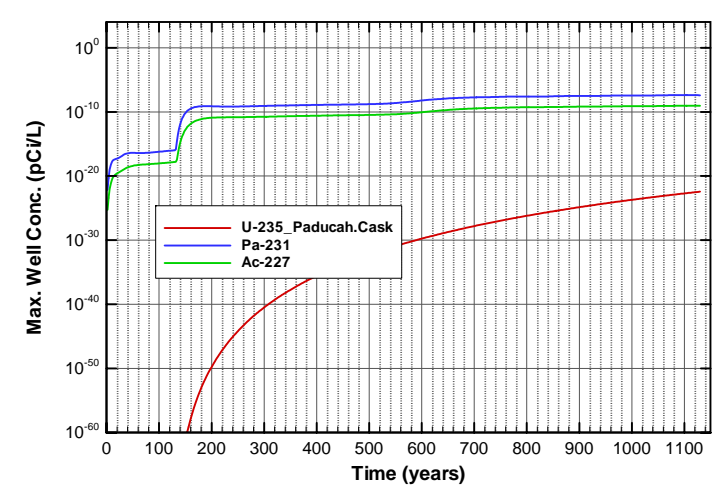

Figure A-1795. Well concentrations for Case01n11_on U-235_Paducah.Cask

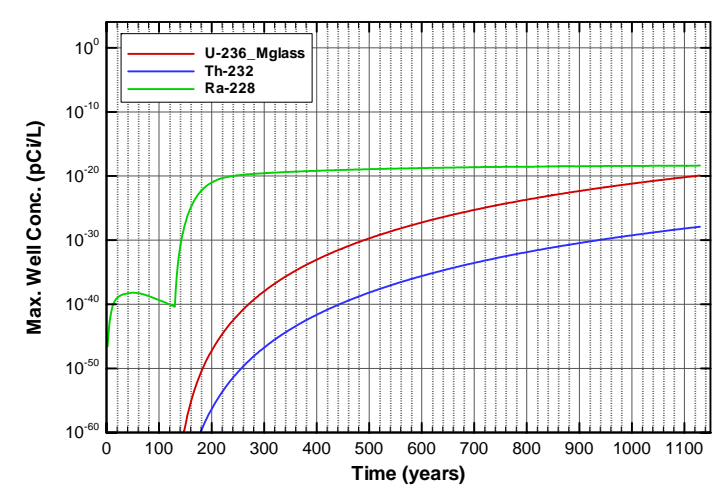

Figure A-1797. Well concentrations for Case01n11_on U-236_Mglass

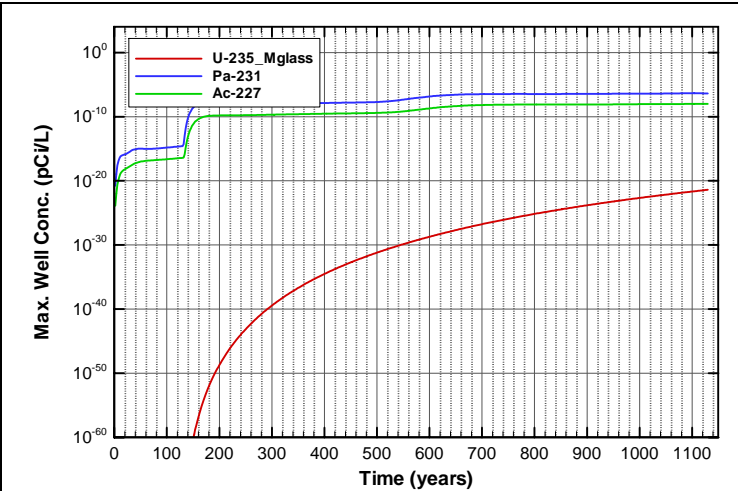

Figure A-1794. Well concentrations for Case01n11_on U-235_Mglass

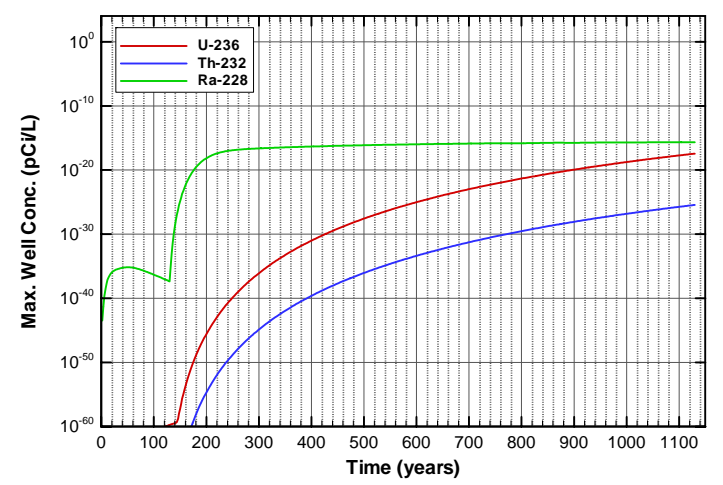

Figure A-1796. Well concentrations for Case01n11_on U-236

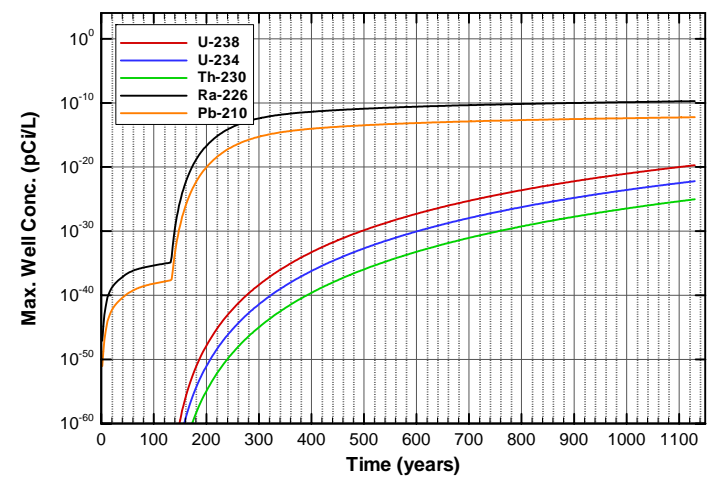

Figure A-1798. Well concentrations for Case01n11_on U-238 


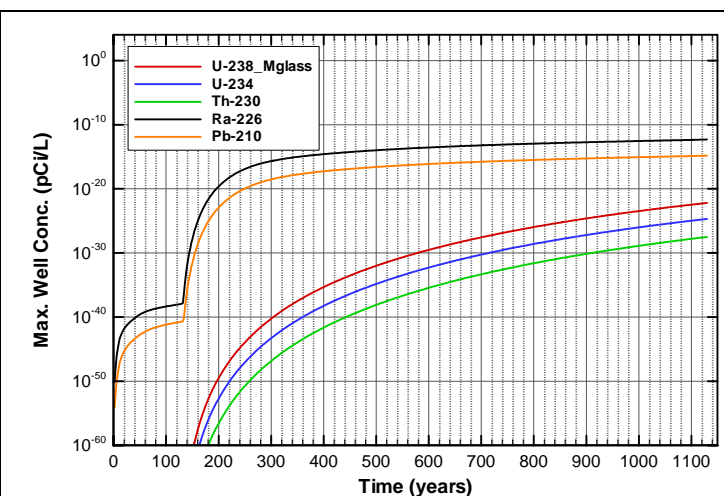

Figure A-1799. Well concentrations for Case01n11_on U-238_Mglass

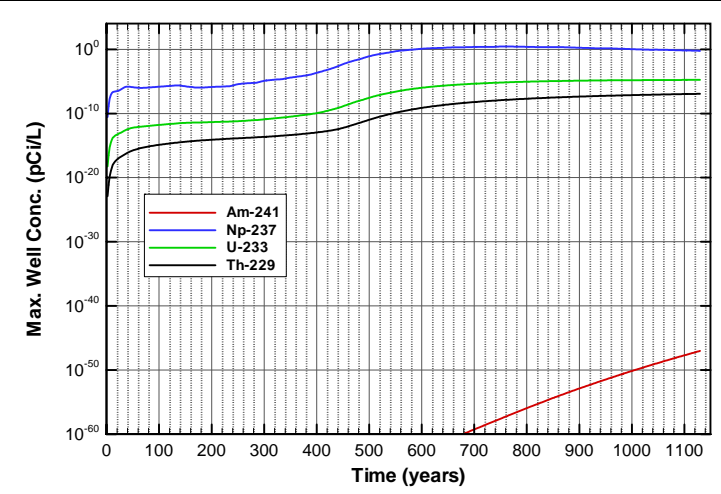

Figure A-1801. Well concentrations for Case01_off Am-241

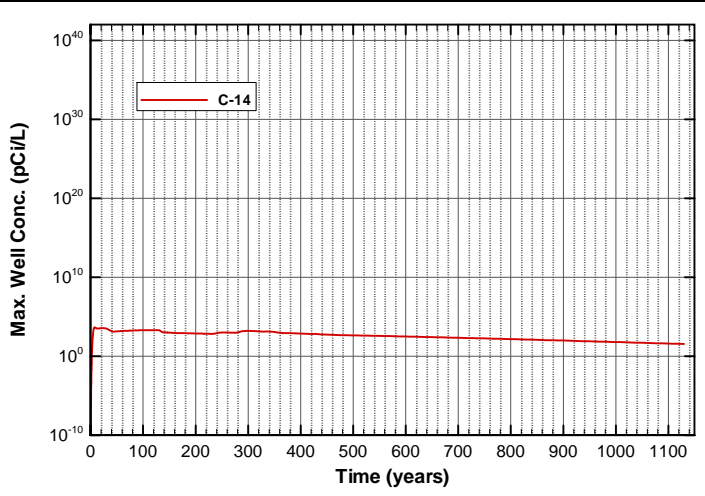

Figure A-1803. Well concentrations for Case01_off C-14

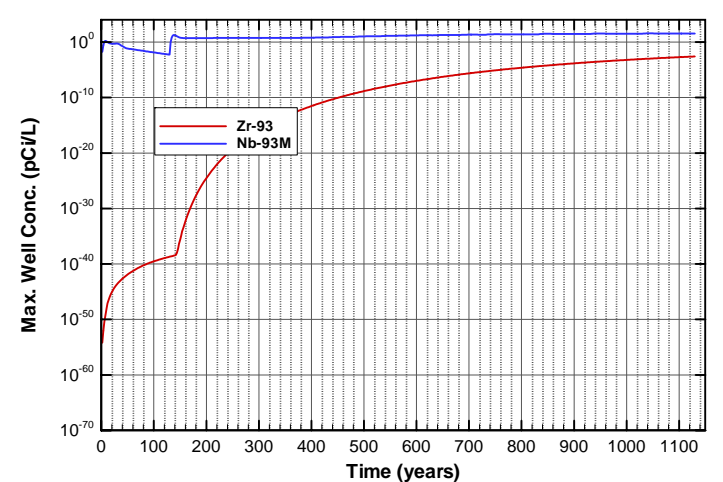

Figure A-1800. Well concentrations for Case01n11_on Zr-93

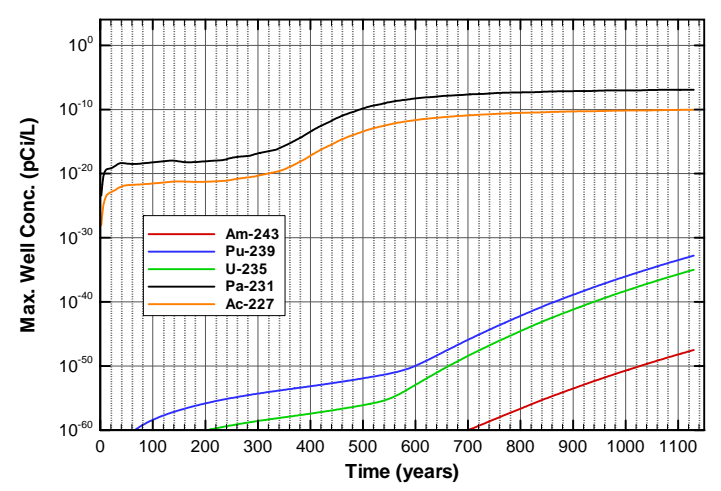

Figure A-1802. Well concentrations for Case01_off Am-243

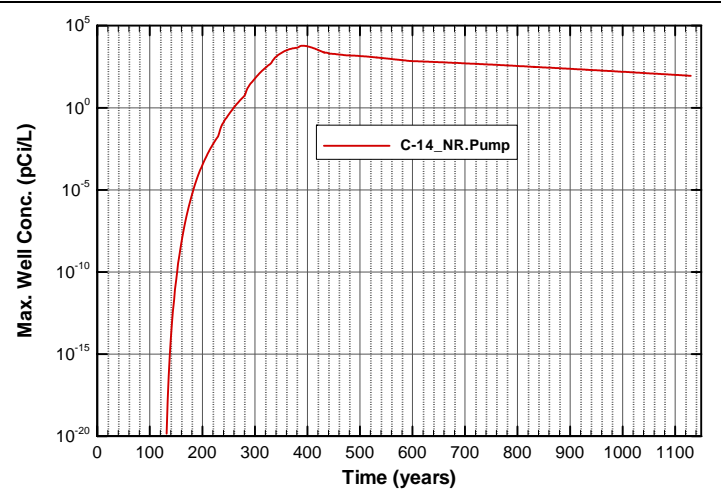

Figure A-1804. Well concentrations for Case01_off C-14_NR.Pump 
SRNL-STI-2008-00397, REVISION 0

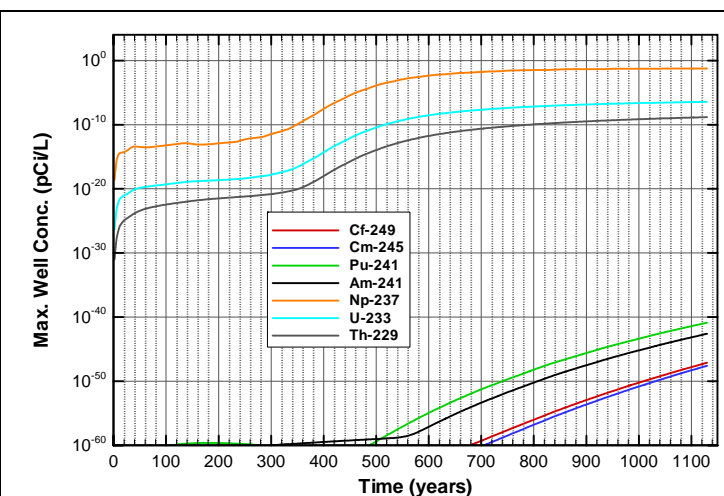

Figure A-1805. Well concentrations for Case01_off Cf-249

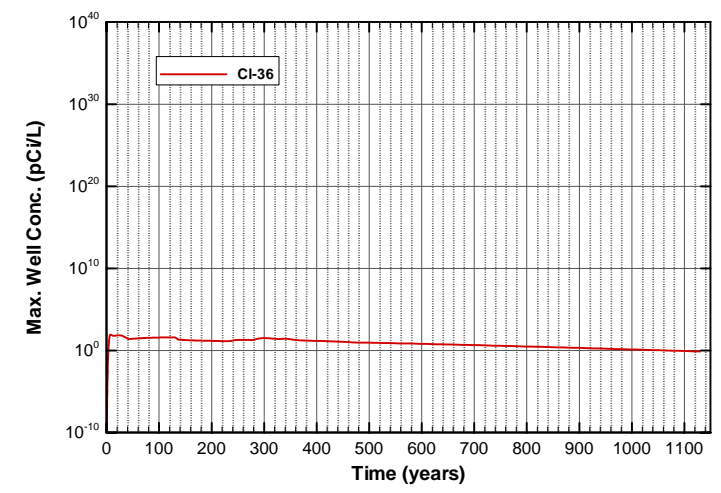

Figure A-1807. Well concentrations for Case01_off Cl-36

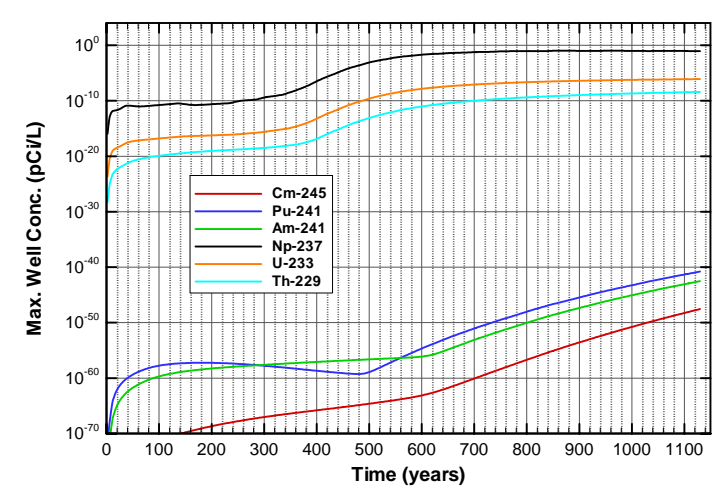

Figure A-1809. Well concentrations for Case01_off Cm-245

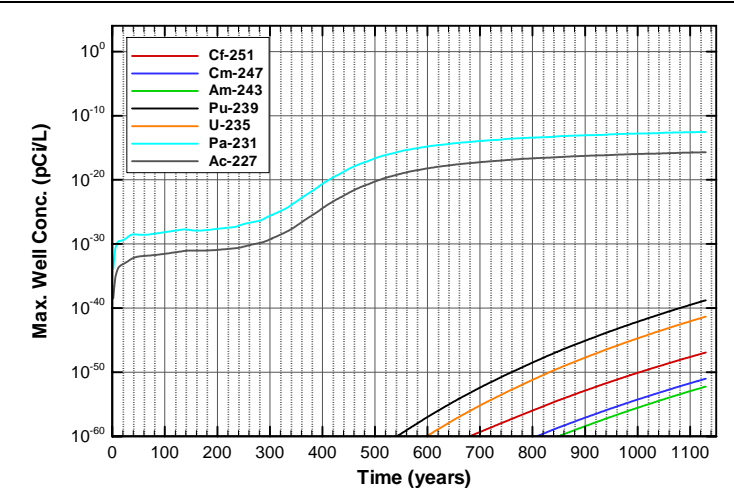

Figure A-1806. Well concentrations for Case01_off Cf-251

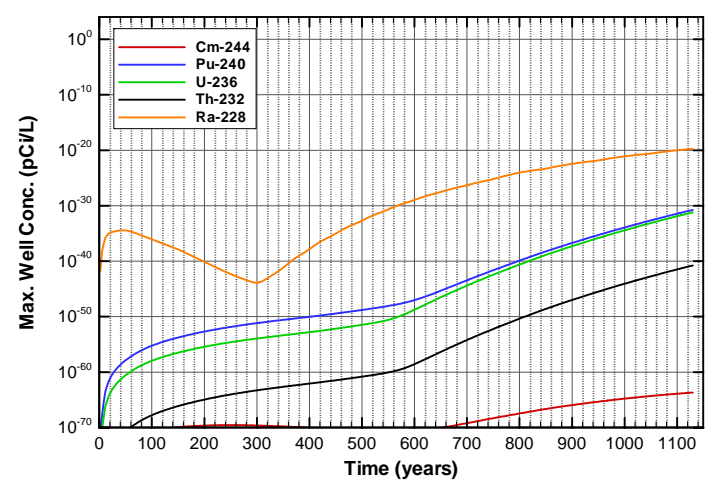

Figure A-1808. Well concentrations for Case01_off Cm-244

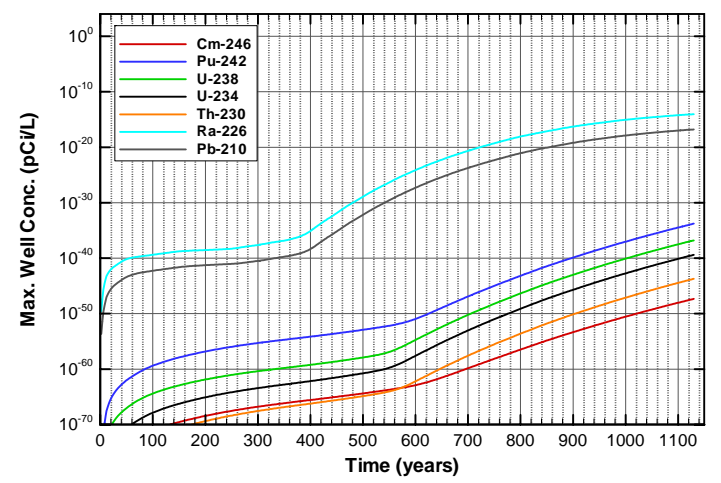

Figure A-1810. Well concentrations for Case01_off Cm-246 
SRNL-STI-2008-00397, REVISION 0

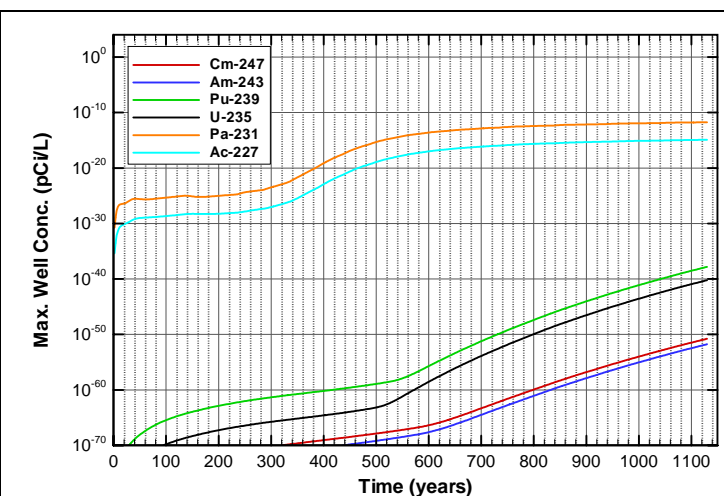

Figure A-1811. Well concentrations for Case01_off Cm-247

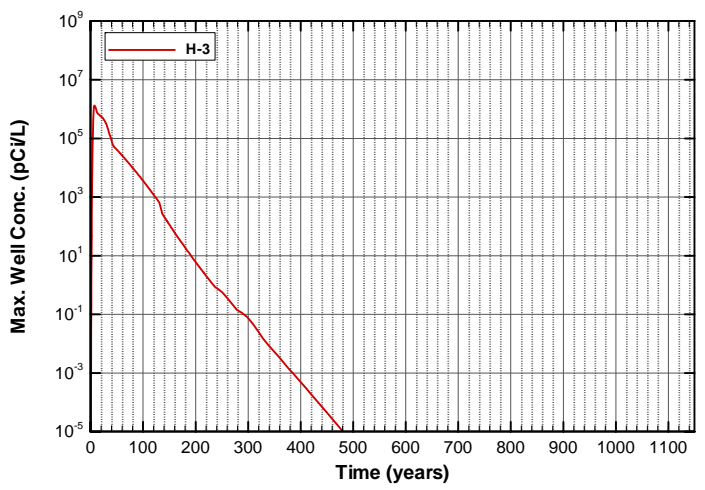

Figure A-1813. Well concentrations for Case01_off H-3

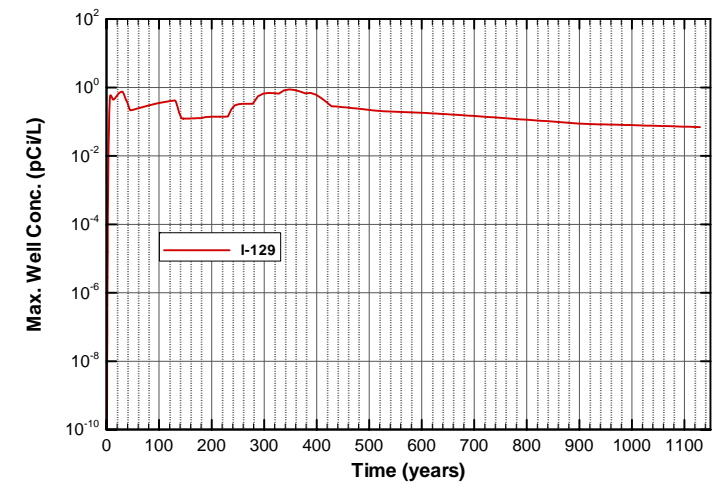

Figure A-1815. Well concentrations for Case01_off I-129

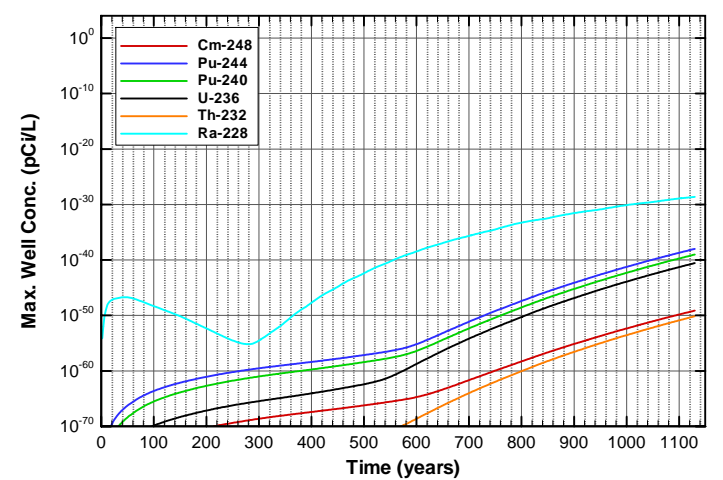

Figure A-1812. Well concentrations for Case01_off Cm-248

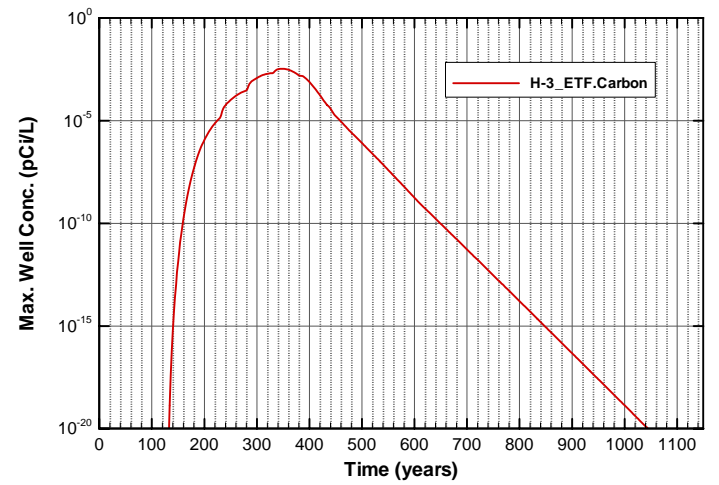

Figure A-1814. Well concentrations for Case01_off H-3_ETF.Carbon

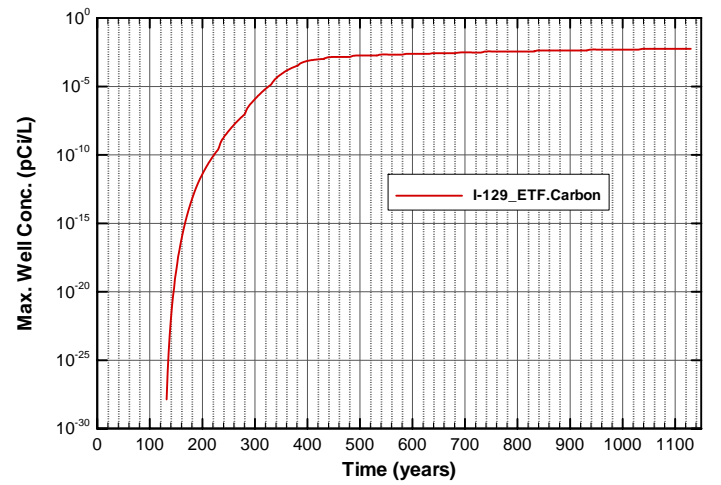

Figure A-1816. Well concentrations for Case01_off I-129_ETF.Carbon 
SRNL-STI-2008-00397, REVISION 0

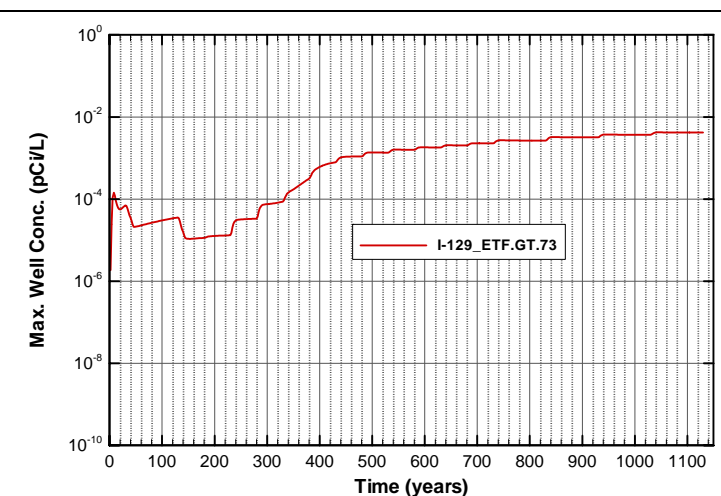

Figure A-1817. Well concentrations for Case01_off I-129_ETF.GT.73

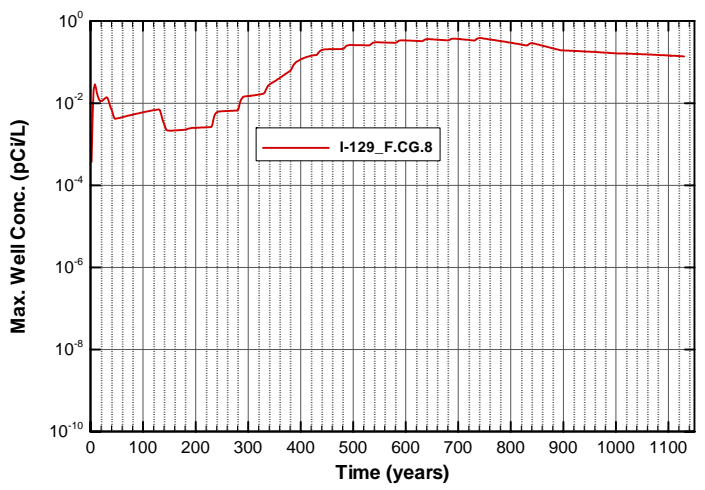

Figure A-1819. Well concentrations for Case01_off I-129_F.CG.8

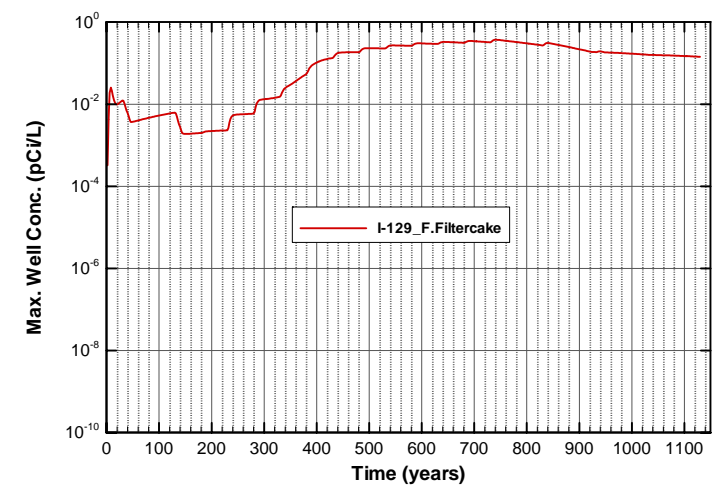

Figure A-1821. Well concentrations for Case01_off I-129_F.Filtercake

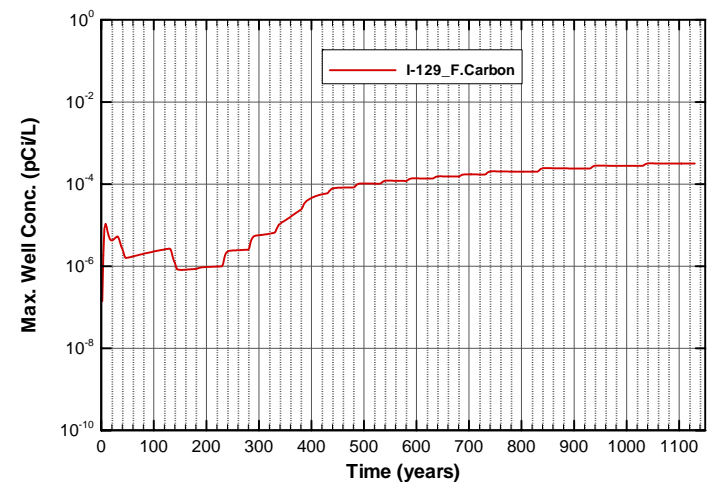

Figure A-1818. Well concentrations for Case01_off I-129_F.Carbon

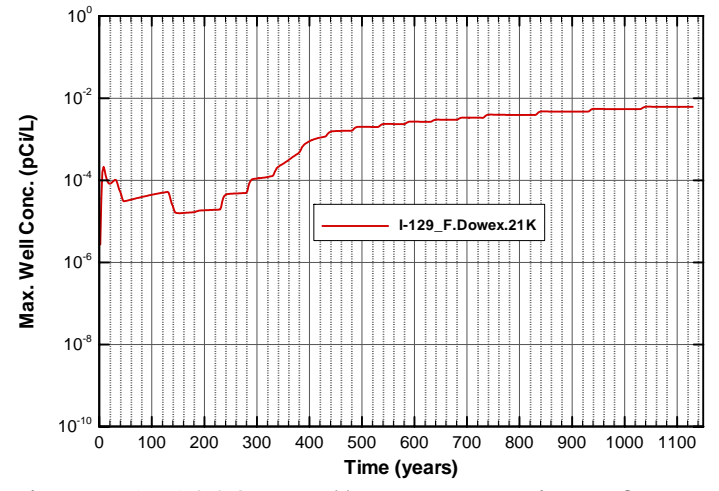

Figure A-1820. Well concentrations for Case01_off I-129_F.Dowex.21K

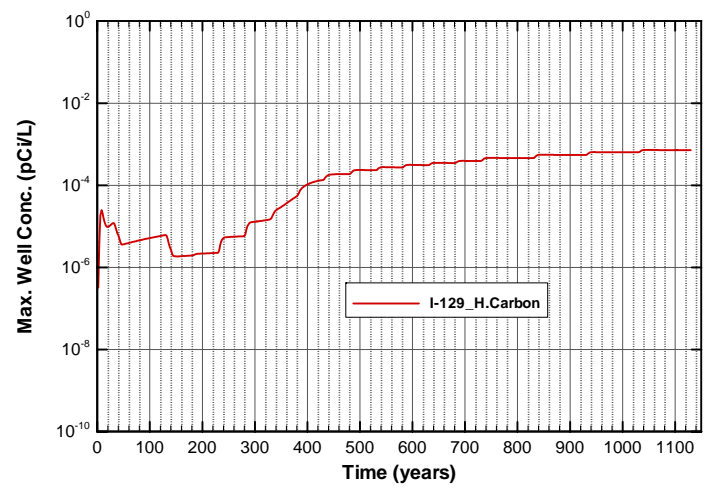

Figure A-1822. Well concentrations for Case01_off I-129_H.Carbon 
SRNL-STI-2008-00397, REVISION 0

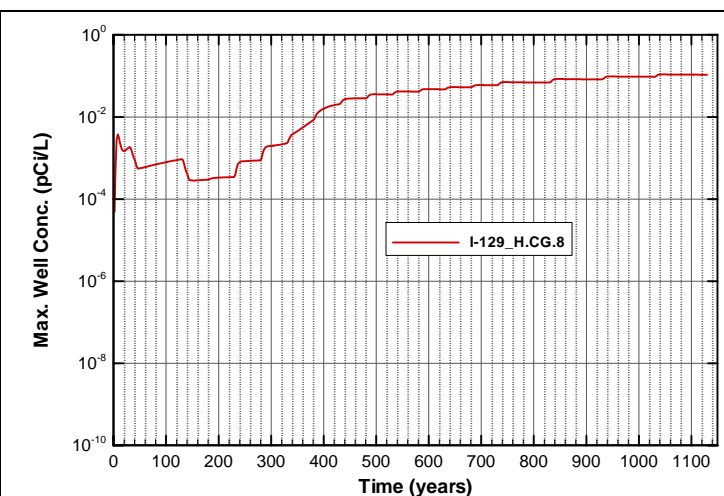

Figure A-1823. Well concentrations for Case01_off I-129_H.CG.8

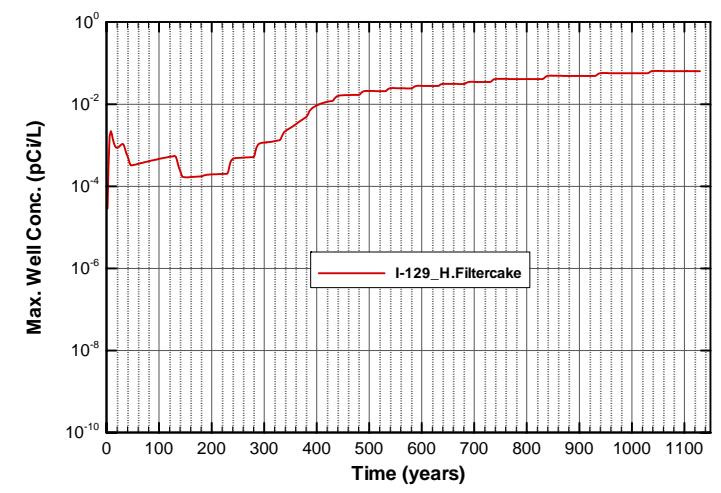

Figure A-1825. Well concentrations for Case01_off I-129_H.Filtercake

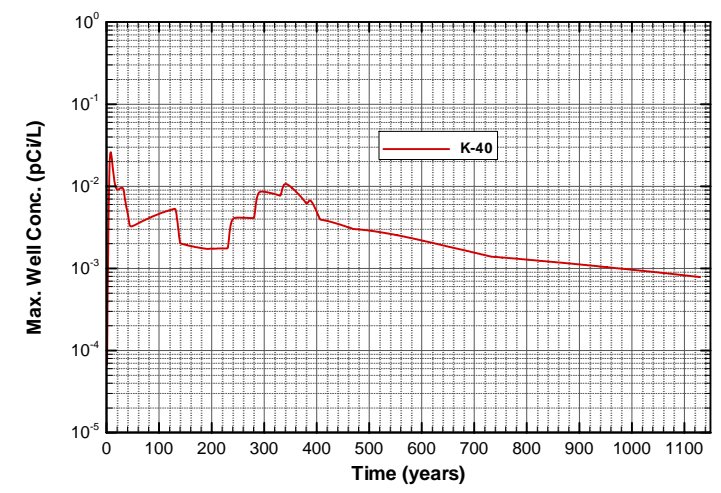

Figure A-1827. Well concentrations for Case01_off K-40

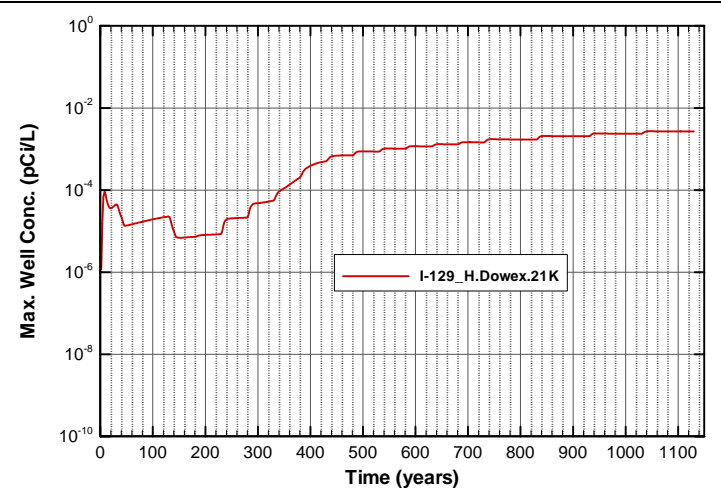

Figure A-1824. Well concentrations for Case01_off I-129_H.Dowex.21K

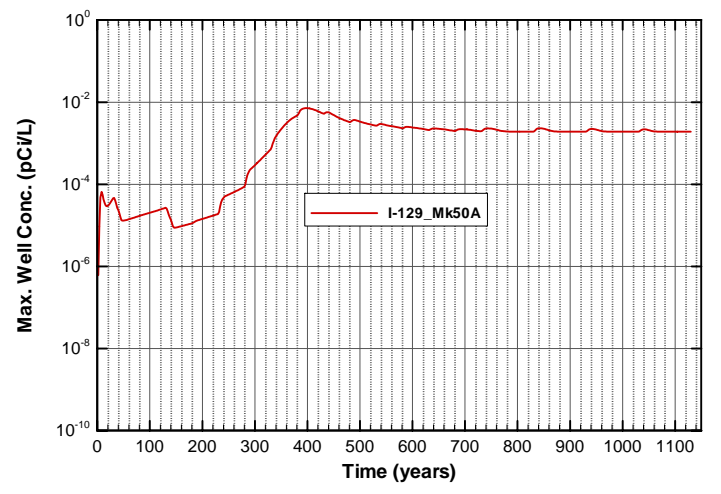

Figure A-1826. Well concentrations for Case01_off I-129_Mk50A

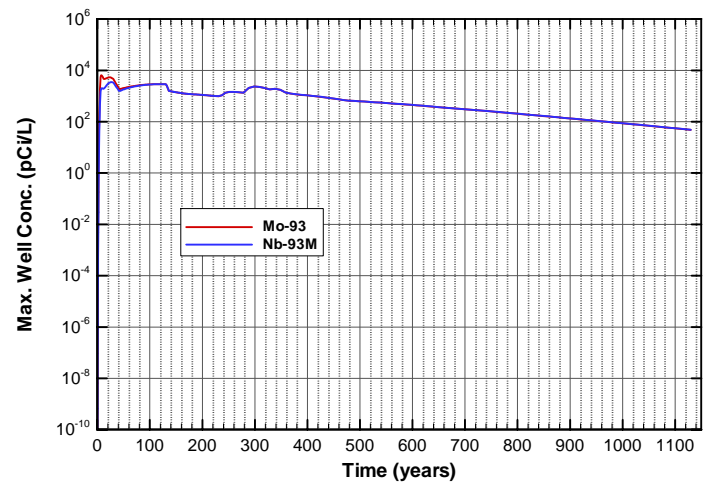

Figure A-1828. Well concentrations for Case01_off Mo-93 
SRNL-STI-2008-00397, REVISION 0

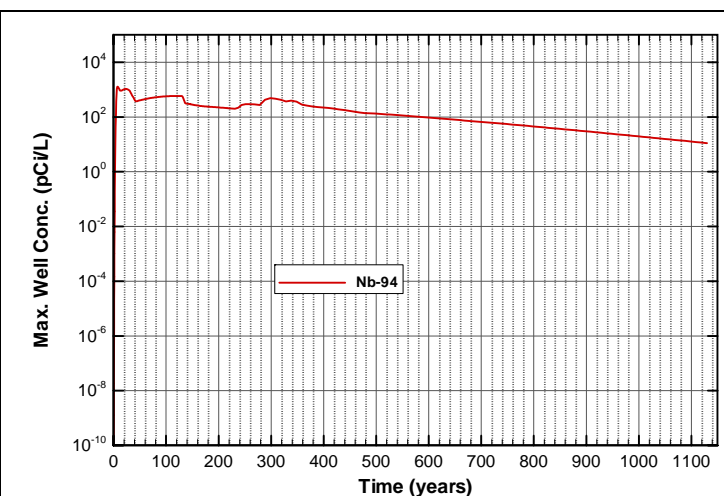

Figure A-1829. Well concentrations for Case01_off Nb-94

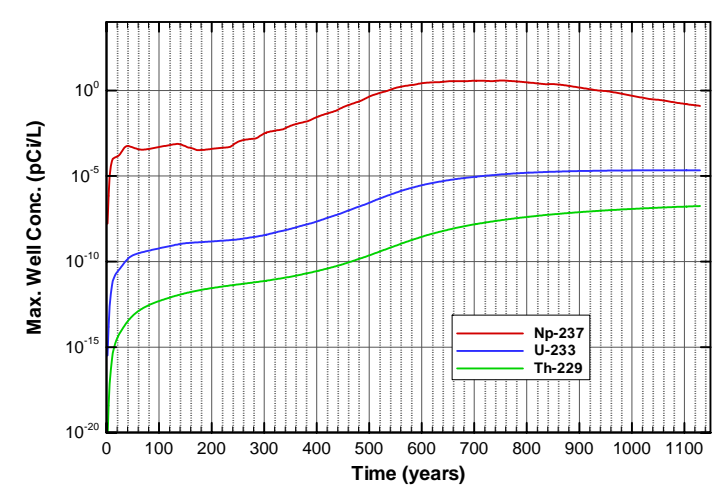

Figure A-1831. Well concentrations for Case01_off Np-237

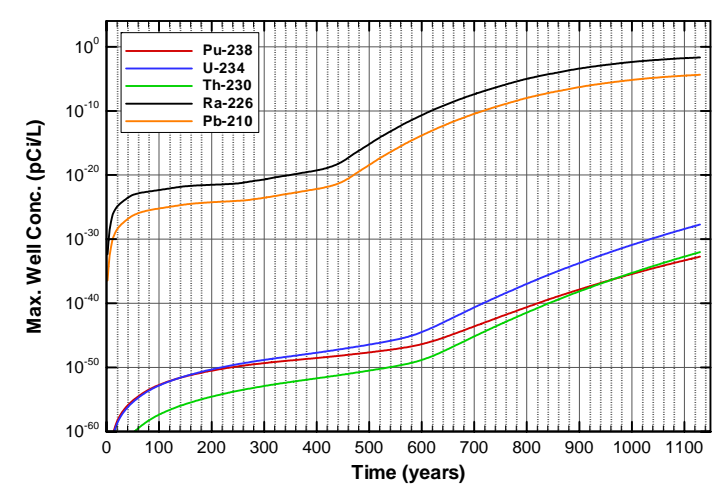

Figure A-1833. Well concentrations for Case01_off Pu-238

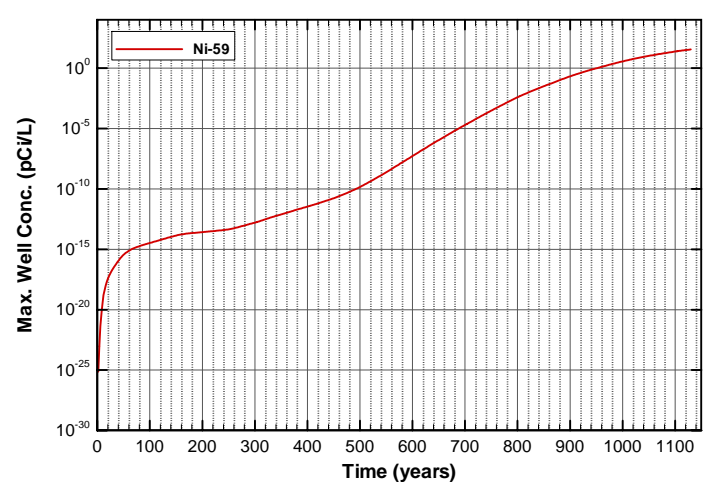

Figure A-1830. Well concentrations for Case01_off Ni-59

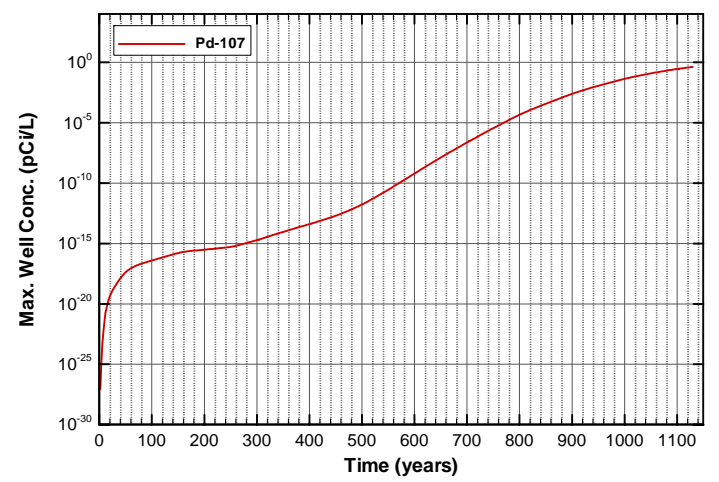

Figure A-1832. Well concentrations for Case01_off Pd-107

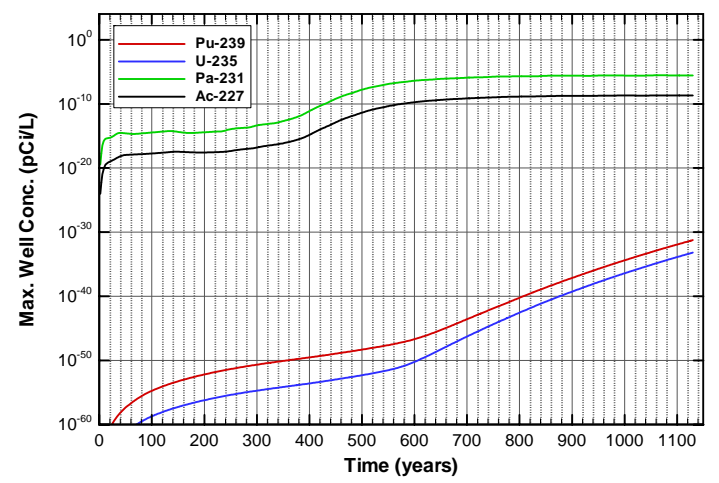

Figure A-1834. Well concentrations for Case01_off Pu-239 
SRNL-STI-2008-00397, REVISION 0

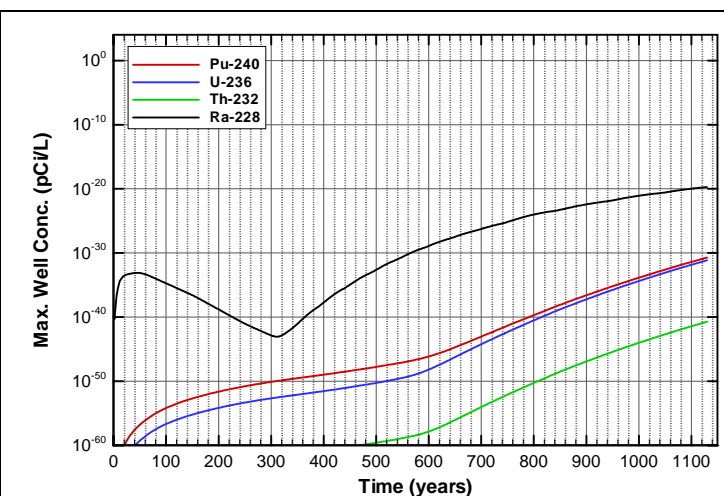

Figure A-1835. Well concentrations for Case01_off Pu-240

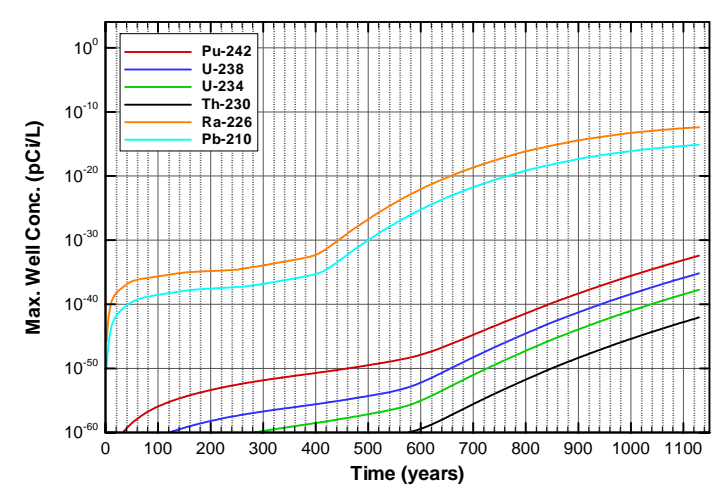

Figure A-1837. Well concentrations for Case01_off Pu-242

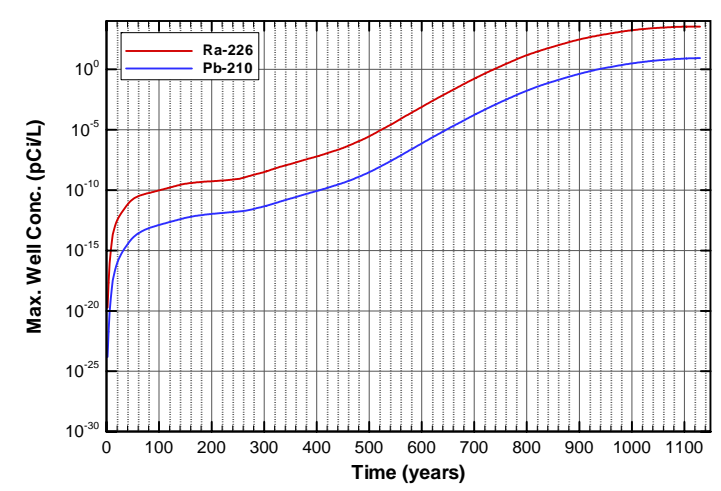

Figure A-1839. Well concentrations for Case01_off Ra-226

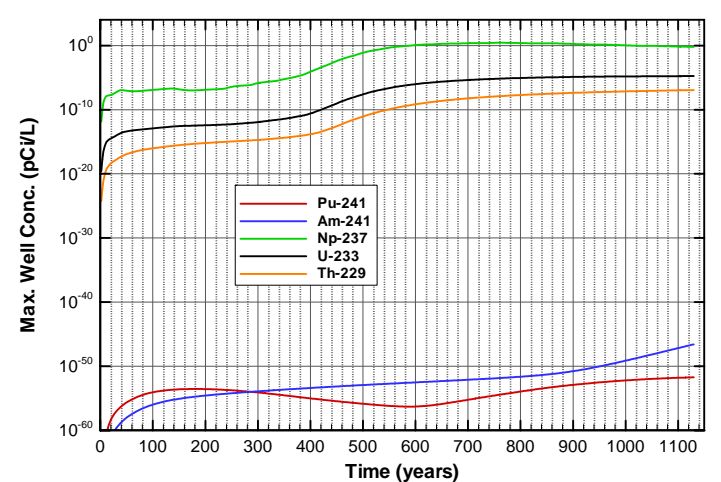

Figure A-1836. Well concentrations for Case01_off Pu-241

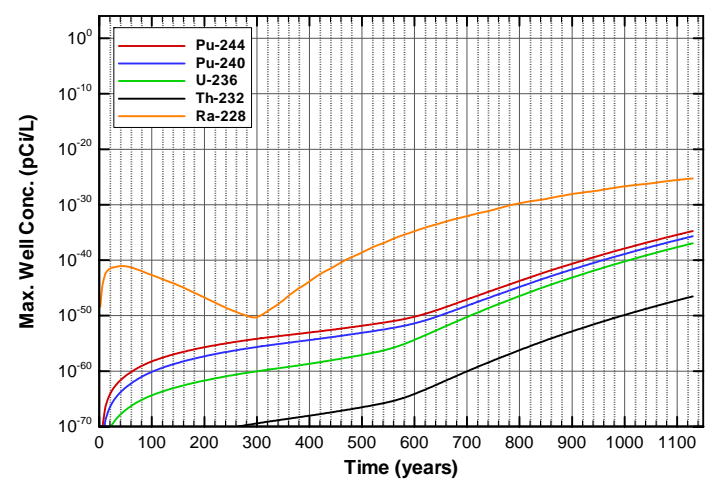

Figure A-1838. Well concentrations for Case01_off Pu-244

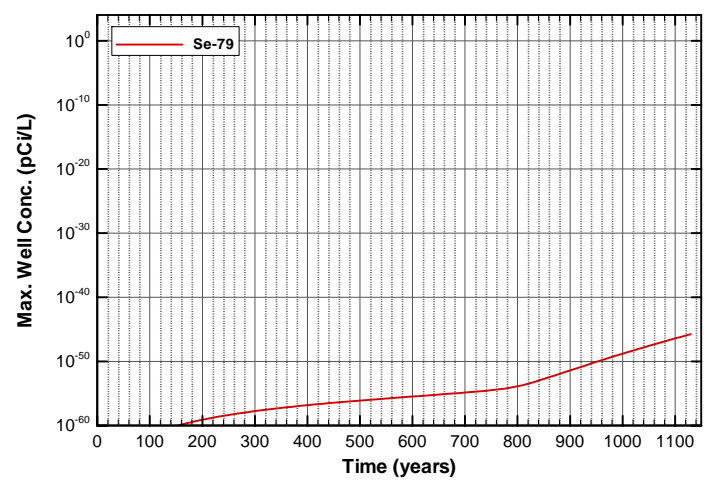

Figure A-1840. Well concentrations for Case01_off Se-79 
SRNL-STI-2008-00397, REVISION 0

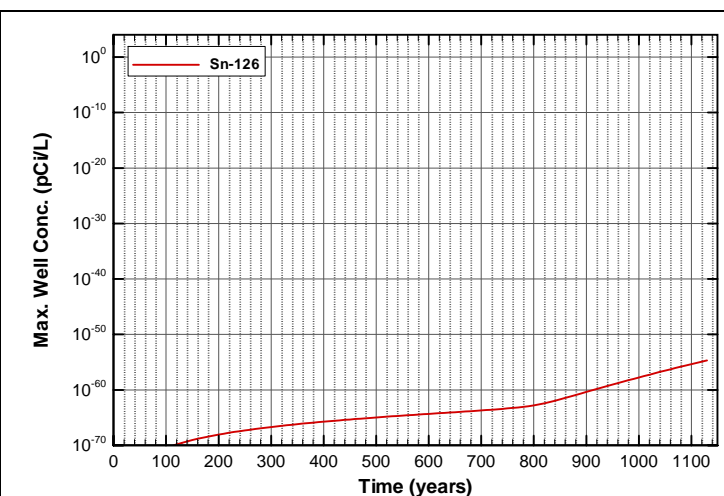

Figure A-1841. Well concentrations for Case01_off Sn-126

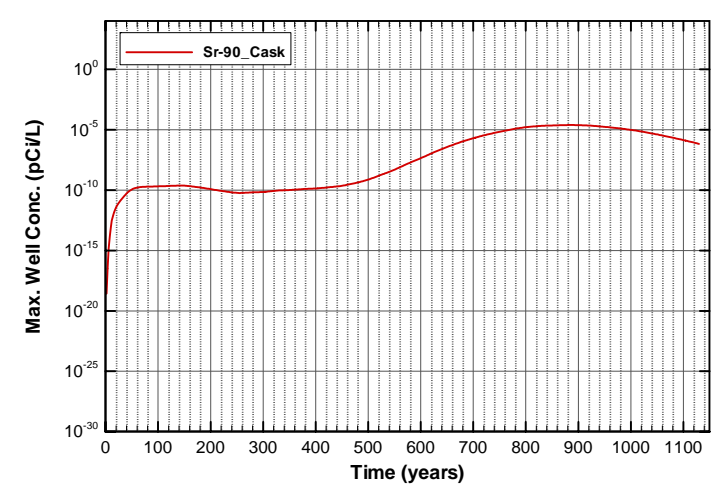

Figure A-1843. Well concentrations for Case01_off Sr-90_Cask

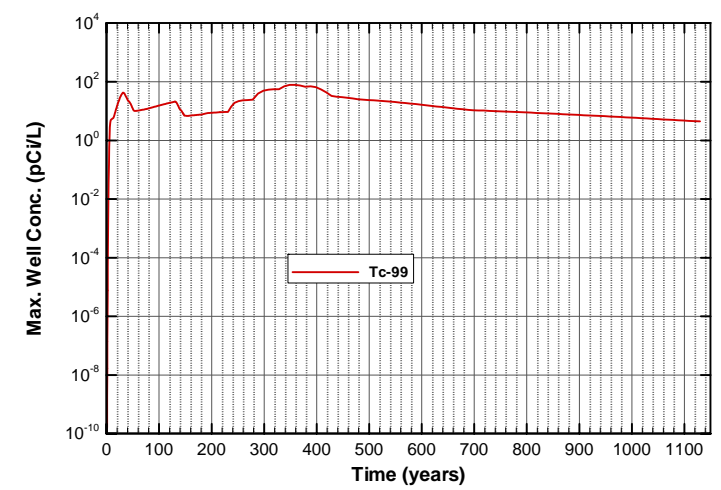

Figure A-1845. Well concentrations for Case01_off Tc-99

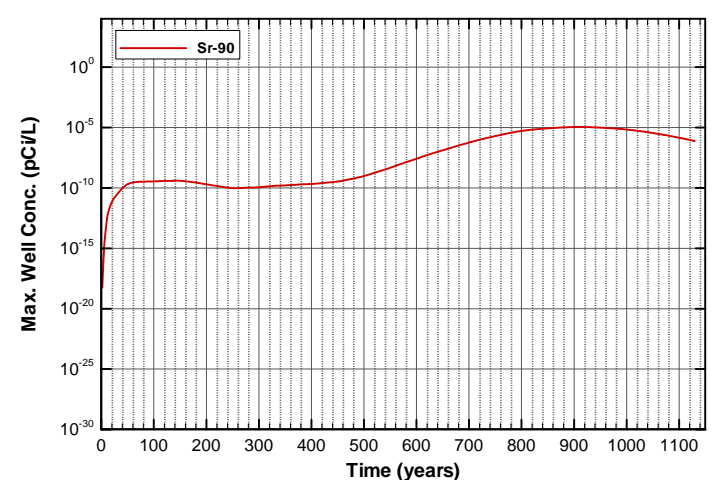

Figure A-1842. Well concentrations for Case01_off Sr-90

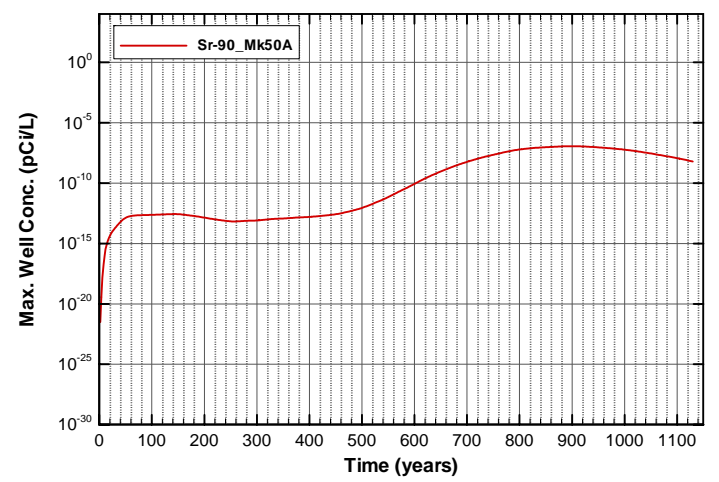

Figure A-1844. Well concentrations for Case01_off Sr-90_Mk50A

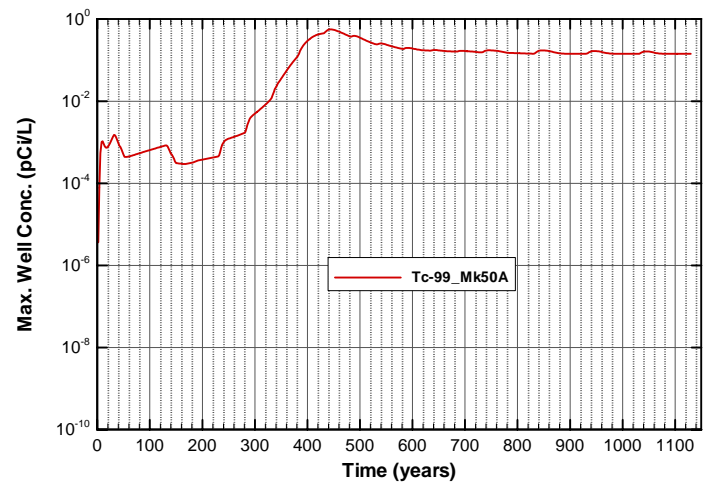

Figure A-1846. Well concentrations for Case01_off Tc-99_Mk50A 


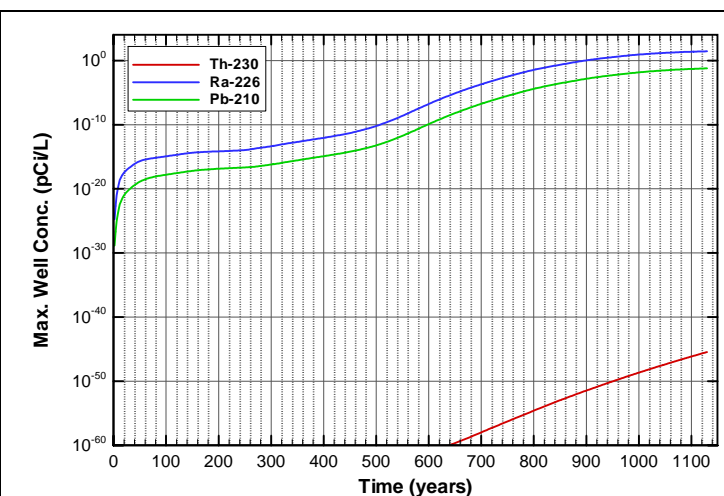

Figure A-1847. Well concentrations for Case01_off Th-230

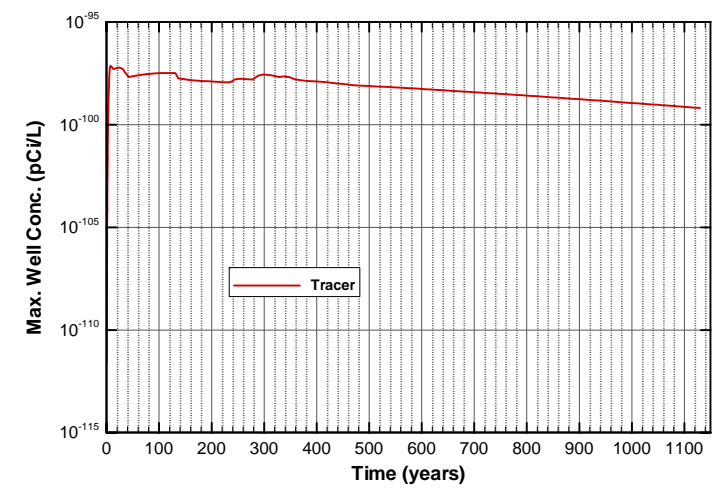

Figure A-1849. Well concentrations for Case01_off Tracer

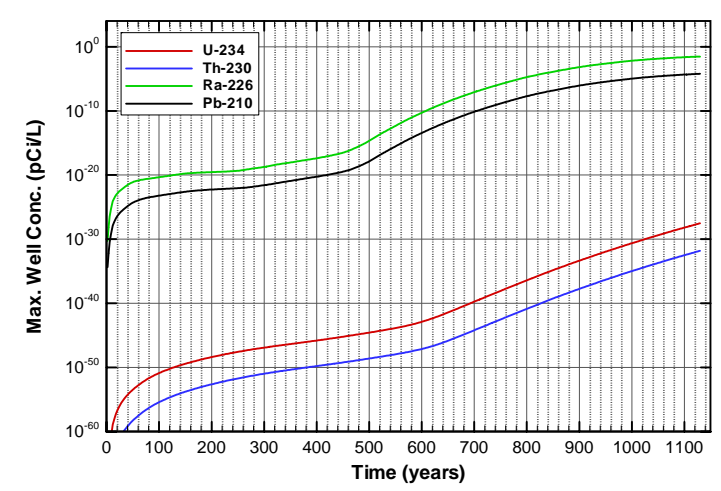

Figure A-1851. Well concentrations for Case01_off U-234

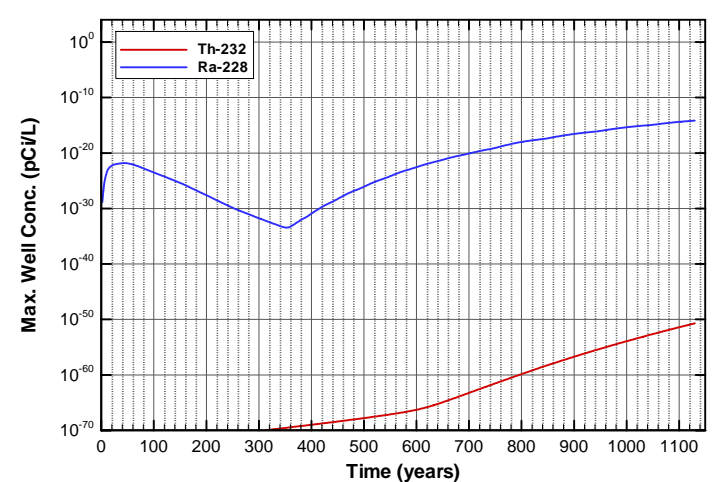

Figure A-1848. Well concentrations for Case01_off Th-232

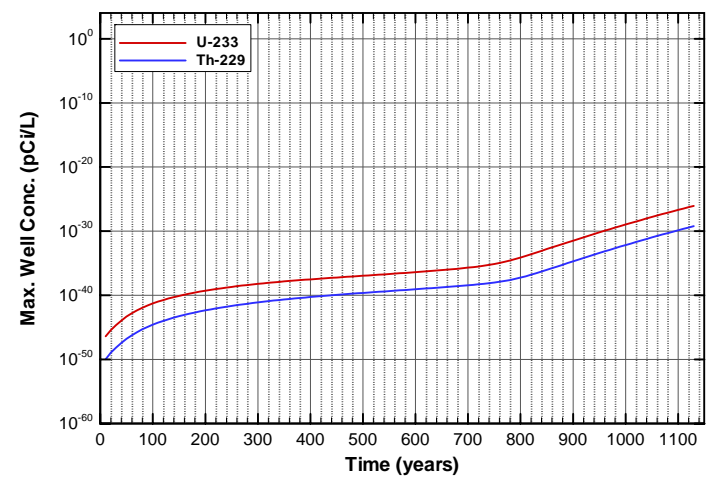

Figure A-1850. Well concentrations for Case01_off U-233

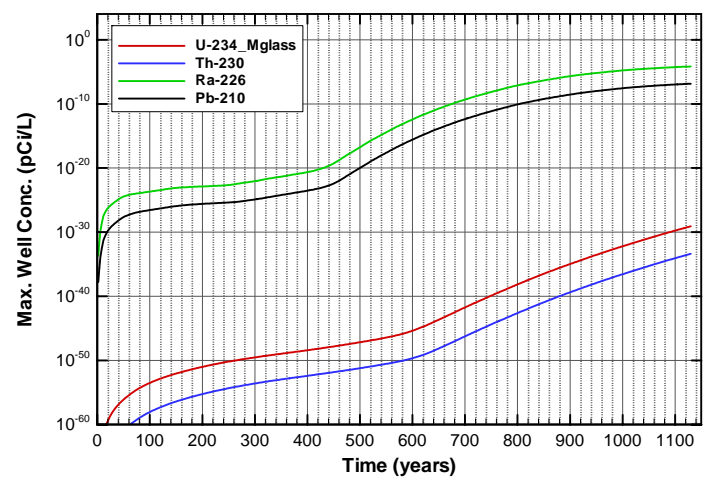

Figure A-1852. Well concentrations for Case01_off U-234_Mglass 


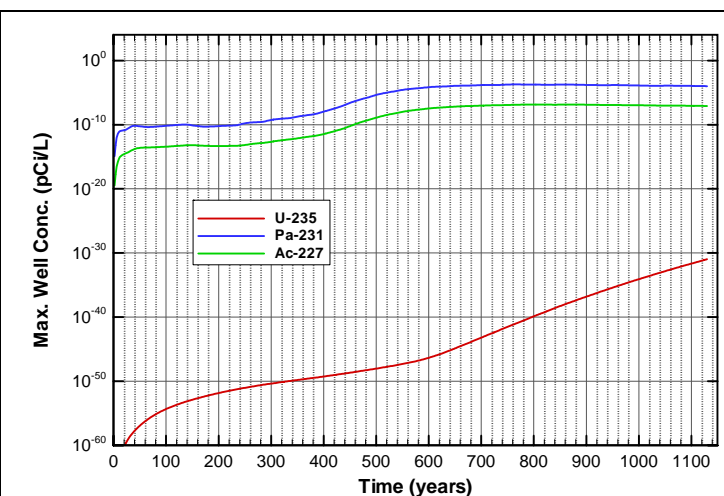

Figure A-1853. Well concentrations for Case01_off U-235

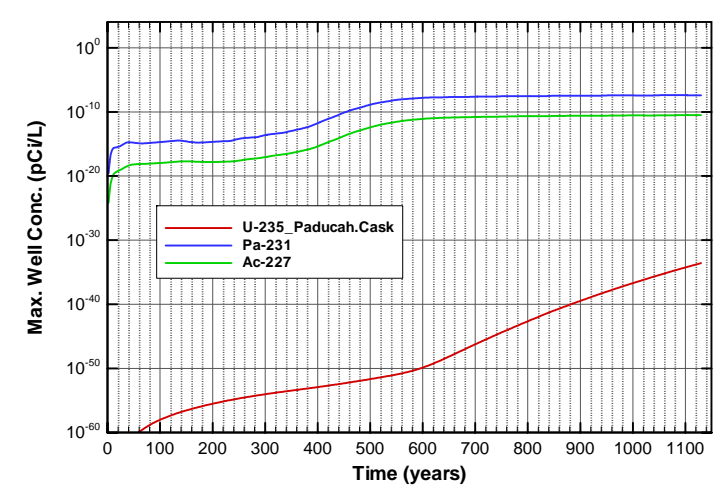

Figure A-1855. Well concentrations for Case01_off U-235_Paducah.Cask

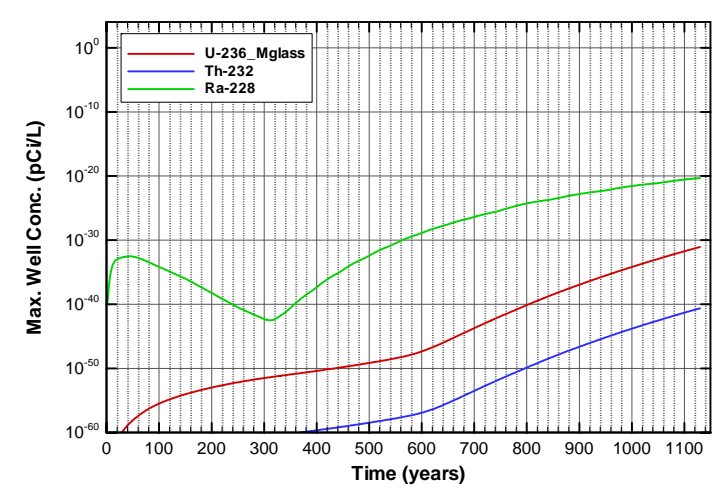

Figure A-1857. Well concentrations for Case01_off U-236_Mglass

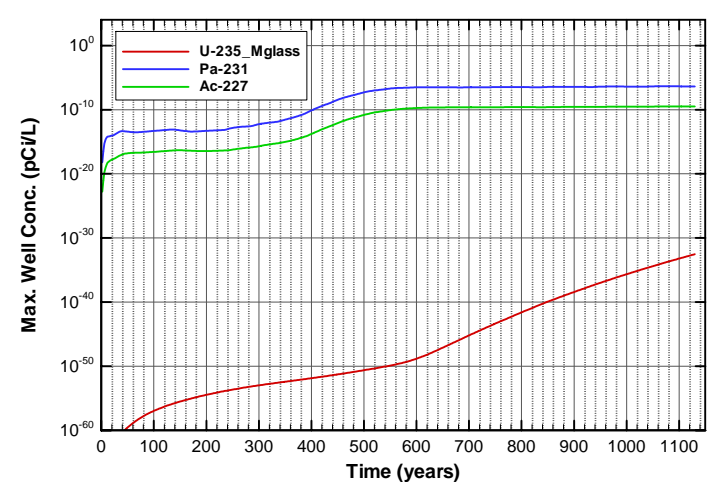

Figure A-1854. Well concentrations for Case01_off U-235_Mglass

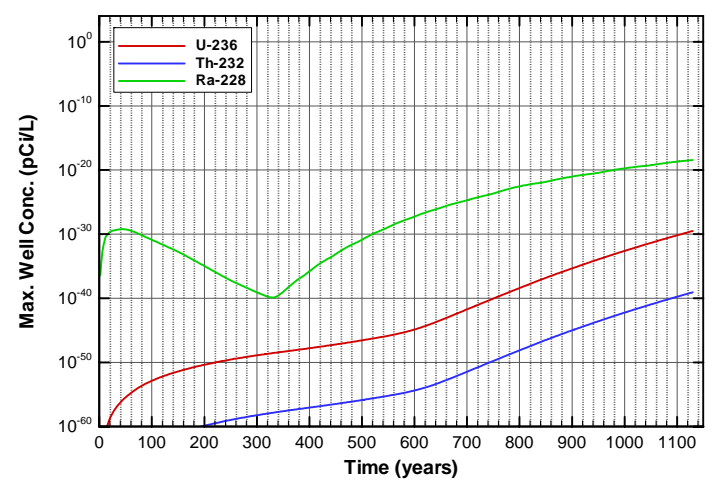

Figure A-1856. Well concentrations for Case01_off U-236

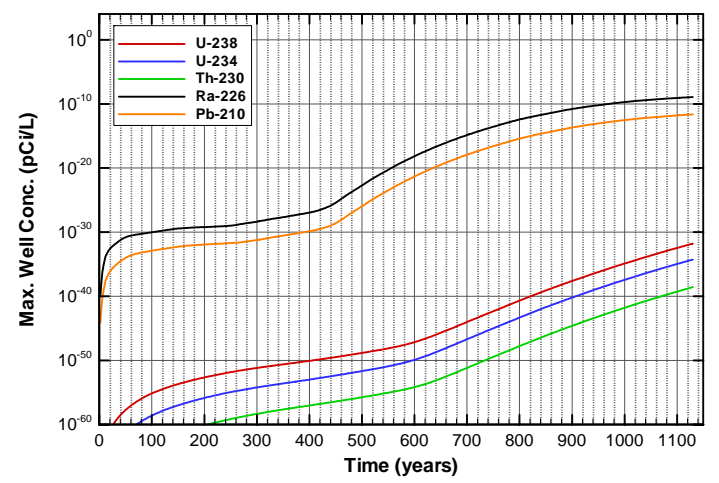

Figure A-1858. Well concentrations for Case01_off U-238 


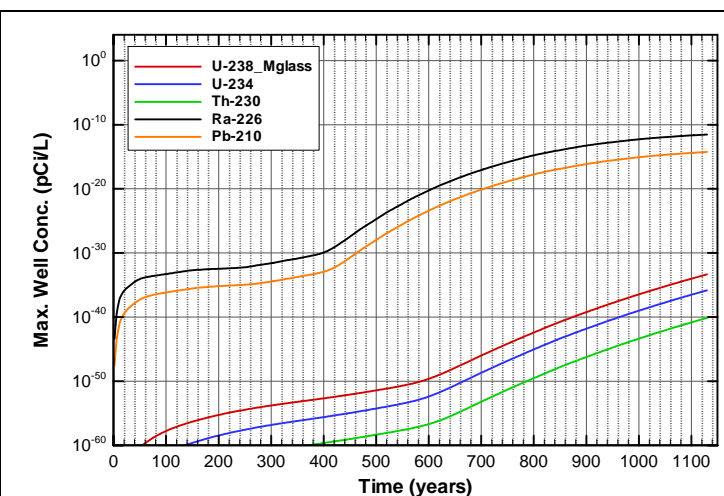

Figure A-1859. Well concentrations for Case01_off U-238_Mglass

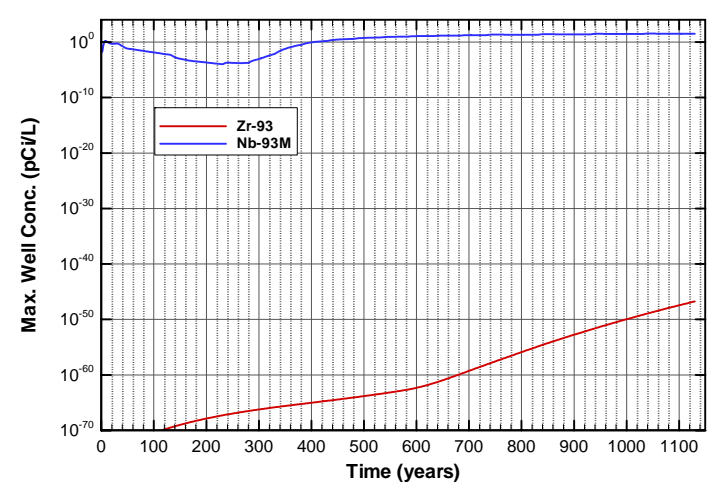

Figure A-1860. Well concentrations for Case01_off Zr-93

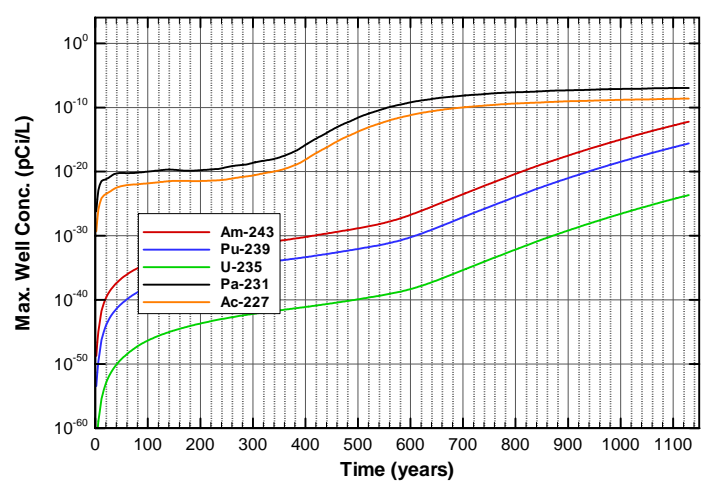

Figure A-1862. Well concentrations for Case01_on Am-243

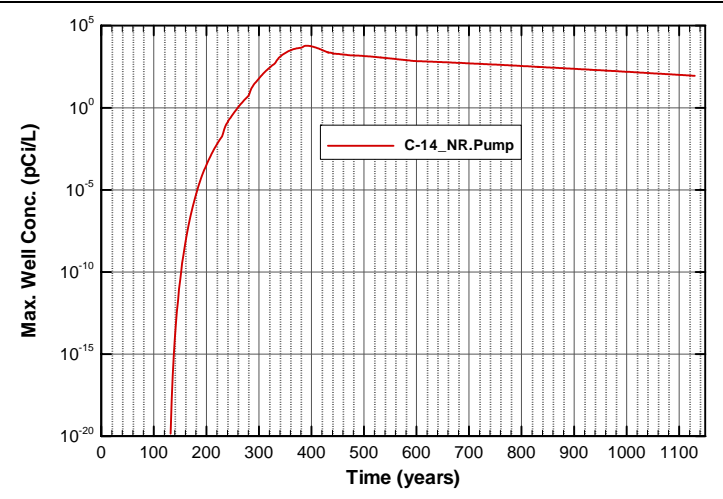

Figure A-1864. Well concentrations for Case01_on C-14_NR.Pump 
SRNL-STI-2008-00397, REVISION 0

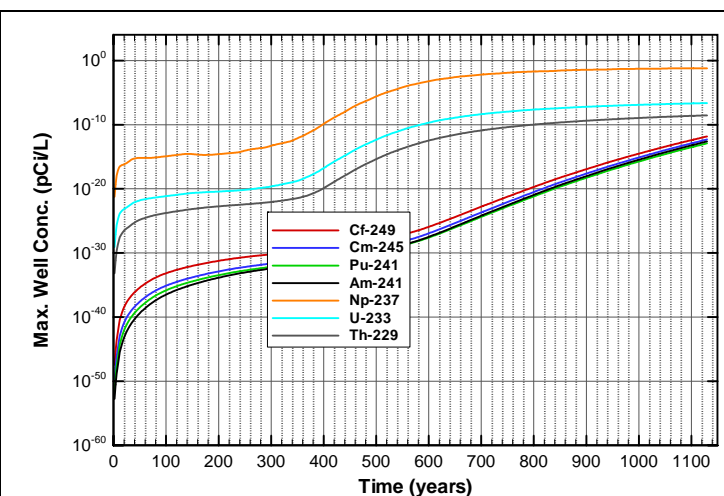

Figure A-1865. Well concentrations for Case01_on Cf-249

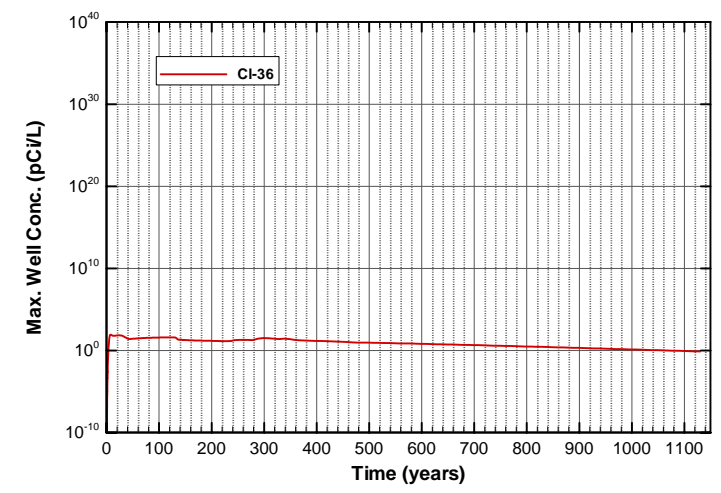

Figure A-1867. Well concentrations for Case01_on Cl-36

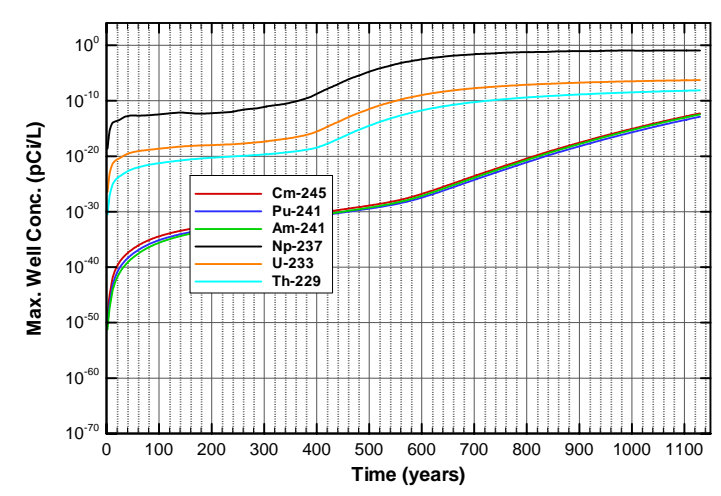

Figure A-1869. Well concentrations for Case01_on Cm-245

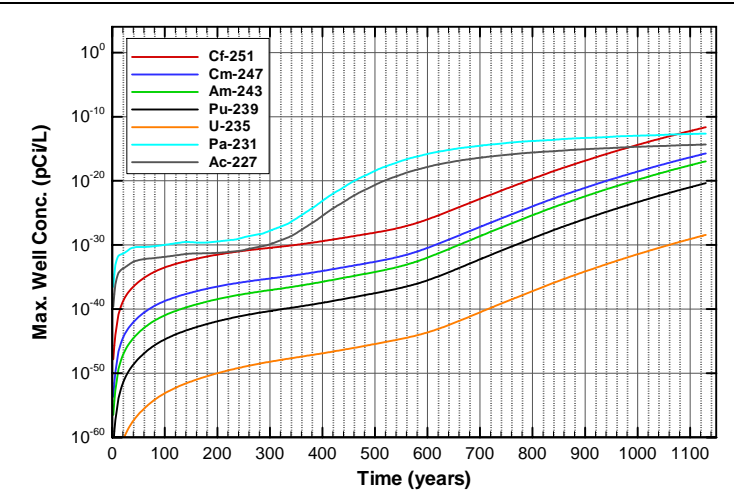

Figure A-1866. Well concentrations for Case01_on Cf-251

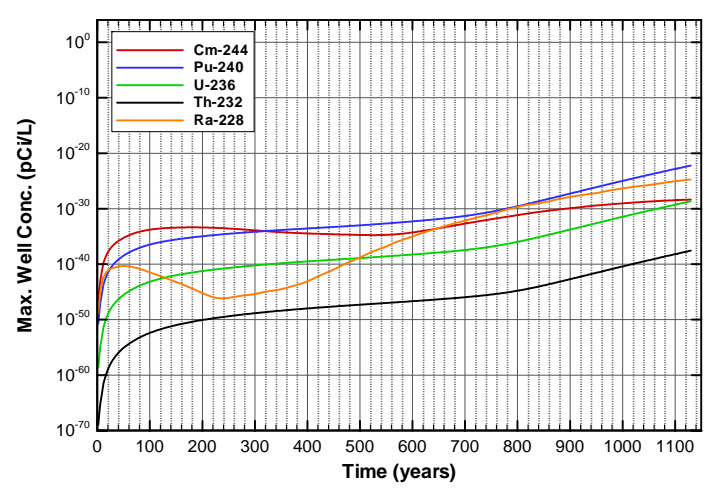

Figure A-1868. Well concentrations for Case01_on Cm-244

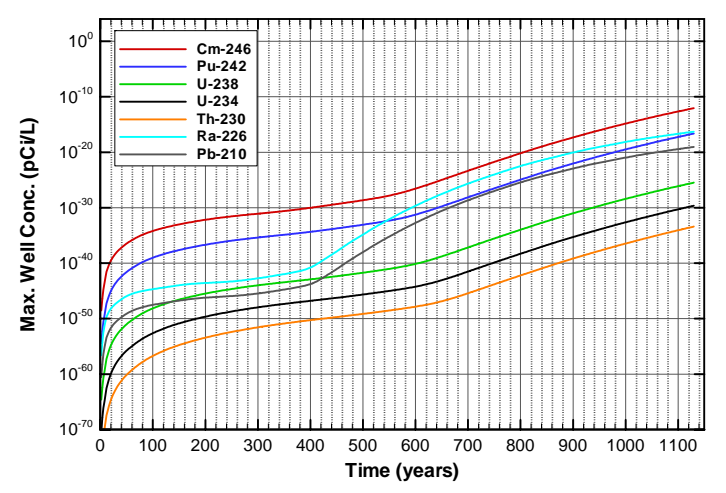

Figure A-1870. Well concentrations for Case01_on Cm-246 
SRNL-STI-2008-00397, REVISION 0

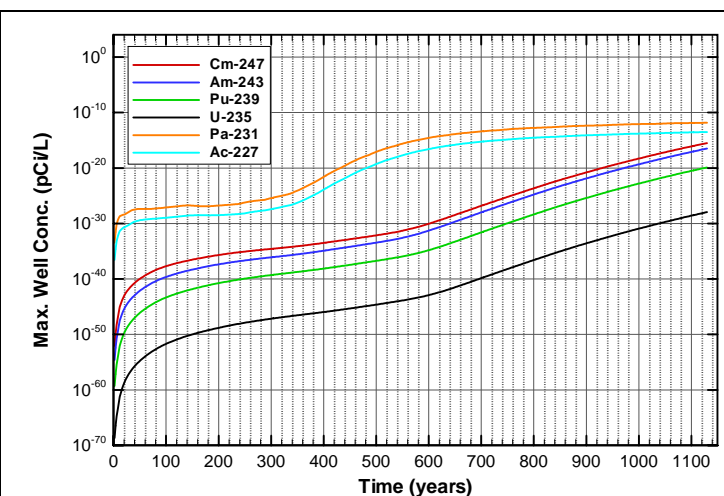

Figure A-1871. Well concentrations for Case01_on Cm-247

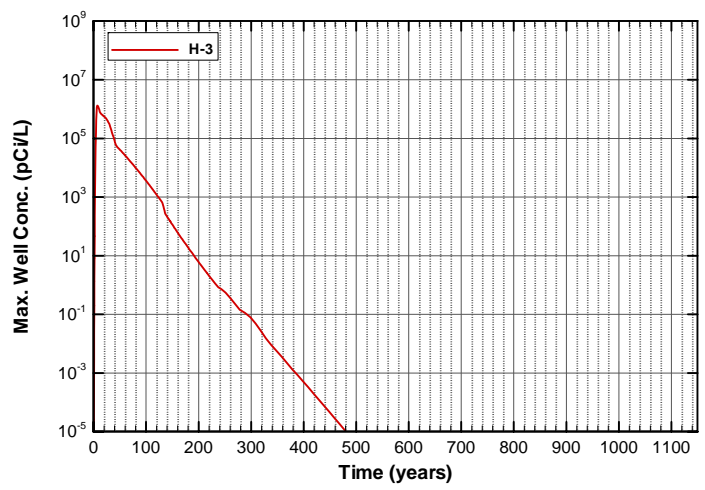

Figure A-1873. Well concentrations for Case01_on H-3

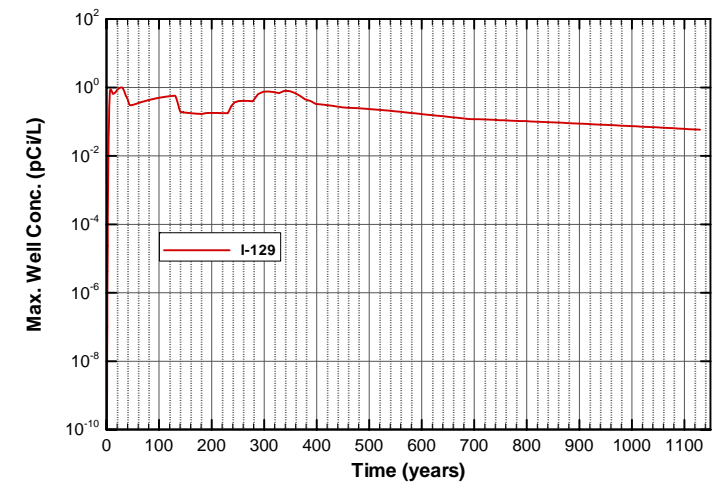

Figure A-1875. Well concentrations for Case01_on I-129

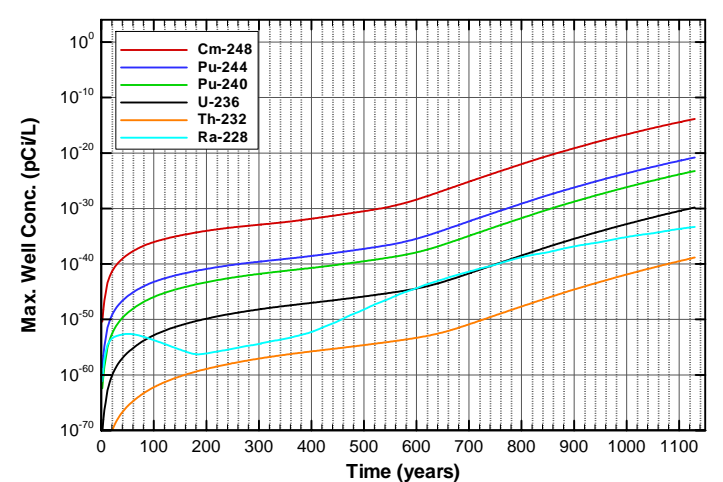

Figure A-1872. Well concentrations for Case01_on Cm-248

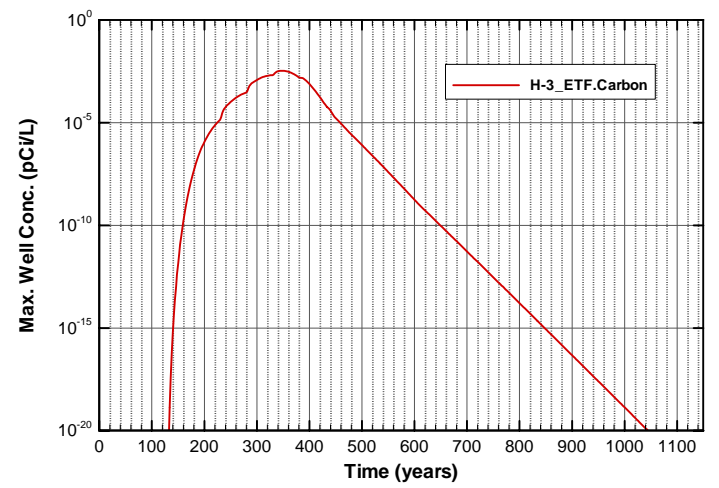

Figure A-1874. Well concentrations for Case01_on H-3_ETF.Carbon

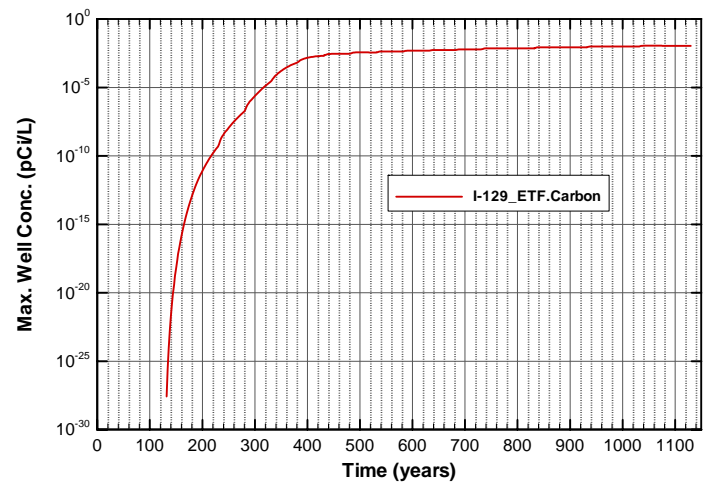

Figure A-1876. Well concentrations for Case01_on I-129_ETF.Carbon 
SRNL-STI-2008-00397, REVISION 0

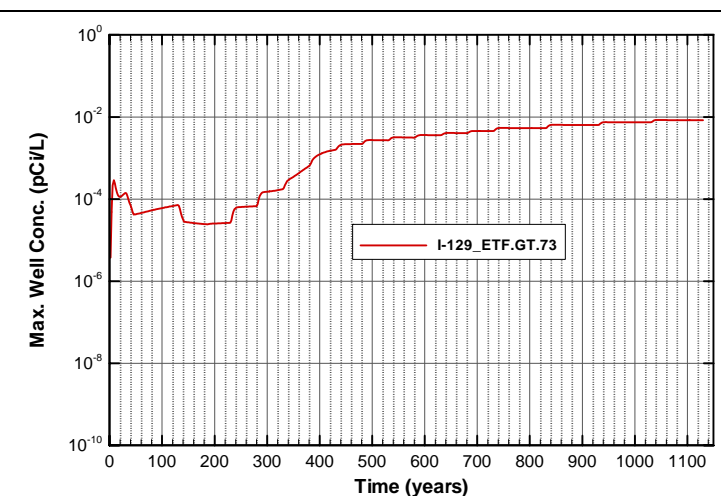

Figure A-1877. Well concentrations for Case01_on I-129_ETF.GT.73

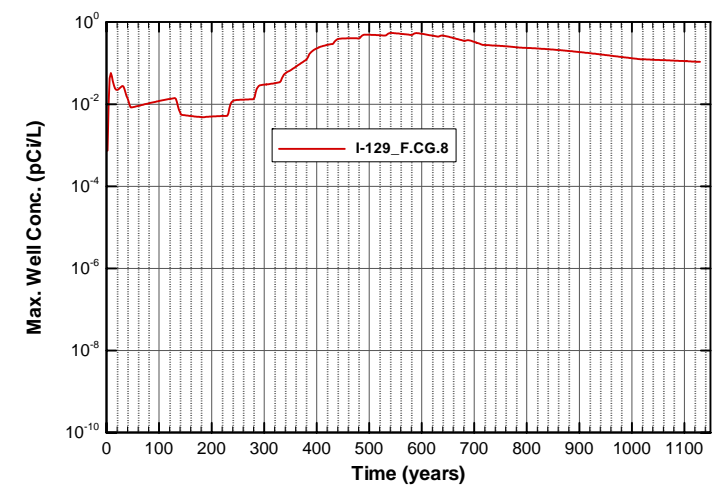

Figure A-1879. Well concentrations for Case01_on I-129_F.CG.8

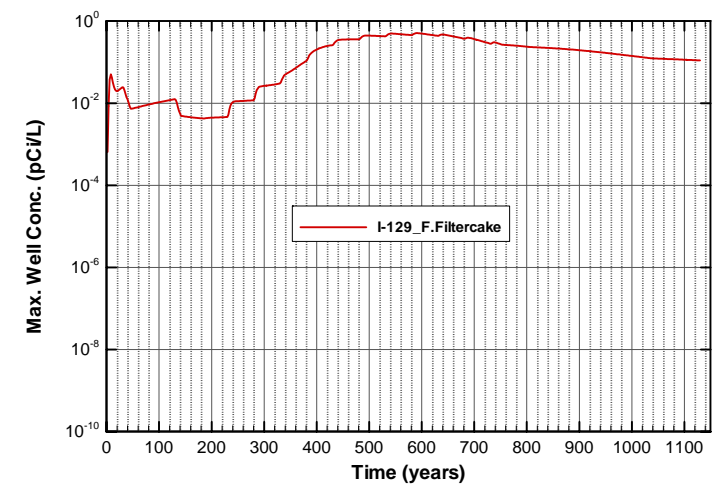

Figure A-1881. Well concentrations for Case01_on I-129_F.Filtercake

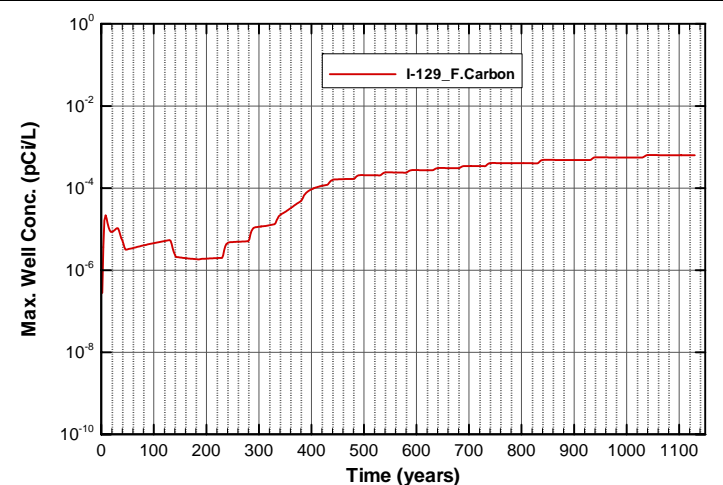

Figure A-1878. Well concentrations for Case01_on I-129_F.Carbon

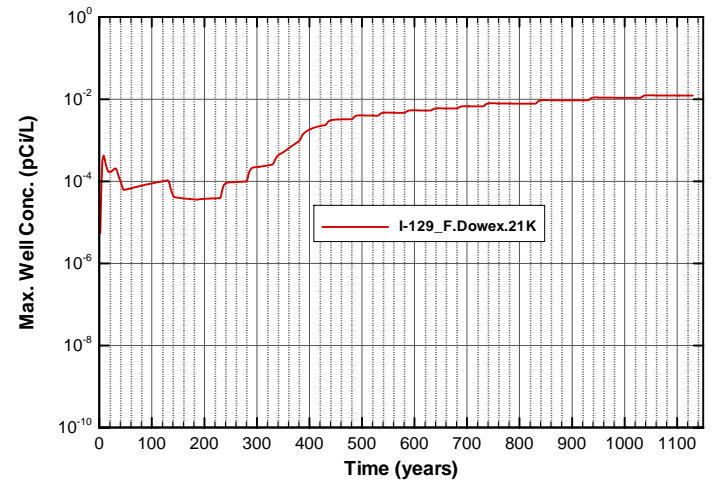

Figure A-1880. Well concentrations for Case01_on I-129_F.Dowex.21K

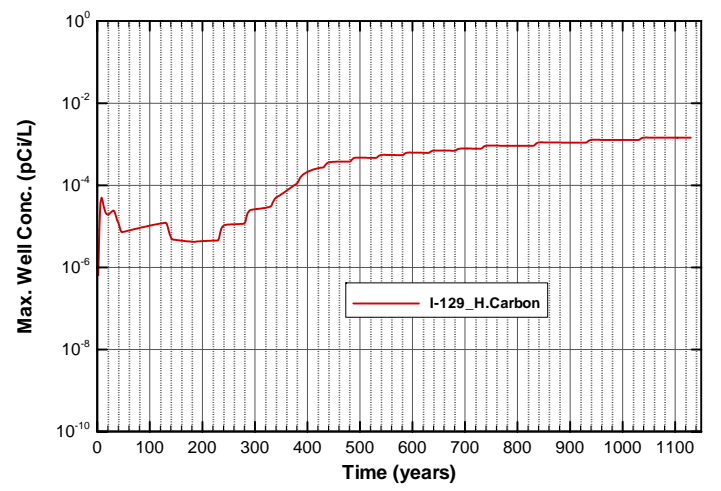

Figure A-1882. Well concentrations for Case01_on I-129_H.Carbon 
SRNL-STI-2008-00397, REVISION 0

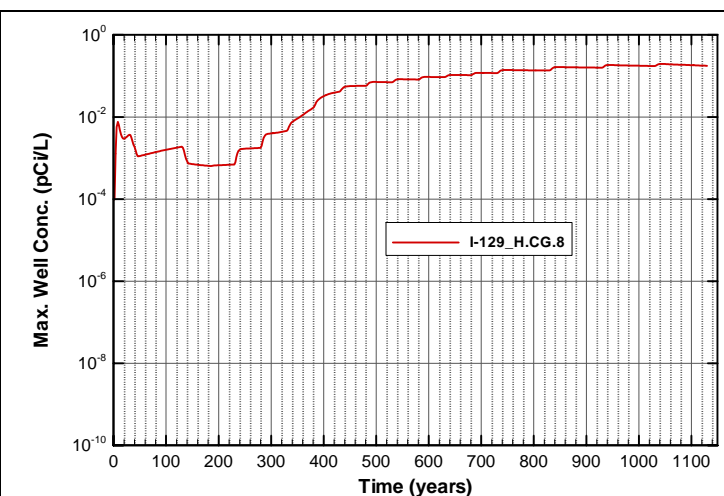

Figure A-1883. Well concentrations for Case01_on I-129_H.CG.8

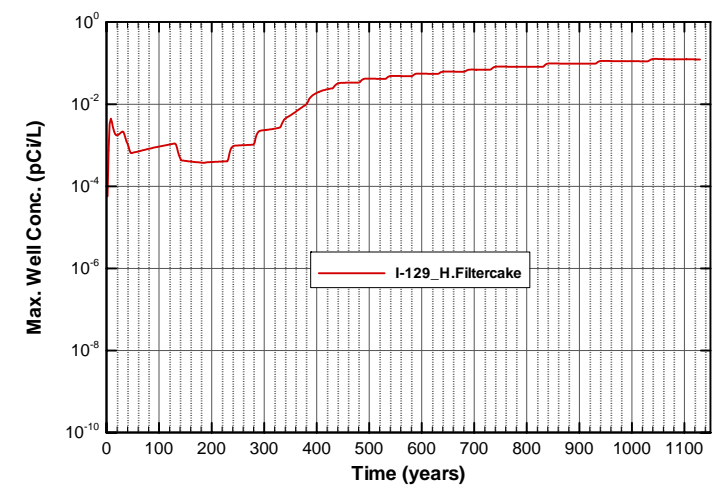

Figure A-1885. Well concentrations for Case01_on I-129_H.Filtercake

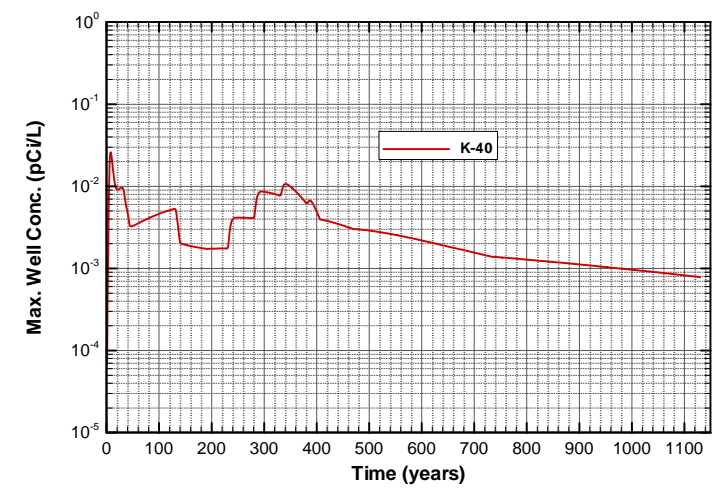

Figure A-1887. Well concentrations for Case01_on K-40

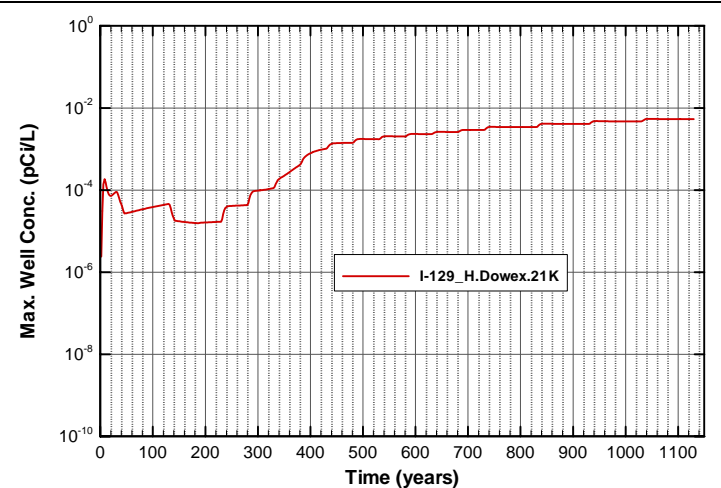

Figure A-1884. Well concentrations for Case01_on I-129_H.Dowex.21K

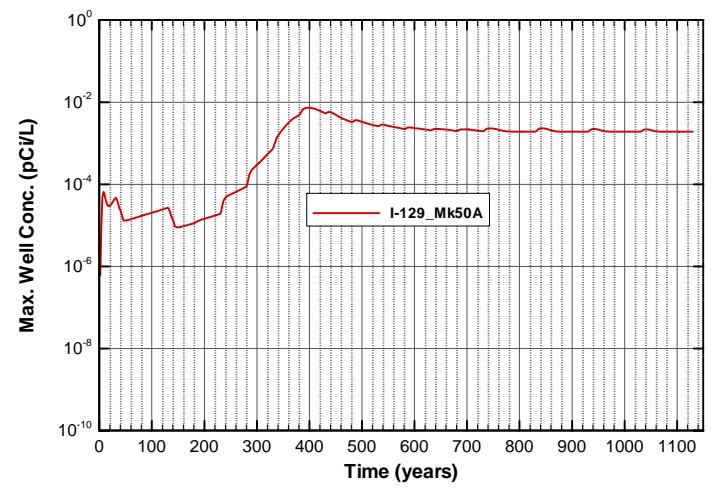

Figure A-1886. Well concentrations for Case01_on I-129_Mk50A

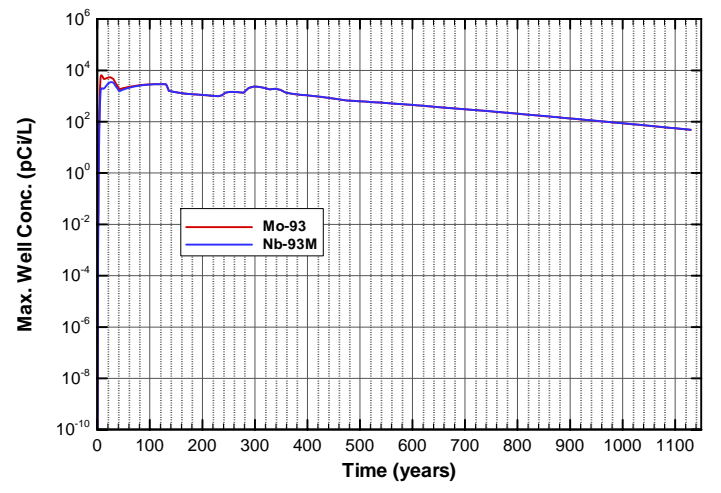

Figure A-1888. Well concentrations for Case01_on Mo-93 
SRNL-STI-2008-00397, REVISION 0

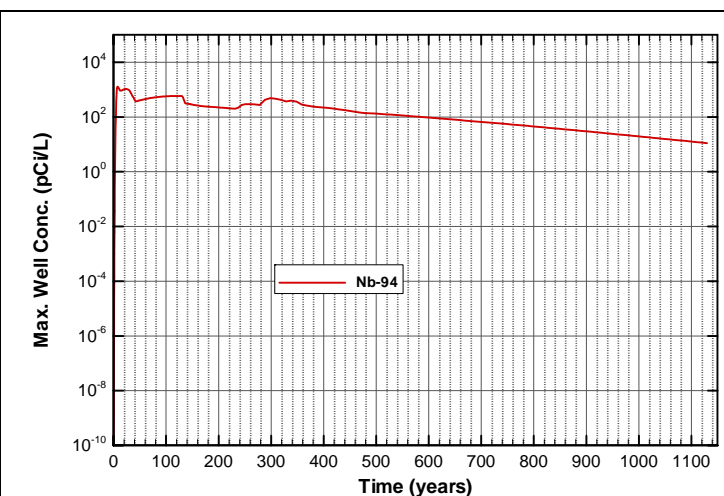

Figure A-1889. Well concentrations for Case01_on Nb-94

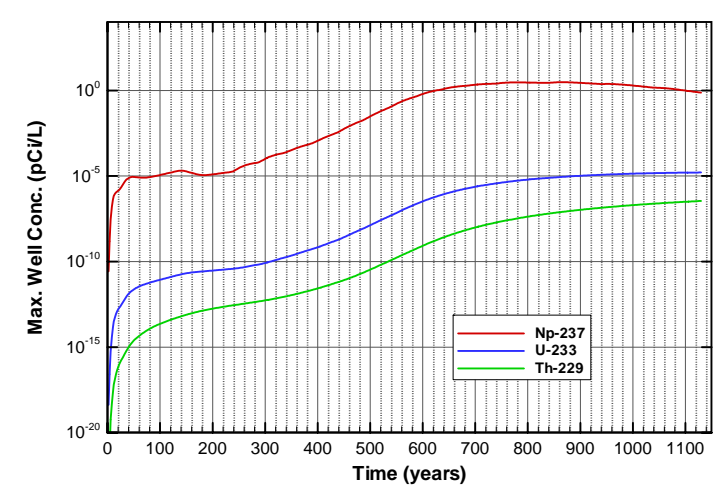

Figure A-1891. Well concentrations for Case01_on Np-237

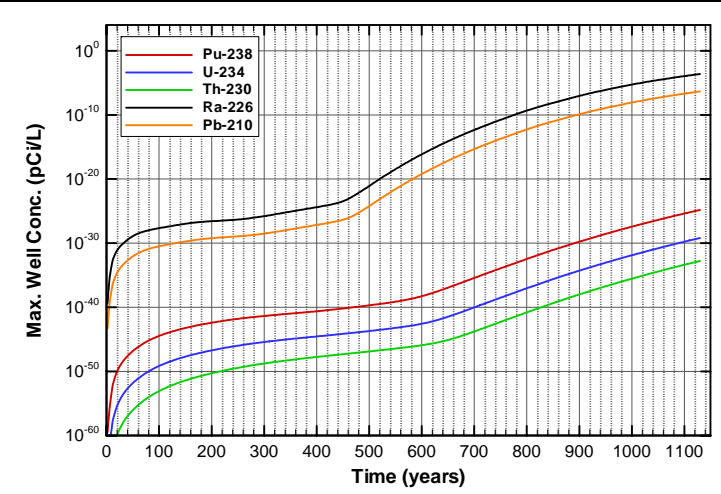

Figure A-1893. Well concentrations for Case01_on Pu-238

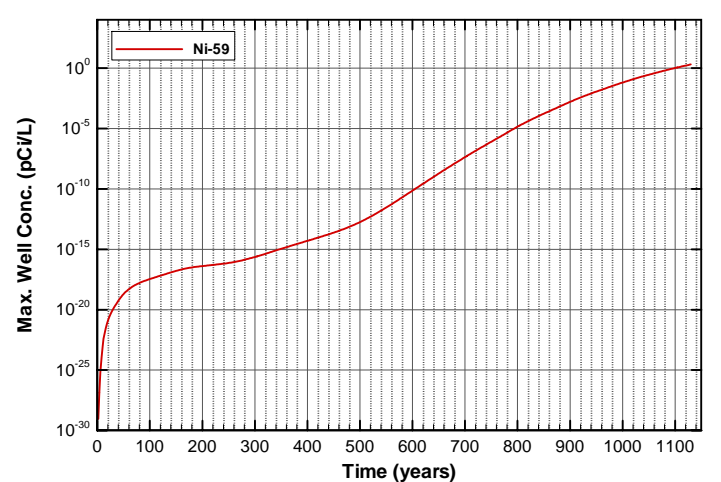

Figure A-1890. Well concentrations for Case01_on Ni-59

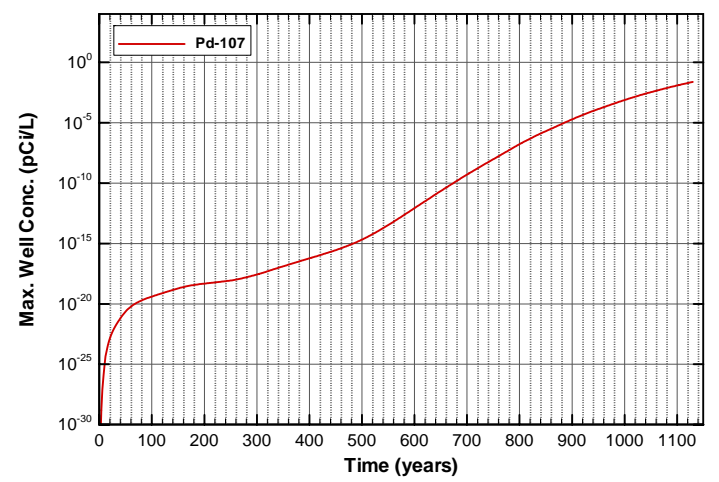

Figure A-1892. Well concentrations for Case01_on Pd-107

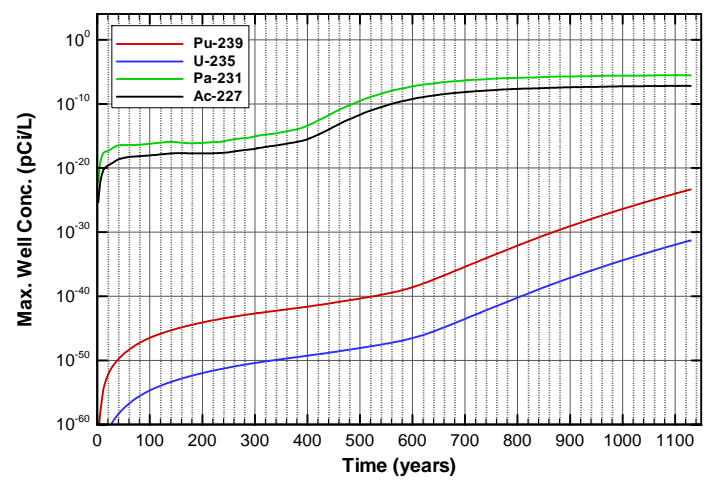

Figure A-1894. Well concentrations for Case01_on Pu-239 
SRNL-STI-2008-00397, REVISION 0

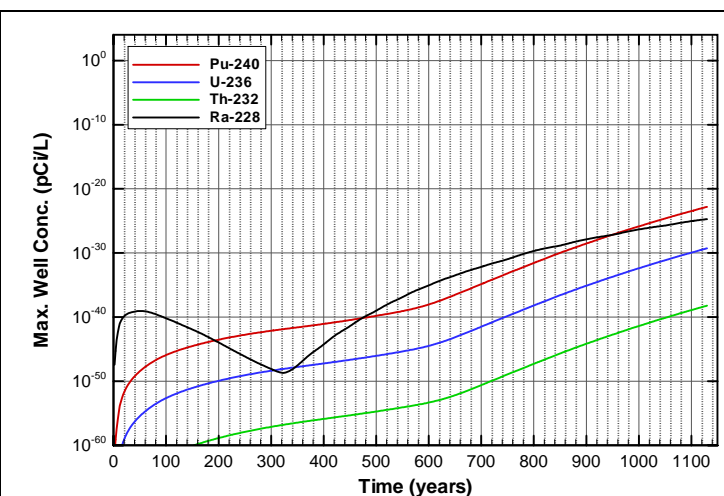

Figure A-1895. Well concentrations for Case01_on Pu-240

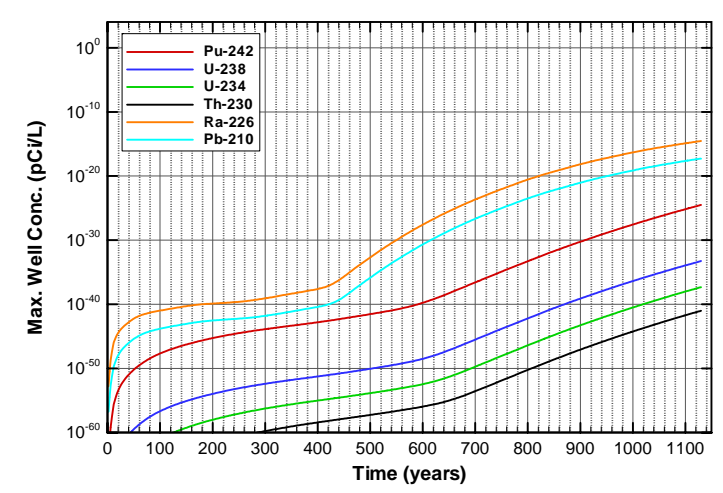

Figure A-1897. Well concentrations for Case01_on Pu-242

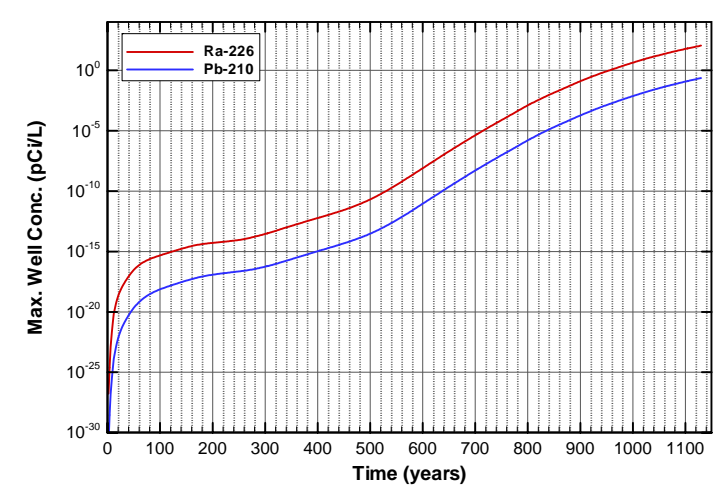

Figure A-1899. Well concentrations for Case01_on Ra-226

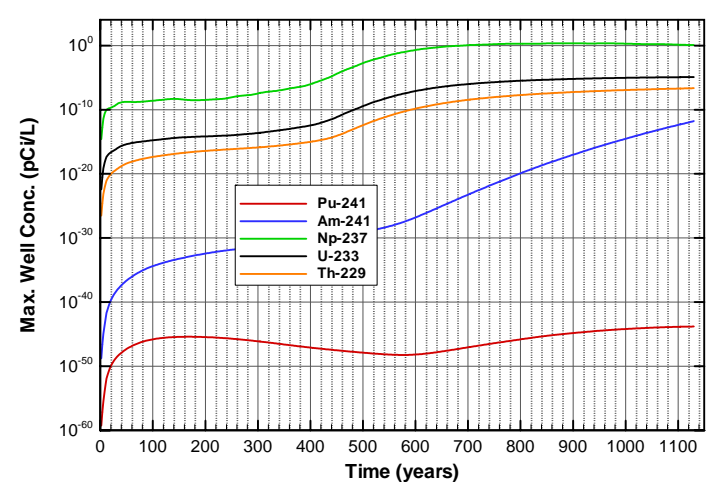

Figure A-1896. Well concentrations for Case01_on Pu-241

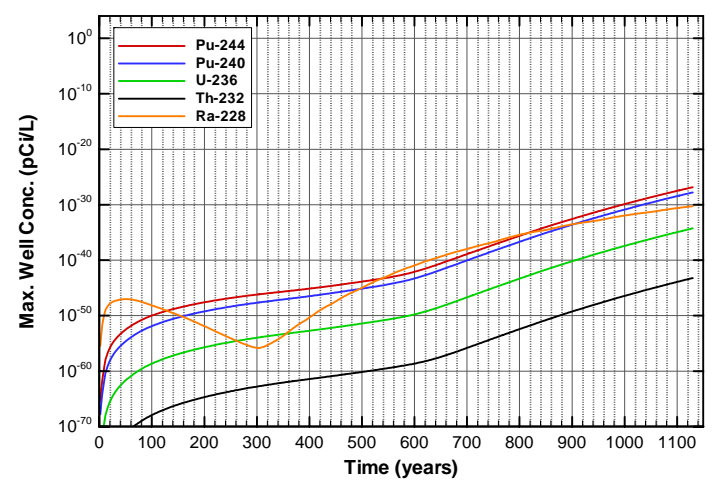

Figure A-1898. Well concentrations for Case01_on Pu-244

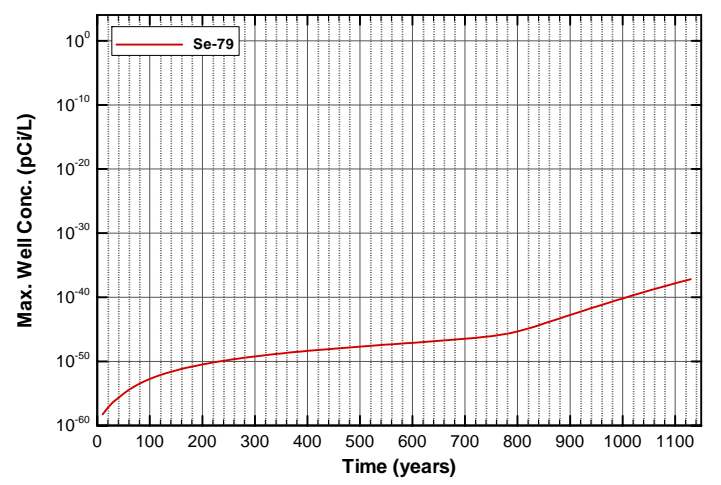

Figure A-1900. Well concentrations for Case01_on Se-79 
SRNL-STI-2008-00397, REVISION 0

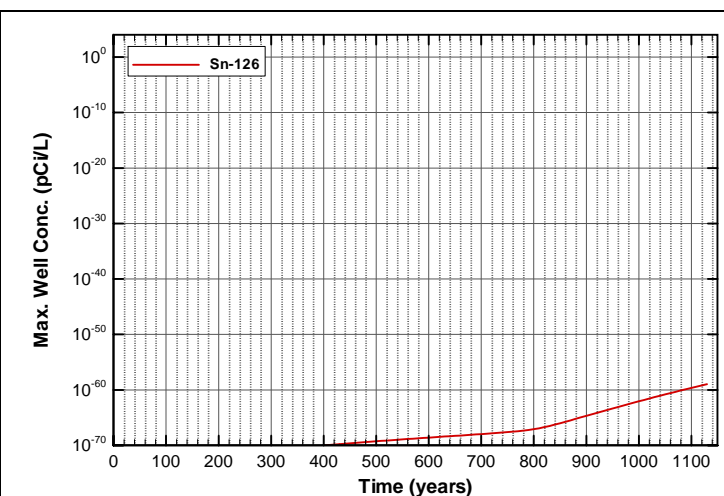

Figure A-1901. Well concentrations for Case01_on Sn-126

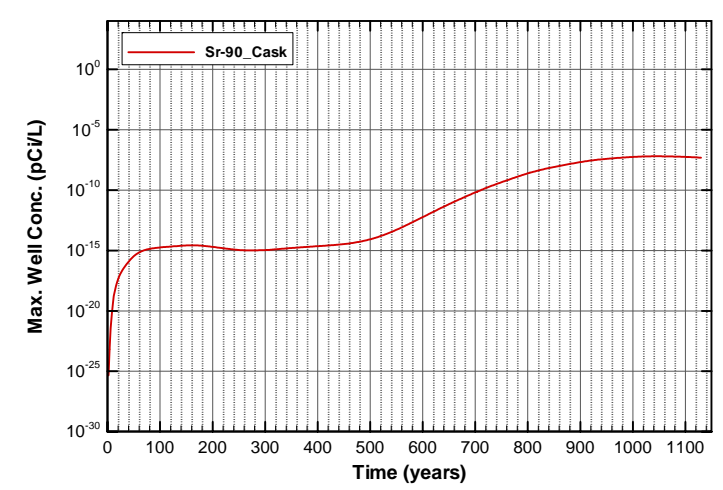

Figure A-1903. Well concentrations for Case01_on Sr-90_Cask

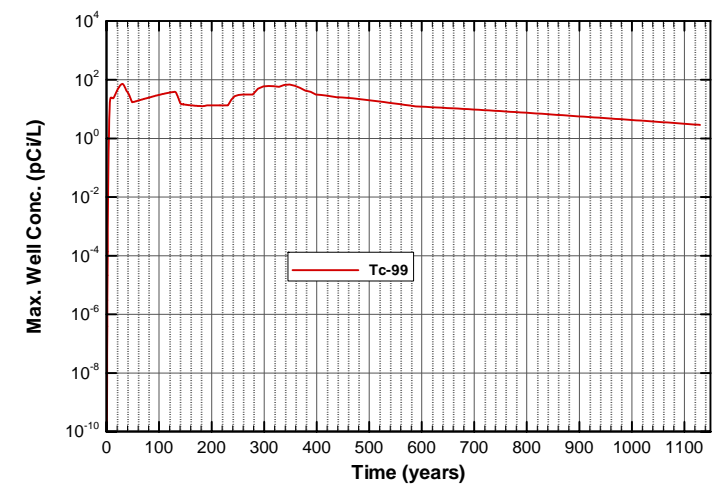

Figure A-1905. Well concentrations for Case01_on Tc-99

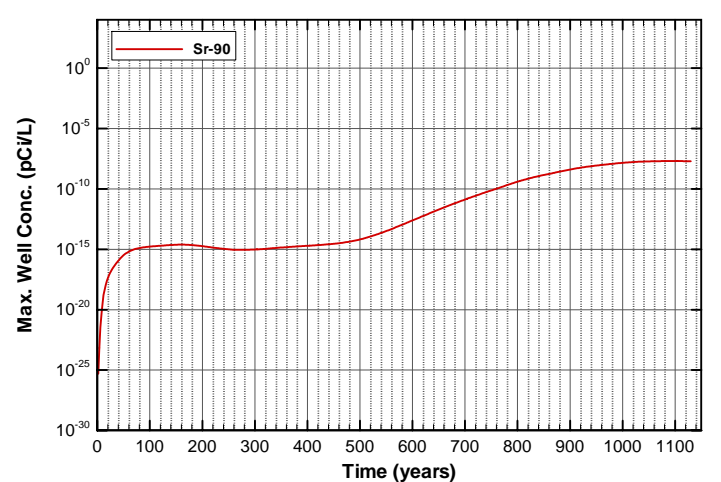

Figure A-1902. Well concentrations for Case01_on Sr-90

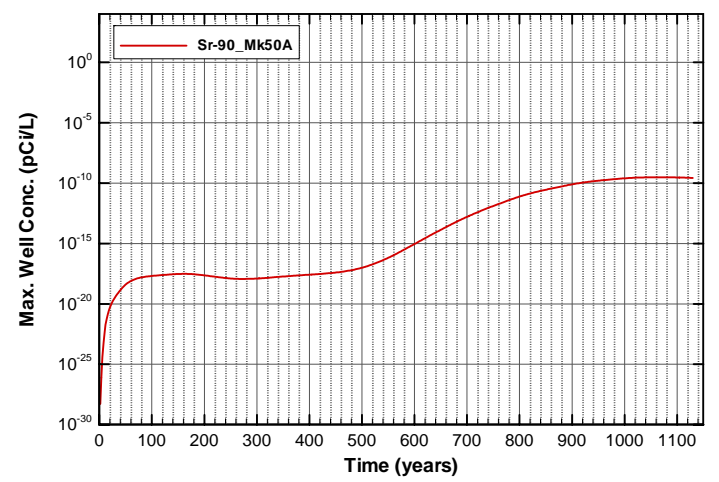

Figure A-1904. Well concentrations for Case01_on Sr-90_Mk50A

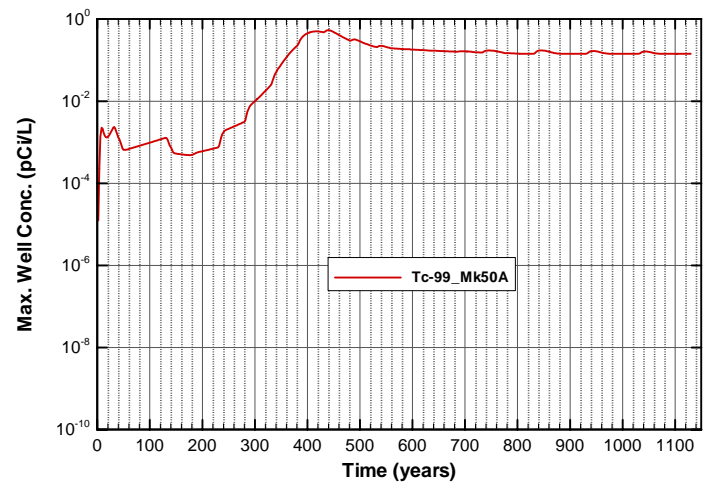

Figure A-1906. Well concentrations for Case01_on Tc-99_Mk50A 


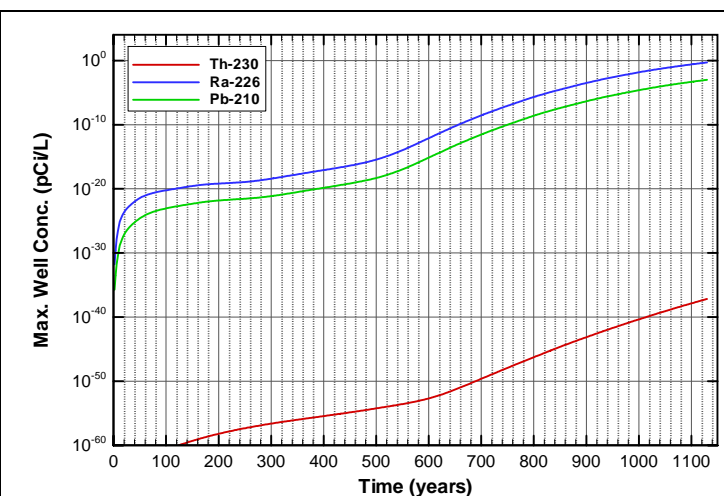

Figure A-1907. Well concentrations for Case01_on Th-230

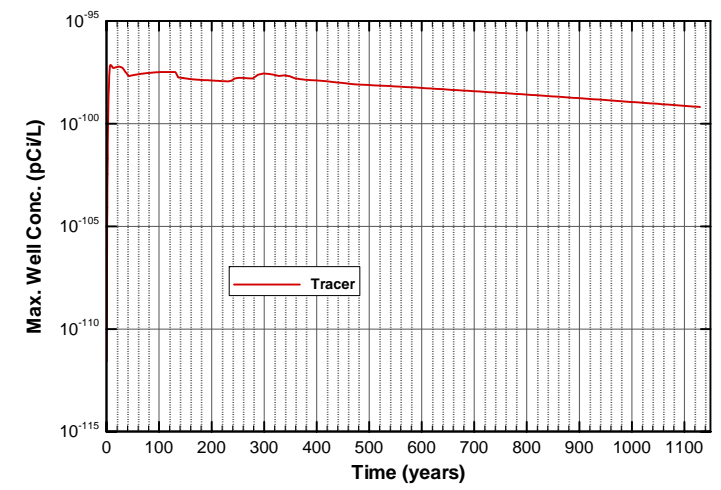

Figure A-1909. Well concentrations for Case01_on Tracer

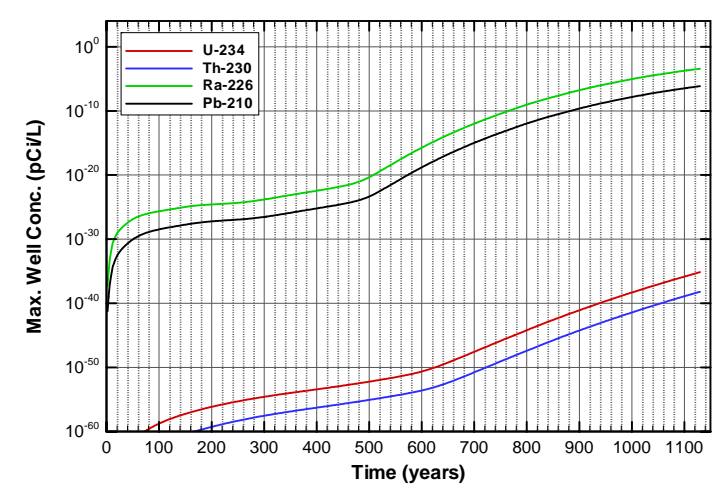

Figure A-1911. Well concentrations for Case01_on U-234

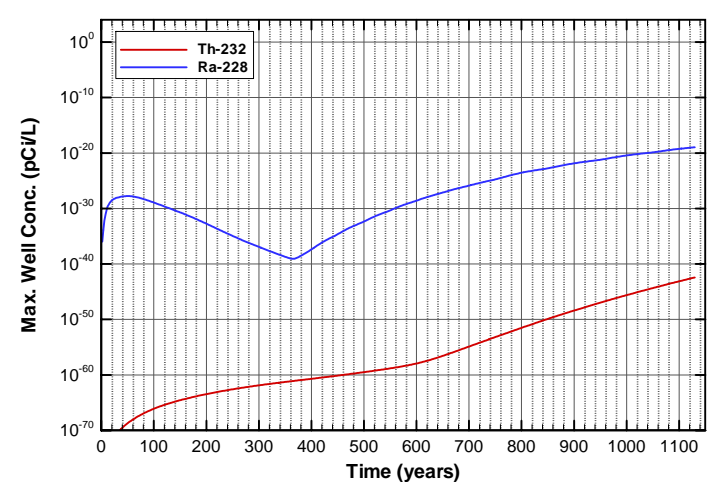

Figure A-1908. Well concentrations for Case01_on Th-232

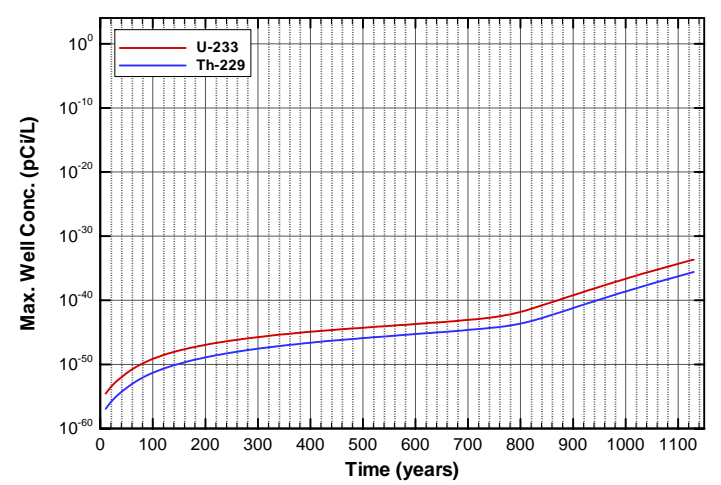

Figure A-1910. Well concentrations for Case01_on U-233

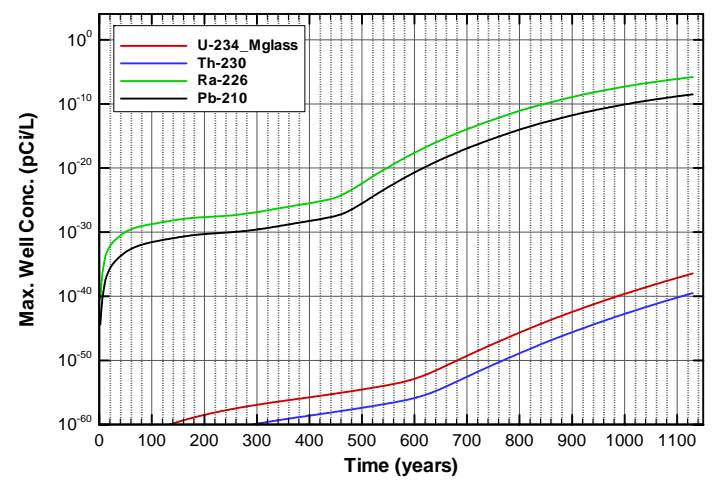

Figure A-1912. Well concentrations for Case01_on U-234_Mglass 


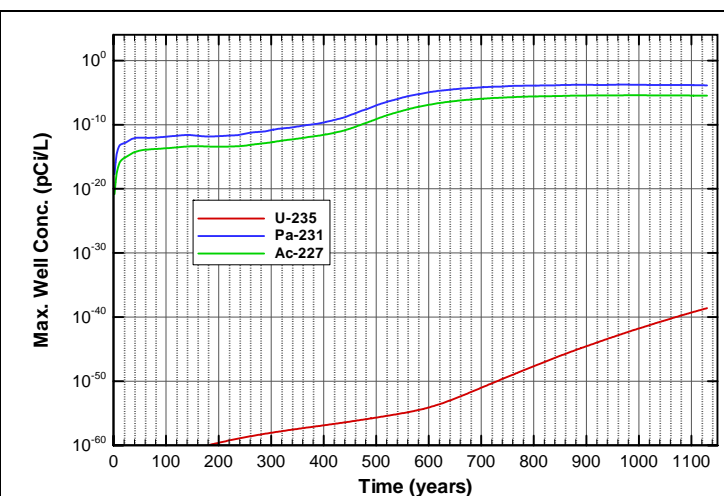

Figure A-1913. Well concentrations for Case01_on U-235

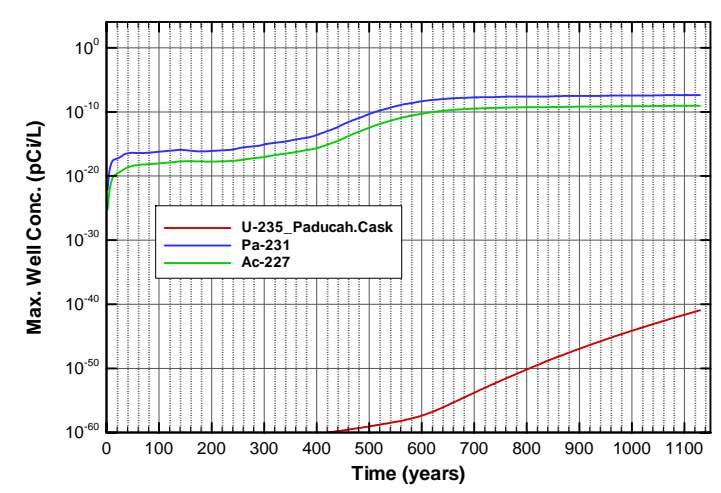

Figure A-1915. Well concentrations for Case01_on U-235_Paducah.Cask

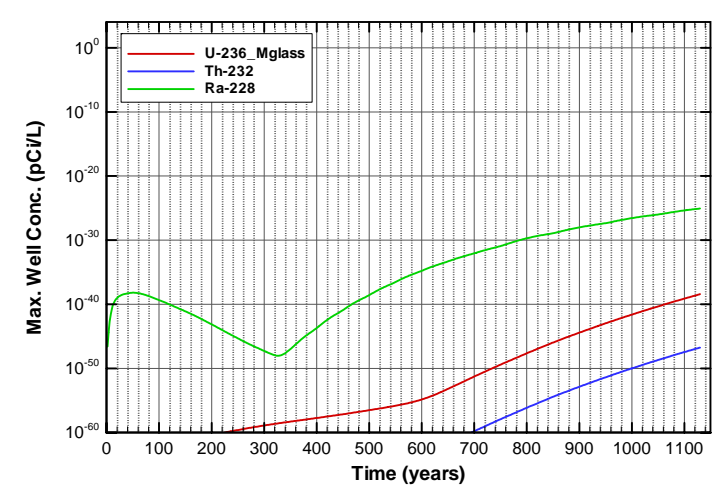

Figure A-1917. Well concentrations for Case01_on U-236_Mglass

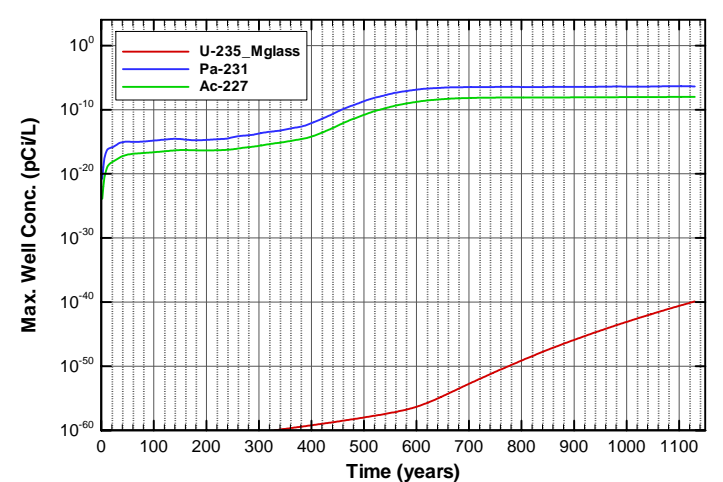

Figure A-1914. Well concentrations for Case01_on U-235_Mglass

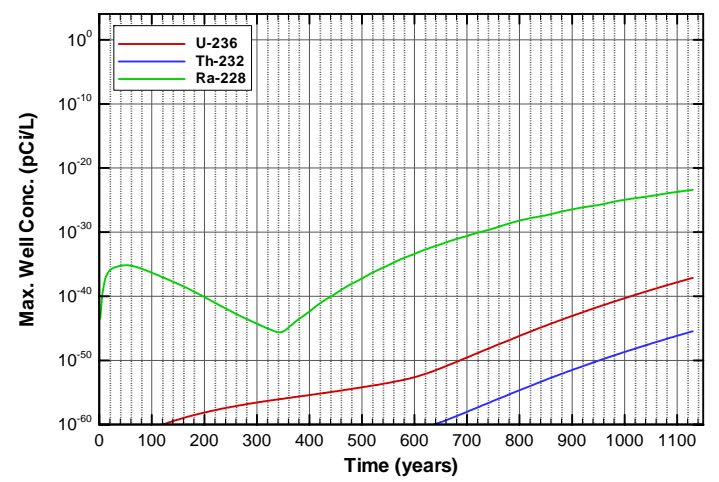

Figure A-1916. Well concentrations for Case01_on U-236

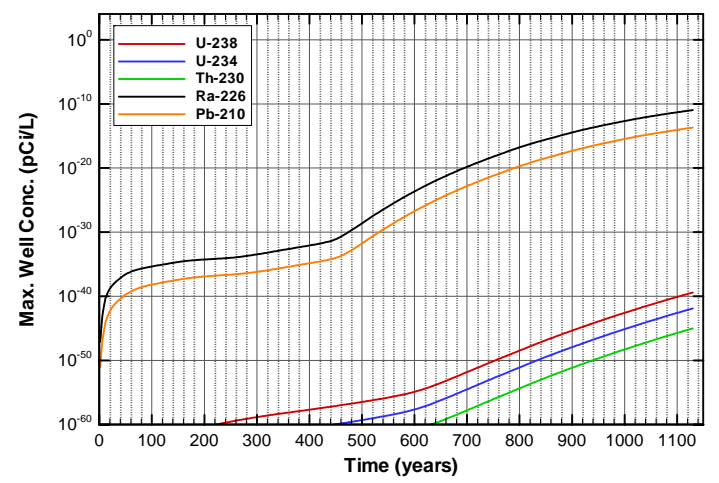

Figure A-1918. Well concentrations for Case01_on U-238 


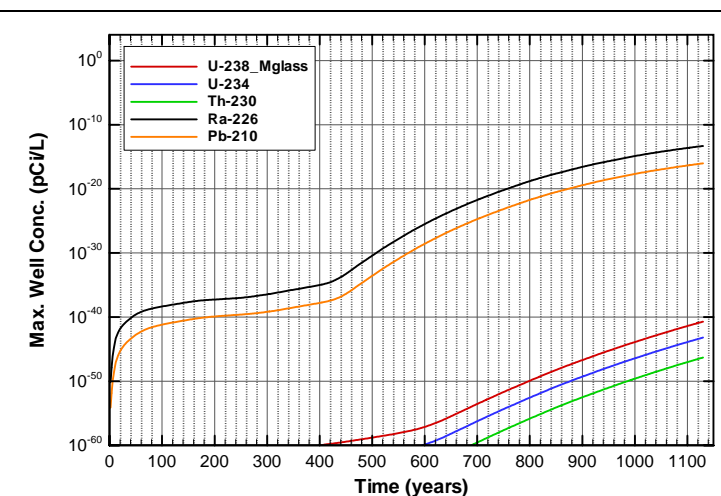

Figure A-1919. Well concentrations for Case01_on U-238_Mglass

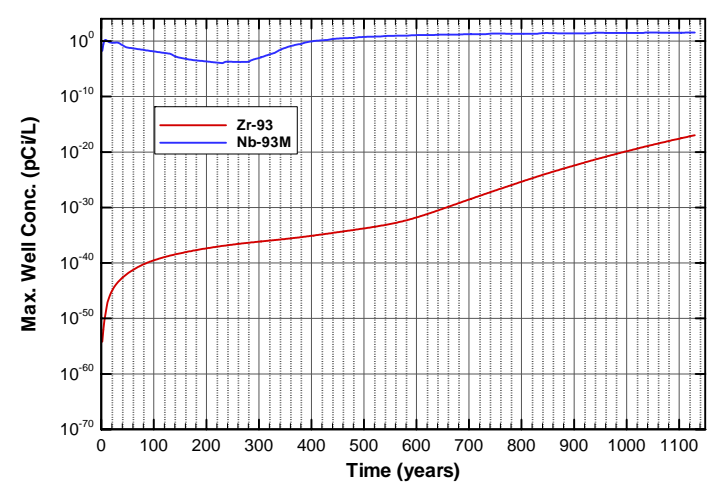

Figure A-1920. Well concentrations for Case01_on Zr-93

1.2.3 Concentration plots for 10-year cover

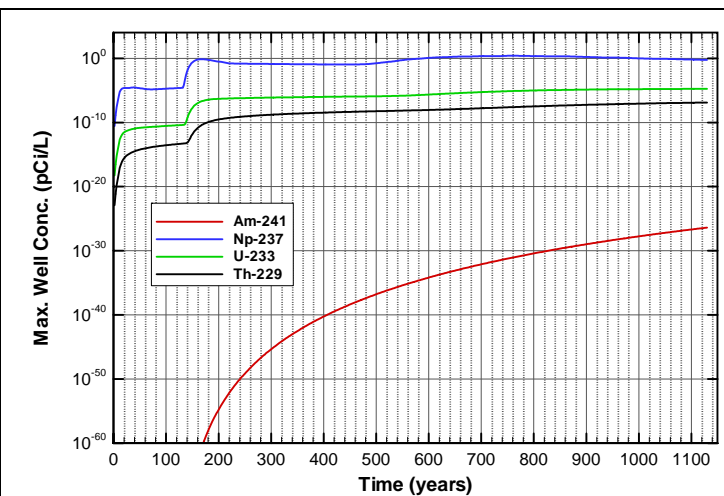

Figure A-1921. Well concentrations for Case01n11_off Am-241

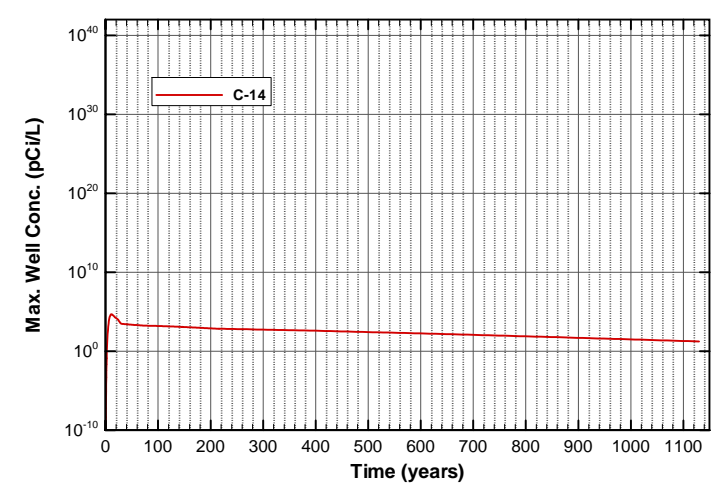

Figure A-1923. Well concentrations for Case01n11_off C-14

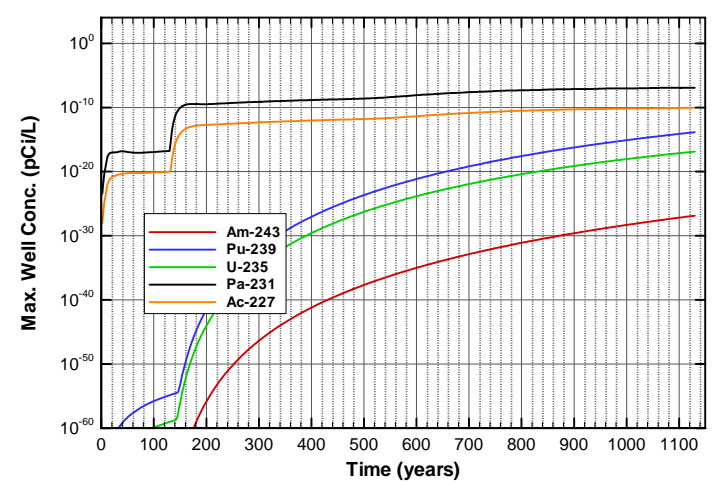

Figure A-1922. Well concentrations for Case01n11_off Am-243

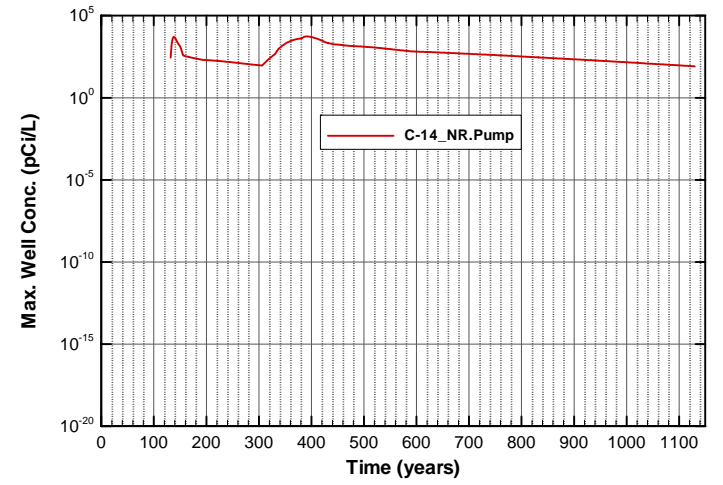

Figure A-1924. Well concentrations for Case01n11_off C-14_NR.Pump 
SRNL-STI-2008-00397, REVISION 0

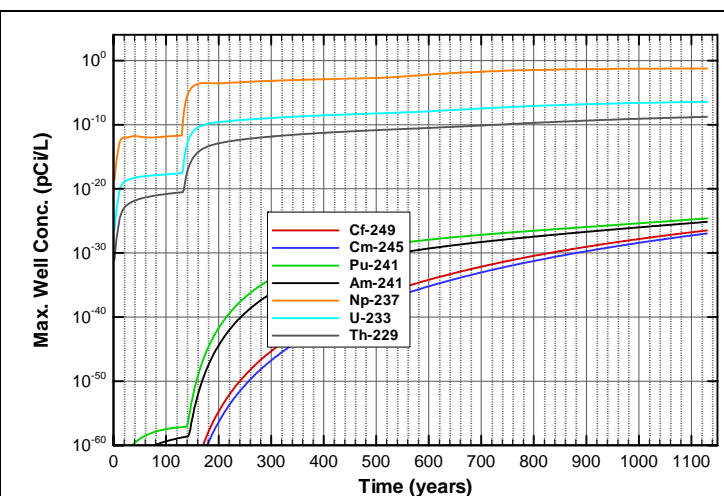

Figure A-1925. Well concentrations for Case01n11_off Cf-249

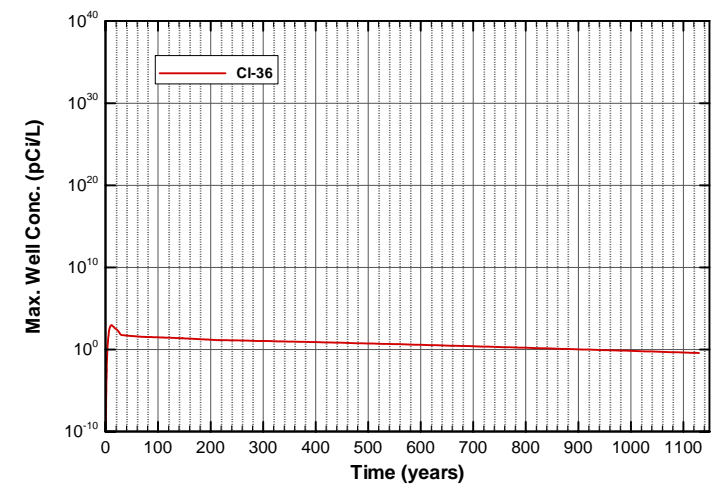

Figure A-1927. Well concentrations for Case01n11_off Cl-36

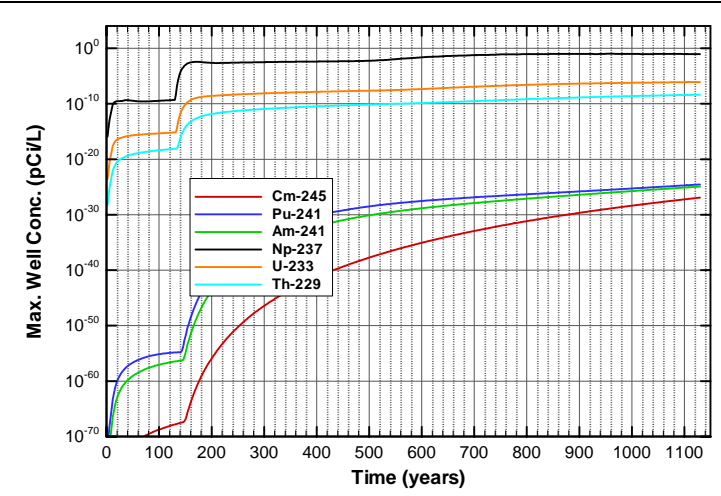

Figure A-1929. Well concentrations for Case01n11_off Cm-245

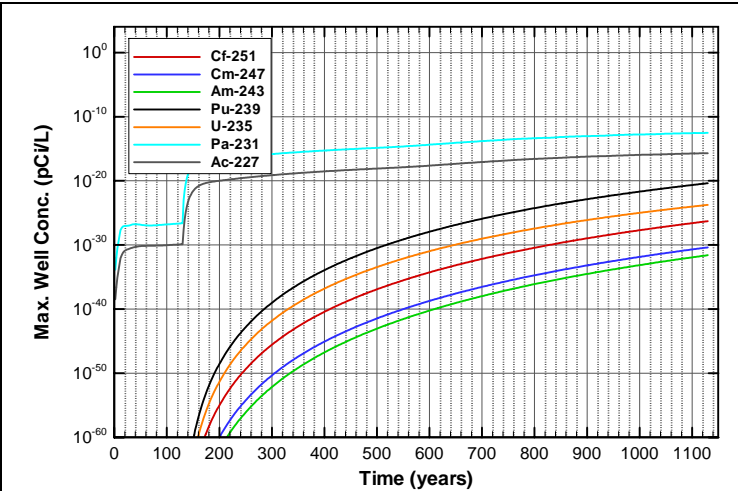

Figure A-1926. Well concentrations for Case01n11_off Cf-251

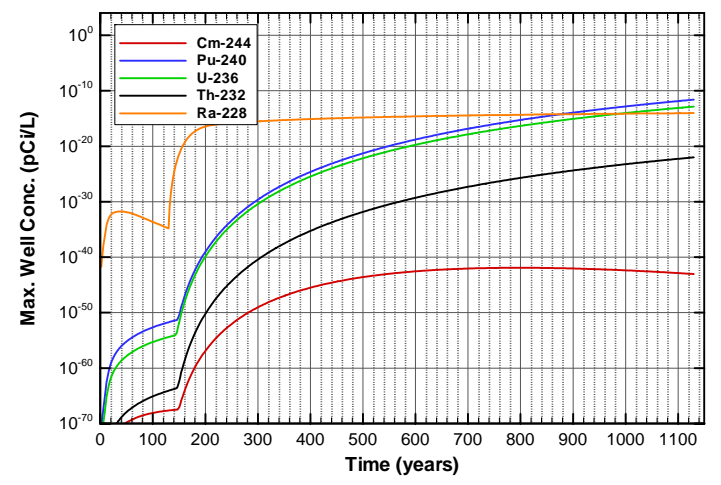

Figure A-1928. Well concentrations for Case01n11_off Cm-244

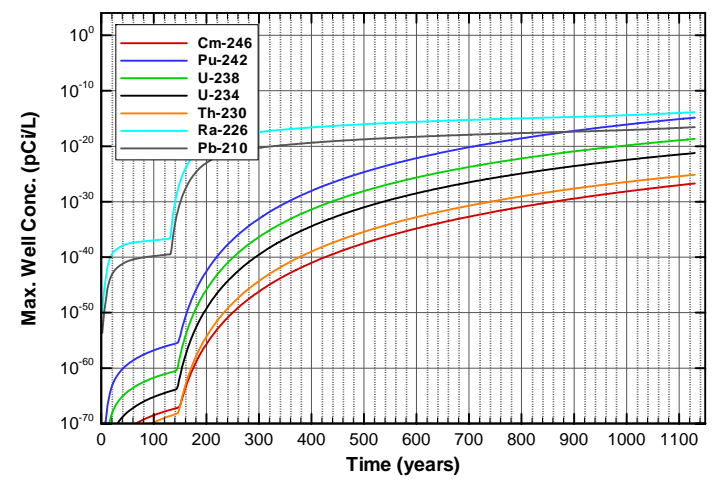

Figure A-1930. Well concentrations for Case01n11_off Cm-246 
SRNL-STI-2008-00397, REVISION 0

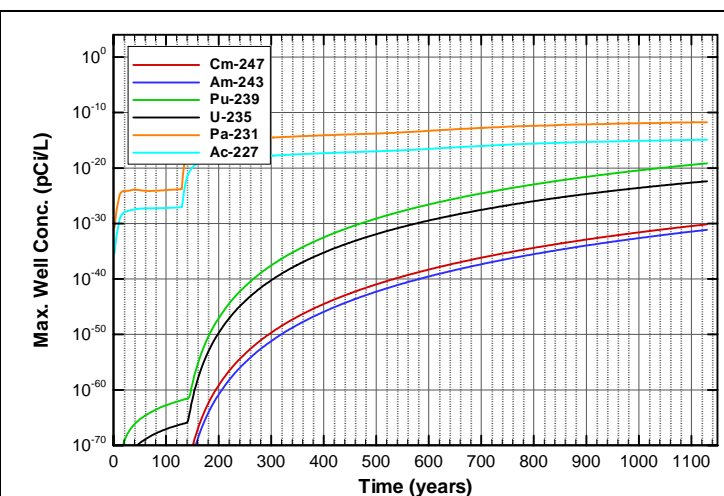

Figure A-1931. Well concentrations for Case01n11_off Cm-247

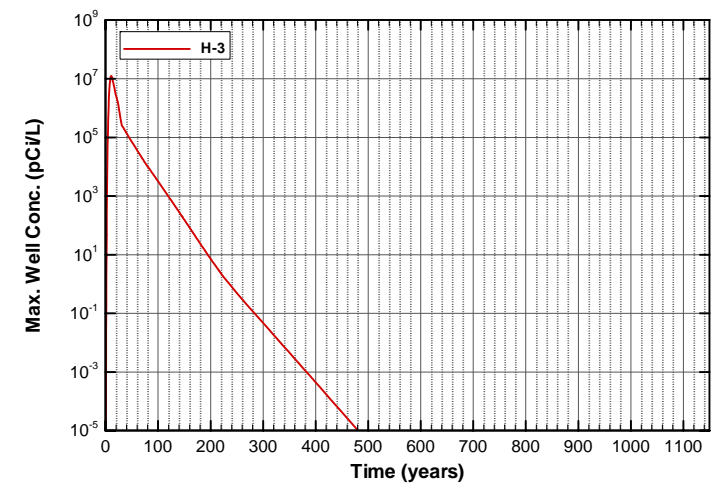

Figure A-1933. Well concentrations for Case01n11_off H-3

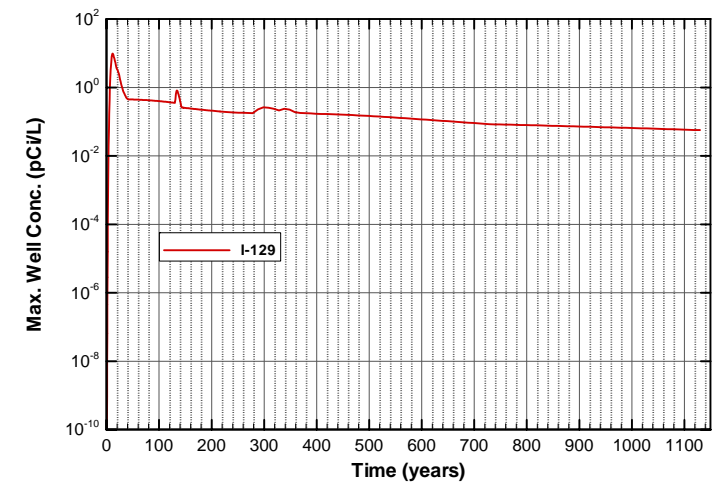

Figure A-1935. Well concentrations for Case01n11_off I-129

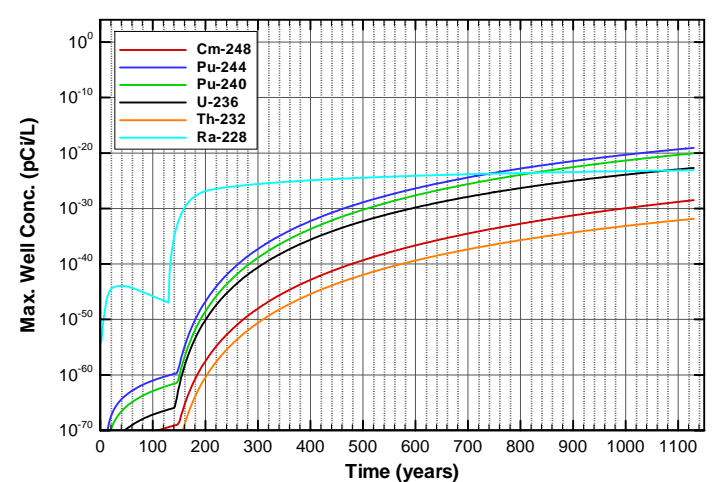

Figure A-1932. Well concentrations for Case01n11_off Cm-248

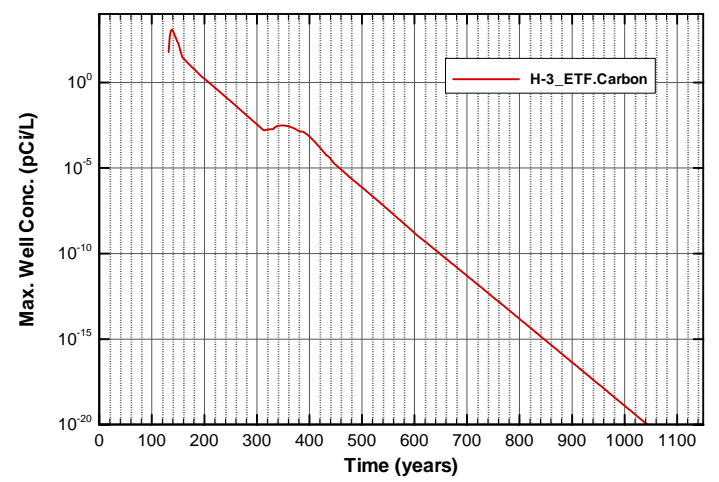

Figure A-1934. Well concentrations for Case01n11_off H-3_ETF.Carbon

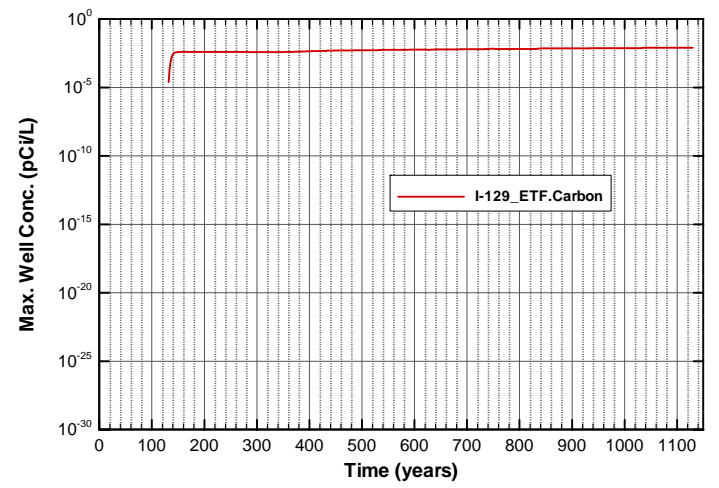

Figure A-1936. Well concentrations for Case01n11_off I-129_ETF.Carbon 
SRNL-STI-2008-00397, REVISION 0

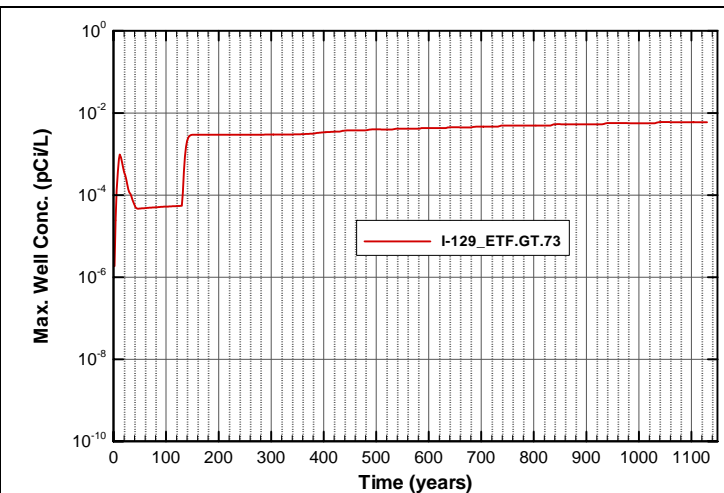

Figure A-1937. Well concentrations for Case01n11_off I-129_ETF.GT.73

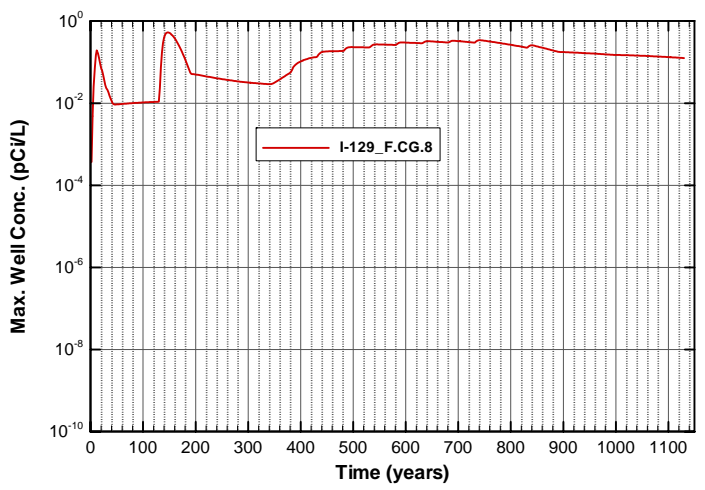

Figure A-1939. Well concentrations for Case01n11_off I-129_F.CG.8

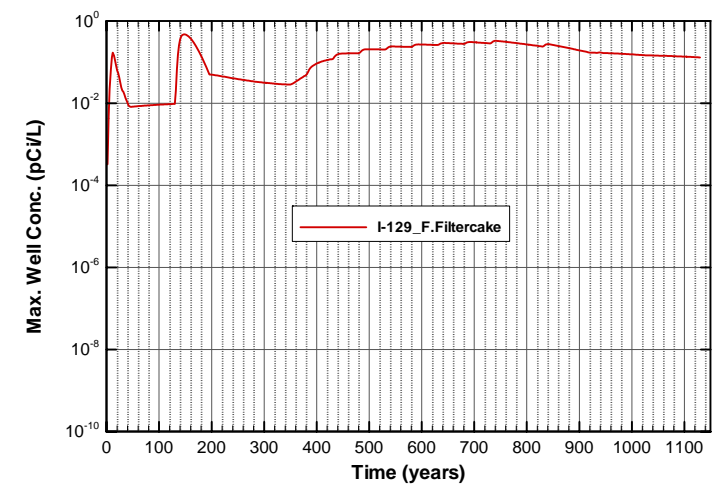

Figure A-1941. Well concentrations for Case01n11_off I-129_F.Filtercake

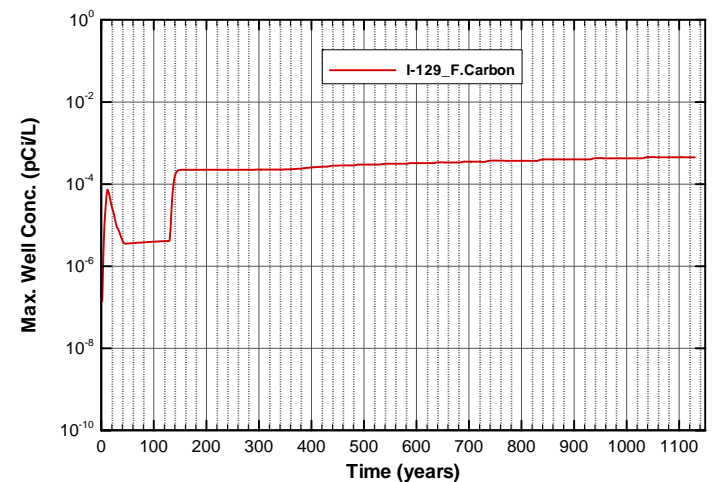

Figure A-1938. Well concentrations for Case01n11_off I-129_F.Carbon

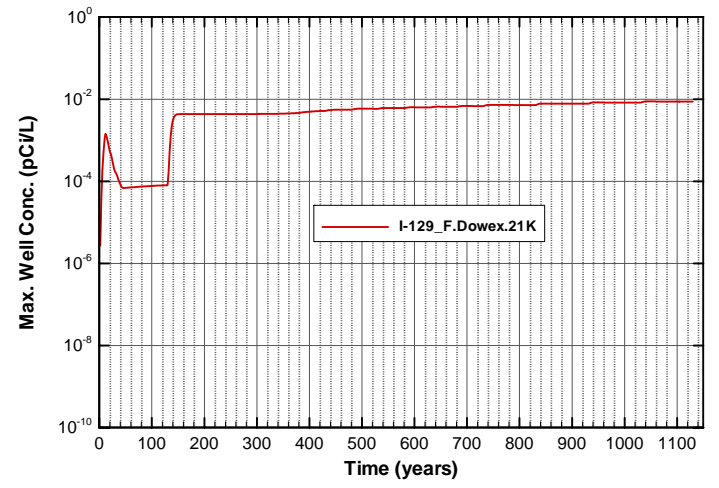

Figure A-1940. Well concentrations for Case01n11_off I-129_F.Dowex.21K

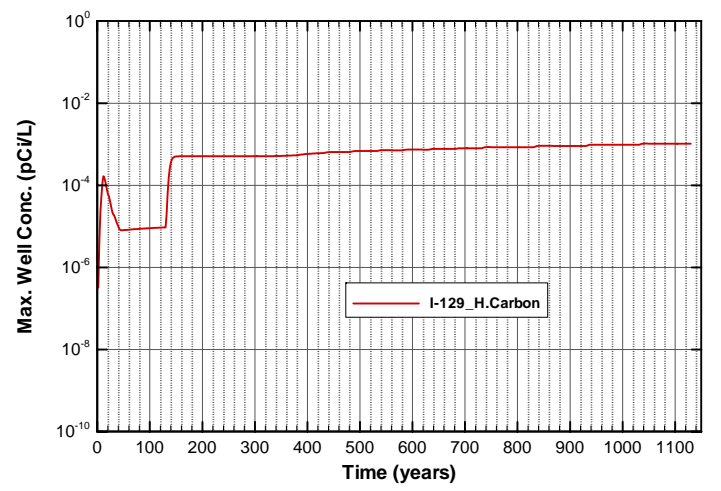

Figure A-1942. Well concentrations for Case01n11_off I-129_H.Carbon 
SRNL-STI-2008-00397, REVISION 0

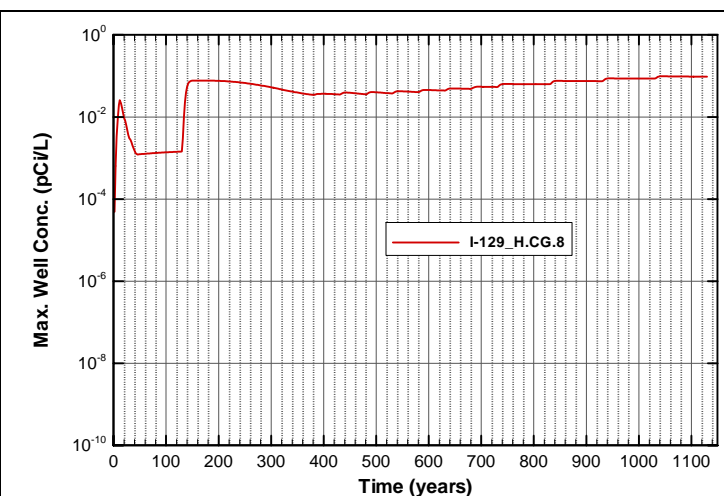

Figure A-1943. Well concentrations for Case01n11_off I-129_H.CG.8

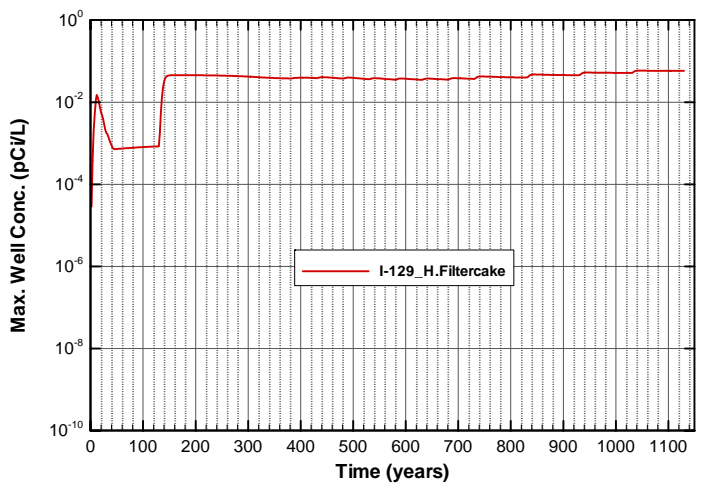

Figure A-1945. Well concentrations for Case01n11_off I-129_H.Filtercake

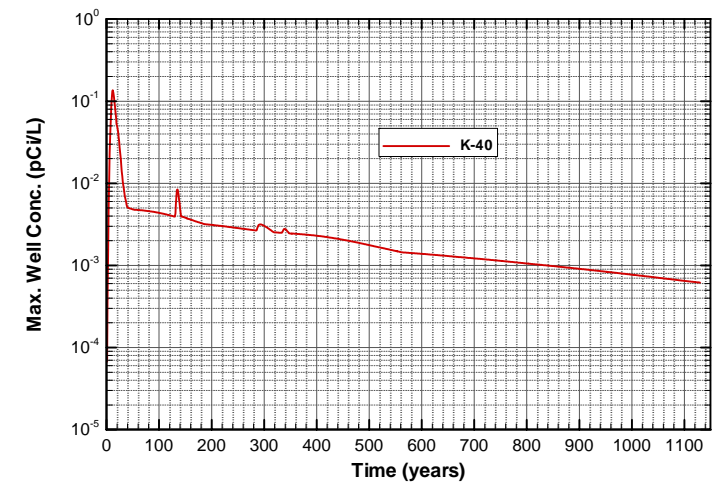

Figure A-1947. Well concentrations for Case01n11_off K-40

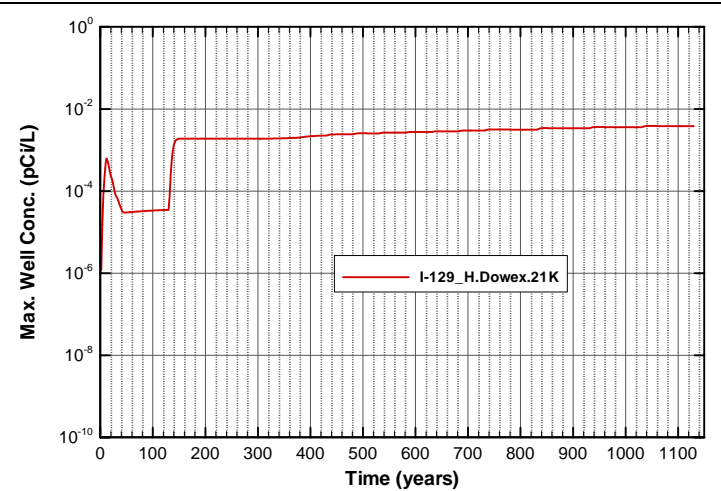

Figure A-1944. Well concentrations for Case01n11_off I-129_H.Dowex.21K

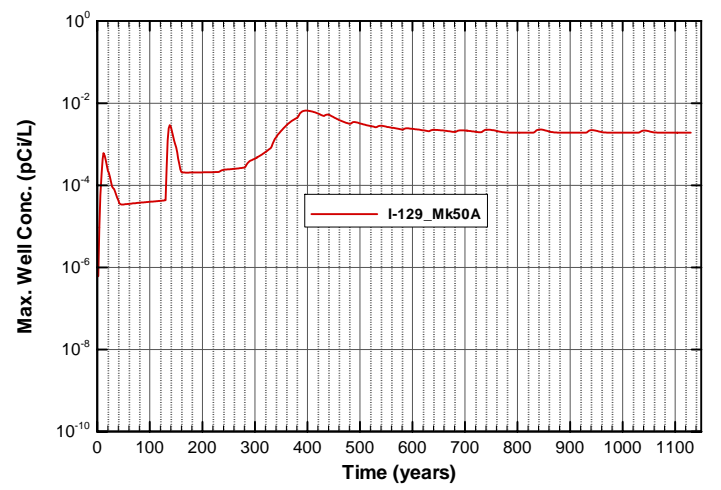

Figure A-1946. Well concentrations for Case01n11_off I-129_Mk50A

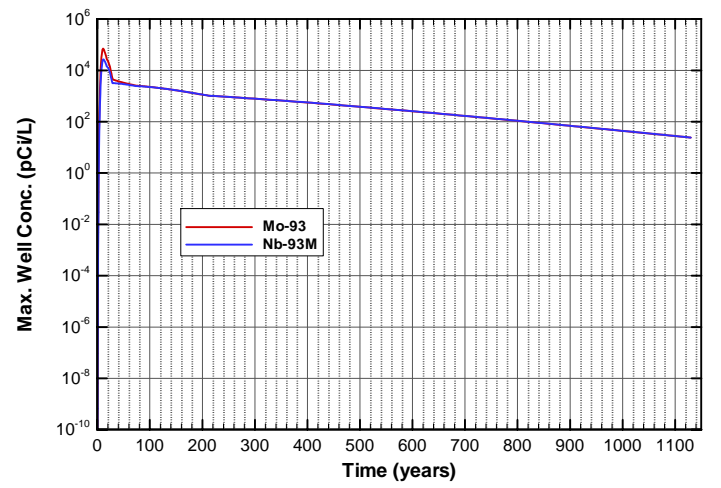

Figure A-1948. Well concentrations for Case01n11_off Mo-93 
SRNL-STI-2008-00397, REVISION 0

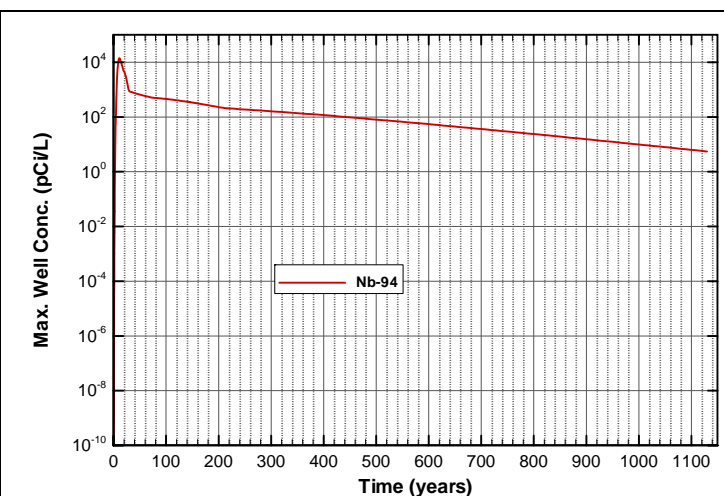

Figure A-1949. Well concentrations for Case01n11_off Nb-94

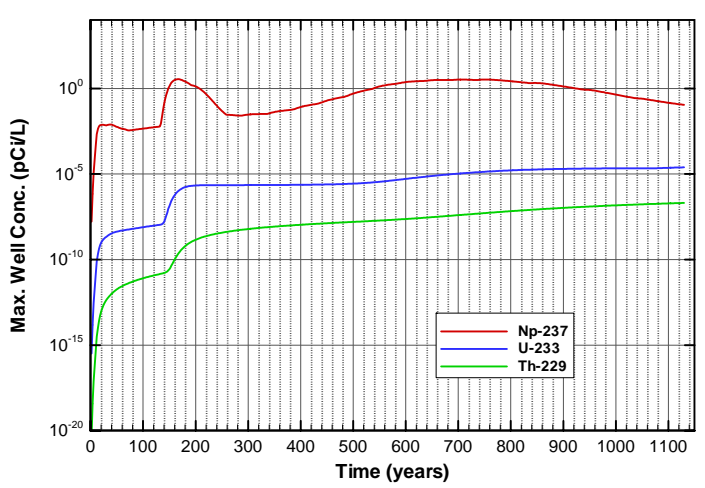

Figure A-1951. Well concentrations for Case01n11_off Np-237

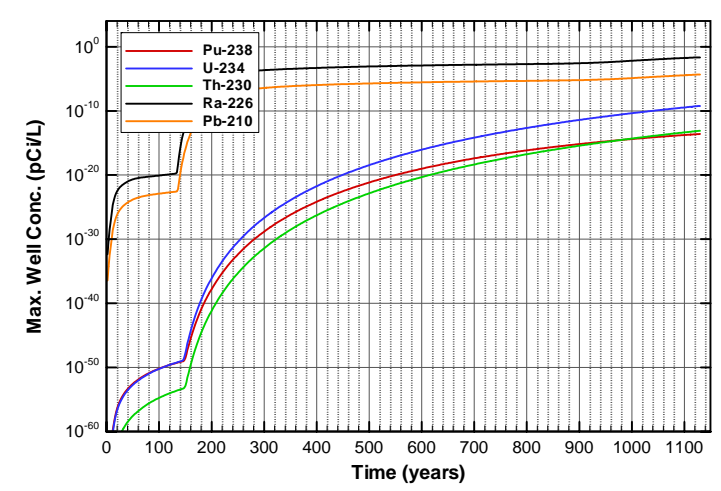

Figure A-1953. Well concentrations for Case01n11_off Pu-238

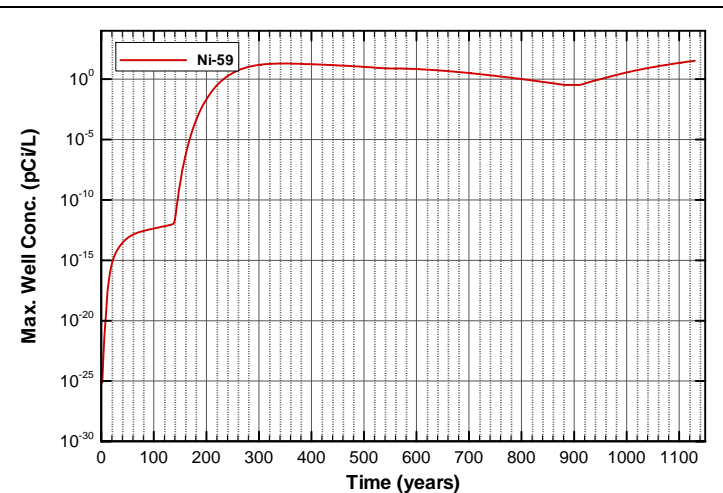

Figure A-1950. Well concentrations for Case01n11_off Ni-59

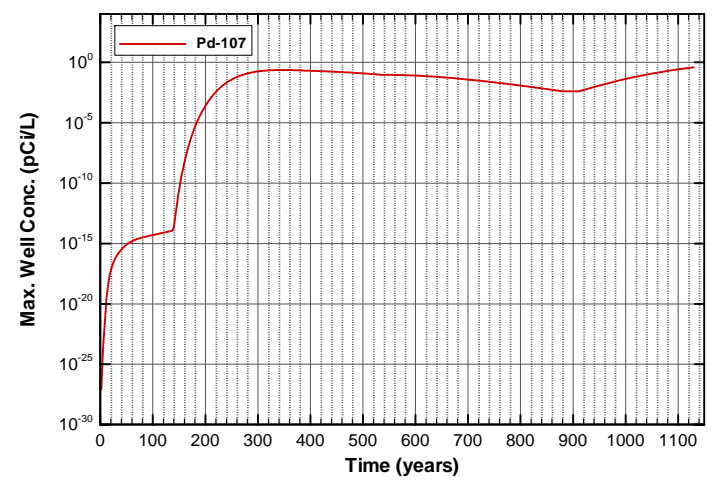

Figure A-1952. Well concentrations for Case01n11_off Pd-107

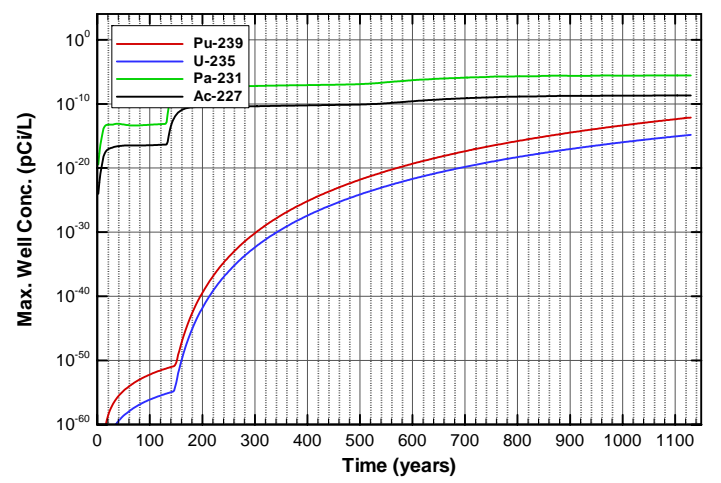

Figure A-1954. Well concentrations for Case01n11_off Pu-239 
SRNL-STI-2008-00397, REVISION 0

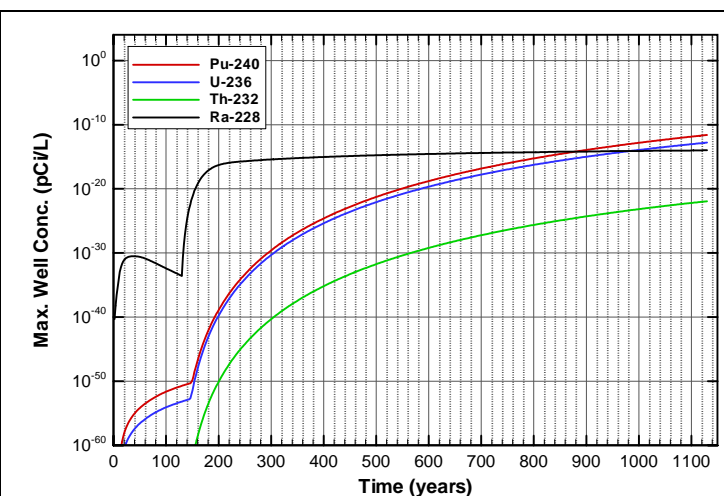

Figure A-1955. Well concentrations for Case01n11_off Pu-240

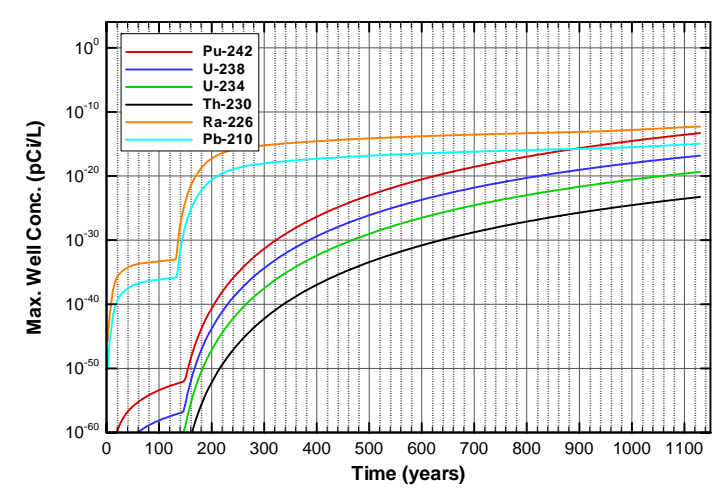

Figure A-1957. Well concentrations for Case01n11_off Pu-242

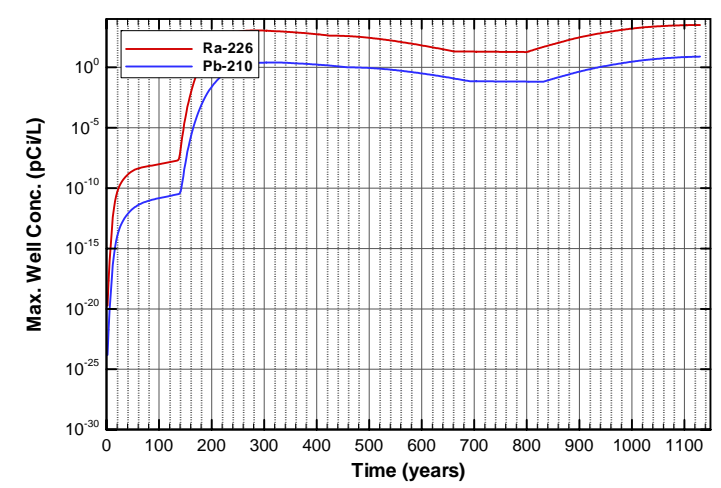

Figure A-1959. Well concentrations for Case01n11_off Ra-226

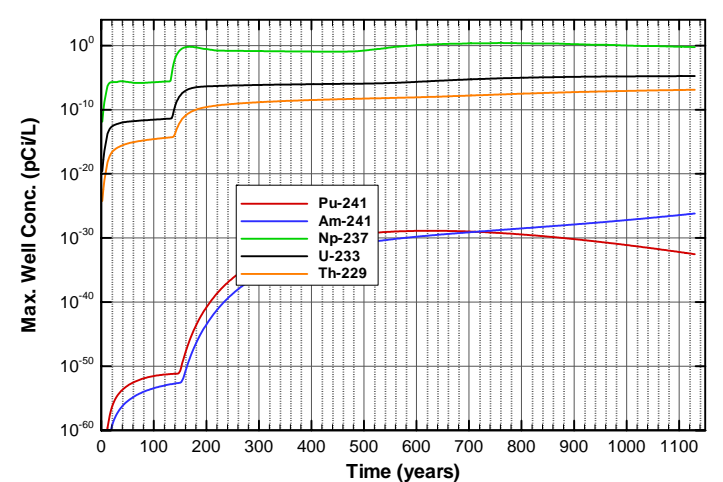

Figure A-1956. Well concentrations for Case01n11_off Pu-241

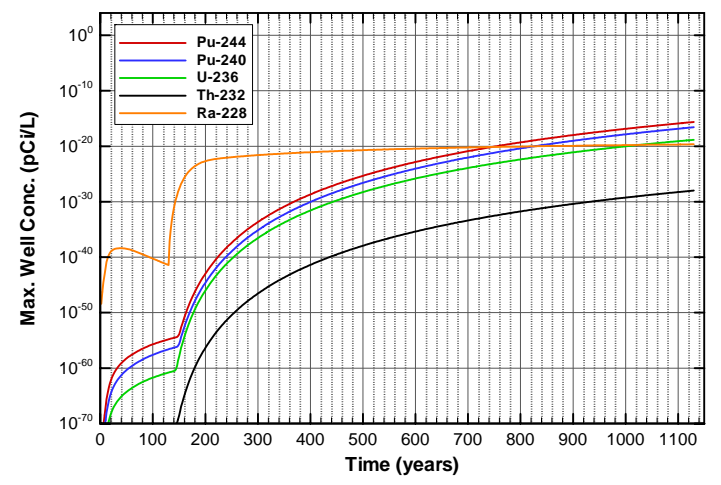

Figure A-1958. Well concentrations for Case01n11_off Pu-244

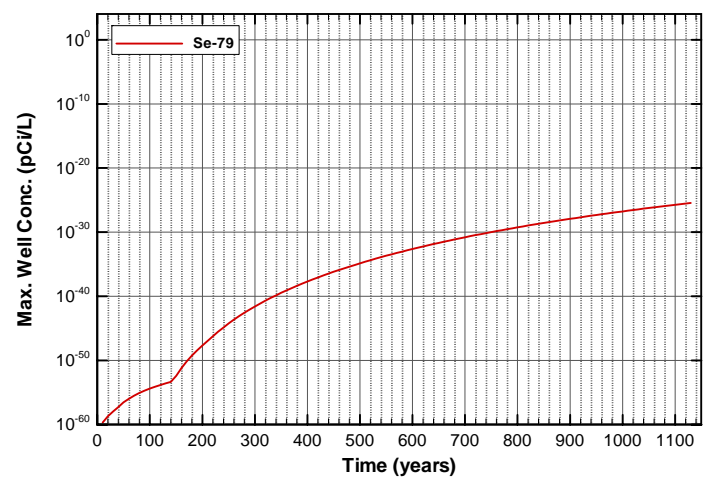

Figure A-1960. Well concentrations for Case01n11_off Se-79 
SRNL-STI-2008-00397, REVISION 0

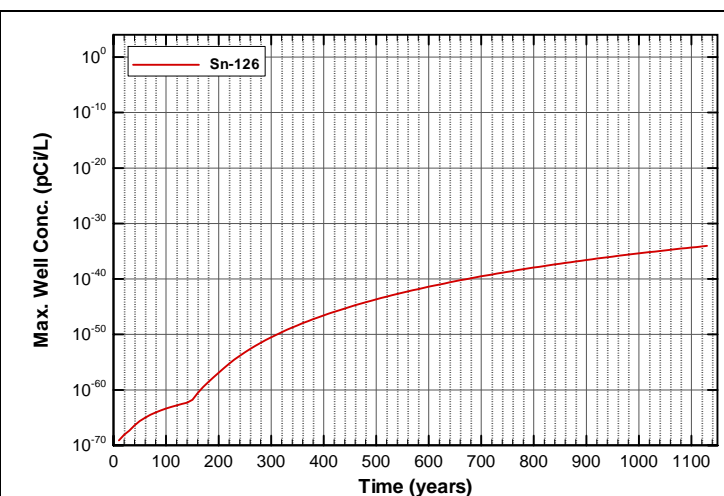

Figure A-1961. Well concentrations for Case01n11_off Sn-126

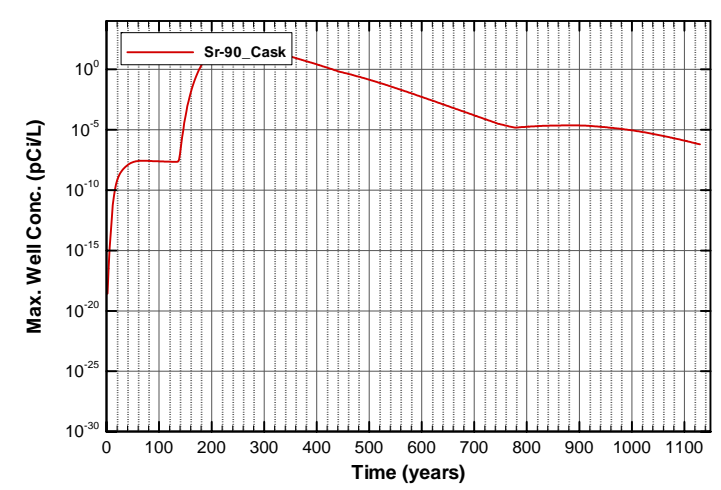

Figure A-1963. Well concentrations for Case01n11_off Sr-90_Cask

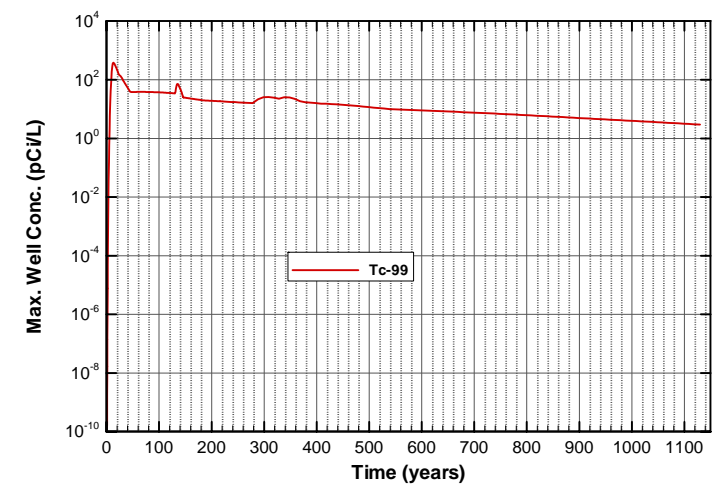

Figure A-1965. Well concentrations for Case01n11_off Tc-99

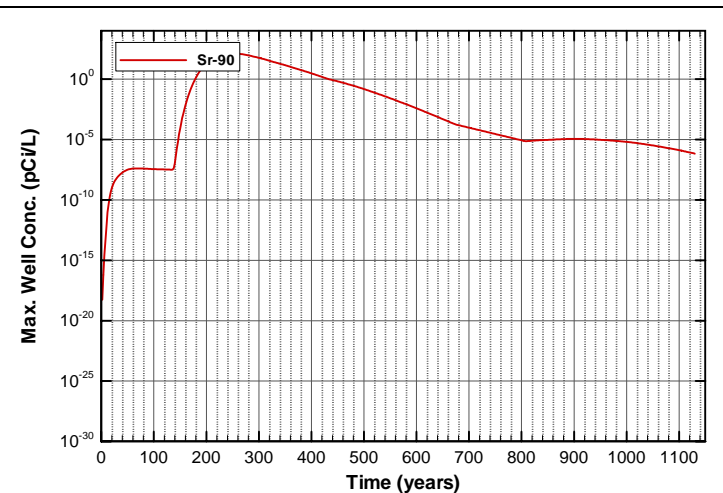

Figure A-1962. Well concentrations for Case01n11_off Sr-90

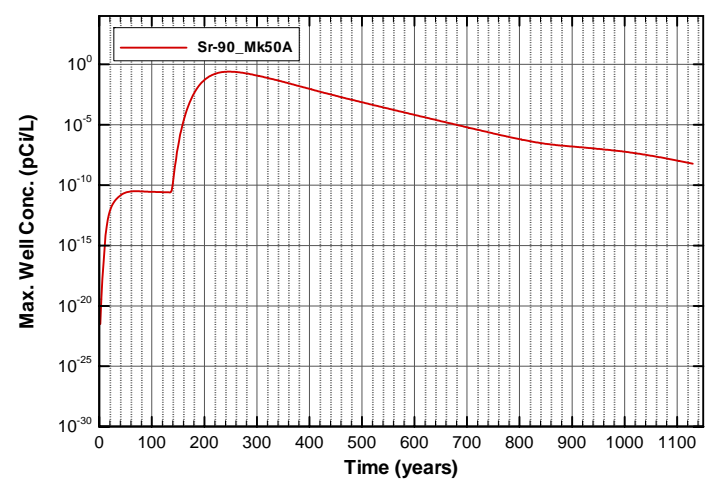

Figure A-1964. Well concentrations for Case01n11_off Sr-90_Mk50A

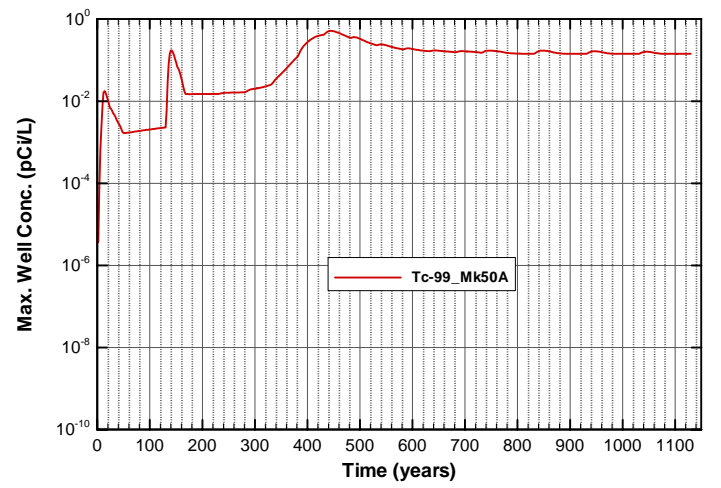

Figure A-1966. Well concentrations for Case01n11_off Tc-99_Mk50A 
SRNL-STI-2008-00397, REVISION 0

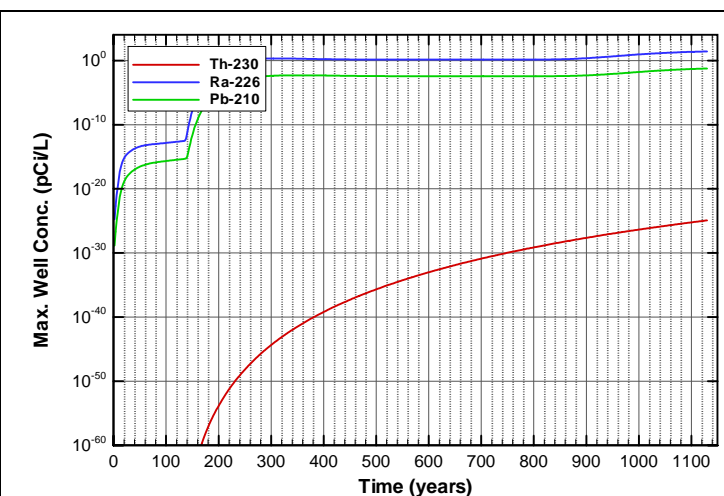

Figure A-1967. Well concentrations for Case01n11_off Th-230

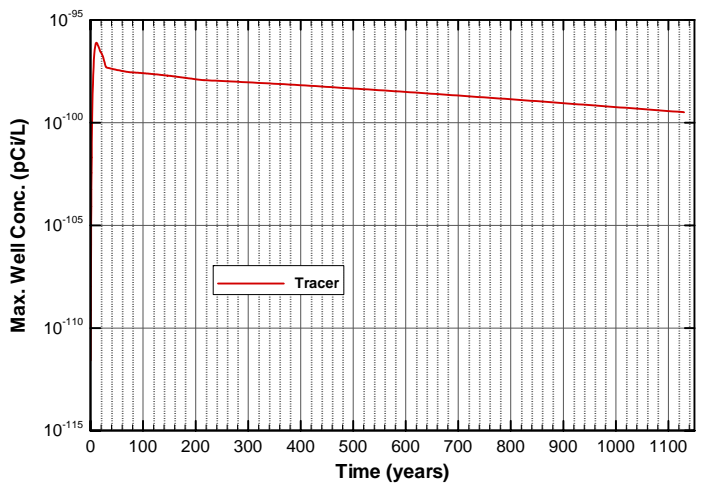

Figure A-1969. Well concentrations for Case01n11_off Tracer

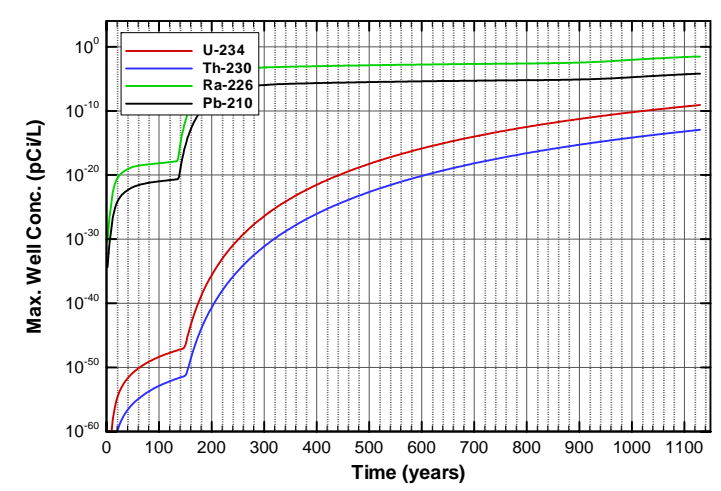

Figure A-1971. Well concentrations for Case01n11_off U-234

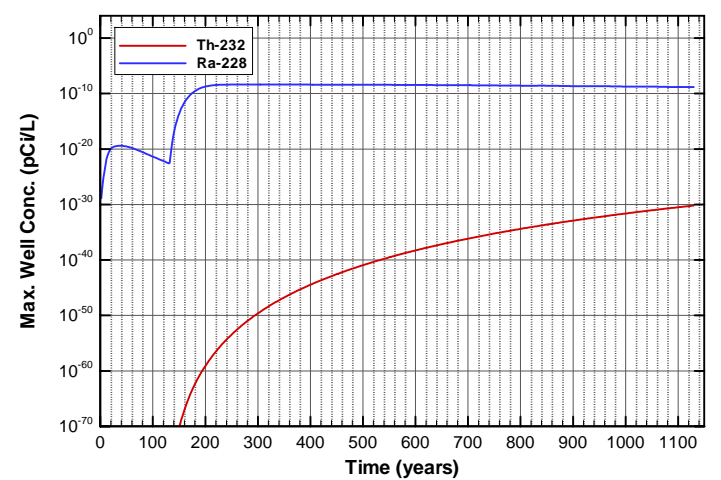

Figure A-1968. Well concentrations for Case01n11_off Th-232

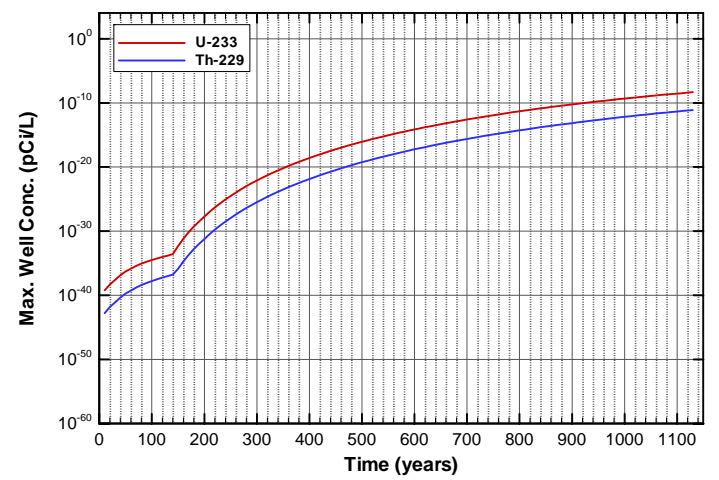

Figure A-1970. Well concentrations for Case01n11_off U-233

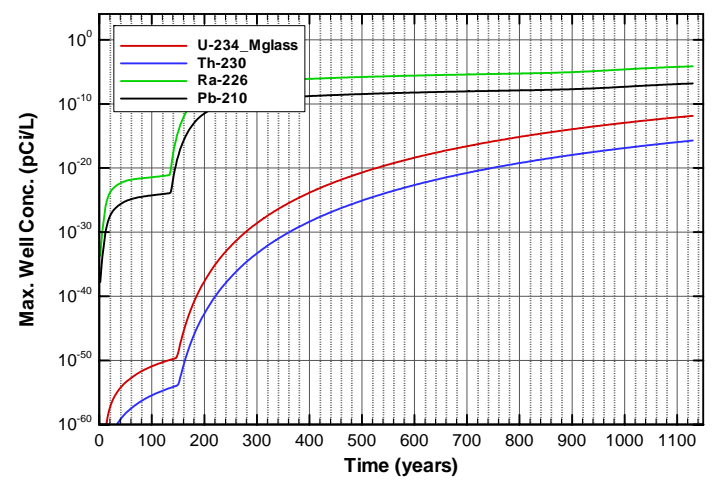

Figure A-1972. Well concentrations for Case01n11_off U-234_Mglass 
SRNL-STI-2008-00397, REVISION 0

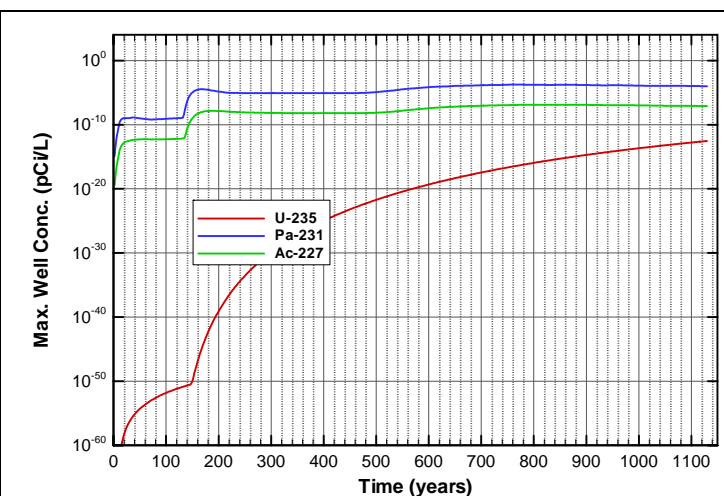

Figure A-1973. Well concentrations for Case01n11_off U-235

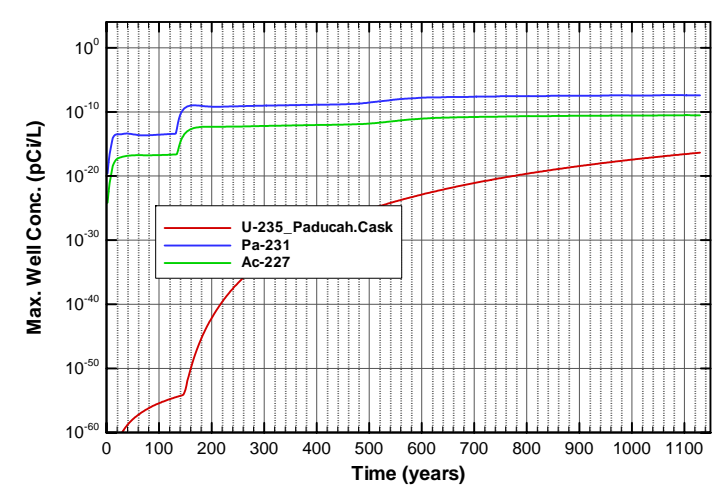

Figure A-1975. Well concentrations for Case01n11_off U-235_Paducah.Cask

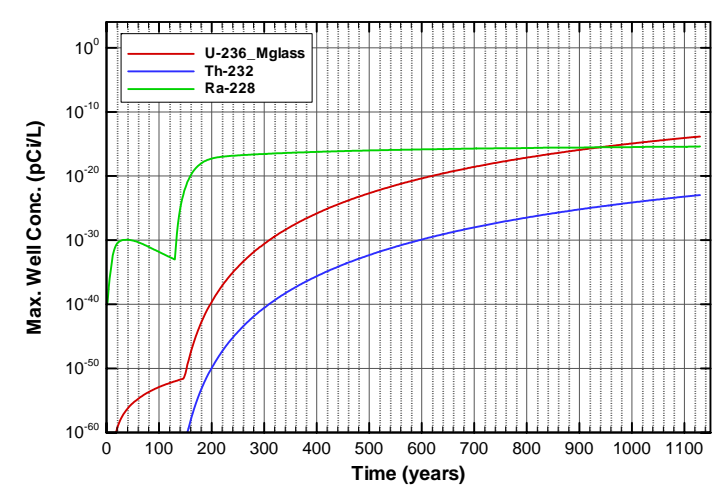

Figure A-1977. Well concentrations for Case01n11_off U-236_Mglass

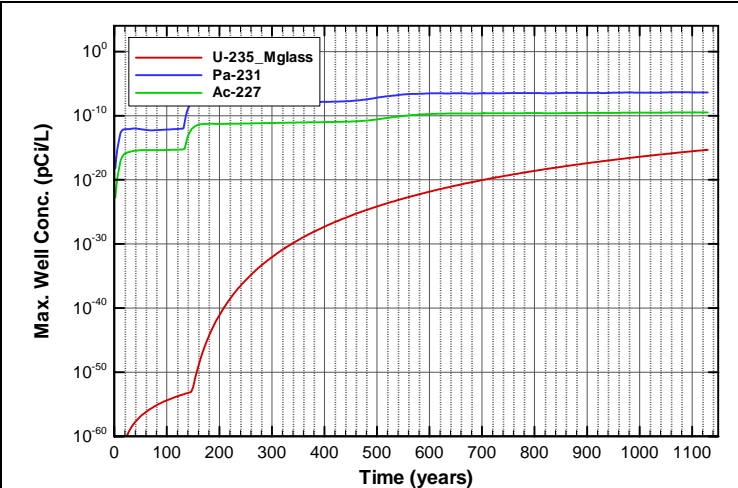

Figure A-1974. Well concentrations for Case01n11_off U-235_Mglass

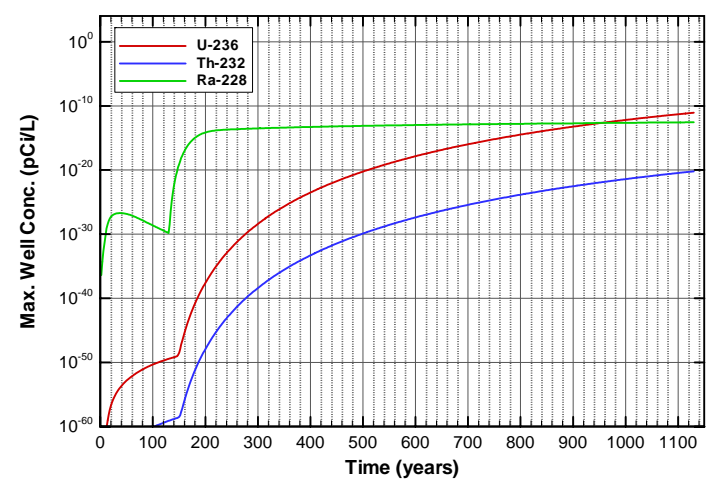

Figure A-1976. Well concentrations for Case01n11_off U-236

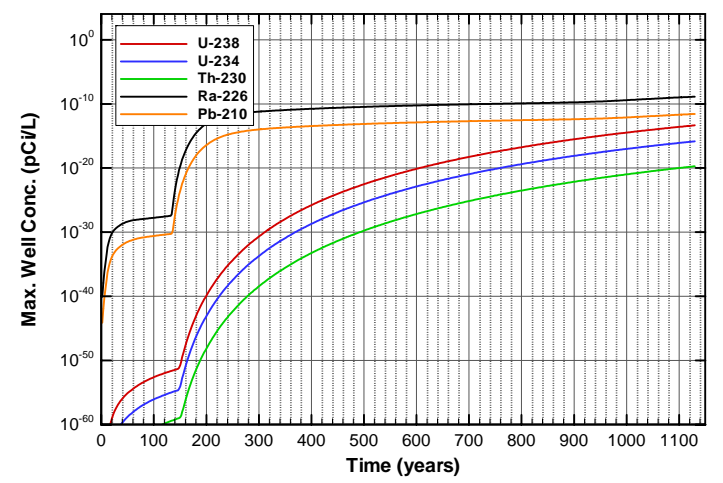

Figure A-1978. Well concentrations for Case01n11_off U-238 


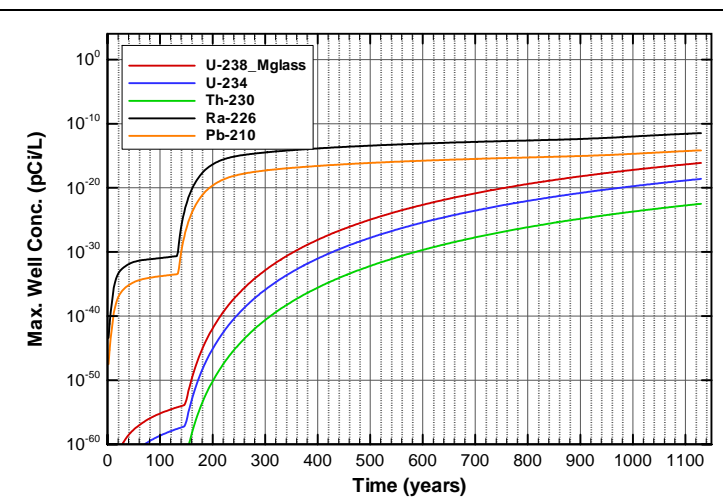

Figure A-1979. Well concentrations for Case01n11_off U-238_Mglass

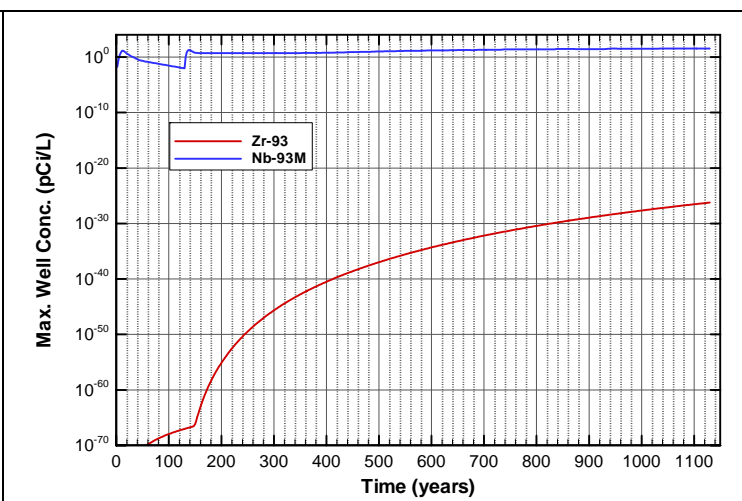

Figure A-1980. Well concentrations for Case01n11_off Zr-93

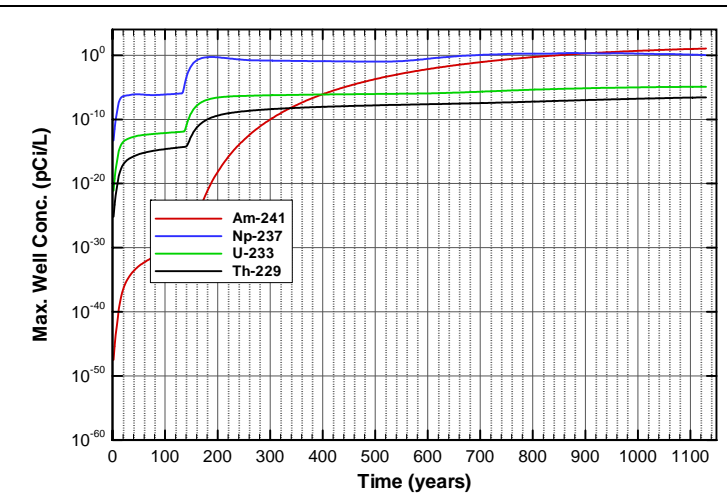

Figure A-1981. Well concentrations for Case01n11_on Am-241

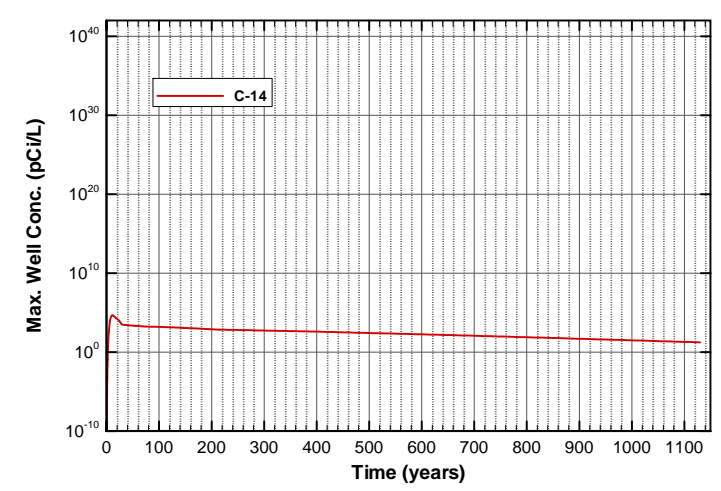

Figure A-1983. Well concentrations for Case01n11_on C-14

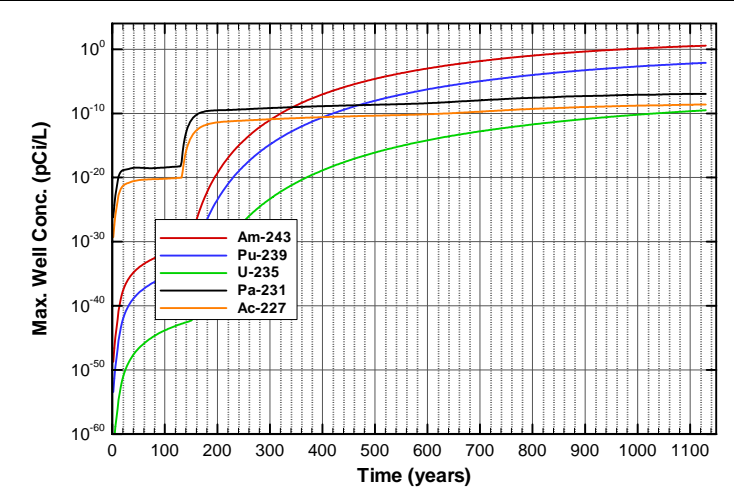

Figure A-1982. Well concentrations for Case01n11_on Am-243

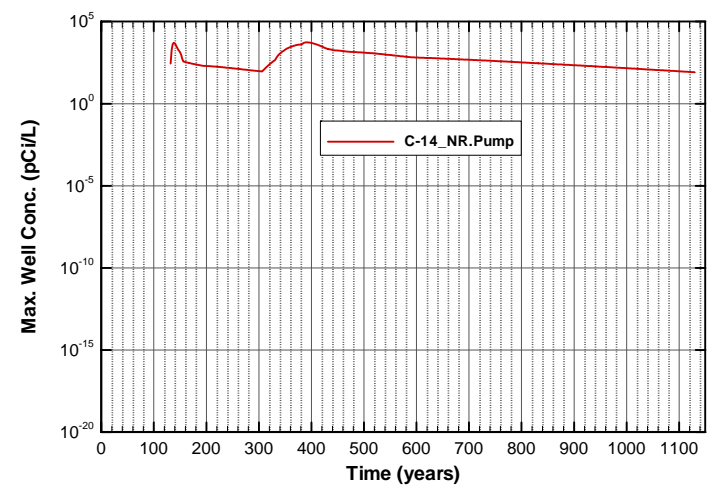

Figure A-1984. Well concentrations for Case01n11_on C-14_NR.Pump 
SRNL-STI-2008-00397, REVISION 0

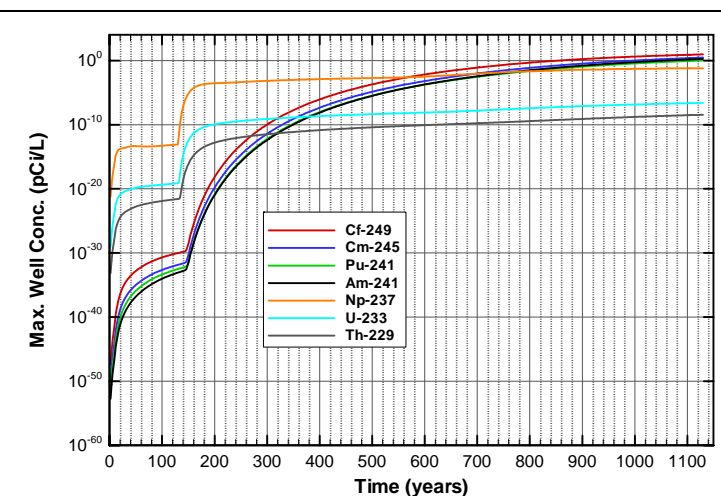

Figure A-1985. Well concentrations for Case01n11_on Cf-249

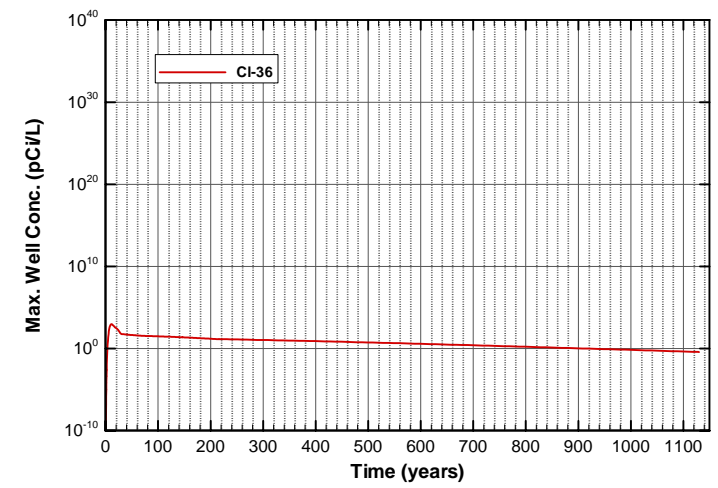

Figure A-1987. Well concentrations for Case01n11_on Cl-36

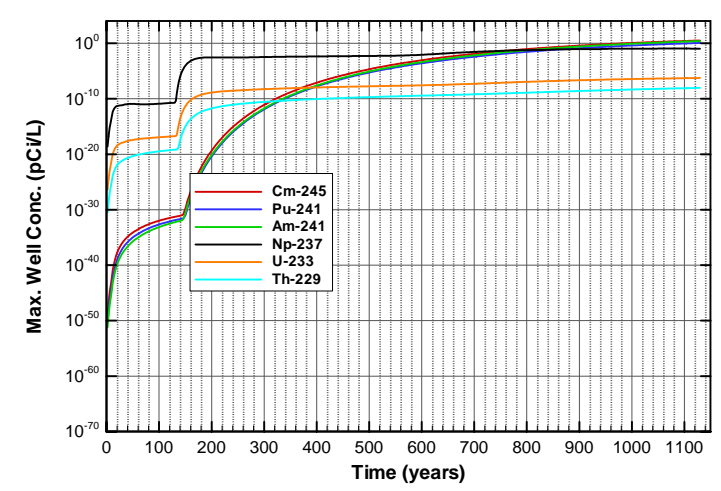

Figure A-1989. Well concentrations for Case01n11_on Cm-245

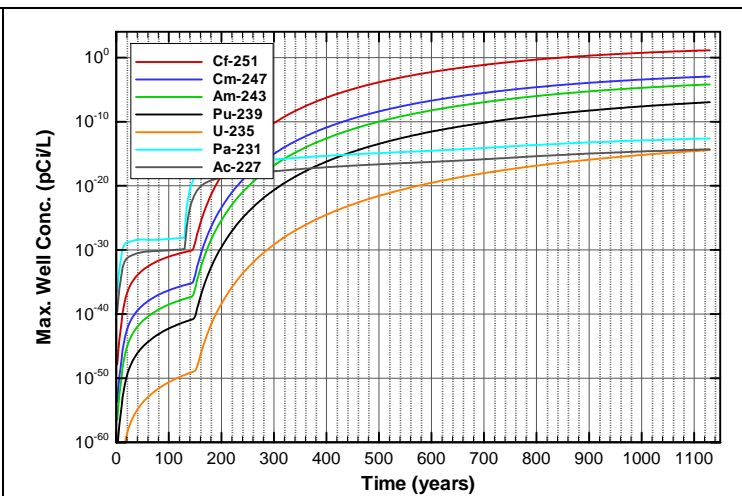

Figure A-1986. Well concentrations for Case01n11_on Cf-251

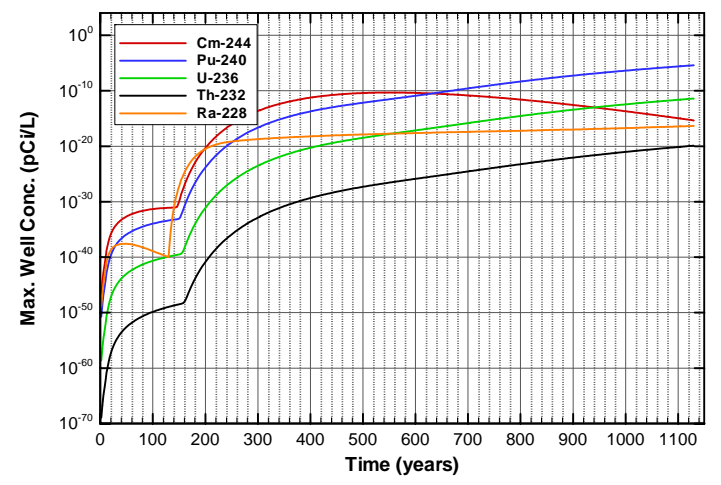

Figure A-1988. Well concentrations for Case01n11_on Cm-244

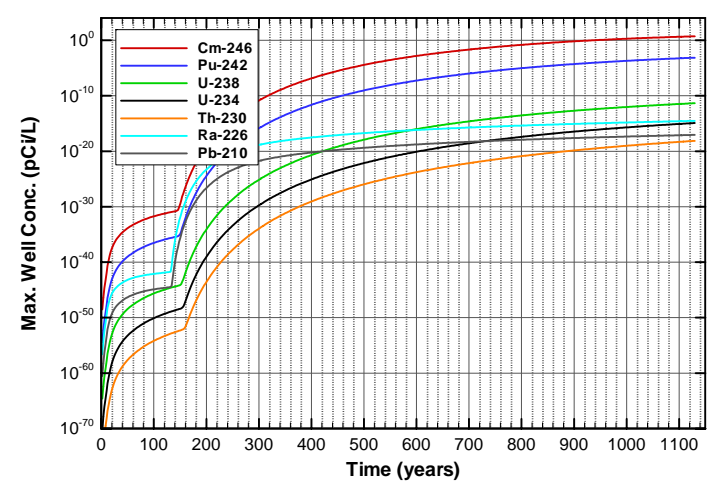

Figure A-1990. Well concentrations for Case01n11_on Cm-246 


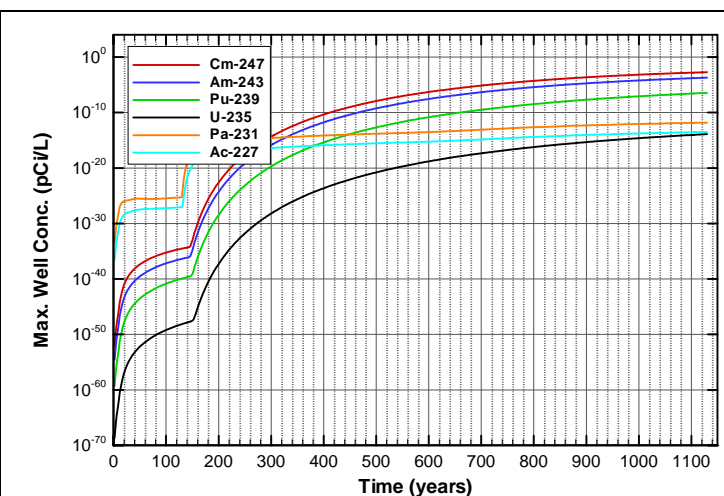

Figure A-1991. Well concentrations for Case01n11_on Cm-247

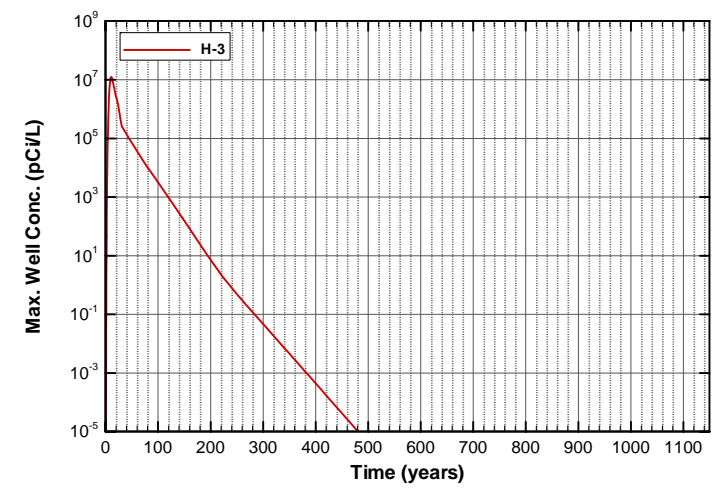

Figure A-1993. Well concentrations for Case01n11_on H-3

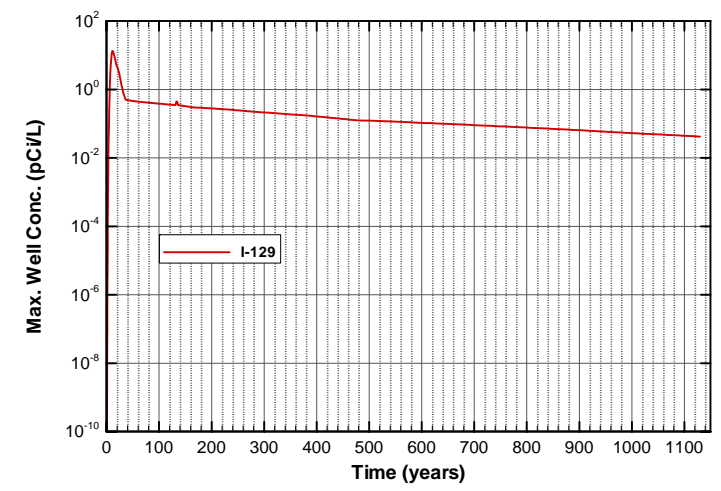

Figure A-1995. Well concentrations for Case01n11_on I-129

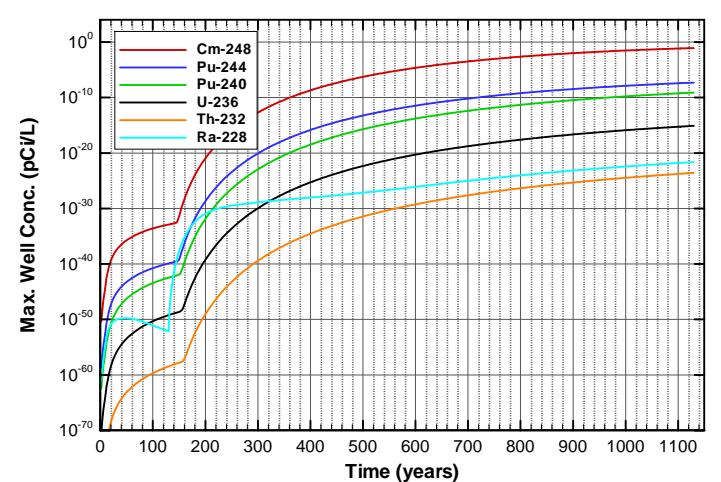

Figure A-1992. Well concentrations for Case01n11_on Cm-248

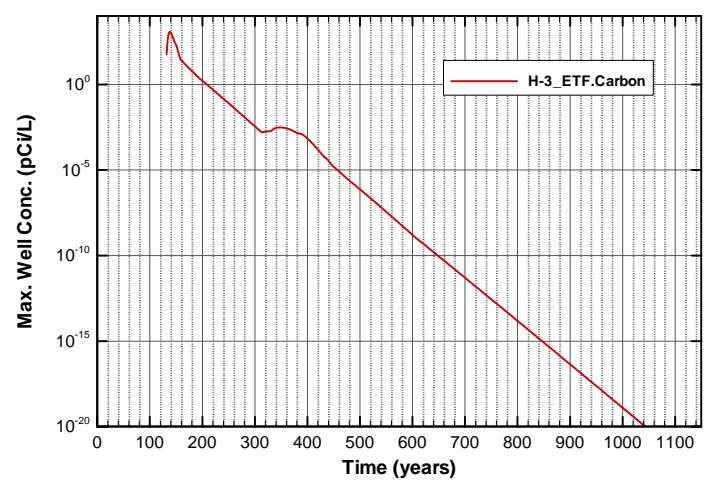

Figure A-1994. Well concentrations for Case01n11_on H-3_ETF.Carbon

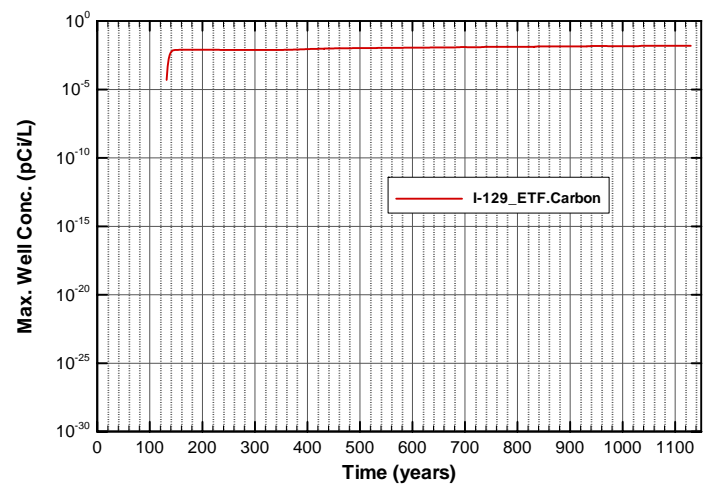

Figure A-1996. Well concentrations for Case01n11_on I-129_ETF.Carbon 
SRNL-STI-2008-00397, REVISION 0

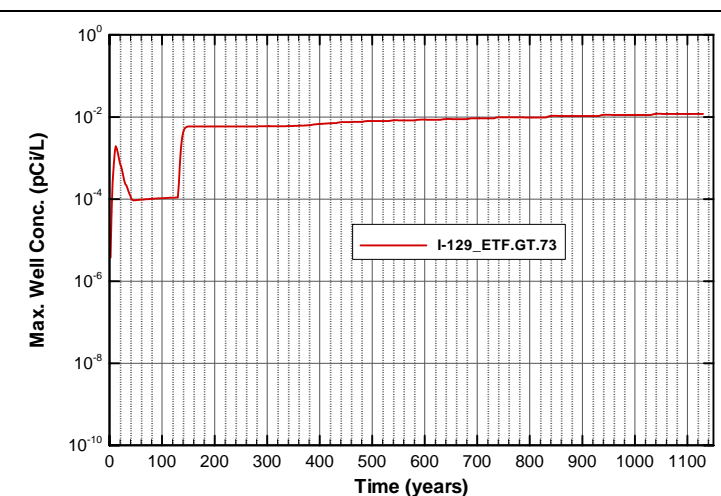

Figure A-1997. Well concentrations for Case01n11_on I-129_ETF.GT.73

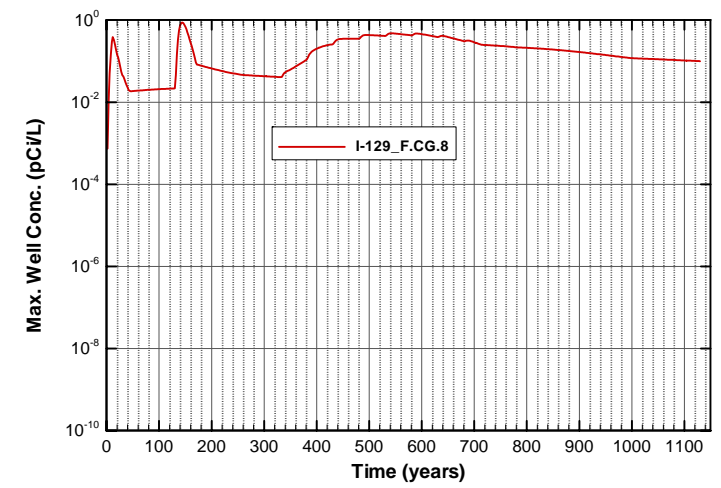

Figure A-1999. Well concentrations for Case01n11_on I-129_F.CG.8

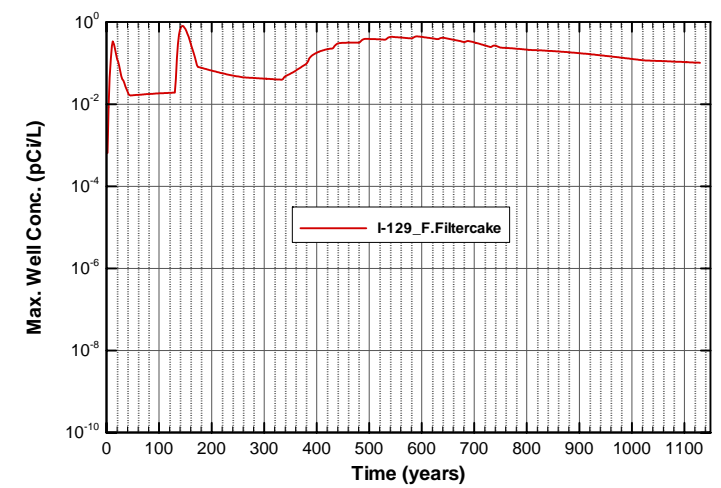

Figure A-2001. Well concentrations for Case01n11_on I-129_F.Filtercake

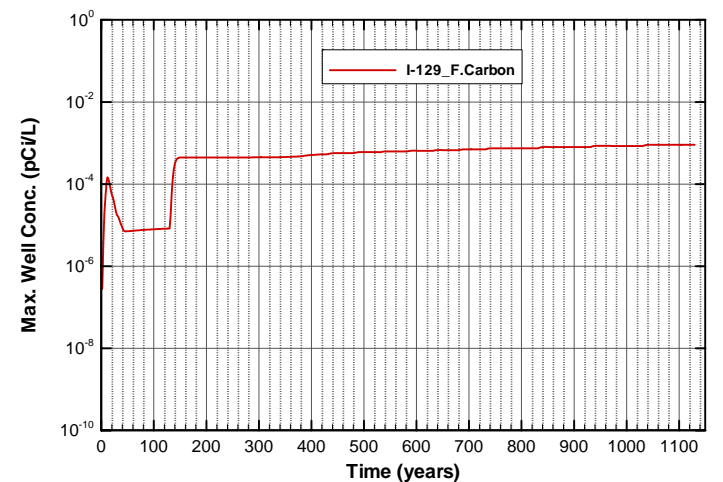

Figure A-1998. Well concentrations for Case01n11_on I-129_F.Carbon

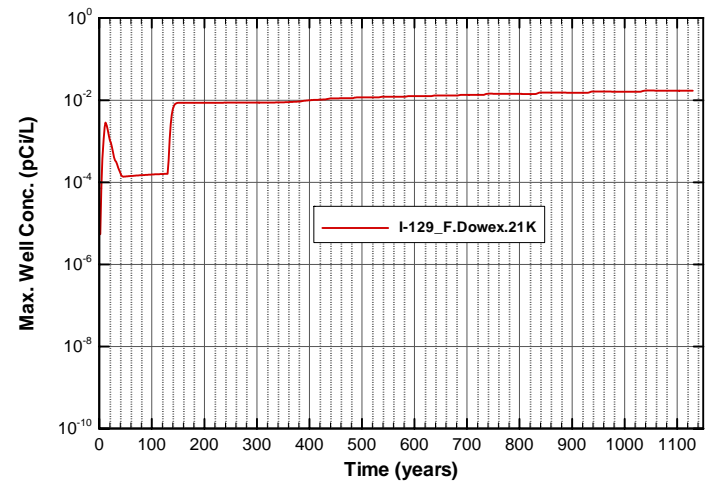

Figure A-2000. Well concentrations for Case01n11_on I-129_F.Dowex.21K

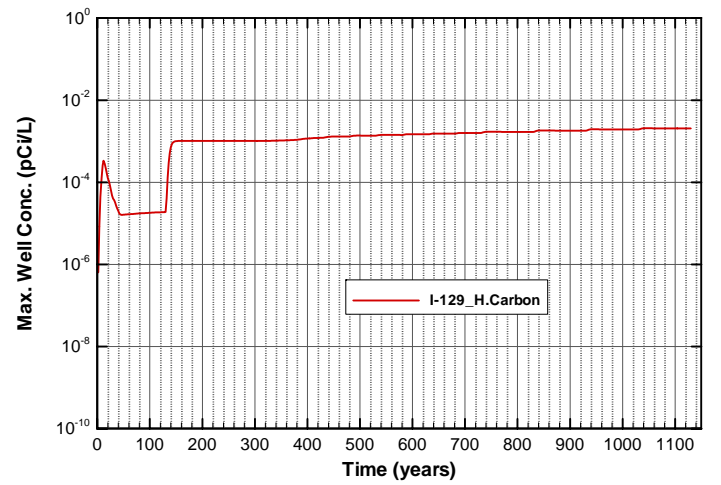

Figure A-2002. Well concentrations for Case01n11_on I-129_H.Carbon 
SRNL-STI-2008-00397, REVISION 0

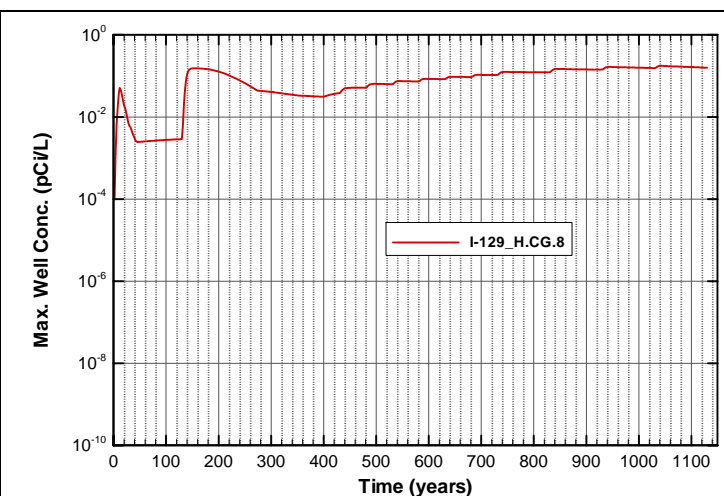

Figure A-2003. Well concentrations for Case01n11_on I-129_H.CG.8

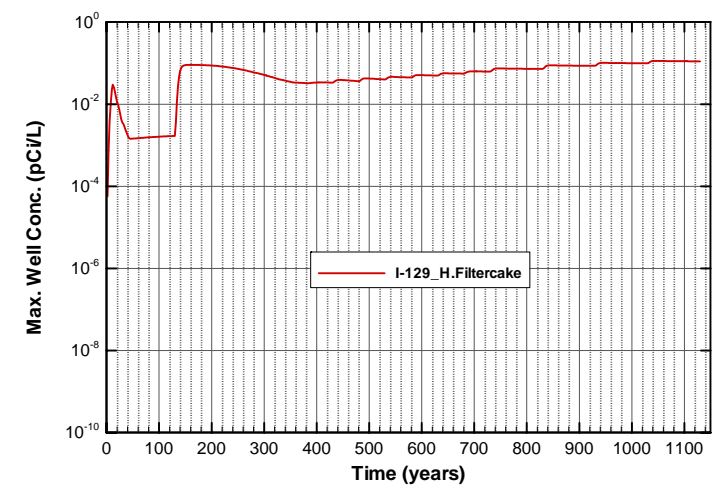

Figure A-2005. Well concentrations for Case01n11_on I-129_H.Filtercake

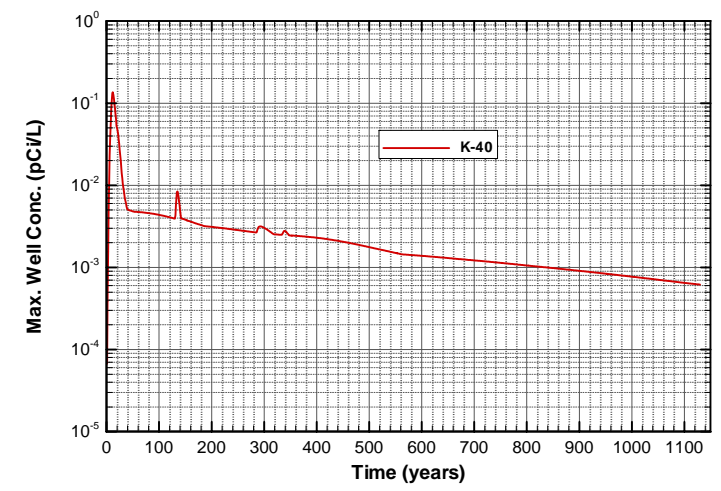

Figure A-2007. Well concentrations for Case01n11_on K-40

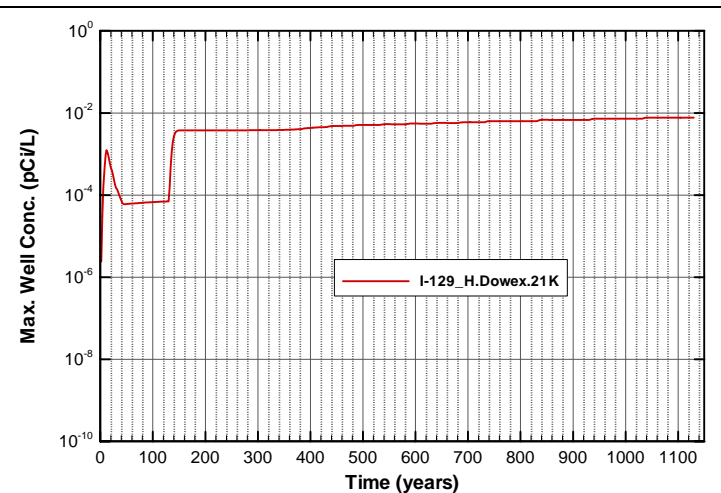

Figure A-2004. Well concentrations for Case01n11_on I-129_H.Dowex.21K

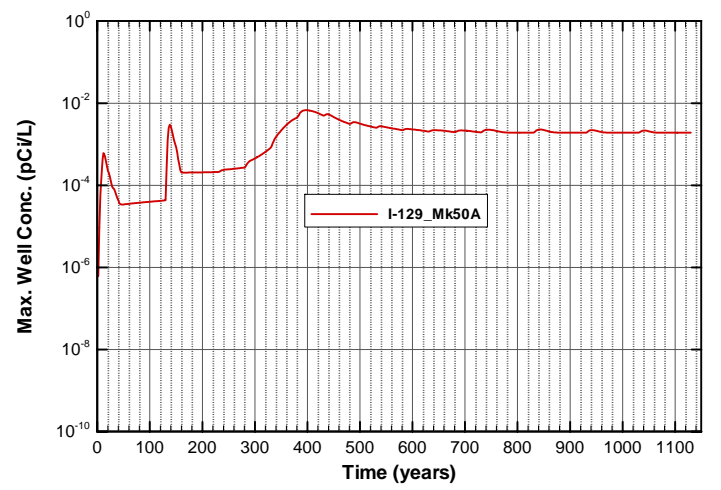

Figure A-2006. Well concentrations for Case01n11_on I-129_Mk50A

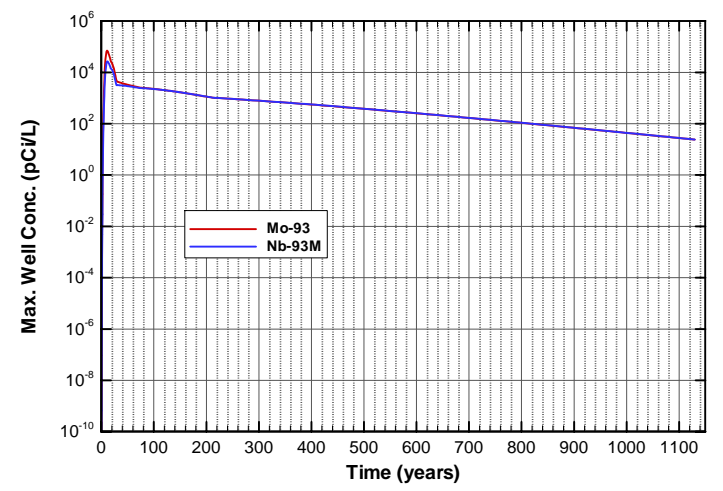

Figure A-2008. Well concentrations for Case01n11_on Mo-93 
SRNL-STI-2008-00397, REVISION 0

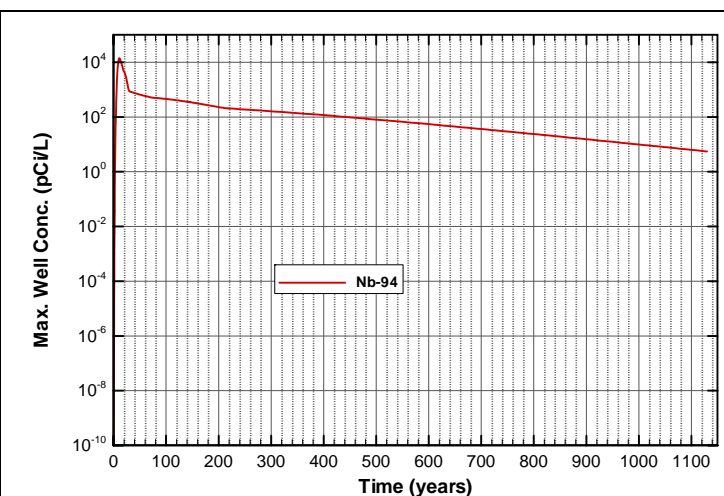

Figure A-2009. Well concentrations for Case01n11_on Nb-94

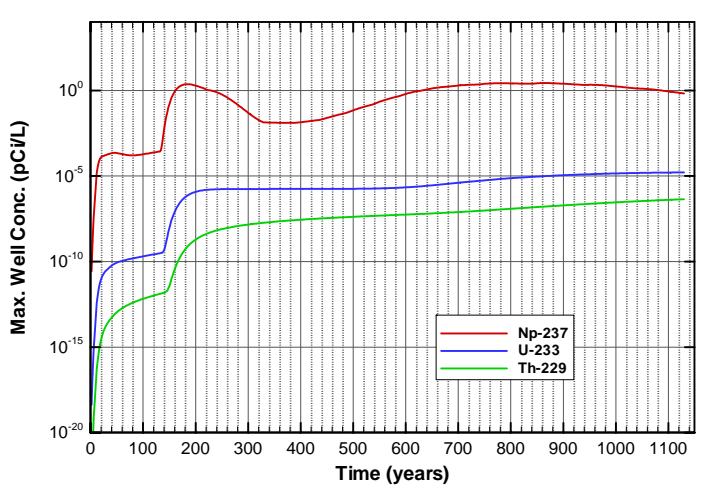

Figure A-2011. Well concentrations for Case01n11_on Np-237

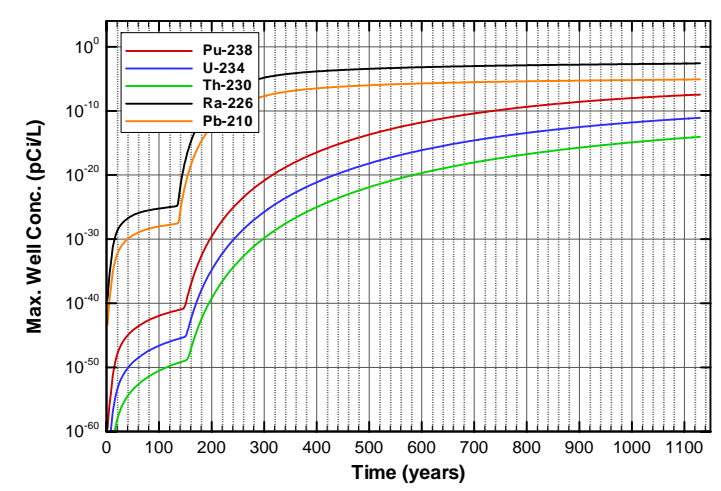

Figure A-2013. Well concentrations for Case01n11_on Pu-238

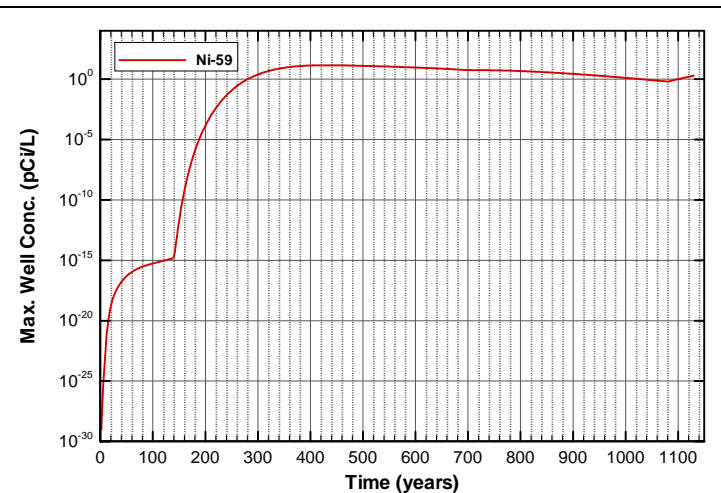

Figure A-2010. Well concentrations for Case01n11_on Ni-59

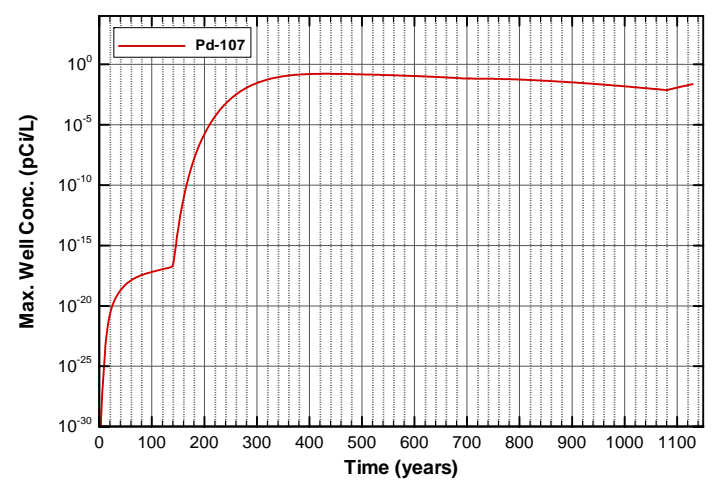

Figure A-2012. Well concentrations for Case01n11_on Pd-107

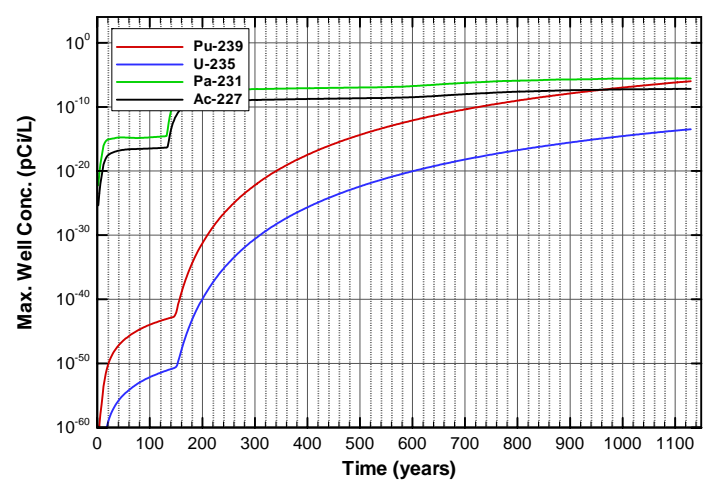

Figure A-2014. Well concentrations for Case01n11_on Pu-239 


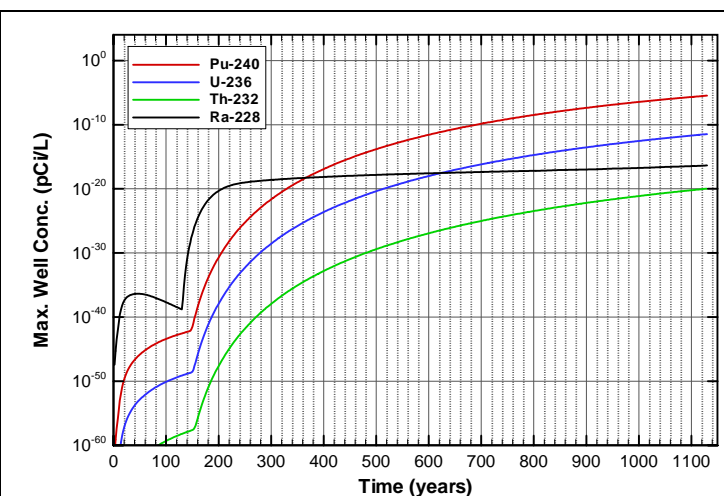

Figure A-2015. Well concentrations for Case01n11_on Pu-240

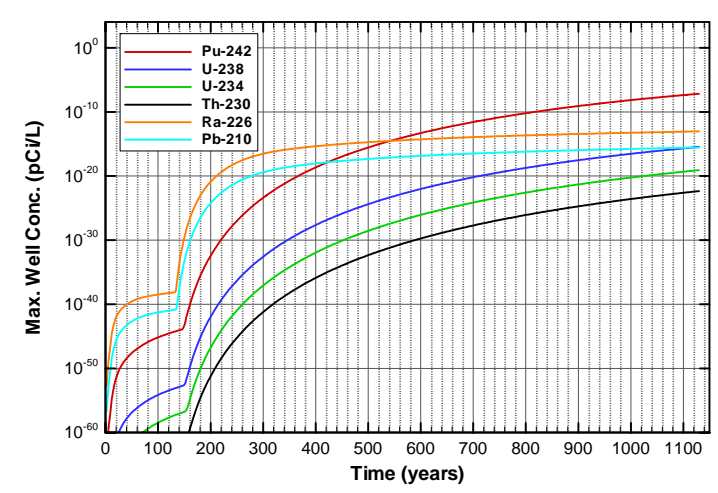

Figure A-2017. Well concentrations for Case01n11_on Pu-242

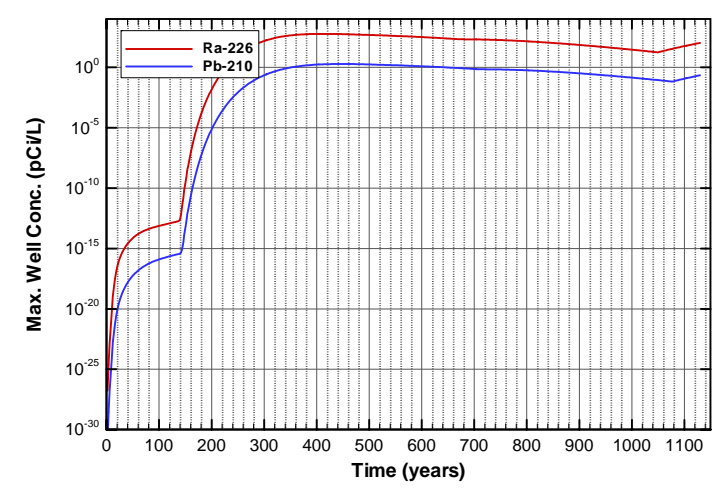

Figure A-2019. Well concentrations for Case01n11_on Ra-226

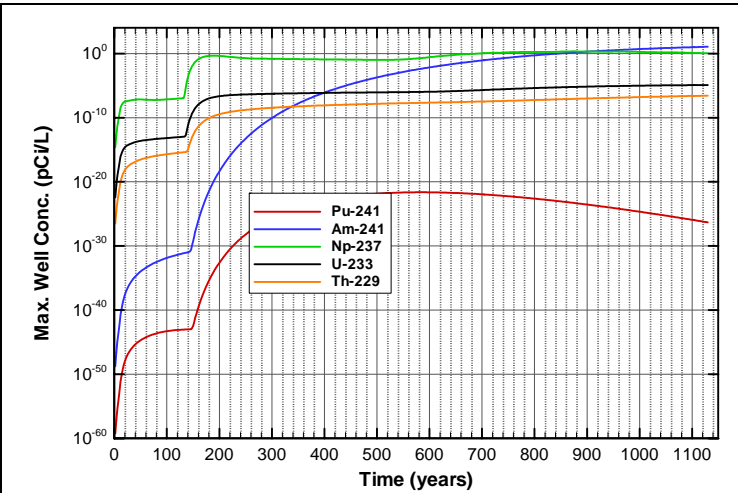

Figure A-2016. Well concentrations for Case01n11_on Pu-241

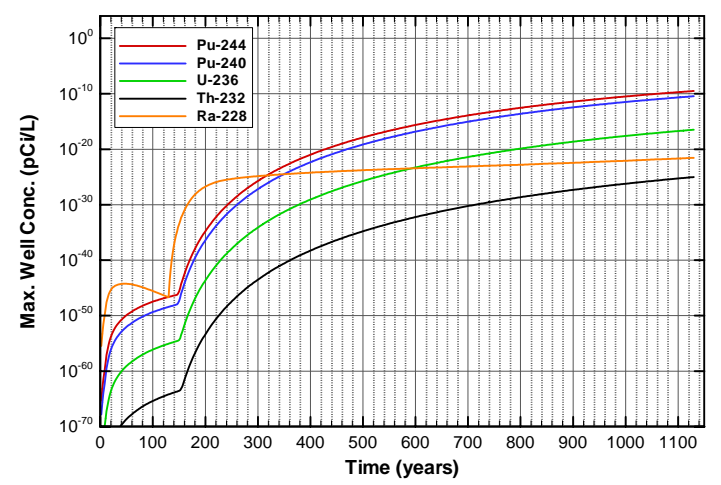

Figure A-2018. Well concentrations for Case01n11_on Pu-244

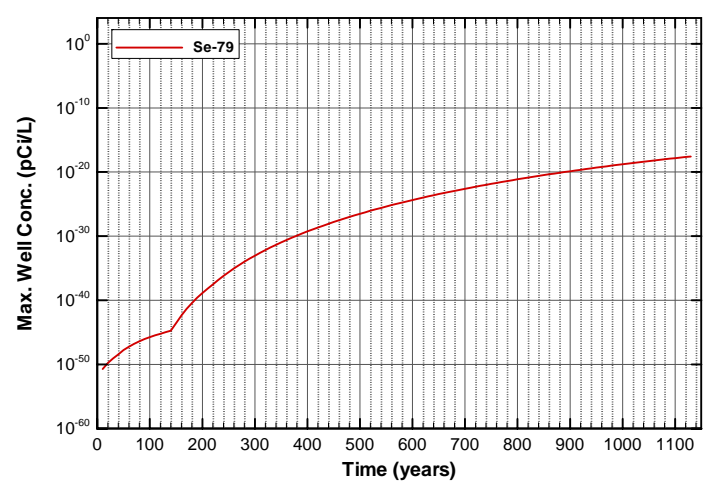

Figure A-2020. Well concentrations for Case01n11_on Se-79 
SRNL-STI-2008-00397, REVISION 0

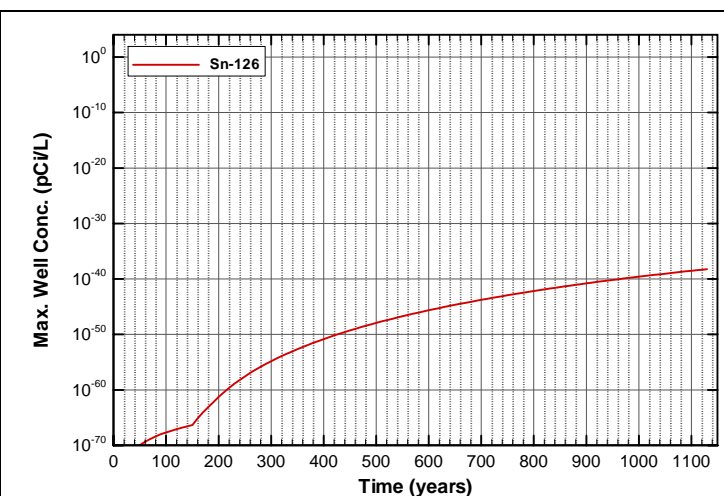

Figure A-2021. Well concentrations for Case01n11_on Sn-126

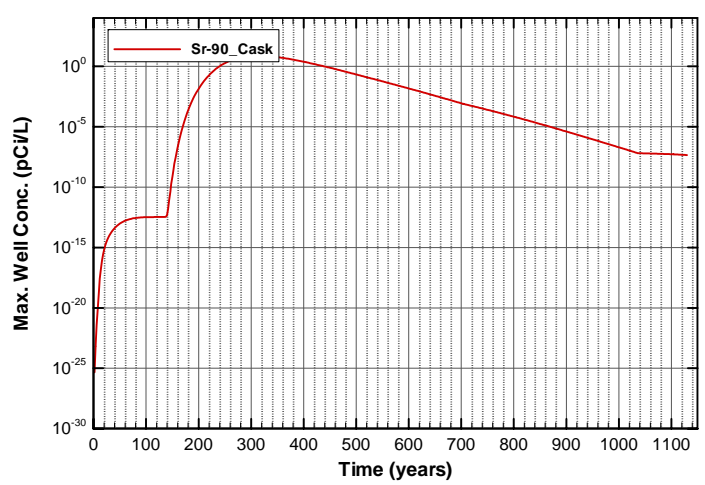

Figure A-2023. Well concentrations for Case01n11_on Sr-90_Cask

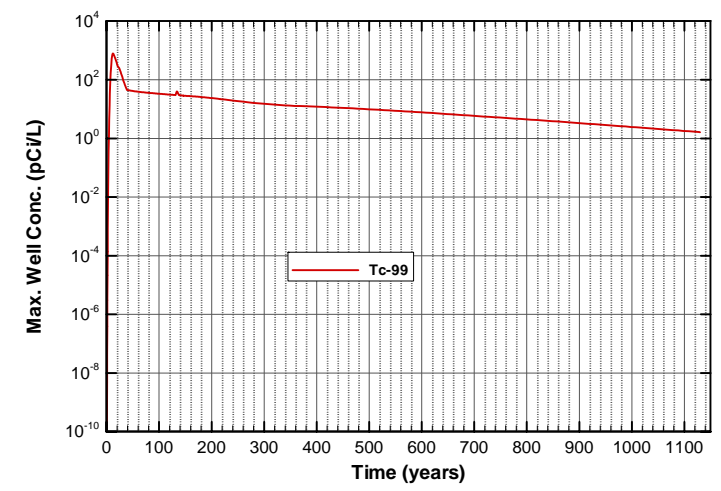

Figure A-2025. Well concentrations for Case01n11_on Tc-99

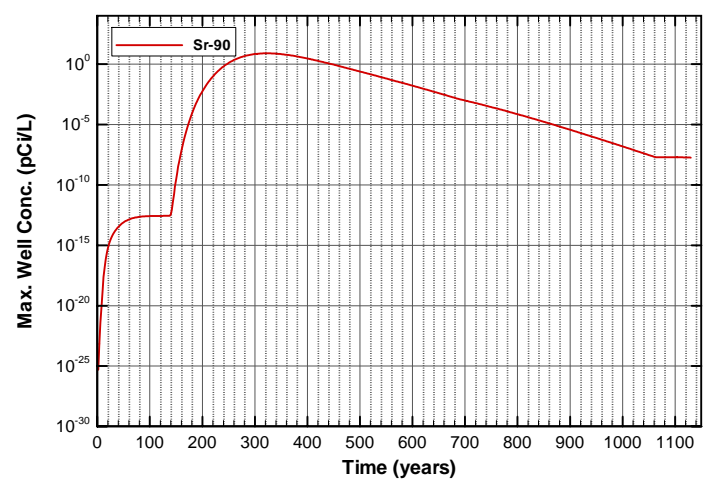

Figure A-2022. Well concentrations for Case01n11_on Sr-90

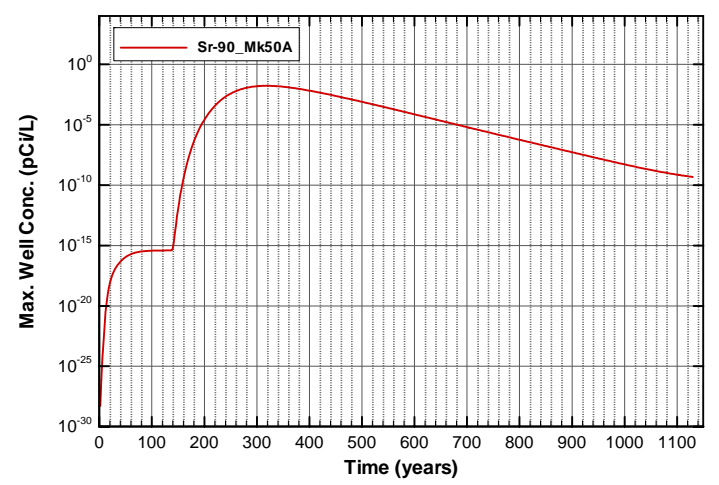

Figure A-2024. Well concentrations for Case01n11_on Sr-90_Mk50A

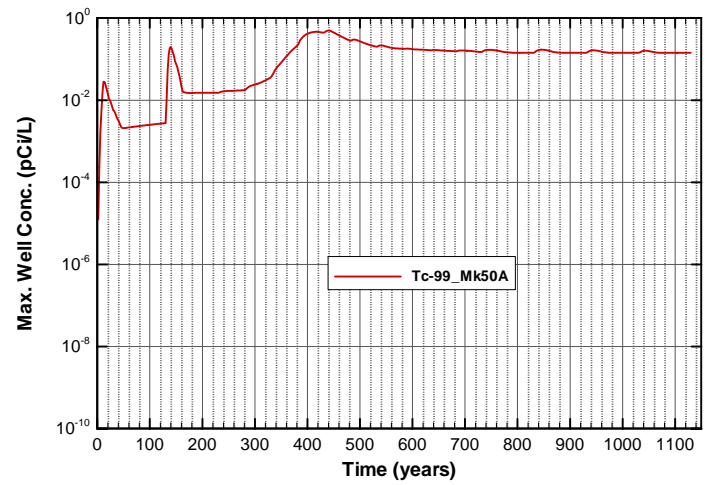

Figure A-2026. Well concentrations for Case01n11_on Tc-99_Mk50A 


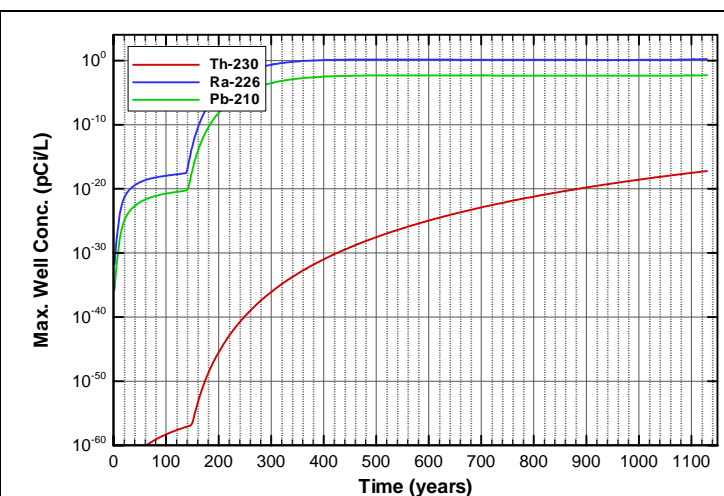

Figure A-2027. Well concentrations for Case01n11_on Th-230

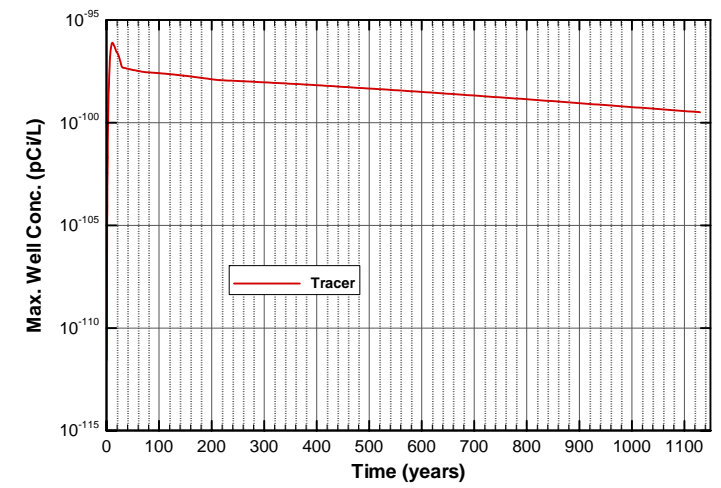

Figure A-2029. Well concentrations for Case01n11_on Tracer

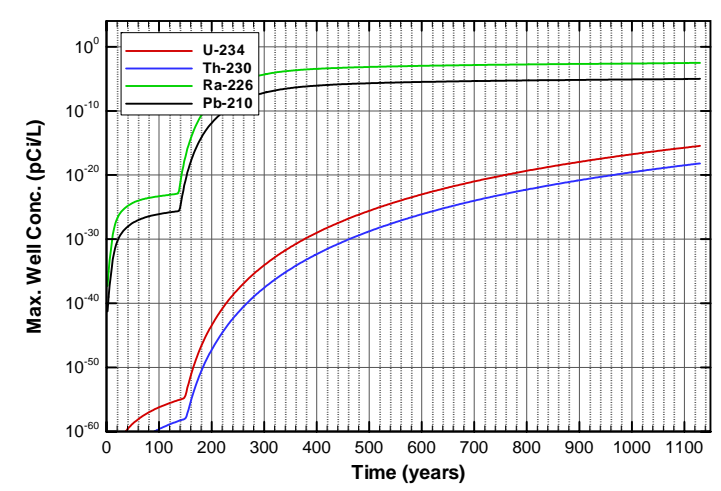

Figure A-2031. Well concentrations for Case01n11_on U-234

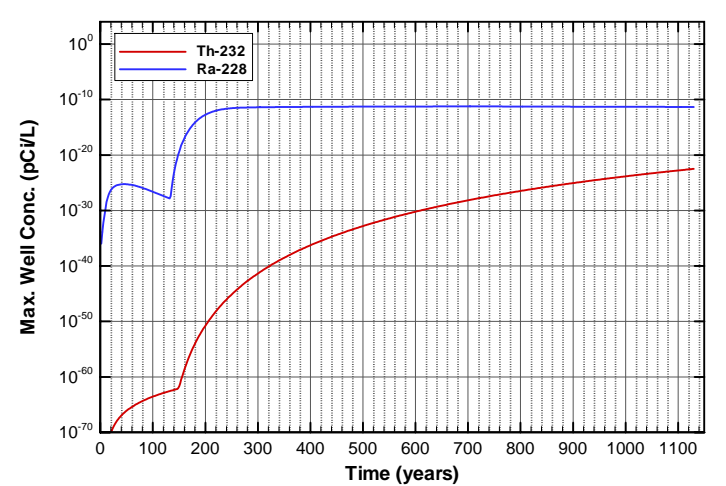

Figure A-2028. Well concentrations for Case01n11_on Th-232

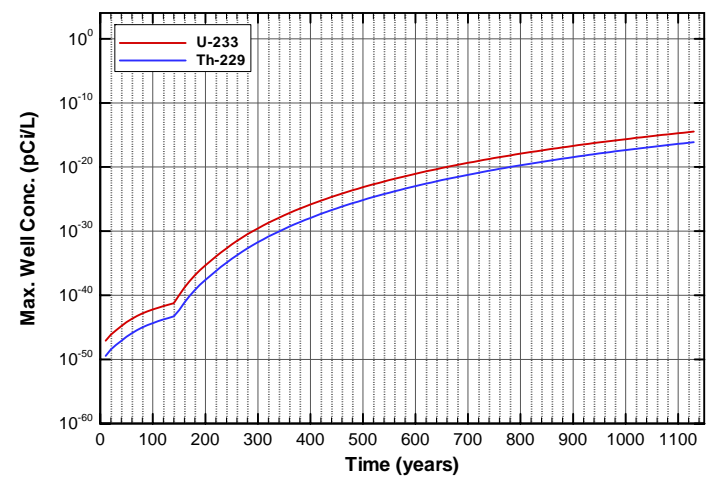

Figure A-2030. Well concentrations for Case01n11_on U-233

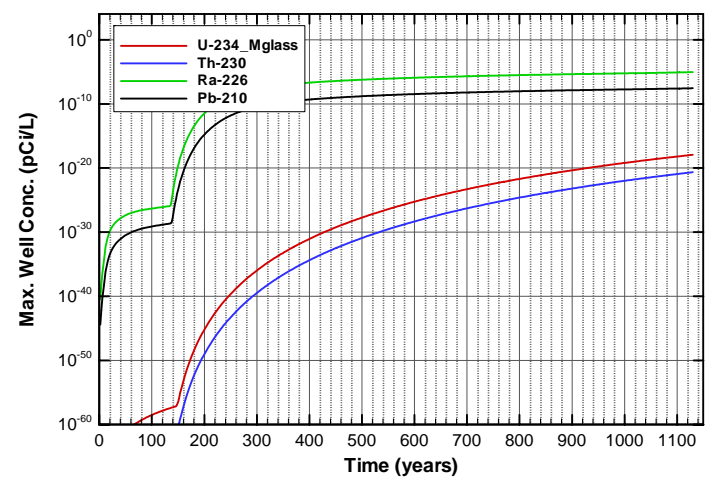

Figure A-2032. Well concentrations for Case01n11_on U-234_Mglass 


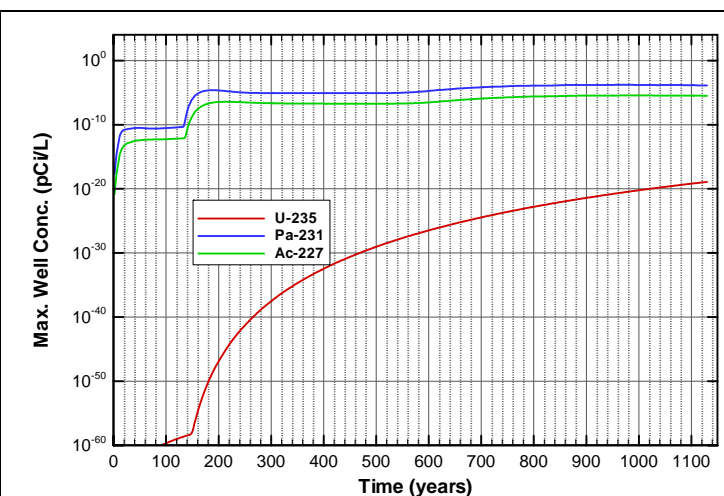

Figure A-2033. Well concentrations for Case01n11_on U-235

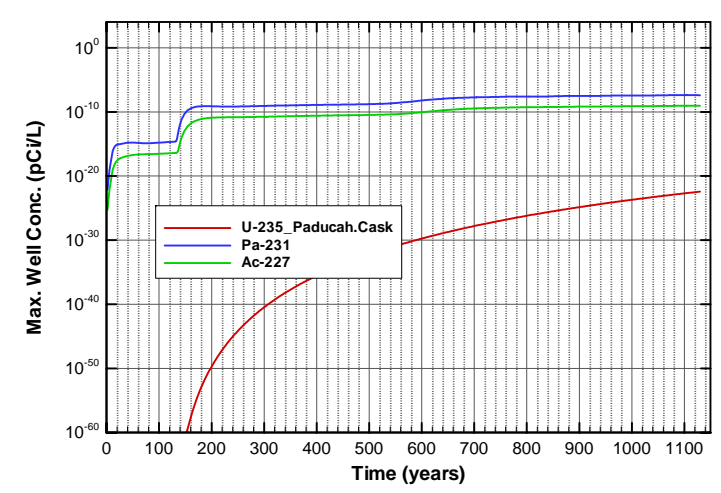

Figure A-2035. Well concentrations for Case01n11_on U-235_Paducah.Cask

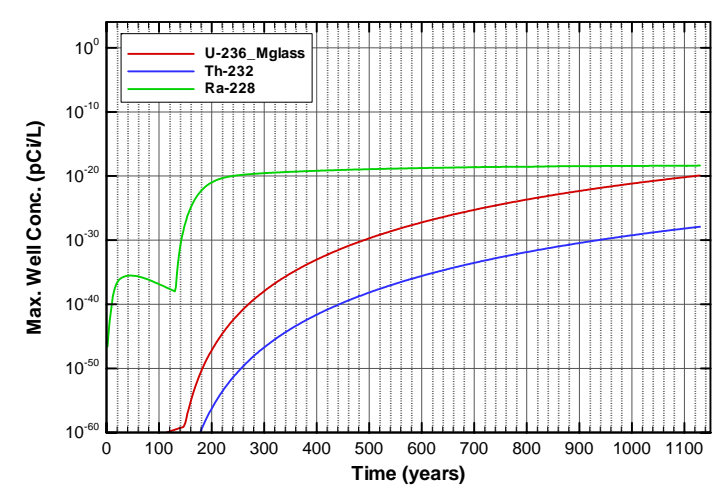

Figure A-2037. Well concentrations for Case01n11_on U-236_Mglass

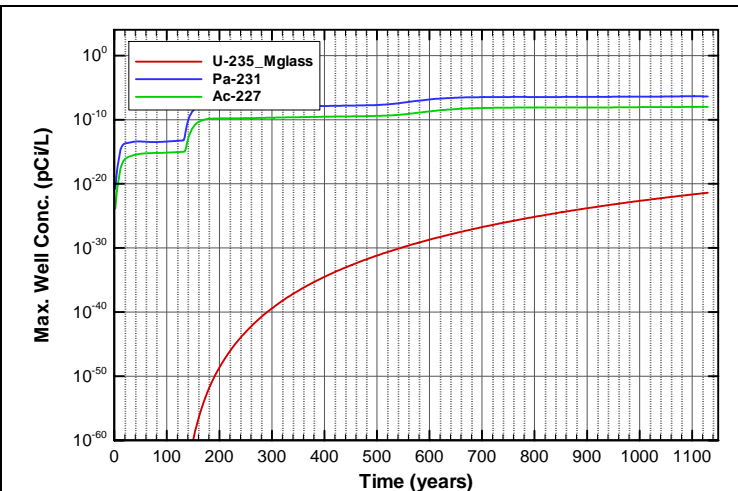

Figure A-2034. Well concentrations for Case01n11_on U-235_Mglass

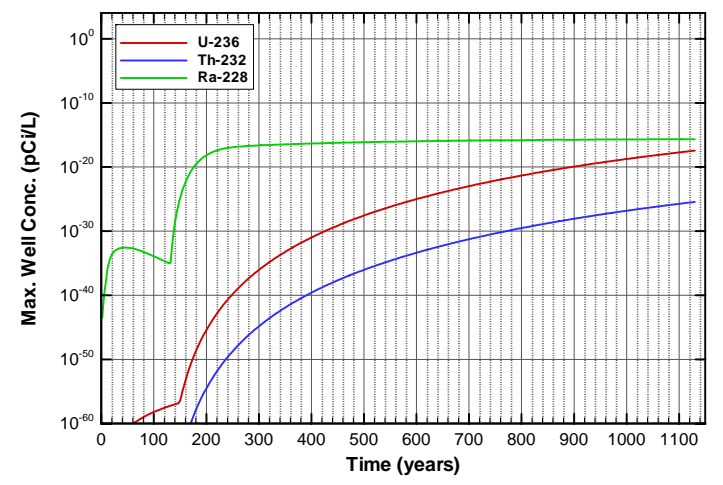

Figure A-2036. Well concentrations for Case01n11_on U-236

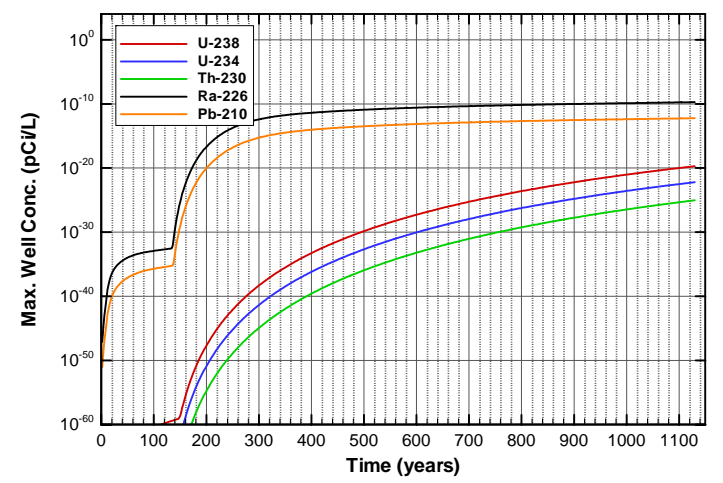

Figure A-2038. Well concentrations for Case01n11_on U-238 


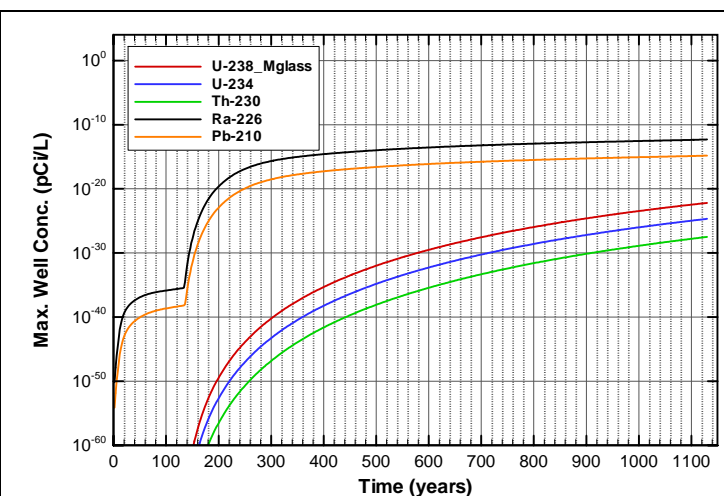

Figure A-2039. Well concentrations for Case01n11_on U-238_Mglass

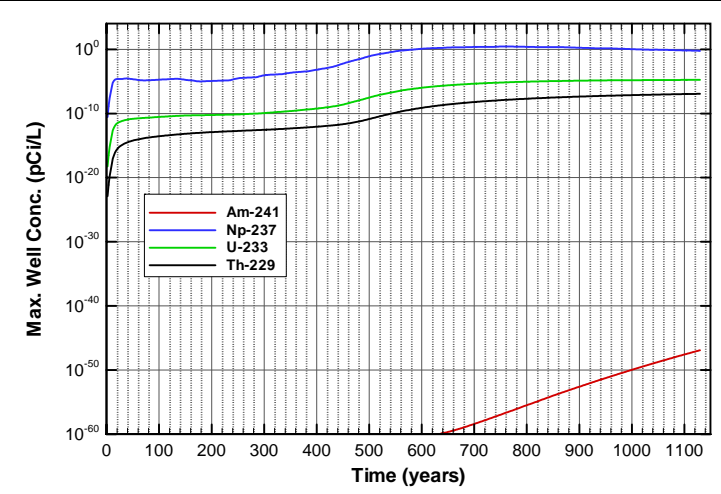

Figure A-2041. Well concentrations for Case01_off Am-241

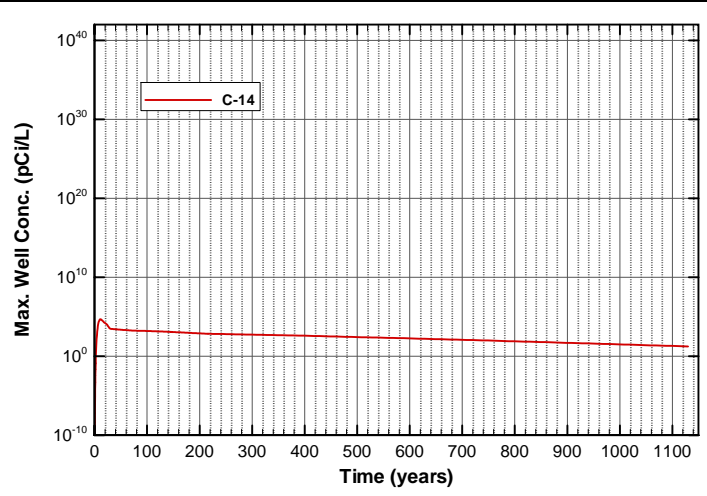

Figure A-2043. Well concentrations for Case01_off C-14

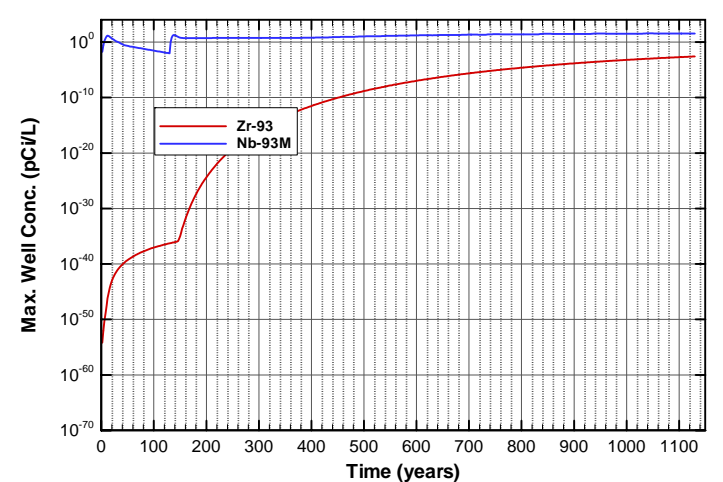

Figure A-2040. Well concentrations for Case01n11_on Zr-93

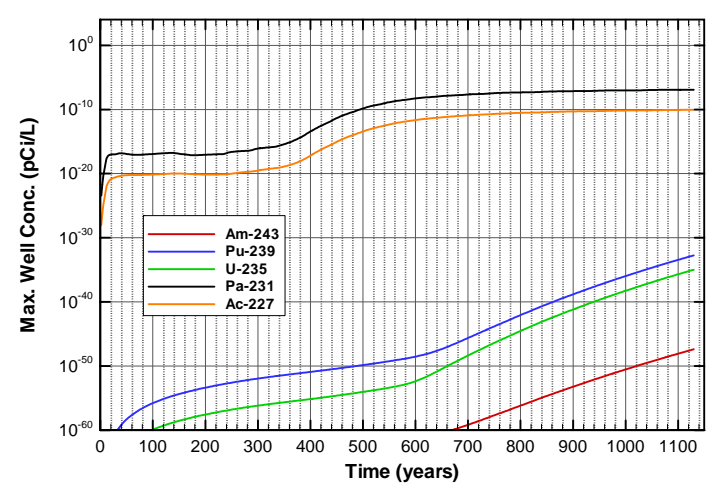

Figure A-2042. Well concentrations for Case01_off Am-243

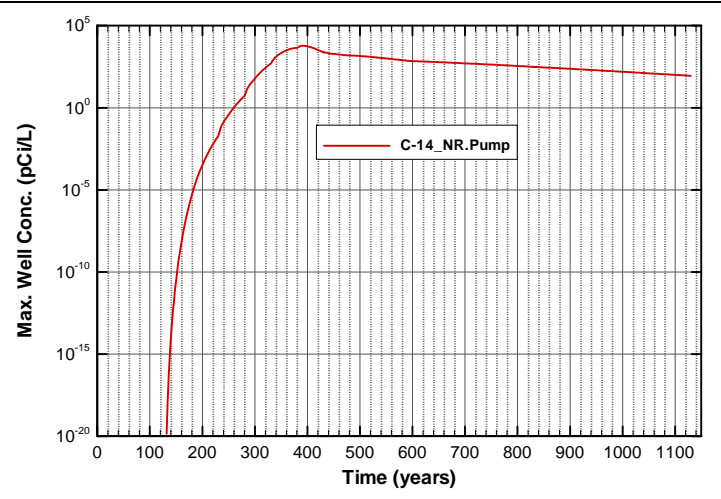

Figure A-2044. Well concentrations for Case01_off C-14_NR.Pump 
SRNL-STI-2008-00397, REVISION 0

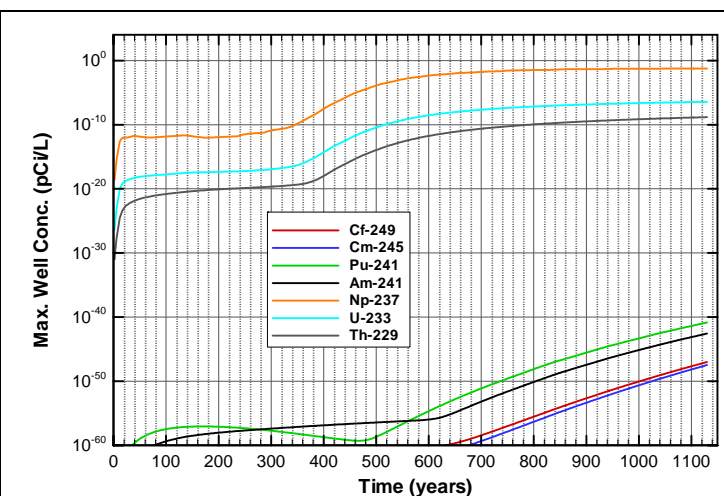

Figure A-2045. Well concentrations for Case01_off Cf-249

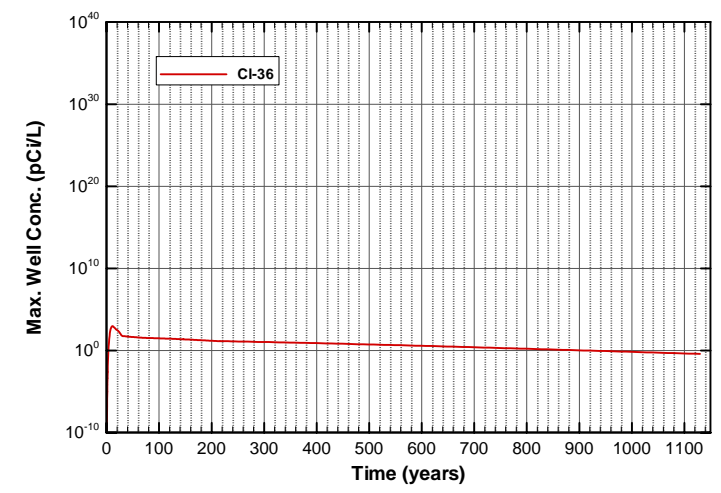

Figure A-2047. Well concentrations for Case01_off Cl-36

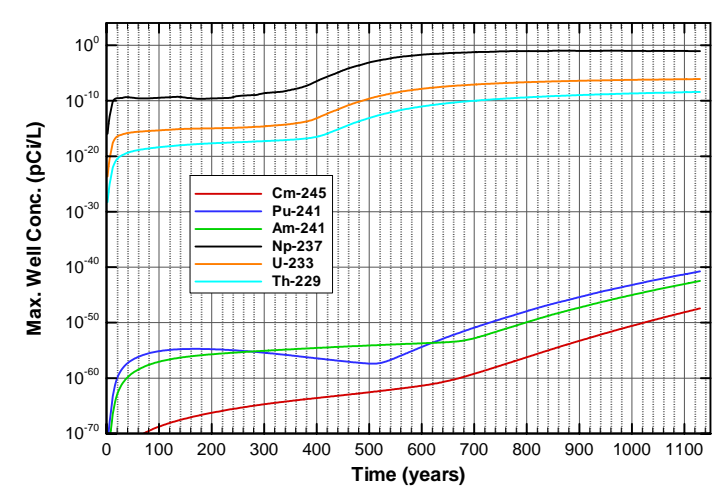

Figure A-2049. Well concentrations for Case01_off Cm-245

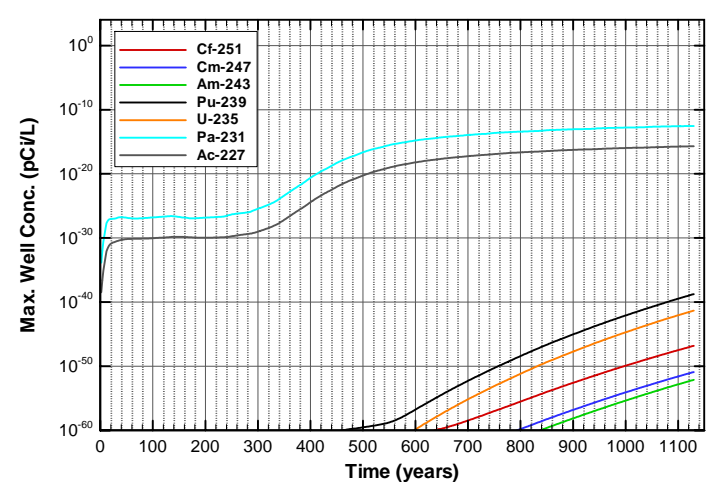

Figure A-2046. Well concentrations for Case01_off Cf-251

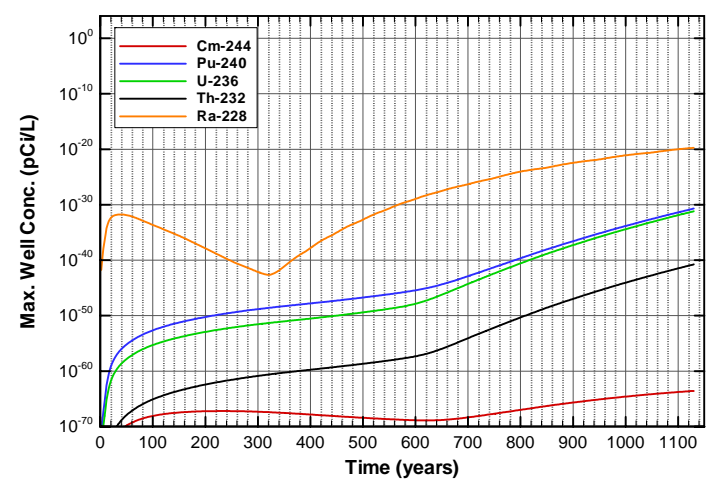

Figure A-2048. Well concentrations for Case01_off Cm-244

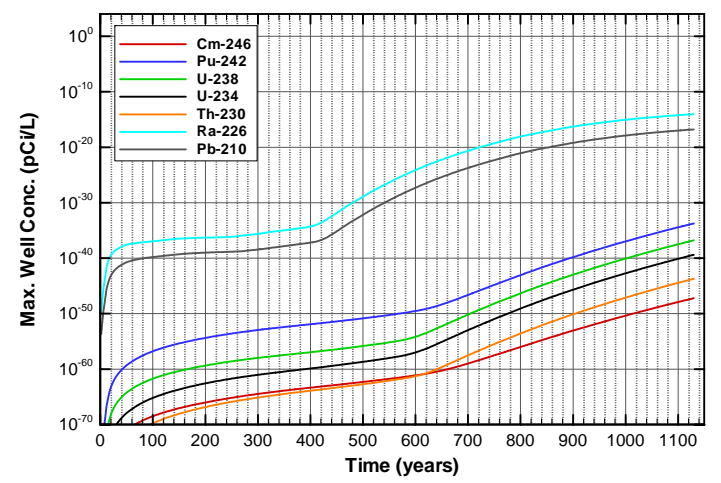

Figure A-2050. Well concentrations for Case01_off Cm-246 
SRNL-STI-2008-00397, REVISION 0

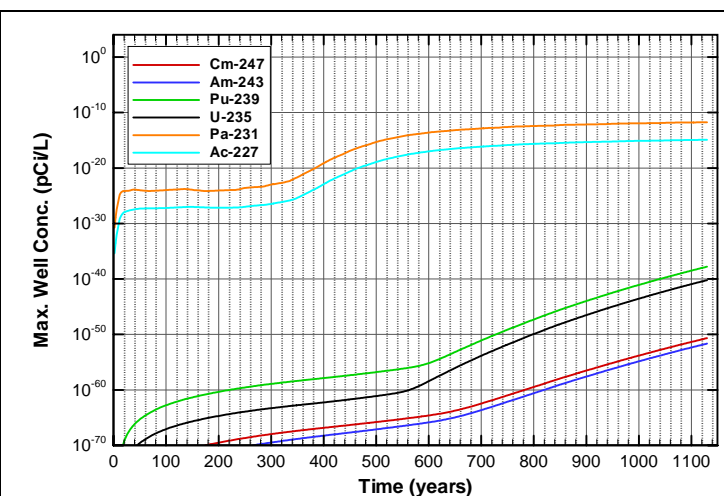

Figure A-2051. Well concentrations for Case01_off Cm-247

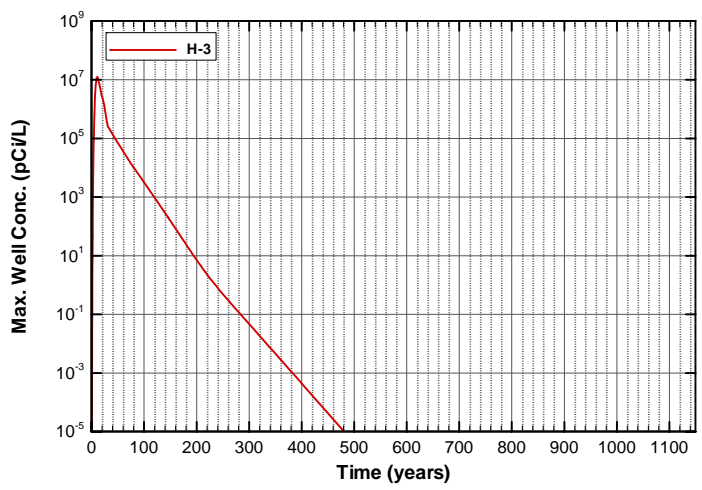

Figure A-2053. Well concentrations for Case01_off H-3

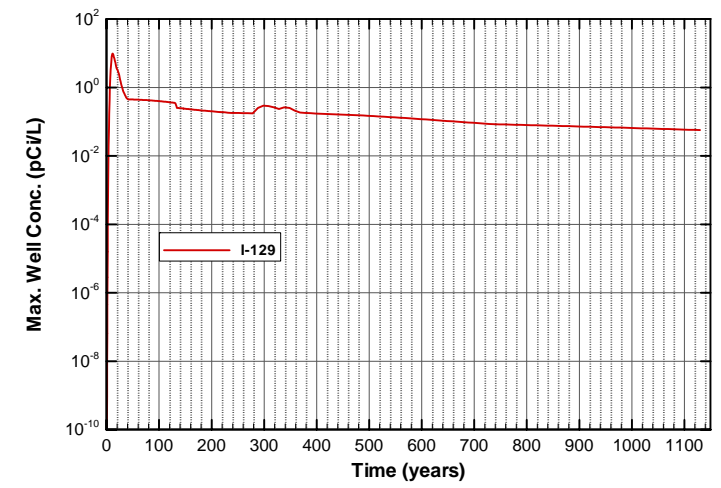

Figure A-2055. Well concentrations for Case01_off I-129

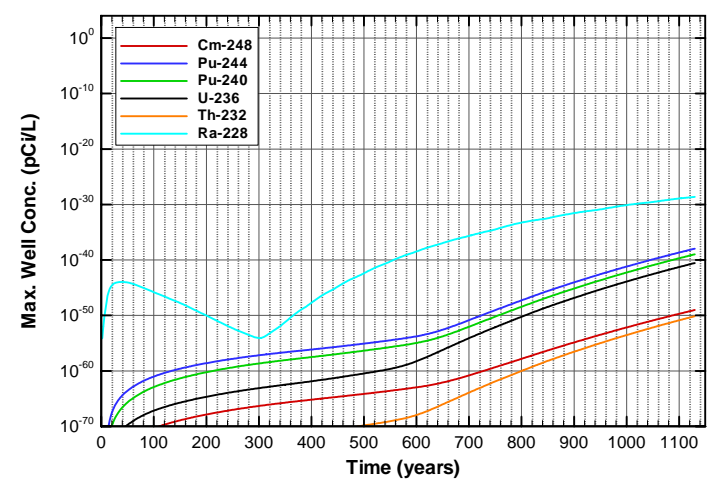

Figure A-2052. Well concentrations for Case01_off Cm-248

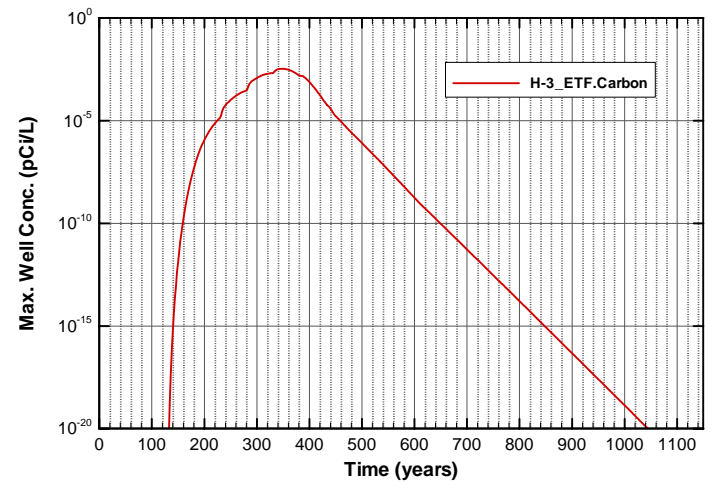

Figure A-2054. Well concentrations for Case01_off H-3_ETF.Carbon

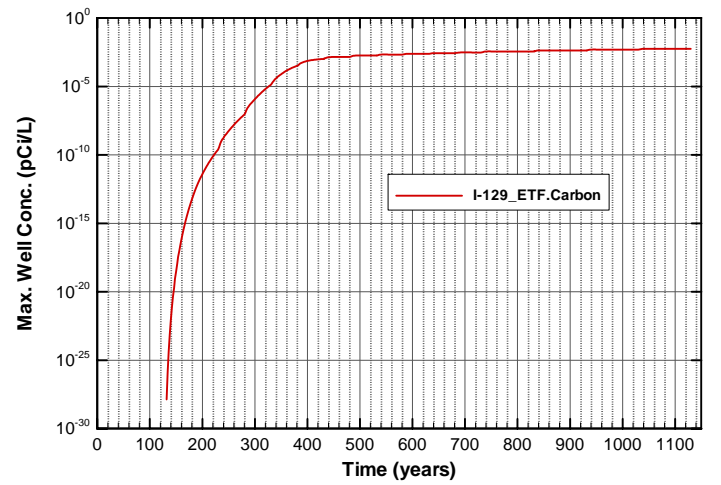

Figure A-2056. Well concentrations for Case01_off I-129_ETF.Carbon 
SRNL-STI-2008-00397, REVISION 0

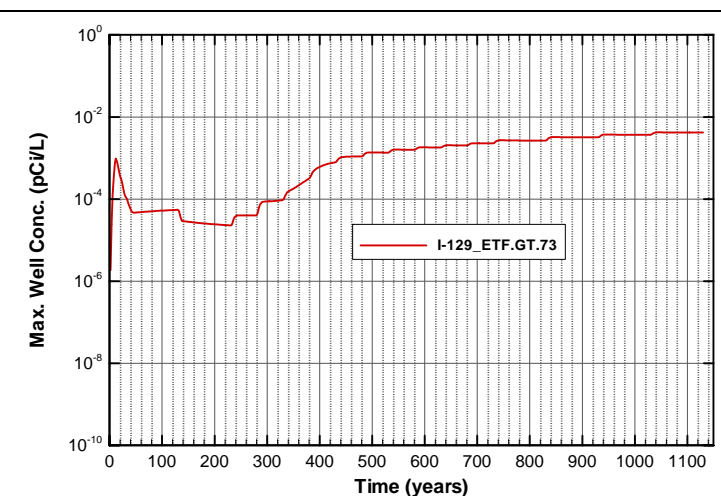

Figure A-2057. Well concentrations for Case01_off I-129_ETF.GT.73

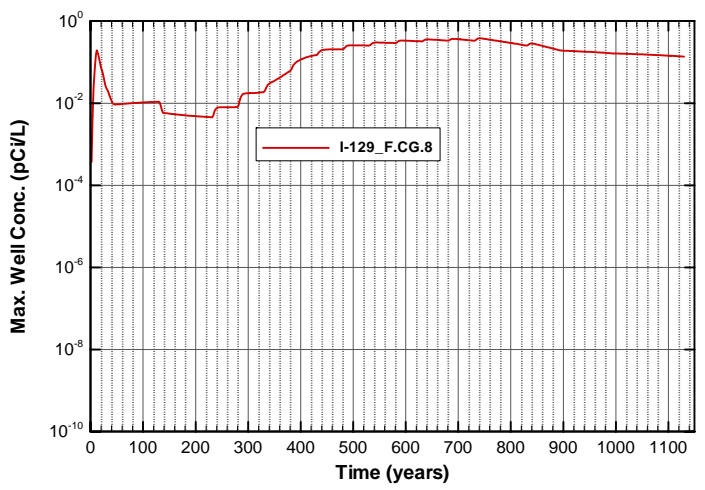

Figure A-2059. Well concentrations for Case01_off I-129_F.CG.8

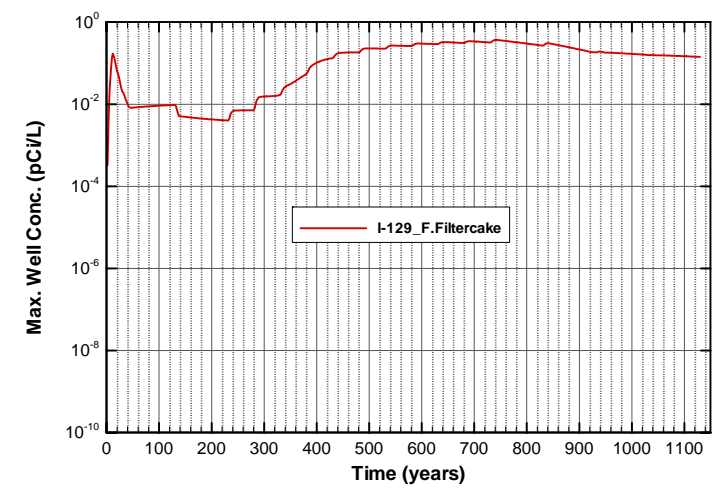

Figure A-2061. Well concentrations for Case01_off I-129_F.Filtercake

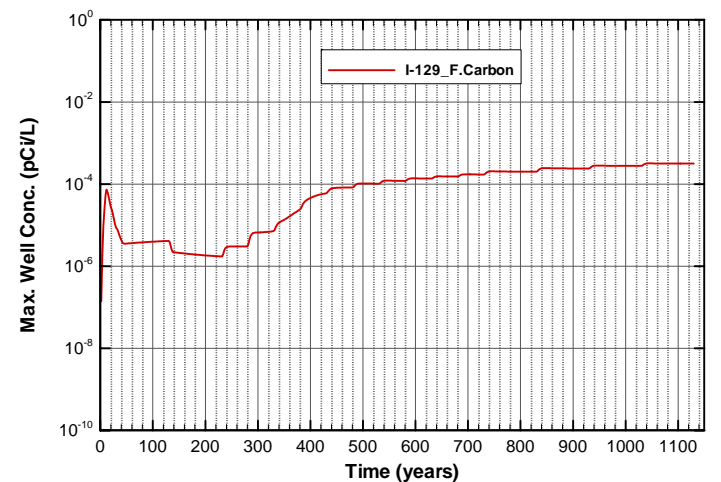

Figure A-2058. Well concentrations for Case01_off I-129_F.Carbon

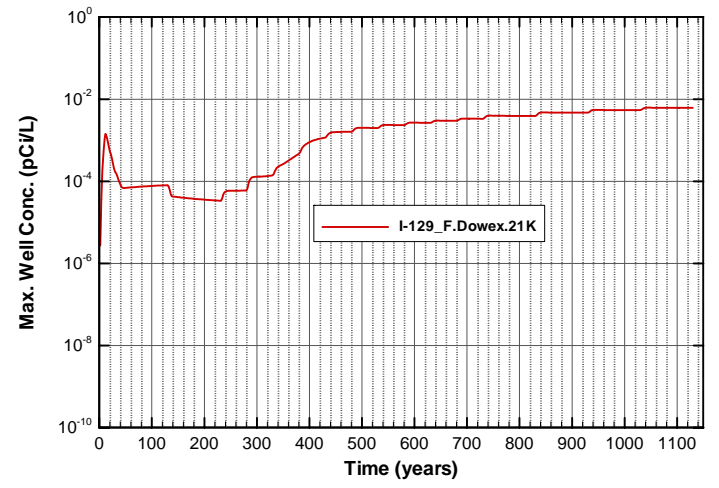

Figure A-2060. Well concentrations for Case01_off I-129_F.Dowex.21K

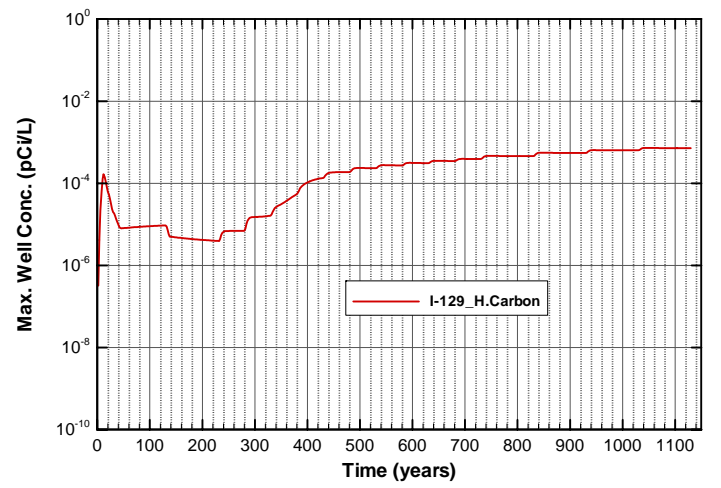

Figure A-2062. Well concentrations for Case01_off I-129_H.Carbon 
SRNL-STI-2008-00397, REVISION 0

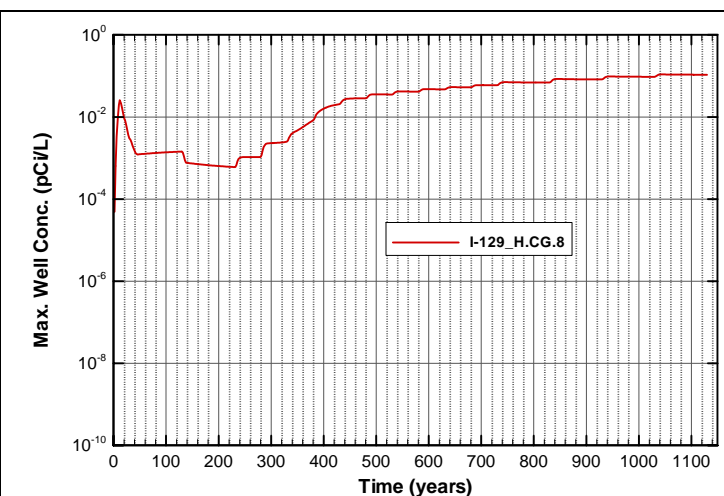

Figure A-2063. Well concentrations for Case01_off I-129_H.CG.8

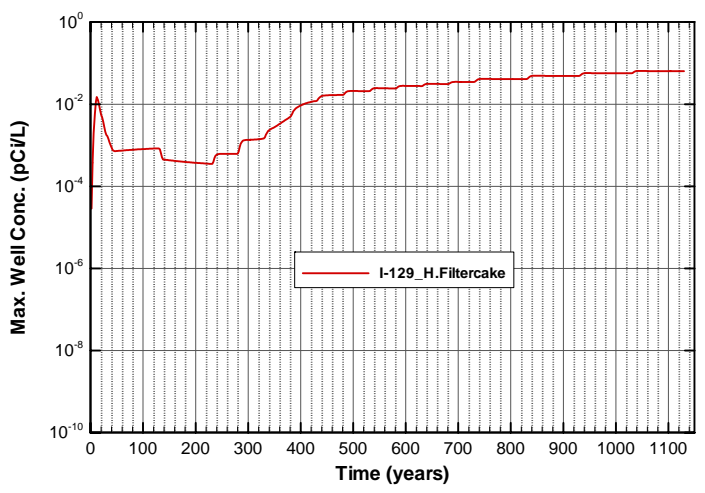

Figure A-2065. Well concentrations for Case01_off I-129_H.Filtercake

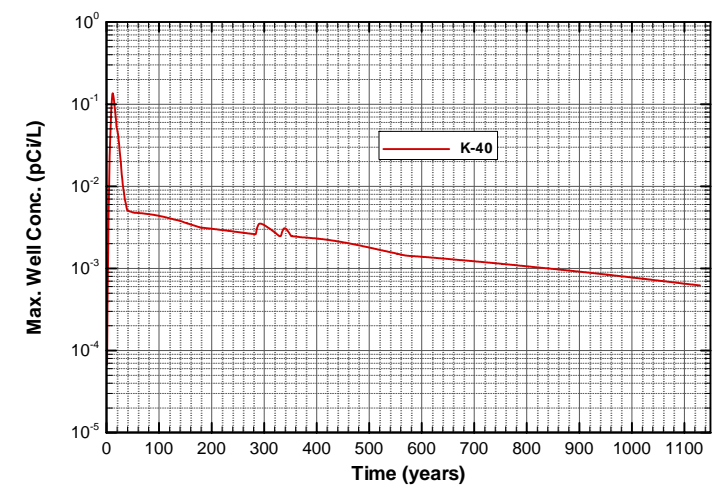

Figure A-2067. Well concentrations for Case01_off K-40

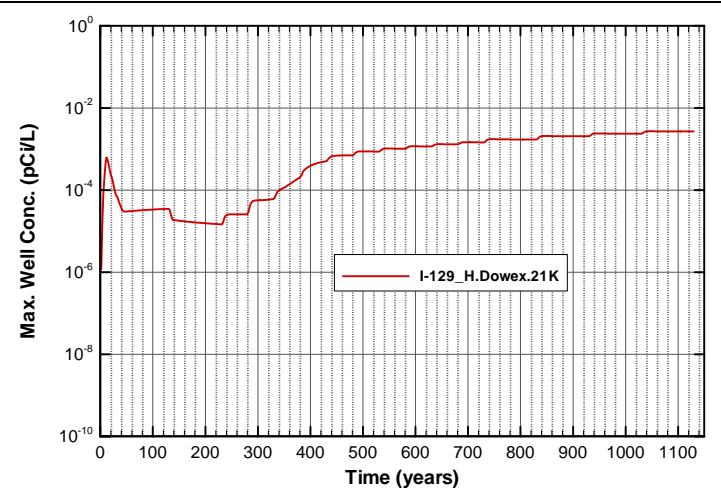

Figure A-2064. Well concentrations for Case01_off I-129_H.Dowex.21K

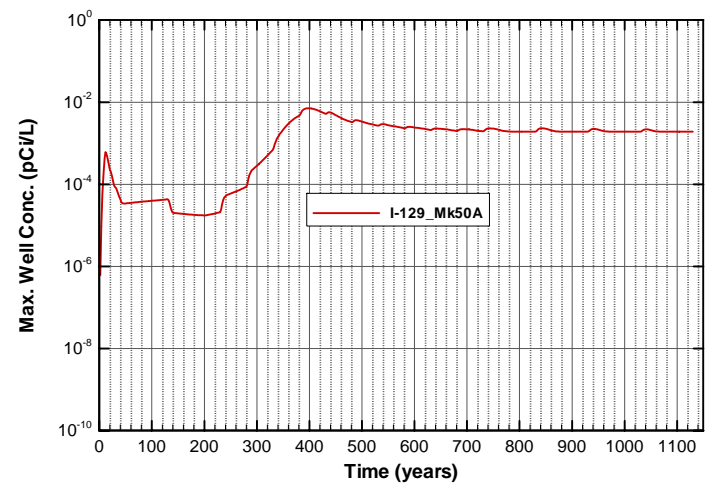

Figure A-2066. Well concentrations for Case01_off I-129_Mk50A

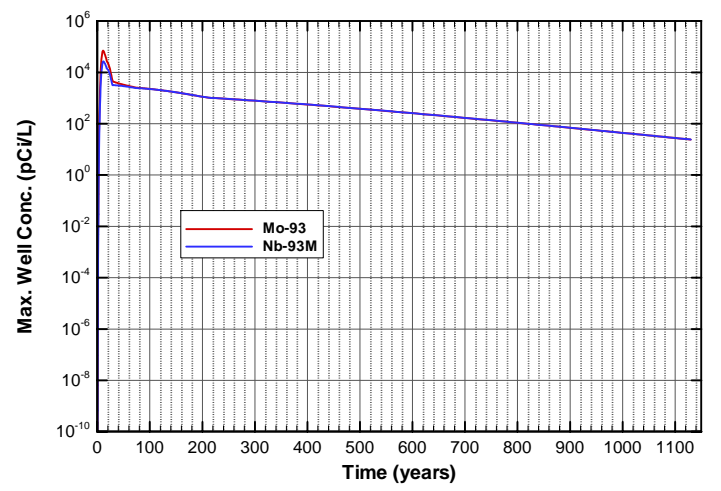

Figure A-2068. Well concentrations for Case01_off Mo-93 
SRNL-STI-2008-00397, REVISION 0

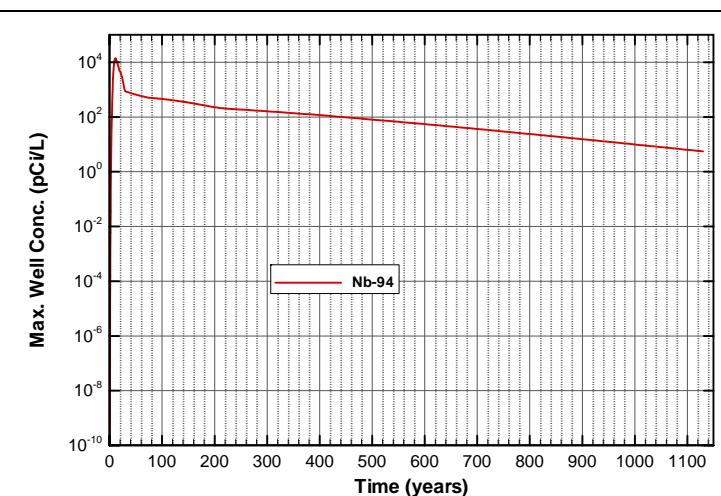

Figure A-2069. Well concentrations for Case01_off Nb-94

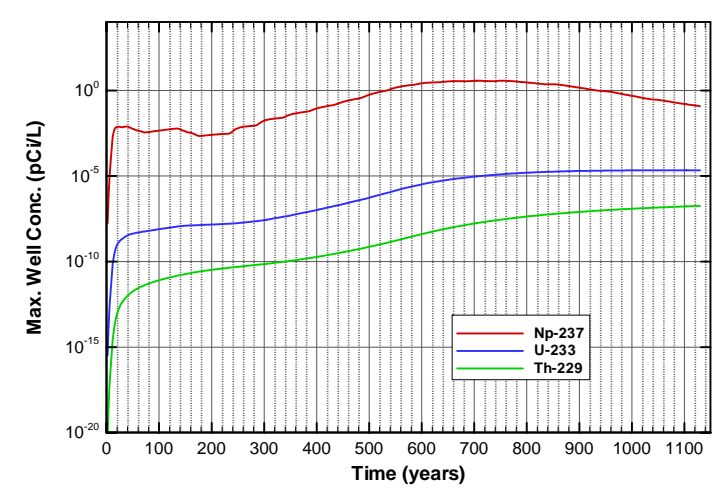

Figure A-2071. Well concentrations for Case01_off Np-237

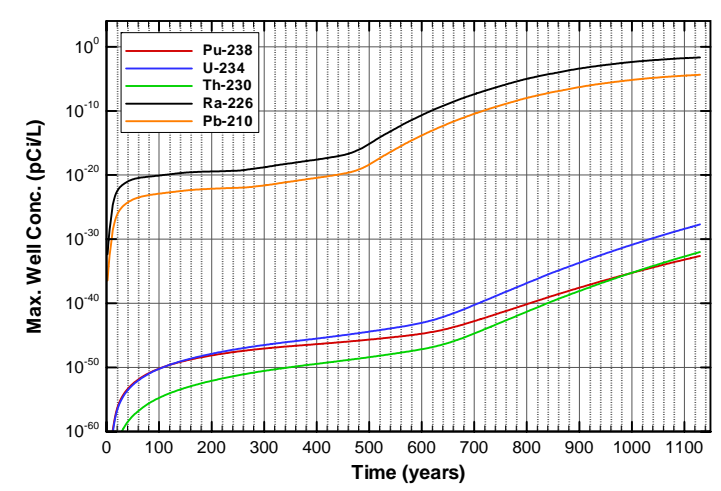

Figure A-2073. Well concentrations for Case01_off Pu-238

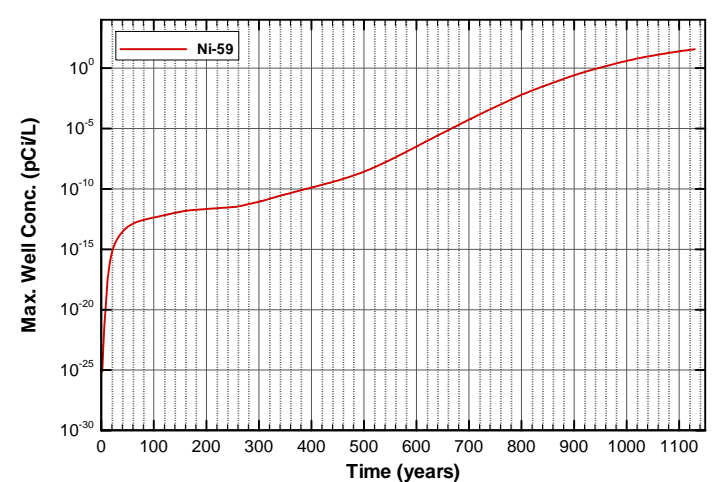

Figure A-2070. Well concentrations for Case01_off Ni-59

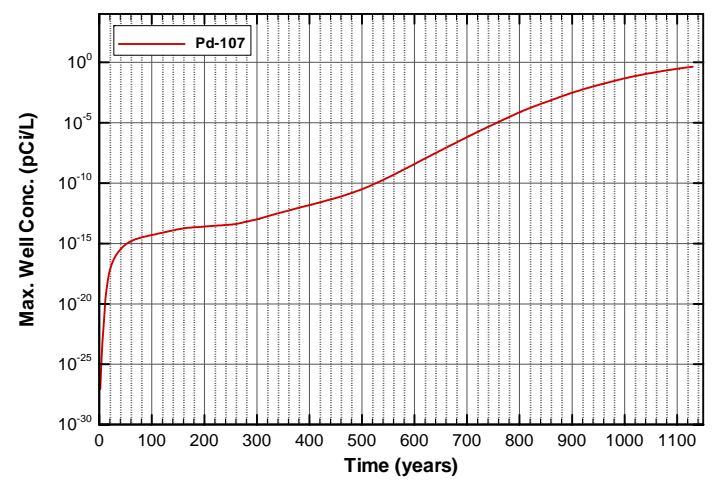

Figure A-2072. Well concentrations for Case01_off Pd-107

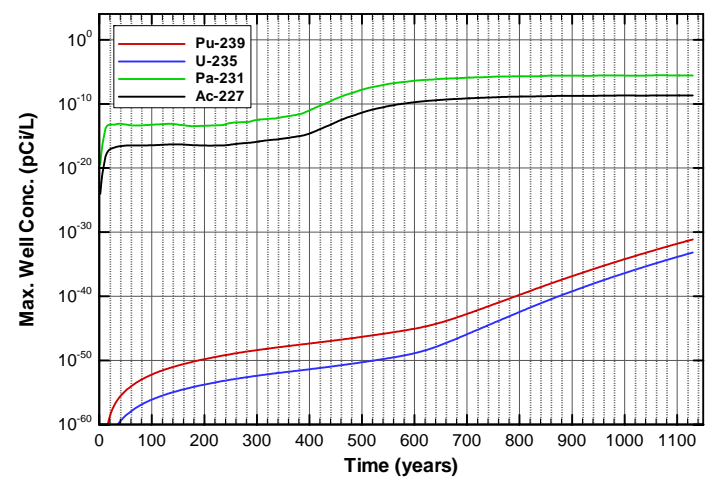

Figure A-2074. Well concentrations for Case01_off Pu-239 
SRNL-STI-2008-00397, REVISION 0

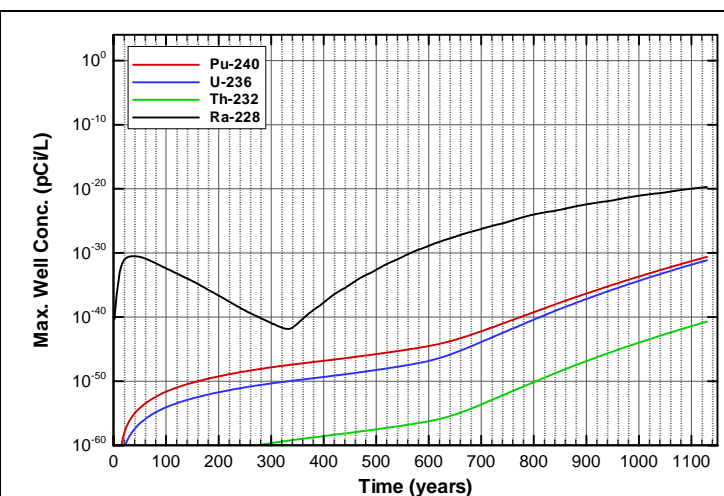

Figure A-2075. Well concentrations for Case01_off Pu-240

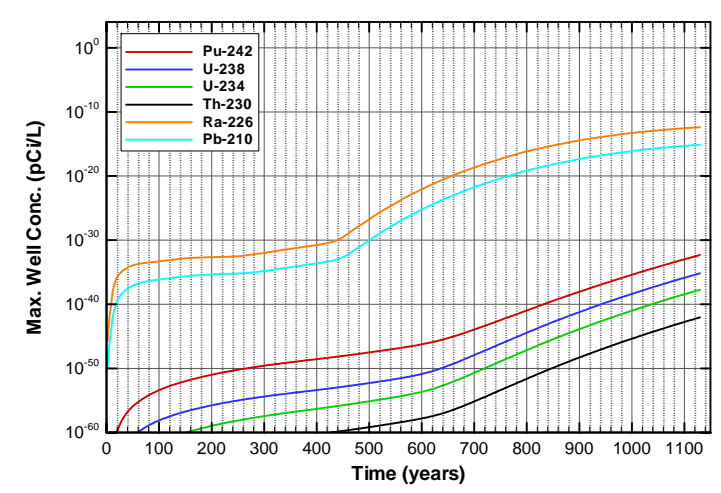

Figure A-2077. Well concentrations for Case01_off Pu-242

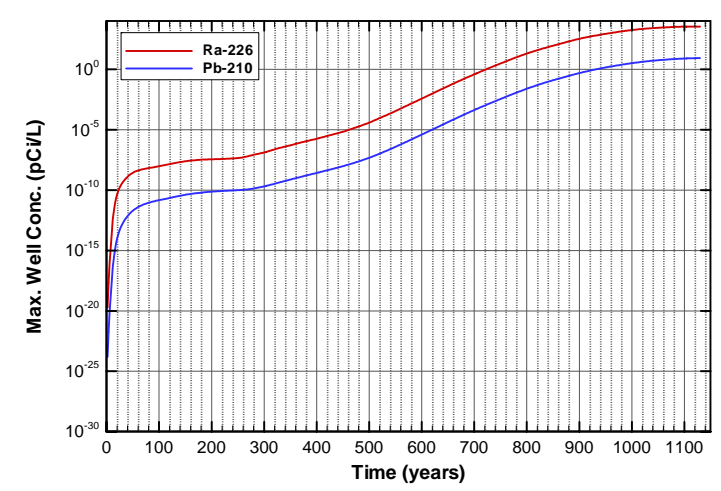

Figure A-2079. Well concentrations for Case01_off Ra-226

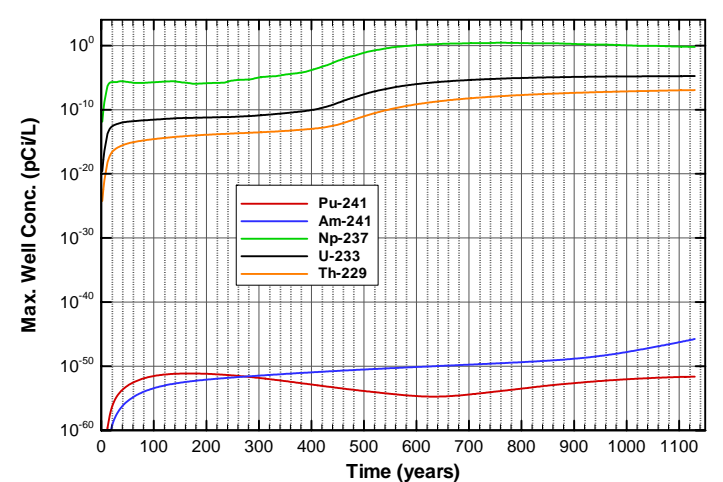

Figure A-2076. Well concentrations for Case01_off Pu-241

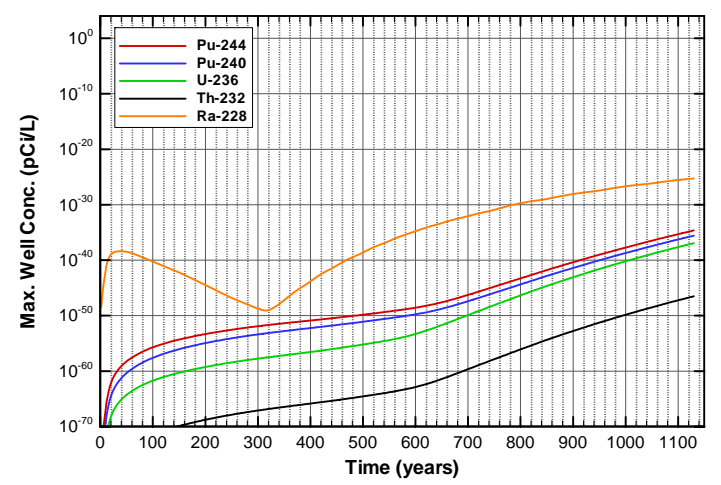

Figure A-2078. Well concentrations for Case01_off Pu-244

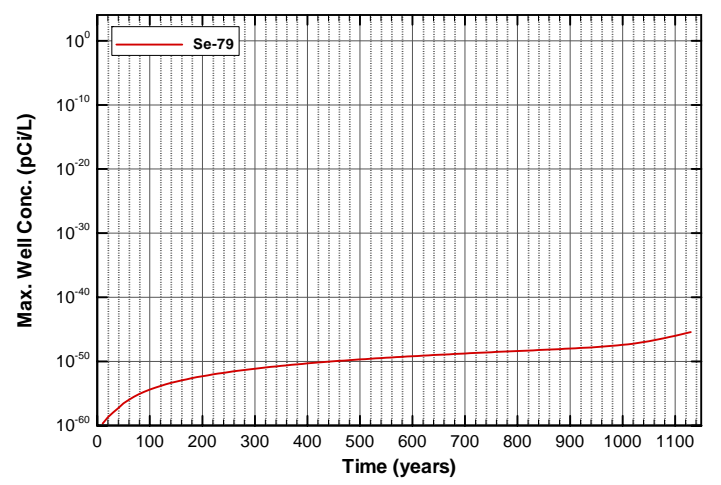

Figure A-2080. Well concentrations for Case01_off Se-79 
SRNL-STI-2008-00397, REVISION 0

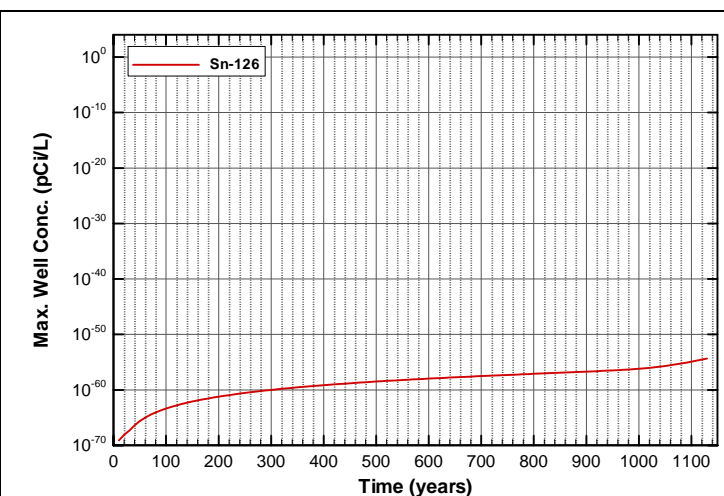

Figure A-2081. Well concentrations for Case01_off Sn-126

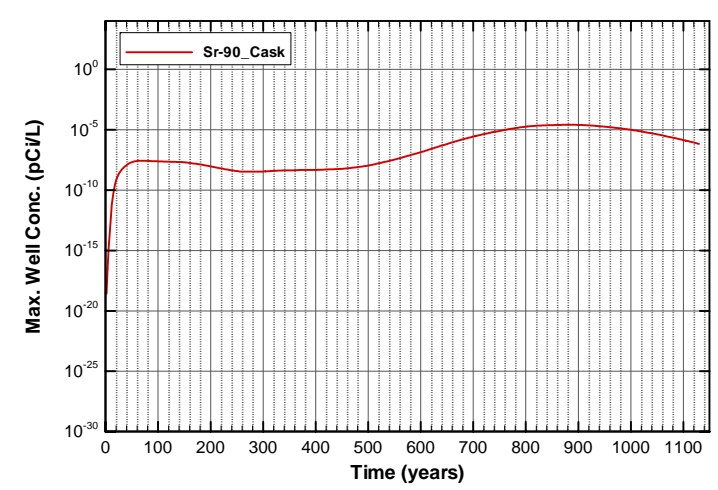

Figure A-2083. Well concentrations for Case01_off Sr-90_Cask

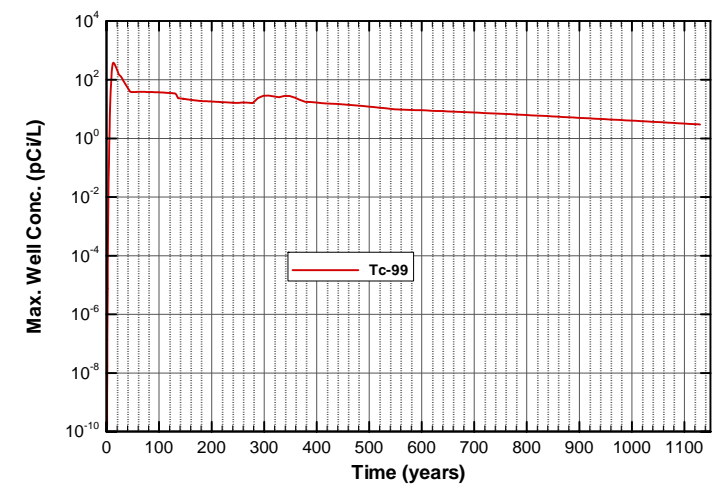

Figure A-2085. Well concentrations for Case01_off Tc-99

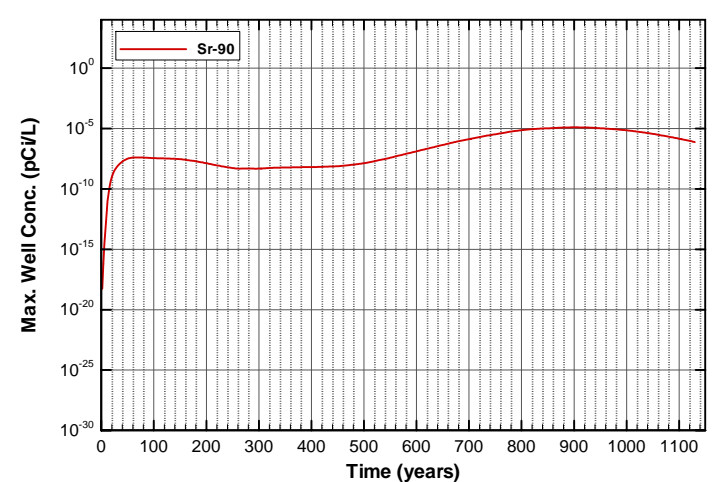

Figure A-2082. Well concentrations for Case01_off Sr-90

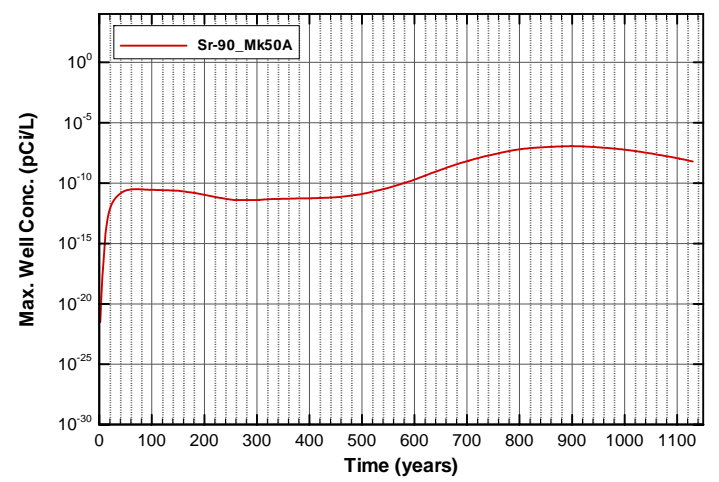

Figure A-2084. Well concentrations for Case01_off Sr-90_Mk50A

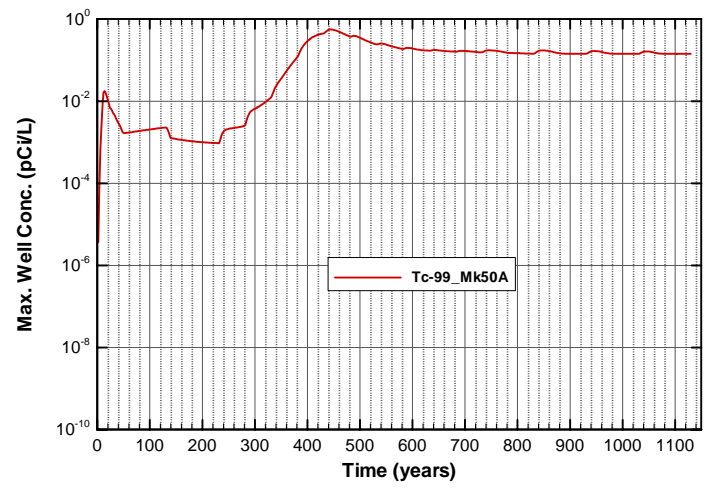

Figure A-2086. Well concentrations for Case01_off Tc-99_Mk50A 
SRNL-STI-2008-00397, REVISION 0

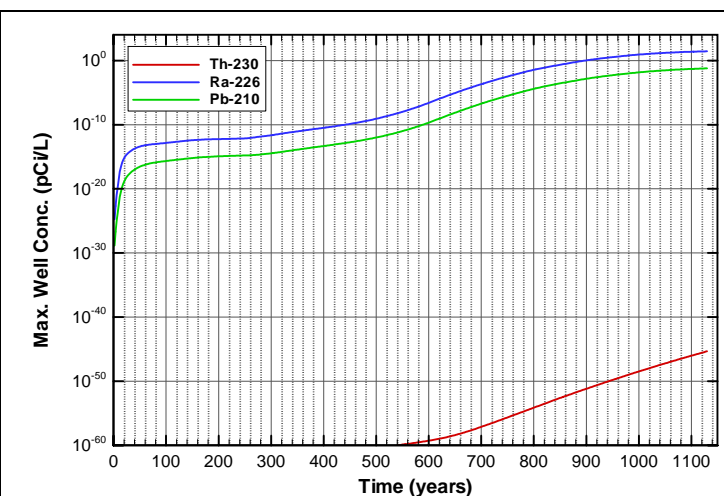

Figure A-2087. Well concentrations for Case01_off Th-230

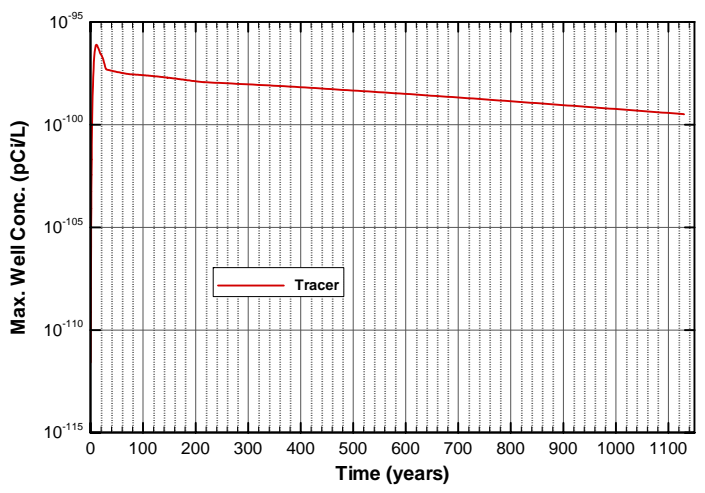

Figure A-2089. Well concentrations for Case01_off Tracer

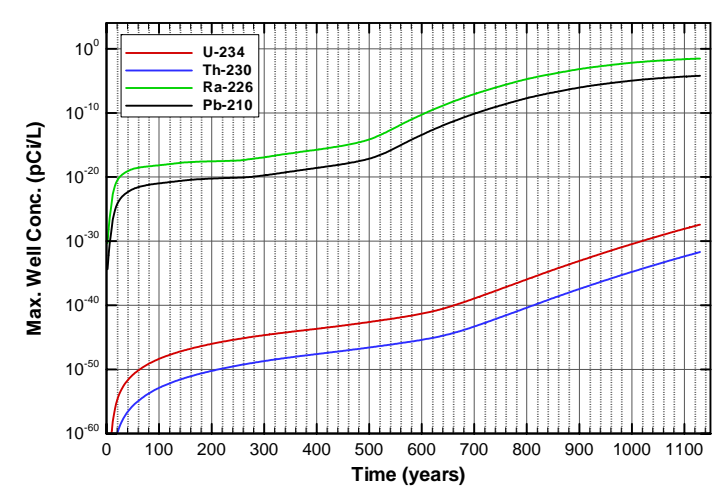

Figure A-2091. Well concentrations for Case01_off U-234

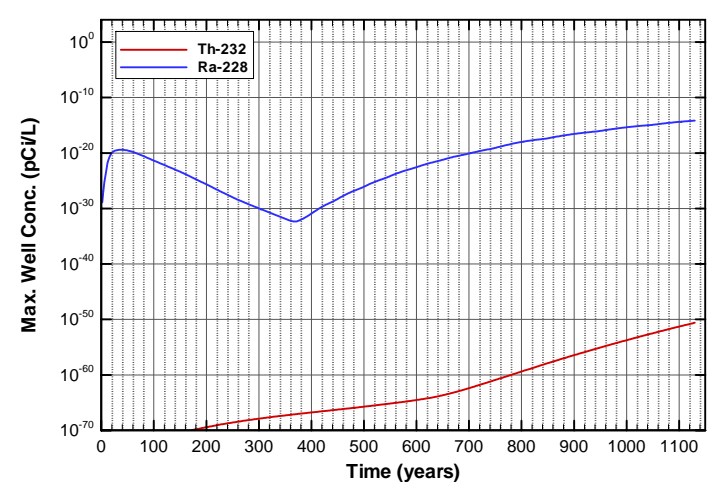

Figure A-2088. Well concentrations for Case01_off Th-232

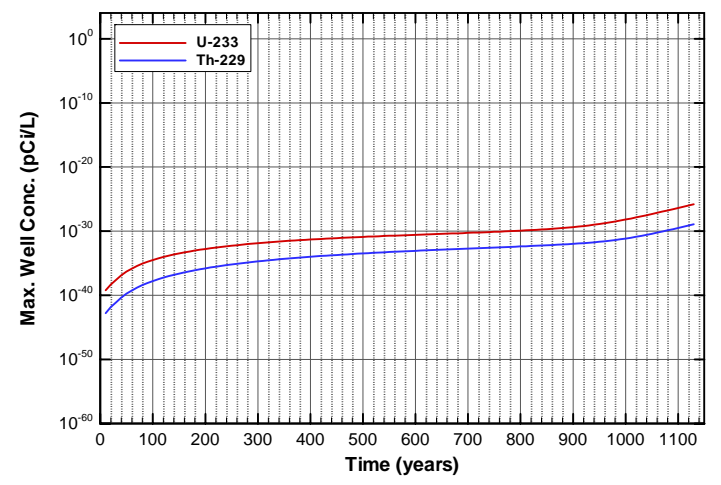

Figure A-2090. Well concentrations for Case01_off U-233

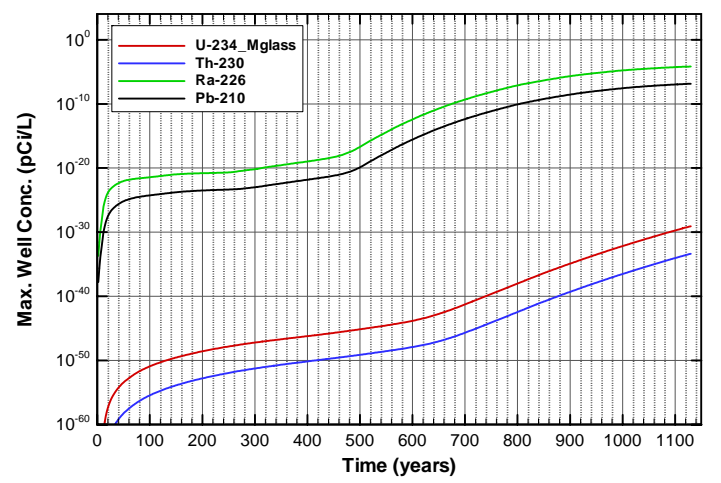

Figure A-2092. Well concentrations for Case01_off U-234_Mglass 


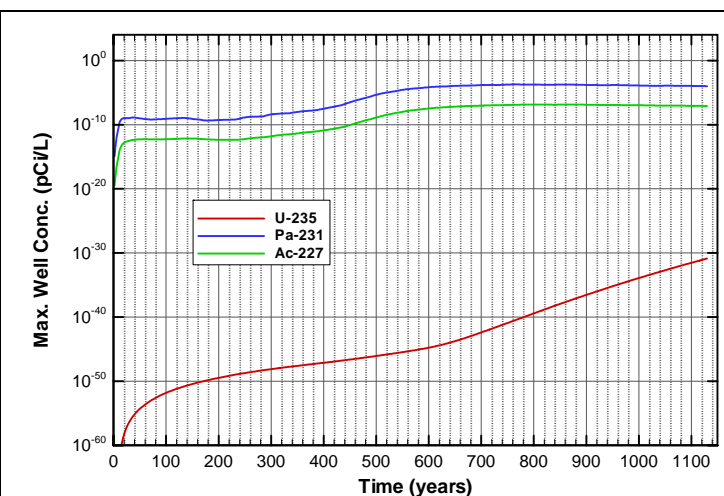

Figure A-2093. Well concentrations for Case01_off U-235

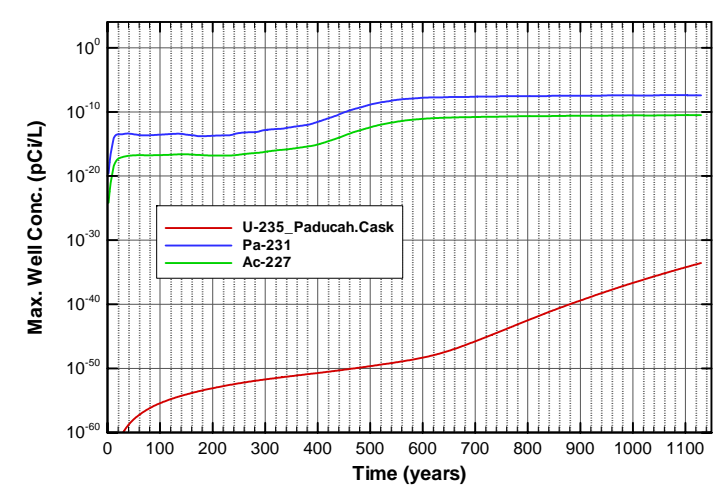

Figure A-2095. Well concentrations for Case01_off U-235_Paducah.Cask

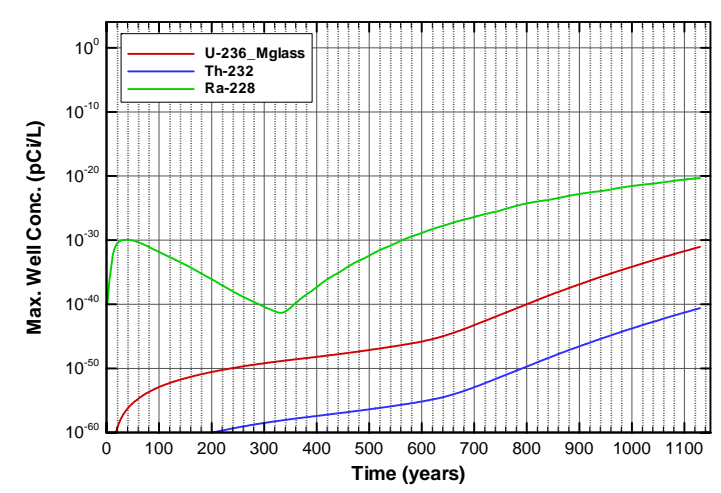

Figure A-2097. Well concentrations for Case01_off U-236_Mglass

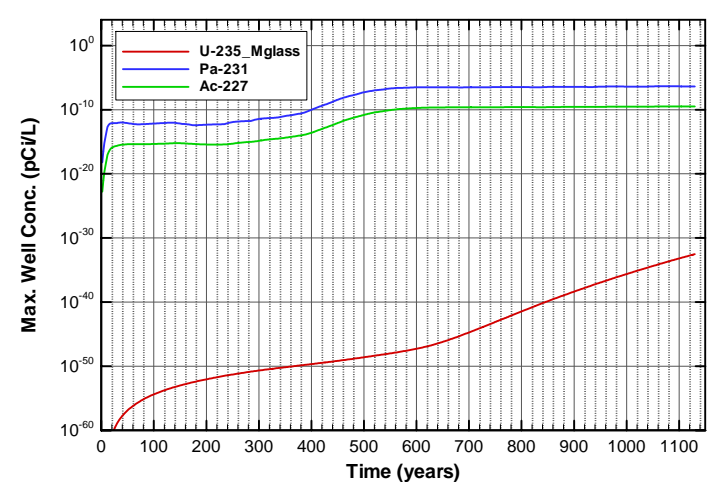

Figure A-2094. Well concentrations for Case01_off U-235_Mglass

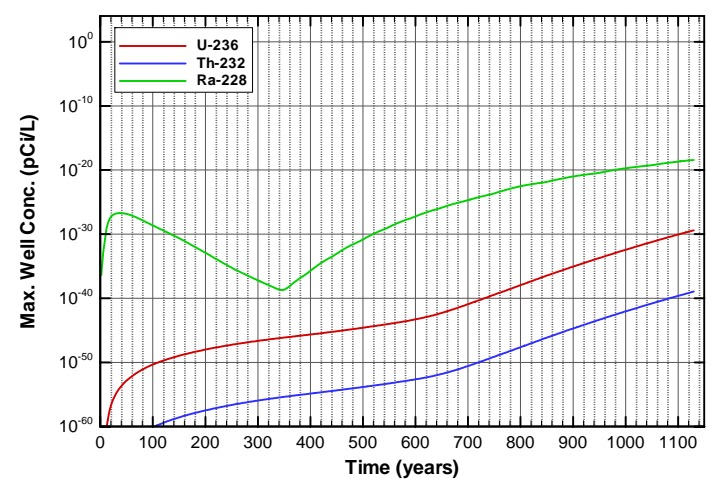

Figure A-2096. Well concentrations for Case01_off U-236

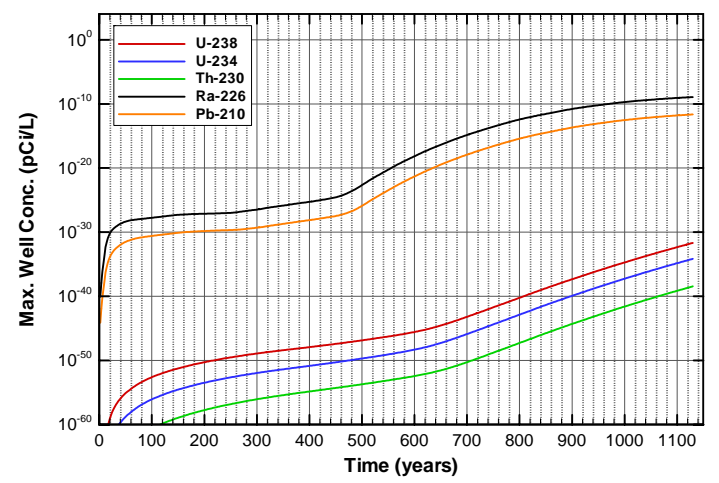

Figure A-2098. Well concentrations for Case01_off U-238 


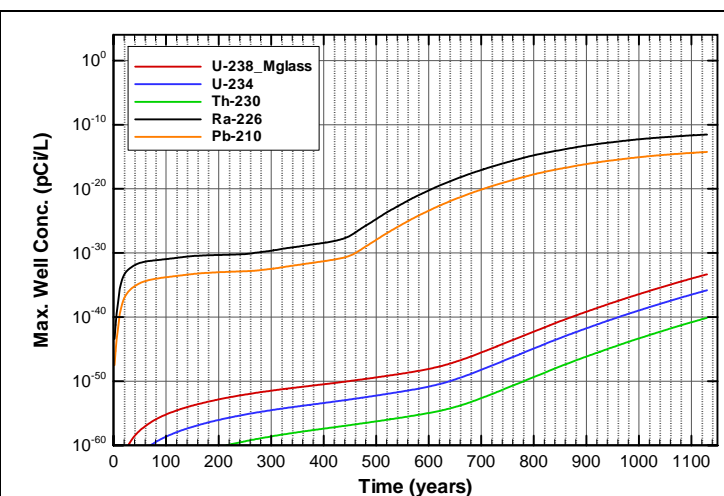

Figure A-2099. Well concentrations for Case01_off U-238_Mglass

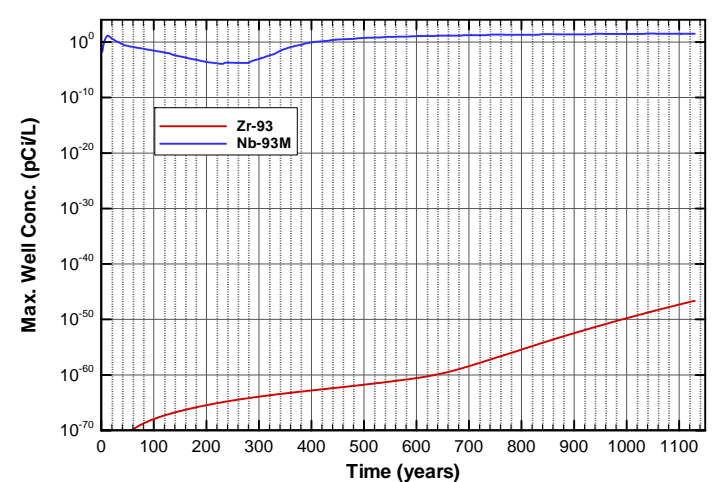

Figure A-2100. Well concentrations for Case01_off Zr-93

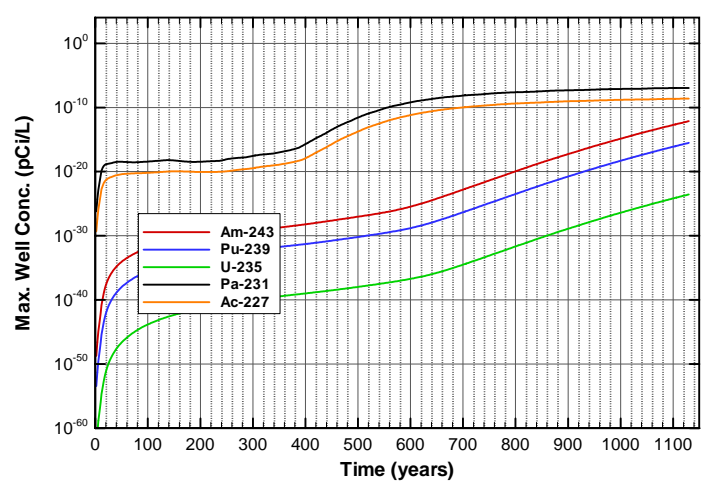

Figure A-2102. Well concentrations for Case01_on Am-243

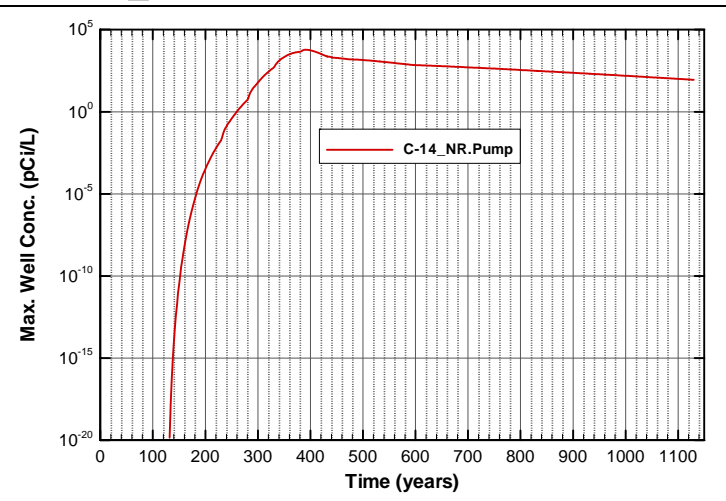

Figure A-2104. Well concentrations for Case01_on C-14_NR.Pump 
SRNL-STI-2008-00397, REVISION 0

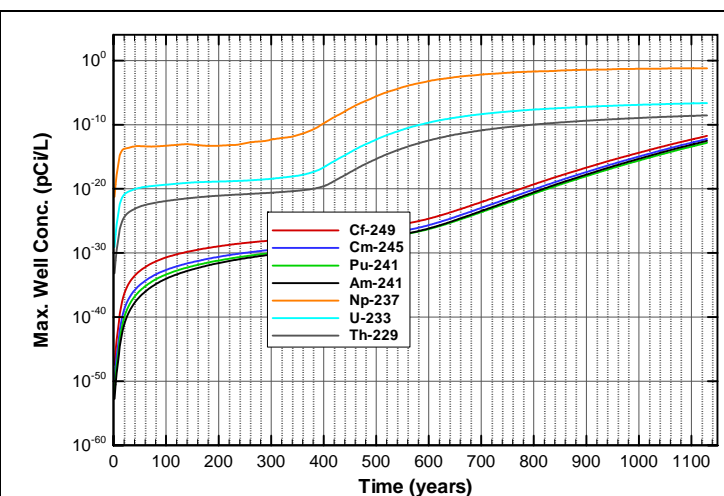

Figure A-2105. Well concentrations for Case01_on Cf-249

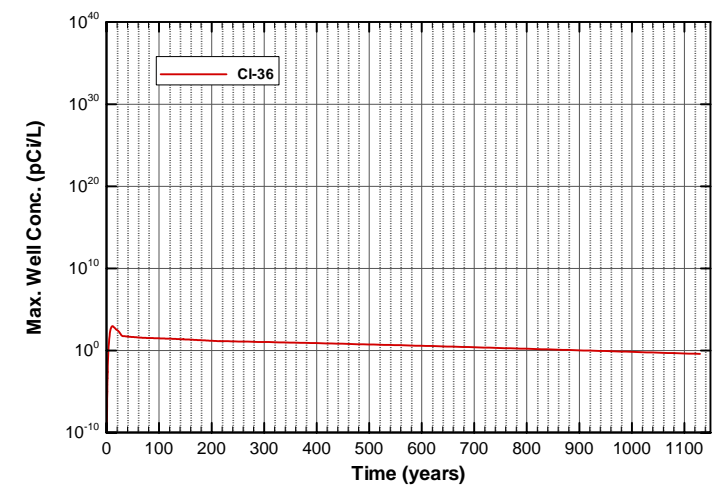

Figure A-2107. Well concentrations for Case01_on Cl-36

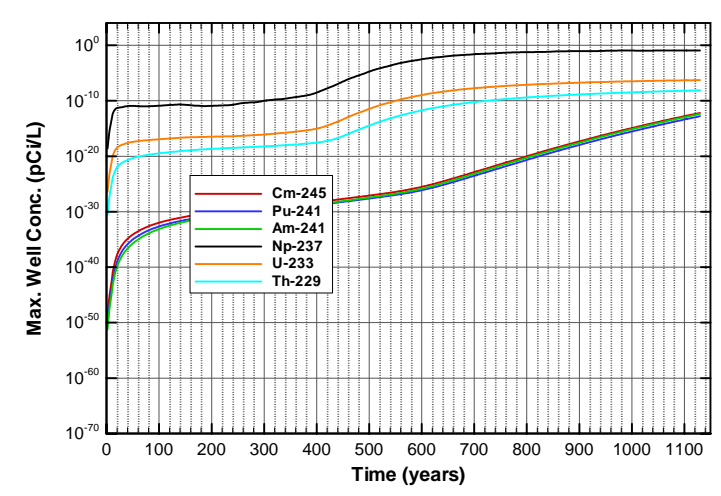

Figure A-2109. Well concentrations for Case01_on Cm-245

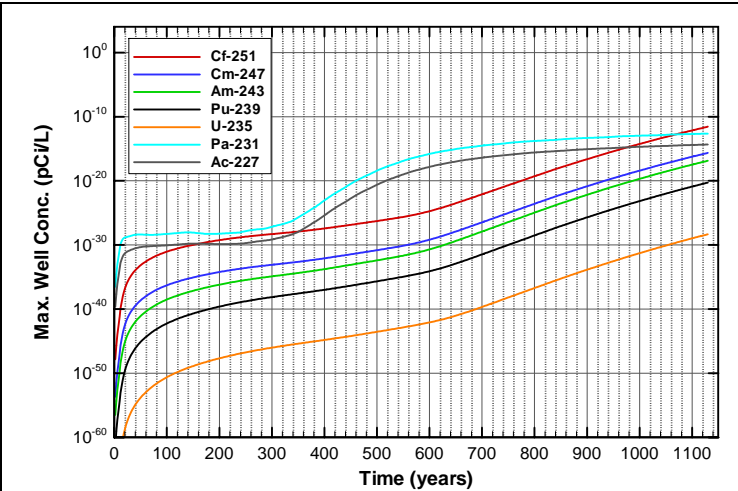

Figure A-2106. Well concentrations for Case01_on Cf-251

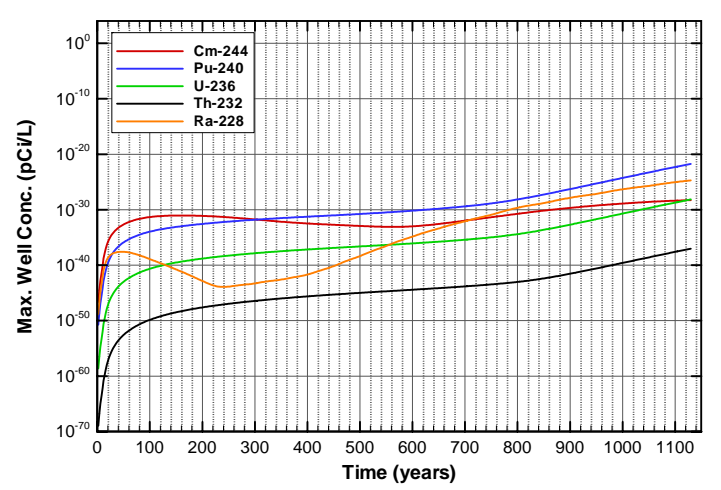

Figure A-2108. Well concentrations for Case01_on Cm-244

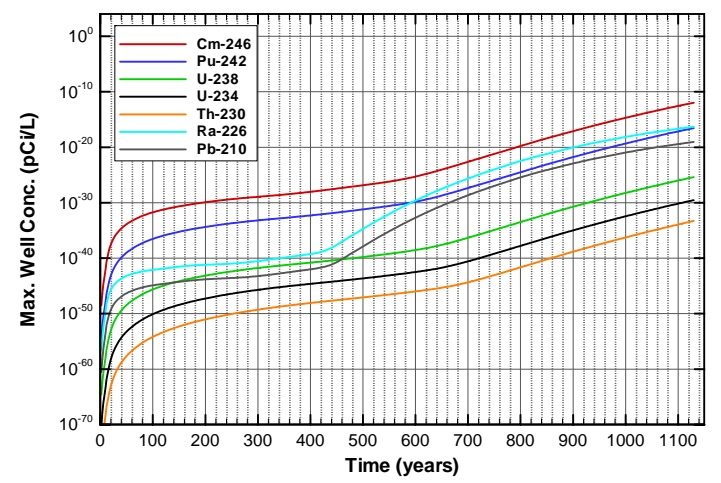

Figure A-2110. Well concentrations for Case01_on Cm-246 
SRNL-STI-2008-00397, REVISION 0

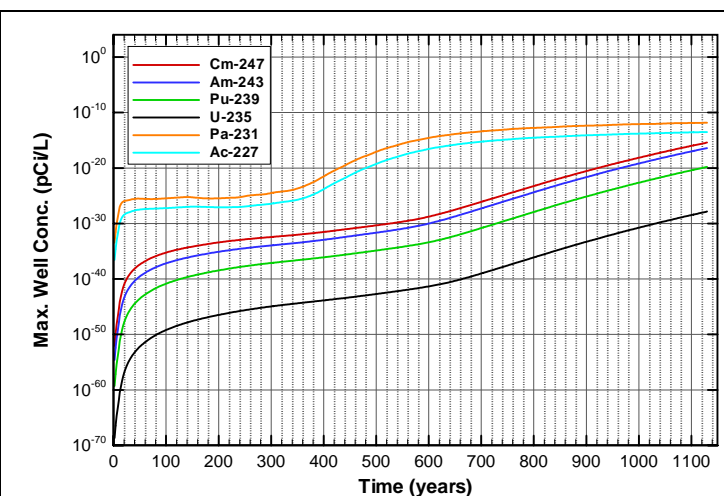

Figure A-2111. Well concentrations for Case01_on Cm-247

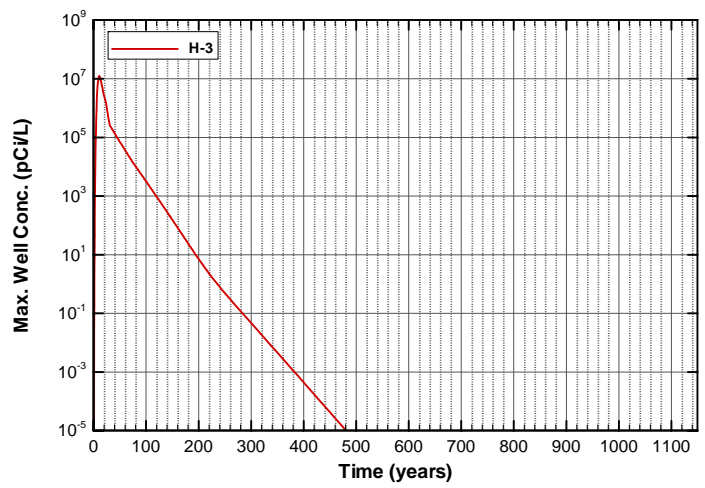

Figure A-2113. Well concentrations for Case01_on H-3

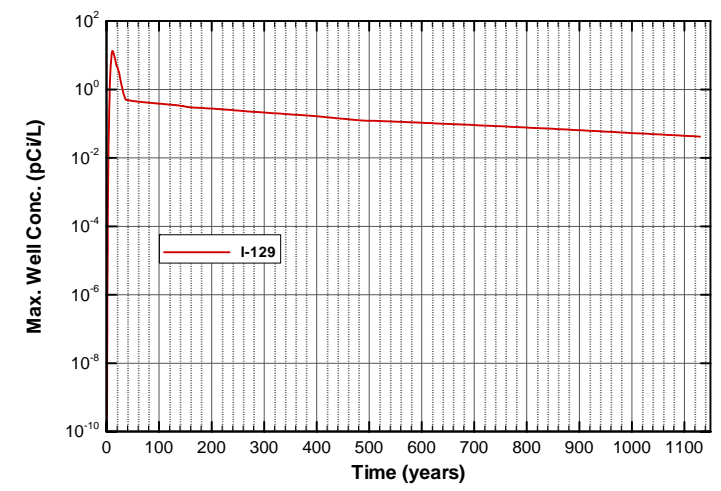

Figure A-2115. Well concentrations for Case01_on I-129

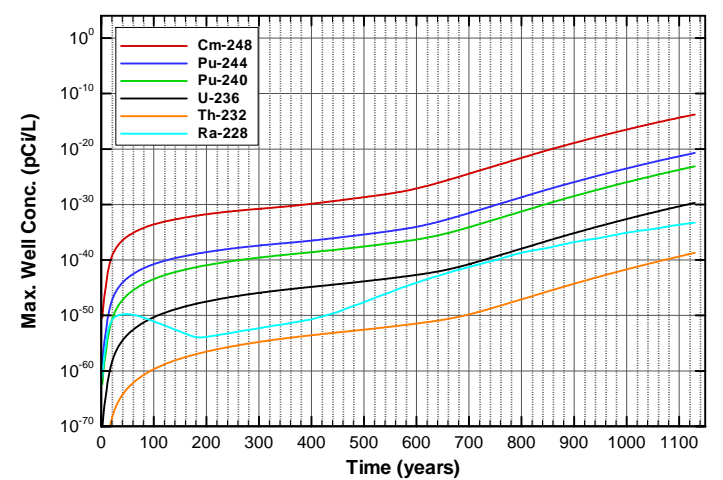

Figure A-2112. Well concentrations for Case01_on Cm-248

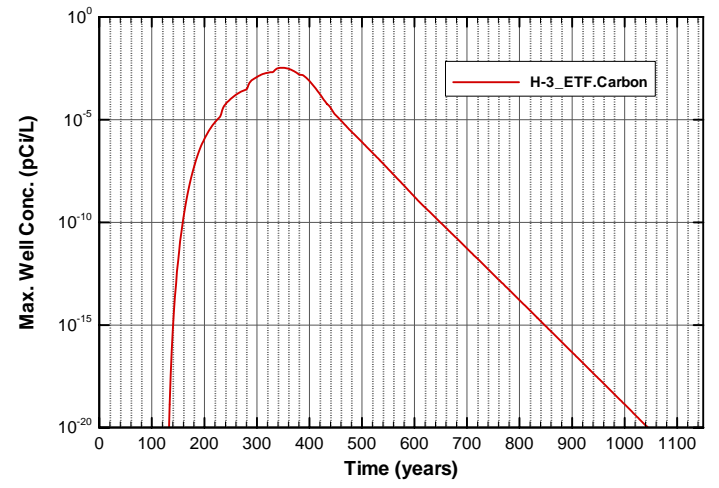

Figure A-2114. Well concentrations for Case01_on H-3_ETF.Carbon

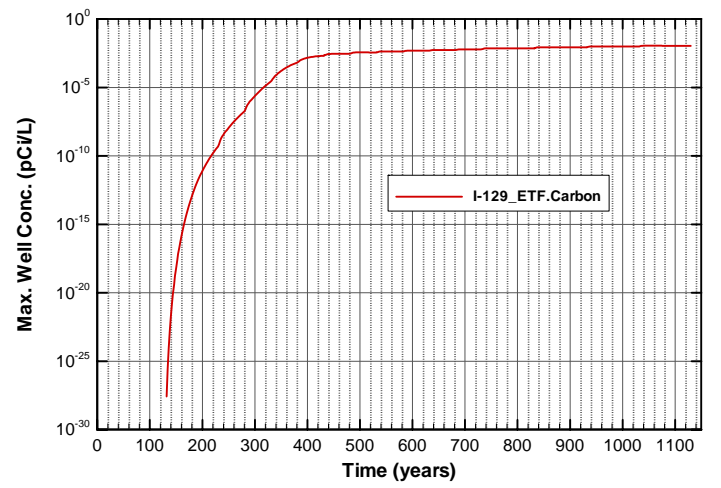

Figure A-2116. Well concentrations for Case01_on I-129_ETF.Carbon 
SRNL-STI-2008-00397, REVISION 0

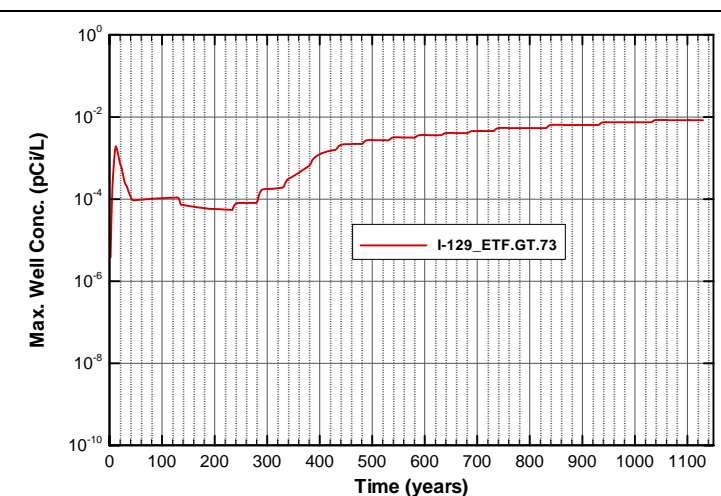

Figure A-2117. Well concentrations for Case01_on I-129_ETF.GT.73

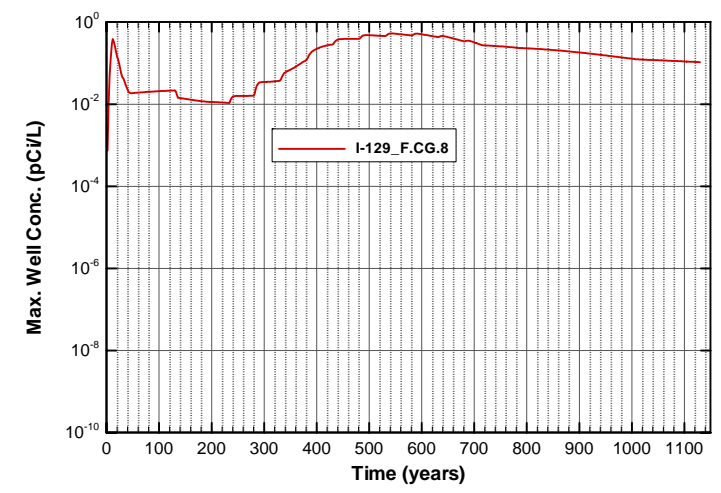

Figure A-2119. Well concentrations for Case01_on I-129_F.CG.8

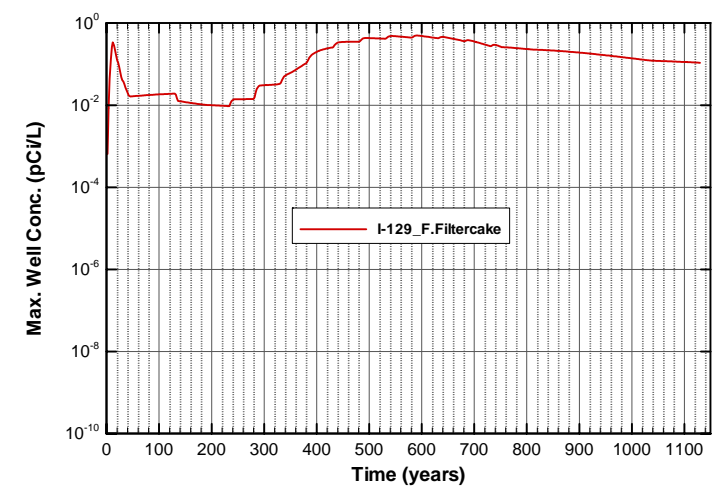

Figure A-2121. Well concentrations for Case01_on I-129_F.Filtercake

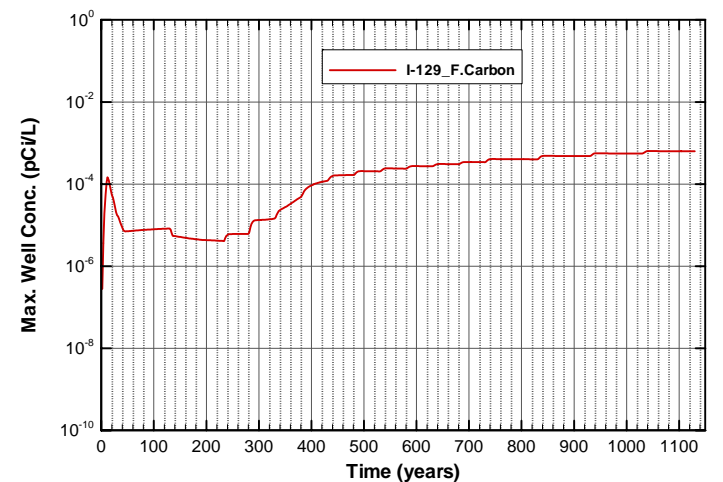

Figure A-2118. Well concentrations for Case01_on I-129_F.Carbon

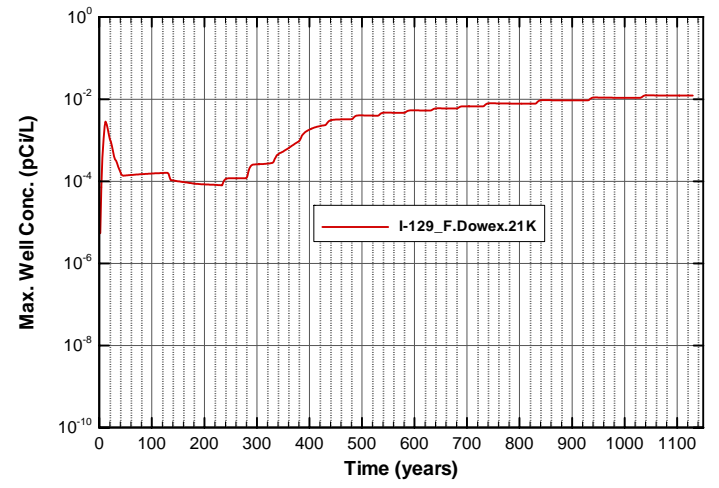

Figure A-2120. Well concentrations for Case01_on I-129_F.Dowex.21K

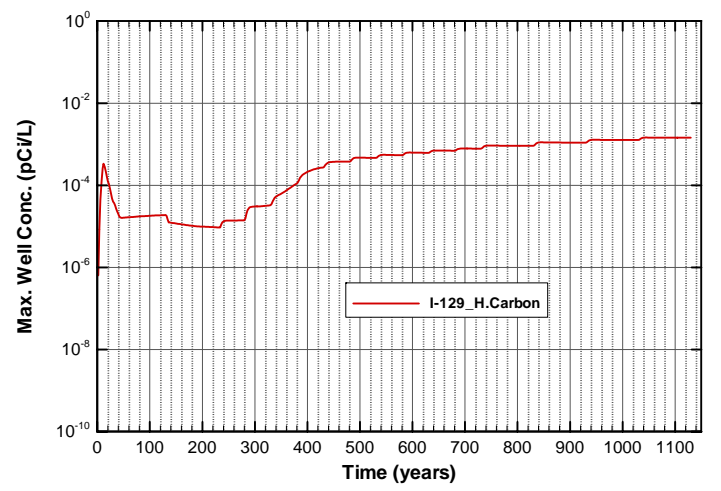

Figure A-2122. Well concentrations for Case01_on I-129_H.Carbon 
SRNL-STI-2008-00397, REVISION 0

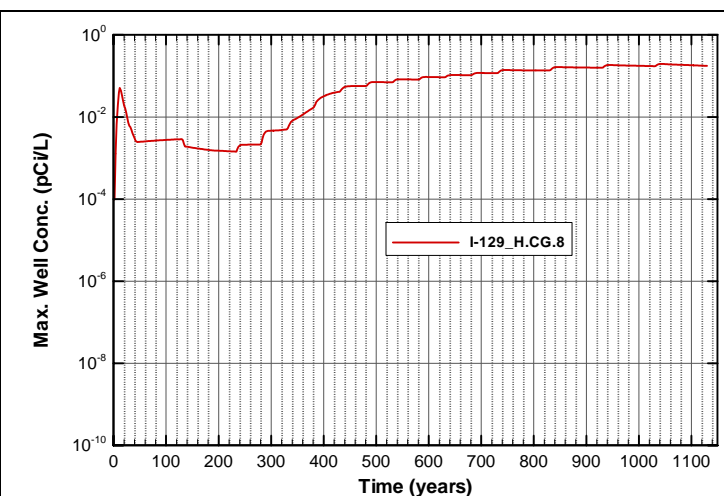

Figure A-2123. Well concentrations for Case01_on I-129_H.CG.8

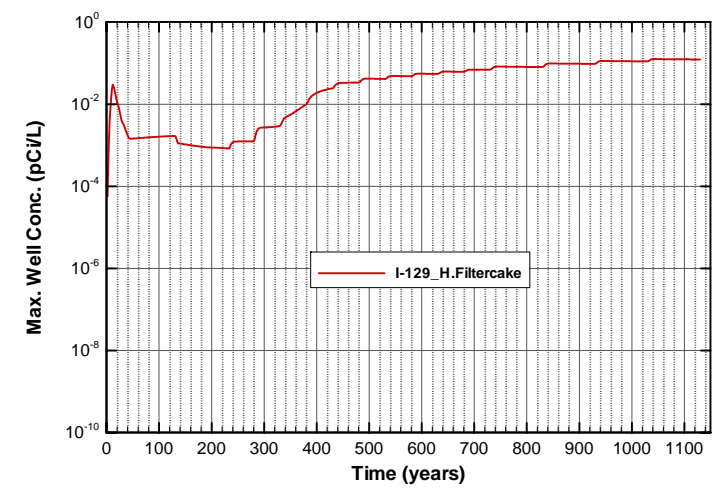

Figure A-2125. Well concentrations for Case01_on I-129_H.Filtercake

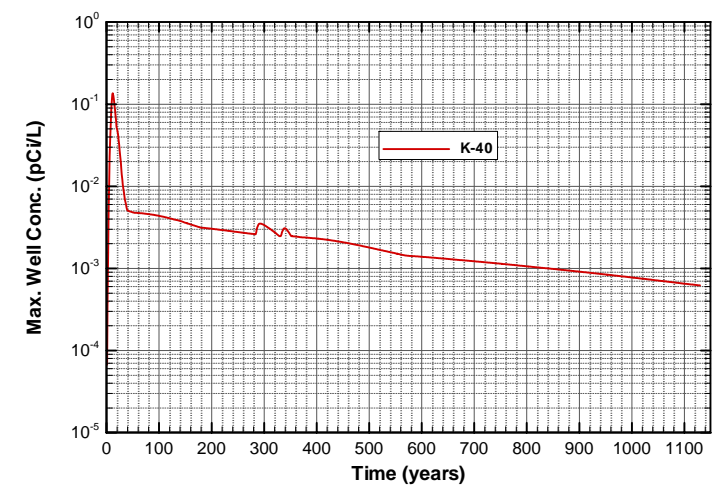

Figure A-2127. Well concentrations for Case01_on K-40

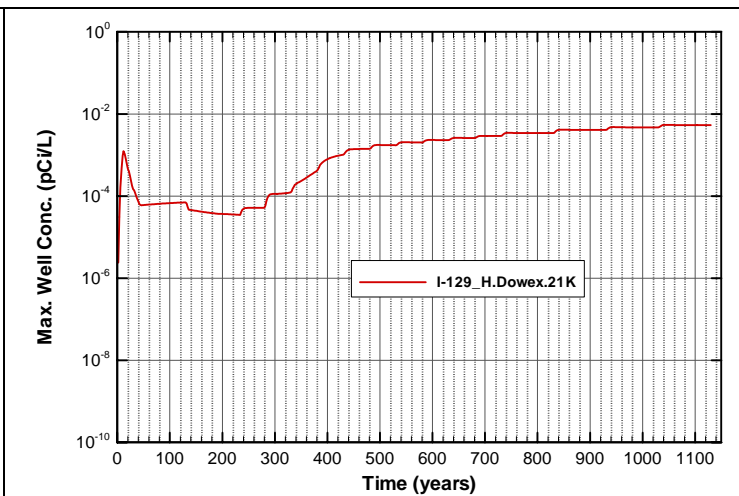

Figure A-2124. Well concentrations for Case01_on I-129_H.Dowex.21K

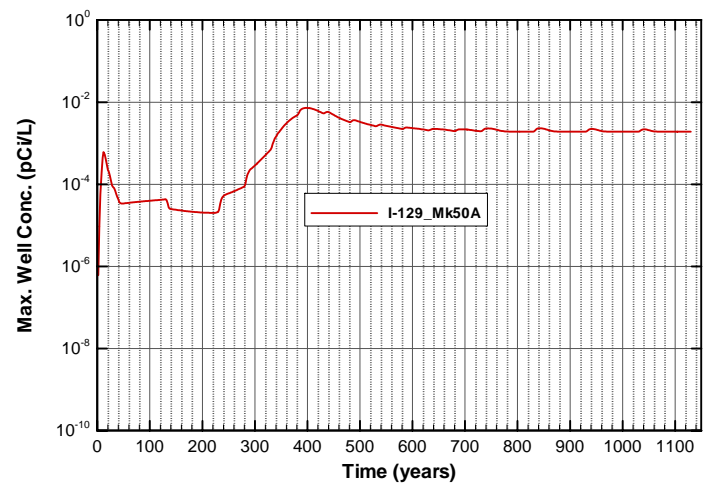

Figure A-2126. Well concentrations for Case01_on I-129_Mk50A

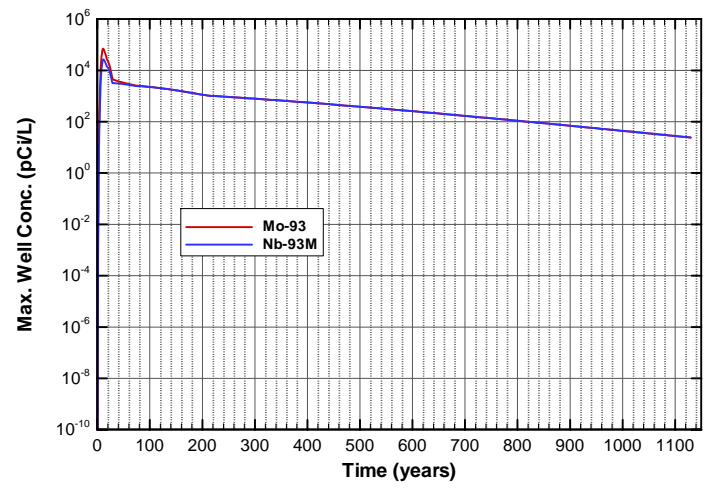

Figure A-2128. Well concentrations for Case01_on Mo-93 
SRNL-STI-2008-00397, REVISION 0

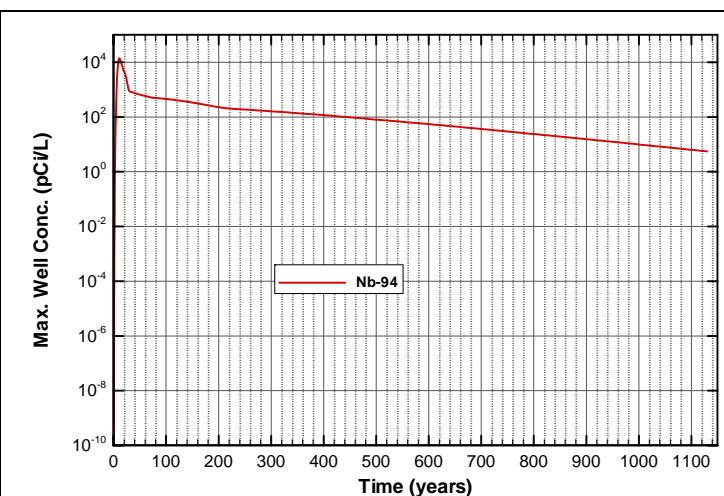

Figure A-2129. Well concentrations for Case01_on Nb-94

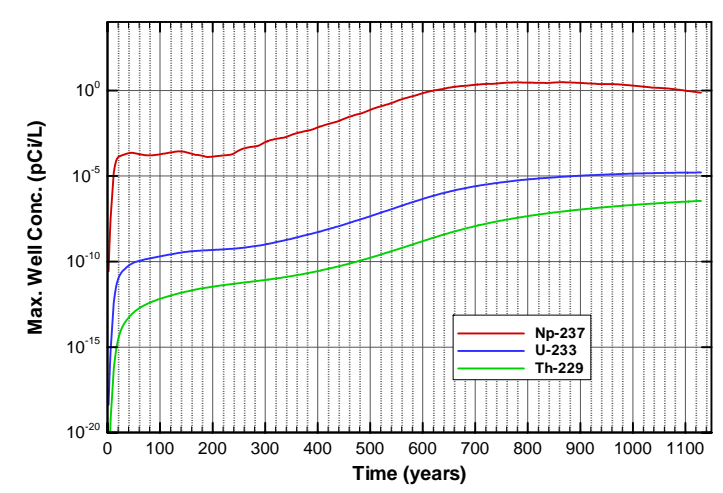

Figure A-2131. Well concentrations for Case01_on Np-237

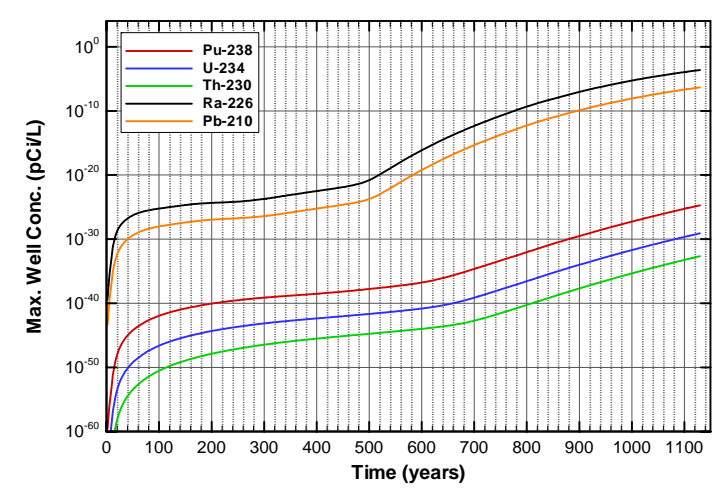

Figure A-2133. Well concentrations for Case01_on Pu-238

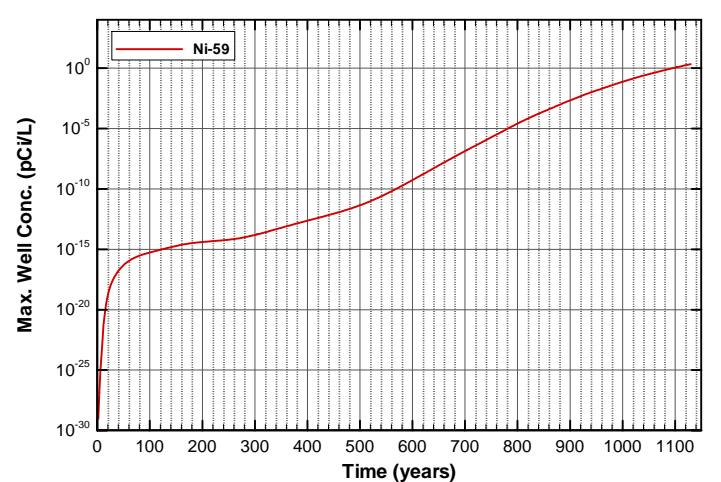

Figure A-2130. Well concentrations for Case01_on Ni-59

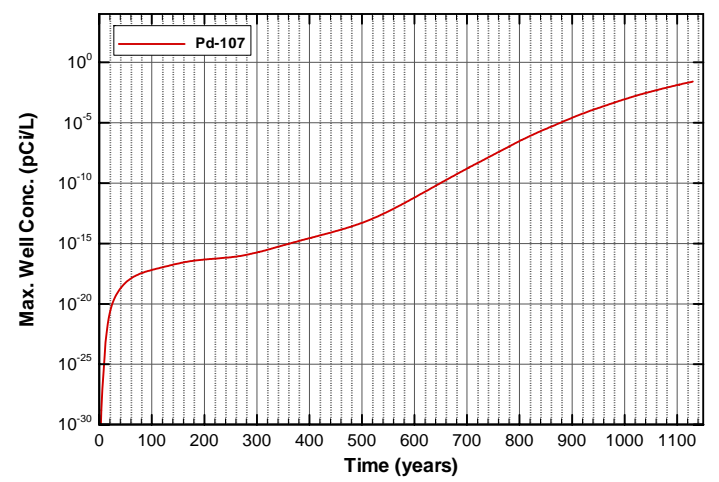

Figure A-2132. Well concentrations for Case01_on Pd-107

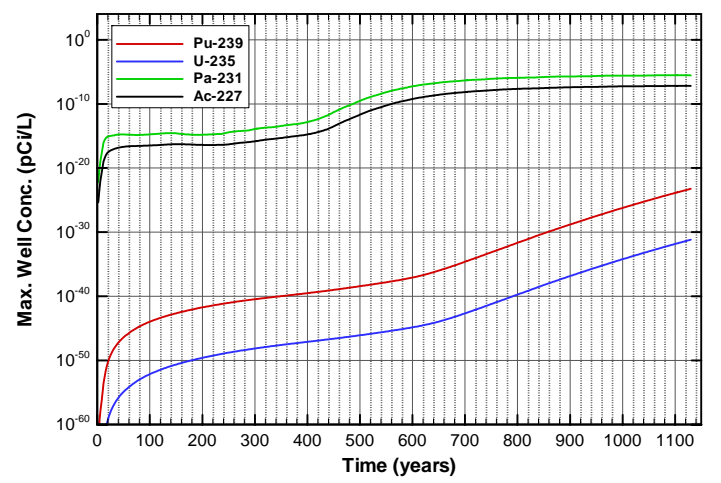

Figure A-2134. Well concentrations for Case01_on Pu-239 
SRNL-STI-2008-00397, REVISION 0

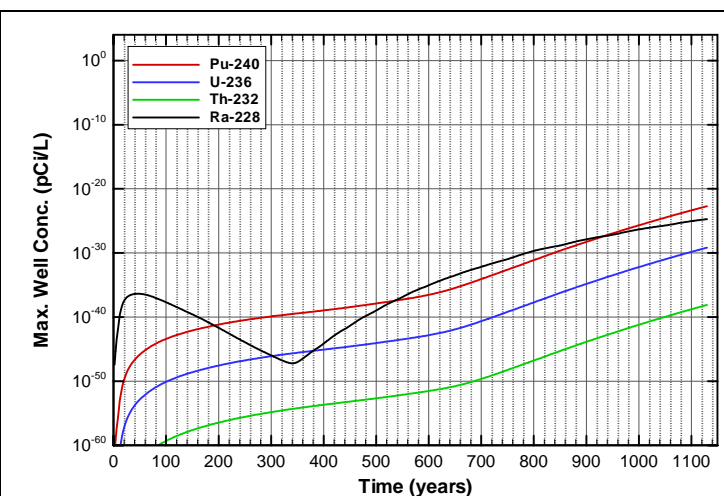

Figure A-2135. Well concentrations for Case01_on Pu-240

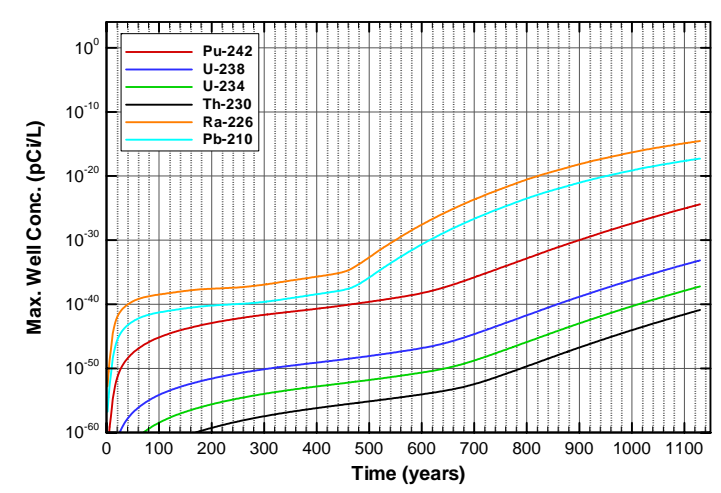

Figure A-2137. Well concentrations for Case01_on Pu-242

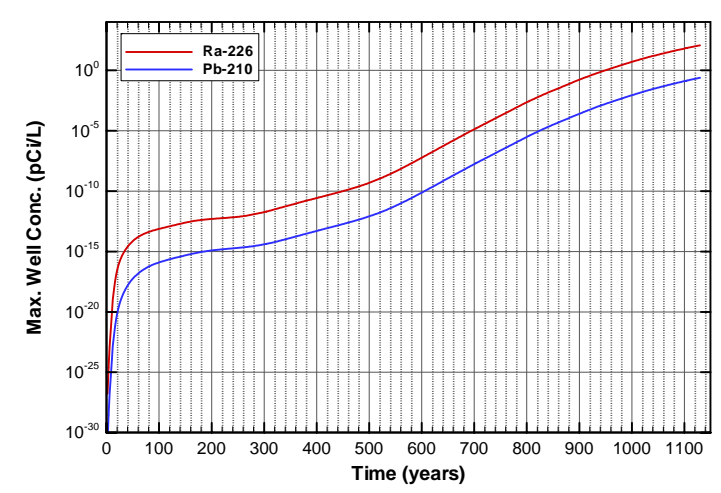

Figure A-2139. Well concentrations for Case01_on Ra-226

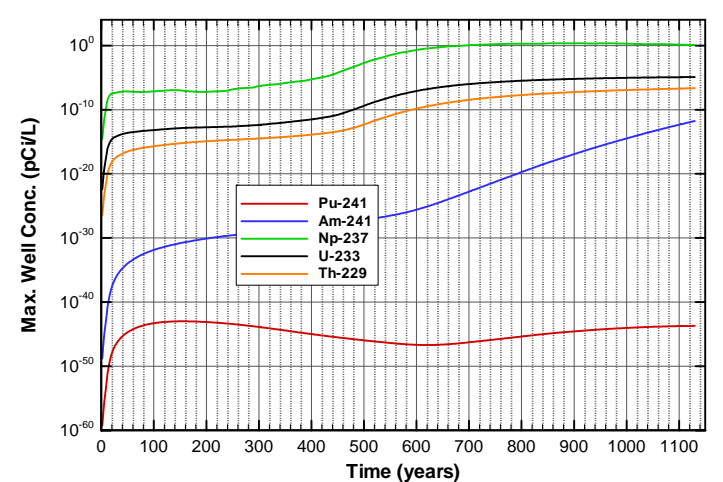

Figure A-2136. Well concentrations for Case01_on Pu-241

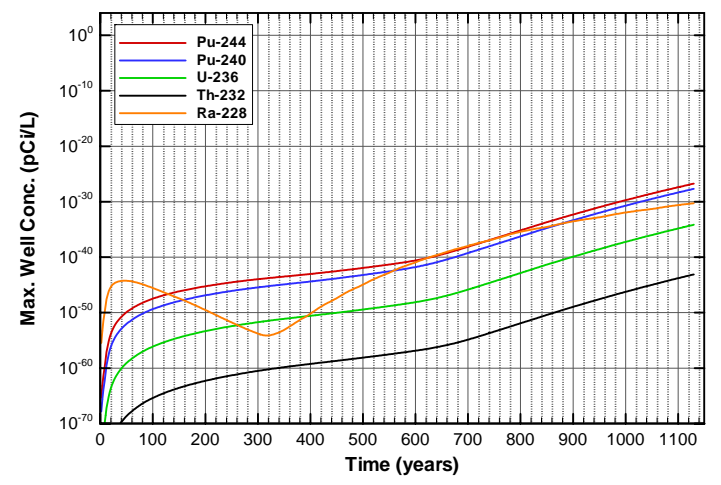

Figure A-2138. Well concentrations for Case01_on Pu-244

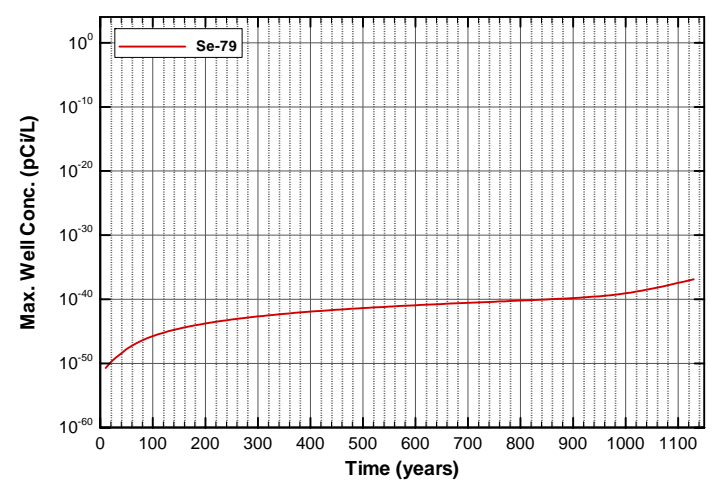

Figure A-2140. Well concentrations for Case01_on Se-79 
SRNL-STI-2008-00397, REVISION 0

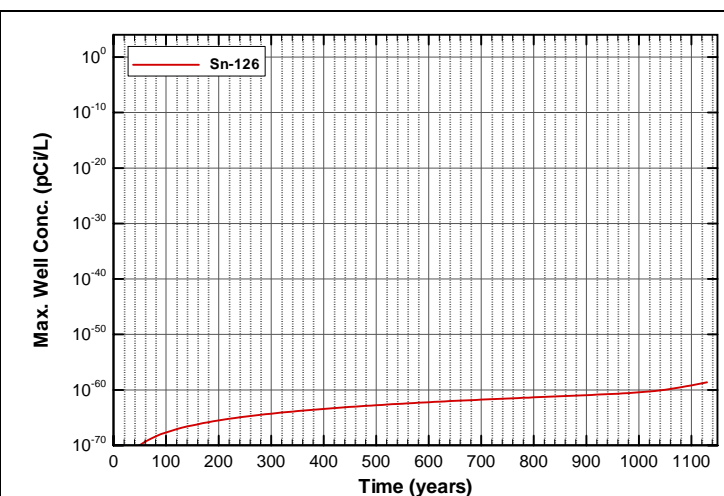

Figure A-2141. Well concentrations for Case01_on Sn-126

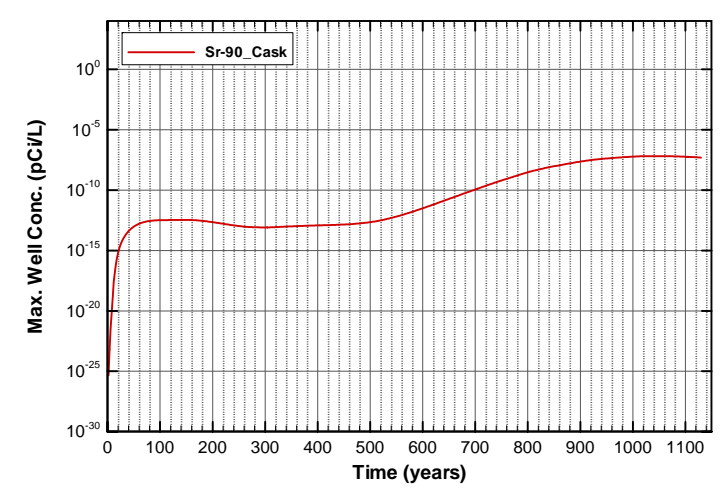

Figure A-2143. Well concentrations for Case01_on Sr-90_Cask

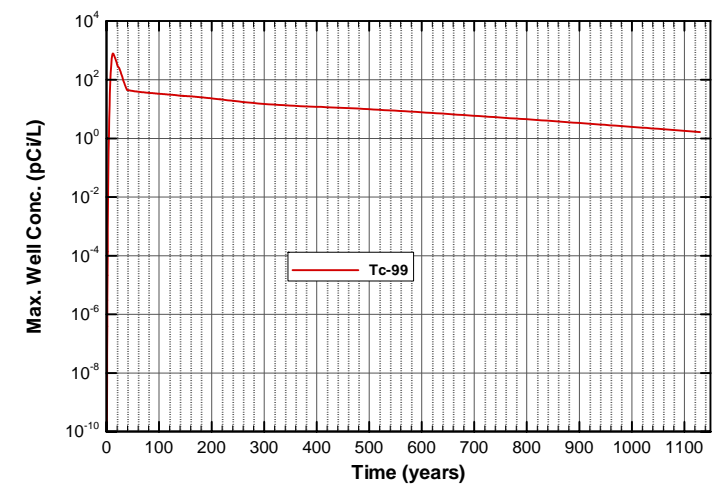

Figure A-2145. Well concentrations for Case01_on Tc-99

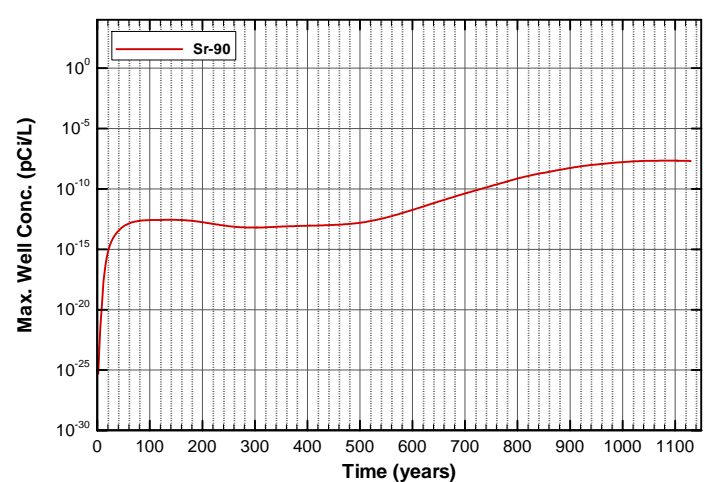

Figure A-2142. Well concentrations for Case01_on Sr-90

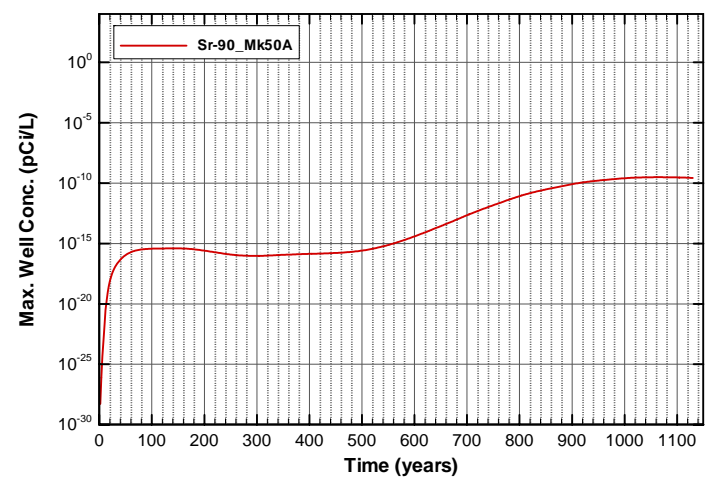

Figure A-2144. Well concentrations for Case01_on Sr-90_Mk50A

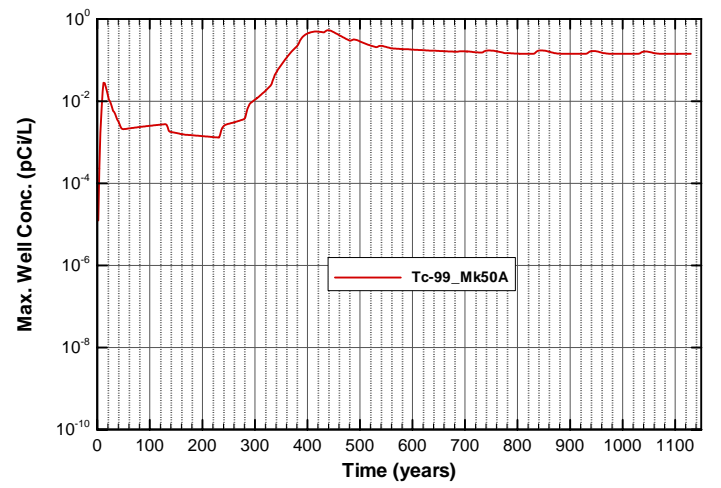

Figure A-2146. Well concentrations for Case01_on Tc-99_Mk50A 


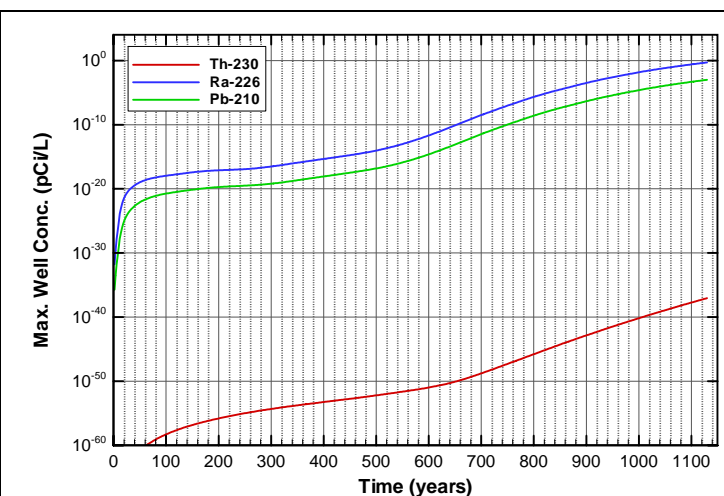

Figure A-2147. Well concentrations for Case01_on Th-230

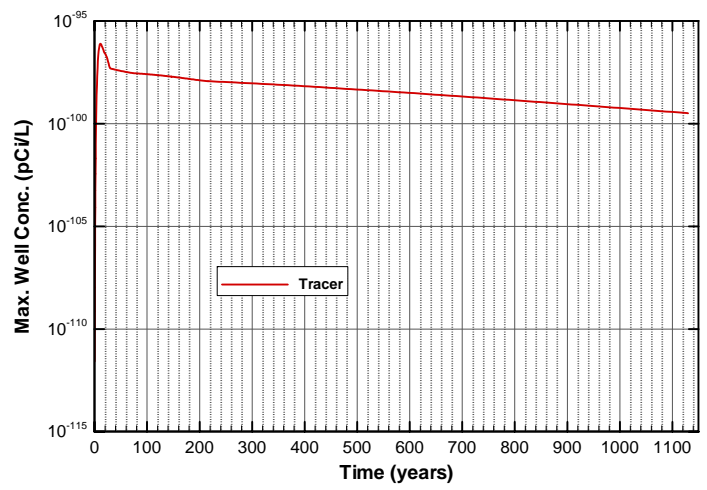

Figure A-2149. Well concentrations for Case01_on Tracer

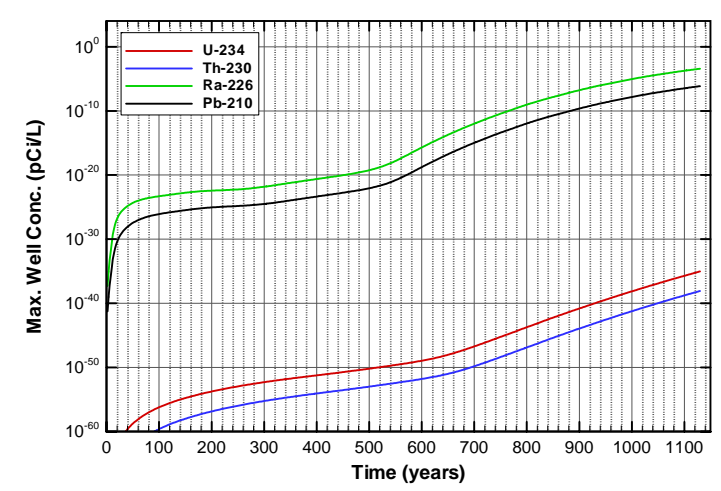

Figure A-2151. Well concentrations for Case01_on U-234

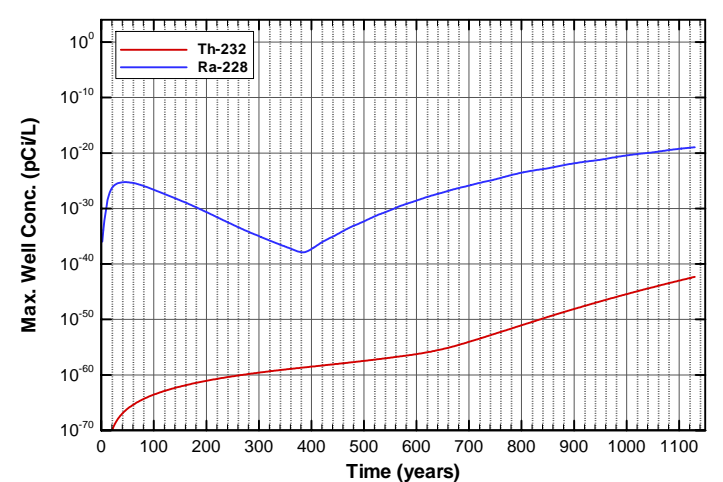

Figure A-2148. Well concentrations for Case01_on Th-232

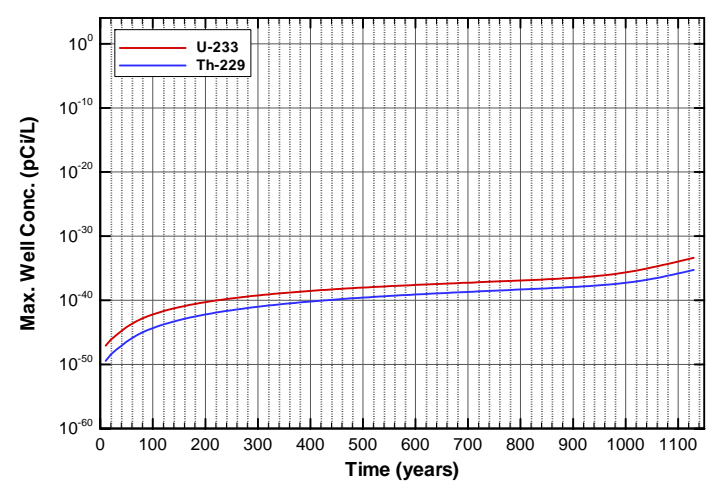

Figure A-2150. Well concentrations for Case01_on U-233

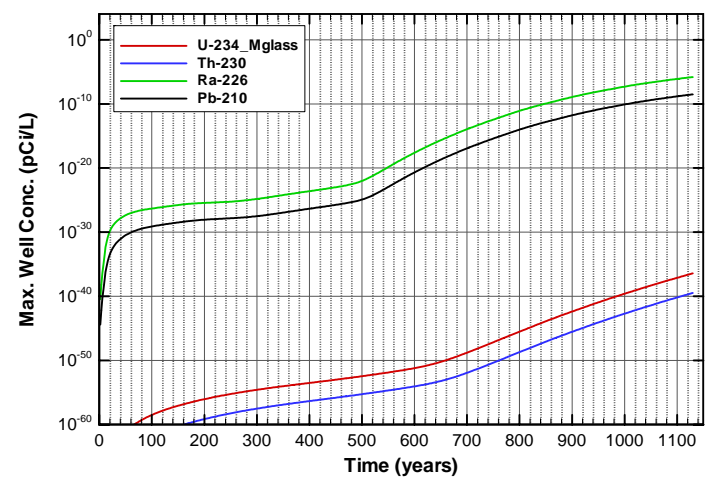

Figure A-2152. Well concentrations for Case01_on U-234_Mglass 


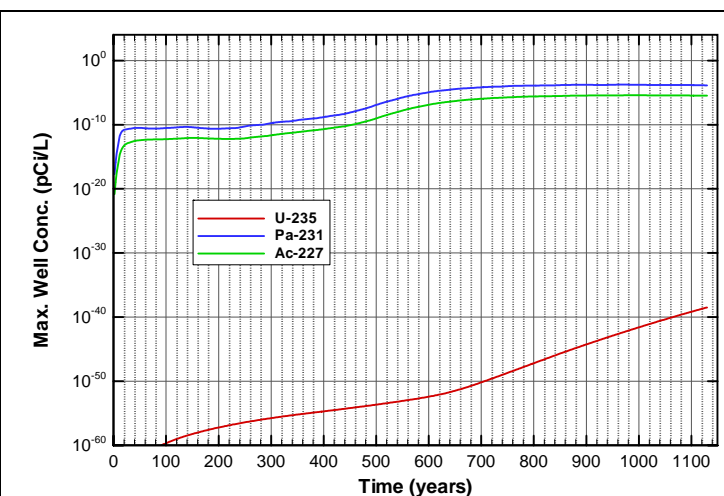

Figure A-2153. Well concentrations for Case01_on U-235

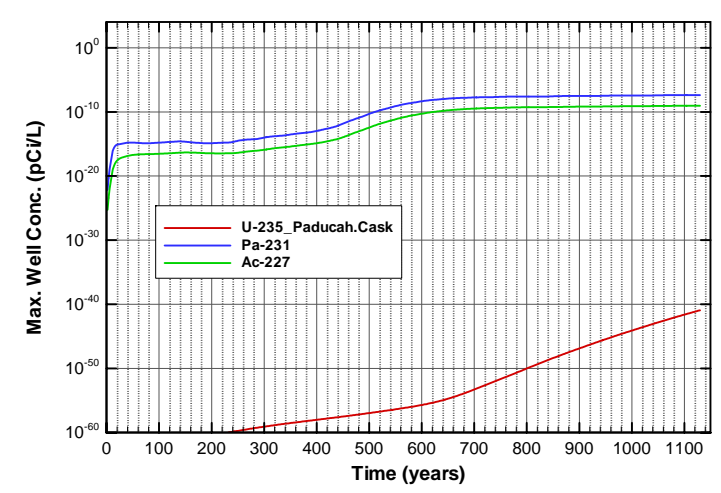

Figure A-2155. Well concentrations for Case01_on U-235_Paducah.Cask

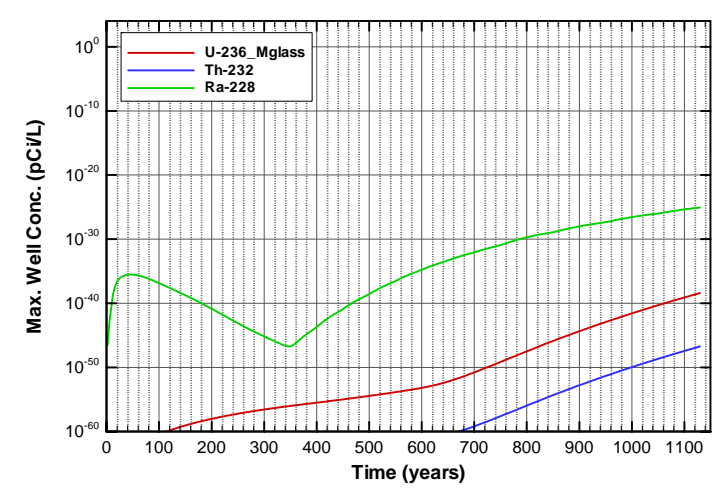

Figure A-2157. Well concentrations for Case01_on U-236_Mglass

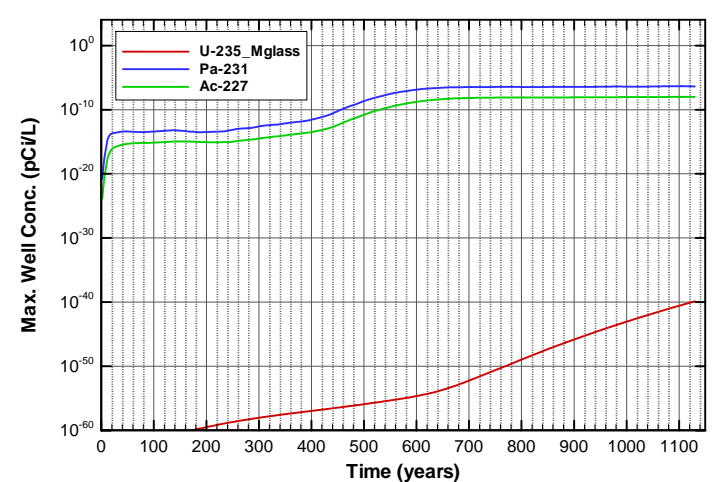

Figure A-2154. Well concentrations for Case01_on U-235_Mglass

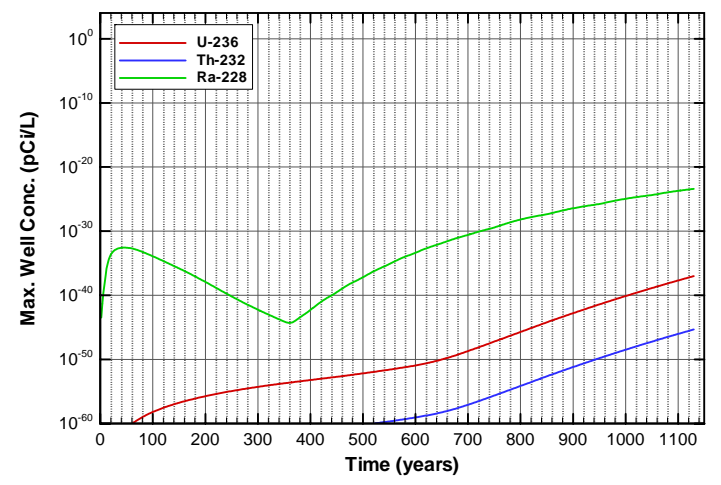

Figure A-2156. Well concentrations for Case01_on U-236

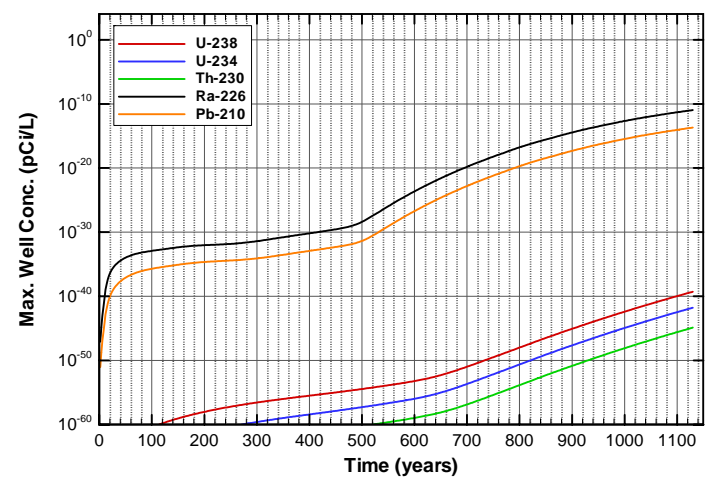

Figure A-2158. Well concentrations for Case01_on U-238 


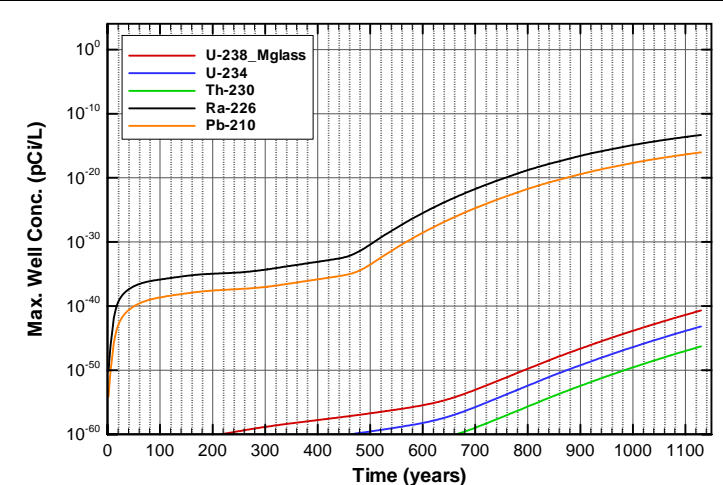

Figure A-2159. Well concentrations for Case01_on U-238_Mglass

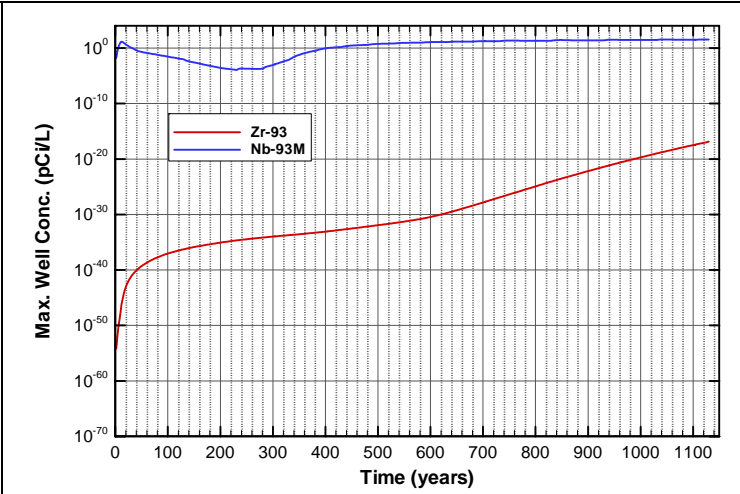

Figure A-2160. Well concentrations for Case01_on Zr-93

1.2.4 Center trench flux plots comparison for 15-year cover for original coarse time stepping and new finer time stepping

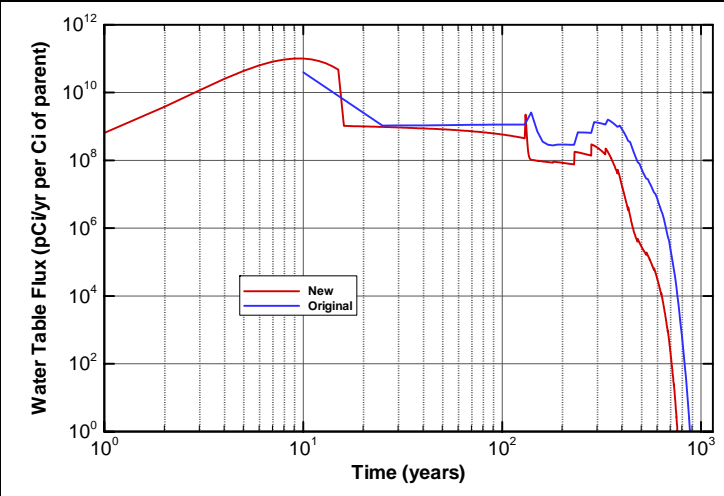

Figure A-2161. Flux at water table for Case01n11_offK-40

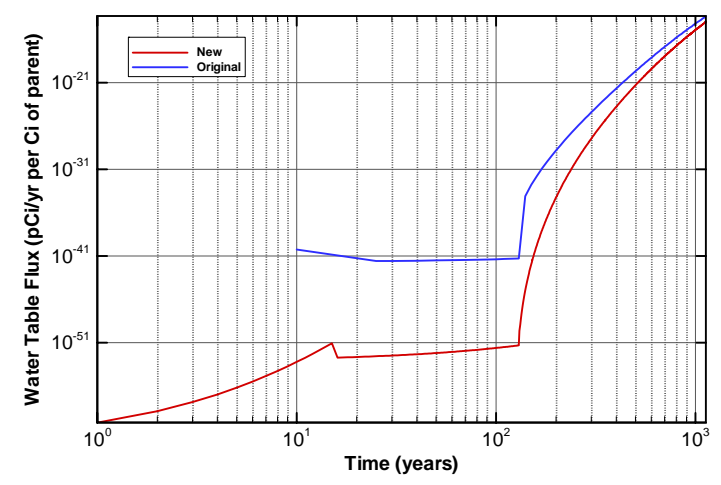

Figure A-2163. Flux at water table for Case01n11_offSn-126

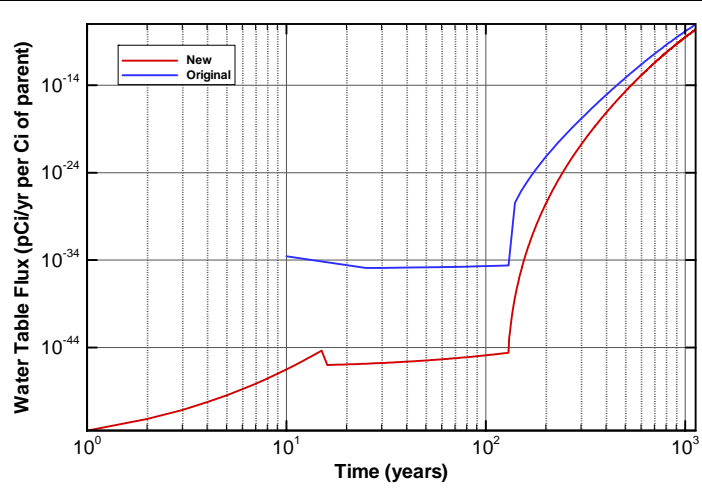

Figure A-2162. Flux at water table for Case01n11_offSe-79

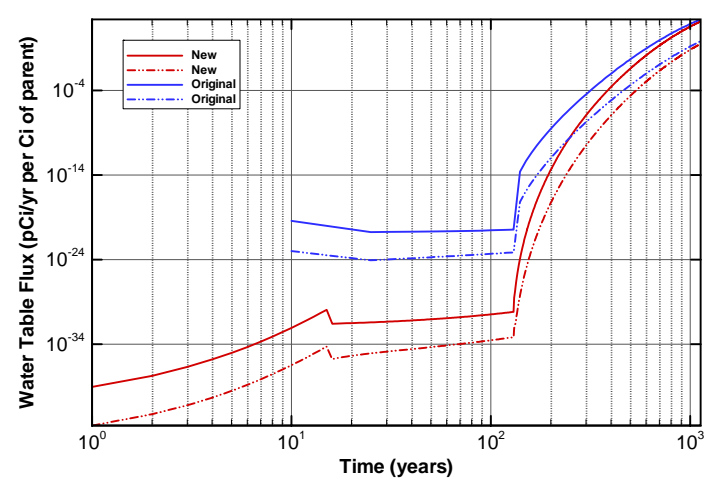

Figure A-2164. Flux at water table for Case01n11_offU-233 


\section{DISTRIBUTION:}

W. T. Goldston, 705-3C, Rm. 105

K. W. Johns-Hughes, 704-60E, Rm. 5

M. G. Looper, 704-36E, Rm. 1

A. R. Hughes, 704-57E, Rm. 4

K. L. Tempel, 704-56E, Rm. 11

S. R. Reed, 704-56E, Rm. 3

J. M. Griffith, 705-3C, Rm. 104

J. C. Griffin, 773-A

S. L. Marra, 773-A

A. M. Murray, 773-A

D. A. Crowley, 773-43A

B. T. Butcher, 773-43A

L. B. Collard, 773-43A

L. L. Hamm, 773-42A, Rm. 145

J. M. Jordan, 773-42A, Rm. 138

G. P. Flach, 773-42A, Rm. 211

RPA Files, 773-43A, Rm. 213 